Cristiano Rangel Moreira

\title{
Relações Filogenéticas na ordem Characiformes (Teleostei: Ostariophysi)
}

Departamento de Zoologia Instituto de Biociências Universidade de São Paulo Junho/2007 
Cristiano Rangel Moreira

Relações Filogenéticas na ordem Characiformes (Ostariophysi, Teleostei)

Tese apresentada ao Instituto de Biociências da Universidade de São Paulo, para a obtenção de Título de Doutor em Ciências, na Área de Zoologia.

Orientador: Mário C. C. de Pinna

Departamento de Zoologia

Instituto de Biociências

Universidade de São Paulo

Junho/2007 
Moreira, Cristiano Rangel

Relações Filogenéticas na ordem

Characiformes (Ostariophysi,

Teleostei)

$468 \mathrm{Pp}$.

Tese (Doutorado) - Instituto de Biociências da Universidade de São

Paulo. Departamento de Zoologia.

1. Characiformes 2.

Ostariophysi 3. Characidae 4

cladismo I. Universidade de São

Paulo. Instituto de Biociências.

Departamento de Zoologia.

Comissão Julgadora:

$\operatorname{Prof}(a) \cdot \operatorname{Dr}(a)$

$\operatorname{Prof}(a) \cdot \operatorname{Dr}(a)$

$\operatorname{Prof}(a) \cdot \operatorname{Dr}(a)$

$\operatorname{Prof}(a) \cdot \operatorname{Dr}(a)$

Prof. Dr. Mário C. C. de Pinna

orientador 


\section{AVISO}

Esta dissertação é parte dos requerimentos necessários à obtenção do título de doutor, área de Zoologia, e como tal, não deve ser vista como uma publicação no senso do Código Internacional de Nomenclatura Zoológica (apesar de disponível publicamente sem restrições). Desta forma, quaisquer informações inéditas, opiniões e hipóteses, bem como nomes novos, não estão disponíveis na literatura zoológica. Pessoas interessadas devem estar cientes de que referências públicas ao conteúdo deste estudo, na sua presente forma, somente devem ser feitas com aprovação prévia do autor.

\section{NOTICE}

This dissertation is a partial requirement for the $\mathrm{PhD}$ degree in Zoology and, as such, should not be considered as a publication in the sense of the International Code of Zoological Nomenclature (although it is available without restrictions). Therefore, any new information, opinions, and hypotheses, as well as new names, are not available in the zoological literature. Interested people are advised that any public reference to this study, in its current form, should only be done after previous acceptance of the author. 
Para Beloca 

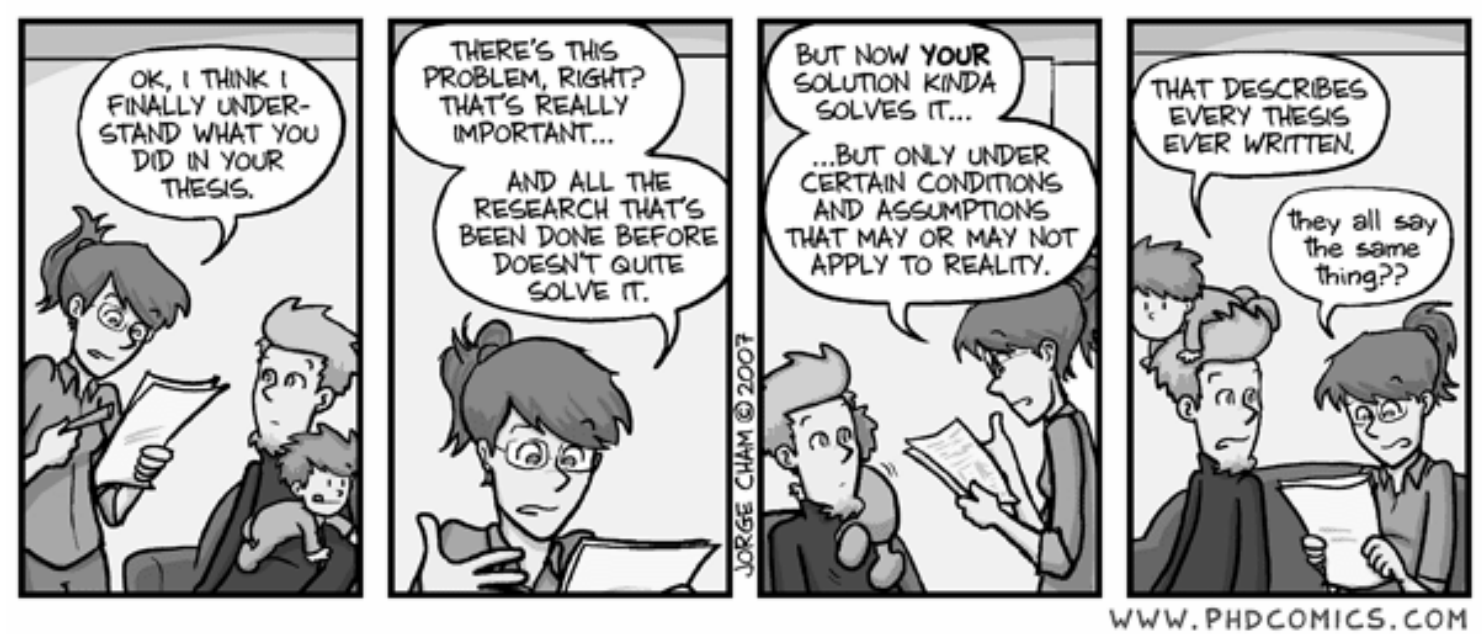

"make the boy interested in natural history if you can - it is better than games"

Última carta de Robert Falcon Scott para a sua esposa (Março, 1912)

"Tiger got to hunt, bird got to fly;

Man got to sit and wonder 'why, why, why?

Tiger got to sleep, bird got to land;

Man got to tell himself he understand."

Book of Bokonon, em Cat's cradle de Kurt Vonnegut (1922-2007) 
A ordem Characiformes é uma diversa ordem de peixes compreendendo 18 famílias, aproximadamente 270 gêneros e mais de 1700 espécies. Representantes desta ordem possuem ampla distribuição em águas continentais do sul dos Estados Unidos, México, Américas Central e do Sul e África. Três análises filogenéticas das relações na ordem foram publicadas na última década, duas moleculares e uma morfológica. Entretanto, estas hipóteses possuem alguns pontos de discordância. No presente estudo, uma abordagem balanceada da diversidade da ordem foi realizada. Foram incluídos ao menos dois terminais de cada uma das famílias reconhecidas para a ordem, ao menos um terminal de cada subfamília de characidae além de diversos terminais considerados incertae sedis em Characidae, em um total de 97 espécies de Characiformes. Esta abordagem teve por objetivo testar o monofiletismo de todas as famílias da ordem, delimitar filogeneticamente characidae e determinar as relações entre as famílias recobradas. Com este objetivo, foi elaborada uma matriz com 410 caracteres morfológicos, derivados de osteologia, lepidologia e morfologia de trato digestivo e bexiga natatória. Apesar da grande base de dados, os dois cladogramas fundamentais encontrados possuem apenas um ponto de incongruência, as relações de Astyanax em um pequeno clado distal. Novas hipóteses acerca das relações em Characiformes são propostas. A ordem é composta por dois grandes clados. o primeiro é composto por Crenuchidae na sua base, seguido por um Distichodontidae parafilético (incluindo Citharinidae). Distichodontidae, como proposto aqui, é grupo-irmão de (Parodontidae (Hemiodontidae ((Anostomidae, Chilodontidae) (Prochilodontidae, Curimatidae)))). 0 outro grande clado também é dividido em dois subgrupos. o primeiro destes grupos é composto por Lebiasinidae parafilético (incluindo Erythrinidae), como grupo-irmão de Alestidae parafilético (incluindo Serrasalminae). 0 outro clado é composto pela maioria das espécies da ordem. Neste clado, a família Characidae é restringida (excluindo Salminus e Brycon), e é considerada como o grupo-irmão de (Salminus (Brycon (Cynodontidae (Acestrorhynchidae (Hepsetidae, Ctenoluciidae). 


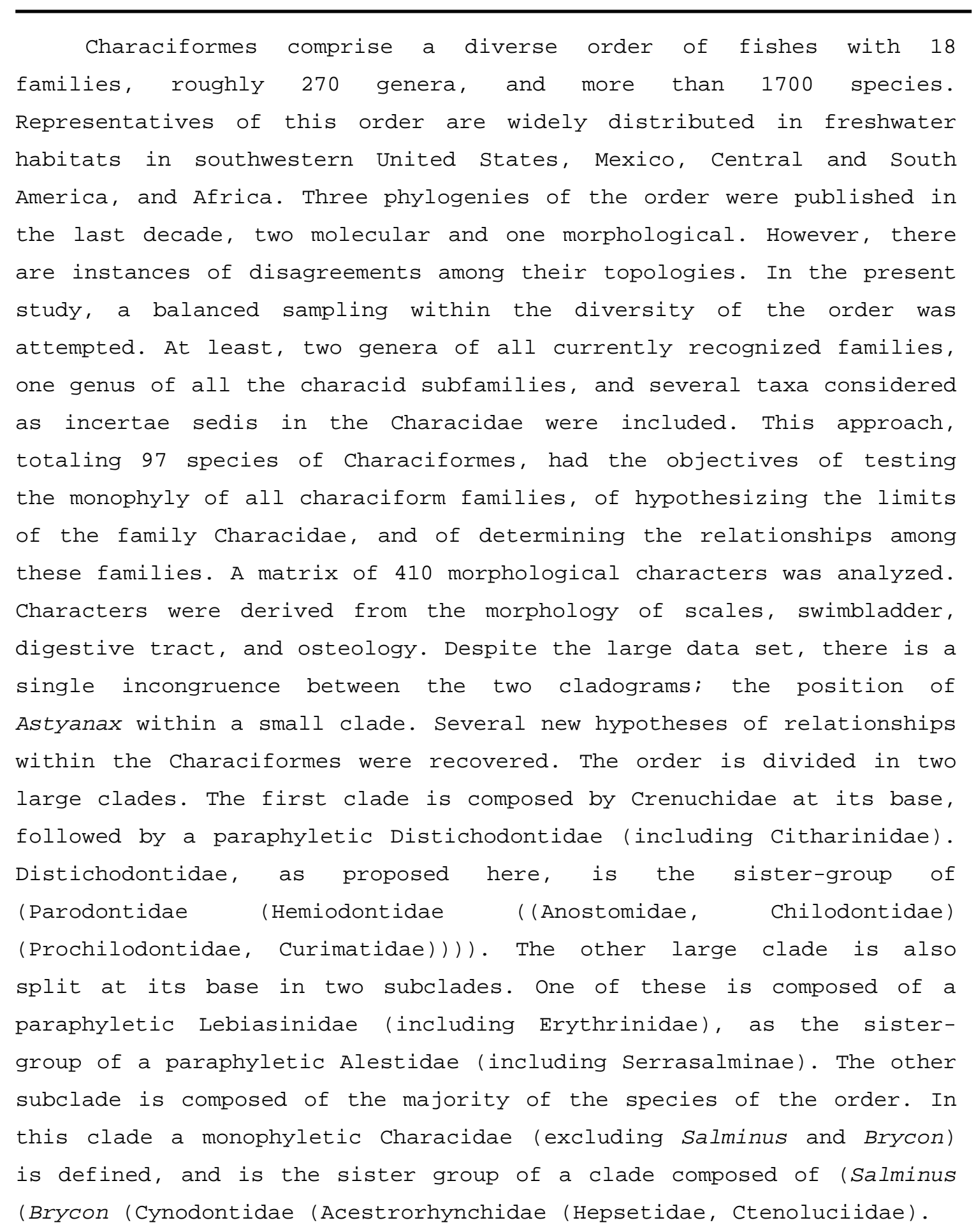


Ao contrário da minha dissertação de mestrado, os agradecimentos desta tese serão bem mais que sucintos (o tempo urge), e espero que com isto eu não cometa a gafe de me esquecer de alguém.

Como é de costume, primeiramente gostaria de agradecer ao meu orientador, Mário de Pinna, que continuou me aturando também nestes anos de doutorado. Entre os constantes "assina isto para mim, Mário" tivemos tempo de interagir sobre diversos assuntos, como cladismo, evolução, peixes, plantas, livros, música, criacionismo, comida, M de M, etc. Os constantes "onde caiu Stygichthys?", "onde caiu fulano?", "onde caiu cicrano?", e diversos outros grupos que ele conseguia se lembrar na hora, foram fundamentais em gerar acidez estomacal suficiente para que eu fosse correndo trabalhar. Sou extremamente grato, por estes quase oito anos de convivência em que foi um amigo e um torcedor irrestrito, com ele não aprendi apenas sobre enraizamento, homoplasias, anatomia, etc, mas também espero ter aprendido bastante com as diversas qualidades pessoais do Mário, como ética, amabilidade, uma certa leveza em relação a vida, curiosidade sobre tudo, etc. Além disto, ele deu total e irrestrito suporte para todas as "vagabundagens patológicas produtivas" minhas e da Bel, mostrando que o doutorado é muito mais que uma tese, é um processo de amadurecimento profissional em diversas frentes. o fato de ele ter uma visão tão clara disto me permitiu realizar atividades que me geraram um prazer enorme, e que eu esperançosamente acredito que tenham sido tão úteis e proveitosas para várias pessoas, conhecidas ou não, quanto foi para mim. Agradeço também a ele, a Flávia e a Júlia, por me receberem na madrugada de sábado e domingo, aos 45 do segundo tempo, para entregar e buscar textos para revisão.

Todo mundo que já esteve no MZUSP, sabe que o Laboratório de Ictiologia (vulgarmente conhecido como Seção de Peixes, ou Peixes, ou catacumbas) é um lugar fantástico para se desenvolver uma tese, não apenas pela coleção, mas principalmente pelas pessoas que tornam o simples fato de você estar no museu, em momentos maravilhosos. Pelo companheirismo, pelas ajudas, pelos papos, nestes muitos anos, agradeço a todos da ictiologia: Heraldo Britski, Osvaldo Oyakawa, Naércio Menezes, José Lima, Alberto Akama, Flávio Lima, Fábio Di Dario, Eduardo Baena, José Birindelli, Luís Olivan, Leandro Sousa, Isabel Landim, André Netto-Ferreira, Carine Chamon, Ilana Fichberg, 
Janice Muriel, Luciana Tosin, Verena Pfser, Camila Kikuchi, Marina e Pedro.

Alguns ictiólogos da minha geração (Siluriano inferiro) merecem um agradecimento muito especial, são eles: Carlos Figueiredo, Fábio Di Dario, Flávio Lima, Marcelo Britto, Ricardo Campos-da-Paz (não tão da minha geração), companheiros dos porões cariocas e paulistanos. Estas pessoas foram igualmente (daí a ordem alfabética) e significativamente importantes em diversos aspectos da minha vida pessoal e profissional. Adoraria me estender em muitas linhas sobre como cada um foi importante para mim, mas infelizmente não tenho tempo (faltam menos de 48 horas para entregar).

Outro agradecimento especial vai para Eduardo Baena, que além de ter feito grande parte dos desenhos desta tese, sempre dispôs do seu tempo para me ajudar quando eu precisava. Além disto, sofreu comigo a agonia final da tese.

Aos funcionários do MZUSP, principalmente a Zina, Isabel e Rogério que mantiveram tudo em ordem, ao Paulo e Luís que me aturaram pelas madrugadas, ao Cauê e Wanderley por sempre estarem verdadeiramente preocupados com a minha saúde mental e física e as meninas da biblioteca que sempre fizeram o possível e o impossível para me conseguir "aquele artigo".

Grande parte do conhecimento que eu tenho sobre este grupo fantástico de peixes decorre da minha interação com ictiólogos da mais alta qualidade e que para a minha felicidade trabalham com o mesmo grupo e sempre estão abertos e receptivos para trocar idéias, e escutar as minhas loucuras: Naércio Menezes, Flávio Lima, Mônica Toledo-Piza, André Netto-Ferreira, Richard Vari, Stanley Weitzman, Ângela Zanata, Ricardo Castro, Luiz Malabarba e Paulo Buckup.

Aos diversos amigos ictiólogos do Brasil e do mundo (em especial aos amigos de Ribeirão Preto), e aos amigos do IB, agradeço muitíssimo por tudo, por uma piada, por uma cerveja, por uma separata, por um software, por uma sugestão, por uma idéia, etc, em congresso, visitas, etc. Não tentarei lembrar-me e agradecer a todos, porque certamente esqueceria alguém, pela pressa, e não pela importância. Sintam-se agradecido .

Agradeço aos componentes da expedição Stygichthys, Eleonora Trajano, Maria Elina Bichuette, Osvaldo Oyakawa, Mário de Pinna e Flávio Passos, por compartilhar comigo da empolgação na descoberta deste animal.

Pelo envio de materiais, informações e ou por me receber da melhor maneira possível nas suas instituições, agradeço a scott schaefer e 
Barbara Brown (AMNH), David Catania, Bill Eschmeyer, Tomio Iwamoto, Mysi Hoang e Jon Fong (CAS), Richard Vari, Stanley Weitzman e Jeffrey Williams (USNM), Douglas Nelson e William Fink (UMMZ), Jos Snoeks (MRAC), Sven Kullander e Anders Silvergrif (NRM), Roberto Reis, Luiz Malabarba, Edson Pereira, José Pezzi, Pablo Lehmann, Alexandre Cardoso, Vinícius Bertaco (MCP), Paulo Buckup, Marcelo Britto (MNRJ), Lúcia Py-Daniel, Jansen Zuanon (INPA), Wolmar Wosiacki (MPEG).

A todos os meus amigos e parentes que consideram que peixes são bons no prato, e só lá, agradeço muitíssimo pelos estímulos outros, e por tentarem, de verdade, entender o que eu faço durante metade do meu dia e noite.

Por mais que este comentário possa soar estranho, eu me considero uma pessoa afortunada por possuir Mãe e Pai separados. Isto me propiciou estímulos múltiplos durante a minha adolescência e até hoje. Apesar de maneiras diferentes, e mesmo sem entender completamente o que eu faço, os dois me estimularam e me apoiaram sempre nesta busca maluca pela compreensão da evolução de peixes e outras atividades mais esquisitas (o que pode parecer difícil). Infelizmente, o meu doutorado em São Paulo me furtou de mais momentos com o meu irmão, Bernardo, o que pode ter sido bom para ele, mas com certeza não foi para mim. Agradeço muito a tolerância dos meus parentes mais próximos, em relação a minha falta de tempo, resultando muitas vezes em uma ausência muito maior do que eu gostaria.

Este último ano e meio de tese foi um momento muito feliz para mim, não pela perspectiva de virar desempregado, ou de ter que virar noites trabalhando, mas de finalmente constituir família nos moldes mais tradicionais, isto é vivendo sob o mesmo teto. A vinda da Bel e do Quim, finalmente, para São Paulo foi e está sendo um momento especial na minha vida. Passado o susto de ter uma série de responsabilidades e atividades que desconhecia, eu só consigo me deliciar com as vantagens e desvantagens de ser casado. Agradeço muito a paciência dela, do Quim, da Nala e do Willi, em aturar os meus horários nada convencionais nestes últimos meses. A Bel tem sido muito mais que a minha esposa nestes últimos 10 anos, tem sido minha amiga e companheira, em todos os cantinhos da minha vida, sem ela, eu não seria quem eu sou e nem faria o que eu faço. Por todos estes momentos de felicidade, e eu só posso ser extremamente grato por ela fazer parte da minha vida.

Este estudo só seria possível com o auxílio luxuoso da Fapesp, através da bolsa de doutorado concedida (03/01056-8). 
RESUMO ..vii

ABSTRACT viii

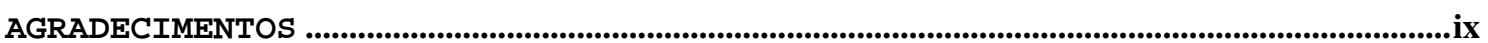

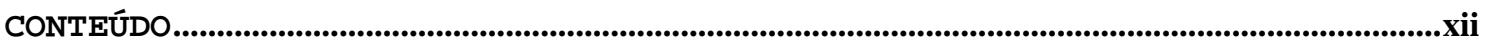

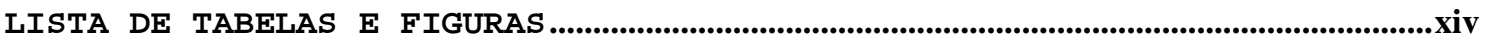

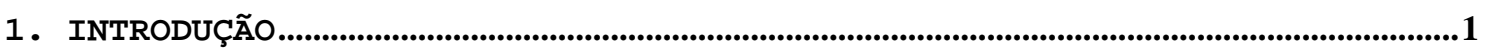

1.1 CONSIDERAÇÕES GERAIS SOBRE A ORDEM CHARACIFORMES ..................................1

1.20 MONOFILETISMO DE CHARACIFORMES, E SUAS RELAÇÕES EM TELEOSTEI....2

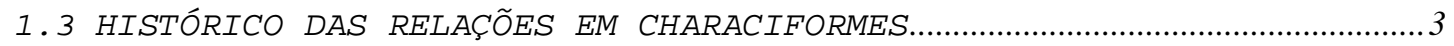

1.4 ESTADO DO CONHECIMENTO DAS RELAÇÕES FILOGENÉTICAS NAS FAMÍLIAS DE CHARACIFORMES

2. OBJETIVOS 18

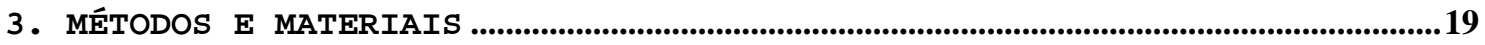

3.1 CONSIDERAÇÕES GERAIS SOBRE A METODOLOGIA E A ANÁLISE.........................19

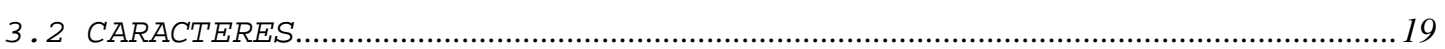

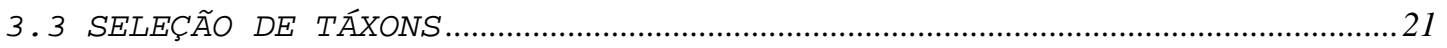

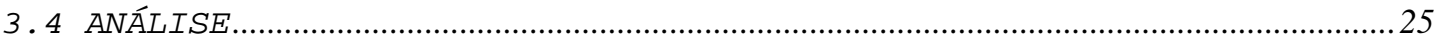

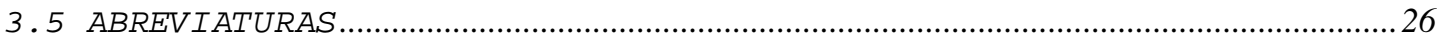

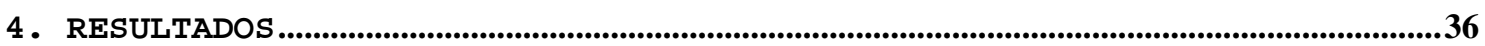

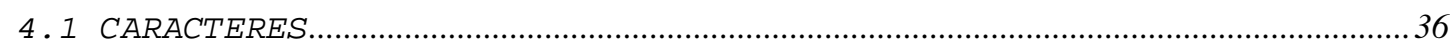

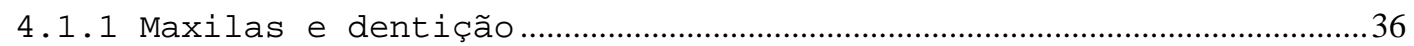

4.1.2 Arcos palatino e mandibular, e série opercular ............................66

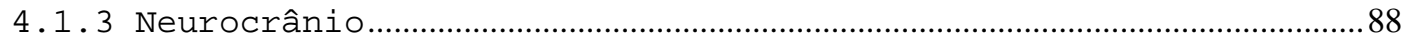

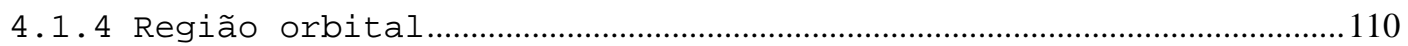

4.1.5 Arcos hióide e branquiais ............................................................................148

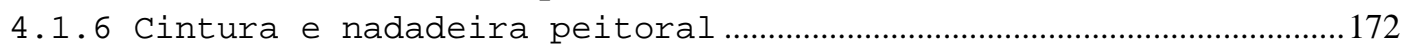

4.1.7 Cintura e nadadeira pélvica........................................................................... 192

4.1.8 Nadadeira dorsal e esqueleto de sustentação.....................................206

4.1.9 Nadadeira anal e esqueleto de sustentação .......................................213

4.1.10 Nadadeira caudal e esqueleto de sustentação ................................218

4.1.11 Vértebras, supraneurais e ossos intermusculares.......................233

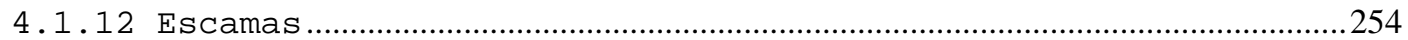

4.1.13 Bexiga natatória e trato digestivo.....................................................267

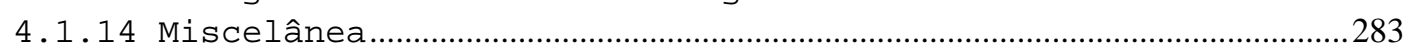

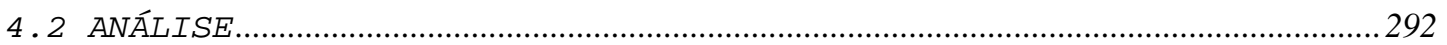

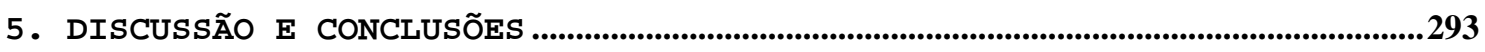

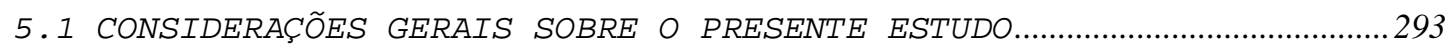

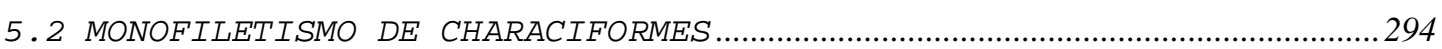




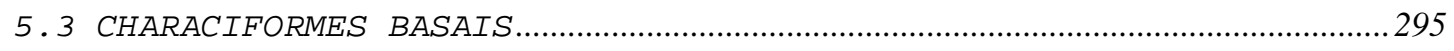

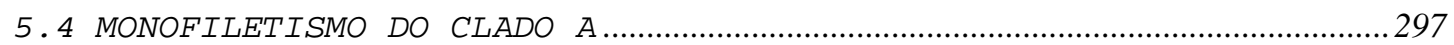

5.5 RELAÇÕES DE DISTICHODONTIDAE E CITHARINIDAE ...........................................2.298

5.6 RELAÇÕES DE PARODONTIDAE, HEMIODONTIDAE E ANOSTOMOIDEA....................299

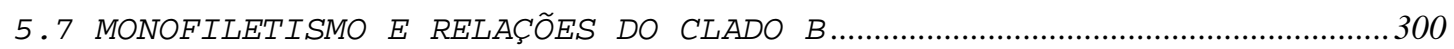

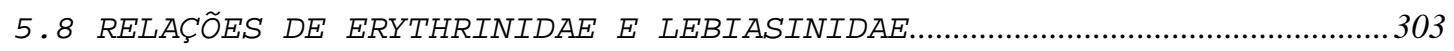

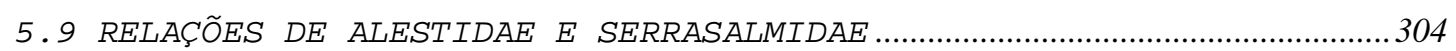

5.10 RELAÇÕES DE BRYCON, SALMINUS, ACESTRORHYNCHIDAE, CYNODONTIDAE, CTENOLUCIIDAE E HEPSETIDAE 306

5.11 MONOFILETISMO DE CHARACIDAE E CONSIDERAÇÕES SOBRE SEUS SUBGRUPOS

307

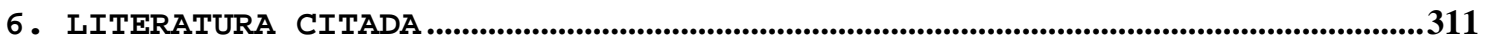


Tabela 01 . Matriz de dados (410 caracteres x 101 terminais). ..... 319

Tabela 02. Índices de consistência (ci) e retenção ( $r i$ ) de cada

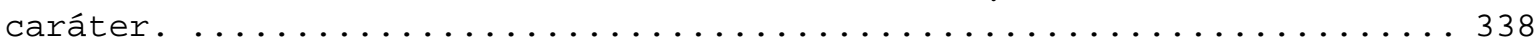

Tabela 03. Tabela comparativa entre as análises filogenéticas mais abrangentes realizadas da ordem Characiformes. . . . . . . . . . . . . 340

Figura 01. Distribuição dos peixes da ordem Characiformes. Adaptado de Berra (2001). ................................. 341

Figura 02. Cladograma das inter-relações entre as ordens de Ostariophysi, segundo Fink \& Fink (1981). .................. 342

Figura 03. Cladograma das relações filogenéticas entre as famílias da Ordem Characiformes, segundo uj (1990). .................... 343

Figura 04. Cladograma de consenso estrito das relações filogenéticas entre gêneros da Ordem Characiformes, segundo Buckup (1998). ...... 344

Figura 05. Cladograma mais parcimonioso para as relações filogenéticas entre as famílias Curimatidae, Prochilodontidae, Anostomidae e Chilodontidae, segundo vari (1983). ...................... 345

Figura 06. Cladograma de consenso estrito das relações entre gêneros da Ordem Characiformes, segundo Lucena (1993). . . . . . . . . . . . . . 346

Figura 07. Esquema das relações filogenéticas entre os peixes das famílias Acestrorhynchidae e Cynodontidae segundo Lucena e Menezes (1998) e Toledo-Piza (200๑). ..........................

Figura 08. Cladograma mais parcimonioso das relações em characiformes, obtido através da pesagem dos caracteres a posteriori, segundo ortí e

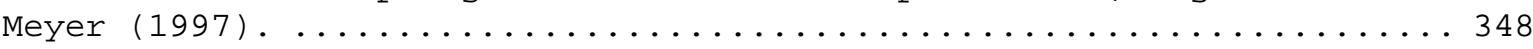

Figura 09. Cladograma de consenso estrito das relações em Characiformes, segundo Calcagnotto et al (2005).

Figura 10. Cladograma de consenso estrito das relações em Lebiasinidae, segundo Netto-Ferreira (2006). . . . . . . . . . . . . . . . 350

Figura 11. Cladograma mais parcimonioso para as relações filogenéticas entre os peixes das famílias Citharinidae e Distichodontidae, segundo

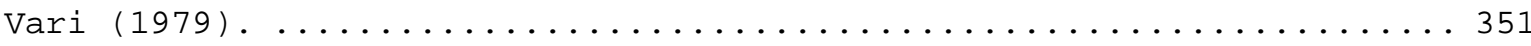

Figura 12. Cladograma das relações filogenéticas entre as famílias Lebiasinidae, Hepsetidae, Erythrinidae e Ctenolucidae, segundo Vari

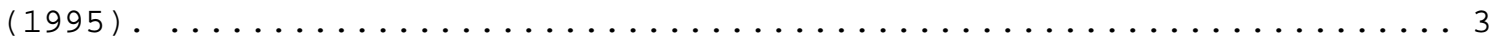

Figura 13. Cladograma de consenso estrito das relações em

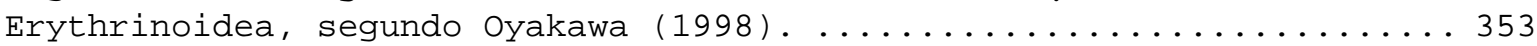

Figura 14. Cladograma das relações entre os gêneros de Hemiodontidae, segundo Langeani (1998). . . . . . . . . . . . . . . . . . . . . . . . . . . . 354

Figura 15. Cladograma mais parcimonioso para as relações filogenéticas entre os gêneros da família Curimatidae, segundo Vari (1989). . . . . . 355 
Figura 16. Esquema das relações filogenéticas na família Characidae, segundo Malabarba e Weitzman (2003). ........................ 356

Figura 17. Vista dorsal do mesetmóide e estruturas associadas de

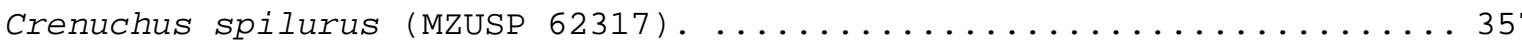

Figura 18. Vista dorsal do mesetmóide e estruturas associadas de Xenocharax spilurus (AMNH 230302). ........................ 358

Figura 19. Vista dorsal do mesetmóide e estruturas associadas de Astyanax mexicanus (UMMZ 203208).

Figura 20. Vista medial do suspensório mandibular e série opercular de Arnoldichthys spilopterus (MRAC 154445-459). ............... 360

Figura 21. Vista medial do suspensório mandibular e série opercular de Acestrorhynchus falcirostris (MZUSP 36824 ). ................. 361

Figura 22. Vista medial do pré-maxilar e dentes associados de Distichodus notospilus (AMNH 230295). ...................... 362

Figura 23. Vista medial do suspensório mandibular e série opercular de Iguanodectes geisleri (MZUSP 29614). Anterior para esquerda. ........ 363

Figura 24. Vista lateral das maxilas de Piaractus mesopotamicus (MZUSP

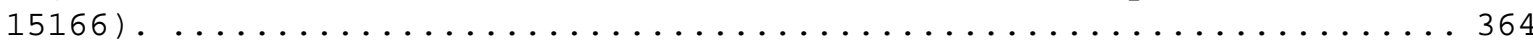

Figura 25. Vista medial do suspensório mandibular e série opercular de

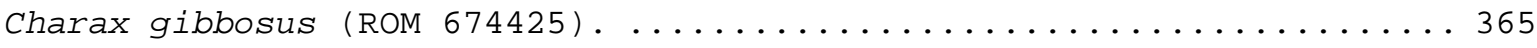

Figura 26. Vista medial do suspensório mandibular e série opercular de

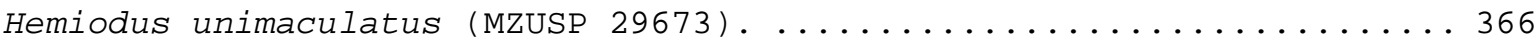

Figura 27. Vista medial do suspensório mandibular e série opercular de Piaractus mesopotamicus (MZUSP 15166). .................... 367

Figura 28. Vista lateral das maxilas de Crenuchus spilurus (MZUSP

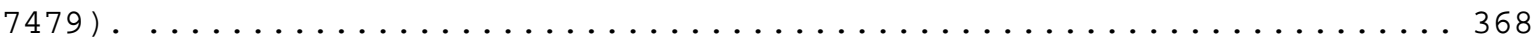

Figura 29. Vista medial do suspensório mandibular e série opercular de

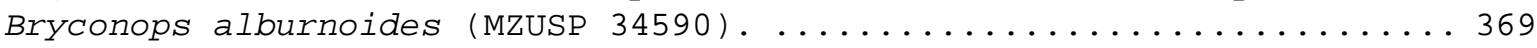

Figura 30. Vista medial do suspensório mandibular e série opercular de Rhoadsia altipinna (FMNH 93168). .......................... 370

Figura 31. Vista medial do opérculo de: (A) Hemiodus unimaculatus (MZUSP 29673); (B) Hepsetus odoe (MZUSP 84469) e; (C) Hollandichthys

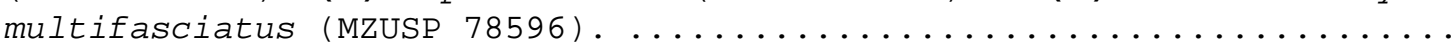

Figura 32. Vista lateral do neurocrânio de Bryconops alburnoides

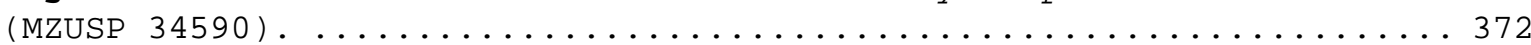

Figura 33. Vista lateral do neurocrânio de Compsura heterura (MZUSP

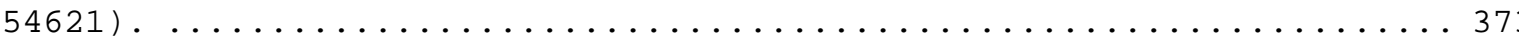

Figura 34. Vista lateral do neurocrânio de Xenocharax spilurus (AMNH

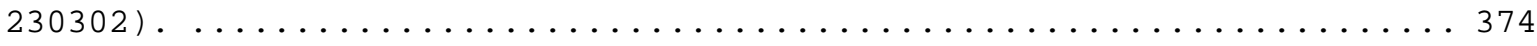

Figura 35. Vista ventral do neurocrânio de Bryconops alburnoides (MZUSP 34590) 
Figura 36. Vista ventral do neurocrânio de Xenocharax spilurus (AMNH 230302). ......................................... 376

Figura 37. Série infra-orbital de Distichodus notospilus (AMNH $230295)$.

Figura 38. Série infra-orbital de Prochilodus nigricans (MZUSP 4837). 378

Figura 39. Série infra-orbital de Acestrorynchus falcirostris (MZUSP

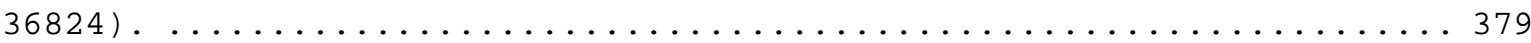

Figura 40. Série infra-orbital de Chalceus epakros (MZUSP 6706). ... 380

Figura 41. Série infra-orbital de Brycon pesus (MZUSP 36794). ..... 381

Figura 42. Vista ventral do basi-hial e basibranquiais de: (A) Hemiodus unimaculatus (MZUSP 29673) e (B) Potamorhina latior (MZUSP 6866). .................................. 382

Figura 43. Vista lateral do arco hióide e raios branquiostégios de: (A) Crenuchus spilurus (MZUSP 62317); (B) Anodus orinocensis (MZUSP 21280 ) e (C) Gymnocorymbus ternetzi (MZUSP 78951).............. 383

Figura 44. Uro-hial de Chalceus epakros (MZUSP 6706): (A) vista lateral e (B) vista ventral. ........................... 384

Figura 45. Uro-hial Crenuchus spilurus (MZUSP 62317): (A) vista

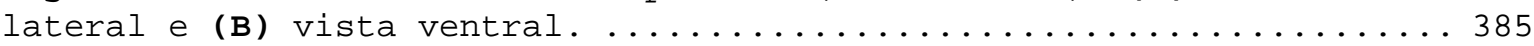

Figura 46. Vista medial da cintura peitoral direita de stygichthys

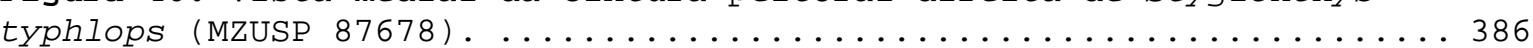

Figura 47. Vista medial da cintura peitoral direita de Acestrorynchus

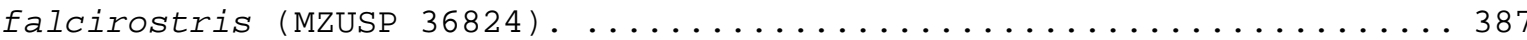

Figura 48. Vista medial da cintura peitoral direita de Hemiodus

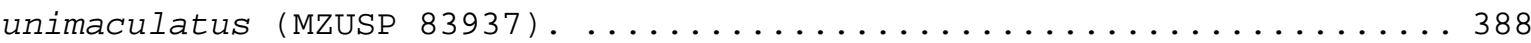

Figura 49. Vista lateral do extra-escapular de: (A) Bivibranchia fowleri (MZUSP 29628) e (B) Hollandichthys multifasciatus (MZUSP

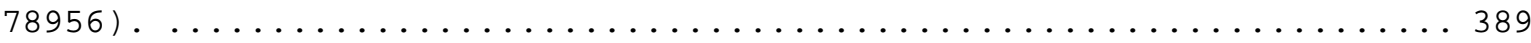

Figura 50. Vista lateral do cleitro de: (A) Apareiodon piracicabae (MZUSP 53885) e (B) Charax cf. leticiae (MZUSP 59511). ........... 390

Figura 51. Vista dorsal da cintura pélvica de Xenocharax spilurus (AMNH 230302). ................................ 391

Figura 52. Vista dorsal da cintura pélvica de Anodus orinocensis

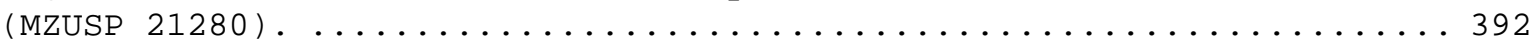

Figura 53. Vista dorsal da cintura pélvica de Hollandichthys

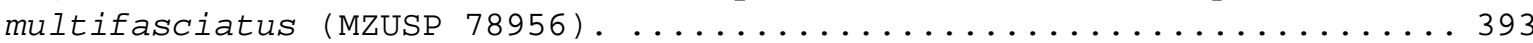

Figura 54. Vista lateral do esqueleto caudal e vértebras associadas de Xenocharax spilurus $($ AMNH 230302). ...................... 394

Figura 55. Vista lateral do esqueleto caudal e vértebras associadas de

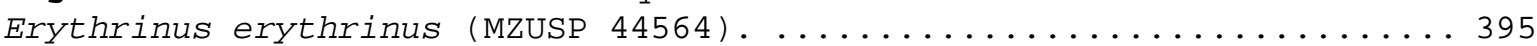


Figura 56. Vista lateral do esqueleto caudal e vértebras associadas de Metynnis lippincottianus (MZUSP 6888). .................... 396

Figura 57. Vista lateral das vértebras caudais anteriores de Bryconops alburnoides (MZUSP 34590 ). ............................. 397

Figura 58. Vista lateral das vértebras caudais anteriores de Metynnis

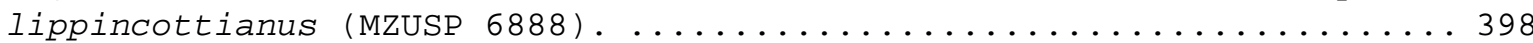

Figura 59. Vista lateral da cabeça de (A) Erythrinus erythrinus (MZUSP 44564), 129,8 mm CP, e (B) Astyanax mexicanus (UMMZ 203208), 62, 96mm

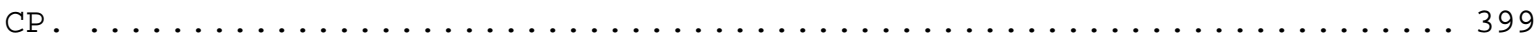

Figura 60. Vista lateral do olho de (A) Anodus orinocensis (MZUSP 21280), 153, $3 \mathrm{~mm} \mathrm{CP}$ e (B) Prochilodus nigricans (MZUSP 4837), 116, $3 \mathrm{~mm}$

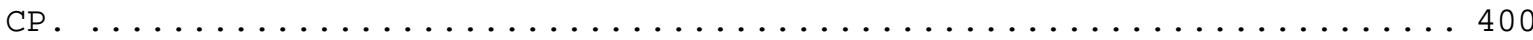

Figura 61. Cladogramas fundamentais mais parcimoniosos com $C I=0,11$,

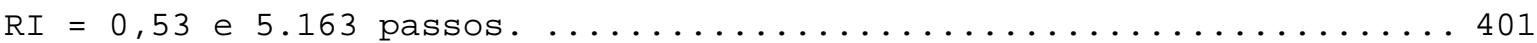

Figura 62. Cladograma de consenso estrito com o suporte de Bremer para os ramos. ........................................ 402

Figura 63. Número dos clados referidos no texto e as variações entre os cladogramas fundamentais e o consenso estrito. ............... 403

Apêndice 01. Lista das transições por caráter e número de passos de cada caráter. .................................. 404

Apêndice 02. Lista das transições comuns aos dois cladogramas

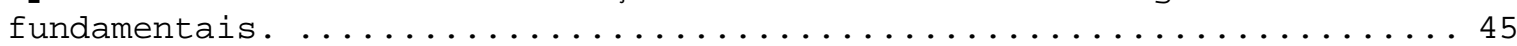




\section{INTRODUÇÃO}

\subsection{CONSIDERAÇÕES GERAIS SOBRE A ORDEM CHARACIFORMES}

A ordem Characiformes é um dos maiores grupos de peixes de água doce, com pelo menos 1674 espécies recentes válidas em 270 gêneros (NELSON, 2006), número este provavelmente subestimado (VARI, 1998). Tradicionalmente, o número das famílias de characiformes varia entre 14 (GÉRY, 1977), 16 (GREenWOod et al, 1966), ou 18 (BUCKUP, 1998; Nelson, 2006). Esta diferença se deve fundamentalmente a diferentes delimitações da família characidae, um grupo reconhecidamente nãomonofilético. Dessa forma, sub-grupos monofiléticos têm sido regularmente excluídos de characidae e transferidos para famílias à parte, como Crenuchidae (Buckup, 1998), Cynodontidae (LuCENA \& MENEZES, 1998) e Alestidae (ZANATA \& VARI, 2005), aumentando o número de famílias em Characiformes.

Membros recentes da ordem Characiformes ocorrem na África subsahariana, sul da América do Norte, Américas Central e do Sul (Fig.1). Atingem sua maior diversidade na região Neotropical representando aproximadamente $43 \%$ das espécies de peixes de água-doce na Amazônia e cerca de $30 \%$ das espécies de peixes Neotropicais. Fósseis na Europa (Portugal, França e Itália) e no Oriente Médio também são atribuídos à ordem (GAYet, 1981; Monod \& GAudAnt, 1998; OTERo \& GAYET, 2001), porém o status taxonômico de alguns destes é controverso (FINK et al., 1984), e sua inclusão em characiformes provisória.

A diversidade de tamanhos na ordem é notável, com espécies miniaturas (sensu WeITZMAN \& VARI, 1988) que não ultrapassam $26 \mathrm{~mm}$ (eg. Lepidarchus e Xenurobrycon), até outras com mais de um metro de comprimento padrão (eg. Hydrocynus e Salminus). Uma grande diversidade de hábitos alimentares também é observada em Characiformes. Algumas espécies são predadoras, como as piranhas, outras iliófagas (eg. Prochilodontidae e Citharinidae), herbívoras (entre as quais algumas com a dieta altamente especializada, limitando-se quase que exclusivamente a frutos que caem na água; eg. Colossoma), lepidófagas (se alimentando de escamas de outros peixes; eg. Catoprion e Probolus; SAZIMA, 1983), e espécies que se alimentam de pedaços de nadadeiras de outros peixes (eg. Eugnathichthys e Phago).

Representantes da ordem Characiformes ocorrem desde ambientes lênticos, até lóticos, com um caso registrado de uma espécie 
(Characidium tinbuiensis) subindo quedas de água por pedras (Buckup et al., 2000), ou de espécies transpondo quedas de água através de saltos (eg. Prochilodus). Vários grupos de Characiformes possuem grande importância na pesca (eg. Brycon, Citharinidae, Hydrocynus, Salminus e Prochilodontidae) sendo muitas vezes a única fonte de proteína animal de algumas populações ribeirinhas. Outras espécies possuem importância no mercado de peixes ornamentais (eg. Hyphessobrycon, Paracheirodon, Phenacogrammus e Gymnocorymbus).

Apesar da longa e rica história taxonômica da ordem Characiformes, relativamente pouco se sabe sobre as relações filogenéticas entre os seus grande subgrupos, e no contexto cladista o número de estudos é ainda mais restrito. A extrema diversidade morfológica, ou a morfologia externa pouco variável de alguns grupos (eg. Astyanax) foram motivos apontadas como dificuldades para a realização de estudos mais abrangentes das relações em characiformes.

\subsection{MONOFILETISMO DE CHARACIFORMES, E SUAS RELAÇõES EM TELEOSTEI}

o primeiro autor a propor que as espécies até então conhecidas de Characiformes formassem um grupo "natural" foi MüLLER (1842), subseqüentemente reafirmado em MülLER \& TROSCHEL (1845). GREENWOOd ET AL. (1966) também reafirmaram Characiformes como um grupo "filético", entretanto, esta condição só foi testada e corroborada por FINK \& FINK (1981 e 1996; Fig.2), já dentro do paradigma cladista. Estes autores, em uma análise filogenética de Ostariophysi, estabeleceram 0 monofiletismo de characiformes com base em sete sinapomorfias. Além disto, estabeleceram a relação de grupo-irmão entre a ordem Characiformes e um grupo composto por Siluriformes+Gymnotiformes. Estas três ordens teriam por sua vez como grupo-irmão a ordem Cypriniformes (FINK \& FINK, 1981). Apesar de vários estudos subseqüentes focarem no monofiletismo de Ostariophysi e sua relação com Clupeomorpha (eg. Lecointre \& NeLSon, 1996; SAItoH ET AL., 2003; Di DARio, 2005), as relações em otophysi foram apenas marginalmente abordadas devido a baixa representatividade das ordens cypriniformes, characiformes e principalmente siluriformes e Gymnotiformes. As relações em ostariophysi também foram marginalmente abordadas em análises realizadas dentro de cada uma destas ordens onde poucos representantes das outras ordens eram usados como grupos-externos (eg. Ortí \& Meyer, 1997; Calcagnotto et al., 2005). Em Ortí \& Meyer (1997) e Saitoh ET AL. (2003), Characiformes é recobrado como grupo-irmão de Gymnotiformes, ao invés de Gymnotiformes+Siluriformes. Apesar das 
relações em Ostariophysi, bem como o monofiletismo de cada uma de suas ordens, serem considerados bem corroborados, estudos abranjentes com o objetivo de testar as hipóteses de FINK \& FINK (1981, 1996) são basicamente inexistentes. De grande relevância também é a recente hipótese de que clupeomorpha, ao invés de Gonorynchiformes, poderia ser proximamente relacionado à otophysi (Di Dario, 2005), diferentemente do proposto por FINK \& FINK (1981, 1996). Isto certamente levará, se não a uma mudança das relações em otophysi, ao menos a uma mudança da interpretação das sinapomorfias propostas para cada grupo de otophysi. Além disto, deve-se atentar ao fato de characiformes ser a ordem com o menor suporte em termos de número de sinapomorfias de ostariophysi no estudo de FINK \& FINK (1981) e que em algumas das análises realizadas por ORTí \& MEYER (1997), baseadas em dados moleculares, Characiformes não é recobrado como monofilético. Sendo assim, uma análise global de ostariophysi em conjunto com clupeomorpha faz-se necessária como teste do monofiletismo de characiformes.

\subsection{HISTÓRICO DAS RELAÇõES EM CHARACIFORMES}

Após o estabelecimento de um grupo natural das espécies conhecidas até então de Characiformes (MüLLER, 1842), a classificação supragenérica destas espécies foi tratada por GüNTHER (1864), GILL (1893 e 1895), Regan (1911), Eigenmann (1910 e 1917), Gregory \& ConRad (1938), GREENWOOD et al. (1966) e GÉRY (1977). Uma retrospectiva destas classificações pré-cladistas foi extensamente abordada por VARI (1998), e estão além do objetivo desta introdução.

Dois fatos contribuíram, significativamente para o avanço na sistemática de characiformes na metade do século passado. 0 primeiro foi uma série de trabalhos nas décadas de 50 e 60 (WEITZMAn, 1954, 1960 e 1962; ROBERTS, 1969), que vieram a estabelecer um novo padrão para o estudo de relações no grupo. Estes trabalhos davam grande ênfase a estudos anatômicos detalhados (principalmente osteológico) em conjunto com o que já era utilizado, de morfologia externa e dentária. Este tipo de abordagem associada com a então nascente metodologia cladista (HENNig, 1950 e 1966) permitiu que os resultados destes estudos anatômicos pudessem ser convertidos em hipóteses de relações testáveis.

Dentro do paradigma cladista alguns trabalhos foram realizados com o intuito de estabelecer hipóteses de relações supragenéricas na ordem Characiformes. Os primeiros foram os de RoSEN (1972) e FINK \& 
WEITZMAN (1974), que lidavam com pequenos grupos em Characidae. Estas publicações foram seguidas de uma série de trabalhos (VARI, 1979, 1983 e 1995) que estabeleceram a maior parte da nossa compreensão sobre grupos suprafamiliaress em Characiformes, e seguidos de diversos estudos focados em famílias específicas (eg. LANGEANI, 1998). Apesar de inúmeros estudos sobre a filogenia de grupos dentro de Characiformes, apenas cinco se pretenderam análises mais amplas (UJ, 1990; LUCENA, 1993; ORtí \& MeYer, 1997; Buckup, 1998; e CAlCAgnotTo et al., 2005). Entretanto, apenas ORTÍ \& MEYER (1997) incluiu exemplares de todas as famílias conhecidas da ordem.

UJ (1990) em uma tese de doutorado não-publicada, propôs a primeira hipótese de relações globais em Characiformes (Fig.3), com apenas duas famílias excluídas da análise (Parodontidae e Lebiasinidae). Apesar da abrangência e da qualidade do estudo anatômico, as suas conclusões devem ser vistas com cuidado. Isto porque grande parte dos caracteres que foram incluídos como "tendências evolutivas", sem que houvesse uma delimitação mais precisas de seus estados. Além disto, Uj parece ter incluído caracteres de forma a sustentar uma hipótese de relações pré-concebida, muito semelhante à classificação proposta por GéRY (1977). o estudo também carece de uma análise de parcimônia global. Apesar disto, o autor levantou uma série de informações anatômicas úteis que têm sido reavaliadas e redefinidas.

Buckup (1991) em sua tese de doutorado, subsequentemente publicada em 1998, com o objetivo de determinar o grupo-irmão de Characidiinae, realizou uma análise filogenética com representantes de 16 famílias de Characiformes (incluindo Acestrorhynchidae [sensu LucENA \& Menezes, 1998] e Crenuchidae, esta proposta pelo autor) e quatro subfamílias de Characidae. Como resultado, ele propôs a primeira hipótese filogenética de Characiformes utilizando explicitamente a metodologia cladística (Fig.4). Nela o autor corrobora a posição basal de Citharinidae e Distichodontidae, como proposto por VARI (1979) e FINK \& FINK (1981) e corrobora também o monofiletismo do grupo formado por Characidiinae e crenuchinae (propondo assim a família crenuchidae para incluir os dois grupos). Também corroborou o clado ((Curimatidae, Prochilodontidae) (Chilodontidae, Anostomidae)) proposto por VARI (1983; Fig 5) e um grupo monofilético composto por Ctenoluciidae, Erythrinidae, Hepsetidae e Lebiasinidae. Com base na topologia encontrada em sua análise, o autor propôs a classificação utilizada atualmente em Characiformes: 
CITHARINOIDEI

\author{
DISTICHODONTIDAE \\ CITHARINIDAE
}

CHARACOIDEI

PARODONTOIDEA

PARODONTIDAE

ANOSTOMOIDEA

CURIMATIDAE

PROCHILODONTIDAE

CHILODONTIDAE

ANOSTOMIDAE

CRENUCHOIDEA

CRENUCHIDAE

HEMIODONTOIDEA

HEMIODONTIDAE

ALESTOIDEA

ALESTIDAE

CHARACOIDEA

CHARACIDAE

GASTEROPELECIDAE

CYNODONTOIDEA

CYNODONTIDAE

ACESTRORHYNCHIDAE

ERYTHRINOIDEA

ERYTHRINIDAE

LEBIASINIDAE

CTENOLUCIIDAE

HEPSETIDAE 
Entretanto, na sua análise, o autor utilizou apenas 28 terminais, não incluindo assim uma parcela importante da diversidade do grupo. Isto torna a hipótese gerada por Buckup potencialmente instável, visto que a representatividade taxonômica é crucial para a estabilidade da análise, devido ao potencial que táxons adicionais possuem de modificar radicalmente hipóteses de relações encontradas previamente (de Pinna, 1992).

LUCENA (1993) realizou um estudo das relações da família Characidae. Com o monofiletismo do grupo tido como incerto, o autor incluiu alguns terminais fora de Characidae, tornando esta uma análise maior que a de Buckup (1991 e 1998), em termos de espécies (68 espécies), mas não em termos de famílias (oito famílias). Como resultado (Fig.6), ele estabeleceu uma definição de characidae como grupo monofilético, incluindo alguns grupos como Alestidae e Serrasalmidae, que por vezes foram consideradas como famílias a parte. Em um estudo posterior (LuCENA \& MENEZES, 1998; Fig.7), Roestes, um dos terminais incluídos em Characidae em LUCENA (1993), foi considerado como grupo-irmão de Gilbertolus, sendo estes dois grupo-irmão de Cynodontinae, formando a família Cynodontidae. Estas mudanças resultam na conclusão de que Characidae, como analisado e definido por LUCENA (1993), é parafilético.

Os dois estudos amplos mais recentes sobre as relações em Characiformes foram moleculares, ORTí \& MEYER (1997) e CALCAGNOTTO ET AL. (2005). No primeiro, os autores incluíram representantes das 18 famílias de Characiformes (Nelson, 2006) e vários grupos de Characidae, utilizando seqüências $12 \mathrm{~S}$ e $16 \mathrm{~S}$ de ADN mitocondrial. Entretanto, como discutido pelos autores (ORTí \& MEYER, 1997: 91), os genes escolhidos não se mostraram úteis em resolver confiavelmente as relações em characiformes. Como exemplo disto, em uma das análises, o grupo composto por Distichodontidae + Citharinidae apareceu como grupo-irmão de Siluriformes, tornando Characiformes parafilético. Os grupos recuperados por esta análise são muito discrepantes com outros estudos da ordem, como Lebiasinidae + Serrasalminae e Prodontidae + Cynodontidae. Entretanto, em uma das análises os autores recuperaram Citharinidae+Distichodontidae na base de Characiformes (Fig.8).

A análise de CALCAgnotTo et al (2005) utilizou dois genes mitocondriais (16S e Citocromo b) e três genes nucleares (RAG2, sia, fkh e trop), e amostrou extensamente a ordem characiformes, com 124 terminais, sendo quase metade pertencente as três famílias africanas (Fig.9). 0 resultado corrobora algumas das hipóteses prévias, como 
Citharinoidei (sensu BucKuP, 1998) monofilético e basal na ordem e Anostomoidea monofilético, os autores, porém, não incluíram nenhum representante da família Curimatidae. Algumas novas propostas foram apresentadas, como a inclusão de Crenuchidae (proposto também por Netto-Ferreira, 2006; Fig.10) e Alestidae (sem Chalceus contra Zanata \& Vari, 2005) em Erythrinoidea. Outro resultado interessante é a relação de Parodontidae como grupo-irmão de Hemiodontidae, e estes mais relacionados à Anostomoidea, grupos que já haviam sido apontados como aparentados em estudos pré-cladistas. Os autores também apontaram o monofiletismo da família characidae, com a inclusão de Acestrorhynchidae e a exclusão de Serrasalminae.

As análises citadas possuem poucos resultados em comum. 0 primeiro ponto de concordância é um componente basal em characiformes composto pelas famílias africanas Distichodontidae + Citharinidae. VARI (1979) foi o primeiro a propor um relacionamento próximo entre estas duas famílias, também corroborando o monofiletismo de cada uma delas (Fig.11). Posteriormente, FINK \& FINK (1981) baseados na presernça de quatro caracteres considerados por eles plesiomórficos em otophysi, propuseram que este clado seria o grupo mais basal em characiformes. A relação mais próxima entre estas duas famílias e sua posição basal tem sido corroborada tanto por estudos morfológicos (BuckUP, 1998; Fig.4), como por alguns estudos moleculares (CALCAgnotto ET AL., 2005; Fig.8).

Outro grupo usualmente visto como monofilético é aquele denominado por BuckUP (1998) Anostomoidea. Este grupo foi primeiramente proposto por VARI (1983). Neste estudo, o autor propôs uma hipótese de relações, com base em uma série de novos caracteres, entre quatro famílias Neotropicais (Fig.5). Estas famílias, de maneiras distintas, haviam sido consideradas como aparentadas por estudos pré-cladísticos (muitas vezes com a inclusão de peixes de outras famílias, como Lebiasinidae e Hemiodontidae). Estas relações foram corroboradas em Buckup (1998), o único a incluir estas quatro famílias em um estudo mais amplo. Já CALCAGNOTTO ET AL. (2005; Fig.9), recupera um esquema igual, mas sem Curimatidae, ausente de sua matriz. Em ORTí \& MEYER (1997;Fig.8), as relações entre estas quatro famílias são quebradas. Sendo Prochilodontidae + Curimatidae, grupo-irmão de Hemiodontidae, enquanto Anostomidae é grupo-irmão de Chilodontidae + Crenuchidae.

Outro agrupamento suprafamiliar usualmente aceito é Erythrinoidea (sensu Buckup, 1998), composto pelas famílias Lebiasinidae, Hepsetidae, Erythrinidae e Ctenoluciidae. A relação próxima entre estas famílias foi proposta por LuCENA (1993), e 
corroborada por VARI (1995; Fig.12) e OYAKAWA (1998; Fig.13). Entretanto, outros autores (CAlCAgnotTo et Al., 2005; NetTo-Ferreira, 2006; Figs. 9 e 10) consideram estas famílias como pertencentes a um grupo monofilético não-exclusivo, com a inclusão de uma ou mais famílias (Alestidae e crenuchidae, e Acestrorhynchidae e crenuchidae respectivamente). Mesmo entre os que consideram Erythrinoidea (sensu Buckup, 1998) monofilético, existe uma divergência nas relações entre as famílias. Duas das análises mais recentes envolvendo este grupo (CAlcagnotto et Al. 2005 e Netto-Ferreira, 2006) incluem crenuchidae, como grupo-irmão de Erythrinidae, ou em uma politomia com os demais Erythrinoidea e Acestrorhynchidae, um fato interessante devido a semelhança externa entre esta família, Lebiasinidae e Erythrinidae.

A incongruência entre os resultados até então propostos, associada, em geral, a uma pequena representatividade da diversidade dos peixes characiformes nestes estudos, demonstra o quão provisório é o esquema de relações entre as famílias de uma das mais importantes ordens de peixes Neotropicais.

\subsection{ESTAdO dO CONHECIMENTO DAS RELAÇÕES FILOGENÉticAS NAS FAMÍliAS DE CHARACIFORMES}

Nos últimos 15 anos diversos estudos têm sido realizados em grande parte das famílias de characiformes. 0 monofiletismo e as relações genéricas de 12 das 16 famílias com mais de um gênero foram estabelecidas. Nesta seção é feita uma breve avaliação do conhecimento filogenético das famílias de characiformes, que permitirá um entendimento da escolhas de terminais (ver em MATERIAIS E MÉTOdos) e para as discussões de relações intra-familiares. A ordem das famílias apresentadas segue a classificação de Buckup (1998).

Citharinidae (3 gêneros, 9 espécies)

Esta pequena família é exclusivamente africana e composta por peixes grandes, atingindo quase $9 \odot \mathrm{cm}$ de comprimento máximo (PAUGY ET AL., 2003). Os peixes desta família são microfágos altamente especializados e possuem grande importância para a pesca em algumas regiões da África. As espécies atualmente incluídas em Citharinidae são todas muito semelhantes, e foram sempre classificadas dentro de um mesmo grupo. Apesar disto, dentro dos grupos supra-genéricos propostos que incluíam estas espécies, alguns autores incluíram também espécies atualmente classificadas em Distichodontidae (eg. GREGORY \& CoNRAD, 
1938). O monofiletismo de Citharinidae é amplamente corroborado, tendo VARI (1979) proposto 32 sinapomorfias para este grupo. Apesar de alguns destes estados poderem ser interpretados como plesiomórficas para Characiformes (eg. maxilar pequeno, ausência de dentes no maxilar e órgão epibranquial), vários outros são indubitavelmente sinapomorfias para este grupo.

CALCAGNOTTO ET AL. (2005), corroboraram o monofiletismo do gênero Citharinus com a inclusão de duas espécies em sua matriz. Este foi, além de VARI (1979) o único estudo a avaliar mais de uma espécie da família. Apesar disto, todos os estudos posteriores a VARI (1979) corroboraram um grupo monofilético composto por Citharinidae e Distichodontidae.

Distichodontidae (15 gêneros, aproximadamente 90 espécies)

Ao contrário de Citharinidae, esta família, também exclusivamente africana, é altamente diversificada na sua morfologia. Com peixes variando de menos de $2 \mathrm{~cm}$ a mais de $80 \mathrm{~cm}$, essa é uma das famílias de characiformes com maior diversidade de hábitos alimentares, possuindo espécies iliófagas, microcarnívoras e cortadores de nadadeiras. A composição desta família variou significativamente ao longo da sua história taxonômica, com alguns gêneros como Xenocharax e Neolebias sendo incluídos em Citharinidae (ver acima), e a alocação de gêneros predadores (eg. Mesoborus) ou comedores de nadadeiras (eg. Phago) em uma família a parte, Ichthyoboridae. As relações filogenéticas em Distichodontidae foram exploradas em apenas dois trabalhos, VARI (1979) e CALCAGnOtTo ET AL. (2005). 0 primeiro incluiu todos os gêneros de Distichodontidae e dos que eram considerados Ichthyoboridae. Como resultado deste estudo temos que, de fato, Ichthyoboridae é um grupo monofilético, mas não pode ser considerado uma família a parte, já que deixaria Distichodontidae parafilética (Fig.11). Xenocharax considerado pelo autor como o gênero mais basal de Distichodontidae é considerado também menos modificado morfologicamente (VARI, 1979; FINK \& FINK, 1981). Isto levou à utilização deste gênero monotípico em praticamente todos os estudos cladisticos de characiformes e ordens relacionadas. 0 estudo de CalcagnotTo Et AL. (2005), que incluiu oitos dos 15 gêneros válidos, corrobora o fato de Xenocharax ser o Distichodontidae mais basal, e de que a família Ichthyoboridae não forma um grupo monofilético dentro de Distichodontidae (Fig.9). Distichodontidae é 
considerada como grupo irmão de Citharinidae (VARI, 1979; ORTí \& MEYER, 1997; Buckup, 1998; e Calcagnotto et Al., 2005).

Parodontidae (3 gêneros, 26 espécies)

Esta pequena família de peixes Neotropicais é relativamente uniforme em relação à sua morfologia externa, com todos estes peixes possuindo formato fusiforme, boca ventral e nadadeiras peitorais dispostas lateralmente no corpo. Apesar de uma recente revisão taxonômica (PAVANelli, 1999), novas espécies continuam a ser descrita (Ingenito \& Buckup, 2005). Segundo StARnes \& SCHIndLER (1993), os três gêneros de Parodontidae são monofiléticos, entretanto os autores só mencionaram possíveis sinapomorfias para Apareiodon. Apesar disto, usualmente as espécies desta família são genericamente alocadas com base em dois caracteres tradicionais, presença vs. ausência de dentes no dentário e um vs. dois raios não-ramificados na nadadeira peitoral (PAVANELLI, 2003), apesar dos problemas relacionados à polarização destes caracteres (ver Ingenito \& BUCKUP, 2005). STARNES \& SchINDLER (1993) ainda propuseram o único esquema até hoje de relações entre estes gêneros, onde Saccodon é grupo-irmão de Apareiodon + Parodon. Apesar de afirmar em que este esquema baseia-se em diversos caracteres, nenhum foi apresentado. Parodontidae usualmente era considerado como relacionado com Hemiodontidae, ou ainda como uma subfamília de Hemiodontidae (GÉRY, 1977). As semelhanças entre estas duas famílias são inegáveis, mas alguns autores preferiram interpretá-las como convergências (LANGEANI, 1998) ou deixar a questão em aberto (eg. ROBERTS, 1974). A relação próxima entre Hemiodontidae e Parodontidae só foi recuperada no estudo de CALCAGnOtTo ET AL. (2005; Fig.9). Nos demais estudos (ORTÍ \& MEYER, 1997; BUCKUP, 1998) elas aparecem como distantemente relacionadas. Apesar do monofiletismo de Parodontidae ser muito provável, devido à presença de vários caracteres não encontrados em nenhum outro Characiformes, ele ainda não foi testado, já que os estudos até o momento utilizaram apenas uma espécie de Parodontidae.

Prochilodontidae (3 gêneros, 21 espécies)

Os membros desta família sempre foram considerados como formando um grupo natural. Isto resulta de uma morfologia externa uniforme entre os seus membros, mas muito discrepante dos demais characiformes. VARI (1983) propôs a família como monofilética com base em 18 
sinapomorfias, principalmente relacionadas aos arcos branquiais e hióide, suspensório e maxilas. 0 autor ainda apontou esta família como mais proximamente relacionada à curimatidae, com base em 11 sinapomorfias. Esta hipótese foi corroborada por mais quatro sinapomorfias propostas posteriormente (VARI, 1989). A relação próxima entre estas duas famílias foi corroborada pela análise molecular de ORTí \& MEYER (1997) e pela análise morfológica de Buckup (1998). Mais recentemente, CASTRO \& VARI (2004) corroboraram a hipótese de monofiletismo da família proposta por VARI (1983), adicionando 40 outras sinapomorfias. Neste estudo, os autores propõem uma hipótese de relação intrafamiliar, onde Prochilodus é grupo-irmão de Semaprochilodus e Ichthyoelephas. As relações das espécies de cada gênero também são abordadas, mas com resolução apenas parcial em Prochilodus e Semaprochilodus.

\section{Chilodontidae (2 gêneros, 7 espécies)}

Esta família foi primeiramente considerada monofilética por VARI (1983) com base em 26 sinapomorfias. Mais tarde esta hipótese foi corroborada por VARI ET AL. (1995), quando 10 sinapomorfias adicionais foram propostas. A relação de grupo-irmão com Anostomidae também foi proposta por VARI (1983) baseada em 15 sinapomorfias. Esta hipótese é corroborada por BuckUP (1998). Entretanto, os estudos moleculares indicam Chilodontidae como grupo-irmão de Crenuchidae (ORTí \& MEYER, 1997) ou como grupo-irmão de Prochilodontidae (CALCAGNOTTO ET AL., 2005).

\section{Anostomidae (12 gêneros, aproximadamente 140 espécies)}

Este grupo de peixes é bem destoante das demais famílias de Anostomoidea (sensu BuckUP, 1998), por possuir dentes bem desenvolvidos, responsáveis pelo sucesso destes animais como herbívoros. Também destoa pelo menor nível de conhecimento da sua taxonomia alfa e relações entre as suas espécies, quando comparada às demais famílias de Anostomoidea. A única publicação a versar sobre relações filogenéticas nesta família foi Winterbottom (1980). Nesta, o autor estabelece o monofiletismo da subfamília Anostominae e as relações entre suas espécies. Apesar de Anostominae compreender cinco dos 12 gêneros da família, a sua diversidade específica é muita baixa, compreendendo menos de $10 \%$ do total de espécies descritas na família. As relações de todos os gêneros conhecidos é atualmente objeto de estudo de Brian Sidlauskas (FMNH) e Richard Vari (USNM), resultados 
preliminares destes autores indicam que o gênero Leporellus seria o gênero mais basal da família. As relações de Anostomidae com Chilodontidae foram propostas primeiramente por VARI (1983) e corroboradas apenas por BUCKUP (1998). ORTÍ \& MEYER (1997) consideraram esta família como grupo-irmão de Chilodontidae+Crenuchidae, enquanto CAlCAgnotTo ET AL. (2005) a consideraram como grupo-irmão de Prochilodontidae + Chilodontidae.

\section{Curimatidae (8 gêneros, 97 espécies)}

Esta família, composta apenas por espécies de peixes iliófagos, sem dentes, é a família de characiformes onde possivelmente reside a melhor compreensão de sua taxonomia-alfa e relações filogenéticas de suas espécies. Isto devido a uma série de publicações por VARI (1984, 1989a, 1989b, 1989c, 1989d, 1991, 1992a e 1992b). A filogenia da família (Fig.15) tem na base o gênero Curimatopsis, seguido de Potamorhina, Curimata, Psectrogaster e um clado não resolvido composto por Steindachnerina, Pseudocurimata, Curimatella e cyphocharax (este sem monofiletismo estabelecido). As hipóteses de relações de Curimatidae no período pré-cladista foram as mais diversas, tendo sido agrupada com Citharinidae, Prochilodontidae, Hemiodontidae e Parodontidae. Entretanto, após VARI (1983), parece ser consenso que Curimatidae seja grupo-irmão de Prochilodontidae (eg. ORTÍ \& MEYER, 1997; BUCKUP, 1998).

\section{Crenuchidae: (12 gêneros, 76 espécies)}

Membros da subfamília Characidiinae já foram classificados como pertencendo aos mais diversos grupos de characiformes (eg. Lebiasinidae, Erythrinidae, Parodontidae e Anostomidae). Apenas em 1974, HOEDEMAN considerou-os aparentados a Crenuchinae. Entretanto, evidências para isto só seriam explicitadas muito mais tarde (Buckup, 1991, 1993 e 1998). Buckup (1991) corroborou o monofiletismo da família crenuchidae, baseado em seis caracteres. As relações em Characidiinae também forma abordadas pelo mesmo autor (Buckup, 1993), enquanto as relações em Crenuchinae foram abordadas por CAMPANARIo (2002). BuckUP (1991 e 1998) considerou Crenuchidae como grupo-irmão de todos os Characiformes, menos Anostomoidea e Citharinoidei (sensu Buckup, 1998). Entretanto, esta relação não foi recobrada em outro estudos. ORTí \& MEYER (1997) consideraram crenuchidae como grupo-irmão de Chilodontidae, enquanto CALCAgnotTo ET AL. (2005) consideraram como 
grupo-irmão de Erythrinidae. NetTo-FERREIRA (2006) recobra uma relação de grupo-irmão de Crenuchidae + (Erythrinidae, Lebiasinidae) em uma das suas árvores, enquanto nas demais Crenuchidae seria grupo irmão de Erythrinoidea, incluindo Acestrorhynchidae.

Hemiodontidae (5 gêneros, 28 espécies)

Os membros desta família são semelhantes entre si, possuindo corpo roliço, membrana adiposa do olho bem desenvolvida e sulco suprapeitoral. Apesar disto, a composição genérica atual da família só foi estabelecida por RoBerts (1974), já que anteriormente o gênero Anodus, um gênero edêntulo, era incluído em Curimatidae. Apesar disto, Anodus continuou sendo classificado em Curimatidae por alguns autores (Géry, 1977).

Uma proposição da família enquanto unidade monofilética em um contexto explicitamente cladista aparece em LANGEANI (1998), que propôs 17 sinapomorfias para a família. Segundo LANGEANI (1998), os gêneros constituintes da família são divididos em duas subfamílias irmãs. A primeira Anodontinae é composta por Anodus e Micromischodus, e a segunda, Hemiodontinae é composta por Hemiodus + (Bivibranchia + Argonectes) (Fig.14). LANGEANI (1998) forneceu ainda sinapomorfias para todo os grupamentos supragenéricos, bem como para seus gêneros.

Antes, acreditava-se que Hemiodontidae estivesse de alguma forma relacionado com Parodontidae (ver acima) ou com as famílias constituintes de Anostomoidea (eg. Boulenger, 1904). De fato, com exceção de Buckup (1998), todas as relações propostas são com Parodontidae (CAlCAgnotTo ET AL., 2005) ou com Anostomoidea (ORTí \& MEYER, 1997). A proposta de Buckup (1998) é de que Hemiodontidae seria mais próximo de um grande grupo composto por todos Characiformes, menos Citharinidae, Distichodontidae, Parodontidae, Anostomoidea e Crenuchidae. LANGEANI (1998) baseou-se na proposta de BuckUP (1998) para considerar estes caracteres que ocorrem em Parodontidae e/ou Anostomoidea como homoplásticos.

Alestidae (sensu ZANATA \& VARI, 2005; 19 gêneros, aproximadamente 120 espécies)

Tida como uma subfamília africana de Characidae por alguns autores (GREENWOOD ET AL., 1966), ela foi recentemente elevada ao nível de família com base em dois estudos filogenéticos (ZANATA \& VARI, 2005 e 
Calcagnotto et al., 2005). Estes dois estudos também exploraram as relações das espécies desta família, obtendo resultados congruentes apenas em alguns pontos. ZANATA \& VARI (2005) consideraram o gênero Neotropical Chalceus como grupo irmão de todos os Alestidae, justificando a ampliação da família de forma a incorporá-lo. Porém, de acordo com a topologia encontrada por CALCAGnOtTo ET AL. (2005), Chalceus estaria mais relacionado com espécies de Characidae, fazendo com que restringissem a família apenas às espécies africanas. Entretanto, os dois estudos concordam na posição de Arnoldichthys como gênero mais basal dos Alestidae africanos. Os dois estudos discordam no monofiletismo de Brycinus e na posição de Hydrocynus. Além da proposta de que Alestidae seria grupo-irmão de Hepsetidae + (Ctenoluciidae + Lebiasinidae) (CALCAgnotto ET AL, 2005), a família foi apontada como grupo-irmão de Acestrorhynchidae (Ortí \& Meyer, 1997), de um grupo composto por Erythrinoidea, Acestrorhynchidae e Characidae (BUCKUP, 1998), inclusa em Characidae (LuCENA, 1993), de um grupo composto por Hemiodontidae, Crenuchidae e Chalceus (ZANATA, 2000) ou ainda grupoirmão de Characidae (Netto-Ferreira, 2006).

Characidae (88 gêneros, aproximadamente 1000 espécies)

Como mencionado acima, a questão do monofiletismo de characidae e de suas relações com os demais characiformes é um dos problemas mais relevantes para o entendimento das relações em characiformes. De acordo com estudos prévios, grande parte das espécies que hoje compõem a família characidae deve formar um grupo monofilético (ver CaLCAGNotTo ET AL., 2005), entretanto, grupos como Acestrorhynchidae, Alestidae e Serrasalminae por vezes são recobrados como mais relacionados com algum grupo dentro deste Characidae monofilético.

Recentemente, Malabarba \& Weitzman (2003; Fig.16) Atualmente existem evidências do monofiletismo de algumas das subfamílias de Characidae, mas a maior parte dos gêneros e espécies encontra-se sem qualquer hipótese de relações. Das subfamílias que já foram indicadas como monofiléticas temos, Glandulocaudinae (WeItZMAN ET AL., 2005), Stervardiinae (WEITZMAN ET AL., 2005), Iguanodectinae (MOREIRA, 2002), Cheirodontinae (MALABARBA, 1998), parte de Paragoniatinae (QUEVEDo, 2006), Serrasalminae (MACHADO-AlLISON, 1983) e Stethaprioninae (REIS, 1989). Estes estudos têm por característica em comum a pouca inclusão de outros terminais de Characidae o que leva a incerteza no monofiletismo de algumas destas subfamílias. Além disto, alguns gêneros são muitas vezes vistos como basais em Characidae, como Chalceus (CALCAGNOTTO ET AL., 
2005), Brycon (Buckup, 1998), Bryconops (ZANATA, 2000) e Salminus (LimA, $2006)$.

Gasteropelecidae (3 gêneros, 9 espécies)

Os peixes desta família são bastante modificados, e apesar da sua osteologia e taxonomia (WEITZMAN, 1960) ser bem conhecida, nenhuma hipótese de relações foi proposta para este grupo. Representantes desta família só foram incluídos no trabalho de ORTí\& MEYER (1997), onde ela aparece como grupo-irmão de Anostomidae + (Chilodontidae + Crenuchidae). Apesar de Buckup (1998) não incluir nenhum representante de Gasteropeleceidae, ele a considerou, em sua classificação, como um Characoidea incertae sedis.

Acestrorhynchidae ( 1 gênero, 15 espécies)

Estes peixes piscívoros formam um grupo monofilético com base em pelo menos em cinco sinapomorfias (Lucena \& Menezes, 1998), entretanto as relações entre as suas espécies ainda são desconhecidas (ToledoPiza, em prep.). As hipóteses de relações de Acestrorhynchidae com os demais Characiformes são as mais diversas, possivelmente em decorrência da sua morfologia extremamente modificada. Buckup (1998) considerou a família como grupo-irmão de Erythrinoidea, relação que foi parcialmente recobrada por NETTO-FERREIRA (2006) que propôs Acestrorhynchidae como grupo-irmão de Ctenoluciidae + Hepsetidae. Entretanto, a hipótese de BuCKuP (1998) foi refutada por LUCENA \& MENEZES (1998; Fig.7) que consideraram Acestrorhynchidae como grupo-irmão de Cynodontidae. As hipóteses moleculares apontam para relações de Acestrorhynchidae totalmente diferente, como grupo-irmão de Alestidae (ORtí \& MeYer, 1997) ou como parte de Characidae (CAlCAgnotto et AL., 2005 ) .

Cynodontidae (5 gêneros, 14 espécies)

A família Cynodontidae é composta por duas subfamílias, Cynodontinae e Roestinae. No geral, as espécies de Cynodontinae sempre foram classificadas em um mesmo grupo, possivelmente pelo seu formato de corpo aberrante (ver TOLEDO-PIZA, 2000). Já as espécies de Roestinae foram classificadas junto a espécies de Characinae (uma subfamília de Characidae composta por predadores especializados) (MENEZES, 1974). Em 1976, Howes forneceu evidências de uma relação filogenética mais 
próxima entre Cynodontinae e Roestinae. LUCENA (1993) refutou esta hipótese, encontrando Cynodontinae como grupo-irmão de Acestrorhynchidae, e Roestinae como grupo-irmão de Heterocharacini (Characinae) (Fig.6). Entretanto, posteriormente este mesmo autor (LUCENA \& MENEZES, 1998) reavaliando a relação entre estes grupos, corroborou a proposta de HowES (1976) fornecendo nove sinapomorfias para o monofiletismo de Cynodontidae, além de outras sustentando as subfamílias Cynodontinae e Roestinae como monofiléticas (Fig.7). As relações entre as espécies de Roestinae também foram abordadas por LUCENA \& MENEZES (1998), enquanto as relações das espécies de Cynodontinae foram elucidadas por TOLEDO-PIZA (2000). ORTÍ \& MEYER (1997) e Calcagnotto et al. (2005), foram os únicos dois outros estudos que incluíram pelo menos uma espécie de cynodontidae (na verdade apenas de Cynodontinae), e recuperaram relações bem distintas das propostas por LUCENA \& MENEzes (1998). No primeiro, Cynodontidae é considerado como grupo-irmão de Parodontidae enquanto no segundo é considerado como grupo-irmão de um grupo composto por Anostomoidea (sensu Buckup, 1998), Hemiodontidae, Parodontidae e Serrasalminae.

Hepsetidae (monotípica)

Esta espécie africana ( $H$. odoe), usualmente tem sido associada a uma ou mais famílias de Erythrinoidea (sensu Buckup, 1998). Roberts (1969) indicou uma relação próxima entre esta família e Ctenoluciidae, outra família com espécies de focinho bem alongado. Esta mesma relação foi recuperada por NetTO-FERREIRA (2006). VARI (1995; Fig.12) considerou Hepsetidae como grupo-irmão de Erythrinidae + Ctenoluciidae, hipótese refutada por OYAKAWA (1998) que considerou Erythrinidae mais relacionado a Lebiasinidae e CALCAGNOTTO ET AL. (2005) que considerou Ctenoluciidae + Lebiasinidae.

Ctenoluciidae (2 gêneros, 7 espécies)

As relações entre as espécies foram abordadas por VARI (1995). Para as relações desta família com os demais Characiformes, ver discussão da família Hepsetidae, acima.

Erythrinidae (3 gêneros, 13 espécies)

Quatro estudos abordaram as relações em Erythrinidae (LucENA, 1993; Oyakawa, 1998; Mattox, 2005; Netto-Ferreira, 2006). Todos eles 
concordam de que Hoplias (dividido por oyakawa em três gêneros) é o grupo-irmão de Erythrinus + Hoplerythrinus. Entretanto, como mencionado na discussão das outras famílias de Erythrinoidea, as propostas de relações de Erythrinidae com os demais Characiformes é bem variável. Tendo sido apontada como grupo-irmão de Ctenoluciidae (VARI, 1995), de Hepsetidae (ORTí \& MEYER, 1997), de Lebiasinidae (LUCENA, 1993; Netto-Ferreira, 2006), de uma parte de Lebiasinidae (OYAKAWA, 1998), ou de relações incertas em Erythrinoidea (BuckUP, 1998). A discussão sobre relações de Erythrinidae com os demais Characiformes já foi abordada nas outras famílias de Erythrinoidea

\section{Lebiasinidae ( 7 gêneros, 61 espécies)}

Os estudos relevantes (OyAKAWA, 1998; Buckup, 1998; NetTo-FerReira, 2006), concordam com a existência de duas subfamílias Pyrrhulinidae e Lebiasinidae. Sendo Lebiasinidae composto por Piabucina e Lebiasina, e Pyrrhulininae composto por todos os outros gêneros da família. OYAKAWA (1998) considerou estas subfamílias como monofiléticas, mas a Lebiasinidae parafilética, já que Lebiasininae seriam mais relacionada à Erythrinidae que a Pyrrhulinidae (Fig.13). Recentemente, NetTo-FerREIRA (2006) demonstrou que apesar de Piabucinae ser monofilético, Lebiasina e Piabucina são parafiléticos (Fig.10), sinonimizando Piabucina em Lebiasina. Neste mesmo estudo, o autor demonstrou que Derhamia, um gênero descrito recentemente, seria o grupo mais basal em Pyrrhulininae. 


\section{OBJETIVOS}

0 presente estudo possui quatro objetivos centrais:

1)Testar o monofiletismo das famílias de Characiformes;

2)Delimitar a família Characidae;

3)Testar o monofiletismo dos grupos suprafamiliares propostos em Characiformes;

4)Estabelecer as relações entre os grupos monofiléticos encontrados;

Como co-produto da análise se espera testar as relações

propostas em cada uma das famílias de characiformes, e avançar no entendimento das relações em Characidae. 


\section{MÉTODOS E MATERIAIS}

\subsection{CONSIDERAÇõES GERAIS SOBRE A METODOLOGIA E A ANÁLISE}

Para o estudo das relações filogenéticas foi utilizada a metodologia cladista (HeNnig, 1950, 1966; WiLEY, 1981; WileY et al. 1991; Forey et al. 1993; Kithching et al., 1998; Schuh, 2000; ScotLAnd \& PenNington, 2000; WIENS, 2000), atual paradigma em sistemática. Esta metodologia visa maximizar o poder explicativo dos estados de caracteres presentes nos terminais ao diminuir a necessidade de hipóteses ad hoc de homoplasia (FARRIS, 1983). A polarização de caracteres, com o auxílio de grupos-externos, seguiu a lógica proposta por NIXON \& CARPENTER (1993). Entretanto, na utilização de "softwares" para análises filogenéticas o método em si é irrelevante, já que as buscas por cladogramas mais parcimoniosos é feita utilizando diagramas nãoenraizados, sendo apenas posteriormente escolhido o ponto de enraizamento deste diagrama, de forma a se obter as direções das transformações entre os estados de caráter. Os caracteres multiestados foram tratados como ordenados, ou "minimamente conectados" (SLOWINSKI, 1993), sempre que possível. Isto é, sempre que foi observada uma morfoclina, onde estados intermediários são encontrados entre duas condições extremas estes foram considerados como ordenados. As sinapomorfias discutidas para os clados encontrados são apenas as nãoambíguas, já que muitas vezes os caracteres de evolução muito complexa possuem diversas otimizações, e a escolha de qualquer uma destas, incluindo os seus extremos DELTRAN ("delayed transformation") ou ACCTRAN ("Accelerated transformation"), é arbitrária.

\section{2 CARACTERES}

0 estudo baseou-se na análise de caracteres da morfologia interna, principalmente osteológicos, da morfologia da bexiga natatória e do trato digestivo, bem como da morfologia externa. A observação do esqueleto foi feita a partir de material diafanizado e corado, seguindo o método descrito por TAYLOR \& VAN DYKE (1985), em alguns casos com modificação proposta por SPRINGER \& JOHNSON (2000), na qual a solução de alizarina é preparada com etanol, ao invés de uma solução a base de água. Esqueletos secos foram utilizados como complemento às observações feitas em material diafanizado e corado. Após o processo de diafanização, os exemplares foram dissecados 
seguindo a técnica proposta por WeITZMAN (1974), de maneira a tornar possível a observação de todos os complexos esqueléticos. A nomenclatura osteológica segue aquela originalmente proposta por WEITZMAN (1962), incluindo modificações sumarizadas por VARI (1995) e Fink \& Fink (1996) e o seu correspondente em português (CASTRO \& CASTRo, 1987), com modificações propostas por BRITTO (2003). Para a observação da morfologia das escamas foi desenvolvida uma modificação da metodologia proposta por LIPPITSCH (2001). Esta metodologia consiste em quatro etapas (retirada da escama, clareamento, dissolução da epiderme e colorização) cujo produto final é montado em uma lâmina para armazenamento. Foram selecionadas cinco regiões do corpo (linha mediana pré-dorsal, látero-dorsal anterior, linha lateral anterior, pré-pélvica e gular). As escamas eram então emersas em uma solução a 20\% de peróxido de hidrogênio, com uma pastilha de hidróxido potássio para cada $100 \mathrm{ml}$, por aproximadamente 10 minutos, ou até a escama estar despigmentada. Em seguida, caso existisse uma camada epidérmica espessa sobre a escama, ela era colocada em uma solução 5\% de hipoclorito de sódio por não mais de 5 minutos, quando essa camada não era retirada mecanicamente com o auxílio de um pincél. Depois de enxaguadas, as escamas foram posta em solução de alizarina seguindo SPRINGER \& JOHNSON (2000) por 10 a 20 minutos, sendo então transferidas para uma solução de $50 \%$ de glicerina, ou álcool $70 \%$, e então montadas em lâminas. A nomenclatura lepidológica utilizada foi a de LAGLER (1947), com modificações propostas por RoBERTS (1993).

Para a observação da bexiga natatória e trato digestivo o lado esquerdo da cavidade abdominal foi exposto através de uma incisão, pouco acima da nadadeira pélvica. Essa incisão seguiu do ânus até a cintura peitoral, com duas incisões aproximadamente verticais a ela anterior e posteriormente; a incisão anterior seguindo toda a margem da cintura peitoral e a posterior seguindo o contorno posterior da cavidade abdominal. No geral, uma quarta incisão, ligando dorsalmente os cortes verticais, era feita na base das costelas. Esta técnica além de permitir a melhor observação das estruturas internas, também permite a sua retirada sem grandes danos. Em alguns exemplares de espécies mais raras, o quarto corte foi eliminado, e a retirada das estruturas foi feita pelo espaço entre estas três incisões, mantendo as costelas intactas e minimizando os danos ao espécime, mas isto usualmente levou a danos à câmara anterior da bexiga natatória. Depois de retirados, a bexiga natatória e o trato digestivo foram guardados em álcool para estudos posteriores. 


\subsection{SELEÇÃO DE TÁXONS}

A escolha de terminais seguiu, sempre que possível, 0 procedimento proposto por PRENDINI (2001) para táxons supra-específicos. A estratégia de inclusão de terminais recomendada por PRENDINI é: (1) o mínimo de duas espécies por táxon, exceto monotípicos; (2) táxon tipo, sempre que possível, especialmente quando o monofiletismo do grupo for contestado; (3) quando existirem hipóteses de relações, um terminal com ramo curto (sem muita autapomorfia); (4) quando tais hipóteses não existirem, exemplares devem ser escolhidos de forma a maximizar a diversidade morfológica para aquele táxon.

Nesta análise, selecionei os terminais de forma a incluir todas as famílias reconhecidas atualmente em Characiformes (BuckUP, 1998; NELSON, 2006), além de todas as subfamílias de Characidae, e diversas espécies de Characidae incertae sedis. Exceto por algumas subfamílias de Characidae, inclui mais de um representante de forma a testar o monofiletismo destes agrupamentos. A seleção de grupos-externos é essencial para qualquer análise filogenética. Em Ostariophysi isto é um problema ainda maior, já que as ordens que compõem este grupo são no geral morfologicamente muito dispares umas das outras, isto é, possuem um elevado número de sinapomorfias na base de cada ordem. Sendo assim, incluí apenas um terminal por ordem, e preferencialmente o mais basal. 0 conhecimento das relações filogenéticas em cypriniformes ainda é muito preliminar, sendo basicamente restrito a um trabalho sobre as relações entre as famílias da ordem (SIEBERT, 1987) e alguns trabalhos dentro de pequenos grupos de Cyprinidae. FINK \& FINK (1981) propuseram que opsariichthys seria o gênero mais conservado morfologicamente. Nenhum outro trabalho sobre Cyprinidae corroborou esta possibilidade e opsariichthys é normalmente visto como um gênero derivado em Cyprinidae (CAVENDER \& COBURN, 1992). Este fato, e a falta de conhecimento das relações em cyprinidae, me levaram a incluir um gênero da segunda família mais basal de cyrpiniformes, Catostomidae ( segundo SIEBERT, 1987).

Segue abaixo explicações mais detalhadas sobre as escolhas dos terminais do grupo interno por família.

Citharinidae: foi incluída a espécie tipo de Citharinus, $C$. citharinus. Isto, devido às incertezas sobre as relações entre as espécies de Citharinidae, e sobre a validade dos outros dois gêneros, 
Citharidium e Citharinops. Além disto, exemplares de Citharidium são raros em coleções e não estiveram disponíveis para o exame.

Distichodontidae: A escolha dos terminais de Distichodontidae visou amostrar todos os "grupos" reconhecidos por VARI (1979). Xenocharax. como representante mais basal da família e menos modificado morfologicamente. Neolebias, que juntamente com Nannaethiops forma o grupo mais basal depois de Xenocharax. Hemistichodus foi incluído por ser o mais basal de um dos grupos, enquanto dois dos três gêneros do outro grupo foram incluídos, Nannocharax e Distichodus.

Parodontidae: Como se desconhecem as relações entre as espécies de cada gênero e seu monofiletismo é incerto, foram incluídas as espécies-tipo de Saccodon e Apareiodon. A espécie-tipo de Parodon, $P$. suborbitalis, é rara em coleções, com isto, incluí Parodon nasus, espécie mais acessível e pertencente ao grupo "suborbitalis" (sensu PAVANelli, 1999), sendo possívelmente relacionada com a mesma.

Hemiodontidae: Foi incluído material das duas subfamílias de Hemiodontidae, Anodontinae e Hemiodontinae. A inclusão de Anodus se justifica pela oportunidade de se testar, em um contexto mais abrangente, a hipótese pré-filogenética de sua inclusão em Curimatidae. Deste gênero, foi incluída a espécie $A$. orinocensis pela disponibilidade de material para o presente estudo. De Hemiodontinae, visto que não existem estudos das relações filogenéticas das espécies dos sues gêneros, foram incluídos Hemiodus unimaculatus e Bivibranchia fowleri. As duas espécies são sinônimos sênior das espécies-tipos dos seus respectivos gêneros. Hemiodus é o gênero mais basal de Hemiodontidae, e Bivibranchia possui várias homoplasias com membros de Anostomoidea, sendo a sua inclusão interessante para testar 0 monofiletismo de Hemiodontidae.

Prochilodontidae: Foram incluídos o gênero mais basal, Prochilodus, e Semaprochilodus que é menos modificado (menos sinapomorfias) que Ichthyoelephas. As espécies selecionadas destes gêneros para o presente estudo não foram nem as mais basais nem as espécies-tipo. A seleção foi baseada apenas na disponibilidade de material.

Chilodontidae: Os dois gêneros desta família foram amostrados. Chilodus punctatus foi escolhido por ser a espécie-tipo de Chilodus na ausência de uma hipótese de relações para suas espécies. Apesar de existir uma hipótese de relações para Caenotropus (VARI ET AL., 1995), 
espécimes da espécie mais basal ( $C$. mestomorgnatos) não estavam disponíveis para este estudo, sendo assim, optei pela espécie-tipo do gênero, c. labyrinthicus.

Curimatidae: Foram escolhidos os três gêneros basais de Curimatidae, Curimatopsis, Curimata e Potamorhina. Destes, foram incluídas curimata ocellata, a espécie mais basal do gênero, curimatopsis macrolepis, uma das duas espécies com menos autapomorfias, e Potamorhina latior. Esta é, segundo VARI (1984), a espécie mais modificada do gênero, entretanto era o material disponível para esse estudo.

Anostomidae: Devido às incertezas sobre as relações nesta família, inclui espécies representantes de quatro gêneros. Baseado nas evidências sobre o seu monofiletismo, apenas uma espécie de Anostominae foi incluída. Foram ainda escolhidas as espécies-tipo de Schizodon e Leporinus, e uma das espécies de Leporellus (resultados preliminares do estudo de relações filogenéticas nesta família [Sidlauskas \& Vari, em preparação] indicam que este gênero seria o mais basal da família).

Crenuchidae: Foi incluído um representante de crenuchinae e um de Characidiinae. Crenuchus spilurus, única espécie de seu gênero é a espécie com menos autapomorfias de crenuchinae e por isto foi incluída. Segundo Buckup (1993), Characidium é o gênero mais basal de Characidiinae, sustentado apenas por uma sinapomorfia (mancha basicaudal). O motivo que me levou à escolha de Characidium bahiensis como representante de characidiinae foi a menor modificação desta espécie para hábitos reófilos/bentônicos, possivelmente plesiomórfico para a subfamília.

Acestrorhynchidae: Pelo fato de não serem conhecidas as relações entre as espécies desta família e ela ser indubitavelmente monofilética, escolhi Acestrorhynchus falcirostris por conveniência na obtenção e preparação do material.

Gasteropelecidae: Devido à ausência de hipóteses filogenéticas nesta família, foram incluídas as espécies-tipo de seus três gêneros.

Cynodontidae: Para testar o monofiletismo desta família, foram incluídos representantes das duas subfamílias. De Cynodontinae, incluí Hydrolycus tatauaia, uma espécie não basal, mas com pequeno número de autapomorfias e pertencente ao gênero mais basal da subfamília. De Roestinae, incluí representantes dos dois gêneros, para testar o 
efeito do estado de caráter "presença de quilha peitoral" em Gilbertolus, nas relações entre as subfamílias de Cynodontidae.

Hepsetidae: Foi incluída a única espécie da família.

Erythrinoidea fam. Nov.: Recentemente (2002) uma espécie extremamente aberrante da ordem Characiformes foi descoberta vivendo em folhiço de trechos do Rio Negro. A descrição desta espécie, bem como as suas relações, estão sendo abordadas por outros autores (ZUANon ET AL., em prep.). O potencial da introdução de espécies com novas combinações de caracteres em modificar hipóteses filogenéticas é bem conhecido (PINNA, 1992). Sendo assim a inclusão desta espécie, com um grande número de caracteres não observados em outros characiformes, pode ser de grande importância para o entendimento das relações em characiformes.

Erythrinidae: Uma espécie de Hoplias e uma de Erythrinus foram incluídas por representarem os dois grupos monofiléticos conhecidos em Erythrinidae.

Ctenoluciidae: Foi incluída uma espécie de cada gênero desta família. A espécie de Boulengerella foi escolhida pela disponibilidade de material.

Lebiasinidae: Foram incluídos representantes das duas subfamílias de Lebiasinidae, baseado na hipótese de OYAKAWA (1998) de que Lebiasinidae não seria monofilético, e que estas subfamílias deveriam ser elevadas a família. Lebiasininae é representada pelos seus dois únicos gêneros, enquanto Pyrrhulininae é representada apenas pela espécie-tipo de Copeina, por Copeina ser aparentemente o gênero menos modificado. Lebiasina bimaculata, além de espécie-tipo de seu gênero parece ser a espécie mais basal do grupo composto por espécies de Lebiasina e Piabucina (NetTo-FerReira, 2006). A espécie de Piabucina foi escolhida pela disponibilidade de material.

Alestidae: A inclusão de Chalceus em Alestidae ainda é controversa (ver em INTRODUÇÃo). Para testar esta hipótese, incluí uma espécie de Chalceus, a espécie (africana) mais basal de Alestidae (Arnoldichthys spilopterus), bem como outros dois Alestidae africanos mais derivados.

Characidae: 0 maior número de terminais incluídos nesta análise pertence a está família. Isto se deve a dois fatores: o primeiro é que nesta família se encontra a maior diversidade de characiformes. 0 segundo é que seus limites ainda são desconhecidos. Foram incluídos representantes de todas as subfamílias (Cheirodontinae, 
Iguanodectinae, Rhoadsiinae, Paragoniatinae, Aphyocharacidae, Clupeocharacinae, Bryconinae, Serrasalminae, Agoniatinae, Characinae, Stethaprioninae, Tetragonopterinae, Glandulocaudinae e Stervardiinae) e grupos monofiléticos reconhecidos.

\subsection{ANÁLISE}

A matriz de caracteres foi construída e editada através do Mesquite - A Modular System for Evolutionary Analysis, versão 1.06 (MADDISON \& MADDISON, 2005). Esse editor de matrizes oferece a vantagem de, através de um editor gráfico, construir os seus arquivo em formato NEXUS. Este formato é muito simples e pode ser editado manualmente por editores de texto, o que permite a simples modificação ou adequação diretamente no arquivo, permitindo sua leitura por "softwares" de outra forma não compatíveis com este tipo de formato. A análise da matriz de caracteres para a obtenção das topologias mais parcimoniosas foi feita com o auxílio do "software" TNT (Goloboff ET AL., 2003). Este "software" foi escolhido por ser atualmente o mais completo em termos de tipos de buscas. Além dos métodos tradicionais de buscas heurísticas, onde são geradas diferentes árvores de Wagner, por adição randômica de terminais, seguidas de métodos de rearranjo de ramos, este "software" aplica as chamadas "novas tecnologias". Estas foram desenvolvidas para responder ao problema dos ótimos locais, versus ótimo global (GoLOBOFF, 2002), ou ilhas de árvores (MADDISON, 1991), onde a paisagem do universo de árvores possíveis é tão complexa que a chance de se encontrar as soluções mais parcimoniosas é drasticamente reduzida. Em análises com menos de 90 terminais, este problema pode ser abordado de forma eficiente através de um maior número de pontos de partida ou "seeds" (árvores de wagner iniciais), e rearranjos menos intensos de ramos. Para matrizes muito maiores, outras metodologias, chamadas de "novas tecnologias" permitem a criação de "atalhos" computacionais, que rapidamente encontram soluções mais parcimoniosas que as encontradas pelos métodos tradicionais. Quatro destes novos métodos são implementados pelo TNT (GoLOBOFF, 2003: Parcimônia "Ratchet" (NIXON, 1999), "Tree-Drifting", "Tree-fusing" e "Sectorial Searches" (as últimas de GolobofF, 1999). Os dois primeiros métodos geram perturbações nos dados, de maneira que mais pontos do espaço de árvores sejam explorados, aumentando a chance de encontrar os ótimos globais. Na parcimônia "Ratchet", existe uma alternância de fases durante o rearranjo de ramos onde, ora os pesos dos caracteres são conforme indicados pelo usuário, e ora parte dos caracteres tem os 
seus pesos modificados conforme alguns parâmetros, também definidos pelo usuário. Já no "Tree-drifting", a perturbação é alcançada ao se permitir, durante o rearranjo de ramos, algumas soluções sub-ótimas. "Sectorial searches" é um método em que uma árvore inicial é seccionada e seus setores são analisados separadamente. Sempre que uma solução melhor para um setor é encontrada, ele é "devolvido" à árvore. No "Tree-fusing" sub-grupos de composição idêntica são trocados entre as diversas árvores na memória, na tentativa de se encontrar uma que diminua o número de transições do diagrama.

Em razão da dimensão da presente matriz, utilizei as novas tecnologias na análise dos dados. Na implementação das novas tecnologias foram feitas 1000 réplicas, cada uma consistindo em Sectorial searches (randômica e com restrições), 10 interações de Ratchet e 10 interações de Tree-drifting e após a conclusão de todas as réplicas, 10 interações de tree-fusing nas árvores mais parcimoniosas (utilizando para cada um destes métodos, os parâmetros "default" do programa). As topologias encontradas nos diversos cladogramas fundamentais foram resumidas em um cladograma de consenso estrito.

o suporte de Bremer (BREMER, 1994) foi calculado através do TNT por meio de um "script" que acompanha o programa, também escrito pelos autores. Este "script" foi implementado ao final da análise e consiste em dois passos. No primeiro, ele faz rearranjos de ramos nas árvores fundamentais encontradas durante a análise, realizada anteriormente, em busca de árvores sub-ótimas. Utilizei os seguintes parâmetros para esta fase: 10 buscas através de rearranjos do tipo TBR aceitando árvores um passo maiores que as fundamentais a cada etapa e salvando no máximo 100000 árvores sub-ótimas com até 10 passos maior que as árvores fundamentais. Esta fase tem por objetivo a identificação dos grupos de baixo suporte. A segunda fase consiste em buscas com condições restritivas negativas e positivas em cada um dos outros grupos das árvores, comparando o número de passos com e sem um determinado grupo. Para cada uma destas condições restritivas foram feitas 100 réplicas e cada uma das réplicas incluindo "Sectorial searches", 10 interações de "Ratchet", 10 interações de "Treedrifting" e um "Tree-fusing" das árvores encontradas em cada réplica.

\subsection{ABREVIATURAS}


Acrônimos das instituições segue LEVINTON ET AL. (1995) e correções em LEVINTON \& GIBBS (1998). CP se refere a comprimento padrão, diaf. a exemplares diafanizados e corados segundo a metodologia explicitada acima, e esq. se refere a esqueletos secos.

As abreviaturas utilizadas para indicar estruturas nas ilustrações são:

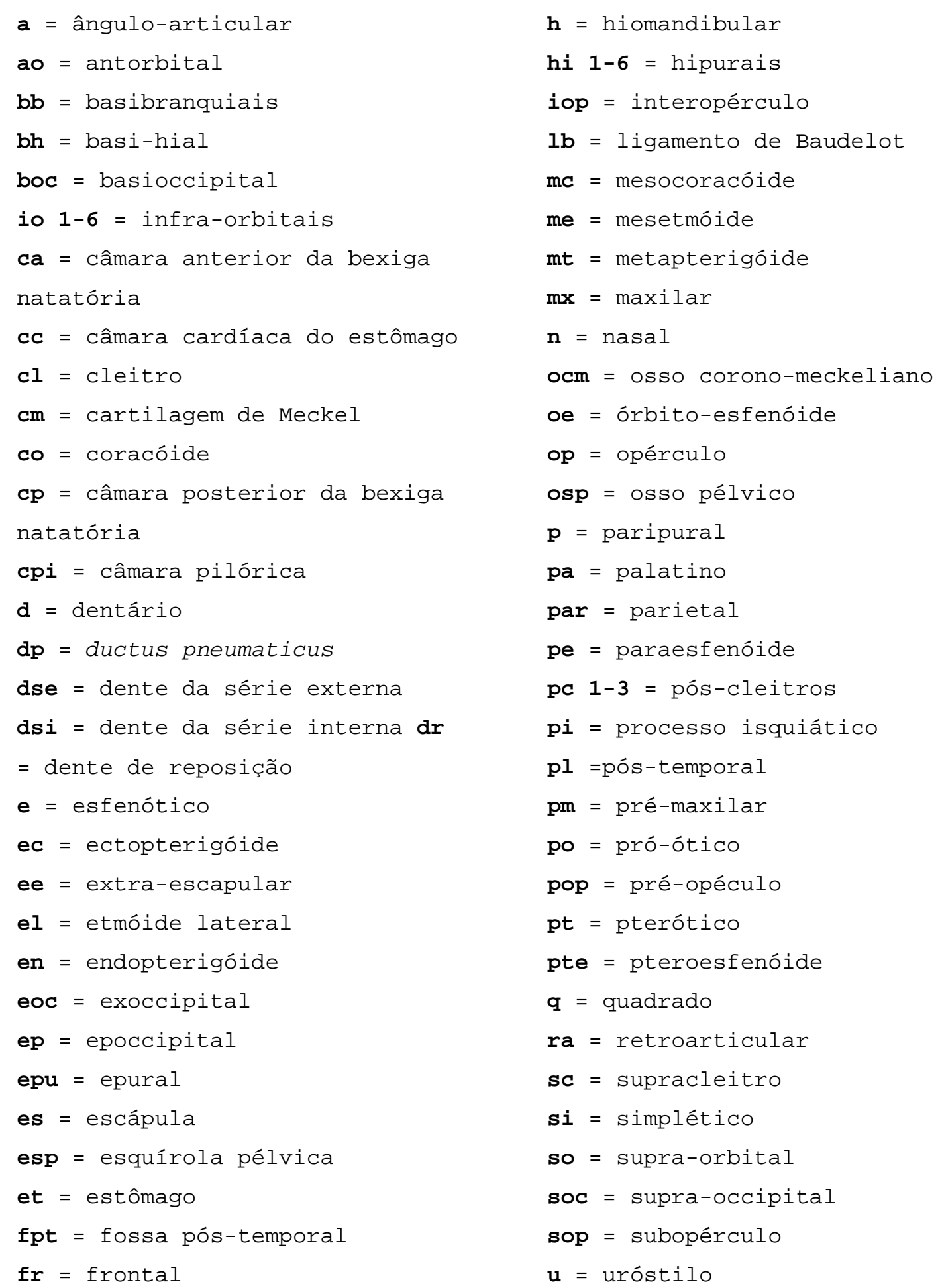




\subsection{MATERIAL EXAMINADO}

\section{GONORHYNCHIFORMES}

\section{CHANIDAE}

Chanos chanos: MZUSP 63361 ( 6 exs.; 1 esq.) Cingapura. M. De Pinna, 1999. MZUSP 62601 (3 exs.; 1 diaf.;78,26 mm SL) Filipinas, Ásia.

\section{CYPRINIFORMES \\ CATOSTOMIDAE}

Catostomus commersonnii UMMZ 237401 ( 5 exs) América do Norte, Estados Unidos, Michigan, Washtenaw, Malletts creek at Chalmers road, Huron River drainage.Latta, WC, et al 15 junho $2000.42^{\circ} 15^{\prime} 45^{\prime \prime} \mathrm{N}, 83^{\circ} 41^{\prime} 12^{\prime \prime} \mathrm{W}$. UMMZ 229545 (15 exs: 2 diaf., 93,02, 92,75 mm SL) América do Norte, Estados Unidos, Michigan, Monroe, Stoney Creek off N. Stoney Creek Road 1/4 mi from Dixie Highway. Latta \& Swank, 9 setembro 1994.

\section{GYMNOTIFORMES}

GYMNOTIDAE

Gymnotus aff. carapo MZUSP 22125 (14 exs.; 1 diaf., 156, $4 \mathrm{~mm} \mathrm{SL}$ ) Utinga, Belém, PA (IAN).

\section{SILURIFORMES}

\section{DIPLOMYSTIDAE}

Olivaichthys mesembrinus MZUSP 62595 (22 exs.; 1 diaf., 143,08 mm SL)

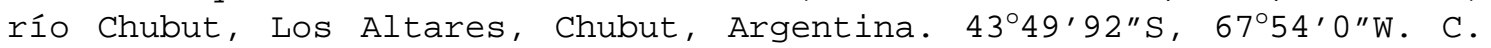
Oliveira \& A. Gosztoni, 24/novembro/1998.

\section{CHARACIFORMES}

\section{ACESTRORHYNCHIDAE}

Acestrorhynchus falcirostris MZUSP 20655 ( 03 de 16 exs.; 1 diaf., $175,45 \mathrm{~mm} C P$ ) lagoa na margem do igarapé Muru, rio Tocantins, abaixo de Tucuruí, PA, Brasil. EPA, 13/setembro/1970.

\section{ALESTIDAE}

Arnoldichthys spilopterus MRAC 154445-449 (5 exs.; 1 diaf., 56.8mm CP)arredores de ABA, baixo Niger, Nigéria. Smyhalo, 1967

Brycinus macrolepidotus MZUSP 84589 (27 exs.; 1 diaf., 106,4 mm CP) river Mono near Kpoba ( $3 \mathrm{~km} \mathrm{~W}$ of Kpoba), Benin-Togo border, Kouffo, Benin, África. $06^{\circ} 47^{\prime} 49^{\prime \prime} \mathrm{N} 01^{\circ} 36^{\prime} 17^{\prime \prime} \mathrm{E}$. M de Pinna, F. Di Dario \& $T$ Moritz, 18/novembro/2003.

Bryconalestes longipinnis MZUSP 84498 (80 exs.; 1 diaf, 93,63 mm SL) Lac Ahémè at bridge (road RNIE 1), Atlantique-Mono border, Benin, África. $06^{\circ} 23^{\prime} 21^{\prime \prime} \mathrm{N} 01^{\circ} 56^{\prime} 22^{\prime \prime} \mathrm{E}$. M de Pinna, F. Di Dario \& T Moritz, 19/novembro/2003.

Chalceus epakros MZUSP 6706 (26 exs.; 1 diaf., 158mm CP) rio Negro, arredores de Manaus, Amaznonas, Brasil. Expedição Permanente a Amazônia, 23/novembro/1967.

\section{ANOSTOMIDAE}

Anostomus ternetzi MZUSP 91677 (5 exs., 01 diaf., 47,77 mm SL) Rio Jatobá, bacia do Rio Xingu, Brasil. AXE 20/10/2004

Leporellus vittatus MZUSP 20690 (17 exs.; 1 diaf., 135,1mm e 147,1mm CP) Cachoeira de Emas, Pirassununga, São Paulo, Brasil. Excursão DZ, $4-5 / a b r i l / 1962$. 
Leporinus fasciatus MZUSP 59059 (05 de 11 exs.; 1 diaf., 139, 0mm CP) rio Negro, Tapera, AM, Brasil. EPA, 05/novembro/2004.

Schizodon fasciatus MZUSP 83543 ( 07 de 697 exs.; 1 diaf., 174,1mm CP) rio Araguari, Ferreira Gomes, AP, Brasil. M. Goulding, janeirofevereiro/1984.

\section{CHARACIDAE}

APHYOCHARACINAE

Aphyocharax pusillus MZUSP 30537 (53 exs.; 2 diaf. 43,37mm e 41,65mm

CP) Rio Madeira, Calama, Brasil. M. Goulding, 10/dezembro/1980.

BRYCONINAE

Brycon pesu MZUSP 36794 (58 exs.; 1 diaf., 94.0mm CP) cachoeira do Espelho, rio Xingu, PA, Brasil. P.E. Vanzolini, 23-26/outubro/1966.

GLANDULOCAUDINAE

Glandulocauda melanogenys MZUSP 87571 (44 exs; 1 diaf., $38.52 \mathrm{~mm} \mathrm{SL}$ ) Córrego afluente do Rio Guaratuba, Boracéia, Salesópolis, São Paulo,

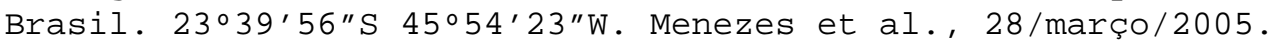

CHEIRODONTINAE

Compsura heterura MZUSP 54621 (126 exs.; 3 diaf., 28,3 e 29,8mm CP) rio Verde Pequeno, na estrada de Urandi para Espinosa, Urandi, BA/MG, Brasil. R.E. Reis et al., 19/julho/1993.

Odontostilbe pequira MZUSP 59499 (2377 alc. e 6 diaf., 28,7mm; 29,4mm; $27,8 \mathrm{~mm}$; 24.3mm; $21.8 \mathrm{~mm}$; e $23.2 \mathrm{~mm} \mathrm{CP)} \mathrm{rio} \mathrm{do} \mathrm{Garimpo,} \mathrm{no} \mathrm{caminho} \mathrm{que}$ cruza em cima da estrada do Rio Negro, Rio Negro, MS, Brasil. $19^{\circ} 21^{\prime} 75^{\prime \prime} \mathrm{S} 54^{\circ} 59^{\prime} 5^{\prime \prime} \mathrm{W}$. 0. Froehlich \& A. Machado, 26/agosto/1998.

\section{STERVARDIINAE}

Diapoma terofali MCP 9035 (20 de 152 exs.; 3 diaf., 42.9; 43.5; e $47.3 \mathrm{~mm}$ CP) Rio Santa Maria na BR $293 \mathrm{~km} 246$, trecho Dom Pedrito/Santana do Livramento, Uruguay, Rio Grande do Sul, Brasil. $30^{\circ} 59^{\prime}$ S $54^{\circ} 42^{\prime}$ W. C.A.S. Lucena \& L.R. Malabaraba, 26/outubro/1982.

Landonia latidens FMNH 105228 (10 de 24 exs; 1 diaf., $33.1 \mathrm{~mm}$ CP) Rio Daule, $200 \mathrm{~m}$, aguas arriba de Colimes, Guayas, Ecuador. R. Barriga, $10 /$ agosto/1995.

STETHAPRIONINAE

Poptella brevispina MZUSP 16903 (37 exs.; 1 diaf., 90mm CP) Igarapé Apeú, PA, Brasil. P. Vanzolini, 3-4/fevereiro/1964.

Orthospinus franciscoensis MZUSP 19664 (16exs.; 1 diaf., 66,0 mm SL) represa de Três Marias, Rio São Francisco, MG, Brasil. H.A. Britski \& I.A. Dias, 14-18/fevereiro/1965.

\section{AGONIATINAE}

Agoniates halecinus MZUSP 34333 (88 exs. ; 1 diaf., 183,6 mm SL) rio Trombetas, Cuminá, Pará, Brasil. M. Goulding, outubro-novembro/1983.

\section{CHARACINAE}

Charax cf. leticiae MZUSP 59511 (94 exs; 2 diaf., 54,5mm;72,1mm CP) rio Taboco, Aquidauana, MS, Brasil. 20004'38"S, 55038'81"W. A. Machado \& B. Chernoff, 30/agosto/1998.

Phenacogaster pectinatus FMNH 104086 (20 de 245 exs; 1 diaf., 43.3mm $\mathrm{CP})$ Tributary to Rio Cuyabeno, just upstream from bridge, $11 \mathrm{~km}$ north 
of Marian (17 km north of ' $Y$ '), Napo, Ecuador. D. Stewart, et al., 29/novembro/1983.

Galeocharax knerii MZUSP (22 exs.; 1 diaf., $128.9 \mathrm{~mm}$ CP) rio Paranaíba, projeto UHE Bocaina, Minas Gerais, Brasil. Leme Engenharia S/A, novembro/1987 - junho/1988.

Gnathocharax steindachneri MZUSP 74248 (46 exs.; 1 diaf., 42,44 mm SL) igarapé Jaradá, afluente da margem direita do rio Cuieira, cerca de 40 km da boca, Manaus, Amazonas, Brasil. Expedição Alpha Helix, 31/janeiro/1977.

IGUANODECTINAE

Iguanodectes geisleri MZUSP 29614 (150 exs.; 01 diaf., 39,9mm CP) rio Negro, ilha de Buiú-Açú. M. Goulding, 06/Fevereiro/1980.

PARAGONIATINAE

Paragoniates alburnus MZUSP 42336 (17 exs. ; 1 diaf..) Paraná Castanho, rio Solimões, AM, Brasil. Coletor indeterminado, agostosetembro/1979.

Phenagoniates macrolepis INHS 35593 (20 exs.; 1 diaf., $37.9 \mathrm{~mm}$ CP) rio Muyapa (rio Torondoy-Lago Maracaibo drainage) Muyapa, ca. $2 \mathrm{~km}$ downstream of highway to Mérida, Venezuela. $\odot 9^{\circ} \odot 7^{\prime} 34^{\prime \prime} \mathrm{N} 71^{\circ} \odot 7^{\prime} 27^{\prime \prime} \mathrm{W}$. D.C. Taphorn, L. M. Page \& K.S. Cummings, 30/janeiro/1995.

Rachoviscus graciliceps MZUSP uncat. (256 exs; 3 diaf., 22,5mm; $26.2 \mathrm{~mm}$; e $22.7 \mathrm{~mm} \mathrm{CP}$ ) rio costeiro na Bahia. Menezes et al. Maio/2006

CLUPEACHARACINAE

Clupeacharax cf. engrauloides MZUSP 49672 (24 exs.; 1 diaf., 31.5mm CP) rio Acre, seringal Bom Destino (1 hora acima de Porto Acre), Porto Acre, Acre, Brasil. Inst. Meio Ambiente do Acre/Univ. Federal do Acre, 19/outubro/1994.

RHOADSIINAE

Rhoadsia altipinna FMNH 93168 (15 exs; 3 diaf., 33,7mm; 34,7mm; e $43,1 \mathrm{~mm}$ CP) rio Quininde, Esmeraldas, Equador. Taphorn et al., ๑9/novembro/1978.

\section{SERRASALMINAE}

Metynnis lippincottianus MZUSP 6888 (32 exs. ; 1 diaf., 84,61 mm SL) Lago Januari, Manaus, AM, Brasil. EPA, 19-20/novembro/2004.

Myleus setiger MZUSP 36824 (7 de 34 exs.; 1 diaf., 114,2mm CP) cachoeira do Espelho, rio Xingu, PA. P.E.Vanzolini, 2326/outubro/1986.

Piaractus mesopotamicus MZUSP 15166 (26 ex. 1 diaf., 135mm CP). Lagoa São paulo, Brasil, ix/1960.

CHARACIDAE INCERTAE SEDIS

Astyanax mexicanus UMMZ 203208 (20 exs.; 1 diaf., $72.5 \mathrm{~mm}$ CP) Río 0jo Frio ao norte de Rascon, San Luis Potosi, México. N. Humphries et al. 18/maio/1976.

Atopomesus pachyodus MZUSP 29607 (723 exs. 3 diaf., 23,7mm; 24,9mm; $25,5 \mathrm{~mm}$ CP) rio Negro, Anavilhanas, AM, Brasil. M. Goulding, outubro/1980. 
Axelrodia reisei MZUSP 58519 (580 exs.; 3 diaf., 19,1mm; 21,3mm; e $20.4 \mathrm{~mm}$ CP) Canal entre lagos em São João, perto de Tapurucuara (rio Negro). EPA, 24/outubro/1972.

Brittanichthys axelrodi MZUSP 26425 (3348 exs.; 6 diaf., ) rio Negro/ rio Urubaxi, AM, Brasil. M. Goulding, 5/fevereiro/1980.

Bryconadenus tanaothoros MZUSP uncat. (23 exs e 2 diaf., 34,3-36,1 mm $\mathrm{SL})$ Rio Ferro, afluente do Rio Von Den Steinen, Nova Ubiratan, MT, Brasil. C. Moreira et al., 23/outubro/2004.

Bryconamericus exodon MZUSP 59650 (250ex. \& 3 diaf., 36.6-35.8mm CP) rio do Peixe, abaixo da queda d'água - Loca das Araras, rio Negro, MS, Brasil. N. Menezes \& B. Chernoff, 27/agosto/1998.

Bryconops alburnoides: MZUSP 34590 (98 exs.; 1 diaf., 135,2mm CP) rio Trobetas, Cuminá, AM, Brasil. M. Goulding, Outubro-novembro/1983

Ctenobrycon hauxwellianus MZUSP 40464 (87 exs.; 1 diaf.) poço da Gandaia (lagoa marginal rio Paranã), faz. Olho d'Água, Flores de Goiás, Go, Brasil. J.C. de Oliveira \& W.J.E.M. da Costa, 11$12 /$ setembro/1988.

Deuterodon iguape MZUSP 54998 (29 ex.; 2 diaf., 57,4mm e 64,3mm CP)rio Betari, próximo à foz, Iporanga, São Paulo, Brasil. S. Buck, 26/junho/1996.

Gymnocorymbus ternetzi MZUSP 78951 (18 exs.; 1 diaf., 40,3mm CP) lagoa na margem esquerda, cerca de $100 \mathrm{~m}$ do rio Cuiabá (viveiro de

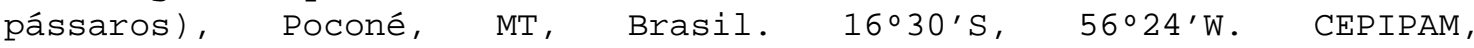
15/setembro/1977.

Hemibrycon polyodon MCZ 93370 (15 de 69 exs; 1 diaf., 51,6mm CP) 2 tributaries 32 and $34 \mathrm{~km}$ NE of Zamora, Zamora-Chinchipe, Equador. T.R. Roberts, et al., 10/novembro/1971

Hemigrammus unilineatus: MZUSP 16543 (17 exs.; 1 diaf., 31,64mm CP) rio Apeú, Boa Vista, PA, Brasil. Vanzolini, 11/junho/1958.

Hollandichthys multifasciatus: MZUSP 78956 (38 exs.; 2 diaf., 66,6mm e $42.9 \mathrm{~mm}$ (P) riacho no $\mathrm{km} 208$ da rodovia Rio-Santos, próximo da entrada de Riviera São Lorenço, Bertioga, São Paulo, Brasil. Expedição USP/MZUSP, 27/março/1999.

Hyphessobrycon compressus MZUSP 28535 (25 exs.; 1 diaf., 21,6mm CP) Baba creeck, Orangewalk district, Belize. Royal Ontario Museum, 12/V/1979. 24 alc. e 1 diaf.

Knodus meridae ANSP 165613 (15 de 73 exs; 1 diaf. 46,7mm CP) Rio Orinoco: Raudales de Atures at Culebra; ca. $7 \mathrm{~km} \mathrm{~S}$ of Puerto Ayacucho, Amazonas, Venezuela. $05^{\circ} 35^{\prime} \mathrm{N} 67^{\circ} 31^{\prime} \mathrm{W}$. S. Schaefer, et al., 10/novembro/1989.

Markiana nigripinnis MZUSP 18850 (48 exs.; 1 diaf., 83,0mm CP) lagoa margem esquerda, à cerca de $100 \mathrm{~m}$ do rio Cuiabá (viveiro de pássaros), rio Paraguai, Poconé, MT, Brasil. CEPIPAM, 15-16/setembro/1977.

Microschemobrycon casiquiare MZUSP 58968 (274 exs.; 2 diaf., 24,5mm e 26,1mm CP) rio Urubaxi, perto da boca, bacia do rio Negro, AM, Brasil. M. Goulding, 11/fevereiro/1980. 
Moenkhausia xinguensis MZUSP 36806 (20 de 635 exs.; 3 diaf., 43,8mm e $54,8 \mathrm{~mm}$ CP) cachoeira do Espelho, rio Xingu, Pará, Brasil. $3^{\circ} 48^{\prime} \mathrm{S}$ $52^{\circ} 32^{\prime}$ W. P. Vanzolini, 23-26/outubro/1986.

Oligosarcus argenteus MZUSP 37256 (66 exs. ; 1 diaf, 98,1 mm SL) rio Piranga, Viçosa, MG, Brasil. A. Copriva, 29/julho/1982.

Paracheirodon axelrodi MZUSP 58336 (102 exs.; 2 diaf., 22,4mm e 23,4mm $\mathrm{CP}$ ) canal entre lagos em São João, perto de Tapurucuara, rio Negro, AM, Brasil. EPA, 24/outubro/1972

Piabina argentea MZUSP 73214 (247 exs. ; 2 diaf., 46,2mm e 52,7mm CP) rio Piedade, fazenda Piedade, c. $45 \mathrm{~km}$ a noroeste de Monte Alegre de Minas, acima da ponte, Centralina, MG, Brasil. $18^{\circ} 38^{\prime} 11^{\prime \prime} \mathrm{S} 49^{\circ} 5^{\prime} 28^{\prime \prime} \mathrm{W}$. P. Gerhard \& F.C.T. Lima, 02/agosto/2001.

Probolodus heterostomus MZUSP 7903 (35 exs.; 3 diaf., 76,8mm CP) rio Paraíba do Sul, Santa Branca, Brasil. H.A. Britski, 10/fevereiro/1962.

Rhinobrycon negrensis MZUSP 29387 (41 exs; 2 diaf., 30,52mm e 29,71 mm CP) rio Marauiá, perto da boca. M. Goulding, outubro/1979.

Roeboexodon sp. MZUSP 52123 (41 exs.; 2 diaf., $87.8 \mathrm{~mm}$ CP) rio Água Fria, Araguaçú, T0, Brasil. Lima et al., 06.VII.1997.

Serrabrycon magoi MZUSP 77753 (165 exs.; 3 diaf., 29,9-35, 0mm CP) rio Negro, confluência com rio Urubaxi, AM, Basil. $0^{\circ} 31^{\prime} \mathrm{S} 64^{\circ} 50^{\prime} \mathrm{W}$. M. Goulding, $07-11 /$ fevereiro/1980.

Salminus hilarii MZUSP 20471 (6 exs. 1 diaf., 112,9 mm SL) Represa do Camargo, Rio Grande, MG. Brasil. CETESB, 2-3/outubro/1975.

Stygichthys typhlops MZUSP 87678 (21 exs. e 4 diaf., 24,3mm; 39, 0mm CP) poço na fazenda do Lajeado or fazenda do Mandioqueu, córrego Escuro, sistema do rio verde Grande, rio São Francisco basin. C.R.Moreira et al, 28/abril/2004

Tetragonopterus argenteus: MZUSP 59491 (35 exs.; 2 diaf., 56,2mm e $69,7 \mathrm{~mm}$ CP), Brejo de Santa Sofia, rio Negro, Aquidauana, MS, Brasil. AQUARAP/1998.

Triportheus albus MZUSP 75708 (31 exs.; 1 diaf., 93,3mm CP) lago Terra Preta, Janauari (\#89), Amazonas, Brasil. P. Bayley, 28/abril/1977. MZUSP 75695 (250 exs.) lago Terra Preta, Janauari, Amazonas, Brasil. P. Bayley, 10/novembro/1977.

\section{CHILODONTIDAE}

Caenotropus labyrinthicus MZUSP 33400 (10 de 128 exs; 1 diaf., 131,3mm CP) rio Tapajós, São Luis acima de Itaituba, Itaituba, Pará, Brasil. M. Goulding, 22/outubro/1983.

Chilodus punctatus MZUSP 29361 (41 exs.; 2 diaf., 41,4mm e 49,3mm CP) rio Tefé, Jurupari, Amazonas, Brasil. M. Goulding, 3/agosto/1979.

\section{CITHARINIDAE}

Citharinus latus MZUSP 84480 (18 exs.;1 diaf.) Ouémé river, Azowlissé, Ouémé, Benin, África. $1^{\circ} 40^{\prime} 29^{\prime \prime} \mathrm{N} 02^{\circ} 29^{\prime} 15^{\prime \prime} \mathrm{E}$. M. De Pinna, F. Di Dario \& T. Moritz, 20/novembro/2003.

\section{CRENUCHIDAE}


Characidium bahiensis MZUSP 83787 (52 exs.; 3 diaf., 20, $0 \mathrm{~mm} ; 20,1 \mathrm{~mm}$ CP) Rio Preto no povoado de Cacimbinhas, Formosa do Rio Preto, Bahia, Brasil. C.R.Moreira \& J. Nolasco, 15/novembro/2002.

Crenuchus spilurus MZUSP 7479 (74 exs; 1 diaf., 40,6mm CP) igarapé afluente do rio Sanabani, Silves, AM, Brasil. EPA, 7/dezembro/1967.

\section{CTENOLUCIIDAE}

Boulengerella maculata MZUSP 8207 ( 07 de 37 exs.; 1 diaf., 242,5mm CP) Lago Jacupá, Oriximiná, Pará, Brasil. EPA, 11/dezembro/1967.

Ctenolucius hujeta FMNH 76353 (10 de 46 exs.; 1 diaf., 139,2mm CP) Soplaviento, town on Dique de Cartagena between Cartagena and Calamar, Colombia. C. H. Eigenmann.

\section{CURIMATIDAE}

Curimata ocellata MZUSP 22097 (30 exs.; 1 diaf., 115,5mm CP) Ilha da Barreirinha, rio Tapajós, São Luis, Pará, Brasil, $94^{\circ} 27^{\prime} \mathrm{S}$, 56²15'W. Expedição Permanente a Amazônia, 21/novembro/1970.

Curimatopsis macrolepis MZUSP 73967 (200 exs.; 2 diaf., 26.47-38.1 mm $\mathrm{CP})$ rio Negro logo abaixo de Daraá, lago central-rapiché, Amazonas, Brasil. $0^{\circ} 28^{\prime} \mathrm{S} 64^{\circ} 46^{\prime} W$. M. Goulding, 11/fevereiro/1980.

Potamorhina latior MZUSP 6866 (26 exs.; 1 diaf., 107,5mm CP) lago Janauari, Manaus, AM, Brasil. $03^{\circ} 13^{\prime} \mathrm{S} 60^{\circ} \circ 4^{\prime} \mathrm{W}$. EPA, 1920/novembro/1967.

\section{CYNODONTIDAE}

Gilbertolus atratoensis NRM 50430 ( 1 ex.; E 1 diaf [NRM 41361]) Río Napiri, bacia do Río Atrato, Departamento de Chocó, Colômbia.6 $40^{\prime} \mathrm{N}$, $76^{\circ} 58^{\prime}$ W. S.0. Kullander \& A. Silfvergrip, 26/janeiro/1989.

Hydrolycus tatauaia MZUSP 32632 (128 exs.; 1 diaf.) rio Trombetas, Cuminá, PA, Brasil.

Roestes molossus MZUSP 89683 (3 exs; 1 diaf., 179,5mm CP) Lago Madalena, foz do rio Jaciparaná, afluente da margem direita do rio Madeira, Brasil. G. T. Vilara, junho/2004.

\section{DISTICHODONTIDAE}

Distichodus notospilus AMNH 230295 ( 07 exs. ; 1 diaf., 79,5mm CP) Lake Zile, near St. Martin village, near Lambarene, Moyen-Ogooue, Gabon, África. $0^{\circ} 39.40^{\prime} \mathrm{S} 10^{\circ} 18.38^{\prime} \mathrm{E} . \mathrm{J}$. P. Sullivan \& M. E. Arnegard, 8/julho/1999; AMNH 230338 (08 exs.) Lake Zile, St. Martin village, near Lambarene, Moyen-Ogooue, Gabon, África. $0^{\circ} 39.40^{\prime} \mathrm{S} 10^{\circ} 18.38^{\prime} \mathrm{E}$. J.P. Sullivan, M.E. Arnegard \& P. Guinzoumbi, 9-10/julho/1999.

Hemistichodus vaillanti AMNH 230296 (12 exs. ; 1 diaf., 55,6mm CP) Lake Zile, near St. Martin village, near Lambarene, Moyen-Ogooue, Gabon, África. $0^{\circ} 39.40^{\prime} \mathrm{S} 10^{\circ} 18.38^{\prime} \mathrm{E} . \mathrm{J}$. P. Sullivan \& M. E. Arnegard, 8/julho/1999.

Nannocharax fasciatus MZUSP 84775 (68 exs.; 2 diaf., 27,5mm e 28,6mm CP) África, Benin, Ouémé, Azowlizzé, Ouémé, $01^{\circ} 40^{\prime} 29^{\prime \prime} \mathrm{N} 02^{\circ} 29^{\prime} 15^{\prime \prime} \mathrm{E}$. De Pinna, M. et al. 20 novembro 2003.

Neolebias unifasciatus MZUSP 84476 (226 exs.; 3 diaf., 20,5mm e 28,5mm $\mathrm{CP})$ Ouémé river, Azowlissé, Ouémé, Benin, África. $1^{\circ} 40^{\prime} 29^{\prime \prime} \mathrm{N} 02^{\circ} 29^{\prime} 15^{\prime \prime} \mathrm{E}$. M. De Pinna, F. Di Dario \& T. Moritz, 20/novembro/2003. 
Xenocharax spilurus AMNH 230302 (15 exs.; 1 diaf., 129,3mm CP) Lake Zile, near St. Martin village, near Lambarene, Moyen-Ogooue, Gabon, África. $0^{\circ} 39.40^{\prime} \mathrm{S} 10^{\circ} 18.38^{\prime} \mathrm{E} . \mathrm{J}$. P. Sullivan \& M. E. Arnegard, 8/julho/1999.

\section{ERYTHRINIDAE}

Erythrinus erythrinus MZUSP 44564 (08 de 29 exs.; 1 diaf., 121, 0mm CP) rio Purus, Seringal Santo Ântonio, próximo a Manoel Urbano, AC, Brasil. P.E. Vanzolini, 18/setembro/1973.

Hoplias malabaricus MZUSP 89505 (01 esq.) Porto do Ceasa, mercado de peixes, Manaus, Amazonas, Brasil. F.C.T. Lima, 13/novembro/2005.

ERYTHRINOIDEA FAM. NOV.

MZUSP uncat

\section{GASTEROPELECIDAE}

Carnegiella strigata MZUSP 38282 (125 exs; 3 diaf., 36,9-37,5mm CP) Tributary to Sisa creek, North side approximately $700 \mathrm{~m}$ downstream of crossing of Amotopo to Camp Geology road, Nickerie district, Surinam. R. P. Vari, et al., 20/stembro/1980.

MZUSP 74249 (36 exs.) Igarapé Jaradá, afluente da margem direita do rio Cuieiras, cerca de $40 \mathrm{~km}$ da boca, Manaus, Amazonas, Brasil. Expedição Alpha Helix, 31/janeiro/1977.

Gasteropelecus sternicla MZUSP 38234 (177 alc.; 3 diaf.) Creek at camp MacClemmer Dalibane, Nickerie district, Surinam. R.P. Vari, et al., $6 /$ setembro/1980.

MZUSP 20953 (440 exs.) Igarapé em Jacaré, próximo de Fonte Boa, Amazonas Brasil. Expedição Permanente a Amazônia, 7/outubro/1968.

Thoracocharax stellatus MZUSP 20923 (472 alc.; 3 diaf., 37,7mm; $46,4 \mathrm{~mm}$; e 48,3mm CP) rio Solimões, ilha Sorubim, acima de Coari, Amazonas, Brasil. Expedição Permanente a Amazônia, 29/setembro/1968.

\section{HEMIODONTIDAE}

Anodus orinocensis MZUSP 21280 (15 exs.; 1 diaf., 159,3mm CP) igarapé Muru, rio Tocantins, abaixo de Tucuruí, PA, Brasil. $03^{\circ} 46^{\prime} \mathrm{S} 49^{\circ} 41^{\prime} \mathrm{W}$. EPA, 12-13/setembro/2004.

Bivibranchia fowleri MZUSP 29628 (200 exs.; 3 diaf., 24,7mm; 45,4mm; e $51,6 \mathrm{~mm}$ CP) rio Branco, praia de Xeruini, Roraima, Brasil. M. Goulding, 11/maio/1979.

Hemiodus unimaculatus MZUSP 83937 ( $\odot 9$ exs.; 1 diaf, 106,3mm CP) ribeirão do Inferno (= ribeirão bonito), na estrada BR-010 em direção a Ponte Alta do Bom Jesus, Ponte Alta do Bom Jesus, Tocantins, Brasil. $11^{\circ} 58^{\prime} 23^{\prime \prime} S 46^{\circ} 29^{\prime} 30^{\prime \prime}$ W. C.R. Moreira \& J.C. Nolasco, $25 /$ novembro/2002.

\section{HEPSETIDAE}

Hepsetus odoe MZUSP 84469 ( 6 exs. ; 1 diaf., 113,8mm CP) Ouémé river, Azowlissé, Ouémé, Benin, África. $1^{\circ} 40^{\prime} 29^{\prime \prime} \mathrm{N} 02^{\circ} 29^{\prime} 15^{\prime \prime} \mathrm{E}$. M. De Pinna, F. Di Dario \& T. Moritz, 20/novembro/2003.

\section{LEBIASINIDAE}

Copeina cf. guttata MZUSP 27088 (218 exs; 1 diaf., 61,7mm CP) Lago Buiuçu, Atí-Paraná, NW de Fonte Boa, Fonte Boa, Amazonas, Brasil. EPA, 11-12/outubro/1968.

Lebiasina bimaculata MZUSP 80085 (80 exs.; 2 diaf., 28,9mm; 48, 0mm; $48,3 \mathrm{~mm}$; e $64.1 \mathrm{~mm}$ CP) rio Jequetepeque (ponto 2), Chilete, Cajamarca, 
Peru. $07^{\circ} 13^{\prime} 35.7^{\prime \prime S} \quad 78^{\circ} 50^{\prime} 00.3^{\prime \prime} \mathrm{W} . \quad \mathrm{C}$. Oliveira, et al. 26/novembro/2002. MCZ 48727 ( 10 de 26 exs) Farm Pond $84 \mathrm{~km}$ SE of Quevedo, Los Rios, Equador. $0^{\circ} 59^{\prime} \mathrm{S} 79^{\circ} 27^{\prime} \mathrm{W}$. T.R. Roberts, et al., 4/novembro/1971.

Piabucina astrigata FMNH 93122 (20 de 80 exs; 1 diaf., 128,6mm CP) Small stream-pool on Centro Cientifico Rio Palenque, Los Rios, Ecuador. D. Taphorn, et al., ๑8/novembro/1978.

\section{PARODONTIDAE}

Apareiodon piracicabae MZUSP 53885 (60 exs; 1 diaf., 106,5mm CP) Represa de Barra Bonita, rio Piracicaba, município de Santa Maria da Serra, São Paulo, Brasil. R. Silvano, abril/1995.

Parodon nasus MZUSP 19496 (120 exs; 1 diaf., 98,9mm CP) rio Mogi Guaçú, município de Emas, São Paulo, Brasil. H. Britski, 22/outubro/1963.

Saccodon wagneri MCZ 48746 (10 de 73 exs; 1 diaf., 71, 0mm CP) Arroyo Bambine, tributary, of Rio Cristal at Montalvo, Guayaquil basin, Los Rios, Equador. T.R. Roberts, et al., 6/novembro/1971.

\section{PROCHILODONTIDAE}

Prochilodus nigricans MZUSP 4837 (18 exs. ; 1 diaf., 131mm CP) rio Araguaia, bacia do rio Tocantins, Aruanã, Go, Brasil. $14^{\circ} 55^{\prime} \mathrm{S} 51^{\circ} 05^{\prime} \mathrm{W}$. H.A. Britski \& P.E. Vanzolini, setembro/1966.

Semaprochilodus insignis MZUSP 9174 (10 exs. ; 1 diaf)rio Maicá, bacia do rio Tapajós, Santarém, PA, Brasil. EPA, 19-27/outubro/1971. 


\subsection{CARACTERES}

Abaixo apresento a listagem dos 410 caracteres provenientes dos complexos morfológicos analisados e utilizados para a elaboração da matriz de dados (Tabela 1). Grande parte dos caracteres utilizados na elaboração desta matriz já foram discutidos na literatura. Assim, para não repetir esta informação já disponível incluí, sempre que possível, uma ou mais referências a estes autores que utilizaram e discutiram estes caracteres (algumas vezes com codificação diferente) em análises filogenéticas anteriores. Estas citações não se propõem a ser exaustivas e se concentram nas que discutiram mais estensamente estes caracteres, ou que a lógica por trás da codificação mais se aproxima da minha. Os caracteres propostos por mim são enunciados de forma auto-explicativa. Segue também, aos estados de caráter, a listagem dos terminais que os apresentam na ordem da classificação atual (Buckup, 1998). Os índices de retenção e consistência de cada caráter são apresentados na Tabela 2 e as suas transições juntamente com o número de passos é dado no Apêndice 1 .

\subsubsection{Maxilas e dentição}

\section{0 - Posição da boca:}

[OYAKAWA, 1998:72, modificado e NETTO-FERREIRA, 2006:73, modificado]

\section{[0] - inferior.}

Catostomus commersonnii, Olivaichthys mesembrinus, Hemistichodus vaillanti, Nannocharax fasciatus, Apareiodon piracicabae, Parodon nasus, Saccodon wagneri, Leporellus vittatus, Schizodon fasciatus e Characidium bahiensis.

\section{[1] - terminal.}

Chanos chanos, Citharinus latus, Distichodus notospilus, Neolebias unifasciatus, Xenocharax spilurus, Anodus orinocensis, Bivibranchia fowleri, Hemiodus unimaculatus, Curimata ocellata, Curimatopsis macrolepis, Potamorhina latior, Prochilodus nigricans, Semaprochilodus insignis, Caenotropus labyrinthicus, Chilodus punctatus, Leporinus fasciatus, Acestrorhynchus falcirostris, Gilbertolus atratoensis, Hydrolycus tatauaia, Roestes molossus, Erythrinoidea fam. nov, Boulengerella maculata, Ctenolucius hujeta, Lebiasina bimaculata, Piabucina astrigata, Erythrinus erythrinus, Hoplias malabaricus, Hepsetus odoe, Arnoldichthys spilopterus, Brycinus macrolepidotus, Bryconalestes longipinnis, Chalceus epakros, Crenuchus spilurus, Agoniates halecinus, Aphyocharax pusillus, Astyanax mexicanus, Atopomesus pachyodus, Axelrodia reisei, Brittanichthys axelrodi, Brycon pesu, Bryconadenos tanaothoros, Bryconamericus exodon, Bryconops alburnoides, Charax cf. leticiae, Clupeacharax cf. engrauloides, Compsura heterura, Ctenobrycon hauxwellianus, Deuterodon iguape, Diapoma terofali, Galeocharax knerii, Gymnocorymbus ternetzi, Hemibrycon polyodon, Hemigrammus unilineatus, Hollandichthys multifasciatus, Hyphessobrycon compressus, Iguanodectes geisleri, Knodus meridae, Landonia latidens, Markiana nigripinnis, Metynnis lippincottianus, Microschemobrycon casiquiare, Moenkhausia xinguensis, Myleus setiger, Odontostilbe pequira, Oligosarcus argenteus, orthospinus franciscoensis, Paracheirodon axelrodi, Paragoniates alburnus, Phenacogaster pectinatus, Phenagoniates macrolepis, Piabina argentea, Piaractus mesopotamicus, Poptella brevispina, Probolus heterostomus, Rachoviscus graciliceps, Rhinobrycon negrensis, Rhoadsia altipinna, Roeboexodon guyanensis, Salminus hilarii, Serrabrycon magoi, Stygichthys typhlops e Tetragonopterus argenteus.

\section{[2] - superior.}


Gymnotus aff. carapo, Anostomus anostomus, Carnegiella strigata, Gasteropelecus sternicla, Thoracocharax stellatus, Copeina cf. guttata, Glandulocauda melanogenys, Gnathocharax steindachneri e Triportheus albus.

1 - Comprimento do processo ascendente do pré-maxilar:

[LUCENA, 1993: 35, modificado; BUCKUP, 1998: 31, modificado; ZANATA, 2000: 39, modificado; MOREIRA, 2002:1, modificado; ZANATA \& VARI, 2005: 54, modificado e NETTO-FERREIRA, 2006: 78, modificado]

\section{(Minimamente conectado) .}

\section{[0] - processo ausente (Fig. 17).}

Catostomus commersonnii, Olivaichthys mesembrinus, Curimata ocellata, Curimatopsis macrolepis, Potamorhina latior, Prochilodus nigricans, Semaprochilodus insignis, Boulengerella maculata, Ctenolucius hujeta, Hepsetus odoe e crenuchus spilurus.

[1] - processo curto, quase não distinto (Fig. 18).

Chanos chanos, Gymnotus aff. carapo, Citharinus latus, Distichodus notospilus, Hemistichodus vaillanti, Neolebias unifasciatus, Nannocharax fasciatus, Xenocharax spilurus, Apareiodon piracicabae, Parodon nasus, Saccodon wagneri, Anodus orinocensis, Bivibranchia fowleri, Hemiodus unimaculatus, Caenotropus labyrinthicus, Chilodus punctatus, Anostomus anostomus, Leporellus vittatus, Leporinus fasciatus, Schizodon fasciatus, Carnegiella strigata, Gasteropelecus sternicla, Thoracocharax stellatus, Acestrorhynchus falcirostris, Gilbertolus atratoensis, Copeina cf. guttata, Lebiasina bimaculata, Piabucina astrigata, Arnoldichthys spilopterus, Brycinus macrolepidotus, Bryconalestes longipinnis, Chalceus epakros, Characidium bahiensis, Axelrodia reisei, Brittanichthys axelrodi, Compsura heterura, Gnathocharax steindachneri, Hyphessobrycon compressus, Iguanodectes geisleri, Odontostilbe pequira, Rhinobrycon negrensis, Rhoadsia altipinna e Roeboexodon guyanensis.

\section{[2] - processo bem distinto (Fig. 19).}

Hydrolycus tatauaia, Roestes molossus, Erythrinoidea fam. nov, Erythrinus erythrinus, Hoplias malabaricus, Agoniates halecinus, Aphyocharax pusillus, Astyanax mexicanus, Atopomesus pachyodus, Brycon pesu, Bryconadenos tanaothoros, Bryconamericus exodon, Bryconops alburnoides, Charax cf. leticiae, Clupeacharax cf. engrauloides, Ctenobrycon hauxwellianus, Deuterodon iguape, Diapoma terofali, Galeocharax knerii, Glandulocauda melanogenys, Gymnocorymbus ternetzi, Hemibrycon polyodon, Hemigrammus unilineatus, Hollandichthys multifasciatus, Knodus meridae, Landonia latidens, Markiana nigripinnis, Metynnis lippincottianus, Microschemobrycon casiquiare, Moenkhausia xinguensis, Myleus setiger, oligosarcus argenteus, orthospinus franciscoensis, Paracheirodon axelrodi, Paragoniates alburnus, Phenacogaster pectinatus, Phenagoniates macrolepis, Piabina argentea, Piaractus mesopotamicus, Poptella brevispina, Probolus heterostomus, Rachoviscus graciliceps, Salminus hilarii, Serrabrycon magoi, Stygichthys typhlops, Tetragonopterus argenteus e Triportheus albus.

\section{2 - Processo ascendente do pré-maxilar:}

[MOREIRA, 2002: 2]

$$
\text { [0] - reto (Fig. 18). }
$$

Catostomus commersonnii, Citharinus latus, Distichodus notospilus, Hemistichodus vaillanti, Neolebias unifasciatus, Nannocharax fasciatus, Xenocharax spilurus, Apareiodon piracicabae, Parodon nasus, Anodus orinocensis, Hemiodus unimaculatus, Caenotropus labyrinthicus, Chilodus punctatus, Anostomus anostomus, Leporellus vittatus, Leporinus fasciatus, Thoracocharax stellatus, Gilbertolus atratoensis, Hydrolycus tatauaia, Erythrinoidea fam. nov, Erythrinus erythrinus, Hoplias malabaricus, Characidium bahiensis, Agoniates halecinus, Aphyocharax pusillus, Astyanax mexicanus, Atopomesus pachyodus, Brittanichthys axelrodi, Bryconamericus exodon, Bryconops alburnoides, Charax cf. leticiae, Clupeacharax cf. engrauloides, Diapoma terofali, Glandulocauda melanogenys, Hollandichthys multifasciatus, Knodus meridae, Landonia latidens, Markiana nigripinnis, Microschemobrycon casiquiare, Moenkhausia xinguensis, orthospinus franciscoensis, Phenagoniates macrolepis, Piaractus mesopotamicus, Roeboexodon guyanensis e Stygichthys typhlops. 
[1] - curvo (Fig. 20 e Fig. 21).

Chanos chanos, Gymnotus aff. carapo, Carnegiella strigata, Gasteropelecus sternicla, Acestrorhynchus falcirostris, Roestes molossus, Copeina cf. guttata, Lebiasina bimaculata, Piabucina astrigata, Arnoldichthys spilopterus, Brycinus macrolepidotus, Bryconalestes longipinnis, Chalceus epakros, Axelrodia reisei, Brycon pesu, Bryconadenos tanaothoros, Compsura heterura, Ctenobrycon hauxwellianus, Deuterodon iguape, Galeocharax knerii, Gnathocharax steindachneri, Gymnocorymbus ternetzi, Hemibrycon polyodon, Hemigrammus unilineatus, Hyphessobrycon compressus, Iguanodectes geisleri, Metynnis lippincottianus, Myleus setiger, odontostilbe pequira, oligosarcus argenteus, Paracheirodon axelrodi, Paragoniates alburnus, Phenacogaster pectinatus, Piabina argentea, Poptella brevispina, Probolus heterostomus, Rachoviscus graciliceps, Rhinobrycon negrensis, Rhoadsia altipinna, Salminus hilarii, serrabrycon magoi, Tetragonopterus argenteus e Triportheus albus.

\section{[-] - inaplicável.}

Olivaichthys mesembrinus, Bivibranchia fowleri, Curimata ocellata, Curimatopsis macrolepis, Potamorhina latior, Prochilodus nigricans, Semaprochilodus insignis, Boulengerella maculata, Ctenolucius hujeta, Hepsetus odoe e crenuchus spilurus.

\section{[?] - indeterminado.}

Saccodon wagneri e Schizodon fasciatus.

3 - Pré-maxilar:

[VARI, 1995: 37; Netto-FerReira, 2006: 77]

\section{(Minimamente conectado).}

\section{[0] - curto.}

Catostomus commersonnii, Apareiodon piracicabae, Parodon nasus, Saccodon wagneri, Bivibranchia fowleri, Caenotropus labyrinthicus, Chilodus punctatus, Anostomus anostomus, Leporellus vittatus, Leporinus fasciatus, Schizodon fasciatus, Gilbertolus atratoensis, Erythrinoidea fam. nov, Erythrinus erythrinus, Hoplias malabaricus, Characidium bahiensis, Agoniates halecinus, Aphyocharax pusillus, Atopomesus pachyodus, Brittanichthys axelrodi, Clupeacharax cf. engrauloides, Roeboexodon guyanensis e Triportheus albus.

\section{[1] - moderado.}

Chanos chanos, olivaichthys mesembrinus, Gymnotus aff. carapo, Citharinus latus, Distichodus notospilus, Hemistichodus vaillanti, Neolebias unifasciatus, Nannocharax fasciatus, Xenocharax spilurus, Anodus orinocensis, Hemiodus unimaculatus, Curimata ocellata, Curimatopsis macrolepis, Potamorhina latior, Prochilodus nigricans, Semaprochilodus insignis, Carnegiella strigata, Gasteropelecus sternicla, Thoracocharax stellatus, Hydrolycus tatauaia, Roestes molossus, Copeina cf. guttata, Lebiasina bimaculata, Piabucina astrigata, Hepsetus odoe, Arnoldichthys spilopterus, Brycinus macrolepidotus, Bryconalestes longipinnis, Chalceus epakros, Crenuchus spilurus, Astyanax mexicanus, Axelrodia reisei, Brycon pesu, Bryconadenos tanaothoros, Bryconamericus exodon, Bryconops alburnoides, Charax cf. leticiae, Compsura heterura, Ctenobrycon hauxwellianus, Deuterodon iguape, Diapoma terofali, Galeocharax knerii, Glandulocauda melanogenys, Gnathocharax steindachneri, Gymnocorymbus ternetzi, Hemibrycon polyodon, Hemigrammus unilineatus, Hollandichthys multifasciatus, Hyphessobrycon compressus, Iguanodectes geisleri, Knodus meridae, Landonia latidens, Markiana nigripinnis, Metynnis lippincottianus, Microschemobrycon casiquiare, Moenkhausia xinguensis, Myleus setiger, Odontostilbe pequira, Oligosarcus argenteus, orthospinus franciscoensis, Paracheirodon axelrodi, Paragoniates alburnus, Phenacogaster pectinatus, Phenagoniates macrolepis, Piabina argentea, Piaractus mesopotamicus, Poptella brevispina, Probolus heterostomus, Rachoviscus graciliceps, Rhinobrycon negrensis, Rhoadsia altipinna, Serrabrycon magoi, Stygichthys typhlops e Tetragonopterus argenteus.

\section{[2] - longo.}

Acestrorhynchus falcirostris, Boulengerella maculata, Ctenolucius hujeta e Salminus hilarii. 
4 - Face ântero-dorsal do pré-maxilar:

[VARI, 1979: 7]

[0] - lisa (Fig. 19).

Chanos chanos, Catostomus commersonnii, Olivaichthys mesembrinus, Gymnotus aff. carapo, Saccodon wagneri, Anodus orinocensis, Hemiodus unimaculatus, Curimata ocellata, Curimatopsis macrolepis, Potamorhina latior, Prochilodus nigricans, Semaprochilodus insignis, Caenotropus labyrinthicus, Chilodus punctatus, Anostomus anostomus, Leporellus vittatus, Leporinus fasciatus, Schizodon fasciatus, Carnegiella strigata, Gasteropelecus sternicla, Thoracocharax stellatus, Acestrorhynchus falcirostris, Gilbertolus atratoensis, Hydrolycus tatauaia, Roestes molossus, Erythrinoidea fam. nov, Boulengerella maculata, Ctenolucius hujeta, Copeina cf. guttata, Lebiasina bimaculata, Piabucina astrigata, Erythrinus erythrinus, Hoplias malabaricus, Hepsetus odoe, Arnoldichthys spilopterus, Brycinus macrolepidotus, Bryconalestes longipinnis, Chalceus epakros, Agoniates halecinus, Aphyocharax pusillus, Astyanax mexicanus, Atopomesus pachyodus, Axelrodia reisei, Brittanichthys axelrodi, Brycon pesu, Bryconadenos tanaothoros, Bryconamericus exodon, Bryconops alburnoides, Charax cf. leticiae, Clupeacharax cf. engrauloides, Compsura heterura, Ctenobrycon hauxwellianus, Deuterodon iguape, Diapoma terofali, Galeocharax knerii, Glandulocauda melanogenys, Gnathocharax steindachneri, Gymnocorymbus ternetzi, Hemibrycon polyodon, Hemigrammus unilineatus, Hollandichthys multifasciatus, Hyphessobrycon compressus, Iguanodectes geisleri, Knodus meridae, Landonia latidens, Markiana nigripinnis, Metynnis lippincottianus, Microschemobrycon casiquiare, Moenkhausia xinguensis, Myleus setiger, Odontostilbe pequira, oligosarcus argenteus, orthospinus franciscoensis, Paracheirodon axelrodi, Paragoniates alburnus, Phenacogaster pectinatus, Phenagoniates macrolepis, Piabina argentea, Piaractus mesopotamicus, Poptella brevispina, Probolus heterostomus, Rachoviscus graciliceps, Rhinobrycon negrensis, Rhoadsia altipinna, Roeboexodon guyanensis, Salminus hilarii, Serrabrycon magoi, Stygichthys typhlops, Tetragonopterus argenteus e Triportheus albus.

[1] - com fossa articular (Fig. 17 e Fig. 18).

Citharinus latus, Distichodus notospilus, Hemistichodus vaillanti, Neolebias unifasciatus, Nannocharax fasciatus, Xenocharax spilurus, Apareiodon piracicabae, Parodon nasus, Characidium bahiensis e Crenuchus spilurus.

\section{[-] - inaplicável.}

Bivibranchia fowleri.

\section{5 - Posição do pré-maxilar em relação ao mesetmóide:}

\section{[0] - ventral (Fig. 17 e Fig. 18).}

Catostomus commersonnii, olivaichthys mesembrinus, Gymnotus aff. carapo, Citharinus latus, Distichodus notospilus, Hemistichodus vaillanti, Neolebias unifasciatus, Nannocharax fasciatus, Xenocharax spilurus, Apareiodon piracicabae, Parodon nasus, Saccodon wagneri, Anodus orinocensis, Bivibranchia fowleri, Hemiodus unimaculatus, Curimata ocellata, Curimatopsis macrolepis, Potamorhina latior, Prochilodus nigricans, Semaprochilodus insignis, Characidium bahiensis e crenuchus spilurus.

\section{[1] - dorsal ou lateral (Fig. 19).}

Caenotropus labyrinthicus, Chilodus punctatus, Anostomus anostomus, Leporellus vittatus, Leporinus fasciatus, Schizodon fasciatus, Carnegiella strigata, Gasteropelecus sternicla, Thoracocharax stellatus, Acestrorhynchus falcirostris, Gilbertolus atratoensis, Hydrolycus tatauaia, Roestes molossus, Erythrinoidea fam. nov, Boulengerella maculata, Ctenolucius hujeta, Copeina cf. guttata, Lebiasina bimaculata, Piabucina astrigata, Erythrinus erythrinus, Hoplias malabaricus, Hepsetus odoe, Arnoldichthys spilopterus, Brycinus macrolepidotus, Bryconalestes longipinnis, Chalceus epakros, Agoniates halecinus, Aphyocharax pusillus, Astyanax mexicanus, Atopomesus pachyodus, Axelrodia reisei, Brittanichthys axelrodi, Brycon pesu, Bryconadenos tanaothoros, Bryconamericus exodon, Bryconops alburnoides, Charax cf. leticiae, Clupeacharax cf. engrauloides, Compsura heterura, Ctenobrycon hauxwellianus, Deuterodon iguape, Diapoma terofali, Galeocharax knerii, Glandulocauda melanogenys, Gnathocharax steindachneri, Gymnocorymbus ternetzi, Hemibrycon polyodon, Hemigrammus unilineatus, Hollandichthys multifasciatus, Hyphessobrycon compressus, Iguanodectes geisleri, Knodus meridae, Landonia latidens, Markiana nigripinnis, Metynnis lippincottianus, Microschemobrycon casiquiare, Moenkhausia xinguensis, Myleus setiger, odontostilbe pequira, oligosarcus argenteus, orthospinus franciscoensis, Paracheirodon axelrodi, 
Paragoniates alburnus, Phenacogaster pectinatus, Phenagoniates macrolepis, Piabina argentea, Piaractus mesopotamicus, Poptella brevispina, Probolus heterostomus , Rachoviscus graciliceps, Rhinobrycon negrensis, Rhoadsia altipinna, Roeboexodon guyanensis, Salminus hilarii, Serrabrycon magoi, Stygichthys typhlops, Tetragonopterus argenteus e Triportheus albus.

\section{[?] - indeterminado.}

Chanos chanos.

6 - Séries de dentes no pré-maxilar:

[LUCENA, 1993: 38 e 39 modificados; BUCKUP, 1998: 32, modificado; OYAKAWA, 1998: 60 modificado; ZANATA, 2000: 42; ZANATA \& VARI, 2005: 57 e NETTOFERREIRA, 2006: 83]

\section{[0] - uma série.}

Gymnotus aff. carapo, Citharinus latus, Hemistichodus vaillanti, Nannocharax fasciatus, Apareiodon piracicabae, Parodon nasus, Saccodon wagneri, Hemiodus unimaculatus Prochilodus nigricans, Semaprochilodus insignis, Caenotropus labyrinthicus, Chilodus punctatus, Anostomus anostomus, Leporellus vittatus, Leporinus fasciatus, Schizodon fasciatus, Carnegiella strigata, Gasteropelecus sternicla, Acestrorhynchus falcirostris, Gilbertolus atratoensis, Hydrolycus tatauaia, Roestes molossus, Boulengerella maculata, Ctenolucius hujeta, Copeina cf. guttata, Lebiasina bimaculata, Piabucina astrigata Erythrinus erythrinus, Hoplias malabaricus, Hepsetus odoe, Characidium bahiensis, Crenuchus spilurus, Aphyocharax pusillus, Atopomesus pachyodus, Axelrodia reisei, Brittanichthys axelrodi, Charax cf. leticiae, Compsura heterura, Gnathocharax steindachneri, Microschemobrycon casiquiare, odontostilbe pequira, oligosarcus argenteus, Paracheirodon axelrodi, Paragoniates alburnus, Phenagoniates macrolepis, Probolus heterostomus e Rhoadsia altipinna.

[1] - duas séries (Fig. 22).

Distichodus notospilus, Neolebias unifasciatus, Xenocharax spilurus, Thoracocharax stellatus, Erythrinoidea fam. nov, Arnoldichthys spilopterus, Brycinus macrolepidotus, Bryconalestes longipinnis, Agoniates halecinus, Astyanax mexicanus, Bryconadenos tanaothoros, Bryconamericus exodon, Clupeacharax cf. engrauloides, Ctenobrycon hauxwellianus, Deuterodon iguape, Diapoma terofali, Galeocharax knerii, Glandulocauda melanogenys, Gymnocorymbus ternetzi, Hemibrycon polyodon, Hemigrammus unilineatus, Hollandichthys multifasciatus, Hyphessobrycon compressus, Iguanodectes geisleri, Knodus meridae, Landonia latidens, Markiana nigripinnis, Metynnis lippincottianus, Moenkhausia xinguensis, Myleus setiger, orthospinus franciscoensis, Phenacogaster pectinatus, Piabina argentea, Piaractus mesopotamicus, Poptella brevispina, Rachoviscus graciliceps, Rhinobrycon negrensis, Salminus hilarii, Serrabrycon magoi, stygichthys typhlops, Tetragonopterus argenteus e Triportheus albus.

\section{[2] - três séries.}

Chalceus epakros, Brycon pesu e Bryconops alburnoides.

\section{[-] - inaplicável.}

Chanos chanos, Catostomus commersonnii, Olivaichthys mesembrinus, Anodus orinocensis, Bivibranchia fowleri, Curimata ocellata, Curimatopsis macrolepis, Potamorhina latior e Roeboexodon guyanensis.

\section{7 - Número de dentes da série externa do pré-maxilar:}

[ZANATA \& VARI, 2005: 59]

(Minimamente conectado).

[0] - dois ou um.

Thoracocharax stellatus, Bryconadenos tanaothoros, clupeacharax cf. engrauloides, Iguanodectes geisleri e Rachoviscus graciliceps.

[1] - três. 
Hepsetus odoe, Arnoldichthys spilopterus, Brycinus macrolepidotus, Bryconalestes longipinnis, Agoniates halecinus, Bryconamericus exodon, Deuterodon iguape, Gymnocorymbus ternetzi, Hollandichthys multifasciatus, Hyphessobrycon compressus, Landonia latidens, Metynnis lippincottianus, Myleus setiger, Piaractus mesopotamicus e Probolus heterostomus.

\section{[2] - quatro.}

Nannocharax fasciatus, Apareiodon piracicabae, Parodon nasus, Saccodon wagneri, Anostomus anostomus, Leporellus vittatus, Leporinus fasciatus, Schizodon fasciatus, Astyanax mexicanus, Ctenobrycon hauxwellianus, Diapoma terofali, Glandulocauda melanogenys, Hemigrammus unilineatus, Knodus meridae, Moenkhausia xinguensis, orthospinus franciscoensis e Poptella brevispina.

\section{[3] - cinco.}

Erythrinoidea fam. nov, Bryconops alburnoides, Hemibrycon polyodon, Markiana nigripinnis, Piabina argentea, Rhinobrycon negrensis, Serrabrycon magoi e Triportheus albus.

\section{[4] - seis ou mais.}

Gymnotus aff. carapo, Citharinus latus, Distichodus notospilus, Hemistichodus vaillanti, Neolebias unifasciatus, Xenocharax spilurus, Hemiodus unimaculatus, Prochilodus nigricans, Semaprochilodus insignis, Caenotropus labyrinthicus, Chilodus punctatus, Acestrorhynchus falcirostris, Gilbertolus atratoensis, Hydrolycus tatauaia, Roestes molossus, Boulengerella maculata, Ctenolucius hujeta, Copeina cf. guttata, Lebiasina bimaculata, Piabucina astrigata, Erythrinus erythrinus, Hoplias malabaricus, Chalceus epakros, Characidium bahiensis, Crenuchus spilurus, Aphyocharax pusillus, Brycon pesu, Charax cf. leticiae, Gnathocharax steindachneri, Oligosarcus argenteus, Phenacogaster pectinatus, Salminus hilarii, Stygichthys typhlops e Tetragonopterus argenteus.

\section{[-] - inaplicável.}

Chanos chanos, Catostomus commersonnii, Olivaichthys mesembrinus, Anodus orinocensis, Bivibranchia fowleri, Curimata ocellata, Curimatopsis macrolepis, Potamorhina latior, Carnegiella strigata, Gasteropelecus sternicla, Atopomesus pachyodus, Axelrodia reisei, Brittanichthys axelrodi, Compsura heterura, Microschemobrycon casiquiare, Odontostilbe pequira, Paracheirodon axelrodi, Paragoniates alburnus, Phenagoniates macrolepis, Rhoadsia altipinna e Roeboexodon guyanensis.

\section{[?] - indeterminado.}

Galeocharax knerii.

8 - Dentes da série interna do pré-maxilar:

[ZANATA, 2000: 43, modificado e ZANATA \& VARI, 2005: 61]

\section{[0] - 4 ou menos.}

Brycinus macrolepidotus, Bryconalestes longipinnis, Agoniates halecinus, Astyanax mexicanus, Bryconadenos tanaothoros, Bryconamericus exodon, compsura heterura, Ctenobrycon hauxwellianus, Diapoma terofali, Hemibrycon polyodon, Knodus meridae, Landonia latidens, Markiana nigripinnis, Metynnis lippincottianus, Myleus setiger, Piabina argentea, Piaractus mesopotamicus e Rhinobrycon negrensis.

\section{[1] - 5 ou mais.}

Distichodus notospilus, Neolebias unifasciatus, Xenocharax spilurus, Carnegiella strigata, Gasteropelecus sternicla, Thoracocharax stellatus, Erythrinoidea fam. nov, Arnoldichthys spilopterus, Chalceus epakros, Atopomesus pachyodus, Axelrodia reisei, Brittanichthys axelrodi, Brycon pesu, Bryconops alburnoides, Clupeacharax cf. engrauloides, Deuterodon iguape, Glandulocauda melanogenys, Gymnocorymbus ternetzi, Hemigrammus unilineatus, Hollandichthys multifasciatus, Hyphessobrycon compressus, Iguanodectes geisleri, Microschemobrycon casiquiare, Moenkhausia xinguensis, odontostilbe pequira, Orthospinus franciscoensis, Paracheirodon axelrodi, Paragoniates alburnus, Phenacogaster pectinatus, Phenagoniates macrolepis, Poptella brevispina, Rachoviscus graciliceps, Rhoadsia altipinna, Salminus hilarii, Serrabrycon magoi, Stygichthys typhlops, Tetragonopterus argenteus e Triportheus albus. 


\section{[-] - inaplicável.}

Chanos chanos, Catostomus commersonnii, Olivaichthys mesembrinus, Gymnotus aff. carapo, Citharinus latus, Hemistichodus vaillanti, Nannocharax fasciatus, Apareiodon piracicabae, Parodon nasus, Saccodon wagneri, Anodus orinocensis, Bivibranchia fowleri, Hemiodus unimaculatus, Curimata ocellata, Curimatopsis macrolepis, Potamorhina latior, Prochilodus nigricans, Semaprochilodus insignis, Caenotropus labyrinthicus, Chilodus punctatus, Anostomus anostomus, Leporellus vittatus, Leporinus fasciatus, Schizodon fasciatus, Acestrorhynchus falcirostris, Gilbertolus atratoensis, Hydrolycus tatauaia, Roestes molossus, Boulengerella maculata, Ctenolucius hujeta, copeina cf. guttata, Lebiasina bimaculata, Piabucina astrigata, Erythrinus erythrinus, Hoplias malabaricus, Characidium bahiensis, Crenuchus spilurus, Aphyocharax pusillus, Charax cf. leticiae, Gnathocharax steindachneri, oligosarcus argenteus, Probolus heterostomus e Roeboexodon guyanensis.

\section{[?] - indeterminado.}

Hepsetus odoe e Galeocharax knerii.

\section{9 - Terceira série de dentes:}

\section{[0] - poucos dentes entre as duas séries.}

Chalceus epakros, Triportheus albus e Bryconops alburnoides.

\section{[1] - poucos dentes posteriores as duas séries.}

Brycon pesu.

\section{[-] - inaplicável.}

Chanos chanos, Catostomus commersonnii, Olivaichthys mesembrinus, Gymnotus aff. carapo, Citharinus latus, Distichodus notospilus, Hemistichodus vaillanti, Neolebias unifasciatus, Nannocharax fasciatus, Xenocharax spilurus, Apareiodon piracicabae, Parodon nasus, Saccodon wagneri, Anodus orinocensis, Bivibranchia fowleri, Hemiodus unimaculatus, Curimata ocellata, Curimatopsis macrolepis, Potamorhina latior, Prochilodus nigricans, Semaprochilodus insignis, Caenotropus labyrinthicus, Chilodus punctatus, Anostomus anostomus, Leporellus vittatus, Leporinus fasciatus, Schizodon fasciatus, Carnegiella strigata, Gasteropelecus sternicla, Thoracocharax stellatus, Acestrorhynchus falcirostris, Gilbertolus atratoensis, Hydrolycus tatauaia, Roestes molossus, Erythrinoidea fam. nov, Boulengerella maculata, Ctenolucius hujeta, Copeina cf. guttata, Lebiasina bimaculata, Piabucina astrigata, Erythrinus erythrinus, Hoplias malabaricus, Hepsetus odoe, Arnoldichthys spilopterus, Brycinus macrolepidotus, Bryconalestes longipinnis, Characidium bahiensis, Crenuchus spilurus, Agoniates halecinus, Aphyocharax pusillus, Astyanax mexicanus, Atopomesus pachyodus, Axelrodia reisei, Brittanichthys axelrodi, Bryconadenos tanaothoros, Bryconamericus exodon, Charax cf. leticiae, Clupeacharax cf. engrauloides, Compsura heterura, Ctenobrycon hauxwellianus, Deuterodon iguape, Diapoma terofali, Galeocharax knerii, Glandulocauda melanogenys, Gnathocharax steindachneri, Gymnocorymbus ternetzi, Hemibrycon polyodon, Hemigrammus unilineatus, Hollandichthys multifasciatus, Hyphessobrycon compressus, Iguanodectes geisleri, Knodus meridae, Landonia latidens, Markiana nigripinnis, Metynnis lippincottianus, Microschemobrycon casiquiare, Moenkhausia xinguensis, Myleus setiger, odontostilbe pequira, Oligosarcus argenteus, orthospinus franciscoensis, Paracheirodon axelrodi, Paragoniates alburnus, Phenacogaster pectinatus, Phenagoniates macrolepis, Piabina argentea, Piaractus mesopotamicus, Poptella brevispina, Probolus heterostomus, Rachoviscus graciliceps, Rhinobrycon negrensis, Rhoadsia altipinna, Roeboexodon guyanensis, Salminus hilarii, Serrabrycon magoi, Stygichthys typhlops e Tetragonopterus argenteus.

10 - Forma dos dentes mais cuspidados da série principal do prémaxilar:

[FINK \& FINK, 1981: 44, modificado; LUCENA, 1993: 53, modificado; BUCKUP, 1998: 72, modificado; ZANATA, 2000: 36, modificado; ZANATA \& VARI, 2005: 49, modificado e NetTo-FerReIrA, 2006: 74, modificado]

\section{[0] - bicuspidados.}

Citharinus latus, Distichodus notospilus, Hemistichodus vaillanti, Neolebias unifasciatus, Nannocharax fasciatus e Xenocharax spilurus. 


\section{[1] - unicuspidados.}

Olivaichthys mesembrinus, Gymnotus aff. carapo, Caenotropus labyrinthicus, Chilodus punctatus, Acestrorhynchus falcirostris, Gilbertolus atratoensis, Hydrolycus tatauaia, Roestes molossus, Erythrinoidea fam. nov, Boulengerella maculata, Ctenolucius hujeta, Copeina cf. guttata, Erythrinus erythrinus, Hoplias malabaricus, Hepsetus odoe, Characidium bahiensis, Atopomesus pachyodus, Axelrodia reisei, Brittanichthys axelrodi, Charax cf. leticiae, Galeocharax knerii, Gnathocharax steindachneri, oligosarcus argenteus, Roeboexodon guyanensis e Salminus hilarii.

\section{[2] - tri- ou multicuspidados.}

Apareiodon piracicabae, Parodon nasus, Saccodon wagneri, Bivibranchia fowleri, Hemiodus unimaculatus, Anostomus anostomus, Schizodon fasciatus, Carnegiella strigata, Gasteropelecus sternicla, Thoracocharax stellatus, Lebiasina bimaculata, Piabucina astrigata, Arnoldichthys spilopterus, Brycinus macrolepidotus, Bryconalestes longipinnis, Chalceus epakros, Crenuchus spilurus, Agoniates halecinus, Aphyocharax pusillus, Astyanax mexicanus, Brycon pesu, Bryconadenos tanaothoros, Bryconamericus exodon, Bryconops alburnoides, Clupeacharax cf. engrauloides, compsura heterura, Ctenobrycon hauxwellianus, Deuterodon iguape, Diapoma terofali, Glandulocauda melanogenys, Gymnocorymbus ternetzi, Hemibrycon polyodon. Hemigrammus unilineatus, Hollandichthys multifasciatus, Hyphessobrycon compressus, Iguanodectes geisleri, Knodus meridae, Landonia latidens, Markiana nigripinnis, Microschemobrycon casiquiare, Moenkhausia xinguensis, odontostilbe pequira, oligosarcus argenteus, orthospinus franciscoensis, Paracheirodon axelrodi, Paragoniates alburnus, Phenacogaster pectinatus, Phenagoniates macrolepis, Piabina argentea, Poptella brevispina, Probolus heterostomus, Rachoviscus graciliceps, Rhinobrycon negrensis, Rhoadsia altipinna, Serrabrycon magoi, Stygichthys typhlops, Tetragonopterus argenteus e Triportheus albus.

\section{[3] - coroa como uma crista.}

Prochilodus nigricans, Semaprochilodus insignis, Leporellus vittatus e Leporinus fasciatus.

\section{[-] - inaplicável.}

Chanos chanos, Catostomus commersonnii, Anodus orinocensis, Curimata ocellata, Curimatopsis macrolepis e Potamorhina latior.

\section{[?] - indeterminado.}

Metynnis lippincottianus, Myleus setiger e Piaractus mesopotamicus.

\section{[1,2] - polimórfico.}

Oligosarcus argenteus.

11 - Coroa dos dentes pré-maxilares:

[LuCENA, 1993: 54, modificado; OYAKAWA, 1998: 62; e NetTo-FerReira, 2006: 76]

\section{[0] - perpendicular ao eixo longitudinal.}

Anostomus anostomus, Leporellus vittatus, Leporinus fasciatus, Schizodon fasciatus, Carnegiella strigata, Gasteropelecus sternicla, Thoracocharax stellatus, Arnoldichthys spilopterus, Brycinus macrolepidotus, Bryconalestes longipinnis, Chalceus epakros, Astyanax mexicanus, Brittanichthys axelrodi, Brycon pesu, Bryconadenos tanaothoros, Bryconamericus exodon, Bryconops alburnoides, Clupeacharax cf. engrauloides, Ctenobrycon hauxwellianus, Deuterodon iguape, Diapoma terofali, Glandulocauda melanogenys, Gymnocorymbus ternetzi, Hemibrycon polyodon, Hemigrammus unilineatus, Hollandichthys multifasciatus, Iguanodectes geisleri, Knodus meridae, Markiana nigripinnis, Metynnis lippincottianus, Microschemobrycon casiquiare, Moenkhausia xinguensis, Myleus setiger, orthospinus franciscoensis, Paracheirodon axelrodi, Phenacogaster pectinatus, Piabina argentea, Piaractus mesopotamicus, Poptella brevispina, Rachoviscus graciliceps, Rhinobrycon negrensis, Roeboexodon guyanensis, Serrabrycon magoi, Tetragonopterus argenteus e Triportheus albus.

\section{[1] - curvada lingualmente.}


Gymnotus aff. carapo, Citharinus latus, Distichodus notospilus, Hemistichodus vaillanti, Neolebias unifasciatus, Nannocharax fasciatus, Xenocharax spilurus, Apareiodon piracicabae, Parodon nasus, Saccodon wagneri, Bivibranchia fowleri, Hemiodus unimaculatus , Prochilodus nigricans, Semaprochilodus insignis, Caenotropus labyrinthicus, Chilodus punctatus, Acestrorhynchus falcirostris, Gilbertolus atratoensis, Hydrolycus tatauaia, Roestes molossus, Erythrinoidea fam. nov, Boulengerella maculata, ctenolucius hujeta, Copeina cf. guttata, Lebiasina bimaculata, Piabucina astrigata, Erythrinus erythrinus, Hoplias malabaricus, Hepsetus odoe, Characidium bahiensis, Crenuchus spilurus, Agoniates halecinus, Aphyocharax pusillus, Atopomesus pachyodus, Axelrodia reisei, Charax cf. leticiae, Compsura heterura, Galeocharax knerii, Gnathocharax steindachneri, Hyphessobrycon compressus, Landonia latidens, Odontostilbe pequira, Oligosarcus argenteus, Phenagoniates macrolepis, Rhoadsia altipinna, Salminus hilarii e Stygichthys typhlops.

\section{[2] - curvada labialmente.}

olivaichthys mesembrinus e Probolus heterostomus.

\section{[-] - inaplicável.}

Chanos chanos, Catostomus commersonnii, Curimata ocellata, Curimatopsis macrolepis e Potamorhina latior.

\section{[?] - indeterminado.}

Anodus orinocensis e Paragoniates alburnus.

\section{Dentes pré-maxilares:}

\section{[0] - com a coroa menor ou igual à base (Fig. 19) .}

olivaichthys mesembrinus, Gymnotus aff. carapo, Carnegiella strigata, Gasteropelecus sternicla, Thoracocharax stellatus, Acestrorhynchus falcirostris, Gilbertolus atratoensis, Hydrolycus tatauaia, Roestes molossus, Erythrinoidea fam. nov, Boulengerella maculata, ctenolucius hujeta, Copeina cf. guttata, Erythrinus erythrinus, Hoplias malabaricus, Hepsetus odoe, Arnoldichthys spilopterus, Brycinus macrolepidotus, Bryconalestes longipinnis, Chalceus epakros, Characidium bahiensis, Agoniates halecinus, Aphyocharax pusillus, Astyanax mexicanus, Atopomesus pachyodus, Axelrodia reisei, Brittanichthys axelrodi, Brycon pesu, Bryconamericus exodon, Charax cf. leticiae, Clupeacharax cf. engrauloides, ctenobrycon hauxwellianus, Deuterodon iguape, Diapoma terofali, Galeocharax knerii, Glandulocauda melanogenys, Gnathocharax steindachneri, Gymnocorymbus ternetzi, Hemibrycon polyodon, Hemigrammus unilineatus, Hollandichthys multifasciatus, Knodus meridae, Markiana nigripinnis, Metynnis lippincottianus, Microschemobrycon casiquiare, Moenkhausia xinguensis, Myleus setiger, oligosarcus argenteus, orthospinus franciscoensis, Paragoniates alburnus, Phenacogaster pectinatus, Piabina argentea, Piaractus mesopotamicus, Poptella brevispina, Probolus heterostomus , Rachoviscus graciliceps, Rhinobrycon negrensis, Rhoadsia altipinna, Salminus hilarii, Serrabrycon magoi, Stygichthys typhlops, Tetragonopterus argenteus e Triportheus albus.

\section{[1] - com a coroa maior que a base (Fig. 23).}

Citharinus latus, Distichodus notospilus, Hemistichodus vaillanti, Neolebias unifasciatus, Nannocharax fasciatus, Xenocharax spilurus, Apareiodon piracicabae, Parodon nasus, Saccodon wagneri, Bivibranchia fowleri, Hemiodus unimaculatus Prochilodus nigricans, Semaprochilodus insignis, Caenotropus labyrinthicus, Chilodus punctatus, Anostomus anostomus, Leporellus vittatus, Leporinus fasciatus, Schizodon fasciatus, Lebiasina bimaculata, Piabucina astrigata, Crenuchus spilurus, Bryconadenos tanaothoros, Bryconops alburnoides, Compsura heterura, Hyphessobrycon compressus, Iguanodectes geisleri, Landonia latidens, Odontostilbe pequira, Paracheirodon axelrodi e Phenagoniates macrolepis.

\section{[-] - inaplicável.}

Chanos chanos, Catostomus commersonnii, Anodus orinocensis, Curimata ocellata, Curimatopsis macrolepis, Potamorhina latior e Roeboexodon guyanensis.

\section{3 - Modo de implantação dos dentes: (Minimamente conectado).}




\section{[0] - ancorado ao osso (Fig. 24).}

Gymnotus aff. carapo, Xenocharax spilurus, Carnegiella strigata, Gasteropelecus sternicla, Thoracocharax stellatus, Acestrorhynchus falcirostris, Gilbertolus atratoensis, Hydrolycus tatauaia, Roestes molossus, Erythrinoidea fam. nov, Boulengerella maculata, Ctenolucius hujeta, Copeina cf. guttata, Lebiasina bimaculata, Piabucina astrigata, Erythrinus erythrinus, Hoplias malabaricus, Hepsetus odoe, Arnoldichthys spilopterus, Brycinus macrolepidotus, Bryconalestes longipinnis, Chalceus epakros, Characidium bahiensis, Crenuchus spilurus, Agoniates halecinus, Aphyocharax pusillus, Astyanax mexicanus, Atopomesus pachyodus, Axelrodia reisei, Brittanichthys axelrodi, Brycon pesu, Bryconadenos tanaothoros, Bryconamericus exodon, Bryconops alburnoides, Charax cf. leticiae, Clupeacharax cf. engrauloides, Compsura heterura, Ctenobrycon hauxwellianus, Deuterodon iguape, Diapoma terofali, Galeocharax knerii

Glandulocauda melanogenys, Gnathocharax steindachneri, Gymnocorymbus ternetzi, Hemibrycon polyodon, Hemigrammus unilineatus, Hollandichthys multifasciatus, Hyphessobrycon compressus, Iguanodectes geisleri, Knodus meridae, Landonia latidens, Markiana nigripinnis, Metynnis lippincottianus, Microschemobrycon casiquiare, Moenkhausia xinguensis, Myleus setiger, Odontostilbe pequira, oligosarcus argenteus, Orthospinus franciscoensis, Paracheirodon axelrodi, Paragoniates alburnus, Phenacogaster pectinatus, Phenagoniates macrolepis, Piabina argentea, Piaractus mesopotamicus, Poptella brevispina, Probolus heterostomus, Rachoviscus graciliceps, Rhinobrycon negrensis, Rhoadsia altipinna, Roeboexodon guyanensis, Salminus hilarii, Serrabrycon magoi, Stygichthys typhlops, Tetragonopterus argenteus e Triportheus albus.

\section{[1] - fracamente ligado ao osso (Fig. 22).}

Olivaichthys mesembrinus, Citharinus latus, Distichodus notospilus, Hemistichodus vaillanti, Neolebias unifasciatus, Nannocharax fasciatus, Apareiodon piracicabae, Parodon nasus, Saccodon wagneri, Bivibranchia fowleri, Hemiodus unimaculatus, Anostomus anostomus, Leporellus vittatus, Leporinus fasciatus e Schizodon fasciatus.

\section{[2] - inserido nos lábio.}

Prochilodus nigricans, Semaprochilodus insignis, Caenotropus labyrinthicus e Chilodus punctatus.

\section{[3] - ausentes.}

Anodus orinocensis, Curimata ocellata, Curimatopsis macrolepis e Potamorhina latior.

\section{[-] - inaplicável.}

Chanos chanos e Catostomus commersonnii.

14 - Cúspides dos dentes pré-maxilares:

[ZANATA, 2000: 44 e ZANATA \& VARI, 2005: 63]

\section{[0] - no mesmo plano.}

Citharinus latus, Distichodus notospilus, Hemistichodus vaillanti, Neolebias unifasciatus, Nannocharax fasciatus, Xenocharax spilurus, Apareiodon piracicabae, Parodon nasus, Saccodon wagneri, Bivibranchia fowleri, Hemiodus unimaculatus, Anostomus anostomus, Schizodon fasciatus, Carnegiella strigata, Gasteropelecus sternicla, Thoracocharax stellatus, Lebiasina bimaculata, Piabucina astrigata, Chalceus epakros, Crenuchus spilurus, Agoniates halecinus, Aphyocharax pusillus, Bryconadenos tanaothoros, Bryconamericus exodon, Bryconops alburnoides, Clupeacharax cf. engrauloides, Compsura heterura, Glandulocauda melanogenys, Gymnocorymbus ternetzi, Hemibrycon polyodon, Hemigrammus unilineatus, Hollandichthys multifasciatus, Hyphessobrycon compressus, Iguanodectes geisleri, Landonia latidens, Microschemobrycon casiquiare, odontostilbe pequira, oligosarcus argenteus, Paracheirodon axelrodi, Paragoniates alburnus, Phenacogaster pectinatus, Phenagoniates macrolepis, Rachoviscus graciliceps, Rhoadsia altipinna, Serrabrycon magoi e Stygichthys typhlops.

\section{[1] - cúspides mais externas progressivamente deslocadas}

\section{labialmente.}

Arnoldichthys spilopterus, Brycinus macrolepidotus, Bryconalestes longipinnis, Astyanax mexicanus, Brycon pesu, Ctenobrycon hauxwellianus, Deuterodon iguape, Diapoma terofali, Knodus meridae, Metynnis lippincottianus, Moenkhausia xinguensis, orthospinus 
franciscoensis, Piabina argentea, Poptella brevispina, Rhinobrycon negrensis, Tetragonopterus argenteus e Triportheus albus.

\section{[-] - inaplicável.}

Chanos chanos, Catostomus commersonnii, Olivaichthys mesembrinus, Gymnotus aff. carapo, Anodus orinocensis, Curimata ocellata, Curimatopsis macrolepis, Potamorhina latior, Prochilodus nigricans, Semaprochilodus insignis, Caenotropus labyrinthicus, Chilodus punctatus, Leporellus vittatus, Leporinus fasciatus, Acestrorhynchus falcirostris, Gilbertolus atratoensis, Hydrolycus tatauaia, Roestes molossus, Erythrinoidea fam. nov, Boulengerella maculata, Ctenolucius hujeta, Copeina cf. guttata, Erythrinus erythrinus, Hoplias malabaricus, Hepsetus odoe, Characidium bahiensis, Atopomesus pachyodus, Axelrodia reisei, Brittanichthys axelrodi, Charax cf. leticiae, Galeocharax knerii, Gnathocharax steindachneri, Markiana nigripinnis, Myleus setiger, Piaractus mesopotamicus, Probolus heterostomus, Roeboexodon guyanensis e Salminus hilarii.

\section{5 - Dentes de substituição do pré-maxilar:}

22) .

[0] - em apenas uma fileira posterior à fileira funcional (Fig.

Gymnotus aff. carapo, Citharinus latus, Distichodus notospilus, Hemistichodus vaillanti, Neolebias unifasciatus, Nannocharax fasciatus, Xenocharax spilurus, Caenotropus labyrinthicus, Chilodus punctatus, Anostomus anostomus, Leporellus vittatus, Leporinus fasciatus, Schizodon fasciatus, Carnegiella strigata, Gasteropelecus sternicla, Thoracocharax stellatus, Acestrorhynchus falcirostris, Gilbertolus atratoensis, Hydrolycus tatauaia, Roestes molossus, Erythrinoidea fam. nov, Boulengerella maculata, Ctenolucius hujeta, Copeina cf. guttata, Lebiasina bimaculata, Piabucina astrigata, Erythrinus erythrinus, Hoplias malabaricus, Hepsetus odoe, Arnoldichthys spilopterus, Brycinus macrolepidotus, Bryconalestes longipinnis, Chalceus epakros, Characidium bahiensis, Crenuchus spilurus, Agoniates halecinus, Aphyocharax pusillus, Astyanax mexicanus, Atopomesus pachyodus, Axelrodia reisei, Brittanichthys axelrodi, Brycon pesu, Bryconadenos tanaothoros, Bryconamericus exodon, Bryconops alburnoides, Charax cf. leticiae, Clupeacharax cf. engrauloides, Compsura heterura, Ctenobrycon hauxwellianus, Deuterodon iguape, Diapoma terofali, Galeocharax knerii, Glandulocauda melanogenys, Gnathocharax steindachneri, Gymnocorymbus ternetzi, Hemibrycon polyodon, Hemigrammus unilineatus, Hollandichthys multifasciatus, Hyphessobrycon compressus, Iguanodectes geisleri, Knodus meridae, Landonia latidens, Markiana nigripinnis, Metynnis lippincottianus, Microschemobrycon casiquiare, Moenkhausia xinguensis, Myleus setiger, odontostilbe pequira, oligosarcus argenteus, Orthospinus franciscoensis, Paracheirodon axelrodi, Paragoniates alburnus, Phenacogaster pectinatus, Phenagoniates macrolepis, Piabina argentea, Piaractus mesopotamicus, Poptella brevispina, Probolus heterostomus, Rachoviscus graciliceps, Rhinobrycon negrensis, Rhoadsia altipinna, Salminus hilarii, Serrabrycon magoi, stygichthys typhlops, Tetragonopterus argenteus e Triportheus albus.

\section{[1] - em mais de uma fileira posterior à fileira funcional.}

Apareiodon piracicabae, Parodon nasus, Saccodon wagneri, Hemiodus unimaculatus Prochilodus nigricans e semaprochilodus insignis.

\section{[-] - inaplicável.}

Chanos chanos, Catostomus commersonnii, Olivaichthys mesembrinus, Anodus orinocensis, Bivibranchia fowleri, Curimata ocellata, Curimatopsis macrolepis, Potamorhina latior e Roeboexodon guyanensis.

16 - Tamanho relativo dos dentes pré-maxilares:

[LuCEnA, 1993: 40, modificado; VARI, 1995: 48; NetTo-FerReIRA, 2006: 88]

[0] - dentes de tamanho semelhante, ou diminuindo de tamanho posteriormente (Figs. 20, 23 e 24).

Olivaichthys mesembrinus, Gymnotus aff. carapo, Citharinus latus, Distichodus notospilus, Hemistichodus vaillanti, Neolebias unifasciatus, Nannocharax fasciatus, Xenocharax spilurus, Apareiodon piracicabae, Parodon nasus, Saccodon wagneri, Hemiodus unimaculatus, Prochilodus nigricans, Semaprochilodus insignis, Caenotropus labyrinthicus, Chilodus punctatus, Anostomus anostomus, Leporellus vittatus, Leporinus fasciatus, Schizodon fasciatus, Carnegiella strigata, Gasteropelecus sternicla, Thoracocharax stellatus, Erythrinoidea fam. nov, Boulengerella maculata, Copeina cf. 
guttata, Lebiasina bimaculata, Piabucina astrigata, Arnoldichthys spilopterus, Brycinus macrolepidotus, Bryconalestes longipinnis, Chalceus epakros, Characidium bahiensis, Crenuchus spilurus, Agoniates halecinus, Aphyocharax pusillus, Astyanax mexicanus, Atopomesus pachyodus, Axelrodia reisei, Brittanichthys axelrodi, Brycon pesu, Bryconadenos tanaothoros, Bryconamericus exodon, Bryconops alburnoides, Clupeacharax cf. engrauloides, Compsura heterura, Ctenobrycon hauxwellianus, Deuterodon iguape, Diapoma terofali, Glandulocauda melanogenys, Gnathocharax steindachneri, Gymnocorymbus ternetzi, Hemibrycon polyodon, Hemigrammus unilineatus, Hollandichthys multifasciatus, Hyphessobrycon compressus, Iguanodectes geisleri, Knodus meridae, Landonia latidens, Markiana nigripinnis, Metynnis lippincottianus, Microschemobrycon casiquiare, Moenkhausia xinguensis, Myleus setiger, odontostilbe pequira, oligosarcus argenteus, orthospinus franciscoensis, Paracheirodon axelrodi, Paragoniates alburnus, Phenacogaster pectinatus, Phenagoniates macrolepis, Piabina argentea, Piaractus mesopotamicus, Poptella brevispina, Probolus heterostomus, Rachoviscus graciliceps, Rhinobrycon negrensis, Rhoadsia altipinna, Roeboexodon guyanensis, Salminus hilarii, Serrabrycon magoi, Stygichthys typhlops, Tetragonopterus argenteus e Triportheus albus.

Fig. 25).

[1] - dentes grandes intercalados por dentes menores (Fig. 21 e

Acestrorhynchus falcirostris, Gilbertolus atratoensis, Hydrolycus tatauaia, Roestes molossus, Ctenolucius hujeta, Erythrinus erythrinus, Hoplias malabaricus, Hepsetus odoe, Charax cf. leticiae e Galeocharax knerii.

\section{[-] - inaplicável.}

Chanos chanos, Catostomus commersonnii, Anodus orinocensis, Bivibranchia fowleri, Curimata ocellata, Curimatopsis macrolepis e Potamorhina latior.

\section{7 - Margem posterior da maxila:}

[LUCENA, 1993: 42, modificado; BUCKUP, 1998: 33 e 34, modificado;

OYAKAWA, 1998: 57, modificado; ZANATA \& VARI, 2005: 72, modificado e NETTOFERREIRA, 2006: 86, modificado]

\section{[0] - posterior à asa do etmóide lateral.}

Xenocharax spilurus, Anodus orinocensis, Semaprochilodus insignis, Acestrorhynchus falcirostris, Gilbertolus atratoensis, Hydrolycus tatauaia, Roestes molossus, Erythrinoidea fam. nov, Boulengerella maculata, Ctenolucius hujeta, Piabucina astrigata, Erythrinus erythrinus, Hoplias malabaricus, Hepsetus odoe, Arnoldichthys spilopterus, Chalceus epakros, Crenuchus spilurus, Agoniates halecinus, Aphyocharax pusillus, Astyanax mexicanus, Axelrodia reisei, Brittanichthys axelrodi, Brycon pesu, Bryconadenos tanaothoros, Bryconamericus exodon, Bryconops alburnoides, Charax cf. leticiae, Clupeacharax cf. engrauloides, Compsura heterura, Ctenobrycon hauxwellianus, Deuterodon iguape, Diapoma terofali, Galeocharax knerii, Glandulocauda melanogenys, Gnathocharax steindachneri, Gymnocorymbus ternetzi, Hemibrycon polyodon, Hemigrammus unilineatus, Hollandichthys multifasciatus, Hyphessobrycon compressus, Knodus meridae, Landonia latidens, Markiana nigripinnis, Metynnis lippincottianus, Odontostilbe pequira, oligosarcus argenteus, Orthospinus franciscoensis, Paracheirodon axelrodi, Paragoniates alburnus, Phenacogaster pectinatus, Phenagoniates macrolepis, Piabina argentea, Piaractus mesopotamicus, Poptella brevispina, Probolus heterostomus, Rachoviscus graciliceps, Rhinobrycon negrensis, Roeboexodon guyanensis, Salminus hilarii, Serrabrycon magoi, Stygichthys typhlops, Tetragonopterus argenteus e Triportheus albus.

\section{[1] - anterior à asa do etmóide lateral.}

Chanos chanos, Catostomus commersonnii, Olivaichthys mesembrinus, Gymnotus aff. carapo, Citharinus latus, Distichodus notospilus, Hemistichodus vaillanti, Neolebias unifasciatus, Nannocharax fasciatus, Apareiodon piracicabae, Parodon nasus, Saccodon wagneri, Bivibranchia fowleri, Hemiodus unimaculatus, Curimata ocellata, Curimatopsis macrolepis, Potamorhina latior, Prochilodus nigricans, Caenotropus labyrinthicus, Chilodus punctatus, Anostomus anostomus, Leporellus vittatus, Leporinus fasciatus, Schizodon fasciatus, Carnegiella strigata, Gasteropelecus sternicla, Thoracocharax stellatus, Copeina cf. guttata, Lebiasina bimaculata, Brycinus macrolepidotus, Bryconalestes longipinnis, Characidium bahiensis, Atopomesus pachyodus, Iguanodectes geisleri, Microschemobrycon casiquiare, Moenkhausia xinguensis, Myleus setiger e Rhoadsia altipinna. 


\section{[0] - porção anterior não alcançando a porção posterior da mandíbula.}

Chanos chanos, Catostomus commersonnii, Olivaichthys mesembrinus, Gymnotus aff. carapo, Citharinus latus, Distichodus notospilus, Hemistichodus vaillanti, Neolebias unifasciatus, Nannocharax fasciatus, Xenocharax spilurus, Apareiodon piracicabae, Parodon nasus, Saccodon wagneri, Anodus orinocensis, Bivibranchia fowleri, Hemiodus unimaculatus, Curimata ocellata, Curimatopsis macrolepis, Potamorhina latior, Prochilodus nigricans, Semaprochilodus insignis, Caenotropus labyrinthicus, chilodus punctatus, Anostomus anostomus, Leporellus vittatus, Leporinus fasciatus, Schizodon fasciatus, Carnegiella strigata, Gasteropelecus sternicla, Thoracocharax stellatus, Acestrorhynchus falcirostris, Erythrinoidea fam. nov, Boulengerella maculata, Ctenolucius hujeta, Copeina cf. guttata, Lebiasina bimaculata, Piabucina astrigata, Erythrinus erythrinus, Hoplias malabaricus, Hepsetus odoe, Arnoldichthys spilopterus, Brycinus macrolepidotus, Bryconalestes longipinnis, Chalceus epakros, Characidium bahiensis, Crenuchus spilurus, Agoniates halecinus, Aphyocharax pusillus, Astyanax mexicanus, Atopomesus pachyodus, Axelrodia reisei, Brittanichthys axelrodi, Brycon pesu, Bryconadenos tanaothoros, Bryconops alburnoides, Compsura heterura, Ctenobrycon hauxwellianus, Deuterodon iguape, Diapoma terofali, Glandulocauda melanogenys, Gymnocorymbus ternetzi, Hemibrycon polyodon, Hemigrammus unilineatus, Hollandichthys multifasciatus, Hyphessobrycon compressus, Knodus meridae, Landonia latidens, Markiana nigripinnis, Metynnis lippincottianus, Microschemobrycon casiquiare, Moenkhausia xinguensis, Myleus setiger, odontostilbe pequira, Oligosarcus argenteus, orthospinus franciscoensis, Paracheirodon axelrodi, Paragoniates alburnus, Phenacogaster pectinatus, Phenagoniates macrolepis, Piabina argentea, Piaractus mesopotamicus, Poptella brevispina, Probolus heterostomus, Rachoviscus graciliceps, Rhinobrycon negrensis, Rhoadsia altipinna, Roeboexodon guyanensis, Salminus hilarii, Serrabrycon magoi, Stygichthys typhlops, Tetragonopterus argenteus e Triportheus albus.

\section{[1] - maxilar aproximadamente do mesmo tamanho da mandíbula.}

Gilbertolus atratoensis, Hydrolycus tatauaia, Roestes molossus, Bryconamericus exodon, Charax cf. leticiae, clupeacharax cf. engrauloides, Galeocharax knerii, Gnathocharax steindachneri e Iguanodectes geisleri.

\section{9 - Superfície látero-posterior do maxilar:}

[VARI, 1983: 29 modificado; CASTRO \& VARI, 2004: 38]

[0] - lisa.

Chanos chanos, Catostomus commersonnii, Olivaichthys mesembrinus, Gymnotus aff. carapo, Citharinus latus, Distichodus notospilus, Hemistichodus vaillanti, Neolebias unifasciatus, Nannocharax fasciatus, Xenocharax spilurus, Apareiodon piracicabae, Parodon nasus, Saccodon wagneri

Anodus orinocensis, Bivibranchia fowleri, Hemiodus unimaculatus, Curimata ocellata, Curimatopsis macrolepis, Semaprochilodus insignis, Caenotropus labyrinthicus, Chilodus punctatus, Anostomus anostomus, Leporellus vittatus, Leporinus fasciatus, Schizodon fasciatus, Carnegiella strigata, Gasteropelecus sternicla, Thoracocharax stellatus, Acestrorhynchus falcirostris, Gilbertolus atratoensis, Hydrolycus tatauaia, Roestes molossus, Erythrinoidea fam. nov, Boulengerella maculata, Ctenolucius hujeta, Copeina cf. guttata, Lebiasina bimaculata, Piabucina astrigata, Erythrinus erythrinus, Hoplias malabaricus, Hepsetus odoe, Arnoldichthys spilopterus, Brycinus macrolepidotus, Bryconalestes longipinnis, Chalceus epakros, Characidium bahiensis, Crenuchus spilurus, Agoniates halecinus, Aphyocharax pusillus, Astyanax mexicanus, Atopomesus pachyodus, Axelrodia reisei, Brittanichthys axelrodi, Brycon pesu, Bryconadenos tanaothoros, Bryconamericus exodon, Bryconops alburnoides, Charax cf. leticiae, Clupeacharax cf. engrauloides, Compsura heterura, Ctenobrycon hauxwellianus, Deuterodon iguape, Diapoma terofali, Galeocharax knerii, Glandulocauda melanogenys, Gnathocharax steindachneri, Gymnocorymbus ternetzi, Hemibrycon polyodon, Hemigrammus unilineatus, Hollandichthys multifasciatus, Hyphessobrycon compressus, Iguanodectes geisleri, Knodus meridae, Landonia latidens, Markiana nigripinnis, Metynnis lippincottianus, Microschemobrycon casiquiare, Moenkhausia xinguensis, Myleus setiger, Odontostilbe pequira, Oligosarcus argenteus, Orthospinus franciscoensis, Paracheirodon axelrodi, Paragoniates alburnus, Phenacogaster pectinatus, Phenagoniates macrolepis, Piabina argentea, Piaractus mesopotamicus, Poptella brevispina, Probolus heterostomus, Rachoviscus graciliceps, Rhinobrycon negrensis, Rhoadsia altipinna, Roeboexodon guyanensis, Salminus hilarii, Serrabrycon magoi, Stygichthys typhlops, Tetragonopterus argenteus e Triportheus albus.

\section{[1] - com fenestras.}

Potamorhina latior e Prochilodus nigricans. 
20 - Margem ântero-dorsal do maxilar:

[Lucena, 1993: 43, modificado; Zanata, 2000: 46; e Zanata \& Vari, 2005: 67]

\section{[0] - convexa.}

Citharinus latus, Distichodus notospilus, Hemistichodus vaillanti, Neolebias unifasciatus, Nannocharax fasciatus, Xenocharax spilurus, Apareiodon piracicabae, Parodon nasus, Saccodon wagneri, Bivibranchia fowleri, Hemiodus unimaculatus, Curimata ocellata, Curimatopsis macrolepis, Potamorhina latior, Prochilodus nigricans, Semaprochilodus insignis, Caenotropus labyrinthicus, Chilodus punctatus, Anostomus anostomus, Leporellus vittatus, Leporinus fasciatus, Schizodon fasciatus, Carnegiella strigata, Gasteropelecus sternicla, Thoracocharax stellatus, Gilbertolus atratoensis, Hydrolycus tatauaia, Roestes molossus, Erythrinoidea fam. nov, Boulengerella maculata, Ctenolucius hujeta, Copeina cf. guttata, Lebiasina bimaculata, Piabucina astrigata, Erythrinus erythrinus, Hoplias malabaricus, Hepsetus odoe, Arnoldichthys spilopterus, Chalceus epakros, Characidium bahiensis, Crenuchus spilurus, Aphyocharax pusillus, Astyanax mexicanus, Atopomesus pachyodus, Axelrodia reisei, Brittanichthys axelrodi, Brycon pesu, Bryconadenos tanaothoros, Bryconamericus exodon, Bryconops alburnoides, Clupeacharax cf. engrauloides, Compsura heterura, Ctenobrycon hauxwellianus, Deuterodon iguape, Diapoma terofali, Galeocharax knerii, Glandulocauda melanogenys, Gnathocharax steindachneri, Gymnocorymbus ternetzi, Hemibrycon polyodon, Hemigrammus unilineatus, Hollandichthys multifasciatus, Hyphessobrycon compressus, Iguanodectes geisleri, Knodus meridae, Landonia latidens, Markiana nigripinnis, Metynnis lippincottianus, Microschemobrycon casiquiare, Moenkhausia xinguensis, Myleus setiger, odontostilbe pequira, Oligosarcus argenteus, Orthospinus franciscoensis, Paracheirodon axelrodi, Paragoniates alburnus, Phenacogaster pectinatus, Phenagoniates macrolepis, Piabina argentea, Piaractus mesopotamicus, Poptella brevispina, Probolus heterostomus, Rachoviscus graciliceps, Rhinobrycon negrensis, Rhoadsia altipinna, Roeboexodon guyanensis, Salminus hilarii, Serrabrycon magoi, Stygichthys typhlops, Tetragonopterus argenteus e Triportheus albus.

\section{[1] - côncava.}

Chanos chanos, Catostomus commersonnii, Olivaichthys mesembrinus, Anodus orinocensis, Acestrorhynchus falcirostris, Brycinus macrolepidotus, Bryconalestes longipinnis, Agoniates halecinus e Charax cf. leticiae.

\section{[-] - inaplicável.}

Gymnotus aff. carapo.

21 - Tamanho do processo ascendente do maxilar:

[ZANATA \& VARI, 2005: 69]

(Minimamente conectado) .

\section{[0] - menor que resto do maxilar (Fig. 24).}

Chanos chanos, Catostomus commersonnii, Olivaichthys mesembrinus, Citharinus latus, Distichodus notospilus, Hemistichodus vaillanti, Neolebias unifasciatus, Nannocharax fasciatus, Xenocharax spilurus, Anodus orinocensis, Bivibranchia fowleri, Hemiodus unimaculatus, Caenotropus labyrinthicus, Chilodus punctatus, Carnegiella strigata, Gasteropelecus sternicla, Thoracocharax stellatus, Acestrorhynchus falcirostris, Gilbertolus atratoensis, Hydrolycus tatauaia, Roestes molossus, Erythrinoidea fam. nov, Copeina cf. guttata, Lebiasina bimaculata, Piabucina astrigata, Erythrinus erythrinus, Hoplias malabaricus, Hepsetus odoe, Arnoldichthys spilopterus, Chalceus epakros, Characidium bahiensis, Crenuchus spilurus, Agoniates halecinus, Aphyocharax pusillus, Astyanax mexicanus, Atopomesus pachyodus, Axelrodia reisei, Brittanichthys axelrodi, Brycon pesu, Bryconadenos tanaothoros, Bryconamericus exodon, Bryconops alburnoides, Charax cf. leticiae, Clupeacharax cf. engrauloides, Compsura heterura, Ctenobrycon hauxwellianus, Deuterodon iguape, Diapoma terofali, Galeocharax knerii, Glandulocauda melanogenys, Gnathocharax steindachneri, Gymnocorymbus ternetzi, Hemibrycon polyodon Hemigrammus unilineatus, Hollandichthys multifasciatus, Hyphessobrycon compressus, Iguanodectes geisleri, Knodus meridae, Landonia latidens, Markiana nigripinnis, Microschemobrycon casiquiare, Moenkhausia xinguensis, odontostilbe pequira, oligosarcus argenteus, Orthospinus franciscoensis, Paracheirodon axelrodi, Paragoniates alburnus, Phenacogaster pectinatus, Phenagoniates macrolepis, Piabina argentea, Piaractus 
mesopotamicus, Poptella brevispina, Probolus heterostomus, Rachoviscus graciliceps, Rhinobrycon negrensis, Rhoadsia altipinna, Roeboexodon guyanensis, Salminus hilarii, Serrabrycon magoi, Stygichthys typhlops, Tetragonopterus argenteus e Triportheus albus.

\section{[1] - aproximadamente igual ao resto do maxilar.}

Apareiodon piracicabae, Parodon nasus, Saccodon wagneri, Curimata ocellata, Curimatopsis macrolepis, Prochilodus nigricans, Semaprochilodus insignis, Brycinus macrolepidotus, Bryconalestes longipinnis, Metynnis lippincottianus e Myleus setiger.

\section{[2] - maior que resto do maxilar.}

Potamorhina latior, Anostomus anostomus, Leporellus vittatus, Leporinus fasciatus, Schizodon fasciatus, Boulengerella maculata, Ctenolucius hujeta.

\section{[-] - inaplicável.}

Gymnotus aff. carapo.

22 - Processo ascendente do maxilar:

[ZANATA \& VARI, 2005: 68]

[0] - direcionado medianamente.

Chanos chanos, Catostomus commersonnii, Citharinus latus, Distichodus notospilus, Hemistichodus vaillanti, Neolebias unifasciatus, Nannocharax fasciatus, Xenocharax spilurus, Curimatopsis macrolepis, Potamorhina latior, Prochilodus nigricans, semaprochilodus insignis, Caenotropus labyrinthicus, Chilodus punctatus, Anostomus anostomus, Leporellus vittatus, Leporinus fasciatus, Schizodon fasciatus, Carnegiella strigata, Gasteropelecus sternicla, Thoracocharax stellatus, Gilbertolus atratoensis, Hydrolycus tatauaia, Roestes molossus, Erythrinoidea fam. nov, Copeina cf. guttata, Lebiasina bimaculata, Piabucina astrigata, Erythrinus erythrinus, Hoplias malabaricus, Characidium bahiensis, Agoniates halecinus, Aphyocharax pusillus, Astyanax mexicanus, Atopomesus pachyodus, Axelrodia reisei, Brittanichthys axelrodi, Brycon pesu, Bryconops alburnoides, Charax cf. leticiae, Clupeacharax cf. engrauloides, Compsura heterura, Ctenobrycon hauxwellianus, Deuterodon iguape, Diapoma terofali, Galeocharax knerii, Glandulocauda melanogenys, Gnathocharax steindachneri, Gymnocorymbus ternetzi, Hemibrycon polyodon, Hollandichthys multifasciatus, Hyphessobrycon compressus, Iguanodectes geisleri, Knodus meridae, Landonia latidens, Metynnis lippincottianus, Moenkhausia xinguensis, Myleus setiger, Odontostilbe pequira, Oligosarcus argenteus, orthospinus franciscoensis, Paracheirodon axelrodi, Phenacogaster pectinatus, Phenagoniates macrolepis, Piabina argentea, Piaractus mesopotamicus, Probolus heterostomus, Rachoviscus graciliceps, Rhoadsia altipinna, Salminus hilarii, Serrabrycon magoi, Stygichthys typhlops, Tetragonopterus argenteus e Triportheus albus.

\section{[1] - reto, ou levemente curvado medianamente.}

Olivaichthys mesembrinus, Apareiodon piracicabae, Parodon nasus, Saccodon wagneri, Anodus orinocensis, Bivibranchia fowleri, Hemiodus unimaculatus, Curimata ocellata, Acestrorhynchus falcirostris, Boulengerella maculata, Ctenolucius hujeta, Hepsetus odoe, Arnoldichthys spilopterus, Brycinus macrolepidotus, Bryconalestes longipinnis, Chalceus epakros, Crenuchus spilurus, Bryconadenos tanaothoros, Bryconamericus exodon, Hemigrammus unilineatus, Markiana nigripinnis, Microschemobrycon casiquiare Paragoniates alburnus, Poptella brevispina, Rhinobrycon negrensis e Roeboexodon guyanensis.

\section{[-] - inaplicável.}

Gymnotus aff. carapo.

\section{3 - Posição do processo ascendente do maxilar:}

[0] - anterior ou no mesmo plano do pré-maxilar (Fig. 26).

Catostomus commersonnii, Citharinus latus, Distichodus notospilus, Hemistichodus vaillanti, Neolebias unifasciatus, Nannocharax fasciatus, Xenocharax spilurus, Apareiodon piracicabae, Parodon nasus, Saccodon wagneri, Anodus orinocensis, Bivibranchia fowleri, Hemiodus unimaculatus, Caenotropus labyrinthicus, Chilodus 
punctatus, Anostomus anostomus, Leporellus vittatus, Leporinus fasciatus, Schizodon fasciatus, Carnegiella strigata, Gasteropelecus sternicla e Thoracocharax stellatus.

\section{[1] - posterior ao pré-maxilar (Fig. 27).}

Chanos chanos, Olivaichthys mesembrinus, Curimata ocellata, Curimatopsis macrolepis, Potamorhina latior, Prochilodus nigricans, Semaprochilodus insignis, Acestrorhynchus falcirostris, Gilbertolus atratoensis, Hydrolycus tatauaia, Roestes molossus, Erythrinoidea fam. nov, Boulengerella maculata, Ctenolucius hujeta, Copeina cf. guttata, Lebiasina bimaculata, Piabucina astrigata, Erythrinus erythrinus, Hoplias malabaricus, Hepsetus odoe, Arnoldichthys spilopterus, Brycinus macrolepidotus, Bryconalestes longipinnis, Chalceus epakros, Characidium bahiensis, Crenuchus spilurus, Agoniates halecinus, Aphyocharax pusillus, Astyanax mexicanus, Atopomesus pachyodus, Axelrodia reisei, Brittanichthys axelrodi, Brycon pesu, Bryconadenos tanaothoros, Bryconamericus exodon, Bryconops alburnoides, Charax cf. leticiae, Clupeacharax cf. engrauloides, Compsura heterura, Ctenobrycon hauxwellianus, Deuterodon iguape, Diapoma terofali, Galeocharax knerii, Glandulocauda melanogenys, Gnathocharax steindachneri, Gymnocorymbus ternetzi, Hemibrycon polyodon, Hemigrammus unilineatus, Hollandichthys multifasciatus, Hyphessobrycon compressus, Iguanodectes geisleri, Knodus meridae, Landonia latidens, Markiana nigripinnis, Metynnis lippincottianus, Microschemobrycon casiquiare, Moenkhausia xinguensis, Myleus setiger, odontostilbe pequira, oligosarcus argenteus, orthospinus franciscoensis, Paracheirodon axelrodi, Paragoniates alburnus, Phenacogaster pectinatus, Phenagoniates macrolepis, Piabina argentea, Piaractus mesopotamicus, Poptella brevispina, Probolus heterostomus, Rachoviscus graciliceps, Rhinobrycon negrensis, Rhoadsia altipinna, Roeboexodon guyanensis, Salminus hilarii, Serrabrycon magoi, Stygichthys typhlops, Tetragonopterus argenteus e Triportheus albus.

\section{[-] - inaplicável.}

Gymnotus aff. carapo.

24 - Maxilar:

[VARI, 1995: 36; e NETTo-FERREIRA, 2006: 88]

[0] - móvel.

Catostomus commersonnii, olivaichthys mesembrinus, Gymnotus aff. carapo, Citharinus latus, Distichodus notospilus, Neolebias unifasciatus, Nannocharax fasciatus, Xenocharax spilurus, Apareiodon piracicabae, Parodon nasus, Saccodon wagneri, Anodus orinocensis, Bivibranchia fowleri, Hemiodus unimaculatus, Curimata ocellata, curimatopsis macrolepis, Potamorhina latior, Prochilodus nigricans, Semaprochilodus insignis, Caenotropus labyrinthicus, Chilodus punctatus, Anostomus anostomus, Leporellus vittatus, Leporinus fasciatus, Carnegiella strigata, Gasteropelecus sternicla, Thoracocharax stellatus, Acestrorhynchus falcirostris, Gilbertolus atratoensis, Hydrolycus tatauaia, Roestes molossus, Erythrinoidea fam. nov, Copeina cf. guttata, Lebiasina bimaculata, Piabucina astrigata, Erythrinus erythrinus, Hoplias malabaricus, Hepsetus odoe, Arnoldichthys spilopterus, Brycinus macrolepidotus, Bryconalestes longipinnis, Chalceus epakros, Characidium bahiensis, Crenuchus spilurus, Agoniates halecinus, Aphyocharax pusillus, Astyanax mexicanus, Atopomesus pachyodus, Axelrodia reisei, Brittanichthys axelrodi, Brycon pesu, Bryconadenos tanaothoros, Bryconamericus exodon, Bryconops alburnoides, Charax cf. leticiae, Clupeacharax cf. engrauloides, Compsura heterura, ctenobrycon hauxwellianus, Deuterodon iguape, Diapoma terofali, Galeocharax knerii, Glandulocauda melanogenys, Gnathocharax steindachneri, Gymnocorymbus ternetzi, Hemibrycon polyodon, Hemigrammus unilineatus, Hollandichthys multifasciatus, Hyphessobrycon compressus, Iguanodectes geisleri, Knodus meridae, Landonia latidens, Markiana nigripinnis, Metynnis lippincottianus, Microschemobrycon casiquiare, Moenkhausia xinguensis, Myleus setiger, odontostilbe pequira, oligosarcus argenteus, orthospinus franciscoensis, Paracheirodon axelrodi, Paragoniates alburnus, Phenacogaster pectinatus, Phenagoniates macrolepis, Piabina argentea, Piaractus mesopotamicus, Poptella brevispina, Probolus heterostomus, Rachoviscus graciliceps, Rhinobrycon negrensis, Rhoadsia altipinna, Roeboexodon guyanensis, Salminus hilarii, Serrabrycon magoi, Stygichthys typhlops, Tetragonopterus argenteus e Triportheus albus.

\section{[1] - imóvel, associado firmemente ao pré-maxilar.}

Hemistichodus vaillanti, Schizodon fasciatus, Boulengerella maculate e ctenolucius hujeta.

[-] - inaplicável. 
25 - Porção posterior do maxilar:

[OYAKAWA, 1998: 58, modificado; e NETTO-FERREIRA, 2006: 89, modificado]

\section{[0] - mais fina, ou da mesma largura que porção mediana exposta.}

Catostomus commersonnii, Gymnotus aff. carapo, Apareiodon piracicabae, Parodon nasus, Saccodon wagneri, Anodus orinocensis, Bivibranchia fowleri, Hemiodus unimaculatus, Carnegiella strigata, Gasteropelecus sternicla, Thoracocharax stellatus Acestrorhynchus falcirostris, Hydrolycus tatauaia, Erythrinoidea fam. nov, Boulengerella maculata, Ctenolucius hujeta, Lebiasina bimaculata, Piabucina astrigata, Hepsetus odoe, Arnoldichthys spilopterus, Brycinus macrolepidotus, Bryconalestes longipinnis, Chalceus epakros, Characidium bahiensis, Crenuchus spilurus, Agoniates halecinus, Aphyocharax pusillus, Astyanax mexicanus, Atopomesus pachyodus, Axelrodia reisei, Brittanichthys axelrodi, Brycon pesu, Bryconamericus exodon, Bryconops alburnoides, Clupeacharax cf. engrauloides, Compsura heterura, Ctenobrycon hauxwellianus, Deuterodon iguape, Diapoma terofali, Galeocharax knerii, Glandulocauda melanogenys, Gnathocharax steindachneri, Gymnocorymbus ternetzi, Hemibrycon polyodon, Hemigrammus unilineatus, Hollandichthys multifasciatus, Hyphessobrycon compressus, Landonia latidens, Markiana nigripinnis, Microschemobrycon casiquiare, Moenkhausia xinguensis, odontostilbe pequira, orthospinus franciscoensis, Paracheirodon axelrodi, Paragoniates alburnus, Phenacogaster pectinatus, Phenagoniates macrolepis, Piabina argentea, Piaractus mesopotamicus, Poptella brevispina, Probolus heterostomus, Rachoviscus graciliceps, Rhinobrycon negrensis, Rhoadsia altipinna, Roeboexodon guyanensis, Salminus hilarii, Tetragonopterus argenteus e Triportheus albus.

\section{[1] - mais larga que a porção mediana exposta.}

Chanos chanos, Olivaichthys mesembrinus, Citharinus latus, Distichodus notospilus, Hemistichodus vaillanti, Neolebias unifasciatus, Nannocharax fasciatus, Xenocharax spilurus, Curimata ocellata, Curimatopsis macrolepis, Potamorhina latior, Prochilodus nigricans, Semaprochilodus insignis, Caenotropus labyrinthicus, Chilodus punctatus, Anostomus anostomus, Leporellus vittatus, Leporinus fasciatus, Schizodon fasciatus, Gilbertolus atratoensis, Roestes molossus, Copeina cf. guttata, Erythrinus erythrinus, Hoplias malabaricus, Bryconadenos tanaothoros, Charax cf. leticiae, Iguanodectes geisleri, Knodus meridae, Metynnis lippincottianus, Myleus setiger, Oligosarcus argenteus, Serrabrycon magoi e Stygichthys typhlops.

26 - Porção posterior da face lateral do maxilar:

[LuCENA \& MENEZES, 1998: 13; ZANATA, 2000: 51 modificado; NetTo-FerREIRA, 2006: 90 modificado]

\section{[0] - lisa, sem canal, ou com canal pouco dividido.}

Chanos chanos, Catostomus commersonnii, Gymnotus aff. carapo, Citharinus latus, Distichodus notospilus, Hemistichodus vaillanti, Neolebias unifasciatus, Nannocharax fasciatus, Xenocharax spilurus, Apareiodon piracicabae, Parodon nasus, Saccodon wagneri, Anodus orinocensis, Bivibranchia fowleri, Hemiodus unimaculatus, Curimata ocellata, Curimatopsis macrolepis, Potamorhina latior, Prochilodus nigricans, Semaprochilodus insignis, Caenotropus labyrinthicus, Chilodus punctatus, Anostomus anostomus, Leporellus vittatus, Leporinus fasciatus, Schizodon fasciatus, Carnegiella strigata, Gasteropelecus sternicla, Thoracocharax stellatus, Gilbertolus atratoensis, Boulengerella maculata, Ctenolucius hujeta, Copeina cf. guttata, Lebiasina bimaculata, Piabucina astrigata, Erythrinus erythrinus, Arnoldichthys spilopterus, Chalceus epakros, Characidium bahiensis, Crenuchus spilurus, Agoniates halecinus, Aphyocharax pusillus, Astyanax mexicanus, Atopomesus pachyodus, Axelrodia reisei, Brittanichthys axelrodi, Brycon pesu, Bryconadenos tanaothoros, Bryconamericus exodon, Bryconops alburnoides, Charax cf. leticiae, Clupeacharax cf. engrauloides, Compsura heterura, Ctenobrycon hauxwellianus, Deuterodon iguape, Diapoma terofali, Galeocharax knerii, Glandulocauda melanogenys, Gnathocharax steindachneri, Gymnocorymbus ternetzi, Hemibrycon polyodon, Hemigrammus unilineatus, Hollandichthys multifasciatus, Hyphessobrycon compressus, Iguanodectes geisleri, Knodus meridae, Landonia latidens, Markiana nigripinnis, Metynnis lippincottianus, Microschemobrycon casiquiare, Moenkhausia xinguensis, Myleus setiger, odontostilbe pequira, oligosarcus argenteus, orthospinus franciscoensis, Paracheirodon axelrodi, Paragoniates alburnus, Phenacogaster pectinatus, Phenagoniates macrolepis, Piabina argentea, Piaractus mesopotamicus, Poptella brevispina, Probolus heterostomus, Rachoviscus graciliceps, Rhinobrycon negrensis, Rhoadsia altipinna, Roeboexodon guyanensis, Serrabrycon magoi, Stygichthys typhlops, Tetragonopterus argenteus e Triportheus albus. 


\section{[1] - canal muito dividido dando o aspecto de possuir estrias.}

Olivaichthys mesembrinus, Acestrorhynchus falcirostris, Hydrolycus tatauaia, Roestes molossus, Erythrinoidea fam. nov, Hoplias malabaricus, Hepsetus odoe, Brycinus macrolepidotus, Bryconalestes longipinnis e Salminus hilarii.

27 - Processo ascendente do maxilar:

[NeTTO-FERREIRA, 2006: 91]

\section{[0] - curto.}

Chanos chanos, Catostomus commersonnii, Olivaichthys mesembrinus, Citharinus latus, Distichodus notospilus, Hemistichodus vaillanti, Neolebias unifasciatus, Nannocharax fasciatus, Xenocharax spilurus, Apareiodon piracicabae, Parodon nasus, Saccodon wagneri, Anodus orinocensis, Bivibranchia fowleri, Hemiodus unimaculatus, Curimata ocellata, Potamorhina latior, Acestrorhynchus falcirostris, Boulengerella maculata, Ctenolucius hujeta, Hepsetus odoe, Crenuchus spilurus, Atopomesus pachyodus, Axelrodia reisei, Brittanichthys axelrodi, Compsura heterura, Gnathocharax steindachneri, Gymnocorymbus ternetzi, Hyphessobrycon compressus, Microschemobrycon casiquiare, Paracheirodon axelrodi, Piaractus mesopotamicus, Rachoviscus graciliceps, Rhinobrycon negrensis, Rhoadsia altipinna, Roeboexodon guyanensis e Triportheus albus.

[1] - bem desenvolvido, quase atingindo o processo ascendente do pré-maxilar.

Curimatopsis macrolepis, Prochilodus nigricans, Semaprochilodus insignis, Caenotropus labyrinthicus, Chilodus punctatus, Anostomus anostomus, Leporellus vittatus, Leporinus fasciatus, Schizodon fasciatus, Carnegiella strigata, Gasteropelecus sternicla, Thoracocharax stellatus, Gilbertolus atratoensis, Hydrolycus tatauaia, Roestes molossus, Erythrinoidea fam. nov, Copeina cf. guttata, Lebiasina bimaculata, Piabucina astrigata, Erythrinus erythrinus, Hoplias malabaricus, Arnoldichthys spilopterus, Brycinus macrolepidotus, Bryconalestes longipinnis, Chalceus epakros, Characidium bahiensis, Agoniates halecinus, Aphyocharax pusillus, Astyanax mexicanus, Brycon pesu, Bryconadenos tanaothoros, Bryconamericus exodon, Bryconops alburnoides, Charax cf. leticiae, Clupeacharax cf. engrauloides, Ctenobrycon hauxwellianus, Deuterodon iguape, Diapoma terofali, Galeocharax knerii, Glandulocauda melanogenys, Hemibrycon polyodon, Hemigrammus unilineatus, Hollandichthys multifasciatus, Iguanodectes geisleri, Knodus meridae, Landonia latidens, Markiana nigripinnis, Metynnis lippincottianus, Moenkhausia xinguensis, Myleus setiger, Odontostilbe pequira, Oligosarcus argenteus, orthospinus franciscoensis, Paragoniates alburnus, Phenacogaster pectinatus, Phenagoniates macrolepis, Piabina argentea, Poptella brevispina, Probolus heterostomus, Salminus hilarii, Serrabrycon magoi, Stygichthys typhlops e Tetragonopterus argenteus.

\section{[-] - inaplicável.}

Gymnotus aff. carapo.

28 - Dentes no maxilar:

[LUCENA, 1993: 44; ZANATA, 2000: 52 e 53 modificados; ZANATA \& VARI, 2005 :

78, modificado e NETTO-FERREIRA, 2006: 92 e 93 modificados]

\section{(Minimamente conectado) .}

[0] - ausentes (Fig. 28).

Chanos chanos, Catostomus commersonnii, Gymnotus aff. carapo, Citharinus latus, Distichodus notospilus, Hemistichodus vaillanti, Nannocharax fasciatus, Anodus orinocensis, Curimata ocellata, Curimatopsis macrolepis, Potamorhina latior, Erythrinus erythrinus, Hepsetus odoe, Arnoldichthys spilopterus, Brycinus macrolepidotus, Bryconalestes longipinnis, Characidium bahiensis, Crenuchus spilurus, Brittanichthys axelrodi, Bryconops alburnoides, Iguanodectes geisleri, Markiana nigripinnis, Metynnis lippincottianus e Myleus setiger.

[1] - porção posterior sem dentes maior ou de mesmo tamanho do que a com dentes (Fig. 24). 
Neolebias unifasciatus, Xenocharax spilurus, Apareiodon piracicabae, Parodon nasus, Bivibranchia fowleri, Carnegiella strigata, Gasteropelecus sternicla, Thoracocharax stellatus, Lebiasina bimaculata, Piabucina astrigata, Astyanax mexicanus, Axelrodia reisei, Bryconadenos tanaothoros, Bryconamericus exodon, Clupeacharax cf. engrauloides, Compsura heterura, Ctenobrycon hauxwellianus, Deuterodon iguape, Diapoma terofali, Glandulocauda melanogenys, Gymnocorymbus ternetzi, Hemigrammus unilineatus, Hyphessobrycon compressus, Knodus meridae, Microschemobrycon casiquiare, Moenkhausia xinguensis, Odontostilbe pequira, Orthospinus franciscoensis, Paracheirodon axelrodi, Piabina argentea, Piaractus mesopotamicus, Poptella brevispina, Rachoviscus graciliceps, Rhinobrycon negrensis, Rhoadsia altipinna, Stygichthys typhlops, Tetragonopterus argenteus e Triportheus albus.

[2] - porção sem dentes posterior menor (ou ausente) do que a com dentes (Fig. 21).

Olivaichthys mesembrinus, Hemiodus unimaculatus, Prochilodus nigricans, Semaprochilodus insignis, Acestrorhynchus falcirostris, Gilbertolus atratoensis, Hydrolycus tatauaia, Roestes molossus, Erythrinoidea fam. nov, Boulengerella maculata, Ctenolucius hujeta, Copeina cf. guttata, Hoplias malabaricus, Chalceus epakros, Agoniates halecinus, Aphyocharax pusillus, Atopomesus pachyodus, Brycon pesu, Charax cf. leticiae, Galeocharax knerii, Gnathocharax steindachneri, Hemibrycon polyodon, Hollandichthys multifasciatus, Landonia latidens, oligosarcus argenteus, Paragoniates alburnus, Phenacogaster pectinatus, Phenagoniates macrolepis, Probolus heterostomus, Roeboexodon guyanensis, Salminus hilarii e Serrabrycon magoi.

\section{[-] - inaplicável.}

Caenotropus labyrinthicus, Chilodus punctatus, Anostomus anostomus, Leporellus vittatus, Leporinus fasciatus e Schizodon fasciatus.

\section{[?] - indeterminado.}

Saccodon wagneri.

29 - Canal na porção exposta do maxilar:

[ZANATA, 2000: 50; e NeTTO-FERREIRA, 2006: 182]

(Minimamente conectado).

[0] - ausente.

Chanos chanos, Catostomus commersonnii, Gymnotus aff. carapo, Distichodus notospilus, Hemistichodus vaillanti, Neolebias unifasciatus, Nannocharax fasciatus, Apareiodon piracicabae, Parodon nasus, Saccodon wagneri, Bivibranchia fowleri, Curimatopsis macrolepis, Prochilodus nigricans, Semaprochilodus insignis, Characidium bahiensis, Axelrodia reisei, Odontostilbe pequira, Paracheirodon axelrodi e Roeboexodon guyanensis.

\section{[1] - presente apenas na metade anterior do osso (Fig. 28).}

Xenocharax spilurus, Hemiodus unimaculatus, Curimata ocellata, Carnegiella strigata, Gasteropelecus sternicla, Thoracocharax stellatus, Crenuchus spilurus, Aphyocharax pusillus, Astyanax mexicanus, Atopomesus pachyodus, Brittanichthys axelrodi, Bryconadenos tanaothoros, Bryconamericus exodon, Charax cf. leticiae, Clupeacharax cf. engrauloides, Compsura heterura, Ctenobrycon hauxwellianus, Deuterodon iguape, Diapoma terofali, Glandulocauda melanogenys, Gymnocorymbus ternetzi, Hemigrammus unilineatus, Hyphessobrycon compressus, Microschemobrycon casiquiare, Moenkhausia xinguensis, oligosarcus argenteus, Orthospinus franciscoensis, Paragoniates alburnus, Phenacogaster pectinatus, Phenagoniates macrolepis, Piabina argentea, Poptella brevispina, Probolus heterostomus, Rachoviscus graciliceps, Rhinobrycon negrensis, Rhoadsia altipinna, Stygichthys typhlops e Tetragonopterus argenteus.

\section{[2] - presente também na metade posterior do osso (Fig. 24).}

Olivaichthys mesembrinus, Citharinus latus, Anodus orinocensis, Potamorhina latior, Caenotropus labyrinthicus, Chilodus punctatus, Anostomus anostomus, Leporellus vittatus, Leporinus fasciatus, Schizodon fasciatus, Acestrorhynchus falcirostris, Gilbertolus atratoensis, Hydrolycus tatauaia, Roestes molossus, Erythrinoidea fam. nov, Boulengerella maculata, Ctenolucius hujeta, Copeina cf. guttata, Lebiasina bimaculata, Piabucina astrigata, Erythrinus erythrinus, Hoplias malabaricus, Hepsetus odoe, Arnoldichthys spilopterus, Brycinus macrolepidotus, Bryconalestes longipinnis, Chalceus 
epakros, Brycon pesu, Bryconops alburnoides, Galeocharax knerii, Gnathocharax steindachneri, Hemibrycon polyodon, Hollandichthys multifasciatus, Iguanodectes geisleri, Knodus meridae, Landonia latidens, Markiana nigripinnis, Metynnis lippincottianus, Myleus setiger, Piaractus mesopotamicus, Salminus hilarii e Serrabrycon magoi.

30 - Supramaxilar:

[ZANATA, 2000: 54 e ZANATA \& VARI, 2005: 81]

\section{[0] - ausente.}

Chanos chanos, Catostomus commersonnii, olivaichthys mesembrinus, Gymnotus aff. carapo, Citharinus latus, Distichodus notospilus, Hemistichodus vaillanti, Neolebias unifasciatus, Nannocharax fasciatus, Xenocharax spilurus, Apareiodon piracicabae, Parodon nasus, Saccodon wagneri, Anodus orinocensis, Bivibranchia fowleri, Hemiodus unimaculatus, Curimata ocellata, Curimatopsis macrolepis, Potamorhina latior, Prochilodus nigricans, Semaprochilodus insignis, Anostomus anostomus, Leporellus vittatus, Leporinus fasciatus, Schizodon fasciatus, Carnegiella strigata, Gasteropelecus sternicla, Thoracocharax stellatus, Acestrorhynchus falcirostris, Gilbertolus atratoensis, Hydrolycus tatauaia, Roestes molossus, Erythrinoidea fam. nov, Boulengerella maculata, ctenolucius hujeta, Copeina cf. guttata, Lebiasina bimaculata, Piabucina astrigata, Erythrinus erythrinus, Hoplias malabaricus, Hepsetus odoe, Arnoldichthys spilopterus, Brycinus macrolepidotus, Bryconalestes longipinnis, Characidium bahiensis, Crenuchus spilurus, Agoniates halecinus, Aphyocharax pusillus, Astyanax mexicanus, Atopomesus pachyodus, Axelrodia reisei, Brittanichthys axelrodi, Brycon pesu, Bryconadenos tanaothoros, Bryconamericus exodon, Bryconops alburnoides, Charax cf. leticiae, Clupeacharax cf. engrauloides, Compsura heterura, ctenobrycon hauxwellianus, Deuterodon iguape, Diapoma terofali, Galeocharax knerii, Glandulocauda melanogenys, Gnathocharax steindachneri, Gymnocorymbus ternetzi, Hemibrycon polyodon , Hemigrammus unilineatus, Hollandichthys multifasciatus, Hyphessobrycon compressus, Iguanodectes geisleri, Knodus meridae, Landonia latidens, Markiana nigripinnis, Metynnis lippincottianus, Microschemobrycon casiquiare, Moenkhausia xinguensis, Myleus setiger, odontostilbe pequira, oligosarcus argenteus, orthospinus franciscoensis, Paracheirodon axelrodi, Paragoniates alburnus, Phenacogaster pectinatus, Phenagoniates macrolepis, Piabina argentea, Piaractus mesopotamicus, Poptella brevispina, Probolus heterostomus, Rachoviscus graciliceps, Rhinobrycon negrensis, Rhoadsia altipinna, Roeboexodon guyanensis, Salminus hilarii, Serrabrycon magoi, Stygichthys typhlops, Tetragonopterus argenteus e Triportheus albus.

\section{[1] - presente.}

Caenotropus labyrinthicus, Chilodus punctatus e Chalceus epakros.

\section{[?] - indeterminado.}

Agoniates halecinus e Triportheus albus.

31 - Sínfise do dentário:

[LUCENA, 1993: 48; BuCKUP, 1998: 35; OYAKAWA, 1998: 68; ZANATA \& VARI, 2005:

82; LIMA, 2006 : 11; e NeTTO-FERREIRA, 2006: 95]

[0] - interdigitada (Fig. 21 e Fig. 23). Carnegiella strigata, Gasteropelecus sternicla, Thoracocharax stellatus ,
Acestrorhynchus falcirostris, Gilbertolus atratoensis, Hydrolycus tatauaia, Roestes molossus, Erythrinoidea fam. nov, Boulengerella maculata, Ctenolucius hujeta, Copeina cf. guttata, Lebiasina bimaculata, Piabucina astrigata, Erythrinus erythrinus, Hoplias malabaricus, Hepsetus odoe, Arnoldichthys spilopterus, Brycinus macrolepidotus, Bryconalestes longipinnis, Chalceus epakros, Crenuchus spilurus, Agoniates halecinus, Aphyocharax pusillus, Astyanax mexicanus, Atopomesus pachyodus, Axelrodia reisei, Brittanichthys axelrodi, Brycon pesu, Bryconadenos tanaothoros, Bryconamericus exodon, Bryconops alburnoides, Charax cf. leticiae, clupeacharax cf. engrauloides, Compsura heterura, ctenobrycon hauxwellianus, Deuterodon iguape, Diapoma terofali, Galeocharax knerii, Glandulocauda melanogenys, Gnathocharax steindachneri, Gymnocorymbus ternetzi, Hemibrycon polyodon , Hemigrammus unilineatus, Hollandichthys multifasciatus, Hyphessobrycon compressus, Iguanodectes geisleri, Knodus meridae, Landonia latidens, Markiana nigripinnis, Metynnis lippincottianus, Microschemobrycon casiquiare, Moenkhausia xinguensis, Myleus setiger, odontostilbe pequira, oligosarcus argenteus, orthospinus franciscoensis, Paracheirodon axelrodi, Paragoniates alburnus, Phenacogaster pectinatus, Phenagoniates macrolepis, Piabina argentea, Piaractus mesopotamicus, 
Poptella brevispina, Probolus heterostomus, Rachoviscus graciliceps, Rhinobrycon negrensis, Rhoadsia altipinna, Roeboexodon guyanensis, Salminus hilarii, Serrabrycon magoi, Stygichthys typhlops, Tetragonopterus argenteus e Triportheus albus.

\section{[1] - sem interdigitação.}

Chanos chanos, Catostomus commersonnii, Olivaichthys mesembrinus, Gymnotus aff. carapo, Citharinus latus, Distichodus notospilus, Hemistichodus vaillanti, Neolebias unifasciatus, Nannocharax fasciatus, Xenocharax spilurus, Apareiodon piracicabae, Parodon nasus, Saccodon wagneri, Anodus orinocensis, Bivibranchia fowleri, Hemiodus unimaculatus, Curimata ocellata, Curimatopsis macrolepis, Potamorhina latior, Prochilodus nigricans, Semaprochilodus insignis, Caenotropus labyrinthicus, Chilodus punctatus, Anostomus anostomus, Leporellus vittatus, Leporinus fasciatus, Schizodon fasciatus e characidium bahiensis.

32 - Mandíbula:

[VARI, 1983: 30, modificado]

(Minimamente conectado).

[0] - curta (Fig. 23 e Fig. 24).

Catostomus commersonnii, Distichodus notospilus, Hemistichodus vaillanti, Neolebias unifasciatus, Nannocharax fasciatus, Prochilodus nigricans, Semaprochilodus insignis, Caenotropus labyrinthicus, Chilodus punctatus, Anostomus anostomus, Leporellus vittatus, Leporinus fasciatus, Schizodon fasciatus, Copeina cf. guttata, Lebiasina bimaculata, Piabucina astrigata, Brycinus macrolepidotus, Bryconalestes longipinnis, Bryconadenos tanaothoros, Bryconamericus exodon, Ctenobrycon hauxwellianus, Deuterodon iguape, Glandulocauda melanogenys, Iguanodectes geisleri, Knodus meridae, Landonia latidens, Markiana nigripinnis, Metynnis lippincottianus, Myleus setiger, Piabina argentea, Piaractus mesopotamicus, Tetragonopterus argenteus e Triportheus albus.

\section{[1] - longa (Fig. 20).}

Chanos chanos, Olivaichthys mesembrinus, Gymnotus aff. carapo, Citharinus latus, Xenocharax spilurus, Apareiodon piracicabae, Parodon nasus, Saccodon wagneri, Anodus orinocensis, Bivibranchia fowleri, Hemiodus unimaculatus, Curimata ocellata, Curimatopsis macrolepis, Potamorhina latior, Carnegiella strigata, Gasteropelecus sternicla, Thoracocharax stellatus, Gilbertolus atratoensis, Hydrolycus tatauaia, Roestes molossus, Erythrinoidea fam. nov, Erythrinus erythrinus, Hoplias malabaricus, Hepsetus odoe, Arnoldichthys spilopterus, Chalceus epakros, Characidium bahiensis, Crenuchus spilurus, Agoniates halecinus, Aphyocharax pusillus, Astyanax mexicanus, Atopomesus pachyodus, Axelrodia reisei, Brittanichthys axelrodi, Brycon pesu, Bryconops alburnoides, Charax cf. leticiae, Clupeacharax cf. engrauloides, compsura heterura, Diapoma terofali, Galeocharax knerii, Gymnocorymbus ternetzi, Hemibrycon polyodon, Hemigrammus unilineatus, Hollandichthys multifasciatus, Hyphessobrycon compressus', Microschemobrycon casiquiare, Moenkhausia xinguensis, Odontostilbe pequira, oligosarcus argenteus, Orthospinus franciscoensis, Paracheirodon axelrodi, Paragoniates alburnus, Phenacogaster pectinatus, Phenagoniates macrolepis, Poptella brevispina, Probolus heterostomus, Rachoviscus graciliceps, Rhinobrycon negrensis, Rhoadsia altipinna, Roeboexodon guyanensis, Salminus hilarii, Serrabrycon magoi e Stygichthys typhlops.

\section{[2] - muito longa (Fig. 21).}

Acestrorhynchus falcirostris, Boulengerella maculata, Ctenolucius hujeta e Gnathocharax steindachneri.

33 - Fossa mandibular:

[VARI, 1995: 42, modificado; e NetTo-FERREIRA, 2006: 98, modificado]

\section{[0] - amplamente aberta anteriormente (Fig. 29).}

Chanos chanos, Catostomus commersonnii, Olivaichthys mesembrinus, Gymnotus aff. carapo, Citharinus latus, Distichodus notospilus, Hemistichodus vaillanti, Neolebias unifasciatus, Nannocharax fasciatus, Xenocharax spilurus, Apareiodon piracicabae, Parodon nasus, Saccodon wagneri, Anodus orinocensis, Bivibranchia fowleri, Hemiodus unimaculatus, Curimata ocellata, Curimatopsis macrolepis, Potamorhina latior, Caenotropus labyrinthicus, Chilodus punctatus, Carnegiella strigata, Gasteropelecus sternicla, Thoracocharax stellatus, Gilbertolus atratoensis, Hydrolycus tatauaia, 
Roestes molossus, Copeina cf. guttata, Lebiasina bimaculata, Piabucina astrigata, Arnoldichthys spilopterus, Brycinus macrolepidotus, Bryconalestes longipinnis, Chalceus epakros, Characidium bahiensis, Crenuchus spilurus, Agoniates halecinus, Aphyocharax pusillus, Astyanax mexicanus, Atopomesus pachyodus, Axelrodia reisei, Brittanichthys axelrodi, Bryconadenos tanaothoros, Bryconamericus exodon, Bryconops alburnoides, Clupeacharax cf. engrauloides, Compsura heterura, Ctenobrycon hauxwellianus, Deuterodon iguape, Diapoma terofali, Glandulocauda melanogenys, Gnathocharax steindachneri, Gymnocorymbus ternetzi, Hemibrycon polyodon, Hemigrammus unilineatus, Hollandichthys multifasciatus, Hyphessobrycon compressus, Iguanodectes geisleri, Knodus meridae, Landonia latidens, Markiana nigripinnis, Metynnis lippincottianus, Microschemobrycon casiquiare, Moenkhausia xinguensis, Myleus setiger, odontostilbe pequira, oligosarcus argenteus, orthospinus franciscoensis, Paracheirodon axelrodi, Paragoniates alburnus, Phenacogaster pectinatus, Phenagoniates macrolepis, Piabina argentea, Poptella brevispina, Probolus heterostomus, Rachoviscus graciliceps, Rhinobrycon negrensis, Rhoadsia altipinna, Roeboexodon guyanensis, Serrabrycon magoi, Stygichthys typhlops, Tetragonopterus argenteus e Triportheus albus.

25).

[1] - levemente coberta por uma sutil expansão do dentário (Fig.

Acestrorhynchus falcirostris, Erythrinoidea fam. nov, Erythrinus erythrinus, Hoplias malabaricus, Hepsetus odoe, Brycon pesu, Charax cf. leticiae, Galeocharax knerii, Piaractus mesopotamicus e Salminus hilarii.

[2] - coberta por uma expansão da margem dorso-medial do dentário, estendendo-se ventralmente.

Boulengerella maculate e Ctenolucius hujeta.

[3] - coberta por uma expansão da margem ventro-medial do dentário, estendendo-se dorsalmente.

Prochilodus nigricans e Semaprochilodus insignis.

[4] - coberta pela fossa para os dentes de reposição.

Anostomus anostomus, Leporellus vittatus, Leporinus fasciatus e Schizodon fasciatus.

34 - Série interna de dentes do dentário:

[LUCENA, 1993: 49, modificado; BUCKUP, 1998: 36, modificado; OYAKAWA, 1998: 61, modificado; ZANATA, 2000: 55 e 56, modificados; LIMA, 2006: 34]

\section{[0] - ausente.}

Gymnotus aff. carapo, Citharinus latus, Hemistichodus vaillanti, Nannocharax fasciatus, Apareiodon piracicabae, Parodon nasus, Saccodon wagneri, Anodus orinocensis, Bivibranchia fowleri, Hemiodus unimaculatus, curimata ocellata, curimatopsis macrolepis, Potamorhina latior, Prochilodus nigricans, Semaprochilodus insignis, Caenotropus labyrinthicus, Chilodus punctatus, Anostomus anostomus, Leporellus vittatus, Leporinus fasciatus, Schizodon fasciatus, Carnegiella strigata, Gasteropelecus sternicla, Thoracocharax stellatus, Gilbertolus atratoensis, Roestes molossus, Arnoldichthys spilopterus, Brycinus' macrolepidotus, Bryconalestes longipinnis, Characidium bahiensis, Agoniates halecinus, Aphyocharax pusillus, Astyanax mexicanus, Atopomesus pachyodus, Axelrodia reisei, Brittanichthys axelrodi, Bryconadenos tanaothoros, Bryconamericus exodon, Bryconops alburnoides, Charax cf. leticiae, Clupeacharax cf. engrauloides, Compsura heterura, ctenobrycon hauxwellianus, Deuterodon iguape, Diapoma terofali, Galeocharax knerii, Glandulocauda melanogenys, Gnathocharax steindachneri, Gymnocorymbus ternetzi, Hemibrycon polyodon, Hemigrammus unilineatus, Hollandichthys multifasciatus, Hyphessobrycon compressus, Iguanodectes geisleri, Knodus meridae, Landonia latidens, Markiana nigripinnis, Metynnis lippincottianus, Microschemobrycon casiquiare, Moenkhausia xinguensis, Myleus setiger, odontostilbe pequira, Oligosarcus argenteus, orthospinus franciscoensis, Paracheirodon axelrodi, Paragoniates alburnus, Phenacogaster pectinatus, Phenagoniates macrolepis, Piabina argentea, Piaractus mesopotamicus, Poptella brevispina, Probolus heterostomus Rachoviscus graciliceps, Rhinobrycon negrensis, Rhoadsia altipinna, Roeboexodon guyanensis, Serrabrycon magoi, Stygichthys typhlops e Tetragonopterus argenteus.

[1] - presente, completa. 
Distichodus notospilus, Neolebias unifasciatus, Xenocharax spilurus, Erythrinoidea fam. nov, Copeina cf. guttata, Lebiasina bimaculata, Piabucina astrigata, Hepsetus odoe e Salminus hilarii.

\section{[2] - presente, incompleta.}

Acestrorhynchus falcirostris, Hydrolycus tatauaia, Boulengerella maculata, Ctenolucius hujeta, Erythrinus erythrinus, Hoplias malabaricus, Chalceus epakros, Crenuchus spilurus, Brycon pesu e Triportheus albus.

\section{[-] - inaplicável.}

Chanos chanos, Catostomus commersonnii e Olivaichthys mesembrinus.

35 - Porção posterior do dentário junto a sínfise:

[ZANATA, 2000: 56, modificado; ZANATA \& VARI, 2005:88; LIMA, 2006 : 14 e NetTo-FERREIRA, 2006: 105]

[0] - com um dente (Fig. 27).

Brycinus macrolepidotus, Bryconalestes longipinnis, Chalceus epakros, Brycon pesu, Metynnis lippincottianus, Myleus setiger, Piaractus mesopotamicus e Triportheus albus.

\section{[1] - sem dentes.}

Gymnotus aff. Carapo, Citharinus latus, Distichodus notospilus, Hemistichodus vaillanti, Neolebias unifasciatus, Nannocharax fasciatus, Xenocharax spilurus, Apareiodon piracicabae, Parodon nasus, Saccodon wagneri, Anodus orinocensis, Bivibranchia fowleri, Hemiodus unimaculatus, Curimata ocellata, Curimatopsis macrolepis, Potamorhina latior, Prochilodus nigricans, Semaprochilodus insignis, Caenotropus labyrinthicus, Chilodus punctatus, Anostomus anostomus, Leporellus vittatus, Leporinus fasciatus, Schizodon fasciatus, Carnegiella strigata, Gasteropelecus sternicla, Thoracocharax stellatus, Acestrorhynchus falcirostris, Gilbertolus atratoensis, Hydrolycus tatauaia, Roestes molossus, Erythrinoidea fam. nov, Boulengerella maculata, Ctenolucius hujeta, Copeina cf. guttata, Lebiasina bimaculata, Piabucina astrigata, Erythrinus erythrinus, Hoplias malabaricus, Hepsetus odoe, Arnoldichthys spilopterus, Characidium bahiensis, Crenuchus spilurus, Agoniates halecinus, Aphyocharax pusillus, Astyanax mexicanus, Atopomesus pachyodus, Axelrodia reisei, Brittanichthys axelrodi, Bryconadenos tanaothoros, Bryconamericus exodon, Bryconops alburnoides, Charax cf. leticiae, Clupeacharax cf. engrauloides, Compsura heterura, Ctenobrycon hauxwellianus, Deuterodon iguape, Diapoma terofali, Galeocharax knerii, Glandulocauda melanogenys, Gnathocharax steindachneri, Gymnocorymbus ternetzi, Hemibrycon polyodon, Hemigrammus unilineatus, Hollandichthys multifasciatus, Hyphessobrycon compressus, Iguanodectes geisleri, Knodus meridae, Landonia latidens, Markiana nigripinnis, Microschemobrycon casiquiare, Moenkhausia xinguensis, Odontostilbe pequira, oligosarcus argenteus, orthospinus franciscoensis, Paracheirodon axelrodi, Paragoniates alburnus, Phenacogaster pectinatus, Phenagoniates macrolepis, Piabina argentea, Poptella brevispina, Probolus heterostomus, Rachoviscus graciliceps, Rhinobrycon negrensis, Rhoadsia altipinna, Roeboexodon guyanensis, Salminus hilarii, Serrabrycon magoi, Stygichthys typhlops e Tetragonopterus argenteus.

\section{[-] - inaplicável.}

Chanos chanos, Catostomus commersonnii e Olivaichthys mesembrinus.

36 - Altura dos dentes anteriores do dentário:

[VARI, 1995: 46, modificado; ZANATA, 2000: 37, modificado; LIMA, 2006: 15, modificado; e NeTTo-FERREIRA, 2006: 75, modificado]

30).

[0] - dentes altos, bem mais altos que largos (Fig. 28 e Fig.

Olivaichthys mesembrinus, Gymnotus aff. carapo, Citharinus latus, Distichodus notospilus, Hemistichodus vaillanti, Neolebias unifasciatus, Nannocharax fasciatus, Xenocharax spilurus, Apareiodon piracicabae, Parodon nasus, Saccodon wagneri, Bivibranchia fowleri, Hemiodus unimaculatus, Prochilodus nigricans, Semaprochilodus insignis, Caenotropus labyrinthicus, Chilodus punctatus, Anostomus anostomus, Leporellus vittatus, Leporinus fasciatus, Schizodon fasciatus, Acestrorhynchus falcirostris, Gilbertolus atratoensis, Hydrolycus tatauaia, Roestes molossus, Erythrinoidea fam. nov, 
Boulengerella maculata, ctenolucius hujeta, copeina cf. guttata, Lebiasina bimaculata, Piabucina astrigata, Erythrinus erythrinus, Hoplias malabaricus, Hepsetus odoe, Characidium bahiensis, Crenuchus spilurus, Agoniates halecinus, Aphyocharax pusillus, Axelrodia reisei, Brittanichthys axelrodi, Brycon pesu, Charax cf. leticiae, Compsura heterura, Galeocharax knerii, Gnathocharax steindachneri, Microschemobrycon casiquiare, odontostilbe pequira, oligosarcus argenteus, Paragoniates alburnus, Phenacogaster pectinatus, Phenagoniates macrolepis, Rachoviscus graciliceps, Rhinobrycon negrensis, Rhoadsia altipinna, Salminus hilarii, Serrabrycon magoi e stygichthys typhlops.

\section{[1] - dentes baixos, altura e base similares (Fig. 24 e Fig. 20).}

Carnegiella strigata, Gasteropelecus sternicla, Thoracocharax stellatus, Arnoldichthys spilopterus, Brycinus macrolepidotus, Bryconalestes longipinnis, Chalceus epakros, Astyanax mexicanus, Atopomesus pachyodus, Bryconadenos tanaothoros, Bryconamericus exodon, Bryconops alburnoides, Clupeacharax cf. engrauloides, Ctenobrycon hauxwellianus, Deuterodon iguape, Diapoma terofali, Glandulocauda melanogenys, Gymnocorymbus ternetzi, Hemibrycon polyodon, Hemigrammus unilineatus, Hollandichthys multifasciatus, Hyphessobrycon compressus, Iguanodectes geisleri, Knodus meridae, Landonia latidens, Markiana nigripinnis, Metynnis lippincottianus, Moenkhausia xinguensis, Myleus setiger, orthospinus franciscoensis, Paracheirodon axelrodi, Piabina argentea, Piaractus mesopotamicus, Poptella brevispina, Probolus heterostomus, Roeboexodon guyanensis, Tetragonopterus argenteus e Triportheus albus.

\section{[-] - inaplicável.}

Chanos chanos e Catostomus commersonnii.

[?] - indeterminado.

Anodus orinocensis, Curimata ocellata, Curimatopsis macrolepis e Potamorhina latior.

\section{7 - Inserção de dentes no dentário:}

[0] - pela porção ventral (Fig. 23).

Olivaichthys mesembrinus, Gymnotus aff. carapo, Citharinus latus, Neolebias unifasciatus, Xenocharax spilurus, Parodon nasus, Carnegiella strigata, Gasteropelecus sternicla, Thoracocharax stellatus, Acestrorhynchus falcirostris, Gilbertolus atratoensis, Hydrolycus tatauaia, Roestes molossus, Erythrinoidea fam. nov, Boulengerella maculata, Ctenolucius hujeta, Erythrinus erythrinus, Hoplias malabaricus, Hepsetus odoe, Arnoldichthys spilopterus, Chalceus epakros, Characidium bahiensis, Agoniates halecinus, Aphyocharax pusillus, Atopomesus pachyodus, Axelrodia reisei, Brittanichthys axelrodi, Bryconops alburnoides, Charax cf. leticiae, Compsura heterura, Galeocharax knerii, Gnathocharax steindachneri, Hollandichthys multifasciatus, Iguanodectes geisleri, Microschemobrycon casiquiare, odontostilbe pequira, oligosarcus argenteus, Paracheirodon axelrodi, Paragoniates alburnus, Phenacogaster pectinatus, Phenagoniates macrolepis, Piabina argentea, Rachoviscus graciliceps, Rhoadsia altipinna, Roeboexodon guyanensis, Salminus hilarii e Stygichthys typhlops.

\section{[1] - pela porção ântero-ventral (Fig. 22).}

Distichodus notospilus, Hemistichodus vaillanti, Nannocharax fasciatus, Anostomus anostomus, Leporellus vittatus, Leporinus fasciatus, Schizodon fasciatus, Copeina cf. guttata, Lebiasina bimaculata, Piabucina astrigata, crenuchus spilurus, Bryconamericus exodon e Serrabrycon magoi.

\section{[2] - pela porção póstero-ventral (Fig. 24).}

Brycinus macrolepidotus, Bryconalestes longipinnis, Astyanax mexicanus, Brycon pesu, Bryconadenos tanaothoros, Clupeacharax cf. engrauloides, Ctenobrycon hauxwellianus, Deuterodon iguape, Diapoma terofali, Glandulocauda melanogenys, Gymnocorymbus ternetzi, Hemibrycon polyodon, Hemigrammus unilineatus, Hyphessobrycon compressus, Knodus meridae, Landonia latidens, Markiana nigripinnis, Metynnis lippincottianus, Moenkhausia xinguensis, Myleus setiger, Orthospinus franciscoensis, Piaractus mesopotamicus, Poptella brevispina, Probolus heterostomus, Rhinobrycon negrensis, Tetragonopterus argenteus e Triportheus albus.

\section{[-] - inaplicável.}


Chanos chanos, Catostomus commersonnii, Apareiodon piracicabae, Saccodon wagneri, Anodus orinocensis, Bivibranchia fowleri, Hemiodus unimaculatus, Curimata ocellata, Curimatopsis macrolepis, Potamorhina latior, Prochilodus nigricans, Semaprochilodus insignis, Caenotropus labyrinthicus e Chilodus punctatus.

\section{8 - Margem dorsal do dentário:}

[MOREIRA, 2002: 11]

\section{[0] - maior que a da área sem dentes (Fig. 21 e Fig. 25).}

Gymnotus aff. carapo, Citharinus latus, Hemistichodus vaillanti, Neolebias unifasciatus, Xenocharax spilurus, Prochilodus nigricans, Semaprochilodus insignis, Anostomus anostomus, Leporellus vittatus, Leporinus fasciatus, Schizodon fasciatus, Carnegiella strigata, Gasteropelecus sternicla, Thoracocharax stellatus, Acestrorhynchus falcirostris, Gilbertolus atratoensis, Hydrolycus tatauaia, Roestes molossus, Erythrinoidea fam. nov, Boulengerella maculata, Ctenolucius hujeta, copeina cf. guttata, Lebiasina bimaculata, Piabucina astrigata, Erythrinus erythrinus, Hoplias malabaricus, Hepsetus odoe, Arnoldichthys spilopterus, Brycinus macrolepidotus, Chalceus epakros, Crenuchus spilurus, Agoniates halecinus, Axelrodia reisei, Brycon pesu, Bryconadenos tanaothoros, Bryconamericus exodon, Charax cf. leticiae, Ctenobrycon hauxwellianus, Diapoma terofali, Galeocharax knerii, Glandulocauda melanogenys, Gnathocharax steindachneri, Hemibrycon polyodon, Hollandichthys multifasciatus, Iguanodectes geisleri, Knodus meridae, Landonia latidens, Moenkhausia xinguensis, Myleus setiger, odontostilbe pequira, oligosarcus argenteus, Paragoniates alburnus, Phenacogaster pectinatus, Phenagoniates macrolepis, Piaractus mesopotamicus, Poptella brevispina, Probolus heterostomus, Rachoviscus graciliceps, Roeboexodon guyanensis, Salminus hilarii, Serrabrycon magoi, Stygichthys typhlops e Triportheus albus.

\section{[1] - menor que área sem dentes (Fig. 29).}

Olivaichthys mesembrinus, Distichodus notospilus, Nannocharax fasciatus, Parodon nasus, Chilodus punctatus, Bryconalestes longipinnis, Characidium bahiensis, Aphyocharax pusillus, Astyanax mexicanus, Atopomesus pachyodus, Brittanichthys axelrodi, Bryconops alburnoides, Clupeacharax cf. engrauloides, Compsura heterura, Deuterodon iguape, Gymnocorymbus ternetzi, Hemigrammus unilineatus, Hyphessobrycon compressus, Markiana nigripinnis, Metynnis lippincottianus, Microschemobrycon casiquiare, orthospinus franciscoensis, Paracheirodon axelrodi, Piabina argentea, Rhinobrycon negrensis, Rhoadsia altipinna e Tetragonopterus argenteus.

\section{[-] - inaplicável.}

Chanos chanos, Catostomus commersonnii, Apareiodon piracicabae, Saccodon wagneri, Anodus orinocensis, Bivibranchia fowleri, Hemiodus unimaculatus, Curimata ocellata, Curimatopsis macrolepis, Potamorhina latior e Caenotropus labyrinthicus.

\section{9 - Dentes de reposição do dentário:}

\section{[0] - alinhados com os dentes funcionais.}

Olivaichthys mesembrinus, Citharinus latus, Distichodus notospilus, Hemistichodus vaillanti, Neolebias unifasciatus, Nannocharax fasciatus, Xenocharax spilurus, Parodon nasus, Prochilodus nigricans, Semaprochilodus insignis, Caenotropus labyrinthicus, Chilodus punctatus, Anostomus anostomus, Leporellus vittatus, Leporinus fasciatus, Schizodon fasciatus, Carnegiella strigata, Gasteropelecus sternicla, Thoracocharax stellatus, Gilbertolus atratoensis, Hydrolycus tatauaia, Roestes molossus, Erythrinoidea fam. nov, Copeina cf. guttata, Lebiasina bimaculata, Piabucina astrigata, Erythrinus erythrinus, Hoplias malabaricus, Arnoldichthys spilopterus, Brycinus macrolepidotus, Bryconalestes longipinnis, Chalceus epakros, Characidium bahiensis, Crenuchus spilurus, Astyanax mexicanus, Brycon pesu, Bryconamericus exodon, Charax cf. leticiae, Clupeacharax cf. engrauloides, Ctenobrycon hauxwellianus, Deuterodon iguape, Diapoma terofali, Galeocharax knerii, Gymnocorymbus ternetzi, Hemibrycon polyodon, Hemigrammus unilineatus, Hyphessobrycon compressus, Knodus meridae, Landonia latidens, Markiana nigripinnis, Moenkhausia xinguensis, Myleus setiger, Orthospinus franciscoensis, Paragoniates alburnus, Phenagoniates macrolepis, Piabina argentea, Poptella brevispina, Probolus heterostomus, Rachoviscus graciliceps, Rhinobrycon negrensis, Salminus hilarii, Serrabrycon magoi, Stygichthys typhlops, Tetragonopterus argenteus e Triportheus albus.

\section{[1] - inclinados lingualmente.}


Gymnotus aff. carapo, Hydrolycus tatauaia, Boulengerella maculata, Ctenolucius hujeta, Aphyocharax pusillus, Atopomesus pachyodus, Axelrodia reisei, Brittanichthys axelrodi, Microschemobrycon casiquiare, Odontostilbe pequira, Phenacogaster pectinatus e Piaractus mesopotamicus.

\section{[2] - inclinados lateralmente.}

Acestrorhynchus falcirostris, Hepsetus odoe, Agoniates halecinus, Bryconadenos tanaothoros, Bryconops alburnoides, Compsura heterura, Glandulocauda melanogenys, Gnathocharax steindachneri, Hollandichthys multifasciatus, Iguanodectes geisleri, oligosarcus argenteus, Paracheirodon axelrodi, Rhoadsia altipinna e Roeboexodon guyanensis.

\section{[-] - inaplicável.}

Chanos chanos, Catostomus commersonnii, Apareiodon piracicabae, Saccodon wagneri, Anodus orinocensis, Bivibranchia fowleri, Hemiodus unimaculatus, Curimata ocellata, Curimatopsis macrolepis e Potamorhina latior.

\section{[?] - indeterminado.}

Metynnis lippincottianus.

\section{[1,2] - polimórfico.}

Hydrolycus tatauaia.

40 - Margem dorsal do dentário:

[MOREIRA, 2002: 12]

[0] - aproximadamente reta (Fig. 21).

Carnegiella strigata, Gasteropelecus sternicla, Thoracocharax stellatus, Acestrorhynchus falcirostris, Gilbertolus atratoensis, Hydrolycus tatauaia, Roestes molossus, Boulengerella maculata, Ctenolucius hujeta, Erythrinus erythrinus, Hoplias malabaricus, Hepsetus odoe, Astyanax mexicanus, Brycon pesu, Bryconops alburnoides, Charax cf. leticiae, Clupeacharax cf. engrauloides, Compsura heterura, ctenobrycon hauxwellianus, Deuterodon iguape, Diapoma terofali, Galeocharax knerii, Glandulocauda melanogenys, Gnathocharax steindachneri, Gymnocorymbus ternetzi, Hemibrycon polyodon, Hemigrammus unilineatus, Hollandichthys multifasciatus, Hyphessobrycon compressus, Markiana nigripinnis, Moenkhausia xinguensis, orthospinus franciscoensis, Paracheirodon axelrodi, Paragoniates alburnus, Piaractus mesopotamicus, Poptella brevispina, Probolus heterostomus, Rachoviscus graciliceps, Rhoadsia altipinna, Roeboexodon guyanensis, Salminus hilarii, Serrabrycon magoi, Stygichthys typhlops e Tetragonopterus argenteus.

[1] - formando um ângulo obtuso (Fig. 28).

Gymnotus aff. carapo, Citharinus latus, Distichodus notospilus, Hemistichodus vaillanti, Neolebias unifasciatus, Nannocharax fasciatus, Xenocharax spilurus, Apareiodon piracicabae, Parodon nasus, Saccodon wagneri, Bivibranchia fowleri, Curimata ocellata, Curimatopsis macrolepis, Potamorhina latior, Prochilodus nigricans, Semaprochilodus insignis, Caenotropus labyrinthicus, Chilodus punctatus, Anostomus anostomus, Leporellus vittatus, Leporinus fasciatus, Schizodon fasciatus, Erythrinoidea fam. nov, Arnoldichthys spilopterus, Brycinus macrolepidotus, Bryconalestes longipinnis, Chalceus epakros, Characidium bahiensis, Crenuchus spilurus, Aphyocharax pusillus, Atopomesus pachyodus, Axelrodia reisei, Brittanichthys axelrodi, Bryconadenos tanaothoros, Bryconamericus exodon, Knodus meridae, Landonia latidens, Microschemobrycon casiquiare, odontostilbe pequira, Oligosarcus argenteus, Phenacogaster pectinatus, Rhinobrycon negrensis e Triportheus albus.

[2] - margem decontínua, com porção posterior mais dorsal que anterior (Fig. 26).

Chanos chanos, Catostomus commersonnii, Olivaichthys mesembrinus, Hemiodus unimaculatus, Copeina cf. guttata, Lebiasina bimaculata, Piabucina astrigata, Agoniates halecinus, Iguanodectes geisleri, Metynnis lippincottianus, Myleus setiger, Phenagoniates macrolepis e Piabina argêntea.

[?] - indeterminado. 
41 - Dentes do dentário:

[OYAKAWA, 1998: 59, modificado e TOLEDO-PIZA, 2000: 36, modificado]

[0] - sem caninos desenvolvidos (Figs. 20, 23 e 24).

Olivaichthys mesembrinus, Gymnotus aff. carapo, Citharinus latus, Distichodus notospilus, Hemistichodus vaillanti, Neolebias unifasciatus, Nannocharax fasciatus, Xenocharax spilurus, Parodon nasus, Potamorhina latior, Prochilodus nigricans, Chilodus punctatus, Anostomus anostomus, Leporellus vittatus, Leporinus fasciatus, Schizodon fasciatus, Carnegiella strigata, Gasteropelecus sternicla, Thoracocharax stellatus , Boulengerella maculata, ctenolucius hujeta, Copeina cf. guttata, Lebiasina bimaculata, Piabucina astrigata, Erythrinus erythrinus, Arnoldichthys spilopterus, Brycinus macrolepidotus, Bryconalestes longipinnis, Chalceus epakros, Characidium bahiensis, Crenuchus spilurus, Aphyocharax pusillus, Astyanax mexicanus, Atopomesus pachyodus, Axelrodia reisei, Brittanichthys axelrodi, Brycon pesu, Bryconadenos tanaothoros, Bryconamericus exodon, Bryconops alburnoides, Clupeacharax cf. engrauloides, Compsura heterura, Ctenobrycon hauxwellianus, Deuterodon iguape, Diapoma terofali, Galeocharax knerii, Glandulocauda melanogenys, Gnathocharax steindachneri, Gymnocorymbus ternetzi, Hemibrycon polyodon, Hemigrammus unilineatus, Hollandichthys multifasciatus, Hyphessobrycon compressus, Iguanodectes geisleri, Knodus meridae, Landonia latidens, Markiana nigripinnis, Metynnis lippincottianus, Microschemobrycon casiquiare, Moenkhausia xinguensis, Myleus setiger, Odontostilbe pequira, orthospinus franciscoensis, Paracheirodon axelrodi, Paragoniates alburnus, Phenacogaster pectinatus, Phenagoniates macrolepis, Piabina argentea, Piaractus mesopotamicus, Poptella brevispina, Probolus heterostomus, Rachoviscus graciliceps, Rhinobrycon negrensis, Rhoadsia altipinna, Roeboexodon guyanensis, Salminus hilarii, Serrabrycon magoi, Stygichthys typhlops, Tetragonopterus argenteus e Triportheus albus.

\section{[1] - com caninos se alojando no pré-maxilar (Fig. 21).}

Acestrorhynchus falcirostris, Hoplias malabaricus e Hepsetus odoe.

\section{[2] - com caninos entre o pré-maxilar, maxilar e neurocrânio.}

Gilbertolus atratoensis, Hydrolycus tatauaia, Roestes molossus, Agoniates halecinus, Charax cf. leticiae, Oligosarcus argenteus.

\section{[-] - inaplicável.}

Chanos chanos, Catostomus commersonnii, Apareiodon piracicabae, Saccodon wagneri, Anodus orinocensis, Bivibranchia fowleri, Hemiodus unimaculatus, Curimata ocellata, Curimatopsis macrolepis, Semaprochilodus insignis e Caenotropus labyrinthicus.

[?] - indeterminado.

Erythrinoidea fam. Nov.

42- Osso corono-meckeliano:

[VARI, 1995: 43; OYAKAWA, 1998: 67; e NetTo-FERREIRA, 2006:109]

[0] - situado dorsalmente ou lateralmente à cartilagem de Meckel (Figs. 23, 26,29 e 30).

Chanos chanos, Citharinus latus, Distichodus notospilus, Hemistichodus vaillanti, Neolebias unifasciatus, Nannocharax fasciatus, Apareiodon piracicabae, Parodon nasus, Saccodon wagneri, Anodus orinocensis, Bivibranchia fowleri, Hemiodus unimaculatus Curimata ocellata, Curimatopsis macrolepis, Potamorhina latior, Prochilodus nigricans, Semaprochilodus insignis, Caenotropus labyrinthicus, Chilodus punctatus, Anostomus anostomus, Leporellus vittatus, Leporinus fasciatus, Schizodon fasciatus, Carnegiella strigata, Gasteropelecus sternicla, Thoracocharax stellatus, Acestrorhynchus falcirostris, Gilbertolus atratoensis, Hydrolycus tatauaia, Roestes molossus, Erythrinoidea fam. nov, Copeina cf. guttata, Lebiasina bimaculata, Piabucina astrigata, Hepsetus odoe, Arnoldichthys spilopterus, Brycinus macrolepidotus, Bryconalestes longipinnis, Chalceus epakros, Characidium bahiensis, Crenuchus spilurus, Aphyocharax pusillus, Astyanax mexicanus, Atopomesus pachyodus, Axelrodia reisei, Brittanichthys axelrodi, Brycon pesu, Bryconadenos tanaothoros, Bryconamericus exodon, Bryconops 
alburnoides, Clupeacharax cf. engrauloides, Compsura heterura, ctenobrycon hauxwellianus, Deuterodon iguape, Diapoma terofali, Galeocharax knerii, Glandulocauda melanogenys, Gnathocharax steindachneri, Gymnocorymbus ternetzi, Hemibrycon polyodon, Hemigrammus unilineatus, Hollandichthys multifasciatus, Hyphessobrycon compressus, Iguanodectes geisleri, Knodus meridae, Landonia latidens, Markiana nigripinnis, Metynnis lippincottianus, Microschemobrycon casiquiare, Moenkhausia xinguensis, Myleus setiger, odontostilbe pequira, oligosarcus argenteus, orthospinus franciscoensis, Paracheirodon axelrodi, Paragoniates alburnus, Phenacogaster pectinatus, Phenagoniates macrolepis, Piabina argentea, Piaractus mesopotamicus, Poptella brevispina, Probolus heterostomus, Rachoviscus graciliceps, Rhinobrycon negrensis, Rhoadsia altipinna, Roeboexodon guyanensis, Salminus hilarii, Serrabrycon magoi, Stygichthys typhlops, Tetragonopterus argenteus e Triportheus albus.

\section{[1] - localizado na cartilagem de Meckel (Fig. 25).}

Xenocharax spilurus, Boulengerella maculata, Ctenolucius hujeta, Erythrinus erythrinus, Hoplias malabaricus, Agoniates halecinus e Charax cf. leticiae.

\section{[?] - indeterminado.}

Catostomus commersonnii, Olivaichthys mesembrinus e Gymnotus aff. Carapo.

43 - Comprimento do osso corono-meckeliano:

[NETTO-FERREIRA, 2006: 110]

[0] - muito pequeno, não menos de oito vezes menor que a cartilagem de cartilagem de Meckel (Fig. 21).

Acestrorhynchus falcirostris, Gilbertolus atratoensis, Hydrolycus tatauaia, Roestes molossus, Boulengerella maculata, Ctenolucius hujeta, Hoplias malabaricus, Hepsetus odoe, Gnathocharax steindachneri e Oligosarcus argenteus.

[1] - pequeno, entre oito e duas vezes menor que a cartilagem de cartilagem de Meckel (Fig. 20 e Fig. 26).

Chanos chanos, Citharinus latus, Hemistichodus vaillanti, Neolebias unifasciatus, Xenocharax spilurus, Apareiodon piracicabae, Parodon nasus, Saccodon wagneri, Anodus orinocensis, Bivibranchia fowleri, Hemiodus unimaculatus, Curimata ocellata, curimatopsis macrolepis, Potamorhina latior, Caenotropus labyrinthicus, Chilodus punctatus, Carnegiella strigata, Gasteropelecus sternicla, Thoracocharax stellatus, Erythrinoidea fam. nov, Copeina cf. guttata, Lebiasina bimaculata, Piabucina astrigata, Erythrinus erythrinus, Arnoldichthys spilopterus, Chalceus epakros, Characidium bahiensis, Crenuchus spilurus, Agoniates halecinus, Aphyocharax pusillus, Astyanax mexicanus, Atopomesus pachyodus, Axelrodia reisei, Brittanichthys axelrodi, Brycon pesu, Bryconadenos tanaothoros, Bryconamericus exodon, Bryconops alburnoides, Charax cf. leticiae, Clupeacharax cf. engrauloides, Compsura heterura, Ctenobrycon hauxwellianus, Deuterodon iguape, Diapoma terofali, Galeocharax knerii, Glandulocauda melanogenys, Gymnocorymbus ternetzi, Hemibrycon polyodon, Hemigrammus unilineatus, Hollandichthys multifasciatus, Hyphessobrycon compressus, Knodus meridae, Landonia latidens, Metynnis lippincottianus, Microschemobrycon casiquiare, Moenkhausia xinguensis, Myleus setiger, odontostilbe pequira, Orthospinus franciscoensis, Paracheirodon axelrodi, Paragoniates alburnus, Phenacogaster pectinatus, Phenagoniates macrolepis, Piabina argentea, Piaractus mesopotamicus, Poptella brevispina, Probolus heterostomus, Rachoviscus graciliceps, Rhinobrycon negrensis, Rhoadsia altipinna, Roeboexodon guyanensis, Salminus hilarii, Serrabrycon magoi, Stygichthys typhlops, Tetragonopterus argenteus e Triportheus albus.

23) .

[2] - aproximadamente do tamanho da cartilagem de Meckel (Fig.

Distichodus notospilus, Nannocharax fasciatus, Prochilodus nigricans, Semaprochilodus insignis, Anostomus anostomus, Leporellus vittatus, Leporinus fasciatus, Schizodon fasciatus, Brycinus macrolepidotus, Bryconalestes longipinnis, Iguanodectes geisleri e Markiana nigripinnis.

\section{[?] - indeterminado.}

Catostomus commersonnii, Olivaichthys mesembrinus e Gymnotus aff. Carapo. 
44 - Retro-articular:

[VARI, 1983: 31]

[0] - pequeno.

Chanos chanos, Prochilodus nigricans, Semaprochilodus insignis e stygichthys typhlops.

\section{[1] - médio.}

Catostomus commersonnii, Gymnotus aff. carapo, Citharinus latus, Distichodus notospilus, Hemistichodus vaillanti, Neolebias unifasciatus, Nannocharax fasciatus, Xenocharax spilurus, Apareiodon piracicabae, Parodon nasus, Saccodon wagneri, Anodus orinocensis, Bivibranchia fowleri, Hemiodus unimaculatus, Curimata ocellata, Curimatopsis macrolepis, Potamorhina latior, Caenotropus labyrinthicus, Chilodus punctatus, Anostomus anostomus, Leporellus vittatus, Leporinus fasciatus, Schizodon fasciatus, Carnegiella strigata, Gasteropelecus sternicla, Thoracocharax stellatus, Acestrorhynchus falcirostris, Gilbertolus atratoensis, Hydrolycus tatauaia, Roestes molossus, Erythrinoidea fam. nov, Boulengerella maculata, Ctenolucius hujeta, Copeina cf. guttata, Lebiasina bimaculata, Piabucina astrigata, Erythrinus erythrinus, Hoplias malabaricus, Hepsetus odoe, Arnoldichthys spilopterus, Brycinus macrolepidotus, Bryconalestes longipinnis, Chalceus epakros, Characidium bahiensis, Crenuchus spilurus, Agoniates halecinus, Aphyocharax pusillus, Astyanax mexicanus, Atopomesus pachyodus, Axelrodia reisei, Brittanichthys axelrodi, Brycon pesu, Bryconadenos tanaothoros, Bryconamericus exodon, Bryconops alburnoides, Charax cf. leticiae, Clupeacharax cf. engrauloides, Compsura heterura, Ctenobrycon hauxwellianus, Deuterodon iguape, Diapoma terofali, Galeocharax knerii, Glandulocauda melanogenys, Gnathocharax steindachneri, Gymnocorymbus ternetzi, Hemibrycon polyodon, Hemigrammus unilineatus, Hollandichthys multifasciatus, Hyphessobrycon compressus, Iguanodectes geisleri, Knodus meridae, Landonia latidens, Markiana nigripinnis, Metynnis lippincottianus, Microschemobrycon casiquiare, Moenkhausia xinguensis, Myleus setiger, Odontostilbe pequira, Oligosarcus argenteus, Orthospinus franciscoensis, Paracheirodon axelrodi, Paragoniates alburnus, Phenacogaster pectinatus, Phenagoniates macrolepis, Piabina argentea, Piaractus mesopotamicus, Poptella brevispina, Probolus heterostomus, Rachoviscus graciliceps, Rhinobrycon negrensis, Rhoadsia altipinna, Roeboexodon guyanensis, Salminus hilarii, Serrabrycon magoi, Tetragonopterus argenteus e Triportheus albus.

\section{[?] - indeterminado.}

Olivaichthys mesembrinus.

\section{5 - Canal do sistema da linha-lateral no dentário:}

\section{[0] - restrito à metade posterior do dentário.}

Distichodus notospilus, Nannocharax fasciatus, Prochilodus nigricans, Semaprochilodus insignis, Anostomus anostomus, Leporellus vittatus, Leporinus fasciatus, Schizodon fasciatus e Stygichthys typhlops.

\section{[1] - presente na metade anterior do dentário.}

Olivaichthys mesembrinus, Gymnotus aff. carapo, Citharinus latus, Hemistichodus vaillanti, Neolebias unifasciatus, Xenocharax spilurus, Apareiodon piracicabae, Parodon nasus, Saccodon wagneri, Anodus orinocensis, Bivibranchia fowleri, Hemiodus unimaculatus , Curimata ocellata, Curimatopsis macrolepis, Potamorhina latior, Caenotropus labyrinthicus, Chilodus punctatus, Carnegiella strigata, Gasteropelecus sternicla, Thoracocharax stellatus, Acestrorhynchus falcirostris, Gilbertolus atratoensis, Hydrolycus tatauaia, Roestes molossus, Erythrinoidea fam. nov, Boulengerella maculata, Ctenolucius hujeta, Copeina cf. guttata, Lebiasina bimaculata, Piabucina astrigata, Erythrinus erythrinus, Hoplias malabaricus, Hepsetus odoe, Arnoldichthys spilopterus, Brycinus macrolepidotus, Bryconalestes longipinnis, Chalceus epakros, Characidium bahiensis, Crenuchus spilurus, Agoniates halecinus, Astyanax mexicanus, Atopomesus pachyodus, Axelrodia reisei, Brittanichthys axelrodi, Brycon pesu, Bryconadenos tanaothoros, Bryconamericus exodon, Bryconops alburnoides, Charax cf. leticiae, Clupeacharax cf. engrauloides, Compsura heterura, Ctenobrycon hauxwellianus, Deuterodon iguape, Diapoma terofali, Galeocharax knerii, Glandulocauda melanogenys, Gnathocharax steindachneri, Gymnocorymbus ternetzi, Hemibrycon polyodon, Hemigrammus unilineatus, Hollandichthys multifasciatus, Hyphessobrycon compressus, Iguanodectes geisleri, Knodus meridae, Landonia latidens, Markiana nigripinnis, Microschemobrycon casiquiare, Moenkhausia xinguensis, Odontostilbe pequira, oligosarcus argenteus, orthospinus franciscoensis, Paracheirodon axelrodi, Paragoniates alburnus, Phenacogaster pectinatus, 
Phenagoniates macrolepis, Piabina argentea, Piaractus mesopotamicus, Poptella brevispina, Probolus heterostomus, Rachoviscus graciliceps, Rhinobrycon negrensis, Rhoadsia altipinna, Roeboexodon guyanensis, Salminus hilarii, Serrabrycon magoi, Tetragonopterus argenteus e Triportheus albus.

\section{[-] - inaplicável.}

Catostomus commersonnii.

[?] - indeterminado.

Chanos chanos, Aphyocharax pusillus, Metynnis lippincottianus e Myleus setiger.

46 - Organização dos dentes das maxilas:

[0] - alinhados em uma ou mais fileiras.

Gymnotus aff. carapo, Citharinus latus, Distichodus notospilus, Hemistichodus vaillanti, Neolebias unifasciatus, Nannocharax fasciatus, Xenocharax spilurus, Apareiodon piracicabae, Parodon nasus, Saccodon wagneri, Hemiodus unimaculatus, Prochilodus nigricans, Semaprochilodus insignis, Caenotropus labyrinthicus, Chilodus punctatus, Anostomus anostomus, Leporellus vittatus, Leporinus fasciatus, Schizodon fasciatus, Carnegiella strigata, Gasteropelecus sternicla, Thoracocharax stellatus Acestrorhynchus falcirostris, Gilbertolus atratoensis, Hydrolycus tatauaia, Roestés molossus, Erythrinoidea fam. nov, Boulengerella maculata, Ctenolucius hujeta, Copeina cf. guttata, Lebiasina bimaculata, Piabucina astrigata, Erythrinus erythrinus, Hoplias malabaricus, Hepsetus odoe, Arnoldichthys spilopterus, Brycinus macrolepidotus, Bryconalestes longipinnis, Chalceus epakros, Characidium bahiensis, Crenuchus spilurus, Agoniates halecinus, Aphyocharax pusillus, Astyanax mexicanus, Atopomesus pachyodus, Axelrodia reisei, Brittanichthys axelrodi, Brycon pesu, Bryconadenos tanaothoros, Bryconamericus exodon, Bryconops alburnoides, Charax cf. leticiae, Clupeacharax cf. engrauloides, Compsura heterura, Ctenobrycon hauxwellianus, Deuterodon iguape, Diapoma terofali, Galeocharax knerii, Glandulocauda melanogenys, Gnathocharax steindachneri, Gymnocorymbus ternetzi, Hemibrycon polyodon, Hemigrammus unilineatus, Hollandichthys multifasciatus, Hyphessobrycon compressus, Iguanodectes geisleri, Knodus meridae, Landonia latidens, Markiana nigripinnis, Metynnis lippincottianus, Microschemobrycon casiquiare, Moenkhausia xinguensis, Myleus setiger, odontostilbe pequira, oligosarcus argenteus, orthospinus franciscoensis, Paracheirodon axelrodi, Paragoniates alburnus, Phenacogaster pectinatus, Phenagoniates macrolepis, Piabina argentea, Piaractus mesopotamicus, Poptella brevispina, Probolus heterostomus, Rachoviscus graciliceps, Rhinobrycon negrensis, Rhoadsia altipinna, Roeboexodon guyanensis, Salminus hilarii, Serrabrycon magoi, Stygichthys typhlops, Tetragonopterus argenteus e Triportheus albus.

\section{[1] - desalinhados.}

Olivaichthys mesembrinus.

\section{[-] - inaplicável.}

Chanos chanos, Catostomus commersonnii, Anodus orinocensis, Bivibranchia fowleri, Curimata ocellata, Curimatopsis macrolepis e Potamorhina latior.

\section{7 - Substituição de dentes:}

[LIMA, 2006:17]

\section{[0] - assincrônica.}

olivaichthys mesembrinus, Gymnotus aff. carapo, Citharinus latus, Distichodus notospilus, Hemistichodus vaillanti, Neolebias unifasciatus, Nannocharax fasciatus, Xenocharax spilurus, Apareiodon piracicabae, Parodon nasus, Saccodon wagneri, Hemiodus unimaculatus , Prochilodus nigricans, Semaprochilodus insignis, Caenotropus labyrinthicus, Chilodus punctatus, Acestrorhynchus falcirostris, Gilbertolus atratoensis, Hydrolycus tatauaia, Roestes molossus, Erythrinoidea fam. nov, Boulengerella maculata, ctenolucius hujeta, Copeina cf. guttata, Lebiasina bimaculata, Piabucina astrigata, Erythrinus erythrinus, Hoplias malabaricus, Hepsetus odoe, Chalceus epakros, Characidium bahiensis, Crenuchus spilurus, Aphyocharax pusillus, Atopomesus pachyodus, Brittanichthys axelrodi, Charax cf. leticiae, Compsura heterura, Galeocharax knerii, Gnathocharax steindachneri, Hollandichthys multifasciatus, Paracheirodon 
axelrodi, Paragoniates alburnus, Phenacogaster pectinatus, Phenagoniates macrolepis, Probolus heterostomus, Roeboexodon guyanensis, Salminus hilarii e Serrabrycon magoi.

\section{[1] - sincrônica.}

Anostomus anostomus, Leporellus vittatus, Leporinus fasciatus, Schizodon fasciatus, Carnegiella strigata, Gasteropelecus sternicla, Thoracocharax stellatus, Brycinus macrolepidotus, Bryconalestes longipinnis, Astyanax mexicanus, Brycon pesu, Bryconamericus exodon, Clupeacharax cf. engrauloides, Hemibrycon polyodon, Iguanodectes geisleri, Knodus meridae, Metynnis lippincottianus, Moenkhausia xinguensis, Myleus setiger, Piabina argentea, Piaractus mesopotamicus e Poptella brevispina.

\section{[-] - inaplicável.}

Chanos chanos, Catostomus commersonnii, Anodus orinocensis, Bivibranchia fowleri, Curimata ocellata, Curimatopsis macrolepis e Potamorhina latior.

\section{[?] - indeterminado.}

Arnoldichthys spilopterus, Agoniates halecinus, Axelrodia reisei, Bryconadenos tanaothoros, Bryconops alburnoides, Ctenobrycon hauxwellianus, Deuterodon iguape, Diapoma terofali, Glandulocauda melanogenys, Gymnocorymbus ternetzi, Hemigrammus unilineatus, Hyphessobrycon compressus, Landonia latidens, Markiana nigripinnis, Microschemobrycon casiquiare, Odontostilbe pequira, oligosarcus argenteus, orthospinus franciscoensis, Rachoviscus graciliceps, Rhinobrycon negrensis, Rhoadsia altipinna, Stygichthys typhlops, Tetragonopterus argenteus e Triportheus albus.

\subsubsection{Suspensório mandibular e série opercular}

\section{8 - Cartilagens entre o palatino e a maxila superior:}

\section{[0] - ausente.}

Nannocharax fasciatus, Bivibranchia fowleri, Hemiodus unimaculatus, Carnegiella strigata, Gasteropelecus sternicla, Thoracocharax stellatus, Acestrorhynchus falcirostris, Gilbertolus atratoensis, Hydrolycus tatauaia, Roestes molossus, Erythrinoidea fam. nov, Boulengerella maculata, Ctenolucius hujeta, Copeina cf. guttata, Piabucina astrigata, Erythrinus erythrinus, Hoplias malabaricus, Hepsetus odoe, Brycinus macrolepidotus, Bryconalestes longipinnis, Chalceus epakros, Characidium bahiensis, crenuchus spilurus, Agoniates halecinus, Aphyocharax pusillus, Astyanax mexicanus, Brittanichthys axelrodi, Brycon pesu, Bryconadenos tanaothoros, Bryconamericus exodon, Clupeacharax cf. engrauloides, Compsura heterura, Diapoma terofali, Glandulocauda melanogenys, Iguanodectes geisleri, Landonia latidens, Moenkhausia xinguensis, odontostilbe pequira, oligosarcus argenteus, orthospinus franciscoensis, Paragoniates alburnus, Phenagoniates macrolepis, Piabina argentea, Piaractus mesopotamicus, Probolus heterostomus, Salminus hilarii e Triportheus albus.

\section{[1] - uma.}

Distichodus notospilus, Hemistichodus vaillanti, Neolebias unifasciatus, Xenocharax spilurus, Apareiodon piracicabae, Parodon nasus, Anodus orinocensis, Curimata ocellata, Curimatopsis macrolepis, Potamorhina latior, Prochilodus nigricans, Semaprochilodus insignis, Caenotropus labyrinthicus, Chilodus punctatus, Anostomus anostomus, Leporellus vittatus, Leporinus fasciatus, Schizodon fasciatus, Lebiasina bimaculata, Arnoldichthys spilopterus, Atopomesus pachyodus, Axelrodia reisei, Bryconops alburnoides, Charax cf. leticiae, Galeocharax knerii, Gnathocharax steindachneri, Gymnocorymbus ternetzi, Hemibrycon polyodon, Hollandichthys multifasciatus, Knodus meridae, Microschemobrycon casiquiare, Paracheirodon axelrodi, Phenacogaster pectinatus, Poptella brevispina, Rachoviscus graciliceps, Rhoadsia altipinna, Serrabrycon magoi e Stygichthys typhlops.

\section{[2] - duas.}

Catostomus commersonnii e Citharinus latus.

\section{[?] - indeterminado.}

Chanos chanos, Olivaichthys mesembrinus, Gymnotus aff. carapo, Saccodon wagneri, Ctenobrycon hauxwellianus, Deuterodon iguape, Hemigrammus unilineatus, Hyphessobrycon compressus, Markiana nigripinnis, Metynnis lippincottianus, Myleus setiger, Rhinobrycon negrensis, Roeboexodon guyanensis e Tetragonopterus argenteus. 
[0] - reta ou côncava (Fig. 20 e Fig. 23).

Chanos chanos, Catostomus commersonnii, Olivaichthys mesembrinus, Distichodus notospilus, Hemistichodus vaillanti, Neolebias unifasciatus, Nannocharax fasciatus, Xenocharax spilurus, Apareiodon piracicabae, Parodon nasus, Saccodon wagneri, Bivibranchia fowleri, Curimata ocellata, Curimatopsis macrolepis, Potamorhina latior, Prochilodus nigricans, Semaprochilodus insignis, Anostomus anostomus, Leporellus vittatus, Leporinus fasciatus, Schizodon fasciatus, Carnegiella strigata, Gasteropelecus sternicla, Thoracocharax stellatus, Acestrorhynchus falcirostris, Gilbertolus atratoensis, Hydrolycus tatauaia, Roestes molossus, Erythrinoidea fam. nov, Boulengerella maculata, Ctenolucius hujeta, Copeina cf. guttata, Lebiasina bimaculata, Piabucina astrigata, Erythrinus erythrinus, Hoplias malabaricus, Hepsetus odoe, Arnoldichthys spilopterus, Brycinus macrolepidotus, Bryconalestes longipinnis, Chalceus epakros, Characidium bahiensis, Crenuchus spilurus, Agoniates halecinus, Aphyocharax pusillus, Astyanax mexicanus, Atopomesus pachyodus, Axelrodia reisei, Brittanichthys axelrodi, Brycon pesu, Bryconadenos tanaothoros, Bryconamericus exodon, Bryconops alburnoides, Charax cf. leticiae, Clupeacharax cf. engrauloides, Compsura heterura, Ctenobrycon hauxwellianus, Deuterodon iguape, Diapoma terofali, Galeocharax knerii, Glandulocauda melanogenys, Gnathocharax steindachneri, Gymnocorymbus ternetzi, Hemibrycon polyodon, Hemigrammus unilineatus, Hollandichthys multifasciatus, Hyphessobrycon compressus, Iguanodectes geisleri, Knodus meridae, Landonia latidens, Markiana nigripinnis, Metynnis lippincottianus, Microschemobrycon casiquiare, Moenkhausia xinguensis, Myleus setiger, Odontostilbe pequira, oligosarcus argenteus, orthospinus franciscoensis, Paracheirodon axelrodi, Paragoniates alburnus, Phenacogaster pectinatus, Phenagoniates macrolepis, Piabina argentea, Piaractus mesopotamicus, Poptella brevispina, Probolus heterostomus, Rachoviscus graciliceps, Rhinobrycon negrensis, Rhoadsia altipinna, Roeboexodon guyanensis, Salminus hilarii, Serrabrycon magoi, Stygichthys typhlops, Tetragonopterus argenteus e Triportheus albus.

\section{[1] - muito convexa (Fig. 26).}

Citharinus latus, Anodus orinocensis, Hemiodus unimaculatus, Caenotropus labyrinthicus e Chilodus punctatus.

\section{[-] - inaplicável.}

Gymnotus aff. carapo.

50

- Margem lateral do palatino:

[0] - lisa.

Chanos chanos, Catostomus commersonnii, olivaichthys mesembrinus, Citharinus latus, Distichodus notospilus, Hemistichodus vaillanti, Neolebias unifasciatus, Nannocharax fasciatus, Xenocharax spilurus, Apareiodon piracicabae, Parodon nasus, Saccodon wagneri, Anodus orinocensis, Bivibranchia fowleri, Hemiodus unimaculatus, Curimata ocellata, Curimatopsis macrolepis, Potamorhina latior, Prochilodus nigricans, Semaprochilodus insignis, Caenotropus labyrinthicus, Chilodus punctatus, Anostomus anostomus, Leporellus vittatus, Gilbertolus atratoensis, Roestes molossus, Ctenolucius hujeta, Copeina cf. guttata, Lebiasina bimaculata, Piabucina astrigata, Erythrinus erythrinus, Hoplias malabaricus, Hepsetus odoe, Arnoldichthys spilopterus, Chalceus epakros, Characidium bahiensis, Crenuchus spilurus, Agoniates halecinus, Aphyocharax pusillus, Astyanax mexicanus, Atopomesus pachyodus, Axelrodia reisei, Brittanichthys axelrodi, Brycon pesu, Bryconadenos tanaothoros, Bryconamericus exodon, Bryconops alburnoides, Charax cf. leticiae, Clupeacharax cf. engrauloides, Compsura heterura, Ctenobrycon hauxwellianus, Deuterodon iguape, Diapoma terofali, Glandulocauda melanogenys, Gnathocharax steindachneri, Gymnocorymbus ternetzi, Hemibrycon polyodon, Hemigrammus unilineatus, Hollandichthys multifasciatus, Hyphessobrycon compressus, Iguanodectes geisleri, Knodus meridae, Landonia latidens, Markiana nigripinnis, Microschemobrycon casiquiare, Moenkhausia xinguensis, Odontostilbe pequira, oligosarcus argenteus, orthospinus franciscoensis, Paracheirodon axelrodi, Paragoniates alburnus, Phenacogaster pectinatus, Phenagoniates macrolepis, Piabina argentea, Poptella brevispina, Probolus heterostomus, Rachoviscus graciliceps, Rhinobrycon negrensis, Rhoadsia altipinna, Roeboexodon guyanensis, Salminus hilarii, Serrabrycon magoi, Stygichthys typhlops, Tetragonopterus argenteus e Triportheus albus.

[1] - com processo muito desenvolvido, alcançando o maxilar. 
Leporinus fasciatus, Schizodon fasciatus, Carnegiella strigata, Gasteropelecus sternicla, Thoracocharax stellatus, Acestrorhynchus falcirostris, Hydrolycus tatauaia, Erythrinoidea fam. nov, Boulengerella maculata, Brycinus macrolepidotus, Bryconalestes longipinnis, Galeocharax knerii, Metynnis lippincottianus, Myleus setiger e Piaractus mesopotamicus.

\section{[-] - inaplicável.}

Gymnotus aff. carapo.

51 - Ectopterigóide:

[NeTTO-FERREIRA, 2006: 115, modificado]

(Minimamente conectado).

[0] - mais de duas vezes o tamanho do palatino (Fig. 25).

Anodus orinocensis, Curimata ocellata, Potamorhina latior, Carnegiella strigata, Gasteropelecus sternicla, Thoracocharax stellatus, Acestrorhynchus falcirostris, Gilbertolus atratoensis, Hydrolycus tatauaia, Roestes molossus, Erythrinoidea fam. nov, Boulengerella maculata, Ctenolucius hujeta, Erythrinus erythrinus, Hoplias malabaricus, Hepsetus odoe, Brycinus macrolepidotus, Bryconalestes longipinnis, Crenuchus spilurus, Agoniates halecinus, Astyanax mexicanus, Brycon pesu, Bryconops alburnoides, Charax cf. leticiae, Clupeacharax cf. engrauloides, Ctenobrycon hauxwellianus, Deuterodon iguape, Diapoma terofali, Galeocharax knerii, Glandulocauda melanogenys, Gnathocharax steindachneri, Gymnocorymbus ternetzi, Hemibrycon polyodon, Hemigrammus unilineatus, Hollandichthys multifasciatus, Hyphessobrycon compressus, Landonia latidens, Microschemobrycon casiquiare, oligosarcus argenteus, orthospinus franciscoensis, Paracheirodon axelrodi, Paragoniates alburnus, Phenagoniates macrolepis, Poptella brevispina, Probolus heterostomus, Rachoviscus graciliceps, Rhoadsia altipinna, Roeboexodon guyanensis, Salminus hilarii, Serrabrycon magoi, stygichthys typhlops, Tetragonopterus argenteus e Triportheus albus.

\section{[1] - menos ou igual a duas vezes o tamanho do palatino.}

Chanos chanos, Catostomus commersonnii, Citharinus latus, Distichodus notospilus, Hemistichodus vaillanti, Neolebias unifasciatus, Nannocharax fasciatus, Xenocharax spilurus, Apareiodon piracicabae, Parodon nasus, Saccodon wagneri, Hemiodus unimaculatus Curimatopsis macrolepis, Prochilodus nigricans, Semaprochilodus insignis, Caenotropus labyrinthicus, Chilodus punctatus, Copeina cf. guttata, Lebiasina bimaculata, Piabucina astrigata, Arnoldichthys spilopterus, Chalceus epakros, Characidium bahiensis, Aphyocharax pusillus, Atopomesus pachyodus, Axelrodia reisei, Brittanichthys axelrodi, Bryconadenos tanaothoros, Bryconamericus exodon, Compsura heterura, Knodus meridae, Markiana nigripinnis, Metynnis lippincottianus, Moenkhausia xinguensis, Odontostilbe pequira, Phenacogaster pectinatus, Piabina argentea, Piaractus mesopotamicus e Rhinobrycon negrensis.

\section{[2] - do mesmo tamanho do palatino (Fig. 23)}

Bivibranchia fowleri, Anostomus anostomus, Leporellus vittatus, Leporinus fasciatus, Schizodon fasciatus, Iguanodectes geisleri e Myleus setiger.

\section{[-] - inaplicável.}

olivaichthys mesembrinus e Gymnotus aff. carapo.

52 - Contato ectopterigóide-palatino:

[ZANATA, 2000: 60, modificado; e NETTO-FERREIRA, 2006: 116, modificado]

\section{[0] - extenso, com o ectopterigóide ultrapassando ou alcançando a margem anterior do palatino (Fig. 21).}

Caenotropus labyrinthicus, Chilodus punctatus, Anostomus anostomus, Leporellus vittatus, Leporinus fasciatus, Schizodon fasciatus, Carnegiella strigata, Gasteropelecus sternicla, Thoracocharax stellatus, Acestrorhynchus falcirostris, Gilbertolus atratoensis, Hydrolycus tatauaia, Roestes molossus, Erythrinoidea fam. nov, 
Boulengerella maculata, Piabucina astrigata, Erythrinus erythrinus, Hoplias malabaricus, Hepsetus odoe, Landonia latidens, Markiana nigripinnis e Salminus hilarii.

\section{[1] - menos extenso, ectopterigóide alcançando apenas a metade posterior do palatino (Fig. 23 e Fig. 25).}

Chanos chanos, Catostomus commersonnii, Citharinus latus, Distichodus notospilus, Hemistichodus vaillanti, Neolebias unifasciatus, Nannocharax fasciatus, Xenocharax spilurus, Apareiodon piracicabae, Parodon nasus, Saccodon wagneri, Anodus orinocensis, Bivibranchia fowleri, Hemiodus unimaculatus, Curimata ocellata, Curimatopsis macrolepis, Potamorhina latior, Prochilodus nigricans, Semaprochilodus insignis, Ctenolucius hujeta, Copeina cf. guttata, Lebiasina bimaculata, Arnoldichthys spilopterus, Brycinus macrolepidotus, Bryconalestes longipinnis, Chalceus epakros, Characidium bahiensis, Crenuchus spilurus, Agoniates halecinus, Aphyocharax pusillus, Astyanax mexicanus, Atopomesus pachyodus, Axelrodia reisei, Brittanichthys axelrodi, Brycon pesu, Bryconadenos tanaothoros, Bryconamericus exodon, Bryconops alburnoides, Charax cf. leticiae, Clupeacharax cf. engrauloides, Compsura heterura, Ctenobrycon hauxwellianus, Deuterodon iguape, Diapoma terofali, Galeocharax knerii, Glandulocauda melanogenys, Gnathocharax steindachneri, Gymnocorymbus ternetzi, Hemibrycon polyodon Hemigrammus unilineatus, Hollandichthys multifasciatus, Hyphessobrycon compressus, Iguanodectes geisleri, Knodus meridae, Metynnis lippincottianus, Microschemobrycon casiquiare, Moenkhausia xinguensis, Myleus setiger, odontostilbe pequira, oligosarcus argenteus, orthospinus franciscoensis, Paracheirodon axelrodi, Paragoniates alburnus, Phenacogaster pectinatus, Phenagoniates macrolepis, Piabina argentea, Piaractus mesopotamicus, Poptella brevispina, Probolus heterostomus, Rachoviscus graciliceps, Rhinobrycon negrensis, Rhoadsia altipinna, Roeboexodon guyanensis, Serrabrycon magoi, Stygichthys typhlops, Tetragonopterus argenteus e Triportheus albus.

\section{[-] - inaplicável.}

Olivaichthys mesembrinus e Gymnotus aff. carapo.

53 - Associação ectopterigóide-quadrado:

[Toledo-PizA, 2000: 31; ZANATA, 2000: 59; e NetTo-FerReira, 2006: 123]

[0] - com contato (Figs. 21, 23, 25, 27 e 29).

Chanos chanos, Catostomus commersonnii, Citharinus latus, Distichodus notospilus, Hemistichodus vaillanti, Neolebias unifasciatus, Nannocharax fasciatus, Xenocharax spilurus, Apareiodon piracicabae, Parodon nasus, Saccodon wagneri, Anodus orinocensis, Bivibranchia fowleri, Hemiodus unimaculatus, Curimata ocellata, Curimatopsis macrolepis, Potamorhina latior, Prochilodus nigricans, Semaprochilodus insignis, Caenotropus labyrinthicus, Chilodus punctatus, Anostomus anostomus, Leporellus vittatus, Leporinus fasciatus, Schizodon fasciatus, Carnegiella strigata, Gasteropelecus sternicla, Thoracocharax stellatus, Acestrorhynchus falcirostris, Gilbertolus atratoensis, Hydrolycus tatauaia, Roestes molossus, Erythrinoidea fam. nov, Boulengerella maculata, ctenolucius hujeta, Copeina cf. guttata, Lebiasina bimaculata, Piabucina astrigata, Erythrinus erythrinus, Hoplias malabaricus, Hepsetus odoe, Arnoldichthys spilopterus, Brycinus macrolepidotus, Bryconalestes longipinnis, Chalceus epakros, Crenuchus spilurus, Agoniates halecinus, Astyanax mexicanus, Brittanichthys axelrodi, Bryconops alburnoides, Charax cf. leticiae, Clupeacharax cf. engrauloides, Galeocharax knerii, Gnathocharax steindachneri, Gymnocorymbus ternetzi, Hemibrycon polyodon, Hemigrammus unilineatus, Hyphessobrycon compressus, Iguanodectes geisleri, Landonia latidens, Markiana nigripinnis, Metynnis lippincottianus, Myleus setiger, oligosarcus argenteus, orthospinus franciscoensis, Paracheirodon axelrodi, Paragoniates alburnus, Phenagoniates macrolepis, Piaractus mesopotamicus, Poptella brevispina, Probolus heterostomus, Rhoadsia altipinna, Roeboexodon guyanensis, Salminus hilarii, Serrabrycon magoi, Stygichthys typhlops e Triportheus albus.

\section{[1] - sem contato.}

Characidium bahiensis, Aphyocharax pusillus, Atopomesus pachyodus, Axelrodia reisei, Brycon pesu, Bryconadenos tanaothoros, Bryconamericus exodon, Compsura heterura, ctenobrycon hauxwellianus, Deuterodon iguape, Diapoma terofali, Glandulocauda melanogenys, Hollandichthys multifasciatus, Knodus meridae, Microschemobrycon casiquiare, Moenkhausia xinguensis, Odontostilbe pequira, Phenacogaster pectinatus, Piabina argentea, Rachoviscus graciliceps, Rhinobrycon negrensis e Tetragonopterus argenteus.

\section{[-] - inaplicável.}




\title{
[?] - indeterminado.
}

Gymnotus aff. carapo.

\section{4 - Mobilidade entre o ectopterigóide e o quadrado:} [VARI, 1983: 38, modificado]

\section{[0] - limitada ou sem mobilidade.}

\begin{abstract}
Chanos chanos, Catostomus commersonnii, Citharinus latus, Distichodus notospilus, Hemistichodus vaillanti, Neolebias unifasciatus, Nannocharax fasciatus, Xenocharax spilurus, Curimata ocellata, Curimatopsis macrolepis, Potamorhina latior, Caenotropus labyrinthicus, Chilodus punctatus, Anostomus anostomus, Leporellus vittatus, Leporinus fasciatus, Schizodon fasciatus, Carnegiella strigata, Gasteropelecus sternicla, Thoracocharax stellatus, Acestrorhynchus falcirostris, Gilbertolus atratoensis, Hydrolycus tatauaia, Roestes molossus, Erythrinoidea fam. nov, Boulengerella maculata, Ctenolucius hujeta, Copeina cf. guttata, Lebiasina bimaculata, Piabucina astrigata, Erythrinus erythrinus, Hoplias malabaricus, Hepsetus odoe, Arnoldichthys spilopterus, Brycinus macrolepidotus, Bryconalestes longipinnis, Chalceus epakros, Crenuchus spilurus, Agoniates halecinus, Astyanax mexicanus, Brittanichthys axelrodi, Bryconops alburnoides, Charax cf. leticiae, Clupeacharax cf. engrauloides, Galeocharax knerii, Gnathocharax steindachneri, Gymnocorymbus ternetzi, Hemibrycon polyodon, Hemigrammus unilineatus, Hyphessobrycon compressus, Iguanodectes geisleri, Landonia latidens, Markiana nigripinnis, Metynnis lippincottianus, Myleus setiger, oligosarcus argenteus, orthospinus franciscoensis, Paracheirodon axelrodi, Paragoniates alburnus, Phenagoniates macrolepis, Piaractus mesopotamicus, Poptella brevispina, Probolus heterostomus Rhoadsia altipinna, Roeboexodon guyanensis, Salminus hilarii, Serrabrycon magoi, Stygichthys typhlops, Tetragonopterus argenteus e Triportheus albus.
\end{abstract}

\section{[1] - com grande mobilidade.}

Apareiodon piracicabae, Parodon nasus, Saccodon wagneri, Anodus orinocensis, Bivibranchia fowleri, Hemiodus unimaculatus, Prochilodus nigricans e Semaprochilodus insignis.

\section{[-] - inaplicável.}

Olivaichthys mesembrinus, Gymnotus aff. carapo, Characidium bahiensis, Aphyocharax pusillus, Atopomesus pachyodus, Axelrodia reisei, Brycon pesu, Bryconadenos tanaothoros, Bryconamericus exodon, Compsura heterura, Ctenobrycon hauxwellianus, Deuterodon iguape, Diapoma terofali, Glandulocauda melanogenys, Hollandichthys multifasciatus, Knodus meridae, Microschemobrycon casiquiare, Moenkhausia xinguensis, Odontostilbe pequira, Phenacogaster pectinatus, Piabina argentea, Rachoviscus graciliceps e Rhinobrycon negrensis.

55 - Ectopterigóide:

[LUCENA, 1993: 56; BUCKUP, 1998: 22; e NetTo-FerReIRA, 2006: 117]

[0] - com dentes (Fig. 21).

Neolebias unifasciatus, Xenocharax spilurus, Acestrorhynchus falcirostris, Hydrolycus tatauaia, Boulengerella maculata, Ctenolucius hujeta, Lebiasina bimaculata, Piabucina astrigata, Erythrinus erythrinus, Hoplias malabaricus, Characidium bahiensis, crenuchus spilurus, Brittanichthys axelrodi e Oligosarcus argenteus.

[1] - sem dentes (Figs. 23, 25, 26, 27, 29 e 30).

Chanos chanos, Catostomus commersonnii, Olivaichthys mesembrinus, Citharinus latus, Distichodus notospilus, Hemistichodus vaillanti, Nannocharax fasciatus, Apareiodon piracicabae, Parodon nasus, Saccodon wagneri, Anodus orinocensis, Bivibranchia fowleri, Hemiodus unimaculatus, Curimata ocellata, Curimatopsis macrolepis, Potamorhina latior, Prochilodus nigricans, Semaprochilodus insignis, Caenotropus labyrinthicus, Chilodus punctatus, Anostomus anostomus, Leporellus vittatus, Leporinus fasciatus, Schizodon fasciatus, Carnegiella strigata, Gasteropelecus sternicla, Thoracocharax stellatus, Gilbertolus atratoensis, Roestes molossus, Erythrinoidea fam. nov, Copeina cf. guttata, Hepsetus odoe, Arnoldichthys spilopterus, Brycinus macrolepidotus, Bryconalestes longipinnis, Chalceus epakros, Agoniates halecinus, Aphyocharax pusillus, Astyanax 
mexicanus, Atopomesus pachyodus, Axelrodia reisei, Brycon pesu, Bryconadenos tanaothoros, Bryconamericus exodon, Bryconops alburnoides, Charax cf. leticiae, Clupeacharax cf. engrauloides, Compsura heterura, Ctenobrycon hauxwellianus, Deuterodon iguape, Diapoma terofali, Galeocharax knerii, Glandulocauda melanogenys, Gnathocharax steindachneri, Gymnocorymbus ternetzi, Hemibrycon polyodon, Hemigrammus unilineatus, Hollandichthys multifasciatus, Hyphessobrycon compressus, Iguanodectes geisleri, Knodus meridae, Landonia latidens, Markiana nigripinnis, Metynnis lippincottianus, Microschemobrycon casiquiare, Moenkhausia xinguensis, Myleus setiger, odontostilbe pequira, Orthospinus franciscoensis, Paracheirodon axelrodi, Paragoniates alburnus, Phenacogaster pectinatus, Phenagoniates macrolepis, Piabina argentea, Piaractus mesopotamicus, Poptella brevispina, Probolus heterostomus, Rachoviscus graciliceps, Rhinobrycon negrensis, Rhoadsia altipinna, Roeboexodon guyanensis, Salminus hilarii, Serrabrycon magoi, Stygichthys typhlops, Tetragonopterus argenteus e Triportheus albus.

\section{[-] - inaplicável.}

Gymnotus aff. carapo.

56 - Distribuição dos dentes do ectopterigóide:

[VARI, 1995: 53, modificado; OYAKAWA, 1998: 36, modificado; TOLEDo-PIZA, 2000: 28, modificado e NeTTO-FerReira, 2006: 118, modificado]

\section{[0] - em uma fileira (Fig. 21).}

Acestrorhynchus falcirostris, Characidium bahiensis, Brittanichthys axelrodi e oligosarcus argenteus.

\section{[1] - em duas ou mais fileira irregulares.}

Distichodus notospilus, Xenocharax spilurus, Ctenolucius hujeta, Lebiasina bimaculata, Piabucina astrigata, Erythrinus erythrinus e Crenuchus spilurus.

\section{[2] - ocupando quase toda face ventral.}

Hydrolycus tatauaia, Boulengerella maculata e Hoplias malabaricus.

\section{[-] - inaplicável.}

Chanos chanos, Catostomus commersonnii, olivaichthys mesembrinus, Gymnotus aff. carapo, Citharinus latus, Hemistichodus vaillanti, Neolebias unifasciatus, Nannocharax fasciatus, Apareiodon piracicabae, Parodon nasus, Saccodon wagneri, Anodus orinocensis, Bivibranchia fowleri, Hemiodus unimaculatus, Curimata ocellata, Curimatopsis macrolepis, Potamorhina latior, Prochilodus nigricans, semaprochilodus insignis, Caenotropus labyrinthicus, Chilodus punctatus, Anostomus anostomus, Leporellus vittatus, Leporinus fasciatus, Schizodon fasciatus, Carnegiella strigata, Gasteropelecus sternicla, Thoracocharax stellatus, Gilbertolus atratoensis, Roestes molossus, Erythrinoidea fam. nov, Copeina cf. guttata, Hepsetus odoe, Arnoldichthys spilopterus, Brycinus macrolepidotus, Bryconalestes longipinnis, Chalceus epakros, Agoniates halecinus, Aphyocharax pusillus, Astyanax mexicanus, Atopomesus pachyodus, Axelrodia reisei, Brycon pesu, Bryconadenos tanaothoros, Bryconamericus exodon, Bryconops alburnoides, Charax cf. leticiae, clupeacharax cf. engrauloides, compsura heterura, Ctenobrycon hauxwellianus, Deuterodon iguape, Diapoma terofali, Galeocharax knerii, Glandulocauda melanogenys, Gnathocharax steindachneri, Gymnocorymbus ternetzi, Hemibrycon polyodon, Hemigrammus unilineatus, Hollandichthys multifasciatus, Hyphessobrycon compressus, Iguanodectes geisleri, Knodus meridae, Landonia latidens, Markiana nigripinnis, Metynnis lippincottianus, Microschemobrycon casiquiare, Moenkhausia xinguensis, Myleus setiger, odontostilbe pequira, orthospinus franciscoensis, Paracheirodon axelrodi, Paragoniates alburnus, Phenacogaster pectinatus, Phenagoniates macrolepis, Piabina argentea, Piaractus mesopotamicus, Poptella brevispina, Probolus heterostomus, Rachoviscus graciliceps, Rhinobrycon negrensis, Rhoadsia altipinna, Roeboexodon guyanensis, Salminus hilarii, Serrabrycon magoi, Stygichthys typhlops, Tetragonopterus argenteus e Triportheus albus.

\section{7 - Tamanho dos dentes no ectopterigóide:}

\section{[0] - muito menores que os dentes do pré-maxilar (Fig. 21).}

Distichodus notospilus, Xenocharax spilurus, Acestrorhynchus falcirostris, Hydrolycus tatauaia, Boulengerella maculata, Ctenolucius hujeta, Lebiasina bimaculata, Piabucina 

oligosarcus argenteus.

\section{[1] - mais que a metade dos dentes do pré-maxilar.}

Erythrinus erythrinus e Hoplias malabaricus.

\section{[-] - inaplicável.}

Chanos chanos, Catostomus commersonnii, olivaichthys mesembrinus, Gymnotus aff. carapo, Citharinus latus, Hemistichodus vaillanti, Neolebias unifasciatus, Nannocharax fasciatus, Apareiodon piracicabae, Parodon nasus, Saccodon wagneri, Anodus orinocensis, Bivibranchia fowleri, Hemiodus unimaculatus, Curimata ocellata, Curimatopsis macrolepis, Potamorhina latior, Prochilodus nigricans, Semaprochilodus insignis, Caenotropus labyrinthicus, Chilodus punctatus, Anostomus anostomus, Leporellus vittatus, Leporinus fasciatus, Schizodon fasciatus, Carnegiella strigata, Gasteropelecus sternicla, Thoracocharax stellatus, Gilbertolus atratoensis, Roestes molossus, Erythrinoidea fam. nov, Copeina cf. guttata, Hepsetus odoe, Arnoldichthys spilopterus, Brycinus macrolepidotus, Bryconalestes longipinnis, Chalceus epakros, Agoniates halecinus, Aphyocharax pusillus, Astyanax mexicanus, Atopomesus pachyodus, Axelrodia reisei, Brycon pesu, Bryconadenos tanaothoros, Bryconamericus exodon, Bryconops alburnoides, Charax cf. leticiae, Clupeacharax cf. engrauloides, Compsura heterura, ctenobrycon hauxwellianus, Deuterodon iguape, Diapoma terofali, Galeocharax knerii, Glandulocauda melanogenys, Gnathocharax steindachneri, Gymnocorymbus ternetzi, Hemibrycon polyodon, Hemigrammus unilineatus, Hollandichthys multifasciatus, Hyphessobrycon compressus, Iguanodectes geisleri, Knodus meridae, Landonia latidens, Markiana nigripinnis, Metynnis lippincottianus, Microschemobrycon casiquiare, Moenkhausia xinguensis, Myleus setiger, Odontostilbe pequira, orthospinus franciscoensis, Paracheirodon axelrodi, Paragoniates alburnus, Phenacogaster pectinatus, Phenagoniates macrolepis, Piabina argentea, Piaractus mesopotamicus, Poptella brevispina, Probolus heterostomus, Rachoviscus graciliceps, Rhinobrycon negrensis, Rhoadsia altipinna, Roeboexodon guyanensis, Salminus hilarii, Serrabrycon magoi, Stygichthys typhlops, Tetragonopterus argenteus, Triportheus albus.

58 - Endopterigóide:

[LUCENA, 1993: 55; VARI, 1995: 54; BUCKUP, 1998: 23; LUCENA \& MENEZES, 1998: 24; OYAKAWA, 1998: 40; TOledo-PizA, 2000: 29 e NetTo-FerReira, 2006: 121]

\section{[0] - com dentes.}

Chanos chanos, Catostomus commersonnii, olivaichthys mesembrinus, Gymnotus aff. carapo, Citharinus latus, Hemistichodus vaillanti, Neolebias unifasciatus, Nannocharax fasciatus, Xenocharax spilurus, Apareiodon piracicabae, Parodon nasus, Saccodon wagneri, Anodus orinocensis, Bivibranchia fowleri, Hemiodus unimaculatus , Curimata ocellata, Curimatopsis macrolepis, Potamorhina latior, Prochilodus nigricans, Semaprochilodus insignis, Caenotropus labyrinthicus, Chilodus punctatus, Anostomus anostomus, Leporellus vittatus, Leporinus fasciatus, Schizodon fasciatus, Carnegiella strigata, Gasteropelecus sternicla, Thoracocharax stellatus, Acestrorhynchus falcirostris, Hydrolycus tatauaia, Roestes molossus, Erythrinoidea fam. nov, Ctenolucius hujeta, copeina cf. guttata, Lebiasina bimaculata, Piabucina astrigata, Erythrinus erythrinus, Hoplias malabaricus, Hepsetus odoe, Arnoldichthys spilopterus, Brycinus macrolepidotus, Bryconalestes longipinnis, Chalceus epakros, Characidium bahiensis, Agoniates halecinus, Aphyocharax pusillus, Astyanax mexicanus, Atopomesus pachyodus, Axelrodia reisei, Brycon pesu, Bryconadenos tanaothoros, Bryconamericus exodon, Bryconops alburnoides, Charax cf. leticiae, Clupeacharax cf. engrauloides, Compsura heterura, ctenobrycon hauxwellianus, Deuterodon iguape, Diapoma terofali, Galeocharax knerii, Glandulocauda melanogenys, Gnathocharax steindachneri, Gymnocorymbus ternetzi, Hemibrycon polyodon, Hemigrammus unilineatus, Hollandichthys multifasciatus, Hyphessobrycon compressus, Iguanodectes geisleri, Knodus meridae, Landonia latidens, Markiana nigripinnis, Metynnis lippincottianus, Microschemobrycon casiquiare, Moenkhausia xinguensis, Myleus setiger, odontostilbe pequira, oligosarcus argenteus, orthospinus franciscoensis, Paracheirodon axelrodi, Paragoniates alburnus, Phenacogaster pectinatus, Phenagoniates macrolepis, Piabina argentea, Piaractus mesopotamicus, Poptella brevispina, Probolus heterostomus, Rachoviscus graciliceps, Rhinobrycon negrensis, Rhoadsia altipinna, Roeboexodon guyanensis, Salminus hilarii, Serrabrycon magoi, Stygichthys typhlops, Tetragonopterus argenteus e Triportheus albus.

\section{[1] - sem dentes.}

Distichodus notospilus, Boulengerella maculata, crenuchus spilurus e Brittanichthys axelrodi. 


\section{[-] - inaplicável.}

Gilbertolus atratoensis.

59 - Ectopterigóide:

[MOREIRA, 2002: 18]

\section{[0] - com expansão ou calha.}

Curimata ocellata, Caenotropus labyrinthicus, Chilodus punctatus, Anostomus anostomus, Leporellus vittatus, Leporinus fasciatus, Schizodon fasciatus, Acestrorhynchus falcirostris, Gilbertolus atratoensis, Erythrinoidea fam. nov, Boulengerella maculata, Ctenolucius hujeta, Erythrinus erythrinus, Hoplias malabaricus, Brittanichthys axelrodi, Charax cf. leticiae, Compsura heterura, Galeocharax knerii, Landonia latidens, Metynnis lippincottianus, Myleus setiger, Oligosarcus argenteus, Phenagoniates macrolepis e Salminus hilarii.

\section{[1] - sem modificação (osso chato).}

Chanos chanos, Citharinus latus, Distichodus notospilus, Hemistichodus vaillanti, Neolebias unifasciatus, Nannocharax fasciatus, Xenocharax spilurus, Apareiodon piracicabae, Parodon nasus, Saccodon wagneri, Anodus orinocensis, Bivibranchia fowleri, Hemiodus unimaculatus, Curimatopsis macrolepis, Potamorhina latior, Prochilodus nigricans, Semaprochilodus insignis, Carnegiella strigata, Gasteropelecus sternicla, Thoracocharax stellatus, Hydrolycus tatauaia, Roestes molossus, Copeina cf. guttata, Lebiasina bimaculata, Piabucina astrigata, Hepsetus odoe, Arnoldichthys spilopterus, Brycinus macrolepidotus, Bryconalestes longipinnis, Chalceus epakros, Characidium bahiensis, Crenuchus spilurus, Agoniates halecinus, Aphyocharax pusillus, Astyanax mexicanus, Atopomesus pachyodus, Axelrodia reisei, Brycon pesu, Bryconadenos tanaothoros, Bryconamericus exodon, Bryconops alburnoides, Clupeacharax cf. engrauloides, Ctenobrycon hauxwellianus, Deuterodon iguape, Diapoma terofali, Glandulocauda melanogenys, Gnathocharax steindachneri, Gymnocorymbus ternetzi, Hemibrycon polyodon, Hemigrammus unilineatus, Hollandichthys multifasciatus, Hyphessobrycon compressus, Iguanodectes geisleri, Knodus meridae, Markiana nigripinnis, Microschemobrycon casiquiare, Moenkhausia xinguensis, Odontostilbe pequira, orthospinus franciscoensis, Paracheirodon axelrodi, Paragoniates alburnus, Phenacogaster pectinatus, Piabina argentea, Piaractus mesopotamicus, Poptella brevispina, Probolus heterostomus Rachoviscus graciliceps, Rhinobrycon negrensis, Rhoadsia altipinna, Roeboexodon guyanensis, Serrabrycon magoi, Stygichthys typhlops, Tetragonopterus argenteus e Triportheus albus.

\section{[-] - inaplicável.}

Olivaichthys mesembrinus e Gymnotus aff. carapo.

\section{[?] - indeterminado.}

Catostomus commersonnii.

60 - Porção posterior do ectopterigóide:

[MOREIRA, 2002: 19]

\section{[0] - sem alargamento.}

Chanos chanos, Catostomus commersonnii, Citharinus latus, Distichodus notospilus, Hemistichodus vaillanti, Neolebias unifasciatus, Nannocharax fasciatus, Xenocharax spilurus, Apareiodon piracicabae, Parodon nasus, Saccodon wagneri, Anodus orinocensis, Bivibranchia fowleri, Hemiodus unimaculatus, Curimata ocellata, Curimatopsis macrolepis, Caenotropus labyrinthicus, Chilodus punctatus, Anostomus anostomus, Leporellus vittatus, Leporinus fasciatus, Schizodon fasciatus, Carnegiella strigata, Gasteropelecus sternicla, Thoracocharax stellatus, Acestrorhynchus falcirostris, Gilbertolus atratoensis, Hydrolycus tatauaia, Roestes molossus, Erythrinoidea fam. nov, Boulengerella maculata, Ctenolucius hujeta, Copeina cf. guttata, Lebiasina bimaculata, Piabucina astrigata, Erythrinus erythrinus, Hoplias malabaricus, Hepsetus odoe, Arnoldichthys spilopterus, Brycinus macrolepidotus, Bryconalestes longipinnis, Chalceus epakros, Characidium bahiensis, Crenuchus spilurus, Agoniates halecinus, Aphyocharax pusillus, Astyanax mexicanus, Atopomesus pachyodus, Axelrodia reisei, Brittanichthys axelrodi, Brycon pesu, Bryconadenos tanaothoros, Bryconamericus exodon, Bryconops 
alburnoides, charax cf. leticiae, clupeacharax cf. engrauloides, Compsura heterura, Ctenobrycon hauxwellianus, Deuterodon iguape, Diapoma terofali, Galeocharax knerii, Glandulocauda melanogenys, Gnathocharax steindachneri, Gymnocorymbus ternetzi, Hemibrycon polyodon, Hemigrammus unilineatus, Hollandichthys multifasciatus, Hyphessobrycon compressus, Iguanodectes geisleri, Knodus meridae, Landonia latidens, Markiana nigripinnis, Metynnis lippincottianus, Microschemobrycon casiquiare, Moenkhausia xinguensis, Myleus setiger, odontostilbe pequira, oligosarcus argenteus, orthospinus franciscoensis, Paracheirodon axelrodi, Paragoniates alburnus, Phenacogaster pectinatus, Phenagoniates macrolepis, Piabina argentea, Piaractus mesopotamicus, Poptella brevispina, Probolus heterostomus, Rachoviscus graciliceps, Rhinobrycon negrensis, Rhoadsia altipinna, Roeboexodon guyanensis, Salminus hilarii, Serrabrycon magoi, Stygichthys typhlops, Tetragonopterus argenteus e Triportheus albus.

\title{
[1] - com alargamento.
}

Potamorhina latior, Prochilodus nigricans e Semaprochilodus insignis.

\section{[-] - inaplicável.}

Olivaichthys mesembrinus e Gymnotus aff. carapo.

\author{
61 - Posição relativa das margens anteriores do ectopterigóide e \\ endopterigóide:
}

[MOREIRA, 2002: 21]

(Minimamente conectado).

[0] - margem anterior do ectopterigóide mais anterior que a do endopterigóide (Figs. 20, 21, 26 e 30).

\begin{abstract}
Chanos chanos, Catostomus commersonnii, Citharinus latus, Distichodus notospilus, Hemistichodus vaillanti, Neolebias unifasciatus, Xenocharax spilurus, Apareiodon piracicabae, Parodon nasus, Saccodon wagneri, Anodus orinocensis, Hemiodus unimaculatus - Curimata ocellata, Curimatopsis macrolepis, Potamorhina latior, Prochilodus nigricans, Semaprochilodus insignis, Caenotropus labyrinthicus, Chilodus punctatus, Anostomus anostomus, Leporellus vittatus, Leporinus fasciatus, schizodon fasciatus, Acestrorhynchus falcirostris, Gilbertolus atratoensis, Hydrolycus tatauaia, Roestes molossus, Hepsetus odoe, Arnoldichthys spilopterus, Brycinus macrolepidotus, Bryconalestes longipinnis, Chalceus epakros, Characidium bahiensis, Crenuchus spilurus, Aphyocharax pusillus, Atopomesus pachyodus, Axelrodia reisei, Brittanichthys axelrodi, Brycon pesu, Bryconadenos tanaothoros, Bryconamericus exodon, Charax cf. leticiae, Clupeacharax cf. engrauloides, Compsura heterura, Diapoma terofali, Galeocharax knerii, Glandulocauda melanogenys, Gnathocharax steindachneri, Gymnocorymbus ternetzi, Hemibrycon polyodon, Landonia latidens, Microschemobrycon casiquiare, Moenkhausia xinguensis, Odontostilbe pequira, oligosarcus argenteus, orthospinus franciscoensis, Paracheirodon axelrodi, Paragoniates alburnus, Phenacogaster pectinatus, Phenagoniates macrolepis, Piabina argentea, Poptella brevispina, Probolus heterostomus, Rachoviscus graciliceps, Rhinobrycon negrensis, Rhoadsia altipinna, Roeboexodon guyanensis, Serrabrycon magoi, Stygichthys typhlops e Tetragonopterus argenteus.
\end{abstract}

[1] - margem anterior do ectopterigóide igual a do
endopterigóide.

Nannocharax fasciatus, Bivibranchia fowleri, Carnegiella strigata, Gasteropelecus sternicla, Thoracocharax stellatus, Ctenolucius hujeta, Lebiasina bimaculata, Piabucina astrigata, Erythrinus erythrinus, Hoplias malabaricus, Astyanax mexicanus, Bryconops alburnoides, Ctenobrycon hauxwellianus, Deuterodon iguape, Hemigrammus unilineatus, Hollandichthys multifasciatus, Hyphessobrycon compressus, Iguanodectes geisleri, Knodus meridae, Markiana nigripinnis, Metynnis lippincottianus, Myleus setiger, Piaractus mesopotamicus, Salminus hilarii e Triportheus albus.

[2] - margem anterior do endopterigóide mais anterior que a do ectopterigóide.

Erythrinoidea fam. nov, Boulengerella maculata, Copeina cf. guttata e Agoniates halecinus.

\section{[-] - inaplicável.}

Olivaichthys mesembrinus e Gymnotus aff. carapo. 
62 - Tamanho do endopterigóide:

[MOREIRA, 2002: 20]

[0] - menor que o metapterigóide.

Olivaichthys mesembrinus, Hemistichodus vaillanti, Neolebias unifasciatus, Nannocharax fasciatus, Anostomus anostomus, Leporellus vittatus, Leporinus fasciatus, Schizodon fasciatus, Erythrinoidea fam. nov, Brycinus macrolepidotus, Astyanax mexicanus, Metynnis lippincottianus, Myleus setiger, Piabina argêntea e Stygichthys typhlops.

[1] - aproximadamente do mesmo tamanho do metapterigóide (Fig. 20 e Fig. 23).

Catostomus commersonnii, Citharinus latus, Distichodus notospilus, Xenocharax spilurus, Bivibranchia fowleri, Hemiodus unimaculatus, Curimata ocellata, Curimatopsis macrolepis, Potamorhina latior, Prochilodus nigricans, Semaprochilodus insignis, Arnoldichthys spilopterus, Bryconalestes longipinnis, Chalceus epakros, Bryconadenos tanaothoros, Glandulocauda melanogenys, Hemibrycon polyodon, Iguanodectes geisleri, Markiana nigripinnis e Piaractus mesopotamicus.

[2] - maior que o metapterigóide (Fig. 21).

Chanos chanos, Gymnotus aff. carapo, Apareiodon piracicabae, Parodon nasus, Saccodon wagneri, Anodus orinocensis, Caenotropus labyrinthicus, Chilodus punctatus, Carnegiella strigata, Gasteropelecus sternicla, Thoracocharax stellatus, Acestrorhynchus falcirostris, Gilbertolus atratoensis, Hydrolycus tatauaia, Roestes molossus, Boulengerella maculata, Ctenolucius hujeta, Copeina cf. guttata, Lebiasina bimaculata, Piabucina astrigata, Erythrinus erythrinus, Hoplias malabaricus, Hepsetus odoe, Characidium bahiensis, Crenuchus spilurus, Agoniates halecinus, Aphyocharax pusillus, Atopomesus pachyodus, Axelrodia reisei, Brittanichthys axelrodi, Brycon pesu, Bryconops alburnoides, Charax cf. leticiae, Clupeacharax cf. engrauloides, Compsura heterura, ctenobrycon hauxwellianus, Deuterodon iguape, Diapoma terofali, Galeocharax knerii, Gnathocharax steindachneri, Gymnocorymbus ternetzi, Hemigrammus unilineatus, Hollandichthys multifasciatus, Hyphessobrycon compressus, Knodus meridae, Landonia latidens, Microschemobrycon casiquiare, Moenkhausia xinguensis, Odontostilbe pequira, oligosarcus argenteus, Orthospinus franciscoensis, Paracheirodon axelrodi, Paragoniates alburnus, Phenacogaster pectinatus, Phenagoniates macrolepis, Poptella brevispina, Probolus heterostomus, Rachoviscus graciliceps, Rhinobrycon negrensis, Rhoadsia altipinna, Roeboexodon guyanensis, Salminus hilarii, Serrabrycon magoi, Tetragonopterus argenteus e Triportheus albus.

\section{[?] - indeterminado.}

Bryconamericus exodon.

63 - Extensão do endopterigóide:

[MOREIRA, 2002: 22]

(Minimamente conectado).

[0] - sob a porção óssea do palatino (Figs. 21, 23, 25 e 27).

Chanos chanos, Apareiodon piracicabae, Parodon nasus, Saccodon wagneri, Anodus orinocensis, Bivibranchia fowleri, Hemiodus unimaculatus, Curimata ocellata, Curimatopsis macrolepis, Potamorhina latior, Prochilodus nigricans, Semaprochilodus insignis, Caenotropus labyrinthicus, Chilodus punctatus, Anostomus anostomus, Leporellus vittatus, Leporinus fasciatus, Schizodon fasciatus, Carnegiella strigata, Gasteropelecus sternicla, Thoracocharax stellatus, Acestrorhynchus falcirostris, Hydrolycus tatauaia, Roestes molossus, Erythrinoidea fam. nov, Boulengerella maculata, Ctenolucius hujeta, Lebiasina bimaculata, Piabucina astrigata, Erythrinus erythrinus, Hoplias malabaricus, Hepsetus odoe, Agoniates halecinus, Bryconops alburnoides, Charax cf. leticiae, Hollandichthys multifasciatus, Iguanodectes geisleri, Knodus meridae, Metynnis lippincottianus, Myleus setiger, oligosarcus argenteus, Piaractus mesopotamicus, Probolus heterostomus, Salminus hilarii e Triportheus albus.

[1] - alcança o palatino, mas não fica sob o palatino. 
Citharinus latus, Distichodus notospilus, Hemistichodus vaillanti, Nannocharax fasciatus, Gilbertolus atratoensis, Aphyocharax pusillus, Astyanax mexicanus, Brycon pesu, Clupeacharax cf. engrauloides, Compsura heterura, Ctenobrycon hauxwellianus, Deuterodon iguape, Diapoma terofali, Galeocharax knerii, Gnathocharax steindachneri, Gymnocorymbus ternetzi, Hemibrycon polyodon, Hemigrammus unilineatus, Markiana nigripinnis, Moenkhausia xinguensis, Odontostilbe pequira, Orthospinus franciscoensis, Piabina argentea, Poptella brevispina, Roeboexodon guyanensis, Stygichthys typhlops e Tetragonopterus argenteus.

\section{[2] - não alcança o palatino, fica separado deste por um espaço (Figs. 20, 26 e 30).}

Catostomus commersonnii, Neolebias unifasciatus, Xenocharax spilurus, Copeina cf. guttata, Arnoldichthys spilopterus, Brycinus macrolepidotus, Bryconalestes longipinnis, Chalceus epakros, Characidium bahiensis, Crenuchus spilurus, Atopomesus pachyodus, Axelrodia reisei, Brittanichthys axelrodi, Bryconadenos tanaothoros, Bryconamericus exodon, Glandulocauda melanogenys, Landonia latidens, Microschemobrycon casiquiare, Paracheirodon axelrodi, Paragoniates alburnus, Phenacogaster pectinatus, Phenagoniates macrolepis, Rhinobrycon negrensis, Rhoadsia altipinna e Serrabrycon magoi.

\section{[-] - inaplicável.}

Olivaichthys mesembrinus e Gymnotus aff. carapo.

\section{[?] - indeterminado.}

Hyphessobrycon compressus e Rachoviscus graciliceps.

\section{4 - Face dorso-medial do metapterigóide:}

$$
\text { [0] - lisa. }
$$

Catostomus commersonnii, Gymnotus aff. carapo, Citharinus latus, Distichodus notospilus, Hemistichodus vaillanti, Neolebias unifasciatus, Nannocharax fasciatus, Xenocharax spilurus, Apareiodon piracicabae, Parodon nasus, Anodus orinocensis, Bivibranchia fowleri, Hemiodus unimaculatus, Curimata ocellata, Curimatopsis macrolepis, Potamorhina latior, Prochilodus nigricans, Semaprochilodus insignis, Caenotropus labyrinthicus, Chilodus punctatus, Anostomus anostomus, Leporellus vittatus, Leporinus fasciatus, Schizodon fasciatus, Carnegiella strigata, Gasteropelecus sternicla, Thoracocharax stellatus, Gilbertolus atratoensis, Hydrolycus tatauaia, Roestes molossus, Erythrinoidea fam. nov, Copeina cf. guttata, Hepsetus odoe, Arnoldichthys spilopterus, Brycinus macrolepidotus, Atopomesus pachyodus, Brittanichthys axelrodi, Bryconamericus exodon, Compsura heterura, Gnathocharax steindachneri, Hemigrammus unilineatus, Metynnis lippincottianus, Moenkhausia xinguensis, Myleus setiger, Phenacogaster pectinatus, Piaractus mesopotamicus, Roeboexodon guyanensis e Stygichthys typhlops.

\section{[1] - com projeção ao longo.}

Chanos chanos, Olivaichthys mesembrinus, Acestrorhynchus falcirostris, Boulengerella maculata, Ctenolucius hujeta, Lebiasina bimaculata, Piabucina astrigata, Erythrinus erythrinus, Hoplias malabaricus, Bryconalestes longipinnis, Chalceus epakros, Characidium bahiensis, Crenuchus spilurus, Agoniates halecinus, Aphyocharax pusillus, Astyanax mexicanus, Axelrodia reisei, Brycon pesu, Bryconadenos tanaothoros, Bryconops alburnoides, Charax cf. leticiae, Clupeacharax cf. engrauloides, Ctenobrycon hauxwellianus, Deuterodon iguape, Diapoma terofali, Galeocharax knerii, Glandulocauda melanogenys, Gymnocorymbus ternetzi, Hemibrycon polyodon, Hollandichthys multifasciatus, Hyphessobrycon compressus, Iguanodectes geisleri, Knodus meridae, Landonia latidens, Markiana nigripinnis, Microschemobrycon casiquiare, Odontostilbe pequira, oligosarcus argenteus, orthospinus franciscoensis, Paracheirodon axelrodi, Paragoniates alburnus, Phenagoniates macrolepis, Piabina argentea, Poptella brevispina, Probolus heterostomus, Rachoviscus graciliceps, Rhinobrycon negrensis, Rhoadsia altipinna, Salminus hilarii, Serrabrycon magoi, Tetragonopterus argenteus e Triportheus albus.

[?] - indeterminado.

Saccodon wagneri. 
[Lucena, 1993: 57, modificado; ZanatA, 2000: 63; Lima, 2006: 22; e NetToFERREIRA, 2006: 128]

[0] - entre o metapterigóide e o hiomandibular (Figs. 20, 21 e 23) .

Chanos chanos, Catostomus commersonnii, Gymnotus aff. carapo, Citharinus latus, Distichodus notospilus, Hemistichodus vaillanti, Neolebias unifasciatus, Nannocharax fasciatus, Xenocharax spilurus, Apareiodon piracicabae, Parodon nasus, Anodus orinocensis, Bivibranchia fowleri, Hemiodus unimaculatus, Curimata ocellata, Curimatopsis macrolepis, Potamorhina latior, Prochilodus nigricans, Semaprochilodus insignis, Caenotropus labyrinthicus, Chilodus punctatus, Anostomus anostomus, Leporellus vittatus, Leporinus fasciatus, Schizodon fasciatus, Carnegiella strigata, Gasteropelecus sternicla, Thoracocharax stellatus, Acestrorhynchus falcirostris, Gilbertolus atratoensis, Hydrolycus tatauaia, Roestes molossus, Erythrinoidea fam. nov, Boulengerella maculata, Ctenolucius hujeta, Lebiasina bimaculata, Erythrinus erythrinus, Hoplias malabaricus, Hepsetus odoe, Arnoldichthys spilopterus, Brycinus macrolepidotus, Bryconalestes longipinnis, Chalceus epakros, Characidium bahiensis, Agoniates halecinus, Atopomesus pachyodus, Axelrodia reisei, Brittanichthys axelrodi, Brycon pesu, Bryconops alburnoides, Clupeacharax cf. engrauloides, Diapoma terofali, Glandulocauda melanogenys, Hemigrammus unilineatus, Hyphessobrycon compressus, Iguanodectes geisleri, Metynnis lippincottianus, Microschemobrycon casiquiare, Myleus setiger, Paracheirodon axelrodi, Paragoniates alburnus, Phenacogaster pectinatus, Piaractus mesopotamicus, Rachoviscus graciliceps, Salminus hilarii, Stygichthys typhlops, Tetragonopterus argenteus e Triportheus albus.

[1] - totalmente incluso no metapterigóide (Fig. 25 e Fig. 30).

Copeina cf. guttata, Piabucina astrigata, Crenuchus spilurus, Aphyocharax pusillus, Astyanax mexicanus, Bryconadenos tanaothoros, Bryconamericus exodon, Charax cf. leticiae, Compsura heterura, Ctenobrycon hauxwellianus, Deuterodon iguape, Galeocharax knerii, Gnathocharax steindachneri, Gymnocorymbus ternetzi, Hemibrycon polyodon, Hollandichthys multifasciatus, Knodus meridae, Landonia latidens, Markiana nigripinnis, Moenkhausia xinguensis, Odontostilbe pequira, Oligosarcus argenteus, orthospinus franciscoensis, Phenagoniates macrolepis, Piabina argentea, Poptella brevispina, Probolus heterostomus, Rhinobrycon negrensis, Rhoadsia altipinna, Roeboexodon guyanensis e Serrabrycon magoi.

[?] - indeterminado.

olivaichthys mesembrinus e Saccodon wagneri.

66 - Contato entre regiões ântero-inferior do metapterigóide e ânterosuperior do quadrado:

[ZANATA, 2000: 64; LIMA, 2006: 58]

[0] - com contato, ou pequeno espaço.

Catostomus commersonnii, olivaichthys mesembrinus, Gymnotus aff. carapo, Citharinus latus, Distichodus notospilus, Hemistichodus vaillanti, Neolebias unifasciatus, Nannocharax fasciatus, Xenocharax spilurus, Apareiodon piracicabae, Parodon nasus, Saccodon wagneri, Anodus orinocensis, Bivibranchia fowleri, Hemiodus unimaculatus, Curimata ocellata, Curimatopsis macrolepis, Potamorhina latior, Prochilodus nigricans, Semaprochilodus insignis, Caenotropus labyrinthicus, Chilodus punctatus, Anostomus anostomus, Leporellus vittatus, Leporinus fasciatus, schizodon fasciatus, Carnegiella strigata, Gasteropelecus sternicla, Thoracocharax stellatus, Acestrorhynchus falcirostris, Gilbertolus atratoensis, Hydrolycus tatauaia, Roestes molossus, Erythrinoidea fam. nov, Boulengerella maculata, Ctenolucius hujeta, copeina cf. guttata, Lebiasina bimaculata, Piabucina astrigata, Erythrinus erythrinus, Hoplias malabaricus, Hepsetus odoe, Arnoldichthys spilopterus, Brycinus macrolepidotus, Bryconalestes longipinnis, Chalceus epakros, Characidium bahiensis, Crenuchus spilurus, Agoniates halecinus, Aphyocharax pusillus, Astyanax mexicanus, Atopomesus pachyodus, Axelrodia reisei, Brycon pesu, Bryconadenos tanaothoros, Bryconamericus exodon, Charax cf. leticiae, Compsura heterura, Ctenobrycon hauxwellianus, Deuterodon iguape, Diapoma terofali, Galeocharax knerii, Glandulocauda melanogenys, Gnathocharax steindachneri, Gymnocorymbus ternetzi, Hemibrycon polyodon, Hemigrammus unilineatus, Hollandichthys multifasciatus, Hyphessobrycon compressus, Knodus meridae, Landonia latidens, Markiana nigripinnis, Metynnis lippincottianus, Microschemobrycon casiquiare, Moenkhausia xinguensis, Myleus setiger, Odontostilbe pequira, Oligosarcus argenteus, orthospinus franciscoensis, Paracheirodon axelrodi, Paragoniates alburnus, Phenacogaster pectinatus, Phenagoniates macrolepis, Piabina argentea, Piaractus mesopotamicus, Poptella 
brevispina, Probolus heterostomus, Rachoviscus graciliceps, Rhinobrycon negrensis, Rhoadsia altipinna, Roeboexodon guyanensis, Salminus hilarii, Serrabrycon magoi, Stygichthys typhlops e Tetragonopterus argenteus.

\title{
[1] - com grande espaço.
}

Chanos chanos, Brittanichthys axelrodi, Bryconops alburnoides, Clupeacharax cf. engrauloides, Iguanodectes geisleri e Triportheus albus.

\author{
67 - Contato entre as regiões ântero-inferior do metapterigóide e \\ ântero-superior do quadrado: \\ [MOREIRA, 2002: 25]
}

\section{[0] - vertical (Fig. 21 e Fig. 25).}

olivaichthys mesembrinus, Acestrorhynchus falcirostris, Gilbertolus atratoensis, Hydrolycus tatauaia, Roestes molossus, Boulengerella maculata, ctenolucius hujeta, Erythrinus erythrinus, Hoplias malabaricus, Hepsetus odoe, Arnoldichthys spilopterus, Chalceus epakros, Agoniates halecinus, Astyanax mexicanus, Brycon pesu, Bryconamericus exodon, Charax cf. leticiae, Galeocharax knerii, Glandulocauda melanogenys, Gnathocharax steindachneri, Gymnocorymbus ternetzi, Hemibrycon polyodon, Hollandichthys multifasciatus, Hyphessobrycon compressus, Markiana nigripinnis, Metynnis lippincottianus, Moenkhausia xinguensis, Myleus setiger, oligosarcus argenteus, orthospinus franciscoensis, Paragoniates alburnus, Piabina argentea, Poptella brevispina, Salminus hilarii, Stygichthys typhlops e Tetragonopterus argenteus.

\section{[1] - horizontal (Figs. 20, 23, 26, 27, 29 e 30).}

Chanos chanos, Catostomus commersonnii, Gymnotus aff. carapo, Citharinus latus, Distichodus notospilus, Hemistichodus vaillanti, Neolebias unifasciatus, Nannocharax fasciatus, Xenocharax spilurus, Apareiodon piracicabae, Parodon nasus, Saccodon wagneri, Anodus orinocensis, Bivibranchia fowleri, Hemiodus unimaculatus, Curimata ocellata, Curimatopsis macrolepis, Potamorhina latior, Prochilodus nigricans, Semaprochilodus insignis, Caenotropus labyrinthicus, Chilodus punctatus, Anostomus anostomus, Leporellus vittatus, Leporinus fasciatus, Schizodon fasciatus, Carnegiella strigata, Gasteropelecus sternicla, Thoracocharax stellatus, Erythrinoidea fam. nov, Brycinus macrolepidotus, Bryconalestes longipinnis, Characidium bahiensis, Crenuchus spilurus, Aphyocharax pusillus, Atopomesus pachyodus, Axelrodia reisei, Brittanichthys axelrodi, Bryconadenos tanaothoros, Bryconops alburnoides, Clupeacharax cf. engrauloides, compsura heterura, Ctenobrycon hauxwellianus, Deuterodon iguape, Diapoma terofali, Hemigrammus unilineatus, Iguanodectes geisleri, Knodus meridae, Landonia latidens, Microschemobrycon casiquiare, odontostilbe pequira, Paracheirodon axelrodi, Phenacogaster pectinatus, Phenagoniates macrolepis, Piaractus mesopotamicus, Probolus heterostomus, Rachoviscus graciliceps, Rhinobrycon negrensis, Rhoadsia altipinna, Roeboexodon guyanensis, Serrabrycon magoi e Triportheus albus.

\section{[-] - inaplicável.}

Copeina cf. guttata, Lebiasina bimaculata e Piabucina astrigata.

\section{8 - Articulação do ângulo-articular com o quadrado:}

\section{[0] - situada na vertical posterior ao etmóide lateral.}

Chanos chanos, Catostomus commersonnii, Olivaichthys mesembrinus, Gymnotus aff. carapo, Citharinus latus, Distichodus notospilus, Neolebias unifasciatus, Nannocharax fasciatus, Xenocharax spilurus, Apareiodon piracicabae, Parodon nasus, Saccodon wagneri, Anodus orinocensis, Bivibranchia fowleri, Hemiodus unimaculatus, Acestrorhynchus falcirostris, Gilbertolus atratoensis, Hydrolycus tatauaia, Roestes molossus, Erythrinoidea fam. nov, Boulengerella maculata, Ctenolucius hujeta, Copeina cf. guttata, Lebiasina bimaculata, Piabucina astrigata, Erythrinus erythrinus, Hoplias malabaricus, Hepsetus odoe, Arnoldichthys spilopterus, Brycinus macrolepidotus, Bryconalestes longipinnis, Chalceus epakros, Characidium bahiensis, Crenuchus spilurus, Agoniates halecinus, Aphyocharax pusillus, Astyanax mexicanus, Atopomesus pachyodus, Axelrodia reisei, Brittanichthys axelrodi, Brycon pesu, Bryconadenos tanaothoros, Bryconamericus exodon, Bryconops alburnoides, Charax cf. leticiae, Clupeacharax cf. engrauloides, Compsura heterura, Ctenobrycon hauxwellianus, Deuterodon iguape, Diapoma terofali, Galeocharax knerii, Glandulocauda melanogenys, Gnathocharax steindachneri, Gymnocorymbus ternetzi, Hemibrycon polyodon, Hemigrammus unilineatus, Hollandichthys multifasciatus, 
Hyphessobrycon compressus, Knodus meridae, Landonia latidens, Markiana nigripinnis, Metynnis lippincottianus, Microschemobrycon casiquiare, Moenkhausia xinguensis, Myleus setiger, Odontostilbe pequira, oligosarcus argenteus, orthospinus franciscoensis, Paracheirodon axelrodi, Paragoniates alburnus, Phenacogaster pectinatus, Phenagoniates macrolepis, Piabina argentea, Piaractus mesopotamicus, Poptella brevispina, Probolus heterostomus, Rachoviscus graciliceps, Rhinobrycon negrensis, Rhoadsia altipinna, Roeboexodon guyanensis, Salminus hilarii, Serrabrycon magoi, Stygichthys typhlops, Tetragonopterus argenteus e Triportheus albus.

\section{[1] - situada na vertical anterior ao etmóide lateral.}

Hemistichodus vaillanti, Curimata ocellata, Curimatopsis macrolepis, Potamorhina latior, Prochilodus nigricans, Semaprochilodus insignis, Caenotropus labyrinthicus, Chilodus punctatus, Anostomus anostomus, Leporellus vittatus, Leporinus fasciatus, Schizodon fasciatus, Carnegiella strigata, Gasteropelecus sternicla, Thoracocharax stellatus e Iguanodectes geisleri.

69 - Fenestra metapterigóide-quadrado:

[LUCENA, 1993: 60 e 61, modificados; BUCKUP, 1998: 24, modificado; LUCENA \& MENEZES, 1998: 26, modificado; OYAKAWA, 1998: 44 e 45, modificados;

ZANATA, 2000: 66, modificado; Moreira, 2002: 28, modificado; NetTo-Ferreira, 2006: 124 e 125, modificados ]

(Minimamente conectado).

[0] - redonda ou verticalmente alongada (Figs. 21, 25 e 27).

Xenocharax spilurus, Acestrorhynchus falcirostris, Gilbertolus atratoensis, Hydrolycus tatauaia, Roestes molossus, Boulengerella maculata, Ctenolucius hujeta, Erythrinus erythrinus, Hepsetus odoe, Crenuchus spilurus, Agoniates halecinus, Astyanax mexicanus, Brycon pesu, Charax cf. leticiae, Clupeacharax cf. engrauloides, Galeocharax knerii, Gnathocharax steindachneri, Hemigrammus unilineatus, Hollandichthys multifasciatus, oligosarcus argenteus, Orthospinus franciscoensis, Piaractus mesopotamicus, Salminus hilarii e Stygichthys typhlops.

\section{[1] - horizontalmente alongada (Figs. 20, 26, 29 e 30).}

Citharinus latus, Distichodus notospilus, Neolebias unifasciatus, Apareiodon piracicabae, Parodon nasus, Saccodon wagneri, Anodus orinocensis, Hemiodus unimaculatus , Curimata ocellata, Potamorhina latior, Prochilodus nigricans, Semaprochilodus 'insignis, Leporellus vittatus, Leporinus fasciatus, Schizodon fasciatus, Carnegiella strigata, Gasteropelecus sternicla, Thoracocharax stellatus, Erythrinoidea fam. nov, Hoplias malabaricus, Arnoldichthys spilopterus, Brycinus macrolepidotus, Bryconalestes longipinnis, Chalceus epakros, Aphyocharax pusillus, Atopomesus pachyodus, Axelrodia reisei, Brittanichthys axelrodi, Bryconadenos tanaothoros, Bryconamericus exodon, Bryconops alburnoides, Compsura heterura, Ctenobrycon hauxwellianus, Deuterodon iguape, Diapoma terofali, Glandulocauda melanogenys, Gymnocorymbus ternetzi, Hemibrycon polyodon , Hyphessobrycon compressus, Knodus meridae, Landonia latidens, Markiana nigripinnis, Metynnis lippincottianus, Microschemobrycon casiquiare, Moenkhausia xinguensis, Myleus setiger, Odontostilbe pequira, Paracheirodon axelrodi, Paragoniates alburnus, Phenacogaster pectinatus, Phenagoniates macrolepis, Piabina argentea, Poptella brevispina, Probolus heterostomus, Rachoviscus graciliceps, Rhinobrycon negrensis, Rhoadsia altipinna, Serrabrycon magoi, Tetragonopterus argenteus e Triportheus albus.

\section{a altura) ou ausente (Fig. 23).}

[2] - muito alongada horizontalmente (largura mais de três vezes

Chanos chanos, Catostomus commersonnii, Olivaichthys mesembrinus, Gymnotus aff. carapo, Hemistichodus vaillanti, Nannocharax fasciatus, Bivibranchia fowleri, Curimatopsis macrolepis, Caenotropus labyrinthicus, Chilodus punctatus, Anostomus anostomus, Copeina cf. guttata, Lebiasina bimaculata, Piabucina astrigata, Characidium bahiensis e Iguanodectes geisleri.

\section{[?] - indeterminado.}

Roeboexodon guyanensis. 
[OYAKAWA, 1998: 46, modificado; e NetTo-FerReIRA, 2006: 131, modificado]

\section{[0] - aproximadamente cilíndrico.}

Chanos chanos, Catostomus commersonnii, Gymnotus aff. carapo, Citharinus latus, Distichodus notospilus, Hemistichodus vaillanti, Neolebias unifasciatus, Nannocharax fasciatus, Xenocharax spilurus, Apareiodon piracicabae, Parodon nasus, Saccodon wagneri, Anodus orinocensis, Bivibranchia fowleri, Hemiodus unimaculatus, Curimata ocellata, Curimatopsis macrolepis, Potamorhina latior, Prochilodus nigricans, Semaprochilodus insignis, Caenotropus labyrinthicus, Chilodus punctatus, Anostomus anostomus, Leporellus vittatus, Carnegiella strigata, Gasteropelecus sternicla, Thoracocharax stellatus, Gilbertolus atratoensis, Hydrolycus tatauaia, Roestes molossus, Erythrinoidea fam. nov, Copeina cf. guttata, Lebiasina bimaculata, Piabucina astrigata, Hepsetus odoe, Arnoldichthys spilopterus, Brycinus macrolepidotus, Bryconalestes longipinnis, Chalceus epakros, Crenuchus spilurus, Aphyocharax pusillus, Astyanax mexicanus, Atopomesus pachyodus, Axelrodia reisei, Brittanichthys axelrodi, Brycon pesu, Bryconadenos tanaothoros, Bryconamericus exodon, Bryconops alburnoides, Charax cf. leticiae, Clupeacharax cf. engrauloides, Compsura heterura, Ctenobrycon hauxwellianus, Deuterodon iguape, Diapoma terofali, Galeocharax knerii, Glandulocauda melanogenys, Gnathocharax steindachneri, Gymnocorymbus ternetzi, Hemibrycon polyodon, Hemigrammus unilineatus, Hollandichthys multifasciatus, Hyphessobrycon compressus, Iguanodectes geisleri, Knodus meridae, Landonia latidens, Markiana nigripinnis, Metynnis lippincottianus, Microschemobrycon casiquiare, Moenkhausia xinguensis, Myleus setiger, Odontostilbe pequira, oligosarcus argenteus, Orthospinus franciscoensis, Paracheirodon axelrodi, Paragoniates alburnus, Phenacogaster pectinatus, Phenagoniates macrolepis, Piabina argentea, Piaractus mesopotamicus, Poptella brevispina, Probolus heterostomus, Rachoviscus graciliceps, Rhinobrycon negrensis, Rhoadsia altipinna, Roeboexodon guyanensis, Salminus hilarii, Serrabrycon magoi, Stygichthys typhlops, Tetragonopterus argenteus e Triportheus albus.

\section{[1] - com expansões ósseas.}

Leporinus fasciatus, Schizodon fasciatus, Acestrorhynchus falcirostris, Boulengerella maculata, Ctenolucius hujeta e Characidium bahiensis.

[2] - lamelar.

Erythrinus erythrinus e Hoplias malabaricus.

\section{[-] - inaplicável.}

olivaichthys mesembrinus.

[?] - indeterminado.

Agoniates halecinus.

71 - Face externa do quadrado e pré-operculo:

\section{[0] - lisa ou quase sem expansão.}

Chanos chanos, Catostomus commersonnii, Olivaichthys mesembrinus, Gymnotus aff. carapo, Citharinus latus, Distichodus notospilus, Hemistichodus vaillanti, Neolebias unifasciatus, Nannocharax fasciatus, Xenocharax spilurus, Apareiodon piracicabae, Parodon nasus, Saccodon wagneri, Anodus orinocensis, Bivibranchia fowleri, Hemiodus unimaculatus, Curimata ocellata, Curimatopsis macrolepis, Potamorhina latior, Prochilodus nigricans, Carnegiella strigata, Gasteropelecus sternicla, Thoracocharax stellatus, Acestrorhynchus falcirostris, Gilbertolus atratoensis, Hydrolycus tatauaia, Erythrinoidea fam. nov, Boulengerella maculata, Ctenolucius hujeta, Copeina cf. guttata, Lebiasina bimaculata, Piabucina astrigata, Erythrinus erythrinus, Hoplias malabaricus, Hepsetus odoe, Arnoldichthys spilopterus, Brycinus macrolepidotus, Bryconalestes longipinnis, Chalceus epakros, Characidium bahiensis, Crenuchus spilurus, Agoniates halecinus, Aphyocharax pusillus, Astyanax mexicanus, Atopomesus pachyodus, Axelrodia reisei, Brittanichthys axelrodi, Brycon pesu, Bryconadenos tanaothoros, Bryconamericus exodon, Bryconops alburnoides, Charax cf. leticiae, Clupeacharax cf. engrauloides, compsura heterura, Ctenobrycon hauxwellianus, Deuterodon iguape, Diapoma terofali, Galeocharax knerii, Glandulocauda melanogenys, Gnathocharax steindachneri, Gymnocorymbus ternetzi, Hemibrycon polyodon, Hemigrammus unilineatus, Hollandichthys multifasciatus, Hyphessobrycon compressus, Knodus meridae, Landonia latidens, Markiana nigripinnis, Metynnis lippincottianus, Microschemobrycon casiquiare, Moenkhausia xinguensis, Myleus setiger, Odontostilbe pequira, oligosarcus argenteus, orthospinus franciscoensis, 
Paracheirodon axelrodi, Paragoniates alburnus, Phenacogaster pectinatus, Phenagoniates macrolepis, Piabina argentea, Piaractus mesopotamicus, Poptella brevispina, Probolus heterostomus, Rachoviscus graciliceps, Rhinobrycon negrensis, Rhoadsia altipinna, Roeboexodon guyanensis, Salminus hilarii, Serrabrycon magoi, stygichthys typhlops, Tetragonopterus argenteus e Triportheus albus.

\section{[1] - em forma de calha.}

Semaprochilodus insignis, Caenotropus labyrinthicus, Chilodus punctatus, Anostomus anostomus, Leporellus vittatus, Leporinus fasciatus, Schizodon fasciatus, Roestes molossus, Iguanodectes geisleri.

72 - Forma do hiomandibular:

[NETTO-FERREIRA, 2006: 133]

[0] - eixo vertical aproximadamente igual ao eixo horizontal.

Catostomus commersonnii, Olivaichthys mesembrinus, Gymnotus aff. carapo, Erythrinoidea fam. nov., Boulengerella maculata, Ctenolucius hujeta, Piabucina astrigata, Galeocharax knerii, Hemibrycon polyodon e Microschemobrycon casiquiare.

\section{[1] - eixo vertical maior que eixo horizontal.}

Chanos chanos, Citharinus latus, Distichodus notospilus, Hemistichodus vaillanti, Neolebias unifasciatus, Nannocharax fasciatus, Xenocharax spilurus, Apareiodon piracicabae, Parodon nasus, Saccodon wagneri, Anodus orinocensis, Bivibranchia fowleri, Hemiodus unimaculatus, Curimata ocellata, Curimatopsis macrolepis, Potamorhina latior, Prochilodus nigricans, Semaprochilodus insignis, Caenotropus labyrinthicus, chilodus punctatus, Anostomus anostomus, Leporellus vittatus, Leporinus fasciatus, Schizodon fasciatus, Carnegiella strigata, Gasteropelecus sternicla, Thoracocharax stellatus, Acestrorhynchus falcirostris, Gilbertolus atratoensis, Hydrolycus tatauaia, Roestes molossus, Copeina cf. guttata, Lebiasina bimaculata, Erythrinus erythrinus, Hoplias malabaricus, Hepsetus odoe, Arnoldichthys spilopterus, Brycinus macrolepidotus, Bryconalestes longipinnis, Chalceus epakros, Characidium bahiensis, Crenuchus spilurus, Agoniates halecinus, Aphyocharax pusillus, Astyanax mexicanus, Atopomesus pachyodus, Axelrodia reisei, Brittanichthys axelrodi, Brycon pesu, Bryconadenos tanaothoros, Bryconamericus exodon, Bryconops alburnoides, Charax cf. leticiae, Clupeacharax cf. engrauloides, Compsura heterura, Ctenobrycon hauxwellianus, Deuterodon iguape, Diapoma terofali, Glandulocauda melanogenys, Gnathocharax steindachneri, Gymnocorymbus ternetzi, Hemigrammus unilineatus, Hollandichthys multifasciatus, Hyphessobrycon compressus, Iguanodectes geisleri, Knodus meridae, Landonia latidens, Markiana nigripinnis, Metynnis lippincottianus, Moenkhausia xinguensis, Myleus setiger, odontostilbe pequira, oligosarcus argenteus, orthospinus franciscoensis, Paracheirodon axelrodi, Paragoniates alburnus, Phenacogaster pectinatus, Phenagoniates macrolepis, Piabina argentea, Piaractus mesopotamicus, Poptella brevispina, Probolus heterostomus, Rachoviscus graciliceps, Rhinobrycon negrensis, Rhoadsia altipinna, Roeboexodon guyanensis, Salminus hilarii, Serrabrycon magoi, Stygichthys typhlops, Tetragonopterus argenteus e Triportheus albus.

\section{3 - Margem anterior do hiomandibular:}

$$
\text { [0] - lisa (Fig. 29). }
$$

Citharinus latus, Distichodus notospilus, Hemistichodus vaillanti, Neolebias unifasciatus, Nannocharax fasciatus, Xenocharax spilurus, Anodus orinocensis, Curimata ocellata, Curimatopsis macrolepis, Potamorhina latior, Prochilodus nigricans, Semaprochilodus insignis, Carnegiella strigata, Gasteropelecus sternicla, Thoracocharax stellatus, Gilbertolus atratoensis, Hydrolycus tatauaia, Roestes molossus, Erythrinoidea fam. nov, Astyanax mexicanus, Atopomesus pachyodus, Axelrodia reisei, Brittanichthys axelrodi, Brycon pesu, Bryconadenos tanaothoros, Bryconamericus exodon, Bryconops alburnoides, Clupeacharax cf. engrauloides, Compsura heterura, Ctenobrycon hauxwellianus, Deuterodon iguape, Glandulocauda melanogenys, Gnathocharax steindachneri, Gymnocorymbus ternetzi, Hemibrycon polyodon, Hemigrammus unilineatus, Hollandichthys multifasciatus, Knodus meridae, Landonia latidens, Markiana nigripinnis, Microschemobrycon casiquiare, orthospinus franciscoensis, Paracheirodon axelrodi, Phenacogaster pectinatus, Phenagoniates macrolepis, Piabina argentea, Poptella brevispina, Rachoviscus graciliceps, Serrabrycon magoi e Triportheus albus.

[1] - com projeção anterior na porção póstero-dorsal do metapterigóide (Figs. 21, 26 e 27). 
Chanos chanos, Catostomus commersonnii, olivaichthys mesembrinus, Gymnotus aff. carapo, Apareiodon piracicabae, Parodon nasus, Saccodon wagneri, Bivibranchia fowleri, Hemiodus unimaculatus, Caenotropus labyrinthicus, Chilodus punctatus, Anostomus anostomus, Leporellus vittatus, Leporinus fasciatus, Schizodon fasciatus, Acestrorhynchus falcirostris, Boulengerella maculata, Ctenolucius hujeta, Copeina cf. guttata, Lebiasina bimaculata, Piabucina astrigata, Erythrinus erythrinus, Hoplias malabaricus, Hepsetus odoe, Arnoldichthys spilopterus, Brycinus macrolepidotus, Bryconalestes longipinnis, Chalceus epakros, Characidium bahiensis, crenuchus spilurus, Agoniates halecinus, Aphyocharax pusillus, Charax cf. leticiae, Diapoma terofali, Galeocharax knerii, Hyphessobrycon compressus, Iguanodectes geisleri, Metynnis lippincottianus, Moenkhausia xinguensis, Myleus setiger, Odontostilbe pequira, oligosarcus argenteus, Paragoniates alburnus, Piaractus mesopotamicus, Probolus heterostomus, Rhinobrycon negrensis, Rhoadsia altipinna, Roeboexodon guyanensis, Salminus hilarii, stygichthys typhlops e Tetragonopterus argenteus.

74 - Margem dorso-posterior do hiomandibular:

[Moreira, 2002: 31, modificado; Zanata \& Vari, 2005: 104 e Netto-

Ferreira, 2006: 136, modificado]

[0] - lisa, sem nenhum processo.

Olivaichthys mesembrinus, Gymnotus aff. carapo, Distichodus notospilus, Hemistichodus vaillanti, Neolebias unifasciatus, Nannocharax fasciatus, Xenocharax spilurus, Parodon nasus, Anodus orinocensis, Bivibranchia fowleri, curimata ocellata, Curimatopsis macrolepis, Potamorhina latior, Prochilodus nigricans, Semaprochilodus insignis, Anostomus anostomus, Leporellus vittatus, Leporinus fasciatus, Schizodon fasciatus, Carnegiella strigata, Gasteropelecus sternicla, Thoracocharax stellatus, Hydrolycus tatauaia, Roestes molossus, Erythrinoidea fam. nov, Boulengerella maculata, Ctenolucius hujeta, Copeina cf. guttata, Lebiasina bimaculata, Bryconalestes longipinnis, Chalceus epakros, Axelrodia reisei, Clupeacharax cf. engrauloides, Compsura heterura, Deuterodon iguape, Glandulocauda melanogenys, Gnathocharax steindachneri, Hemibrycon polyodon, Hollandichthys multifasciatus, Moenkhausia xinguensis, oligosarcus argenteus, Salminus hilarii, Serrabrycon magoi, Stygichthys typhlops, Tetragonopterus argenteus e Triportheus albus.

[1] - com processo, mas este muito curto e posicionado lateralmente (Figs. 21, 23, 25 e 30).

Chanos chanos, Catostomus commersonnii, Citharinus latus, Apareiodon piracicabae, Hemiodus unimaculatus, Caenotropus labyrinthicus, Chilodus punctatus, Acestrorhynchus falcirostris, Gilbertolus atratoensis, Piabucina astrigata, Erythrinus erythrinus, Hoplias malabaricus, Hepsetus odoe, Arnoldichthys spilopterus, Brycinus macrolepidotus, Characidium bahiensis, Crenuchus spilurus, Agoniates halecinus, Astyanax mexicanus, Atopomesus pachyodus, Brittanichthys axelrodi, Brycon pesu, Bryconadenos tanaothoros, Bryconamericus exodon, Bryconops alburnoides, Charax cf. leticiae, Ctenobrycon hauxwellianus, Diapoma terofali, Gymnocorymbus ternetzi, Hemigrammus unilineatus, Hyphessobrycon compressus, Iguanodectes geisleri, Landonia latidens, Markiana nigripinnis, Metynnis lippincottianus, Microschemobrycon casiquiare, Myleus setiger, odontostilbe pequira, orthospinus franciscoensis, Paracheirodon axelrodi, Paragoniates alburnus, Phenacogaster pectinatus, Phenagoniates macrolepis, Piabina argentea, Piaractus mesopotamicus, Poptella brevispina, Probolus heterostomus , Rachoviscus graciliceps, Rhinobrycon negrensis, Rhoadsia altipinna e Roeboexodon guyanensis.

\title{
[2] - processo mais desenvolvido.
}

Saccodon wagneri, Aphyocharax pusillus e Galeocharax knerii.

$$
\text { [?] - indeterminado. }
$$

Knodus meridae.

\author{
75 - Porção anterior do canal pré-opercular: \\ [VARI, 1983: 40]
}

\section{[0] - contínua.}

Chanos chanos, olivaichthys mesembrinus, Gymnotus aff. carapo, Citharinus latus, Distichodus notospilus, Hemistichodus vaillanti, Neolebias unifasciatus, Nannocharax fasciatus, Xenocharax spilurus, Apareiodon piracicabae, Parodon nasus, Saccodon wagneri, 
Anodus orinocensis, Bivibranchia fowleri, Hemiodus unimaculatus, Curimata ocellata, Curimatopsis macrolepis, Potamorhina latior, Caenotropus labyrinthicus, Chilodus punctatus, Carnegiella strigata, Gasteropelecus sternicla, Thoracocharax stellatus , Acestrorhynchus falcirostris, Gilbertolus atratoensis, Hydrolycus tatauaia, Roestes molossus, Erythrinoidea fam. nov, Boulengerella maculata, Ctenolucius hujeta, Copeina cf. guttata, Lebiasina bimaculata, Piabucina astrigata, Erythrinus erythrinus, Hoplias malabaricus, Hepsetus odoe, Arnoldichthys spilopterus, Brycinus macrolepidotus, Bryconalestes longipinnis, Chalceus epakros, Characidium bahiensis, Crenuchus spilurus, Agoniates halecinus, Aphyocharax pusillus, Astyanax mexicanus, Atopomesus pachyodus, Axelrodia reisei, Brittanichthys axelrodi, Brycon pesu, Bryconadenos tanaothoros, Bryconamericus exodon, Bryconops alburnoides, Charax cf. leticiae, clupeacharax cf. engrauloides, Compsura heterura, Ctenobrycon hauxwellianus, Deuterodon iguape, Diapoma terofali, Galeocharax knerii, Glandulocauda melanogenys, Gnathocharax steindachneri, Gymnocorymbus ternetzi, Hemibrycon polyodon, Hemigrammus unilineatus, Hollandichthys multifasciatus, Hyphessobrycon compressus, Iguanodectes geisleri, Knodus meridae, Landonia latidens, Markiana nigripinnis, Metynnis lippincottianus, Microschemobrycon casiquiare, Moenkhausia xinguensis, Myleus setiger, odontostilbe pequira, oligosarcus argenteus, orthospinus franciscoensis, Paracheirodon axelrodi, Paragoniates alburnus, Phenacogaster pectinatus, Phenagoniates macrolepis, Piabina argentea, Piaractus mesopotamicus, Poptella brevispina, Probolus heterostomus, Rachoviscus graciliceps, Rhinobrycon negrensis, Rhoadsia altipinna, Roeboexodon guyanensis, Salminus hilarii, Serrabrycon magoi, Stygichthys typhlops, Tetragonopterus argenteus e Triportheus albus.

\section{[1] - subdividida.}

Prochilodus nigricans, Semaprochilodus insignis, Anostomus anostomus, Leporellus vittatus, Leporinus fasciatus e Schizodon fasciatus.

\section{[-] - inaplicável.}

Catostomus commersonnii.

76 - Margem ventral do opérculo:

[0] - curva, contígua com a margem posterior (Fig. 31A e C).

Gymnotus aff. carapo, Bivibranchia fowleri, Hemiodus unimaculatus, Prochilodus nigricans, Semaprochilodus insignis, Schizodon fasciatus, Acestrorhynchus falcirostris, Brycinus macrolepidotus, Agoniates halecinus, Astyanax mexicanus, Atopomesus pachyodus, Brycon pesu, Bryconamericus exodon, Bryconops alburnoides, Charax cf. leticiae, Clupeacharax cf. engrauloides, Compsura heterura, Ctenobrycon hauxwellianus, Deuterodon iguape, Galeocharax knerii, Glandulocauda melanogenys, Hemibrycon polyodon, Hollandichthys multifasciatus, Iguanodectes geisleri, Knodus meridae, Markiana nigripinnis, Metynnis lippincottianus, Moenkhausia xinguensis, Myleus setiger, orthospinus franciscoensis, Phenacogaster pectinatus, Phenagoniates macrolepis, Piaractus mesopotamicus, Poptella brevispina, Rhinobrycon negrensis, Rhoadsia altipinna, Tetragonopterus argenteus e Triportheus albus.

[1] - reta, formando um ângulo mais fechado com a margem posterior (Fig. 31B).

Chanos chanos, Catostomus commersonnii, Olivaichthys mesembrinus, Citharinus latus, Distichodus notospilus, Hemistichodus vaillanti, Neolebias unifasciatus, Nannocharax fasciatus, Xenocharax spilurus, Apareiodon piracicabae, Parodon nasus, Saccodon wagneri, Anodus orinocensis, Curimata ocellata, Curimatopsis macrolepis, Potamorhina latior, Caenotropus labyrinthicus, Chilodus punctatus, Anostomus anostomus, Leporellus vittatus, Leporinus fasciatus, Carnegiella strigata, Gasteropelecus sternicla, Thoracocharax stellatus, Gilbertolus atratoensis, Hydrolycus tatauaia, Roestes molossus, Erythrinoidea fam. nov, Boulengerella maculata, Ctenolucius hujeta, copeina cf. guttata, Lebiasina bimaculata, Piabucina astrigata, Erythrinus erythrinus, Hoplias malabaricus, Hepsetus odoe, Arnoldichthys spilopterus, Bryconalestes longipinnis, Chalceus epakros, Characidium bahiensis, Crenuchus spilurus, Aphyocharax pusillus, Axelrodia reisei, Brittanichthys axelrodi, Bryconadenos tanaothoros, Diapoma terofali, Gnathocharax steindachneri, Gymnocorymbus ternetzi, Hemigrammus unilineatus, Hyphessobrycon compressus, Landonia latidens, Microschemobrycon casiquiare, odontostilbe pequira, Oligosarcus argenteus, Paragoniates alburnus, Piabina argentea, Probolus heterostomus, Rachoviscus graciliceps, Roeboexodon guyanensis, Salminus hilarii, Serrabrycon magoi e stygichthys typhlops. 
Chanos chanos, Catostomus commersonnii, Gymnotus aff. carapo, Citharinus latus, Distichodus notospilus, Hemistichodus vaillanti, Neolebias unifasciatus, Nannocharax fasciatus, Xenocharax spilurus, Apareiodon piracicabae, Parodon nasus, Saccodon wagneri, Anodus orinocensis, Bivibranchia fowleri, Hemiodus unimaculatus, curimata ocellata, Curimatopsis macrolepis, Potamorhina latior, Prochilodus nigricans, Semaprochilodus insignis, Caenotropus labyrinthicus, Chilodus punctatus, Anostomus anostomus, Leporellus vittatus, Leporinus fasciatus, Schizodon fasciatus, Carnegiella strigata, Gasteropelecus sternicla, Thoracocharax stellatus, Acestrorhynchus falcirostris, Boulengerella maculata, Ctenolucius hujeta, Moenkhausia xinguensis, Salminus hilarii e Triportheus albus.

\section{[1] - reta ou côncava (Fig 31B e C).}

Olivaichthys mesembrinus, Gilbertolus atratoensis, Hydrolycus tatauaia, Roestes molossus, Copeina cf. guttata, Lebiasina bimaculata, Piabucina astrigata, Erythrinus erythrinus, Hoplias malabaricus, Hepsetus odoe, Arnoldichthys spilopterus, Brycinus macrolepidotus, Bryconalestes longipinnis, Chalceus epakros, Characidium bahiensis, Crenuchus spilurus, Agoniates halecinus, Aphyocharax pusillus, Astyanax mexicanus, Atopomesus pachyodus, Axelrodia reisei, Brittanichthys axelrodi, Brycon pesu, Bryconadenos tanaothoros, Bryconamericus exodon, Bryconops alburnoides, Charax cf. leticiae, Clupeacharax cf. engrauloides, Compsura heterura, ctenobrycon hauxwellianus, Deuterodon iguape, Diapoma terofali, Galeocharax knerii, Glandulocauda melanogenys, Gnathocharax steindachneri, Gymnocorymbus ternetzi, Hemibrycon polyodon, Hemigrammus unilineatus, Hollandichthys multifasciatus, Hyphessobrycon compressus, Iguanodectes geisleri, Knodus meridae, Landonia latidens, Markiana nigripinnis, Metynnis lippincottianus, Microschemobrycon casiquiare, Myleus setiger, odontostilbe pequira, oligosarcus argenteus, Orthospinus franciscoensis, Paracheirodon axelrodi, Paragoniates alburnus, Phenacogaster pectinatus, Phenagoniates macrolepis, Piabina argentea, Piaractus mesopotamicus, Poptella brevispina, Probolus heterostomus, Rachoviscus graciliceps, Rhinobrycon negrensis, Rhoadsia altipinna, Roeboexodon guyanensis, Serrabrycon magoi, Stygichthys typhlops e Tetragonopterus argenteus.

78 - Margem ântero-dorsal do opérculo:

[ZANATA, 2000: 69; e NETTO-FERREIRA, 2006: 138]

[0] - lisa (Fig. 31C).

olivaichthys mesembrinus, Curimata ocellata, Curimatopsis macrolepis, Potamorhina latior, Carnegiella strigata, Gasteropelecus sternicla, Thoracocharax stellatus, Acestrorhynchus falcirostris, Gilbertolus atratoensis, Hydrolycus tatauaia, Roestes molossus, Boulengerella maculata, ctenolucius hujeta, Lebiasina bimaculata, Piabucina astrigata, Arnoldichthys spilopterus, Brycinus macrolepidotus, Bryconalestes longipinnis, Chalceus epakros, Characidium bahiensis, Agoniates halecinus, Aphyocharax pusillus, Astyanax mexicanus, Atopomesus pachyodus, Axelrodia reisei, Brittanichthys axelrodi, Brycon pesu, Bryconadenos tanaothoros, Bryconamericus exodon, Bryconops alburnoides, Charax cf. leticiae, Clupeacharax cf. engrauloides, compsura heterura, Ctenobrycon hauxwellianus, Deuterodon iguape, Diapoma terofali, Galeocharax knerii, Glandulocauda melanogenys, Gnathocharax steindachneri, Gymnocorymbus ternetzi, Hemibrycon polyodon, Hemigrammus unilineatus, Hollandichthys multifasciatus, Hyphessobrycon compressus, Iguanodectes geisleri, Knodus meridae, Landonia latidens, Markiana nigripinnis, Metynnis lippincottianus, Microschemobrycon casiquiare, Moenkhausia xinguensis, Myleus setiger, oligosarcus argenteus, orthospinus franciscoensis, Paracheirodon axelrodi, Paragoniates alburnus, Phenacogaster pectinatus, Phenagoniates macrolepis, Piabina argentea, Piaractus mesopotamicus, Poptella brevispina, Probolus heterostomus, Rachoviscus graciliceps, Rhinobrycon negrensis, Rhoadsia altipinna, Roeboexodon guyanensis, Salminus hilarii, Serrabrycon magoi, Stygichthys typhlops, Tetragonopterus argenteus e Triportheus albus.

\section{[1] - com processo (Fig. 31A e B).}

Chanos chanos, Catostomus commersonnii, Gymnotus aff. carapo, Citharinus latus, Distichodus notospilus, Hemistichodus vaillanti, Neolebias unifasciatus, Nannocharax fasciatus, Xenocharax spilurus, Apareiodon piracicabae, Parodon nasus, Saccodon wagneri, Anodus orinocensis, Bivibranchia fowleri, Hemiodus unimaculatus, Prochilodus nigricans, Semaprochilodus insignis, Caenotropus labyrinthicus, Chilodus punctatus, Anostomus anostomus, Leporellus vittatus, Leporinus fasciatus, Schizodon fasciatus, Erythrinoidea fam. nov, Copeina cf. guttata, Erythrinus erythrinus, Hoplias malabaricus, Hepsetus odoe, Crenuchus spilurus e Odontostilbe pequira. 
[0] - côncava (Fig. 31A).

Chanos chanos, Catostomus commersonnii, Anodus orinocensis, Hemiodus unimaculatus , Caenotropus labyrinthicus, Chilodus punctatus, Acestrorhynchus falcirostris, Bryconalestes longipinnis, Crenuchus spilurus, Astyanax mexicanus, Charax cf. leticiae, ctenobrycon hauxwellianus, Gymnocorymbus ternetzi, Hemigrammus unilineatus, orthospinus franciscoensis, Paracheirodon axelrodi, Paragoniates alburnus, Phenacogaster pectinatus e Stygichthys typhlops.

\section{[1] - reta (Fig. 31B).}

Olivaichthys mesembrinus, Gymnotus aff. carapo, Citharinus latus, Neolebias unifasciatus, Nannocharax fasciatus, Xenocharax spilurus, Bivibranchia fowleri, Curimata ocellata, Curimatopsis macrolepis, Potamorhina latior, Prochilodus nigricans, Semaprochilodus insignis, Carnegiella strigata, Gasteropelecus sternicla, Thoracocharax stellatus, Gilbertolus atratoensis, Hydrolycus tatauaia, Erythrinoidea fam. nov, Boulengerella maculata, ctenolucius hujeta, Erythrinus erythrinus, Hoplias malabaricus, Hepsetus odoe, Characidium bahiensis, Agoniates halecinus, Axelrodia reisei, Brittanichthys axelrodi, Bryconadenos tanaothoros, Gnathocharax steindachneri, Landonia latidens, Markiana nigripinnis, Oligosarcus argenteus, Rachoviscus graciliceps e Rhinobrycon negrensis. Serrabrycon magoi.

\section{[2] - convexa (Fig. 31C).}

Distichodus notospilus, Hemistichodus vaillanti, Apareiodon piracicabae, Parodon nasus, Saccodon wagneri, Anostomus anostomus, Leporellus vittatus, Leporinus fasciatus, Schizodon fasciatus, Roestes molossus, Copeina cf. guttata, Lebiasina bimaculata, Piabucina astrigata, Arnoldichthys spilopterus, Brycinus macrolepidotus, Chalceus epakros, Aphyocharax pusillus, Atopomesus pachyodus, Brycon pesu, Bryconamericus exodon, Bryconops alburnoides, Clupeacharax cf. engrauloides, Compsura heterura, Deuterodon iguape, Diapoma terofali, Galeocharax knerii, Glandulocauda melanogenys, Hemibrycon polyodon, Hollandichthys multifasciatus, Hyphessobrycon compressus, Iguanodectes geisleri, Knodus meridae, Metynnis lippincottianus, Microschemobrycon casiquiare, Moenkhausia xinguensis, Myleus setiger, odontostilbe pequira, Phenagoniates macrolepis, Piabina argentea, Piaractus mesopotamicus, Poptella brevispina, Probolus heterostomus, Rhoadsia altipinna, Roeboexodon guyanensis, Salminus hilarii, Tetragonopterus argenteus e Triportheus albus.

\section{0 - Margem anterior do opérculo:}

\section{[0] - aproximadamente em um ângulo reto com o eixo longitudinal.}

Chanos chanos, Catostomus commersonnii, Gymnotus aff. carapo, Anostomus anostomus, Leporellus vittatus, Leporinus fasciatus, Carnegiella strigata, Gasteropelecus sternicla, Thoracocharax stellatus, Acestrorhynchus falcirostris, Erythrinoidea fam. nov, Boulengerella maculata, Ctenolucius hujeta, Copeina cf. guttata, Lebiasina bimaculata, Piabucina astrigata, Erythrinus erythrinus, Hoplias malabaricus, Hepsetus odoe, Characidium bahiensis, Aphyocharax pusillus, Atopomesus pachyodus, Axelrodia reisei, Brittanichthys axelrodi, Brycon pesu, Bryconadenos tanaothoros, Bryconamericus exodon, Bryconops alburnoides, Charax cf. leticiae, clupeacharax cf. engrauloides, Compsura heterura, Ctenobrycon hauxwellianus, Deuterodon iguape, Diapoma terofali, Galeocharax knerii, Glandulocauda melanogenys, Gnathocharax steindachneri, Gymnocorymbus ternetzi, Hemibrycon polyodon, Hemigrammus unilineatus, Hyphessobrycon compressus, Iguanodectes geisleri, Knodus meridae, Landonia latidens, Markiana nigripinnis, Metynnis lippincottianus, Microschemobrycon casiquiare, Moenkhausia xinguensis, Myleus setiger, odontostilbe pequira, oligosarcus argenteus, orthospinus franciscoensis, Paracheirodon axelrodi, Paragoniates alburnus, Phenacogaster pectinatus, Phenagoniates macrolepis, Piabina argentea, Piaractus mesopotamicus, Poptella brevispina, Probolus heterostomus , Rachoviscus graciliceps, Rhinobrycon negrensis, Rhoadsia altipinna, Roeboexodon guyanensis, Salminus hilarii, Serrabrycon magoi, Stygichthys typhlops, Tetragonopterus argenteus e Triportheus albus.

\section{[1] - inclinado ântero-dorsalmente.}

Olivaichthys mesembrinus, Citharinus latus, Distichodus notospilus, Hemistichodus vaillanti, Neolebias unifasciatus, Nannocharax fasciatus, Xenocharax spilurus, 
Apareiodon piracicabae, Parodon nasus, Saccodon wagneri, Anodus orinocensis, Bivibranchia fowleri, Hemiodus unimaculatus, Curimata ocellata, Curimatopsis macrolepis, Potamorhina latior, Prochilodus nigricans, Semaprochilodus insignis, Caenotropus labyrinthicus, Chilodus punctatus, Schizodon fasciatus, Gilbertolus atratoensis, Hydrolycus tatauaia, Roestes molossus, Arnoldichthys spilopterus, Brycinus macrolepidotus, Bryconalestes longipinnis, Chalceus epakros, Crenuchus spilurus, Agoniates halecinus, Astyanax mexicanus e Hollandichthys multifasciatus.

81 - Supra-pré-opérculo:

[LUCENA, 1993: 64, modificado; BUCKUP, 1998: 27, modificado; OYAKAWA, 1998: 42, modificado e ZANATA \& VARI, 2005: 106, modificado]

[0] - ausente.

Catostomus commersonnii, Gymnotus aff. carapo, Neolebias unifasciatus, Carnegiella strigata, Gasteropelecus sternicla, Thoracocharax stellatus, Acestrorhynchus falcirostris, Erythrinoidea fam. nov, Boulengerella maculata, Ctenolucius hujeta, Copeina cf. guttata, Lebiasina bimaculata, Piabucina astrigata, Erythrinus erythrinus, Hoplias malabaricus, Characidium bahiensis, Crenuchus spilurus, Aphyocharax pusillus, Axelrodia reisei, Brittanichthys axelrodi, Bryconamericus exodon, Clupeacharax cf. engrauloides, Diapoma terofali, Glandulocauda melanogenys, Gnathocharax steindachneri, Hemigrammus unilineatus, Hollandichthys multifasciatus, Hyphessobrycon compressus, odontostilbe pequira, Paracheirodon axelrodi, Rachoviscus graciliceps e stygichthys typhlops. opérculo.

[1] - presente, só ossificação do canal conectado ao pré-

Citharinus latus, Nannocharax fasciatus, Apareiodon piracicabae, Parodon nasus, Anodus orinocensis, Bivibranchia fowleri, Hemiodus unimaculatus, Anostomus anostomus, Gilbertolus atratoensis, Roestes molossus, Bryconalestes longipinnis, Agoniates halecinus, Astyanax mexicanus, Brycon pesu, Bryconadenos tanaothoros, Bryconops alburnoides, Charax cf. leticiae, Compsura heterura, ctenobrycon hauxwellianus, Deuterodon iguape, Gymnocorymbus ternetzi, Hemibrycon polyodon, Iguanodectes geisleri, Knodus meridae, Landonia latidens, Metynnis lippincottianus, Microschemobrycon casiquiare, orthospinus franciscoensis, Paragoniates alburnus, Phenacogaster pectinatus, Phenagoniates macrolepis, Piabina argentea, Poptella brevispina, Probolus heterostomus, Rhinobrycon negrensis, Rhoadsia altipinna, Salminus hilarii, Serrabrycon magoi e Triportheus albus.

\section{[2] - presente, só ossificação do canal (autógeno).}

Chanos chanos, Olivaichthys mesembrinus, Distichodus notospilus, Hemistichodus vaillanti, Saccodon wagneri, Curimata ocellata, Curimatopsis macrolepis, Potamorhina latior, Prochilodus nigricans, Semaprochilodus insignis, Caenotropus labyrinthicus, Chilodus punctatus, Leporellus vittatus, Leporinus fasciatus, Schizodon fasciatus, Hepsetus odoe, Arnoldichthys spilopterus, Brycinus macrolepidotus, Chalceus epakros, Atopomesus pachyodus, Galeocharax knerii, Moenkhausia xinguensis, Myleus setiger, oligosarcus argenteus, Piaractus mesopotamicus, Roeboexodon guyanensis e Tetragonopterus argenteus.

\section{[3] - presente laminar.}

Xenocharax spilurus, Hydrolycus tatauaia e Markiana nigripinnis.

82 - Posição do supra-pré-opérculo:

[BUCKUP, 1998: 26, modificado; ZANATA \& VARI, 2005: 107, e NeTTO-FERREIRA, 2006: 197, modificado]

\section{[0] - não sobrepondo lateralmente ao opérculo.}

Olivaichthys mesembrinus, Hemistichodus vaillanti, Nannocharax fasciatus, Xenocharax spilurus, Gilbertolus atratoensis, Hydrolycus tatauaia, Roestes molossus, Arnoldichthys spilopterus, Agoniates halecinus, Astyanax mexicanus, Bryconadenos tanaothoros, Bryconops alburnoides, Charax cf. leticiae, Ctenobrycon hauxwellianus, Deuterodon iguape, Galeocharax knerii, Gymnocorymbus ternetzi, Hemibrycon polyodon, Iguanodectes geisleri, Landonia latidens, Markiana nigripinnis, Metynnis lippincottianus, 
Microschemobrycon casiquiare, oligosarcus argenteus, orthospinus franciscoensis, Paragoniates alburnus, Phenacogaster pectinatus, Phenagoniates macrolepis, Piabina argentea, Piaractus mesopotamicus, Poptella brevispina, Probolus heterostomus, Rhoadsia altipinna, Roeboexodon guyanensis, Salminus hilarii, Serrabrycon magoi, Tetragonopterus argenteus e Triportheus albus.

\section{[1] - sobrepondo lateralmente ao opérculo.}

Chanos chanos, Citharinus latus, Distichodus notospilus, Apareiodon piracicabae, Parodon nasus, Saccodon wagneri, Anodus orinocensis, Bivibranchia fowleri, Hemiodus unimaculatus , Curimata ocellata, Curimatopsis macrolepis, Potamorhina latior, Prochilodus nigricans, Semaprochilodus insignis, Caenotropus labyrinthicus, Chilodus punctatus, Anostomus anostomus, Leporellus vittatus, Leporinus fasciatus, Schizodon fasciatus, Hepsetus odoe, Brycinus macrolepidotus, Bryconalestes longipinnis, Chalceus epakros, Atopomesus pachyodus, Brycon pesu, Compsura heterura, Knodus meridae, Moenkhausia xinguensis, Myleus setiger e Rhinobrycon negrensis.

\section{[-] - inaplicável.}

Catostomus commersonnii, Gymnotus aff. carapo, Neolebias unifasciatus, Carnegiella strigata, Gasteropelecus sternicla, Thoracocharax stellatus, Acestrorhynchus falcirostris, Erythrinoidea fam. nov, Boulengerella maculata, ctenolucius hujeta, Copeina cf. guttata, Lebiasina bimaculata, Piabucina astrigata, Erythrinus erythrinus, Hoplias malabaricus, Characidium bahiensis, crenuchus spilurus, Aphyocharax pusillus, Axelrodia reisei, Brittanichthys axelrodi, Bryconamericus exodon, Clupeacharax cf. engrauloides, Diapoma terofali, Glandulocauda melanogenys, Gnathocharax steindachneri, Hemigrammus unilineatus, Hollandichthys multifasciatus, Hyphessobrycon compressus, odontostilbe pequira, Paracheirodon axelrodi, Rachoviscus graciliceps e Stygichthys typhlops.

[0] - reto.

Chanos chanos, Olivaichthys mesembrinus, Citharinus latus, Apareiodon piracicabae, Parodon nasus, Anodus orinocensis, Caenotropus labyrinthicus, Chilodus punctatus, Anostomus anostomus, Gilbertolus atratoensis, Hydrolycus tatauaia, Roestes molossus, Hepsetus odoe, Arnoldichthys spilopterus, Agoniates halecinus, Astyanax mexicanus, Bryconadenos tanaothoros, Bryconops alburnoides, Charax cf. leticiae, Ctenobrycon hauxwellianus, Deuterodon iguape, Galeocharax knerii, Gymnocorymbus ternetzi, Hemibrycon polyodon, Iguanodectes geisleri, Knodus meridae, Landonia latidens, Markiana nigripinnis, Metynnis lippincottianus, Microschemobrycon casiquiare, oligosarcus argenteus, Orthospinus franciscoensis, Paragoniates alburnus, Phenacogaster pectinatus, Phenagoniates macrolepis, Piabina argentea, Poptella brevispina, Probolus heterostomus, Rhinobrycon negrensis, Roeboexodon guyanensis, Salminus hilarii e Serrabrycon magoi.

\section{[1] - com curvatura posterior.}

Distichodus notospilus, Hemistichodus vaillanti, Saccodon wagneri, Bivibranchia fowleri, Hemiodus unimaculatus, Prochilodus nigricans, Semaprochilodus insignis, Leporellus vittatus, Leporinus fasciatus, schizodon fasciatus, Brycinus macrolepidotus, Bryconalestes longipinnis, Chalceus epakros, Atopomesus pachyodus, Brycon pesu, Compsura heterura, Moenkhausia xinguensis, Myleus setiger, Piaractus mesopotamicus, Rhoadsia altipinna e Triportheus albus.

\section{[2] - com curvatura anterior.}

Nannocharax fasciatus, Xenocharax spilurus e Tetragonopterus argenteus.

\section{[3] - como um "s" invertido.}

Curimata ocellata, Curimatopsis macrolepis e Potamorhina latior.

\section{[-] - inaplicável.}

Catostomus commersonnii, Gymnotus aff. carapo, Neolebias unifasciatus, Carnegiella strigata, Gasteropelecus sternicla, Thoracocharax stellatus, Acestrorhynchus falcirostris, Erythrinoidea fam. nov, Boulengerella maculata, ctenolucius hujeta, Copeina cf. guttata, Lebiasina bimaculata, Piabucina astrigata, Erythrinus erythrinus, Hoplias malabaricus, Characidium bahiensis, Crenuchus spilurus, Aphyocharax pusillus, 
Axelrodia reisei, Brittanichthys axelrodi, Bryconamericus exodon, Clupeacharax cf. engrauloides, Diapoma terofali, Glandulocauda melanogenys, Gnathocharax steindachneri, Hemigrammus unilineatus, Hollandichthys multifasciatus, Hyphessobrycon compressus, odontostilbe pequira, Paracheirodon axelrodi, Rachoviscus graciliceps e Stygichthys typhlops.

84 - Supra-opérculo:

[LUCENA, 1993: 67, VARI, 1995: 32; e BUCKUP, 1998: 27]

\section{[0] - ausente.}

Chanos chanos, Catostomus commersonnii, Olivaichthys mesembrinus, Gymnotus aff. carapo, Citharinus latus, Distichodus notospilus, Hemistichodus vaillanti, Neolebias unifasciatus, Nannocharax fasciatus, Xenocharax spilurus, Apareiodon piracicabae, Parodon nasus, Saccodon wagneri, Anodus orinocensis, Bivibranchia fowleri, Hemiodus unimaculatus, Curimata ocellata, Curimatopsis macrolepis, Potamorhina latior, Prochilodus nigricans, Semaprochilodus insignis, Caenotropus labyrinthicus, Chilodus punctatus, Anostomus anostomus, Leporellus vittatus, Leporinus fasciatus, Schizodon fasciatus, Carnegiella strigata, Gasteropelecus sternicla, Thoracocharax stellatus, Acestrorhynchus falcirostris, Gilbertolus atratoensis, Hydrolycus tatauaia, Roestes molossus, Erythrinoidea fam. nov, Boulengerella maculata, Ctenolucius hujeta, Copeina cf. guttata, Lebiasina bimaculata, Piabucina astrigata, Arnoldichthys spilopterus, Brycinus macrolepidotus, Bryconalestes longipinnis, Chalceus epakros, Characidium bahiensis, Crenuchus spilurus, Agoniates halecinus, Aphyocharax pusillus, Astyanax mexicanus, Atopomesus pachyodus, Axelrodia reisei, Brittanichthys axelrodi, Brycon pesu, Bryconadenos tanaothoros, Bryconamericus exodon, Bryconops alburnoides, Charax cf. leticiae, Compsura heterura, Ctenobrycon hauxwellianus, Deuterodon iguape, Diapoma terofali, Galeocharax knerii, Glandulocauda melanogenys, Gnathocharax steindachneri, Gymnocorymbus ternetzi, Hemibrycon polyodon, Hemigrammus unilineatus, Hollandichthys multifasciatus, Hyphessobrycon compressus, Iguanodectes geisleri, Knodus meridae, Landonia latidens, Markiana nigripinnis, Metynnis lippincottianus, Microschemobrycon casiquiare, Moenkhausia xinguensis, Myleus setiger, Odontostilbe pequira, oligosarcus argenteus, Paracheirodon axelrodi, Paragoniates alburnus, Phenacogaster pectinatus, Phenagoniates macrolepis, Piabina argentea, Piaractus mesopotamicus, Poptella brevispina, Probolus heterostomus, Rachoviscus graciliceps, Rhinobrycon negrensis, Rhoadsia altipinna, Roeboexodon guyanensis, Salminus hilarii, Serrabrycon magoi, Stygichthys typhlops, Tetragonopterus argenteus e Triportheus albus.

\section{[1] - presente.}

Erythrinus erythrinus, Hoplias malabaricus e Hepsetus odoe.

\section{[-] - inaplicável.}

Clupeacharax cf. engrauloides e Orthospinus franciscoensis.

\subsubsection{Neurocrânio}

85 - Processos ântero-ventrais do mesetmóide:

[FINK \& FINK, 1981: 3; LUCENA, 1993: 1 modificado; BUCKUP, 1998: 1 modificado; NetTo-FerReIrA, 2006: 27 modificado]

\section{[0] - ausentes (Figs. 19, 32 e 33).}

Chanos chanos, Catostomus commersonnii, Bivibranchia fowleri, Hemiodus unimaculatus, Curimata ocellata, Curimatopsis macrolepis, Potamorhina latior, Caenotropus labyrinthicus, Chilodus punctatus, Anostomus anostomus, Leporellus vittatus, Leporinus fasciatus, Schizodon fasciatus, Carnegiella strigata, Gasteropelecus sternicla, Thoracocharax stellatus, Acestrorhynchus falcirostris, Gilbertolus atratoensis, Hydrolycus tatauaia, Roestes molossus, Boulengerella maculata, ctenolucius hujeta, Copeina cf. guttata, Lebiasina bimaculata, Piabucina astrigata, Erythrinus erythrinus, Hoplias malabaricus, Hepsetus odoe, Arnoldichthys spilopterus, Brycinus macrolepidotus, Bryconalestes longipinnis, Chalceus epakros, Agoniates halecinus, Aphyocharax pusillus, Astyanax mexicanus, Atopomesus pachyodus, Axelrodia reisei, Brittanichthys axelrodi, Brycon pesu, Bryconadenos tanaothoros, Bryconamericus exodon, Bryconops alburnoides, Clupeacharax cf. engrauloides, Compsura heterura, Ctenobrycon hauxwellianus, Deuterodon iguape, Diapoma terofali, Galeocharax knerii, Glandulocauda melanogenys, Gnathocharax steindachneri, Gymnocorymbus ternetzi, Hemibrycon polyodon, Hemigrammus unilineatus, 
Hollandichthys multifasciatus, Hyphessobrycon compressus, Iguanodectes geisleri, Knodus meridae, Landonia latidens, Markiana nigripinnis, Metynnis lippincottianus, Microschemobrycon casiquiare, Moenkhausia xinguensis, Myleus setiger, Odontostilbe pequira, Oligosarcus argenteus, orthospinus franciscoensis, Paracheirodon axelrodi, Paragoniates alburnus, Phenagoniates macrolepis, Piabina argentea, Piaractus mesopotamicus, Poptella brevispina, Probolus heterostomus, Rachoviscus graciliceps, Rhinobrycon negrensis, Rhoadsia altipinna, Roeboexodon guyanensis, Salminus hilarii, Serrabrycon magoi, Stygichthys typhlops, Tetragonopterus argenteus e Triportheus albus.

$34)$.

[1] - presentes, encaixando-se nos pré-maxilares (Figs. 17, 18,

Gymnotus aff. Carapo, Citharinus latus, Distichodus notospilus, Hemistichodus vaillanti, Neolebias unifasciatus, Nannocharax fasciatus, Xenocharax spilurus, Apareiodon piracicabae, Parodon nasus, Saccodon wagneri, Anodus orinocensis, Prochilodus nigricans, Semaprochilodus insignis, Erythrinoidea fam. nov, Characidium bahiensis, Crenuchus spilurus, Charax cf. leticiae e Phenacogaster pectinatus.

[?] - indeterminado.

Olivaichthys mesembrinus.

86 - Processos ântero-laterais do mesetmóide (asa lateral do mesetmóide sensu WEITZMAN, 1962):

[LUCENA, 1993: 3 modificado; BUCKUP, 1998: 2 modificado; ZANATA, 2000: 11; ZANATA \& VARI, 2005: 23 modificado; NETTO-FERREIRA, 2006: 31 modificado]

(Minimamente conectado).

$$
\text { [0] - ausente. }
$$

Distichodus notospilus, Nannocharax fasciatus, Apareiodon piracicabae, Parodon nasus, Saccodon wagneri, Bivibranchia fowleri, Curimatopsis macrolepis, Prochilodus nigricans, Semaprochilodus insignis, Caenotropus labyrinthicus, Chilodus punctatus, Anostomus anostomus, Leporellus vittatus, Leporinus fasciatus, Schizodon fasciatus, Erythrinoidea fam. nov, Copeina cf. guttata, Lebiasina bimaculata, Piabucina astrigata, Erythrinus erythrinus, Arnoldichthys spilopterus e Characidium bahiensis.

\section{[1] - pequeno, quase não distinto do restante do mesetmóide.}

Anodus orinocensis, Curimata ocellata, Potamorhina latior, Gilbertolus atratoensis, Hydrolycus tatauaia, Roestes molossus, Boulengerella maculata, Ctenolucius hujeta, Hepsetus odoe, Chalceus epakros, Brittanichthys axelrodi, Galeocharax knerii, oligosarcus argenteus e Salminus hilarii.

\section{[2] - grande (Figs. 17, 18 e 19).}

Chanos chanos, Olivaichthys mesembrinus, Gymnotus aff. carapo, Citharinus latus, Neolebias unifasciatus, Xenocharax spilurus, Carnegiella strigata, Gasteropelecus sternicla, Thoracocharax stellatus, Acestrorhynchus falcirostris, Hoplias malabaricus, Brycinus macrolepidotus, Bryconalestes longipinnis, Crenuchus spilurus, Agoniates halecinus, Aphyocharax pusillus, Astyanax mexicanus, Atopomesus pachyodus, Axelrodia reisei, Brycon pesu, Bryconadenos tanaothoros, Bryconamericus exodon, Bryconops alburnoides, Charax cf. leticiae, Clupeacharax cf. engrauloides, Compsura heterura, ctenobrycon hauxwellianus, Deuterodon iguape, Diapoma terofali, Glandulocauda melanogenys, Gnathocharax steindachneri, Gymnocorymbus ternetzi, Hemibrycon polyodon Hemigrammus unilineatus, Hollandichthys multifasciatus, Hyphessobrycon compressus, Iguanodectes geisleri, Knodus meridae, Landonia latidens, Markiana nigripinnis, Metynnis lippincottianus, Microschemobrycon casiquiare, Moenkhausia xinguensis, Myleus setiger, odontostilbe pequira, Orthospinus franciscoensis, Paracheirodon axelrodi, Paragoniates alburnus, Phenacogaster pectinatus, Phenagoniates macrolepis, Piabina argentea, Piaractus mesopotamicus, Poptella brevispina, Probolus heterostomus, Rachoviscus graciliceps, Rhinobrycon negrensis, Rhoadsia altipinna, Roeboexodon guyanensis, Serrabrycon magoi, Stygichthys typhlops, Tetragonopterus argenteus e Triportheus albus.

\section{[?] - indeterminado.}

Catostomus commersonnii, Hemistichodus vaillanti e Hemiodus unimaculatus. 
87 - Projeção ântero-mediana do mesetmóide:

[OYAKAWA, 1998: 20 modificado]

[0] - ausente.

Olivaichthys mesembrinus, Gymnotus aff. carapo, Citharinus latus, Hemistichodus vaillanti, Nannocharax fasciatus, Anodus orinocensis, Bivibranchia fowleri, Curimata ocellata, Curimatopsis macrolepis, Potamorhina latior e Compsura heterura.

17).

[1] - pequena, não separando totalmente os pré-maxilares (Fig.

Chanos chanos, Catostomus commersonnii, Distichodus notospilus, Neolebias unifasciatus, Apareiodon piracicabae, Parodon nasus, Saccodon wagneri, Hemiodus unimaculatus, Prochilodus nigricans, Semaprochilodus insignis, Caenotropus labyrinthicus, Chilodus punctatus, Anostomus anostomus, Hydrolycus tatauaia, Roestes molossus, Erythrinoidea fam. nov, Lebiasina bimaculata, Piabucina astrigata, Erythrinus erythrinus, Hoplias malabaricus, Arnoldichthys spilopterus, Brycinus macrolepidotus, Bryconalestes longipinnis, chalceus epakros, Characidium bahiensis, crenuchus spilurus, Brittanichthys axelrodi, Brycon pesu, Ctenobrycon hauxwellianus, Microschemobrycon casiquiare, Myleus setiger, Odontostilbe pequira, Paracheirodon axelrodi, Paragoniates alburnus, Phenacogaster pectinatus, Phenagoniates macrolepis, Piaractus mesopotamicus, Poptella brevispina, Probolus heterostomus, Rachoviscus graciliceps, Rhinobrycon negrensis e Rhoadsia altipinna.

[2] - grande, separando totalmente os pré-maxilares (Fig. 19).

Xenocharax spilurus, Leporellus vittatus, Leporinus fasciatus, schizodon fasciatus, Carnegiella strigata, Gasteropelecus sternicla, Thoracocharax stellatus, Acestrorhynchus falcirostris, Gilbertolus atratoensis, Boulengerella maculata, Ctenolucius hujeta, Copeina cf. guttata, Hepsetus odoe, Agoniates halecinus, Aphyocharax pusillus, Astyanax mexicanus, Atopomesus pachyodus, Axelrodia reisei, Bryconadenos tanaothoros, Bryconamericus exodon, Bryconops alburnoides, Charax cf. leticiae, Clupeacharax cf. engrauloides, Deuterodon iguape, Diapoma terofali, Galeocharax knerii, Glandulocauda melanogenys, Gnathocharax steindachneri, Gymnocorymbus ternetzi, Hemibrycon polyodon, Hemigrammus unilineatus, Hollandichthys multifasciatus, Hyphessobrycon compressus, Iguanodectes geisleri, Knodus meridae, Landonia latidens, Markiana nigripinnis, Metynnis lippincottianus, Moenkhausia xinguensis, oligosarcus argenteus, Orthospinus franciscoensis, Piabina argentea, Roeboexodon guyanensis, Salminus hilarii, Serrabrycon magoi, Stygichthys typhlops, Tetragonopterus argenteus e Triportheus albus.

88 - Orientação da projeção ântero-mediana do mesetmóide:

[VARI \& HAROLD, 2001: 35 modificado]

(Minimamente conectado).

[0] - contínua com a porção posterior do mesetmóide (Fig. 34).

Chanos chanos, Catostomus commersonnii, Citharinus latus, Distichodus notospilus, Neolebias unifasciatus, Xenocharax spilurus, Apareiodon piracicabae, Parodon nasus, Hemiodus unimaculatus, Prochilodus nigricans, Semaprochilodus insignis, Anostomus anostomus, Carnegiella strigata, Gasteropelecus sternicla, Thoracocharax stellatus, Acestrorhynchus falcirostris, Gilbertolus atratoensis, Hydrolycus tatauaia, Roestes molossus, Boulengerella maculata, Ctenolucius hujeta, Copeina cf. guttata, Piabucina astrigata, Hoplias malabaricus, Hepsetus odoe, Chalceus epakros, Agoniates halecinus, Brycon pesu, Clupeacharax cf. engrauloides, Ctenobrycon hauxwellianus, Galeocharax knerii, Gnathocharax steindachneri, odontostilbe pequira, oligosarcus argenteus, orthospinus franciscoensis, Rachoviscus graciliceps e Rhoadsia altipinna.

[1] - inclinada ventralmente (Fig. 32).

Caenotropus labyrinthicus, Chilodus punctatus, Leporellus vittatus, Leporinus fasciatus, Schizodon fasciatus, Erythrinoidea fam. nov, Lebiasina bimaculata, Erythrinus erythrinus, Arnoldichthys spilopterus, Brycinus macrolepidotus, Bryconalestes longipinnis, Characidium bahiensis, Crenuchus spilurus, Aphyocharax pusillus, Astyanax mexicanus, Brittanichthys axelrodi, Bryconadenos tanaothoros, Bryconops alburnoides, Charax cf. leticiae, Deuterodon iguape, Diapoma terofali, Gymnocorymbus ternetzi, Hemibrycon polyodon, Hemigrammus unilineatus, Hollandichthys multifasciatus, 
Hyphessobrycon compressus, Iguanodectes geisleri, Markiana nigripinnis, Metynnis lippincottianus, Microschemobrycon casiquiare, Moenkhausia xinguensis, Myleus setiger, Paracheirodon axelrodi, Paragoniates alburnus, Phenacogaster pectinatus, Phenagoniates macrolepis, Poptella brevispina, Probolus heterostomus, Rhinobrycon negrensis, Salminus hilarii, Serrabrycon magoi, Stygichthys typhlops, Tetragonopterus argenteus e Triportheus albus.

[2] - muito inclinada ventralmente, quase $99^{\circ}$ com a porção posterior do mesetmóide.

Saccodon wagneri, Atopomesus pachyodus, Axelrodia reisei, Bryconamericus exodon, Glandulocauda melanogenys, Knodus meridae, Landonia latidens, Piabina argentea, Piaractus mesopotamicus, Roeboexodon guyanensis.

\section{[-] - inaplicável.}

Olivaichthys mesembrinus, Gymnotus aff. carapo, Hemistichodus vaillanti, Nannocharax fasciatus, Anodus orinocensis, Bivibranchia fowleri, Curimata ocellata, Curimatopsis macrolepis, Potamorhina latior e Compsura heterura.

89 - Articulação anterior entre o mesetmóide e vômer:

[BUCKUP, 1998: 4 modificado]

[0] - articulação reta, vômer aproximadamente plano (Fig. 35).

olivaichthys mesembrinus, Gymnotus aff. carapo, Saccodon wagneri, Curimata ocellata, Curimatopsis macrolepis, Potamorhina latior, Caenotropus labyrinthicus, Chilodus punctatus, Anostomus anostomus, Leporellus vittatus, Schizodon fasciatus, Carnegiella strigata, Gasteropelecus sternicla, Thoracocharax stellatus, Acestrorhynchus falcirostris, Gilbertolus atratoensis, Hydrolycus tatauaia, Roestes molossus, Erythrinoidea fam. nov, Boulengerella maculata, Ctenolucius hujeta, copeina cf. guttata, Lebiasina bimaculata, Piabucina astrigata, Erythrinus erythrinus, Hepsetus odoe, Arnoldichthys spilopterus, Brycinus macrolepidotus, Bryconalestes longipinnis, Chalceus epakros, Agoniates halecinus, Astyanax mexicanus, Axelrodia reisei, Brycon pesu, Bryconadenos tanaothoros, Bryconamericus exodon, Bryconops alburnoides, Clupeacharax cf. engrauloides, Ctenobrycon hauxwellianus, Deuterodon iguape, Diapoma terofali, Galeocharax knerii, Glandulocauda melanogenys, Gnathocharax steindachneri, Gymnocorymbus ternetzi, Hemibrycon polyodon, Hemigrammus unilineatus, Hollandichthys multifasciatus, Hyphessobrycon compressus, Iguanodectes geisleri, Knodus meridae, Landonia latidens, Markiana nigripinnis, Metynnis lippincottianus, Microschemobrycon casiquiare, Moenkhausia xinguensis, Myleus setiger, Odontostilbe pequira, oligosarcus argenteus, orthospinus franciscoensis, Paracheirodon axelrodi, Paragoniates alburnus, Phenacogaster pectinatus, Phenagoniates macrolepis, Piabina argentea, Piaractus mesopotamicus, Poptella brevispina, Probolus heterostomus, Rachoviscus graciliceps, Rhinobrycon negrensis, Rhoadsia altipinna, Roeboexodon guyanensis, Salminus hilarii, Serrabrycon magoi, Tetragonopterus argenteus e Triportheus albus.

\section{[1] - articulação curva, vômer côncavo.}

Anodus orinocensis, Hemiodus unimaculatus, Leporinus fasciatus, Hoplias malabaricus, Characidium bahiensis, Aphyocharax pusillus, Atopomesus pachyodus, Brittanichthys axelrodi, Charax cf. leticiae, Compsura heterura e Stygichthys typhlops.

[2] - vômer muito côncavo, dando a impressão de dois pontos de articulação laterais (Fig. 36).

Citharinus latus, Distichodus notospilus, Hemistichodus vaillanti, Neolebias unifasciatus, Nannocharax fasciatus, Xenocharax spilurus, Apareiodon piracicabae, Parodon nasus e Bivibranchia fowleri.

[3] - vômer côncavo, com projeção mediana.

Prochilodus nigricans, Semaprochilodus insignis e Crenuchus spilurus.

[-] - inaplicável.

Chanos chanos e Catostomus commersonnii. 
[FINK \& FINK, 1981: 2]

[0] - vômer mais anterior que o mesetmóide.

Chanos chanos e Catostomus commersonnii.

[1] - mesetmóide mais anterior que o vômer (Figs. 32, 33 e 34).

Olivaichthys mesembrinus, Gymnotus aff. carapo, Citharinus latus, Distichodus notospilus, Hemistichodus vaillanti, Neolebias unifasciatus, Nannocharax fasciatus, Xenocharax spilurus, Apareiodon piracicabae, Parodon nasus, Saccodon wagneri, Anodus orinocensis, Bivibranchia fowleri, Hemiodus unimaculatus, Curimata ocellata, Curimatopsis macrolepis, Potamorhina latior, Prochilodus nigricans, Semaprochilodus insignis, Caenotropus labyrinthicus, Chilodus punctatus, Anostomus anostomus, Leporellus vittatus, Leporinus fasciatus, Schizodon fasciatus, Carnegiella strigata, Gasteropelecus sternicla, Thoracocharax stellatus, Acestrorhynchus falcirostris, Gilbertolus atratoensis, Hydrolycus tatauaia, Roestes molossus, Erythrinoidea fam. nov, Boulengerella maculata, Ctenolucius hujeta, Copeina cf. guttata, Lebiasina bimaculata, Piabucina astrigata, Erythrinus erythrinus, Hoplias malabaricus, Hepsetus odoe, Arnoldichthys spilopterus, Brycinus macrolepidotus, Bryconalestes longipinnis, Chalceus epakros, Characidium bahiensis, Crenuchus spilurus, Agoniates halecinus, Aphyocharax pusillus, Astyanax mexicanus, Atopomesus pachyodus, Axelrodia reisei, Brittanichthys axelrodi, Brycon pesu, Bryconadenos tanaothoros, Bryconamericus exodon, Bryconops alburnoides, Charax cf. leticiae, Clupeacharax cf. engrauloides, compsura heterura, Ctenobrycon hauxwellianus, Deuterodon iguape, Diapoma terofali, Galeocharax knerii, Glandulocauda melanogenys, Gnathocharax steindachneri, Gymnocorymbus ternetzi, Hemibrycon polyodon, Hemigrammus unilineatus, Hollandichthys multifasciatus, Hyphessobrycon compressus, Iguanodectes geisleri, Knodus meridae, Landonia latidens, Markiana nigripinnis, Metynnis lippincottianus, Microschemobrycon casiquiare, Moenkhausia xinguensis, Myleus setiger, Odontostilbe pequira, Oligosarcus argenteus, orthospinus franciscoensis, Paracheirodon axelrodi, Paragoniates alburnus, Phenacogaster pectinatus, Phenagoniates macrolepis, Piabina argentea, Piaractus mesopotamicus, Poptella brevispina, Probolus heterostomus, Rachoviscus graciliceps, Rhinobrycon negrensis, Rhoadsia altipinna, Roeboexodon guyanensis, Salminus hilarii, Serrabrycon magoi, Stygichthys typhlops, Tetragonopterus argenteus e Triportheus albus.

91 - Lamelas divergentes ventrais do mesetmóide:

[LUCENA, 1993: 0; BUCKUP, 1998: 3; TOLEDO-PIZA, 2000:8; ZANATA \& VARI, 2005: 22; NetTo-Ferreira, 2006: 28]

\section{[0] - desenvolvidas (Fig. 32 e Fig. 33)}

Olivaichthys mesembrinus, Acestrorhynchus falcirostris, Gilbertolus atratoensis, Hydrolycus tatauaia, Roestes molossus, Erythrinoidea fam. nov, Erythrinus erythrinus, Astyanax mexicanus, Atopomesus pachyodus, Axelrodia reisei, Brycon pesu, Bryconops alburnoides, Charax cf. leticiae, Compsura heterura, ctenobrycon hauxwellianus, Deuterodon iguape, Diapoma terofali, Galeocharax knerii, Gnathocharax steindachneri, Gymnocorymbus ternetzi, Hemibrycon polyodon, Hollandichthys multifasciatus, Landonia latidens, Markiana nigripinnis, Metynnis lippincottianus, Microschemobrycon casiquiare, Moenkhausia xinguensis, Oligosarcus argenteus, Orthospinus franciscoensis, Piaractus mesopotamicus, Poptella brevispina, Probolus heterostomus, Rachoviscus graciliceps, Rhinobrycon negrensis, Rhoadsia altipinna, Roeboexodon guyanensis, Salminus hilarii, Serrabrycon magoi, Tetragonopterus argenteus e Triportheus albus.

\section{[1] - curtas ou ausentes (Fig. 34).}

Chanos chanos, Catostomus commersonnii, Gymnotus aff. carapo, Citharinus latus, Distichodus notospilus, Hemistichodus vaillanti, Neolebias unifasciatus, Nannocharax fasciatus, Xenocharax spilurus, Apareiodon piracicabae, Parodon nasus, Saccodon wagneri, Anodus orinocensis, Bivibranchia fowleri, Hemiodus unimaculatus, Curimata ocellata, Curimatopsis macrolepis, Potamorhina latior, Prochilodus nigricans, Semaprochilodus insignis, Caenotropus labyrinthicus, Chilodus punctatus, Anostomus anostomus, Leporellus vittatus, Leporinus fasciatus, Schizodon fasciatus, Carnegiella strigata, Gasteropelecus sternicla, Thoracocharax stellatus, Boulengerella maculata, Ctenolucius hujeta, Copeina cf. guttata, Lebiasina bimaculata, Piabucina astrigata, Hoplias malabaricus, Hepsetus odoe, Arnoldichthys spilopterus, Brycinus macrolepidotus, Bryconalestes longipinnis, Chalceus epakros, Characidium bahiensis, crenuchus spilurus, Agoniates halecinus, Aphyocharax pusillus, Brittanichthys axelrodi, Bryconadenos tanaothoros, Bryconamericus exodon, Clupeacharax cf. engrauloides, Glandulocauda melanogenys, Hemigrammus unilineatus, Hyphessobrycon compressus, Iguanodectes geisleri, Knodus meridae, Myleus setiger, Odontostilbe pequira, Paracheirodon axelrodi, Paragoniates alburnus, 
Phenacogaster pectinatus, Phenagoniates macrolepis, Piabina argêntea e Stygichthys typhlops.

92 - Crista óssea longitudinal da face dorsal do vômer:

[LucenA, 1993: 4; OyakaWA, 1998: 14; Netto-FerReira, 2006, 35]

\section{[0] - muito curta ou ausente (Fig. 32).}

Chanos chanos, Catostomus commersonnii, olivaichthys mesembrinus, Gymnotus aff. carapo, Nannocharax fasciatus, Curimata ocellata, Curimatopsis macrolepis, Potamorhina latior, Caenotropus labyrinthicus, Chilodus punctatus, Anostomus anostomus, Carnegiella strigata, Gasteropelecus sternicla, Acestrorhynchus falcirostris, Boulengerella maculata, Ctenolucius hujeta, Copeina cf. guttata, Hepsetus odoe, Characidium bahiensis, Crenuchus spilurus, Astyanax mexicanus, Atopomesus pachyodus, Axelrodia reisei, Brittanichthys axelrodi, Bryconamericus exodon, Bryconops alburnoides, Charax cf. leticiae, Ctenobrycon hauxwellianus, Deuterodon iguape, Diapoma terofali, Gnathocharax steindachneri, Hemibrycon polyodon, Hemigrammus unilineatus, Hollandichthys multifasciatus, Hyphessobrycon compressus, Iguanodectes geisleri, Knodus meridae, Markiana nigripinnis, Microschemobrycon casiquiare, Odontostilbe pequira, Oligosarcus argenteus, Paracheirodon axelrodi, Paragoniates alburnus, Phenacogaster pectinatus, Poptella brevispina, Probolus heterostomus, Rachoviscus graciliceps, Rhinobrycon negrensis, Rhoadsia altipinna, Roeboexodon guyanensis, Serrabrycon magoi, Stygichthys typhlops e Tetragonopterus argenteus.

[1] - desenvolvida, quase atingindo a porção ventral do mesetmóide (Fig. 34).

Distichodus notospilus, Neolebias unifasciatus, Xenocharax spilurus, Apareiodon piracicabae, Parodon nasus, Saccodon wagneri, Anodus orinocensis, Bivibranchia fowleri, Hemiodus unimaculatus, Prochilodus nigricans, Semaprochilodus insignis, Leporellus vittatus, Leporinus fasciatus, Schizodon fasciatus, Thoracocharax stellatus, Gilbertolus atratoensis, Hydrolycus tatauaia, Lebiasina bimaculata, Piabucina astrigata, Erythrinus erythrinus, Hoplias malabaricus, Brycinus macrolepidotus, Bryconalestes longipinnis, Chalceus epakros, Agoniates halecinus, Aphyocharax pusillus, Brycon pesu, Bryconadenos tanaothoros, Clupeacharax cf. engrauloides, Compsura heterura, Galeocharax knerii, Glandulocauda melanogenys, Gymnocorymbus ternetzi, Metynnis lippincottianus, Myleus setiger, Phenagoniates macrolepis, Piabina argentea, Salminus hilarii e Triportheus albus.

\section{[-] - inaplicável.}

Citharinus latus, Hemistichodus vaillanti, Roestes molossus, Erythrinoidea fam. nov, Arnoldichthys spilopterus, Landonia latidens, Moenkhausia xinguensis, orthospinus franciscoensis e Piaractus mesopotamicus.

93 - Vômer:

[ZANATA, 2000: 12; MOREIRA, 2002: 32 modificado]

\section{[0] - porção anterior e posterior do vômer contínuas.}

Chanos chanos, Olivaichthys mesembrinus, Citharinus latus, Distichodus notospilus, Hemistichodus vaillanti, Neolebias unifasciatus, Nannocharax fasciatus, Apareiodon piracicabae, Parodon nasus, Saccodon wagneri, Bivibranchia fowleri, Prochilodus nigricans, Acestrorhynchus falcirostris, Hepsetus odoe, Characidium bahiensis, Brittanichthys axelrodi, Bryconadenos tanaothoros, Hyphessobrycon compressus, Myleus setiger e Rhoadsia altipinna.

\section{[1] - porção anterior muito mais larga que a porção posterior, formando discontinuidade lateral.}

Catostomus commersonnii, Gymnotus aff. carapo, Xenocharax spilurus, Anodus orinocensis, Hemiodus unimaculatus, Curimata ocellata, Curimatopsis macrolepis, Potamorhina latior, Semaprochilodus insignis, Caenotropus labyrinthicus, Chilodus punctatus, Anostomus anostomus, Leporellus vittatus, Leporinus fasciatus, schizodon fasciatus, Carnegiella strigata, Gasteropelecus sternicla, Thoracocharax stellatus, Gilbertolus atratoensis, Erythrinoidea fam. nov, Boulengerella maculata, Ctenolucius hujeta, Copeina cf. guttata, Lebiasina bimaculata, Piabucina astrigata, Erythrinus erythrinus, Hoplias malabaricus, Arnoldichthys spilopterus, Brycinus macrolepidotus, Bryconalestes longipinnis, Chalceus epakros, Crenuchus spilurus, Agoniates halecinus, Aphyocharax pusillus, Astyanax 
mexicanus, Atopomesus pachyodus, Axelrodia reisei, Brycon pesu, Bryconamericus exodon, Bryconops alburnoides, Charax cf. leticiae, Clupeacharax cf. engrauloides, Compsura heterura, Ctenobrycon hauxwellianus, Deuterodon iguape, Diapoma terofali, Galeocharax knerii, Glandulocauda melanogenys, Gnathocharax steindachneri, Gymnocorymbus ternetzi, Hemibrycon polyodon, Hemigrammus unilineatus, Hollandichthys multifasciatus, Iguanodectes geisleri, Knodus meridae, Landonia latidens, Markiana nigripinnis, Metynnis lippincottianus, Microschemobrycon casiquiare, Moenkhausia xinguensis, odontostilbe pequira, Oligosarcus argenteus, orthospinus franciscoensis, Paracheirodon axelrodi, Paragoniates alburnus, Phenacogaster pectinatus, Phenagoniates macrolepis, Piabina argentea, Piaractus mesopotamicus, Poptella brevispina, Probolus heterostomus Rachoviscus graciliceps, Rhinobrycon negrensis, Roeboexodon guyanensis, Salminus hilarii, Serrabrycon magoi, Stygichthys typhlops, Tetragonopterus argenteus e Triportheus albus.

\section{[-] - inaplicável.}

Hydrolycus tatauaia e Roestes molossus.

\section{4 - Face ventral do vômer:}

$$
\text { [0] - lisa. }
$$

Chanos chanos, Catostomus commersonnii, olivaichthys mesembrinus, Gymnotus aff. carapo, Citharinus latus, Distichodus notospilus, Hemistichodus vaillanti, Neolebias unifasciatus, Nannocharax fasciatus, Xenocharax spilurus, Apareiodon piracicabae, Parodon nasus, Saccodon wagneri, Anodus orinocensis, Bivibranchia fowleri, Hemiodus unimaculatus, Acestrorhynchus falcirostris, Gilbertolus atratoensis, Hydrolycus tatauaia, Roestes molossus, Erythrinoidea fam. nov, Copeina cf. guttata, Lebiasina bimaculata, Piabucina astrigata, Erythrinus erythrinus, Hepsetus odoe, Arnoldichthys spilopterus, Brycinus macrolepidotus, Bryconalestes longipinnis, chalceus epakros, Characidium bahiensis, Crenuchus spilurus, Agoniates halecinus, Aphyocharax pusillus, Astyanax mexicanus, Atopomesus pachyodus, Axelrodia reisei, Brittanichthys axelrodi, Brycon pesu, Bryconadenos tanaothoros, Bryconamericus exodon, Bryconops alburnoides, Charax cf. leticiae, Clupeacharax cf. engrauloides, Compsura heterura, Ctenobrycon hauxwellianus, Deuterodon iguape, Diapoma terofali, Galeocharax knerii, Glandulocauda melanogenys, Gnathocharax steindachneri, Gymnocorymbus ternetzi, Hemibrycon polyodon , Hemigrammus unilineatus, Hollandichthys multifasciatus, Hyphessobrycon compressus, Iguanodectes geisleri, Knodus meridae, Landonia latidens, Markiana nigripinnis, Microschemobrycon casiquiare, Moenkhausia xinguensis, Myleus setiger, odontostilbe pequira, oligosarcus argenteus, orthospinus franciscoensis, Paracheirodon axelrodi, Paragoniates alburnus, Phenacogaster pectinatus, Phenagoniates macrolepis, Piabina argentea, Piaractus mesopotamicus, Poptella brevispina, Probolus heterostomus , Rachoviscus graciliceps, Rhinobrycon negrensis, Rhoadsia altipinna, Roeboexodon guyanensis, Salminus hilarii, Serrabrycon magoi, Stygichthys typhlops, Tetragonopterus argenteus e Triportheus albus.

\section{[1] - com crista longitudinal.}

Curimata ocellata, Curimatopsis macrolepis, Potamorhina latior, Prochilodus nigricans, Semaprochilodus insignis, Caenotropus labyrinthicus, Chilodus punctatus, Anostomus anostomus, Leporellus vittatus, Leporinus fasciatus, Schizodon fasciatus, Carnegiella strigata, Gasteropelecus sternicla, Thoracocharax stellatus, Boulengerella maculata, ctenolucius hujeta, Hoplias malabaricus e Metynnis lippincottianus.

95 - Paresfenóide:

[ZANATA, 2000: 27 modificado; ZANATA \& VARI, 2005: 41 modificado; NetToFERREIRA, 2006: 39 modificado]

\section{[0] - reto em toda a sua extensão.}

Catostomus commersonnii, Olivaichthys mesembrinus, Gymnotus aff. carapo, Nannocharax fasciatus, Apareiodon piracicabae, Parodon nasus, Saccodon wagneri, Anostomus anostomus, Leporellus vittatus, Leporinus fasciatus, Acestrorhynchus falcirostris, Erythrinoidea fam. nov, Boulengerella maculata, Ctenolucius hujeta, Piabucina astrigata, Erythrinus erythrinus, Hoplias malabaricus, Hepsetus odoe, Crenuchus spilurus, Charax cf. leticiae, Galeocharax knerii, Salminus hilarii e Stygichthys typhlops.

[1] - reto apenas na região da órbita (Fig. 34). 
Chanos chanos, Citharinus latus, Distichodus notospilus, Xenocharax spilurus, Carnegiella strigata, Gasteropelecus sternicla, Thoracocharax stellatus, Copeina cf. guttata, Lebiasina bimaculata, Aphyocharax pusillus, Hollandichthys multifasciatus, Knodus meridae, Phenagoniates macrolepis e Roeboexodon guyanensis.

33)

[2] - curvo ventralmente em toda sua extensão (Fig. 32 e Fig.

Hemistichodus vaillanti, Neolebias unifasciatus, Anodus orinocensis, Bivibranchia fowleri, Hemiodus unimaculatus, Schizodon fasciatus, Gilbertolus atratoensis, Hydrolycus tatauaia, Roestes molossus, Arnoldichthys spilopterus, Brycinus macrolepidotus, Bryconalestes longipinnis, Chalceus epakros, Characidium bahiensis, Agoniates halecinus, Astyanax mexicanus, Atopomesus pachyodus, Axelrodia reisei, Brittanichthys axelrodi, Brycon pesu, Bryconadenos tanaothoros, Bryconamericus exodon, Bryconops alburnoides, Clupeacharax cf. engrauloides, Compsura heterura, Ctenobrycon hauxwellianus, Deuterodon iguape, Diapoma terofali, Glandulocauda melanogenys, Gnathocharax steindachneri, Gymnocorymbus ternetzi, Hemibrycon polyodon, Hemigrammus unilineatus, Hyphessobrycon compressus, Iguanodectes geisleri, Landonia latidens, Markiana nigripinnis, Metynnis lippincottianus, Microschemobrycon casiquiare, Moenkhausia xinguensis, Myleus setiger, odontostilbe pequira, oligosarcus argenteus, orthospinus franciscoensis, Paracheirodon axelrodi, Paragoniates alburnus, Phenacogaster pectinatus, Piabina argentea, Piaractus mesopotamicus, Poptella brevispina, Probolus heterostomus, Rachoviscus graciliceps, Rhinobrycon negrensis, Rhoadsia altipinna, Serrabrycon magoi, Tetragonopterus argenteus e Triportheus albus.

[3] - sua extensão formando um "s" esticado (porção anterior no mesmo plano da posteiror, com parte mediana ântero-dorsal).

Curimata ocellata, Curimatopsis macrolepis, Potamorhina latior, Prochilodus nigricans, Semaprochilodus insignis, Caenotropus labyrinthicus e Chilodus punctatus.

96 - Crista óssea longitudinal medial da face ventral do paresfenóide, formando uma quilha:

[NeTTO-FERREIRA, 2006: 36 modificado]

(Minimamente conectado).

[0] - ausente (Fig. 32).

Chanos chanos, Catostomus commersonnii, olivaichthys mesembrinus, Gymnotus aff. carapo, Nannocharax fasciatus, Anodus orinocensis, Bivibranchia fowleri, Hemiodus unimaculatus, Curimata ocellata, Acestrorhynchus falcirostris, Gilbertolus atratoensis, Hydrolycus tatauaia, Roestes molossus, Erythrinoidea fam. nov, Aphyocharax pusillus, Astyanax mexicanus, Brittanichthys axelrodi, Brycon pesu, Bryconadenos tanaothoros, Bryconamericus exodon, Bryconops alburnoides, Charax cf. leticiae, Galeocharax knerii, Hemigrammus unilineatus, Hyphessobrycon compressus, Iguanodectes geisleri, oligosarcus argenteus, Paracheirodon axelrodi, Paragoniates alburnus, Phenagoniates macrolepis, Rachoviscus graciliceps, Rhinobrycon negrensis e Stygichthys typhlops.

$33)$.

[1] - posterior, não alcançando a articulação com o vômer (Fig.

Citharinus latus, Distichodus notospilus, Hemistichodus vaillanti, Neolebias unifasciatus, Xenocharax spilurus, Apareiodon piracicabae, Parodon nasus, Saccodon wagneri, Lebiasina bimaculata, Arnoldichthys spilopterus, Brycinus macrolepidotus, Bryconalestes longipinnis, Characidium bahiensis, crenuchus spilurus, Agoniates halecinus, Atopomesus pachyodus, Axelrodia reisei, Clupeacharax cf. engrauloides, Compsura heterura, Ctenobrycon hauxwellianus, Deuterodon iguape, Diapoma terofali, Glandulocauda melanogenys, Gnathocharax steindachneri, Gymnocorymbus ternetzi, Hemibrycon polyodon, Hollandichthys multifasciatus, Knodus meridae, Landonia latidens, Metynnis lippincottianus, Microschemobrycon casiquiare, Moenkhausia xinguensis, odontostilbe pequira, Orthospinus franciscoensis, Phenacogaster pectinatus, Piabina argentea, Piaractus mesopotamicus, Poptella brevispina, Probolus heterostomus, Rhoadsia altipinna, Roeboexodon guyanensis, Salminus hilarii, Serrabrycon magoi, Tetragonopterus argenteus e Triportheus albus.

\section{[2] - por toda a extensão do paresfenóide.}

Curimatopsis macrolepis, Potamorhina latior, Prochilodus nigricans, Semaprochilodus insignis, Caenotropus labyrinthicus, Chilodus punctatus, Anostomus anostomus, Leporellus 
vittatus, Leporinus fasciatus, Schizodon fasciatus, Carnegiella strigata, Gasteropelecus sternicla, Thoracocharax stellatus, Boulengerella maculata, Ctenolucius hujeta, Copeina cf. guttata, Piabucina astrigata, Erythrinus erythrinus, Hoplias malabaricus, Hepsetus odoe, Chalceus epakros, Markiana nigripinnis e Myleus setiger.

97 - Porção posterior do paresfenóide:

[ZANATA, 2000: 28; NeTto-FERREIRA, 2006: 40]

(Minimamente conectado).

[0] - bastante furcado posteriormente.

Bivibranchia fowleri, Hemiodus unimaculatus, Curimatopsis macrolepis, Potamorhina latior, Caenotropus labyrinthicus, Chilodus punctatus, Anostomus anostomus, Leporellus vittatus, Leporinus fasciatus, Schizodon fasciatus, Acestrorhynchus falcirostris, Gilbertolus atratoensis, Hydrolycus tatauaia, Roestes molossus, Ctenolucius hujeta, Hepsetus odoe, Characidium bahiensis, Agoniates halecinus, Aphyocharax pusillus, Astyanax mexicanus, Atopomesus pachyodus, Brycon pesu, Iguanodectes geisleri, Knodus meridae, Microschemobrycon casiquiare, Myleus setiger, Phenagoniates macrolepis, Piabina argentea, Roeboexodon guyanensis, Salminus hilarii e Triportheus albus.

[1] - bifurcação menos acentuada, ocorrendo próximo à cápsula lagenar.

Gymnotus aff. carapo, Hemistichodus vaillanti, Neolebias unifasciatus, Xenocharax spilurus, Apareiodon piracicabae, Parodon nasus, Saccodon wagneri, Anodus orinocensis, Erythrinoidea fam. nov, Boulengerella maculata, Hoplias malabaricus, Arnoldichthys spilopterus, Brycinus macrolepidotus, Bryconalestes longipinnis, Chalceus epakros, Crenuchus spilurus, Axelrodia reisei, Brittanichthys axelrodi, Bryconadenos tanaothoros, Bryconamericus exodon, Bryconops alburnoides, Charax cf. leticiae, Clupeacharax cf. engrauloides, Compsura heterura, Ctenobrycon hauxwellianus, Deuterodon iguape, Diapoma terofali, Galeocharax knerii, Glandulocauda melanogenys, Gnathocharax steindachneri, Gymnocorymbus ternetzi, Hemibrycon polyodon, Hollandichthys multifasciatus, Landonia latidens, Markiana nigripinnis, Metynnis lippincottianus, Moenkhausia xinguensis, odontostilbe pequira, oligosarcus argenteus, orthospinus franciscoensis, Paragoniates alburnus, Phenacogaster pectinatus, Poptella brevispina, Probolus heterostomus Rhoadsia altipinna, Serrabrycon magoi e Tetragonopterus argenteus.

\section{[2] - quase não furcado ou não furcado.}

Chanos chanos, Catostomus commersonnii, olivaichthys mesembrinus, Citharinus latus, Distichodus notospilus, Nannocharax fasciatus, Curimata ocellata, Prochilodus nigricans, Semaprochilodus insignis, Carnegiella strigata, Gasteropelecus sternicla, Thoracocharax stellatus, Copeina cf. guttata, Lebiasina bimaculata, Piabucina astrigata, Erythrinus erythrinus, Hemigrammus unilineatus, Hyphessobrycon compressus, Paracheirodon axelrodi, Piaractus mesopotamicus, Rachoviscus graciliceps, Rhinobrycon negrensis e stygichthys typhlops.

98 - Extremidade posterior do paresfenóide:

[Zanata, 2000: 29; Netto-Ferreira, 2006: 41]

\section{[0] - não atingindo a margem posterior da cápsula lagenar.}

Catostomus commersonnii, Citharinus latus, Distichodus notospilus, Hemistichodus vaillanti, Neolebias unifasciatus, Nannocharax fasciatus, Saccodon wagneri, Curimata ocellata, Semaprochilodus insignis, Anostomus anostomus, Carnegiella strigata, Gasteropelecus sternicla, Thoracocharax stellatus, Erythrinoidea fam. nov, Copeina cf. guttata, Lebiasina bimaculata, Piabucina astrigata, Arnoldichthys spilopterus, Brycinus macrolepidotus, Bryconalestes longipinnis, Chalceus epakros, Crenuchus spilurus, Aphyocharax pusillus, Astyanax mexicanus, Atopomesus pachyodus, Axelrodia reisei, Brittanichthys axelrodi, Brycon pesu, Bryconadenos tanaothoros, Bryconamericus exodon, Bryconops alburnoides, Charax cf. leticiae, Clupeacharax cf. engrauloides, Compsura heterura, Ctenobrycon hauxwellianus, Deuterodon iguape, Diapoma terofali, Galeocharax knerii, Glandulocauda melanogenys, Gnathocharax steindachneri, Gymnocorymbus ternetzi, Hemibrycon polyodon, Hemigrammus unilineatus, Hollandichthys multifasciatus, Hyphessobrycon compressus, Iguanodectes geisleri, Knodus meridae, Landonia latidens, Markiana nigripinnis, Metynnis lippincottianus, Moenkhausia xinguensis, Myleus setiger, odontostilbe pequira, oligosarcus argenteus, orthospinus franciscoensis, Paracheirodon axelrodi, Paragoniates alburnus, Phenacogaster pectinatus, Phenagoniates macrolepis, Piaractus mesopotamicus, Poptella brevispina, Probolus heterostomus, Rachoviscus 
graciliceps, Rhinobrycon negrensis, Rhoadsia altipinna, Roeboexodon guyanensis, Serrabrycon magoi, Stygichthys typhlops e Tetragonopterus argenteus.

\section{[1] - atingindo ou ultrapassando a margem posterior da cápsula} lagenar.

Chanos chanos, Olivaichthys mesembrinus, Gymnotus aff. carapo, Xenocharax spilurus, Apareiodon piracicabae, Parodon nasus, Anodus orinocensis, Bivibranchia fowleri, Hemiodus unimaculatus, Curimatopsis macrolepis, Potamorhina latior, Prochilodus nigricans, Caenotropus labyrinthicus, Chilodus punctatus, Leporellus vittatus, Leporinus fasciatus, Schizodon fasciatus, Acestrorhynchus falcirostris, Gilbertolus atratoensis, Hydrolycus tatauaia, Roestes molossus, Boulengerella maculata, Ctenolucius hujeta, Erythrinus erythrinus, Hoplias malabaricus, Hepsetus odoe, Characidium bahiensis, Agoniates halecinus, Microschemobrycon casiquiare, Piabina argentea, Salminus hilarii e Triportheus albus.

99 - Etmóide lateral:

[VARI， 1995:21; NetTo-FerReira， 2006:42]

[0] - com processos laminares bem desenvolvidos lateralmente.

Chanos chanos, Catostomus commersonnii, Olivaichthys mesembrinus, Citharinus latus, Distichodus notospilus, Hemistichodus vaillanti, Neolebias unifasciatus, Nannocharax fasciatus, Xenocharax spilurus, Apareiodon piracicabae, Parodon nasus, Saccodon wagneri, Anodus orinocensis, Bivibranchia fowleri, Hemiodus unimaculatus, curimata ocellata, Curimatopsis macrolepis, Potamorhina latior, Prochilodus nigricans, Semaprochilodus insignis, Caenotropus labyrinthicus, Chilodus punctatus, Anostomus anostomus, Leporellus vittatus, Leporinus fasciatus, Schizodon fasciatus, Carnegiella strigata, Gasteropelecus sternicla, Thoracocharax stellatus, Acestrorhynchus falcirostris, Gilbertolus atratoensis, Hydrolycus tatauaia, Roestes molossus, Copeina cf. guttata, Piabucina astrigata, Erythrinus erythrinus, Arnoldichthys spilopterus, Brycinus macrolepidotus, Bryconalestes longipinnis, Chalceus epakros, Characidium bahiensis, Crenuchus spilurus, Agoniates halecinus, Aphyocharax pusillus, Astyanax mexicanus, Atopomesus pachyodus, Axelrodia reisei, Brittanichthys axelrodi, Brycon pesu, Bryconadenos tanaothoros, Bryconamericus exodon, Bryconops alburnoides, Charax cf. leticiae, Clupeacharax cf. engrauloides, Compsura heterura, Ctenobrycon hauxwellianus, Deuterodon iguape, Diapoma terofali, Galeocharax knerii, Glandulocauda melanogenys, Gnathocharax steindachneri, Gymnocorymbus ternetzi, Hemibrycon polyodon, Hemigrammus unilineatus, Hollandichthys multifasciatus, Hyphessobrycon compressus, Iguanodectes geisleri, Knodus meridae, Landonia latidens, Markiana nigripinnis, Metynnis lippincottianus, Microschemobrycon casiquiare, Moenkhausia xinguensis, Myleus setiger, Odontostilbe pequira, Oligosarcus argenteus, orthospinus franciscoensis, Paracheirodon axelrodi, Paragoniates alburnus, Phenacogaster pectinatus, Phenagoniates macrolepis, Piabina argentea, Piaractus mesopotamicus, Poptella brevispina, Probolus heterostomus, Rachoviscus graciliceps, Rhinobrycon negrensis, Rhoadsia altipinna, Roeboexodon guyanensis, Salminus hilarii, Serrabrycon magoi, Tetragonopterus argenteus e Triportheus albus.

\section{[1] - com processos laminares laterais pouco desenvolvidos.}

Gymnotus aff. carapo, Erythrinoidea fam. nov, Boulengerella maculata, Ctenolucius hujeta, Lebiasina bimaculata, Hoplias malabaricus, Hepsetus odoe e Stygichthys typhlops.

\section{0 - Porção posterior dos processos laminares laterais do etmóide lateral:}

\section{[0] - com processo pareado posterior (Fig. 34).}

Catostomus commersonnii, Olivaichthys mesembrinus, Citharinus latus, Distichodus notospilus, Hemistichodus vaillanti, Nannocharax fasciatus, Xenocharax spilurus, Apareiodon piracicabae, Parodon nasus, Saccodon wagneri, Curimata ocellata, Curimatopsis macrolepis, Potamorhina latior, Prochilodus nigricans, Semaprochilodus insignis, Anostomus anostomus, Leporellus vittatus, Leporinus fasciatus e Schizodon fasciatus.

$$
\text { [1] - lisa (Fig. 33). }
$$

Chanos chanos, Neolebias unifasciatus, Anodus orinocensis, Bivibranchia fowleri, Hemiodus unimaculatus, Caenotropus labyrinthicus, Chilodus punctatus, Carnegiella strigata, Gasteropelecus sternicla, Thoracocharax stellatus, Acestrorhynchus falcirostris, Gilbertolus atratoensis, Hydrolycus tatauaia, Roestes molossus, 
Erythrinoidea fam. nov, Boulengerella maculata, Ctenolucius hujeta, Copeina cf. guttata, Lebiasina bimaculata, Piabucina astrigata, Erythrinus erythrinus, Hoplias malabaricus, Hepsetus odoe, Arnoldichthys spilopterus, Brycinus macrolepidotus, Bryconalestes longipinnis, Chalceus epakros, Characidium bahiensis, Crenuchus spilurus, Agoniates halecinus, Aphyocharax pusillus, Astyanax mexicanus, Atopomesus pachyodus, Axelrodia reisei, Brittanichthys axelrodi, Brycon pesu, Bryconadenos tanaothoros, Bryconamericus exodon, Bryconops alburnoides, Charax cf. leticiae, clupeacharax cf. engrauloides, Compsura heterura, Ctenobrycon hauxwellianus, Deuterodon iguape, Diapoma terofali, Galeocharax knerii, Glandulocauda melanogenys, Gnathocharax steindachneri, Gymnocorymbus ternetzi, Hemibrycon polyodon, Hemigrammus unilineatus, Hollandichthys multifasciatus, Hyphessobrycon compressus, Iguanodectes geisleri, Knodus meridae, Landonia latidens, Markiana nigripinnis, Metynnis lippincottianus, Microschemobrycon casiquiare, Moenkhausia xinguensis, Myleus setiger, odontostilbe pequira, oligosarcus argenteus, orthospinus franciscoensis, Paracheirodon axelrodi, Paragoniates alburnus, Phenacogaster pectinatus, Phenagoniates macrolepis, Piabina argentea, Piaractus mesopotamicus, Poptella brevispina, Probolus heterostomus, Rachoviscus graciliceps, Rhinobrycon negrensis, Rhoadsia altipinna, Roeboexodon guyanensis, Salminus hilarii, Serrabrycon magoi, Stygichthys typhlops, Tetragonopterus argenteus, Triportheus albus.

\section{[?] - indeterminado.}

Gymnotus aff. carapo.

101 - Rinosfenóide:

[LuCENA, 1993: 8; BuCKup, 1998: 7; TOLEDO-PIZA, 2000: 16; ZANATA, 2000: 16; Benine, 2004:20; Zanata \& VAri, 2005: 31; NetTo-Ferreira, 2006: 44]

\section{[0] - ausente.}

Chanos chanos, Catostomus commersonnii, Olivaichthys mesembrinus, Gymnotus aff. carapo, Citharinus latus, Distichodus notospilus, Hemistichodus vaillanti, Neolebias unifasciatus, Nannocharax fasciatus, Xenocharax spilurus, Apareiodon piracicabae, Parodon nasus, Saccodon wagneri, Curimata ocellata, Curimatopsis macrolepis, Potamorhina latior, Prochilodus nigricans, Semaprochilodus insignis, Caenotropus labyrinthicus, Chilodus punctatus, Anostomus anostomus, Leporellus vittatus, Leporinus fasciatus, Schizodon fasciatus, Carnegiella strigata, Gasteropelecus sternicla, Thoracocharax stellatus, Erythrinoidea fam. nov, Boulengerella maculata, Ctenolucius hujeta, Copeina cf. guttata, Lebiasina bimaculata, Piabucina astrigata, Erythrinus erythrinus, Hoplias malabaricus, Hepsetus odoe, Arnoldichthys spilopterus, Brycinus macrolepidotus, Bryconalestes longipinnis, Chalceus epakros, Characidium bahiensis, Crenuchus spilurus, Astyanax mexicanus, Charax cf. leticiae, Compsura heterura, Galeocharax knerii, Glandulocauda melanogenys, Hollandichthys multifasciatus, Landonia latidens, Markiana nigripinnis, Metynnis lippincottianus, Myleus setiger, Odontostilbe pequira, Paragoniates alburnus, Phenagoniates macrolepis, Piaractus mesopotamicus, Rachoviscus graciliceps, Salminus hilarii e Stygichthys typhlops.

\section{[1] - presente.}

Anodus orinocensis, Bivibranchia fowleri, Hemiodus unimaculatus, Acestrorhynchus falcirostris, Gilbertolus atratoensis, Hydrolycus tatauaia, Roestes molossus, Agoniates halecinus, Aphyocharax pusillus, Atopomesus pachyodus, Axelrodia reisei, Brittanichthys axelrodi, Brycon pesu, Bryconadenos tanaothoros, Bryconamericus exodon, Bryconops alburnoides, Clupeacharax cf. engrauloides, Ctenobrycon hauxwellianus, Deuterodon iguape, Diapoma terofali, Gnathocharax steindachneri, Gymnocorymbus ternetzi, Hemibrycon polyodon, Hemigrammus unilineatus, Iguanodectes geisleri, Knodus meridae, Microschemobrycon casiquiare, Moenkhausia xinguensis, oligosarcus argenteus, orthospinus franciscoensis, Paracheirodon axelrodi, Phenacogaster pectinatus, Piabina argentea, Poptella brevispina, Probolus heterostomus, Rhinobrycon negrensis, Rhoadsia altipinna, Roeboexodon guyanensis, Serrabrycon magoi, Tetragonopterus argenteus e Triportheus albus.

[?] - indeterminado.

Hyphessobrycon compressus.

102 - Porção dorsal do rinosfenóide:

[LUCENA \& MENEZES, 1998: 19 modificado; BenINE, 2004: 21]

[0] - lisa ou com pequena projeção dorsal. 
Anodus orinocensis, Bivibranchia fowleri, Hemiodus unimaculatus, Acestrorhynchus falcirostris, Gilbertolus atratoensis, Hydrolycus tatauaia, Agoniates halecinus, Aphyocharax pusillus, Atopomesus pachyodus, Brycon pesu, Bryconadenos tanaothoros, Bryconamericus exodon, Clupeacharax cf. engrauloides, Ctenobrycon hauxwellianus, Deuterodon iguape, Diapoma terofali, Gnathocharax steindachneri, Hemibrycon polyodon, Hemigrammus unilineatus, Iguanodectes geisleri, Knodus meridae, Microschemobrycon casiquiare, Oligosarcus argenteus, Phenacogaster pectinatus, Piabina argentea, Probolus heterostomus, Rhinobrycon negrensis, Rhoadsia altipinna, Roeboexodon guyanensis, Serrabrycon magoi, Tetragonopterus argenteus e Triportheus albus.

\section{[1] - com um grande processo dorsal.}

Axelrodia reisei, Brittanichthys axelrodi, Bryconops alburnoides, Gymnocorymbus ternetzi, Moenkhausia xinguensis, orthospinus franciscoensis, Paracheirodon axelrodi e Poptella brevispina.

\section{[-] - inaplicável.}

Chanos chanos, Catostomus commersonnii, Olivaichthys mesembrinus, Gymnotus aff. carapo, Citharinus latus, Distichodus notospilus, Hemistichodus vaillanti, Neolebias unifasciatus, Nannocharax fasciatus, Xenocharax spilurus, Apareiodon piracicabae, Parodon nasus, Saccodon wagneri, Curimata ocellata, Curimatopsis macrolepis, Potamorhina latior, Prochilodus nigricans, Semaprochilodus insignis, Caenotropus labyrinthicus, Chilodus punctatus, Anostomus anostomus, Leporellus vittatus, Leporinus fasciatus, Schizodon fasciatus, Carnegiella strigata, Gasteropelecus sternicla, Thoracocharax stellatus, Erythrinoidea fam. nov, Boulengerella maculata, Ctenolucius hujeta, Copeina cf. guttata, Lebiasina bimaculata, Piabucina astrigata, Erythrinus erythrinus, Hoplias malabaricus, Hepsetus odoe, Arnoldichthys spilopterus, Brycinus macrolepidotus, Bryconalestes longipinnis, Chalceus epakros, Characidium bahiensis, Crenuchus spilurus, Astyanax mexicanus, Charax cf. leticiae, Compsura heterura, Galeocharax knerii, Glandulocauda melanogenys, Hollandichthys multifasciatus, Landonia latidens, Markiana nigripinnis, Metynnis lippincottianus, Myleus setiger, odontostilbe pequira, Paragoniates alburnus, Phenagoniates macrolepis, Piaractus mesopotamicus, Rachoviscus graciliceps, Salminus hilarii e Stygichthys typhlops.

\section{[?] - indeterminado.}

Roestes molossus e Hyphessobrycon compressus.

\section{3 - Porção mediana do órbito-esfenóide:}

\section{[0] - sem constrição acentuada.}

Catostomus commersonnii, Olivaichthys mesembrinus, Citharinus latus, Distichodus notospilus, Hemistichodus vaillanti, Neolebias unifasciatus, Nannocharax fasciatus, Xenocharax spilurus, Apareiodon piracicabae, Parodon nasus, Saccodon wagneri, Anodus orinocensis, Bivibranchia fowleri, Hemiodus unimaculatus, Curimata ocellata, Curimatopsis macrolepis, Potamorhina latior, Prochilodus nigricans, Semaprochilodus insignis, Caenotropus labyrinthicus, Chilodus punctatus, Anostomus anostomus, Leporellus vittatus, Leporinus fasciatus, Schizodon fasciatus, Acestrorhynchus falcirostris, Gilbertolus atratoensis, Hydrolycus tatauaia, Roestes molossus, Erythrinoidea fam. nov, Boulengerella maculata, Ctenolucius hujeta, Copeina cf. guttata, Lebiasina bimaculata, Piabucina astrigata, Erythrinus erythrinus, Hoplias malabaricus, Hepsetus odoe, Arnoldichthys spilopterus, Brycinus macrolepidotus, Bryconalestes longipinnis, Chalceus epakros, Characidium bahiensis, Crenuchus spilurus, Agoniates halecinus, Aphyocharax pusillus, Astyanax mexicanus, Atopomesus pachyodus, Axelrodia reisei, Brittanichthys axelrodi, Brycon pesu, Bryconadenos tanaothoros, Bryconamericus exodon, Bryconops alburnoides, Charax cf. leticiae, Clupeacharax cf. engrauloides, Compsura heterura, Ctenobrycon hauxwellianus, Deuterodon iguape, Diapoma terofali, Galeocharax knerii, Glandulocauda melanogenys, Gymnocorymbus ternetzi, Hemibrycon polyodon, Hemigrammus unilineatus, Hollandichthys multifasciatus, Iguanodectes geisleri, Knodus meridae, Markiana nigripinnis, Metynnis lippincottianus, Moenkhausia xinguensis, Myleus setiger, oligosarcus argenteus, Orthospinus franciscoensis, Paragoniates alburnus, Phenacogaster pectinatus, Phenagoniates macrolepis, Piabina argentea, Piaractus mesopotamicus, Poptella brevispina, Probolus heterostomus, Rhinobrycon negrensis, Rhoadsia altipinna, Roeboexodon guyanensis, Salminus hilarii, Serrabrycon magoi, stygichthys typhlops, Tetragonopterus argenteus e Triportheus albus.

\section{[1] - com constrição acentuada.}


Carnegiella strigata, Gasteropelecus sternicla, Thoracocharax stellatus, Gnathocharax steindachneri, Hyphessobrycon compressus, Landonia latidens, Odontostilbe pequira, Paracheirodon axelrodi e Rachoviscus graciliceps.

\section{[-] - inaplicável.}

Chanos chanos.

\section{[?] - indeterminado.}

Gymnotus aff. carapo e Microschemobrycon casiquiare.

104 - Relação entre o órbito-esfenóide e o paresfenóide:

[ZANATA, 2000: 18 modificado; BENINE, 2004: 25 modificado; NETTO-FERREIRA, 2006: 48 modificado]

[0] - bem separados (Fig. 32 e Fig. 33).

Hemistichodus vaillanti, Anodus orinocensis, Bivibranchia fowleri, Hemiodus unimaculatus , Carnegiella strigata, Gasteropelecus sternicla, Thoracocharax stellatus, Gilbertolus atratoensis, Roestes molossus, Agoniates halecinus, Astyanax mexicanus, Atopomesus pachyodus, Axelrodia reisei, Brittanichthys axelrodi, Brycon pesu, Bryconadenos tanaothoros, Bryconamericus exodon, Bryconops alburnoides, clupeacharax cf. engrauloides, Compsura heterura, Ctenobrycon hauxwellianus, Deuterodon iguape, Diapoma terofali, Glandulocauda melanogenys, Gnathocharax steindachneri, Gymnocorymbus ternetzi, Hemibrycon polyodon, Hemigrammus unilineatus, Hyphessobrycon compressus, Iguanodectes geisleri, Knodus meridae, Landonia latidens, Microschemobrycon casiquiare, Moenkhausia xinguensis, Odontostilbe pequira, Oligosarcus argenteus, Orthospinus franciscoensis, Paracheirodon axelrodi, Phenacogaster pectinatus, Piabina argentea, Poptella brevispina, Probolus heterostomus, Rhinobrycon negrensis, Rhoadsia altipinna, Roeboexodon guyanensis, Serrabrycon magoi, Tetragonopterus argenteus e Triportheus albus.

\section{[1] - em contato, ou muito próximos (Fig. 34).}

Catostomus commersonnii, Olivaichthys mesembrinus, Citharinus latus, Distichodus notospilus, Neolebias unifasciatus, Nannocharax fasciatus, Xenocharax spilurus, Apareiodon piracicabae, Parodon nasus, Saccodon wagneri, Curimata ocellata, Curimatopsis macrolepis, Potamorhina latior, Prochilodus nigricans, Semaprochilodus insignis, Caenotropus labyrinthicus, Chilodus punctatus, Anostomus anostomus, Leporellus vittatus, Leporinus fasciatus, Schizodon fasciatus, Acestrorhynchus falcirostris, Hydrolycus tatauaia, Erythrinoidea fam. nov, Boulengerella maculata, Ctenolucius hujeta, Copeina cf. guttata, Lebiasina bimaculata, Piabucina astrigata, Erythrinus erythrinus, Hoplias malabaricus, Hepsetus odoe, Arnoldichthys spilopterus, Brycinus macrolepidotus, Bryconalestes longipinnis, Chalceus epakros, Characidium bahiensis, crenuchus spilurus, Aphyocharax pusillus, Charax cf. leticiae, Galeocharax knerii, Hollandichthys multifasciatus, Markiana nigripinnis, Metynnis lippincottianus, Myleus setiger, Paragoniates alburnus, Phenagoniates macrolepis, Piaractus mesopotamicus, Rachoviscus graciliceps, Salminus hilarii e Stygichthys typhlops.

\section{[-] - inaplicável.}

Chanos chanos.

\section{[?] - indeterminado.}

Gymnotus aff. carapo.

105 - Fontanela frontal:

[LUCENA, 1993: 7; VARI, 1995: 26; BUCKUP, 1998: 9; OYAKAWA, 1998: 21; ZANATA, 2000: 20; ZANATA \& VARI, 2005: 36; NETTO-FERREIRA, 2006: 53]

[0] - ausente.

Chanos chanos, Gymnotus aff. carapo, Apareiodon piracicabae, Parodon nasus, Saccodon wagneri, Carnegiella strigata, Gasteropelecus sternicla, Thoracocharax stellatus, Erythrinoidea fam. nov, Boulengerella maculata, Ctenolucius hujeta, Copeina cf. guttata, Lebiasina bimaculata, Piabucina astrigata, Erythrinus erythrinus, Hoplias malabaricus, 
Hepsetus odoe, Arnoldichthys spilopterus, Brycinus macrolepidotus, Chalceus epakros, Characidium bahiensis e Brycon pesu.

\section{[1] - presente.}

Catostomus commersonnii, Olivaichthys mesembrinus, Citharinus latus, Distichodus notospilus, Hemistichodus vaillanti, Neolebias unifasciatus, Nannocharax fasciatus, Xenocharax spilurus, Anodus orinocensis, Bivibranchia fowleri, Hemiodus unimaculatus , Curimata ocellata, Curimatopsis macrolepis, Potamorhina latior, Prochilodus nigricans, Semaprochilodus insignis, Caenotropus labyrinthicus, Chilodus punctatus, Anostomus anostomus, Leporellus vittatus, Leporinus fasciatus, Schizodon fasciatus, Acestrorhynchus falcirostris, Gilbertolus atratoensis, Hydrolycus tatauaia, Roestes molossus, Bryconalestes longipinnis, crenuchus spilurus, Agoniates halecinus, Aphyocharax pusillus, Astyanax mexicanus, Atopomesus pachyodus, Axelrodia reisei, Brittanichthys axelrodi, Bryconadenos tanaothoros, Bryconamericus exodon, Bryconops alburnoides, charax cf. leticiae, Clupeacharax cf. engrauloides, Compsura heterura, Ctenobrycon hauxwellianus, Deuterodon iguape, Diapoma terofali, Galeocharax knerii, Glandulocauda melanogenys, Gnathocharax steindachneri, Gymnocorymbus ternetzi, Hemibrycon polyodon, Hemigrammus unilineatus, Hollandichthys multifasciatus, Hyphessobrycon compressus, Iguanodectes geisleri, Knodus meridae, Landonia latidens, Markiana nigripinnis, Metynnis lippincottianus, Microschemobrycon casiquiare, Moenkhausia xinguensis, Myleus setiger, odontostilbe pequira, oligosarcus argenteus, orthospinus franciscoensis, Paracheirodon axelrodi, Paragoniates alburnus, Phenacogaster pectinatus, Phenagoniates macrolepis, Piabina argentea, Piaractus mesopotamicus, Poptella brevispina, Probolus heterostomus, Rachoviscus graciliceps, Rhinobrycon negrensis, Rhoadsia altipinna, Roeboexodon guyanensis, Salminus hilarii, Serrabrycon magoi, Stygichthys typhlops, Tetragonopterus argenteus e Triportheus albus.

106 - Extensão da fontanela frontal:

[ZANATA, 200०: 21; MOREIRA, 2002: 35; BENINE, 2004: 9 modificado]

\section{[0] - extensão anterior não alcançando o mesetmóide (Fig. 19).}

Catostomus commersonnii, Distichodus notospilus, Hemistichodus vaillanti, Neolebias unifasciatus, Nannocharax fasciatus, Xenocharax spilurus, Acestrorhynchus falcirostris, Bryconalestes longipinnis, Crenuchus spilurus, Agoniates halecinus, Aphyocharax pusillus, Astyanax mexicanus, Atopomesus pachyodus, Axelrodia reisei, Bryconadenos tanaothoros, Bryconops alburnoides, Charax cf. leticiae, Compsura heterura, Ctenobrycon hauxwellianus, Deuterodon iguape, Galeocharax knerii, Glandulocauda melanogenys, Gymnocorymbus ternetzi, Iguanodectes geisleri, Knodus meridae, Landonia latidens, Microschemobrycon casiquiare, Myleus setiger, odontostilbe pequira, oligosarcus argenteus, Rhinobrycon negrensis, Rhoadsia altipinna, Salminus hilarii, Serrabrycon magoi, Stygichthys typhlops e Triportheus albus.

\section{[1] - extensão anterior até o mesetmóide.}

Olivaichthys mesembrinus, Citharinus latus, Anodus orinocensis, Bivibranchia fowleri, Hemiodus unimaculatus, Curimata ocellata, Curimatopsis macrolepis, Potamorhina latior, Prochilodus nigricans, Semaprochilodus insignis, Caenotropus labyrinthicus, Chilodus punctatus, Leporellus vittatus, Leporinus fasciatus, Schizodon fasciatus, Gilbertolus atratoensis, Hydrolycus tatauaia, Roestes molossus, Brittanichthys axelrodi, Bryconamericus exodon, Clupeacharax cf. engrauloides, Diapoma terofali, Gnathocharax steindachneri, Hemibrycon polyodon, Hemigrammus unilineatus, Hollandichthys multifasciatus, Hyphessobrycon compressus, Markiana nigripinnis, Metynnis lippincottianus, Moenkhausia xinguensis, orthospinus franciscoensis, Paracheirodon axelrodi, Paragoniates alburnus, Phenacogaster pectinatus, Phenagoniates macrolepis, Piabina argentea, Poptella brevispina, Probolus heterostomus, Rachoviscus graciliceps, Roeboexodon guyanensis e Tetragonopterus argenteus.

\section{[-] - inaplicável.}

Chanos chanos, Gymnotus aff. carapo, Apareiodon piracicabae, Parodon nasus, Saccodon wagneri, Carnegiella strigata, Gasteropelecus sternicla, Thoracocharax stellatus , Erythrinoidea fam. nov, Boulengerella maculata, ctenolucius hujeta, Copeina cf. guttata, Lebiasina bimaculata, Piabucina astrigata, Erythrinus erythrinus, Hoplias malabaricus, Hepsetus odoe, Arnoldichthys spilopterus, Brycinus macrolepidotus, Chalceus epakros, Characidium bahiensis e Brycon pesu.

\section{[?] - indeterminado.}

Anostomus anostomus e Piaractus mesopotamicus. 
107 - Barra epifiseana:

[LuCEnA, 1993: 13; VARI, 1995: 26; OYAKAWA, 1998: 2; NetTo-FerReira, 2006: $54]$

[0] - ausente.

Chanos chanos, Erythrinoidea fam. nov, Boulengerella maculata e Ctenolucius hujeta.

\section{[1] - presente.}

Catostomus commersonnii, Olivaichthys mesembrinus, Gymnotus aff. carapo, Citharinus latus, Distichodus notospilus, Hemistichodus vaillanti, Neolebias unifasciatus, Nannocharax fasciatus, Xenocharax spilurus, Apareiodon piracicabae, Parodon nasus, Saccodon wagneri, Anodus orinocensis, Bivibranchia fowleri, Hemiodus unimaculatus, Curimata ocellata, Curimatopsis macrolepis, Potamorhina latior, Prochilodus nigricans, Semaprochilodus insignis, Caenotropus labyrinthicus, Chilodus punctatus, Anostomus anostomus, Leporellus vittatus, Leporinus fasciatus, schizodon fasciatus, Acestrorhynchus falcirostris, Gilbertolus atratoensis, Hydrolycus tatauaia, Roestes molossus, Copeina cf. guttata, Lebiasina bimaculata, Piabucina astrigata, Erythrinus erythrinus, Hoplias malabaricus, Hepsetus odoe, Arnoldichthys spilopterus, Brycinus macrolepidotus, Bryconalestes longipinnis, Chalceus epakros, Characidium bahiensis, Crenuchus spilurus, Agoniates halecinus, Aphyocharax pusillus, Astyanax mexicanus, Atopomesus pachyodus, Axelrodia reisei, Brittanichthys axelrodi, Brycon pesu, Bryconadenos tanaothoros, Bryconamericus exodon, Bryconops alburnoides, Charax cf. leticiae, Clupeacharax cf. engrauloides, Compsura heterura, Ctenobrycon hauxwellianus, Deuterodon iguape, Diapoma terofali, Galeocharax knerii, Glandulocauda melanogenys, Gnathocharax steindachneri, Gymnocorymbus ternetzi, Hemibrycon polyodon, Hemigrammus unilineatus, Hollandichthys multifasciatus, Hyphessobrycon compressus, Iguanodectes geisleri, Knodus meridae, Landonia latidens, Markiana nigripinnis, Metynnis lippincottianus, Microschemobrycon casiquiare, Moenkhausia xinguensis, Myleus setiger, odontostilbe pequira, Oligosarcus argenteus, orthospinus franciscoensis, Paracheirodon axelrodi, Paragoniates alburnus, Phenacogaster pectinatus, Phenagoniates macrolepis, Piabina argentea, Piaractus mesopotamicus, Poptella brevispina, Probolus heterostomus, Rachoviscus graciliceps, Rhinobrycon negrensis, Rhoadsia altipinna, Roeboexodon guyanensis, Salminus hilarii, Serrabrycon magoi, Stygichthys typhlops, Tetragonopterus argenteus e Triportheus albus.

\section{[?] - indeterminado.}

Carnegiella strigata, Gasteropelecus sternicla e Thoracocharax stellatus.

108 - Fontanela parietal:

[LUCENA, 1993: 12; BUCKUP, 1998: 15; ZANATA, 2000: 22; ZANATA \& VARI, 2005: 37; NETTO-FERREIRA, 2006: 55]

\section{[0] - presente.}

Catostomus commersonnii, Olivaichthys mesembrinus, Citharinus latus, Distichodus notospilus, Hemistichodus vaillanti, Neolebias unifasciatus, Nannocharax fasciatus, Xenocharax spilurus, Anodus orinocensis, Bivibranchia fowleri, Hemiodus unimaculatus, Curimata ocellata, Curimatopsis macrolepis, Potamorhina latior, Prochilodus nigricans, Semaprochilodus insignis, Caenotropus labyrinthicus, Chilodus punctatus, Anostomus anostomus, Leporellus vittatus, Leporinus fasciatus, schizodon fasciatus, Acestrorhynchus falcirostris, Gilbertolus atratoensis, Hydrolycus tatauaia, Roestes molossus, Bryconalestes longipinnis, Characidium bahiensis, Crenuchus spilurus, Agoniates halecinus, Aphyocharax pusillus, Astyanax mexicanus, Atopomesus pachyodus, Axelrodia reisei, Brittanichthys axelrodi, Brycon pesu, Bryconadenos tanaothoros, Bryconamericus exodon, Bryconops alburnoides, Charax cf. leticiae, Clupeacharax cf. engrauloides, Compsura heterura, Ctenobrycon hauxwellianus, Deuterodon iguape, Diapoma terofali, Galeocharax knerii, Glandulocauda melanogenys, Gnathocharax steindachneri, Gymnocorymbus ternetzi, Hemibrycon polyodon, Hemigrammus unilineatus, Hollandichthys multifasciatus, Hyphessobrycon compressus, Iguanodectes geisleri, Knodus meridae, Landonia latidens, Markiana nigripinnis, Metynnis lippincottianus, Microschemobrycon casiquiare, Moenkhausia xinguensis, Myleus setiger, odontostilbe pequira, Oligosarcus argenteus, Orthospinus franciscoensis, Paracheirodon axelrodi, Paragoniates alburnus, Phenacogaster pectinatus, Phenagoniates macrolepis, Piabina argentea, Piaractus mesopotamicus, Poptella brevispina, Probolus heterostomus, Rachoviscus graciliceps, Rhinobrycon negrensis, Rhoadsia altipinna, Roeboexodon guyanensis, Salminus hilarii, Serrabrycon magoi, Stygichthys typhlops, Tetragonopterus argenteus e Triportheus albus.

[1] - ausente. 
Chanos chanos, Gymnotus aff. carapo, Apareiodon piracicabae, Parodon nasus, Saccodon wagneri, Carnegiella strigata, Gasteropelecus sternicla, Thoracocharax stellatus , Erythrinoidea fam. nov, Boulengerella maculata, Ctenolucius hujeta, Copeina cf. guttata, Lebiasina bimaculata, Piabucina astrigata, Erythrinus erythrinus, Hoplias malabaricus, Hepsetus odoe, Arnoldichthys spilopterus, Brycinus macrolepidotus e Chalceus epakros.

\section{9 - Porção dorsal do frontal e do parietal:}

[ZANATA, 2000: 24; NeTto-FERREIRA, 2006: 57]

$$
\text { [0] - lisa. }
$$

Chanos chanos, Catostomus commersonnii, Gymnotus aff. carapo, Citharinus latus, Distichodus notospilus, Hemistichodus vaillanti, Neolebias unifasciatus, Nannocharax fasciatus, Xenocharax spilurus, Apareiodon piracicabae, Parodon nasus, Saccodon wagneri, Anodus orinocensis, Bivibranchia fowleri, Hemiodus unimaculatus, Curimata ocellata, Curimatopsis macrolepis, Potamorhina latior, Prochilodus nigricans, Semaprochilodus insignis, Caenotropus labyrinthicus, Chilodus punctatus, Anostomus anostomus, Leporellus vittatus, Leporinus fasciatus, Schizodon fasciatus, Carnegiella strigata, Gasteropelecus sternicla, Thoracocharax stellatus, Acestrorhynchus falcirostris, Gilbertolus atratoensis, Hydrolycus tatauaia, Roestes molossus, Erythrinoidea fam. nov, Copeina cf. guttata, Lebiasina bimaculata, Piabucina astrigata, Erythrinus erythrinus, Brycinus macrolepidotus, Bryconalestes longipinnis, Chalceus epakros, Characidium bahiensis, Crenuchus spilurus, Agoniates halecinus, Aphyocharax pusillus, Astyanax mexicanus, Atopomesus pachyodus, Axelrodia reisei, Brittanichthys axelrodi, Brycon pesu, Bryconadenos tanaothoros, Bryconamericus exodon, Bryconops alburnoides, Charax cf. leticiae, Clupeacharax cf. engrauloides, Compsura heterura, Ctenobrycon hauxwellianus, Deuterodon iguape, Diapoma terofali, Galeocharax knerii, Glandulocauda melanogenys, Gnathocharax steindachneri, Gymnocorymbus ternetzi, Hemibrycon polyodon, Hemigrammus unilineatus, Hollandichthys multifasciatus, Hyphessobrycon compressus, Iguanodectes geisleri, Knodus meridae, Landonia latidens, Markiana nigripinnis, Metynnis lippincottianus, Microschemobrycon casiquiare, Moenkhausia xinguensis, Myleus setiger, odontostilbe pequira, Oligosarcus argenteus, orthospinus franciscoensis, Paracheirodon axelrodi, Paragoniates alburnus, Phenacogaster pectinatus, Phenagoniates macrolepis, Piabina argentea, Piaractus mesopotamicus, Poptella brevispina, Probolus heterostomus, Rachoviscus graciliceps, Rhinobrycon negrensis, Rhoadsia altipinna, Roeboexodón guyanensis, Salminus hilarii, Serrabrycon magoi, Stygichthys typhlops, Tetragonopterus argenteus, Triportheus albus.

\section{[1] - com ornamentações.}

Olivaichthys mesembrinus, Boulengerella maculata, Ctenolucius hujeta, Hoplias malabaricus, Hepsetus odoe e Arnoldichthys spilopterus.

110 - Margem dorso-lateral do crânio:

[Lucena, 1993: 11; Buckup，1998: 13; Zanata, 2000: 23; Netto-Ferreira, 2006: $50]$

\section{[0] - reta.}

Chanos chanos, Acestrorhynchus falcirostris, Hydrolycus tatauaia, Boulengerella maculata, Ctenolucius hujeta, Copeina cf. guttata, Lebiasina bimaculata, Piabucina astrigata, Erythrinus erythrinus, Hoplias malabaricus, Hepsetus odoe, Arnoldichthys spilopterus, Chalceus epakros e Characidium bahiensis.

\section{[1] - com entalhe, onde se origina o músculo dilatator operculi.}

Catostomus commersonnii, Olivaichthys mesembrinus, Gymnotus aff. carapo, Citharinus latus, Distichodus notospilus, Hemistichodus vaillanti, Neolebias unifasciatus, Nannocharax fasciatus, Xenocharax spilurus, Apareiodon piracicabae, Parodon nasus, Saccodon wagneri, Anodus orinocensis, Bivibranchia fowleri, Hemiodus unimaculatus, Curimata ocellata, Curimatopsis macrolepis, Potamorhina latior, Prochilodus nigricans, Semaprochilodus insignis, Caenotropus labyrinthicus, Chilodus punctatus, Anostomus anostomus, Leporellus vittatus, Leporinus fasciatus, schizodon fasciatus, Carnegiella strigata, Gasteropelecus sternicla, Thoracocharax stellatus, Gilbertolus atratoensis, Roestes molossus, Brycinus macrolepidotus, Bryconalestes longipinnis, Crenuchus spilurus, Agoniates halecinus, Aphyocharax pusillus, Astyanax mexicanus, Atopomesus pachyodus, Axelrodia reisei, Brittanichthys axelrodi, Brycon pesu, Bryconadenos tanaothoros, Bryconamericus exodon, Bryconops alburnoides, Charax cf. leticiae, Clupeacharax cf. engrauloides, Compsura heterura, Ctenobrycon hauxwellianus, Deuterodon iguape, Diapoma terofali, Galeocharax knerii, Glandulocauda melanogenys, Gnathocharax steindachneri, Gymnocorymbus ternetzi, Hemibrycon polyodon, Hemigrammus unilineatus, 
Hollandichthys multifasciatus, Hyphessobrycon compressus, Iguanodectes geisleri, Knodus meridae, Landonia latidens, Markiana nigripinnis, Metynnis lippincottianus, Microschemobrycon casiquiare, Moenkhausia xinguensis, Myleus setiger, Odontostilbe pequira, Oligosarcus argenteus, Orthospinus franciscoensis, Paracheirodon axelrodi, Paragoniates alburnus, Phenacogaster pectinatus, Phenagoniates macrolepis, Piabina argentea, Piaractus mesopotamicus, Poptella brevispina, Probolus heterostomus Rachoviscus graciliceps, Rhinobrycon negrensis, Rhoadsia altipinna, Roeboexodon guyanensis, salminus hilarii, Serrabrycon magoi, Stygichthys typhlops, Tetragonopterus argenteus e Triportheus albus.

\section{[?] - indeterminado.}

Erythrinoidea fam. nov.

\section{1 - Terceira fossa pós-temporal:}

[LUCENA, 1993: 20 modificado; BUCKUP, 1998: 19 modificado; ZANATA, 2000: 31 modificado; TOLEDO-PIZA, 2000: 23 modificado; ZANATA \& VARI, 2005: 43 modificado; NeTTO-FERREIRA, 2006: 65 modificado]

\section{[0] - ausente.}

Chanos chanos, Catostomus commersonnii, Olivaichthys mesembrinus, Gymnotus aff. carapo, Prochilodus nigricans, Semaprochilodus insignis, Caenotropus labyrinthicus, Chilodus punctatus, Anostomus anostomus, Leporellus vittatus, Leporinus fasciatus, Schizodon fasciatus, Carnegiella strigata, Gasteropelecus sternicla, Thoracocharax stellatus, Acestrorhynchus falcirostris, Erythrinoidea fam. nov, Boulengerella maculata, Ctenolucius hujeta, Copeina cf. guttata, Lebiasina bimaculata, Piabucina astrigata, Erythrinus erythrinus, Hoplias malabaricus, Hepsetus odoe, Arnoldichthys spilopterus, Chalceus epakros, Agoniates halecinus, Aphyocharax pusillus, Astyanax mexicanus, Atopomesus pachyodus, Axelrodia reisei, Brittanichthys axelrodi, Brycon pesu, Bryconadenos tanaothoros, Bryconamericus exodon, Bryconops alburnoides, Charax cf. leticiae, Clupeacharax cf. engrauloides, Compsura heterura, Ctenobrycon hauxwellianus, Deuterodon iguape, Diapoma terofali, Galeocharax knerii, Glandulocauda melanogenys, Gnathocharax steindachneri, Gymnocorymbus ternetzi, Hemibrycon polyodon, Hemigrammus unilineatus, Hollandichthys multifasciatus, Hyphessobrycon compressus, Iguanodectes geisleri, Knodus meridae, Landonia latidens, Markiana nigripinnis, Metynnis lippincottianus, Microschemobrycon casiquiare, Moenkhausia xinguensis, Myleus setiger, odontostilbe pequira, Oligosarcus argenteus, Orthospinus franciscoensis, Paracheirodon axelrodi, Paragoniates alburnus, Phenacogaster pectinatus, Phenagoniates macrolepis, Piabina argentea, Piaractus mesopotamicus, Poptella brevispina, Probolus heterostomus, Rachoviscus graciliceps, Rhinobrycon negrensis, Rhoadsia altipinna, Roeboexodon guyanensis, Salminus hilarii, Serrabrycon magoi, Stygichthys typhlops, Tetragonopterus argenteus e Triportheus albus.

\section{[1] - presente, restrita ao epoccipital.}

Apareiodon piracicabae, Parodon nasus, Saccodon wagneri, Anodus orinocensis, Bivibranchia fowleri, Hemiodus unimaculatus, Curimata ocellata, Potamorhina latior Brycinus macrolepidotus e Bryconalestes longipinnis.

\section{[2] - presente, formada pelo epoccipital e o exoccipital.}

Citharinus latus, Distichodus notospilus, Hemistichodus vaillanti, Neolebias unifasciatus, Nannocharax fasciatus, Xenocharax spilurus, Curimatopsis macrolepis, Gilbertolus atratoensis, Hydrolycus tatauaia, Roestes molossus, Characidium bahiensis e Crenuchus spilurus.

112 - Tamanho das fossas pós-temporais anteriores:

[FINK \& FINK, 1981: 12, modificado; MOREIRA, 2002: 36; ZANATA \& VARI, 2005 : 44]

(Minimamente conectado).

\section{[0] - dorsal quase do tamanho da ventral.}

Hemistichodus vaillanti, Anodus orinocensis, Gilbertolus atratoensis, Arnoldichthys spilopterus, Brycinus macrolepidotus, Bryconalestes longipinnis, Chalceus epakros, Characidium bahiensis, Aphyocharax pusillus, Astyanax mexicanus, Atopomesus pachyodus, 
Brycon pesu, Bryconadenos tanaothoros, Bryconamericus exodon, Bryconops alburnoides, Clupeacharax cf. engrauloides, Compsura heterura, Diapoma terofali, Glandulocauda melanogenys, Gnathocharax steindachneri, Iguanodectes geisleri, Knodus meridae, Markiana nigripinnis, Myleus setiger e Piaractus mesopotamicus.

\section{[1] - dorsal bem menor do que a ventral.}

Distichodus notospilus, Neolebias unifasciatus, Nannocharax fasciatus, Xenocharax spilurus, Apareiodon piracicabae, Parodon nasus, Saccodon wagneri, Bivibranchia fowleri, Hemiodus unimaculatus, Curimata ocellata, Curimatopsis macrolepis, Potamorhina latior, Prochilodus nigricans, Semaprochilodus insignis, Anostomus anostomus, Leporellus vittatus, Leporinus fasciatus, Schizodon fasciatus, Hydrolycus tatauaia, Roestes molossus, Ctenolucius hujeta, Lebiasina bimaculata, Piabucina astrigata, Erythrinus erythrinus, Hoplias malabaricus, Hepsetus odoe, Crenuchus spilurus, Agoniates halecinus, Axelrodia reisei, Brittanichthys axelrodi, Charax cf. leticiae, Ctenobrycon hauxwellianus, Deuterodon iguape, Galeocharax knerii, Gymnocorymbus ternetzi, Hemibrycon polyodon, Hemigrammus unilineatus, Hollandichthys multifasciatus, Hyphessobrycon compressus, Landonia latidens, Metynnis lippincottianus, Microschemobrycon casiquiare, Moenkhausia xinguensis, Odontostilbe pequira, oligosarcus argenteus, orthospinus franciscoensis, Paracheirodon axelrodi, Paragoniates alburnus, Phenacogaster pectinatus, Phenagoniates macrolepis, Piabina argentea, Poptella brevispina, Probolus heterostomus, Rachoviscus graciliceps, Rhinobrycon negrensis, Rhoadsia altipinna, Roeboexodon guyanensis, Salminus hilarii, Serrabrycon magoi, Stygichthys typhlops, Tetragonopterus argenteus e Triportheus albus.

\section{[2] - dorsal ausente.}

Chanos chanos, Catostomus commersonnii, Olivaichthys mesembrinus, Gymnotus aff. carapo, Carnegiella strigata, Gasteropelecus sternicla, Thoracocharax stellatus, Acestrorhynchus falcirostris, Erythrinoidea fam. nov. e Boulengerella maculata.

\section{[-] - inaplicável.}

Citharinus latus, Caenotropus labyrinthicus, Chilodus punctatus e copeina cf. guttata.

\section{3 - Margem posterior do epoccipital:}

[NeTto-FERREIRA, 2006: 67]

[0] - lisa.

Chanos chanos, Catostomus commersonnii, Olivaichthys mesembrinus, Gymnotus aff. carapo, Citharinus latus, Distichodus notospilus, Hemistichodus vaillanti, Neolebias unifasciatus, Nannocharax fasciatus, Xenocharax spilurus, Caenotropus labyrinthicus, Chilodus punctatus, Anostomus anostomus, Leporinus fasciatus, Schizodon fasciatus, Carnegiella strigata, Gasteropelecus sternicla, Thoracocharax stellatus Acestrorhynchus falcirostris, Hydrolycus tatauaia, Roestes molossus, Erythrinoidea fam. nov, Copeina cf. guttata, Lebiasina bimaculata, Piabucina astrigata, Erythrinus erythrinus, Hoplias malabaricus, Arnoldichthys spilopterus, Brycinus macrolepidotus, Bryconalestes longipinnis, Chalceus epakros, Characidium bahiensis, Crenuchus spilurus, Aphyocharax pusillus, Astyanax mexicanus, Atopomesus pachyodus, Axelrodia reisei, Brittanichthys axelrodi, Brycon pesu, Bryconadenos tanaothoros, Bryconamericus exodon, Bryconops alburnoides, Charax cf. leticiae, Clupeacharax cf. engrauloides, Compsura heterura, Ctenobrycon hauxwellianus, Deuterodon iguape, Diapoma terofali, Galeocharax knerii, Glandulocauda melanogenys, Gnathocharax steindachneri, Gymnocorymbus ternetzi, Hemibrycon polyodon, Hemigrammus unilineatus, Hollandichthys multifasciatus, Hyphessobrycon compressus, Iguanodectes geisleri, Knodus meridae, Landonia latidens, Markiana nigripinnis, Metynnis lippincottianus, Microschemobrycon casiquiare, Moenkhausia xinguensis, Myleus setiger, odontostilbe pequira, Orthospinus franciscoensis, Paracheirodon axelrodi, Paragoniates alburnus, Phenacogaster pectinatus, Phenagoniates macrolepis, Piabina argentea, Piaractus mesopotamicus, Poptella brevispina, Probolus heterostomus, Rachoviscus graciliceps, Rhinobrycon negrensis, Rhoadsia altipinna, Roeboexodon guyanensis, Salminus hilarii, Serrabrycon magoi, Stygichthys typhlops e Tetragonopterus argenteus.

\section{[1] - com processo posterior.}

Apareiodon piracicabae, Parodon nasus, Saccodon wagneri, Anodus orinocensis, Bivibranchia fowleri, Hemiodus unimaculatus, Curimata ocellata, Curimatopsis macrolepis, Potamorhina latior, Prochilodus nigricans, semaprochilodus insignis, Leporellus vittatus, Gilbertolus atratoensis, Boulengerella maculata, ctenolucius hujeta, Hepsetus odoe, Agoniates halecinus, Oligosarcus argenteus e Triportheus albus. 
114 - Pterótico:

[LuCENA, 1993: 17 modificado; NetTo-FerReira, 2006: 62 modificado]

\section{[0] - sem processo posterior.}

Gymnotus aff. carapo, Carnegiella strigata, Gilbertolus atratoensis, Erythrinoidea fam. nov, Characidium bahiensis, Crenuchus spilurus, Atopomesus pachyodus, Axelrodia reisei, Brittanichthys axelrodi, Bryconadenos tanaothoros, Bryconamericus exodon, Compsura heterura, Ctenobrycon hauxwellianus, Diapoma terofali, Glandulocauda melanogenys, Hyphessobrycon compressus, Knodus meridae, Landonia latidens, Microschemobrycon casiquiare, Odontostilbe pequira, orthospinus franciscoensis, Paracheirodon axelrodi, Paragoniates alburnus, Rachoviscus graciliceps, Rhoadsia altipinna e serrabrycon magoi.

\section{[1] - processo posterior pequeno (Fig. 35 e Fig. 36).}

Distichodus notospilus, Hemistichodus vaillanti, Neolebias unifasciatus, Nannocharax fasciatus, Xenocharax spilurus, Saccodon wagneri, Curimatopsis macrolepis, Caenotropus labyrinthicus, Chilodus punctatus, Schizodon fasciatus, Gasteropelecus sternicla, Acestrorhynchus falcirostris, Hydrolycus tatauaia, Roestes molossus, Boulengerella maculata, Ctenolucius hujeta, Copeina cf. guttata, Lebiasina bimaculata, Erythrinus erythrinus, Hoplias malabaricus, Hepsetus odoe, Arnoldichthys spilopterus, Brycinus macrolepidotus, Bryconalestes longipinnis, Chalceus epakros, Aphyocharax pusillus, Astyanax mexicanus, Brycon pesu, Bryconops alburnoides, Charax cf. leticiae, Clupeacharax cf. engrauloides, Deuterodon iguape, Galeocharax knerii, Gnathocharax steindachneri, Gymnocorymbus ternetzi, Hemibrycon polyodon, Hemigrammus unilineatus, Hollandichthys multifasciatus, Iguanodectes geisleri, Markiana nigripinnis, Metynnis lippincottianus, Moenkhausia xinguensis, Myleus setiger, oligosarcus argenteus, Phenacogaster pectinatus, Phenagoniates macrolepis, Piabina argentea, Piaractus mesopotamicus, Poptella brevispina, Probolus heterostomus, Rhinobrycon negrensis, Roeboexodon guyanensis, Stygichthys typhlops e Tetragonopterus argenteus.

\section{[2] - processo posterior longo.}

Chanos chanos, Catostomus commersonnii, olivaichthys mesembrinus, Citharinus latus, Apareiodon piracicabae, Parodon nasus, Anodus orinocensis, Bivibranchia fowleri, Hemiodus unimaculatus, Curimata ocellata, Potamorhina latior, Prochilodus nigricans, Semaprochilodus insignis, Anostomus anostomus, Leporellus vittatus, Leporinus fasciatus, Thoracocharax stellatus, Piabucina astrigata, Agoniates halecinus, Salminus hilarii e Triportheus albus.

115 - Espinho do esfenótico:

[VARI， 1995: 23; OYAKAWA, 1998: 11; NETTO-FERREIRA, 2006: 59]

[0] - aproximadamente vertical, contínuo com a superfície ventral do frontal.

Catostomus commersonnii, Citharinus latus, Distichodus notospilus, Hemistichodus vaillanti, Neolebias unifasciatus, Nannocharax fasciatus, Xenocharax spilurus, Apareiodon piracicabae, Parodon nasus, Saccodon wagneri, Anodus orinocensis, Bivibranchia fowleri, Hemiodus unimaculatus, Curimata ocellata, Curimatopsis macrolepis, Potamorhina latior, Prochilodus nigricans, Semaprochilodus insignis, Caenotropus labyrinthicus, Chilodus punctatus, Anostomus anostomus, Leporellus vittatus, Leporinus fasciatus, Schizodon fasciatus, Carnegiella strigata, Gasteropelecus sternicla, Thoracocharax stellatus, Gilbertolus atratoensis, Hydrolycus tatauaia, Roestes molossus, Copeina cf. guttata, Arnoldichthys spilopterus, Brycinus macrolepidotus, Bryconalestes longipinnis, Chalceus epakros, Crenuchus spilurus, Agoniates halecinus, Aphyocharax pusillus, Astyanax mexicanus, Atopomesus pachyodus, Axelrodia reisei, Brittanichthys axelrodi, Brycon pesu, Bryconadenos tanaothoros, Bryconamericus exodon, Bryconops alburnoides, Charax cf. leticiae, Clupeacharax cf. engrauloides, Compsura heterura, Ctenobrycon hauxwellianus, Deuterodon iguape, Diapoma terofali, Gnathocharax steindachneri, Gymnocorymbus ternetzi, Hemigrammus unilineatus, Hollandichthys multifasciatus, Hyphessobrycon compressus, Iguanodectes geisleri, Knodus meridae, Landonia latidens, Markiana nigripinnis, Metynnis lippincottianus, Microschemobrycon casiquiare, Moenkhausia xinguensis, Myleus setiger, Odontostilbe pequira, oligosarcus argenteus, orthospinus franciscoensis, Paracheirodon axelrodi, Paragoniates alburnus, Phenacogaster pectinatus, Phenagoniates macrolepis, Piabina argentea, Piaractus mesopotamicus, Poptella brevispina, Probolus heterostomus Rachoviscus graciliceps, Rhinobrycon negrensis, Rhoadsia altipinna, Roeboexodon guyanensis, Serrabrycon magoi, Stygichthys typhlops, Tetragonopterus argenteus e Triportheus albus. 
[1] - aproximadamente horizontal, não contínuo com a superfície ventral do frontal.

Chanos chanos, Acestrorhynchus falcirostris, Boulengerella maculata, Ctenolucius hujeta, Lebiasina bimaculata, Piabucina astrigata, Erythrinus erythrinus, Hoplias malabaricus, Hepsetus odoe, Galeocharax knerii, Hemibrycon polyodon e Salminus hilarii.

\section{[-] - inaplicável.}

Olivaichthys mesembrinus, Gymnotus aff. carapo, Erythrinoidea fam. nov. e Characidium bahiensis.

\section{[?] - indeterminado.}

Glandulocauda melanogenys.

\section{6 - Forame no pró-ótico (forame auditivo): [FINK \& FINK, 1981: 9]}

[0] - ausente.

Chanos chanos, Catostomus commersonnii, Olivaichthys mesembrinus, Gymnotus aff. carapo e Bryconadenos tanaothoros.

\section{[1] - presente.}

Citharinus latus, Distichodus notospilus, Hemistichodus vaillanti, Neolebias unifasciatus, Nannocharax fasciatus, Xenocharax spilurus, Apareiodon piracicabae, Parodon nasus, Saccodon wagneri, Anodus orinocensis, Bivibranchia fowleri, Hemiodus unimaculatus, Curimata ocellata, Curimatopsis macrolepis, Potamorhina latior, Prochilodus nigricans, Semaprochilodus insignis, Caenotropus labyrinthicus, Chilodus punctatus, Anostomus anostomus, Leporellus vittatus, Leporinus fasciatus, Schizodon fasciatus, Carnegiella strigata, Gasteropelecus sternicla, Thoracocharax stellatus, Acestrorhynchus falcirostris, Gilbertolus atratoensis, Hydrolycus tatauaia, Roestes molossus, Erythrinoidea fam. nov, Boulengerella maculata, Ctenolucius hujeta, Copeina cf. guttata, Lebiasina bimaculata, Piabucina astrigata, Erythrinus erythrinus, Hoplias malabaricus, Hepsetus odoe, Arnoldichthys spilopterus, Brycinus macrolepidotus, Bryconalestes longipinnis, Chalceus epakros, Characidium bahiensis, Crenuchus spilurus, Agoniates halecinus, Aphyocharax pusillus, Astyanax mexicanus, Atopomesus pachyodus, Axelrodia reisei, Brittanichthys axelrodi, Brycon pesu, Bryconamericus exodon, Bryconops alburnoides, Charax cf. leticiae, Clupeacharax cf. engrauloides, Compsura heterura, ctenobrycon hauxwellianus, Deuterodon iguape, Diapoma terofali, Galeocharax knerii, Glandulocauda melanogenys, Gnathocharax steindachneri, Gymnocorymbus ternetzi, Hemibrycon polyodon, Hemigrammus unilineatus, Hollandichthys multifasciatus, Hyphessobrycon compressus, Iguanodectes geisleri, Knodus meridae, Landonia latidens, Markiana nigripinnis, Metynnis lippincottianus, Microschemobrycon casiquiare, Moenkhausia xinguensis, Myleus setiger, Odontostilbe pequira, Oligosarcus argenteus, orthospinus franciscoensis, Paracheirodon axelrodi, Paragoniates alburnus, Phenacogaster pectinatus, Phenagoniates macrolepis, Piabina argentea, Piaractus mesopotamicus, Poptella brevispina, Probolus heterostomus, Rachoviscus graciliceps, Rhinobrycon negrensis, Rhoadsia altipinna, Roeboexodon guyanensis, Salminus hilarii, Serrabrycon magoi, Stygichthys typhlops, Tetragonopterus argenteus e Triportheus albus.

117 - Comprimento do espinho do supra-occipital:

[ZanatA, 2000: 33 modificado; Moreira, 2002: 34; Benine, 2004: 19; NetToFERREIRA, 2006: 72]

\section{(Minimamente conectado).}

[0] - não atingindo a vertical que passa pela face anterior da primeira vértebra.

Catostomus commersonnii, Olivaichthys mesembrinus, Gymnotus aff. carapo, Hemistichodus vaillanti, Neolebias unifasciatus, Nannocharax fasciatus, Saccodon wagneri, Anodus orinocensis, Bivibranchia fowleri, Hemiodus unimaculatus, Curimata ocellata, Anostomus anostomus, Leporellus vittatus, Leporinus fasciatus, Schizodon fasciatus, Carnegiella strigata, Gasteropelecus sternicla, Thoracocharax stellatus, Acestrorhynchus 
falcirostris, Hydrolycus tatauaia, Erythrinoidea fam. nov, Boulengerella maculata, Ctenolucius hujeta, Copeina cf. guttata, Lebiasina bimaculata, Piabucina astrigata, Erythrinus erythrinus, Hoplias malabaricus, Hepsetus odoe, Arnoldichthys spilopterus, Chalceus epakros, Characidium bahiensis, Crenuchus spilurus, Agoniates halecinus, Aphyocharax pusillus, Atopomesus pachyodus, Axelrodia reisei, Brittanichthys axelrodi, Bryconadenos tanaothoros, Bryconamericus exodon, Gnathocharax steindachneri, Hyphessobrycon compressus, Iguanodectes geisleri, Knodus meridae, Microschemobrycon casiquiare, Paracheirodon axelrodi, Piabina argentea, Rachoviscus graciliceps, Rhinobrycon negrensis e Stygichthys typhlops.

\section{[1] - atingindo a vertical entre a primeira e a terceira} vértebra.

Distichodus notospilus, Apareiodon piracicabae, Parodon nasus, Curimatopsis macrolepis, Potamorhina latior, Caenotropus labyrinthicus, Chilodus punctatus, Brycinus macrolepidotus, Bryconalestes longipinnis, Brycon pesu, Bryconops alburnoides, Clupeacharax cf. engrauloides, Compsura heterura, Deuterodon iguape, Diapoma terofali, Galeocharax knerii, Glandulocauda melanogenys, Hemibrycon polyodon, Hollandichthys multifasciatus, Landonia latidens, Moenkhausia xinguensis, Odontostilbe pequira, oligosarcus argenteus, Paragoniates alburnus, Roeboexodon guyanensis, Salminus hilarii, Serrabrycon magoi e Triportheus albus.

\section{[2] - atingindo a vertical que passa entre a terceira e a quarta} vértebra.

Chanos chanos, Citharinus latus, Xenocharax spilurus, Prochilodus nigricans, Semaprochilodus insignis, Gilbertolus atratoensis, Roestes molossus, Astyanax mexicanus, Charax cf. leticiae, Ctenobrycon hauxwellianus, Gymnocorymbus ternetzi, Hemigrammus unilineatus, Markiana nigripinnis, Metynnis lippincottianus, Myleus setiger, orthospinus franciscoensis, Phenacogaster pectinatus, Phenagoniates macrolepis, Piaractus mesopotamicus, Poptella brevispina, Probolus heterostomus, Rhoadsia altipinna e Tetragonopterus argenteus.

118 - Ramo parietal do canal supra-orbital:

[VARI, 1995: 27; OYAKAWA, 1998: 23 modificado; BUCKUP, 1998: 16; ZANATA \& VARI, 2005: 156; NetTo-FerReira, 2006: 185]

\section{[0] - presente no parietal.}

Olivaichthys mesembrinus, Gymnotus aff. carapo, Citharinus latus, Distichodus notospilus, Hemistichodus vaillanti, Neolebias unifasciatus, Nannocharax fasciatus, Xenocharax spilurus, Apareiodon piracicabae, Parodon nasus, Saccodon wagneri, Anodus orinocensis, Bivibranchia fowleri, Hemiodus unimaculatus , Curimata ocellata, Curimatopsis macrolepis, Potamorhina latior, Prochilodus nigricans, Semaprochilodus insignis, Caenotropus labyrinthicus, Chilodus punctatus, Anostomus anostomus, Leporellus vittatus, Leporinus fasciatus, Schizodon fasciatus, Gilbertolus atratoensis, Roestes molossus, Erythrinus erythrinus, Hoplias malabaricus, Arnoldichthys spilopterus, Brycinus macrolepidotus, Bryconalestes longipinnis, Chalceus epakros, Agoniates halecinus, Aphyocharax pusillus, Astyanax mexicanus, Atopomesus pachyodus, Brittanichthys axelrodi, Brycon pesu, Bryconadenos tanaothoros, Bryconamericus exodon, Bryconops alburnoides, Charax cf. leticiae, clupeacharax cf. engrauloides, Compsura heterura, Ctenobrycon hauxwellianus, Deuterodon iguape, Diapoma terofali, Galeocharax knerii, Glandulocauda melanogenys, Gymnocorymbus ternetzi, Hemibrycon polyodon , Hemigrammus unilineatus, Hollandichthys multifasciatus, Knodus meridae, Landonia latidens, Markiana nigripinnis, Metynnis lippincottianus, Microschemobrycon casiquiare, Moenkhausia xinguensis, Myleus setiger, odontostilbe pequira, oligosarcus argenteus, orthospinus franciscoensis, Paragoniates alburnus, Phenacogaster pectinatus, Piabina argentea, Piaractus mesopotamicus, Poptella brevispina, Probolus heterostomus , Rhinobrycon negrensis, Rhoadsia altipinna, Roeboexodon guyanensis, Salminus hilarii, Serrabrycon magoi, Tetragonopterus argenteus e Triportheus albus.

\section{[1] - ausente no parietal.}

Chanos chanos, Catostomus commersonnii, Carnegiella strigata, Gasteropelecus sternicla, Thoracocharax stellatus, Acestrorhynchus falcirostris, Erythrinoidea fam. nov, Boulengerella maculata, ctenolucius hujeta, Copeina cf. guttata, Lebiasina bimaculata, Piabucina astrigata, Hepsetus odoe, Characidium bahiensis, Crenuchus spilurus, Axelrodia reisei, Gnathocharax steindachneri, Hyphessobrycon compressus, Iguanodectes geisleri, Paracheirodon axelrodi, Phenagoniates macrolepis e Rachoviscus graciliceps.

\section{[-] - inaplicável.}


Stygichthys typhlops.

\section{[?] - indeterminado.}

Hydrolycus tatauaia.

119 - Conexão do ligamento de Baudelot:

[FINK \& FINK, 1981:97]

\section{[0] - nas primeiras vértebras.}

Chanos chanos e Catostomus commersonnii.

\section{[1] - no crânio.}

Olivaichthys mesembrinus, Gymnotus aff. carapo, Citharinus latus, Distichodus notospilus, Hemistichodus vaillanti, Neolebias unifasciatus, Nannocharax fasciatus, Xenocharax spilurus, Apareiodon piracicabae, Parodon nasus, Saccodon wagneri, Anodus orinocensis, Bivibranchia fowleri, Hemiodus unimaculatus, Curimata ocellata, Curimatopsis macrolepis, Potamorhina latior, Prochilodus nigricans, Semaprochilodus insignis, Caenotropus labyrinthicus, Chilodus punctatus, Anostomus anostomus, Leporellus vittatus, Leporinus fasciatus, Schizodon fasciatus, Carnegiella strigata, Gasteropelecus sternicla, Thoracocharax stellatus, Acestrorhynchus falcirostris, Gilbertolus atratoensis, Hydrolycus tatauaia, Roestes molossus, Erythrinoidea fam. nov, Boulengerella maculata, Ctenolucius hujeta, Copeina cf. guttata, Lebiasina bimaculata, Piabucina astrigata, Erythrinus erythrinus, Hoplias malabaricus, Hepsetus odoe, Arnoldichthys spilopterus, Brycinus macrolepidotus, Bryconalestes longipinnis, Chalceus epakros, Characidium bahiensis, Crenuchus spilurus, Agoniates halecinus, Aphyocharax pusillus, Astyanax mexicanus, Atopomesus pachyodus, Axelrodia reisei, Brittanichthys axelrodi, Brycon pesu, Bryconadenos tanaothoros, Bryconamericus exodon, Bryconops alburnoides, Charax cf. leticiae, Clupeacharax cf. engrauloides, Compsura heterura, Ctenobrycon hauxwellianus, Deuterodon iguape, Diapoma terofali, Galeocharax knerii, Glandulocauda melanogenys, Gnathocharax steindachneri, Gymnocorymbus ternetzi, Hemibrycon polyodon, Hemigrammus unilineatus, Hollandichthys multifasciatus, Hyphessobrycon compressus, Iguanodectes geisleri, Knodus meridae, Landonia latidens, Markiana nigripinnis, Metynnis lippincottianus, Microschemobrycon casiquiare, Moenkhausia xinguensis, Myleus setiger, Odontostilbe pequira, oligosarcus argenteus, Orthospinus franciscoensis, Paracheirodon axelrodi, Paragoniates alburnus, Phenacogaster pectinatus, Phenagoniates macrolepis, Piabina argentea, Piaractus mesopotamicus, Poptella brevispina, Probolus heterostomus, Rachoviscus graciliceps, Rhinobrycon negrensis, Rhoadsia altipinna, Roeboexodon guyanensis, Salminus hilarii, Serrabrycon magoi, Stygichthys typhlops, Tetragonopterus argenteus e Triportheus albus.

\section{0 - Área de inserção do ligamento de Baudelot no neurocrânio: [ZANATA \& VARI, 2005: 48]}

\section{[0] - na porção posterior da cápsula lagenar.}

Olivaichthys mesembrinus, Gymnotus aff. carapo, Citharinus latus, Apareiodon piracicabae, Parodon nasus, Saccodon wagneri, Anodus orinocensis, Bivibranchia fowleri, Hemiodus unimaculatus, Curimata ocellata, Curimatopsis macrolepis, Potamorhina latior, Prochilodus nigricans, Semaprochilodus insignis, Caenotropus labyrinthicus, Chilodus punctatus, Anostomus anostomus, Leporellus vittatus, Leporinus fasciatus, Schizodon fasciatus, Acestrorhynchus falcirostris, Hydrolycus tatauaia, Roestes molossus, Erythrinoidea fam. nov, Boulengerella maculata, Ctenolucius hujeta, Lebiasina bimaculata, Piabucina astrigata, Erythrinus erythrinus, Hoplias malabaricus, Hepsetus odoe, Galeocharax knerii, Salminus hilarii e Triportheus albus.

\section{[1] - na porção anterior da cápsula lagenar (Fig. 36).}

Distichodus notospilus, Hemistichodus vaillanti, Neolebias unifasciatus, Nannocharax fasciatus, Xenocharax spilurus, Carnegiella strigata, Gasteropelecus sternicla, Thoracocharax stellatus, Gilbertolus atratoensis, Copeina cf. guttata, Arnoldichthys spilopterus, Brycinus macrolepidotus, Bryconalestes longipinnis, Chalceus epakros, Characidium bahiensis, Crenuchus spilurus, Agoniates halecinus, Aphyocharax pusillus, Astyanax mexicanus, Axelrodia reisei, Brittanichthys axelrodi, Brycon pesu, Bryconadenos tanaothoros, Bryconamericus exodon, Bryconops alburnoides, Charax cf. leticiae, Clupeacharax cf. engrauloides, Compsura heterura, Ctenobrycon hauxwellianus, Deuterodon 
iguape, Diapoma terofali, Glandulocauda melanogenys, Gnathocharax steindachneri, Gymnocorymbus ternetzi, Hemibrycon polyodon, Hemigrammus unilineatus, Hollandichthys multifasciatus, Iguanodectes geisleri, Markiana nigripinnis, Metynnis lippincottianus, Moenkhausia xinguensis, Myleus setiger, orthospinus franciscoensis, Paracheirodon axelrodi, Phenacogaster pectinatus, Phenagoniates macrolepis, Piabina argentea, Piaractus mesopotamicus, Poptella brevispina, Probolus heterostomus, Rachoviscus graciliceps, Rhinobrycon negrensis, Rhoadsia altipinna, Roeboexodon guyanensis, Serrabrycon magoi e Tetragonopterus argenteus.

\section{[-] - inaplicável.}

Chanos chanos e Catostomus commersonnii.

\section{[?] - indeterminado.}

Atopomesus pachyodus, Hyphessobrycon compressus, Knodus meridae, Landonia latidens, Microschemobrycon casiquiare, Odontostilbe pequira, oligosarcus argenteus, Paragoniates alburnus e Stygichthys typhlops.

\section{1 - Capsula lagenar:}

[Fink \& Fink, 1981: 15]

\section{[0] - grande.}

Citharinus latus, Distichodus notospilus, Hemistichodus vaillanti, Neolebias unifasciatus, Nannocharax fasciatus, Xenocharax spilurus, Anodus orinocensis, Bivibranchia fowleri, Hemiodus unimaculatus, Curimata ocellata, Curimatopsis macrolepis, Potamorhina latior, Prochilodus nigricans, Semaprochilodus insignis, Caenotropus labyrinthicus, Chilodus punctatus, Anostomus anostomus, Schizodon fasciatus, Carnegiella strigata, Gasteropelecus sternicla, Thoracocharax stellatus, Acestrorhynchus falcirostris, Gilbertolus atratoensis, Hydrolycus tatauaia, Roestes molossus, Erythrinoidea fam. nov, Copeina cf. guttata, Lebiasina bimaculata, Piabucina astrigata, Erythrinus erythrinus, Hoplias malabaricus, Hepsetus odoe, Arnoldichthys spilopterus, Brycinus macrolepidotus, Bryconalestes longipinnis, Chalceus epakros, Characidium bahiensis, Crenuchus spilurus, Agoniates halecinus, Aphyocharax pusillus, Astyanax mexicanus, Atopomesus pachyodus, Axelrodia reisei, Brittanichthys axelrodi, Brycon pesu, Bryconadenos tanaothoros, Bryconamericus exodon, Bryconops alburnoides, Charax cf. leticiae, Clupeacharax cf. engrauloides, Compsura heterura, Ctenobrycon hauxwellianus, Deuterodon iguape, Diapoma terofali, Galeocharax knerii, Glandulocauda melanogenys, Gnathocharax steindachneri, Gymnocorymbus ternetzi, Hemibrycon polyodon Hemigrammus unilineatus, Hollandichthys multifasciatus, Hyphessobrycon compressus, Iguanodectes geisleri, Knodus meridae, Landonia latidens, Markiana nigripinnis, Metynnis lippincottianus, Microschemobrycon casiquiare, Moenkhausia xinguensis, Myleus setiger, odontostilbe pequira, oligosarcus argenteus, orthospinus franciscoensis, Paracheirodon axelrodi, Paragoniates alburnus, Phenacogaster pectinatus, Phenagoniates macrolepis, Piabina argentea, Poptella brevispina, Probolus heterostomus, Rachoviscus graciliceps, Rhinobrycon negrensis, Rhoadsia altipinna, Roeboexodon guyanensis, Salminus hilarii, Serrabrycon magoi, Stygichthys typhlops, Tetragonopterus argenteus e Triportheus albus.

\section{[1] - pequena.}

Chanos chanos, Catostomus commersonnii, Olivaichthys mesembrinus, Gymnotus aff. carapo, Apareiodon piracicabae, Parodon nasus, Saccodon wagneri, Leporellus vittatus, Leporinus fasciatus, Boulengerella maculata e Ctenolucius hujeta.

\section{[?] - indeterminado.}

Piaractus mesopotamicus.

\subsubsection{Região orbital}

122 - Antorbital:

[LUCENA, 1993: 25; VARI, 1995: 1; BUCKUP, 1998: 20; OYAKAWA, 1998: 28; ZANATA \& VARI, 2005: 1 e NetTo-FerReira, 2006: 1]

[0] - ausente. 
Catostomus commersonnii, Curimatopsis macrolepis, Erythrinoidea fam. nov, Boulengerella maculata, Ctenolucius hujeta, Erythrinus erythrinus, Hoplias malabaricus, Astyanax mexicanus e Glandulocauda melanogenys.

[1] - presente (Figs. 37, 38, 39, 40 e 41).

Chanos chanos, Olivaichthys mesembrinus, Gymnotus aff. carapo, Citharinus latus, Distichodus notospilus, Hemistichodus vaillanti, Neolebias unifasciatus, Nannocharax fasciatus, Xenocharax spilurus, Apareiodon piracicabae, Parodon nasus, Saccodon wagneri, Anodus orinocensis, Bivibranchia fowleri, Hemiodus unimaculatus, Curimata ocellata, Potamorhina latior, Prochilodus nigricans, Semaprochilodus insignis, Caenotropus labyrinthicus, Chilodus punctatus, Anostomus anostomus, Leporellus vittatus, Leporinus fasciatus, Schizodon fasciatus, Carnegiella strigata, Gasteropelecus sternicla, Thoracocharax stellatus, Acestrorhynchus falcirostris, Gilbertolus atratoensis, Hydrolycus tatauaia, Roestes molossus, Copeina cf. guttata, Lebiasina bimaculata, Piabucina astrigata, Hepsetus odoe, Arnoldichthys spilopterus, Brycinus macrolepidotus, Bryconalestes longipinnis, Chalceus epakros, Characidium bahiensis, Crenuchus spilurus, Agoniates halecinus, Aphyocharax pusillus, Atopomesus pachyodus, Axelrodia reisei, Brittanichthys axelrodi, Brycon pesu, Bryconadenos tanaothoros, Bryconamericus exodon, Bryconops alburnoides, Charax cf. leticiae, Clupeacharax cf. engrauloides, Compsura heterura, Ctenobrycon hauxwellianus, Deuterodon iguape, Diapoma terofali, Galeocharax knerii, Gnathocharax steindachneri, Gymnocorymbus ternetzi, Hemibrycon polyodon Hemigrammus unilineatus, Hollandichthys multifasciatus, Hyphessobrycon compressus, Iguanodectes geisleri, Knodus meridae, Landonia latidens, Markiana nigripinnis, Metynnis lippincottianus, Microschemobrycon casiquiare, Moenkhausia xinguensis, Myleus setiger, odontostilbe pequira, Oligosarcus argenteus, Orthospinus franciscoensis, Paracheirodon axelrodi, Paragoniates alburnus, Phenacogaster pectinatus, Phenagoniates macrolepis, Piabina argentea, Piaractus mesopotamicus, Poptella brevispina, Probolus heterostomus, Rachoviscus graciliceps, Rhinobrycon negrensis, Rhoadsia altipinna, Roeboexodon guyanensis, Salminus hilarii, Serrabrycon magoi, Stygichthys typhlops, Tetragonopterus argenteus e Triportheus albus.

\section{3 - Margens ventral e posterior do antorbital:}

[NeTto-FERREIRA, 2006: 1]

\section{[0] - ventral menor que a posterior (Figs. 37, 38, 39 e 40).}

Citharinus latus, Distichodus notospilus, Hemistichodus vaillanti, Neolebias unifasciatus, Nannocharax fasciatus, Xenocharax spilurus, Apareiodon piracicabae, Parodon nasus, Saccodon wagneri, Anodus orinocensis, Bivibranchia fowleri, Hemiodus unimaculatus, Curimata ocellata, Potamorhina latior, Prochilodus nigricans, Semaprochilodus insignis, Caenotropus labyrinthicus, Chilodus punctatus, Leporellus vittatus, Thoracocharax stellatus, Acestrorhynchus falcirostris, Gilbertolus atratoensis, Hydrolycus tatauaia, Roestes molossus, Lebiasina bimaculata, Arnoldichthys spilopterus, Chalceus epakros, Characidium bahiensis, Crenuchus spilurus, Aphyocharax pusillus, Astyanax mexicanus, Atopomesus pachyodus, Axelrodia reisei, Brittanichthys axelrodi, Bryconadenos tanaothoros, Bryconamericus exodon, Bryconops alburnoides, Charax cf. leticiae, Clupeacharax cf. engrauloides, Compsura heterura, Ctenobrycon hauxwellianus, Deuterodon iguape, Diapoma terofali, Galeocharax knerii, Glandulocauda melanogenys, Gnathocharax steindachneri, Gymnocorymbus ternetzi, Hemibrycon polyodon, Hemigrammus unilineatus, Hollandichthys multifasciatus, Hyphessobrycon compressus, Iguanodectes geisleri, Knodus meridae, Landonia latidens, Markiana nigripinnis, Metynnis lippincottianus, Microschemobrycon casiquiare, Moenkhausia xinguensis, Myleus setiger, odontostilbe pequira, oligosarcus argenteus, orthospinus franciscoensis, Paracheirodon axelrodi, Paragoniates alburnus, Phenacogaster pectinatus, Phenagoniates macrolepis, Piabina argentea, Piaractus mesopotamicus, Poptella brevispina, Probolus heterostomus, Rachoviscus graciliceps, Rhinobrycon negrensis, Rhoadsia altipinna, Roeboexodon guyanensis, Salminus hilarii, Serrabrycon magoi, Tetragonopterus argenteus e Triportheus albus.

41).

[1] - ventral do mesmo tamanho, ou maior que a posterior (Fig.

Chanos chanos, Olivaichthys mesembrinus, Anostomus anostomus, Leporinus fasciatus, Schizodon fasciatus, Carnegiella strigata, Gasteropelecus sternicla, Copeina cf. guttata, Piabucina astrigata, Hepsetus odoe, Brycinus macrolepidotus, Bryconalestes longipinnis, Agoniates halecinus, Brycon pesu e Stygichthys typhlops.

\section{[-] - inaplicável.}


Catostomus commersonnii, Gymnotus aff. carapo, Curimatopsis macrolepis, Erythrinoidea fam. nov, Boulengerella maculata, Ctenolucius hujeta, Erythrinus erythrinus e Hoplias malabaricus.

\section{4 - Margem anterior do antorbital:}

\section{[0] - reta ou convexa (Fig. 38).}

Chanos chanos, Citharinus latus, Hemistichodus vaillanti, Apareiodon piracicabae, Parodon nasus, Saccodon wagneri, Anodus orinocensis, Bivibranchia fowleri, Curimata ocellata, Prochilodus nigricans, Semaprochilodus insignis, Caenotropus labyrinthicus, Chilodus punctatus, Anostomus anostomus, Gilbertolus atratoensis, Roestes molossus, Arnoldichthys spilopterus, Brycinus macrolepidotus, Bryconadenos tanaothoros, Bryconamericus exodon, Clupeacharax cf. engrauloides, ctenobrycon hauxwellianus, Gnathocharax steindachneri, Gymnocorymbus ternetzi, Hemibrycon polyodon, Hemigrammus unilineatus, Hollandichthys multifasciatus, Hyphessobrycon compressus, Markiana nigripinnis, Microschemobrycon casiquiare, Paracheirodon axelrodi, Paragoniates alburnus, Phenagoniates macrolepis, Poptella brevispina, Probolus heterostomus, Rhoadsia altipinna e Tetragonopterus argenteus.

\section{[1] - côncava (Figs. 37, 39, 40 e 41).}

Olivaichthys mesembrinus, Distichodus notospilus, Neolebias unifasciatus, Nannocharax fasciatus, Xenocharax spilurus, Potamorhina latior, Leporellus vittatus, Leporinus fasciatus, Schizodon fasciatus, Carnegiella strigata, Gasteropelecus sternicla, Thoracocharax stellatus, Acestrorhynchus falcirostris, Hydrolycus tatauaia, Copeina cf. guttata, Lebiasina bimaculata, Piabucina astrigata, Hepsetus odoe, Bryconalestes longipinnis, Chalceus epakros, Characidium bahiensis, Crenuchus spilurus, Agoniates halecinus, Aphyocharax pusillus, Astyanax mexicanus, Atopomesus pachyodus, Axelrodia reisei, Brittanichthys axelrodi, Brycon pesu, Bryconops alburnoides, Charax cf. leticiae, Compsura heterura, Deuterodon iguape, Diapoma terofali, Galeocharax knerii, Glandulocauda melanogenys, Iguanodectes geisleri, Knodus meridae, Landonia latidens, Metynnis lippincottianus, Moenkhausia xinguensis, Myleus setiger, odontostilbe pequira, oligosarcus argenteus, Orthospinus franciscoensis, Phenacogaster pectinatus, Piabina argentea, Piaractus mesopotamicus, Rachoviscus graciliceps, Rhinobrycon negrensis, Roeboexodon guyanensis, Salminus hilarii, Serrabrycon magoi, Stygichthys typhlops e Triportheus albus.

\section{[-] - inaplicável.}

Catostomus commersonnii, Gymnotus aff. carapo, Curimatopsis macrolepis, Erythrinoidea fam. nov, Boulengerella maculata, Ctenolucius hujeta, Erythrinus erythrinus, Hoplias malabaricus

\section{[?] - indeterminado.}

Hemiodus unimaculatus

125 - Canal sensorial no antorbital:

[ZANATA, 2000: 1, modificado; e NETTO-FERREIRA, 2006: 186]

\section{[0] - ausente.}

Chanos chanos, Olivaichthys mesembrinus, Citharinus latus, Distichodus notospilus, Hemistichodus vaillanti, Neolebias unifasciatus, Nannocharax fasciatus, Xenocharax spilurus, Apareiodon piracicabae, Parodon nasus, Saccodon wagneri, Anodus orinocensis, Bivibranchia fowleri, Hemiodus unimaculatus, Curimata ocellata, Potamorhina latior, Prochilodus nigricans, Caenotropus labyrinthicus, Chilodus punctatus, Anostomus anostomus, Leporellus vittatus, Leporinus fasciatus, Schizodon fasciatus, Carnegiella strigata, Gasteropelecus sternicla, Thoracocharax stellatus, Acestrorhynchus falcirostris, Gilbertolus atratoensis, Roestes molossus, Hepsetus odoe, Arnoldichthys spilopterus, Brycinus macrolepidotus, Bryconalestes longipinnis, Chalceus epakros, Characidium bahiensis, Crenuchus spilurus, Agoniates halecinus, Aphyocharax pusillus, Astyanax mexicanus, Atopomesus pachyodus, Axelrodia reisei, Brittanichthys axelrodi, Brycon pesu, Bryconadenos tanaothoros, Bryconamericus exodon, Charax cf. leticiae, Clupeacharax cf. engrauloides, Compsura heterura, Ctenobrycon hauxwellianus, Deuterodon iguape, Diapoma terofali, Galeocharax knerii, Glandulocauda melanogenys, Gnathocharax steindachneri, Gymnocorymbus ternetzi, Hemibrycon polyodon, Hemigrammus unilineatus, Hollandichthys multifasciatus, Hyphessobrycon compressus, Iguanodectes geisleri, Knodus meridae, Landonia latidens, Markiana nigripinnis, Metynnis lippincottianus, Microschemobrycon casiquiare, Moenkhausia xinguensis, Myleus setiger, Odontostilbe 
pequira, oligosarcus argenteus, orthospinus franciscoensis, Paracheirodon axelrodi, Paragoniates alburnus, Phenacogaster pectinatus, Phenagoniates macrolepis, Piabina argentea, Piaractus mesopotamicus, Poptella brevispina, Probolus heterostomus Rachoviscus graciliceps, Rhinobrycon negrensis, Rhoadsia altipinna, Roeboexodon guyanensis, Serrabrycon magoi, Stygichthys typhlops, Tetragonopterus argenteus e Triportheus albus.

\section{[1] - presente.}

Gymnotus aff. carapo, Semaprochilodus insignis, Hydrolycus tatauaia, Copeina cf. guttata, Lebiasina bimaculata, Piabucina astrigata, Bryconops alburnoides e Salminus hilarii.

\section{[-] - inaplicável.}

Catostomus commersonnii, Curimatopsis macrolepis, Erythrinoidea fam. nov, Boulengerella maculata, ctenolucius hujeta, Erythrinus erythrinus e Hoplias malabaricus.

[0] - plano.

Arnoldichthys spilopterus, Brycinus macrolepidotus, Bryconalestes longipinnis, crenuchus spilurus, Agoniates halecinus, Brycon pesu, Clupeacharax cf. engrauloides.

\section{[1] - tri-dimensional.}

Chanos chanos, Olivaichthys mesembrinus, Citharinus latus, Distichodus notospilus, Hemistichodus vaillanti, Neolebias unifasciatus, Nannocharax fasciatus, Xenocharax spilurus, Apareiodon piracicabae, Parodon nasus, Anodus orinocensis, Bivibranchia fowleri, Hemiodus unimaculatus, Curimata ocellata, Potamorhina latior, Prochilodus nigricans, Semaprochilodus insignis, Caenotropus labyrinthicus, Chilodus punctatus, Anostomus anostomus, Leporellus vittatus, Leporinus fasciatus, Schizodon fasciatus, Carnegiella strigata, Gasteropelecus sternicla, Thoracocharax stellatus Acestrorhynchus falcirostris, Gilbertolus atratoensis, Hydrolycus tatauaia, Roestes molossus, Copeina cf. guttata, Lebiasina bimaculata, Piabucina astrigata, Hepsetus odoe, Chalceus epakros, Characidium bahiensis, Aphyocharax pusillus, Astyanax mexicanus, Atopomesus pachyodus, Axelrodia reisei, Brittanichthys axelrodi, Bryconadenos tanaothoros, Bryconamericus exodon, Bryconops alburnoides, Charax cf. leticiae, Compsura heterura, Ctenobrycon hauxwellianus, Deuterodon iguape, Diapoma terofali, Galeocharax knerii, Glandulocauda melanogenys, Gnathocharax steindachneri, Gymnocorymbus ternetzi, Hemibrycon polyodon, Hemigrammus unilineatus, Hollandichthys multifasciatus, Hyphessobrycon compressus, Iguanodectes geisleri, Knodus meridae, Landonia latidens, Markiana nigripinnis, Metynnis lippincottianus, Microschemobrycon casiquiare, Moenkhausia xinguensis, Myleus setiger, Odontostilbe pequira, Oligosarcus argenteus, orthospinus franciscoensis, Paracheirodon axelrodi, Paragoniates alburnus, Phenacogaster pectinatus, Phenagoniates macrolepis, Piabina argentea, Piaractus mesopotamicus, Poptella brevispina, Probolus heterostomus, Rachoviscus graciliceps, Rhinobrycon negrensis, Rhoadsia altipinna, Roeboexodon guyanensis, Salminus hilarii, Serrabrycon magoi, Stygichthys typhlops, Tetragonopterus argenteus, Triportheus albus

\section{[-] - inaplicável.}

Catostomus commersonnii, Gymnotus aff. carapo, Curimatopsis macrolepis, Erythrinoidea fam. nov, Boulengerella maculata, Ctenolucius hujeta, Erythrinus erythrinus e Hoplias malabaricus.

\section{[?] - indeterminado.}

Saccodon wagneri.

\section{7 - Posição do antorbital em relação ao etmóide lateral:} [TOLEDO-PIZA, 2000: 2]

\section{[0] - sobreposto ao etmóide lateral.}

Chanos chanos, Carnegiella strigata, Gasteropelecus sternicla, Thoracocharax stellatus , Hydrolycus tatauaia, Copeina cf. guttata, Lebiasina bimaculata, Piabucina astrigata, 
Agoniates halecinus, Clupeacharax cf. engrauloides, Galeocharax knerii, oligosarcus argenteus e Triportheus albus.

\section{[1] - sem contato com o etmóide lateral.}

Olivaichthys mesembrinus, Gymnotus aff. carapo, Citharinus latus, Distichodus notospilus, Hemistichodus vaillanti, Neolebias unifasciatus, Nannocharax fasciatus, Xenocharax spilurus, Apareiodon piracicabae, Parodon nasus, Saccodon wagneri, Anodus orinocensis, Bivibranchia fowleri, Hemiodus unimaculatus, Curimata ocellata, Potamorhina latior, Prochilodus nigricans, Semaprochilodus insignis, Caenotropus labyrinthicus, Chilodus punctatus, Anostomus anostomus, Leporellus vittatus, Leporinus fasciatus, Schizodon fasciatus, Acestrorhynchus falcirostris, Gilbertolus atratoensis, Roestes molossus, Hepsetus odoe, Arnoldichthys spilopterus, Brycinus macrolepidotus, Bryconalestes longipinnis, Chalceus epakros, Characidium bahiensis, Crenuchus spilurus, Aphyocharax pusillus, Astyanax mexicanus, Atopomesus pachyodus, Axelrodia reisei, Brittanichthys axelrodi, Brycon pesu, Bryconadenos tanaothoros, Bryconamericus exodon, Bryconops alburnoides, Charax cf. leticiae, Compsura heterura, Ctenobrycon hauxwellianus, Deuterodon iguape, Diapoma terofali, Glandulocauda melanogenys, Gnathocharax steindachneri, Gymnocorymbus ternetzi, Hemibrycon polyodon, Hemigrammus unilineatus, Hollandichthys multifasciatus, Hyphessobrycon compressus, Iguanodectes geisleri, Knodus meridae, Landonia latidens, Markiana nigripinnis, Metynnis lippincottianus, Microschemobrycon casiquiare, Moenkhausia xinguensis, Myleus setiger, odontostilbe pequira, Orthospinus franciscoensis, Paracheirodon axelrodi, Paragoniates alburnus, Phenacogaster pectinatus, Phenagoniates macrolepis, Piabina argentea, Piaractus mesopotamicus, Poptella brevispina, Probolus heterostomus, Rachoviscus graciliceps, Rhinobrycon negrensis, Rhoadsia altipinna, Roeboexodon guyanensis, Salminus hilarii, Serrabrycon magoi, Stygichthys typhlops e Tetragonopterus argenteus.

\section{[-] - inaplicável.}

Catostomus commersonnii, Curimatopsis macrolepis, Erythrinoidea fam. nov, Boulengerella maculata, Ctenolucius hujeta, Erythrinus erythrinus e Hoplias malabaricus.

\section{8 - Margem ântero-dorsal do infra-orbital 1:}

\section{[0] - reta.}

Chanos chanos, Catostomus commersonnii, Citharinus latus, Apareiodon piracicabae, Parodon nasus, Anodus orinocensis, Bivibranchia fowleri, Hemiodus unimaculatus, Curimata ocellata, Curimatopsis macrolepis, Potamorhina latior, Caenotropus labyrinthicus, Chilodus punctatus, Anostomus anostomus, Leporellus vittatus, Leporinus fasciatus, Schizodon fasciatus, Gasteropelecus sternicla, Thoracocharax stellatus, Acestrorhynchus falcirostris, Gilbertolus atratoensis, Hydrolycus tatauaia, Roestes molossus, Copeina cf. guttata, Lebiasina bimaculata, Piabucina astrigata, Arnoldichthys spilopterus, Brycinus macrolepidotus, Bryconalestes longipinnis, Chalceus epakros, Crenuchus spilurus, Agoniates halecinus, Aphyocharax pusillus, Astyanax mexicanus, Atopomesus pachyodus, Axelrodia reisei, Brittanichthys axelrodi, Brycon pesu, Bryconadenos tanaothoros, Bryconamericus exodon, Charax cf. leticiae, Compsura heterura, Ctenobrycon hauxwellianus, Galeocharax knerii, Glandulocauda melanogenys, Gymnocorymbus ternetzi, Hemibrycon polyodon, Hyphessobrycon compressus, Iguanodectes geisleri, Landonia latidens, Markiana nigripinnis, Metynnis lippincottianus, Microschemobrycon casiquiare, Odontostilbe pequira, oligosarcus argenteus, orthospinus franciscoensis, Paragoniates alburnus, Phenacogaster pectinatus, Phenagoniates macrolepis, Piabina argentea, Poptella brevispina, Rhinobrycon negrensis, Rhoadsia altipinna, Roeboexodon guyanensis e Triportheus albus.

\section{[1] - ligeiramente curva medialmente, ou espessada.}

Distichodus notospilus, Hemistichodus vaillanti, Neolebias unifasciatus, Nannocharax fasciatus, Xenocharax spilurus, Prochilodus nigricans, Semaprochilodus insignis, Boulengerella maculata, Ctenolucius hujeta, Erythrinus erythrinus, Hoplias malabaricus, Hepsetus odoe, Bryconops alburnoides, Clupeacharax cf. engrauloides, Deuterodon iguape, Diapoma terofali, Gnathocharax steindachneri, Hemigrammus unilineatus, Hollandichthys multifasciatus, Knodus meridae, Moenkhausia xinguensis, Myleus setiger, Paracheirodon axelrodi, Probolus heterostomus, Rachoviscus graciliceps, Salminus hilarii, Serrabrycon magoi e Tetragonopterus argenteus.

\section{[-] - inaplicável.}

Olivaichthys mesembrinus, Gymnotus aff. carapo, Carnegiella strigata, Erythrinoidea fam. nov, Characidium bahiensis e Stygichthys typhlops. 


\section{[?] - indeterminado.}

Saccodon wagneri e Piaractus mesopotamicus.

129 - Face medial do infra-orbital 1:

[0] - lisa.

Chanos chanos, Catostomus commersonnii, Citharinus latus, Distichodus notospilus, Hemistichodus vaillanti, Neolebias unifasciatus, Nannocharax fasciatus, Xenocharax spilurus, Apareiodon piracicabae, Parodon nasus, Anodus orinocensis, Bivibranchia fowleri, Hemiodus unimaculatus, Curimata ocellata, Curimatopsis macrolepis, Potamorhina latior, Prochilodus nigricans, Semaprochilodus insignis, Caenotropus labyrinthicus, Chilodus punctatus, Anostomus anostomus, Leporellus vittatus, Leporinus fasciatus, Schizodon fasciatus, Gasteropelecus sternicla, Thoracocharax stellatus, Hydrolycus tatauaia, Boulengerella maculata, Ctenolucius hujeta, Copeina cf. guttata, Lebiasina bimaculata, Piabucina astrigata, Hepsetus odoe, Arnoldichthys spilopterus, Brycinus macrolepidotus, Bryconalestes longipinnis, Chalceus epakros, Characidium bahiensis, Crenuchus spilurus, Agoniates halecinus, Aphyocharax pusillus, Astyanax mexicanus, Atopomesus pachyodus, Axelrodia reisei, Brittanichthys axelrodi, Brycon pesu, Bryconadenos tanaothoros, Bryconamericus exodon, Bryconops alburnoides, Charax cf. leticiae, Clupeacharax cf. engrauloides, Compsura heterura, Ctenobrycon hauxwellianus, Deuterodon iguape, Diapoma terofali, Galeocharax knerii, Glandulocauda melanogenys, Gnathocharax steindachneri, Gymnocorymbus ternetzi, Hemibrycon polyodon, Hemigrammus unilineatus, Hollandichthys multifasciatus, Hyphessobrycon compressus, Iguanodectes geisleri, Knodus meridae, Landonia latidens, Markiana nigripinnis, Metynnis lippincottianus, Microschemobrycon casiquiare, Moenkhausia xinguensis, Myleus setiger, odontostilbe pequira, Oligosarcus argenteus, orthospinus franciscoensis, Paracheirodon axelrodi, Paragoniates alburnus, Phenacogaster pectinatus, Phenagoniates macrolepis, Piabina argentea, Piaractus mesopotamicus, Poptella brevispina, Probolus heterostomus, Rachoviscus graciliceps, Rhinobrycon negrensis, Rhoadsia altipinna, Roeboexodon guyanensis, Salminus hilarii, Serrabrycon magoi, Tetragonopterus argenteus e Triportheus albus.

\section{[1] - com quilha na porção mediana.}

Gilbertolus atratoensis, Roestes molossus, Erythrinus erythrinus e Hoplias malabaricus.

\section{[2] - com processo na porção mediana.}

Acestrorhynchus falcirostris.

\section{[-] - inaplicável.}

Olivaichthys mesembrinus, Gymnotus aff. carapo, Carnegiella strigata E Erythrinoidea fam. nov.

\section{[?] - indeterminado.}

Saccodon wagneri e Stygichthys typhlops.

\section{0 - Participação do infra-orbital 1 na órbita:}

\section{[0] - bem pequena.}

Chanos chanos, Catostomus commersonnii, Distichodus notospilus, Hemistichodus vaillanti, Neolebias unifasciatus, Nannocharax fasciatus, Apareiodon piracicabae, Parodon nasus, Bivibranchia fowleri, Hemiodus unimaculatus, Curimata ocellata, Curimatopsis macrolepis, Potamorhina latior, Caenotropus labyrinthicus, Chilodus punctatus, Anostomus anostomus, Leporellus vittatus, Leporinus fasciatus, Schizodon fasciatus, copeina cf. guttata, Lebiasina bimaculata, Piabucina astrigata, Hepsetus odoe e Agoniates halecinus.

\section{[1] - extensa.}

Citharinus latus, Xenocharax spilurus, Anodus orinocensis, Prochilodus nigricans, Semaprochilodus insignis, Gasteropelecus sternicla, Thoracocharax stellatus, Acestrorhynchus falcirostris, Gilbertolus atratoensis, Hydrolycus tatauaia, Roestes molossus, Boulengerella maculata, Ctenolucius hujeta, Erythrinus erythrinus, Hoplias 
malabaricus, Arnoldichthys spilopterus, Brycinus macrolepidotus, Bryconalestes longipinnis, Chalceus epakros, Characidium bahiensis, crenuchus spilurus, Aphyocharax pusillus, Astyanax mexicanus, Atopomesus pachyodus, Axelrodia reisei, Brittanichthys axelrodi, Brycon pesu, Bryconadenos tanaothoros, Bryconamericus exodon, Bryconops alburnoides, Charax cf. leticiae, Clupeacharax cf. engrauloides, Compsura heterura, Ctenobrycon hauxwellianus, Deuterodon iguape, Diapoma terofali, Galeocharax knerii, Glandulocauda melanogenys, Gnathocharax steindachneri, Gymnocorymbus ternetzi, Hemibrycon polyodon, Hemigrammus unilineatus, Hollandichthys multifasciatus, Hyphessobrycon compressus, Iguanodectes geisleri, Knodus meridae, Landonia latidens, Markiana nigripinnis, Metynnis lippincottianus, Microschemobrycon casiquiare, Moenkhausia xinguensis, Myleus setiger, odontostilbe pequira, oligosarcus argenteus, orthospinus franciscoensis, Paracheirodon axelrodi, Paragoniates alburnus, Phenacogaster pectinatus, Phenagoniates macrolepis, Piabina argentea, Piaractus mesopotamicus, Poptella brevispina, Probolus heterostomus, Rachoviscus graciliceps, Rhinobrycon negrensis, Rhoadsia altipinna, Roeboexodon guyanensis, Salminus hilarii, Serrabrycon magoi, Tetragonopterus argenteus e Triportheus albus.

\section{[-] - inaplicável.}

olivaichthys mesembrinus, Gymnotus aff. carapo, Carnegiella strigata, Erythrinoidea fam. nov.

\section{[?] - indeterminado.}

Saccodon wagneri e Stygichthys typhlops.

131 - Posição relativa do infra-orbital 1 e 0 antorbital:

[ZANATA \& VARI, 2005: 6, modificado]

(Minimamente conectado).

[0] - porção anterior do infra-orbital 1 anterior ao antorbital (Fig. 37 e Fig. 38).

Chanos chanos, Citharinus latus, Distichodus notospilus, Hemistichodus vaillanti, Neolebias unifasciatus, Nannocharax fasciatus, Xenocharax spilurus, Apareiodon piracicabae, Parodon nasus, Saccodon wagneri, Anodus orinocensis, Bivibranchia fowleri, Hemiodus unimaculatus, Curimata ocellata, Potamorhina latior, Prochilodus nigricans, Semaprochilodus insignis, Caenotropus labyrinthicus, Chilodus punctatus, Anostomus anostomus, Leporellus vittatus, Schizodon fasciatus, Gilbertolus atratoensis, Copeina cf. guttata, Hepsetus odoe, Arnoldichthys spilopterus, Brycinus macrolepidotus, Bryconalestes longipinnis, Characidium bahiensis, Crenuchus spilurus, Brittanichthys axelrodi, Galeocharax knerii e Gnathocharax steindachneri.

\section{[1] - porção anterior do infra-orbital 1 alinhado (Fig. 40).}

Gymnotus aff. carapo, Leporinus fasciatus, Gasteropelecus sternicla, Thoracocharax stellatus, Lebiasina bimaculata, Piabucina astrigata, Chalceus epakros, Agoniates halecinus, Aphyocharax pusillus, Clupeacharax cf. engrauloides, Markiana nigripinnis, Paracheirodon axelrodi e Salminus hilarii.

\section{[2] - porção anterior do infra-orbital 1 posterior ao antorbital} (Fig. 39 e Fig. 41).

olivaichthys mesembrinus, Acestrorhynchus falcirostris, Hydrolycus tatauaia, Roestes molossus, Astyanax mexicanus, Atopomesus pachyodus, Axelrodia reisei, Brycon pesu, Bryconadenos tanaothoros, Bryconamericus exodon, Bryconops alburnoides, Charax cf. leticiae, Compsura heterura, Ctenobrycon hauxwellianus, Deuterodon iguape, Diapoma terofali, Glandulocauda melanogenys, Gymnocorymbus ternetzi, Hemibrycon polyodon , Hemigrammus unilineatus, Hollandichthys multifasciatus, Hyphessobrycon compressus, Iguanodectes geisleri, Knodus meridae, Landonia latidens, Metynnis lippincottianus, Microschemobrycon casiquiare, Moenkhausia xinguensis, Myleus setiger, odontostilbe pequira, oligosarcus argenteus, orthospinus franciscoensis, Paragoniates alburnus, Phenacogaster pectinatus, Phenagoniates macrolepis, Piabina argentea, Piaractus mesopotamicus, Poptella brevispina, Probolus heterostomus, Rachoviscus graciliceps, Rhinobrycon negrensis, Rhoadsia altipinna, Roeboexodon guyanensis, Serrabrycon magoi, Stygichthys typhlops, Tetragonopterus argenteus e Triportheus albus.

\section{[-] - inaplicável.}


Catostomus commersonnii, Curimatopsis macrolepis, Carnegiella strigata, Erythrinoidea fam. nov, Boulengerella maculata, Ctenolucius hujeta, Erythrinus erythrinus e Hoplias malabaricus.

\section{2 - Contato entre o infra-orbital 1 e o antorbital: [MOREIRA, 2002: 37, modificado]}

\section{[0] - sem sobreposição (Figs, 39, 40 e 41).}

Chanos chanos, Olivaichthys mesembrinus, Citharinus latus, Anodus orinocensis, Bivibranchia fowleri, Hemiodus unimaculatus, Leporellus vittatus, Leporinus fasciatus, Schizodon fasciatus, Acestrorhynchus falcirostris, Gilbertolus atratoensis, Roestes molossus, Hepsetus odoe, Chalceus epakros, Agoniates halecinus, Aphyocharax pusillus, Astyanax mexicanus, Atopomesus pachyodus, Axelrodia reisei, Brittanichthys axelrodi, Brycon pesu, Bryconadenos tanaothoros, Bryconamericus exodon, Bryconops alburnoides, Charax cf. leticiae, Clupeacharax cf. engrauloides, Compsura heterura, Ctenobrycon hauxwellianus, Deuterodon iguape, Diapoma terofali, Galeocharax knerii, Glandulocauda melanogenys, Gnathocharax steindachneri, Gymnocorymbus ternetzi, Hemibrycon polyodon, Hemigrammus unilineatus, Hyphessobrycon compressus, Iguanodectes geisleri, Knodus meridae, Landonia latidens, Markiana nigripinnis, Metynnis lippincottianus, Microschemobrycon casiquiare, Moenkhausia xinguensis, Myleus setiger, odontostilbe pequira, oligosarcus argenteus, orthospinus franciscoensis, Paragoniates alburnus, Phenacogaster pectinatus, Phenagoniates macrolepis, Piabina argentea, Piaractus mesopotamicus, Poptella brevispina, Probolus heterostomus, Rachoviscus graciliceps, Rhinobrycon negrensis, Rhoadsia altipinna, Roeboexodon guyanensis, Serrabrycon magoi, stygichthys typhlops, Tetragonopterus argenteus e Triportheus albus.

\section{[1] - com sobreposição (Fig. 38).}

Hemistichodus vaillanti, Neolebias unifasciatus, Nannocharax fasciatus, Xenocharax spilurus, Parodon nasus, Curimata ocellata, Potamorhina latior, Prochilodus nigricans, Semaprochilodus insignis, Caenotropus labyrinthicus, Chilodus punctatus, Anostomus anostomus, Gasteropelecus sternicla, Thoracocharax stellatus, Hydrolycus tatauaia, Piabucina astrigata, Arnoldichthys spilopterus, Brycinus macrolepidotus, Bryconalestes longipinnis, Hollandichthys multifasciatus, Paracheirodon axelrodi e Salminus hilarii.

[2] - com encaixe (Fig. 37).

Distichodus notospilus, Copeina cf. guttata, Lebiasina bimaculata, Characidium bahiensis e Crenuchus spilurus.

\section{[-] - inaplicável.}

Catostomus commersonnii, Gymnotus aff. carapo, Curimatopsis macrolepis, Carnegiella strigata, Erythrinoidea fam. nov, Boulengerella maculata, Ctenolucius hujeta e Erythrinus erythrinus.

\section{[?] - indeterminado.}

Apareiodon piracicabae, Saccodon wagneri e Hoplias malabaricus.

133 - Direção do infra-orbital 1:

VARI, 1995: 2, modificado; OYAKAWA, 1998: 29, modificado; e NETTO-FERREIRA, 2006: 3, modificado]

\section{[0] - direcionado anteriormente (Figs. 37, 38 e 40).}

Chanos chanos, Catostomus commersonnii, Citharinus latus, Distichodus notospilus, Hemistichodus vaillanti, Neolebias unifasciatus, Nannocharax fasciatus, Xenocharax spilurus, Apareiodon piracicabae, Parodon nasus, Anodus orinocensis, Bivibranchia fowleri, Hemiodus unimaculatus, Curimata ocellata, Curimatopsis macrolepis, Potamorhina latior, Prochilodus nigricans, Semaprochilodus insignis, Caenotropus labyrinthicus, Chilodus punctatus, Anostomus anostomus, Leporellus vittatus, Leporinus fasciatus, Schizodon fasciatus, Hydrolycus tatauaia, Piabucina astrigata, Brycinus macrolepidotus, Bryconalestes longipinnis, Chalceus epakros, Agoniates halecinus, Atopomesus pachyodus, Brittanichthys axelrodi, Bryconadenos tanaothoros, Bryconamericus exodon, Charax cf. leticiae, Clupeacharax cf. engrauloides, Galeocharax knerii, Gymnocorymbus ternetzi, Hemigrammus unilineatus, Hollandichthys multifasciatus, Hyphessobrycon compressus, knodus meridae, Microschemobrycon casiquiare, Odontostilbe pequira, oligosarcus 
argenteus, Paracheirodon axelrodi, Paragoniates alburnus, Phenacogaster pectinatus, Piabina argentea, Piaractus mesopotamicus, Probolus heterostomus, Rachoviscus graciliceps, Rhoadsia altipinna, Roeboexodon guyanensis e Salminus hilarii.

\section{[1] - com um ramo anterior e outro dorsal.}

Boulengerella maculata, Ctenolucius hujeta, Erythrinus erythrinus, Hoplias malabaricus, Hepsetus odoe, Arnoldichthys spilopterus, Characidium bahiensis e Crenuchus spilurus.

\section{[2] - direcionado dorsalmente (Fig. 41).}

Gasteropelecus sternicla, Thoracocharax stellatus, Gilbertolus atratoensis, Roestes molossus, Copeina cf. guttata, Lebiasina bimaculata, Aphyocharax pusillus, Astyanax mexicanus, Axelrodia reisei, Brycon pesu, Bryconops alburnoides, Compsura heterura, Ctenobrycon hauxwellianus, Deuterodon iguape, Diapoma terofali, Glandulocauda melanogenys, Gnathocharax steindachneri, Hemibrycon polyodon, Iguanodectes geisleri, Landonia latidens, Markiana nigripinnis, Metynnis lippincottianus, Moenkhausia xinguensis, Myleus setiger, orthospinus franciscoensis, Phenagoniates macrolepis, Poptella brevispina, Rhinobrycon negrensis, Serrabrycon magoi, Tetragonopterus argenteus e Triportheus albus.

\section{[-] - inaplicável.}

olivaichthys mesembrinus, Gymnotus aff. carapo, Carnegiella strigata e Erythrinoidea fam. nov.

\section{[?] - indeterminado.}

Saccodon wagneri, Acestrorhynchus falcirostris e Stygichthys typhlops.

\section{4 - Canal da linha lateral do infra-orbital 1:}

[0] - direcionado anteriormente (Fig. 38 e Fig. 40).

Catostomus commersonnii, Olivaichthys mesembrinus, Hemistichodus vaillanti, Neolebias unifasciatus, Nannocharax fasciatus, Xenocharax spilurus, Apareiodon piracicabae, Parodon nasus, Anodus orinocensis, Hemiodus unimaculatus, Curimata ocellata, Potamorhina latior, Leporellus vittatus, Hydrolycus tatauaia, Boulengerella maculata, Ctenolucius hujeta, Piabucina astrigata, Hepsetus odoe, Arnoldichthys spilopterus, Brycinus macrolepidotus, Bryconalestes longipinnis, Chalceus epakros, Characidium bahiensis, Agoniates halecinus, Atopomesus pachyodus, Bryconadenos tanaothoros, Bryconamericus exodon, Charax cf. leticiae, Clupeacharax cf. engrauloides, Galeocharax knerii, Gymnocorymbus ternetzi, Hemigrammus unilineatus, Hollandichthys multifasciatus, Knodus meridae, Microschemobrycon casiquiare, Odontostilbe pequira, oligosarcus argenteus, Orthospinus franciscoensis, Paragoniates alburnus, Piabina argentea, Piaractus mesopotamicus, Poptella brevispina, Probolus heterostomus, Rachoviscus graciliceps, Rhoadsia altipinna e Salminus hilarii.

\section{[1] - direcionado dorsalmente (Fig. 37 e Fig. 41).}

Chanos chanos, Gymnotus aff. carapo, Distichodus notospilus, Bivibranchia fowleri, Prochilodus nigricans, Semaprochilodus insignis, Caenotropus labyrinthicus, Chilodus punctatus, Anostomus anostomus, Leporinus fasciatus, Schizodon fasciatus, Gasteropelecus sternicla, Thoracocharax stellatus, Gilbertolus atratoensis, Roestes molossus, Copeina cf. guttata, Lebiasina bimaculata, Erythrinus erythrinus, Hoplias malabaricus, Crenuchus spilurus, Aphyocharax pusillus, Astyanax mexicanus, Brycon pesu, Bryconops alburnoides, Compsura heterura, Ctenobrycon hauxwellianus, Deuterodon iguape, Diapoma terofali, Glandulocauda melanogenys, Gnathocharax steindachneri, Hemibrycon polyodon, Iguanodectes geisleri, Landonia latidens, Markiana nigripinnis, Metynnis lippincottianus, Moenkhausia xinguensis, Myleus setiger, Phenacogaster pectinatus, Phenagoniates macrolepis, Rhinobrycon negrensis, Roeboexodon guyanensis, Serrabrycon magoi, Tetragonopterus argenteus e Triportheus albus.

\section{[-] - inaplicável.}

Curimatopsis macrolepis, Carnegiella strigata, Erythrinoidea fam. nov, Axelrodia reisei, Brittanichthys axelrodi, Hyphessobrycon compressus e Paracheirodon axelrodi. 
[0] - tubo simples (Figs. 38,39, 40 e 41).

Chanos chanos, Catostomus commersonnii, olivaichthys mesembrinus, Gymnotus aff. carapo, Citharinus latus, Hemistichodus vaillanti, Neolebias unifasciatus, Xenocharax spilurus, Apareiodon piracicabae, Parodon nasus, Anodus orinocensis, Bivibranchia fowleri, Hemiodus unimaculatus, Curimata ocellata, Potamorhina latior, Prochilodus nigricans, Semaprochilodus insignis, Chilodus punctatus, Gasteropelecus sternicla, Thoracocharax stellatus, Acestrorhynchus falcirostris, Gilbertolus atratoensis, Hydrolycus tatauaia, Roestes molossus, Copeina cf. guttata, Lebiasina bimaculata, Piabucina astrigata, Erythrinus erythrinus, Hoplias malabaricus, Hepsetus odoe, Arnoldichthys spilopterus, Brycinus macrolepidotus, Bryconalestes longipinnis, Chalceus epakros, Characidium bahiensis, Crenuchus spilurus, Agoniates halecinus, Aphyocharax pusillus, Astyanax mexicanus, Atopomesus pachyodus, Brycon pesu, Bryconadenos tanaothoros, Bryconamericus exodon, Bryconops alburnoides, Charax cf. leticiae, Clupeacharax cf. engrauloides, Compsura heterura, Ctenobrycon hauxwellianus, Deuterodon iguape, Diapoma terofali, Galeocharax knerii, Glandulocauda melanogenys, Gnathocharax steindachneri, Gymnocorymbus ternetzi, Hemibrycon polyodon, Hemigrammus unilineatus, Hollandichthys multifasciatus, Iguanodectes geisleri, Knodus meridae, Landonia latidens, Markiana nigripinnis, Metynnis lippincottianus, Microschemobrycon casiquiare, Moenkhausia xinguensis, Myleus setiger, odontostilbe pequira, Oligosarcus argenteus, orthospinus franciscoensis, Paragoniates alburnus, Phenacogaster pectinatus, Phenagoniates macrolepis, Piabina argentea, Piaractus mesopotamicus, Poptella brevispina, Probolus heterostomus, Rachoviscus graciliceps, Rhinobrycon negrensis, Rhoadsia altipinna, Roeboexodon guyanensis, Salminus hilarii, Serrabrycon magoi, Stygichthys typhlops, Tetragonopterus argenteus e Triportheus albus.

\section{[1] - com bifurcação anterior (Fig. 37).}

Distichodus notospilus, Nannocharax fasciatus, Caenotropus labyrinthicus, Anostomus anostomus, Leporellus vittatus, Leporinus fasciatus, Schizodon fasciatus, Boulengerella maculata e Ctenolucius hujeta.

\section{[-] - inaplicável.}

Curimatopsis macrolepis, Carnegiella strigata, Erythrinoidea fam. nov, Axelrodia reisei, Brittanichthys axelrodi, Hyphessobrycon compressus e Paracheirodon axelrodi.

\section{[?] - indeterminado.}

Saccodon wagneri.

136 - porção ântero-ventral do canal do infra-orbital 1:

[LUCENA, 1993: 30; ZANATA, 2000: 6]

\section{[0] - com lâmina óssea (Figs. 37, 38 e 40).}

Chanos chanos, Catostomus commersonnii, Gymnotus aff. carapo, Citharinus latus, Distichodus notospilus, Hemistichodus vaillanti, Neolebias unifasciatus, Nannocharax fasciatus, Xenocharax spilurus, Apareiodon piracicabae, Parodon nasus, Anodus orinocensis, Bivibranchia fowleri, Hemiodus unimaculatus, Curimata ocellata, Potamorhina latior, Prochilodus nigricans, Semaprochilodus insignis, Caenotropus labyrinthicus, Chilodus punctatus, Anostomus anostomus, Leporellus vittatus, Leporinus fasciatus, Schizodon fasciatus, Hydrolycus tatauaia, Boulengerella maculata, Ctenolucius hujeta, Copeina cf. guttata, Lebiasina bimaculata, Piabucina astrigata, Erythrinus erythrinus, Hepsetus odoe, Arnoldichthys spilopterus, Brycinus macrolepidotus, Bryconalestes longipinnis, Chalceus epakros, Characidium bahiensis, Crenuchus spilurus, Aphyocharax pusillus, Astyanax mexicanus, Charax cf. leticiae, Ctenobrycon hauxwellianus, Deuterodon iguape, Diapoma terofali, Galeocharax knerii, Gymnocorymbus ternetzi, Hemigrammus unilineatus, Hollandichthys multifasciatus, Iguanodectes geisleri, Landonia latidens, Metynnis lippincottianus, Myleus setiger, Odontostilbe pequira, oligosarcus argenteus, Orthospinus franciscoensis, Paracheirodon axelrodi, Phenacogaster pectinatus, Piabina argentea, Poptella brevispina, Probolus heterostomus, Rachoviscus graciliceps, Rhoadsia altipinna, Roeboexodon guyanensis, Salminus hilarii, Serrabrycon magoi e Tetragonopterus argenteus.

\section{[1] - sem lâmina óssea (Fig. 39 e Fig. 41).} Olivaichthys mesembrinus, Gasteropelecus sternicla, Thoracocharax stellatus
Acestrorhynchus falcirostris, Gilbertolus atratoensis, Roestes molossus, Hoplias 
malabaricus, Agoniates halecinus, Atopomesus pachyodus, Brycon pesu, Bryconadenos tanaothoros, Bryconamericus exodon, Bryconops alburnoides, Clupeacharax cf. engrauloides, Glandulocauda melanogenys, Gnathocharax steindachneri, Hemibrycon polyodon Knodus meridae, Markiana nigripinnis, Microschemobrycon casiquiare, Moenkhausia xinguensis, Paragoniates alburnus, Phenagoniates macrolepis, Piaractus mesopotamicus, Rhinobrycon negrensis e Triportheus albus.

\section{[-] - inaplicável.}

Curimatopsis macrolepis, Carnegiella strigata, Erythrinoidea fam. nov, Axelrodia reisei, Brittanichthys axelrodi, Compsura heterura e Hyphessobrycon compressus.

\section{[?] - indeterminado.}

Saccodon wagneri e Stygichthys typhlops.

\section{7 - Porção lamelar do infra-orbital 1:}

[NeTto-FERREIRA, 2006: 4]

\section{[0] - simples.}

Chanos chanos, Catostomus commersonnii, Distichodus notospilus, Hemistichodus vaillanti, Nannocharax fasciatus, Xenocharax spilurus, Apareiodon piracicabae, Parodon nasus, Anodus orinocensis, Bivibranchia fowleri, Hemiodus unimaculatus , Curimata ocellata, Curimatopsis macrolepis, Potamorhina latior, Prochilodus nigricans, Semaprochilodus insignis, Caenotropus labyrinthicus, Chilodus punctatus, Anostomus anostomus, Leporellus vittatus, Leporinus fasciatus, Schizodon fasciatus, Gasteropelecus sternicla, Thoracocharax stellatus, Acestrorhynchus falcirostris, Gilbertolus atratoensis, Hydrolycus tatauaia, Roestes molossus, Boulengerella maculata, ctenolucius hujeta, Copeina cf. guttata, Lebiasina bimaculata, Piabucina astrigata, Hepsetus odoe, Arnoldichthys spilopterus, Brycinus macrolepidotus, Bryconalestes longipinnis, Chalceus epakros, Characidium bahiensis, Crenuchus spilurus, Agoniates halecinus, Aphyocharax pusillus, Astyanax mexicanus, Axelrodia reisei, Brittanichthys axelrodi, Brycon pesu, Bryconadenos tanaothoros, Bryconamericus exodon, Bryconops alburnoides, Charax cf. leticiae, Clupeacharax cf. engrauloides, compsura heterura, ctenobrycon hauxwellianus, Deuterodon iguape, Diapoma terofali, Galeocharax knerii, Gnathocharax steindachneri, Gymnocorymbus ternetzi, Hemibrycon polyodon, Hollandichthys multifasciatus, Knodus meridae, Landonia latidens, Markiana nigripinnis, Metynnis lippincottianus, Moenkhausia xinguensis, Myleus setiger, oligosarcus argenteus, orthospinus franciscoensis, Paracheirodon axelrodi, Phenacogaster pectinatus, Piaractus mesopotamicus, Roeboexodon guyanensis, Salminus hilarii, Stygichthys typhlops e Triportheus albus.

\section{[1] - pouco desenvolvida.}

Olivaichthys mesembrinus, Gymnotus aff. carapo, Citharinus latus, Neolebias unifasciatus, Erythrinus erythrinus, Hoplias malabaricus, Atopomesus pachyodus, Glandulocauda melanogenys, Hemigrammus unilineatus, Hyphessobrycon compressus, Iguanodectes geisleri, Microschemobrycon casiquiare, odontostilbe pequira, Paragoniates alburnus, Phenagoniates macrolepis, Piabina argentea, Poptella brevispina, Probolus heterostomus, Rachoviscus graciliceps, Rhinobrycon negrensis, Rhoadsia altipinna, Serrabrycon magoi e Tetragonopterus argenteus.

\section{[-] - inaplicável.}

Carnegiella strigata e Erythrinoidea fam. nov.

\section{[?] - indeterminado.}

Saccodon wagneri.

\section{8 - Extensão do canal sensorial do infra-orbital 1:}

\section{[0] - percorrendo todo o osso (Figs. 37, 39, 40 e 41).}

Chanos chanos, Distichodus notospilus, Nannocharax fasciatus, Anostomus anostomus, Leporellus vittatus, Leporinus fasciatus, Schizodon fasciatus, Gasteropelecus sternicla, Thoracocharax stellatus, Gilbertolus atratoensis, Hydrolycus tatauaia, Roestes molossus, Ctenolucius hujeta, Copeina cf. guttata, Lebiasina bimaculata, Piabucina 
astrigata, Erythrinus erythrinus, Hoplias malabaricus, Arnoldichthys spilopterus, Brycinus macrolepidotus, Bryconalestes longipinnis, Chalceus epakros, Crenuchus spilurus, Aphyocharax pusillus, Atopomesus pachyodus, Brycon pesu, Bryconadenos tanaothoros, Bryconamericus exodon, Bryconops alburnoides, Clupeacharax cf. engrauloides, Glandulocauda melanogenys, Gnathocharax steindachneri, Hemibrycon polyodon

Iguanodectes geisleri, Knodus meridae, Landonia latidens, Markiana nigripinnis, Microschemobrycon casiquiare, Paragoniates alburnus, Phenagoniates macrolepis, Piabina argentea, Piaractus mesopotamicus, Rhinobrycon negrensis, Salminus hilarii, Serrabrycon magoi e Triportheus albus.

\section{[1] - não atingindo a porção final da ossificação (Fig. 38).}

Catostomus commersonnii, Citharinus latus, Hemistichodus vaillanti, Neolebias unifasciatus, Xenocharax spilurus, Apareiodon piracicabae, Parodon nasus, Anodus orinocensis, Bivibranchia fowleri, Hemiodus unimaculatus, Curimata ocellata, Potamorhina latior, Prochilodus nigricans, Semaprochilodus insignis, Caenotropus labyrinthicus, Chilodus punctatus, Acestrorhynchus falcirostris, Boulengerella maculata, Hepsetus odoe, Characidium bahiensis, Agoniates halecinus, Astyanax mexicanus, Charax cf. leticiae, Compsura heterura, Ctenobrycon hauxwellianus, Deuterodon iguape, Diapoma terofali, Galeocharax knerii, Gymnocorymbus ternetzi, Hemigrammus unilineatus, Hollandichthys multifasciatus, Metynnis lippincottianus, Moenkhausia xinguensis, Myleus setiger, odontostilbe pequira, oligosarcus argenteus, orthospinus franciscoensis, Phenacogaster pectinatus, Poptella brevispina, Probolus heterostomus , Rachoviscus graciliceps, Rhoadsia altipinna, Roeboexodon guyanensis e Tetragonopterus argenteus.

\section{[-] - inaplicável.}

Olivaichthys mesembrinus, Gymnotus aff. carapo, Curimatopsis macrolepis, Carnegiella strigata, Erythrinoidea fam. nov, Axelrodia reisei, Brittanichthys axelrodi, Hyphessobrycon compressus e Paracheirodon axelrodi.

\section{[?] - indetermiando.}

Saccodon wagneri e Stygichthys typhlops.

139 - Margem posterior do infra-orbital 1:

[MOREIRA, 2002: 43]

[0] - menor que a margem anterior do $2^{\circ}$ infra-orbital (Fig. 37).

Distichodus notospilus, Neolebias unifasciatus, Apareiodon piracicabae, Hydrolycus tatauaia, Atopomesus pachyodus, Brittanichthys axelrodi, Deuterodon iguape, Iguanodectes geisleri, Knodus meridae, Moenkhausia xinguensis, Myleus setiger, odontostilbe pequira, Phenacogaster pectinatus, Phenagoniates macrolepis e Piabina argêntea.

\section{[1] - do mesmo tamanho da margem anterior do $2^{\circ}$ infra-orbital} (Fig. 40).

Citharinus latus, Hemistichodus vaillanti, Nannocharax fasciatus, Xenocharax spilurus, Parodon nasus, Bivibranchia fowleri, Hemiodus unimaculatus, Curimata ocellata, Curimatopsis macrolepis, Potamorhina latior, Prochilodus nigricans, Semaprochilodus insignis, Caenotropus labyrinthicus, Chilodus punctatus, Gasteropelecus sternicla, Thoracocharax stellatus, Boulengerella maculata, ctenolucius hujeta, copeina cf. guttata, Lebiasina bimaculata, Piabucina astrigata, Erythrinus erythrinus, Hoplias malabaricus, Hepsetus odoe, Arnoldichthys spilopterus, Brycinus macrolepidotus, Bryconalestes longipinnis, Chalceus epakros, Axelrodia reisei, Bryconamericus exodon, Bryconops alburnoides, Charax cf. leticiae, Clupeacharax cf. engrauloides, Ctenobrycon hauxwellianus, Diapoma terofali, Galeocharax knerii, Glandulocauda melanogenys, Hemibrycon polyodon, Hollandichthys multifasciatus, Hyphessobrycon compressus, Metynnis lippincottianus, orthospinus franciscoensis, Paracheirodon axelrodi, Paragoniates alburnus, Piaractus mesopotamicus, Poptella brevispina, Rachoviscus graciliceps, Rhinobrycon negrensis, Rhoadsia altipinna, Salminus hilarii e Tetragonopterus argenteus.

\section{[2] - maior que a margem anterior do infra-orbital 2 (Fig. 39).}

Chanos chanos, Catostomus commersonnii, Anodus orinocensis, Anostomus anostomus, Leporellus vittatus, Leporinus fasciatus, Schizodon fasciatus, Acestrorhynchus falcirostris, Gilbertolus atratoensis, Roestes molossus, Characidium bahiensis, crenuchus spilurus, Agoniates halecinus, Aphyocharax pusillus, Astyanax mexicanus, Brycon pesu, Bryconadenos tanaothoros, Compsura heterura, Gnathocharax steindachneri, 
Gymnocorymbus ternetzi, Hemigrammus unilineatus, Markiana nigripinnis, Microschemobrycon casiquiare, oligosarcus argenteus, Probolus heterostomus, Roeboexodon guyanensis, Serrabrycon magoi e Triportheus albus.

\section{[-] - inaplicável.}

Olivaichthys mesembrinus, Gymnotus aff. carapo, Carnegiella strigata, Erythrinoidea fam. nov, Landonia latidens e Stygichthys typhlops.

\section{[?] - indeterminado.}

Saccodon wagneri.

140 - Sobreposição entre o infra-orbital 1 e o maxilar:

[LUCENA, 1993: 29, modificado; OYAKAWA, 1998: 31, modificado; ZANATA, 2000: 4, modificado; e NetTo-FERREIRA, 2006: 6, modificado]

[0] - sobrepondo parcialmente, ou não sobrepondo a porção ânterodorsal maxilar.

Chanos chanos, Catostomus commersonnii, Olivaichthys mesembrinus, Gymnotus aff. carapo, Citharinus latus, Distichodus notospilus, Neolebias unifasciatus, Nannocharax fasciatus, Xenocharax spilurus, Apareiodon piracicabae, Parodon nasus, Anodus orinocensis, Bivibranchia fowleri, Hemiodus unimaculatus, Curimata ocellata, Curimatopsis macrolepis, Potamorhina latior, Caenotropus labyrinthicus, Chilodus punctatus, Anostomus anostomus, Leporellus vittatus, Leporinus fasciatus, Schizodon fasciatus, Gasteropelecus sternicla, Thoracocharax stellatus, Gilbertolus atratoensis, Roestes molossus, Boulengerella maculata, ctenolucius hujeta, Copeina cf. guttata, Lebiasina bimaculata, Piabucina astrigata, Hoplias malabaricus, Arnoldichthys spilopterus, Chalceus epakros, Characidium bahiensis, Crenuchus spilurus, Aphyocharax pusillus, Astyanax mexicanus, Atopomesus pachyodus, Axelrodia reisei, Brittanichthys axelrodi, Brycon pesu, Bryconadenos tanaothoros, Bryconamericus exodon, Bryconops alburnoides, Charax cf. leticiae, Clupeacharax cf. engrauloides, Compsura heterura, Ctenobrycon hauxwellianus, Deuterodon iguape, Diapoma terofali, Galeocharax knerii, Glandulocauda melanogenys, Gnathocharax steindachneri, Gymnocorymbus ternetzi, Hemibrycon polyodon, Hemigrammus unilineatus, Hollandichthys multifasciatus, Hyphessobrycon compressus, Iguanodectes geisleri, Knodus meridae, Markiana nigripinnis, Metynnis lippincottianus, Microschemobrycon casiquiare, Moenkhausia xinguensis, Myleus setiger, odontostilbe pequira, oligosarcus argenteus, orthospinus franciscoensis, Paracheirodon axelrodi, Paragoniates alburnus, Phenacogaster pectinatus, Phenagoniates macrolepis, Piabina argentea, Piaractus mesopotamicus, Poptella brevispina, Rachoviscus graciliceps, Rhinobrycon negrensis, Rhoadsia altipinna, Serrabrycon magoi, Stygichthys typhlops, Tetragonopterus argenteus e Triportheus albus.

\section{[1] - sobrepondo totalmente a região ântero-dorsal do maxilar.}

Hemistichodus vaillanti, Prochilodus nigricans, Semaprochilodus insignis, Acestrorhynchus falcirostris, Hydrolycus tatauaia, Erythrinus erythrinus, Hepsetus odoe, Brycinus macrolepidotus, Bryconalestes longipinnis, Agoniates halecinus, Probolus heterostomus, Roeboexodon guyanensis e Salminus hilarii.

\section{[-] - inaplicável.}

Carnegiella strigata, Erythrinoidea fam. nov, Landonia latidens,

\section{[?] - indeterminado.}

Saccodon wagneri.

\section{1 - Margem ventral do infra-orbital 1:}

[0] - contactando o infra-orbital 2 (Figs. 37, 38 e 40).

Catostomus commersonnii, Citharinus latus, Distichodus notospilus, Neolebias unifasciatus, Nannocharax fasciatus, Xenocharax spilurus, Apareiodon piracicabae, Parodon nasus, Hemiodus unimaculatus, Curimata ocellata, Curimatopsis macrolepis, Potamorhina latior, Prochilodus nigricans, Semaprochilodus insignis, Caenotropus labyrinthicus, Chilodus punctatus, Anostomus anostomus, Leporellus vittatus, Leporinus fasciatus, Schizodon fasciatus, Gasteropelecus sternicla, Thoracocharax stellatus , 
Boulengerella maculata, ctenolucius hujeta, copeina cf. guttata, Lebiasina bimaculata, Piabucina astrigata, Erythrinus erythrinus, Hoplias malabaricus, Hepsetus odoe, Arnoldichthys spilopterus, Brycinus macrolepidotus, Bryconalestes longipinnis, Chalceus epakros, Characidium bahiensis, Crenuchus spilurus, Axelrodia reisei, Brittanichthys axelrodi, Bryconops alburnoides, Charax cf. leticiae, Clupeacharax cf. engrauloides, Compsura heterura, Galeocharax knerii, Glandulocauda melanogenys, Hollandichthys multifasciatus, Hyphessobrycon compressus, Iguanodectes geisleri, Metynnis lippincottianus, Microschemobrycon casiquiare, Myleus setiger, oligosarcus argenteus, Paracheirodon axelrodi, Paragoniates alburnus, Phenacogaster pectinatus, Phenagoniates macrolepis, Piaractus mesopotamicus, Rhinobrycon negrensis, Rhoadsia altipinna e Salminus hilarii.

[1] - projetada posteriormente sobrepondo a margem ventral do infra-orbital 2 (Fig. 39 e Fig. 41).

Chanos chanos, Hemistichodus vaillanti, Anodus orinocensis, Bivibranchia fowleri, Acestrorhynchus falcirostris, Gilbertolus atratoensis, Hydrolycus tatauaia, Roestes molossus, Agoniates halecinus, Aphyocharax pusillus, Astyanax mexicanus, Brycon pesu, Bryconadenos tanaothoros, Bryconamericus exodon, Ctenobrycon hauxwellianus, Deuterodon iguape, Diapoma terofali, Gnathocharax steindachneri, Gymnocorymbus ternetzi, Hemibrycon polyodon, Hemigrammus unilineatus, Knodus meridae, Markiana nigripinnis, Moenkhausia xinguensis, Odontostilbe pequira, Orthospinus franciscoensis, Piabina argentea, Poptella brevispina, Probolus heterostomus, Rachoviscus graciliceps, Roeboexodon guyanensis, Serrabrycon magoi, Tetragonopterus argenteus e Triportheus albus.

\section{[-] - inaplicável.}

Olivaichthys mesembrinus, Gymnotus aff. carapo, Carnegiella strigata, Erythrinoidea fam. nov, Atopomesus pachyodus e Landonia latidens.

\section{[?] - indeterminado.}

Saccodon wagneri e Stygichthys typhlops.

\section{2 - relação entre os infra-orbitais 1 e 2:}

\section{[0] - sem sobreposição}

Catostomus commersonnii, Curimata ocellata, Curimatopsis macrolepis, Caenotropus labyrinthicus, Anostomus anostomus, Gasteropelecus sternicla, Thoracocharax stellatus, Hepsetus odoe, Characidium bahiensis, Crenuchus spilurus, Agoniates halecinus, Aphyocharax pusillus, Atopomesus pachyodus, Axelrodia reisei, Bryconadenos tanaothoros, Bryconamericus exodon, Charax cf. leticiae, Clupeacharax cf. engrauloides, Galeocharax knerii, Glandulocauda melanogenys, Hemibrycon polyodon, Hyphessobrycon compressus, Iguanodectes geisleri, Microschemobrycon casiquiare, Moenkhausia xinguensis, Oligosarcus argenteus, Paracheirodon axelrodi, Paragoniates alburnus, Phenacogaster pectinatus, Rhinobrycon negrensis e Serrabrycon magoi.

\section{[1] - com sobreposição (Figs. 37, 38,39,40 e 41).}

Chanos chanos, Distichodus notospilus, Hemistichodus vaillanti, Neolebias unifasciatus, Nannocharax fasciatus, Xenocharax spilurus, Apareiodon piracicabae, Parodon nasus, Anodus orinocensis, Bivibranchia fowleri, Hemiodus unimaculatus, Potamorhina latior, Prochilodus nigricans, Semaprochilodus insignis, Chilodus punctatus, Leporellus vittatus, Leporinus fasciatus, Schizodon fasciatus, Acestrorhynchus falcirostris, Gilbertolus atratoensis, Hydrolycus tatauaia, Roestes molossus, Boulengerella maculata, Ctenolucius hujeta, Copeina cf. guttata, Lebiasina bimaculata, Piabucina astrigata, Erythrinus erythrinus, Hoplias malabaricus, Arnoldichthys spilopterus, Brycinus macrolepidotus, Bryconalestes longipinnis, Chalceus epakros, Astyanax mexicanus, Brittanichthys axelrodi, Brycon pesu, Bryconops alburnoides, Compsura heterura, Ctenobrycon hauxwellianus, Deuterodon iguape, Diapoma terofali, Gnathocharax steindachneri, Gymnocorymbus ternetzi, Hemigrammus unilineatus, Hollandichthys multifasciatus, Knodus meridae, Markiana nigripinnis, Metynnis lippincottianus, Myleus setiger, Odontostilbe pequira, Orthospinus franciscoensis, Phenagoniates macrolepis, Piabina argentea, Piaractus mesopotamicus, Poptella brevispina, Probolus heterostomus Rachoviscus graciliceps, Rhoadsia altipinna, Roeboexodon guyanensis, Salminus hilarii, Tetragonopterus argenteus e Triportheus albus.

\section{[-] - inaplicável.}


olivaichthys mesembrinus, Gymnotus aff. carapo, Carnegiella strigata, Erythrinoidea fam. nov. e Landonia latidens.

\section{[?] - indeterminado.}

Citharinus latus, Saccodon wagneri e Stygichthys typhlops.

\section{3 - Processo do tubo da linha lateral do infra-orbital 2 por sobre o infra-orbital 1:}

[0] - ausente.

Chanos chanos, Catostomus commersonnii, Citharinus latus, Distichodus notospilus, Hemistichodus vaillanti, Neolebias unifasciatus, Nannocharax fasciatus, Xenocharax spilurus, Apareiodon piracicabae, Parodon nasus, Anodus orinocensis, Bivibranchia fowleri, Hemiodus unimaculatus, Curimata ocellata, Curimatopsis macrolepis, Potamorhina latior, Prochilodus nigricans, Semaprochilodus insignis, Caenotropus labyrinthicus, Chilodus punctatus, Anostomus anostomus, Leporellus vittatus, Leporinus fasciatus, Schizodon fasciatus, Gasteropelecus sternicla, Thoracocharax stellatus, Acestrorhynchus falcirostris, Hydrolycus tatauaia, Boulengerella maculata, ctenolucius hujeta, Copeina cf. guttata, Lebiasina bimaculata, Piabucina astrigata, Erythrinus erythrinus, Hoplias malabaricus, Hepsetus odoe, Arnoldichthys spilopterus, Brycinus macrolepidotus, Bryconalestes longipinnis, Chalceus epakros, characidium bahiensis, Crenuchus spilurus, Agoniates halecinus, Aphyocharax pusillus, Astyanax mexicanus, Atopomesus pachyodus, Axelrodia reisei, Brittanichthys axelrodi, Brycon pesu, Bryconadenos tanaothoros, Bryconamericus exodon, Charax cf. leticiae, clupeacharax cf. engrauloides, Compsura heterura, Ctenobrycon hauxwellianus, Deuterodon iguape, Diapoma terofali, Galeocharax knerii, Glandulocauda melanogenys, Gnathocharax steindachneri, Gymnocorymbus ternetzi, Hemibrycon polyodon, Hemigrammus unilineatus, Hollandichthys multifasciatus, Hyphessobrycon compressus, Iguanodectes geisleri, Knodus meridae, Markiana nigripinnis, Microschemobrycon casiquiare, Moenkhausia xinguensis, Myleus setiger, odontostilbe pequira, oligosarcus argenteus, orthospinus franciscoensis, Paragoniates alburnus, Phenacogaster pectinatus, Phenagoniates macrolepis, Piabina argentea, Piaractus mesopotamicus, Poptella brevispina, Probolus heterostomus, Rhinobrycon negrensis, Rhoadsia altipinna, Roeboexodon guyanensis, Salminus hilarii, Serrabrycon magoi e Tetragonopterus argenteus.

[1] - presente.

Gilbertolus atratoensis, Roestes molossus, Bryconops alburnoides, Metynnis lippincottianus, Rachoviscus graciliceps e Triportheus albus.

\section{[-] - inaplicável.}

Olivaichthys mesembrinus, Gymnotus aff. carapo, Carnegiella strigata, Erythrinoidea fam. nov, Landonia latidens, Paracheirodon axelrodi e Stygichthys typhlops.

[?] - indeterminado.

Saccodon wagneri.

144 - margem posterior do infra-orbital 2:

[LIMA, $2006: 1$, modificado]

[0] - aproximadamente vertical, ou não ultrapassando a margem anterior do infra-orbital 3.

Chanos chanos, Catostomus commersonnii, Citharinus latus, Distichodus notospilus, Hemistichodus vaillanti, Neolebias unifasciatus, Nannocharax fasciatus, Xenocharax spilurus, Parodon nasus, Bivibranchia fowleri, Hemiodus unimaculatus , Curimata ocellata, Curimatopsis macrolepis, Potamorhina latior, Prochilodus nigricans, Caenotropus labyrinthicus, Chilodus punctatus, Anostomus anostomus, Leporellus vittatus, Leporinus fasciatus, Schizodon fasciatus, Gasteropelecus sternicla, Thoracocharax stellatus, Acestrorhynchus falcirostris, Gilbertolus atratoensis, Roestes molossus, Boulengerella maculata, Ctenolucius hujeta, Copeina cf. guttata, Lebiasina bimaculata, Piabucina astrigata, Erythrinus erythrinus, Hoplias malabaricus, Arnoldichthys spilopterus, Brycinus macrolepidotus, Bryconalestes longipinnis, Chalceus epakros, crenuchus spilurus, Agoniates halecinus, Aphyocharax pusillus, Astyanax mexicanus, Atopomesus pachyodus, Axelrodia reisei, Brittanichthys axelrodi, Brycon pesu, 
Bryconadenos tanaothoros, Bryconamericus exodon, Bryconops alburnoides, Clupeacharax cf. engrauloides, Compsura heterura, Ctenobrycon hauxwellianus, Deuterodon iguape, Diapoma terofali, Glandulocauda melanogenys, Gymnocorymbus ternetzi, Hemibrycon polyodon , Hemigrammus unilineatus, Hollandichthys multifasciatus, Hyphessobrycon compressus, Iguanodectes geisleri, Knodus meridae, Landonia latidens, Markiana nigripinnis, Metynnis lippincottianus, Microschemobrycon casiquiare, Moenkhausia xinguensis, Myleus setiger, odontostilbe pequira, Orthospinus franciscoensis, Paracheirodon axelrodi, Paragoniates alburnus, Phenacogaster pectinatus, Phenagoniates macrolepis, Piabina argentea, Piaractus mesopotamicus, Poptella brevispina, Probolus heterostomus, Rachoviscus graciliceps, Rhinobrycon negrensis, Rhoadsia altipinna, Roeboexodon guyanensis, Serrabrycon magoi, Tetragonopterus argenteus e Triportheus albus.

[1] - com projeção posterior, ventral a margem ventral do infraorbital 3 .

Apareiodon piracicabae, Anodus orinocensis, Semaprochilodus insignis, Hepsetus odoe, Charax cf. leticiae, Galeocharax knerii, Gnathocharax steindachneri, oligosarcus argenteus e Salminus hilarii.

\section{[2] - projeção posterior muito desenvolvida.}

Hydrolycus tatauaia.

\section{[-] - inaplicável.}

Olivaichthys mesembrinus, Gymnotus aff. carapo, Carnegiella strigata, Erythrinoidea fam. nov, Characidium bahiensis e Stygichthys typhlops.

\section{[?] - indeterminado.}

Saccodon wagneri.

\section{5 - Margem anterior do infra-orbital 2:}

\section{[0] - aproximadamente reta.}

Catostomus commersonnii, Citharinus latus, Distichodus notospilus, Neolebias unifasciatus, Nannocharax fasciatus, Xenocharax spilurus, Hemiodus unimaculatus , Curimata ocellata, Curimatopsis macrolepis, Potamorhina latior, Prochilodus nigricans, Semaprochilodus insignis, Caenotropus labyrinthicus, Chilodus punctatus, Anostomus anostomus, Leporellus vittatus, Leporinus fasciatus, Schizodon fasciatus, Gasteropelecus sternicla, Thoracocharax stellatus, Acestrorhynchus falcirostris, Boulengerella maculata, ctenolucius hujeta, Copeina cf. guttata, Lebiasina bimaculata, Piabucina astrigata, Erythrinus erythrinus, Hoplias malabaricus, Brycinus macrolepidotus, Bryconalestes longipinnis, Chalceus epakros, Crenuchus spilurus, Agoniates halecinus, Atopomesus pachyodus, Brycon pesu, Bryconops alburnoides, Charax cf. leticiae, Compsura heterura, Diapoma terofali, Galeocharax knerii, Glandulocauda melanogenys, Hyphessobrycon compressus, Iguanodectes geisleri, Landonia latidens, Metynnis lippincottianus, Microschemobrycon casiquiare, oligosarcus argenteus, Paracheirodon axelrodi, Phenacogaster pectinatus, Piaractus mesopotamicus, Rachoviscus graciliceps, Rhinobrycon negrensis, Rhoadsia altipinna e Salminus hilarii.

\section{[1] - com projeção dorsal ao infra-orbital 1.}

Hemistichodus vaillanti, Apareiodon piracicabae, Parodon nasus, Anodus orinocensis, Bivibranchia fowleri, Gilbertolus atratoensis, Hydrolycus tatauaia, Roestes molossus, Hepsetus odoe, Arnoldichthys spilopterus, Aphyocharax pusillus, Astyanax mexicanus, Axelrodia reisei, Brittanichthys axelrodi, Bryconadenos tanaothoros, Bryconamericus exodon, Clupeacharax cf. engrauloides, Ctenobrycon hauxwellianus, Deuterodon iguape, Gnathocharax steindachneri, Gymnocorymbus ternetzi, Hemibrycon polyodon, Hemigrammus unilineatus, Hollandichthys multifasciatus, Knodus meridae, Markiana nigripinnis, Moenkhausia xinguensis, Myleus setiger, Odontostilbe pequira, orthospinus franciscoensis, Paragoniates alburnus, Phenagoniates macrolepis, Piabina argentea, Poptella brevispina, Probolus heterostomus, Roeboexodon guyanensis, Serrabrycon magoi, Tetragonopterus argenteus e Triportheus albus.

\section{[-] - inaplicável.}

olivaichthys mesembrinus, Gymnotus aff. carapo, Carnegiella strigata, Erythrinoidea fam. nov, Characidium bahiensis e Stygichthys typhlops. 
Chanos chanos e Saccodon wagneri.

146 - Infra-orbital 2:

[MOREIRA, 2002: 41]

[0] - quadrado ou retangular, altura não variando bastante no seu comprimento (Fig. 37).

Chanos chanos, Citharinus latus, Distichodus notospilus, Parodon nasus, Curimata ocellata, Schizodon fasciatus, Lebiasina bimaculata, Bryconalestes longipinnis, Bryconops alburnoides, Clupeacharax cf. engrauloides, Iguanodectes geisleri e Phenacogaster pectinatus.

\section{[1] - porção anterior mais larga que restante (Fig. 38).}

Catostomus commersonnii, Nannocharax fasciatus, Apareiodon piracicabae, Hemiodus unimaculatus, Prochilodus nigricans, Semaprochilodus insignis, Brycinus macrolepidotus e Metynnis lippincottianus.

\section{[2] - porção mediana maior que restante.}

Hemistichodus vaillanti, Xenocharax spilurus, Bivibranchia fowleri, Potamorhina latior, Caenotropus labyrinthicus, Chilodus punctatus, Anostomus anostomus, Leporellus vittatus, Leporinus fasciatus, Gilbertolus atratoensis, Roestes molossus, Copeina cf. guttata, Arnoldichthys spilopterus, Bryconadenos tanaothoros, Bryconamericus exodon, Compsura heterura, Ctenobrycon hauxwellianus, Hemigrammus unilineatus, Knodus meridae, Markiana nigripinnis, Moenkhausia xinguensis, Myleus setiger, Phenagoniates macrolepis, Piabina argentea, Piaractus mesopotamicus, Poptella brevispina, Rhinobrycon negrensis, Rhoadsia altipinna e Tetragonopterus argenteus.

\section{[3] - porção posterior maior que restante (Figs. 39, 40 e 41).}

Neolebias unifasciatus, Anodus orinocensis, Curimatopsis macrolepis, Gasteropelecus sternicla, Thoracocharax stellatus, Acestrorhynchus falcirostris, Hydrolycus tatauaia, Boulengerella maculata, Ctenolucius hujeta, Piabucina astrigata, Erythrinus erythrinus, Hoplias malabaricus, Hepsetus odoe, Chalceus epakros, Crenuchus spilurus, Agoniates halecinus, Aphyocharax pusillus, Astyanax mexicanus, Atopomesus pachyodus, Axelrodia reisei, Brittanichthys axelrodi, Brycon pesu, Charax cf. leticiae, Deuterodon iguape, Diapoma terofali, Galeocharax knerii, Glandulocauda melanogenys, Gnathocharax steindachneri, Gymnocorymbus ternetzi, Hemibrycon polyodon, Hollandichthys multifasciatus, Hyphessobrycon compressus, Microschemobrycon casiquiare, Odontostilbe pequira, Oligosarcus argenteus, Orthospinus franciscoensis, Paracheirodon axelrodi, Paragoniates alburnus, Probolus heterostomus, Rachoviscus graciliceps, Roeboexodon guyanensis, Salminus hilarii, Serrabrycon magoi e Triportheus albus.

\section{[-] - inaplicável.}

Olivaichthys mesembrinus, Gymnotus aff. carapo, Carnegiella strigata, Erythrinoidea fam. nov, Characidium bahiensis, Landonia latidens e Stygichthys typhlops.

\section{[?] - indeterminado.}

Saccodon wagneri.

\section{7 - Porção anterior do infra-orbital 2:}

$$
\text { [0] - lisa. }
$$

Chanos chanos, Catostomus commersonnii, Citharinus latus, Distichodus notospilus, Hemistichodus vaillanti, Neolebias unifasciatus, Nannocharax fasciatus, Xenocharax spilurus, Apareiodon piracicabae, Parodon nasus, Anodus orinocensis, Bivibranchia fowleri, Hemiodus unimaculatus, Curimata ocellata, Curimatopsis macrolepis, Potamorhina latior, Caenotropus labyrinthicus, Chilodus punctatus, Anostomus anostomus, Leporellus vittatus, Leporinus fasciatus, Schizodon fasciatus, Gasteropelecus sternicla, Thoracocharax stellatus, Acestrorhynchus falcirostris, Gilbertolus atratoensis, 
Hydrolycus tatauaia, Roestes molossus, Copeina cf. guttata, Lebiasina bimaculata, Piabucina astrigata, Erythrinus erythrinus, Hoplias malabaricus, Hepsetus odoe, Arnoldichthys spilopterus, Brycinus macrolepidotus, Bryconalestes longipinnis, Chalceus epakros, Characidium bahiensis, Crenuchus spilurus, Agoniates halecinus, Aphyocharax pusillus, Astyanax mexicanus, Atopomesus pachyodus, Axelrodia reisei, Brittanichthys axelrodi, Brycon pesu, Bryconadenos tanaothoros, Bryconamericus exodon, Charax cf. leticiae, Clupeacharax cf. engrauloides, Compsura heterura, Ctenobrycon hauxwellianus, Deuterodon iguape, Diapoma terofali, Galeocharax knerii, Glandulocauda melanogenys, Gnathocharax steindachneri, Gymnocorymbus ternetzi, Hemibrycon polyodon, Hemigrammus unilineatus, Hollandichthys multifasciatus, Hyphessobrycon compressus, Iguanodectes geisleri, Knodus meridae, Markiana nigripinnis, Metynnis lippincottianus, Microschemobrycon casiquiare, Moenkhausia xinguensis, Myleus setiger, odontostilbe pequira, oligosarcus argenteus, orthospinus franciscoensis, Paracheirodon axelrodi, Paragoniates alburnus, Phenacogaster pectinatus, Phenagoniates macrolepis, Piabina argentea, Poptella brevispina, Probolus heterostomus, Rachoviscus graciliceps, Rhinobrycon negrensis, Rhoadsia altipinna, Roeboexodon guyanensis, Serrabrycon magoi, Tetragonopterus argenteus e Triportheus albus.

\section{[1] - com identação.}

Semaprochilodus insignis, Boulengerella maculata, Ctenolucius hujeta, Bryconops alburnoides, Piaractus mesopotamicus e Salminus hilarii.

\section{[-] - inaplicável.}

olivaichthys mesembrinus, Gymnotus aff. carapo, Carnegiella strigata, Erythrinoidea fam. nov, Landonia latidens e Stygichthys typhlops.

\section{[?] - indeterminado.}

Saccodon wagneri.

148 - Margem ventral do infra-orbital 3:

[NETTO-FERREIRA, 2006: 7]

[0] - contígua à margem ventral do infra-orbital 2 (Figs. 37,38 e 39) .

Chanos chanos, Catostomus commersonnii, Citharinus latus, Distichodus notospilus, Hemistichodus vaillanti, Neolebias unifasciatus, Apareiodon piracicabae, Parodon nasus, Hemiodus unimaculatus, Curimata ocellata, Curimatopsis macrolepis, Prochilodus nigricans, Anostomus anostomus, Schizodon fasciatus, Gasteropelecus sternicla, Acestrorhynchus falcirostris, Hydrolycus tatauaia, Boulengerella maculata, ctenolucius hujeta, Lebiasina bimaculata, Piabucina astrigata, Erythrinus erythrinus, Hoplias malabaricus, Hepsetus odoe, Arnoldichthys spilopterus, Characidium bahiensis, crenuchus spilurus, Aphyocharax pusillus, Bryconadenos tanaothoros, Bryconamericus exodon, Diapoma terofali, Galeocharax knerii, Gnathocharax steindachneri, Iguanodectes geisleri, Markiana nigripinnis, Metynnis lippincottianus, odontostilbe pequira, oligosarcus argenteus, Paragoniates alburnus, Phenagoniates macrolepis, Piabina argentea, Piaractus mesopotamicus, Rhoadsia altipinna, Roeboexodon guyanensis e Salminus hilarii.

Fig. 41).

\section{[1] - não contígua à margem ventral do infra-orbital 2 (Fig. 40 e}

Nannocharax fasciatus, Xenocharax spilurus, Anodus orinocensis, Bivibranchia fowleri, Potamorhina latior, Semaprochilodus insignis, Caenotropus labyrinthicus, Chilodus punctatus, Leporellus vittatus, Leporinus fasciatus, Thoracocharax stellatus Gilbertolus atratoensis, Roestes molossus, Copeina cf. guttata, Brycinus macrolepidotus, Bryconalestes longipinnis, Chalceus epakros, Agoniates halecinus, Astyanax mexicanus, Atopomesus pachyodus, Axelrodia reisei, Brittanichthys axelrodi, Brycon pesu, Bryconops alburnoides, Charax cf. leticiae, Clupeacharax cf. engrauloides, Compsura heterura, ctenobrycon hauxwellianus, Deuterodon iguape, Glandulocauda melanogenys, Gymnocorymbus ternetzi, Hemibrycon polyodon, Hemigrammus unilineatus, Hollandichthys multifasciatus, Hyphessobrycon compressus, Knodus meridae, Landonia latidens, Microschemobrycon casiquiare, Moenkhausia xinguensis, Myleus setiger, orthospinus franciscoensis, Paracheirodon axelrodi, Phenacogaster pectinatus, Poptella brevispina, Probolus heterostomus, Rachoviscus graciliceps, Rhinobrycon negrensis, Serrabrycon magoi, Tetragonopterus argenteus e Triportheus albus.

[-] - inaplicável. 
Olivaichthys mesembrinus, Gymnotus aff. carapo, Carnegiella strigata, Erythrinoidea fam. nov. e Stygichthys typhlops.

\section{[?] - indeterminado.}

Saccodon wagneri.

149 - Infra-orbital 3:

[OYAKAWA, 1998: 32; NETTO-FERREIRA, 2006: 8] orbital.

[0] - ocupando a maior porção da margem ventral da série infra-

Chanos chanos, Catostomus commersonnii, Distichodus notospilus, Hemistichodus vaillanti, Neolebias unifasciatus, Nannocharax fasciatus, Hemiodus unimaculatus, Curimata ocellata, Curimatopsis macrolepis, Potamorhina latior, Prochilodus nigricans, Semaprochilodus insignis, Caenotropus labyrinthicus, Chilodus punctatus, Anostomus anostomus, Leporellus vittatus, Leporinus fasciatus, Schizodon fasciatus, Gasteropelecus sternicla, Thoracocharax stellatus, Copeina cf. guttata, Lebiasina bimaculata, Aphyocharax pusillus, Bryconadenos tanaothoros, compsura heterura, Ctenobrycon hauxwellianus, Iguanodectes geisleri, Knodus meridae, Landonia latidens, Moenkhausia xinguensis, Myleus setiger, Paracheirodon axelrodi, Phenacogaster pectinatus, Phenagoniates macrolepis, Piabina argentea, Rhinobrycon negrensis, Rhoadsia altipinna, Tetragonopterus argenteus e Triportheus albus.

\section{[1] - não ocupando a maior porção da série infra-orbital.}

Olivaichthys mesembrinus, Citharinus latus, Xenocharax spilurus, Apareiodon piracicabae, Parodon nasus, Anodus orinocensis, Bivibranchia fowleri, Acestrorhynchus falcirostris, Gilbertolus atratoensis, Hydrolycus tatauaia, Roestes molossus, Boulengerella maculata, Ctenolucius hujeta, Piabucina astrigata, Erythrinus erythrinus, Hoplias malabaricus, Hepsetus odoe, Arnoldichthys spilopterus, Brycinus macrolepidotus, Bryconalestes longipinnis, Chalceus epakros, Characidium bahiensis, Crenuchus spilurus, Agoniates halecinus, Astyanax mexicanus, Atopomesus pachyodus, Axelrodia reisei, Brittanichthys axelrodi, Brycon pesu, Bryconamericus exodon, Bryconops alburnoides, Charax cf. leticiae, Clupeacharax cf. engrauloides, Deuterodon iguape, Diapoma terofali, Galeocharax knerii, Glandulocauda melanogenys, Gnathocharax steindachneri, Gymnocorymbus ternetzi, Hemibrycon polyodon, Hemigrammus unilineatus, Hollandichthys multifasciatus, Hyphessobrycon compressus, Markiana nigripinnis, Metynnis lippincottianus, Microschemobrycon casiquiare, Odontostilbe pequira, Oligosarcus argenteus, orthospinus franciscoensis, Paragoniates alburnus, Piaractus mesopotamicus, Poptella brevispina, Probolus heterostomus, Rachoviscus graciliceps, Roeboexodon guyanensis, Salminus hilarii e Serrabrycon magoi.

\section{[-] - inaplicável.}

Gymnotus aff. carapo, Carnegiella strigata, Erythrinoidea fam. nov. e Stygichthys typhlops.

\section{[?] - indeterminado.}

Saccodon wagneri.

150 - Contato entre os infra-orbitais 3 e 4 :

$$
\text { [0] - liso. }
$$

Catostomus commersonnii, Citharinus latus, Distichodus notospilus, Hemistichodus vaillanti, Nannocharax fasciatus, Xenocharax spilurus, Apareiodon piracicabae, Parodon nasus, Anodus orinocensis, Bivibranchia fowleri, Hemiodus unimaculatus, Curimata ocellata, Curimatopsis macrolepis, Potamorhina latior, Caenotropus labyrinthicus, Chilodus punctatus, Anostomus anostomus, Leporellus vittatus, Leporinus fasciatus, Schizodon fasciatus, Gasteropelecus sternicla, Thoracocharax stellatus, Acestrorhynchus falcirostris, Hydrolycus tatauaia, Ctenolucius hujeta, Copeina cf. guttata, Lebiasina bimaculata, Erythrinus erythrinus, Hoplias malabaricus, Hepsetus odoe, Arnoldichthys spilopterus, Brycinus macrolepidotus, Bryconalestes longipinnis, Chalceus epakros, Characidium bahiensis, Crenuchus spilurus, Astyanax mexicanus, Atopomesus pachyodus, Brittanichthys axelrodi, Bryconadenos tanaothoros, Bryconamericus exodon, Bryconops 
alburnoides, Compsura heterura, Ctenobrycon hauxwellianus, Deuterodon iguape, Diapoma terofali, Galeocharax knerii, Glandulocauda melanogenys, Gymnocorymbus ternetzi, Hemibrycon polyodon, Hemigrammus unilineatus, Iguanodectes geisleri, Knodus meridae, Landonia latidens, Markiana nigripinnis, Metynnis lippincottianus, Microschemobrycon casiquiare, Moenkhausia xinguensis, odontostilbe pequira, oligosarcus argenteus, orthospinus franciscoensis, Paragoniates alburnus, Phenacogaster pectinatus, Phenagoniates macrolepis, Piabina argentea, Poptella brevispina, Probolus heterostomus, Rhinobrycon negrensis, Roeboexodon guyanensis, Salminus hilarii, Serrabrycon magoi, Tetragonopterus argenteus e Triportheus albus.

\section{[1] - interdigitado dorsalmente.}

Prochilodus nigricans, Semaprochilodus insignis, Roestes molossus, Piabucina astrigata, Agoniates halecinus, Brycon pesu, Charax cf. leticiae, Myleus setiger e Piaractus mesopotamicus.

\section{[-] - inaplicável.}

Chanos chanos, Olivaichthys mesembrinus, Gymnotus aff. carapo, Neolebias unifasciatus, Carnegiella strigata, Erythrinoidea fam. nov, Boulengerella maculata, Aphyocharax pusillus, Axelrodia reisei, Clupeacharax cf. engrauloides, Gnathocharax steindachneri, Hollandichthys multifasciatus, Hyphessobrycon compressus, Paracheirodon axelrodi, Rachoviscus graciliceps, Rhoadsia altipinna e Stygichthys typhlops.

\section{[?] - indeterminado.}

Saccodon wagneri e Gilbertolus atratoensis.

\section{1 - Tamanho do infra-orbital 4:}

[NETTO-FERREIRA, 2006: 9]

\section{[0] - desenvolvido.}

Olivaichthys mesembrinus, Citharinus latus, Distichodus notospilus, Hemistichodus vaillanti, Xenocharax spilurus, Apareiodon piracicabae, Anodus orinocensis, Bivibranchia fowleri, Hemiodus unimaculatus, Curimata ocellata, Curimatopsis macrolepis, Potamorhina latior, Prochilodus nigricans, Semaprochilodus insignis, Caenotropus labyrinthicus, Chilodus punctatus, Anostomus anostomus, Leporellus vittatus, Leporinus fasciatus, Schizodon fasciatus, Acestrorhynchus falcirostris, Gilbertolus atratoensis, Hydrolycus tatauaia, Roestes molossus, Copeina cf. guttata, Lebiasina bimaculata, Piabucina astrigata, Erythrinus erythrinus, Hoplias malabaricus, Hepsetus odoe, Arnoldichthys spilopterus, Brycinus macrolepidotus, Bryconalestes longipinnis, Chalceus epakros, Characidium bahiensis, Crenuchus spilurus, Agoniates halecinus, Astyanax mexicanus, Atopomesus pachyodus, Brittanichthys axelrodi, Brycon pesu, Bryconadenos tanaothoros, Bryconamericus exodon, Bryconops alburnoides, Compsura heterura, Ctenobrycon hauxwellianus, Deuterodon iguape, Diapoma terofali, Galeocharax knerii, Glandulocauda melanogenys, Gymnocorymbus ternetzi, Hemibrycon polyodon, Hemigrammus unilineatus, Iguanodectes geisleri, Knodus meridae, Markiana nigripinnis, Microschemobrycon casiquiare, Moenkhausia xinguensis, Myleus setiger, Odontostilbe pequira, Oligosarcus argenteus, orthospinus franciscoensis, Paragoniates alburnus, Phenacogaster pectinatus, Phenagoniates macrolepis, Piaractus mesopotamicus, Poptella brevispina, Probolus heterostomus, Rhinobrycon negrensis, Roeboexodon guyanensis, Salminus hilarii, Serrabrycon magoi, Tetragonopterus argenteus e Triportheus albus.

\section{[1] - muito pequeno ou ausente.}

Catostomus commersonnii, Carnegiella strigata, Erythrinoidea fam. nov, Boulengerella maculata, Ctenolucius hujeta, Aphyocharax pusillus, Axelrodia reisei, Gnathocharax steindachneri, Paracheirodon axelrodi, Piabina argentea, Rhoadsia altipinna e stygichthys typhlops.

\section{[-] - inaplicável.}

Chanos chanos, Neolebias unifasciatus, Nannocharax fasciatus, Thoracocharax stellatus, Clupeacharax cf. engrauloides, Hollandichthys multifasciatus, Hyphessobrycon compressus, Landonia latidens, Metynnis lippincottianus e Rachoviscus graciliceps. 
Gymnotus aff. carapo, Parodon nasus, Saccodon wagneri, Gasteropelecus sternicla e Charax cf. leticiae.

\section{2 - Orientação da margem ventral do infra-orbital 4:} [MOREIRA, 2002: 44]

\section{[0] - paralela ao maior eixo do corpo.}

Distichodus notospilus, Hemistichodus vaillanti, Xenocharax spilurus, Apareiodon piracicabae, Parodon nasus, Potamorhina latior, Semaprochilodus insignis, Caenotropus labyrinthicus, Chilodus punctatus, Anostomus anostomus, Leporinus fasciatus, Acestrorhynchus falcirostris, Gilbertolus atratoensis, Hydrolycus tatauaia, Roestes molossus, Erythrinus erythrinus, Chalceus epakros, Crenuchus spilurus, Agoniates halecinus, Atopomesus pachyodus, Brittanichthys axelrodi, Brycon pesu, Bryconadenos tanaothoros, Bryconamericus exodon, Compsura heterura, Diapoma terofali, Galeocharax knerii, Glandulocauda melanogenys, Gymnocorymbus ternetzi, Hemibrycon polyodon , Hemigrammus unilineatus, Hollandichthys multifasciatus, Iguanodectes geisleri, Knodus meridae, Landonia latidens, Markiana nigripinnis, Microschemobrycon casiquiare, Moenkhausia xinguensis, odontostilbe pequira, oligosarcus argenteus, orthospinus franciscoensis, Paragoniates alburnus, Piabina argentea, Poptella brevispina, Probolus heterostomus, Rhinobrycon negrensis, Roeboexodon guyanensis, Salminus hilarii, Serrabrycon magoi e Tetragonopterus argenteus.

\section{[1] - oblíqua ao maior eixo do corpo.}

Citharinus latus, Anodus orinocensis, Bivibranchia fowleri, Hemiodus unimaculatus, Curimata ocellata, Curimatopsis macrolepis, Prochilodus nigricans, Leporellus vittatus, Schizodon fasciatus, Copeina cf. guttata, Lebiasina bimaculata, Piabucina astrigata, Hoplias malabaricus, Hepsetus odoe, Arnoldichthys spilopterus, Brycinus macrolepidotus, Bryconalestes longipinnis, Astyanax mexicanus, Bryconops alburnoides, Myleus setiger, Phenagoniates macrolepis, Piaractus mesopotamicus e Triportheus albus.

\section{[-] - inaplicável.}

Chanos chanos, Catostomus commersonnii, Olivaichthys mesembrinus, Gymnotus aff. carapo, Neolebias unifasciatus, Nannocharax fasciatus, Carnegiella strigata, Gasteropelecus sternicla, Thoracocharax stellatus, Erythrinoidea fam. nov, Boulengerella maculata, Ctenolucius hujeta, Characidium bahiensis, Aphyocharax pusillus, Axelrodia reisei, Charax cf. leticiae, Clupeacharax cf. engrauloides, Gnathocharax steindachneri, Hyphessobrycon compressus, Metynnis lippincottianus, Paracheirodon axelrodi, Phenacogaster pectinatus, Rachoviscus graciliceps, Rhoadsia altipinna e stygichthys typhlops.

\section{[?] - indeterminado.}

Saccodon wagneri, Ctenobrycon hauxwellianus e Deuterodon iguape.

\section{3 - Proporção entre a altura e comprimento do infra-orbital 4: \\ [0] - altura maior que comprimento (Fig. 38).}

Citharinus latus, Curimatopsis macrolepis, Prochilodus nigricans, Semaprochilodus insignis, Caenotropus labyrinthicus, Chilodus punctatus, Anostomus anostomus, Schizodon fasciatus, Copeina cf. guttata, Brycinus macrolepidotus, Brittanichthys axelrodi, Bryconadenos tanaothoros, Bryconops alburnoides, Compsura heterura, Ctenobrycon hauxwellianus, Deuterodon iguape, Gymnocorymbus ternetzi, Hemigrammus unilineatus, Markiana nigripinnis, Myleus setiger, Odontostilbe pequira, Poptella brevispina, Probolus heterostomus e Tetragonopterus argenteus.

[1] - aproximadamente iguais (Fig. 37).

Distichodus notospilus, Hemistichodus vaillanti, Xenocharax spilurus, Apareiodon piracicabae, Parodon nasus, Anodus orinocensis, Bivibranchia fowleri, Curimata ocellata, Leporellus vittatus, Leporinus fasciatus, Gilbertolus atratoensis, Roestes molossus, Lebiasina bimaculata, Arnoldichthys spilopterus, Bryconalestes longipinnis, Atopomesus pachyodus, Bryconamericus exodon, Glandulocauda melanogenys, Hemibrycon polyodon, Iguanodectes geisleri, Moenkhausia xinguensis, Orthospinus franciscoensis, Phenacogaster pectinatus, Piabina argentea, Piaractus mesopotamicus, Rhinobrycon negrensis, Serrabrycon magoi e Triportheus albus. 
[2] - comprimento maior que altura (Figs. 39, 40 e 41).

Hemiodus unimaculatus, Potamorhina latior, Acestrorhynchus falcirostris, Hydrolycus tatauaia, Erythrinus erythrinus, Hoplias malabaricus, Hepsetus odoe, Chalceus epakros, Crenuchus spilurus, Agoniates halecinus, Astyanax mexicanus, Brycon pesu, Diapoma terofali, Galeocharax knerii, Knodus meridae, Microschemobrycon casiquiare, oligosarcus argenteus, Paragoniates alburnus, Phenagoniates macrolepis, Roeboexodon guyanensis e Salminus hilarii.

\section{[-] - inaplicável.}

Chanos chanos, Catostomus commersonnii, Olivaichthys mesembrinus, Gymnotus aff. carapo, Neolebias unifasciatus, Nannocharax fasciatus, Carnegiella strigata, Gasteropelecus sternicla, Thoracocharax stellatus, Erythrinoidea fam. nov, Boulengerella maculata, Ctenolucius hujeta, Characidium bahiensis, Aphyocharax pusillus, Axelrodia reisei, Charax cf. leticiae, Clupeacharax cf. engrauloides, Gnathocharax steindachneri, Hollandichthys multifasciatus, Hyphessobrycon compressus, Landonia latidens, Metynnis lippincottianus, Paracheirodon axelrodi, Rachoviscus graciliceps, Rhoadsia altipinna e stygichthys typhlops.

\section{[?] - indeterminado.}

Saccodon wagneri e Piabucina astrigata.

\section{4 - Margem posterior do infra-orbital 4:}

\section{[0] - não recobrindo o canal látero-sensorial do pré-opérculo.}

Chanos chanos, Distichodus notospilus, Hemistichodus vaillanti, Nannocharax fasciatus, Xenocharax spilurus, Leporellus vittatus, Leporinus fasciatus, Hydrolycus tatauaia, Roestes molossus, Brycinus macrolepidotus, Crenuchus spilurus, Agoniates halecinus, Astyanax mexicanus, Atopomesus pachyodus, Brittanichthys axelrodi, Brycon pesu, Bryconadenos tanaothoros, Bryconamericus exodon, Charax cf. leticiae, Clupeacharax cf. engrauloides, Compsura heterura, Ctenobrycon hauxwellianus, Deuterodon iguape, Diapoma terofali, Galeocharax knerii, Glandulocauda melanogenys, Gnathocharax steindachneri, Gymnocorymbus ternetzi, Hemibrycon polyodon, Hemigrammus unilineatus, Hollandichthys multifasciatus, Knodus meridae, Landonia latidens, Markiana nigripinnis, Metynnis lippincottianus, Microschemobrycon casiquiare, Moenkhausia xinguensis, Odontostilbe pequira, oligosarcus argenteus, orthospinus franciscoensis, Paragoniates alburnus, Phenacogaster pectinatus, Phenagoniates macrolepis, Piabina argentea, Piaractus mesopotamicus, Poptella brevispina, Probolus heterostomus, Rachoviscus graciliceps, Rhinobrycon negrensis, Rhoadsia altipinna, Roeboexodon guyanensis, Salminus hilarii, Serrabrycon magoi e Tetragonopterus argenteus.

\section{[1] - recobrindo o canal látero-sensorial do pré-opérculo.}

Citharinus latus, Apareiodon piracicabae, Parodon nasus, Anodus orinocensis, Bivibranchia fowleri, Hemiodus unimaculatus, Curimata ocellata, curimatopsis macrolepis, Potamorhina latior, Prochilodus nigricans, Semaprochilodus insignis, Caenotropus labyrinthicus, Chilodus punctatus, Anostomus anostomus, Acestrorhynchus falcirostris, Copeina cf. guttata, Lebiasina bimaculata, Piabucina astrigata, Erythrinus erythrinus, Hoplias malabaricus, Hepsetus odoe, Arnoldichthys spilopterus, Bryconalestes longipinnis, Chalceus epakros, Bryconops alburnoides, Iguanodectes geisleri, Myleus setiger e Triportheus albus.

\section{[-] - inaplicável.}

Catostomus commersonnii, Olivaichthys mesembrinus, Gymnotus aff. carapo, Neolebias unifasciatus, Carnegiella strigata, Gasteropelecus sternicla, Thoracocharax stellatus, Erythrinoidea fam. nov, Boulengerella maculata, ctenolucius hujeta, Characidium bahiensis, Aphyocharax pusillus, Axelrodia reisei, Hyphessobrycon compressus, Paracheirodon axelrodi e Stygichthys typhlops.

\section{[?] - indeterminado.}

Saccodon wagneri, Schizodon fasciatus e Gilbertolus atratoensis. 
[Zanata, 2000: 8, modificado; e NetTo-FerReira, 2006: 10, modificado] tamanho.

[0] - margens anterior e posterior aproximadamente do mesmo

Bivibranchia fowleri, Potamorhina latior, Caenotropus labyrinthicus, Chilodus punctatus, Anostomus anostomus, Leporinus fasciatus, Erythrinus erythrinus, crenuchus spilurus, Agoniates halecinus, Brittanichthys axelrodi, Glandulocauda melanogenys, Iguanodectes geisleri, Knodus meridae, Markiana nigripinnis, Microschemobrycon casiquiare, odontostilbe pequira, Paragoniates alburnus, Rhinobrycon negrensis, Tetragonopterus argenteus e Triportheus albus.

39) .

[1] - margem posterior maior que margem anterior (Fig. 38 e Fig.

Hemistichodus vaillanti, Apareiodon piracicabae, Parodon nasus, Anodus orinocensis, Hemiodus unimaculatus, Curimata ocellata, Curimatopsis macrolepis, Prochilodus nigricans, Leporellus vittatus, Schizodon fasciatus, Acestrorhynchus falcirostris, Gilbertolus atratoensis, Roestes molossus, Copeina cf. guttata, Lebiasina bimaculata, Piabucina astrigata, Hoplias malabaricus, Hepsetus odoe, Arnoldichthys spilopterus, Brycinus macrolepidotus, Bryconalestes longipinnis, Bryconops alburnoides, Galeocharax knerii, Hemibrycon polyodon, Myleus setiger, Oligosarcus argenteus e Piaractus mesopotamicus.

41).

[2] - margem posterior menor que margem anterior (Figs. 37, 40 e

Distichodus notospilus, Xenocharax spilurus, Semaprochilodus insignis, Hydrolycus tatauaia, Chalceus epakros, Astyanax mexicanus, Atopomesus pachyodus, Brycon pesu, Bryconadenos tanaothoros, Bryconamericus exodon, Compsura heterura, Ctenobrycon hauxwellianus, Deuterodon iguape, Diapoma terofali, Gymnocorymbus ternetzi, Hemigrammus unilineatus, Moenkhausia xinguensis, Orthospinus franciscoensis, Phenacogaster pectinatus, Phenagoniates macrolepis, Piabina argentea, Poptella brevispina, Probolus heterostomus, Roeboexodon guyanensis, Salminus hilarii e Serrabrycon magoi.

\section{[-] - inaplicável.}

Chanos chanos, Catostomus commersonnii, Olivaichthys mesembrinus, Gymnotus aff. carapo, Neolebias unifasciatus, Nannocharax fasciatus, Carnegiella strigata, Thoracocharax stellatus, Erythrinoidea fam. nov, Boulengerella maculata, ctenolucius hujeta, Characidium' bahiensis, Aphyocharax pusillus, Axelrodia reisei, Clupeacharax cf. engrauloides, Gnathocharax steindachneri, Hollandichthys multifasciatus, Hyphessobrycon compressus, Landonia latidens, Metynnis lippincottianus, Paracheirodon axelrodi, Rachoviscus graciliceps, Rhoadsia altipinna e Stygichthys typhlops.

\section{[?] - indeterminado.}

Citharinus latus, Saccodon wagneri, Gasteropelecus sternicla e Charax cf. leticiae.

\section{Forma do infra-orbital 4:}

\section{[0] - margens anterior e posterior aproximadamente paralelas.}

Hemistichodus vaillanti, Xenocharax spilurus, Anodus orinocensis, Bivibranchia fowleri, Curimatopsis macrolepis, Prochilodus nigricans, Anostomus anostomus, Schizodon fasciatus, Acestrorhynchus falcirostris, Gilbertolus atratoensis, Roestes molossus, Copeina cf. guttata, Lebiasina bimaculata, Piabucina astrigata, Erythrinus erythrinus, Hepsetus odoe, Brycinus macrolepidotus, Chalceus epakros, Crenuchus spilurus, Agoniates halecinus, Atopomesus pachyodus, Brycon pesu, Bryconadenos tanaothoros, Compsura heterura, ctenobrycon hauxwellianus, Deuterodon iguape, Diapoma terofali, Glandulocauda melanogenys, Gymnocorymbus ternetzi, Hemibrycon polyodon, Hemigrammus unilineatus, Iguanodectes geisleri, Knodus meridae, Markiana nigripinnis, Microschemobrycon casiquiare, Moenkhausia xinguensis, Myleus setiger, Odontostilbe pequira, Oligosarcus argenteus, orthospinus franciscoensis, Paragoniates alburnus, Phenacogaster pectinatus, Phenagoniates macrolepis, Poptella brevispina, Probolus heterostomus, Rhinobrycon negrensis, Roeboexodon guyanensis, Salminus hilarii, Serrabrycon magoi e Triportheus albus.

[1] - margem posterior com inclinação ântero-dorsal. 
Distichodus notospilus, Apareiodon piracicabae, Parodon nasus, Curimata ocellata, Caenotropus labyrinthicus, Chilodus punctatus, Leporinus fasciatus, Hydrolycus tatauaia, Arnoldichthys spilopterus, Bryconalestes longipinnis, Brittanichthys axelrodi, Bryconamericus exodon, Bryconops alburnoides, Galeocharax knerii e Tetragonopterus argenteus.

\section{[2] - margem anterior inclinada póstero-dorsalmente.}

Hemiodus unimaculatus, Semaprochilodus insignis, Leporellus vittatus e Piaractus mesopotamicus.

\section{[-] - inaplicável.}

Chanos chanos, Catostomus commersonnii, olivaichthys mesembrinus, Gymnotus aff. carapo, Neolebias unifasciatus, Nannocharax fasciatus, Potamorhina latior, Carnegiella strigata, Thoracocharax stellatus, Erythrinoidea fam. nov, Boulengerella maculata, Ctenolucius hujeta, Hoplias malabaricus, Characidium bahiensis, Aphyocharax pusillus, Astyanax mexicanus, Axelrodia reisei, clupeacharax cf. engrauloides, Gnathocharax steindachneri, Hollandichthys multifasciatus, Hyphessobrycon compressus, Landonia latidens, Metynnis lippincottianus, Paracheirodon axelrodi, Piabina argentea, Rachoviscus graciliceps, Rhoadsia altipinna e stygichthys typhlops.

\section{[?] - indeterminado.}

Citharinus latus, Saccodon wagneri, Gasteropelecus sternicla e Charax cf. leticiae.

\section{7 - Canal sensorial do infra-orbital 4:}

[LIMA, 2006: 53, modificado]

[0] - com ou sem poro posterior (Fig. 37 e Fig. 39).

Citharinus latus, Distichodus notospilus, Hemistichodus vaillanti, Nannocharax fasciatus, Xenocharax spilurus, Apareiodon piracicabae, Parodon nasus, Chilodus punctatus, Acestrorhynchus falcirostris, Copeina cf. guttata, Lebiasina bimaculata, Piabucina astrigata, Erythrinus erythrinus, Arnoldichthys spilopterus, Crenuchus spilurus, Astyanax mexicanus, Atopomesus pachyodus, Bryconadenos tanaothoros, Bryconamericus exodon, Bryconops alburnoides, Compsura heterura, Ctenobrycon hauxwellianus, Deuterodon iguape, Diapoma terofali, Glandulocauda melanogenys, Gnathocharax steindachneri, Gymnocorymbus ternetzi, Hemigrammus unilineatus, Iguanodectes geisleri, Knodus meridae, Landonia latidens, Microschemobrycon casiquiare, odontostilbe pequira, oligosarcus argenteus, Paragoniates alburnus, Phenacogaster pectinatus, Phenagoniates macrolepis, Piabina argentea, Rhinobrycon negrensis, Serrabrycon magoi e Tetragonopterus argenteus.

\section{[1] - com ramo posterior (Figs. 38, 40 e 41).}

Anodus orinocensis, Bivibranchia fowleri, Hemiodus unimaculatus, Curimata ocellata, Curimatopsis macrolepis, Potamorhina latior, Prochilodus nigricans, Semaprochilodus insignis, Caenotropus labyrinthicus, Anostomus anostomus, Leporellus vittatus, Leporinus fasciatus, Schizodon fasciatus, Gilbertolus atratoensis, Roestes molossus, Hoplias malabaricus, Hepsetus odoe, Brycinus macrolepidotus, Bryconalestes longipinnis, Chalceus epakros, Agoniates halecinus, Brycon pesu, Galeocharax knerii, Hemibrycon polyodon, Markiana nigripinnis, Moenkhausia xinguensis, Myleus setiger, orthospinus franciscoensis, Piaractus mesopotamicus, Poptella brevispina, Probolus heterostomus , Roeboexodon guyanensis, Salminus hilarii e Triportheus albus.

\section{[-] - inaplicável.}

Chanos chanos, Catostomus commersonnii, Olivaichthys mesembrinus, Gymnotus aff. carapo, Neolebias unifasciatus, Carnegiella strigata, Thoracocharax stellatus, Hydrolycus tatauaia, Erythrinoidea fam. nov, Boulengerella maculata, ctenolucius hujeta, Characidium bahiensis, Aphyocharax pusillus, Axelrodia reisei, Brittanichthys axelrodi, Clupeacharax cf. engrauloides, Hollandichthys multifasciatus, Hyphessobrycon compressus, Metynnis lippincottianus, Paracheirodon axelrodi, Rachoviscus graciliceps, Rhoadsia altipinna e Stygichthys typhlops.

\section{[?] - indeterminado.}

Saccodon wagneri, Gasteropelecus sternicla e Charax cf. leticiae. 
158 - Margem anterior do infra-orbital 4:

[NETTO-FERREIRA, 2006: 11, modificado]

[0] - margem anterior participando da margem do anel orbital.

\begin{abstract}
Citharinus latus, Distichodus notospilus, Hemistichodus vaillanti, Nannocharax fasciatus, Xenocharax spilurus, Apareiodon piracicabae, Parodon nasus, Anodus orinocensis, Bivibranchia fowleri, Hemiodus unimaculatus, Curimata ocellata, Curimatopsis macrolepis, Potamorhina latior, Prochilodus nigricans, Semaprochilodus insignis, Caenotropus labyrinthicus, Chilodus punctatus, Anostomus anostomus, Leporellus vittatus, Leporinus fasciatus, Schizodon fasciatus, Gilbertolus atratoensis, Hydrolycus tatauaia, Roestes molossus, Copeina cf. guttata, Erythrinus erythrinus, Arnoldichthys spilopterus, Brycinus macrolepidotus, Bryconalestes longipinnis, Chalceus epakros, crenuchus spilurus, Agoniates halecinus, Astyanax mexicanus, Atopomesus pachyodus, Brittanichthys axelrodi, Brycon pesu, Bryconadenos tanaothoros, Bryconamericus exodon, Bryconops alburnoides, Compsura heterura, Ctenobrycon hauxwellianus, Deuterodon iguape, Diapoma terofali, Glandulocauda melanogenys, Gymnocorymbus ternetzi, Hemibrycon polyodon , Hemigrammus unilineatus, Iguanodectes geisleri, Knodus meridae, Markiana nigripinnis, Microschemobrycon casiquiare, Moenkhausia xinguensis, Myleus setiger, odontostilbe pequira, oligosarcus argenteus, orthospinus franciscoensis, Paragoniates alburnus, Phenacogaster pectinatus, Phenagoniates macrolepis, Piabina argentea, Piaractus mesopotamicus, Poptella brevispina, Probolus heterostomus, Rhinobrycon negrensis, Roeboexodon guyanensis, Salminus hilarii, Serrabrycon magoi, Tetragonopterus argenteus e Triportheus albus.
\end{abstract}

[1] - margem anterior com participação bem reduzida da margem do anel orbital.

Acestrorhynchus falcirostris, Lebiasina bimaculata, Piabucina astrigata, Hepsetus odoe e Galeocharax knerii.

\title{
[2] - margem anterior excluída da margem do anel orbital.
}

Hoplias malabaricus.

\section{[-] - inaplicável.}

Chanos chanos, Catostomus commersonnii, olivaichthys mesembrinus, Gymnotus aff. carapo, Neolebias unifasciatus, Carnegiella strigata, Thoracocharax stellatus, Erythrinoidea fam. nov, Boulengerella maculata, Ctenolucius hujeta, Characidium bahiensis, Aphyocharax pusillus, Axelrodia reisei, Clupeacharax cf. engrauloides, Gnathocharax steindachneri, Hollandichthys multifasciatus, Hyphessobrycon compressus, Landonia latidens, Metynnis lippincottianus, Paracheirodon axelrodi, Rachoviscus graciliceps, Rhoadsia altipinna e stygichthys typhlops.

[?] - indeterminado.

Saccodon wagneri, Gasteropelecus sternicla e Charax cf. leticiae.

\section{9 - Margem ventral do infra-orbital 4:}

[0] - aproximadamente reta (Figs. 37, 38, 39 e 40).

Distichodus notospilus, Hemistichodus vaillanti, Hemiodus unimaculatus, Curimata ocellata, Curimatopsis macrolepis, Potamorhina latior, Prochilodus nigricans, Chilodus punctatus, Anostomus anostomus, Leporellus vittatus, Leporinus fasciatus, Schizodon fasciatus, Copeina cf. guttata, Lebiasina bimaculata, Hoplias malabaricus, Arnoldichthys spilopterus, Brycinus macrolepidotus, Bryconalestes longipinnis, Chalceus epakros, crenuchus spilurus, Atopomesus pachyodus, Brittanichthys axelrodi, Compsura heterura, Galeocharax knerii, Glandulocauda melanogenys, Iguanodectes geisleri, Knodus meridae, Markiana nigripinnis, Myleus setiger, Odontostilbe pequira, oligosarcus argenteus e Phenagoniates macrolepis.

[1] - porção anterior com projeção ventral (Fig. 41).

Xenocharax spilurus, Apareiodon piracicabae, Parodon nasus, Anodus orinocensis, Bivibranchia fowleri, Semaprochilodus insignis, Caenotropus labyrinthicus, 
Acestrorhynchus falcirostris, Hydrolycus tatauaia, Roestes molossus, Piabucina astrigata, Erythrinus erythrinus, Hepsetus odoe, Agoniates halecinus, Astyanax mexicanus, Brycon pesu, Bryconadenos tanaothoros, Bryconamericus exodon, Bryconops alburnoides, Ctenobrycon hauxwellianus, Deuterodon iguape, Diapoma terofali, Gymnocorymbus ternetzi, Hemibrycon polyodon, Hemigrammus unilineatus, Landonia latidens, Microschemobrycon casiquiare, Moenkhausia xinguensis, orthospinus franciscoensis, Paragoniates alburnus, Phenacogaster pectinatus, Piabina argentea, Piaractus mesopotamicus, Poptella brevispina, Probolus heterostomus, Rhinobrycon negrensis, Roeboexodon guyanensis, Salminus hilarii, Serrabrycon magoi, Tetragonopterus argenteus e Triportheus albus.

\section{[-] - inaplicável.}

Chanos chanos, Catostomus commersonnii, olivaichthys mesembrinus, Gymnotus aff. carapo, Neolebias unifasciatus, Nannocharax fasciatus, Carnegiella strigata, Thoracocharax stellatus, Erythrinoidea fam. nov, Boulengerella maculata, Ctenolucius hujeta, Characidium bahiensis, Aphyocharax pusillus, Axelrodia reisei, clupeacharax cf. engrauloides, Gnathocharax steindachneri, Hollandichthys multifasciatus, Hyphessobrycon compressus, Metynnis lippincottianus, Paracheirodon axelrodi, Rachoviscus graciliceps, Rhoadsia altipinna e Stygichthys typhlops.

\section{[?] - indeterminado.}

Citharinus latus, Saccodon wagneri, Gasteropelecus sternicla, Gilbertolus atratoensis e Charax cf. leticiae.

\section{0 - Infra-orbital 5 :}

\section{[0] - com processo medial}

Schizodon fasciatus, Copeina cf. guttata e Piabucina astrigata.

\section{[1] - liso medialmente}

Citharinus latus, Distichodus notospilus, Hemistichodus vaillanti, Xenocharax spilurus, Apareiodon piracicabae, Parodon nasus, Saccodon wagneri, Anodus orinocensis, Bivibranchia fowleri, Hemiodus unimaculatus, curimata ocellata, Curimatopsis macrolepis, Potamorhina latior, Prochilodus nigricans, Semaprochilodus insignis, Caenotropus labyrinthicus, Chilodus punctatus, Anostomus anostomus, Leporellus vittatus, Leporinus fasciatus, Acestrorhynchus falcirostris, Hydrolycus tatauaia, Roestes molossus, Boulengerella maculata, Ctenolucius hujeta, Lebiasina bimaculata, Erythrinus erythrinus, Hoplias malabaricus, Hepsetus odoe, Arnoldichthys spilopterus, Brycinus macrolepidotus, Bryconalestes longipinnis, Chalceus epakros, Crenuchus spilurus, Agoniates halecinus, Aphyocharax pusillus, Astyanax mexicanus, Brycon pesu, Bryconadenos tanaothoros, Bryconamericus exodon, Bryconops alburnoides, Clupeacharax cf. engrauloides, Ctenobrycon hauxwellianus, Deuterodon iguape, Diapoma terofali, Galeocharax knerii, Gymnocorymbus ternetzi, Hemibrycon polyodon, Hemigrammus unilineatus, Hollandichthys multifasciatus, Iguanodectes geisleri, Knodus meridae, Markiana nigripinnis, Microschemobrycon casiquiare, Moenkhausia xinguensis, Myleus setiger, Odontostilbe pequira, oligosarcus argenteus, orthospinus franciscoensis, Paragoniates alburnus, Phenacogaster pectinatus, Phenagoniates macrolepis, Piabina argentea, Piaractus mesopotamicus, Poptella brevispina, Probolus heterostomus Rhinobrycon negrensis, Rhoadsia altipinna, Roeboexodon guyanensis, Salminus hilarii, Serrabrycon magoi, Tetragonopterus argenteus e Triportheus albus.

\section{[-] - inaplicável.}

Chanos chanos, Catostomus commersonnii, olivaichthys mesembrinus, Gymnotus aff. carapo, Neolebias unifasciatus, Nannocharax fasciatus, Carnegiella strigata, Thoracocharax stellatus, Erythrinoidea fam. nov, Characidium bahiensis, Atopomesus pachyodus, Axelrodia reisei, Brittanichthys axelrodi, Compsura heterura, Glandulocauda melanogenys, Gnathocharax steindachneri, Hyphessobrycon compressus, Landonia latidens, Metynnis lippincottianus, Paracheirodon axelrodi, Rachoviscus graciliceps e Stygichthys typhlops.

\section{[?] - indeterminado.}

Gasteropelecus sternicla, Gilbertolus atratoensis e Charax cf. leticiae.

161 - Porção ventral do infra-orbital 6:

[TOLEDO-PIZA, 2000: 1 e LIMA, 2006: 3] 


\section{[0] - aproximadamente horizontal.}

Chanos chanos, Citharinus latus, Distichodus notospilus, Hemistichodus vaillanti, Neolebias unifasciatus, Nannocharax fasciatus, Xenocharax spilurus, Apareiodon piracicabae, Parodon nasus, Bivibranchia fowleri, Hemiodus unimaculatus, Curimata ocellata, Curimatopsis macrolepis, Potamorhina latior, Prochilodus nigricans, Semaprochilodus insignis, Caenotropus labyrinthicus, Chilodus punctatus, Leporellus vittatus, Schizodon fasciatus, Acestrorhynchus falcirostris, Gilbertolus atratoensis, Hydrolycus tatauaia, Roestes molossus, Arnoldichthys spilopterus, Agoniates halecinus, Aphyocharax pusillus, Astyanax mexicanus, Bryconadenos tanaothoros, Bryconamericus exodon, Bryconops alburnoides, Charax cf. leticiae, Clupeacharax cf. engrauloides, Compsura heterura, Ctenobrycon hauxwellianus, Deuterodon iguape, Diapoma terofali, Gymnocorymbus ternetzi, Hemibrycon polyodon, Hemigrammus unilineatus, Hollandichthys multifasciatus, Iguanodectes geisleri, Knodus meridae, Landonia latidens, Markiana nigripinnis, Metynnis lippincottianus, Microschemobrycon casiquiare, Moenkhausia xinguensis, Myleus setiger, Orthospinus franciscoensis, Phenacogaster pectinatus, Phenagoniates macrolepis, Piabina argentea, Piaractus mesopotamicus, Poptella brevispina, Probolus heterostomus, Rhoadsia altipinna, Roeboexodon guyanensis, Serrabrycon magoi, Tetragonopterus argenteus e Triportheus albus.

[1] - projetando-se ventralmente, limitando margem anterior do infra-orbital 5 .

Anodus orinocensis, Anostomus anostomus, Leporinus fasciatus, Boulengerella maculata, ctenolucius hujeta, Lebiasina bimaculata, Piabucina astrigata, Erythrinus erythrinus, Hoplias malabaricus, Hepsetus odoe, Brycinus macrolepidotus, Bryconalestes longipinnis, Chalceus epakros, Brycon pesu, Galeocharax knerii, Oligosarcus argenteus, Paragoniates alburnus e Salminus hilarii.

\section{[-] - inaplicável.}

Catostomus commersonnii, Olivaichthys mesembrinus, Gymnotus aff. carapo, Carnegiella strigata, Gasteropelecus sternicla, Thoracocharax stellatus, Erythrinoidea fam. nov, Copeina cf. guttata, Characidium bahiensis, Crenuchus spilurus, Atopomesus pachyodus, Axelrodia reisei, Brittanichthys axelrodi, Glandulocauda melanogenys, Gnathocharax steindachneri, Hyphessobrycon compressus, odontostilbe pequira, Paracheirodon axelrodi, Rachoviscus graciliceps, Rhinobrycon negrensis e Stygichthys typhlops.

\section{[?] - indeterminado.}

Saccodon wagneri.

162 - Infra-orbital 6:

[ZANATA \& VARI, 2005: 16; LIMA, 2006: 28, modificado; e NETTO-FERREIRA, 2006 : 14 e 192, modificados]

\section{(Minimamente conectado) .}

\section{[0] - ausente.}

Curimatopsis macrolepis, Carnegiella strigata, Thoracocharax stellatus, Erythrinoidea fam. nov, Copeina cf. guttata, Axelrodia reisei, Paracheirodon axelrodi, Rachoviscus graciliceps, Rhinobrycon negrensis e Stygichthys typhlops.

\section{[1] - presente, como ossificação do canal apenas.}

Curimatopsis macrolepis, Chilodus punctatus, Gasteropelecus sternicla, Roestes molossus, Characidium bahiensis, Crenuchus spilurus, Atopomesus pachyodus, Compsura heterura, Hemigrammus unilineatus, Iguanodectes geisleri, Odontostilbe pequira, Phenacogaster pectinatus, Probolus heterostomus e Rhoadsia altipinna.

\section{[2] - presente, com abas ósseas.}

Chanos chanos, Citharinus latus, Distichodus notospilus, Hemistichodus vaillanti, Neolebias unifasciatus, Nannocharax fasciatus, Xenocharax spilurus, Apareiodon piracicabae, Parodon nasus, Saccodon wagneri, Anodus orinocensis, Bivibranchia fowleri, Hemiodus unimaculatus, Curimata ocellata, Potamorhina latior, Prochilodus nigricans, Semaprochilodus insignis, Caenotropus labyrinthicus, Anostomus anostomus, Leporellus 
vittatus, Leporinus fasciatus, Schizodon fasciatus, Acestrorhynchus falcirostris, Gilbertolus atratoensis, Hydrolycus tatauaia, Boulengerella maculata, ctenolucius hujeta, Lebiasina bimaculata, Piabucina astrigata, Erythrinus erythrinus, Hoplias malabaricus, Hepsetus odoe, Arnoldichthys spilopterus, Brycinus macrolepidotus, Bryconalestes longipinnis, Chalceus epakros, Agoniates halecinus, Aphyocharax pusillus, Astyanax mexicanus, Brycon pesu, Bryconadenos tanaothoros, Bryconamericus exodon, Bryconops alburnoides, Clupeacharax cf. engrauloides, Ctenobrycon hauxwellianus, Deuterodon iguape, Diapoma terofali, Galeocharax knerii, Gymnocorymbus ternetzi, Hemibrycon polyodon, Hollandichthys multifasciatus, Knodus meridae, Landonia latidens, Markiana nigripinnis, Metynnis lippincottianus, Microschemobrycon casiquiare, Moenkhausia xinguensis, Myleus setiger, oligosarcus argenteus, orthospinus franciscoensis, Paragoniates alburnus, Phenagoniates macrolepis, Piabina argentea, Piaractus mesopotamicus, Poptella brevispina, Roeboexodon guyanensis, Salminus hilarii, Serrabrycon magoi, Tetragonopterus argenteus e Triportheus albus.

\section{[-] - inaplicável.}

Catostomus commersonnii, Brittanichthys axelrodi, Glandulocauda melanogenys, Gnathocharax steindachneri e Hyphessobrycon compressus.

\section{[?] - indeterminado.}

Charax cf. leticiae.

\section{[1,2] - polimórfico.}

Curimatopsis macrolepis.

\section{3 - Poro póstero-dorsal do infra-orbital 6:}

\section{[0] - na margem do osso, ou lateral.}

Chanos chanos, Citharinus latus, Distichodus notospilus, Hemistichodus vaillanti, Neolebias unifasciatus, Nannocharax fasciatus, Xenocharax spilurus, Anodus orinocensis, Bivibranchia fowleri, Hemiodus unimaculatus, Curimata ocellata, Curimatopsis macrolepis, Potamorhina latior, Prochilodus nigricans, Semaprochilodus insignis, Caenotropus labyrinthicus, Chilodus punctatus, Anostomus anostomus, Leporellus vittatus, Leporinus fasciatus, Schizodon fasciatus, Gasteropelecus sternicla, Acestrorhynchus falcirostris, Gilbertolus atratoensis, Hydrolycus tatauaia, Roestes molossus, Boulengerella maculata, Ctenolucius hujeta, Lebiasina bimaculata, Piabucina astrigata, Erythrinus erythrinus, Hoplias malabaricus, Hepsetus odoe, Arnoldichthys spilopterus, Brycinus macrolepidotus, Bryconalestes longipinnis, Chalceus epakros, Agoniates halecinus, Aphyocharax pusillus, Astyanax mexicanus, Brycon pesu, Bryconadenos tanaothoros, Bryconamericus exodon, Bryconops alburnoides, Clupeacharax cf. engrauloides, Ctenobrycon hauxwellianus, Deuterodon iguape, Diapoma terofali, Galeocharax knerii, Gymnocorymbus ternetzi, Hemibrycon polyodon, Hollandichthys multifasciatus, Knodus meridae, Landonia latidens, Markiana nigripinnis, Metynnis lippincottianus, Microschemobrycon casiquiare, Moenkhausia xinguensis, Myleus setiger, oligosarcus argenteus, orthospinus franciscoensis, Paragoniates alburnus, Phenagoniates macrolepis, Piabina argentea, Piaractus mesopotamicus, Poptella brevispina, Probolus heterostomus, Roeboexodon guyanensis, Salminus hilarii, Serrabrycon magoi, Tetragonopterus' argenteus e Triportheus albus.

[1] - medial.

Apareiodon piracicabae, Parodon nasus e Saccodon wagneri.

\section{[-] - inaplicável.}

Catostomus commersonnii, Olivaichthys mesembrinus, Gymnotus aff. carapo, Carnegiella strigata, Thoracocharax stellatus, Erythrinoidea fam. nov, Copeina cf. guttata, Characidium bahiensis, Crenuchus spilurus, Atopomesus pachyodus, Axelrodia reisei, Brittanichthys axelrodi, Charax cf. leticiae, Compsura heterura, Glandulocauda melanogenys, Gnathocharax steindachneri, Hemigrammus unilineatus, Hyphessobrycon compressus, Iguanodectes geisleri, Odontostilbe pequira, Paracheirodon axelrodi, Phenacogaster pectinatus, Rachoviscus graciliceps, Rhinobrycon negrensis, Rhoadsia altipinna e Stygichthys typhlops. 
[OYAKAWA, 1998: 34; e NetTo-FerReira, 2006: 15]

$$
\text { [0] - único. }
$$

Chanos chanos, Olivaichthys mesembrinus, Gymnotus aff. carapo, Citharinus latus, Distichodus notospilus, Hemistichodus vaillanti, Neolebias unifasciatus, Nannocharax fasciatus, Xenocharax spilurus, Apareiodon piracicabae, Parodon nasus, Saccodon wagneri, Anodus orinocensis, Bivibranchia fowleri, Hemiodus unimaculatus, Curimata ocellata, Curimatopsis macrolepis, Prochilodus nigricans, Semaprochilodus insignis, Caenotropus labyrinthicus, Chilodus punctatus, Anostomus anostomus, Leporellus vittatus, Leporinus fasciatus, Schizodon fasciatus, Gasteropelecus sternicla, Acestrorhynchus falcirostris, Gilbertolus atratoensis, Hydrolycus tatauaia, Roestes molossus, Boulengerella maculata, Ctenolucius hujeta, Lebiasina bimaculata, Piabucina astrigata, Hoplias malabaricus, Hepsetus odoe, Arnoldichthys spilopterus, Brycinus macrolepidotus, Bryconalestes longipinnis, Chalceus epakros, Agoniates halecinus, Aphyocharax pusillus, Astyanax mexicanus, Atopomesus pachyodus, Brycon pesu, Bryconadenos tanaothoros, Bryconamericus exodon, Bryconops alburnoides, Clupeacharax cf. engrauloides, Compsura heterura, Ctenobrycon hauxwellianus, Deuterodon iguape, Diapoma terofali, Galeocharax knerii, Gymnocorymbus ternetzi, Hemibrycon polyodon, Hemigrammus unilineatus, Hollandichthys multifasciatus, Iguanodectes geisleri, Knodus meridae, Landonia latidens, Markiana nigripinnis, Metynnis lippincottianus, Microschemobrycon casiquiare, Moenkhausia xinguensis, Myleus setiger, Odontostilbe pequira, Oligosarcus argenteus, Orthospinus franciscoensis, Paragoniates alburnus, Phenacogaster pectinatus, Phenagoniates macrolepis, Piabina argentea, Piaractus mesopotamicus, Poptella brevispina, Probolus heterostomus, Rhoadsia altipinna, Roeboexodon guyanensis, Salminus hilarii, Serrabrycon magoi, Tetragonopterus argenteus e Triportheus albus.

$$
\text { [1] - duplo. }
$$

Potamorhina latior e Erythrinus erythrinus.

\section{[-] - inaplicável.}

Catostomus commersonnii, Carnegiella strigata, Thoracocharax stellatus, Erythrinoidea fam. nov, Copeina cf. guttata, Characidium bahiensis, Crenuchus spilurus, Axelrodia reisei, Brittanichthys axelrodi, Glandulocauda melanogenys, Gnathocharax steindachneri, Hyphessobrycon compressus, Paracheirodon axelrodi, Rachoviscus graciliceps, Rhinobrycon negrensis e Stygichthys typhlops.

\section{[?] - indeterminado.}

Charax cf. leticiae.

\section{5 - Tamanho do infra-orbital 6:}

\section{[0] - maior do que infra-orbital 5.}

Nannocharax fasciatus, Apareiodon piracicabae, Parodon nasus, Saccodon wagneri, Prochilodus nigricans, Semaprochilodus insignis, Anostomus anostomus, Leporinus fasciatus, Schizodon fasciatus, Hydrolycus tatauaia, Erythrinus erythrinus, Hepsetus odoe, Arnoldichthys spilopterus, Brycinus macrolepidotus, Bryconalestes longipinnis, Galeocharax knerii, Gymnocorymbus ternetzi, Markiana nigripinnis e Salminus hilarii.

\section{[1] - igual que infra-orbital 5 (Fig. 37 e Fig. 38).}

Citharinus latus, Distichodus notospilus, Hemistichodus vaillanti, Anodus orinocensis, Hemiodus unimaculatus, Potamorhina latior, Characidium bahiensis, Atopomesus pachyodus, Ctenobrycon hauxwellianus, Deuterodon iguape, Myleus setiger, orthospinus franciscoensis, Roeboexodon guyanensis e Triportheus albus.

\section{[2] - menor que infra-orbital 5 (Figs. 39, 40 e 41).}

Curimata ocellata, Curimatopsis macrolepis, Caenotropus labyrinthicus, Chilodus punctatus, Leporellus vittatus, Acestrorhynchus falcirostris, Roestes molossus, Boulengerella maculata, Ctenolucius hujeta, Lebiasina bimaculata, Piabucina astrigata, Hoplias malabaricus, Chalceus epakros, Agoniates halecinus, Aphyocharax pusillus, Astyanax mexicanus, Brycon pesu, Bryconadenos tanaothoros, Bryconamericus exodon, Bryconops alburnoides, Clupeacharax cf. engrauloides, Compsura heterura, Diapoma terofali, Hemibrycon polyodon, Hemigrammus unilineatus, Hollandichthys multifasciatus, Iguanodectes geisleri, Knodus meridae, Microschemobrycon casiquiare, Moenkhausia 
xinguensis, Odontostilbe pequira, oligosarcus argenteus, Paragoniates alburnus, Phenacogaster pectinatus, Phenagoniates macrolepis, Piabina argentea, Piaractus mesopotamicus, Poptella brevispina, Probolus heterostomus, Rhoadsia altipinna, Serrabrycon magoi e Tetragonopterus argenteus.

\section{[-] - inaplicável.}

Chanos chanos, Catostomus commersonnii, olivaichthys mesembrinus, Gymnotus aff. carapo, Neolebias unifasciatus, Carnegiella strigata, Thoracocharax stellatus, Erythrinoidea fam. nov, Copeina cf. guttata, Crenuchus spilurus, Axelrodia reisei, Brittanichthys axelrodi, Glandulocauda melanogenys, Gnathocharax steindachneri, Hyphessobrycon compressus, Landonia latidens, Metynnis lippincottianus, Paracheirodon axelrodi, Rachoviscus graciliceps, Rhinobrycon negrensis e stygichthys typhlops.

\section{[?] - indeterminado.}

Gasteropelecus sternicla, Gilbertolus atratoensis e Charax cf. leticiae.

166 - Canal sensorial no infra-orbital 6:

[LimA, 2006: 54, modificado; e NetTo-FerREIRA, 2006: 193, modificado]

(Minimamente conectado).

\section{[0] - tubo simples.}

Olivaichthys mesembrinus, Gymnotus aff. carapo, Apareiodon piracicabae, Parodon nasus, Saccodon wagneri, Curimatopsis macrolepis, Potamorhina latior, Anostomus anostomus, Gasteropelecus sternicla, Acestrorhynchus falcirostris, Boulengerella maculata, Lebiasina bimaculata, Piabucina astrigata, Characidium bahiensis, Crenuchus spilurus, Agoniates halecinus, Aphyocharax pusillus, Atopomesus pachyodus, clupeacharax cf. engrauloides, Compsura heterura, Ctenobrycon hauxwellianus, Deuterodon iguape, Diapoma terofali, Gymnocorymbus ternetzi, Hemibrycon polyodon, Hemigrammus unilineatus, Hollandichthys multifasciatus, Iguanodectes geisleri, Knodus meridae, Landonia latidens, Markiana nigripinnis, Metynnis lippincottianus, Microschemobrycon casiquiare, Moenkhausia xinguensis, Odontostilbe pequira, oligosarcus argenteus, orthospinus franciscoensis, Paragoniates alburnus, Phenagoniates macrolepis, Piabina argentea, Poptella brevispina, Probolus heterostomus, Rhoadsia altipinna e Serrabrycon magoi.

\section{[1] - com ramo anterior.}

Chanos chanos, Citharinus latus, Distichodus notospilus, Hemistichodus vaillanti, Nannocharax fasciatus, Xenocharax spilurus, Anodus orinocensis, Bivibranchia fowleri, Hemiodus unimaculatus, Curimata ocellata, Potamorhina latior, Prochilodus nigricans, Semaprochilodus insignis, Caenotropus labyrinthicus, Chilodus punctatus, Leporellus vittatus, Leporinus fasciatus, Schizodon fasciatus, Hydrolycus tatauaia, Roestes molossus, Ctenolucius hujeta, Erythrinus erythrinus, Hoplias malabaricus, Hepsetus odoe, Arnoldichthys spilopterus, Brycinus macrolepidotus, Bryconalestes longipinnis, Chalceus epakros, Astyanax mexicanus, Brycon pesu, Bryconadenos tanaothoros, Bryconamericus exodon, Bryconops alburnoides, Galeocharax knerii, Myleus setiger, Phenacogaster pectinatus, Piaractus mesopotamicus, Roeboexodon guyanensis, Salminus hilarii, Tetragonopterus argenteus e Triportheus albus.

\section{[-] - inaplicável.}

Catostomus commersonnii, Neolebias unifasciatus, Carnegiella strigata, Thoracocharax stellatus, Erythrinoidea fam. nov, Axelrodia reisei, Brittanichthys axelrodi, Glandulocauda melanogenys, Gnathocharax steindachneri, Hyphessobrycon compressus, Paracheirodon axelrodi, Rachoviscus graciliceps, Rhinobrycon negrensis e stygichthys typhlops.

[?] - indeterminado.

Gilbertolus atratoensis, Copeina cf. guttata e Charax cf. leticiae.

$$
\text { [0 } 0 \text { e 1] - polimórfico. }
$$

Potamorhina latior. 
[ZANATA \& VARI, 2005: 154, modificado]

\section{[0] - ligando-se ao canal pterótico.}

Chanos chanos, Catostomus commersonnii, Olivaichthys mesembrinus, Distichodus notospilus, Hemistichodus vaillanti, Neolebias unifasciatus, Nannocharax fasciatus, Xenocharax spilurus, Hemiodus unimaculatus, Curimatopsis macrolepis, Semaprochilodus insignis, Caenotropus labyrinthicus, Chilodus punctatus, Ctenolucius hujeta, Erythrinus erythrinus, Hoplias malabaricus, Hepsetus odoe, Arnoldichthys spilopterus, Characidium bahiensis, Crenuchus spilurus, Bryconops alburnoides, Hollandichthys multifasciatus, Phenacogaster pectinatus e Serrabrycon magoi.

\section{[1] - ligando-se aos canais supra-orbital e pterótico.}

Citharinus latus, Apareiodon piracicabae, Parodon nasus, Anodus orinocensis, Bivibranchia fowleri, Curimata ocellata, Potamorhina latior, Prochilodus nigricans, Anostomus anostomus, Leporellus vittatus, Leporinus fasciatus, Schizodon fasciatus, Gilbertolus atratoensis, Hydrolycus tatauaia, Roestes molossus, Brycinus macrolepidotus, Bryconalestes longipinnis, Chalceus epakros, Astyanax mexicanus, Atopomesus pachyodus, Bryconadenos tanaothoros, Bryconamericus exodon, Charax cf. leticiae, Clupeacharax cf. engrauloides, Compsura heterura, Ctenobrycon hauxwellianus, Deuterodon iguape, Diapoma terofali, Galeocharax knerii, Glandulocauda melanogenys, Gnathocharax steindachneri, Gymnocorymbus ternetzi, Hemibrycon polyodon, Hemigrammus unilineatus, Knodus meridae, Markiana nigripinnis, Metynnis lippincottianus, Microschemobrycon casiquiare, Moenkhausia xinguensis, Myleus setiger, Odontostilbe pequira, oligosarcus argenteus, orthospinus franciscoensis, Paragoniates alburnus, Piaractus mesopotamicus, Poptella brevispina, Probolus heterostomus, Rhinobrycon negrensis, Rhoadsia altipinna, Roeboexodon guyanensis, Tetragonopterus argenteus e Triportheus albus.

\section{[2] - ligando-se apenas ao canal supra-orbital.}

Gymnotus aff. carapo, Saccodon wagneri, Acestrorhynchus falcirostris, Boulengerella maculata, Copeina cf. guttata, Lebiasina bimaculata, Piabucina astrigata, Brycon pesu, Agoniates halecinus, Aphyocharax pusillus, Iguanodectes geisleri, Landonia latidens, Phenagoniates macrolepis, Piabina argêntea e Salminus hilarii.

\section{[-] - inaplicável.}

Carnegiella strigata, Erythrinoidea fam. nov, Axelrodia reisei, Brittanichthys axelrodi, Hyphessobrycon compressus, Paracheirodon axelrodi, Rachoviscus graciliceps e Stygichthys typhlops.

\section{[?] - indeterminado.}

Gasteropelecus sternicla e Thoracocharax stellatus.

\section{8 - Supra-orbital:}

[LUCENA, 1993: 26; BUCKUP, 1998: 21; OYAKAWA, 1998: 7; ZANATA, 2000: 2; ZANATA \& VArI, 2005: 2; Lima, 2006: 6; e NetTo-Ferreira, 2006: 18]

\section{[0] - presente (Figs. 37, 38, 39, 40 e 41).}

Chanos chanos, Citharinus latus, Distichodus notospilus, Hemistichodus vaillanti, Neolebias unifasciatus, Nannocharax fasciatus, Xenocharax spilurus, Apareiodon piracicabae, Parodon nasus, Anodus orinocensis, Bivibranchia fowleri, Hemiodus unimaculatus, Curimata ocellata, Curimatopsis macrolepis, potamorhina latior, Prochilodus nigricans, Semaprochilodus insignis, Caenotropus labyrinthicus, Chilodus punctatus, Anostomus anostomus, Leporellus vittatus, Leporinus fasciatus, Schizodon fasciatus, Acestrorhynchus falcirostris, Gilbertolus atratoensis, Hydrolycus tatauaia, Roestes molossus, Boulengerella maculata, Ctenolucius hujeta, Hepsetus odoe, Arnoldichthys spilopterus, Brycinus macrolepidotus, Bryconalestes longipinnis, Chalceus epakros, Characidium bahiensis, Agoniates halecinus, Brycon pesu, Bryconops alburnoides, Clupeacharax cf. engrauloides, Iguanodectes geisleri, Metynnis lippincottianus, Myleus setiger, Piaractus mesopotamicus, Salminus hilarii e Triportheus albus.

\section{[1] - ausente.}

Catostomus commersonnii, Olivaichthys mesembrinus, Gymnotus aff. carapo, Carnegiella strigata, Gasteropelecus sternicla, Thoracocharax stellatus, Erythrinoidea fam. nov, 
Copeina cf. guttata, Lebiasina bimaculata, Piabucina astrigata, Erythrinus erythrinus, Hoplias malabaricus, Crenuchus spilurus, Aphyocharax pusillus, Astyanax mexicanus, Atopomesus pachyodus, Axelrodia reisei, Brittanichthys axelrodi, Bryconadenos tanaothoros, Bryconamericus exodon, Charax cf. leticiae, Compsura heterura, Ctenobrycon hauxwellianus, Deuterodon iguape, Diapoma terofali, Galeocharax knerii, Glandulocauda melanogenys, Gnathocharax steindachneri, Gymnocorymbus ternetzi, Hemibrycon polyodon, Hemigrammus unilineatus, Hollandichthys multifasciatus, Hyphessobrycon compressus, Knodus meridae, Landonia latidens, Markiana nigripinnis, Microschemobrycon casiquiare, Moenkhausia xinguensis, odontostilbe pequira, oligosarcus argenteus, orthospinus franciscoensis, Paracheirodon axelrodi, Paragoniates alburnus, Phenacogaster pectinatus, Phenagoniates macrolepis, Piabina argentea, Poptella brevispina, Probolus heterostomus, Rachoviscus graciliceps, Rhinobrycon negrensis, Rhoadsia altipinna, Roeboexodon guyanensis, serrabrycon magoi, Stygichthys typhlops e Tetragonopterus argenteus.

\section{[?] - indeterminado.}

Saccodon wagneri.

169 - Face ventral do supra-orbital:

[ZANATA \& VARI, 2005: 3]

$$
\text { [0] - lisa. }
$$

Chanos chanos, Citharinus latus, Distichodus notospilus, Hemistichodus vaillanti, Neolebias unifasciatus, Nannocharax fasciatus, Xenocharax spilurus, Apareiodon piracicabae, Parodon nasus, Anodus orinocensis, Bivibranchia fowleri, Hemiodus unimaculatus, Curimata ocellata, Curimatopsis macrolepis, Potamorhina latior, Prochilodus nigricans, Semaprochilodus insignis, Caenotropus labyrinthicus, Chilodus punctatus, Anostomus anostomus, Leporellus vittatus, Leporinus fasciatus, Schizodon fasciatus, Hydrolycus tatauaia, Roestes molossus, Arnoldichthys spilopterus, Chalceus epakros, Characidium bahiensis, Agoniates halecinus, Brycon pesu, Bryconops alburnoides, Clupeacharax cf. engrauloides, Iguanodectes geisleri, Myleus setiger, Salminus hilarii e Triportheus albus.

\section{[1] - com processo.}

Acestrorhynchus falcirostris, Boulengerella maculata, Ctenolucius hujeta, Hepsetus odoe, Brycinus macrolepidotus, Bryconalestes longipinnis, Metynnis lippincottianus e Piaractus mesopotamicus.

\section{[-] - inaplicável.}

Catostomus commersonnii, Olivaichthys mesembrinus, Gymnotus aff. carapo, Carnegiella strigata, Gasteropelecus sternicla, Thoracocharax stellatus, Erythrinoidea fam. nov, Copeina cf. guttata, Lebiasina bimaculata, Piabucina astrigata, Erythrinus erythrinus, Hoplias malabaricus, Crenuchus spilurus, Aphyocharax pusillus, Astyanax mexicanus, Atopomesus pachyodus, Axelrodia reisei, Brittanichthys axelrodi, Bryconadenos tanaothoros, Bryconamericus exodon, Charax cf. leticiae, Compsura heterura, Ctenobrycon hauxwellianus, Deuterodon iguape, Diapoma terofali, Galeocharax knerii, Glandulocauda melanogenys, Gnathocharax steindachneri, Gymnocorymbus ternetzi, Hemibrycon polyodon , Hemigrammus unilineatus, Hollandichthys multifasciatus, Hyphessobrycon compressus, Knodus meridae, Landonia latidens, Markiana nigripinnis, Microschemobrycon casiquiare, Moenkhausia xinguensis, odontostilbe pequira, oligosarcus argenteus, orthospinus franciscoensis, Paracheirodon axelrodi, Paragoniates alburnus, Phenacogaster pectinatus, Phenagoniates macrolepis, Piabina argentea, Poptella brevispina, Probolus heterostomus, Rachoviscus graciliceps, Rhinobrycon negrensis, Rhoadsia altipinna, Roeboexodon guyanensis, Serrabrycon magoi, Stygichthys typhlops e Tetragonopterus argenteus.

\section{[?] - indeterminado.}

Saccodon wagneri e Gilbertolus atratoensis.

170 - Orientação da porção anterior do supra-orbital:

[ZANATA \& VARI, 2005: 4, modificado]

\section{[0] - contínua à porção posterior .}

Chanos chanos, Citharinus latus, Distichodus notospilus, Hemistichodus vaillanti, Neolebias unifasciatus, Nannocharax fasciatus, Xenocharax spilurus, Apareiodon 
piracicabae, Parodon nasus, Anodus orinocensis, Bivibranchia fowleri, Hemiodus unimaculatus, Curimatopsis macrolepis, Potamorhina latior, Caenotropus labyrinthicus, chilodus punctatus, Schizodon fasciatus, Acestrorhynchus falcirostris, Gilbertolus atratoensis, Hydrolycus tatauaia, Roestes molossus, Boulengerella maculata, Ctenolucius hujeta, Hepsetus odoe, Arnoldichthys spilopterus, Brycinus macrolepidotus, Bryconalestes longipinnis, Chalceus epakros, Characidium bahiensis, Agoniates halecinus, Brycon pesu, Bryconops alburnoides, Clupeacharax cf. engrauloides, Iguanodectes geisleri, Metynnis lippincottianus, Myleus setiger, Piaractus mesopotamicus, Salminus hilarii e Triportheus albus.

\section{[1] - em outro plano, mais horizontal.}

Curimata ocellata, Prochilodus nigricans, Semaprochilodus insignis, Anostomus anostomus, Leporellus vittatus e Leporinus fasciatus.

\section{[-] - inaplicável.}

Catostomus commersonnii, Olivaichthys mesembrinus, Gymnotus aff. carapo, Carnegiella strigata, Gasteropelecus sternicla, Thoracocharax stellatus, Erythrinoidea fam. nov, Copeina cf. guttata, Lebiasina bimaculata, Piabucina astrigata, Erythrinus erythrinus, Hoplias malabaricus, Crenuchus spilurus, Aphyocharax pusillus, Astyanax mexicanus, Atopomesus pachyodus, Axelrodia reisei, Brittanichthys axelrodi, Bryconadenos tanaothoros, Bryconamericus exodon, Charax cf. leticiae, Compsura heterura, Ctenobrycon hauxwellianus, Deuterodon iguape, Diapoma terofali, Galeocharax knerii, Glandulocauda melanogenys, Gnathocharax steindachneri, Gymnocorymbus ternetzi, Hemibrycon polyodon Hemigrammus unilineatus, Hollandichthys multifasciatus, Hyphessobrycon compressus, Knodus meridae, Landonia latidens, Markiana nigripinnis, Microschemobrycon casiquiare, Moenkhausia xinguensis, Odontostilbe pequira, oligosarcus argenteus, orthospinus franciscoensis, Paracheirodon axelrodi, Paragoniates alburnus, Phenacogaster pectinatus, Phenagoniates macrolepis, Piabina argentea, Poptella brevispina, Probolus heterostomus, Rachoviscus graciliceps, Rhinobrycon negrensis, Rhoadsia altipinna, Roeboexodon guyanensis, Serrabrycon magoi, Stygichthys typhlops e Tetragonopterus argenteus.

\section{[?] - indeterminado.}

Saccodon wagneri.

171 - Infra-orbital 1 e supra-orbital:

[VARI, 1995: 3]

[0] - com contato.

Boulengerella maculata, Ctenolucius hujeta e Hepsetus odoe.

\section{[1] - sem contato.}

Citharinus latus, Distichodus notospilus, Hemistichodus vaillanti, Neolebias unifasciatus, Nannocharax fasciatus, Xenocharax spilurus, Apareiodon piracicabae, Parodon nasus, Anodus orinocensis, Bivibranchia fowleri, Hemiodus unimaculatus, Curimata ocellata, Curimatopsis macrolepis, Potamorhina latior, Prochilodus nigricans, Semaprochilodus insignis, Caenotropus labyrinthicus, Chilodus punctatus, Anostomus anostomus, Leporellus vittatus, Leporinus fasciatus, Schizodon fasciatus, Acestrorhynchus falcirostris, Gilbertolus atratoensis, Hydrolycus tatauaia, Roestes molossus, Arnoldichthys spilopterus, Brycinus macrolepidotus, Bryconalestes longipinnis, Chalceus epakros, Characidium bahiensis, Agoniates halecinus, Brycon pesu, Bryconops alburnoides, Clupeacharax cf. engrauloides, Iguanodectes geisleri, Myleus setiger, Piaractus mesopotamicus, Salminus hilarii e Triportheus albus.

\section{[-] - inaplicável.}

Catostomus commersonnii, Olivaichthys mesembrinus, Gymnotus aff. carapo, Carnegiella strigata, Gasteropelecus sternicla, Thoracocharax stellatus, Erythrinoidea fam. nov, Copeina cf. guttata, Lebiasina bimaculata, Piabucina astrigata, Erythrinus erythrinus, Hoplias malabaricus, Crenuchus spilurus, Aphyocharax pusillus, Astyanax mexicanus, Atopomesus pachyodus, Axelrodia reisei, Brittanichthys axelrodi, Bryconadenos tanaothoros, Bryconamericus exodon, Charax cf. leticiae, Compsura heterura, Ctenobrycon hauxwellianus, Deuterodon iguape, Diapoma terofali, Galeocharax knerii, Glandulocauda melanogenys, Gnathocharax steindachneri, Gymnocorymbus ternetzi, Hemibrycon polyodon , Hemigrammus unilineatus, Hollandichthys multifasciatus, Hyphessobrycon compressus, Knodus meridae, Landonia latidens, Markiana nigripinnis, Metynnis lippincottianus, Microschemobrycon casiquiare, Moenkhausia xinguensis, Odontostilbe pequira, oligosarcus 
argenteus, orthospinus franciscoensis, Paracheirodon axelrodi, Paragoniates alburnus, Phenacogaster pectinatus, Phenagoniates macrolepis, Piabina argentea, Poptella brevispina, probolus heterostomus, Rachoviscus graciliceps, Rhinobrycon negrensis, Rhoadsia altipinna, Roeboexodon guyanensis, Serrabrycon magoi, Stygichthys typhlops e Tetragonopterus argenteus.

\section{[?] - indeterminado.}

Saccodon wagneri.

\section{2 - Contato entre infra-orbital 1 e supraorbital:}

[VARI, 1995: 4; e OYAKAWA, 1998: 20]

[0] - interdigitado.

Boulengerella maculata e Ctenolucius hujeta.

[1] - não interdigitado.

Hepsetus odoe.

\section{[-] - inaplicável.}

Chanos chanos, Catostomus commersonnii, Olivaichthys mesembrinus, Gymnotus aff. carapo, Citharinus latus, Distichodus notospilus, Hemistichodus vaillanti, Neolebias unifasciatus, Nannocharax fasciatus, Xenocharax spilurus, Apareiodon piracicabae, Parodon nasus, Anodus orinocensis, Bivibranchia fowleri, Hemiodus unimaculatus Curimata ocellata, Curimatopsis macrolepis, Potamorhina latior, Prochilodus nigricans, Semaprochilodus insignis, Caenotropus labyrinthicus, Chilodus punctatus, Anostomus anostomus, Leporellus vittatus, Leporinus fasciatus, Schizodon fasciatus, Carnegiella strigata, Gasteropelecus sternicla, Thoracocharax stellatus, Acestrorhynchus falcirostris, Gilbertolus atratoensis, Hydrolycus tatauaia, Roestes molossus, Erythrinoidea fam. nov, Copeina cf. guttata, Lebiasina bimaculata, Piabucina astrigata, Erythrinus erythrinus, Hoplias malabaricus, Arnoldichthys spilopterus, Brycinus macrolepidotus, Bryconalestes longipinnis, Chalceus epakros, Characidium bahiensis, Crenuchus spilurus, Agoniates halecinus, Aphyocharax pusillus, Astyanax mexicanus, Atopomesus pachyodus, Axelrodia reisei, Brittanichthys axelrodi, Brycon pesu, Bryconadenos tanaothoros, Bryconamericus exodon, Bryconops alburnoides, Charax cf. leticiae, Clupeacharax cf. engrauloides, Compsura heterura, Ctenobrycon hauxwellianus, Deuterodon iguape, Diapoma terofali, Galeocharax knerii, Glandulocauda melanogenys, Gnathocharax steindachneri, Gymnocorymbus ternetzi, Hemibrycon polyodon, Hemigrammus unilineatus, Hollandichthys multifasciatus, Hyphessobrycon compressus, Iguanodectes geisleri, Knodus meridae, Landonia latidens, Markiana nigripinnis, Metynnis lippincottianus, Microschemobrycon casiquiare, Moenkhausia xinguensis, Myleus setiger, odontostilbe pequira, oligosarcus argenteus, orthospinus franciscoensis, Paracheirodon axelrodi, Paragoniates alburnus, Phenacogaster pectinatus, Phenagoniates macrolepis, Piabina argentea, Piaractus mesopotamicus, Poptella brevispina, Probolus heterostomus, Rachoviscus graciliceps, Rhinobrycon negrensis, Rhoadsia altipinna, Roeboexodon guyanensis, Salminus hilarii, Serrabrycon magoi, Stygichthys typhlops, Tetragonopterus argenteus e Triportheus albus.

[?] - indeterminado.

Saccodon wagneri.

173 - Posição do supra-orbital:

[MOREIRA, 20९2]

\section{[0] - maior porção anterior da asa do etmóide lateral.}

Distichodus notospilus, Xenocharax spilurus, Gilbertolus atratoensis, Chalceus epakros, Iguanodectes geisleri e Metynnis lippincottianus.

\section{[1] - maior porção posterior da asa do etmóide lateral.}

Citharinus latus, Hemistichodus vaillanti, Neolebias unifasciatus, Nannocharax fasciatus, Apareiodon piracicabae, Parodon nasus, Anodus orinocensis, Bivibranchia fowleri, Hemiodus unimaculatus, Curimata ocellata, Curimatopsis macrolepis, Potamorhina latior, Prochilodus nigricans, Semaprochilodus insignis, Caenotropus labyrinthicus, 
Chilodus punctatus, Anostomus anostomus, Leporellus vittatus, Leporinus fasciatus, Schizodon fasciatus, Acestrorhynchus falcirostris, Hydrolycus tatauaia, Roestes molossus, Boulengerella maculata, Ctenolucius hujeta, Hepsetus odoe, Arnoldichthys spilopterus, Brycinus macrolepidotus, Bryconalestes longipinnis, Characidium bahiensis, Agoniates halecinus, Brycon pesu, Bryconops alburnoides, Clupeacharax cf. engrauloides, Myleus setiger, Salminus hilarii e Triportheus albus.

\section{[-] - inaplicável.}

Chanos chanos, Catostomus commersonnii, olivaichthys mesembrinus, Gymnotus aff. carapo, Carnegiella strigata, Gasteropelecus sternicla, Thoracocharax stellatus, Erythrinoidea fam. nov, Copeina cf. guttata, Lebiasina bimaculata, Piabucina astrigata, Erythrinus erythrinus, Hoplias malabaricus, Crenuchus spilurus, Aphyocharax pusillus, Astyanax mexicanus, Atopomesus pachyodus, Axelrodia reisei, Brittanichthys axelrodi, Bryconadenos tanaothoros, Bryconamericus exodon, Charax cf. leticiae, Compsura heterura, ctenobrycon hauxwellianus, Deuterodon iguape, Diapoma terofali, Galeocharax knerii, Glandulocauda melanogenys, Gnathocharax steindachneri, Gymnocorymbus ternetzi, Hemibrycon polyodon , Hemigrammus unilineatus, Hollandichthys multifasciatus, Hyphessobrycon compressus, Knodus meridae, Landonia latidens, Markiana nigripinnis, Microschemobrycon casiquiare, Moenkhausia xinguensis, odontostilbe pequira, oligosarcus argenteus, orthospinus franciscoensis, Paracheirodon axelrodi, Paragoniates alburnus, Phenacogaster pectinatus, Phenagoniates macrolepis, Piabina argentea, Piaractus mesopotamicus, Poptella brevispina, Probolus heterostomus, Rachoviscus graciliceps, Rhinobrycon negrensis, Rhoadsia altipinna, Roeboexodon guyanensis, Serrabrycon magoi, Stygichthys typhlops e Tetragonopterus argenteus.

\section{[?] - indeterminado.}

Saccodon wagneri.

174 - Anel orbital:

[LUCENA, 1993: 27; e ZANATA, 2000: 3]

[0] - incompleto, frontal entre o supra-orbital e o infra-orbital 6 (Figs. 37, 39 e 40).

Chanos chanos, Citharinus latus, Distichodus notospilus, Hemistichodus vaillanti, Nannocharax fasciatus, Xenocharax spilurus, Bivibranchia fowleri, Curimatopsis macrolepis, Semaprochilodus insignis, Caenotropus labyrinthicus, Chilodus punctatus, Anostomus anostomus, Leporellus vittatus, Leporinus fasciatus, Schizodon fasciatus, Acestrorhynchus falcirostris, Gilbertolus atratoensis, Roestes molossus, Chalceus epakros, Characidium bahiensis, Agoniates halecinus, Bryconops alburnoides, Clupeacharax cf. engrauloides, Metynnis lippincottianus, Myleus setiger e Piaractus mesopotamicus.

[1] - completo, sem participação do frontal (Fig. 38 e Fig. 41).

Neolebias unifasciatus, Apareiodon piracicabae, Parodon nasus, Anodus orinocensis, Hemiodus unimaculatus, Curimata ocellata, Potamorhina latior, Prochilodus nigricans, Hydrolycus tatauaia, Boulengerella maculata, Ctenolucius hujeta, Hepsetus odoe, Arnoldichthys spilopterus, Brycinus macrolepidotus, Bryconalestes longipinnis, Brycon pesu, Salminus hilarii e Triportheus albus.

\section{[-] - inaplicável.}

Catostomus commersonnii, olivaichthys mesembrinus, Gymnotus aff. carapo, Carnegiella strigata, Gasteropelecus sternicla, Thoracocharax stellatus, Erythrinoidea fam. nov, Copeina cf. guttata, Lebiasina bimaculata, Piabucina astrigata, Erythrinus erythrinus, Hoplias malabaricus, Crenuchus spilurus, Aphyocharax pusillus, Astyanax mexicanus, Atopomesus pachyodus, Axelrodia reisei, Brittanichthys axelrodi, Bryconadenos tanaothoros, Bryconamericus exodon, Charax cf. leticiae, Compsura heterura, Ctenobrycon hauxwellianus, Deuterodon iguape, Diapoma terofali, Galeocharax knerii, Glandulocauda melanogenys, Gnathocharax steindachneri, Gymnocorymbus ternetzi, Hemibrycon polyodon, Hemigrammus unilineatus, Hollandichthys multifasciatus, Hyphessobrycon compressus, Iguanodectes geisleri, Knodus meridae, Landonia latidens, Markiana nigripinnis, Microschemobrycon casiquiare, Moenkhausia xinguensis, odontostilbe pequira, oligosarcus argenteus, Orthospinus franciscoensis, Paracheirodon axelrodi, Paragoniates alburnus, Phenacogaster pectinatus, Phenagoniates macrolepis, Piabina argentea, Poptella brevispina, Probolus heterostomus, Rachoviscus graciliceps, Rhinobrycon negrensis, Rhoadsia altipinna, Roeboexodon guyanensis, Serrabrycon magoi, Stygichthys typhlops e Tetragonopterus argenteus.

[?] - inaplicável. 
Saccodon wagneri.

175 - Nasal:

[LUCENA, 1993: 31; VARI, 1995: 17; OYAKAWA, 1998: 3; e LIMA, 2006: 7]

\section{[0] - com abas desenvolvidas.}

Prochilodus nigricans, Anostomus anostomus, Leporellus vittatus, Leporinus fasciatus, Schizodon fasciatus, Hydrolycus tatauaia, Boulengerella maculata, Ctenolucius hujeta, Copeina cf. guttata, Piabucina astrigata, Erythrinus erythrinus, Hoplias malabaricus, Hepsetus odoe, Brycinus macrolepidotus, Myleus setiger e Roeboexodon guyanensis.

\section{[1] - abas pouco desenvolvidas ou ausente.}

Chanos chanos, Catostomus commersonnii, Olivaichthys mesembrinus, Gymnotus aff. carapo, Citharinus latus, Distichodus notospilus, Hemistichodus vaillanti, Neolebias unifasciatus, Nannocharax fasciatus, Xenocharax spilurus, Apareiodon piracicabae, Parodon nasus, Saccodon wagneri, Anodus orinocensis, Bivibranchia fowleri, Hemiodus unimaculatus, Curimata ocellata, Curimatopsis macrolepis, Potamorhina latior, Semaprochilodus insignis, Caenotropus labyrinthicus, Chilodus punctatus, Carnegiella strigata, Gasteropelecus sternicla, Thoracocharax stellatus, Acestrorhynchus falcirostris, Gilbertolus atratoensis, Roestes molossus, Lebiasina bimaculata, Arnoldichthys spilopterus, Bryconalestes longipinnis, Chalceus epakros, Characidium bahiensis, Crenuchus spilurus, Agoniates halecinus, Aphyocharax pusillus, Astyanax mexicanus, Atopomesus pachyodus, Axelrodia reisei, Brittanichthys axelrodi, Brycon pesu, Bryconadenos tanaothoros, Bryconamericus exodon, Bryconops alburnoides, Charax cf. leticiae, Clupeacharax cf. engrauloides, Compsura heterura, Ctenobrycon hauxwellianus, Deuterodon iguape, Diapoma terofali, Galeocharax knerii, Glandulocauda melanogenys, Gnathocharax steindachneri, Gymnocorymbus ternetzi, Hemibrycon polyodon, Hemigrammus unilineatus, Hollandichthys multifasciatus, Hyphessobrycon compressus, Iguanodectes geisleri, Knodus meridae, Landonia latidens, Markiana nigripinnis, Metynnis lippincottianus, Microschemobrycon casiquiare, Moenkhausia xinguensis, Odontostilbe pequira, Oligosarcus argenteus, Orthospinus franciscoensis, Paracheirodon axelrodi, Paragoniates alburnus, Phenacogaster pectinatus, Phenagoniates macrolepis, Piabina argentea, Piaractus mesopotamicus, Poptella brevispina, Probolus heterostomus Rachoviscus graciliceps, Rhinobrycon negrensis, Rhoadsia altipinna, Salminus hilarii, Serrabrycon magoi, Stygichthys typhlops, Tetragonopterus argenteus e Triportheus albus.

\section{[-] - inaplicável.}

Erythrinoidea fam. nov.

\section{6 - Forma do nasal:}

$$
[0] \text { - reto. }
$$

Catostomus commersonnii, Olivaichthys mesembrinus, Gymnotus aff. carapo, Distichodus notospilus, Hemistichodus vaillanti, Neolebias unifasciatus, Xenocharax spilurus, Curimata ocellata, Potamorhina latior, Prochilodus nigricans, Semaprochilodus insignis, Carnegiella strigata, Gasteropelecus sternicla, Thoracocharax stellatus Acestrorhynchus falcirostris, Gilbertolus atratoensis, Hydrolycus tatauaia', Boulengerella maculata, Ctenolucius hujeta, Lebiasina bimaculata, Piabucina astrigata, clupeacharax cf. engrauloides, Ctenobrycon hauxwellianus e Rachoviscus graciliceps.

\section{[1] - margem lateral côncava.}

Chanos chanos, Anodus orinocensis, Bivibranchia fowleri, Hemiodus unimaculatus Curimatopsis macrolepis, Caenotropus labyrinthicus, Chilodus punctatus, Anostomus anostomus, Leporellus vittatus, Leporinus fasciatus, Schizodon fasciatus, Roestes molossus, Bryconalestes longipinnis, Chalceus epakros, Characidium bahiensis, Crenuchus spilurus, Agoniates halecinus, Aphyocharax pusillus, Astyanax mexicanus, Atopomesus pachyodus, Axelrodia reisei, Brittanichthys axelrodi, Brycon pesu, Bryconadenos tanaothoros, Bryconamericus exodon, Bryconops alburnoides, Charax cf. leticiae, Compsura heterura, Deuterodon iguape, Diapoma terofali, Galeocharax knerii, Glandulocauda melanogenys, Gnathocharax steindachneri, Gymnocorymbus ternetzi, Hemibrycon polyodon, Hemigrammus unilineatus, Hollandichthys multifasciatus, Hyphessobrycon compressus, Knodus meridae, Landonia latidens, Markiana nigripinnis, Microschemobrycon casiquiare, 
Moenkhausia xinguensis, Myleus setiger, odontostilbe pequira, oligosarcus argenteus, orthospinus franciscoensis, Paracheirodon axelrodi, Paragoniates alburnus, Phenacogaster pectinatus, Phenagoniates macrolepis, Piabina argentea, Piaractus mesopotamicus, Poptella brevispina, Probolus heterostomus, Rhinobrycon negrensis, Rhoadsia altipinna, Roeboexodon guyanensis, Salminus hilarii, Serrabrycon magoi, Stygichthys typhlops, Tetragonopterus argenteus e Triportheus albus.

\section{[2] - margem lateral convexa.}

Citharinus latus, Nannocharax fasciatus, Apareiodon piracicabae, Parodon nasus, Arnoldichthys spilopterus, Iguanodectes geisleri e Metynnis lippincottianus.

\section{[-] - inaplicável.}

Erythrinoidea fam. nov.

\section{[?] - indeterminado.}

Saccodon wagneri, Copeina cf. guttata, Erythrinus erythrinus, Hoplias malabaricus, Hepsetus odoe e Brycinus macrolepidotus.

\section{7 - Porção posterior do nasal:}

\section{[0] - sobrepondo ao frontal.}

Hemistichodus vaillanti, Parodon nasus, Caenotropus labyrinthicus, Leporellus vittatus, Leporinus fasciatus, Schizodon fasciatus, Gasteropelecus sternicla, Thoracocharax stellatus, Acestrorhynchus falcirostris, Boulengerella maculata, Ctenolucius hujeta, Brycinus macrolepidotus, Chalceus epakros e Stygichthys typhlops.

\section{[1] - separado do frontal pelo espaço de um poro.}

Gymnotus aff. carapo, Citharinus latus, Distichodus notospilus, Neolebias unifasciatus, Nannocharax fasciatus, Xenocharax spilurus, Apareiodon piracicabae, Bivibranchia fowleri, Hemiodus unimaculatus, Potamorhina latior, Prochilodus nigricans, Semaprochilodus insignis, Chilodus punctatus, Anostomus anostomus, Carnegiella strigata, Hydrolycus tatauaia, Copeina cf. guttata, Lebiasina bimaculata, Piabucina astrigata, Erythrinus erythrinus, Hoplias malabaricus, Hepsetus odoe, Arnoldichthys spilopterus, Bryconalestes longipinnis, Characidium bahiensis, Crenuchus spilurus, Agoniates halecinus, Aphyocharax pusillus, Astyanax mexicanus, Axelrodia reisei, Brycon pesu, Bryconadenos tanaothoros, Bryconamericus exodon, Bryconops alburnoides, Compsura heterura, Ctenobrycon hauxwellianus, Deuterodon iguape, Diapoma terofali, Glandulocauda melanogenys, Gnathocharax steindachneri, Gymnocorymbus ternetzi, Hemibrycon polyodon Hemigrammus unilineatus, Iguanodectes geisleri, Knodus meridae, Landonia latidens, Markiana nigripinnis, Metynnis lippincottianus, Microschemobrycon casiquiare, Moenkhausia xinguensis, Myleus setiger, Odontostilbe pequira, oligosarcus argenteus, orthospinus franciscoensis, Paracheirodon axelrodi, Paragoniates alburnus, Phenagoniates macrolepis, Piabina argentea, Piaractus mesopotamicus, Poptella brevispina, Probolus heterostomus, Rhinobrycon negrensis, Rhoadsia altipinna, Roeboexodon guyanensis, Salminus hilarii, Serrabrycon magoi, Tetragonopterus argenteus e Triportheus albus.

\section{[2] - espaço entre o frontal e nasal, maior que um poro.}

Chanos chanos, Anodus orinocensis, Curimata ocellata, Curimatopsis macrolepis, Gilbertolus atratoensis, Roestes molossus, Atopomesus pachyodus, Brittanichthys axelrodi, Charax cf. leticiae, Clupeacharax cf. engrauloides, Galeocharax knerii, Hollandichthys multifasciatus, Hyphessobrycon compressus, Phenacogaster pectinatus e Rachoviscus graciliceps.

\section{[-] - inaplicável.}

Erythrinoidea fam. nov.

[?] - indeterminado.

Catostomus commersonnii, Olivaichthys mesembrinus e Saccodon wagneri. 


\section{[0] - menor que a órbita.}

Chanos chanos, Catostomus commersonnii, Gymnotus aff. carapo, Citharinus latus, Distichodus notospilus, Hemistichodus vaillanti, Neolebias unifasciatus, Nannocharax fasciatus, Xenocharax spilurus, Apareiodon piracicabae, Parodon nasus, Saccodon wagneri, Anodus orinocensis, Bivibranchia fowleri, Hemiodus unimaculatus, curimata ocellata, curimatopsis macrolepis, Potamorhina latior, Prochilodus nigricans, Caenotropus labyrinthicus, Chilodus punctatus, Anostomus anostomus, Leporellus vittatus, Leporinus fasciatus, Schizodon fasciatus, Carnegiella strigata, Gasteropelecus sternicla, Thoracocharax stellatus, Acestrorhynchus falcirostris, Gilbertolus atratoensis, Hydrolycus tatauaia, Roestes molossus, Copeina cf. guttata, Lebiasina bimaculata, Piabucina astrigata, Erythrinus erythrinus, Hoplias malabaricus, Hepsetus odoe, Arnoldichthys spilopterus, Brycinus macrolepidotus, Bryconalestes longipinnis, Chalceus epakros, Characidium bahiensis, Crenuchus spilurus, Agoniates halecinus, Aphyocharax pusillus, Astyanax mexicanus, Atopomesus pachyodus, Axelrodia reisei, Brittanichthys axelrodi, Brycon pesu, Bryconadenos tanaothoros, Bryconamericus exodon, Bryconops alburnoides, Charax cf. leticiae, Clupeacharax cf. engrauloides, Compsura heterura, Ctenobrycon hauxwellianus, Deuterodon iguape, Diapoma terofali, Galeocharax knerii, Glandulocauda melanogenys, Gnathocharax steindachneri, Gymnocorymbus ternetzi, Hemibrycon polyodon, Hemigrammus unilineatus, Hollandichthys multifasciatus, Hyphessobrycon compressus, Iguanodectes geisleri, Knodus meridae, Landonia latidens, Markiana nigripinnis, Metynnis lippincottianus, Microschemobrycon casiquiare, Moenkhausia xinguensis, Myleus setiger, Odontostilbe pequira, Oligosarcus argenteus, orthospinus franciscoensis, Paracheirodon axelrodi, Paragoniates alburnus, Phenacogaster pectinatus, Phenagoniates macrolepis, Piabina argentea, Piaractus mesopotamicus, Poptella brevispina, Probolus heterostomus, Rachoviscus graciliceps, Rhinobrycon negrensis, Rhoadsia altipinna, Roeboexodon guyanensis, Salminus hilarii, Serrabrycon magoi, Stygichthys typhlops, Tetragonopterus argenteus e Triportheus albus.

\section{[1] - maior ou igual à órbita.}

Olivaichthys mesembrinus, Semaprochilodus insignis, Boulengerella maculata e Ctenolucius hujeta.

\section{[-] - inaplicável.}

Erythrinoidea fam. nov.

\section{9 - Posição do nasal em relação ao frontal:}

\section{[0] - Situado anteriormente ao frontal (Figs. 17, 18 e 19).}

Chanos chanos, Catostomus commersonnii, Olivaichthys mesembrinus, Gymnotus aff. carapo, Citharinus latus, Distichodus notospilus, Hemistichodus vaillanti, Neolebias unifasciatus, Nannocharax fasciatus, Xenocharax spilurus, Anodus orinocensis, Bivibranchia fowleri, Hemiodus unimaculatus, Curimata ocellata, Curimatopsis macrolepis, Potamorhina latior, Caenotropus labyrinthicus, Chilodus punctatus, Anostomus anostomus, Leporellus vittatus, Schizodon fasciatus, Carnegiella strigata, Gasteropelecus sternicla, Thoracocharax stellatus, Acestrorhynchus falcirostris, Gilbertolus atratoensis, Hydrolycus tatauaia, Roestes molossus, Copeina cf. guttata, Lebiasina bimaculata, Piabucina astrigata, Erythrinus erythrinus, Hoplias malabaricus, Arnoldichthys spilopterus, Brycinus macrolepidotus, Bryconalestes longipinnis, Chalceus epakros, Characidium bahiensis, Crenuchus spilurus, Agoniates halecinus, Aphyocharax pusillus, Astyanax mexicanus, Atopomesus pachyodus, Axelrodia reisei, Brittanichthys axelrodi, Brycon pesu, Bryconadenos tanaothoros, Bryconamericus exodon, Bryconops alburnoides, Charax cf. leticiae, Clupeacharax cf. engrauloides, Compsura heterura, Ctenobrycon hauxwellianus, Deuterodon iguape, Diapoma terofali, Glandulocauda melanogenys, Gnathocharax steindachneri, Gymnocorymbus ternetzi, Hemibrycon polyodon, Hemigrammus unilineatus, Hollandichthys multifasciatus, Hyphessobrycon compressus, Iguanodectes geisleri, Knodus meridae, Landonia latidens, Markiana nigripinnis, Metynnis lippincottianus, Microschemobrycon casiquiare, Moenkhausia xinguensis, Myleus setiger, odontostilbe pequira, oligosarcus argenteus, Orthospinus franciscoensis, Paracheirodon axelrodi, Paragoniates alburnus, Phenacogaster pectinatus, Phenagoniates macrolepis, Piabina argentea, Piaractus mesopotamicus, Poptella brevispina, Probolus heterostomus, Rachoviscus graciliceps, Rhinobrycon negrensis, Rhoadsia altipinna, Roeboexodon guyanensis, Salminus hilarii, Serrabrycon magoi, Stygichthys typhlops, Tetragonopterus argenteus e Triportheus albus.

[1] - situado pelo menos parcialmente lateral ao frontal. 
Apareiodon piracicabae, Parodon nasus, Saccodon wagneri, Prochilodus nigricans, Semaprochilodus insignis, Leporinus fasciatus, Boulengerella maculata, ctenolucius hujeta, Hepsetus odoe e Galeocharax knerii.

\section{[-] - inaplicável.}

Erythrinoidea fam. nov.

\subsubsection{Arcos hióide e branquiais}

180 - Cartilagem do basi-hial:

[VARI, 1995: 56 modificado; OYAKAWA, 1998; 53 modificado; NETTO-FERREIRA, 2006: 139 modificado]

$$
\text { [0] - inteira (Fig. 42B). }
$$

Chanos chanos, Catostomus commersonnii, Gymnotus aff. carapo, Nannocharax fasciatus, Curimata ocellata, Potamorhina latior, Prochilodus nigricans, Semaprochilodus insignis, Caenotropus labyrinthicus, Chilodus punctatus, Anostomus anostomus, Leporellus vittatus, Leporinus fasciatus, Schizodon fasciatus, Acestrorhynchus falcirostris, Glandulocauda melanogenys e Triportheus albus.

\section{[1] - dividida longitudinalmente (Fig. 42A).}

Erythrinus erythrinus, Hoplias malabaricus e Gnathocharax steindachneri.

\section{[2] - dividida transversalmente.}

Citharinus latus, Distichodus notospilus, Hemistichodus vaillanti, Neolebias unifasciatus, Xenocharax spilurus, Apareiodon piracicabae, Parodon nasus, Anodus orinocensis, Bivibranchia fowleri, Hemiodus unimaculatus, Curimatopsis macrolepis, Gilbertolus atratoensis, Hydrolycus tatauaia, Roestes molossus, Erythrinoidea fam. nov, Boulengerella maculata, Ctenolucius hujeta, Copeina cf. guttata, Lebiasina bimaculata, Piabucina astrigata, Hepsetus odoe, Arnoldichthys spilopterus, Brycinus macrolepidotus, Bryconalestes longipinnis, Chalceus epakros, Characidium bahiensis, Crenuchus spilurus, Agoniates halecinus, Aphyocharax pusillus, Astyanax mexicanus, Atopomesus pachyodus, Axelrodia reisei, Brittanichthys axelrodi, Brycon pesu, Bryconadenos tanaothoros, Bryconamericus exodon, Bryconops alburnoides, Charax cf. leticiae, clupeacharax cf. engrauloides, Compsura heterura, Ctenobrycon hauxwellianus, Deuterodon iguape, Diapoma terofali, Galeocharax knerii, Gymnocorymbus ternetzi, Hemibrycon polyodon Hollandichthys multifasciatus, Hyphessobrycon compressus, Iguanodectes geisleri, Knodus meridae, Landonia latidens, Markiana nigripinnis, Metynnis lippincottianus, Microschemobrycon casiquiare, Moenkhausia xinguensis, Myleus setiger, Odontostilbe pequira, Oligosarcus argenteus, orthospinus franciscoensis, Paracheirodon axelrodi, Paragoniates alburnus, Phenacogaster pectinatus, Phenagoniates macrolepis, Piabina argentea, Piaractus mesopotamicus, Poptella brevispina, Probolus heterostomus Rachoviscus graciliceps, Rhinobrycon negrensis, Rhoadsia altipinna, Roeboexodón guyanensis, Salminus hilarii, Serrabrycon magoi, Stygichthys typhlops e Tetragonopterus argenteus.

\section{[-] - inaplicável.}

olivaichthys mesembrinus.

\section{[?] - indeterminado.}

Saccodon wagneri, Carnegiella strigata, Gasteropelecus sternicla, Thoracocharax stellatus e Hemigrammus unilineatus.

\section{1 - Largura da cartilagem do basi-hial:}

\section{[0] - contínua com a porção óssea do basi-hial (Fig. 42A).}

Chanos chanos, Catostomus commersonnii, Gymnotus aff. carapo, Citharinus latus, Distichodus notospilus, Hemistichodus vaillanti, Neolebias unifasciatus, Nannocharax fasciatus, Xenocharax spilurus, Apareiodon piracicabae, Parodon nasus, Saccodon wagneri, Anodus orinocensis, Bivibranchia fowleri, Hemiodus unimaculatus , Curimata ocellata, 
Curimatopsis macrolepis, Anostomus anostomus, Leporellus vittatus, Leporinus fasciatus, Schizodon fasciatus, Acestrorhynchus falcirostris, Gilbertolus atratoensis, Hydrolycus tatauaia, Roestes molossus, Erythrinoidea fam. nov, Boulengerella maculata, ctenolucius hujeta, Copeina cf. guttata, Lebiasina bimaculata, Piabucina astrigata, Erythrinus erythrinus, Hoplias malabaricus, Hepsetus odoe, Arnoldichthys spilopterus, Brycinus macrolepidotus, Bryconalestes longipinnis, Chalceus epakros, Characidium bahiensis, Crenuchus spilurus, Agoniates halecinus, Aphyocharax pusillus, Astyanax mexicanus, Atopomesus pachyodus, Axelrodia reisei, Brittanichthys axelrodi, Brycon pesu, Bryconadenos tanaothoros, Bryconamericus exodon, Bryconops alburnoides, Charax cf. leticiae, Clupeacharax cf. engrauloides, Compsura heterura, ctenobrycon hauxwellianus, Deuterodon iguape, Diapoma terofali, Galeocharax knerii, Glandulocauda melanogenys, Gnathocharax steindachneri, Gymnocorymbus ternetzi, Hemibrycon polyodon, Hemigrammus unilineatus, Hollandichthys multifasciatus, Hyphessobrycon compressus, Iguanodectes geisleri, Knodus meridae, Landonia latidens, Markiana nigripinnis, Metynnis lippincottianus, Microschemobrycon casiquiare, Moenkhausia xinguensis, Myleus setiger, odontostilbe pequira, oligosarcus argenteus, orthospinus franciscoensis, Paracheirodon axelrodi, Paragoniates alburnus, Phenacogaster pectinatus, Phenagoniates macrolepis, Piabina argentea, Piaractus mesopotamicus, Poptella brevispina, Probolus heterostomus, Rachoviscus graciliceps, Rhinobrycon negrensis, Rhoadsia altipinna, Roeboexodon guyanensis, Salminus hilarii, Serrabrycon magoi, Stygichthys typhlops, Tetragonopterus argenteus e Triportheus albus.

\section{[1] - com projeção lateral (Fig. 42B).}

Potamorhina latior, Prochilodus nigricans, Semaprochilodus insignis, Caenotropus labyrinthicus e Chilodus punctatus.

\section{[-] - inaplicável.}

olivaichthys mesembrinus.

\section{[?] - indeterminado.}

Carnegiella strigata, Gasteropelecus sternicla e Thoracocharax stellatus.

182 - Cartilagem do basi-hial:

[OYAKAWA, 1998: 52; ZANATA \& VARI, 2005: 109; NETTO-FERREIRA, 2006: 142]

\section{[0] - com ossificação superficial dorsal (Fig. 42A e B).}

Chanos chanos, Citharinus latus, Distichodus notospilus, Hemistichodus vaillanti, Neolebias unifasciatus, Nannocharax fasciatus, Xenocharax spilurus, Apareiodon piracicabae, Parodon nasus, Saccodon wagneri, Anodus orinocensis, Bivibranchia fowleri, Hemiodus unimaculatus, Curimata ocellata, Prochilodus nigricans, Semaprochilodus insignis, Caenotropus labyrinthicus, Chilodus punctatus, Anostomus anostomus, Leporellus vittatus, Leporinus fasciatus, Schizodon fasciatus, Acestrorhynchus falcirostris, Gilbertolus atratoensis, Hydrolycus tatauaia, Roestes molossus, Boulengerella maculata, Ctenolucius hujeta, Copeina cf. guttata, Lebiasina bimaculata, Piabucina astrigata, Erythrinus erythrinus, Hoplias malabaricus, Hepsetus odoe, Arnoldichthys spilopterus, Brycinus macrolepidotus, Bryconalestes longipinnis, Chalceus epakros, Characidium bahiensis, Crenuchus spilurus, Agoniates halecinus, Gnathocharax steindachneri e Triportheus albus,

\section{[1] - sem qualquer ossificação.}

Catostomus commersonnii, Gymnotus aff. carapo, Curimatopsis macrolepis, Potamorhina latior, Erythrinoidea fam. nov, Aphyocharax pusillus, Astyanax mexicanus, Atopomesus pachyodus, Axelrodia reisei, Brittanichthys axelrodi, Brycon pesu, Bryconadenos tanaothoros, Bryconamericus exodon, Bryconops alburnoides, charax cf. leticiae, Clupeacharax cf. engrauloides, Compsura heterura, Ctenobrycon hauxwellianus, Deuterodon iguape, Diapoma terofali, Galeocharax knerii, Glandulocauda melanogenys, Gymnocorymbus ternetzi, Hemibrycon polyodon, Hemigrammus unilineatus, Hollandichthys multifasciatus, Hyphessobrycon compressus, Iguanodectes geisleri, Knodus meridae, Landonia latidens, Markiana nigripinnis, Metynnis lippincottianus, Microschemobrycon casiquiare, Moenkhausia xinguensis, Myleus setiger, Odontostilbe pequira, oligosarcus argenteus, orthospinus franciscoensis, Paracheirodon axelrodi, Paragoniates alburnus, Phenacogaster pectinatus, Phenagoniates macrolepis, Piabina argentea, Piaractus mesopotamicus, Poptella brevispina, Probolus heterostomus, Rachoviscus graciliceps, Rhinobrycon negrensis, Rhoadsia altipinna, Roeboexodon guyanensis, Salminus hilarii, Serrabrycon magoi, Stygichthys typhlops e Tetragonopterus argenteus. 


\section{[-] - inaplicável.}

olivaichthys mesembrinus.

[?] - indeterminado.

Carnegiella strigata, Gasteropelecus sternicla e Thoracocharax stellatus.

183 - Porção anterior do basi-hial:

[OYAKAWA, 1998: 51 modificado; CASTRO \& VARI, 2004: 14; NetTo-Ferreira, 2006: 141 modificado]

(Minimamente conectado).

[0] - da mesma largura que a porção posterior (Fig. 42A)

Catostomus commersonnii, Gymnotus aff. carapo, Nannocharax fasciatus, Apareiodon piracicabae, Parodon nasus, Saccodon wagneri, Bivibranchia fowleri, Hemiodus unimaculatus, Curimata ocellata, Anostomus anostomus, Leporinus fasciatus, Schizodon fasciatus, Carnegiella strigata, Gasteropelecus sternicla, Thoracocharax stellatus, Gilbertolus atratoensis, Hydrolycus tatauaia, Hepsetus odoe, Characidium bahiensis, crenuchus spilurus, Galeocharax knerii, Glandulocauda melanogenys, oligosarcus argenteus, Piaractus mesopotamicus, Stygichthys typhlops e Triportheus albus.

\section{[1] - mais larga que a porção posterior (Fig. 42B).}

Chanos chanos, Distichodus notospilus, Hemistichodus vaillanti, Neolebias unifasciatus, Anodus orinocensis, Curimatopsis macrolepis, Potamorhina latior, Prochilodus nigricans, Semaprochilodus insignis, Caenotropus labyrinthicus, Chilodus punctatus, Leporellus vittatus, Acestrorhynchus falcirostris, Roestes molossus, Boulengerella maculata, Ctenolucius hujeta, Copeina cf. guttata, Lebiasina bimaculata, Piabucina astrigata, Erythrinus erythrinus, Hoplias malabaricus, Arnoldichthys spilopterus, Brycinus macrolepidotus, Bryconalestes longipinnis, Chalceus epakros, Agoniates halecinus, Aphyocharax pusillus, Astyanax mexicanus, Brittanichthys axelrodi, Brycon pesu, Bryconadenos tanaothoros, Bryconamericus exodon, Bryconops alburnoides, Charax cf. leticiae, Clupeacharax cf. engrauloides, Compsura heterura, Ctenobrycon hauxwellianus, Deuterodon iguape, Diapoma terofali, Gnathocharax steindachneri, Gymnocorymbus ternetzi, Hemibrycon polyodon, Hemigrammus unilineatus, Hollandichthys multifasciatus, Hyphessobrycon compressus, Iguanodectes geisleri, Knodus meridae, Landonia latidens, Markiana nigripinnis, Metynnis lippincottianus, Microschemobrycon casiquiare, Moenkhausia xinguensis, odontostilbe pequira, Orthospinus franciscoensis, Paragoniates alburnus, Phenacogaster pectinatus, Phenagoniates macrolepis, Piabina argentea, Poptella brevispina, Probolus heterostomus, Rachoviscus graciliceps, Rhoadsia altipinna, Roeboexodon guyanensis, Salminus hilarii, Serrabrycon magoi e Tetragonopterus argenteus.

\section{[2] - bem mais larga que a porção posterior.}

Citharinus latus, Xenocharax spilurus, Erythrinoidea fam. nov, Atopomesus pachyodus, Axelrodia reisei, Myleus setiger, Paracheirodon axelrodi e Rhinobrycon negrensis.

\section{[-] - inaplicável.}

Olivaichthys mesembrinus.

184 - Comprimento do basi-hial:

[OYAKAWA, 1998: 50; NetTo-FerReira, 2006: 140]

(Minimamente conectado).

[0] - curto.

Carnegiella strigata, Gasteropelecus sternicla, Thoracocharax stellatus e Acestrorhynchus falcirostris.

[1] - longo. 
Chanos chanos, Catostomus commersonnii, Citharinus latus, Distichodus notospilus, Hemistichodus vaillanti, Neolebias unifasciatus, Nannocharax fasciatus, Xenocharax spilurus, Apareiodon piracicabae, Parodon nasus, Saccodon wagneri, Anodus orinocensis, Bivibranchia fowleri, Hemiodus unimaculatus, Curimata ocellata, Curimatopsis macrolepis, Potamorhina latior, Prochilodus nigricans, Semaprochilodus insignis, Caenotropus labyrinthicus, Chilodus punctatus, Leporellus vittatus, Gilbertolus atratoensis, Hydrolycus tatauaia, Roestes molossus, Erythrinoidea fam. nov, Boulengerella maculata, ctenolucius hujeta, Copeina cf. guttata, Lebiasina bimaculata, Piabucina astrigata, Erythrinus erythrinus, Hoplias malabaricus, Hepsetus odoe, Arnoldichthys spilopterus, Brycinus macrolepidotus, Bryconalestes longipinnis, Chalceus epakros, Characidium bahiensis, Crenuchus spilurus, Agoniates halecinus, Aphyocharax pusillus, Astyanax mexicanus, Atopomesus pachyodus, Axelrodia reisei, Brittanichthys axelrodi, Brycon pesu, Bryconadenos tanaothoros, Bryconamericus exodon, Bryconops alburnoides, Charax cf. leticiae, Clupeacharax cf. engrauloides, Compsura heterura, Ctenobrycon hauxwellianus, Deuterodon iguape, Diapoma terofali, Glandulocauda melanogenys, Gnathocharax steindachneri, Gymnocorymbus ternetzi, Hemibrycon polyodon , Hemigrammus unilineatus, Hollandichthys multifasciatus, Hyphessobrycon compressus, Iguanodectes geisleri, Knodus meridae, Landonia latidens, Markiana nigripinnis, Metynnis lippincottianus, Microschemobrycon casiquiare, Moenkhausia xinguensis, Myleus setiger, odontostilbe pequira, Oligosarcus argenteus, orthospinus franciscoensis, Paracheirodon axelrodi, Paragoniates alburnus, Phenacogaster pectinatus, Phenagoniates macrolepis, Piabina argentea, Piaractus mesopotamicus, Poptella brevispina, Probolus heterostomus Rachoviscus graciliceps, Rhinobrycon negrensis, Rhoadsia altipinna, Roeboexodon guyanensis, Salminus hilarii, Serrabrycon magoi, Stygichthys typhlops, Tetragonopterus argenteus e Triportheus albus.

\section{[2] - muito longo.}

Gymnotus aff. carapo, Anostomus anostomus, Leporinus fasciatus, Schizodon fasciatus e Galeocharax knerii.

\section{[-] - inaplicável.}

olivaichthys mesembrinus.

185 - Superfície lateral dos cerato-hiais anterior e posterior:

[VARI, 1995: 57; NetTo-FerReIRA, 2006: 144]

[0] - com interdigitações (Fig. 43B).

Anodus orinocensis, Acestrorhynchus falcirostris, Gilbertolus atratoensis, Roestes molossus, Boulengerella maculata, Ctenolucius hujeta, Erythrinus erythrinus, Hoplias malabaricus, Charax cf. leticiae, Galeocharax knerii e Piaractus mesopotamicus.

\section{[1] - articulação simples (Fig. 43A e C).}

Chanos chanos, Catostomus commersonnii, olivaichthys mesembrinus, Gymnotus aff. carapo, Citharinus latus, Distichodus notospilus, Hemistichodus vaillanti, Neolebias unifasciatus, Nannocharax fasciatus, Xenocharax spilurus, Apareiodon piracicabae, Parodon nasus, Saccodon wagneri, Bivibranchia fowleri, Hemiodus unimaculatus, Curimata ocellata, Curimatopsis macrolepis, Potamorhina latior, Prochilodus nigricans, Semaprochilodus insignis, Caenotropus labyrinthicus, Chilodus punctatus, Anostomus anostomus, Leporellus vittatus, Leporinus fasciatus, Schizodon fasciatus, Carnegiella strigata, Gasteropelecus sternicla, Thoracocharax stellatus, Hydrolycus tatauaia, Erythrinoidea fam. nov, Copeina cf. guttata, Lebiasina bimaculata, Piabucina astrigata, Hepsetus odoe, Arnoldichthys spilopterus, Brycinus macrolepidotus, Bryconalestes longipinnis, Chalceus epakros, Characidium bahiensis, Crenuchus spilurus, Agoniates halecinus, Aphyocharax pusillus, Astyanax mexicanus, Atopomesus pachyodus, Axelrodia reisei, Brittanichthys axelrodi, Brycon pesu, Bryconadenos tanaothoros, Bryconamericus exodon, Bryconops alburnoides, Clupeacharax cf. engrauloides, Compsura heterura, Ctenobrycon hauxwellianus, Deuterodon iguape

Diapoma terofali, Glandulocauda melanogenys, Gnathocharax steindachneri, Gymnocorymbus ternetzi, Hemibrycon polyodon, Hemigrammus unilineatus, Hollandichthys multifasciatus, Hyphessobrycon compressus, Iguanodectes geisleri, Knodus meridae, Landonia latidens, Markiana nigripinnis, Metynnis lippincottianus, Microschemobrycon casiquiare, Moenkhausia xinguensis, Myleus setiger, odontostilbe pequira, oligosarcus argenteus, orthospinus franciscoensis, Paracheirodon axelrodi, Paragoniates alburnus, Phenacogaster pectinatus, Phenagoniates macrolepis, Piabina argentea, Poptella brevispina, Probolus heterostomus, Rachoviscus graciliceps, Rhinobrycon negrensis, Rhoadsia altipinna, Roeboexodon guyanensis, Salminus hilarii, Serrabrycon magoi, Stygichthys typhlops, Tetragonopterus argenteus e Triportheus albus. 
186 - Superfície medial dos cerato-hiais anterior e posterior:

[VARI, 1995: 58; OYAKAWA, 1998: 49; ZANATA, 2000, 72; NETTO-FERREIRA, 2006 : 145]

\section{[0] - sem interdigitações.}

Chanos chanos, Catostomus commersonnii, Olivaichthys mesembrinus, Gymnotus aff. carapo, Citharinus latus, Distichodus notospilus, Hemistichodus vaillanti, Neolebias unifasciatus, Nannocharax fasciatus, Xenocharax spilurus, Apareiodon piracicabae, Parodon nasus, Saccodon wagneri, Bivibranchia fowleri, Hemiodus unimaculatus, Curimata ocellata, Curimatopsis macrolepis, Potamorhina latior, Prochilodus nigricans, Semaprochilodus insignis, Caenotropus labyrinthicus, Chilodus punctatus, Anostomus anostomus, Leporellus vittatus, Leporinus fasciatus, Schizodon fasciatus, Carnegiella strigata, Gasteropelecus sternicla, Thoracocharax stellatus, Erythrinoidea fam. nov, Copeina cf. guttata, Lebiasina bimaculata, Piabucina astrigata, Hepsetus odoe, Arnoldichthys spilopterus, Brycinus macrolepidotus, Bryconalestes longipinnis, Chalceus epakros, Characidium bahiensis, Crenuchus spilurus, Agoniates halecinus, Aphyocharax pusillus, Astyanax mexicanus, Atopomesus pachyodus, Axelrodia reisei, Brittanichthys axelrodi, Brycon pesu, Bryconadenos tanaothoros, Bryconamericus exodon, Bryconops alburnoides, Clupeacharax cf. engrauloides, Compsura heterura, Ctenobrycon hauxwellianus, Deuterodon iguape, Diapoma terofali, Glandulocauda melanogenys, Gnathocharax steindachneri, Gymnocorymbus ternetzi, Hemibrycon polyodon, Hemigrammus unilineatus, Hollandichthys multifasciatus, Hyphessobrycon compressus, Iguanodectes geisleri, Knodus meridae, Landonia latidens, Markiana nigripinnis, Metynnis lippincottianus, Microschemobrycon casiquiare, Moenkhausia xinguensis, Myleus setiger, odontostilbe pequira, oligosarcus argenteus, orthospinus franciscoensis, Paracheirodon axelrodi, Paragoniates alburnus, Phenacogaster pectinatus, Phenagoniates macrolepis, Piabina argentea, Poptella brevispina, Probolus heterostomus, Rachoviscus graciliceps, Rhinobrycon negrensis, Rhoadsia altipinna, Roeboexodon guyanensis, Serrabrycon magoi, Stygichthys typhlops, Tetragonopterus argenteus e Triportheus albus.

\section{[1] - com interdigitações.}

Gilbertolus atratoensis, Hydrolycus tatauaia, Roestes molossus, Boulengerella maculata, Ctenolucius hujeta, Erythrinus erythrinus, Hoplias malabaricus, Charax cf. leticiae, Piaractus mesopotamicus e Salminus hilarii.

\section{[2] - com interdigitações altamente desenvolvidas.}

Anodus orinocensis, Acestrorhynchus falcirostris e Galeocharax knerii.

\section{7 - Articulação entre os cerato-hiais anterior e posterior: [VARI, 1983: 54]}

\section{[0] - perpendicular ao maior eixo.}

Chanos chanos, Catostomus commersonnii, Olivaichthys mesembrinus, Gymnotus aff. carapo, Citharinus latus, Distichodus notospilus, Hemistichodus vaillanti, Neolebias unifasciatus, Nannocharax fasciatus, Xenocharax spilurus, Apareiodon piracicabae, Parodon nasus, Saccodon wagneri, Anodus orinocensis, Bivibranchia fowleri, Hemiodus unimaculatus, Curimata ocellata, Curimatopsis macrolepis, Potamorhina latior, Prochilodus nigricans, Semaprochilodus insignis, Carnegiella strigata, Gasteropelecus sternicla, Thoracocharax stellatus, Acestrorhynchus falcirostris, Gilbertolus atratoensis, Hydrolycus tatauaia, Roestes molossus, Erythrinoidea fam. nov, Boulengerella maculata, Ctenolucius hujeta, Copeina cf. guttata, Lebiasina bimaculata, Piabucina astrigata, Erythrinus erythrinus, Hoplias malabaricus, Hepsetus odoe, Arnoldichthys spilopterus, Brycinus macrolepidotus, Bryconalestes longipinnis, Chalceus epakros, Characidium bahiensis, Crenuchus spilurus, Agoniates halecinus, Aphyocharax pusillus, Astyanax mexicanus, Atopomesus pachyodus, Axelrodia reisei, Brittanichthys axelrodi, Brycon pesu, Bryconadenos tanaothoros, Bryconamericus exodon, Bryconops alburnoides, Charax cf. leticiae, Clupeacharax cf. engrauloides, Compsura heterura, Ctenobrycon hauxwellianus, Deuterodon iguape, Diapoma terofali, Galeocharax knerii, Glandulocauda melanogenys, Gnathocharax steindachneri, Gymnocorymbus ternetzi, Hemibrycon polyodon, Hemigrammus unilineatus, Hollandichthys multifasciatus, Hyphessobrycon compressus, Iguanodectes geisleri, Knodus meridae, Landonia latidens, Markiana nigripinnis, Metynnis lippincottianus, Microschemobrycon casiquiare, Moenkhausia xinguensis, Myleus setiger, Odontostilbe pequira, oligosarcus argenteus, orthospinus franciscoensis, Paracheirodon axelrodi, Paragoniates alburnus, Phenacogaster pectinatus, Phenagoniates macrolepis, Piabina argentea, Piaractus mesopotamicus, Poptella brevispina, Probolus heterostomus, Rachoviscus graciliceps, Rhinobrycon 
negrensis, Rhoadsia altipinna, Roeboexodon guyanensis, Salminus hilarii, Serrabrycon magoi, Stygichthys typhlops, Tetragonopterus argenteus e Triportheus albus.

[1] - oblíquo.

Caenotropus labyrinthicus, Chilodus punctatus, Anostomus anostomus, Leporellus vittatus, Leporinus fasciatus e Schizodon fasciatus.

188 - Canal percorrendo o cerato-hial anterior:

[0] - ausente.

Caenotropus labyrinthicus, Chilodus punctatus, Anostomus anostomus, Leporellus vittatus, Leporinus fasciatus e Schizodon fasciatus.

\section{[1] - presente (Fig. 43A, B e C).}

Citharinus latus, Distichodus notospilus, Hemistichodus vaillanti, Neolebias unifasciatus, Nannocharax fasciatus, Xenocharax spilurus, Apareiodon piracicabae, Parodon nasus, Saccodon wagneri, Anodus orinocensis, Bivibranchia fowleri, Hemiodus unimaculatus, Curimata ocellata, Curimatopsis macrolepis, Potamorhina latior, Prochilodus nigricans, Semaprochilodus insignis, Caenotropus labyrinthicus, Chilodus punctatus, Anostomus anostomus, Leporellus vittatus, Leporinus fasciatus, Schizodon fasciatus, Carnegiella strigata, Gasteropelecus sternicla, Thoracocharax stellatus , Acestrorhynchus falcirostris, Gilbertolus atratoensis, Hydrolycus tatauaia, Roestes molossus, Erythrinoidea fam. nov, Boulengerella maculata, Ctenolucius hujeta, Copeina cf. guttata, Lebiasina bimaculata, Piabucina astrigata, Erythrinus erythrinus, Hoplias malabaricus, Hepsetus odoe, Arnoldichthys spilopterus, Brycinus macrolepidotus, Bryconalestes longipinnis, Chalceus epakros, Characidium bahiensis, Crenuchus spilurus, Agoniates halecinus, Aphyocharax pusillus, Astyanax mexicanus, Atopomesus pachyodus, Axelrodia reisei, Brittanichthys axelrodi, Brycon pesu, Bryconadenos tanaothoros, Bryconamericus exodon, Bryconops alburnoides, charax cf. leticiae, clupeacharax cf. engrauloides, Compsura heterura, Ctenobrycon hauxwellianus, Deuterodon iguape, Diapoma terofali, Galeocharax knerii, Glandulocauda melanogenys, Gnathocharax steindachneri, Gymnocorymbus ternetzi, Hemibrycon polyodon, Hemigrammus unilineatus, Hollandichthys multifasciatus, Hyphessobrycon compressus, Iguanodectes geisleri, Knodus meridae, Landonia latidens, Markiana nigripinnis, Metynnis lippincottianus, Microschemobrycon casiquiare, Moenkhausia xinguensis, Myleus setiger, odontostilbe pequira, oligosarcus argenteus, orthospinus franciscoensis, Paracheirodon axelrodi, Paragoniates alburnus, Phenacogaster pectinatus, Phenagoniates macrolepis, Piabina argentea, Piaractus mesopotamicus, Poptella brevispina, Probolus heterostomus, Rachoviscus graciliceps, Rhinobrycon negrensis, Rhoadsia altipinna, Roeboexodon guyanensis, Salminus hilarii, Serrabrycon magoi, Stygichthys typhlops, Tetragonopterus argenteus e Triportheus albus.

189 - Abertura do canal do cerato-hial anterior:

[ZANATA, 2000: 71]

\section{[0] - na porção anterior do cerato-hial (Fig. 43A e B).}

Citharinus latus, Distichodus notospilus, Nannocharax fasciatus, Xenocharax spilurus, Apareiodon piracicabae, Parodon nasus, Saccodon wagneri, Anodus orinocensis, Bivibranchia fowleri, Hemiodus unimaculatus, Curimata ocellata, Curimatopsis macrolepis, Potamorhina latior, Prochilodus nigricans, Semaprochilodus insignis, Caenotropus labyrinthicus, Chilodus punctatus, Anostomus anostomus, Leporellus vittatus, Leporinus fasciatus, Schizodon fasciatus, Carnegiella strigata, Gasteropelecus sternicla, Thoracocharax stellatus, Acestrorhynchus falcirostris, Gilbertolus atratoensis, Hydrolycus tatauaia, Roestes molossus, Erythrinoidea fam. nov, Boulengerella maculata, ctenolucius hujeta, Copeina cf. guttata, Lebiasina bimaculata, Piabucina astrigata, Erythrinus erythrinus, Hoplias malabaricus, Hepsetus odoe, Arnoldichthys spilopterus, Brycinus macrolepidotus, Bryconalestes longipinnis, Chalceus epakros, Characidium bahiensis, Crenuchus spilurus, Agoniates halecinus, Brycon pesu, Bryconops alburnoides, Clupeacharax cf. engrauloides, Galeocharax knerii, Gnathocharax steindachneri, Iguanodectes geisleri, Metynnis lippincottianus, Myleus setiger, Piaractus mesopotamicus, Salminus hilarii e Triportheus albus.

\section{[1] - na porção póstero-dorsal do ceratohial (Fig. 43C).}

Hemistichodus vaillanti, Neolebias unifasciatus, Aphyocharax pusillus, Astyanax mexicanus, Atopomesus pachyodus, Axelrodia reisei, Brittanichthys axelrodi, Bryconadenos tanaothoros, Bryconamericus exodon, Charax cf. leticiae, Compsura heterura, Ctenobrycon 
hauxwellianus, Deuterodon iguape, Diapoma terofali, Glandulocauda melanogenys, Gymnocorymbus ternetzi, Hemibrycon polyodon, Hemigrammus unilineatus, Hollandichthys multifasciatus, Hyphessobrycon compressus, Knodus meridae, Landonia latidens, Markiana nigripinnis, Microschemobrycon casiquiare, Moenkhausia xinguensis, Odontostilbe pequira, oligosarcus argenteus, orthospinus franciscoensis, Paracheirodon axelrodi, Paragoniates alburnus, Phenacogaster pectinatus, Phenagoniates macrolepis, Piabina argentea, Poptella brevispina, Probolus heterostomus, Rachoviscus graciliceps, Rhinobrycon negrensis, Rhoadsia altipinna, Roeboexodon guyanensis, Serrabrycon magoi, Stygichthys typhlops, Tetragonopterus argenteus.

\section{[-] - inaplicável.}

Chanos chanos, Catostomus commersonnii, Olivaichthys mesembrinus e Gymnotus aff. carapo.

190 - Margem ventral do cerato-hial anterior:

[ZANATA, 2000:70; NETTO-FERREIRA, 2006: 146]

$$
\text { [0] - lisa (Fig. 43A e B). }
$$

Chanos chanos, Catostomus commersonnii, Olivaichthys mesembrinus, Gymnotus aff. carapo, Citharinus latus, Apareiodon piracicabae, Parodon nasus, Saccodon wagneri, Anodus orinocensis, Hemiodus unimaculatus, Curimata ocellata, Potamorhina latior, Caenotropus labyrinthicus, Chilodus punctatus, Carnegiella strigata, Acestrorhynchus falcirostris, Erythrinoidea fam. nov, Copeina cf. guttata, Hepsetus odoe, Chalceus epakros, Characidium bahiensis, Crenuchus spilurus, Agoniates halecinus, Bryconops alburnoides, Gnathocharax steindachneri, Metynnis lippincottianus, Poptella brevispina e Triportheus albus.

\section{[1] - apresentando reentrâncias (Fig. 43C).}

Distichodus notospilus, Hemistichodus vaillanti, Neolebias unifasciatus, Nannocharax fasciatus, Xenocharax spilurus, Bivibranchia fowleri, Curimatopsis macrolepis, Prochilodus nigricans, Semaprochilodus insignis, Anostomus anostomus, Leporellus vittatus, Leporinus fasciatus, Schizodon fasciatus, Gasteropelecus sternicla, Thoracocharax stellatus, Gilbertolus atratoensis, Hydrolycus tatauaia, Roestes molossus, Boulengerella maculata, Ctenolucius hujeta, Lebiasina bimaculata, Piabucina astrigata, Erythrinus erythrinus, Hoplias malabaricus, Arnoldichthys spilopterus, Brycinus macrolepidotus, Bryconalestes longipinnis, Aphyocharax pusillus, Astyanax mexicanus, Atopomesus pachyodus, Axelrodia reisei, Brittanichthys axelrodi, Brycon pesu, Bryconadenos tanaothoros, Bryconamericus exodon, Charax cf. leticiae, Clupeacharax cf. engrauloides, Compsura heterura, Ctenobrycon hauxwellianus, Deuterodon iguape, Diapoma terofali, Galeocharax knerii, Glandulocauda melanogenys, Gymnocorymbus ternetzi, Hemibrycon polyodon, Hemigrammus unilineatus, Hollandichthys multifasciatus, Hyphessobrycon compressus, Iguanodectes geisleri, Knodus meridae, Landonia latidens, Markiana nigripinnis, Microschemobrycon casiquiare, Moenkhausia xinguensis, Myleus setiger, Odontostilbe pequira, oligosarcus argenteus, orthospinus franciscoensis, Paracheirodon axelrodi, Paragoniates alburnus, Phenacogaster pectinatus, Phenagoniates macrolepis, Piabina argentea, Piaractus mesopotamicus, Probolus heterostomus, Rachoviscus graciliceps, Rhinobrycon negrensis, Rhoadsia altipinna, Roeboexodon guyanensis, Salminus hilarii, Serrabrycon magoi, Stygichthys typhlops e Tetragonopterus argenteus.

191 - Número de raios branquiostégios:

[LUCENA, 1993: 70; VARI, 1995: 61; Bukup, 1998: 30; TOledo-PIZA, 2000: 35, modificado; ZANATA e VARI, 2005: 112]

\section{(Minimamente conectado).}

$$
\text { [0] - } 3 \text {. }
$$

Catostomus commersonnii, Neolebias unifasciatus, Anostomus anostomus, Copeina cf. guttata e Clupeacharax cf. engrauloides.

$$
\text { [1] - } 4 \text { (Fig. 43C). }
$$

Chanos chanos, Gymnotus aff. carapo, Citharinus latus, Distichodus notospilus, Hemistichodus vaillanti, Nannocharax fasciatus, Xenocharax spilurus, Apareiodon piracicabae, Parodon nasus, Saccodon wagneri, Curimata ocellata, Curimatopsis 
macrolepis, Potamorhina latior, Prochilodus nigricans, Semaprochilodus insignis, Caenotropus labyrinthicus, Chilodus punctatus, Leporellus vittatus, Leporinus fasciatus, Schizodon fasciatus, Carnegiella strigata, Gasteropelecus sternicla, Acestrorhynchus falcirostris, Gilbertolus atratoensis, Roestes molossus, Erythrinoidea fam. nov, Boulengerella maculata, Lebiasina bimaculata, Piabucina astrigata, Hepsetus odoe, Arnoldichthys spilopterus, Brycinus macrolepidotus, Bryconalestes longipinnis, Chalceus epakros, Characidium bahiensis, Agoniates halecinus, Aphyocharax pusillus, Astyanax mexicanus, Atopomesus pachyodus, Axelrodia reisei, Brittanichthys axelrodi, Brycon pesu, Bryconadenos tanaothoros, Bryconamericus exodon, Bryconops alburnoides, Charax cf. leticiae, Compsura heterura, Ctenobrycon hauxwellianus, Deuterodon iguape, Diapoma terofali, Galeocharax knerii, Glandulocauda melanogenys, Gnathocharax steindachneri, Gymnocorymbus ternetzi, Hemibrycon polyodon, Hemigrammus unilineatus, Hollandichthys multifasciatus, Hyphessobrycon compressus, Iguanodectes geisleri, Knodus meridae, Landonia latidens, Markiana nigripinnis, Metynnis lippincottianus, Microschemobrycon casiquiare, Moenkhausia xinguensis, Myleus setiger, odontostilbe pequira, oligosarcus argenteus, orthospinus franciscoensis, Paracheirodon axelrodi, Paragoniates alburnus, Phenacogaster pectinatus, Phenagoniates macrolepis, Piabina argentea, Poptella brevispina, Probolus heterostomus, Rachoviscus graciliceps, Rhinobrycon negrensis, Rhoadsia altipinna, Roeboexodon guyanensis, Salminus hilarii, Serrabrycon magoi, Stygichthys typhlops, Tetragonopterus argenteus e Triportheus albus.

\section{[2] - 5 (Fig. 43A e B).}

Anodus orinocensis, Bivibranchia fowleri, Hemiodus unimaculatus, Thoracocharax stellatus, Hydrolycus tatauaia, Ctenolucius hujeta, Erythrinus erythrinus, Hoplias malabaricus, Crenuchus spilurus e Piaractus mesopotamicus.

\section{[3] - 6 ou mais.}

olivaichthys mesembrinus.

192 - Número de branquiostégios ligados ao cerato-hial posterior: [LUCENA, 1993: 69; VARI, 1995: 60; TOledo-PizA, 2000: 34; e NetTo-FerReira, 2006: 148]

\section{(Minimamente conectado).}

\section{[0] - ausente.}

Neolebias unifasciatus, Apareiodon piracicabae e Parodon nasus.

$$
\text { [1] - um. }
$$

Catostomus commersonnii, olivaichthys mesembrinus, Gymnotus aff. carapo, Citharinus latus, Distichodus notospilus, Hemistichodus vaillanti, Nannocharax fasciatus, Xenocharax spilurus, Anodus orinocensis, Bivibranchia fowleri, Hemiodus unimaculatus , Curimata ocellata, Curimatopsis macrolepis, Potamorhina latior, Prochilodus nigricans, Semaprochilodus insignis, Caenotropus labyrinthicus, Chilodus punctatus, Carnegiella strigata, Gasteropelecus sternicla, Thoracocharax stellatus, Gilbertolus atratoensis, Roestes molossus, Erythrinoidea fam. nov, Boulengerella maculata, Copeina cf. guttata, Lebiasina bimaculata, Piabucina astrigata, Erythrinus erythrinus, Hoplias malabaricus, Hepsetus odoe, Arnoldichthys spilopterus, Brycinus macrolepidotus, Bryconalestes longipinnis, Chalceus epakros, Characidium bahiensis, crenuchus spilurus, Agoniates halecinus, Aphyocharax pusillus, Astyanax mexicanus, Atopomesus pachyodus, Axelrodia reisei, Brittanichthys axelrodi, Brycon pesu, Bryconadenos tanaothoros, Bryconamericus exodon, Bryconops alburnoides, Charax cf. leticiae, Clupeacharax cf. engrauloides, Compsura heterura, Ctenobrycon hauxwellianus, Deuterodon iguape, Diapoma terofali, Galeocharax knerii, Glandulocauda melanogenys, Gnathocharax steindachneri, Gymnocorymbus ternetzi, Hemibrycon polyodon, Hemigrammus unilineatus, Hollandichthys multifasciatus, Hyphessobrycon compressus, Iguanodectes geisleri, Knodus meridae, Landonia latidens, Markiana nigripinnis, Metynnis lippincottianus, Microschemobrycon casiquiare, Moenkhausia xinguensis, Myleus setiger, odontostilbe pequira, oligosarcus argenteus, orthospinus franciscoensis, Paracheirodon axelrodi, Paragoniates alburnus, Phenacogaster pectinatus, Phenagoniates macrolepis, Piabina argentea, Piaractus mesopotamicus, Poptella brevispina, Probolus heterostomus, Rachoviscus graciliceps, Rhinobrycon negrensis, Rhoadsia altipinna, Roeboexodon guyanensis, Salminus hilarii, Serrabrycon magoi, Stygichthys typhlops, Tetragonopterus argenteus e Triportheus albus. 
Chanos chanos, Anostomus anostomus, Leporellus vittatus, Leporinus fasciatus, Schizodon fasciatus, Acestrorhynchus falcirostris, Hydrolycus tatauaia e ctenolucius hujeta.

[?] - indeterminado.

Saccodon wagneri.

193 - Raio branquiostégio 1 e 2:

[MOREIRA, 2002: 53]

elaboração.

[0] - porção proximal em contato com o ceratohial chato, sem

Chanos chanos, Catostomus commersonnii, Olivaichthys mesembrinus, Gymnotus aff. carapo, Citharinus latus, Hemistichodus vaillanti, Neolebias unifasciatus, Nannocharax fasciatus, Xenocharax spilurus, Apareiodon piracicabae, Parodon nasus, Curimata ocellata, Curimatopsis macrolepis, Caenotropus labyrinthicus, Chilodus punctatus, Anostomus anostomus, Carnegiella strigata, Gasteropelecus sternicla, Thoracocharax stellatus, Acestrorhynchus falcirostris, Gilbertolus atratoensis, Hydrolycus tatauaia, Roestes molossus, Erythrinoidea fam. nov, Copeina cf. guttata, Hepsetus odoe, Arnoldichthys spilopterus, Brycinus macrolepidotus, Bryconalestes longipinnis, Chalceus epakros, Characidium bahiensis, crenuchus spilurus, Agoniates halecinus, Aphyocharax pusillus, Brycon pesu, Bryconops alburnoides, Gnathocharax steindachneri, Gymnocorymbus ternetzi, Metynnis lippincottianus, Myleus setiger, Orthospinus franciscoensis, Poptella brevispina e Triportheus albus.

[1] - porção proximal em contato com o ceratohial com uma bifurcação, ou uma expansão robusta pelo lado de dentro do ceratohial.

Distichodus notospilus, Saccodon wagneri, Anodus orinocensis, Bivibranchia fowleri, Hemiodus unimaculatus, Potamorhina latior, Prochilodus nigricans, Semaprochilodus insignis, Leporellus vittatus, Leporinus fasciatus, Schizodon fasciatus, Boulengerella maculata, Ctenolucius hujeta, Lebiasina bimaculata, Piabucina astrigata, Erythrinus erythrinus, Hoplias malabaricus, Astyanax mexicanus, Atopomesus pachyodus, Axelrodia reisei, Brittanichthys axelrodi, Bryconadenos tanaothoros, Bryconamericus exodon, Charax cf. leticiae, Clupeacharax cf. engrauloides, Compsura heterura, Ctenobrycon hauxwellianus, Deuterodon iguape, Diapoma terofali, Galeocharax knerii, Glandulocauda melanogenys, Hemibrycon polyodon, Hemigrammus unilineatus, Hollandichthys multifasciatus, Hyphessobrycon compressus, Iguanodectes geisleri, Knodus meridae, Landonia latidens, Markiana nigripinnis, Microschemobrycon casiquiare, Moenkhausia xinguensis, Odontostilbe pequira, oligosarcus argenteus, Paracheirodon axelrodi, Paragoniates alburnus, Phenacogaster pectinatus, Phenagoniates macrolepis, Piabina argentea, Piaractus mesopotamicus, Probolus heterostomus, Rachoviscus graciliceps, Rhinobrycon negrensis, Rhoadsia altipinna, Roeboexodon guyanensis, Salminus hilarii, Serrabrycon magoi, Stygichthys typhlops e Tetragonopterus argenteus.

194 - Raio branquiostégio 1:

[MOREIRA, 2002: 54]

\section{[0] - sem projeção anterior distinta (Fig. 43A).}

Olivaichthys mesembrinus, Gymnotus aff. carapo, Citharinus latus, Distichodus notospilus, Hemistichodus vaillanti, Neolebias unifasciatus, Nannocharax fasciatus, Xenocharax spilurus, Apareiodon piracicabae, Parodon nasus, Saccodon wagneri, Bivibranchia fowleri, Prochilodus nigricans, Semaprochilodus insignis, Caenotropus labyrinthicus, Chilodus punctatus, Anostomus anostomus, Leporellus vittatus, Leporinus fasciatus, Schizodon fasciatus, Carnegiella strigata, Gasteropelecus sternicla, Thoracocharax stellatus, Hydrolycus tatauaia, Roestes molossus, Erythrinoidea fam. nov, Characidium bahiensis, Crenuchus spilurus, Aphyocharax pusillus, Brittanichthys axelrodi, Charax cf. leticiae, Galeocharax knerii, Gnathocharax steindachneri, Microschemobrycon casiquiare e Stygichthys typhlops.

\section{[1] - com projeção distinta anterior (Fig. 43B e C).}

Chanos chanos, Catostomus commersonnii, Anodus orinocensis, Hemiodus unimaculatus curimata ocellata, Curimatopsis macrolepis, Potamorhina latior, Acestrorhynchus falcirostris, Gilbertolus atratoensis, Boulengerella maculata, ctenolucius hujeta, Copeina cf. guttata, Lebiasina bimaculata, Piabucina astrigata, Erythrinus erythrinus, Hoplias malabaricus, Hepsetus odoe, Arnoldichthys spilopterus, Brycinus macrolepidotus, 
Bryconalestes longipinnis, Chalceus epakros, Agoniates halecinus, Astyanax mexicanus, Atopomesus pachyodus, Axelrodia reisei, Brycon pesu, Bryconadenos tanaothoros, Bryconamericus exodon, Bryconops alburnoides, Clupeacharax cf. engrauloides, Compsura heterura, Ctenobrycon hauxwellianus, Deuterodon iguape, Diapoma terofali, Glandulocauda melanogenys, Gymnocorymbus ternetzi, Hemibrycon polyodon, Hemigrammus unilineatus, Hollandichthys multifasciatus, Hyphessobrycon compressus, Iguanodectes geisleri, Knodus meridae, Landonia latidens, Markiana nigripinnis, Metynnis lippincottianus, Moenkhausia xinguensis, Myleus setiger, Odontostilbe pequira, oligosarcus argenteus, orthospinus franciscoensis, Paracheirodon axelrodi, Paragoniates alburnus, Phenacogaster pectinatus, Phenagoniates macrolepis, Piabina argentea, Piaractus mesopotamicus, Poptella brevispina, Probolus heterostomus, Rachoviscus graciliceps, Rhinobrycon negrensis, Rhoadsia altipinna, Roeboexodon guyanensis, Salminus hilarii, Serrabrycon magoi, Tetragonopterus argenteus e Triportheus albus.

\section{5 - Raio branquistégio 2:}

[MOREIRA, 2002: 55]

\section{[0] - sem projeção distinta anterior (Fig. 43A).}

Olivaichthys mesembrinus, Gymnotus aff. carapo, Citharinus latus, Distichodus notospilus, Hemistichodus vaillanti, Neolebias unifasciatus, Nannocharax fasciatus, Xenocharax spilurus, Apareiodon piracicabae, Parodon nasus, Prochilodus nigricans, Semaprochilodus insignis, Caenotropus labyrinthicus, Chilodus punctatus, Anostomus anostomus, Leporellus vittatus, Leporinus fasciatus, Schizodon fasciatus, Carnegiella strigata, Gasteropelecus sternicla, Thoracocharax stellatus, Gilbertolus atratoensis, Hydrolycus tatauaia, Roestes molossus, Erythrinoidea fam. nov, characidium bahiensis, Crenuchus spilurus, Aphyocharax pusillus, Brittanichthys axelrodi, Charax cf. leticiae, Galeocharax knerii, Gnathocharax steindachneri, Microschemobrycon casiquiare e Stygichthys typhlops.

\section{[1] - com projeção distinta anterior, extendendo-se quase até a margem anterior do primiero raio branquiostégio (Fig. 43B e C).}

Chanos chanos, Catostomus commersonnii, Saccodon wagneri, Anodus orinocensis, Bivibranchia fowleri, Hemiodus unimaculatus, curimata ocellata, curimatopsis macrolepis, Potamorhina latior, Acestrorhynchus falcirostris, Boulengerella maculata, Ctenolucius hujeta, Copeina cf. guttata, Lebiasina bimaculata, Piabucina astrigata, Erythrinus erythrinus, Hoplias malabaricus, Hepsetus odoe, Arnoldichthys spilopterus, Brycinus macrolepidotus, Bryconalestes longipinnis, Chalceus epakros, Agoniates halecinus, Astyanax mexicanus, Atopomesus pachyodus, Axelrodia reisei, Brycon pesu, Bryconadenos tanaothoros, Bryconamericus exodon, Bryconops alburnoides, Clupeacharax cf. engrauloides, Compsura heterura, Ctenobrycon hauxwellianus, Deuterodon iguape, Diapoma terofali, Glandulocauda melanogenys, Gymnocorymbus ternetzi, Hemibrycon polyodon , Hemigrammus unilineatus, Hollandichthys multifasciatus, Hyphessobrycon compressus, Iguanodectes geisleri, Knodus meridae, Landonia latidens, Markiana nigripinnis, Metynnis lippincottianus, Moenkhausia xinguensis, Myleus setiger, odontostilbe pequira, oligosarcus argenteus, orthospinus franciscoensis, Paracheirodon axelrodi, Paragoniates alburnus, Phenacogaster pectinatus, Phenagoniates macrolepis, Piabina argentea, Piaractus mesopotamicus, Poptella brevispina, Probolus heterostomus, Rachoviscus graciliceps, Rhinobrycon negrensis, Rhoadsia altipinna, Roeboexodon guyanensis, Salminus hilarii, Serrabrycon magoi, Tetragonopterus argenteus e Triportheus albus.

196 - Porção anterior do uro-hial:

[MOREIRA, 2002: 52; NeTTO-FERREIRA, 2006: 151 modificado]

\section{[0] - bifurcado (Fig. 44 e Fig 45).}

hanos chanos, Catostomus commersonnii, Olivaichthys mesembrinus, Gymnotus aff. carapo, Citharinus latus, Distichodus notospilus, Hemistichodus vaillanti, Neolebias unifasciatus, Nannocharax fasciatus, Xenocharax spilurus, Saccodon wagneri, Curimata ocellata, Curimatopsis macrolepis, Potamorhina latior, Anostomus anostomus, Leporellus vittatus, Leporinus fasciatus, Schizodon fasciatus, Acestrorhynchus falcirostris, Gilbertolus atratoensis, Erythrinoidea fam. nov, Copeina cf. guttata, Lebiasina bimaculata, Piabucina astrigata, Hepsetus odoe, Arnoldichthys spilopterus, Brycinus macrolepidotus, Bryconalestes longipinnis, Chalceus epakros, Characidium bahiensis, crenuchus spilurus, Agoniates halecinus, Aphyocharax pusillus, Astyanax mexicanus, Atopomesus pachyodus, Axelrodia reisei, Brittanichthys axelrodi, Bryconadenos tanaothoros, Bryconamericus exodon, Charax cf. leticiae, Clupeacharax cf. engrauloides, Compsura heterura, Ctenobrycon hauxwellianus, Diapoma terofali, Galeocharax knerii, Glandulocauda melanogenys, Gymnocorymbus ternetzi, Hemibrycon polyodon, Hemigrammus unilineatus, Hollandichthys multifasciatus, Hyphessobrycon compressus, Iguanodectes 
geisleri, Knodus meridae, Landonia latidens, Markiana nigripinnis, Microschemobrycon casiquiare, Moenkhausia xinguensis, Odontostilbe pequira, oligosarcus argenteus, orthospinus franciscoensis, Paracheirodon axelrodi, Phenagoniates macrolepis, Piabina argentea, Rachoviscus graciliceps, Rhinobrycon negrensis, Rhoadsia altipinna, Stygichthys typhlops, Tetragonopterus argenteus e Triportheus albus.

\section{[1] - com forame.}

Apareiodon piracicabae, Parodon nasus, Anodus orinocensis, Bivibranchia fowleri, Hemiodus unimaculatus, Prochilodus nigricans, Semaprochilodus insignis e Phenacogaster pectinatus.

$$
\text { [2] - lisa. }
$$

Carnegiella strigata, Gasteropelecus sternicla, Thoracocharax stellatus, Hydrolycus tatauaia, Boulengerella maculata, Ctenolucius hujeta, Erythrinus erythrinus, Hoplias malabaricus, Brycon pesu, Bryconops alburnoides, Deuterodon iguape, Gnathocharax steindachneri, Metynnis lippincottianus, Myleus setiger, Paragoniates alburnus, Piaractus mesopotamicus, Poptella brevispina, Probolus heterostomus , Roeboexodon guyanensis, Salminus hilarii e Serrabrycon magoi.

\section{7 - Asas laterais do uro-hial:}

[ZANATA, 2000: 74; ZANATA \& VARI, 2005: 113; NetTo-FerReira, 2006: 152]

\section{[0] - ausentes ou pequenas (Fig. 45).}

Chanos chanos, Citharinus latus, Neolebias unifasciatus, Curimata ocellata, Curimatopsis macrolepis, Potamorhina latior, Anostomus anostomus, Leporellus vittatus, Schizodon fasciatus, Carnegiella strigata, Gasteropelecus sternicla, Thoracocharax stellatus , Acestrorhynchus falcirostris, Gilbertolus atratoensis, Hydrolycus tatauaia, Roestes molossus, Erythrinoidea fam. nov, Boulengerella maculata, Ctenolucius hujeta, Copeina cf. guttata, Lebiasina bimaculata, Piabucina astrigata, Erythrinus erythrinus, Hoplias malabaricus, Hepsetus odoe, Arnoldichthys spilopterus, Crenuchus spilurus, Agoniates halecinus, Aphyocharax pusillus, Astyanax mexicanus, Atopomesus pachyodus, Axelrodia reisei, Brittanichthys axelrodi, Bryconamericus exodon, Charax cf. leticiae, Clupeacharax cf. engrauloides, Ctenobrycon hauxwellianus, Diapoma terofali, Galeocharax knerii, Gnathocharax steindachneri, Gymnocorymbus ternetzi, Hemibrycon polyodon Hemigrammus unilineatus, Hollandichthys multifasciatus, Hyphessobrycon compressus, Markiana nigripinnis, Microschemobrycon casiquiare, Moenkhausia xinguensis, odontostilbe pequira, Oligosarcus argenteus, Orthospinus franciscoensis, Paracheirodon axelrodi, Paragoniates alburnus, Phenacogaster pectinatus, Phenagoniates macrolepis, Piabina argentea, Poptella brevispina, Probolus heterostomus, Rachoviscus graciliceps, Rhinobrycon negrensis, Rhoadsia altipinna, Roeboexodon guyanensis, Serrabrycon magoi, Stygichthys typhlops, Tetragonopterus argenteus e Triportheus albus.

\section{[1] - grandes (Fig. 44).}

Catostomus commersonnii, Olivaichthys mesembrinus, Gymnotus aff. carapo, Distichodus notospilus, Hemistichodus vaillanti, Nannocharax fasciatus, xenocharax spilurus, Apareiodon piracicabae, Parodon nasus, Saccodon wagneri, Anodus orinocensis, Bivibranchia fowleri, Hemiodus unimaculatus, Prochilodus nigricans, Semaprochilodus insignis, Caenotropus labyrinthicus, Chilodus punctatus, Leporinus fasciatus, Brycinus macrolepidotus, Bryconalestes longipinnis, Chalceus epakros, Characidium bahiensis, Brycon pesu, Bryconadenos tanaothoros, Bryconops alburnoides, Compsura heterura, Deuterodon iguape, Glandulocauda melanogenys, Iguanodectes geisleri, Knodus meridae, Landonia latidens, Metynnis lippincottianus, Myleus setiger, Piaractus mesopotamicus e Salminus hilarii.

\section{8 - Margem posterior da face ventral do uro-hial: [LIMA, 2006: 41 modificado]}

\section{[0] - confluente.}

Catostomus commersonnii, Neolebias unifasciatus, Nannocharax fasciatus, Xenocharax spilurus, Curimata ocellata, Curimatopsis macrolepis, Caenotropus labyrinthicus, chilodus punctatus, Anostomus anostomus, Leporellus vittatus, Schizodon fasciatus, Gilbertolus atratoensis, Hydrolycus tatauaia, Roestes molossus, Boulengerella maculata, Ctenolucius hujeta, Copeina cf. guttata, Lebiasina bimaculata, Piabucina astrigata, Erythrinus erythrinus, Hoplias malabaricus, Arnoldichthys spilopterus, Characidium 
bahiensis, Agoniates halecinus, Aphyocharax pusillus, Astyanax mexicanus, Atopomesus pachyodus, Axelrodia reisei, Bryconadenos tanaothoros, Bryconamericus exodon, Charax cf. leticiae, Clupeacharax cf. engrauloides, Ctenobrycon hauxwellianus, Diapoma terofali, Galeocharax knerii, Glandulocauda melanogenys, Gnathocharax steindachneri, Gymnocorymbus ternetzi, Hemibrycon polyodon, Hemigrammus unilineatus, Hollandichthys multifasciatus, Hyphessobrycon compressus, Knodus meridae, Landonia latidens, Markiana nigripinnis, Metynnis lippincottianus, Microschemobrycon casiquiare, Moenkhausia xinguensis, odontostilbe pequira, oligosarcus argenteus, orthospinus franciscoensis, Paracheirodon axelrodi, Paragoniates alburnus, Phenacogaster pectinatus, Phenagoniates macrolepis, Piabina argentea, Piaractus mesopotamicus, Poptella brevispina, Probolus heterostomus , Rachoviscus graciliceps, Rhinobrycon negrensis, Roeboexodon guyanensis, Salminus hilarii, Serrabrycon magoi, Stygichthys typhlops e Tetragonopterus argenteus.

\section{[1] - reta (Fig. 44).}

Chanos chanos, Olivaichthys mesembrinus, Gymnotus aff. carapo, Distichodus notospilus, Hemistichodus vaillanti, Apareiodon piracicabae, Parodon nasus, Saccodon wagneri, Potamorhina latior, Prochilodus nigricans, Semaprochilodus insignis, Leporinus fasciatus, Chalceus epakros, Bryconops alburnoides, Compsura heterura, Deuterodon iguape, Iguanodectes geisleri, Myleus setiger, Rhoadsia altipinna e Triportheus albus.

\section{[2] - divergente.}

Anodus orinocensis, Bivibranchia fowleri, Hemiodus unimaculatus, Brycinus macrolepidotus, Bryconalestes longipinnis e Brycon pesu.

\section{[-] - inaplicável.}

Citharinus latus, Carnegiella strigata, Gasteropelecus sternicla, Thoracocharax stellatus, Acestrorhynchus falcirostris, Erythrinoidea fam. nov, Hepsetus odoe, Crenuchus spilurus e Brittanichthys axelrodi.

\section{9 - Superfície ventral do uro-hial:} [LIMA, 2006: 41 modificado]

\section{[0] - côncava (Fig. 44).}

Chanos chanos, Apareiodon piracicabae, Parodon nasus, Saccodon wagneri, Anodus orinocensis, Bivibranchia fowleri, Hemiodus unimaculatus, Curimata ocellata, Curimatopsis macrolepis, Potamorhina latior, Anostomus anostomus, Leporellus vittatus, Schizodon fasciatus, Boulengerella maculata, ctenolucius hujeta, Arnoldichthys spilopterus, Brycinus macrolepidotus, Bryconalestes longipinnis, Chalceus epakros, Aphyocharax pusillus, Astyanax mexicanus, Atopomesus pachyodus, Axelrodia reisei, Brycon pesu, Bryconops alburnoides, Charax cf. leticiae, clupeacharax cf. engrauloides, Compsura heterura, Ctenobrycon hauxwellianus, Diapoma terofali, Galeocharax knerii, Gymnocorymbus ternetzi, Hyphessobrycon compressus, Iguanodectes geisleri, Knodus meridae, Landonia latidens, Markiana nigripinnis, Metynnis lippincottianus, Microschemobrycon casiquiare, Moenkhausia xinguensis, Myleus setiger, odontostilbe pequira, oligosarcus argenteus, orthospinus franciscoensis, Paracheirodon axelrodi, Paragoniates alburnus, Phenacogaster pectinatus, Phenagoniates macrolepis, Piabina argentea, Piaractus mesopotamicus, Probolus heterostomus, Rachoviscus graciliceps, Rhinobrycon negrensis, Rhoadsia altipinna, Roeboexodon guyanensis, Tetragonopterus argenteus e Triportheus albus.

\section{[1] - plana.}

Catostomus commersonnii, Olivaichthys mesembrinus, Gymnotus aff. carapo, Distichodus notospilus, Hemistichodus vaillanti, Neolebias unifasciatus, Nannocharax fasciatus, Xenocharax spilurus, Prochilodus nigricans, Semaprochilodus insignis, Caenotropus labyrinthicus, Chilodus punctatus, Leporinus fasciatus, Gilbertolus atratoensis, Hydrolycus tatauaia, Roestes molossus, Copeina cf. guttata, Lebiasina bimaculata, Piabucina astrigata, Erythrinus erythrinus, Hoplias malabaricus, Characidium bahiensis, Bryconadenos tanaothoros, Bryconamericus exodon, Deuterodon iguape, Glandulocauda melanogenys, Gnathocharax steindachneri, Hemibrycon polyodon, Hemigrammus unilineatus, Hollandichthys multifasciatus, Piabina argentea, Poptella brevispina, Salminus hilarii, Serrabrycon magoi e Stygichthys typhlops.

\section{[2] - convexa.}

Agoniates halecinus. 


\section{[-] - inaplicável.}

Citharinus latus, Carnegiella strigata, Gasteropelecus sternicla, Thoracocharax stellatus, Acestrorhynchus falcirostris, Erythrinoidea fam. nov, Hepsetus odoe, crenuchus spilurus, Brittanichthys axelrodi

\section{$[1,2]$ - polimórfico.}

Piabina argêntea.

200 - Asa dorsal do uro-hial:

[MOREIRA, 2006: 51]

\section{[0] - aproximadamente do mesmo tamanho da face ventral, ou mais curta (Fig. 45).}

Hemistichodus vaillanti, Neolebias unifasciatus, Xenocharax spilurus, Carnegiella strigata, Gasteropelecus sternicla, Thoracocharax stellatus, Erythrinoidea fam. nov, Arnoldichthys spilopterus, crenuchus spilurus, Gnathocharax steindachneri, Hollandichthys multifasciatus e Salminus hilarii.

[1] - mais comprida, mas contínua (Fig. 44).

Chanos chanos, Catostomus commersonnii, Olivaichthys mesembrinus, Gymnotus aff. carapo, Distichodus notospilus, Apareiodon piracicabae, Parodon nasus, Saccodon wagneri, Hemiodus unimaculatus, Curimata ocellata, Curimatopsis macrolepis, Potamorhina latior, Prochilodus nigricans, Semaprochilodus insignis, Caenotropus labyrinthicus, Chilodus punctatus, Acestrorhynchus falcirostris, Boulengerella maculata, Ctenolucius hujeta, Copeina cf. guttata, Lebiasina bimaculata, Piabucina astrigata, Erythrinus erythrinus, Hoplias malabaricus, Hepsetus odoe, Chalceus epakros, Characidium bahiensis, Agoniates halecinus, Aphyocharax pusillus, Astyanax mexicanus, Atopomesus pachyodus, Brittanichthys axelrodi, Bryconadenos tanaothoros, Bryconamericus exodon, Charax cf. leticiae, Clupeacharax cf. engrauloides, Ctenobrycon hauxwellianus, Deuterodon iguape, Diapoma terofali, Galeocharax knerii, Glandulocauda melanogenys, Gymnocorymbus ternetzi, Hemibrycon polyodon, Hyphessobrycon compressus, Knodus meridae, Landonia latidens, Markiana nigripinnis, Metynnis lippincottianus, Microschemobrycon casiquiare Moenkhausia xinguensis, Myleus setiger, Odontostilbe pequira, oligosarcus argenteus, orthospinus franciscoensis, Paracheirodon axelrodi, Paragoniates alburnus, Phenacogaster pectinatus, Phenagoniates macrolepis, Piabina argentea, Piaractus mesopotamicus, Probolus heterostomus, Rhinobrycon negrensis, Rhoadsia altipinna, Roeboexodon guyanensis, Serrabrycon magoi, Tetragonopterus argenteus e Triportheus albus.

[2] - mais comprida, mas com grande concavidade entre a a porção mais dorsal e a face ventral.

Citharinus latus, Nannocharax fasciatus, Anodus orinocensis, Bivibranchia fowleri, Anostomus anostomus, Leporellus vittatus, Leporinus fasciatus, Schizodon fasciatus, Gilbertolus atratoensis, Hydrolycus tatauaia, Roestes molossus, Brycinus macrolepidotus, Bryconalestes longipinnis, Axelrodia reisei, Brycon pesu, Bryconops alburnoides, Compsura heterura, Hemigrammus unilineatus, Iguanodectes geisleri, Poptella brevispina, Rachoviscus graciliceps e Stygichthys typhlops.

201 - Basibranquial 1:

[VARI, 1983: 10]

\section{[0] - desenvolvido (Fig. 42A e B).}

Hemistichodus vaillanti, Neolebias unifasciatus, Caenotropus labyrinthicus, Chilodus punctatus, Leporellus vittatus, Acestrorhynchus falcirostris, Gilbertolus atratoensis, Hydrolycus tatauaia, Roestes molossus, Erythrinoidea fam. nov, Boulengerella maculata, Ctenolucius hujeta, Copeina cf. guttata, Lebiasina bimaculata, Piabucina astrigata, Erythrinus erythrinus, Hoplias malabaricus, Hepsetus odoe, Brycinus macrolepidotus, Bryconalestes longipinnis, Chalceus epakros, Characidium bahiensis, Crenuchus spilurus, Agoniates halecinus, Aphyocharax pusillus, Astyanax mexicanus, Atopomesus pachyodus, Axelrodia reisei, Brittanichthys axelrodi, Brycon pesu, Bryconadenos tanaothoros, Bryconamericus exodon, Bryconops alburnoides, Charax cf. leticiae, Clupeacharax cf. engrauloides, Compsura heterura, Ctenobrycon hauxwellianus, Deuterodon iguape, Diapoma terofali, Galeocharax knerii, Glandulocauda melanogenys, Gnathocharax steindachneri, Gymnocorymbus ternetzi, Hemibrycon polyodon, Hemigrammus unilineatus, Hollandichthys multifasciatus, Hyphessobrycon compressus, Iguanodectes geisleri, Knodus meridae, 
Landonia latidens, Markiana nigripinnis, Metynnis lippincottianus, Microschemobrycon casiquiare, Moenkhausia xinguensis, Myleus setiger, odontostilbe pequira, oligosarcus argenteus, orthospinus franciscoensis, Paracheirodon axelrodi, Paragoniates alburnus, Phenacogaster pectinatus, Phenagoniates macrolepis, Piabina argentea, Piaractus mesopotamicus, Poptella brevispina, Probolus heterostomus, Rachoviscus graciliceps, Rhinobrycon negrensis, Rhoadsia altipinna, Roeboexodon guyanensis, Salminus hilarii, Serrabrycon magoi e Tetragonopterus argenteus.

\section{[1] - ausente ou reduzido.}

Catostomus commersonnii, Olivaichthys mesembrinus, Gymnotus aff. carapo, Nannocharax fasciatus, Xenocharax spilurus, Apareiodon piracicabae, Parodon nasus, Saccodon wagneri, Anodus orinocensis, Bivibranchia fowleri, Hemiodus unimaculatus, Curimata ocellata, Curimatopsis macrolepis, Potamorhina latior, Prochilodus nigricans, Semaprochilodus insignis, Anostomus anostomus, Leporinus fasciatus, Schizodon fasciatus, Carnegiella strigata, Gasteropelecus sternicla, Thoracocharax stellatus, Arnoldichthys spilopterus, stygichthys typhlops e Triportheus albus.

\section{Basibranchiais 1-3:}

\section{[0] - com placas dentígeras.}

Distichodus notospilus, Hemistichodus vaillanti, Xenocharax spilurus e Hoplias malabaricus.

\section{[1] - sem placas dentígeras (Fig. 42A e B).}

Chanos chanos, Catostomus commersonnii, Olivaichthys mesembrinus, Gymnotus aff. carapo, Citharinus latus, Neolebias unifasciatus, Apareiodon piracicabae, Parodon nasus, Saccodon wagneri, Anodus orinocensis, Bivibranchia fowleri, Hemiodus unimaculatus, Curimata ocellata, Curimatopsis macrolepis, Potamorhina latior, Prochilodus nigricans, Semaprochilodus insignis, Caenotropus labyrinthicus, Chilodus punctatus, Anostomus anostomus, Leporellus vittatus, Leporinus fasciatus, schizodon fasciatus, Carnegiella strigata, Gasteropelecus sternicla, Thoracocharax stellatus, Acestrorhynchus falcirostris, Gilbertolus atratoensis, Hydrolycus tatauaia, Roestes molossus, Erythrinoidea fam. nov, Boulengerella maculata, Ctenolucius hujeta, copeina cf. guttata, Lebiasina bimaculata, Piabucina astrigata, Erythrinus erythrinus, Hepsetus odoe, Arnoldichthys spilopterus, Brycinus macrolepidotus, Bryconalestes longipinnis, Chalceus epakros, Characidium bahiensis, Crenuchus spilurus, Agoniates halecinus, Aphyocharax pusillus, Astyanax mexicanus, Atopomesus pachyodus, Axelrodia reisei, Brittanichthys axelrodi, Brycon pesu, Bryconadenos tanaothoros, Bryconamericus exodon, Bryconops alburnoides, Charax cf. leticiae, Clupeacharax cf. engrauloides, compsura heterura, Ctenobrycon hauxwellianus, Deuterodon iguape, Diapoma terofali, Galeocharax knerii, Glandulocauda melanogenys, Gnathocharax steindachneri, Gymnocorymbus ternetzi, Hemibrycon polyodon, Hemigrammus unilineatus, Hollandichthys multifasciatus, Hyphessobrycon compressus, Iguanodectes geisleri, Knodus meridae, Landonia latidens, Markiana nigripinnis, Metynnis lippincottianus, Microschemobrycon casiquiare, Moenkhausia xinguensis, Myleus setiger, Odontostilbe pequira, Oligosarcus argenteus, orthospinus franciscoensis, Paracheirodon axelrodi, Paragoniates alburnus, Phenacogaster pectinatus, Phenagoniates macrolepis, Piabina argentea, Piaractus mesopotamicus, Poptella brevispina, Probolus heterostomus, Rachoviscus graciliceps, Rhinobrycon negrensis, Rhoadsia altipinna, Roeboexodon guyanensis, Salminus hilarii, Serrabrycon magoi, Stygichthys typhlops, Tetragonopterus argenteus e Triportheus albus.

\section{[?] - indeterminado.}

Nannocharax fasciatus.

203 - Basi-branquial 2:

[NETTO-FERREIRA, 2006: 156 modificado]

\section{[0] - margens anterior lisa.}

Catostomus commersonnii, Citharinus latus, Hemistichodus vaillanti, Neolebias unifasciatus, Nannocharax fasciatus, Apareiodon piracicabae, Parodon nasus, Saccodon wagneri, Bivibranchia fowleri, Caenotropus labyrinthicus, Erythrinoidea fam. nov, Copeina cf. guttata, Lebiasina bimaculata, Piabucina astrigata, Erythrinus erythrinus, Hoplias malabaricus, Hepsetus odoe, Arnoldichthys spilopterus, Brycinus macrolepidotus, Bryconalestes longipinnis, Characidium bahiensis, Aphyocharax pusillus, Astyanax mexicanus, Atopomesus pachyodus, Axelrodia reisei, Brittanichthys axelrodi, Bryconadenos 
tanaothoros, Bryconamericus exodon, Charax cf. leticiae, Clupeacharax cf. engrauloides, Compsura heterura, Ctenobrycon hauxwellianus, Diapoma terofali, Galeocharax knerii, Gnathocharax steindachneri, Gymnocorymbus ternetzi, Hemibrycon polyodon, Hemigrammus unilineatus, Hollandichthys multifasciatus, Hyphessobrycon compressus, Iguanodectes geisleri, Knodus meridae, Landonia latidens, Markiana nigripinnis, Metynnis lippincottianus, Microschemobrycon casiquiare, Moenkhausia xinguensis, Myleus setiger, Odontostilbe pequira, oligosarcus argenteus, orthospinus franciscoensis, Paracheirodon axelrodi, Paragoniates alburnus, Phenacogaster pectinatus, Phenagoniates macrolepis, Piabina argentea, Piaractus mesopotamicus, Poptella brevispina, Probolus heterostomus Rachoviscus graciliceps, Rhinobrycon negrensis, Rhoadsia altipinna, Roeboexodon guyanensis, Stygichthys typhlops e Tetragonopterus argenteus.

\section{[1] - com expansões dorsal na margem anterior (Fig. 42A e B).}

Chanos chanos, Olivaichthys mesembrinus, Distichodus notospilus, Xenocharax spilurus, Anodus orinocensis, Hemiodus unimaculatus, Curimata ocellata, Curimatopsis macrolepis, Potamorhina latior, Prochilodus nigricans, Semaprochilodus insignis, Chilodus punctatus, Anostomus anostomus, Leporellus vittatus, Leporinus fasciatus, Schizodon fasciatus, Carnegiella strigata, Gasteropelecus sternicla, Thoracocharax stellatus Acestrorhynchus falcirostris, Gilbertolus atratoensis, Hydrolycus tatauaia, Roeste's molossus, Boulengerella maculata, Ctenolucius hujeta, Chalceus epakros, Crenuchus spilurus, Agoniates halecinus, Brycon pesu, Bryconops alburnoides, Deuterodon iguape, Glandulocauda melanogenys, Salminus hilarii, Serrabrycon magoi e Triportheus albus.

\section{[-] - inaplicável.}

Gymnotus aff. carapo.

204 - Basibranquial 4:

[LuCenA, 1993: 74, Zanata, 2000: 78; Netto-FerReira, 2006: 157]

\section{[0] - totalmente cartilaginoso.}

Chanos chanos, Catostomus commersonnii, Olivaichthys mesembrinus, Gymnotus aff. carapo, Citharinus latus, Distichodus notospilus, Hemistichodus vaillanti, Neolebias unifasciatus, Nannocharax fasciatus, Xenocharax spilurus, Apareiodon piracicabae, Parodon nasus, Saccodon wagneri, Anodus orinocensis, Bivibranchia fowleri, Hemiodus unimaculatus, Curimata ocellata, Curimatopsis macrolepis, Potamorhina latior, Caenotropus labyrinthicus, Chilodus punctatus, Leporellus vittatus, Leporinus fasciatus, Schizodon fasciatus, Acestrorhynchus falcirostris, Gilbertolus atratoensis, Hydrolycus tatauaia, Roestes molossus, Erythrinoidea fam. nov, Boulengerella maculata, Ctenolucius hujeta, Copeina cf. guttata, Lebiasina bimaculata, Piabucina astrigata, Erythrinus erythrinus, Hoplias malabaricus, Hepsetus odoe, Arnoldichthys spilopterus, Brycinus macrolepidotus, Bryconalestes longipinnis, Chalceus epakros, Characidium bahiensis, Atopomesus pachyodus, Axelrodia reisei, Brittanichthys axelrodi, Brycon pesu, Bryconamericus exodon, Bryconops alburnoides, Charax cf. leticiae, Clupeacharax cf. engrauloides, Compsura heterura, Ctenobrycon hauxwellianus, Diapoma terofali, Galeocharax knerii, Gnathocharax steindachneri, Hemigrammus unilineatus, Hollandichthys multifasciatus, Hyphessobrycon compressus, Iguanodectes geisleri, Knodus meridae, Metynnis lippincottianus, Myleus setiger, Paracheirodon axelrodi, Piabina argentea, Piaractus mesopotamicus, Poptella brevispina, Rachoviscus graciliceps, Rhinobrycon negrensis, Salminus hilarii, Serrabrycon magoi e stygichthys typhlops.

\section{[1] - parcialmente ossificado.}

Prochilodus nigricans, Semaprochilodus insignis, Anostomus anostomus, Carnegiella strigata, Gasteropelecus sternicla, Thoracocharax stellatus, Crenuchus spilurus, Agoniates halecinus, Aphyocharax pusillus, Astyanax mexicanus, Bryconadenos tanaothoros, Deuterodon iguape, Glandulocauda melanogenys, Gymnocorymbus ternetzi, Hemibrycon polyodon, Landonia latidens, Markiana nigripinnis, Microschemobrycon casiquiare, Moenkhausia xinguensis, Odontostilbe pequira, Oligosarcus argenteus, orthospinus franciscoensis, Paragoniates alburnus, Phenacogaster pectinatus, Phenagoniates macrolepis, Probolus heterostomus, Rhoadsia altipinna, Roeboexodon guyanensis, Tetragonopterus argenteus e Triportheus albus.

205 - Dentículos dos basi-branquial 4:

[ZANATA, 2000: 79; NetTo-FerReira, 2006: 159 modificado]

[0] - ausentes. 
Chanos chanos, Catostomus commersonnii, olivaichthys mesembrinus, Gymnotus aff. carapo, Citharinus latus, Distichodus notospilus, Hemistichodus vaillanti, Neolebias unifasciatus, Nannocharax fasciatus, Xenocharax spilurus, Apareiodon piracicabae, Parodon nasus, Saccodon wagneri, Anodus orinocensis, Bivibranchia fowleri, Hemiodus unimaculatus, Curimata ocellata, Curimatopsis macrolepis, Potamorhina latior, Prochilodus nigricans, Semaprochilodus insignis, Caenotropus labyrinthicus, Chilodus punctatus, Anostomus anostomus, Leporellus vittatus, Leporinus fasciatus, Schizodon fasciatus, Carnegiella strigata, Gasteropelecus sternicla, Thoracocharax stellatus, Acestrorhynchus falcirostris, Gilbertolus atratoensis, Hydrolycus tatauaia, Roestes molossus, Erythrinoidea fam. nov, Boulengerella maculata, Ctenolucius hujeta, Copeina cf. guttata, Lebiasina bimaculata, Piabucina astrigata, Erythrinus erythrinus, Hoplias malabaricus, Hepsetus odoe, Arnoldichthys spilopterus, Brycinus macrolepidotus, Bryconalestes longipinnis, Chalceus epakros, Characidium bahiensis, Aphyocharax pusillus, Astyanax mexicanus, Atopomesus pachyodus, Axelrodia reisei, Brittanichthys axelrodi, Brycon pesu, Bryconadenos tanaothoros, Bryconamericus exodon, Bryconops alburnoides, Charax cf. leticiae, Clupeacharax cf. engrauloides, Compsura heterura, ctenobrycon hauxwellianus, Deuterodon iguape, Diapoma terofali, Galeocharax knerii, Glandulocauda melanogenys, Gnathocharax steindachneri, Gymnocorymbus ternetzi, Hemibrycon polyodon, Hemigrammus unilineatus, Hollandichthys multifasciatus, Hyphessobrycon compressus, Iguanodectes geisleri, Knodus meridae, Landonia latidens, Markiana nigripinnis, Metynnis lippincottianus, Microschemobrycon casiquiare, Moenkhausia xinguensis, Myleus setiger, odontostilbe pequira, oligosarcus argenteus, orthospinus franciscoensis, Paracheirodon axelrodi, Paragoniates alburnus, Phenacogaster pectinatus, Phenagoniates macrolepis, Piabina argentea, Piaractus mesopotamicus, Poptella brevispina, Probolus heterostomus, Rachoviscus graciliceps, Rhinobrycon negrensis, Rhoadsia altipinna, Roeboexodon guyanensis, Salminus hilarii, Serrabrycon magoi, Stygichthys typhlops, Tetragonopterus argenteus e Triportheus albus.

\section{[1] - presentes.}

Crenuchus spilurus e Agoniates halecinus.

206 - Faringo-branquial 1:

[NeTTO-FERREIRA, 2006: 153 modificado]

[0] - porção ventral, mais larga que dorsal.

Distichodus notospilus, Hemistichodus vaillanti, Neolebias unifasciatus, Nannocharax fasciatus, Xenocharax spilurus, Apareiodon piracicabae, Parodon nasus, Saccodon wagneri, Anodus orinocensis, Bivibranchia fowleri, Hemiodus unimaculatus, Curimata ocellata, Curimatopsis macrolepis, Potamorhina latior, Prochilodus nigricans, Semaprochilodus insignis, Chilodus punctatus, Gilbertolus atratoensis, Roestes molossus, Hepsetus odoe, Arnoldichthys spilopterus, Brycinus macrolepidotus, Bryconalestes longipinnis, Chalceus epakros, Characidium bahiensis, Crenuchus spilurus, Aphyocharax pusillus, Astyanax mexicanus, Atopomesus pachyodus, Axelrodia reisei, Brittanichthys axelrodi, Brycon pesu, Bryconadenos tanaothoros, Bryconamericus exodon, Bryconops alburnoides, Charax cf. leticiae, Clupeacharax cf. engrauloides, Compsura heterura, Ctenobrycon hauxwellianus, Deuterodon iguape, Diapoma terofali, Galeocharax knerii, Glandulocauda melanogenys, Gnathocharax steindachneri, Gymnocorymbus ternetzi, Hemibrycon polyodon, Hemigrammus unilineatus, Hollandichthys multifasciatus, Knodus meridae, Landonia latidens, Markiana nigripinnis, Metynnis lippincottianus, Microschemobrycon casiquiare, Moenkhausia xinguensis, Odontostilbe pequira, Oligosarcus argenteus, orthospinus franciscoensis, Paracheirodon axelrodi, Phenacogaster pectinatus, Phenagoniates macrolepis, Piabina argêntea, Poptella brevispina, Probolus heterostomus, Rachoviscus graciliceps, Rhinobrycon negrensis, Rhoadsia altipinna, Roeboexodon guyanensis, Salminus hilarii, Serrabrycon magoi, Stygichthys typhlops, Tetragonopterus argenteus e Triportheus albus.

\section{[1] - osso cilíndrico, aproximadamente com a mesma largura.}

Olivaichthys mesembrinus, Caenotropus labyrinthicus, Anostomus anostomus, Leporellus vittatus, Leporinus fasciatus, Schizodon fasciatus, Acestrorhynchus falcirostris, Hydrolycus tatauaia, Erythrinoidea fam. nov, Boulengerella maculata, Ctenolucius hujeta, Erythrinus erythrinus, Hoplias malabaricus, Agoniates halecinus, Hyphessobrycon compressus, Myleus setiger e Piaractus mesopotamicus.

[2] - osso arredondado.

Copeina cf. guttata, Lebiasina bimaculata e Piabucina astrigata.

$$
\text { [-] - inaplicável. }
$$


Chanos chanos, Catostomus commersonnii, Carnegiella strigata, Gasteropelecus sternicla e Thoracocharax stellatus.

\section{[?] - indeterminado.}

Gymnotus aff. carapo, Citharinus latus, Iguanodectes geisleri e Paragoniates alburnus.

207 - Faringobranquial 2:

[LuCENA, 1993: 72; NetTo-FerReira, 2006: 155]

\section{[0] - com dentes.}

Distichodus notospilus, Hemistichodus vaillanti, Neolebias unifasciatus, Hemiodus unimaculatus, Acestrorhynchus falcirostris, Hydrolycus tatauaia, Roestes molossus, Boulengerella maculata, Copeina cf. guttata, Lebiasina bimaculata, Piabucina astrigata, Erythrinus erythrinus, Hoplias malabaricus, Hepsetus odoe, Brycinus macrolepidotus, Chalceus epakros, Characidium bahiensis, Crenuchus spilurus, Agoniates halecinus, Aphyocharax pusillus, Brittanichthys axelrodi, Brycon pesu, Compsura heterura, Deuterodon iguape, Diapoma terofali, Galeocharax knerii, Hemibrycon polyodon Hollandichthys multifasciatus, Landonia latidens, Markiana nigripinnis, Metynnis lippincottianus, Microschemobrycon casiquiare, Moenkhausia xinguensis, Myleus setiger, odontostilbe pequira, Oligosarcus argenteus, orthospinus franciscoensis, Piabina argentea, Piaractus mesopotamicus, Poptella brevispina, Probolus heterostomus, Rhoadsia altipinna, Salminus hilarii, Tetragonopterus argenteus e Triportheus albus.

\section{[1] - sem dentes.}

Chanos chanos, Catostomus commersonnii, olivaichthys mesembrinus, Gymnotus aff. carapo, Citharinus latus, Nannocharax fasciatus, Xenocharax spilurus, Apareiodon piracicabae, Parodon nasus, Saccodon wagneri, Anodus orinocensis, Bivibranchia fowleri, Curimata ocellata, Curimatopsis macrolepis, Potamorhina latior, Prochilodus nigricans, Semaprochilodus insignis, Caenotropus labyrinthicus, Chilodus punctatus, Anostomus anostomus, Leporellus vittatus, Leporinus fasciatus, schizodon fasciatus, Carnegiella strigata, Gasteropelecus sternicla, Thoracocharax stellatus, Gilbertolus atratoensis, Erythrinoidea fam. nov, Ctenolucius hujeta, Arnoldichthys spilopterus, Bryconalestes longipinnis, Astyanax mexicanus, Atopomesus pachyodus, Axelrodia reisei, Bryconadenos tanaothoros, Bryconamericus exodon, Charax cf. leticiae, Clupeacharax cf. engrauloides, ctenobrycon hauxwellianus, Glandulocauda melanogenys, Gnathocharax steindachneri, Gymnocorymbus ternetzi, Hemigrammus unilineatus, Hyphessobrycon compressus, Iguanodectes geisleri, Knodus meridae, Paracheirodon axelrodi, Paragoniates alburnus, Phenacogaster pectinatus, Phenagoniates macrolepis, Rachoviscus graciliceps, Rhinobrycon negrensis, Roeboexodon guyanensis, Serrabrycon magoi e Stygichthys typhlops.

\section{[-] - inaplicável.}

Bryconops alburnoides.

208 - Faringobranquial 3:

[VARI \& HAROLD, 2001: 34; MoREIRA, 2002: 57]

\section{[0] - com dentes.}

Distichodus notospilus, Hemistichodus vaillanti, Neolebias unifasciatus, Nannocharax fasciatus, Xenocharax spilurus, Apareiodon piracicabae, Parodon nasus, Saccodon wagneri, Hemiodus unimaculatus, Acestrorhynchus falcirostris, Gilbertolus atratoensis, Hydrolycus tatauaia, Roestes molossus, Boulengerella maculata, Ctenolucius hujeta, Copeina cf. guttata, Lebiasina bimaculata, Piabucina astrigata, Erythrinus erythrinus, Hoplias malabaricus, Hepsetus odoe, Arnoldichthys spilopterus, Brycinus macrolepidotus, Bryconalestes longipinnis, Chalceus epakros, Characidium bahiensis, Crenuchus spilurus, Agoniates halecinus, Aphyocharax pusillus, Axelrodia reisei, Brittanichthys axelrodi, Brycon pesu, Bryconadenos tanaothoros, Bryconamericus exodon, Bryconops alburnoides, Charax cf. leticiae, Compsura heterura, Deuterodon iguape, Diapoma terofali, Galeocharax knerii, Glandulocauda melanogenys, Gymnocorymbus ternetzi, Hemibrycon polyodon, Hemigrammus unilineatus, Hollandichthys multifasciatus, Hyphessobrycon compressus, Knodus meridae, Landonia latidens, Markiana nigripinnis, Metynnis lippincottianus, Microschemobrycon casiquiare, Moenkhausia xinguensis, Myleus setiger, Odontostilbe pequira, oligosarcus argenteus, orthospinus franciscoensis, Paracheirodon axelrodi, Paragoniates alburnus, Phenacogaster pectinatus, Phenagoniates macrolepis, Piabina argentea, Piaractus mesopotamicus, Poptella brevispina, Probolus heterostomus , 
Rachoviscus graciliceps, Rhinobrycon negrensis, Rhoadsia altipinna, Roeboexodon guyanensis, Salminus hilarii, Serrabrycon magoi, Tetragonopterus argenteus e Triportheus albus.

\section{[1] - sem dentes.}

Chanos chanos, Catostomus commersonnii, olivaichthys mesembrinus, Gymnotus aff. carapo, Citharinus latus, Anodus orinocensis, Bivibranchia fowleri, Curimata ocellata, Curimatopsis macrolepis, Potamorhina latior, Prochilodus nigricans, Semaprochilodus insignis, Caenotropus labyrinthicus, Chilodus punctatus, Anostomus anostomus, Leporellus vittatus, Leporinus fasciatus, Schizodon fasciatus, Carnegiella strigata, Gasteropelecus sternicla, Thoracocharax stellatus, Erythrinoidea fam. nov, Astyanax mexicanus, Atopomesus pachyodus, clupeacharax' cf. engrauloides, ctenobrycon hauxwellianus, Gnathocharax steindachneri, Iguanodectes geisleri e Stygichthys typhlops.

\section{9 - Placas dorsais faríngeas 4 e 5 : \\ [VARI, 1979: 27; VARI, 1983: 1]}

\section{[0] - separadas.}

Curimata ocellata, Curimatopsis macrolepis, Potamorhina latior, Prochilodus nigricans, Semaprochilodus insignis, Caenotropus labyrinthicus, Chilodus punctatus, Anostomus anostomus, Leporellus vittatus, Leporinus fasciatus, schizodon fasciatus, Carnegiella strigata, Gasteropelecus sternicla, Thoracocharax stellatus e Acestrorhynchus falcirostris.

\section{[1] - com contato.}

Citharinus latus, Distichodus notospilus, Hemistichodus vaillanti, Neolebias unifasciatus, Nannocharax fasciatus, Xenocharax spilurus, Apareiodon piracicabae, Parodon nasus, Saccodon wagneri, Anodus orinocensis, Bivibranchia fowleri, Hemiodus unimaculatus, Gilbertolus atratoensis, Hydrolycus tatauaia, Roestes molossus, Boulengerella maculata, Ctenolucius hujeta, Copeina cf. guttata, Lebiasina bimaculata, Piabucina astrigata, Erythrinus erythrinus, Hoplias malabaricus, Hepsetus odoe, Arnoldichthys spilopterus, Brycinus macrolepidotus, Bryconalestes longipinnis, Chalceus epakros, Characidium bahiensis, Crenuchus spilurus, Agoniates halecinus, Aphyocharax pusillus, Astyanax mexicanus, Atopomesus pachyodus, Axelrodia reisei, Brittanichthys axelrodi, Brycon pesu, Bryconadenos tanaothoros, Bryconamericus exodon, Bryconops alburnoides, Charax cf. leticiae, Clupeacharax cf. engrauloides, compsura heterura, Ctenobrycon hauxwellianus, Deuterodon iguape, Diapoma terofali, Galeocharax knerii, Glandulocauda melanogenys, Gnathocharax steindachneri, Gymnocorymbus ternetzi, Hemibrycon polyodon, Hemigrammus unilineatus, Hollandichthys multifasciatus, Hyphessobrycon compressus, Iguanodectes geisleri, Knodus meridae, Landonia latidens, Markiana nigripinnis, Metynnis lippincottianus, Microschemobrycon casiquiare, Moenkhausia xinguensis, Myleus setiger, Odontostilbe pequira, oligosarcus argenteus, orthospinus franciscoensis, Paracheirodon axelrodi, Paragoniates alburnus, Phenacogaster pectinatus, Phenagoniates macrolepis, Piabina argentea, Piaractus mesopotamicus, Poptella brevispina, Probolus heterostomus, Rachoviscus graciliceps, Rhinobrycon negrensis, Rhoadsia altipinna, Roeboexodon guyanensis, Salminus hilarii, Serrabrycon magoi, Stygichthys typhlops, Tetragonopterus argenteus e Triportheus albus.

\section{[-] - inaplicável.}

Chanos chanos e Catostomus commersonnii.

\section{[?] - indeterminado.}

olivaichthys mesembrinus, Gymnotus aff. carapo e Erythrinoidea fam. nov.

\section{0 - Dentição na placa dorsal faríngea 4: \\ [VARI, 1983: 2]}

\section{[0] - ausente.}

Chanos chanos, Catostomus commersonnii, Citharinus latus, Nannocharax fasciatus, Anodus orinocensis, Curimata ocellata, Curimatopsis macrolepis, Potamorhina latior, Prochilodus nigricans, Semaprochilodus insignis, Caenotropus labyrinthicus, Chilodus punctatus, Anostomus anostomus, Leporellus vittatus, Leporinus fasciatus e Schizodon fasciatus.

\section{[1] - presente.}


Olivaichthys mesembrinus, Gymnotus aff. carapo, Distichodus notospilus, Hemistichodus vaillanti, Neolebias unifasciatus, Xenocharax spilurus, Apareiodon piracicabae, Parodon nasus, Saccodon wagneri, Bivibranchia fowleri, Hemiodus unimaculatus, Carnegiella strigata, Gasteropelecus sternicla, Thoracocharax stellatus, Acestrorhynchus falcirostris, Gilbertolus atratoensis, Hydrolycus tatauaia, Roestes molossus, Erythrinoidea fam. nov, Boulengerella maculata, Ctenolucius hujeta, Copeina cf. guttata, Lebiasina bimaculata, Piabucina astrigata, Erythrinus erythrinus, Hoplias malabaricus, Hepsetus odoe, Arnoldichthys spilopterus, Brycinus macrolepidotus, Bryconalestes longipinnis, Chalceus epakros, Characidium bahiensis, Crenuchus spilurus, Agoniates halecinus, Aphyocharax pusillus, Astyanax mexicanus, Atopomesus pachyodus, Axelrodia reisei, Brittanichthys axelrodi, Brycon pesu, Bryconadenos tanaothoros, Bryconamericus exodon, Bryconops alburnoides, Charax cf. leticiae, clupeacharax cf. engrauloides, Compsura heterura, Ctenobrycon hauxwellianus, Deuterodon iguape, Diapoma terofali, Galeocharax knerii, Glandulocauda melanogenys, Gnathocharax steindachneri, Gymnocorymbus ternetzi, Hemibrycon polyodon, Hemigrammus unilineatus, Hollandichthys multifasciatus, Hyphessobrycon compressus, Iguanodectes geisleri, Knodus meridae, Landonia latidens, Markiana nigripinnis, Metynnis lippincottianus, Microschemobrycon casiquiare, Moenkhausia xinguensis, Myleus setiger, odontostilbe pequira, oligosarcus argenteus, orthospinus franciscoensis, Paracheirodon axelrodi, Paragoniates alburnus, Phenacogaster pectinatus, Phenagoniates macrolepis, Piabina argentea, Piaractus mesopotamicus, Poptella brevispina, Probolus heterostomus, Rachoviscus graciliceps, Rhinobrycon negrensis, Rhoadsia altipinna, Roeboexodon guyanensis, Salminus hilarii, Serrabrycon magoi, Stygichthys typhlops, Tetragonopterus argenteus e Triportheus albus.

\section{1 - Rastros no cerato-branquial 1:}

\section{[0] - ausentes.}

Gymnotus aff. carapo, Citharinus latus, Hemiodus unimaculatus, Curimatopsis macrolepis, Potamorhina latior e Anostomus anostomus.

\section{[1] - com uma fileira na margem lateral.}

Carnegiella strigata, Gasteropelecus sternicla, Thoracocharax stellatus , Acestrorhynchus falcirostris, Gilbertolus atratoensis, Erythrinoidea fam. nov,
Boulengerella maculata, ctenolucius hujeta, Arnoldichthys spilopterus, Brycinus macrolepidotus, Bryconalestes longipinnis, chalceus epakros, characidium bahiensis, Crenuchus spilurus, Agoniates halecinus, Aphyocharax pusillus, Astyanax mexicanus, Atopomesus pachyodus, Axelrodia reisei, Brittanichthys axelrodi, Brycon pesu, Bryconadenos tanaothoros, Bryconamericus exodon, Bryconops alburnoides, Charax cf. leticiae, Clupeacharax cf. engrauloides, compsura heterura, ctenobrycon hauxwellianus, Deuterodon iguape, Diapoma terofali, Galeocharax knerii, Glandulocauda melanogenys, Gnathocharax steindachneri, Gymnocorymbus ternetzi, Hemibrycon polyodon, Hemigrammus unilineatus, Hollandichthys multifasciatus, Hyphessobrycon compressus, Landonia latidens, Markiana nigripinnis, Metynnis lippincottianus, Microschemobrycon casiquiare, Moenkhausia xinguensis, Odontostilbe pequira, oligosarcus argenteus, orthospinus franciscoensis, Paracheirodon axelrodi, Paragoniates alburnus, Phenacogaster pectinatus, Phenagoniates macrolepis, Piabina argentea, Piaractus mesopotamicus, Poptella brevispina, Probolus heterostomus, Rachoviscus graciliceps, Rhinobrycon negrensis, Rhoadsia altipinna, Roeboexodon guyanensis, Salminus hilarii, Serrabrycon magoi, Stygichthys typhlops, Tetragonopterus argenteus e Triportheus albus.

\section{[2] - com duas fileiras, nas faces lateral e medial.}

Chanos chanos, Catostomus commersonnii, olivaichthys mesembrinus, Distichodus notospilus, Hemistichodus vaillanti, Neolebias unifasciatus, Nannocharax fasciatus, Xenocharax spilurus, Apareiodon piracicabae, Parodon nasus, Saccodon wagneri, Anodus orinocensis, Bivibranchia fowleri, Curimata ocellata, Leporellus vittatus, Leporinus fasciatus, Schizodon fasciatus, Hydrolycus tatauaia, Roestes molossus, Copeina cf. guttata, Lebiasina bimaculata, Piabucina astrigata, Erythrinus erythrinus, Hoplias malabaricus, Hepsetus odoe, Iguanodectes geisleri, Knodus meridae e Myleus setiger.

\section{[?] - indeterminado.}

Prochilodus nigricans, Semaprochilodus insignis, Caenotropus labyrinthicus e chilodus punctatus.

212 - Cerato-branquial 5:

[ZANATA, 200: 80 modificado; MOREIRA, 2002: 58 modificado] 


\section{[0] - placa continua com o ceratobranquial.}

Chanos chanos, Catostomus commersonnii, olivaichthys mesembrinus, Hydrolycus tatauaia, Hoplias malabaricus, Arnoldichthys spilopterus, Bryconalestes longipinnis, Chalceus epakros, Ctenobrycon hauxwellianus e Hemigrammus unilineatus.

\section{[1] - margem posterior aproximadamente reta.}

Distichodus notospilus, Hemistichodus vaillanti, Neolebias unifasciatus, Xenocharax spilurus, Saccodon wagneri, Anodus orinocensis, Bivibranchia fowleri, Caenotropus labyrinthicus, Chilodus punctatus, Anostomus anostomus, Leporellus vittatus, Leporinus fasciatus, Schizodon fasciatus, Roestes molossus, Erythrinoidea fam. nov, Copeina cf. guttata, Lebiasina bimaculata, Piabucina astrigata, Erythrinus erythrinus, Hepsetus odoe, Brycinus macrolepidotus, Crenuchus spilurus, Aphyocharax pusillus, Astyanax mexicanus, Axelrodia reisei, Brittanichthys axelrodi, Bryconadenos tanaothoros, Bryconops alburnoides, Charax cf. leticiae, Clupeacharax cf. engrauloides, Compsura heterura, Deuterodon iguape, Diapoma terofali, Galeocharax knerii, Glandulocauda melanogenys, Gnathocharax steindachneri, Gymnocorymbus ternetzi, Hemibrycon polyodon, Hollandichthys multifasciatus, Hyphessobrycon compressus, Knodus meridae, Landonia latidens, Markiana nigripinnis, Moenkhausia xinguensis, Odontostilbe pequira, Orthospinus franciscoensis, Paracheirodon axelrodi, Paragoniates alburnus, Phenacogaster pectinatus, Phenagoniates macrolepis, Probolus heterostomus, Rachoviscus graciliceps, Rhoadsia altipinna, Roeboexodon guyanensis, Salminus hilarii, Serrabrycon magoi, Stygichthys typhlops e Triportheus albus.

\section{[2] - reentrância posterior entre a placa e o ceratobranquial.}

Gymnotus aff. carapo, Citharinus latus, Nannocharax fasciatus, Apareiodon piracicabae, Parodon nasus, Hemiodus unimaculatus, Curimata ocellata, Curimatopsis macrolepis, Potamorhina latior, Prochilodus nigricans, Semaprochilodus insignis, Carnegiella strigata, Gasteropelecus sternicla, Thoracocharax stellatus, Acestrorhynchus falcirostris, Gilbertolus atratoensis, Boulengerella maculata, Ctenolucius hujeta, Characidium bahiensis, Agoniates halecinus, Atopomesus pachyodus, Brycon pesu, Bryconamericus exodon, Iguanodectes geisleri, Metynnis lippincottianus, Microschemobrycon casiquiare, Myleus setiger, Oligosarcus argenteus, Piabina argentea, Piaractus mesopotamicus, Poptella brevispina, Rhinobrycon negrensis e Tetragonopterus argenteus.

213 - Dentição no cerato-branquial 5:

[VARI, 1983: 11]

\section{[0] - ausente ou reduzida.}

Chanos chanos, Citharinus latus, Anodus orinocensis, Curimata ocellata, Curimatopsis macrolepis, Potamorhina latior, Prochilodus nigricans e Semaprochilodus insignis.

\section{[1] - desenvolvida.}

Catostomus commersonnii, Olivaichthys mesembrinus, Gymnotus aff. carapo, Distichodus notospilus, Hemistichodus vaillanti, Neolebias unifasciatus, Nannocharax fasciatus, Xenocharax spilurus, Apareiodon piracicabae, Parodon nasus, Saccodon wagneri, Bivibranchia fowleri, Hemiodus unimaculatus, Caenotropus labyrinthicus, Chilodus punctatus, Anostomus anostomus, Leporellus vittatus, Leporinus fasciatus, Schizodon fasciatus, Carnegiella strigata, Gasteropelecus sternicla, Thoracocharax stellatus, Acestrorhynchus falcirostris, Gilbertolus atratoensis, Hydrolycus tatauaia, Roestes molossus, Erythrinoidea fam. nov, Boulengerella maculata, Ctenolucius hujeta, Copeina cf. guttata, Lebiasina bimaculata, Piabucina astrigata, Erythrinus erythrinus, Hoplias malabaricus, Hepsetus odoe, Arnoldichthys spilopterus, Brycinus macrolepidotus, Bryconalestes longipinnis, Chalceus epakros, Characidium bahiensis, Crenuchus spilurus, Agoniates halecinus, Aphyocharax pusillus, Astyanax mexicanus, Atopomesus pachyodus, Axelrodia reisei, Brittanichthys axelrodi, Brycon pesu, Bryconadenos tanaothoros, Bryconamericus exodon, Bryconops alburnoides, Charax cf. leticiae, Clupeacharax cf. engrauloides, Compsura heterura, Ctenobrycon hauxwellianus, Deuterodon iguape, Diapoma terofali, Galeocharax knerii, Glandulocauda melanogenys, Gnathocharax steindachneri, Gymnocorymbus ternetzi, Hemibrycon polyodon, Hemigrammus unilineatus, Hollandichthys multifasciatus, Hyphessobrycon compressus, Iguanodectes geisleri, Knodus meridae, Landonia latidens, Markiana nigripinnis, Metynnis lippincottianus, Microschemobrycon casiquiare, Moenkhausia xinguensis, Myleus setiger, Odontostilbe pequira, oligosarcus argenteus, orthospinus franciscoensis, Paracheirodon axelrodi, Paragoniates alburnus, Phenacogaster pectinatus, Phenagoniates macrolepis, Piabina argentea, Piaractus 
mesopotamicus, Poptella brevispina, Probolus heterostomus, Rachoviscus graciliceps, Rhinobrycon negrensis, Rhoadsia altipinna, Roeboexodon guyanensis, Salminus hilarii, Serrabrycon magoi, Stygichthys typhlops, Tetragonopterus argenteus e Triportheus albus.

\section{4 - Série principal de rastros branquiais do cerato-branquial 4: [VARI, 1995: 63 modificado; NETTO-FERREIRA, 2006: 160 modificado]}

\section{[0] - alongado.}

Chanos chanos, Olivaichthys mesembrinus, Distichodus notospilus, Hemistichodus vaillanti, Neolebias unifasciatus, Nannocharax fasciatus, Xenocharax spilurus, Anodus orinocensis, Curimata ocellata, Leporellus vittatus Leporinus fasciatus, Schizodon fasciatus, Carnegiella strigata, Gasteropelecus sternicla, Thoracocharax stellatus, Gilbertolus atratoensis, Erythrinoidea fam. nov, Ctenolucius hujeta, copeina cf.' guttata, Lebiasina bimaculata, Piabucina astrigata, Arnoldichthys spilopterus, Brycinus macrolepidotus, Bryconalestes longipinnis, Characidium bahiensis, Crenuchus spilurus, Aphyocharax pusillus, Astyanax mexicanus, Atopomesus pachyodus, Axelrodia reisei, Brittanichthys axelrodi, Brycon pesu, Bryconadenos tanaothoros, Bryconamericus exodon, Bryconops alburnoides, Charax cf. leticiae, Clupeacharax cf. engrauloides, Compsura heterura, Ctenobrycon hauxwellianus, Deuterodon iguape, Diapoma terofali, Glandulocauda melanogenys, Gnathocharax steindachneri, Gymnocorymbus ternetzi, Hemibrycon polyodon Hemigrammus unilineatus, Hollandichthys multifasciatus, Hyphessobrycon compressus, Iguanodectes geisleri, Knodus meridae, Landonia latidens, Markiana nigripinnis, Metynnis lippincottianus, Microschemobrycon casiquiare, Moenkhausia xinguensis, Myleus setiger, odontostilbe pequira, oligosarcus argenteus, Orthospinus franciscoensis, Paracheirodon axelrodi, Paragoniates alburnus, Phenacogaster pectinatus, Phenagoniates macrolepis, Piabina argentea, Piaractus mesopotamicus, Poptella brevispina, Probolus heterostomus, Rachoviscus graciliceps, Rhinobrycon negrensis, Rhoadsia altipinna, Roeboexodon guyanensis, Salminus hilarii, Serrabrycon magoi, Stygichthys typhlops e Tetragonopterus argenteus.

\section{[1] - em placa.}

Acestrorhynchus falcirostris, Hydrolycus tatauaia, Roestes molossus, Boulengerella maculata, Erythrinus erythrinus, Hoplias malabaricus, Hepsetus odoe, Chalceus epakros, Agoniates halecinus, Galeocharax knerii e Triportheus albus.

\section{[2] - em leque.}

Catostomus commersonnii, Apareiodon piracicabae, Parodon nasus, Saccodon wagneri e Hemiodus unimaculatus.

\section{[-] - inaplicável.}

Gymnotus aff. carapo, Citharinus latus, Bivibranchia fowleri, Curimatopsis macrolepis, Potamorhina latior, Prochilodus nigricans, Semaprochilodus insignis e Anostomus anostomus.

[?] - indeterminado.

Caenotropus labyrinthicus e Chilodus punctatus.

215 - Porção proximal dos rastros branquiais do cerato-branquial 1: [OYAKAWA, 1998: 55; NETTO-FERREIRA, 2006: 161]

\section{[0] - com espinhos.}

Distichodus notospilus, Carnegiella strigata, Gasteropelecus sternicla, Thoracocharax stellatus, Acestrorhynchus falcirostris, Hydrolycus tatauaia, Roestes molossus, Erythrinus erythrinus, Hoplias malabaricus, Hepsetus odoe, Chalceus epakros, Agoniates halecinus, Aphyocharax pusillus, Astyanax mexicanus, Brittanichthys axelrodi, Brycon pesu, Bryconops alburnoides, Charax cf. leticiae, Ctenobrycon hauxwellianus, Deuterodon iguape, Galeocharax knerii, Gnathocharax steindachneri, Hollandichthys multifasciatus, Hyphessobrycon compressus, Moenkhausia xinguensis, odontostilbe pequira, oligosarcus argenteus, Orthospinus franciscoensis, Paragoniates alburnus, Phenacogaster pectinatus, Piaractus mesopotamicus, Poptella brevispina, Probolus heterostomus, Roeboexodon guyanensis, Salminus hilarii, Serrabrycon magoi e Tetragonopterus argenteus. 


\section{[1] - sem espinhos.}

Chanos chanos, Catostomus commersonnii, Olivaichthys mesembrinus, Hemistichodus vaillanti, Neolebias unifasciatus, Nannocharax fasciatus, Xenocharax spilurus, Apareiodon piracicabae, Parodon nasus, Saccodon wagneri, Anodus orinocensis, Hemiodus unimaculatus, Curimata ocellata, Leporellus vittatus, Leporinus fasciatus, Schizodon fasciatus, Gilbertolus atratoensis, Erythrinoidea fam. nov, Boulengerella maculata, Ctenolucius hujeta, Copeina cf. guttata, Lebiasina bimaculata, Piabucina astrigata, Arnoldichthys spilopterus, Brycinus macrolepidotus, Bryconalestes longipinnis, Characidium bahiensis, Crenuchus spilurus, Atopomesus pachyodus, Axelrodia reisei, Bryconadenos tanaothoros, Bryconamericus exodon, Clupeacharax cf. engrauloides, Compsura heterura, Diapoma terofali, Glandulocauda melanogenys, Gymnocorymbus ternetzi, Hemibrycon polyodon, Hemigrammus unilineatus, Iguanodectes geisleri, Knodus meridae, Landonia latidens, Markiana nigripinnis, Metynnis lippincottianus, Microschemobrycon casiquiare, Myleus setiger, Paracheirodon axelrodi, Phenagoniates macrolepis, Piabina argentea, Rachoviscus graciliceps, Rhinobrycon negrensis, Rhoadsia altipinna, Stygichthys typhlops e Triportheus albus.

\section{[-] - inaplicável.}

Gymnotus aff. carapo, Citharinus latus,Bivibranchia fowleri, Curimatopsis macrolepis, Potamorhina latior, Prochilodus nigricans, Semaprochilodus insignis, Caenotropus labyrinthicus, Chilodus punctatus e Anostomus anostomus.

\section{6 - Porção distal dos rastros branquiais do cerato-branquial 1:} [OYAKAWA, 1998: 56; NeTTO-FERREIRA, 2006: 162]

\section{[0] - com espinhos.}

Apareiodon piracicabae, Parodon nasus, Saccodon wagneri, Anodus orinocensis, Hemiodus unimaculatus, Curimata ocellata, Acestrorhynchus falcirostris, Gilbertolus atratoensis, Hydrolycus tatauaia, Roestes molossus, Erythrinus erythrinus, Hoplias malabaricus, Chalceus epakros, Agoniates halecinus, Aphyocharax pusillus, Astyanax mexicanus, Brittanichthys axelrodi, Brycon pesu, Bryconops alburnoides, Charax cf. leticiae, Galeocharax knerii, Gnathocharax steindachneri, Gymnocorymbus ternetzi, Hollandichthys multifasciatus, Hyphessobrycon compressus, Moenkhausia xinguensis, Oligosarcus argenteus, Orthospinus franciscoensis, Paragoniates alburnus, Phenacogaster pectinatus, Poptella brevispina, Probolus heterostomus, Roeboexodon guyanensis, Salminus hilarii, Serrabrycon magoi e Tetragonopterus argenteus.

\section{[1] - sem espinhos.}

Chanos chanos, Catostomus commersonnii, olivaichthys mesembrinus, Distichodus notospilus, Hemistichodus vaillanti, Neolebias unifasciatus, Nannocharax fasciatus, Xenocharax spilurus, Leporellus vittatus, Leporinus fasciatus, Schizodon fasciatus, Carnegiella strigata, Gasteropelecus sternicla, Thoracocharax stellatus, Erythrinoidea fam. nov, Boulengerella maculata, Ctenolucius hujeta, Copeina cf. guttata, Lebiasina bimaculata, Piabucina astrigata, Hepsetus odoe, Arnoldichthys spilopterus, Brycinus macrolepidotus, Bryconalestes longipinnis, Characidium bahiensis, Crenuchus spilurus, Atopomesus pachyodus, Axelrodia reisei, Bryconadenos tanaothoros, Bryconamericus exodon, Clupeacharax cf. engrauloides, Compsura heterura, Ctenobrycon hauxwellianus, Deuterodon iguape, Diapoma terofali, Glandulocauda melanogenys, Hemibrycon polyodon, Hemigrammus unilineatus, Iguanodectes geisleri, Knodus meridae, Landonia latidens, Markiana nigripinnis, Metynnis lippincottianus, Microschemobrycon casiquiare, Myleus setiger, odontostilbe pequira, Paracheirodon axelrodi, Phenagoniates macrolepis, Piabina argentea, Piaractus mesopotamicus, Rachoviscus graciliceps, Rhinobrycon negrensis, Rhoadsia altipinna, Stygichthys typhlops e Triportheus albus.

\section{[-] - inaplicável.}

Gymnotus aff. carapo, Citharinus latus, Bivibranchia fowleri, Curimatopsis macrolepis, Potamorhina latior, Prochilodus nigricans, Semaprochilodus insignis, Caenotropus labyrinthicus, Chilodus punctatus e Anostomus anostomus.

217 - Rastros da margem anterior do cerato-branquial 1: [TOLEDO-PIZA, 2000: 38 modificado]

[0] - todos alongados. 
Chanos chanos, Olivaichthys mesembrinus, Distichodus notospilus, Hemistichodus vaillanti, Neolebias unifasciatus, Nannocharax fasciatus, Xenocharax spilurus, Anodus orinocensis, Curimata ocellata, Anostomus anostomus, Leporellus vittatus, Leporinus fasciatus, Schizodon fasciatus, Carnegiella strigata, Gasteropelecus sternicla, Thoracocharax stellatus, Gilbertolus atratoensis, Roestes molossus, Erythrinoidea fam. nov, Copeina cf. guttata, Lebiasina bimaculata, Piabucina astrigata, Arnoldichthys spilopterus, Brycinus macrolepidotus, Bryconalestes longipinnis, Chalceus epakros, characidium bahiensis, Crenuchus spilurus, Aphyocharax pusillus, Astyanax mexicanus, Atopomesus pachyodus, Axelrodia reisei, Brittanichthys axelrodi, Brycon pesu, Bryconadenos tanaothoros, Bryconamericus exodon, Bryconops alburnoides, Charax cf. leticiae, Clupeacharax cf. engrauloides, compsura heterura, ctenobrycon hauxwellianus, Deuterodon iguape, Diapoma terofali, Glandulocauda melanogenys, Gnathocharax steindachneri, Gymnocorymbus ternetzi, Hemibrycon polyodon, Hemigrammus unilineatus, Hollandichthys multifasciatus, Hyphessobrycon compressus, Iguanodectes geisleri, Knodus meridae, Landonia latidens, Markiana nigripinnis, Metynnis lippincottianus, Microschemobrycon casiquiare, Moenkhausia xinguensis, Myleus setiger, odontostilbe pequira, oligosarcus argenteus, orthospinus franciscoensis, Paracheirodon axelrodi, Paragoniates alburnus, Phenacogaster pectinatus, Phenagoniates macrolepis, Piabina argentea, Piaractus mesopotamicus, Poptella brevispina, Probolus heterostomus , Rachoviscus graciliceps, Rhinobrycon negrensis, Rhoadsia altipinna, Roeboexodon guyanensis, Serrabrycon magoi, Stygichthys typhlops, Tetragonopterus argenteus e Triportheus albus.

\title{
[1] - anteriores em forma de pequenas placas.
}

Hydrolycus tatauaia, Boulengerella maculata, Ctenolucius hujeta, Erythrinus erythrinus, Hoplias malabaricus, Hepsetus odoe, Agoniates halecinus, Galeocharax knerii e Salminus hilarii.

\section{[2] - todos em forma de pequenas placas.}

Acestrorhynchus falcirostris.

\section{[3] - em leque}

Catostomus commersonnii, Apareiodon piracicabae, Parodon nasus, Saccodon wagneri e Hemiodus unimaculatus.

\section{[-] - inaplicável.}

Gymnotus aff. carapo,Citharinus latus, Bivibranchia fowleri, Curimatopsis macrolepis, Potamorhina latior, Prochilodus nigricans e Semaprochilodus insignis.

\section{[?] - indeterminado.}

Caenotropus labyrinthicus e Chilodus punctatus.

\author{
218 - Dentes faríngeos: \\ [VARI, 1983: 46]
}

\section{[0] - unicúspides.}

Olivaichthys mesembrinus, Gymnotus aff. carapo, Distichodus notospilus, Hemistichodus vaillanti, Neolebias unifasciatus, Nannocharax fasciatus, Xenocharax spilurus, Apareiodon piracicabae, Parodon nasus, Saccodon wagneri, Anodus orinocensis, Hemiodus unimaculatus, Prochilodus nigricans, Semaprochilodus insignis, Carnegiella strigata, Gasteropelecus sternicla, Thoracocharax stellatus, Acestrorhynchus falcirostris, Gilbertolus atratoensis, Hydrolycus tatauaia, Roestes molossus, Erythrinoidea fam. nov, Boulengerella maculata, ctenolucius hujeta, Copeina cf. guttata, Lebiasina bimaculata, Piabucina astrigata, Erythrinus erythrinus, Hoplias malabaricus, Hepsetus odoe, Arnoldichthys spilopterus, Brycinus macrolepidotus, Bryconalestes longipinnis, Chalceus epakros, Characidium bahiensis, Crenuchus spilurus, Agoniates halecinus, Aphyocharax pusillus, Astyanax mexicanus, Atopomesus pachyodus, Axelrodia reisei, Brittanichthys axelrodi, Brycon pesu, Bryconadenos tanaothoros, Bryconamericus exodon, Bryconops alburnoides, Charax cf. leticiae, Clupeacharax cf. engrauloides, Compsura heterura, ctenobrycon hauxwellianus, Deuterodon iguape, Diapoma terofali, Galeocharax knerii, Glandulocauda melanogenys, Gnathocharax steindachneri, Gymnocorymbus ternetzi, Hemibrycon polyodon, Hemigrammus unilineatus, Hollandichthys multifasciatus, Hyphessobrycon compressus, Iguanodectes geisleri, Knodus meridae, Landonia latidens, Markiana nigripinnis, Metynnis lippincottianus, Microschemobrycon casiquiare, Moenkhausia xinguensis, Myleus setiger, odontostilbe pequira, oligosarcus argenteus, 
orthospinus franciscoensis, Paracheirodon axelrodi, Paragoniates alburnus, Phenacogaster pectinatus, Phenagoniates macrolepis, Piabina argentea, Piaractus mesopotamicus, Poptella brevispina, Probolus heterostomus, Rachoviscus graciliceps, Rhinobrycon negrensis, Rhoadsia altipinna, Roeboexodon guyanensis, Salminus hilarii, Serrabrycon magoi, Stygichthys typhlops, Tetragonopterus argenteus e Triportheus albus.

\section{[1] - com duas ou mais cúspides.}

Catostomus commersonnii, Bivibranchia fowleri, Caenotropus labyrinthicus, Chilodus punctatus, Anostomus anostomus, Leporellus vittatus, Leporinus fasciatus e Schizodon fasciatus.

\section{[-] - inaplicável.}

Chanos chanos, Citharinus latus, Curimata ocellata, Curimatopsis macrolepis e Potamorhina latior.

219 - Orgão epibranquial:

[FINK \& FINK, 1981: 46; VARI, 1979: 31; VARI, 1983: 7]

\section{[0] - ausente.}

Catostomus commersonnii, Olivaichthys mesembrinus, Gymnotus aff. carapo, Distichodus notospilus, Hemistichodus vaillanti, Neolebias unifasciatus, Nannocharax fasciatus, Xenocharax spilurus, Apareiodon piracicabae, Parodon nasus, Saccodon wagneri, Anodus orinocensis, Bivibranchia fowleri, Hemiodus unimaculatus, Anostomus anostomus, Leporellus vittatus, Leporinus fasciatus, Schizodon fasciatus, Carnegiella strigata, Gasteropelecus sternicla, Thoracocharax stellatus, Acestrorhynchus falcirostris, Gilbertolus atratoensis, Hydrolycus tatauaia, Roestes molossus, Erythrinoidea fam. nov, Boulengerella maculata, Ctenolucius hujeta, Copeina cf. guttata, Lebiasina bimaculata, Piabucina astrigata, Erythrinus erythrinus, Hoplias malabaricus, Hepsetus odoe, Arnoldichthys spilopterus, Brycinus macrolepidotus, Bryconalestes longipinnis, Chalceus epakros, Characidium bahiensis, Crenuchus spilurus, Agoniates halecinus, Aphyocharax pusillus, Astyanax mexicanus, Atopomesus pachyodus, Axelrodia reisei, Brittanichthys axelrodi, Brycon pesu, Bryconadenos tanaothoros, Bryconamericus exodon, Bryconops alburnoides, Charax cf. leticiae, Clupeacharax cf. engrauloides, Compsura heterura, Ctenobrycon hauxwellianus, Deuterodon iguape, Diapoma terofali, Galeocharax knerii, Glandulocauda melanogenys, Gnathocharax steindachneri, Gymnocorymbus ternetzi, Hemibrycon polyodon, Hemigrammus unilineatus, Hollandichthys multifasciatus, Hyphessobrycon compressus, Iguanodectes geisleri, Knodus meridae, Landonia latidens, Markiana nigripinnis, Metynnis lippincottianus, Microschemobrycon casiquiare, Moenkhausia xinguensis, Myleus setiger, Odontostilbe pequira, Oligosarcus argenteus, Orthospinus franciscoensis, Paracheirodon axelrodi, Paragoniates alburnus, Phenacogaster pectinatus, Phenagoniates macrolepis, Piabina argentea, Piaractus mesopotamicus, Poptella brevispina, probolus heterostomus, Rachoviscus graciliceps, Rhinobrycon negrensis, Rhoadsia altipinna, Roeboexodon guyanensis, Salminus hilarii, Serrabrycon magoi, Stygichthys typhlops, Tetragonopterus argenteus e Triportheus albus.

\section{[1] - presente.}

Chanos chanos, Citharinus latus, Curimata ocellata, Curimatopsis macrolepis, Potamorhina latior, Prochilodus nigricans, Semaprochilodus insignis, Caenotropus labyrinthicus e chilodus punctatus.

\section{0 - Microbranquiespinhos: \\ [VARI, 1979: 30]}

\section{[0] - ausentes.}

Chanos chanos, Catostomus commersonnii, olivaichthys mesembrinus, Gymnotus aff. carapo, Distichodus notospilus, Hemistichodus vaillanti, Neolebias unifasciatus, Nannocharax fasciatus, Xenocharax spilurus, Apareiodon piracicabae, Parodon nasus, Saccodon wagneri, Anodus orinocensis, Caenotropus labyrinthicus, Chilodus punctatus, Anostomus anostomus, Leporellus vittatus, Leporinus fasciatus, Schizodon fasciatus, Carnegiella strigata, Gasteropelecus sternicla, Thoracocharax stellatus, Acestrorhynchus falcirostris, Gilbertolus atratoensis, Hydrolycus tatauaia, Roestes molossus, Erythrinoidea fam. nov, Boulengerella maculata, Ctenolucius hujeta, Copeina cf. guttata, Lebiasina bimaculata, Piabucina astrigata, Erythrinus erythrinus, Hoplias malabaricus, Hepsetus odoe, Arnoldichthys spilopterus, Brycinus macrolepidotus, Bryconalestes longipinnis, Chalceus 
epakros, Characidium bahiensis, Crenuchus spilurus, Agoniates halecinus, Aphyocharax pusillus, Astyanax mexicanus, Atopomesus pachyodus, Axelrodia reisei, Brittanichthys axelrodi, Brycon pesu, Bryconadenos tanaothoros, Bryconamericus exodon, Bryconops alburnoides, Charax cf. leticiae, Clupeacharax cf. engrauloides, Compsura heterura, Ctenobrycon hauxwellianus, Deuterodon iguape, Diapoma terofali, Galeocharax knerii, Glandulocauda melanogenys, Gnathocharax steindachneri, Gymnocorymbus ternetzi, Hemibrycon polyodon, Hemigrammus unilineatus, Hollandichthys multifasciatus, Hyphessobrycon compressus, Iguanodectes geisleri, Knodus meridae, Landonia latidens, Markiana nigripinnis, Metynnis lippincottianus, Microschemobrycon casiquiare Moenkhausia xinguensis, Myleus setiger, Odontostilbe pequira, oligosarcus argenteus, orthospinus franciscoensis, Paracheirodon axelrodi, Paragoniates alburnus, Phenacogaster pectinatus, Phenagoniates macrolepis, Piabina argentea, Piaractus mesopotamicus, Poptella brevispina, Probolus heterostomus, Rachoviscus graciliceps, Rhinobrycon negrensis, Rhoadsia altipinna, Roeboexodon guyanensis, Salminus hilarii, Serrabrycon magoi, Stygichthys typhlops, Tetragonopterus argenteus e Triportheus albus.

\section{[1] - presentes.}

Citharinus latus, Bivibranchia fowleri, Hemiodus unimaculatus , Curimata ocellata, Curimatopsis macrolepis, Potamorhina latior, Prochilodus nigricans e Semaprochilodus insignis.

\subsubsection{Cintura e nadadeira peitoral}

\section{1 - Relação entre o pós-temporal e o supracleitro:} [Zanata \& Vari, 2005: 128]

\section{[0] - separados.}

Chanos chanos, Catostomus commersonnii, Gymnotus aff. carapo, Citharinus latus, Distichodus notospilus, Hemistichodus vaillanti, Neolebias unifasciatus, Nannocharax fasciatus, Xenocharax spilurus, Apareiodon piracicabae, Parodon nasus, Saccodon wagneri, Anodus orinocensis, Bivibranchia fowleri, Hemiodus unimaculatus, curimata ocellata, Curimatopsis macrolepis, Potamorhina latior, Prochilodus nigricans, Semaprochilodus insignis, Caenotropus labyrinthicus, Chilodus punctatus, Anostomus anostomus, Leporellus vittatus, Leporinus fasciatus, Schizodon fasciatus, Acestrorhynchus falcirostris, Gilbertolus atratoensis, Hydrolycus tatauaia, Roestes molossus, Erythrinoidea fam. nov, Boulengerella maculata, Ctenolucius hujeta, Copeina cf. guttata, Lebiasina bimaculata, Piabucina astrigata, Erythrinus erythrinus, Hoplias malabaricus, Hepsetus odoe, Arnoldichthys spilopterus, Brycinus macrolepidotus, Bryconalestes longipinnis, Chalceus epakros, Characidium bahiensis, Crenuchus spilurus, Agoniates halecinus, Aphyocharax pusillus, Astyanax mexicanus, Atopomesus pachyodus, Axelrodia reisei, Brittanichthys axelrodi, Brycon pesu, Bryconadenos tanaothoros, Bryconamericus exodon, Bryconops alburnoides, Charax cf. leticiae, Clupeacharax cf. engrauloides, Compsura heterura, Ctenobrycon hauxwellianus, Deuterodon iguape, Diapoma terofali, Galeocharax knerii, Glandulocauda melanogenys, Gnathocharax steindachneri, Gymnocorymbus ternetzi, Hemibrycon polyodon, Hemigrammus unilineatus, Hollandichthys multifasciatus, Hyphessobrycon compressus, Iguanodectes geisleri, Knodus meridae, Landonia latidens, Markiana nigripinnis, Metynnis lippincottianus, Microschemobrycon casiquiare, Moenkhausia xinguensis, Myleus setiger, Odontostilbe pequira, oligosarcus argenteus, Orthospinus franciscoensis, Paracheirodon axelrodi, Paragoniates alburnus, Phenacogaster pectinatus, Phenagoniates macrolepis, Piabina argentea, Piaractus mesopotamicus, Poptella brevispina, Probolus heterostomus, Rachoviscus graciliceps, Rhinobrycon negrensis, Rhoadsia altipinna, Roeboexodon guyanensis, Salminus hilarii, Serrabrycon magoi, Stygichthys typhlops, Tetragonopterus argenteus e Triportheus albus.

\section{[1] - fusionados.}

Olivaichthys mesembrinus, Carnegiella strigata, Gasteropelecus sternicla e Thoracocharax stellatus.

222 - Pós-cleitro 1:

[LANGEANI, 1998: 67; VARI \& HAROLD, 2001: 50; ZANATA \& VARI, 2005:132]

[0] - ausente (Fig. 46).

Chanos chanos, Catostomus commersonnii, Olivaichthys mesembrinus, Nannocharax fasciatus, Bivibranchia fowleri, Caenotropus labyrinthicus, chilodus punctatus, Carnegiella strigata, Gasteropelecus sternicla, Thoracocharax stellatus, Erythrinoidea fam. nov, Rachoviscus graciliceps e Stygichthys typhlops. 
[1] - presente (Fig. 47 e Fig. 48).

Gymnotus aff. carapo, Citharinus latus, Distichodus notospilus, Hemistichodus vaillanti, Neolebias unifasciatus, Xenocharax spilurus, Apareiodon piracicabae, Parodon nasus, Saccodon wagneri, Anodus orinocensis, Hemiodus unimaculatus, Curimata ocellata, Curimatopsis macrolepis, Potamorhina latior, Prochilodus nigricans, Semaprochilodus insignis, Anostomus anostomus, Leporellus vittatus, Leporinus fasciatus, Schizodon fasciatus, Acestrorhynchus falcirostris, Gilbertolus atratoensis, Hydrolycus tatauaia, Roestes molossus, Boulengerella maculata, Ctenolucius hujeta, copeina cf. guttata, Lebiasina bimaculata, Piabucina astrigata, Erythrinus erythrinus, Hoplias malabaricus, Hepsetus odoe, Arnoldichthys spilopterus, Brycinus macrolepidotus, Bryconalestes longipinnis, Chalceus epakros, Characidium bahiensis, Crenuchus spilurus, Agoniates halecinus, Aphyocharax pusillus, Astyanax mexicanus, Atopomesus pachyodus, Axelrodia reisei, Brittanichthys axelrodi, Brycon pesu, Bryconadenos tanaothoros, Bryconamericus exodon, Bryconops alburnoides, Charax cf. leticiae, Clupeacharax cf. engrauloides, Compsura heterura, Ctenobrycon hauxwellianus, Deuterodon iguape, Galeocharax knerii, Glandulocauda melanogenys, Gnathocharax steindachneri, Gymnocorymbus ternetzi, Hemibrycon polyodon, Hemigrammus unilineatus, Hollandichthys multifasciatus, Hyphessobrycon compressus, Iguanodectes geisleri, Knodus meridae, Landonia latidens, Markiana nigripinnis, Metynnis lippincottianus, Microschemobrycon casiquiare, Moenkhausia xinguensis, Myleus setiger, Odontostilbe pequira, Oligosarcus argenteus, orthospinus franciscoensis, Paracheirodon axelrodi, Paragoniates alburnus, Phenacogaster pectinatus, Phenagoniates macrolepis, Piabina argentea, Piaractus mesopotamicus, Poptella brevispina, Probolus heterostomus, Rhinobrycon negrensis, Rhoadsia altipinna, Roeboexodon guyanensis, Salminus hilarii, Serrabrycon magoi, Tetragonopterus argenteus e Triportheus albus.

\section{[?] - indeterminado.}

Diapoma terofali.

\section{3 - Tamano relativo do pós-cleitro 1:} [MOREIRA, 2002: 59]

\section{[0] - do mesmo tamanho, ou maior que uma escama.}

Gymnotus aff. carapo, Citharinus latus, Distichodus notospilus, Hemistichodus vaillanti, Xenocharax spilurus, Hemiodus unimaculatus, Potamorhina latior, Acestrorhynchus falcirostris, Gilbertolus atratoensis, Hydrolycus tatauaia, Roestes molossus, Boulengerella maculata, Ctenolucius hujeta, Hepsetus odoe, Brycon pesu, Clupeacharax cf. engrauloides, Compsura heterura, Hemibrycon polyodon, Hemigrammus unilineatus, Hollandichthys multifasciatus, Hyphessobrycon compressus, Metynnis lippincottianus, Myleus setiger, Piaractus mesopotamicus, Rhoadsia altipinna, Roeboexodon guyanensis e Salminus hilarii.

\section{[1] - menor que uma escama.}

Neolebias unifasciatus, Apareiodon piracicabae, Parodon nasus, Saccodon wagneri, Anodus orinocensis, Curimata ocellata, Curimatopsis macrolepis, Prochilodus nigricans, Semaprochilodus insignis, Anostomus anostomus, Leporellus vittatus, Leporinus fasciatus, Schizodon fasciatus, Copeina cf. guttata, Lebiasina bimaculata, Piabucina astrigata, Erythrinus erythrinus, Hoplias malabaricus, Arnoldichthys spilopterus, Brycinus macrolepidotus, Bryconalestes longipinnis, Chalceus epakros, Characidium bahiensis, crenuchus spilurus, Agoniates halecinus, Aphyocharax pusillus, Astyanax mexicanus, Atopomesus pachyodus, Axelrodia reisei, Brittanichthys axelrodi, Bryconadenos tanaothoros, Bryconamericus exodon, Bryconops alburnoides, Charax cf. leticiae, Ctenobrycon hauxwellianus, Deuterodon iguape, Galeocharax knerii, Glandulocauda melanogenys, Gnathocharax steindachneri, Gymnocorymbus ternetzi, Iguanodectes geisleri, Knodus meridae, Landonia latidens, Markiana nigripinnis, Microschemobrycon casiquiare, Moenkhausia xinguensis, Odontostilbe pequira, oligosarcus argenteus, orthospinus franciscoensis, Paracheirodon axelrodi, Paragoniates alburnus, Phenacogaster pectinatus, Phenagoniates macrolepis, Piabina argentea, Poptella brevispina, Probolus heterostomus, Rhinobrycon negrensis, Serrabrycon magoi, Tetragonopterus argenteus e Triportheus albus.

\section{[-] - inplicável.}

Chanos chanos, Catostomus commersonnii,olivaichthys mesembrinus, Nannocharax fasciatus, Bivibranchia fowleri, Caenotropus labyrinthicus, Chilodus punctatus, Carnegiella strigata, Gasteropelecus sternicla, Thoracocharax stellatus, Erythrinoidea fam. nov, Rachoviscus graciliceps e Stygichthys typhlops. 
Diapoma terofali.

224 - Margem anterior do pós-cleitro 1:

[OYAKAWA, 1998: 87; NETTO-FERREIRA, 2006: 167]

$$
\text { [0] - lisa (Fig. 47). }
$$

Gymnotus aff. carapo, Citharinus latus, Neolebias unifasciatus, Curimatopsis macrolepis, Prochilodus nigricans, Semaprochilodus insignis, Caenotropus labyrinthicus, Chilodus punctatus, Acestrorhynchus falcirostris, Gilbertolus atratoensis, Hydrolycus tatauaia, Roestes molossus, Copeina cf. guttata, Hepsetus odoe, Arnoldichthys spilopterus, Characidium bahiensis, Crenuchus spilurus, Atopomesus pachyodus, Axelrodia reisei, Brittanichthys axelrodi, Bryconadenos tanaothoros, Bryconops alburnoides, Deuterodon iguape, Glandulocauda melanogenys, Gnathocharax steindachneri, Hemibrycon polyodon, Hyphessobrycon compressus, Iguanodectes geisleri, Microschemobrycon casiquiare, Myleus setiger, Paracheirodon axelrodi, Phenagoniates macrolepis e Piaractus mesopotamicus.

\section{[1] - com processo anterior (Fig. 48).}

Distichodus notospilus, Hemistichodus vaillanti, Xenocharax spilurus, Apareiodon piracicabae, Parodon nasus, Saccodon wagneri, Anodus orinocensis, Hemiodus unimaculatus, Curimata ocellata, Potamorhina latior, Anostomus anostomus, Leporellus vittatus, Leporinus fasciatus, Schizodon fasciatus, Boulengerella maculata, Ctenolucius hujeta, Lebiasina bimaculata, Piabucina astrigata, Erythrinus erythrinus, Hoplias malabaricus, Brycinus macrolepidotus, Bryconalestes longipinnis, Chalceus epakros, Agoniates halecinus, Aphyocharax pusillus, Astyanax mexicanus, Brycon pesu, Bryconamericus exodon, Charax cf. leticiae, Clupeacharax cf. engrauloides, Compsura heterura, Ctenobrycon hauxwellianus, Galeocharax knerii, Gymnocorymbus ternetzi, Hemigrammus unilineatus, Hollandichthys multifasciatus, Knodus meridae, Landonia latidens, Markiana nigripinnis, Metynnis lippincottianus, Moenkhausia xinguensis, Odontostilbe pequira, oligosarcus argenteus, Orthospinus franciscoensis, Paragoniates alburnus, Phenacogaster pectinatus, Piabina argentea, Poptella brevispina, Probolus heterostomus, Rhinobrycon negrensis, Rhoadsia altipinna, Roeboexodon guyanensis, Salminus hilarii, serrabrycon magoi, Tetragonopterus argenteus e Triportheus albus.

\section{[-] - inaplicável.}

$\begin{array}{lll}\text { Chanos chanos, Catostomus } & \text { commersonnii, olivaichthys } & \text { mesembrinus, Nannocharax } \\ \text { fasciatus, Bivibranchia } & \text { fowleri, Carnegiella } & \text { strigata, Gasteropelecus }\end{array}$ fowleri, Carnegiella strigata, Gasteropelecus
sternicla, Thoracocharax stellatus, Erythrinoidea fam. nov, Rachoviscus graciliceps e stygichthys typhlops.

\section{[?] - indeterminado.}

Diapoma terofali.

225 - Pós-cleitro 2:

[LUCENA, 1993: 89; VARI, 1995: 65; BUCKUP, 1998: 58; LUCENA \& MENEZES, 1998: 30; ZANATA, 2000: 104 modificado; MOREIRA, 2002: 60; ZANATA \& VARI, 2005: 133; TOLEDO-PIZA, 2000:55]

\section{[0] - presente (Fig. 47 e Fig. 48).}

Citharinus latus, Distichodus notospilus, Hemistichodus vaillanti, Neolebias unifasciatus, Nannocharax fasciatus, Xenocharax spilurus, Apareiodon piracicabae, Parodon nasus, Saccodon wagneri, Anodus orinocensis, Bivibranchia fowleri, Hemiodus unimaculatus, Curimata ocellata, Curimatopsis macrolepis, Potamorhina latior, Prochilodus nigricans, Semaprochilodus insignis, Caenotropus labyrinthicus, Chilodus punctatus, Anostomus anostomus, Leporellus vittatus, Leporinus fasciatus, Schizodon fasciatus, Acestrorhynchus falcirostris, Roestes molossus, Copeina cf. guttata, Lebiasina bimaculata, Piabucina astrigata, Erythrinus erythrinus, Hoplias malabaricus, Arnoldichthys spilopterus, Brycinus macrolepidotus, Bryconalestes longipinnis, Chalceus epakros, Characidium bahiensis, Crenuchus spilurus, Agoniates halecinus, Aphyocharax pusillus, Astyanax mexicanus, Atopomesus pachyodus, Axelrodia reisei, Brittanichthys axelrodi, Brycon pesu, Bryconadenos tanaothoros, Bryconamericus exodon, Bryconops alburnoides, Charax cf. leticiae, compsura heterura, Ctenobrycon hauxwellianus, 
Deuterodon iguape, Diapoma terofali, Galeocharax knerii, Glandulocauda melanogenys, Gymnocorymbus ternetzi, Hemibrycon polyodon, Hemigrammus unilineatus, Hollandichthys multifasciatus, Hyphessobrycon compressus, Iguanodectes geisleri, Knodus meridae, Landonia latidens, Markiana nigripinnis, Metynnis lippincottianus, Microschemobrycon casiquiare, Moenkhausia xinguensis, Myleus setiger, odontostilbe pequira, oligosarcus argenteus, Orthospinus franciscoensis, Paracheirodon axelrodi, Phenacogaster pectinatus, Piabina argentea, Piaractus mesopotamicus, Poptella brevispina, Probolus heterostomus , Rachoviscus graciliceps, Rhinobrycon negrensis, Rhoadsia altipinna, Roeboexodon guyanensis, Salminus hilarii, Serrabrycon magoi e Tetragonopterus argenteus.

\section{[1] - ausente (Fig. 46).}

Chanos chanos, Olivaichthys mesembrinus, Gymnotus aff. carapo, Carnegiella strigata, Gasteropelecus sternicla, Thoracocharax stellatus, Gilbertolus atratoensis, Hydrolycus tatauaia, Erythrinoidea fam. nov, Boulengerella maculata, Ctenolucius hujeta, Hepsetus odoe, Clupeacharax cf. engrauloides, Gnathocharax steindachneri, Paragoniates alburnus, Phenagoniates macrolepis, Stygichthys typhlops e Triportheus albus.

\section{[?] - indeterminado.}

Catostomus commersonnii.

226 - Posição do pós-cleitro 1 em relação ao pós-cleitro 2:

[OYAKAWA, 1998: 86 modificado; NETTO-FERREIRA, 2006: 170 modificado]

\section{[0] - separados.}

Apareiodon piracicabae, Parodon nasus, Curimatopsis macrolepis, Potamorhina latior, Bryconalestes longipinnis, Chalceus epakros, Aphyocharax pusillus, Brittanichthys axelrodi, Brycon pesu, Bryconadenos tanaothoros, Bryconamericus exodon, Charax cf. leticiae, Compsura heterura, ctenobrycon hauxwellianus, Galeocharax knerii, Glandulocauda melanogenys, Gymnocorymbus ternetzi, Hemigrammus unilineatus, Hyphessobrycon compressus, Iguanodectes geisleri, Knodus meridae, Markiana nigripinnis, Metynnis lippincottianus, orthospinus franciscoensis, Poptella brevispina e Tetragonopterus argenteus.

\section{[1] - quase em contato, espaço menor que altura do pós-cleitro 1 (Fig. 47 e Fig. 48).}

Citharinus latus, Distichodus notospilus, Hemistichodus vaillanti, Neolebias unifasciatus, Xenocharax spilurus, Saccodon wagneri, Anodus orinocensis, Hemiodus unimaculatus, Curimata ocellata, Prochilodus nigricans, Semaprochilodus insignis, Anostomus anostomus, Leporellus vittatus, Leporinus fasciatus, Schizodon fasciatus, Acestrorhynchus falcirostris, Roestes molossus, Copeina cf. guttata, Lebiasina bimaculata, Piabucina astrigata, Erythrinus erythrinus, Hoplias malabaricus, Arnoldichthys spilopterus, Brycinus macrolepidotus, Characidium bahiensis, Crenuchus spilurus, Agoniates halecinus, Astyanax mexicanus, Atopomesus pachyodus, Axelrodia reisei, Bryconops alburnoides, Deuterodon iguape, Hemibrycon polyodon, Hollandichthys multifasciatus, Landonia latidens, Microschemobrycon casiquiare, Moenkhausia xinguensis, Myleus setiger, Odontostilbe pequira, oligosarcus argenteus, Paracheirodon axelrodi, Phenacogaster pectinatus, Piabina argentea, Piaractus mesopotamicus, Probolus heterostomus, Rhinobrycon negrensis, Rhoadsia altipinna, Roeboexodon guyanensis, Salminus hilarii e Serrabrycon magoi.

\section{[-] - inaplicável.}

Chanos chanos, Catostomus commersonnii,olivaichthys mesembrinus, Gymnotus aff. carapo, Nannocharax fasciatus, Bivibranchia fowleri, Caenotropus labyrinthicus, chilodus punctatus, Carnegiella strigata, Gasteropelecus sternicla, Thoracocharax stellatus , Gilbertolus atratoensis, Hydrolycus tatauaia, Erythrinoidea fam. nov, Boulengerella maculata, Ctenolucius hujeta, Hepsetus odoe, Clupeacharax cf. engrauloides, Gnathocharax steindachneri, Paragoniates alburnus, Phenagoniates macrolepis, Rachoviscus graciliceps, Stygichthys typhlops e Triportheus albus.

\section{[?] - indeterminado.}

Diapoma terofali.

227 - Pós-cleitros 2 e 3 : 
[VARI，1979: 3; BUCKUP，1998: 60; NETTO-FERREIRA，2006: 171]

\section{[0] - fusionados.}

Citharinus latus, Distichodus notospilus, Hemistichodus vaillanti, Neolebias unifasciatus, Xenocharax spilurus e Crenuchus spilurus.

\section{[1] - não fusionados.}

Apareiodon piracicabae, Parodon nasus, Saccodon wagneri, Anodus orinocensis, Bivibranchia fowleri, Hemiodus unimaculatus, Curimata ocellata, Curimatopsis macrolepis, Potamorhina latior, Prochilodus nigricans, Semaprochilodus insignis, Caenotropus labyrinthicus, Anostomus anostomus, Leporellus vittatus, Leporinus fasciatus, Schizodon fasciatus, Copeina cf. guttata, Lebiasina bimaculata, Piabucina astrigata, Erythrinus erythrinus, Hoplias malabaricus, Arnoldichthys spilopterus, Brycinus macrolepidotus, Bryconalestes longipinnis, Chalceus epakros, Characidium bahiensis, Aphyocharax pusillus, Astyanax mexicanus, Atopomesus pachyodus, Axelrodia reisei, Brittanichthys axelrodi, Brycon pesu, Bryconadenos tanaothoros, Bryconamericus exodon, Bryconops alburnoides, Charax cf. leticiae, Compsura heterura, Ctenobrycon hauxwellianus, Deuterodon iguape, Diapoma terofali, Galeocharax knerii, Glandulocauda melanogenys, Gymnocorymbus ternetzi, Hemibrycon polyodon, Hemigrammus unilineatus, Hollandichthys multifasciatus, Hyphessobrycon compressus, Iguanodectes geisleri, Knodus meridae, Landonia latidens, Markiana nigripinnis, Metynnis lippincottianus, Microschemobrycon casiquiare, Moenkhausia xinguensis, Myleus setiger, odontostilbe pequira, oligosarcus argenteus, orthospinus franciscoensis, Paracheirodon axelrodi, Phenacogaster pectinatus, Piabina argentea, Piaractus mesopotamicus, Poptella brevispina, Probolus heterostomus, Rachoviscus graciliceps, Rhinobrycon negrensis, Rhoadsia altipinna, Roeboexodon guyanensis, Salminus hilarii, Serrabrycon magoi e Tetragonopterus argenteus.

\section{[-] - inaplicável.}

Chanos chanos, olivaichthys mesembrinus, Gymnotus aff. carapo, Chilodus punctatus, Carnegiella strigata, Gasteropelecus sternicla, Thoracocharax stellatus , Acestrorhynchus falcirostris, Gilbertolus atratoensis, Hydrolycus tatauaia, Roestes molossus, Erythrinoidea fam. nov, Boulengerella maculata, Ctenolucius hujeta, Hepsetus odoe, Agoniates halecinus, Clupeacharax cf. engrauloides, Gnathocharax steindachneri, Paragoniates alburnus, Phenagoniates macrolepis, stygichthys typhlops e Triportheus albus.

\section{[?] - indeterminado.}

Catostomus commersonnii e Nannocharax fasciatus.

228 - Pós-cleitro 3:

[LUCENA, 1993: 90; VARI, 1995: 64; BUCKUP, 1998: 59; LUCENA \& MENEZES, 1998: 31; ZANATA, 2000: 104 modificado; MOREIRA, 2002: 61; ZANATA \& VARI, 2005: 134; TOLEDO-PIZA, 2000: 56]

\section{[0] - presente (Fig. 48).}

atostomus commersonnii, Citharinus latus, Distichodus notospilus, Hemistichodus vaillanti, Neolebias unifasciatus, Xenocharax spilurus, Apareiodon piracicabae, Parodon nasus, Saccodon wagneri, Anodus orinocensis, Bivibranchia fowleri, Hemiodus unimaculatus , Curimata ocellata, Curimatopsis macrolepis, Potamorhina latior, Prochilodus nigricans, Semaprochilodus insignis, Caenotropus labyrinthicus, Anostomus anostomus, Leporellus vittatus, Leporinus fasciatus, Schizodon fasciatus, Copeina cf. guttata, Lebiasina bimaculata, Piabucina astrigata, Erythrinus erythrinus, Hoplias malabaricus, Arnoldichthys spilopterus, Brycinus macrolepidotus, Chalceus epakros, Characidium bahiensis, Crenuchus spilurus, Aphyocharax pusillus, Astyanax mexicanus, Atopomesus pachyodus, Axelrodia reisei, Brittanichthys axelrodi, Brycon pesu, Bryconadenos tanaothoros, Bryconamericus exodon, Bryconops alburnoides, Charax cf. leticiae, Compsura heterura, Ctenobrycon hauxwellianus, Deuterodon iguape, Diapoma terofali, Galeocharax knerii, Glandulocauda melanogenys, Gymnocorymbus ternetzi, Hemibrycon polyodon, Hemigrammus unilineatus, Hollandichthys multifasciatus, Hyphessobrycon compressus, Iguanodectes geisleri, Knodus meridae, Landonia latidens, Markiana nigripinnis, Metynnis lippincottianus, Microschemobrycon casiquiare, Moenkhausia xinguensis, Myleus setiger, odontostilbe pequira, Oligosarcus argenteus, Orthospinus franciscoensis, Paracheirodon axelrodi, Phenacogaster pectinatus, Piabina argentea, Piaractus mesopotamicus, Poptella brevispina, Probolus heterostomus, Rhinobrycon negrensis, Rhoadsia altipinna, Roeboexodon guyanensis, Salminus hilarii, Serrabrycon magoi e Tetragonopterus argenteus. 
[1] - ausente (Fig. 46 e Fig. 47).

Chanos chanos, Olivaichthys mesembrinus, Gymnotus aff. carapo, Chilodus punctatus, Carnegiella strigata, Gasteropelecus sternicla, Thoracocharax stellatus,
Acestrorhynchus falcirostris, Gilbertolus atratoensis, Hydrolycus tatauaia, Roestes molossus, Erythrinoidea fam. nov, Boulengerella maculata, Ctenolucius hujeta, Hepsetus odoe, Agoniates halecinus, Clupeacharax cf. engrauloides, Gnathocharax steindachneri, Paragoniates alburnus, Phenagoniates macrolepis, Stygichthys typhlops e Triportheus albus.

\section{[?] - indeterminado.}

Nannocharax fasciatus, Bryconalestes longipinnis e Rachoviscus graciliceps.

\section{9 - Forma do pós-cleitro 3:}

[BENINE, 2004: 69; ZANATA \& VARI, 2005: 135; SERRA, 2003: 70]

[0] - com lamela (Fig. 48).

Anodus orinocensis, Bivibranchia fowleri, Hemiodus unimaculatus, Curimata ocellata, Potamorhina latior, Prochilodus nigricans, Semaprochilodus insignis, Arnoldichthys spilopterus, Bryconalestes longipinnis, Chalceus epakros, Astyanax mexicanus, Atopomesus pachyodus, Axelrodia reisei, Brittanichthys axelrodi, Charax cf. leticiae, Compsura heterura, Ctenobrycon hauxwellianus, Deuterodon iguape, Galeocharax knerii, Glandulocauda melanogenys, Gymnocorymbus ternetzi, Hemigrammus unilineatus, Hollandichthys multifasciatus, Hyphessobrycon compressus, Landonia latidens, Metynnis lippincottianus, Microschemobrycon casiquiare, Moenkhausia xinguensis, Myleus setiger, odontostilbe pequira, oligosarcus argenteus, orthospinus franciscoensis, Paracheirodon axelrodi, Phenacogaster pectinatus, Piaractus mesopotamicus, Poptella brevispina, Probolus heterostomus, Rhoadsia altipinna, Serrabrycon magoi e Tetragonopterus argenteus.

\section{[1] - sem lamela.}

Apareiodon piracicabae, Parodon nasus, Saccodon wagneri, Curimatopsis macrolepis, Caenotropus labyrinthicus, Anostomus anostomus, Leporellus vittatus, Leporinus fasciatus, Schizodon fasciatus, Copeina cf. guttata, Lebiasina bimaculata, Piabucina astrigata, Erythrinus erythrinus, Hoplias malabaricus, Brycinus macrolepidotus, Characidium bahiensis, Crenuchus spilurus, Aphyocharax pusillus, Brycon pesu, Bryconadenos tanaothoros, Bryconamericus exodon, Bryconops alburnoides, Diapoma terofali, Hemibrycon polyodon, Iguanodectes geisleri, Knodus meridae, Markiana nigripinnis, Piabina argentea, Rhinobrycon negrensis, Roeboexodon guyanensis e Salminus hilarii.

\section{[-] - inaplicável.}

Chanos chanos, Olivaichthys mesembrinus, Gymnotus aff. carapo, Citharinus latus, Distichodus notospilus, Hemistichodus vaillanti, Neolebias unifasciatus, Xenocharax spilurus, Chilodus punctatus, Carnegiella strigata, Gasteropelecus sternicla, Thoracocharax stellatus , Acestrorhynchus falcirostris,Gilbertolus atratoensis, Hydrolycus tatauaia, Roestes molossus, Erythrinoidea fam. nov, Boulengerella maculata, Ctenolucius hujeta, Hepsetus odoe, Agoniates halecinus, Clupeacharax cf. engrauloides, Gnathocharax steindachneri, Paragoniates alburnus, Phenagoniates macrolepis, stygichthys typhlops e Triportheus albus.

\section{[?] - indeterminado.}

Catostomus commersonnii, Nannocharax fasciatus e Rachoviscus graciliceps.

230 - Raios da nadadeira peitoral:

[BUCKUP, 1998: 61; NetTo-FeRREIRA, 2006: 180]

\section{[0] - um raio não ramificado anterior.}

Chanos chanos, Olivaichthys mesembrinus, Gymnotus aff. carapo, Citharinus latus, Distichodus notospilus, Hemistichodus vaillanti, Neolebias unifasciatus, Xenocharax spilurus, Apareiodon piracicabae, Parodon nasus, Anodus orinocensis, Bivibranchia 
fowleri, Hemiodus unimaculatus, Curimata ocellata, Curimatopsis macrolepis, Potamorhina latior, Prochilodus nigricans, Semaprochilodus insignis, Caenotropus labyrinthicus, Chilodus punctatus, Anostomus anostomus, Leporellus vittatus, Leporinus fasciatus, Schizodon fasciatus, Carnegiella strigata, Gasteropelecus sternicla, Thoracocharax stellatus, Acestrorhynchus falcirostris, Gilbertolus atratoensis, Hydrolycus tatauaia, Roestes molossus, Boulengerella maculata, Ctenolucius hujeta, Copeina cf. guttata, Lebiasina bimaculata, Piabucina astrigata, Erythrinus erythrinus, Hoplias malabaricus, Hepsetus odoe, Arnoldichthys spilopterus, Brycinus macrolepidotus, Bryconalestes longipinnis, Chalceus epakros, Agoniates halecinus, Aphyocharax pusillus, Astyanax mexicanus, Atopomesus pachyodus, Axelrodia reisei, Brittanichthys axelrodi, Brycon pesu, Bryconadenos tanaothoros, Bryconamericus exodon, Bryconops alburnoides, Charax cf. leticiae, Clupeacharax cf. engrauloides, Compsura heterura, Ctenobrycon hauxwellianus, Deuterodon iguape, Diapoma terofali, Galeocharax knerii, Glandulocauda melanogenys, Gnathocharax steindachneri, Gymnocorymbus ternetzi, Hemibrycon polyodon, Hemigrammus unilineatus, Hollandichthys multifasciatus, Hyphessobrycon compressus, Iguanodectes geisleri, Knodus meridae, Landonia latidens, Markiana nigripinnis, Metynnis lippincottianus, Microschemobrycon casiquiare, Moenkhausia xinguensis, Myleus setiger, odontostilbe pequira, oligosarcus argenteus, orthospinus franciscoensis, Paracheirodon axelrodi, Paragoniates alburnus, Phenacogaster pectinatus, Phenagoniates macrolepis, Piabina argentea, Piaractus mesopotamicus, Poptella brevispina, Probolus heterostomus, Rhinobrycon negrensis, Rhoadsia altipinna, Roeboexodon guyanensis, Salminus hilarii, Serrabrycon magoi, Stygichthys typhlops, Tetragonopterus argenteus e Triportheus albus.

\section{[1] - dois ou mais raios não ramificados anteriores.}

Catostomus commersonnii, Nannocharax fasciatus, Saccodon wagneri, Erythrinoidea fam. nov, Characidium bahiensis e Crenuchus spilurus.

[?] - indeterminado.

Rachoviscus graciliceps.

231 - Canal sensorial no pós-temporal:

[OYAKAWA, 1998: 79; MOREIRA, 2002: 62 modificado]

(Minimamente conectado).

\section{[0] - ausente.}

Catostomus commersonnii, Gymnotus aff. carapo, Caenotropus labyrinthicus, Chilodus punctatus, Erythrinoidea fam. nov, Copeina cf. guttata, Erythrinus erythrinus, Atopomesus pachyodus, Brittanichthys axelrodi, Hyphessobrycon compressus, Paracheirodon axelrodi, Rachoviscus graciliceps e Stygichthys typhlops.

\section{[1] - presente, como um orifício.}

Hepsetus odoe, Aphyocharax pusillus, Compsura heterura, ctenobrycon hauxwellianus, Glandulocauda melanogenys, Knodus meridae, Microschemobrycon casiquiare, Odontostilbe pequira, Paragoniates alburnus, Phenacogaster pectinatus, Phenagoniates macrolepis, Rhinobrycon negrensis, Rhoadsia altipinna e Serrabrycon magoi.

\section{[2] - presente, como um canal.}

Chanos chanos, Citharinus latus, Distichodus notospilus, Hemistichodus vaillanti, Neolebias unifasciatus, Nannocharax fasciatus, Xenocharax spilurus, Apareiodon piracicabae, Parodon nasus, Saccodon wagneri, Anodus orinocensis, Bivibranchia fowleri, Hemiodus unimaculatus, Curimata ocellata, Curimatopsis macrolepis, Potamorhina latior, Prochilodus nigricans, Semaprochilodus insignis, Anostomus anostomus, Leporellus vittatus, Leporinus fasciatus, Schizodon fasciatus, Acestrorhynchus falcirostris, Gilbertolus atratoensis, Hydrolycus tatauaia, Roestes molossus, Boulengerella maculata, Ctenolucius hujeta, Lebiasina bimaculata, Piabucina astrigata, Hoplias malabaricus, Arnoldichthys spilopterus, Brycinus macrolepidotus, Bryconalestes longipinnis, Chalceus epakros, Characidium bahiensis, Crenuchus spilurus, Agoniates halecinus, Astyanax mexicanus, Brycon pesu, Bryconadenos tanaothoros, Bryconamericus exodon, Bryconops alburnoides, Charax cf. leticiae, Clupeacharax cf. engrauloides, Deuterodon iguape, Diapoma terofali, Galeocharax knerii, Gnathocharax steindachneri, Gymnocorymbus ternetzi, Hemibrycon polyodon, Hemigrammus unilineatus, Hollandichthys multifasciatus, Iguanodectes geisleri, Landonia latidens, Markiana nigripinnis, Metynnis lippincottianus, Moenkhausia xinguensis, Myleus setiger, oligosarcus argenteus, orthospinus franciscoensis, Piabina argentea, Piaractus mesopotamicus, Poptella 
brevispina, Probolus heterostomus, Roeboexodon guyanensis, Salminus hilarii, Tetragonopterus argenteus e Triportheus albus.

\section{[-] - inaplicável.}

Olivaichthys mesembrinus, Carnegiella strigata, Gasteropelecus sternicla, Thoracocharax stellatus e Axelrodia reisei.

[0] - fina (Figs. 46, 47 e 48).

Chanos chanos, Catostomus commersonnii, Gymnotus aff. carapo, Citharinus latus, Distichodus notospilus, Hemistichodus vaillanti, Neolebias unifasciatus, Nannocharax fasciatus, Xenocharax spilurus, Anodus orinocensis, Bivibranchia fowleri, Hemiodus unimaculatus, Curimata ocellata, Curimatopsis macrolepis, Potamorhina latior, Prochilodus nigricans, Semaprochilodus insignis, Caenotropus labyrinthicus, Chilodus punctatus, Anostomus anostomus, Leporellus vittatus, Leporinus fasciatus, Schizodon fasciatus, Acestrorhynchus falcirostris, Gilbertolus atratoensis, Hydrolycus tatauaia, Roestes molossus, Erythrinoidea fam. nov, Boulengerella maculata, Ctenolucius hujeta, Copeina cf. guttata, Lebiasina bimaculata, Piabucina astrigata, Erythrinus erythrinus, Hoplias malabaricus, Hepsetus odoe, Arnoldichthys spilopterus, Brycinus macrolepidotus, Bryconalestes longipinnis, Chalceus epakros, Characidium bahiensis, Crenuchus spilurus, Agoniates halecinus, Aphyocharax pusillus, Astyanax mexicanus, Atopomesus pachyodus, Axelrodia reisei, Brittanichthys axelrodi, Brycon pesu, Bryconadenos tanaothoros, Bryconamericus exodon, Bryconops alburnoides, Charax cf. leticiae, Clupeacharax cf. engrauloides, Compsura heterura, Ctenobrycon hauxwellianus, Deuterodon iguape, Diapoma terofali, Galeocharax knerii, Glandulocauda melanogenys, Gnathocharax steindachneri, Gymnocorymbus ternetzi, Hemibrycon polyodon, Hemigrammus unilineatus, Hollandichthys multifasciatus, Hyphessobrycon compressus, Iguanodectes geisleri, Knodus meridae, Landonia latidens, Markiana nigripinnis, Metynnis lippincottianus, Microschemobrycon casiquiare, Moenkhausia xinguensis, Myleus setiger, Odontostilbe pequira, oligosarcus argenteus, orthospinus franciscoensis, Paracheirodon axelrodi, Paragoniates alburnus, Phenacogaster pectinatus, Phenagoniates macrolepis, Piabina argentea, Piaractus mesopotamicus, Poptella brevispina, Probolus heterostomus, Rachoviscus graciliceps, Rhinobrycon negrensis, Rhoadsia altipinna, Roeboexodon guyanensis, Salminus hilarii, Serrabrycon magoi, Stygichthys typhlops e Tetragonopterus argenteus.

\section{[1] - larga.}

Apareiodon piracicabae, Parodon nasus e Saccodon wagneri.

\section{[-] - ianplicável.}

Olivaichthys mesembrinus, Carnegiella strigata, Gasteropelecus sternicla e Thoracocharax stellatus.

\section{[?] - indeterminado.}

Triportheus albus.

- Extra-escapular:

\section{[0] - presente.}

Chanos chanos, Catostomus commersonnil, Citharinus latus, Distichodus notospilus, Hemistichodus vaillanti, Neolebias unifasciatus, Nannocharax fasciatus, Xenocharax spilurus, Apareiodon piracicabae, Parodon nasus, Saccodon wagneri, Anodus orinocensis, Bivibranchia fowleri, Hemiodus unimaculatus, Curimata ocellata, Curimatopsis macrolepis, Potamorhina latior, Prochilodus nigricans, Semaprochilodus insignis, Caenotropus labyrinthicus, Chilodus punctatus, Anostomus anostomus, Leporellus vittatus, Leporinus fasciatus, Schizodon fasciatus, Carnegiella strigata, Gasteropelecus sternicla, Thoracocharax stellatus, Acestrorhynchus falcirostris, Gilbertolus atratoensis, Hydrolycus tatauaia, Roestes molossus, Boulengerella maculata, Ctenolucius hujeta, Piabucina astrigata, Erythrinus erythrinus, Hoplias malabaricus, Hepsetus odoe, Arnoldichthys spilopterus, Brycinus macrolepidotus, Bryconalestes longipinnis, Chalceus epakros, Characidium bahiensis, Crenuchus spilurus, Agoniates halecinus, Aphyocharax pusillus, Astyanax mexicanus, Atopomesus pachyodus, Brycon pesu, Bryconadenos tanaothoros, Bryconamericus exodon, Bryconops alburnoides, Charax cf. leticiae, Clupeacharax cf. engrauloides, Compsura heterura, Ctenobrycon hauxwellianus, Deuterodon 
iguape, Diapoma terofali, Galeocharax knerii, Glandulocauda melanogenys, Gnathocharax steindachneri, Gymnocorymbus ternetzi, Hemibrycon polyodon, Hemigrammus unilineatus, Hollandichthys multifasciatus, Iguanodectes geisleri, Knodus meridae, Landonia latidens, Markiana nigripinnis, Metynnis lippincottianus, Microschemobrycon casiquiare Moenkhausia xinguensis, Myleus setiger, Odontostilbe pequira, oligosarcus argenteus, orthospinus franciscoensis, Paragoniates alburnus, Phenacogaster pectinatus, Phenagoniates macrolepis, Piabina argentea, Piaractus mesopotamicus, Poptella brevispina, Probolus heterostomus, Rachoviscus graciliceps, Rhinobrycon negrensis, Rhoadsia altipinna, Roeboexodon guyanensis, Salminus hilarii, Serrabrycon magoi, Tetragonopterus argenteus e Triportheus albus.

\section{[1] - ausente.}

olivaichthys mesembrinus, Gymnotus aff. carapo, Erythrinoidea fam. nov, Copeina cf. guttata, Lebiasina bimaculata, Axelrodia reisei, Brittanichthys axelrodi e Paracheirodon axelrodi.

\section{[?] - indeterminado.}

Hyphessobrycon compressus e Stygichthys typhlops.

\section{4 - Canal sensorial do extra-escapular: \\ [VARI, 1983: 67]}

\section{[0] - com três ramos (Fig. 49B).}

Citharinus latus, Distichodus notospilus, Hemistichodus vaillanti, Neolebias unifasciatus, Nannocharax fasciatus, Xenocharax spilurus, Apareiodon piracicabae, Parodon nasus, Saccodon wagneri, Curimata ocellata, Curimatopsis macrolepis, Potamorhina latior, Caenotropus labyrinthicus, Chilodus punctatus, Carnegiella strigata, Gasteropelecus sternicla, Thoracocharax stellatus, Boulengerella maculata, ctenolucius hujeta, Lebiasina bimaculata, Erythrinus erythrinus, Hoplias malabaricus, Hepsetus odoe, Arnoldichthys spilopterus, Chalceus epakros, Characidium bahiensis, Crenuchus spilurus, Agoniates halecinus, Aphyocharax pusillus, Atopomesus pachyodus, Bryconadenos tanaothoros, Bryconamericus exodon, Charax cf. leticiae, Clupeacharax cf. engrauloides, Compsura heterura, Deuterodon iguape, Galeocharax knerii, Glandulocauda melanogenys, Hemigrammus unilineatus, Hollandichthys multifasciatus, Iguanodectes geisleri, Knodus meridae, Landonia latidens, Microschemobrycon casiquiare, Moenkhausia xinguensis, odontostilbe pequira, Paragoniates alburnus, Phenagoniates macrolepis, Rachoviscus graciliceps, Rhinobrycon negrensis, Rhoadsia altipinna, Roeboexodon guyanensis, Serrabrycon magoi e Triportheus albus.

\section{[1] - com quatro ramos (Fig. 49A).}

Chanos chanos, Anodus orinocensis, Bivibranchia fowleri, Hemiodus unimaculatus Prochilodus nigricans, Semaprochilodus insignis, Anostomus anostomus, Leporellus vittatus, Leporinus fasciatus, Schizodon fasciatus, Acestrorhynchus falcirostris, Gilbertolus atratoensis, Hydrolycus tatauaia, Roestes molossus, Piabucina astrigata, Brycinus macrolepidotus, Bryconalestes longipinnis, Astyanax mexicanus, Brycon pesu, Bryconops alburnoides, Ctenobrycon hauxwellianus, Diapoma terofali, Gnathocharax steindachneri, Gymnocorymbus ternetzi, Hemibrycon polyodon, Markiana nigripinnis, Metynnis lippincottianus, Myleus setiger, oligosarcus argenteus, orthospinus franciscoensis, Phenacogaster pectinatus, Piabina argentea, Piaractus mesopotamicus, Poptella brevispina, Probolus heterostomus, Salminus hilarii e Tetragonopterus argenteus.

\section{[-] - inaplicável.}

Olivaichthys mesembrinus, Gymnotus aff. carapo, Erythrinoidea fam. nov, Copeina cf. guttata, Axelrodia reisei,Brittanichthys axelrodi, Paracheirodon axelrodi e Stygichthys typhlops.

\section{[?] - indeterminado.}

Catostomus commersonnii e Hyphessobrycon compressus.

235 - Forma do coracóide:

[Toledo-PizA, 2000: 58; ZanATA, 2000: 106; Moreira, 2002: 63] 
[0] - não expandido (Figs. 46, 47 e 48).

Chanos chanos, Catostomus commersonnii, Olivaichthys mesembrinus, Gymnotus aff. carapo, Citharinus latus, Distichodus notospilus, Hemistichodus vaillanti, Neolebias unifasciatus, Nannocharax fasciatus, Xenocharax spilurus, Apareiodon piracicabae, Parodon nasus, Saccodon wagneri, Anodus orinocensis, Bivibranchia fowleri, Hemiodus unimaculatus, Curimata ocellata, Curimatopsis macrolepis, Potamorhina latior, Prochilodus nigricans, Semaprochilodus insignis, Caenotropus labyrinthicus, Chilodus punctatus, Anostomus anostomus, Leporellus vittatus, Leporinus fasciatus, Schizodon fasciatus, Acestrorhynchus falcirostris, Gilbertolus atratoensis, Roestes molossus, Erythrinoidea fam. nov, Boulengerella maculata, Ctenolucius hujeta, copeina cf. guttata, Lebiasina bimaculata, Piabucina astrigata, Erythrinus erythrinus, Hoplias malabaricus, Hepsetus odoe, Arnoldichthys spilopterus, Brycinus macrolepidotus, Bryconalestes longipinnis, Chalceus epakros, Characidium bahiensis, Crenuchus spilurus, Aphyocharax pusillus, Astyanax mexicanus, Atopomesus pachyodus, Axelrodia reisei, Brittanichthys axelrodi, Brycon pesu, Bryconadenos tanaothoros, Bryconamericus exodon, Bryconops alburnoides, Charax cf. leticiae, Compsura heterura, Ctenobrycon hauxwellianus, Deuterodon iguape, Diapoma terofali, Galeocharax knerii, Glandulocauda melanogenys, Gymnocorymbus ternetzi, Hemibrycon polyodon, Hemigrammus unilineatus, Hollandichthys multifasciatus, Hyphessobrycon compressus, Iguanodectes geisleri, Knodus meridae, Landonia latidens, Markiana nigripinnis, Metynnis lippincottianus, Microschemobrycon casiquiare, Moenkhausia xinguensis, Myleus setiger, Odontostilbe pequira, Oligosarcus argenteus, orthospinus franciscoensis, Paracheirodon axelrodi, Phenacogaster pectinatus, Phenagoniates macrolepis, Piabina argentea, Piaractus mesopotamicus, Poptella brevispina, Probolus heterostomus, Rachoviscus graciliceps, Rhinobrycon negrensis, Rhoadsia altipinna, Roeboexodon guyanensis, Salminus hilarii, Serrabrycon magoi, Stygichthys typhlops e Tetragonopterus argenteus.

\section{[1] - expandido ventralmente de maneira a formar uma quilha.}

Carnegiella strigata, Gasteropelecus sternicla, Thoracocharax stellatus, Hydrolycus tatauaia, Agoniates halecinus, clupeacharax cf. engrauloides, Gnathocharax steindachneri, Paragoniates alburnus e Triportheus albus.

\section{6 - Orientação da porção anterior do coracóide:}

\section{[0] - inclinado, quase horizontal (Fig. 46 e Fig. 48).}

Catostomus commersonnii, olivaichthys mesembrinus, Gymnotus aff. carapo, Citharinus latus, Distichodus notospilus, Hemistichodus vaillanti, Neolebias unifasciatus, Xenocharax spilurus, Anodus orinocensis, Bivibranchia fowleri, Hemiodus unimaculatus, Curimata ocellata, Curimatopsis macrolepis, Potamorhina latior, Prochilodus nigricans, Semaprochilodus insignis, Anostomus anostomus, Leporellus vittatus, Schizodon fasciatus, Erythrinoidea fam. nov, Erythrinus erythrinus, Hoplias malabaricus, crenuchus spilurus e Stygichthys typhlops.

\section{[1] - vertical (Fig. 47).}

Chanos chanos, Nannocharax fasciatus, Apareiodon piracicabae, Parodon nasus, Saccodon wagneri, Caenotropus labyrinthicus, Chilodus punctatus, Leporinus fasciatus, Carnegiella strigata, Gasteropelecus sternicla, Thoracocharax stellatus, Acestrorhynchus falcirostris, Gilbertolus atratoensis, Hydrolycus tatauaia, Roestes molossus, Boulengerella maculata, Ctenolucius hujeta, Copeina cf. guttata, Lebiasina bimaculata, Piabucina astrigata, Hepsetus odoe, Arnoldichthys spilopterus, Brycinus macrolepidotus, Bryconalestes longipinnis, Chalceus epakros, Agoniates halecinus, Aphyocharax pusillus, Astyanax mexicanus, Atopomesus pachyodus, Axelrodia reisei, Brittanichthys axelrodi, Brycon pesu, Bryconadenos tanaothoros, Bryconamericus exodon, Bryconops alburnoides, Charax cf. leticiae, Clupeacharax cf. engrauloides, Compsura heterura, Ctenobrycon hauxwellianus, Deuterodon iguape, Diapoma terofali, Galeocharax knerii, Glandulocauda melanogenys, Gnathocharax steindachneri, Gymnocorymbus ternetzi, Hemibrycon polyodon , Hemigrammus unilineatus, Hollandichthys multifasciatus, Hyphessobrycon compressus, Iguanodectes geisleri, Knodus meridae, Landonia latidens, Markiana nigripinnis, Metynnis lippincottianus, Microschemobrycon casiquiare, Moenkhausia xinguensis, Myleus setiger, odontostilbe pequira, oligosarcus argenteus, orthospinus franciscoensis, Paracheirodon axelrodi, Paragoniates alburnus, Phenacogaster pectinatus, Phenagoniates macrolepis, Piabina argentea, Piaractus mesopotamicus, Poptella brevispina, Probolus heterostomus, Rachoviscus graciliceps, Rhinobrycon negrensis, Rhoadsia altipinna, Roeboexodon guyanensis, Salminus hilarii, Serrabrycon magoi, Tetragonopterus argenteus e Triportheus albus.

[-] - inaplicável. 


\section{7 - Processo que suporta o ligamento entre a cintura peitoral e parte posterior do crânio:}

[LUCENA, 1993: 92 modificado; BUCKUP, 1998: 53 modificado; MOREIRA, 2002: 64; ZANATA \& VARI, 2005:130 \& 131 modificados; NETTO-FERREIRA, 2006: 164 modificado]

[0] - processo ausente (Fig. 46).

Catostomus commersonnii, Gymnotus aff. carapo, Distichodus notospilus, Hemistichodus vaillanti, Neolebias unifasciatus, Nannocharax fasciatus, Caenotropus labyrinthicus, Chilodus punctatus, Erythrinoidea fam. nov, Copeina cf. guttata, Characidium bahiensis, Axelrodia reisei, Glandulocauda melanogenys, Microschemobrycon casiquiare, Odontostilbe pequira, Paracheirodon axelrodi, Rhinobrycon negrensis e Stygichthys typhlops.

\section{[1] - presente no pós-temporal (Fig. 47 e 48).}

Chanos chanos, Citharinus latus, Xenocharax spilurus, Apareiodon piracicabae, Parodon nasus, Saccodon wagneri, Anodus orinocensis, Bivibranchia fowleri, Hemiodus unimaculatus , Curimata ocellata, Curimatopsis macrolepis, Potamorhina latior, Prochilodus nigricans, Semaprochilodus insignis, Anostomus anostomus, Leporellus vittatus, Leporinus fasciatus, Schizodon fasciatus, Acestrorhynchus falcirostris

Gilbertolus atratoensis, Hydrolycus tatauaia, Roestes molossus, Boulengerella maculata, Ctenolucius hujeta, Lebiasina bimaculata, Piabucina astrigata, Erythrinus erythrinus, Hoplias malabaricus, Hepsetus odoe, Arnoldichthys spilopterus, Brycinus macrolepidotus, Bryconalestes longipinnis, Chalceus epakros, crenuchus spilurus, Agoniates halecinus, Astyanax mexicanus, Atopomesus pachyodus, Brittanichthys axelrodi, Brycon pesu, Bryconadenos tanaothoros, Bryconamericus exodon, Bryconops alburnoides, Charax cf. leticiae, Clupeacharax cf. engrauloides, Compsura heterura, Ctenobrycon hauxwellianus, Deuterodon iguape, Diapoma terofali, Galeocharax knerii, Gnathocharax steindachneri, Gymnocorymbus ternetzi, Hemibrycon polyodon, Hemigrammus unilineatus, Hollandichthys multifasciatus, Hyphessobrycon compressus, Iguanodectes geisleri, Knodus meridae, Landonia latidens, Markiana nigripinnis, Moenkhausia xinguensis, Myleus setiger, Oligosarcus argenteus, Orthospinus franciscoensis, Phenacogaster pectinatus, Piabina argentea, Piaractus mesopotamicus, Poptella brevispina, Probolus heterostomus, Rachoviscus graciliceps, Rhoadsia altipinna, Roeboexodon guyanensis, Salminus hilarii, Serrabrycon magoi, Tetragonopterus argenteus e Triportheus albus.

\section{[2] - presente no supracleitro.}

Aphyocharax pusillus, Metynnis lippincottianus, Paragoniates alburnus e Phenagoniates macrolepis.

\section{[-] - inaplicável.}

Olivaichthys mesembrinus, Carnegiella strigata, Gasteropelecus sternicla e Thoracocharax stellatus.

\section{8 - Altura do supracleitro:}

\section{[0] - menos da metade da altura da cintura.}

Citharinus latus, Hemistichodus vaillanti, Xenocharax spilurus, Parodon nasus, Saccodon wagneri, Anodus orinocensis, Hemiodus unimaculatus, curimata ocellata, Curimatopsis macrolepis, Potamorhina latior, Prochilodus nigricans, Semaprochilodus insignis, Anostomus anostomus, Leporellus vittatus, Leporinus fasciatus, Schizodon fasciatus, Acestrorhynchus falcirostris, Gilbertolus atratoensis, Hydrolycus tatauaia, Roestes molossus, Erythrinoidea fam. nov, Boulengerella maculata, Ctenolucius hujeta, Hepsetus odoe, Arnoldichthys spilopterus, Brycinus macrolepidotus, Bryconalestes longipinnis, Chalceus epakros, Agoniates halecinus, Aphyocharax pusillus, Astyanax mexicanus, Brittanichthys axelrodi, Brycon pesu, Bryconadenos tanaothoros, Bryconamericus exodon, Bryconops alburnoides, Charax cf. leticiae, clupeacharax cf. engrauloides, Compsura heterura, Ctenobrycon hauxwellianus, Deuterodon iguape, Diapoma terofali, Galeocharax knerii, Gnathocharax steindachneri, Gymnocorymbus ternetzi, Hemibrycon polyodon , Hemigrammus unilineatus, Hollandichthys multifasciatus, Hyphessobrycon compressus, Iguanodectes geisleri, Knodus meridae, Landonia latidens, Markiana nigripinnis, Metynnis lippincottianus, Moenkhausia xinguensis, Myleus setiger, oligosarcus argenteus, 
orthospinus franciscoensis, Paragoniates alburnus, Phenacogaster pectinatus, Phenagoniates macrolepis, Piabina argentea, Piaractus mesopotamicus, Poptella brevispina, probolus heterostomus, Rachoviscus graciliceps, Rhinobrycon negrensis, Rhoadsia altipinna, Roeboexodon guyanensis, Salminus hilarii, Tetragonopterus argenteus e Triportheus albus.

\section{[1] - metade ou mais da metade do tamanho da cintura.}

Chanos chanos, Catostomus commersonnii, Gymnotus aff. carapo, Distichodus notospilus, Neolebias unifasciatus, Nannocharax fasciatus, Apareiodon piracicabae, Bivibranchia fowleri, Caenotropus labyrinthicus, Chilodus punctatus, Copeina cf. guttata, Lebiasina bimaculata, Piabucina astrigata, Erythrinus erythrinus, Hoplias malabaricus, Characidium bahiensis, Crenuchus spilurus, Atopomesus pachyodus, Axelrodia reisei, Glandulocauda melanogenys, Microschemobrycon casiquiare, odontostilbe pequira, Paracheirodon axelrodi, Serrabrycon magoi e stygichthys typhlops.

\section{[-] - inaplicável.}

Olivaichthys mesembrinus, Carnegiella strigata, Gasteropelecus sternicla e Thoracocharax stellatus.

\section{9 - Canal da linha lateral no supracleitro:}

[LUCENA, 1993: 91 modificado; BUCKUP, 1998: 54 modificado; OYAKAWA, 1998: $80]$

\section{[0] - ausente.}

Brittanichthys axelrodi, Paracheirodon axelrodi e Stygichthys typhlops.

\section{[1] - simples.}

Chanos chanos, Gymnotus aff. carapo, Citharinus latus, Hemistichodus vaillanti, Neolebias unifasciatus, Nannocharax fasciatus, Xenocharax spilurus, Bivibranchia fowleri, Hemiodus unimaculatus, Caenotropus labyrinthicus, chilodus punctatus, Anostomus anostomus, Schizodon fasciatus, Gilbertolus atratoensis, Hydrolycus tatauaia, Roestes molossus, Copeina cf. guttata, Arnoldichthys spilopterus, Bryconalestes longipinnis, Chalceus epakros, Characidium bahiensis, Crenuchus spilurus, Agoniates halecinus, Astyanax mexicanus, Atopomesus pachyodus, Bryconadenos tanaothoros, Bryconamericus exodon, Bryconops alburnoides, Clupeacharax cf. engrauloides, Compsura heterura, Ctenobrycon hauxwellianus, Deuterodon iguape, Diapoma terofali, Glandulocauda melanogenys, Gnathocharax steindachneri, Gymnocorymbus ternetzi, Hemibrycon polyodon , Hemigrammus unilineatus, Hyphessobrycon compressus, Iguanodectes geisleri, Knodus meridae, Landonia latidens, Markiana nigripinnis, Microschemobrycon casiquiare, Moenkhausia xinguensis, Myleus setiger, odontostilbe pequira, oligosarcus argenteus, orthospinus franciscoensis, Paragoniates alburnus, Phenacogaster pectinatus, Phenagoniates macrolepis, Piabina argentea, Poptella brevispina, Probolus heterostomus, Rhinobrycon negrensis, Rhoadsia altipinna, Roeboexodon guyanensis, Serrabrycon magoi, Tetragonopterus argenteus e Triportheus albus.

\section{[2] - bifurcado.}

Distichodus notospilus, Apareiodon piracicabae, Parodon nasus, Saccodon wagneri, Anodus orinocensis, Curimata ocellata, Curimatopsis macrolepis, Potamorhina latior, Prochilodus nigricans, Semaprochilodus insignis, Leporellus vittatus, Leporinus fasciatus, Acestrorhynchus falcirostris, Boulengerella maculata, ctenolucius hujeta, Lebiasina bimaculata, Piabucina astrigata, Erythrinus erythrinus, Hoplias malabaricus, Hepsetus odoe, Brycinus macrolepidotus, Aphyocharax pusillus, Brycon pesu, Charax cf. leticiae, Galeocharax knerii, Hollandichthys multifasciatus, Metynnis lippincottianus, Piaractus mesopotamicus, Rachoviscus graciliceps e Salminus hilarii.

\section{[-] - inaplicável.}

Catostomus commersonnii, Olivaichthys mesembrinus, Carnegiella strigata, Gasteropelecus sternicla, Thoracocharax stellatus, Erythrinoidea fam. nov. e Axelrodia reisei.

\section{0 - cleitro:}

[LUCENA, 1993: 88; OYAKAWA, 1998: 81; BUCKUP, 1998: 57; MOREIRA, 2002: 65; NetTo-FerReIRA, 2006: 165] 


\section{[0] - margem posterior sinuosa ou levemente convexa (Fig. 50A).}

Chanos chanos, Catostomus commersonnii, Gymnotus aff. carapo, Citharinus latus, Distichodus notospilus, Hemistichodus vaillanti, Neolebias unifasciatus, Nannocharax fasciatus, Xenocharax spilurus, Apareiodon piracicabae, Parodon nasus, Saccodon wagneri, Anodus orinocensis, Bivibranchia fowleri, Hemiodus unimaculatus, Curimata ocellata, Curimatopsis macrolepis, Potamorhina latior, Prochilodus nigricans, Semaprochilodus insignis, Anostomus anostomus, Leporellus vittatus, Leporinus fasciatus, Schizodon fasciatus, Carnegiella strigata, Gasteropelecus sternicla, Thoracocharax stellatus, Hydrolycus tatauaia, Erythrinoidea fam. nov, Copeina cf. guttata, Lebiasina bimaculata, Piabucina astrigata, Erythrinus erythrinus, Hoplias malabaricus, Arnoldichthys spilopterus, Brycinus macrolepidotus, Bryconalestes longipinnis, Chalceus epakros, Characidium bahiensis, Crenuchus spilurus, Agoniates halecinus, Aphyocharax pusillus, Astyanax mexicanus, Atopomesus pachyodus, Axelrodia reisei, Brittanichthys axelrodi, Bryconadenos tanaothoros, Bryconamericus exodon, Bryconops alburnoides, Clupeacharax cf. engrauloides, Compsura heterura, Deuterodon iguape, Diapoma terofali, Galeocharax knerii, Glandulocauda melanogenys, Gnathocharax steindachneri, Gymnocorymbus ternetzi, Hemibrycon polyodon, Hemigrammus unilineatus, Hollandichthys multifasciatus, Hyphessobrycon compressus, Iguanodectes geisleri, Knodus meridae, Landonia latidens, Markiana nigripinnis, Metynnis lippincottianus, Microschemobrycon casiquiare, Moenkhausia xinguensis, Myleus setiger, odontostilbe pequira, orthospinus franciscoensis, Paracheirodon axelrodi, Paragoniates alburnus, Phenagoniates macrolepis, Piabina argentea, Piaractus mesopotamicus, Poptella brevispina, Probolus heterostomus, Rachoviscus graciliceps, Rhinobrycon negrensis, Rhoadsia altipinna, Salminus hilarii, Serrabrycon magoi, Stygichthys typhlops, Tetragonopterus argenteus e Triportheus albus.

\section{[1] - margem posterior marcadamente côncava, com uma projeção distinta ("notch") (Fig. 50B).}

Olivaichthys mesembrinus, Caenotropus labyrinthicus, Chilodus punctatus, Acestrorhynchus falcirostris, Gilbertolus atratoensis, Roestes molossus, Boulengerella maculata, Ctenolucius hujeta, Hepsetus odoe, Brycon pesu, Charax cf. leticiae, Ctenobrycon hauxwellianus, Oligosarcus argenteus, Phenacogaster pectinatus e Roeboexodon guyanensis.

241 - Coracóide:

[LUCENA, 1993: 84; Buckup，1998: 55; OYAKAWA，1998: 85; NetTo-Ferreira, 2006: 173]

\section{[0] - atingindo a borda anterior do cleitro (Fig. 47 e Fig. 48).}

Olivaichthys mesembrinus, Citharinus latus, Distichodus notospilus, Hemistichodus vaillanti, Neolebias unifasciatus, Xenocharax spilurus, Apareiodon piracicabae, Parodon nasus, Saccodon wagneri, Anodus orinocensis, Bivibranchia fowleri, Hemiodus unimaculatus - Curimatopsis macrolepis, Prochilodus nigricans, Semaprochilodus insignis, Caenotropus labyrinthicus, Anostomus anostomus, Leporellus vittatus, Leporinus fasciatus, Schizodon fasciatus, Carnegiella strigata, Gasteropelecus sternicla, Thoracocharax stellatus, Gilbertolus atratoensis, Hydrolycus tatauaia, Roestes molossus, Boulengerella maculata, Ctenolucius hujeta, Copeina cf. guttata, Lebiasina bimaculata, Piabucina astrigata, Hepsetus odoe, Arnoldichthys spilopterus, Brycinus macrolepidotus, Bryconalestes longipinnis, Chalceus epakros, Characidium bahiensis, Agoniates halecinus, Aphyocharax pusillus, Astyanax mexicanus, Axelrodia reisei, Brittanichthys axelrodi, Brycon pesu, Bryconadenos tanaothoros, Bryconamericus exodon, Bryconops alburnoides, Charax cf. leticiae, Clupeacharax cf. engrauloides, Compsura heterura, Ctenobrycon hauxwellianus, Deuterodon iguape, Diapoma terofali, Galeocharax knerii, Glandulocauda melanogenys, Gnathocharax steindachneri, Gymnocorymbus ternetzi, Hemibrycon polyodon, Hemigrammus unilineatus, Hollandichthys multifasciatus, Hyphessobrycon compressus, Iguanodectes geisleri, Knodus meridae, Landonia latidens, Markiana nigripinnis, Metynnis lippincottianus, Microschemobrycon casiquiare, Moenkhausia xinguensis, Myleus setiger, odontostilbe pequira, oligosarcus argenteus, orthospinus franciscoensis, Paracheirodon axelrodi, Paragoniates alburnus, Phenacogaster pectinatus, Phenagoniates macrolepis, Piabina argentea, Piaractus mesopotamicus, Poptella brevispina, Probolus heterostomus, Rachoviscus graciliceps, Rhinobrycon negrensis, Rhoadsia altipinna, Roeboexodon guyanensis, Salminus hilarii, Serrabrycon magoi, Tetragonopterus argenteus e Triportheus albus.

\section{[1] - não atingindo a borda anterior do cleitro (Fig. 46).}

Chanos chanos, Catostomus commersonnii, Gymnotus aff. carapo, Nannocharax fasciatus, Curimata ocellata, Potamorhina latior, Chilodus punctatus, Acestrorhynchus falcirostris, Erythrinoidea fam. nov, Erythrinus erythrinus, Hoplias malabaricus, Crenuchus spilurus, Atopomesus pachyodus e Stygichthys typhlops. 
242 - Forame coracoidal:

[LuCENA, 1993: 83 \& 85 modificados; LuCENA \& Menezes, 1998:27; Toledo-PizA, 2000: 57; NeTTO-FeRREIRA, 2006: 175 modificado]

(Minimamente conectado).

\section{[0] - ausente (Fig. 46 e Fig. 48).}

Olivaichthys mesembrinus, Gymnotus aff. carapo, Citharinus latus, Distichodus notospilus, Hemistichodus vaillanti, Neolebias unifasciatus, Nannocharax fasciatus, Xenocharax spilurus, Apareiodon piracicabae, Parodon nasus, Saccodon wagneri, Anodus orinocensis, Bivibranchia fowleri, Hemiodus unimaculatus, Curimata ocellata, Curimatopsis macrolepis, Potamorhina latior, Prochilodus nigricans, Semaprochilodus insignis, Caenotropus labyrinthicus, Chilodus punctatus, Anostomus anostomus, Copeina cf. guttata, Lebiasina bimaculata, Piabucina astrigata, Erythrinus erythrinus, Hoplias malabaricus, Hepsetus odoe, Characidium bahiensis, Crenuchus spilurus, Aphyocharax pusillus, Astyanax mexicanus, Atopomesus pachyodus, Axelrodia reisei, Brittanichthys axelrodi, Bryconadenos tanaothoros, Bryconamericus exodon, Charax cf. leticiae, Compsura heterura, Galeocharax knerii, Glandulocauda melanogenys, Gymnocorymbus ternetzi, Landonia latidens, Microschemobrycon casiquiare, Myleus setiger, odontostilbe pequira, Paracheirodon axelrodi, Phenacogaster pectinatus, Phenagoniates macrolepis, Piabina argentea, Rhinobrycon negrensis e Stygichthys typhlops.

\section{[1] - pequeno (Fig. 47).}

Chanos chanos, Catostomus commersonnii, Leporellus vittatus, Leporinus fasciatus, Schizodon fasciatus, Carnegiella strigata, Gasteropelecus sternicla, Thoracocharax stellatus, Acestrorhynchus falcirostris, Boulengerella maculata, Ctenolucius hujeta, Arnoldichthys spilopterus, Brycinus macrolepidotus, Bryconalestes longipinnis, Chalceus epakros, Agoniates halecinus, Brycon pesu, Bryconops alburnoides, Clupeacharax cf. engrauloides, Ctenobrycon hauxwellianus, Deuterodon iguape, Diapoma terofali, Gnathocharax steindachneri, Hemibrycon polyodon, Hemigrammus unilineatus, Hollandichthys multifasciatus, Hyphessobrycon compressus, Iguanodectes geisleri, Knodus meridae, Markiana nigripinnis, Metynnis lippincottianus, Moenkhausia xinguensis, oligosarcus argenteus, orthospinus franciscoensis, Paragoniates alburnus, Piaractus mesopotamicus, Poptella brevispina, Probolus heterostomus, Rachoviscus graciliceps, Rhoadsia altipinna, Roeboexodon guyanensis, Salminus hilarii, Serrabrycon magoi, Tetragonopterus argenteus e Triportheus albus.

[2] - grande.

Gilbertolus atratoensis, Hydrolycus tatauaia e Roestes molossus.

\section{[-] - inaplicável.}

Erythrinoidea fam. nov.

\section{3 - Porção posterior do coracóide:}

\section{[0] - curto, não recobrindo os radiais.}

Chanos chanos, Catostomus commersonnii, Olivaichthys mesembrinus, Gymnotus aff. carapo, Citharinus latus, Distichodus notospilus, Hemistichodus vaillanti, Neolebias unifasciatus, Nannocharax fasciatus, Xenocharax spilurus, Apareiodon piracicabae, Parodon nasus, Saccodon wagneri, Anodus orinocensis, Bivibranchia fowleri, Hemiodus unimaculatus, Curimata ocellata, Curimatopsis macrolepis, Potamorhina latior, Prochilodus nigricans, Semaprochilodus insignis, Caenotropus labyrinthicus, chilodus punctatus, Anostomus anostomus, Leporellus vittatus, Leporinus fasciatus, Schizodon fasciatus, Acestrorhynchus falcirostris, Gilbertolus atratoensis, Hydrolycus tatauaia, Roestes molossus, Copeina cf. guttata, Lebiasina bimaculata, Piabucina astrigata, Erythrinus erythrinus, Hoplias malabaricus, Hepsetus odoe, Arnoldichthys spilopterus, Brycinus macrolepidotus, Bryconalestes longipinnis, Chalceus epakros, Characidium bahiensis, Crenuchus spilurus, Agoniates halecinus, Aphyocharax pusillus, Astyanax mexicanus, Atopomesus pachyodus, Axelrodia reisei, Brittanichthys axelrodi, Brycon pesu, Bryconadenos tanaothoros, Bryconamericus exodon, Bryconops alburnoides, Charax cf. leticiae, Clupeacharax cf. engrauloides, Compsura heterura, Ctenobrycon hauxwellianus, Deuterodon iguape, Diapoma terofali, Galeocharax knerii, Glandulocauda melanogenys, Gymnocorymbus ternetzi, Hemibrycon polyodon, Hemigrammus unilineatus, Hollandichthys multifasciatus, Hyphessobrycon compressus, Iguanodectes geisleri, Knodus meridae, 
Landonia latidens, Markiana nigripinnis, Metynnis lippincottianus, Microschemobrycon casiquiare, Moenkhausia xinguensis, Myleus setiger, odontostilbe pequira, oligosarcus argenteus, orthospinus franciscoensis, Paracheirodon axelrodi, Paragoniates alburnus, Phenacogaster pectinatus, Phenagoniates macrolepis, Piabina argentea, Piaractus mesopotamicus, Poptella brevispina, Probolus heterostomus, Rachoviscus graciliceps, Rhinobrycon negrensis, Rhoadsia altipinna, Roeboexodon guyanensis, Salminus hilarii, Serrabrycon magoi, Stygichthys typhlops, Tetragonopterus argenteus e Triportheus albus.

\section{[1] - longo, recobrindo os radiais.}

Carnegiella strigata, Gasteropelecus sternicla, Thoracocharax stellatus, Boulengerella maculata, Ctenolucius hujeta e Gnathocharax steindachneri.

\section{[-] - inaplicável.}

Erythrinoidea fam. nov.

244 - Processo postero-ventral do coracóide:

[MOREIRA, 2002: 66; NETTO-FERREIRA, 2006: 174]

\section{[0] - curto ou ausente (Fig 46).}

Catostomus commersonnii, Olivaichthys mesembrinus, Gymnotus aff. carapo, Neolebias unifasciatus, Xenocharax spilurus, Saccodon wagneri, Anodus orinocensis, Bivibranchia fowleri, Curimatopsis macrolepis, Potamorhina latior, Caenotropus labyrinthicus, Chilodus punctatus, Leporellus vittatus, Gilbertolus atratoensis, Hydrolycus tatauaia, Roestes molossus, Boulengerella maculata, Ctenolucius hujeta, Lebiasina bimaculata, Piabucina astrigata, Erythrinus erythrinus, Hoplias malabaricus, Arnoldichthys spilopterus, Bryconalestes longipinnis, Aphyocharax pusillus, Astyanax mexicanus, Atopomesus pachyodus, Axelrodia reisei, Brittanichthys axelrodi, Bryconadenos tanaothoros, Bryconamericus exodon, Charax cf. leticiae, Compsura heterura, Ctenobrycon hauxwellianus, Deuterodon iguape, Diapoma terofali, Galeocharax knerii, Glandulocauda melanogenys, Gymnocorymbus ternetzi, Hemibrycon polyodon, Hemigrammus unilineatus, Hollandichthys multifasciatus, Hyphessobrycon compressus, Knodus meridae, Landonia latidens, Markiana nigripinnis, Metynnis lippincottianus, Microschemobrycon casiquiare, Moenkhausia xinguensis, Myleus setiger, Odontostilbe pequira, oligosarcus argenteus, orthospinus franciscoensis, Paracheirodon axelrodi, Paragoniates alburnus, Phenacogaster pectinatus, Phenagoniates macrolepis, Piabina argentea, Poptella brevispina, Probolus heterostomus, Rachoviscus graciliceps, Rhinobrycon negrensis, Rhoadsia altipinna, Roeboexodon guyanensis, Salminus hilarii, Serrabrycon magoi, stygichthys typhlops, Tetragonopterus argenteus e Triportheus albus.

\section{[1] - longo (Fig. 47 e Fig. 48).}

Chanos chanos, Citharinus latus, Distichodus notospilus, Hemistichodus vaillanti, Nannocharax fasciatus, Apareiodon piracicabae, Hemiodus unimaculatus, Curimata ocellata, Prochilodus nigricans, Semaprochilodus insignis, Anostomus anostomus, Leporinus fasciatus, schizodon fasciatus, Acestrorhynchus falcirostris, Copeina cf. guttata, Hepsetus odoe, Brycinus macrolepidotus, Chalceus epakros, Characidium bahiensis, Crenuchus spilurus, Agoniates halecinus, Brycon pesu, Bryconops alburnoides, Clupeacharax cf. engrauloides, Iguanodectes geisleri e Piaractus mesopotamicus.

\section{[-] - inaplicável.}

Carnegiella strigata, Gasteropelecus sternicla, Thoracocharax stellatus , Erythrinoidea fam. nov. e Gnathocharax steindachneri.

\section{[?] - indeterminado.}

Parodon nasus.

245 - Porção anterior da margem dorsal do cleitro: [TOLEDO-PIZA, 2000: 62; ZANATA, 2000: 105]

\section{[0] - continua com a porção posterior.}

Chanos chanos, Catostomus commersonnii, Olivaichthys mesembrinus, Gymnotus aff. carapo, Citharinus latus, Distichodus notospilus, Hemistichodus vaillanti, Neolebias 
unifasciatus, Nannocharax fasciatus, Xenocharax spilurus, Apareiodon piracicabae, Parodon nasus, Saccodon wagneri, Anodus orinocensis, Bivibranchia fowleri, Hemiodus unimaculatus, Curimata ocellata, Curimatopsis macrolepis, Potamorhina latior, Prochilodus nigricans, Semaprochilodus insignis, Caenotropus labyrinthicus, Chilodus punctatus, Anostomus anostomus, Leporellus vittatus, Leporinus fasciatus, Schizodon fasciatus, Carnegiella strigata, Gasteropelecus sternicla, Thoracocharax stellatus , Acestrorhynchus falcirostris, Gilbertolus atratoensis, Roestes molossus, Erythrinoidea fam. nov, Boulengerella maculata, Ctenolucius hujeta, Copeina cf. guttata, Lebiasina bimaculata, Piabucina astrigata, Erythrinus erythrinus, Hoplias malabaricus, Hepsetus odoe, Arnoldichthys spilopterus, Brycinus macrolepidotus, Bryconalestes longipinnis, chalceus epakros, characidium bahiensis, crenuchus spilurus, Agoniates halecinus, Aphyocharax pusillus, Astyanax mexicanus, Atopomesus pachyodus, Axelrodia reisei, Brittanichthys axelrodi, Brycon pesu, Bryconadenos tanaothoros, Bryconamericus exodon, Bryconops alburnoides, Charax cf. leticiae, clupeacharax cf. engrauloides, Compsura heterura, Ctenobrycon hauxwellianus, Deuterodon iguape, Diapoma terofali, Galeocharax knerii, Glandulocauda melanogenys, Gnathocharax steindachneri, Gymnocorymbus ternetzi, Hemibrycon polyodon, Hemigrammus unilineatus, Hollandichthys multifasciatus, Hyphessobrycon compressus, Iguanodectes geisleri, Knodus meridae, Landonia latidens, Markiana nigripinnis, Metynnis lippincottianus, Microschemobrycon casiquiare, Moenkhausia xinguensis, Myleus setiger, odontostilbe pequira, oligosarcus argenteus, orthospinus franciscoensis, Paracheirodon axelrodi, Paragoniates alburnus, Phenacogaster pectinatus, Phenagoniates macrolepis, Piabina argentea, Piaractus mesopotamicus, Poptella brevispina, Probolus heterostomus, Rachoviscus graciliceps, Rhinobrycon negrensis, Rhoadsia altipinna, Roeboexodon guyanensis, Salminus hilarii, Serrabrycon magoi, Tetragonopterus argenteus.

\section{[1] - abruptamente mais estreita.}

Hydrolycus tatauaia e Triportheus albus.

[?] - indeterminado.

Stygichthys typhlops.

\section{6 - Disposição dos raios da peitoral:}

\section{[0] - dispostos em suave arco.}

Catostomus commersonnii, Olivaichthys mesembrinus, Gymnotus aff. carapo, Citharinus latus, Distichodus notospilus, Hemistichodus vaillanti, Neolebias unifasciatus, Nannocharax fasciatus, Xenocharax spilurus, Apareiodon piracicabae, Parodon nasus, Saccodon wagneri, Anodus orinocensis, Bivibranchia fowleri, Hemiodus unimaculatus, Curimata ocellata, Curimatopsis macrolepis, Potamorhina latior, Prochilodus nigricans, Semaprochilodus insignis, Caenotropus labyrinthicus, Chilodus punctatus, Anostomus anostomus, Leporellus vittatus, Leporinus fasciatus, Schizodon fasciatus, Carnegiella strigata, Gasteropelecus sternicla, Thoracocharax stellatus, Acestrorhynchus falcirostris, Gilbertolus atratoensis, Hydrolycus tatauaia, Roestes molossus, Boulengerella maculata, Ctenolucius hujeta, Copeina cf. guttata, Lebiasina bimaculata, Piabucina astrigata, Erythrinus erythrinus, Hoplias malabaricus, Arnoldichthys spilopterus, Brycinus macrolepidotus, Bryconalestes longipinnis, Chalceus epakros, Characidium bahiensis, Crenuchus spilurus, Aphyocharax pusillus, Astyanax mexicanus, Atopomesus pachyodus, Axelrodia reisei, Bryconamericus exodon, Bryconops alburnoides, Charax cf. leticiae, Compsura heterura, Ctenobrycon hauxwellianus, Diapoma terofali, Glandulocauda melanogenys, Gnathocharax steindachneri, Gymnocorymbus ternetzi, Hemigrammus unilineatus, Hollandichthys multifasciatus, Hyphessobrycon compressus, Iguanodectes geisleri, Metynnis lippincottianus, Microschemobrycon casiquiare, Myleus setiger, Oligosarcus argenteus, orthospinus franciscoensis, Paracheirodon axelrodi, Paragoniates alburnus, Phenacogaster pectinatus, Phenagoniates macrolepis, Piabina argentea, Piaractus mesopotamicus, Poptella brevispina, Probolus heterostomus, Rachoviscus graciliceps, Rhinobrycon negrensis, Rhoadsia altipinna, Serrabrycon magoi e Stygichthys typhlops.

\section{[1] - dispostos em uma linha reta.}

Chanos chanos, Agoniates halecinus, Brittanichthys axelrodi, Brycon pesu, Bryconadenos tanaothoros, Clupeacharax cf. engrauloides, Deuterodon iguape, Galeocharax knerii, Hemibrycon polyodon, Knodus meridae, Landonia latidens, Markiana nigripinnis, Moenkhausia xinguensis, odontostilbe pequira, Roeboexodon guyanensis, Salminus hilarii, Tetragonopterus argenteus e Triportheus albus.

[-] - inaplicável. 
Erythrinoidea fam. nov.

[?] - indeterminado.

Hepsetus odoe.

247 - Porção póstero-ventral do cleitro:

[LANGEANI, 1998: 12; BENINE, 2004: 68 modificado]

[0] - acompanhando as margens dorsal e ventral, ou com uma leve projeção (Fig. 50B).

Catostomus commersonnii, Gymnotus aff. carapo, Citharinus latus, Neolebias unifasciatus, Xenocharax spilurus, Curimata ocellata, Curimatopsis macrolepis, Potamorhina latior, Prochilodus nigricans, Semaprochilodus insignis, Carnegiella strigata, Gasteropelecus sternicla, Thoracocharax stellatus, Acestrorhynchus falcirostris, Gilbertolus atratoensis, Hydrolycus tatauaia, Roestes molossus, Erythrinoidea fam. nov, Boulengerella maculata, Ctenolucius hujeta, Copeina cf. guttata, Lebiasina bimaculata, Piabucina astrigata, Erythrinus erythrinus, Hoplias malabaricus, Hepsetus odoe, Arnoldichthys spilopterus, Brycinus macrolepidotus, Bryconalestes longipinnis, Chalceus epakros, Astyanax mexicanus, Brittanichthys axelrodi, Brycon pesu, Bryconadenos tanaothoros, Bryconamericus exodon, Bryconops alburnoides, Charax cf. leticiae, Clupeacharax cf. engrauloides, Compsura heterura, Ctenobrycon hauxwellianus, Deuterodon iguape, Diapoma terofali, Galeocharax knerii, Glandulocauda melanogenys, Gnathocharax steindachneri, Gymnocorymbus ternetzi, Hemibrycon polyodon, Hemigrammus unilineatus, Hollandichthys multifasciatus, Hyphessobrycon compressus, Markiana nigripinnis, Metynnis lippincottianus, Moenkhausia xinguensis, Myleus setiger, oligosarcus argenteus, Orthospinus franciscoensis, Paracheirodon axelrodi, Paragoniates alburnus, Phenacogaster pectinatus, Piaractus mesopotamicus, Poptella brevispina, Probolus heterostomus, Rachoviscus graciliceps, Rhinobrycon negrensis, Rhoadsia altipinna, Roeboexodon guyanensis, Salminus hilarii, Serrabrycon magoi, Stygichthys typhlops, Tetragonopterus argenteus e Triportheus albus,

\section{[1] - com distinta projeção posterior (Fig. 50A).}

Chanos chanos, Olivaichthys mesembrinus, Distichodus notospilus, Hemistichodus vaillanti, Nannocharax fasciatus, Apareiodon piracicabae, Parodon nasus, Saccodon wagneri, Anodus orinocensis, Bivibranchia fowleri, Hemiodus unimaculatus, Caenotropus labyrinthicus, Chilodus punctatus, Anostomus anostomus, Leporellus vittatus, Leporinus fasciatus, Schizodon fasciatus, Characidium bahiensis, crenuchus spilurus, Agoniates halecinus, Aphyocharax pusillus, Atopomesus pachyodus, Axelrodia reisei, Iguanodectes geisleri, Knodus meridae, Landonia latidens, Microschemobrycon casiquiare, odontostilbe pequira, Phenagoniates macrolepis e Piabina argêntea.

248 - Espaço delimitado pelo coracóide e o cleitro:

[LUCENA, 1993: 82; BUCKUP, 1998: 56; OYAKAWA, 1998: 83; NetTO-FerReIRA, 2006 : 176]

[0] - estreito ou ausente (Fig. 46).

Gymnotus aff. carapo, Erythrinoidea fam. nov, Erythrinus erythrinus, Hoplias malabaricus, Characidium bahiensis, Crenuchus spilurus, Atopomesus pachyodus, Brittanichthys axelrodi e Stygichthys typhlops.

\section{[1] - presente (Fig. 47 e Fig. 48).}

Chanos chanos, Catostomus commersonnii, olivaichthys mesembrinus, Citharinus latus, Distichodus notospilus, Hemistichodus vaillanti, Neolebias unifasciatus, Nannocharax fasciatus, Xenocharax spilurus, Apareiodon piracicabae, Parodon nasus, Saccodon wagneri, Anodus orinocensis, Bivibranchia fowleri, Hemiodus unimaculatus, curimata ocellata, Curimatopsis macrolepis, Potamorhina latior, Prochilodus nigricans, Semaprochilodus insignis, Caenotropus labyrinthicus, Chilodus punctatus, Anostomus anostomus, Leporellus vittatus, Leporinus fasciatus, Schizodon fasciatus, Carnegiella strigata, Gasteropelecus sternicla, Thoracocharax stellatus, Acestrorhynchus falcirostris, Gilbertolus atratoensis, Hydrolycus tatauaia, Roestes molossus, Boulengerella maculata, Ctenolucius hujeta, Copeina cf. guttata, Lebiasina bimaculata, Piabucina astrigata, Hepsetus odoe, Arnoldichthys spilopterus, Brycinus macrolepidotus, Bryconalestes longipinnis, Chalceus epakros, Agoniates halecinus, Aphyocharax pusillus, Astyanax mexicanus, Axelrodia 
reisei, Brycon pesu, Bryconadenos tanaothoros, Bryconamericus exodon, Bryconops alburnoides, Charax cf. leticiae, Clupeacharax cf. engrauloides, Compsura heterura, ctenobrycon hauxwellianus, Deuterodon iguape, Diapoma terofali, Galeocharax knerii, Glandulocauda melanogenys, Gnathocharax steindachneri, Gymocorymbus ternetzi, Hemibrycon polyodon, Hemigrammus unilineatus, Hollandichthys multifasciatus, Hyphessobrycon compressus, Iguanodectes geisleri, Knodus meridae, Landonia latidens, Markiana nigripinnis, Metynnis lippincottianus, Microschemobrycon casiquiare, Moenkhausia xinguensis, Myleus setiger, odontostilbe pequira, oligosarcus argenteus, orthospinus franciscoensis, Paracheirodon axelrodi, Paragoniates alburnus, Phenacogaster pectinatus, Phenagoniates macrolepis, Piabina argentea, Piaractus mesopotamicus, Poptella brevispina, Probolus heterostomus, Rachoviscus graciliceps, Rhinobrycon negrensis, Rhoadsia altipinna, Roeboexodon guyanensis, Salminus hilarii, Serrabrycon magoi, Tetragonopterus argenteus e Triportheus albus.

\section{[-] - inaplicável.}

olivaichthys mesembrinus.

\section{[?] - indeterminado.}

Gymnotus aff. carapo.

249 - Forame escapular:

[LUCENA, 1993: 87 modificado; VARI \& HAROLD, 2001: 48 e 49 modificados; ZANATA \& VARI, 2005:136 modificado; NETTO-FERREIRA, 2006: 172 modificado]

\section{[0] - incluso na escápula.}

Chanos chanos, Catostomus commersonnii, Citharinus latus, Distichodus notospilus, Hemistichodus vaillanti, Neolebias unifasciatus, Nannocharax fasciatus, Xenocharax spilurus, Apareiodon piracicabae, Parodon nasus, Saccodon wagneri, Thoracocharax stellatus, Gilbertolus atratoensis, Hydrolycus tatauaia, Roestes molossus, Ctenolucius hujeta, Piabucina astrigata, Characidium bahiensis, crenuchus spilurus, Agoniates halecinus, clupeacharax cf. engrauloides, Iguanodectes geisleri, Rachoviscus graciliceps, Stygichthys typhlops e Triportheus albus.

[1] - delimitado pela escápula e cleitro (processo anterior da escápula fino e incompleto).

Anodus orinocensis, Hemiodus unimaculatus, Prochilodus nigricans, Semaprochilodus insignis, Anostomus anostomus, Leporellus 'vittatus, Leporinus fasciatus, Schizodon fasciatus, Carnegiella strigata, Gasteropelecus sternicla, Acestrorhynchus falcirostris, Boulengerella maculata, Lebiasina bimaculata, Arnoldichthys spilopterus, Brycinus macrolepidotus, Bryconalestes longipinnis, Chalceus epakros, Astyanax mexicanus, Atopomesus pachyodus, Axelrodia reisei, Brittanichthys axelrodi, Brycon pesu, Bryconadenos tanaothoros, Bryconamericus exodon, Bryconops alburnoides, Deuterodon iguape, Galeocharax knerii, Glandulocauda melanogenys, Gnathocharax steindachneri, Gymnocorymbus ternetzi, Hemibrycon polyodon, Hollandichthys multifasciatus, Hyphessobrycon compressus, Landonia latidens, Markiana nigripinnis, Metynnis lippincottianus, Myleus setiger, odontostilbe pequira, oligosarcus argenteus, orthospinus franciscoensis, Piabina argentea, Piaractus mesopotamicus, Poptella brevispina, Probolus heterostomus, Rhinobrycon negrensis, Rhoadsia altipinna, Roeboexodon guyanensis, Salminus hilarii, Serrabrycon magoi e Tetragonopterus argenteus.

\section{[2] - delimitado pela cleitro e coracóide.}

Bivibranchia fowleri, Curimata ocellata, Curimatopsis macrolepis, Potamorhina latior, Caenotropus labyrinthicus, Chilodus punctatus, Erythrinoidea fam. nov, Copeina cf. guttata, Erythrinus erythrinus, Hoplias malabaricus, Hepsetus odoe, Aphyocharax pusillus, Charax cf. leticiae, Compsura heterura, Ctenobrycon hauxwellianus, Diapoma terofali, Hemigrammus unilineatus, Knodus meridae, Microschemobrycon casiquiare, Moenkhausia xinguensis, Paracheirodon axelrodi, Paragoniates alburnus, Phenacogaster pectinatus e Phenagoniates macrolepis.

250 - Radial proximal 4:

[NeTto-FERREIRA, 2006: 178 modificado]

[0] - articulando apenas com o coracóide. 
Chanos chanos, Catostomus commersonnii, Gymnotus aff. carapo, Citharinus latus, Distichodus notospilus, Hemistichodus vaillanti, Neolebias unifasciatus, Nannocharax fasciatus, Xenocharax spilurus, Apareiodon piracicabae, Saccodon wagneri, Anodus orinocensis, Curimata ocellata, Potamorhina latior, Prochilodus nigricans, Semaprochilodus insignis, Caenotropus labyrinthicus, Acestrorhynchus falcirostris, Gilbertolus atratoensis, Hydrolycus tatauaia, Roestes molossus, Boulengerella maculata, Ctenolucius hujeta, Piabucina astrigata, Brycinus macrolepidotus, Bryconalestes longipinnis, Agoniates halecinus, Aphyocharax pusillus, Brittanichthys axelrodi, Brycon pesu, Bryconops alburnoides, Deuterodon iguape, Glandulocauda melanogenys, Gnathocharax steindachneri, Hemibrycon polyodon, Iguanodectes geisleri, Knodus meridae, Landonia latidens, Phenacogaster pectinatus, Phenagoniates macrolepis, Roeboexodon guyanensis e Triportheus albus.

\section{[1] - articulando com o coracóide e a escápula.}

Parodon nasus, Bivibranchia fowleri, Hemiodus unimaculatus, Curimatopsis macrolepis, Chilodus punctatus, Anostomus anostomus, Leporellus vittatus, Leporinus fasciatus, Schizodon fasciatus, Carnegiella strigata, Gasteropelecus sternicla, copeina cf. guttata, Lebiasina bimaculata, Hepsetus odoe, Arnoldichthys spilopterus, Chalceus epakros, Characidium bahiensis, crenuchus spilurus, Astyanax mexicanus, Atopomesus pachyodus, Axelrodia reisei, Bryconadenos tanaothoros, Bryconamericus exodon, Charax cf. leticiae, Clupeacharax cf. engrauloides, Compsura heterura, Ctenobrycon hauxwellianus, Diapoma terofali, Galeocharax knerii, Gymnocorymbus ternetzi, Hollandichthys multifasciatus, Hyphessobrycon compressus, Markiana nigripinnis, Metynnis lippincottianus, Microschemobrycon casiquiare, Moenkhausia xinguensis, Myleus setiger, odontostilbe pequira, Oligosarcus argenteus, Orthospinus franciscoensis, Paracheirodon axelrodi, Paragoniates alburnus, Piabina argentea, Piaractus mesopotamicus, Poptella brevispina, Probolus heterostomus, Rachoviscus graciliceps, Rhinobrycon negrensis, Rhoadsia altipinna, Salminus hilarii, Serrabrycon magoi e Tetragonopterus argenteus.

\section{[2] - articulando apenas com a escápula.}

Stygichthys typhlops.

\section{[-] - inaplicável.}

Olivaichthys mesembrinus, Thoracocharax stellatus, Erythrinoidea fam. nov.

\section{[?] - indeterminado.}

Erythrinus erythrinus, Hoplias malabaricus e Hemigrammus unilineatus.

251 - Radial proximal 1:

[ZANATA \& VARI, 2005:137]

[0] - com quatro áreas de articulação.

Citharinus latus, Distichodus notospilus, Hemistichodus vaillanti, Xenocharax spilurus, Bivibranchia fowleri, Hemiodus unimaculatus e Curimata ocellata.

\section{[1] - com três áreas de articulação.}

Neolebias unifasciatus, Nannocharax fasciatus, Saccodon wagneri, Anodus orinocensis, Curimatopsis macrolepis, Potamorhina latior, Prochilodus nigricans, Semaprochilodus insignis, Caenotropus labyrinthicus, Leporellus vittatus, Leporinus fasciatus, Schizodon fasciatus, Gilbertolus atratoensis, Copeina cf. guttata, Lebiasina bimaculata, Piabucina astrigata, Erythrinus erythrinus, Arnoldichthys spilopterus, Brycinus macrolepidotus, Bryconalestes longipinnis, Chalceus epakros, Characidium bahiensis, Crenuchus spilurus, Aphyocharax pusillus, Astyanax mexicanus, Atopomesus pachyodus, Axelrodia reisei, Brittanichthys axelrodi, Brycon pesu, Bryconadenos tanaothoros, Bryconamericus exodon, Charax cf. leticiae, Compsura heterura, Deuterodon iguape, Galeocharax knerii, Gymnocorymbus ternetzi, Hemibrycon polyodon, Iguanodectes geisleri, Landonia latidens, Metynnis lippincottianus, Microschemobrycon casiquiare, Moenkhausia xinguensis, Myleus setiger, Odontostilbe pequira, oligosarcus argenteus, orthospinus franciscoensis, Paracheirodon axelrodi, Phenacogaster pectinatus, Phenagoniates macrolepis, Piabina argentea, Piaractus mesopotamicus, Poptella brevispina, Probolus heterostomus, Rhinobrycon negrensis, Rhoadsia altipinna, Roeboexodon guyanensis, salminus hilarii, Serrabrycon magoi e Tetragonopterus argenteus.

\section{[2] - com duas áreas de articulação.}


Apareiodon piracicabae, Parodon nasus, Chilodus punctatus, Anostomus anostomus, Boulengerella maculata, Ctenolucius hujeta, Hoplias malabaricus, Hepsetus odoe, Agoniates halecinus, Clupeacharax cf. engrauloides, Ctenobrycon hauxwellianus, Diapoma terofali, Glandulocauda melanogenys, Hemigrammus unilineatus, Hollandichthys multifasciatus, Hyphessobrycon compressus, Knodus meridae, Markiana nigripinnis, Paragoniates alburnus, Rachoviscus graciliceps e Stygichthys typhlops.

\section{[3] - com uma área de articulação.}

Chanos chanos, Catostomus commersonnii, Gymnotus aff. carapo, Gasteropelecus sternicla, Gnathocharax steindachneri e Triportheus albus.

\section{[-] - inaplicável.}

Olivaichthys mesembrinus, Carnegiella strigata, Thoracocharax stellatus e Erythrinoidea fam. nov.

\section{[?] - indeterminado.}

Acestrorhynchus falcirostris, Hydrolycus tatauaia, Roestes molossus e Bryconops alburnoides.

\section{2 - Desenvolvimento do processo dorsal na base do primeiro raio ramificado da peitoral:}

[0] - presente.

Chanos chanos, Catostomus commersonnii, olivaichthys mesembrinus, Citharinus latus, Distichodus notospilus, Hemistichodus vaillanti, Xenocharax spilurus, Apareiodon piracicabae, Parodon nasus, Anodus orinocensis, Curimatopsis macrolepis, Potamorhina latior, Prochilodus nigricans, Semaprochilodus insignis, Caenotropus labyrinthicus, Chilodus punctatus, Anostomus anostomus, Leporellus vittatus, Leporinus fasciatus, Schizodon fasciatus, Piabucina astrigata, Hoplias malabaricus, Hepsetus odoe, Arnoldichthys spilopterus, Brycinus macrolepidotus, Bryconalestes longipinnis, Characidium bahiensis, crenuchus spilurus, Aphyocharax pusillus, Astyanax mexicanus, Atopomesus pachyodus, Axelrodia reisei, Bryconops alburnoides, Ctenobrycon hauxwellianus, Galeocharax knerii, Iguanodectes geisleri, orthospinus franciscoensis, Phenacogaster pectinatus, Piaractus mesopotamicus, Poptella brevispina, Roeboexodon guyanensis e Salminus hilarii.

\section{[1] - ausente.}

Gymnotus aff. carapo, Neolebias unifasciatus, Nannocharax fasciatus, Saccodon wagneri, Bivibranchia fowleri, Hemiodus unimaculatus, Curimata ocellata, Carnegiella strigata, Gasteropelecus sternicla, Thoracocharax stellatus, Acestrorhynchus falcirostris, Gilbertolus atratoensis, Hydrolycus tatauaia, Roestes molossus, Boulengerella maculata, Ctenolucius hujeta, Copeina cf. guttata, Lebiasina bimaculata, Erythrinus erythrinus, Chalceus epakros, Agoniates halecinus, Brittanichthys axelrodi, Brycon pesu, Bryconadenos tanaothoros, Bryconamericus exodon, Charax cf. leticiae, clupeacharax cf. engrauloides, Compsura heterura, Deuterodon iguape, Diapoma terofali, Glandulocauda melanogenys, Gnathocharax steindachneri, Gymnocorymbus ternetzi, Hemibrycon polyodon, Hemigrammus unilineatus, Hollandichthys multifasciatus, Hyphessobrycon compressus, Knodus meridae, Landonia latidens, Markiana nigripinnis, Metynnis lippincottianus, Microschemobrycon casiquiare, Moenkhausia xinguensis, Myleus setiger, odontostilbe pequira, oligosarcus argenteus, Paracheirodon axelrodi, Paragoniates alburnus, Phenagoniates macrolepis, Piabina argentea, Probolus heterostomus, Rachoviscus graciliceps, Rhinobrycon negrensis, Rhoadsia altipinna, Serrabrycon magoi, Stygichthys typhlops, Tetragonopterus argenteus e Triportheus albus.

[?] - indeterminado.

Erythrinoidea fam. nov.

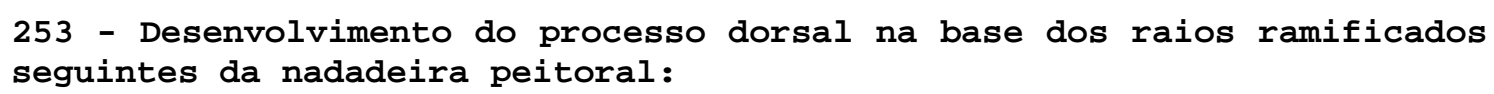

[0] - presente. 
Chanos chanos, Catostomus commersonnii, olivaichthys mesembrinus, Citharinus latus, Distichodus notospilus, Hemistichodus vaillanti, Nannocharax fasciatus, Xenocharax spilurus, Apareiodon piracicabae, Parodon nasus, Saccodon wagneri, Anodus orinocensis, Hemiodus unimaculatus, Curimata ocellata, Curimatopsis macrolepis, Potamorhina latior, Prochilodus nigricans, Semaprochilodus insignis, Caenotropus labyrinthicus, Chilodus punctatus, Anostomus anostomus, Leporellus vittatus, Leporinus fasciatus, Schizodon fasciatus, Carnegiella strigata, Gasteropelecus sternicla, Thoracocharax stellatus , Gilbertolus atratoensis, Roestes molossus, Boulengerella maculata, ctenolucius hujeta, Copeina cf. guttata, Lebiasina bimaculata, Piabucina astrigata, Erythrinus erythrinus, Hoplias malabaricus, Arnoldichthys spilopterus, Chalceus epakros, Characidium bahiensis, Crenuchus spilurus, Astyanax mexicanus, Atopomesus pachyodus, Axelrodia reisei, Brycon pesu, Bryconops alburnoides, Charax cf. leticiae, Clupeacharax cf. engrauloides, Ctenobrycon hauxwellianus, Galeocharax knerii, Hemigrammus unilineatus, Iguanodectes geisleri, Metynnis lippincottianus, Myleus setiger, orthospinus franciscoensis, Phenacogaster pectinatus, Piaractus mesopotamicus, Poptella brevispina e Salminus hilarii.

\section{[1] - ausente.}

Gymnotus aff. carapo, Neolebias unifasciatus, Bivibranchia fowleri, Acestrorhynchus falcirostris, Hydrolycus tatauaia, Hepsetus odoe, Brycinus macrolepidotus, Bryconalestes longipinnis, Agoniates halecinus, Aphyocharax pusillus, Brittanichthys axelrodi, Bryconadenos tanaothoros, Bryconamericus exodon, Compsura heterura, Deuterodon iguape, Diapoma terofali, Glandulocauda melanogenys, Gnathocharax steindachneri, Gymnocorymbus ternetzi, Hemibrycon polyodon, Hollandichthys multifasciatus, Hyphessobrycon compressus, Knodus meridae, Landonia latidens, Markiana nigripinnis, Microschemobrycon casiquiare, Moenkhausia xinguensis, odontostilbe pequira, oligosarcus argenteus, Paracheirodon axelrodi, Paragoniates alburnus, Phenagoniates macrolepis, Piabina argentea, Probolus heterostomus, Rachoviscus graciliceps, Rhinobrycon negrensis, Rhoadsia altipinna, Roeboexodon guyanensis, Serrabrycon magoi, Stygichthys typhlops, Tetragonopterus argenteus e Triportheus albus.

\section{[?] - indeterminado.}

Erythrinoidea fam. nov.

\subsubsection{Cintura e nadadeira pélvica}

254 - Números de raios ramificados da nadadeira pélvica:

[LUCENA, 1993: 95, modificado; BUCKUP, 1998: 63, modificado; ZANATA, 2000: 108, modificado; ZANATA \& VARI, 2005: 138, modificado e NeTTo-FerREIRA, 2006: 230, modificado]

\section{(Minimamente conectado).}

\section{[0] - menos que 7 .}

Olivaichthys mesembrinus, Carnegiella strigata, Gasteropelecus sternicla, Thoracocharax stellatus, Erythrinus erythrinus, Agoniates halecinus, Clupeacharax cf. engrauloides, Diapoma terofali, Gymnocorymbus ternetzi, Hollandichthys multifasciatus, Metynnis lippincottianus, Orthospinus franciscoensis, Paracheirodon axelrodi, Phenagoniates macrolepis, Rachoviscus graciliceps, Stygichthys typhlops e Triportheus albus.

$$
\text { [1] }-7 \text {. }
$$

Nannocharax fasciatus, Apareiodon piracicabae, Parodon nasus, Acestrorhynchus falcirostris, Gilbertolus atratoensis, Hydrolycus tatauaia, Roestes molossus, Erythrinoidea fam. nov, Boulengerella maculata, Ctenolucius hujeta, Copeina cf. guttata, Lebiasina bimaculata, Piabucina astrigata, Erythrinus erythrinus, Hoplias malabaricus, Arnoldichthys spilopterus, Bryconalestes longipinnis, Aphyocharax pusillus, Astyanax mexicanus, Atopomesus pachyodus, Axelrodia reisei, Brittanichthys axelrodi, Brycon pesu, Bryconadenos tanaothoros, Bryconamericus exodon, Charax cf. leticiae, Compsura heterura, ctenobrycon hauxwellianus, Deuterodon iguape, Galeocharax knerii, Glandulocauda melanogenys, Gnathocharax steindachneri, Hemibrycon polyodon, Hemigrammus unilineatus, Hyphessobrycon compressus, Iguanodectes geisleri, Knodus meridae, Landonia latidens, Markiana nigripinnis, Microschemobrycon casiquiare, Moenkhausia xinguensis, Myleus setiger, Odontostilbe pequira, Oligosarcus argenteus, orthospinus franciscoensis, Paragoniates alburnus, Phenacogaster pectinatus, Piabina argentea, Piaractus 
mesopotamicus, Poptella brevispina, Probolus heterostomus, Rhinobrycon negrensis, Rhoadsia altipinna, Roeboexodon guyanensis, Salminus hilarii, Serrabrycon magoi e Tetragonopterus argenteus.

\section{[2] - 8 .}

Neolebias unifasciatus, Saccodon wagneri, Curimatopsis macrolepis, Potamorhina latior, Prochilodus nigricans, Semaprochilodus insignis, Caenotropus labyrinthicus, Chilodus punctatus, Anostomus anostomus, Leporellus vittatus, Schizodon fasciatus, Boulengerella maculata, Ctenolucius hujeta, Lebiasina bimaculata, Hepsetus odoe, Brycinus macrolepidotus, Chalceus epakros, Characidium bahiensis, Crenuchus spilurus e Bryconops alburnoides.

\section{[3] -9 .}

Chanos chanos, Citharinus latus, Distichodus notospilus, Hemistichodus vaillanti, Bivibranchia fowleri, Caenotropus labyrinthicus e Leporinus fasciatus.

\section{[4] - mais que 9.}

Chanos chanos, Catostomus commersonnii, Xenocharax spilurus, Anodus orinocensis, Hemiodus unimaculatus e Curimata ocellata.

\section{[-] - inaplicável.}

Gymnotus aff. carapo.

\section{[1, 2] - polimórfico.}

Chanos chanos, Caenotropus labyrinthicus, Boulengerella maculata, ctenolucius hujeta, Lebiasina bimaculata, Erythrinus erythrinus e orthospinus franciscoensis.

255 - Osso pélvico:

[FINK \& FINK, 1981:102, modificado; BUCKUP, 1998: 62, modificado; ZANATA, 2000: 109, modificado; ZANATA \& VARI, 2005: 139, modificado; e NETTOFERREIRA, 2006: 227, modificado]

\section{[0] - bifurcado (Fig. 51).}

Catostomus commersonnii, Olivaichthys mesembrinus, Distichodus notospilus, Hemistichodus vaillanti, Neolebias unifasciatus, Nannocharax fasciatus, Xenocharax spilurus, Curimata ocellata, Potamorhina latior, Diapoma terofali e Hyphessobrycon compressus.

\section{[1] - triangular (Fig. 53).}

Chanos chanos, Citharinus latus, Apareiodon piracicabae, Parodon nasus, Saccodon wagneri, Prochilodus nigricans, Semaprochilodus insignis, Anostomus anostomus, Carnegiella strigata, Gasteropelecus sternicla, Thoracocharax stellatus Acestrorhynchus falcirostris, Gilbertolus atratoensis, Hydrolycus tatauaia, Roestes molossus, Erythrinoidea fam. nov, Boulengerella maculata, Ctenolucius hujeta, copeina cf. guttata, Lebiasina bimaculata, Piabucina astrigata, Erythrinus erythrinus, Hoplias malabaricus, Hepsetus odoe, Arnoldichthys spilopterus, Brycinus macrolepidotus, Bryconalestes longipinnis, Chalceus epakros, Characidium bahiensis, Crenuchus spilurus, Agoniates halecinus, Aphyocharax pusillus, Astyanax mexicanus, Atopomesus pachyodus, Axelrodia reisei, Brittanichthys axelrodi, Brycon pesu, Bryconadenos tanaothoros, Bryconamericus exodon, Charax cf. leticiae, Clupeacharax cf. engrauloides, Compsura heterura, Ctenobrycon hauxwellianus, Deuterodon iguape, Galeocharax knerii, Glandulocauda melanogenys, Gnathocharax steindachneri, Gymnocorymbus ternetzi, Hemibrycon polyodon, Hemigrammus unilineatus, Hollandichthys multifasciatus, Knodus meridae, Landonia latidens, Markiana nigripinnis, Metynnis lippincottianus, Microschemobrycon casiquiare, Moenkhausia xinguensis, Myleus setiger, Odontostilbe pequira, Oligosarcus argenteus, Orthospinus franciscoensis, Paracheirodon axelrodi, Paragoniates alburnus, Phenacogaster pectinatus, Phenagoniates macrolepis, Piabina argentea, Poptella brevispina, Probolus heterostomus, Rachoviscus graciliceps, Rhinobrycon negrensis, Rhoadsia altipinna, Roeboexodon guyanensis, Salminus hilarii, Serrabrycon magoi, Stygichthys typhlops, Tetragonopterus argenteus e Triportheus albus.

(Fig. 52).

[2] - quase bifurcado, formando uma meia-lua entre as duas pontas 
Anodus orinocensis, Bivibranchia fowleri, Hemiodus unimaculatus, Curimatopsis macrolepis, Caenotropus labyrinthicus, Chilodus punctatus, Leporellus vittatus, Leporinus fasciatus, Schizodon fasciatus, Bryconops alburnoides, Iguanodectes geisleri e Piaractus mesopotamicus.

\section{[-] - inaplicável.}

Gymnotus aff. carapo.

256 - Origem do osso pélvico:

[LUCENA, 1993: 94, modificado]

(Minimamente conectado).

\section{[0] - anterior a segunda costela.}

Prochilodus nigricans, Semaprochilodus insignis, Caenotropus labyrinthicus, Chilodus punctatus, Roestes molossus, Atopomesus pachyodus, Axelrodia reisei, Charax cf. leticiae, Ctenobrycon hauxwellianus, Galeocharax knerii, Glandulocauda melanogenys, Gnathocharax steindachneri, Gymnocorymbus ternetzi, Hemigrammus unilineatus, Hollandichthys multifasciatus, Hyphessobrycon compressus, Markiana nigripinnis, Microschemobrycon casiquiare, orthospinus franciscoensis, Paracheirodon axelrodi, Paragoniates alburnus, Phenacogaster pectinatus, Phenagoniates macrolepis, Poptella brevispina, Probolus heterostomus e Tetragonopterus argenteus.

\section{[1] - entre a segunda e a quarta.}

Citharinus latus, Distichodus notospilus, Neolebias unifasciatus, Nannocharax fasciatus, Curimatopsis macrolepis, Potamorhina latior, Gilbertolus atratoensis, Brycinus macrolepidotus, Bryconalestes longipinnis, Crenuchus spilurus, Astyanax mexicanus, Brittanichthys axelrodi, Bryconadenos tanaothoros, Bryconamericus exodon, Compsura heterura, Deuterodon iguape, Diapoma terofali, Hemibrycon polyodon, Knodus meridae, Landonia latidens, Metynnis lippincottianus, Moenkhausia xinguensis, Myleus setiger, odontostilbe pequira, Oligosarcus argenteus, Piabina argentea, Piaractus mesopotamicus, Rachoviscus graciliceps, Rhinobrycon negrensis, Rhoadsia altipinna, Roeboexodon guyanensis e Serrabrycon magoi.

\section{[2] - entre a quarta e a sexta costela.}

Xenocharax spilurus, Curimata ocellata, Anostomus anostomus, Leporellus vittatus, Leporinus fasciatus, Copeina cf. guttata, Lebiasina bimaculata, Erythrinus erythrinus, Arnoldichthys spilopterus, Chalceus epakros, Characidium bahiensis, Agoniates halecinus, Aphyocharax pusillus, Brycon pesu, Bryconops alburnoides, Clupeacharax cf. engrauloides, Iguanodectes geisleri, Salminus hilarii, Stygichthys typhlops e Triportheus albus.

\section{[3] - depois da sexta costela.}

Chanos chanos, Catostomus commersonnii, Hemistichodus vaillanti, Apareiodon piracicabae, Parodon nasus, Saccodon wagneri, Anodus orinocensis, Bivibranchia fowleri, Hemiodus unimaculatus, Acestrorhynchus falcirostris, Erythrinoidea fam. nov, Boulengerella maculata, Ctenolucius hujeta, Piabucina astrigata, Hoplias malabaricus e Hepsetus odoe.

\section{[-] - inaplicável.}

Gymnotus aff. carapo, Carnegiella strigata, Gasteropelecus sternicla e Thoracocharax stellatus.

\section{[?] - indeterminado.}

Olivaichthys mesembrinus, Schizodon fasciatus e Hydrolycus tatauaia.

257 - Orientação entre os osso pélvicos:

[0] - formando um ângulo obstuso. 
Chanos chanos, Catostomus commersonnii, Citharinus latus, Distichodus notospilus, Hemistichodus vaillanti, Neolebias unifasciatus, Nannocharax fasciatus, Xenocharax spilurus, Apareiodon piracicabae, Parodon nasus, Saccodon wagneri, Anodus orinocensis, Bivibranchia fowleri, Hemiodus unimaculatus, Curimata ocellata, Curimatopsis macrolepis, Caenotropus labyrinthicus, Chilodus punctatus, Anostomus anostomus, Leporellus vittatus, Leporinus fasciatus, Schizodon fasciatus, Acestrorhynchus falcirostris, Hydrolycus tatauaia, Boulengerella maculata, Ctenolucius hujeta, Copeina cf. guttata, Lebiasina bimaculata, Piabucina astrigata, Erythrinus erythrinus, Hoplias malabaricus, Hepsetus odoe, Bryconalestes longipinnis, Aphyocharax pusillus, Atopomesus pachyodus, Axelrodia reisei, Bryconadenos tanaothoros, Bryconamericus exodon, Bryconops alburnoides, Compsura heterura, Deuterodon iguape, Diapoma terofali, Galeocharax knerii, Glandulocauda melanogenys, Gnathocharax steindachneri, Iguanodectes geisleri, Knodus meridae, Markiana nigripinnis, Microschemobrycon casiquiare, odontostilbe pequira, Paracheirodon axelrodi, Paragoniates alburnus, Piabina argentea, Probolus heterostomus, Rachoviscus graciliceps, Rhinobrycon negrensis, Rhoadsia altipinna, Roeboexodon guyanensis, Salminus hilarii, Serrabrycon magoi e stygichthys typhlops.

\section{[1] - formando um ângulo agudo.}

Olivaichthys mesembrinus, Potamorhina latior, Prochilodus nigricans, Semaprochilodus insignis, Carnegiella strigata, Gasteropelecus sternicla, Thoracocharax stellatus, Erythrinoidea fam. nov, Arnoldichthys spilopterus, Brycinus macrolepidotus, Chalceus epakros, Characidium bahiensis, Crenuchus spilurus, Agoniates halecinus, Astyanax mexicanus, Brittanichthys axelrodi, Brycon pesu, Charax cf. leticiae, clupeacharax cf. engrauloides, Ctenobrycon hauxwellianus, Gymnocorymbus ternetzi, Hemibrycon polyodon Hemigrammus unilineatus, Hollandichthys multifasciatus, Hyphessobrycon compressus, Landonia latidens, Metynnis lippincottianus, Moenkhausia xinguensis, Myleus setiger, orthospinus franciscoensis, Phenacogaster pectinatus, Phenagoniates macrolepis, Piaractus mesopotamicus, Poptella brevispina, Tetragonopterus argenteus e Triportheus albus.

\section{[-] - inaplicável.}

Gymnotus aff. carapo.

\section{[?] - indeterminado.}

Gilbertolus atratoensis, Roestes molossus e Oligosarcus argenteus.

258 - Posição entre ossos pélvicos:

[NETTO-FERREIRA, 2006: 229, modificado]

\section{[0] - distantes.}

Acestrorhynchus falcirostris, Boulengerella maculata, Ctenolucius hujeta, Hepsetus odoe, Brycinus macrolepidotus, Bryconalestes longipinnis, Chalceus epakros, Gnathocharax steindachneri e Stygichthys typhlops.

\section{[1] - próximos (Fig. 51).}

Chanos chanos, Citharinus latus, Distichodus notospilus, Neolebias unifasciatus, Xenocharax spilurus, Curimata ocellata, Curimatopsis macrolepis, Prochilodus nigricans, Anostomus anostomus, Leporinus fasciatus, Schizodon fasciatus, Carnegiella strigata, Gasteropelecus sternicla, Thoracocharax stellatus, Hydrolycus tatauaia, Erythrinoidea fam. nov, Copeina cf. guttata, Piabucina astrigata, Arnoldichthys spilopterus, Aphyocharax pusillus, Astyanax mexicanus, Atopomesus pachyodus, Axelrodia reisei, Brycon pesu, Bryconadenos tanaothoros, Bryconamericus exodon, Bryconops alburnoides, Charax cf. leticiae, Clupeacharax cf. engrauloides, Compsura heterura, Ctenobrycon hauxwellianus, Deuterodon iguape, Diapoma terofali, Glandulocauda melanogenys, Hemibrycon polyodon, Hemigrammus unilineatus, Hollandichthys multifasciatus, Hyphessobrycon compressus, Iguanodectes geisleri, Knodus meridae, Landonia latidens, Markiana nigripinnis, Microschemobrycon casiquiare, Moenkhausia xinguensis, odontostilbe pequira, orthospinus franciscoensis, Phenagoniates macrolepis, Piabina argentea, Poptella brevispina, Probolus heterostomus, Rhinobrycon negrensis, Rhoadsia altipinna, Roeboexodon guyanensis, Serrabrycon magoi, Tetragonopterus argenteus e Triportheus albus.

\section{[2] - associados anteriormente (Fig. 53).}

Hemistichodus vaillanti, Nannocharax fasciatus, Semaprochilodus insignis, Lebiasina bimaculata, Erythrinus erythrinus, Hoplias malabaricus, Gymnocorymbus ternetzi, Metynnis 
lippincottianus, Paracheirodon axelrodi, Phenacogaster pectinatus e Rachoviscus graciliceps.

\section{[3] - associados medianamente (Fig. 52).}

Catostomus commersonnii, olivaichthys mesembrinus, Apareiodon piracicabae, Parodon nasus, Saccodon wagneri, Anodus orinocensis, Bivibranchia fowleri, Hemiodus unimaculatus , Potamorhina latior, Caenotropus labyrinthicus, Chilodus punctatus, Leporellus vittatus, Characidium bahiensis, crenuchus spilurus, Agoniates halecinus, Brittanichthys axelrodi, Myleus setiger e Piaractus mesopotamicus.

\section{[-] - inaplicável.}

Gymnotus aff. carapo.

[?] - indeterminado.

Gilbertolus atratoensis, Roestes molossus, Galeocharax knerii, oligosarcus argenteus, Paragoniates alburnus e Salminus hilarii.

\section{9 - Orientação do osso pélvico:}

\section{[0] - aproximadamente perpendiculara a altura.}

Chanos chanos, Catostomus commersonnii, olivaichthys mesembrinus, Citharinus latus, Distichodus notospilus, Hemistichodus vaillanti, Neolebias unifasciatus, Nannocharax fasciatus, Xenocharax spilurus, Apareiodon piracicabae, Parodon nasus, Saccodon wagneri, Anodus orinocensis, Bivibranchia fowleri, Hemiodus unimaculatus, curimata ocellata, Curimatopsis macrolepis, Potamorhina latior, Prochilodus nigricans, Semaprochilodus insignis, Caenotropus labyrinthicus, Chilodus punctatus, Anostomus anostomus, Leporellus vittatus, Leporinus fasciatus, Schizodon fasciatus, Acestrorhynchus falcirostris, Gilbertolus atratoensis, Hydrolycus tatauaia, Roestes molossus, Erythrinoidea fam. nov., Boulengerella maculata, Ctenolucius hujeta, Copeina cf. guttata, Lebiasina bimaculata, Piabucina astrigata, Erythrinus erythrinus, Hoplias malabaricus, Hepsetus odoe, Arnoldichthys spilopterus, Brycinus macrolepidotus, Bryconalestes longipinnis, Chalceus epakros, Characidium bahiensis, Crenuchus spilurus, Agoniates halecinus, Aphyocharax pusillus, Astyanax mexicanus, Atopomesus pachyodus, Axelrodia reisei, Brittanichthys axelrodi, Brycon pesu, Bryconadenos tanaothoros, Bryconamericus exodon, Bryconops alburnoides, Clupeacharax cf. engrauloides, Compsura heterura, Ctenobrycon hauxwellianus, Deuterodon iguape, Diapoma terofali, Galeocharax knerii, Glandulocauda melanogenys, Hemibrycon polyodon, Hemigrammus unilineatus, Hollandichthys multifasciatus, Hyphessobrycon compressus, Iguanodectes geisleri, Knodus meridae, Landonia latidens, Markiana nigripinnis, Metynnis lippincottianus, Microschemobrycon casiquiare, Moenkhausia xinguensis, Myleus setiger, Odontostilbe pequira, oligosarcus argenteus, orthospinus franciscoensis, Paracheirodon axelrodi, Paragoniates alburnus, Phenacogaster pectinatus, Phenagoniates macrolepis, Piabina argentea, Piaractus mesopotamicus, Probolus heterostomus, Rachoviscus graciliceps, Rhinobrycon negrensis, Rhoadsia altipinna, Roeboexodon guyanensis, Salminus hilarii, Serrabrycon magoi, stygichthys typhlops, Tetragonopterus argenteus e Triportheus albus.

\section{[1] - em um ângulo obtuso com a altura.}

Charax cf. leticiae, Gnathocharax steindachneri, Gymnocorymbus ternetzi e Poptella brevispina.

\section{[2] - aproximadamente paralelo com a altura.}

Carnegiella strigata, Gasteropelecus sternicla e Thoracocharax stellatus.

$$
\text { [-] - inaplicável. }
$$

Gymnotus aff. carapo.

260 - Tamanho da esquírola pélvica:

raio).

[0] - pequeno (menor que a metade da proção não segmentada do 
Catostomus commersonnii, Nannocharax fasciatus, Apareiodon piracicabae, Parodon nasus, Saccodon wagneri, Anodus orinocensis, Hemiodus unimaculatus, Prochilodus nigricans, Gilbertolus atratoensis, Hydrolycus tatauaia, Roestes molossus, Boulengerella maculata, Ctenolucius hujeta, Copeina cf. guttata, Erythrinus erythrinus, Hoplias malabaricus, Chalceus epakros, Crenuchus spilurus, Astyanax mexicanus, Atopomesus pachyodus, Brittanichthys axelrodi, Bryconamericus exodon, Bryconops alburnoides, Charax cf. leticiae, Compsura heterura, Ctenobrycon hauxwellianus, Diapoma terofali, Galeocharax knerii, Glandulocauda melanogenys, Gymnocorymbus ternetzi, Hemigrammus unilineatus, Hollandichthys multifasciatus, Hyphessobrycon compressus, Iguanodectes geisleri, Markiana nigripinnis, Metynnis lippincottianus, Microschemobrycon casiquiare, Moenkhausia xinguensis, Myleus setiger, odontostilbe pequira, orthospinus franciscoensis, Paracheirodon axelrodi, Phenacogaster pectinatus, Phenagoniates macrolepis, Piaractus mesopotamicus, Poptella brevispina, Serrabrycon magoi, Tetragonopterus argenteus e Triportheus albus. raio)

[1] - médio (aproximadamente a metade da proção não segmentada do

Bivibranchia fowleri, Curimata ocellata, Curimatopsis macrolepis, Chilodus punctatus, Anostomus anostomus, Schizodon fasciatus, Acestrorhynchus falcirostris, Lebiasina bimaculata, Piabucina astrigata, Hepsetus odoe, Brycinus macrolepidotus, Bryconalestes longipinnis, Agoniates halecinus, Aphyocharax pusillus, Axelrodia reisei, Brycon pesu, Bryconadenos tanaothoros, Deuterodon iguape, Gnathocharax steindachneri, Hemibrycon polyodon, Knodus meridae, Landonia latidens, Piabina argentea, Probolus heterostomus , Roeboexodon guyanensis e Salminus hilarii.

raio)

[2] - grande (maior que a metade da porção não segmentada do

Chanos chanos, Olivaichthys mesembrinus, Citharinus latus, Distichodus notospilus, Hemistichodus vaillanti, Neolebias unifasciatus, Xenocharax spilurus, Potamorhina latior, Semaprochilodus insignis, Caenotropus labyrinthicus, Leporellus vittatus, Leporinus fasciatus, Arnoldichthys spilopterus, Clupeacharax cf. engrauloides, oligosarcus argenteus, Paragoniates alburnus, Rachoviscus graciliceps, Rhinobrycon negrensis, Rhoadsia altipinna e Stygichthys typhlops.

\section{[-] - inaplicável.}

Gymnotus aff. carapo, Carnegiella strigata, Gasteropelecus sternicla e Thoracocharax stellatus.

\section{[?] - indeterminado.}

Erythrinoidea fam. nov., Characidium bahiensis.

\section{1 - Porção anterior do primeiro raio da nadadeira pélvica:}

\section{[0] - processo medial formando um ângulo quase reto com o corpo principal do raio (Fig. 51 e Fig. 52).}

Chanos chanos, Catostomus commersonnii, olivaichthys mesembrinus, Citharinus latus, Distichodus notospilus, Hemistichodus vaillanti, Neolebias unifasciatus, Nannocharax fasciatus, Xenocharax spilurus, Apareiodon piracicabae, Parodon nasus, Saccodon wagneri, Anodus orinocensis, Bivibranchia fowleri, Hemiodus unimaculatus , Curimata ocellata, Curimatopsis macrolepis, Potamorhina latior, Prochilodus nigricans, Semaprochilodus insignis, Caenotropus labyrinthicus, Chilodus punctatus, Anostomus anostomus, Leporellus vittatus, Leporinus fasciatus, Schizodon fasciatus, Acestrorhynchus falcirostris, Hydrolycus tatauaia, Boulengerella maculata, Ctenolucius hujeta, Copeina cf. guttata, Lebiasina bimaculata, Piabucina astrigata, Erythrinus erythrinus, Hoplias malabaricus, Hepsetus odoe, Arnoldichthys spilopterus, Brycinus macrolepidotus, Bryconalestes longipinnis, Chalceus epakros, Characidium bahiensis, Crenuchus spilurus, Agoniates halecinus, Aphyocharax pusillus, Atopomesus pachyodus, Brycon pesu, clupeacharax cf. engrauloides, Compsura heterura, Ctenobrycon hauxwellianus, Deuterodon iguape, Hemibrycon polyodon, Hemigrammus unilineatus, Knodus meridae, oligosarcus argenteus, Piabina argentea, Piaractus mesopotamicus, Salminus hilarii, Serrabrycon magoi, Stygichthys typhlops e Triportheus albus.

[1] - uma curva suave entre o processo e o raio (Fig. 53). 
Gilbertolus atratoensis, Roestes molossus, Astyanax mexicanus, Axelrodia reisei, Brittanichthys axelrodi, Bryconadenos tanaothoros, Bryconamericus exodon, Charax cf. leticiae, Diapoma terofali, Galeocharax knerii, Glandulocauda melanogenys, Gnathocharax steindachneri, Gymnocorymbus ternetzi, Hollandichthys multifasciatus, Hyphessobrycon compressus, Iguanodectes geisleri, Landonia latidens, Markiana nigripinnis, Metynnis lippincottianus, Microschemobrycon casiquiare, Moenkhausia xinguensis, Myleus setiger, odontostilbe pequira, orthospinus franciscoensis, Paracheirodon axelrodi, Paragoniates alburnus, Phenacogaster pectinatus, Phenagoniates macrolepis, Poptella brevispina, Probolus heterostomus, Rachoviscus graciliceps, Rhinobrycon negrensis, Rhoadsia altipinna, Roeboexodon guyanensis e Tetragonopterus argenteus.

\section{[-] - inaplicável.}

Gymnotus aff. carapo, Carnegiella strigata, Gasteropelecus sternicla e Thoracocharax stellatus.

\section{[?] - indeterminado.}

Erythrinoidea fam. nov. e Bryconops alburnoides.

\section{2 - Eixo cilíndrico do osso pélvico:}

\section{[0] - com lamela lateral similar a lamela medial.}

Curimata ocellata, Semaprochilodus insignis, Schizodon fasciatus, Carnegiella strigata, Gasteropelecus sternicla, Thoracocharax stellatus, Clupeacharax cf. engrauloides, Gymnocorymbus ternetzi e Tetragonopterus argenteus.

[1] - com lamela lateral muito mais estreita (Figs. 51, 52 e 53).

Chanos chanos, Catostomus commersonnii, olivaichthys mesembrinus, Citharinus latus, Distichodus notospilus, Hemistichodus vaillanti, Neolebias unifasciatus, Nannocharax fasciatus, Xenocharax spilurus, Apareiodon piracicabae, Parodon nasus, Saccodon wagneri, Anodus orinocensis, Bivibranchia fowleri, Hemiodus unimaculatus , Curimatopsis macrolepis, Potamorhina latior, Prochilodus nigricans, Caenotropus labyrinthicus, Chilodus punctatus, Anostomus anostomus, Leporellus vittatus, Leporinus fasciatus, Acestrorhynchus falcirostris, Hydrolycus tatauaia, Roestes molossus, Boulengerella maculata, Ctenolucius hujeta, Copeina cf. guttata, Lebiasina bimaculata, Piabucina astrigata, Erythrinus erythrinus, Hoplias malabaricus, Hepsetus odoe, Arnoldichthys spilopterus, Brycinus macrolepidotus, Bryconalestes longipinnis, Chalceus epakros, Characidium bahiensis, Crenuchus spilurus, Agoniates halecinus, Aphyocharax pusillus, Astyanax mexicanus, Atopomesus pachyodus, Axelrodia reisei, Brittanichthys axelrodi, Brycon pesu, Bryconadenos tanaothoros, Bryconamericus exodon, Bryconops alburnoides, Charax cf. leticiae, Compsura heterura, Ctenobrycon hauxwellianus, Deuterodon iguape, Diapoma terofali, Galeocharax knerii, Glandulocauda melanogenys, Gnathocharax steindachneri, Hemibrycon polyodon, Hemigrammus unilineatus, Hollandichthys multifasciatus, Hyphessobrycon compressus, Iguanodectes geisleri, Knodus meridae, Landonia latidens, Markiana nigripinnis, Metynnis lippincottianus, Microschemobrycon casiquiare, Moenkhausia xinguensis, Myleus setiger, Odontostilbe pequira, Oligosarcus argenteus, orthospinus franciscoensis, Paracheirodon axelrodi, Paragoniates alburnus, Phenacogaster pectinatus, Phenagoniates macrolepis, Piabina argentea, Piaractus mesopotamicus, Poptella brevispina, Probolus heterostomus, Rachoviscus graciliceps, Rhinobrycon negrensis, Rhoadsia altipinna, Roeboexodon guyanensis, Salminus hilarii, Serrabrycon magoi e Triportheus albus.

\section{[2] - sem lamela lateral.}

Gilbertolus atratoensis, Erythrinoidea fam. nov. e Stygichthys typhlops.

$$
\text { [-] - inaplicável. }
$$

Gymnotus aff. carapo.

- Margem lateral do osso pélvico:

[0] - lisa (Fig. 52 e Fig. 53). 
Chanos chanos, Catostomus commersonnii, olivaichthys mesembrinus, Citharinus latus, Hemistichodus vaillanti, Neolebias unifasciatus, Nannocharax fasciatus, Apareiodon piracicabae, Parodon nasus, Saccodon wagneri, Anodus orinocensis, Bivibranchia fowleri, Hemiodus unimaculatus, Curimata ocellata, Curimatopsis macrolepis, Potamorhina latior, Prochilodus nigricans, Semaprochilodus insignis, Caenotropus labyrinthicus, chilodus punctatus, Anostomus anostomus, Leporellus vittatus, Schizodon fasciatus, Carnegiella strigata, Gasteropelecus sternicla, Thoracocharax stellatus, Gilbertolus atratoensis, Hydrolycus tatauaia, Roestes molossus, Erythrinoidea fam. nov, Boulengerella maculata, ctenolucius hujeta, Lebiasina bimaculata, Piabucina astrigata, Erythrinus erythrinus, Hoplias malabaricus, Hepsetus odoe, Brycinus macrolepidotus, Bryconalestes longipinnis, Chalceus epakros, Characidium bahiensis, Crenuchus spilurus, Aphyocharax pusillus, Astyanax mexicanus, Atopomesus pachyodus, Axelrodia reisei, Brittanichthys axelrodi, Brycon pesu, Bryconadenos tanaothoros, Bryconamericus exodon, Bryconops alburnoides, Charax cf. leticiae, Clupeacharax cf. engrauloides, Compsura heterura, ctenobrycon hauxwellianus, Deuterodon iguape, Diapoma terofali, Galeocharax knerii, Glandulocauda melanogenys, Gnathocharax steindachneri, Gymnocorymbus ternetzi, Hemibrycon polyodon , Hemigrammus unilineatus, Hollandichthys multifasciatus, Hyphessobrycon compressus, Iguanodectes geisleri, Knodus meridae, Landonia latidens, Markiana nigripinnis, Metynnis lippincottianus, Microschemobrycon casiquiare, Moenkhausia xinguensis, Myleus setiger, odontostilbe pequira, Oligosarcus argenteus, orthospinus franciscoensis, Paracheirodon axelrodi, Paragoniates alburnus, Phenacogaster pectinatus, Phenagoniates macrolepis, Piabina argentea, Poptella brevispina, Probolus heterostomus, Rachoviscus graciliceps, Rhinobrycon negrensis, Rhoadsia altipinna, Roeboexodon guyanensis, Salminus hilarii, Serrabrycon magoi, Tetragonopterus argenteus e Triportheus albus.

[1] - discontínua, com porção posterior mais larga que anterior (Fig. 51).

Distichodus notospilus, Xenocharax spilurus, Leporinus fasciatus, Acestrorhynchus falcirostris, Copeina cf. guttata, Arnoldichthys spilopterus, Agoniates halecinus e Piaractus mesopotamicus.

\section{[-] - inaplicável.}

Gymnotus aff. Carapo e Stygichthys typhlops.

264 - Extensão da lamela lateral do osso pélvico:

[ZANATA \& VARI, 2005: 140, modificado]

\section{[0] - do mesmo tamanho do processo cilíndrico.}

Hemistichodus vaillanti, Nannocharax fasciatus, Parodon nasus, Caenotropus labyrinthicus, Chilodus punctatus, Bryconalestes longipinnis, Chalceus epakros, Atopomesus pachyodus, Gymnocorymbus ternetzi, Knodus meridae, Landonia latidens, Metynnis lippincottianus e Tetragonopterus argenteus.

\section{[1] - em mais da metade do processo cilíndrico.}

Citharinus latus, Apareiodon piracicabae, Saccodon wagneri, Hemiodus unimaculatus, Curimata ocellata, Potamorhina latior, Prochilodus nigricans, Semaprochilodus insignis, Leporellus vittatus, Leporinus fasciatus, Schizodon fasciatus, Roestes molossus, Copeina cf. guttata, Hepsetus odoe, Charax cf. leticiae, Glandulocauda melanogenys, Myleus setiger, Orthospinus franciscoensis, Paragoniates alburnus, Phenacogaster pectinatus, Poptella brevispina e Triportheus albus.

\section{[2] - em aproximadamente metade do processo cilíndrico.}

Anodus orinocensis, Hydrolycus tatauaia, Brycon pesu, Clupeacharax cf. engrauloides, Hemigrammus unilineatus, Markiana nigripinnis, Microschemobrycon casiquiare, Moenkhausia xinguensis, Piaractus mesopotamicus e Serrabrycon magoi.

\section{[3] - em menos da metade, normalmente só na base.}

Chanos chanos, Catostomus commersonnii, Olivaichthys mesembrinus, Distichodus notospilus, Neolebias unifasciatus, Xenocharax spilurus, Bivibranchia fowleri, Curimatopsis macrolepis, Anostomus anostomus, Carnegiella strigata, Gasteropelecus sternicla, Thoracocharax stellatus, Acestrorhynchus falcirostris, Gilbertolus atratoensis, Erythrinoidea fam. nov, Boulengerella maculata, Ctenolucius hujeta, Lebiasina bimaculata, Piabucina astrigata, Erythrinus erythrinus, Hoplias malabaricus, 
Arnoldichthys spilopterus, Brycinus macrolepidotus, characidium bahiensis, crenuchus spilurus, Agoniates halecinus, Aphyocharax pusillus, Astyanax mexicanus, Axelrodia reisei, Brittanichthys axelrodi, Bryconadenos tanaothoros, Bryconamericus exodon, Bryconops alburnoides, Compsura heterura, Ctenobrycon hauxwellianus, Deuterodon iguape, Diapoma terofali, Galeocharax knerii, Gnathocharax steindachneri, Hemibrycon polyodon, Hollandichthys multifasciatus, Hyphessobrycon compressus, Iguanodectes geisleri, odontostilbe pequira, oligosarcus argenteus, Paracheirodon axelrodi, Phenagoniates macrolepis, Piabina argentea, probolus heterostomus, Rachoviscus graciliceps, Rhinobrycon negrensis, Rhoadsia altipinna, Roeboexodon guyanensis e Salminus hilarii.

\section{[-] - inaplicável.}

Gymnotus aff. Carapo e Stygichthys typhlops.

265 - Extensão da lamela medial do osso pélvico:
[ZANATA \& VARI, 2005: 140, modificado]

[0] - do mesmo tamanho do processo cilíndrico.

Chanos chanos, Citharinus latus, Apareiodon piracicabae, Parodon nasus, Saccodon wagneri, Anodus orinocensis, Curimatopsis macrolepis, Potamorhina latior, Prochilodus nigricans, Semaprochilodus insignis, Anostomus anostomus, Leporellus vittatus, Leporinus fasciatus, Hydrolycus tatauaia, Roestes molossus, Arnoldichthys spilopterus, Chalceus epakros, Characidium bahiensis, crenuchus spilurus, Aphyocharax pusillus, Astyanax mexicanus, Atopomesus pachyodus, Brycon pesu, Bryconadenos tanaothoros, Charax cf. leticiae, Compsura heterura, Ctenobrycon hauxwellianus, Deuterodon iguape, Diapoma terofali, Galeocharax knerii, Glandulocauda melanogenys, Gymnocorymbus ternetzi, Hemibrycon polyodon, Hemigrammus unilineatus, Knodus meridae, Landonia latidens, Markiana nigripinnis, Metynnis lippincottianus, Microschemobrycon casiquiare, Moenkhausia xinguensis, Myleus setiger, oligosarcus argenteus, orthospinus franciscoensis, Paracheirodon axelrodi, Phenacogaster pectinatus, Phenagoniates macrolepis, Piabina argentea, Piaractus mesopotamicus, Probolus heterostomus, Rachoviscus graciliceps, Rhinobrycon negrensis, Rhoadsia altipinna, Roeboexodon guyanensis, Salminus hilarii, Serrabrycon magoi, Tetragonopterus argenteus e Triportheus albus.

\section{[1] - mais curto que o processo cilíndrico.}

Bivibranchia fowleri, Hemiodus unimaculatus, Caenotropus labyrinthicus, Chilodus punctatus, Schizodon fasciatus, Carnegiella strigata, Gasteropelecus sternicla, Thoracocharax stellatus, Acestrorhynchus falcirostris, Gilbertolus atratoensis, Erythrinoidea fam. nov, Boulengerella maculata, Ctenolucius hujeta, Copeina cf. guttata, Lebiasina bimaculata, Piabucina astrigata, Erythrinus erythrinus, Hoplias malabaricus, Hepsetus odoe, Brycinus macrolepidotus, Bryconalestes longipinnis, Agoniates halecinus, Axelrodia reisei, Brittanichthys axelrodi, Bryconamericus exodon, Bryconops alburnoides, Clupeacharax cf. engrauloides, Gnathocharax steindachneri, Hollandichthys multifasciatus, Hyphessobrycon compressus, Iguanodectes geisleri, Odontostilbe pequira, Paragoniates alburnus, Poptella brevispina e Stygichthys typhlops.

\section{[-] - inaplicável.}

Catostomus commersonnii, Olivaichthys mesembrinus, Gymnotus aff. carapo, Distichodus notospilus, Hemistichodus vaillanti, Neolebias unifasciatus, Nannocharax fasciatus, Xenocharax spilurus e Curimata ocellata.

\section{6 - Porção medial do processo isquiático:}

\section{[0] - um eixo simples.}

Chanos chanos, Catostomus commersonnii, olivaichthys mesembrinus, Citharinus latus, Distichodus notospilus, Hemistichodus vaillanti, Neolebias unifasciatus, Nannocharax fasciatus, Xenocharax spilurus, Apareiodon piracicabae, Parodon nasus, Saccodon wagneri, Bivibranchia fowleri, Potamorhina latior, Anostomus anostomus, Leporellus vittatus, Leporinus fasciatus, Schizodon fasciatus, Carnegiella strigata, Acestrorhynchus falcirostris, Hydrolycus tatauaia, Roestes molossus, Boulengerella maculata, Ctenolucius hujeta, Copeina cf. guttata, Lebiasina bimaculata, Piabucina astrigata, Hepsetus odoe, Arnoldichthys spilopterus, Chalceus epakros, Characidium bahiensis, crenuchus spilurus, Aphyocharax pusillus, Astyanax mexicanus, Clupeacharax cf. engrauloides, Compsura heterura, Hollandichthys multifasciatus, Hyphessobrycon compressus, Iguanodectes geisleri, Markiana nigripinnis, Metynnis lippincottianus, oligosarcus argenteus, 
orthospinus franciscoensis, Poptella brevispina, Probolus heterostomus , Salminus hilarii, Stygichthys typhlops e Triportheus albus.

\section{[1] - com projeção ântero-ventral.}

Anodus orinocensis, Hemiodus unimaculatus, Curimata ocellata, Curimatopsis macrolepis, Prochilodus nigricans, Semaprochilodus insignis, Caenotropus labyrinthicus, Chilodus punctatus, Erythrinus erythrinus, Hoplias malabaricus, Bryconalestes longipinnis, Agoniates halecinus, Atopomesus pachyodus, Axelrodia reisei, Brittanichthys axelrodi, Brycon pesu, Bryconadenos tanaothoros, Bryconamericus exodon, Bryconops alburnoides, Charax cf. leticiae, Ctenobrycon hauxwellianus, Deuterodon iguape, Diapoma terofali, Galeocharax knerii, Glandulocauda melanogenys, Gnathocharax steindachneri, Gymnocorymbus ternetzi, Hemibrycon polyodon, Hemigrammus unilineatus, Knodus meridae, Landonia latidens, Microschemobrycon casiquiare, Moenkhausia xinguensis, Myleus setiger, odontostilbe pequira, Paracheirodon axelrodi, Paragoniates alburnus, Phenacogaster pectinatus, Phenagoniates macrolepis, Piabina argentea, Piaractus mesopotamicus, Rhinobrycon negrensis, Rhoadsia altipinna, Roeboexodon guyanensis, Serrabrycon magoi e Tetragonopterus argenteus.

\section{[-] - inaplicável.}

Gymnotus aff. carapo, Gasteropelecus sternicla e Thoracocharax stellatus.

\section{[?] - indeterminado.}

Gilbertolus atratoensis, Erythrinoidea fam. nov., Brycinus macrolepidotus e Rachoviscus graciliceps.

267 - Processo posterior do processo isquiático:

[0] - na margem medial (Figs. 51, 52 e 53).

Chanos chanos, Catostomus commersonnii, Olivaichthys mesembrinus, Citharinus latus, Distichodus notospilus, Hemistichodus vaillanti, Neolebias unifasciatus, Nannocharax fasciatus, Xenocharax spilurus, Parodon nasus, Saccodon wagneri, Anodus orinocensis, Bivibranchia fowleri, Hemiodus unimaculatus, Curimata ocellata, curimatopsis macrolepis, Potamorhina latior, Prochilodus nigricans, Semaprochilodus insignis, Caenotropus labyrinthicus, Chilodus punctatus, Anostomus anostomus, Leporellus vittatus, Leporinus fasciatus, Schizodon fasciatus, Acestrorhynchus falcirostris, Gilbertolus atratoensis, Hydrolycus tatauaia, Roestes molossus, Boulengerella maculata, Ctenolucius hujeta, Copeina cf. guttata, Lebiasina bimaculata, Piabucina astrigata, Hepsetus odoe, Arnoldichthys spilopterus, Brycinus macrolepidotus, Bryconalestes longipinnis, Chalceus epakros, Characidium bahiensis, Crenuchus spilurus, Agoniates halecinus, Aphyocharax pusillus, Astyanax mexicanus, Atopomesus pachyodus, Axelrodia reisei, Brittanichthys axelrodi, Brycon pesu, Bryconadenos tanaothoros, Bryconamericus exodon, Bryconops alburnoides, Charax cf. leticiae, Compsura heterura, ctenobrycon hauxwellianus, Deuterodon iguape, Diapoma terofali, Galeocharax knerii, Glandulocauda melanogenys, Gnathocharax steindachneri, Gymnocorymbus ternetzi, Hemibrycon polyodon, Hemigrammus unilineatus, Hollandichthys multifasciatus, Hyphessobrycon compressus, Iguanodectes geisleri, Knodus meridae, Landonia latidens, Markiana nigripinnis, Metynnis lippincottianus, Microschemobrycon casiquiare, Moenkhausia xinguensis, Myleus setiger, odontostilbe pequira, oligosarcus argenteus, orthospinus franciscoensis, Paracheirodon axelrodi, Paragoniates alburnus, Phenacogaster pectinatus, Phenagoniates macrolepis, Piabina argentea, Piaractus mesopotamicus, Poptella brevispina, Probolus heterostomus , Rachoviscus graciliceps, Rhinobrycon negrensis, Rhoadsia altipinna, Roeboexodon guyanensis, Salminus hilarii, Serrabrycon magoi, Stygichthys typhlops, Tetragonopterus argenteus e Triportheus albus.

\section{[1] - na porção mediana.}

Apareiodon piracicabae, Erythrinus erythrinus e Hoplias malabaricus.

\section{[-] - inaplicável.}

Gymnotus aff. carapo, Carnegiella strigata, Gasteropelecus sternicla, Thoracocharax stellatus e Clupeacharax cf. engrauloides.

\section{[?] - indeterminado.}

Erythrinoidea fam. nov. 


\section{[0] - lisa, ou com quilha no eixo cilíndrico.}

Chanos chanos, Catostomus commersonnii, Olivaichthys mesembrinus, Carnegiella strigata, Gasteropelecus sternicla, Thoracocharax stellatus, Gilbertolus atratoensis, Hydrolycus tatauaia, Roestes molossus, Erythrinoidea fam. nov, Copeina cf. guttata, Lebiasina bimaculata, Piabucina astrigata, Erythrinus erythrinus, Hoplias malabaricus, Hepsetus odoe, Arnoldichthys spilopterus, Brycinus macrolepidotus, Bryconalestes longipinnis, Chalceus epakros, Characidium bahiensis, Crenuchus spilurus, Agoniates halecinus, Aphyocharax pusillus, Astyanax mexicanus, Atopomesus pachyodus, Axelrodia reisei, Brittanichthys axelrodi, Brycon pesu, Bryconadenos tanaothoros, Bryconamericus exodon, Bryconops alburnoides, Charax cf. leticiae, Clupeacharax cf. engrauloides, Compsura heterura, Ctenobrycon hauxwellianus, Deuterodon iguape, Diapoma terofali, Galeocharax knerii, Glandulocauda melanogenys, Gymnocorymbus ternetzi, Hemibrycon polyodon, Hemigrammus unilineatus, Hollandichthys multifasciatus, Hyphessobrycon compressus, Iguanodectes geisleri, Knodus meridae, Landonia latidens, Metynnis lippincottianus, Microschemobrycon casiquiare, Moenkhausia xinguensis, Myleus setiger, Odontostilbe pequira, Orthospinus franciscoensis, Paracheirodon axelrodi, Paragoniates alburnus, Phenacogaster pectinatus, Phenagoniates macrolepis, Piabina argentea, Piaractus mesopotamicus, Poptella brevispina, Probolus heterostomus, Rachoviscus graciliceps, Rhinobrycon negrensis, Rhoadsia altipinna, Roeboexodon guyanensis, Salminus hilarii, Serrabrycon magoi, Stygichthys typhlops e Triportheus albus.

\section{[1] - com quilha.}

Citharinus latus, Distichodus notospilus, Hemistichodus vaillanti, Neolebias unifasciatus, Nannocharax fasciatus, Xenocharax spilurus, Apareiodon piracicabae, Parodon nasus, Saccodon wagneri, Anodus orinocensis, Hemiodus unimaculatus, Curimata ocellata, Curimatopsis macrolepis, Potamorhina latior, Prochilodus nigricans, Semaprochilodus insignis, Caenotropus labyrinthicus, Chilodus punctatus, Anostomus anostomus, Leporellus vittatus, Leporinus fasciatus, schizodon fasciatus, Acestrorhynchus falcirostris, Boulengerella maculata, Ctenolucius hujeta, Markiana nigripinnis, oligosarcus argenteus e Tetragonopterus argenteus.

\section{[-] - inaplicável.}

Gymnotus aff. Carapo e Gnathocharax steindachneri.

\section{[?] - indeterminado.}

Bivibranchia fowleri.

\section{9 - Cartilagem do processo isquiático:}

\section{[0] - totalmente calcificada, ou com cartilagem menor que a metade do componente ósseo (Figs. 51, 52 e 53).}

Chanos chanos, Catostomus commersonnii, olivaichthys mesembrinus, Citharinus latus, Distichodus notospilus, Hemistichodus vaillanti, Neolebias unifasciatus, Nannocharax fasciatus, Xenocharax spilurus, Apareiodon piracicabae, Parodon nasus, Saccodon wagneri, Anodus orinocensis, Bivibranchia fowleri, Hemiodus unimaculatus, curimata ocellata, Curimatopsis macrolepis, Potamorhina latior, Prochilodus nigricans, Semaprochilodus insignis, Caenotropus labyrinthicus, Chilodus punctatus, Anostomus anostomus, Leporellus vittatus, Leporinus fasciatus, Schizodon fasciatus, Carnegiella strigata, Gasteropelecus sternicla, Gilbertolus atratoensis, Hydrolycus tatauaia, Roestes molossus, Boulengerella maculata, Ctenolucius hujeta, Copeina cf. guttata, Lebiasina bimaculata, Piabucina astrigata, Erythrinus erythrinus, Hoplias malabaricus, Characidium bahiensis, Crenuchus spilurus, Agoniates halecinus, Aphyocharax pusillus, Astyanax mexicanus, Axelrodia reisei, Brycon pesu, Bryconadenos tanaothoros, Charax cf. leticiae, clupeacharax cf. engrauloides, Galeocharax knerii, Hyphessobrycon compressus, Knodus meridae, Markiana nigripinnis, Metynnis lippincottianus, Myleus setiger, orthospinus franciscoensis, Paragoniates alburnus, Phenagoniates macrolepis, Piabina argentea, Piaractus mesopotamicus, Probolus heterostomus, Rhinobrycon negrensis, Rhoadsia altipinna, Salminus hilarii e Serrabrycon magoi.

maior.

[1] - com cartilagem igual a metade do componente ósseo, ou 
Acestrorhynchus falcirostris, Hepsetus odoe, Arnoldichthys spilopterus, Brycinus macrolepidotus, Bryconalestes longipinnis, Chalceus epakros, Atopomesus pachyodus, Brittanichthys axelrodi, Bryconamericus exodon, Bryconops alburnoides, Compsura heterura, Ctenobrycon hauxwellianus, Deuterodon iguape, Glandulocauda melanogenys, Gnathocharax steindachneri, Gymnocorymbus ternetzi, Hemibrycon polyodon, Hemigrammus unilineatus, Hollandichthys multifasciatus, Iguanodectes geisleri, Landonia latidens, Microschemobrycon casiquiare, Moenkhausia xinguensis, Odontostilbe pequira, oligosarcus argenteus, Paracheirodon axelrodi, Phenacogaster pectinatus, Poptella brevispina, Rachoviscus graciliceps, Roeboexodon guyanensis, Stygichthys typhlops, Tetragonopterus argenteus e Triportheus albus.

\section{[-] - inaplicável.}

Gymnotus aff. Carapo e Thoracocharax stellatus.

\section{[?] - indeterminado.}

Erythrinoidea fam. nov. e Diapoma terofali.

270 - Processo isquiático:

[ZANATA, 2000: 110, modificado e ZANATA \& VARI, 2005: 141, modificado]

[0] - com porções basais apenas em contato.

Olivaichthys mesembrinus, Nannocharax fasciatus, Potamorhina latior, Caenotropus labyrinthicus, Chilodus punctatus, Anostomus anostomus, Leporellus vittatus, Leporinus fasciatus, Schizodon fasciatus, Hydrolycus tatauaia, Bryconalestes longipinnis, characidium bahiensis, crenuchus spilurus, Agoniates halecinus, Glandulocauda melanogenys, Gnathocharax steindachneri, Gymnocorymbus ternetzi, Iguanodectes geisleri, Metynnis lippincottianus, Microschemobrycon casiquiare, Myleus setiger, orthospinus franciscoensis, Paracheirodon axelrodi, Phenacogaster pectinatus, Piaractus mesopotamicus, Roeboexodon guyanensis e Triportheus albus.

\section{[1] - com porções basais em contato mais próximo, muitas vezes interdigitado.}

Chanos chanos, Catostomus commersonnii, Citharinus latus, Distichodus notospilus, Hemistichodus vaillanti, Neolebias unifasciatus, Xenocharax spilurus, Apareiodon piracicabae, Parodon nasus, Saccodon wagneri, Anodus orinocensis, Bivibranchia fowleri, Hemiodus unimaculatus, Curimata ocellata, Curimatopsis macrolepis, Prochilodus nigricans, Semaprochilodus insignis, Carnegiella strigata, Gasteropelecus sternicla, Acestrorhynchus falcirostris, Roestes molossus, Boulengerella maculata, Ctenolucius hujeta, Copeina cf. guttata, Lebiasina bimaculata, Piabucina astrigata, Erythrinus erythrinus, Hoplias malabaricus, Hepsetus odoe, Arnoldichthys spilopterus, Brycinus macrolepidotus, Chalceus epakros, Aphyocharax pusillus, Astyanax mexicanus, Atopomesus pachyodus, Axelrodia reisei, Brittanichthys axelrodi, Brycon pesu, Bryconadenos tanaothoros, Bryconamericus exodon, Bryconops alburnoides, Charax cf. leticiae, Clupeacharax cf. engrauloides, Compsura heterura, Ctenobrycon hauxwellianus, Deuterodon iguape, Diapoma terofali, Galeocharax knerii, Hemibrycon polyodon, Hemigrammus unilineatus, Hollandichthys multifasciatus, Hyphessobrycon compressus, Knodus meridae, Landonia latidens, Markiana nigripinnis, Moenkhausia xinguensis, odontostilbe pequira, Phenagoniates macrolepis, Piabina argentea, Poptella brevispina, Probolus heterostomus, Rhinobrycon negrensis, Rhoadsia altipinna, Serrabrycon magoi, stygichthys typhlops e Tetragonopterus argenteus.

\section{[-] - inaplicável.}

Gymnotus aff. Carapo e Thoracocharax stellatus.

\section{[?] - indeterminado.}

Gilbertolus atratoensis, Erythrinoidea fam. nov., Oligosarcus argenteus, Paragoniates alburnus, Rachoviscus graciliceps e Salminus hilarii.

271 - Porção posterior do processo isquiático:

[0] - com porções posteriores divergentes (Fig. 51). 
Distichodus notospilus, Xenocharax spilurus, Potamorhina latior, Prochilodus nigricans, Semaprochilodus insignis, Caenotropus labyrinthicus, chilodus punctatus, Schizodon fasciatus, Hydrolycus tatauaia, Agoniates halecinus, Stygichthys typhlops e Triportheus albus.

\section{[1] - com porções posteriores paralelas (Fig. 53).}

Citharinus latus, Nannocharax fasciatus, Apareiodon piracicabae, Parodon nasus, Saccodon wagneri, Anodus orinocensis, Bivibranchia fowleri, Hemiodus unimaculatus, Curimata ocellata, Myleus setiger e Piaractus mesopotamicus.

\section{[2] - com porções posteriores convergente.}

Neolebias unifasciatus, Curimatopsis macrolepis, Anostomus anostomus, Leporellus vittatus, Leporinus fasciatus, Bryconalestes longipinnis, Chalceus epakros, Crenuchus spilurus, Brittanichthys axelrodi, Brycon pesu, Bryconamericus exodon, Bryconops alburnoides, Landonia latidens e Piabina argêntea.

\section{[-] - inaplicável.}

Chanos chanos, Catostomus commersonnii, Olivaichthys mesembrinus, Gymnotus aff. carapo, Carnegiella strigata, Gasteropelecus sternicla, Thoracocharax stellatus Acestrorhynchus falcirostris, Boulengerella maculata, ctenolucius hujeta, Copeina cf. guttata, Lebiasina bimaculata, Piabucina astrigata, Erythrinus erythrinus, Hoplias malabaricus, Hepsetus odoe, Arnoldichthys spilopterus, Brycinus macrolepidotus, Characidium bahiensis, Aphyocharax pusillus, Astyanax mexicanus, Atopomesus pachyodus, Axelrodia reisei, Bryconadenos tanaothoros, Charax cf. leticiae, Clupeacharax cf. engrauloides, Compsura heterura, Ctenobrycon hauxwellianus, Deuterodon iguape, Diapoma terofali, Galeocharax knerii, Glandulocauda melanogenys, Gnathocharax steindachneri, Gymnocorymbus ternetzi, Hemibrycon polyodon, Hemigrammus unilineatus, Hollandichthys multifasciatus, Hyphessobrycon compressus, Iguanodectes geisleri, Knodus meridae, Markiana nigripinnis, Metynnis lippincottianus, Microschemobrycon casiquiare, Moenkhausia xinguensis, Odontostilbe pequira, oligosarcus argenteus, orthospinus franciscoensis, Paracheirodon axelrodi, Paragoniates alburnus, Phenacogaster pectinatus, Phenagoniates macrolepis, Poptella brevispina, Probolus heterostomus, Rachoviscus graciliceps, Rhinobrycon negrensis, Rhoadsia altipinna, Roeboexodon guyanensis, Salminus hilarii, Serrabrycon magoi e Tetragonopterus argenteus.

\section{[?] - indeterminado.}

Hemistichodus vaillanti, Gilbertolus atratoensis, Roestes molossus, Erythrinoidea fam. nov.

272 - Comprimento do processo isquiático:

[NeTto-FERREIRA, 2006: 228, modificado]

\section{(Minimamente conectado).}

\section{[0] - muito curto (apenas com processo mediano).}

Bivibranchia fowleri, Carnegiella strigata, Gasteropelecus sternicla, Thoracocharax stellatus, Piabucina astrigata e Hemibrycon polyodon.

\section{[1] - curto (só com curvatural lateral) (Fig. 53).}

Chanos chanos, Catostomus commersonnii, Olivaichthys mesembrinus, Acestrorhynchus falcirostris, Gilbertolus atratoensis, Boulengerella maculata, Ctenolucius hujeta, Copeina cf. guttata, Lebiasina bimaculata, Erythrinus erythrinus, Hoplias malabaricus, Hepsetus odoe, Arnoldichthys spilopterus, Brycinus macrolepidotus, Characidium bahiensis, Aphyocharax pusillus, Astyanax mexicanus, Atopomesus pachyodus, Axelrodia reisei, Bryconadenos tanaothoros, Charax cf. leticiae, Clupeacharax cf. engrauloides, Compsura heterura, Ctenobrycon hauxwellianus, Deuterodon iguape, Diapoma terofali, Galeocharax knerii, Glandulocauda melanogenys, Gnathocharax steindachneri, Gymnocorymbus ternetzi, Hemigrammus unilineatus, Hollandichthys multifasciatus, Hyphessobrycon compressus, Iguanodectes geisleri, Knodus meridae, Markiana nigripinnis, Metynnis lippincottianus, Microschemobrycon casiquiare, Moenkhausia xinguensis, Odontostilbe pequira, oligosarcus argenteus, orthospinus franciscoensis, Paracheirodon axelrodi, Paragoniates alburnus, Phenacogaster pectinatus, Phenagoniates macrolepis, Poptella brevispina, Probolus heterostomus, Rachoviscus graciliceps, Rhinobrycon negrensis, Rhoadsia altipinna, Roeboexodon guyanensis, Salminus hilarii, Serrabrycon magoi e Tetragonopterus argenteus. 
51).

[2] - médio (com pequena projeção após curvatura lateral) (Fig.

Distichodus notospilus, Hemistichodus vaillanti, Neolebias unifasciatus, Nannocharax fasciatus, Xenocharax spilurus, Apareiodon piracicabae, Parodon nasus, Saccodon wagneri, Curimata ocellata, Curimatopsis macrolepis, Prochilodus nigricans, Semaprochilodus insignis, Caenotropus labyrinthicus, Chilodus punctatus, Anostomus anostomus, Leporinus fasciatus, Schizodon fasciatus, Roestes molossus, Bryconalestes longipinnis, Chalceus epakros, Crenuchus spilurus, Brittanichthys axelrodi, Brycon pesu, Bryconamericus exodon, Bryconops alburnoides, Landonia latidens, Piabina argêntea e Stygichthys typhlops.

52 ).

[3] - longo (com projeção maior que a curvatura lateral) (Fig.

Citharinus latus, Anodus orinocensis, Hemiodus unimaculatus, Potamorhina latior, Leporellus vittatus, Hydrolycus tatauaia, Agoniates halecinus, Myleus setiger e Piaractus mesopotamicus. Triportheus albus

\section{[-] - inaplicável.}

Gymnotus aff. carapo.

[?] - indeterminado.

Erythrinoidea fam. nov.

273 - Porção basal projeção posterior do processo isquiático:

\section{[0] - com margem lateral côncava.}

Chanos chanos, Catostomus commersonnii, olivaichthys mesembrinus, Citharinus latus, Distichodus notospilus, Hemistichodus vaillanti, Neolebias unifasciatus, Nannocharax fasciatus, Xenocharax spilurus, Apareiodon piracicabae, Parodon nasus, Saccodon wagneri, Anodus orinocensis, Hemiodus unimaculatus, Curimata ocellata, Curimatopsis macrolepis, Potamorhina latior, Prochilodus nigricans, Semaprochilodus insignis, Caenotropus labyrinthicus, Chilodus punctatus, Anostomus anostomus, Leporellus vittatus, Leporinus fasciatus, Schizodon fasciatus, Acestrorhynchus falcirostris, Gilbertolus atratoensis, Roestes molossus, Boulengerella maculata, Ctenolucius hujeta, copeina cf. guttata, Lebiasina bimaculata, Erythrinus erythrinus, Hoplias malabaricus, Hepsetus odoe, Arnoldichthys spilopterus, Brycinus macrolepidotus, Bryconalestes longipinnis, Chalceus epakros, Characidium bahiensis, Crenuchus spilurus, Agoniates halecinus, Aphyocharax pusillus, Astyanax mexicanus, Atopomesus pachyodus, Axelrodia reisei, Brittanichthys axelrodi, Brycon pesu, Bryconadenos tanaothoros, Bryconamericus exodon, Bryconops alburnoides, Charax cf. leticiae, Clupeacharax cf. engrauloides, Compsura heterura, Ctenobrycon hauxwellianus, Deuterodon iguape, Galeocharax knerii, Glandulocauda melanogenys, Gnathocharax steindachneri, Gymnocorymbus ternetzi, Hemibrycon polyodon, Hemigrammus unilineatus, Hollandichthys multifasciatus, Hyphessobrycon compressus, Iguanodectes geisleri, Knodus meridae, Landonia latidens, Markiana nigripinnis, Metynnis lippincottianus, Microschemobrycon casiquiare, Moenkhausia xinguensis, odontostilbe pequira, oligosarcus argenteus, orthospinus franciscoensis, Paracheirodon axelrodi, Paragoniates alburnus, Phenacogaster pectinatus, Phenagoniates macrolepis, Piabina argentea, Poptella brevispina, Probolus heterostomus, Rachoviscus graciliceps, Rhinobrycon negrensis, Rhoadsia altipinna, Roeboexodon guyanensis, Salminus hilarii, Serrabrycon magoi, Stygichthys typhlops e Tetragonopterus argenteus.

\section{[1] - com margem lateral reta.}

Hydrolycus tatauaia, Myleus setiger, Piaractus mesopotamicus e Triportheus albus.

\section{[-] - inaplicável.}

Gymnotus aff. carapo, Bivibranchia fowleri, Carnegiella strigata, Gasteropelecus sternicla, Thoracocharax stellatus, Piabucina astrigata e Diapoma terofali.

[?] - indeterminado.

Erythrinoidea fam. nov. 


\subsubsection{Nadadeira dorsal e esqueleto de sustentação}

274 - Nadadeira dorsal:

[ZANATA, 2000: 98, modificado; e NetTo-FerReira, 2006: 239, modificado]

[0] - base da nadadeira dorsal à frente da vertical que passa pela origem da nadadeira anal.

Chanos chanos, Catostomus commersonnii, olivaichthys mesembrinus, Citharinus latus, Distichodus notospilus, Hemistichodus vaillanti, Neolebias unifasciatus, Nannocharax fasciatus, Xenocharax spilurus, Apareiodon piracicabae, Parodon nasus, Saccodon wagneri, Anodus orinocensis, Bivibranchia fowleri, Hemiodus unimaculatus, Curimata ocellata, Curimatopsis macrolepis, Potamorhina latior, Prochilodus nigricans, Semaprochilodus insignis, Caenotropus labyrinthicus, Chilodus punctatus, Anostomus anostomus, Leporellus vittatus, Leporinus fasciatus, Schizodon fasciatus, Hydrolycus tatauaia, Erythrinoidea fam. nov, Copeina cf. guttata, Lebiasina bimaculata, Piabucina astrigata, Erythrinus erythrinus, Hoplias malabaricus, Hepsetus odoe, Arnoldichthys spilopterus, Brycinus macrolepidotus, Bryconalestes longipinnis, Chalceus epakros, Characidium bahiensis, crenuchus spilurus, Aphyocharax pusillus, Astyanax mexicanus, Axelrodia reisei, Brittanichthys axelrodi, Brycon pesu, Compsura heterura, Deuterodon iguape, Hemigrammus unilineatus, Iguanodectes geisleri, Knodus meridae, Microschemobrycon casiquiare, Moenkhausia xinguensis, Odontostilbe pequira, Paracheirodon axelrodi, Piabina argentea, Piaractus mesopotamicus, Probolus heterostomus, Roeboexodon guyanensis, Salminus hilarii, Serrabrycon magoi, Stygichthys typhlops e Triportheus albus. dorsal.

[1] - origem da anal com vertical em algum ponto da nadadeira

Acestrorhynchus falcirostris, Roestes molossus, Boulengerella maculata, Ctenolucius hujeta, Agoniates halecinus, Atopomesus pachyodus, Bryconadenos tanaothoros, Bryconamericus exodon, Bryconops alburnoides, Charax cf. leticiae, Ctenobrycon hauxwellianus, Diapoma terofali, Galeocharax knerii, Glandulocauda melanogenys, Gymnocorymbus ternetzi, Hemibrycon polyodon, Hollandichthys multifasciatus, Hyphessobrycon compressus, Landonia latidens, Markiana nigripinnis, Metynnis lippincottianus, Myleus setiger, oligosarcus argenteus, orthospinus franciscoensis, Phenacogaster pectinatus, Poptella brevispina, Rachoviscus graciliceps, Rhinobrycon negrensis, Rhoadsia altipinna e Tetragonopterus argenteus.

\section{[2] - base da nadadeira dorsal posterior à vertical que passa} pela origem da anal.

Carnegiella strigata, Gasteropelecus sternicla, Thoracocharax stellatus, Gilbertolus atratoensis, Clupeacharax cf. engrauloides, Gnathocharax steindachneri, Paragoniates alburnus e Phenagoniates macrolepis.

\section{[-] - inaplicável.}

Gymnotus aff. carapo.

275 - Primeiro pterigióforo da nadadeira dorsal:

[LUCENA, 1993: 98; ZANATA, 2000: 100; ZANATA \& VARI, 2005: 126, modificado e NetTo-FerREIRA, 2006: 235]

[0] - sustentando mais de dois raios.

Chanos chanos, Catostomus commersonnii, Citharinus latus, Distichodus notospilus, Nannocharax fasciatus, Leporinus fasciatus, Schizodon fasciatus, Clupeacharax cf. engrauloides, Piabina argentea, Piaractus mesopotamicus e Rachoviscus graciliceps.

\section{[1] - sustentando dois raios.}

Olivaichthys mesembrinus, Hemistichodus vaillanti, Neolebias unifasciatus, Xenocharax spilurus, Apareiodon piracicabae, Parodon nasus, Saccodon wagneri, Anodus orinocensis, Bivibranchia fowleri, Hemiodus unimaculatus, Curimata ocellata, Curimatopsis macrolepis, Potamorhina latior, Prochilodus nigricans, Semaprochilodus insignis, 
Caenotropus labyrinthicus, Chilodus punctatus, Anostomus anostomus, Leporellus vittatus, Carnegiella strigata, Gasteropelecus sternicla, Thoracocharax stellatus Acestrorhynchus falcirostris, Gilbertolus atratoensis, Hydrolycus tatauaia, Roestes molossus, Erythrinoidea fam. nov, Boulengerella maculata, Ctenolucius hujeta, Copeina cf. guttata, Lebiasina bimaculata, Piabucina astrigata, Erythrinus erythrinus, Hoplias malabaricus, Hepsetus odoe, Arnoldichthys spilopterus, Brycinus macrolepidotus, Bryconalestes longipinnis, Chalceus epakros, Crenuchus spilurus, Agoniates halecinus, Aphyocharax pusillus, Astyanax mexicanus, Atopomesus pachyodus, Axelrodia reisei, Brittanichthys axelrodi, Brycon pesu, Bryconadenos tanaothoros, Bryconamericus exodon, Bryconops alburnoides, Charax cf. leticiae, Compsura heterura, Ctenobrycon hauxwellianus, Deuterodon iguape, Diapoma terofali, Galeocharax knerii, Glandulocauda melanogenys, Gnathocharax steindachneri, Gymnocorymbus ternetzi, Hemibrycon polyodon Hemigrammus unilineatus, Hollandichthys multifasciatus, Hyphessobrycon compressus, Iguanodectes geisleri, Knodus meridae, Landonia latidens, Markiana nigripinnis, Metynnis lippincottianus, Microschemobrycon casiquiare, Moenkhausia xinguensis, Myleus setiger, odontostilbe pequira, oligosarcus argenteus, orthospinus franciscoensis, Paracheirodon axelrodi, Paragoniates alburnus, Phenacogaster pectinatus, Phenagoniates macrolepis, Poptella brevispina, Probolus heterostomus, Rhinobrycon negrensis, Rhoadsia altipinna, Roeboexodon guyanensis, Salminus hilarii, Serrabrycon magoi, stygichthys typhlops, Tetragonopterus argenteus e Triportheus albus.

\title{
[-] - inaplicável.
}

Gymnotus aff. carapo.

\section{[?] - indeterminado.}

Characidium bahiensis.

\author{
276 - Pequena ossificação associada com o primeiro radial da nadadeira \\ dorsal: \\ [ZANATA \& VARI, 2005: 124, modificado]
}

(Minimamente conectado).

[0] - ausente.

Catostomus commersonnii, Apareiodon piracicabae, Carnegiella strigata, Gasteropelecus sternicla, Thoracocharax stellatus, Acestrorhynchus falcirostris, Gilbertolus atratoensis, Hydrolycus tatauaia, Roestes molossus, Boulengerella maculata, Ctenolucius hujeta, Copeina cf. guttata, Lebiasina bimaculata, Piabucina astrigata, Erythrinus erythrinus, Hoplias malabaricus, Hepsetus odoe, Arnoldichthys spilopterus, Brycinus macrolepidotus, Bryconalestes longipinnis, Chalceus epakros, Agoniates halecinus, Aphyocharax pusillus, Atopomesus pachyodus, Axelrodia reisei, Brittanichthys axelrodi, Brycon pesu, Bryconadenos tanaothoros, Bryconamericus exodon, Bryconops alburnoides, Charax cf. leticiae, Clupeacharax cf. engrauloides, Diapoma terofali, Galeocharax knerii, Glandulocauda melanogenys, Gnathocharax steindachneri, Hemibrycon polyodon, Iguanodectes geisleri, Knodus meridae, Landonia latidens, Markiana nigripinnis, Microschemobrycon casiquiare, Oligosarcus argenteus, Paracheirodon axelrodi, Paragoniates alburnus, Phenacogaster pectinatus, Phenagoniates macrolepis, Piabina argentea, Rachoviscus graciliceps, Rhinobrycon negrensis, Roeboexodon guyanensis, stygichthys typhlops e Triportheus albus.

\section{[1] - presente, sem projeção anterior.}

Citharinus latus, Distichodus notospilus, Hemistichodus vaillanti, Neolebias unifasciatus, Nannocharax fasciatus, Xenocharax spilurus, Parodon nasus, Saccodon wagneri, Anodus orinocensis, Bivibranchia fowleri, Hemiodus unimaculatus, Curimata ocellata, Curimatopsis macrolepis, Potamorhina latior, Caenotropus labyrinthicus, Anostomus anostomus, Characidium bahiensis, crenuchus spilurus, Astyanax mexicanus, Compsura heterura, Deuterodon iguape, Gymnocorymbus ternetzi, Hemigrammus unilineatus, Hollandichthys multifasciatus, Hyphessobrycon compressus, Metynnis lippincottianus, Moenkhausia xinguensis, Myleus setiger, odontostilbe pequira, Piaractus mesopotamicus, Probolus heterostomus, Rhoadsia altipinna, Salminus hilarii, Serrabrycon magoi e Tetragonopterus argenteus.

\section{[2] - presente, com projeção anterior.}

Prochilodus nigricans, Semaprochilodus insignis, Chilodus punctatus, Leporellus vittatus, Leporinus fasciatus, Schizodon fasciatus, ctenobrycon hauxwellianus, orthospinus franciscoensis e Poptella brevispina. 


\section{[-] - inaplicável.}

Gymnotus aff. carapo.

[?] - indeterminado.

Chanos chanos, Olivaichthys mesembrinus e Erythrinoidea fam. nov.

277 - Último pterigióforo da nadadeira dorsal:

[LuCena, 1993: 100; Buckup, 1998: 64; ZanAtA, 2000: 101; NetTo-Ferreira, 2006 : 236]

\section{[0] - sustentando dois raios.}

Chanos chanos, Catostomus commersonnii, Olivaichthys mesembrinus, Citharinus latus, Distichodus notospilus, Neolebias unifasciatus, Nannocharax fasciatus, Xenocharax spilurus, Apareiodon piracicabae, Parodon nasus, Saccodon wagneri, Anodus orinocensis, Bivibranchia fowleri, Hemiodus unimaculatus, Curimata ocellata, Potamorhina latior, Prochilodus nigricans, Semaprochilodus insignis, Caenotropus labyrinthicus, Chilodus punctatus, Anostomus anostomus, Leporellus vittatus, Leporinus fasciatus, Schizodon fasciatus, Acestrorhynchus falcirostris, Arnoldichthys spilopterus, Brycinus macrolepidotus, Bryconalestes longipinnis, Chalceus epakros, Metynnis lippincottianus e Myleus setiger.

\section{[1] - sustentando um raio.}

Hemistichodus vaillanti, Curimatopsis macrolepis, Carnegiella strigata, Gasteropelecus sternicla, Thoracocharax stellatus, Gilbertolus atratoensis, Hydrolycus tatauaia, Roestes molossus, Erythrinoidea fam. nov., Boulengerella maculata, ctenolucius hujeta, Copeina cf. guttata, Lebiasina bimaculata, Piabucina astrigata, Erythrinus erythrinus, Hoplias malabaricus, Hepsetus odoe, Characidium bahiensis, Crenuchus spilurus, Agoniates halecinus, Aphyocharax pusillus, Astyanax mexicanus, Atopomesus pachyodus, Axelrodia reisei, Brittanichthys axelrodi, Brycon pesu, Bryconadenos tanaothoros, Bryconamericus exodon, Bryconops alburnoides, Charax cf. leticiae, Clupeacharax cf. engrauloides, Compsura heterura, Ctenobrycon hauxwellianus, Deuterodon iguape, Diapoma terofali, Galeocharax knerii, Glandulocauda melanogenys, Gnathocharax steindachneri, Gymnocorymbus ternetzi, Hemibrycon polyodon, Hemigrammus unilineatus, Hollandichthys multifasciatus, Hyphessobrycon compressus, Iguanodectes geisleri, Knodus meridae, Landonia latidens, Markiana nigripinnis, Microschemobrycon casiquiare, Moenkhausia xinguensis, Odontostilbe pequira, oligosarcus argenteus, Orthospinus franciscoensis, Paracheirodon axelrodi, Paragoniates alburnus, Phenacogaster pectinatus, Phenagoniates macrolepis, Piabina argentea, Piaractus mesopotamicus, Poptella brevispina, Probolus heterostomus, Rachoviscus graciliceps, Rhinobrycon negrensis, Rhoadsia altipinna, Roeboexodon guyanensis, Salminus hilarii, Serrabrycon magoi, Stygichthys typhlops, Tetragonopterus argenteus e Triportheus albus.

\section{[-] - inaplicável.}

Gymnotus aff. carapo.

278 - Número de raios ramificados da nadadeira dorsal:

[ZANATA, 2000: 102, modificado; e NETTO-FERREIRA, 2006: 232, modificado]

\section{(Minimamente conectado).}

\section{[0] - 8 ou menos.}

Olivaichthys mesembrinus, Caenotropus labyrinthicus, Erythrinoidea fam. nov, Boulengerella maculata, Ctenolucius hujeta, Copeina cf. guttata, Lebiasina bimaculata, Piabucina astrigata, Erythrinus erythrinus, Hepsetus odoe, Agoniates halecinus, Bryconadenos tanaothoros, Bryconamericus exodon, Clupeacharax cf. engrauloides, Diapoma terofali, Glandulocauda melanogenys, Gnathocharax steindachneri, Hemibrycon polyodon, Knodus meridae, Piabina argentea, Rhinobrycon negrensis e Stygichthys typhlops.

$$
\text { [1] }-9 .
$$


Curimatopsis macrolepis, Potamorhina latior, Caenotropus labyrinthicus, Carnegiella strigata, Gasteropelecus sternicla, Acestrorhynchus falcirostris, Roestes molossus, Erythrinus erythrinus, Brycinus macrolepidotus, Bryconalestes longipinnis, Agoniates halecinus, Aphyocharax pusillus, Astyanax mexicanus, Atopomesus pachyodus, Axelrodia reisei, Brittanichthys axelrodi, Brycon pesu, Bryconops alburnoides, Charax cf. leticiae, Compsura heterura, Ctenobrycon hauxwellianus, Deuterodon iguape, Galeocharax knerii, Gymnocorymbus ternetzi, Hemigrammus unilineatus, Hollandichthys multifasciatus, Hyphessobrycon compressus, Iguanodectes geisleri, Landonia latidens, Markiana nigripinnis, Microschemobrycon casiquiare, Moenkhausia xinguensis, odontostilbe pequira, oligosarcus argenteus, orthospinus franciscoensis, Paracheirodon axelrodi, Paragoniates alburnus, Phenacogaster pectinatus, Phenagoniates macrolepis, Probolus heterostomus, Rachoviscus graciliceps, Rhoadsia altipinna, Roeboexodon guyanensis, Salminus hilarii, Serrabrycon magoi, Tetragonopterus argenteus e Triportheus albus.

\section{[2] - 10 .}

Chanos chanos, Hemistichodus vaillanti, Neolebias unifasciatus, Saccodon wagneri, Anodus orinocensis, Bivibranchia fowleri, Hemiodus unimaculatus , Curimata ocellata, Potamorhina latior, Prochilodus nigricans, Semaprochilodus insignis, Caenotropus labyrinthicus, Chilodus punctatus, Gilbertolus atratoensis, Hydrolycus tatauaia e Poptella brevispina.

\section{[3] - mais de 10 .}

Chanos chanos, Catostomus commersonnii, Citharinus latus, Distichodus notospilus, Hemistichodus vaillanti, Neolebias unifasciatus, Nannocharax fasciatus, Xenocharax spilurus, Apareiodon piracicabae, Parodon nasus, Anostomus anostomus, Leporellus vittatus, Leporinus fasciatus, Schizodon fasciatus, Thoracocharax stellatus , Hoplias malabaricus, Arnoldichthys spilopterus, Chalceus epakros, Crenuchus spilurus, Metynnis lippincottianus, Myleus setiger e Piaractus mesopotamicus.

\section{[-] - inaplicável.}

Gymnotus aff. carapo.

\section{[?] - indeterminado.}

Characidium bahiensis.

\section{$[1,2]$ - polimórfico.}

Chanos chanos, Hemistichodus vaillanti, Neolebias unifasciatus, Potamorhina latior, Caenotropus labyrinthicus, Erythrinus erythrinus e Agoniates halecinus.

279 - Número de pterigióforos da nadadeira dorsal:

[LUCENA, 1993: 97, modificado; ZANATA, 2000: 99, modificado; ZANATA \& VARI, 2005: 125 e NETTO-FERREIRA, 2006: 233, modificado]

\section{(Minimamente conectado).}

\section{[0] - 12 ou mais.}

Chanos chanos, Catostomus commersonnii, Citharinus latus, Distichodus notospilus, Hemistichodus vaillanti, Neolebias unifasciatus, Xenocharax spilurus, Thoracocharax stellatus, Hoplias malabaricus, Crenuchus spilurus, Metynnis lippincottianus, Myleus setiger e Piaractus mesopotamicus.

\section{[1] - 11.}

Nannocharax fasciatus, Apareiodon piracicabae, Parodon nasus, Saccodon wagneri, Anostomus anostomus, Leporellus vittatus, Leporinus fasciatus, Schizodon fasciatus, Hydrolycus tatauaia, Chalceus epakros, Characidium bahiensis e Poptella brevispina.

[2] - 10 .

Anodus orinocensis, Bivibranchia fowleri, Hemiodus unimaculatus, Curimata ocellata, Curimatopsis macrolepis, Potamorhina latior, Prochilodus nigricans, Semaprochilodus insignis, Caenotropus labyrinthicus, Chilodus punctatus, Gasteropelecus sternicla, Acestrorhynchus falcirostris, Gilbertolus atratoensis, Erythrinus erythrinus, 
Arnoldichthys spilopterus, Agoniates halecinus, Aphyocharax pusillus, Atopomesus pachyodus, Axelrodia reisei, Brittanichthys axelrodi, Brycon pesu, Bryconops alburnoides, Charax cf. leticiae, Compsura heterura, ctenobrycon hauxwellianus, Deuterodon iguape, Galeocharax knerii, Gymnocorymbus ternetzi, Hemigrammus unilineatus, Hollandichthys multifasciatus, Hyphessobrycon compressus, Iguanodectes geisleri, Landonia latidens, Markiana nigripinnis, Microschemobrycon casiquiare, Moenkhausia xinguensis, Odontostilbe pequira, oligosarcus argenteus, orthospinus franciscoensis, Paracheirodon axelrodi, Paragoniates alburnus, Phenacogaster pectinatus, Phenagoniates macrolepis, Probolus heterostomus, Rachoviscus graciliceps, Rhoadsia altipinna, Roeboexodon guyanensis, Salminus hilarii, Serrabrycon magoi, Tetragonopterus argenteus e Triportheus albus.

$$
\text { [3] }-9 .
$$

Carnegiella strigata, Roestes molossus, Boulengerella maculata, Ctenolucius hujeta, Copeina cf. guttata, Lebiasina bimaculata, Piabucina astrigata, Brycinus macrolepidotus, Bryconalestes longipinnis, Bryconadenos tanaothoros, Bryconamericus exodon, Clupeacharax cf. engrauloides, Diapoma terofali, Glandulocauda melanogenys, Gnathocharax steindachneri, Hemibrycon polyodon, Knodus meridae, Piabina argêntea e Rhinobrycon negrensis.

\section{[4] - 8 ou menos.}

Olivaichthys mesembrinus, Erythrinoidea fam. nov, Hepsetus odoe e Stygichthys typhlops.

\section{[-] - inaplicável.}

Gymnotus aff. carapo.

\section{[?] - indeterminado.}

Astyanax mexicanus.

280 - Radiais mediais da nadadeira dorsal:

[NETTO-FERREIRA, 2006: 234]

[0] - presente.

Chanos chanos, Catostomus commersonnii, Anodus orinocensis, Bivibranchia fowleri, Hemiodus unimaculatus, Curimata ocellata, Curimatopsis macrolepis, Potamorhina latior, Prochilodus nigricans, Semaprochilodus insignis, Caenotropus labyrinthicus, Chilodus punctatus, Anostomus anostomus, Leporellus vittatus, Leporinus fasciatus, Acestrorhynchus falcirostris, Gilbertolus atratoensis, Roestes molossus, Lebiasina bimaculata, Piabucina astrigata, Erythrinus erythrinus, Hepsetus odoe, Arnoldichthys spilopterus, Brycinus macrolepidotus, Chalceus epakros, Agoniates halecinus, Aphyocharax pusillus, Astyanax mexicanus, Atopomesus pachyodus, Brittanichthys axelrodi, Brycon pesu, Bryconamericus exodon, Charax cf. leticiae, Clupeacharax cf. engrauloides, Diapoma terofali, Galeocharax knerii, Glandulocauda melanogenys, Gnathocharax steindachneri, Hemibrycon polyodon, Hemigrammus unilineatus, Hollandichthys multifasciatus, Iguanodectes geisleri, Landonia latidens, Markiana nigripinnis, Metynnis lippincottianus, Microschemobrycon casiquiare, Moenkhausia xinguensis, Myleus setiger, odontostilbe pequira, Oligosarcus argenteus, orthospinus franciscoensis, Paragoniates alburnus, Phenagoniates macrolepis, Piabina argentea, Piaractus mesopotamicus, Poptella brevispina, Probolus heterostomus, Rachoviscus graciliceps, Rhinobrycon negrensis, Rhoadsia altipinna, Salminus hilarii, Serrabrycon magoi, stygichthys typhlops, Tetragonopterus argenteus e Triportheus albus.

\section{[1] - ausente.}

Olivaichthys mesembrinus, Citharinus latus, Distichodus notospilus, Hemistichodus vaillanti, Neolebias unifasciatus, Nannocharax fasciatus, Xenocharax spilurus, Apareiodon piracicabae, Parodon nasus, Saccodon wagneri, Schizodon fasciatus, Carnegiella strigata, Gasteropelecus sternicla, Thoracocharax stellatus, Hydrolycus tatauaia, Erythrinoidea fam. nov, Boulengerella maculata, Ctenolucius hujeta, Copeina cf. guttata, Hoplias malabaricus, Bryconalestes longipinnis, Characidium bahiensis, Crenuchus spilurus, Axelrodia reisei, Bryconadenos tanaothoros, Bryconops alburnoides, Compsura heterura, Ctenobrycon hauxwellianus, Deuterodon iguape, Gymnocorymbus ternetzi, Hyphessobrycon compressus, Knodus meridae, Paracheirodon axelrodi, Phenacogaster pectinatus e Roeboexodon guyanensis. 


\section{[-] - inaplicável.}

Gymnotus aff. carapo.

\section{1 - Peça terminal ou suporte da nadadeira dorsal:} [NETTO-FERREIRA, 2006: 237]

\section{[0] - presente.}

Chanos chanos, Citharinus latus, Distichodus notospilus, Hemistichodus vaillanti, Neolebias unifasciatus, Nannocharax fasciatus, Xenocharax spilurus, Saccodon wagneri, Anodus orinocensis,

Bivibranchia fowleri, Hemiodus unimaculatus, curimata ocellata, Potamorhina latior, Prochilodus nigricans, Semaprochilodus insignis, Caenotropus labyrinthicus, Chilodus punctatus, Anostomus anostomus, Leporellus vittatus, Leporinus fasciatus, Schizodon fasciatus, Carnegiella strigata, Gasteropelecus sternicla, Thoracocharax stellatus Acestrorhynchus falcirostris, Hydrolycus tatauaia, Erythrinoidea fam. nov, Boulengerella maculata, Lebiasina bimaculata, Piabucina astrigata, Erythrinus erythrinus, Hepsetus odoe, Arnoldichthys spilopterus, Brycinus macrolepidotus, Bryconalestes longipinnis, Chalceus epakros, Characidium bahiensis, Agoniates halecinus, Aphyocharax pusillus, Astyanax mexicanus, Brittanichthys axelrodi, Brycon pesu, Bryconadenos tanaothoros, Bryconamericus exodon, Bryconops alburnoides, Charax cf. leticiae, Compsura heterura, ctenobrycon hauxwellianus, Deuterodon iguape, Diapoma terofali, Galeocharax knerii, Glandulocauda melanogenys, Gnathocharax steindachneri, Gymnocorymbus ternetzi, Hemibrycon polyodon , Hemigrammus unilineatus, Hollandichthys multifasciatus, Hyphessobrycon compressus, Knodus meridae, Landonia latidens, Markiana nigripinnis, Metynnis lippincottianus, Moenkhausia xinguensis, Myleus setiger, Odontostilbe pequira, oligosarcus argenteus, orthospinus franciscoensis, Paracheirodon axelrodi, Paragoniates alburnus, Phenacogaster pectinatus, Phenagoniates macrolepis, Piabina argentea, Piaractus mesopotamicus, Poptella brevispina, Probolus heterostomus, Rhinobrycon negrensis, Rhoadsia altipinna, Roeboexodon guyanensis, Salminus hilarii, Serrabrycon magoi, Stygichthys typhlops, Tetragonopterus argenteus e Triportheus albus.

\section{[1] - fusionada ao último raio ou ausente.}

Catostomus commersonnii, olivaichthys mesembrinus, Apareiodon piracicabae, Parodon nasus, Curimatopsis macrolepis, Gilbertolus atratoensis, Ctenolucius hujeta, Copeina cf. guttata, Hoplias malabaricus, Crenuchus spilurus, Atopomesus pachyodus, Clupeacharax cf. engrauloides e Microschemobrycon casiquiare.

\section{[-] - inaplicável.}

Gymnotus aff. carapo.

[?] - indeterminado.

Roestes molossus, Axelrodia reisei, Iguanodectes geisleri e Rachoviscus graciliceps.

282 - Posição da nadadeira dorsal:

[ZANATA, 2000:97 modificado; e NeTto-FERREIRA, 2006: 238]

(Minimamente conectado).

[0] - situada no meio do corpo, ou anterior.

Catostomus commersonnii, olivaichthys mesembrinus, Citharinus latus, Distichodus notospilus, Hemistichodus vaillanti, Neolebias unifasciatus, Nannocharax fasciatus, Xenocharax spilurus, Apareiodon piracicabae, Parodon nasus, Saccodon wagneri, Anodus orinocensis, Bivibranchia fowleri, Hemiodus unimaculatus, Curimata ocellata, Curimatopsis macrolepis, Potamorhina latior, Prochilodus nigricans, Semaprochilodus insignis, Caenotropus labyrinthicus, Chilodus punctatus, Anostomus anostomus, Leporellus vittatus, Leporinus fasciatus, Schizodon fasciatus, Arnoldichthys spilopterus, Bryconalestes longipinnis, Characidium bahiensis, crenuchus spilurus, Aphyocharax pusillus, Astyanax mexicanus, Atopomesus pachyodus, Axelrodia reisei, Brittanichthys axelrodi, Bryconadenos tanaothoros, Bryconamericus exodon, Bryconops alburnoides, Charax cf. leticiae, Compsura heterura, Ctenobrycon hauxwellianus, Deuterodon iguape, Diapoma terofali, Galeocharax knerii, Glandulocauda melanogenys, Gymnocorymbus ternetzi, Hemibrycon polyodon, Hemigrammus unilineatus, Hollandichthys multifasciatus, Hyphessobrycon compressus, Iguanodectes geisleri, Knodus meridae, Landonia latidens, 
Markiana nigripinnis, Metynnis lippincottianus, Microschemobrycon casiquiare, Moenkhausia xinguensis, Myleus setiger, odontostilbe pequira, oligosarcus argenteus, orthospinus franciscoensis, Paracheirodon axelrodi, Phenacogaster pectinatus, Piabina argentea, Poptella brevispina, Probolus heterostomus, Rachoviscus graciliceps, Rhinobrycon negrensis, Rhoadsia altipinna, Roeboexodon guyanensis, Serrabrycon magoi e Tetragonopterus argenteus.

\section{[1] - situada no terço posterior do corpo.}

State 1 : Chanos chanos, Carnegiella strigata, Gasteropelecus sternicla, Acestrorhynchus falcirostris, Gilbertolus atratoensis, Hydrolycus tatauaia, Roestes molossus, Erythrinoidea fam. nov, Copeina cf. guttata, Lebiasina bimaculata, Piabucina astrigata, Erythrinus erythrinus, Hoplias malabaricus, Hepsetus odoe, Brycinus macrolepidotus, Chalceus epakros, Agoniates halecinus, Brycon pesu, Clupeacharax cf. engrauloides, Gnathocharax steindachneri, Paragoniates alburnus, Phenagoniates macrolepis, Piaractus mesopotamicus, Salminus hilarii, stygichthys typhlops e Triportheus albus.

\section{[2] - situada no quarto posterior do corpo.}

Thoracocharax stellatus, Boulengerella maculata e Ctenolucius hujeta.

\section{[-] - inaplicável.}

Gymnotus aff. carapo.

\section{3 - Porção proximal do primeiro pterigióforo da nadadeira dorsal:}

$$
\text { [0] - simples. }
$$

Distichodus notospilus, Xenocharax spilurus, Parodon nasus, Saccodon wagneri, Curimata ocellata, Curimatopsis macrolepis, Potamorhina latior, Prochilodus nigricans, Semaprochilodus insignis, Caenotropus labyrinthicus, Chilodus punctatus, Anostomus anostomus, Leporellus vittatus, Leporinus fasciatus, Schizodon fasciatus, Carnegiella strigata, Gasteropelecus sternicla, Gilbertolus atratoensis, Hydrolycus tatauaia, Roestes molossus, Erythrinoidea fam. nov, Copeina cf. guttata, Lebiasina bimaculata, Piabucina astrigata, Erythrinus erythrinus, Brycinus macrolepidotus, Bryconalestes longipinnis, Crenuchus spilurus, Agoniates halecinus, Axelrodia reisei, Bryconamericus exodon, Compsura heterura, Ctenobrycon hauxwellianus, Iguanodectes geisleri, Markiana nigripinnis, Metynnis lippincottianus, Myleus setiger, Odontostilbe pequira, Piaractus mesopotamicus, Salminus hilarii e Stygichthys typhlops.

\section{[1] - bífida.}

Chanos chanos, Catostomus commersonnii, Olivaichthys mesembrinus, Citharinus latus, Hemistichodus vaillanti, Neolebias unifasciatus, Nannocharax fasciatus, Apareiodon piracicabae, Anodus orinocensis, Bivibranchia fowleri, Hemiodus unimaculatus , Thoracocharax stellatus, Acestrorhynchus falcirostris, Boulengerella maculata, Ctenolucius hujeta, Hoplias malabaricus, Hepsetus odoe, Arnoldichthys spilopterus, Chalceus epakros, Characidium bahiensis, Aphyocharax pusillus, Astyanax mexicanus, Atopomesus pachyodus, Brittanichthys axelrodi, Brycon pesu, Bryconadenos tanaothoros, Bryconops alburnoides, Charax cf. leticiae, Clupeacharax cf. engrauloides, Deuterodon iguape, Galeocharax knerii, Glandulocauda melanogenys, Gnathocharax steindachneri, Gymnocorymbus ternetzi, Hemibrycon polyodon, Hemigrammus unilineatus, Hollandichthys multifasciatus, Hyphessobrycon compressus, Knodus meridae, Landonia latidens, Microschemobrycon casiquiare, Moenkhausia xinguensis, oligosarcus argenteus, orthospinus franciscoensis, Paracheirodon axelrodi, Paragoniates alburnus, Phenacogaster pectinatus, Phenagoniates macrolepis, Piabina argentea, Poptella brevispina, Probolus heterostomus, Rachoviscus graciliceps, Rhinobrycon negrensis, Rhoadsia altipinna, Roeboexodon guyanensis, Serrabrycon magoi, Tetragonopterus argenteus e Triportheus albus.

\section{[-] - inaplicável.}

Gymnotus aff. carapo.

[?] - indeterminado.

Diapoma terofali. 


\section{[0] - liso, sem projeção anterior.}

Chanos chanos, Catostomus commersonnii, Olivaichthys mesembrinus, Citharinus latus, Distichodus notospilus, Hemistichodus vaillanti, Neolebias unifasciatus, Nannocharax fasciatus, Xenocharax spilurus, Apareiodon piracicabae, Parodon nasus, Saccodon wagneri, Anodus orinocensis, Bivibranchia fowleri, Hemiodus unimaculatus, Curimata ocellata, Curimatopsis macrolepis, Potamorhina latior, Prochilodus nigricans, Semaprochilodus insignis, Caenotropus labyrinthicus, Chilodus punctatus, Anostomus anostomus, Leporellus vittatus, Leporinus fasciatus, Schizodon fasciatus, Carnegiella strigata, Gasteropelecus sternicla, Thoracocharax stellatus, Acestrorhynchus falcirostris, Gilbertolus atratoensis, Hydrolycus tatauaia, Roestes molossus, Erythrinoidea fam. nov, Boulengerella maculata, Ctenolucius hujeta, Copeina cf. guttata, Lebiasina bimaculata, Piabucina astrigata, Erythrinus erythrinus, Hoplias malabaricus, Hepsetus odoe, Arnoldichthys spilopterus, Brycinus macrolepidotus, Bryconalestes longipinnis, Chalceus epakros, Characidium bahiensis, Crenuchus spilurus, Agoniates halecinus, Aphyocharax pusillus, Astyanax mexicanus, Atopomesus pachyodus, Axelrodia reisei, Brittanichthys axelrodi, Brycon pesu, Bryconadenos tanaothoros, Bryconamericus exodon, Bryconops alburnoides, Charax cf. leticiae, Clupeacharax cf. engrauloides, Compsura heterura, Ctenobrycon hauxwellianus, Deuterodon iguape, Diapoma terofali, Galeocharax knerii, Glandulocauda melanogenys, Gnathocharax steindachneri, Gymnocorymbus ternetzi, Hemibrycon polyodon, Hemigrammus unilineatus, Hollandichthys multifasciatus, Hyphessobrycon compressus, Iguanodectes geisleri, Knodus meridae, Landonia latidens, Markiana nigripinnis, Microschemobrycon casiquiare, Moenkhausia xinguensis, Odontostilbe pequira, oligosarcus argenteus, Orthospinus franciscoensis, Paracheirodon axelrodi, Paragoniates alburnus, Phenacogaster pectinatus, Phenagoniates macrolepis, Piabina argentea, Piaractus mesopotamicus, Poptella brevispina, Probolus heterostomus, Rachoviscus graciliceps, Rhinobrycon negrensis, Rhoadsia altipinna, Roeboexodon guyanensis, Salminus hilarii, Serrabrycon magoi, Stygichthys typhlops, Tetragonopterus argenteus e Triportheus albus.

\section{[1] - com projeção anterior formando um espinho.}

Metynnis lippincottianus e Myleus setiger.

\section{[-] - inaplicável.}

Gymnotus aff. carapo.

\subsubsection{Nadadeira anal e esqueleto de sustentação}

285 - Primeiros pterigióforos da nadadeira anal:

[LUCENA, 1993: 102]

\section{[0] - dirigidos para cima, ou para frente.}

Chanos chanos, Catostomus commersonnii, Olivaichthys mesembrinus, Gymnotus aff. carapo, Citharinus latus, Distichodus notospilus, Hemistichodus vaillanti, Neolebias unifasciatus, Nannocharax fasciatus, Xenocharax spilurus, Apareiodon piracicabae, Parodon nasus, Saccodon wagneri, Anodus orinocensis, Bivibranchia fowleri, Hemiodus unimaculatus, Curimata ocellata, Curimatopsis macrolepis, Potamorhina latior, Prochilodus nigricans, Semaprochilodus insignis, Caenotropus labyrinthicus, Chilodus punctatus, Anostomus anostomus, Leporellus vittatus, Leporinus fasciatus, Schizodon fasciatus, Carnegiella strigata, Gasteropelecus sternicla, Thoracocharax stellatus, Acestrorhynchus falcirostris, Gilbertolus atratoensis, Hydrolycus tatauaia, Roestes molossus, Erythrinoidea fam. nov, Boulengerella maculata, Ctenolucius hujeta, Copeina cf. guttata, Lebiasina bimaculata, Piabucina astrigata, Erythrinus erythrinus, Hoplias malabaricus, Hepsetus odoe, Arnoldichthys spilopterus, Brycinus macrolepidotus, Bryconalestes longipinnis, Chalceus epakros, Characidium bahiensis, Crenuchus spilurus, Agoniates halecinus, Aphyocharax pusillus, Astyanax mexicanus, Axelrodia reisei, Brittanichthys axelrodi, Brycon pesu, Bryconadenos tanaothoros, Bryconamericus exodon, Bryconops alburnoides, Clupeacharax cf. engrauloides, Compsura heterura, Deuterodon iguape, Diapoma terofali, Galeocharax knerii, Glandulocauda melanogenys, Gnathocharax steindachneri, Hemibrycon polyodon, Hemigrammus unilineatus, Hollandichthys multifasciatus, Hyphessobrycon compressus, Iguanodectes geisleri, Knodus meridae, Landonia latidens, Microschemobrycon casiquiare, Odontostilbe pequira, oligosarcus argenteus, Paracheirodon axelrodi, Piabina argentea, Probolus heterostomus, Rachoviscus graciliceps, Rhinobrycon negrensis, Roeboexodon guyanensis, Salminus hilarii, Serrabrycon magoi, Stygichthys typhlops, Tetragonopterus argenteus e Triportheus albus. 


\section{[1] - dirigidos para cima e para trás.}

Atopomesus pachyodus, Charax cf. leticiae, Ctenobrycon hauxwellianus, Gymnocorymbus ternetzi, Markiana nigripinnis, Metynnis lippincottianus, Myleus setiger, orthospinus franciscoensis, Paragoniates alburnus, Phenacogaster pectinatus, Phenagoniates macrolepis, Piaractus mesopotamicus, Poptella brevispina e Rhoadsia altipinna.

\section{[?] - indeterminado.}

Moenkhausia xinguensis.

286 - Pterigióforos antes do primeiro espinho hemal:

[LUCENA, 1993: 81, modificado)

\section{[0] - 5 ou menos.}

Chanos chanos, Catostomus commersonnii, Olivaichthys mesembrinus, Citharinus latus, Distichodus notospilus, Hemistichodus vaillanti, Neolebias unifasciatus, Nannocharax fasciatus, Xenocharax spilurus, Apareiodon piracicabae, Parodon nasus, Saccodon wagneri, Anodus orinocensis, Bivibranchia fowleri, Hemiodus unimaculatus, curimata ocellata, Curimatopsis macrolepis, Potamorhina latior, Prochilodus nigricans, Semaprochilodus insignis, Caenotropus labyrinthicus, Chilodus punctatus, Anostomus anostomus, Leporellus vittatus, Leporinus fasciatus, Schizodon fasciatus, Carnegiella strigata, Gasteropelecus sternicla, Thoracocharax stellatus, Acestrorhynchus falcirostris, Gilbertolus atratoensis, Hydrolycus tatauaia, Roestes molossus, Erythrinoidea fam. nov, Boulengerella maculata, Ctenolucius hujeta, Copeina cf. guttata, Lebiasina bimaculata, Piabucina astrigata, Erythrinus erythrinus, Hoplias malabaricus, Hepsetus odoe, Arnoldichthys spilopterus, Brycinus macrolepidotus, Bryconalestes longipinnis, Chalceus epakros, Characidium bahiensis, Crenuchus spilurus, Agoniates halecinus, Aphyocharax pusillus, Astyanax mexicanus, Atopomesus pachyodus, Axelrodia reisei, Brittanichthys axelrodi, Brycon pesu, Bryconadenos tanaothoros, Bryconamericus exodon, Bryconops alburnoides, Clupeacharax cf. engrauloides, Compsura heterura, Deuterodon iguape, Diapoma terofali, Galeocharax knerii, Glandulocauda melanogenys, Gnathocharax steindachneri, Hemibrycon polyodon, Hemigrammus unilineatus, Hollandichthys multifasciatus, Hyphessobrycon compressus, Iguanodectes geisleri, Knodus meridae, Landonia latidens, Markiana nigripinnis, Metynnis lippincottianus, Microschemobrycon casiquiare, Moenkhausia xinguensis, Myleus setiger, Odontostilbe pequira, Oligosarcus argenteus, Paracheirodon axelrodi, Paragoniates alburnus, Phenacogaster pectinatus, Phenagoniates macrolepis, Piabina argentea, Piaractus mesopotamicus, Poptella brevispina, Probolus heterostomus, Rachoviscus graciliceps, Rhinobrycon negrensis, Rhoadsia altipinna, Roeboexodon guyanensis, Salminus hilarii, Serrabrycon magoi, Stygichthys typhlops, Tetragonopterus argenteus e Triportheus albus.

\section{[1] - 6 ou mais.}

Charax cf. leticiae, Ctenobrycon hauxwellianus, Gymnocorymbus ternetzi e orthospinus franciscoensis.

\section{[-] - inaplicável.}

Gymnotus aff. carapo.

\section{7 - Lâmina óssea do primeiro pterigióforo da nadadeira anal: [MOREIRA, 2002: 82]}

\section{[0] - ausente ou pequena.}

Chanos chanos, Olivaichthys mesembrinus, Gymnotus aff. carapo, Citharinus latus, Distichodus notospilus, Hemistichodus vaillanti, Neolebias unifasciatus, Nannocharax fasciatus, Xenocharax spilurus, Anodus orinocensis, Bivibranchia fowleri, Hemiodus unimaculatus, Curimatopsis macrolepis, Potamorhina latior, Prochilodus nigricans, Semaprochilodus insignis, Caenotropus labyrinthicus, Chilodus punctatus, Anostomus anostomus, Leporellus vittatus, Leporinus fasciatus, schizodon fasciatus, Carnegiella strigata, Gasteropelecus sternicla, Thoracocharax stellatus, Acestrorhynchus falcirostris, Gilbertolus atratoensis, Hydrolycus tatauaia, Roestes molossus, Erythrinoidea fam. nov, Boulengerella maculata, Ctenolucius hujeta, Copeina cf. guttata, Lebiasina bimaculata, Piabucina astrigata, Erythrinus erythrinus, Hoplias malabaricus, Hepsetus odoe, Arnoldichthys spilopterus, Brycinus macrolepidotus, Bryconalestes 
longipinnis, Chalceus epakros, Characidium bahiensis, Crenuchus spilurus, Agoniates halecinus, Aphyocharax pusillus, Astyanax mexicanus, Axelrodia reisei, Brittanichthys axelrodi, Brycon pesu, Bryconadenos tanaothoros, Bryconamericus exodon, Bryconops alburnoides, Charax cf. leticiae, Clupeacharax cf. engrauloides, Compsura heterura, Deuterodon iguape, Diapoma terofali, Galeocharax knerii, Glandulocauda melanogenys, Gnathocharax steindachneri, Gymnocorymbus ternetzi, Hemibrycon polyodon, Knodus meridae, Landonia latidens, Metynnis lippincottianus, Microschemobrycon casiquiare, Moenkhausia xinguensis, Myleus setiger, Odontostilbe pequira, oligosarcus argenteus, Paracheirodon axelrodi, Phenagoniates macrolepis, Piabina argentea, Piaractus mesopotamicus, Probolus heterostomus, Rachoviscus graciliceps, Rhinobrycon negrensis, Roeboexodon guyanensis, Salminus hilarii, Serrabrycon magoi, stygichthys typhlops, Tetragonopterus argenteus e Triportheus albus.

\section{[1] - grande, formando uma projeção distinta anteriormente.}

Catostomus commersonnii, Apareiodon piracicabae, Parodon nasus, Saccodon wagneri, Curimata ocellata, Atopomesus pachyodus, Ctenobrycon hauxwellianus, Hemigrammus unilineatus, Hollandichthys multifasciatus, Hyphessobrycon compressus, Iguanodectes geisleri, Markiana nigripinnis, orthospinus franciscoensis, Paragoniates alburnus, Phenacogaster pectinatus, Poptella brevispina e Rhoadsia altipinna.

\section{8 - Primeiro pterigióforo da nadadeira anal:}

\section{[0] - simples.}

Chanos chanos, Olivaichthys mesembrinus, Gymnotus aff. carapo, Citharinus latus, Distichodus notospilus, Hemistichodus vaillanti, Neolebias unifasciatus, Xenocharax spilurus, Anodus orinocensis, Bivibranchia fowleri, Hemiodus unimaculatus, Curimata ocellata, Curimatopsis macrolepis, Potamorhina latior, Prochilodus nigricans, Semaprochilodus insignis, Caenotropus labyrinthicus, Chilodus punctatus, Anostomus anostomus, Leporellus vittatus, Leporinus fasciatus, schizodon fasciatus, Carnegiella strigata, Gasteropelecus sternicla, Thoracocharax stellatus, Acestrorhynchus falcirostris, Gilbertolus atratoensis, Hydrolycus tatauaia, Roestes molossus, Erythrinoidea fam. nov, Boulengerella maculata, Ctenolucius hujeta, Copeina cf. guttata, Lebiasina bimaculata, Piabucina astrigata, Erythrinus erythrinus, Hoplias malabaricus, Hepsetus odoe, Arnoldichthys spilopterus, Brycinus macrolepidotus, Bryconalestes longipinnis, Chalceus epakros, Characidium bahiensis, Crenuchus spilurus, Agoniates halecinus, Aphyocharax pusillus, Astyanax mexicanus, Atopomesus pachyodus, Axelrodia reisei, Brittanichthys axelrodi, Brycon pesu, Bryconadenos tanaothoros, Bryconamericus exodon, Bryconops alburnoides, Charax cf. leticiae, Clupeacharax cf. engrauloides, Compsura heterura, Ctenobrycon hauxwellianus, Deuterodon iguape, Diapoma terofali, Galeocharax knerii, Glandulocauda melanogenys, Gnathocharax steindachneri, Gymnocorymbus ternetzi, Hemibrycon polyodon, Hemigrammus unilineatus, Hollandichthys multifasciatus, Hyphessobrycon compressus, Iguanodectes geisleri, Knodus meridae, Landonia latidens, Markiana nigripinnis, Metynnis lippincottianus, Microschemobrycon casiquiare, Moenkhausia xinguensis, Myleus setiger, Odontostilbe pequira, Orthospinus franciscoensis, Paracheirodon axelrodi, Paragoniates alburnus, Phenacogaster pectinatus, Phenagoniates macrolepis, Piabina argentea, Piaractus mesopotamicus, Poptella brevispina, Probolus heterostomus, Rachoviscus graciliceps, Rhinobrycon negrensis, Rhoadsia altipinna, Roeboexodon guyanensis, Salminus hilarii, serrabrycon magoi, stygichthys typhlops, Tetragonopterus argenteus e Triportheus albus.

\section{[1] - bífido.}

Catostomus commersonnii, Nannocharax fasciatus, Apareiodon piracicabae, Parodon nasus e Saccodon wagneri.

\section{[?] - indeterminado.}

oligosarcus argenteus.

289 - Margem lateral dos primeiros pterigióforos da nadadeira anal: [ZANATA \& VARI, 2005: 144, modificado] distal.

[0] - lisa, ou com crista lateral pequena e restrita a porção

Olivaichthys mesembrinus, Gymnotus aff. carapo, Carnegiella strigata, Gasteropelecus sternicla, Thoracocharax stellatus, Acestrorhynchus falcirostris, Gilbertolus 
atratoensis, Roestes molossus, Erythrinoidea fam. nov, Bryconalestes longipinnis, Agoniates halecinus, Aphyocharax pusillus, Astyanax mexicanus, Atopomesus pachyodus, Axelrodia reisei, Brittanichthys axelrodi, Brycon pesu, Bryconamericus exodon, Charax cf. leticiae, Clupeacharax cf. engrauloides, Compsura heterura, ctenobrycon hauxwellianus, Deuterodon iguape, Diapoma terofali, Galeocharax knerii, Glandulocauda melanogenys, Gnathocharax steindachneri, Gymnocorymbus ternetzi, Hemibrycon polyodon, Hemigrammus unilineatus, Hollandichthys multifasciatus, Hyphessobrycon compressus, Iguanodectes geisleri, Knodus meridae, Landonia latidens, Markiana nigripinnis, Metynnis lippincottianus, Microschemobrycon casiquiare, Moenkhausia xinguensis, odontostilbe pequira, oligosarcus argenteus, orthospinus franciscoensis, Paracheirodon axelrodi, Paragoniates alburnus, Phenacogaster pectinatus, Phenagoniates macrolepis, Piabina argentea, Piaractus mesopotamicus, Poptella brevispina, Probolus heterostomus Rachoviscus graciliceps, Rhinobrycon negrensis, Rhoadsia altipinna, Roeboexodón guyanensis, Salminus hilarii, Serrabrycon magoi, Tetragonopterus argenteus e Triportheus albus.

\section{[1] - crista lateral conspícua e por quase todo o pterigióforo.}

Chanos chanos, Catostomus commersonnii, Citharinus latus, Distichodus notospilus, Hemistichodus vaillanti, Neolebias unifasciatus, Nannocharax fasciatus, Xenocharax spilurus, Apareiodon piracicabae, Parodon nasus, Saccodon wagneri, Anodus orinocensis, Bivibranchia fowleri, Hemiodus unimaculatus, curimata ocellata, Curimatopsis macrolepis, Potamorhina latior, Prochilodus nigricans, Semaprochilodus insignis, Caenotropus labyrinthicus, Chilodus punctatus, Anostomus anostomus, Leporellus vittatus, Leporinus fasciatus, Schizodon fasciatus, Hydrolycus tatauaia, Boulengerella maculata, Ctenolucius hujeta, Copeina cf. guttata, Lebiasina bimaculata, Piabucina astrigata, Erythrinus erythrinus, Hoplias malabaricus, Hepsetus odoe, Arnoldichthys spilopterus, Brycinus macrolepidotus, Chalceus epakros, Characidium bahiensis, crenuchus spilurus, Bryconadenos tanaothoros, Bryconops alburnoides e Myleus setiger.

\section{[?] - indeterminado.}

Stygichthys typhlops.

290 - Radial distal da nadadeira anal:

[MOREIRA, 2002: 84]

\section{[0] - sem processo.}

Chanos chanos, Catostomus commersonnii, Olivaichthys mesembrinus, Bivibranchia fowleri, Hemiodus unimaculatus, Chilodus punctatus, Anostomus anostomus, Schizodon fasciatus, Chalceus epakros, Agoniates halecinus, Aphyocharax pusillus, Axelrodia reisei, Brittanichthys axelrodi, Bryconadenos tanaothoros, Deuterodon iguape, Hyphessobrycon compressus, Metynnis lippincottianus, Moenkhausia xinguensis, Rhinobrycon negrensis, Roeboexodon guyanensis, Salminus hilarii e Serrabrycon magoi.

\section{[1] - processo pareado ventral.}

Citharinus latus, Distichodus notospilus, Hemistichodus vaillanti, Neolebias unifasciatus, Nannocharax fasciatus, Xenocharax spilurus, Apareiodon piracicabae, Parodon nasus, Saccodon wagneri, Anodus orinocensis, Curimata ocellata, Curimatopsis macrolepis, Potamorhina latior, Prochilodus nigricans, Semaprochilodus insignis, Caenotropus labyrinthicus, Leporellus vittatus, Leporinus fasciatus, Carnegiella strigata, Gasteropelecus sternicla, Thoracocharax stellatus, Acestrorhynchus falcirostris, Gilbertolus atratoensis, Hydrolycus tatauaia, Roestes molossus, Boulengerella maculata, Ctenolucius hujeta, Copeina cf. guttata, Lebiasina bimaculata, Piabucina astrigata, Erythrinus erythrinus, Hoplias malabaricus, Hepsetus odoe, Brycinus macrolepidotus, Bryconalestes longipinnis, Characidium bahiensis, crenuchus spilurus, Astyanax mexicanus, Atopomesus pachyodus, Brycon pesu, Bryconamericus exodon, Bryconops alburnoides, Charax cf. leticiae, Clupeacharax cf. engrauloides, Compsura heterura, Ctenobrycon hauxwellianus, Diapoma terofali, Galeocharax knerii, Glandulocauda melanogenys, Gnathocharax steindachneri, Gymnocorymbus ternetzi, Hemibrycon polyodon, Hemigrammus unilineatus, Hollandichthys multifasciatus, Knodus meridae, Landonia latidens, Markiana nigripinnis, Microschemobrycon casiquiare, Myleus setiger, odontostilbe pequira, oligosarcus argenteus, Orthospinus franciscoensis, Paracheirodon axelrodi, Paragoniates alburnus, Phenacogaster pectinatus, Phenagoniates macrolepis, Piabina argentea, Piaractus mesopotamicus, Poptella brevispina, Probolus heterostomus, Rhoadsia altipinna, Stygichthys typhlops, Tetragonopterus argenteus e Triportheus albus.

\section{[-] - inaplicável.}

Gymnotus aff. carapo. 


\section{[?] - indeterminado.}

Erythrinoidea fam. nov., Arnoldichthys spilopterus, Iguanodectes geisleri e Rachoviscus graciliceps.

291 - Radiais mediais da nadadeira anal:

[ZANATA \& VARI, 2005: 191 e NETTO-FERREIRA, 2006: 245]

\section{[0] - presentes.}

Chanos chanos, Catostomus commersonnii, Neolebias unifasciatus, Nannocharax fasciatus, Anodus orinocensis, Bivibranchia fowleri, Hemiodus unimaculatus, Curimata ocellata, Curimatopsis macrolepis, Potamorhina latior, Prochilodus nigricans, Semaprochilodus insignis, Caenotropus labyrinthicus, Chilodus punctatus, Anostomus anostomus, Leporellus vittatus, Leporinus fasciatus, schizodon fasciatus, Acestrorhynchus falcirostris, Gilbertolus atratoensis, Hydrolycus tatauaia, Lebiasina bimaculata, Piabucina astrigata, Hepsetus odoe, Brycinus macrolepidotus, Bryconalestes longipinnis, Chalceus epakros, Agoniates halecinus, Aphyocharax pusillus, Astyanax mexicanus, Atopomesus pachyodus, Brittanichthys axelrodi, Brycon pesu, Bryconadenos tanaothoros, Bryconamericus exodon, Bryconops alburnoides, Charax cf. leticiae, Clupeacharax cf. engrauloides, Deuterodon iguape, Diapoma terofali, Galeocharax knerii, Glandulocauda melanogenys, Gnathocharax steindachneri, Hemibrycon polyodon, Hemigrammus unilineatus, Hollandichthys multifasciatus, Knodus meridae, Markiana nigripinnis, Microschemobrycon casiquiare, Moenkhausia xinguensis, Odontostilbe pequira, oligosarcus argenteus, orthospinus franciscoensis, Paracheirodon axelrodi, Paragoniates alburnus, Phenacogaster pectinatus, Piabina argentea, Poptella brevispina, Probolus heterostomus, Rhinobrycon negrensis, Rhoadsia altipinna, Roeboexodon guyanensis, Salminus hilarii, serrabrycon magoi, Stygichthys typhlops, Tetragonopterus argenteus e Triportheus albus.

\section{[1] - ausentes.}

olivaichthys mesembrinus, Gymnotus aff. carapo, Citharinus latus, Distichodus notospilus, Hemistichodus vaillanti, Xenocharax spilurus, Apareiodon piracicabae, Parodon nasus, Saccodon wagneri, Carnegiella strigata, Gasteropelecus sternicla, Thoracocharax stellatus, Roestes molossus, Boulengerella maculata, Ctenolucius hujeta, Copeina cf. guttata, Erythrinus erythrinus, Hoplias malabaricus, Characidium bahiensis, crenuchus spilurus, Axelrodia reisei, Compsura heterura, ctenobrycon hauxwellianus, Gymnocorymbus ternetzi, Metynnis lippincottianus, Myleus setiger, Phenagoniates macrolepis e Piaractus mesopotamicus.

\section{[?] - indeterminado.}

Erythrinoidea fam. nov., Arnoldichthys spilopterus, Hyphessobrycon compressus, Iguanodectes geisleri, Landonia latidens e Rachoviscus graciliceps.

292 - Número de raios ramificados da nadadeira anal:

[LUCENA, 1993: 103 e 104, modificados; BUCKUP, 1998: 65 e 66, modificados; ZANATA, 2000: 112, modificado; e NETTO-FERREIRA, 2006: 247, modificado]

\section{(Minimamente conectado).}

\section{[0] - nove ou menos.}

Catostomus commersonnii, Hemistichodus vaillanti, Neolebias unifasciatus, Nannocharax fasciatus, Apareiodon piracicabae, Parodon nasus, Saccodon wagneri, Bivibranchia fowleri, Hemiodus unimaculatus, Curimata ocellata, Curimatopsis macrolepis, Prochilodus nigricans, Semaprochilodus insignis, Caenotropus labyrinthicus, Chilodus punctatus, Anostomus anostomus, Leporellus vittatus, Leporinus fasciatus, Schizodon fasciatus, Boulengerella maculata, Ctenolucius hujeta, Copeina cf. guttata, Lebiasina bimaculata, Piabucina astrigata, Erythrinus erythrinus, Hepsetus odoe, Chalceus epakros, Characidium bahiensis, Crenuchus spilurus e Stygichthys typhlops.

\section{[1] - 10-19.}

Chanos chanos, Olivaichthys mesembrinus, Distichodus notospilus, Xenocharax spilurus, Anodus orinocensis, Potamorhina latior, chilodus punctatus, Erythrinoidea fam. nov, Hoplias malabaricus, Arnoldichthys spilopterus, Brycinus macrolepidotus, Bryconalestes longipinnis, Chalceus epakros, Aphyocharax pusillus, Astyanax mexicanus, Atopomesus 
pachyodus, Axelrodia reisei, Brittanichthys axelrodi, Bryconadenos tanaothoros, Bryconamericus exodon, Compsura heterura, Glandulocauda melanogenys, Knodus meridae, Microschemobrycon casiquiare, odontostilbe pequira, Paracheirodon axelrodi, Piabina argentea, Rhinobrycon negrensis, Serrabrycon magoi e Stygichthys typhlops.

\section{[2] - 20-30.}

Citharinus latus, Carnegiella strigata, Gasteropelecus sternicla, Acestrorhynchus falcirostris, Hoplias malabaricus, Agoniates halecinus, Atopomesus pachyodus, Brycon pesu, Deuterodon iguape, Diapoma terofali, Gnathocharax steindachneri, Hemibrycon polyodon, Hemigrammus unilineatus, Hollandichthys multifasciatus, Hyphessobrycon compressus, Iguanodectes geisleri, Landonia latidens, Moenkhausia xinguensis, oligosarcus argenteus, Orthospinus franciscoensis, Piaractus mesopotamicus, Probolus heterostomus, Rachoviscus graciliceps, Rhoadsia altipinna, Roeboexodon guyanensis, Salminus hilarii e Triportheus albus.

\section{[3] - mais de 30 .}

Gymnotus aff. carapo, Thoracocharax stellatus, Gilbertolus atratoensis, Hydrolycus tatauaia, Roestes molossus, Bryconops alburnoides, Charax cf. leticiae, Clupeacharax cf. engrauloides, Ctenobrycon hauxwellianus, Galeocharax knerii, Gymnocorymbus ternetzi, Hollandichthys multifasciatus, Landonia latidens, Markiana nigripinnis, Metynnis lippincottianus, Myleus setiger, orthospinus franciscoensis, Paragoniates alburnus, Phenacogaster pectinatus, Phenagoniates macrolepis, Poptella brevispina e Tetragonopterus argenteus.

\section{$[1,2]$ - polimórfico.}

Chilodus punctatus, Hoplias malabaricus, Chalceus epakros, Atopomesus pachyodus, Hollandichthys multifasciatus, Landonia latidens, Orthospinus franciscoensis e Stygichthys typhlops.

\section{3 - Margem distal da nadadeira anal:}

\section{[0] - concava distalmente.}

Chanos chanos, Citharinus latus, Neolebias unifasciatus, Xenocharax spilurus, Parodon nasus, Saccodon wagneri, Anodus orinocensis, Bivibranchia fowleri, Hemiodus unimaculatus - Curimata ocellata, Curimatopsis macrolepis, Potamorhina latior, Prochilodus nigricans, Semaprochilodus insignis, Caenotropus labyrinthicus, Leporellus vittatus, Acestrorhynchus falcirostris, Gilbertolus atratoensis, Hydrolycus tatauaia, Hepsetus odoe, Brycinus macrolepidotus, Crenuchus spilurus, Agoniates halecinus, Aphyocharax pusillus, Astyanax mexicanus, Atopomesus pachyodus, Axelrodia reisei, Brycon pesu, Bryconadenos tanaothoros, Bryconamericus exodon, Bryconops alburnoides, Clupeacharax cf. engrauloides, Compsura heterura, Deuterodon iguape, Diapoma terofali, Galeocharax knerii, Glandulocauda melanogenys, Gnathocharax steindachneri, Hemibrycon polyodon. Hemigrammus unilineatus, Hollandichthys multifasciatus, Hyphessobrycon compressus, Iguanodectes geisleri, Landonia latidens, Microschemobrycon casiquiare, Moenkhausia xinguensis, Myleus setiger, Odontostilbe pequira, Oligosarcus argenteus, orthospinus franciscoensis, Paracheirodon axelrodi, Phenacogaster pectinatus, Piabina argentea, Poptella brevispina, Probolus heterostomus, Rachoviscus graciliceps, Rhinobrycon negrensis, Rhoadsia altipinna, Roeboexodon guyanensis, Salminus hilarii, Serrabrycon magoi e Triportheus albus.

\section{[1] - reta ou convexa distalmente.}

Catostomus commersonnii, Olivaichthys mesembrinus, Gymnotus aff. carapo, Distichodus notospilus, Hemistichodus vaillanti, Nannocharax fasciatus, Apareiodon piracicabae, Chilodus punctatus, Anostomus anostomus, Leporinus fasciatus, Schizodon fasciatus, Carnegiella strigata, Gasteropelecus sternicla, Thoracocharax stellatus, Roestes molossus, Erythrinoidea fam. nov, Boulengerella maculata, Ctenolucius hujeta, Copeina cf. guttata, Lebiasina bimaculata, Piabucina astrigata, Erythrinus erythrinus, Hoplias malabaricus, Bryconalestes longipinnis, Chalceus epakros, Characidium bahiensis, Brittanichthys axelrodi, Charax cf. leticiae, Ctenobrycon hauxwellianus, Gymnocorymbus ternetzi, Knodus meridae, Markiana nigripinnis, Metynnis lippincottianus, Paragoniates alburnus, Phenagoniates macrolepis, Piaractus mesopotamicus, stygichthys typhlops e Tetragonopterus argenteus.

\section{[?] - indeterminado.}




\section{4 - Primeira divisão dos raios da nadadeira anal: [NeTto-FERREIRA, 2006: 281, modificado]}

\section{[0] - na porção proximal ou mediana.}

Chanos chanos, Catostomus commersonnii, Olivaichthys mesembrinus, Gymnotus aff. carapo, Citharinus latus, Distichodus notospilus, Hemistichodus vaillanti, Neolebias unifasciatus, Nannocharax fasciatus, Xenocharax spilurus, Apareiodon piracicabae, Parodon nasus, Saccodon wagneri, Anodus orinocensis, Bivibranchia fowleri, Hemiodus unimaculatus, Curimata ocellata, Curimatopsis macrolepis, Potamorhina latior, Prochilodus nigricans, Semaprochilodus insignis, Caenotropus labyrinthicus, Chilodus punctatus, Leporellus vittatus, Schizodon fasciatus, Gilbertolus atratoensis, Hydrolycus tatauaia, Roestes molossus, Boulengerella maculata, Ctenolucius hujeta, copeina cf. guttata, Lebiasina bimaculata, Piabucina astrigata, Erythrinus erythrinus, Hoplias malabaricus, Hepsetus odoe, Arnoldichthys spilopterus, Brycinus macrolepidotus, Bryconalestes longipinnis, Chalceus epakros, Crenuchus spilurus, Aphyocharax pusillus, Axelrodia reisei, Brycon pesu, Glandulocauda melanogenys, Metynnis lippincottianus, Myleus setiger, orthospinus franciscoensis, Paracheirodon axelrodi, Phenacogaster pectinatus, Piaractus mesopotamicus, Roeboexodon guyanensis, Salminus hilarii, Stygichthys typhlops e Tetragonopterus argenteus.

\section{[1] - na porção distal.}

Anostomus anostomus, Leporinus fasciatus, Carnegiella strigata, Gasteropelecus sternicla, Thoracocharax stellatus, Acestrorhynchus falcirostris, Erythrinoidea fam. nov, Characidium bahiensis, Agoniates halecinus, Astyanax mexicanus, Atopomesus pachyodus, Brittanichthys axelrodi, Bryconadenos tanaothoros, Bryconamericus exodon, Bryconops alburnoides, Charax cf. leticiae, Clupeacharax cf. engrauloides, Compsura heterura, Ctenobrycon hauxwellianus, Deuterodon iguape, Diapoma terofali, Galeocharax knerii, Gnathocharax steindachneri, Gymnocorymbus ternetzi, Hemibrycon polyodon, Hemigrammus unilineatus, Hollandichthys multifasciatus, Hyphessobrycon compressus, Iguanodectes geisleri, Knodus meridae, Landonia latidens, Microschemobrycon casiquiare, Moenkhausia xinguensis, Odontostilbe pequira, Oligosarcus argenteus, Paragoniates alburnus, Phenagoniates macrolepis, Piabina argentea, Poptella brevispina, Probolus heterostomus, Rachoviscus graciliceps, Rhinobrycon negrensis, Rhoadsia altipinna, Serrabrycon magoi e Triportheus albus.

\section{[?] - indeterminado.}

Markiana nigripinnis.

295 - Peça terminal ou suporte da nadadeira anal:

[NETTO-FERREIRA, 2006: 246]

\section{[0] - presente.}

Chanos chanos, Neolebias unifasciatus, Nannocharax fasciatus, Saccodon wagneri, Anodus orinocensis, Bivibranchia fowleri, Hemiodus unimaculatus, curimata ocellata, Potamorhina latior, Prochilodus nigricans, Semaprochilodus insignis, Anostomus anostomus, Leporellus vittatus, Leporinus fasciatus, Schizodon fasciatus, Carnegiella strigata, Gasteropelecus sternicla, Thoracocharax stellatus, Acestrorhynchus falcirostris, Hydrolycus tatauaia, Roestes molossus, Ctenolucius hujeta, Lebiasina bimaculata, Piabucina astrigata, Hepsetus odoe, Arnoldichthys spilopterus, Brycinus macrolepidotus, Bryconalestes longipinnis, Chalceus epakros, Characidium bahiensis, Agoniates halecinus, Aphyocharax pusillus, Astyanax mexicanus, Atopomesus pachyodus, Brittanichthys axelrodi, Brycon pesu, Bryconadenos tanaothoros, Bryconamericus exodon, Bryconops alburnoides, Charax cf. leticiae, Clupeacharax cf. engrauloides, Compsura heterura, Ctenobrycon hauxwellianus, Deuterodon iguape, Diapoma terofali, Glandulocauda melanogenys, Gnathocharax steindachneri, Gymnocorymbus ternetzi, Hemibrycon polyodon, Hemigrammus unilineatus, Hollandichthys multifasciatus, Knodus meridae, Markiana nigripinnis, Moenkhausia xinguensis, Myleus setiger, Oligosarcus argenteus, orthospinus franciscoensis, Paracheirodon axelrodi, Paragoniates alburnus, Phenacogaster pectinatus, Phenagoniates macrolepis, Piabina argentea, Piaractus mesopotamicus, Poptella brevispina, Probolus heterostomus, Rhinobrycon negrensis, Rhoadsia altipinna, Roeboexodon guyanensis, Stygichthys typhlops, Tetragonopterus argenteus e Triportheus albus. 


\section{[1] - fusionada ao último pterigióforo ou ausente.}

Catostomus commersonnii, Olivaichthys mesembrinus, Gymnotus aff. carapo, Citharinus latus, Distichodus notospilus, Hemistichodus vaillanti, Xenocharax spilurus, Apareiodon piracicabae, Parodon nasus, Curimatopsis macrolepis, Caenotropus labyrinthicus, Chilodus punctatus, Erythrinoidea fam. nov, Boulengerella maculata, Copeina cf. guttata, Erythrinus erythrinus, Hoplias malabaricus, crenuchus spilurus, Galeocharax knerii, Metynnis lippincottianus, Microschemobrycon casiquiare e serrabrycon magoi.

\section{[?] - indeterminado.}

Gilbertolus atratoensis, Axelrodia reisei, Hyphessobrycon compressus, Iguanodectes geisleri, Landonia latidens, Odontostilbe pequira, Rachoviscus graciliceps e Salminus hilarii.

\subsubsection{Nadadeira caudal e esqueleto de sustentação}

296 - Espinho neural da última vértebra:

[NETTO-FERREIRA, 2006: 253]

[0] - tão ou mais desenvolvido que o espinho anterior (Fig. 54 e Fig. 55).

Chanos chanos, Catostomus commersonnii, olivaichthys mesembrinus, Citharinus latus, Distichodus notospilus, Hemistichodus vaillanti, Neolebias unifasciatus, Nannocharax fasciatus, Xenocharax spilurus, Apareiodon piracicabae, Parodon nasus, Saccodon wagneri, Anodus orinocensis, Bivibranchia fowleri, Hemiodus unimaculatus, Curimata ocellata, Curimatopsis macrolepis, Potamorhina latior, Prochilodus nigricans, Semaprochilodus insignis, Caenotropus labyrinthicus, Chilodus punctatus, Anostomus anostomus, Leporellus vittatus, Leporinus fasciatus, Schizodon fasciatus, Carnegiella strigata, Gasteropelecus sternicla, Thoracocharax stellatus, Acestrorhynchus falcirostris, Gilbertolus atratoensis, Hydrolycus tatauaia, Roestes molossus, Erythrinoidea fam. nov, Boulengerella maculata, Ctenolucius hujeta, Copeina cf. guttata, Lebiasina bimaculata, Piabucina astrigata, Erythrinus erythrinus, Hoplias malabaricus, Arnoldichthys spilopterus, Chalceus epakros, Characidium bahiensis, Crenuchus spilurus, Agoniates halecinus, Aphyocharax pusillus, Astyanax mexicanus, Atopomesus pachyodus, Axelrodia reisei, Brittanichthys axelrodi, Brycon pesu, Bryconadenos tanaothoros, Bryconamericus exodon, Bryconops alburnoides, Charax cf. leticiae, Clupeacharax cf. engrauloides, Compsura heterura, Ctenobrycon hauxwellianus, Deuterodon iguape, Diapoma terofali, Galeocharax knerii, Glandulocauda melanogenys, Gnathocharax steindachneri, Gymnocorymbus ternetzi, Hemibrycon polyodon, Hemigrammus unilineatus, Hollandichthys multifasciatus, Hyphessobrycon compressus, Iguanodectes geisleri, Knodus meridae, Landonia latidens, Markiana nigripinnis, Microschemobrycon casiquiare, Moenkhausia xinguensis, Odontostilbe pequira, oligosarcus argenteus, orthospinus franciscoensis, Paracheirodon axelrodi, Paragoniates alburnus, Phenacogaster pectinatus, Phenagoniates macrolepis, Piabina argentea, Piaractus mesopotamicus, Poptella brevispina, Probolus heterostomus, Rachoviscus graciliceps, Rhinobrycon negrensis, Rhoadsia altipinna, Roeboexodon guyanensis, Salminus hilarii, Serrabrycon magoi, Stygichthys typhlops, Tetragonopterus argenteus e Triportheus albus.

\section{[1] - nitidamente mais curto que o espinho neural da vértebra anterior (Fig. 56).}

Hepsetus odoe, Brycinus macrolepidotus, Bryconalestes longipinnis, Metynnis lippincottianus, Myleus setiger e Rhoadsia altipinna.

\section{[-] - inaplicável.}

Gymnotus aff. carapo.

$[0,1]$ - polimórfico.

Rhoadsia altipinna.

297 - "Caudal fin bony stays":

[LUCENA, 1993: 105; BUCKUP, 1998: 67; ZANATA \& VARI, 2005: 147, modificado

e NetTo-Ferreira, 2006: 254] 


\section{[0] - presente.}

Potamorhina latior, Boulengerella maculata, Ctenolucius hujeta, Hoplias malabaricus, Brycinus macrolepidotus, Bryconalestes longipinnis e Chalceus epakros.

\section{[1] - ausente.}

Chanos chanos, Catostomus commersonnii, Olivaichthys mesembrinus, Citharinus latus, Distichodus notospilus, Hemistichodus vaillanti, Neolebias unifasciatus, Nannocharax fasciatus, Xenocharax spilurus, Apareiodon piracicabae, Parodon nasus, Saccodon wagneri, Anodus orinocensis, Bivibranchia fowleri, Hemiodus unimaculatus, Curimata ocellata, Curimatopsis macrolepis, Prochilodus nigricans, Semaprochilodus insignis, Caenotropus labyrinthicus, Chilodus punctatus, Anostomus anostomus, Leporellus vittatus, Leporinus fasciatus, Schizodon fasciatus, Carnegiella strigata, Gasteropelecus sternicla, Thoracocharax stellatus, Acestrorhynchus falcirostris, Gilbertolus atratoensis, Hydrolycus tatauaia, Roestes molossus, Erythrinoidea fam. nov, Copeina cf. guttata, Lebiasina bimaculata, Piabucina astrigata, Erythrinus erythrinus, Hepsetus odoe, Arnoldichthys spilopterus, Characidium bahiensis, Crenuchus spilurus, Agoniates halecinus, Aphyocharax pusillus, Astyanax mexicanus, Atopomesus pachyodus, Axelrodia reisei, Brittanichthys axelrodi, Brycon pesu, Bryconadenos tanaothoros, Bryconamericus exodon, Bryconops alburnoides, Charax cf. leticiae, Clupeacharax cf. engrauloides, Compsura heterura, Ctenobrycon hauxwellianus, Deuterodon iguape, Diapoma terofali, Galeocharax knerii, Glandulocauda melanogenys, Gnathocharax steindachneri, Gymnocorymbus ternetzi, Hemibrycon polyodon, Hemigrammus unilineatus, Hollandichthys multifasciatus, Hyphessobrycon compressus, Iguanodectes geisleri, Knodus meridae, Landonia latidens, Markiana nigripinnis, Metynnis lippincottianus, Microschemobrycon casiquiare, Moenkhausia xinguensis, Myleus setiger, Odontostilbe pequira, Oligosarcus argenteus, Orthospinus franciscoensis, Paracheirodon axelrodi, Paragoniates alburnus, Phenacogaster pectinatus, Phenagoniates macrolepis, Piabina argentea, Piaractus mesopotamicus, Poptella brevispina, Probolus heterostomus, Rachoviscus graciliceps, Rhinobrycon negrensis, Rhoadsia altipinna, Roeboexodon guyanensis, Salminus hilarii, Serrabrycon magoi, Stygichthys typhlops, Tetragonopterus argenteus e Triportheus albus.

\section{[-] - inaplicável.}

Gymnotus aff. carapo.

298 - Número de epurais:

[LUCENA, 1993: 106 e 107, modificados; BUCKUP, 1998: 68 e 69, modificados; OYAKAWA, 1998: 88; ZANATA, 2000: 115, modificado; ZANATA \& VARI, 2005: $150 \mathrm{e}$ NETTO-FERREIRA，2006: 256]

(Minimamente conectado).

[0] - 3 .

Anodus orinocensis, Bivibranchia fowleri, Hemiodus unimaculatus, Curimata ocellata, Curimatopsis macrolepis, Prochilodus nigricans, Semaprochilodus insignis, Caenotropus labyrinthicus, Chilodus punctatus, Anostomus anostomus, Leporellus vittatus, Leporinus fasciatus, Schizodon fasciatus, Ctenolucius hujeta, Hepsetus odoe, Arnoldichthys spilopterus, Brycinus macrolepidotus, Bryconalestes longipinnis, Chalceus epakros, crenuchus spilurus e Myleus setiger.

[1] - 2 (Fig. 54 e Fig. 56).

Citharinus latus, Distichodus notospilus, Neolebias unifasciatus, Nannocharax fasciatus, Xenocharax spilurus, Apareiodon piracicabae, Parodon nasus, Saccodon wagneri, Carnegiella strigata, Gasteropelecus sternicla, Acestrorhynchus falcirostris, Gilbertolus atratoensis, Hydrolycus tatauaia, Roestes molossus, Boulengerella maculata, Lebiasina bimaculata, Characidium bahiensis, Agoniates halecinus, Aphyocharax pusillus, Astyanax mexicanus, Atopomesus pachyodus, Axelrodia reisei, Brittanichthys axelrodi, Brycon pesu, Bryconadenos tanaothoros, Bryconops alburnoides, Charax cf. leticiae, Clupeacharax cf. engrauloides, Compsura heterura, Ctenobrycon hauxwellianus, Deuterodon iguape, Diapoma terofali, Galeocharax knerii, Glandulocauda melanogenys, Gnathocharax steindachneri, Gymnocorymbus ternetzi, Hemibrycon polyodon, Hollandichthys multifasciatus, Hyphessobrycon compressus, Iguanodectes geisleri, Knodus meridae, Landonia latidens, Markiana nigripinnis, Metynnis lippincottianus, Microschemobrycon casiquiare, Moenkhausia xinguensis, Odontostilbe pequira, oligosarcus argenteus, orthospinus franciscoensis, Paracheirodon axelrodi, Paragoniates alburnus, Phenacogaster pectinatus, Phenagoniates macrolepis, Piabina argentea, Piaractus mesopotamicus, Poptella brevispina, Probolus heterostomus, Rachoviscus graciliceps, Rhoadsia 
altipinna, Roeboexodon guyanensis, Salminus hilarii, Serrabrycon magoi, Tetragonopterus argenteus e Triportheus albus.

\section{[2] - 1 (Fig. 55).}

Chanos chanos, Catostomus commersonnii, olivaichthys mesembrinus, Hemistichodus vaillanti, Thoracocharax stellatus, Erythrinoidea fam. nov, Copeina cf. guttata, Piabucina astrigata, Erythrinus erythrinus, Hoplias malabaricus, Bryconamericus exodon, Compsura heterura, Hemigrammus unilineatus, Rhinobrycon negrensis e Stygichthys typhlops.

\section{[-] - inaplicável.}

Gymnotus aff. carapo.

\section{[?] - indeterminado.}

Potamorhina latior.

$$
\text { [1, 2] - polimórfico. }
$$

Compsura heterura.

$56)$.

$$
\text { [0] - porção proximal inclinada posteriormente (Fig. } 54 \text { e Fig. }
$$

Olivaichthys mesembrinus, Citharinus latus, Distichodus notospilus, Neolebias unifasciatus, Nannocharax fasciatus, Xenocharax spilurus, Apareiodon piracicabae, Parodon nasus, Saccodon wagneri, Anodus orinocensis, Bivibranchia fowleri, Hemiodus unimaculatus, Curimata ocellata, Curimatopsis macrolepis, Prochilodus nigricans, Semaprochilodus insignis, Caenotropus labyrinthicus, Acestrorhynchus falcirostris, Gilbertolus atratoensis, Roestes molossus, Boulengerella maculata, Ctenolucius hujeta, Piabucina astrigata, Hepsetus odoe, Arnoldichthys spilopterus, Brycinus macrolepidotus, Bryconalestes longipinnis, Chalceus epakros, Characidium bahiensis, Agoniates halecinus, Aphyocharax pusillus, Astyanax mexicanus, Atopomesus pachyodus, Brycon pesu, Bryconadenos tanaothoros, Bryconops alburnoides, Charax cf. leticiae, clupeacharax cf. engrauloides, Compsura heterura, Ctenobrycon hauxwellianus, Deuterodon iguape, Diapoma terofali, Glandulocauda melanogenys, Gnathocharax steindachneri, Gymnocorymbus ternetzi, Hemibrycon polyodon, Hemigrammus unilineatus, Hollandichthys multifasciatus, Hyphessobrycon compressus, Iguanodectes geisleri, Landonia latidens, Metynnis lippincottianus, Moenkhausia xinguensis, Myleus setiger, odontostilbe pequira, oligosarcus argenteus, orthospinus franciscoensis, Paracheirodon axelrodi, Paragoniates alburnus, Phenacogaster pectinatus, Piabina argentea, Piaractus mesopotamicus, Poptella brevispina, Probolus heterostomus, Rachoviscus graciliceps, Rhoadsia altipinna, Roeboexodon guyanensis, Salminus hilarii, Stygichthys typhlops e Tetragonopterus argenteus.

\section{[1] - reto (Fig. 55).}

Chanos chanos, Hemistichodus vaillanti, Potamorhina latior, Chilodus punctatus, Anostomus anostomus, Leporellus vittatus, Leporinus fasciatus, Schizodon fasciatus, Carnegiella strigata, Gasteropelecus sternicla, Crenuchus spilurus, Axelrodia reisei, Brittanichthys axelrodi, Galeocharax knerii, Knodus meridae, Markiana nigripinnis, Microschemobrycon casiquiare, Phenagoniates macrolepis, Rhinobrycon negrensis, Serrabrycon magoi e Triportheus albus.

\section{[2] - porção proximal inclinada anteriormente.}

Catostomus commersonnii, Thoracocharax stellatus, Copeina cf. guttata, Lebiasina bimaculata, Erythrinus erythrinus, Hoplias malabaricus, Bryconamericus exodon e Rhinobrycon negrensis.

\section{[?] - indeterminado.}

Gymnotus aff. carapo.

[?] - indeterminado. 
Hydrolycus tatauaia e Erythrinoidea fam. nov.

\section{$[1,2]$ - polimórfico.}

Rhinobrycon negrensis.

\section{0 - Tamanho do maior epural:}

\section{[0] - menor ou igual à metade do uróstilo.}

Potamorhina latior, Prochilodus nigricans, Chilodus punctatus, Leporinus fasciatus, Thoracocharax stellatus, Hydrolycus tatauaia, Boulengerella maculata, ctenolucius hujeta, Hepsetus odoe, Arnoldichthys spilopterus, Brycinus macrolepidotus, Chalceus epakros, Agoniates halecinus, Aphyocharax pusillus, Astyanax mexicanus, Atopomesus pachyodus, Axelrodia reisei, Brittanichthys axelrodi, Charax cf. leticiae, Compsura heterura, Hemibrycon polyodon, Hemigrammus unilineatus, Hollandichthys multifasciatus, Hyphessobrycon compressus, Iguanodectes geisleri, Markiana nigripinnis, Microschemobrycon casiquiare, Moenkhausia xinguensis, Odontostilbe pequira, oligosarcus argenteus, Paracheirodon axelrodi, Phenacogaster pectinatus, Phenagoniates macrolepis, Piaractus mesopotamicus, Poptella brevispina, Rachoviscus graciliceps, Rhoadsia altipinna, Roeboexodon guyanensis, Serrabrycon magoi, Tetragonopterus argenteus e Triportheus albus.

\section{[1] - maior que metade do uróstilo.}

Chanos chanos, Catostomus commersonnii, olivaichthys mesembrinus, Citharinus latus, Distichodus notospilus, Hemistichodus vaillanti, Neolebias unifasciatus, Nannocharax fasciatus, Xenocharax spilurus, Apareiodon piracicabae, Parodon nasus, Saccodon wagneri, Anodus orinocensis, Bivibranchia fowleri, Hemiodus unimaculatus, Curimata ocellata, Curimatopsis macrolepis, Semaprochilodus insignis, Caenotropus labyrinthicus, Anostomus anostomus, Leporellus vittatus, Schizodon fasciatus, Carnegiella strigata, Gasteropelecus sternicla, Acestrorhynchus falcirostris, Gilbertolus atratoensis, Roestes molossus, Erythrinoidea fam. nov, Copeina cf. guttata, Lebiasina bimaculata, Piabucina astrigata, Erythrinus erythrinus, Hoplias malabaricus, Bryconalestes longipinnis, Characidium bahiensis, Crenuchus spilurus, Brycon pesu, Bryconadenos tanaothoros, Bryconamericus exodon, Bryconops alburnoides, Clupeacharax cf. engrauloides, Ctenobrycon hauxwellianus, Deuterodon iguape, Diapoma terofali, Galeocharax knerii, Glandulocauda melanogenys, Gnathocharax steindachneri, Gymnocorymbus ternetzi, Knodus meridae, Landonia latidens, Metynnis lippincottianus, Myleus setiger, Orthospinus franciscoensis, Paragoniates alburnus, Piabina argentea, Probolus heterostomus, Rhinobrycon negrensis, Salminus hilarii e stygichthys typhlops.

\section{[-] - inaplicável.}

Gymnotus aff. carapo.

301 - Uroneurais:

[LUCENA, 1993: 108, modificado; BUCKUP, 1998: 70, modificado; ZANATA, 2000: 116, modificado; OYAKAWA, 1998: 89, modificado; ZANATA \& VARI, 2005: 149, modificado e NETTO-FERREIRA, 2006: 258, modificado]

(Minimamente conectado).

[0] - ausente (Fig. 55).

Erythrinoidea fam. nov., Erythrinus erythrinus e Stygichthys typhlops.

[1] - um par (Fig. 54 e Fig. 56).

Chanos chanos, Olivaichthys mesembrinus, Citharinus latus, Distichodus notospilus, Hemistichodus vaillanti, Neolebias unifasciatus, Nannocharax fasciatus, Xenocharax spilurus, Curimatopsis macrolepis, Potamorhina latior, Chilodus punctatus, Carnegiella strigata, Gasteropelecus sternicla, Thoracocharax stellatus, Gilbertolus atratoensis, Boulengerella maculata, Ctenolucius hujeta, Copeina cf. guttata, Lebiasina bimaculata, Piabucina astrigata, Hoplias malabaricus, Hepsetus odoe, Arnoldichthys spilopterus, Characidium bahiensis, Crenuchus spilurus, Aphyocharax pusillus, Astyanax mexicanus, Atopomesus pachyodus, Axelrodia reisei, Brittanichthys axelrodi, Bryconadenos tanaothoros, Bryconamericus exodon, Charax cf. leticiae, Clupeacharax cf. engrauloides, compsura heterura, Ctenobrycon hauxwellianus, Deuterodon iguape, Diapoma terofali, 
Galeocharax knerii, Glandulocauda melanogenys, Gnathocharax steindachneri, Gymnocorymbus ternetzi, Hemibrycon polyodon, Hemigrammus unilineatus, Hollandichthys multifasciatus, Hyphessobrycon compressus, Iguanodectes geisleri, Knodus meridae, Landonia latidens, Markiana nigripinnis, Metynnis lippincottianus, Microschemobrycon casiquiare, odontostilbe pequira, oligosarcus argenteus, orthospinus franciscoensis, Paracheirodon axelrodi, Paragoniates alburnus, Phenacogaster pectinatus, Phenagoniates macrolepis, Piabina argentea, Poptella brevispina, Probolus heterostomus, Rachoviscus graciliceps, Rhinobrycon negrensis, Rhoadsia altipinna, Roeboexodon guyanensis, Serrabrycon magoi e Tetragonopterus argenteus.

\section{[2] - dois pares.}

Catostomus commersonnii, Apareiodon piracicabae, Parodon nasus, Saccodon wagneri, Anodus orinocensis, Bivibranchia fowleri, Hemiodus unimaculatus, Curimata ocellata, Prochilodus nigricans, Semaprochilodus insignis, Caenotropus labyrinthicus, Anostomus anostomus, Leporellus vittatus, Leporinus fasciatus, Schizodon fasciatus, Acestrorhynchus falcirostris, Hydrolycus tatauaia, Roestes molossus, Brycinus macrolepidotus, Bryconalestes longipinnis, Chalceus epakros, Agoniates halecinus, Brycon pesu, Bryconops alburnoides, Moenkhausia xinguensis, Myleus setiger, Piaractus mesopotamicus, Salminus hilarii e Triportheus albus.

\section{[-] - inaplicável.}

Gymnotus aff. carapo.

\section{2 - Lamela do espinho neural mais posterior: (Minimamente conectado).}

\section{[0] - lamela muito pequena apenas na base, ou ausente (Fig. 55).}

Chanos chanos, Catostomus commersonnii, Olivaichthys mesembrinus, Chilodus punctatus, Carnegiella strigata, Gasteropelecus sternicla, Hydrolycus tatauaia, Roestes molossus, Erythrinoidea fam. nov, Erythrinus erythrinus, Hoplias malabaricus, Arnoldichthys spilopterus, Characidium bahiensis, Crenuchus spilurus, Agoniates halecinus, Atopomesus pachyodus, Axelrodia reisei, Brittanichthys axelrodi, Bryconamericus exodon, Charax cf. leticiae, Clupeacharax cf. engrauloides, Ctenobrycon hauxwellianus, Deuterodon iguape, Diapoma terofali, Gymnocorymbus ternetzi, Hemibrycon polyodon, Hemigrammus unilineatus, Hollandichthys multifasciatus, Hyphessobrycon compressus, Iguanodectes geisleri, Knodus meridae, Markiana nigripinnis, Microschemobrycon casiquiare, odontostilbe pequira, orthospinus franciscoensis, Paracheirodon axelrodi, Paragoniates alburnus, Phenagoniates macrolepis, Piabina argentea, Poptella brevispina, Probolus heterostomus, Rachoviscus graciliceps, Rhinobrycon negrensis, Rhoadsia altipinna, Serrabrycon magoi, Stygichthys typhlops, Tetragonopterus argenteus e Triportheus albus.

\section{[1] - lamela presente até metade do espinho.}

Curimatopsis macrolepis, Anostomus anostomus, Thoracocharax stellatus, Gilbertolus atratoensis, Ctenolucius hujeta, Copeina cf. guttata, Lebiasina bimaculata, Hepsetus odoe, Aphyocharax pusillus, Bryconadenos tanaothoros, Compsura heterura, Galeocharax knerii, Gnathocharax steindachneri, Landonia latidens, Moenkhausia xinguensis, Myleus setiger, Oligosarcus argenteus, Phenacogaster pectinatus e Piaractus mesopotamicus.

\section{[2] - lamela presente além da metade do espinho (Fig. 54).}

Citharinus latus, Distichodus notospilus, Hemistichodus vaillanti, Neolebias unifasciatus, Nannocharax fasciatus, Xenocharax spilurus, Apareiodon piracicabae, Parodon nasus, Saccodon wagneri, Anodus orinocensis, Bivibranchia fowleri, Hemiodus unimaculatus, Curimata ocellata, Potamorhina latior, Prochilodus nigricans, Semaprochilodus insignis, Caenotropus labyrinthicus, Leporellus vittatus, Leporinus fasciatus, Schizodon fasciatus, Acestrorhynchus falcirostris, Boulengerella maculata, Piabucina astrigata, Brycinus macrolepidotus, Bryconalestes longipinnis, Chalceus epakros, Astyanax mexicanus, Brycon pesu, Bryconops alburnoides, Glandulocauda melanogenys, Metynnis lippincottianus, Roeboexodon guyanensis e Salminus hilarii.

\section{[-] - inaplicável.}

Gymnotus aff. carapo. 
[FINK \& FINK, 1981: 113]

\section{[0] - fusionado ao centro vertebral.}

Catostomus commersonnii e Olivaichthys mesembrinus.

\section{[1] - com um hiato (Figs. 54. 55 e 56).}

State $1:$, Chanos chanos, Citharinus latus, Distichodus notospilus, Hemistichodus vaillanti, Neolebias unifasciatus, Nannocharax fasciatus, Xenocharax spilurus, Apareiodon piracicabae, Parodon nasus, Saccodon wagneri, Anodus orinocensis, Bivibranchia fowleri, Hemiodus unimaculatus, curimata ocellata, curimatopsis macrolepis, Potamorhina latior, Prochilodus nigricans, Semaprochilodus insignis, Caenotropus labyrinthicus, Chilodus punctatus, Anostomus anostomus, Leporellus vittatus, Leporinus fasciatus, Schizodon fasciatus, Carnegiella strigata, Gasteropelecus sternicla, Thoracocharax stellatus, Acestrorhynchus falcirostris, Gilbertolus atratoensis, Hydrolycus tatauaia, Roestes molossus, Erythrinoidea fam. nov, Boulengerella maculata, Ctenolucius hujeta, Copeina cf. guttata, Lebiasina bimaculata, Piabucina astrigata, Erythrinus erythrinus, Hoplias malabaricus, Hepsetus odoe, Arnoldichthys spilopterus, Brycinus macrolepidotus, Bryconalestes longipinnis, Chalceus epakros, Characidium bahiensis, Crenuchus spilurus, Agoniates halecinus, Aphyocharax pusillus, Astyanax mexicanus, Atopomesus pachyodus, Axelrodia reisei, Brittanichthys axelrodi, Brycon pesu, Bryconadenos tanaothoros, Bryconamericus exodon, Bryconops alburnoides, Charax cf. leticiae, Clupeacharax cf. engrauloides, compsura heterura, Ctenobrycon hauxwellianus, Deuterodon iguape, Diapoma terofali, Galeocharax knerii, Glandulocauda melanogenys, Gnathocharax steindachneri, Gymnocorymbus ternetzi, Hemibrycon polyodon, Hemigrammus unilineatus, Hollandichthys multifasciatus, Hyphessobrycon compressus, Iguanodectes geisleri, Knodus meridae, Landonia latidens, Markiana nigripinnis, Metynnis lippincottianus, Microschemobrycon casiquiare, Moenkhausia xinguensis, Myleus setiger, Odontostilbe pequira, oligosarcus argenteus, orthospinus franciscoensis, Paracheirodon axelrodi, Paragoniates alburnus, Phenacogaster pectinatus, Phenagoniates macrolepis, Piabina argentea, Piaractus mesopotamicus, Poptella brevispina, Probolus heterostomus, Rachoviscus graciliceps, Rhinobrycon negrensis, Rhoadsia altipinna, Roeboexodon guyanensis, Salminus hilarii, Serrabrycon magoi, Stygichthys typhlops, Tetragonopterus argenteus e Triportheus albus.

\section{[-] - inaplicável.}

Gymnotus aff. carapo.

304 - Hipural 2:

[NETTO-FERREIRA, 2006: 260]

\section{[0] - fusionado ao uróstilo (Fig. 56).}

Catostomus commersonnii, olivaichthys mesembrinus, Apareiodon piracicabae, Parodon nasus, Saccodon wagneri, Curimata ocellata, Curimatopsis macrolepis, Potamorhina latior, Prochilodus nigricans, Semaprochilodus insignis, Caenotropus labyrinthicus, Chilodus punctatus, Anostomus anostomus, Leporellus vittatus, Leporinus fasciatus, Schizodon fasciatus, Carnegiella strigata, Gasteropelecus sternicla, Thoracocharax stellatus, Acestrorhynchus falcirostris, Gilbertolus atratoensis, Hydrolycus tatauaia, Roestes molossus, Boulengerella maculata, Ctenolucius hujeta, Copeina cf. guttata, Lebiasina bimaculata, Hepsetus odoe, Arnoldichthys spilopterus, Bryconalestes longipinnis, Chalceus epakros, Characidium bahiensis, crenuchus spilurus, Agoniates halecinus, Aphyocharax pusillus, Astyanax mexicanus, Atopomesus pachyodus, Axelrodia reisei, Brittanichthys axelrodi, Brycon pesu, Bryconadenos tanaothoros, Bryconamericus exodon, Bryconops alburnoides, Charax cf. leticiae, Clupeacharax cf. engrauloides, Compsura heterura, Ctenobrycon hauxwellianus, Deuterodon iguape, Diapoma terofali, Galeocharax knerii, Glandulocauda melanogenys, Gnathocharax steindachneri, Gymnocorymbus ternetzi, Hemibrycon polyodon, Hemigrammus unilineatus, Hollandichthys multifasciatus, Hyphessobrycon compressus, Iguanodectes geisleri, Knodus meridae, Landonia latidens, Markiana nigripinnis, Metynnis lippincottianus, Microschemobrycon casiquiare, Moenkhausia xinguensis, Myleus setiger, Odontostilbe pequira, Oligosarcus argenteus, orthospinus franciscoensis, Paracheirodon axelrodi, Paragoniates alburnus, Phenacogaster pectinatus, Phenagoniates macrolepis, Piabina argentea, Piaractus mesopotamicus, Poptella brevispina, Probolus heterostomus, Rachoviscus graciliceps, Rhinobrycon negrensis, Rhoadsia altipinna, Roeboexodon gúyanensis, Salminus hilarii, Serrabrycon magoi, Stygichthys typhlops, Tetragonopterus argenteus e Triportheus albus.

[1] - não ligado (Fig. 54 e Fig. 55). 
Chanos chanos, Citharinus latus, Distichodus notospilus, Hemistichodus vaillanti, Neolebias unifasciatus, Nannocharax fasciatus, Xenocharax spilurus, Anodus orinocensis, Bivibranchia fowleri, Hemiodus unimaculatus, Erythrinoidea fam. nov, Piabucina astrigata, Erythrinus erythrinus, Hoplias malabaricus e Brycinus macrolepidotus.

\section{[-] - inaplicável.}

Gymnotus aff. carapo.

305 - hipurais 1 e 2:

[BUCKUP, 1998: 71; e ZANATA, 2000: 117]

[0] - fusionados (Fig. 54 e Fig. 56).

Citharinus latus, Distichodus notospilus, Hemistichodus vaillanti, Neolebias unifasciatus, Nannocharax fasciatus, Xenocharax spilurus, Anodus orinocensis, Hemiodus unimaculatus, Hydrolycus tatauaia, Crenuchus spilurus, Metynnis lippincottianus e Piabina argêntea.

\section{[1] - separados (Fig. 55).}

Chanos chanos, Catostomus commersonnii, Olivaichthys mesembrinus, Apareiodon piracicabae, Parodon nasus, Saccodon wagneri, Bivibranchia fowleri, Curimata ocellata, Curimatopsis macrolepis, Potamorhina latior, Prochilodus nigricans, Semaprochilodus insignis, Caenotropus labyrinthicus, Chilodus punctatus, Anostomus anostomus, Leporellus vittatus, Leporinus fasciatus, Schizodon fasciatus, Carnegiella strigata, Gasteropelecus sternicla, Thoracocharax stellatus, Acestrorhynchus falcirostris, Gilbertolus atratoensis, Roestes molossus, Erythrinoidea fam. nov, Boulengerella maculata, Ctenolucius hujeta, Copeina cf. guttata, Lebiasina bimaculata, Piabucina astrigata, Erythrinus erythrinus, Hoplias malabaricus, Hepsetus odoe, Arnoldichthys spilopterus, Brycinus macrolepidotus, Bryconalestes longipinnis, Chalceus epakros, Characidium bahiensis, Agoniates halecinus, Aphyocharax pusillus, Astyanax mexicanus, Atopomesus pachyodus, Axelrodia reisei, Brittanichthys axelrodi, Brycon pesu, Bryconadenos tanaothoros, Bryconamericus exodon, Bryconops alburnoides, Charax cf. leticiae, Clupeacharax cf. engrauloides, Compsura heterura, Ctenobrycon hauxwellianus, Deuterodon iguape, Diapoma terofali, Galeocharax knerii, Glandulocauda melanogenys, Gnathocharax steindachneri, Gymnocorymbus ternetzi, Hemibrycon polyodon, Hemigrammus unilineatus, Hollandichthys multifasciatus, Hyphessobrycon compressus, Iguanodectes geisleri, Knodus meridae, Landonia latidens, Markiana nigripinnis, Microschemobrycon casiquiare, Moenkhausia xinguensis, Myleus setiger, Odontostilbe pequira, oligosarcus argenteus, orthospinus franciscoensis, Paracheirodon axelrodi, Paragoniates alburnus, Phenacogaster pectinatus, Phenagoniates macrolepis, Piaractus mesopotamicus, Poptella brevispina, Probolus heterostomus, Rachoviscus graciliceps, Rhinobrycon negrensis, Rhoadsia altipinna, Roeboexodon guyanensis, Salminus hilarii, Serrabrycon magoi, Stygichthys typhlops, Tetragonopterus argenteus e Triportheus albus.

\section{[-] - inaplicável.}

Gymnotus aff. carapo.

306 - Porção anterior dos hipurais 2 e 3 :

[LUCENA \& MENEZES, 1998: 41, modificado]

\section{[0] - separados (Fig. 55).}

Catostomus commersonnii, Olivaichthys mesembrinus, Bivibranchia fowleri, Hemiodus unimaculatus, Curimata ocellata, Curimatopsis macrolepis, Potamorhina latior, Prochilodus nigricans, Semaprochilodus insignis, Caenotropus labyrinthicus, Chilodus punctatus, Anostomus anostomus, Leporellus vittatus, Leporinus fasciatus, Schizodon fasciatus, Carnegiella strigata, Gasteropelecus sternicla, Thoracocharax stellatus, Copeina cf. guttata, Erythrinus erythrinus, Hoplias malabaricus, Arnoldichthys spilopterus, Bryconalestes longipinnis, Chalceus epakros, Characidium bahiensis, Crenuchus spilurus, Atopomesus pachyodus, Axelrodia reisei, Brycon pesu, Bryconadenos tanaothoros, Bryconamericus exodon, Charax cf. leticiae, Clupeacharax cf. engrauloides, Compsura heterura, Ctenobrycon hauxwellianus, Deuterodon iguape, Galeocharax knerii, Glandulocauda melanogenys, Gymnocorymbus ternetzi, Hemigrammus unilineatus, Hollandichthys multifasciatus, Hyphessobrycon compressus, Iguanodectes geisleri, Knodus meridae, Landonia latidens, Markiana nigripinnis, Microschemobrycon casiquiare, Moenkhausia xinguensis, Odontostilbe pequira, Orthospinus franciscoensis, Paracheirodon 
axelrodi, Paragoniates alburnus, Phenacogaster pectinatus, Piabina argentea, Poptella brevispina, Probolus heterostomus, Rhinobrycon negrensis, Rhoadsia altipinna, Salminus hilarii, Serrabrycon magoi, Tetragonopterus argenteus e Triportheus albus.

\section{[1] - juntos, não fusionados (Fig. 54 e Fig. 56).}

Chanos chanos, Citharinus latus, Distichodus notospilus, Hemistichodus vaillanti, Neolebias unifasciatus, Nannocharax fasciatus, Xenocharax spilurus, Apareiodon piracicabae, Parodon nasus, Saccodon wagneri, Anodus orinocensis, Acestrorhynchus falcirostris, Gilbertolus atratoensis, Roestes molossus, Erythrinoidea fam. nov, Boulengerella maculata, Ctenolucius hujeta, Lebiasina bimaculata, Piabucina astrigata, Hepsetus odoe, Brycinus macrolepidotus, Agoniates halecinus, Aphyocharax pusillus, Astyanax mexicanus, Brittanichthys axelrodi, Bryconops alburnoides, Diapoma terofali, Gnathocharax steindachneri, Hemibrycon polyodon, Metynnis lippincottianus, Myleus setiger, Oligosarcus argenteus, Phenagoniates macrolepis, Piaractus mesopotamicus, Rachoviscus graciliceps, Roeboexodon guyanensis e Stygichthys typhlops.

\section{[2] - fusionados.}

Hydrolycus tatauaia.

\section{[-] - inaplicável.}

Gymnotus aff. carapo.

\section{7 - Porção posterior dos hipurais 2 e 3 :}

\section{[0] - afastando-se progressivamente (Fig. 55).}

Chanos chanos, Catostomus commersonnii, olivaichthys mesembrinus, Apareiodon piracicabae, Parodon nasus, Saccodon wagneri, Anodus orinocensis, Bivibranchia fowleri, Hemiodus unimaculatus, Curimata ocellata, Curimatopsis macrolepis, Potamorhina latior, Prochilodus nigricans, Semaprochilodus insignis, Caenotropus labyrinthicus, Chilodus punctatus, Anostomus anostomus, Leporellus vittatus, Leporinus fasciatus, Schizodon fasciatus, Carnegiella strigata, Gasteropelecus sternicla, Thoracocharax stellatus , Boulengerella maculata, Ctenolucius hujeta, Copeina cf. guttata, Lebiasina bimaculata, Piabucina astrigata, Erythrinus erythrinus, Hoplias malabaricus, Hepsetus odoe, Arnoldichthys spilopterus, Bryconalestes longipinnis, Chalceus epakros, Characidium bahiensis, Crenuchus spilurus, Agoniates halecinus, Aphyocharax pusillus, Astyanax mexicanus, Atopomesus pachyodus, Axelrodia reisei, Bryconadenos tanaothoros, Bryconamericus exodon, Bryconops alburnoides, charax cf. leticiae, clupeacharax cf. engrauloides, Compsura heterura, Ctenobrycon hauxwellianus, Deuterodon iguape, Diapoma terofali, Galeocharax knerii, Glandulocauda melanogenys, Gnathocharax steindachneri, Hemibrycon polyodon, Hemigrammus unilineatus, Hollandichthys multifasciatus, Hyphessobrycon compressus, Iguanodectes geisleri, Knodus meridae, Landonia latidens, Markiana nigripinnis, Microschemobrycon casiquiare, Moenkhausia xinguensis, odontostilbe pequira, orthospinus franciscoensis, Paracheirodon axelrodi, Paragoniates alburnus, Phenacogaster pectinatus, Phenagoniates macrolepis, Piabina argentea, Piaractus mesopotamicus, Poptella brevispina, Probolus heterostomus, Rachoviscus graciliceps, Rhinobrycon negrensis, Rhoadsia altipinna, Roeboexodon guyanensis, Salminus hilarii, Serrabrycon magoi, Stygichthys typhlops, Tetragonopterus argenteus e Triportheus albus.

\section{[1] - afastando-se bruscamente (Fig. 54 e Fig. 56).}

Citharinus latus, Distichodus notospilus, Hemistichodus vaillanti, Neolebias unifasciatus, Nannocharax fasciatus, Xenocharax spilurus, Gymnocorymbus ternetzi, Metynnis lippincottianus e Myleus setiger.

\section{[2] - afastando-se bruscamente, apenas no hipural 3.}

Acestrorhynchus falcirostris, Gilbertolus atratoensis, Roestes molossus, Brycinus macrolepidotus, Brittanichthys axelrodi, Brycon pesu e oligosarcus argenteus.

\section{[-] - inaplicável.}

Gymnotus aff. carapo e Hydrolycus tatauaia. 
[FINK \& FINK, 1981:112, modificado]

\section{[0] - autógeno.}

Chanos chanos e Catostomus commersonnii.

\section{[1] - fusionado ao centro composto.}

Olivaichthys mesembrinus, Citharinus latus, Distichodus notospilus, Hemistichodus vaillanti, Neolebias unifasciatus, Nannocharax fasciatus, Xenocharax spilurus, Apareiodon piracicabae, Parodon nasus, Saccodon wagneri, Anodus orinocensis, Bivibranchia fowleri, Hemiodus unimaculatus, Curimata ocellata, Curimatopsis macrolepis, Potamorhina latior, Prochilodus nigricans, Semaprochilodus insignis, Caenotropus labyrinthicus, Chilodus punctatus, Anostomus anostomus, Leporellus vittatus, Leporinus fasciatus, Schizodon fasciatus, Carnegiella strigata, Gasteropelecus sternicla, Thoracocharax stellatus, Acestrorhynchus falcirostris, Gilbertolus atratoensis, Hydrolycus tatauaia, Roestes molossus, Erythrinoidea fam. nov, Boulengerella maculata, Ctenolucius hujeta, Copeina cf. guttata, Lebiasina bimaculata, Piabucina astrigata, Erythrinus erythrinus, Hoplias malabaricus, Hepsetus odoe, Arnoldichthys spilopterus, Brycinus macrolepidotus, Bryconalestes longipinnis, Chalceus epakros, Characidium bahiensis, Crenuchus spilurus, Agoniates halecinus, Aphyocharax pusillus, Astyanax mexicanus, Atopomesus pachyodus, Axelrodia reisei, Brittanichthys axelrodi, Brycon pesu, Bryconadenos tanaothoros, Bryconamericus exodon, Bryconops alburnoides, Charax cf. leticiae, Clupeacharax cf. engrauloides, Compsura heterura, Ctenobrycon hauxwellianus, Deuterodon iguape, Diapoma terofali, Galeocharax knerii, Glandulocauda melanogenys, Gnathocharax steindachneri, Gymnocorymbus ternetzi, Hemibrycon polyodon, Hemigrammus unilineatus, Hollandichthys multifasciatus, Hyphessobrycon compressus, Iguanodectes geisleri, Knodus meridae, Landonia latidens, Markiana nigripinnis, Metynnis lippincottianus, Microschemobrycon casiquiare, Moenkhausia xinguensis, Myleus setiger, Odontostilbe pequira, Oligosarcus argenteus, orthospinus franciscoensis, Paracheirodon axelrodi, Paragoniates alburnus, Phenacogaster pectinatus, Phenagoniates macrolepis, Piabina argentea, Piaractus mesopotamicus, Poptella brevispina, Probolus heterostomus, Rachoviscus graciliceps, Rhinobrycon negrensis, Rhoadsia altipinna, Roeboexodon guyanensis, Salminus hilarii, Serrabrycon magoi, Stygichthys typhlops, Tetragonopterus argenteus e Triportheus albus.

\section{[-] - inaplicável.}

Gymnotus aff. carapo.

309 - Raios principais do lóbulo superior da nadadeira caudal:

[NETTO-FERREIRA, 2006: 264]

[0] - 10 .

Chanos chanos, Citharinus latus, Distichodus notospilus, Hemistichodus vaillanti, Neolebias unifasciatus, Nannocharax fasciatus, Xenocharax spilurus, Apareiodon piracicabae, Parodon nasus, Saccodon wagneri, Anodus orinocensis, Bivibranchia fowleri, Hemiodus unimaculatus, Curimata ocellata, Curimatopsis macrolepis, Potamorhina latior, Prochilodus nigricans, Semaprochilodus insignis, Caenotropus labyrinthicus, Chilodus punctatus, Anostomus anostomus, Leporellus vittatus, Leporinus fasciatus, Schizodon fasciatus, Carnegiella strigata, Gasteropelecus sternicla, Thoracocharax stellatus Acestrorhynchus falcirostris, Gilbertolus atratoensis, Hydrolycus tatauaia, Roestes molossus, Boulengerella maculata, Ctenolucius hujeta, Copeina cf. guttata, Lebiasina bimaculata, Piabucina astrigata, Hepsetus odoe, Arnoldichthys spilopterus, Brycinus macrolepidotus, Bryconalestes longipinnis, Chalceus epakros, Characidium bahiensis, Crenuchus spilurus, Agoniates halecinus, Aphyocharax pusillus, Astyanax mexicanus, Atopomesus pachyodus, Axelrodia reisei, Brittanichthys axelrodi, Brycon pesu, Bryconadenos tanaothoros, Bryconamericus exodon, Bryconops alburnoides, Charax cf. leticiae, Clupeacharax cf. engrauloides, compsura heterura, ctenobrycon hauxwellianus, Deuterodon iguape, Diapoma terofali, Galeocharax knerii, Glandulocauda melanogenys, Gnathocharax steindachneri, Gymnocorymbus ternetzi, Hemibrycon polyodon, Hemigrammus unilineatus, Hollandichthys multifasciatus, Hyphessobrycon compressus, Iguanodectes geisleri, Knodus meridae, Landonia latidens, Markiana nigripinnis, Metynnis lippincottianus, Microschemobrycon casiquiare, Moenkhausia xinguensis, Myleus setiger, odontostilbe pequira, Oligosarcus argenteus, Orthospinus franciscoensis, Paracheirodon axelrodi, Paragoniates alburnus, Phenacogaster pectinatus, Phenagoniates macrolepis, Piabina argentea, Piaractus mesopotamicus, Poptella brevispina, Probolus heterostomus, Rachoviscus graciliceps, Rhinobrycon negrensis, Rhoadsia altipinna, Roeboexodon guyanensis, salminus hilarii, Serrabrycon magoi, Stygichthys typhlops, Tetragonopterus argenteus e Triportheus albus. 
[1] - 9 .

Catostomus commersonnii, Olivaichthys mesembrinus, Erythrinoidea fam. nov, Erythrinus erythrinus e Hoplias malabaricus.

\section{[-] - inaplicável.}

Gymnotus aff. carapo.

\section{0 - Raios principais do lóbulo inferior da nadadeira caudal:} [NETTO-FERREIRA, 2006: 266]

$[0]-9$.

Chanos chanos, Catostomus commersonnii, Olivaichthys mesembrinus, Citharinus latus, Distichodus notospilus, Hemistichodus vaillanti, Nannocharax fasciatus, Neolebias unifasciatus, Xenocharax spilurus, Apareiodon piracicabae, Parodon nasus, Saccodon wagneri, Anodus orinocensis, Bivibranchia fowleri, Hemiodus unimaculatus, Curimata ocellata, Curimatopsis macrolepis, Potamorhina latior, Prochilodus nigricans, Semaprochilodus insignis, Caenotropus labyrinthicus, Chilodus punctatus, Anostomus anostomus, Leporellus vittatus, Leporinus fasciatus, Schizodon fasciatus, Carnegiella strigata, Gasteropelecus sternicla, Thoracocharax stellatus, Acestrorhynchus falcirostris, Gilbertolus atratoensis, Hydrolycus tatauaia, Roestes molossus, Erythrinoidea fam. nov, Boulengerella maculata, Ctenolucius hujeta, Copeina cf. guttata, Lebiasina bimaculata, Piabucina astrigata, Hepsetus odoe, Arnoldichthys spilopterus, Brycinus macrolepidotus, Bryconalestes longipinnis, Chalceus epakros, Characidium bahiensis, Crenuchus spilurus, Agoniates halecinus, Aphyocharax pusillus, Astyanax mexicanus, Atopomesus pachyodus, Axelrodia reisei, Brittanichthys axelrodi, Brycon pesu, Bryconadenos tanaothoros, Bryconamericus exodon, Bryconops alburnoides, Charax cf. leticiae, Clupeacharax cf. engrauloides, Compsura heterura, Ctenobrycon hauxwellianus, Deuterodon iguape, Diapoma terofali, Galeocharax knerii, Glandulocauda melanogenys, Gnathocharax steindachneri, Gymnocorymbus ternetzi, Hemibrycon polyodon, Hemigrammus unilineatus, Hollandichthys multifasciatus, Hyphessobrycon compressus, Iguanodectes geisleri, Knodus meridae, Landonia latidens, Markiana nigripinnis, Metynnis lippincottianus, Microschemobrycon casiquiare, Moenkhausia xinguensis, Myleus setiger, odontostilbe pequira, Oligosarcus argenteus, Orthospinus franciscoensis, Paracheirodon axelrodi, Paragoniates alburnus, Phenacogaster pectinatus, Phenagoniates macrolepis, Piabina argentea, Piaractus mesopotamicus, Poptella brevispina, Probolus heterostomus, Rachoviscus graciliceps, Rhinobrycon negrensis, Rhoadsia altipinna, Roeboexodon guyanensis, Salminus hilarii, Serrabrycon magoi, Stygichthys typhlops, Tetragonopterus argenteus e Triportheus albus.

$$
\text { [1] - } 8 \text {. }
$$

Erythrinus erythrinus e Hoplias malabaricus.

$$
\text { [-] - inaplicável. }
$$

Gymnotus aff. carapo.

\section{1 - Raio pró-corrente mais anterior:}

\section{[0] - inclinação similar aos outros.}

Chanos chanos, Catostomus commersonnii, Olivaichthys mesembrinus, Citharinus latus, Distichodus notospilus, Hemistichodus vaillanti, Neolebias unifasciatus, Nannocharax fasciatus, Xenocharax spilurus, Apareiodon piracicabae, Parodon nasus, Saccodon wagneri, Anodus orinocensis, Bivibranchia fowleri, Hemiodus unimaculatus, Curimata ocellata, Curimatopsis macrolepis, Prochilodus nigricans, Semaprochilodus insignis, Caenotropus labyrinthicus, Chilodus punctatus, Anostomus anostomus, Leporellus vittatus, Leporinus fasciatus, Schizodon fasciatus, Carnegiella strigata, Gasteropelecus sternicla, Thoracocharax stellatus, Acestrorhynchus falcirostris, Gilbertolus atratoensis, Hydrolycus tatauaia, Roestes molossus, Boulengerella maculata, Ctenolucius hujeta, Copeina cf. guttata, Lebiasina bimaculata, Piabucina astrigata, Erythrinus erythrinus, Hoplias malabaricus, Hepsetus odoe, Characidium bahiensis, Crenuchus spilurus, Aphyocharax pusillus, Atopomesus pachyodus, Axelrodia reisei, Brittanichthys axelrodi, Brycon pesu, Bryconadenos tanaothoros, Bryconamericus exodon, Bryconops alburnoides, 
Charax cf. leticiae, Clupeacharax cf. engrauloides, Compsura heterura, ctenobrycon hauxwellianus, Deuterodon iguape, Diapoma terofali, Galeocharax knerii, Glandulocauda melanogenys, Gnathocharax steindachneri, Gymnocorymbus ternetzi, Hemibrycon polyodon, Hemigrammus unilineatus, Hollandichthys multifasciatus, Hyphessobrycon compressus, Iguanodectes geisleri, Knodus meridae, Landonia latidens, Markiana nigripinnis, Metynnis lippincottianus, Microschemobrycon casiquiare, Moenkhausia xinguensis, odontostilbe pequira, Oligosarcus argenteus, orthospinus franciscoensis, Paracheirodon axelrodi, Paragoniates alburnus, Phenacogaster pectinatus, Phenagoniates macrolepis, Piabina argentea, Piaractus mesopotamicus, Probolus heterostomus, Rachoviscus graciliceps, Rhinobrycon negrensis, Rhoadsia altipinna, Roeboexodon guyanensis, Salminus hilarii, Serrabrycon magoi, Stygichthys typhlops e Tetragonopterus argenteus.

\section{[1] - mais horizontal que os demais.}

Potamorhina latior, Arnoldichthys spilopterus, Brycinus macrolepidotus, Bryconalestes longipinnis, Chalceus epakros, Agoniates halecinus, Astyanax mexicanus, Myleus setiger, Poptella brevispina e Triportheus albus.

\section{[ - ] - inaplicável.}

Gymnotus aff. carapo, Erythrinoidea fam. nov.

312 - Raios pró-correntes superiores:

[NETTO-FERREIRA, 2006: 263]

(Minimamente conectado).

[0] - 4 ou menos.

Erythrinoidea fam. nov.

[1] - 5 ou 6 .

Apareiodon piracicabae, Parodon nasus, Caenotropus labyrinthicus, Chilodus punctatus, Schizodon fasciatus, Copeina cf. guttata, Arnoldichthys spilopterus e crenuchus spilurus.

\section{[2] - 7 ou mais.}

Chanos chanos, Catostomus commersonnii, olivaichthys mesembrinus, Citharinus latus, Distichodus notospilus, Hemistichodus vaillanti, Neolebias unifasciatus, Nannocharax fasciatus, Xenocharax spilurus, Saccodon wagneri, Anodus orinocensis, Bivibranchia fowleri, Hemiodus unimaculatus, Curimata ocellata, Curimatopsis macrolepis, Potamorhina latior, Prochilodus nigricans, Semaprochilodus insignis, Anostomus anostomus, Leporellus vittatus, Leporinus fasciatus, Carnegiella strigata, Gasteropelecus sternicla, Thoracocharax stellatus, Acestrorhynchus falcirostris, Gilbertolus atratoensis, Hydrolycus tatauaia, Roestes molossus, Boulengerella maculata, ctenolucius hujeta, Lebiasina bimaculata, Piabucina astrigata, Erythrinus erythrinus, Hoplias malabaricus, Hepsetus odoe, Brycinus macrolepidotus, Bryconalestes longipinnis, Chalceus epakros, Characidium bahiensis, Agoniates halecinus, Aphyocharax pusillus, Astyanax mexicanus, Atopomesus pachyodus, Axelrodia reisei, Brittanichthys axelrodi, Brycon pesu, Bryconadenos tanaothoros, Bryconamericus exodon, Bryconops alburnoides, Charax cf. leticiae, Clupeacharax cf. engrauloides, compsura heterura, ctenobrycon hauxwellianus, Deuterodon iguape, Diapoma terofali, Galeocharax knerii, Glandulocauda melanogenys, Gnathocharax steindachneri, Gymnocorymbus ternetzi, Hemibrycon polyodon, Hemigrammus unilineatus, Hollandichthys multifasciatus, Hyphessobrycon compressus, Iguanodectes geisleri, Knodus meridae, Landonia latidens, Markiana nigripinnis, Metynnis lippincottianus, Microschemobrycon casiquiare, Moenkhausia xinguensis, Myleus setiger, odontostilbe pequira, oligosarcus argenteus, orthospinus franciscoensis, Paracheirodon axelrodi, Paragoniates alburnus, Phenacogaster pectinatus, Phenagoniates macrolepis, Piabina argentea, Piaractus mesopotamicus, Poptella brevispina, Probolus heterostomus, Rachoviscus graciliceps, Rhinobrycon negrensis, Rhoadsia altipinna, Roeboexodon guyanensis, Salminus hilarii, Serrabrycon magoi, Stygichthys typhlops, Tetragonopterus argenteus e Triportheus albus.

313 - Raios pró-correntes inferiores:

[NETTO-FERREIRA, 2006: 265] 


\section{(Minimamente conectado).}

\section{[0] - 4 ou menos.}

Caenotropus labyrinthicus, Chilodus punctatus, Erythrinoidea fam. nov. e Rhoadsia altipinna.

\section{[1] - 5 ou 6 .}

Citharinus latus, Apareiodon piracicabae, Parodon nasus, Saccodon wagneri, Hemiodus unimaculatus, Curimata ocellata, Curimatopsis macrolepis, Prochilodus nigricans, Semaprochilodus insignis, Anostomus anostomus, Leporellus vittatus, Leporinus fasciatus, Schizodon fasciatus, Carnegiella strigata, Gasteropelecus sternicla, Gilbertolus atratoensis, Roestes molossus, Ctenolucius hujeta, Copeina cf. guttata, Erythrinus erythrinus, Hoplias malabaricus, Arnoldichthys spilopterus, Characidium bahiensis, crenuchus spilurus, Gnathocharax steindachneri, Metynnis lippincottianus, Myleus setiger, Paragoniates alburnus e Rhoadsia altipinna.

\section{[2] - 7 ou mais.}

State 2 :, Chanos chanos, Catostomus commersonnii, Olivaichthys mesembrinus, Distichodus notospilus, Hemistichodus vaillanti, Neolebias unifasciatus, Nannocharax fasciatus, Xenocharax spilurus, Anodus orinocensis, Bivibranchia fowleri, Potamorhina latior, Thoracocharax stellatus, Acestrorhynchus falcirostris, Hydrolycus tatauaia, Boulengerella maculata, Lebiasina bimaculata, Piabucina astrigata, Hepsetus odoe, Brycinus macrolepidotus, Bryconalestes longipinnis, Chalceus epakros, Agoniates halecinus, Aphyocharax pusillus, Astyanax mexicanus, Atopomesus pachyodus, Axelrodia reisei, Brittanichthys axelrodi, Brycon pesu, Bryconadenos tanaothoros, Bryconamericus exodon, Bryconops alburnoides, Charax cf. leticiae, Clupeacharax cf. engrauloides, Compsura heterura, Ctenobrycon hauxwellianus, Deuterodon iguape, Diapoma terofali, Galeocharax knerii, Glandulocauda melanogenys, Gymnocorymbus ternetzi, Hemibrycon polyodon, Hemigrammus unilineatus, Hollandichthys multifasciatus, Hyphessobrycon compressus, Iguanodectes geisleri, Knodus meridae, Landonia latidens, Markiana nigripinnis, Microschemobrycon casiquiare, Moenkhausia xinguensis, odontostilbe pequira, oligosarcus argenteus, Orthospinus franciscoensis, Paracheirodon axelrodi, Phenacogaster pectinatus, Phenagoniates macrolepis, Piabina argentea, Piaractus mesopotamicus, Poptella brevispina, Probolus heterostomus, Rachoviscus graciliceps, Rhinobrycon negrensis, Roeboexodon guyanensis, Salminus hilarii, Serrabrycon magoi, stygichthys typhlops, Tetragonopterus argenteus, Triportheus albus

\section{[-] - inaplicável.}

Gymnotus aff. carapo.

\section{$[1,2]$ - polimórfico.}

Rhoadsia altipinna.

\section{4 - Segmentos dos raios da nadadeira caudal:}

\section{[0] - mais compridos que altos.}

Chanos chanos, Catostomus commersonnii, Citharinus latus, Distichodus notospilus, Hemistichodus vaillanti, Neolebias unifasciatus, Nannocharax fasciatus, Saccodon wagneri, Anodus orinocensis, Bivibranchia fowleri, Hemiodus unimaculatus, Curimata ocellata, Curimatopsis macrolepis, Potamorhina latior, Prochilodus 'nigricans, Semaprochilodus insignis, Caenotropus labyrinthicus, Chilodus punctatus, Anostomus anostomus, Carnegiella strigata, Gasteropelecus sternicla, Thoracocharax stellatus, Acestrorhynchus falcirostris, Gilbertolus atratoensis, Erythrinoidea fam. nov, Boulengerella maculata, Ctenolucius hujeta, Copeina cf. guttata, Lebiasina bimaculata, Hepsetus odoe, Arnoldichthys spilopterus, Chalceus epakros, Characidium bahiensis, Crenuchus spilurus, Aphyocharax pusillus, Astyanax mexicanus, Atopomesus pachyodus, Axelrodia reisei, Brittanichthys axelrodi, Brycon pesu, Bryconadenos tanaothoros, Bryconamericus exodon, Charax cf. leticiae, Clupeacharax cf. engrauloides, Compsura heterura, Ctenobrycon hauxwellianus, Diapoma terofali, Galeocharax knerii, Glandulocauda melanogenys, Gnathocharax steindachneri, Gymnocorymbus ternetzi, Hemibrycon polyodon, Hemigrammus unilineatus, Hollandichthys multifasciatus, Hyphessobrycon compressus, Iguanodectes geisleri, Knodus meridae, Landonia latidens, Markiana nigripinnis, Microschemobrycon casiquiare, Moenkhausia xinguensis, odontostilbe pequira, orthospinus franciscoensis, Paracheirodon axelrodi, Paragoniates alburnus, Phenacogaster pectinatus, Phenagoniates macrolepis, Piabina argentea, Probolus heterostomus, Rachoviscus 
graciliceps, Rhinobrycon negrensis, Rhoadsia altipinna, Salminus hilarii, Serrabrycon magoi e Tetragonopterus argenteus.

\section{[1] - mais altos que compridos.}

Olivaichthys mesembrinus, Xenocharax spilurus, Apareiodon piracicabae, Parodon nasus, Leporellus vittatus, Leporinus fasciatus, Hydrolycus tatauaia, Roestes molossus, Piabucina astrigata, Erythrinus erythrinus, Hoplias malabaricus, Brycinus macrolepidotus, Bryconalestes longipinnis, Agoniates halecinus, Bryconops alburnoides, Deuterodon iguape, Metynnis lippincottianus, Myleus setiger, oligosarcus argenteus, Piaractus mesopotamicus, Poptella brevispina, Roeboexodon guyanensis, Stygichthys typhlops e Triportheus albus.

\section{[-] - inaplicável.}

Gymnotus aff. carapo.

\section{[?] - indeterminado.}

Schizodon fasciatus.

315 - Margem posterior da nadadeira caudal:

[OYAKAWA, 1998: 105, modificado; ZANATA, 2000: 114; e NETTO-FERREIRA, 2006: 268, modificado]

\section{[0] - bifurcada.}

Catostomus commersonnii, Olivaichthys mesembrinus, Citharinus latus, Distichodus notospilus, Hemistichodus vaillanti, Neolebias unifasciatus, Nannocharax fasciatus, Xenocharax spilurus, Apareiodon piracicabae, Parodon nasus, Saccodon wagneri, Anodus orinocensis, Bivibranchia fowleri, Hemiodus unimaculatus, Curimata ocellata, Curimatopsis macrolepis, Potamorhina latior, Prochilodus nigricans, Semaprochilodus insignis, Caenotropus labyrinthicus, Chilodus punctatus, Anostomus anostomus, Leporellus vittatus, Leporinus fasciatus, Schizodon fasciatus, Carnegiella strigata, Gasteropelecus sternicla, Thoracocharax stellatus, Acestrorhynchus falcirostris, Gilbertolus atratoensis, Hydrolycus tatauaia, Roestes molossus, Boulengerella maculata, Ctenolucius hujeta, Copeina cf. guttata, Lebiasina bimaculata, Piabucina astrigata, Hepsetus odoe, Arnoldichthys spilopterus, Brycinus macrolepidotus, Bryconalestes longipinnis, Chalceus epakros, Characidium bahiensis, Crenuchus spilurus, Agoniates halecinus, Aphyocharax pusillus, Astyanax mexicanus, Atopomesus pachyodus, Axelrodia reisei, Brittanichthys axelrodi, Brycon pesu, Bryconadenos tanaothoros, Bryconamericus exodon, Bryconops alburnoides, Charax cf. leticiae, Clupeacharax cf. engrauloides, Compsura heterura, Ctenobrycon hauxwellianus, Deuterodon iguape, Diapoma terofali, Galeocharax knerii, Glandulocauda melanogenys, Gnathocharax steindachneri, Gymnocorymbus ternetzi, Hemibrycon polyodon, Hemigrammus unilineatus, Hollandichthys multifasciatus, Hyphessobrycon compressus, Iguanodectes geisleri, Knodus meridae, Landonia latidens, Markiana nigripinnis, Metynnis lippincottianus, Microschemobrycon casiquiare, Moenkhausia xinguensis, Myleus setiger, Odontostilbe pequira, Oligosarcus argenteus, orthospinus franciscoensis, Paracheirodon axelrodi, Paragoniates alburnus, Phenacogaster pectinatus, Phenagoniates macrolepis, Piabina argentea, Piaractus mesopotamicus, Poptella brevispina, Probolus heterostomus, Rachoviscus graciliceps, Rhinobrycon negrensis, Rhoadsia altipinna, Roeboexodon guyanensis, Serrabrycon magoi, Stygichthys typhlops, Tetragonopterus argenteus e Triportheus albus.

[1] - lunada.

Chanos chanos.

[2] - arredondada.

Erythrinoidea fam. nov, Erythrinus erythrinus e Hoplias malabaricus.

\section{[-] - inaplicável.}

Gymnotus aff. carapo.

$$
\text { [?] - indeterminado. }
$$




\subsubsection{Vértebras, supraneurais e ossos intermusculares}

\section{6 - Parapófises da primeira vértebra:}

[FINK \& FINK, 1981: 82]

[0] - presente.

Chanos chanos e Catostomus commersonnii.

[1] - ausente.

Olivaichthys mesembrinus, Gymnotus aff. carapo, Citharinus latus, Distichodus notospilus, Hemistichodus vaillanti, Neolebias unifasciatus, Nannocharax fasciatus, Xenocharax spilurus, Apareiodon piracicabae, Parodon nasus, Saccodon wagneri, Anodus orinocensis, Bivibranchia fowleri, Hemiodus unimaculatus, Curimata ocellata, Curimatopsis macrolepis, Potamorhina latior, Prochilodus nigricans, Semaprochilodus insignis, Caenotropus labyrinthicus, Chilodus punctatus, Anostomus anostomus, Leporellus vittatus, Leporinus fasciatus, Schizodon fasciatus, Carnegiella strigata, Gasteropelecus sternicla, Thoracocharax stellatus, Acestrorhynchus falcirostris, Gilbertolus atratoensis, Hydrolycus tatauaia, Roestes molossus, Erythrinoidea fam. nov, Boulengerella maculata, Ctenolucius hujeta, Copeina cf. guttata, Lebiasina bimaculata, Piabucina astrigata, Erythrinus erythrinus, Hoplias malabaricus, Hepsetus odoe, Arnoldichthys spilopterus, Brycinus macrolepidotus, Bryconalestes longipinnis, Chalceus epakros, Characidium bahiensis, Crenuchus spilurus, Agoniates halecinus, Aphyocharax pusillus, Astyanax mexicanus, Atopomesus pachyodus, Axelrodia reisei, Brittanichthys axelrodi, Brycon pesu, Bryconadenos tanaothoros, Bryconamericus exodon, Bryconops alburnoides, Charax cf. leticiae, Clupeacharax cf. engrauloides, Compsura heterura, Ctenobrycon hauxwellianus, Deuterodon iguape, Diapoma terofali, Galeocharax knerii, Glandulocauda melanogenys, Gnathocharax steindachneri, Gymnocorymbus ternetzi, Hemibrycon polyodon, Hemigrammus unilineatus, Hollandichthys multifasciatus, Hyphessobrycon compressus, Iguanodectes geisleri, Knodus meridae, Landonia latidens, Markiana nigripinnis, Metynnis lippincottianus, Microschemobrycon casiquiare, Moenkhausia xinguensis, Myleus setiger, Odontostilbe pequira, oligosarcus argenteus, orthospinus franciscoensis, Paracheirodon axelrodi, Paragoniates alburnus, Phenacogaster pectinatus, Phenagoniates macrolepis, Piabina argentea, Piaractus mesopotamicus, Poptella brevispina, Probolus heterostomus, Rachoviscus graciliceps, Rhinobrycon negrensis, Rhoadsia altipinna, Roeboexodon guyanensis, Salminus hilarii, Serrabrycon magoi, Stygichthys typhlops, Tetragonopterus argenteus e Triportheus albus.

\section{7 - Processos ventrais da segunda e terceira vértebra:}

[LUCENA, 1993: 75 modificado; BUCKUP, 1998: 44 modificado; OYAKAWA, 1998: 73 e 74 modificados; NetTo-Ferreira, 2006: 205 e 206 modificados]

\section{(Minimamente conectado).}

\section{[0] - ausentes.}

Chanos chanos, Olivaichthys mesembrinus, Gymnotus aff. carapo, Apareiodon piracicabae, Parodon nasus, Anodus orinocensis, Bivibranchia fowleri, Hemiodus unimaculatus, Curimata ocellata, Curimatopsis macrolepis, Potamorhina latior, Prochilodus nigricans, Semaprochilodus insignis, Caenotropus labyrinthicus, Chilodus punctatus, Anostomus anostomus, Leporellus vittatus, Leporinus fasciatus, schizodon fasciatus, Carnegiella strigata, Gasteropelecus sternicla, Thoracocharax stellatus, Acestrorhynchus falcirostris, Gilbertolus atratoensis, Boulengerella maculata, ctenolucius hujeta, Copeina cf. guttata, Lebiasina bimaculata, Piabucina astrigata, Brycinus macrolepidotus, Bryconalestes longipinnis, Chalceus epakros, Characidium bahiensis, Crenuchus spilurus, Agoniates halecinus, Aphyocharax pusillus, Astyanax mexicanus, Atopomesus pachyodus, Axelrodia reisei, Brittanichthys axelrodi, Brycon pesu, Bryconadenos tanaothoros, Bryconamericus exodon, Bryconops alburnoides, Charax cf. leticiae, Clupeacharax cf. engrauloides, Compsura heterura, Ctenobrycon hauxwellianus, Deuterodon iguape, Diapoma terofali, Galeocharax knerii, Gymnocorymbus ternetzi, Hemibrycon polyodon, Hemigrammus unilineatus, Hyphessobrycon compressus, Iguanodectes geisleri, Knodus meridae, Landonia latidens, Markiana nigripinnis, Metynnis lippincottianus, Microschemobrycon casiquiare, Moenkhausia xinguensis, Myleus setiger, Odontostilbe pequira, oligosarcus argenteus, orthospinus franciscoensis, Paracheirodon axelrodi, Paragoniates alburnus, Phenacogaster pectinatus, Phenagoniates macrolepis, Piabina argentea, Piaractus mesopotamicus, Poptella brevispina, Probolus heterostomus, Rachoviscus graciliceps, Rhinobrycon 
negrensis, Rhoadsia altipinna, Roeboexodon guyanensis, Salminus hilarii, Serrabrycon magoi, Stygichthys typhlops, Tetragonopterus argenteus e Triportheus albus.

\section{[1] - presente apenas na segunda vértebra.}

Catostomus commersonnii, Arnoldichthys spilopterus, Glandulocauda melanogenys e Hollandichthys multifasciatus.

[2] - presente na segunda e terceira vértebra.

Citharinus latus, Distichodus notospilus, Hemistichodus vaillanti, Neolebias unifasciatus, Nannocharax fasciatus, Xenocharax spilurus, Roestes molossus, Erythrinus erythrinus, Hoplias malabaricus, Hepsetus odoe e Gnathocharax steindachneri.

\section{[?] - indeterminado.}

Saccodon wagneri, Hydrolycus tatauaia e Erythrinoidea fam. nov.

318 - Arco neural da primeira vértebra:

[FINK \& FINK, 1981: 66]

[0] - como os demais.

Chanos chanos.

[1] - modificado como scaphium.

Catostomus commersonnii, Olivaichthys mesembrinus, Gymnotus aff. carapo, Citharinus latus, Distichodus notospilus, Hemistichodus vaillanti, Neolebias unifasciatus, Nannocharax fasciatus, Xenocharax spilurus, Apareiodon piracicabae, Parodon nasus, Saccodon wagneri, Anodus orinocensis, Bivibranchia fowleri, Hemiodus unimaculatus, Curimata ocellata, Curimatopsis macrolepis, Potamorhina latior, Prochilodus nigricans, Semaprochilodus insignis, Caenotropus labyrinthicus, Chilodus punctatus, Anostomus anostomus, Leporellus vittatus, Leporinus fasciatus, Schizodon fasciatus, Carnegiella strigata, Gasteropelecus sternicla, Thoracocharax stellatus, Acestrorhynchus falcirostris, Gilbertolus atratoensis, Hydrolycus tatauaia, Roestes molossus, Erythrinoidea fam. nov, Boulengerella maculata, Ctenolucius hujeta, copeina cf. guttata, Lebiasina bimaculata, Piabucina astrigata, Erythrinus erythrinus, Hoplias malabaricus, Hepsetus odoe, Arnoldichthys spilopterus, Brycinus macrolepidotus, Bryconalestes longipinnis, Chalceus epakros, Characidium bahiensis, Crenuchus spilurus, Agoniates halecinus, Aphyocharax pusillus, Astyanax mexicanus, Atopomesus pachyodus, Axelrodia reisei, Brittanichthys axelrodi, Brycon pesu, Bryconadenos tanaothoros, Bryconamericus exodon, Bryconops alburnoides, Charax cf. leticiae, Clupeacharax cf. engrauloides, Compsura heterura, Ctenobrycon hauxwellianus, Deuterodon iguape, Diapoma terofali, Galeocharax knerii, Glandulocauda melanogenys, Gnathocharax steindachneri, Gymnocorymbus ternetzi, Hemibrycon polyodon, Hemigrammus unilineatus, Hollandichthys multifasciatus, Hyphessobrycon compressus, Iguanodectes geisleri, Knodus meridae, Landonia latidens, Markiana nigripinnis, Metynnis lippincottianus, Microschemobrycon casiquiare, Moenkhausia xinguensis, Myleus setiger, Odontostilbe pequira, oligosarcus argenteus, Orthospinus franciscoensis, Paracheirodon axelrodi, Paragoniates alburnus, Phenacogaster pectinatus, Phenagoniates macrolepis, Piabina argentea, Piaractus mesopotamicus, Poptella brevispina, Probolus heterostomus, Rachoviscus graciliceps, Rhinobrycon negrensis, Rhoadsia altipinna, Roeboexodon guyanensis, Salminus hilarii, Serrabrycon magoi, Stygichthys typhlops, Tetragonopterus argenteus e Triportheus albus.

319 - Arco neural da segunda vértebra:

[FINK \& FINK, 1981: 69]

[0] - como o das vértebras posteriores.

Chanos chanos.

\section{[1] - como intercalarium.}

Catostomus commersonnii, olivaichthys mesembrinus, Gymnotus aff. carapo, Citharinus latus, Distichodus notospilus, Hemistichodus vaillanti, Neolebias unifasciatus, Nannocharax fasciatus, Xenocharax spilurus, Apareiodon piracicabae, Parodon nasus, Saccodon wagneri, Anodus orinocensis, Bivibranchia fowleri, Hemiodus unimaculatus , Curimata ocellata, Curimatopsis macrolepis, Potamorhina latior, Prochilodus nigricans, 
Semaprochilodus insignis, Caenotropus labyrinthicus, Chilodus punctatus, Anostomus anostomus, Leporellus vittatus, Leporinus fasciatus, Schizodon fasciatus, Carnegiella strigata, Gasteropelecus sternicla, Thoracocharax stellatus, Acestrorhynchus falcirostris, Gilbertolus atratoensis, Hydrolycus tatauaia, Roestes molossus, Erythrinoidea fam. nov, Boulengerella maculata, ctenolucius hujeta, Copeina cf. guttata, Lebiasina bimaculata, Piabucina astrigata, Erythrinus erythrinus, Hoplias malabaricus, Hepsetus odoe, Arnoldichthys spilopterus, Brycinus macrolepidotus, Bryconalestes longipinnis, Chalceus epakros, Characidium bahiensis, Crenuchus spilurus, Agoniates halecinus, Aphyocharax pusillus, Astyanax mexicanus, Atopomesus pachyodus, Axelrodia reisei, Brittanichthys axelrodi, Brycon pesu, Bryconadenos tanaothoros, Bryconamericus exodon, Bryconops alburnoides, Charax cf. leticiae, clupeacharax cf. engrauloides, Compsura heterura, Ctenobrycon hauxwellianus, Deuterodon iguape, Diapoma terofali, Galeocharax knerii, Glandulocauda melanogenys, Gnathocharax steindachneri, Gymnocorymbus ternetzi, Hemibrycon polyodon, Hemigrammus unilineatus, Hollandichthys multifasciatus, Hyphessobrycon compressus, Iguanodectes geisleri, Knodus meridae, Landonia latidens, Markiana nigripinnis, Metynnis lippincottianus, Microschemobrycon casiquiare, Moenkhausia xinguensis, Myleus setiger, odontostilbe pequira, oligosarcus argenteus, orthospinus franciscoensis, Paracheirodon axelrodi, Paragoniates alburnus, Phenacogaster pectinatus, Phenagoniates macrolepis, Piabina argentea, Piaractus mesopotamicus, Poptella brevispina, Probolus heterostomus, Rachoviscus graciliceps, Rhinobrycon negrensis, Rhoadsia altipinna, Roeboexodon guyanensis, Salminus hilarii, Serrabrycon magoi, Stygichthys typhlops, Tetragonopterus argenteus e Triportheus albus.

320 - Espinho do terceiro arco neural:

[LuCENA, 1993: 76; BuCKup, 1998: 45; ZANATA, 2000: 84 modificado; NetToFERREIRA, 2006: 208]

\section{[0] - ausente.}

Citharinus latus, Hemistichodus vaillanti, Neolebias unifasciatus, Nannocharax fasciatus, Xenocharax spilurus, Apareiodon piracicabae, Parodon nasus, Bivibranchia fowleri, Curimata ocellata, Curimatopsis macrolepis, Potamorhina latior, Caenotropus labyrinthicus, Chilodus punctatus, Anostomus anostomus, Leporellus vittatus, Carnegiella strigata, Gasteropelecus sternicla, Thoracocharax stellatus, Erythrinoidea fam. nov, Boulengerella maculata, ctenolucius hujeta, Copeina cf. guttata, Lebiasina bimaculata, Piabucina astrigata, Erythrinus erythrinus, Hepsetus odoe, Arnoldichthys spilopterus, Characidium bahiensis, Agoniates halecinus, Atopomesus pachyodus, Gnathocharax steindachneri, Phenagoniates macrolepis e Salminus hilarii.

\section{[1] - presente.}

Chanos chanos, Catostomus commersonnii, olivaichthys mesembrinus, Gymnotus aff. carapo, Distichodus notospilus, Anodus orinocensis, Hemiodus unimaculatus, Prochilodus nigricans, Semaprochilodus insignis, Leporinus fasciatus, Schizodon fasciatus, Acestrorhynchus falcirostris, Gilbertolus atratoensis, Hydrolycus tatauaia, Hoplias malabaricus, Brycinus macrolepidotus, Bryconalestes longipinnis, Chalceus epakros, Crenuchus spilurus, Aphyocharax pusillus, Astyanax mexicanus, Axelrodia reisei, Brittanichthys axelrodi, Brycon pesu, Bryconadenos tanaothoros, Bryconamericus exodon, Bryconops alburnoides, Charax cf. leticiae, clupeacharax cf. engrauloides, Compsura heterura, Ctenobrycon hauxwellianus, Deuterodon iguape, Diapoma terofali, Galeocharax knerii, Glandulocauda melanogenys, Gymnocorymbus ternetzi, Hemibrycon polyodon, Hemigrammus unilineatus, Hollandichthys multifasciatus, Hyphessobrycon compressus, Iguanodectes geisleri, Knodus meridae, Landonia latidens, Markiana nigripinnis, Metynnis lippincottianus, Microschemobrycon casiquiare, Moenkhausia xinguensis, Myleus setiger, odontostilbe pequira, oligosarcus argenteus, orthospinus franciscoensis, Paracheirodon axelrodi, Paragoniates alburnus, Phenacogaster pectinatus, Piabina argentea, Piaractus mesopotamicus, Poptella brevispina, Probolus heterostomus, Rachoviscus graciliceps, Rhinobrycon negrensis, Rhoadsia altipinna, Roeboexodon guyanensis, Serrabrycon magoi, Stygichthys typhlops, Tetragonopterus argenteus e Triportheus albus.

\section{[?] - indeterminado.}

Saccodon wagneri e Roestes molossus.

\section{1 - Processo transverso do terceiro arco neural:} [FINK \& FINK, 1981:71]

[0] - ausente. 
Chanos chanos, olivaichthys mesembrinus, Gymnotus aff. carapo, Nannocharax fasciatus e Characidium bahiensis.

\section{[1] - presente.}

Catostomus commersonnii, Citharinus latus, Distichodus notospilus, Hemistichodus vaillanti, Neolebias unifasciatus, Xenocharax spilurus, Apareiodon piracicabae, Parodon nasus, Anodus orinocensis, Bivibranchia fowleri, Hemiodus unimaculatus , Curimata ocellata, Curimatopsis macrolepis, Potamorhina latior, Prochilodus nigricans, Semaprochilodus insignis, Caenotropus labyrinthicus, Chilodus punctatus, Anostomus anostomus, Leporellus vittatus, Leporinus fasciatus, Schizodon fasciatus, Carnegiella strigata, Gasteropelecus sternicla, Thoracocharax stellatus , Acestrorhynchus falcirostris, Gilbertolus atratoensis, Hydrolycus tatauaia, Roestes molossus, Erythrinoidea fam. nov, Boulengerella maculata, Ctenolucius hujeta, Copeina cf. guttata, Lebiasina bimaculata, Piabucina astrigata, Erythrinus erythrinus, Hoplias malabaricus, Hepsetus odoe, Arnoldichthys spilopterus, Brycinus macrolepidotus, Bryconalestes longipinnis, Chalceus epakros, Crenuchus spilurus, Agoniates halecinus, Aphyocharax pusillus, Astyanax mexicanus, Atopomesus pachyodus, Axelrodia reisei, Brittanichthys axelrodi, Brycon pesu, Bryconadenos tanaothoros, Bryconamericus exodon, Bryconops alburnoides, Charax cf. leticiae, Clupeacharax cf. engrauloides, Compsura heterura, ctenobrycon hauxwellianus, Deuterodon iguape, Diapoma terofali, Galeocharax knerii, Glandulocauda melanogenys, Gnathocharax steindachneri, Gymnocorymbus ternetzi, Hemibrycon polyodon, Hemigrammus unilineatus, Hollandichthys multifasciatus, Hyphessobrycon compressus, Iguanodectes geisleri, Knodus meridae, Landonia latidens, Markiana nigripinnis, Metynnis lippincottianus, Microschemobrycon casiquiare, Moenkhausia xinguensis, Myleus setiger, odontostilbe pequira, oligosarcus argenteus, orthospinus franciscoensis, Paracheirodon axelrodi, Paragoniates alburnus, Phenacogaster pectinatus, Phenagoniates macrolepis, Piabina argentea, Piaractus mesopotamicus, Poptella brevispina, Probolus heterostomus, Rachoviscus graciliceps, Rhinobrycon negrensis, Rhoadsia altipinna, Roeboexodon guyanensis, Salminus hilarii, Serrabrycon magoi, Stygichthys typhlops, Tetragonopterus argenteus e Triportheus albus.

\section{[?] - indeterminado.}

Saccodon wagneri.

\section{2 - Relação do terceiro arco neural e o neurocrânio:}

[FINK \& FINK. 1981: 72]

\section{[0] - distante.}

Chanos chanos e Catostomus commersonnii.

[1] - próximo.

Olivaichthys mesembrinus, Gymnotus aff. carapo, Citharinus latus, Distichodus notospilus, Hemistichodus vaillanti, Neolebias unifasciatus, Nannocharax fasciatus, Xenocharax spilurus, Apareiodon piracicabae, Parodon nasus, Saccodon wagneri, Anodus orinocensis, Bivibranchia fowleri, Hemiodus unimaculatus, Curimata ocellata, Curimatopsis macrolepis, Potamorhina latior, Prochilodus nigricans, Semaprochilodus insignis, Caenotropus labyrinthicus, Chilodus punctatus, Anostomus anostomus, Leporellus vittatus, Leporinus fasciatus, Schizodon fasciatus, Carnegiella strigata, Gasteropelecus sternicla, Thoracocharax stellatus, Acestrorhynchus falcirostris, Gilbertolus atratoensis, Hydrolycus tatauaia, Roestes molossus, Erythrinoidea fam. nov, Boulengerella maculata, Ctenolucius hujeta, Copeina cf. guttata, Lebiasina bimaculata, Piabucina astrigata, Erythrinus erythrinus, Hoplias malabaricus, Hepsetus odoe, Arnoldichthys spilopterus, Brycinus macrolepidotus, Bryconalestes longipinnis, Chalceus epakros, Characidium bahiensis, Crenuchus spilurus, Agoniates halecinus, Aphyocharax pusillus, Astyanax mexicanus, Atopomesus pachyodus, Axelrodia reisei, Brittanichthys axelrodi, Brycon pesu, Bryconadenos tanaothoros, Bryconamericus exodon, Bryconops alburnoides, Charax cf. leticiae, Clupeacharax cf. engrauloides, Compsura heterura, Ctenobrycon hauxwellianus, Deuterodon iguape, Diapoma terofali, Galeocharax knerii, Glandulocauda melanogenys, Gnathocharax steindachneri, Gymnocorymbus ternetzi, Hemibrycon polyodon, Hemigrammus unilineatus, Hollandichthys multifasciatus, Hyphessobrycon compressus, Iguanodectes geisleri, Knodus meridae, Landonia latidens, Markiana nigripinnis, Metynnis lippincottianus, Microschemobrycon casiquiare, Moenkhausia xinguensis, Myleus setiger, Odontostilbe pequira, oligosarcus argenteus, orthospinus franciscoensis, Paracheirodon axelrodi, Paragoniates alburnus, Phenacogaster pectinatus, Phenagoniates macrolepis, Piabina argentea, Piaractus mesopotamicus, Poptella brevispina, Probolus heterostomus, Rachoviscus graciliceps, Rhinobrycon negrensis, Rhoadsia altipinna, Roeboexodon guyanensis, Salminus hilarii, Serrabrycon magoi, Stygichthys typhlops, Tetragonopterus argenteus e Triportheus albus. 


\section{3 - Parapófise e costela do terceiro centro vertebral: [FINK \& FINK, 1981:85]}

\section{[0] - presentes.}

Chanos chanos.

\section{[1] - modificadas como tripus.}

Catostomus commersonnii, Olivaichthys mesembrinus, Gymnotus aff. carapo, Citharinus latus, Distichodus notospilus, Hemistichodus vaillanti, Neolebias unifasciatus, Nannocharax fasciatus, Xenocharax spilurus, Apareiodon piracicabae, Parodon nasus, Saccodon wagneri, Anodus orinocensis, Bivibranchia fowleri, Hemiodus unimaculatus, Curimata ocellata, Curimatopsis macrolepis, Potamorhina latior, Prochilodus nigricans, Semaprochilodus insignis, Caenotropus labyrinthicus, Chilodus punctatus, Anostomus anostomus, Leporellus vittatus, Leporinus fasciatus, Schizodon fasciatus, Carnegiella strigata, Gasteropelecus sternicla, Thoracocharax stellatus, Acestrorhynchus falcirostris, Gilbertolus atratoensis, Hydrolycus tatauaia, Roestes molossus, Erythrinoidea fam. nov, Boulengerella maculata, Ctenolucius hujeta, Copeina cf. guttata, Lebiasina bimaculata, Piabucina astrigata, Erythrinus erythrinus, Hoplias malabaricus, Hepsetus odoe, Arnoldichthys spilopterus, Brycinus macrolepidotus, Bryconalestes longipinnis, Chalceus epakros, Characidium bahiensis, Crenuchus spilurus, Agoniates halecinus, Aphyocharax pusillus, Astyanax mexicanus, Atopomesus pachyodus, Axelrodia reisei, Brittanichthys axelrodi, Brycon pesu, Bryconadenos tanaothoros, Bryconamericus exodon, Bryconops alburnoides, Charax cf. leticiae, Clupeacharax cf. engrauloides, Compsura heterura, Ctenobrycon hauxwellianus, Deuterodon iguape, Diapoma terofali, Galeocharax knerii, Glandulocauda melanogenys, Gnathocharax steindachneri, Gymnocorymbus ternetzi, Hemibrycon polyodon, Hemigrammus unilineatus, Hollandichthys multifasciatus, Hyphessobrycon compressus, Iguanodectes geisleri, Knodus meridae, Landonia latidens, Markiana nigripinnis, Metynnis lippincottianus, Microschemobrycon casiquiare, Moenkhausia xinguensis, Myleus setiger, Odontostilbe pequira, Oligosarcus argenteus, orthospinus franciscoensis, Paracheirodon axelrodi, Paragoniates alburnus, Phenacogaster pectinatus, Phenagoniates macrolepis, Piabina argentea, Piaractus mesopotamicus, Poptella brevispina, Probolus heterostomus, Rachoviscus graciliceps, Rhinobrycon negrensis, Rhoadsia altipinna, Roeboexodon guyanensis, Salminus hilarii, Serrabrycon magoi, Stygichthys typhlops, Tetragonopterus argenteus e Triportheus albus.

\section{4 - Margem lateral do tripus em vista ventral:}

\section{[0] - convexo.}

Catostomus commersonnii, Olivaichthys mesembrinus, Gymnotus aff. carapo, Citharinus latus, Distichodus notospilus, Hemistichodus vaillanti, Neolebias unifasciatus, Nannocharax fasciatus, Xenocharax spilurus, Apareiodon piracicabae, Parodon nasus, Anodus orinocensis, Bivibranchia fowleri, Hemiodus unimaculatus, Curimata ocellata, Curimatopsis macrolepis, Potamorhina latior, Prochilodus nigricans, Caenotropus labyrinthicus, Chilodus punctatus, Anostomus anostomus, Leporellus vittatus, Leporinus fasciatus, Schizodon fasciatus, Carnegiella strigata, Gasteropelecus sternicla, Thoracocharax stellatus, Hydrolycus tatauaia, Copeina cf. guttata, Piabucina astrigata, Arnoldichthys spilopterus, Bryconalestes longipinnis, Chalceus epakros, Characidium bahiensis, Crenuchus spilurus, Agoniates halecinus, Aphyocharax pusillus, Astyanax mexicanus, Atopomesus pachyodus, Axelrodia reisei, Brittanichthys axelrodi, Bryconadenos tanaothoros, Bryconamericus exodon, Clupeacharax cf. engrauloides, Compsura heterura, Ctenobrycon hauxwellianus, Deuterodon iguape, Diapoma terofali, Galeocharax knerii, Glandulocauda melanogenys, Gnathocharax steindachneri, Gymnocorymbus ternetzi, Hemibrycon polyodon, Hemigrammus unilineatus, Hollandichthys multifasciatus, Hyphessobrycon compressus, Knodus meridae, Landonia latidens, Markiana nigripinnis, Microschemobrycon casiquiare, Moenkhausia xinguensis, Odontostilbe pequira, Oligosarcus argenteus, Orthospinus franciscoensis, Paracheirodon axelrodi, Paragoniates alburnus, Phenacogaster pectinatus, Phenagoniates macrolepis, Piabina argentea, Poptella brevispina, Probolus heterostomus, Rachoviscus graciliceps, Rhinobrycon negrensis, Rhoadsia altipinna, Roeboexodon guyanensis, Serrabrycon magoi e Tetragonopterus argenteus.

\section{[1] - aproximadamente reto.}

Semaprochilodus insignis, Acestrorhynchus falcirostris, Gilbertolus atratoensis, Roestes molossus, Erythrinoidea fam. nov, Boulengerella maculata, Ctenolucius hujeta, Lebiasina bimaculata, Erythrinus erythrinus, Hoplias malabaricus, Hepsetus odoe, Brycinus macrolepidotus, Brycon pesu, Bryconops alburnoides, Charax cf. leticiae, Iguanodectes 
geisleri, Metynnis lippincottianus, Myleus setiger, Piaractus mesopotamicus, Salminus hilarii, Stygichthys typhlops e Triportheus albus.

\section{[-] - inaplicável.}

Chanos chanos.

\section{[?] - indeterminado.}

Saccodon wagneri.

325 - Porção lamelar do complexo neural:

[LucenA, 1993: 77; Buckup, 1998: 48; NetTo-FerReIRA, 2006: 210]

\section{[0] - estendendo-se posteriormente, dorsalmente ao espinho neural da quarta vértebra.}

Catostomus commersonnii, Citharinus latus, Distichodus notospilus, Hemistichodus vaillanti, Neolebias unifasciatus, Nannocharax fasciatus, Xenocharax spilurus, Curimata ocellata, Prochilodus nigricans, Semaprochilodus insignis, Caenotropus labyrinthicus, Chilodus punctatus, Leporellus vittatus, Leporinus fasciatus, Schizodon fasciatus, Thoracocharax stellatus, Acestrorhynchus falcirostris, Hydrolycus tatauaia, Roestes molossus, Piabucina astrigata, Hepsetus odoe, Arnoldichthys spilopterus, Characidium bahiensis, Crenuchus spilurus, Agoniates halecinus, Aphyocharax pusillus, Astyanax mexicanus, Atopomesus pachyodus, Brycon pesu, Bryconops alburnoides, Charax cf. leticiae, Ctenobrycon hauxwellianus, Deuterodon iguape, Diapoma terofali, Galeocharax knerii, Glandulocauda melanogenys, Gnathocharax steindachneri, Hemigrammus unilineatus, Hollandichthys multifasciatus, Iguanodectes geisleri, Knodus meridae, Landonia latidens, Markiana nigripinnis, Microschemobrycon casiquiare, Moenkhausia xinguensis, Odontostilbe pequira, Oligosarcus argenteus, Orthospinus franciscoensis, Phenacogaster pectinatus, Phenagoniates macrolepis, Piabina argentea, Poptella brevispina, Probolus heterostomus, Rhoadsia altipinna, Roeboexodon guyanensis, Salminus hilarii, Serrabrycon magoi, Tetragonopterus argenteus e Triportheus albus.

\section{[1] - estendendo-se apenas até o arco neural da quarta vértebra.}

Olivaichthys mesembrinus, Gymnotus aff. carapo, Apareiodon piracicabae, Parodon nasus, Anodus orinocensis, Bivibranchia fowleri, Hemiodus unimaculatus, Curimatopsis macrolepis, Potamorhina latior, Anostomus anostomus, Carnegiella strigata, Gasteropelecus sternicla, Gilbertolus atratoensis, Erythrinoidea fam. nov, Boulengerella maculata, Ctenolucius hujeta, Copeina cf. guttata, Lebiasina bimaculata, Erythrinus erythrinus, Hoplias malabaricus, Brycinus macrolepidotus, Bryconalestes longipinnis, Chalceus epakros, Axelrodia reisei, Brittanichthys axelrodi, Bryconadenos tanaothoros, Bryconamericus exodon, Clupeacharax cf. engrauloides, Compsura heterura, Gymnocorymbus ternetzi, Hemibrycon polyodon, Hyphessobrycon compressus, Metynnis lippincottianus, Myleus setiger, Paracheirodon axelrodi, Paragoniates alburnus, Piaractus mesopotamicus, Rachoviscus graciliceps, Rhinobrycon negrensis e Stygichthys typhlops.

\section{[-] - inaplicável.}

Chanos chanos

[?] - indeterminado.

Saccodon wagneri.

326 - Costela da quarta vértebra:

[FINK \& FINK, 1981: 88]

[0] - como a costela da quinta vértebra.

Chanos chanos.

[1] - muito menor que a costela da quinta vértebra.

Catostomus commersonnii, olivaichthys mesembrinus, Gymnotus aff. carapo, Citharinus latus, Distichodus notospilus, Hemistichodus vaillanti, Neolebias unifasciatus, 
Nannocharax fasciatus, Xenocharax spilurus, Apareiodon piracicabae, Parodon nasus, Saccodon wagneri, Anodus orinocensis, Bivibranchia fowleri, Hemiodus unimaculatus Curimata ocellata, Curimatopsis macrolepis, Potamorhina latior, Prochilodus nigricans, Semaprochilodus insignis, Caenotropus labyrinthicus, Chilodus punctatus, Anostomus anostomus, Leporellus vittatus, Leporinus fasciatus, Schizodon fasciatus, Carnegiella strigata, Gasteropelecus sternicla, Thoracocharax stellatus , Acestrorhynchus falcirostris, Gilbertolus atratoensis, Hydrolycus tatauaia, Roestes molossus, Erythrinoidea fam. nov, Boulengerella maculata, ctenolucius hujeta, copeina cf. guttata, Lebiasina bimaculata, Piabucina astrigata, Erythrinus erythrinus, Hoplias malabaricus, Hepsetus odoe, Arnoldichthys spilopterus, Brycinus macrolepidotus, Bryconalestes longipinnis, Chalceus epakros, Characidium bahiensis, Crenuchus spilurus, Agoniates halecinus, Aphyocharax pusillus, Astyanax mexicanus, Atopomesus pachyodus, Axelrodia reisei, Brittanichthys axelrodi, Brycon pesu, Bryconadenos tanaothoros, Bryconamericus exodon, Bryconops alburnoides, Charax cf. leticiae, clupeacharax cf. engrauloides, Compsura heterura, Ctenobrycon hauxwellianus, Deuterodon iguape, Diapoma terofali, Galeocharax knerii, Glandulocauda melanogenys, Gnathocharax steindachneri, Gymnocorymbus ternetzi, Hemibrycon polyodon, Hemigrammus unilineatus, Hollandichthys multifasciatus, Hyphessobrycon compressus, Iguanodectes geisleri, Knodus meridae, Landonia latidens, Markiana nigripinnis, Metynnis lippincottianus, Microschemobrycon casiquiare, Moenkhausia xinguensis, Myleus setiger, odontostilbe pequira, oligosarcus argenteus, orthospinus franciscoensis, Paracheirodon axelrodi, Paragoniates alburnus, Phenacogaster pectinatus, Phenagoniates macrolepis, Piabina argentea, Piaractus mesopotamicus, Poptella brevispina, Probolus heterostomus, Rachoviscus graciliceps, Rhinobrycon negrensis, Rhoadsia altipinna, Roeboexodon guyanensis, Salminus hilarii, Serrabrycon magoi, Stygichthys typhlops, Tetragonopterus argenteus, Triportheus albus.

\section{7 - Forma da costela da quarta vértebra:}

[LUCENA, 1993: 78 modificado; BUCKUP, 1998: 50 modificado; NETTO-FERREIRA, 2006: 212 modificado]

\section{[0] - extremidade cônica ou subcilíndrica.}

Olivaichthys mesembrinus, Gymnotus aff. carapo, Citharinus latus, Distichodus notospilus, Hemistichodus vaillanti, Neolebias unifasciatus, Anodus orinocensis, Bivibranchia fowleri, Hemiodus unimaculatus, Curimata ocellata, Potamorhina latior, Prochilodus nigricans, Semaprochilodus insignis, Caenotropus labyrinthicus, chilodus punctatus, Leporellus vittatus, Leporinus fasciatus, Schizodon fasciatus, Acestrorhynchus falcirostris, Boulengerella maculata, Ctenolucius hujeta, Hepsetus odoe, Arnoldichthys spilopterus, Brycinus macrolepidotus, Bryconalestes longipinnis, Chalceus epakros, Characidium bahiensis, Crenuchus spilurus, Axelrodia reisei, Brittanichthys axelrodi, Bryconadenos tanaothoros, Bryconamericus exodon, Clupeacharax cf. engrauloides, Compsura heterura, Ctenobrycon hauxwellianus, Deuterodon iguape, Diapoma terofali, Galeocharax knerii, Glandulocauda melanogenys, Gnathocharax steindachneri, Gymnocorymbus ternetzi, Hemibrycon polyodon, Hemigrammus unilineatus, Hollandichthys multifasciatus, Hyphessobrycon compressus, Knodus meridae, Landonia latidens, Markiana nigripinnis, Microschemobrycon casiquiare, Moenkhausia xinguensis, Myleus setiger, orthospinus franciscoensis, Paracheirodon axelrodi, Piabina argentea, Poptella brevispina, Rachoviscus graciliceps, Rhinobrycon negrensis, Rhoadsia altipinna, Roeboexodon guyanensis, Salminus hilarii, Serrabrycon magoi, stygichthys typhlops e Tetragonopterus argenteus.

\section{[1] - lamelar.}

Nannocharax fasciatus, Apareiodon piracicabae, Parodon nasus, Curimatopsis macrolepis, Anostomus anostomus, Carnegiella strigata, Gasteropelecus sternicla, Thoracocharax stellatus, Gilbertolus atratoensis, Copeina cf. guttata, Lebiasina bimaculata, Piabucina astrigata, Erythrinus erythrinus, Hoplias malabaricus, Agoniates halecinus, Aphyocharax pusillus, Astyanax mexicanus, Atopomesus pachyodus, Brycon pesu, Bryconops alburnoides, Charax cf. leticiae, Iguanodectes geisleri, odontostilbe pequira, oligosarcus argenteus, Paragoniates alburnus, Phenacogaster pectinatus, Phenagoniates macrolepis, Probolus heterostomus e Triportheus albus.

\section{[-] - inaplicável.}

Chanos chanos e Catostomus commersonnii.

\section{[?] - indeterminado.}

Xenocharax spilurus, Saccodon wagneri, Hydrolycus tatauaia, Roestes molossus, Erythrinoidea fam. nov., Metynnis lippincottianus e Piaractus mesopotamicus. 
328 - Arco neural da quarta vértebra:

[FINK \& FINK, 1981: pág 306; BUCKUP, 1998: 49]

\section{[0] - fusionado à vértebra.}

Apareiodon piracicabae, Parodon nasus, Saccodon wagneri, Anodus orinocensis, Bivibranchia fowleri, Hemiodus unimaculatus, Curimata ocellata, curimatopsis macrolepis, Potamorhina latior, Prochilodus nigricans, Semaprochilodus insignis, Caenotropus labyrinthicus, Chilodus punctatus, Anostomus anostomus, Leporellus vittatus, Leporinus fasciatus, Schizodon fasciatus, Carnegiella strigata, Gasteropelecus sternicla, Thoracocharax stellatus, Acestrorhynchus falcirostris, Gilbertolus atratoensis, Hydrolycus tatauaia, Roestes molossus, Erythrinoidea fam. nov, Boulengerella maculata, Ctenolucius hujeta, Copeina cf. guttata, Lebiasina bimaculata, Piabucina astrigata, Erythrinus erythrinus, Hoplias malabaricus, Hepsetus odoe, Arnoldichthys spilopterus, Brycinus macrolepidotus, Bryconalestes longipinnis, Chalceus epakros, Characidium bahiensis, Crenuchus spilurus, Agoniates halecinus, Aphyocharax pusillus, Astyanax mexicanus, Atopomesus pachyodus, Axelrodia reisei, Brittanichthys axelrodi, Brycon pesu, Bryconadenos tanaothoros, Bryconamericus exodon, Bryconops alburnoides, Charax cf. leticiae, Clupeacharax cf. engrauloides, Compsura heterura, Ctenobrycon hauxwellianus, Deuterodon iguape, Diapoma terofali, Galeocharax knerii, Glandulocauda melanogenys, Gnathocharax steindachneri, Gymnocorymbus ternetzi, Hemibrycon polyodon, Hemigrammus unilineatus, Hollandichthys multifasciatus, Hyphessobrycon compressus, Iguanodectes geisleri, Knodus meridae, Landonia latidens, Markiana nigripinnis, Metynnis lippincottianus, Microschemobrycon casiquiare, Moenkhausia xinguensis, Myleus setiger, Odontostilbe pequira, oligosarcus argenteus, orthospinus franciscoensis, Paracheirodon axelrodi, Paragoniates alburnus, Phenacogaster pectinatus, Phenagoniates macrolepis, Piabina argentea, Piaractus mesopotamicus, Poptella brevispina, Probolus heterostomus, Rachoviscus graciliceps, Rhinobrycon negrensis, Rhoadsia altipinna, Roeboexodon guyanensis, Salminus hilarii, Serrabrycon magoi, Stygichthys typhlops, Tetragonopterus argenteus e Triportheus albus.

\section{[1] - autógeno.}

Chanos chanos, Catostomus commersonnii, Olivaichthys mesembrinus, Gymnotus aff. carapo, Citharinus latus, Distichodus notospilus, Hemistichodus vaillanti, Neolebias unifasciatus, Nannocharax fasciatus e Xenocharax spilurus.

\section{9 - Comprimento do espinho neural da quarta vértebra:}

\section{[0] - menor que metade do espinho neural da quinta vértebra.}

Gymnotus aff. carapo, Hemistichodus vaillanti, Nannocharax fasciatus, Apareiodon piracicabae, Parodon nasus, Bivibranchia fowleri, Curimatopsis macrolepis, Potamorhina latior, Prochilodus nigricans, Chilodus punctatus, Anostomus anostomus, Leporinus fasciatus, Schizodon fasciatus, Gasteropelecus sternicla, Acestrorhynchus falcirostris, Gilbertolus atratoensis, Roestes molossus, Erythrinoidea fam. nov, Copeina cf. guttata, Piabucina astrigata, Erythrinus erythrinus, Agoniates halecinus, Aphyocharax pusillus, Astyanax mexicanus, Clupeacharax cf. engrauloides, Deuterodon iguape, Galeocharax knerii, Gnathocharax steindachneri, Landonia latidens, Microschemobrycon casiquiare, Paragoniates alburnus e Phenagoniates macrolepis.

\section{vértebra.}

\section{[1] - maior ou igual a metade do espinho neural da quinta}

Chanos chanos, Catostomus commersonnii, Olivaichthys mesembrinus, Citharinus latus, Distichodus notospilus, Neolebias unifasciatus, Xenocharax spilurus, Anodus orinocensis, Hemiodus unimaculatus, Curimata ocellata, Semaprochilodus insignis, Caenotropus labyrinthicus, Leporellus vittatus, Carnegiella strigata, Thoracocharax stellatus, Hydrolycus tatauaia, Boulengerella maculata, Ctenolucius hujeta, Lebiasina bimaculata, Hoplias malabaricus, Hepsetus odoe, Arnoldichthys spilopterus, Brycinus macrolepidotus, Bryconalestes longipinnis, Chalceus epakros, Characidium bahiensis, Crenuchus spilurus, Atopomesus pachyodus, Axelrodia reisei, Brittanichthys axelrodi, Brycon pesu, Bryconadenos tanaothoros, Bryconamericus exodon, Bryconops alburnoides, Charax cf. leticiae, Compsura heterura, Ctenobrycon hauxwellianus, Diapoma terofali, Glandulocauda melanogenys, Gymnocorymbus ternetzi, Hemibrycon polyodon, Hemigrammus unilineatus, Hollandichthys multifasciatus, Hyphessobrycon compressus, Iguanodectes geisleri, Knodus meridae, Markiana nigripinnis, Metynnis lippincottianus, Moenkhausia xinguensis, Myleus setiger, Odontostilbe pequira, Oligosarcus argenteus, Orthospinus franciscoensis, Paracheirodon axelrodi, Phenacogaster pectinatus, Piabina argentea, Piaractus mesopotamicus, Poptella brevispina, Probolus heterostomus, Rachoviscus graciliceps, Rhinobrycon negrensis, Rhoadsia altipinna, Roeboexodon guyanensis, Salminus hilarii, Serrabrycon magoi, Stygichthys typhlops, Tetragonopterus argenteus e Triportheus albus. 
[?] - indeterminado.

Saccodon wagneri.

330 - Articulação ventral entre a quarta e quinta vértebras:

[TOLEDO-PiZA, 2000: 51; ZANATA, 2000: 86]

[0] - lisa.

Chanos chanos, Catostomus commersonnii, Olivaichthys mesembrinus, Gymnotus aff. carapo, Citharinus latus, Distichodus notospilus, Hemistichodus vaillanti, Neolebias unifasciatus, Nannocharax fasciatus, Xenocharax spilurus, Apareiodon piracicabae, Parodon nasus, Anodus orinocensis, Bivibranchia fowleri, Hemiodus unimaculatus, Curimata ocellata, Curimatopsis macrolepis, Potamorhina latior, Prochilodus nigricans, Semaprochilodus insignis, Caenotropus labyrinthicus, Chilodus punctatus, Anostomus anostomus, Leporellus vittatus, Leporinus fasciatus, Schizodon fasciatus, Carnegiella strigata, Gasteropelecus sternicla, Thoracocharax stellatus, Acestrorhynchus falcirostris, Gilbertolus atratoensis, Erythrinoidea fam. nov, Boulengerella maculata, Ctenolucius hujeta, Copeina cf. guttata, Lebiasina bimaculata, Piabucina astrigata, Erythrinus erythrinus, Hoplias malabaricus, Hepsetus odoe, Arnoldichthys spilopterus, Brycinus macrolepidotus, Bryconalestes longipinnis, Chalceus epakros, Characidium bahiensis, Crenuchus spilurus, Aphyocharax pusillus, Astyanax mexicanus, Atopomesus pachyodus, Axelrodia reisei, Brittanichthys axelrodi, Brycon pesu, Bryconadenos tanaothoros, Bryconamericus exodon, Bryconops alburnoides, Charax cf. leticiae, Compsura heterura, Ctenobrycon hauxwellianus, Deuterodon iguape, Diapoma terofali, Galeocharax knerii, Glandulocauda melanogenys, Gnathocharax steindachneri, Gymnocorymbus ternetzi, Hemibrycon polyodon, Hemigrammus unilineatus, Hollandichthys multifasciatus, Hyphessobrycon compressus, Iguanodectes geisleri, Knodus meridae, Landonia latidens, Markiana nigripinnis, Metynnis lippincottianus, Microschemobrycon casiquiare, Moenkhausia xinguensis, Myleus setiger, Odontostilbe pequira, oligosarcus argenteus, orthospinus franciscoensis, Paracheirodon axelrodi, Paragoniates alburnus, Phenacogaster pectinatus, Phenagoniates macrolepis, Piabina argentea, Piaractus mesopotamicus, Poptella brevispina, Probolus heterostomus, Rachoviscus graciliceps, Rhinobrycon negrensis, Rhoadsia altipinna, Roeboexodon guyanensis, Salminus hilarii, Serrabrycon magoi, Stygichthys typhlops, Tetragonopterus argenteus e Triportheus albus.

\section{[1] - com processo póstero-lateral.}

Hydrolycus tatauaia, Agoniates halecinus e Clupeacharax cf. engrauloides.

\section{[?] - indeterminado.}

Saccodon wagneri e Roestes molossus.

\section{1 - Junção sincondral entra os espinhos neurais 3 e 4:}

\section{[0] - ausente ou reduzido.}

Chanos chanos, Apareiodon piracicabae, Parodon nasus, Saccodon wagneri, Anodus orinocensis, Bivibranchia fowleri, Hemiodus unimaculatus, Curimata ocellata, Curimatopsis macrolepis, Potamorhina latior, Prochilodus nigricans, Semaprochilodus insignis, Caenotropus labyrinthicus, Chilodus punctatus, Anostomus anostomus, Leporellus vittatus, Leporinus fasciatus, Schizodon fasciatus, Carnegiella strigata, Gasteropelecus sternicla, Thoracocharax stellatus, Acestrorhynchus falcirostris, Gilbertolus atratoensis, Hydrolycus tatauaia, Roestes molossus, Erythrinoidea fam. nov, Boulengerella maculata, Ctenolucius hujeta, Copeina cf. guttata, Lebiasina bimaculata, Piabucina astrigata, Erythrinus erythrinus, Hoplias malabaricus, Hepsetus odoe, Arnoldichthys spilopterus, Brycinus macrolepidotus, Bryconalestes longipinnis, Chalceus epakros, Characidium bahiensis, Crenuchus spilurus, Agoniates halecinus, Aphyocharax pusillus, Astyanax mexicanus, Atopomesus pachyodus, Axelrodia reisei, Brittanichthys axelrodi, Brycon pesu, Bryconadenos tanaothoros, Bryconamericus exodon, Bryconops alburnoides, Charax cf. leticiae, Clupeacharax cf. engrauloides, Compsura heterura, ctenobrycon hauxwellianus, Deuterodon iguape, Diapoma terofali, Galeocharax knerii, Glandulocauda melanogenys, Gnathocharax steindachneri, Gymnocorymbus ternetzi, Hemibrycon polyodon, Hemigrammus unilineatus, Hollandichthys multifasciatus, Hyphessobrycon compressus, Iguanodectes geisleri, Knodus meridae, Landonia latidens, Markiana nigripinnis, Metynnis lippincottianus, Microschemobrycon casiquiare, Moenkhausia xinguensis, Myleus setiger, Odontostilbe pequira, Oligosarcus argenteus, orthospinus franciscoensis, Paracheirodon axelrodi, Paragoniates alburnus, Phenacogaster 
pectinatus, Phenagoniates macrolepis, Piabina argentea, Piaractus mesopotamicus, Poptella brevispina, Probolus heterostomus, Rachoviscus graciliceps, Rhinobrycon negrensis, Rhoadsia altipinna, Roeboexodon guyanensis, Salminus hilarii, Serrabrycon magoi, Stygichthys typhlops, Tetragonopterus argenteus e Triportheus albus.

\section{[1] - presente.}

Catostomus commersonnii, Olivaichthys mesembrinus, Gymnotus aff. carapo, Citharinus latus, Distichodus notospilus, Hemistichodus vaillanti, Neolebias unifasciatus, Nannocharax fasciatus e Xenocharax spilurus.

332 - Pós-zigapófise da quarta vértebra:

[ZANATA, 2000:85 modificado; NETTO-FERREIRA, 2006: 215 modificado]

\section{[0] - ausente, ou não ultrapassando a vértebra posterior.}

Chanos chanos, Catostomus commersonnii, Olivaichthys mesembrinus, Citharinus latus, Distichodus notospilus, Hemistichodus vaillanti, Neolebias unifasciatus, Xenocharax spilurus, Apareiodon piracicabae, Parodon nasus, Anodus orinocensis, Bivibranchia fowleri, Hemiodus unimaculatus, Curimatopsis macrolepis, Gilbertolus atratoensis, Hydrolycus tatauaia, Roestes molossus, Erythrinoidea fam. nov, Boulengerella maculata, Ctenolucius hujeta, Copeina cf. guttata, Lebiasina bimaculata, Piabucina astrigata, Erythrinus erythrinus, Hepsetus odoe, Arnoldichthys spilopterus, Brycinus macrolepidotus, Bryconalestes longipinnis, Chalceus epakros, Characidium bahiensis, Crenuchus spilurus, Astyanax mexicanus, Atopomesus pachyodus, Axelrodia reisei, Brittanichthys axelrodi, Brycon pesu, Bryconadenos tanaothoros, Bryconamericus exodon, Clupeacharax cf. engrauloides, Compsura heterura, Deuterodon iguape, Diapoma terofali, Galeocharax knerii, Glandulocauda melanogenys, Gnathocharax steindachneri, Gymnocorymbus ternetzi, Hemibrycon polyodon, Hemigrammus unilineatus, Hollandichthys multifasciatus, Hyphessobrycon compressus, Iguanodectes geisleri, Knodus meridae, Landonia latidens, Markiana nigripinnis, Metynnis lippincottianus, Microschemobrycon casiquiare, Moenkhausia xinguensis, Odontostilbe pequira, Oligosarcus argenteus, orthospinus franciscoensis, Paragoniates alburnus, Phenacogaster pectinatus, Phenagoniates macrolepis, Piabina argentea, Piaractus mesopotamicus, Poptella brevispina, Probolus heterostomus, Rachoviscus graciliceps, Rhinobrycon negrensis, Rhoadsia altipinna, Roeboexodon guyanensis, Salminus hilarii, stygichthys typhlops, Tetragonopterus argenteus e Triportheus albus.

\section{[1] - ultrapassando a vértebra posterior.}

Gymnotus aff. carapo, Nannocharax fasciatus, Curimata ocellata, Potamorhina latior, Prochilodus nigricans, Semaprochilodus insignis, Caenotropus labyrinthicus, Chilodus punctatus, Anostomus anostomus, Leporellus vittatus, Leporinus fasciatus, Schizodon fasciatus, Carnegiella strigata, Gasteropelecus sternicla, Thoracocharax stellatus, Acestrorhynchus falcirostris, Hoplias malabaricus, Agoniates halecinus, Aphyocharax pusillus, Bryconops alburnoides, Charax cf. leticiae, Ctenobrycon hauxwellianus, Myleus setiger, Paracheirodon axelrodi e Serrabrycon magoi.

\section{[?] - indeterminado.}

Saccodon wagneri.

333 - Pré-zigapófise da quinta vértebra:

[NeTTO-FERREIRA, 2006: 216 modificado]

\section{[0] - ausente, ou não ultrapassando a vértebra anterior.}

Chanos chanos, Catostomus commersonnii, Olivaichthys mesembrinus, Gymnotus aff. carapo, Citharinus latus, Distichodus notospilus, Hemistichodus vaillanti, Neolebias unifasciatus, Xenocharax spilurus, Apareiodon piracicabae, Parodon nasus, Bivibranchia fowleri, Curimata ocellata, Curimatopsis macrolepis, Potamorhina latior, Prochilodus nigricans, Semaprochilodus insignis, Erythrinoidea fam. nov, Boulengerella maculata, Ctenolucius hujeta, Copeina cf. guttata, Lebiasina bimaculata, Piabucina astrigata, Erythrinus erythrinus, Hoplias malabaricus, Arnoldichthys spilopterus, Brycinus macrolepidotus, Bryconalestes longipinnis, Characidium bahiensis, Crenuchus spilurus, Atopomesus pachyodus, Axelrodia reisei, Brittanichthys axelrodi, Charax cf. leticiae, compsura heterura, Ctenobrycon hauxwellianus, Diapoma terofali, Galeocharax knerii, Glandulocauda melanogenys, Gymnocorymbus ternetzi, Hemigrammus unilineatus, Hollandichthys multifasciatus, Hyphessobrycon compressus, Iguanodectes geisleri, Markiana nigripinnis, Metynnis lippincottianus, Microschemobrycon casiquiare, 
Odontostilbe pequira, orthospinus franciscoensis, Paracheirodon axelrodi, Phenacogaster pectinatus, Phenagoniates macrolepis, Piaractus mesopotamicus, Poptella brevispina, Probolus heterostomus, Rachoviscus graciliceps, Roeboexodon guyanensis, Stygichthys typhlops e Tetragonopterus argenteus.

\section{[1] - ultrapassando a vértebra anterior.}

Nannocharax fasciatus, Anodus orinocensis, Hemiodus unimaculatus, Caenotropus labyrinthicus, Chilodus punctatus, Anostomus anostomus, Leporellus vittatus, Leporinus fasciatus, Schizodon fasciatus, Carnegiella strigata, Gasteropelecus sternicla, Thoracocharax stellatus, Acestrorhynchus falcirostris, Gilbertolus atratoensis, Hydrolycus tatauaia, Roestes molossus, Hepsetus odoe, Chalceus epakros, Agoniates halecinus, Aphyocharax pusillus, Astyanax mexicanus, Brycon pesu, Bryconadenos tanaothoros, Bryconamericus exodon, Bryconops alburnoides, Clupeacharax cf. engrauloides, Deuterodon iguape, Gnathocharax steindachneri, Hemibrycon polyodon , Knodus meridae, Landonia latidens, Moenkhausia xinguensis, Myleus setiger, oligosarcus argenteus, Paragoniates alburnus, Piabina argentea, Rhinobrycon negrensis, Rhoadsia altipinna, Salminus hilarii, Serrabrycon magoi e Triportheus albus.

\section{[?] - indeterminado.}

Saccodon wagneri.

334 - Vértebras:

[Lucena, 1993: 80; ZanATA, 2000: 87; MOREIRA, 2002: 87]

\section{vértebras caudais.}

[0] - número de vértebras pré-caudais maior do que o número de

Chanos chanos, Citharinus latus, Distichodus notospilus, Hemistichodus vaillanti, Neolebias unifasciatus, Nannocharax fasciatus, Xenocharax spilurus, Apareiodon piracicabae, Parodon nasus, Anodus orinocensis, Bivibranchia fowleri, Hemiodus unimaculatus, Curimata ocellata, Curimatopsis macrolepis, Potamorhina latior, Prochilodus nigricans, Semaprochilodus insignis, Caenotropus labyrinthicus, Chilodus punctatus, Anostomus anostomus, Leporellus vittatus, Leporinus fasciatus, Schizodon fasciatus, Acestrorhynchus falcirostris, Gilbertolus atratoensis, Erythrinoidea fam. nov, Boulengerella maculata, Ctenolucius hujeta, Copeina cf. guttata, Lebiasina bimaculata, Piabucina astrigata, Erythrinus erythrinus, Hoplias malabaricus, Hepsetus odoe, Arnoldichthys spilopterus, Brycinus macrolepidotus, Chalceus epakros, Characidium bahiensis, Crenuchus spilurus, Brycon pesu, Charax cf. leticiae, compsura heterura, Iguanodectes geisleri, Phenagoniates macrolepis e Salminus hilarii.

\section{[1] - número de vértebras pré-caudais menor ou igual do que o número de vértebras caudais.}

Catostomus commersonnii, olivaichthys mesembrinus, Carnegiella strigata, Gasteropelecus sternicla, Thoracocharax stellatus, Hydrolycus tatauaia, Roestes molossus, Bryconalestes longipinnis, Agoniates halecinus, Aphyocharax pusillus, Astyanax mexicanus, Atopomesus pachyodus, Axelrodia reisei, Brittanichthys axelrodi, Bryconadenos tanaothoros, Bryconamericus exodon, Bryconops alburnoides, Clupeacharax cf. engrauloides, Compsura heterura, Ctenobrycon hauxwellianus, Deuterodon iguape, Diapoma terofali, Galeocharax knerii, Glandulocauda melanogenys, Gnathocharax steindachneri, Gymnocorymbus ternetzi, Hemibrycon polyodon, Hemigrammus unilineatus, Hollandichthys multifasciatus, Hyphessobrycon compressus, Knodus meridae, Landonia latidens, Markiana nigripinnis, Metynnis lippincottianus, Microschemobrycon casiquiare, Moenkhausia xinguensis, Myleus setiger, Odontostilbe pequira, oligosarcus argenteus, orthospinus franciscoensis, Paracheirodon axelrodi, Paragoniates alburnus, Phenacogaster pectinatus, Piabina argentea, Piaractus mesopotamicus, Poptella brevispina, Probolus heterostomus, Rachoviscus graciliceps, Rhinobrycon negrensis, Rhoadsia altipinna, Roeboexodon guyanensis, Serrabrycon magoi, Stygichthys typhlops, Tetragonopterus argenteus e Triportheus albus.

\section{[?] - indeterminado.}

Gymnotus aff. carapo e Saccodon wagneri.

$$
[0,1] \text { - polimórfico. }
$$

Compsura heterura. 
335 - Supraneural à frente do espinho neural da quarta vértebra:

[LUCENA, 1993: 96; BUCKUP, 1998: 47; ZANATA, 2000: 94; MOREIRA, 2002: 74; Benine, 2004: 63; ZANATA \& VARI，2005: 122; NetTo-FerReira, 2006: 214; Lima, 2006: 45]

\section{[0] - presente.}

Chanos chanos, Citharinus latus, Distichodus notospilus, Hemistichodus vaillanti, Neolebias unifasciatus, Nannocharax fasciatus, Xenocharax spilurus, Anodus orinocensis, Hemiodus unimaculatus, Curimata ocellata, Potamorhina latior, Anostomus anostomus, Leporellus vittatus, Leporinus fasciatus, Acestrorhynchus falcirostris, Gilbertolus atratoensis, Hydrolycus tatauaia, Roestes molossus, Boulengerella maculata, Ctenolucius hujeta, Bryconalestes longipinnis, Chalceus epakros, Characidium bahiensis, Agoniates halecinus, Brycon pesu, Bryconops alburnoides, Clupeacharax cf. engrauloides, Hemigrammus unilineatus, Iguanodectes geisleri, Metynnis lippincottianus, Myleus setiger, Piaractus mesopotamicus e Triportheus albus.

\section{[1] - ausente.}

Olivaichthys mesembrinus, Gymnotus aff. carapo, Apareiodon piracicabae, Parodon nasus, Bivibranchia fowleri, Curimatopsis macrolepis, Prochilodus nigricans, Semaprochilodus insignis, Caenotropus labyrinthicus, Chilodus punctatus, Schizodon fasciatus, Carnegiella strigata, Gasteropelecus sternicla, Thoracocharax stellatus, Erythrinoidea fam. nov, Copeina cf. guttata, Lebiasina bimaculata, Piabucina astrigata, Erythrinus erythrinus, Hoplias malabaricus, Hepsetus odoe, Arnoldichthys spilopterus, Brycinus macrolepidotus, Crenuchus spilurus, Aphyocharax pusillus, Astyanax mexicanus, Atopomesus pachyodus, Axelrodia reisei, Brittanichthys axelrodi, Bryconadenos tanaothoros, Bryconamericus exodon, Charax cf. leticiae, Compsura heterura, Ctenobrycon hauxwellianus, Deuterodon iguape, Diapoma terofali, Galeocharax knerii, Glandulocauda melanogenys, Gnathocharax steindachneri, Gymnocorymbus ternetzi, Hemibrycon polyodon, Hollandichthys multifasciatus, Hyphessobrycon compressus, Knodus meridae, Landonia latidens, Markiana nigripinnis, Microschemobrycon casiquiare, Moenkhausia xinguensis, odontostilbe pequira, oligosarcus argenteus, Orthospinus franciscoensis, Paracheirodon axelrodi, Phenacogaster pectinatus, Phenagoniates macrolepis, Piabina argentea, Poptella brevispina, Probolus heterostomus, Rachoviscus graciliceps, Rhinobrycon negrensis, Rhoadsia altipinna, Roeboexodon guyanensis, Salminus hilarii, Serrabrycon magoi, Stygichthys typhlops e Tetragonopterus argenteus.

\section{[-] - inaplicável.}

Catostomus commersonnii.

\section{[?] - indeterminado.}

Saccodon wagneri e Paragoniates alburnus.

\section{6 - Forma do supraneural anterior ao espinho neural da quinta vértebra:}

\section{[0] - maior altura que comprimento.}

Chanos chanos, Citharinus latus, Distichodus notospilus, Hemistichodus vaillanti, Neolebias unifasciatus, Nannocharax fasciatus, Xenocharax spilurus, Anodus orinocensis, Hemiodus unimaculatus, Chilodus punctatus, Anostomus anostomus, Leporellus vittatus, Leporinus fasciatus, Schizodon fasciatus, Acestrorhynchus falcirostris, Gilbertolus atratoensis, Hydrolycus tatauaia, Roestes molossus, Boulengerella maculata, Ctenolucius hujeta, Erythrinus erythrinus, Arnoldichthys spilopterus, Brycinus macrolepidotus, Bryconalestes longipinnis, Chalceus epakros, Characidium bahiensis, Crenuchus spilurus, Agoniates halecinus, Aphyocharax pusillus, Astyanax mexicanus, Atopomesus pachyodus, Axelrodia reisei, Brittanichthys axelrodi, Brycon pesu, Bryconadenos tanaothoros, Bryconamericus exodon, Bryconops alburnoides, Charax cf. leticiae, Compsura heterura, Ctenobrycon hauxwellianus, Deuterodon iguape, Diapoma terofali, Galeocharax knerii, Glandulocauda melanogenys, Gnathocharax steindachneri, Hemigrammus unilineatus, Hollandichthys multifasciatus, Hyphessobrycon compressus, Iguanodectes geisleri, Landonia latidens, Markiana nigripinnis, Metynnis lippincottianus, Microschemobrycon casiquiare, Moenkhausia xinguensis, Myleus setiger, Odontostilbe pequira, oligosarcus argenteus, orthospinus franciscoensis, Paracheirodon axelrodi, Paragoniates alburnus, Phenacogaster pectinatus, Phenagoniates macrolepis, Piabina argentea, Piaractus mesopotamicus, Poptella brevispina, Probolus heterostomus, Rachoviscus graciliceps, 
Rhoadsia altipinna, Roeboexodon guyanensis, Salminus hilarii, Serrabrycon magoi, Tetragonopterus argenteus e Triportheus albus.

\section{[1] - altura e comprimento parecidos ou mais comprido.}

Apareiodon piracicabae, Parodon nasus, Curimata ocellata, Curimatopsis macrolepis, Potamorhina latior, Prochilodus nigricans, Semaprochilodus insignis, Chilodus punctatus, Clupeacharax cf. engrauloides e Rhinobrycon negrensis.

\section{[-] - inaplicável.}

Catostomus commersonnii, Olivaichthys mesembrinus, Gymnotus aff. carapo, Bivibranchia fowleri, Caenotropus labyrinthicus, Carnegiella strigata, Gasteropelecus sternicla, Thoracocharax stellatus, Copeina cf. guttata, Lebiasina bimaculata, Piabucina astrigata, Hoplias malabaricus, Hepsetus odoe, Hemibrycon polyodon, Knodus meridae e Stygichthys typhlops.

\section{[?] - indeterminado.}

Saccodon wagneri, Erythrinoidea fam. nov. e Gymnocorymbus ternetzi.

$$
[0,1] \text { - polimórfico. }
$$

Chilodus punctatus.

\section{7 - Supraneural anterior ao arco neural da segunda vértebra:} [FINK \& FINK, 1981:59]

\section{[0] - ausente.}

Catostomus commersonnii, Olivaichthys mesembrinus, Gymnotus aff. carapo, Citharinus latus, Distichodus notospilus, Hemistichodus vaillanti, Neolebias unifasciatus, Nannocharax fasciatus, Xenocharax spilurus, Apareiodon piracicabae, Parodon nasus, Saccodon wagneri, Anodus orinocensis, Bivibranchia fowleri, Hemiodus unimaculatus , Curimata ocellata, Curimatopsis macrolepis, Potamorhina latior, Prochilodus nigricans, Semaprochilodus insignis, Caenotropus labyrinthicus, Chilodus punctatus, Anostomus anostomus, Leporellus vittatus, Leporinus fasciatus, Schizodon fasciatus, Carnegiella strigata, Gasteropelecus sternicla, Thoracocharax stellatus , Acestrorhynchus falcirostris, Gilbertolus atratoensis, Hydrolycus tatauaia, Roestes molossus, Erythrinoidea fam. nov, Boulengerella maculata, ctenolucius hujeta, Copeina cf. guttata, Lebiasina bimaculata, Piabucina astrigata, Erythrinus erythrinus, Hoplias malabaricus, Hepsetus odoe, Arnoldichthys spilopterus, Brycinus macrolepidotus, Bryconalestes longipinnis, Chalceus epakros, Characidium bahiensis, Crenuchus spilurus, Agoniates halecinus, Aphyocharax pusillus, Astyanax mexicanus, Atopomesus pachyodus, Axelrodia reisei, Brittanichthys axelrodi, Brycon pesu, Bryconadenos tanaothoros, Bryconamericus exodon, Bryconops alburnoides, Charax cf. leticiae, Clupeacharax cf. engrauloides, Compsura heterura, Ctenobrycon hauxwellianus, Deuterodon iguape, Diapoma terofali, Galeocharax knerii, Glandulocauda melanogenys, Gnathocharax steindachneri, Gymnocorymbus ternetzi, Hemibrycon polyodon, Hemigrammus unilineatus, Hollandichthys multifasciatus, Hyphessobrycon compressus, Iguanodectes geisleri, Knodus meridae, Landonia latidens, Markiana nigripinnis, Metynnis lippincottianus, Microschemobrycon casiquiare, Moenkhausia xinguensis, Myleus setiger, odontostilbe pequira, oligosarcus argenteus, orthospinus franciscoensis, Paracheirodon axelrodi, Paragoniates alburnus, Phenacogaster pectinatus, Phenagoniates macrolepis, Piabina argentea, Piaractus mesopotamicus, Poptella brevispina, Probolus heterostomus, Rachoviscus graciliceps, Rhinobrycon negrensis, Rhoadsia altipinna, Roeboexodon guyanensis, Salminus hilarii, Serrabrycon magoi, Stygichthys typhlops, Tetragonopterus argenteus e Triportheus albus.

\section{[1] - presente.}

Chanos chanos.

338 - Supraneurais:

[ZANATA, 200९: 95; Moreira, 2002: 75; Benine, 2004: 62; NetTo-Ferreira, 2006: 219 modificado; LIMA, 2006: 44]

[0] - alargados na porção dorsal. 
Citharinus latus, Distichodus notospilus, Hemistichodus vaillanti, Neolebias unifasciatus, Xenocharax spilurus, Apareiodon piracicabae, Parodon nasus, Curimata ocellata, Curimatopsis macrolepis, Potamorhina latior, Prochilodus nigricans, Semaprochilodus insignis, Caenotropus labyrinthicus, Chilodus punctatus, Anostomus anostomus, Leporellus vittatus, Leporinus fasciatus, Schizodon fasciatus, Carnegiella strigata, Gasteropelecus sternicla, Thoracocharax stellatus, Gilbertolus atratoensis, Hydrolycus tatauaia, Roestes molossus, Bryconalestes longipinnis, Agoniates halecinus, Astyanax mexicanus, Bryconops alburnoides, Charax cf. leticiae, Clupeacharax cf. engrauloides, Compsura heterura, Ctenobrycon hauxwellianus, Deuterodon iguape, Diapoma terofali, Galeocharax knerii, Glandulocauda melanogenys, Gymnocorymbus ternetzi, Hemibrycon polyodon, Hemigrammus unilineatus, Markiana nigripinnis, Metynnis lippincottianus, Moenkhausia xinguensis, Myleus setiger, oligosarcus argenteus, orthospinus franciscoensis, Phenacogaster pectinatus, Piaractus mesopotamicus, Poptella brevispina, Probolus heterostomus, Rhoadsia altipinna, Roeboexodon guyanensis, Tetragonopterus argenteus e Triportheus albus.

\section{[1] - aproximadamente da mesma largura em toda a sua extensão.}

Chanos chanos, Nannocharax fasciatus, Anodus orinocensis, Bivibranchia fowleri, Hemiodus unimaculatus, Acestrorhynchus falcirostris, ctenolucius hujeta, Copeina cf. guttata, Lebiasina bimaculata, Piabucina astrigata, Erythrinus erythrinus, Hoplias malabaricus, Hepsetus odoe, Arnoldichthys spilopterus, Brycinus macrolepidotus, Chalceus epakros, Characidium bahiensis, crenuchus spilurus, Aphyocharax pusillus, Atopomesus pachyodus, Axelrodia reisei, Brittanichthys axelrodi, Brycon pesu, Bryconadenos tanaothoros, Bryconamericus exodon, Gnathocharax steindachneri, Hollandichthys multifasciatus, Hyphessobrycon compressus, Iguanodectes geisleri, Knodus meridae, Landonia latidens, Microschemobrycon casiquiare, odontostilbe pequira, Paracheirodon axelrodi, Paragoniates alburnus, Phenagoniates macrolepis, Piabina argentea, Rachoviscus graciliceps, Rhinobrycon negrensis, Salminus hilarii, Serrabrycon magoi e Stygichthys typhlops.

\section{[-] - inaplicável.}

Catostomus commersonnii, Olivaichthys mesembrinus e Gymnotus aff. carapo.

[?] - indeterminado.

Saccodon wagneri, Erythrinoidea fam. nov. e Boulengerella maculata.

\section{9 - Supraneural anterior ao primeiro pterigióforo da nadadeira dorsal: \\ (Minimamente conectado).}

\section{[0] - entre os espinhos hemais imediatamente anteriores.}

Nannocharax fasciatus, Xenocharax spilurus, Parodon nasus, Anodus orinocensis, Bivibranchia fowleri, Hemiodus unimaculatus, Potamorhina latior, Semaprochilodus insignis, Caenotropus labyrinthicus, Chilodus punctatus, schizodon fasciatus, Gasteropelecus sternicla, Gilbertolus atratoensis, Hydrolycus tatauaia, Copeina cf. guttata, Erythrinus erythrinus, Hoplias malabaricus, Brycinus macrolepidotus, Bryconalestes longipinnis, Crenuchus spilurus, Atopomesus pachyodus, Brittanichthys axelrodi, Brycon pesu, Charax cf. leticiae, Ctenobrycon hauxwellianus, Deuterodon iguape, Gymnocorymbus ternetzi, Hemibrycon polyodon, Hemigrammus unilineatus, Hyphessobrycon compressus, Landonia latidens, Markiana nigripinnis, Microschemobrycon casiquiare, Moenkhausia xinguensis, orthospinus franciscoensis, Piaractus mesopotamicus, Poptella brevispina, Probolus heterostomus, Salminus hilarii, Tetragonopterus argenteus e Triportheus albus.

\section{pterigióforo.}

\section{[1] - a partir do segundo espinho neural anterior ao}

Citharinus latus, Distichodus notospilus, Hemistichodus vaillanti, Neolebias unifasciatus, Apareiodon piracicabae, Curimata ocellata, Curimatopsis macrolepis, Prochilodus nigricans, Anostomus anostomus, Leporellus vittatus, Leporinus fasciatus, Carnegiella strigata, Thoracocharax stellatus, Roestes molossus, Lebiasina bimaculata, Piabucina astrigata, Arnoldichthys spilopterus, Chalceus epakros, Characidium bahiensis, Agoniates halecinus, Aphyocharax pusillus, Astyanax mexicanus, Axelrodia reisei, Bryconadenos tanaothoros, Bryconamericus exodon, Bryconops alburnoides, Compsura heterura, Diapoma terofali, Galeocharax knerii, Glandulocauda melanogenys, Gnathocharax steindachneri, Hollandichthys multifasciatus, Iguanodectes geisleri, Metynnis lippincottianus, Myleus setiger, odontostilbe pequira, oligosarcus argenteus, Paracheirodon axelrodi, Paragoniates alburnus, Phenacogaster pectinatus, Piabina argentea, Rachoviscus graciliceps, Rhoadsia altipinna, Roeboexodon guyanensis e Serrabrycon magoi. 


\section{[2] - mais anteriormente.}

Chanos chanos, Catostomus commersonnii, Acestrorhynchus falcirostris, Boulengerella maculata, Hepsetus odoe, Clupeacharax cf. engrauloides, Knodus meridae, Phenagoniates macrolepis, Rhinobrycon negrensis e Stygichthys typhlops.

\section{[-] - inaplicável.}

Olivaichthys mesembrinus e Gymnotus aff. carapo.

\section{[?] - indeterminado.}

Saccodon wagneri, Erythrinoidea fam. nov. e Ctenolucius hujeta.

340 - Número de supraneurais:

[MOREIRA, 2002: 76; BENINE, 2004: 61 modificado; LIMA, 2006: 46 modificado]

(Minimamente conectado).

\section{[0] - 3 ou menos.}

Catostomus commersonnii, Gymnotus aff. carapo, Curimatopsis macrolepis, Caenotropus labyrinthicus, Gymnocorymbus ternetzi, Knodus meridae, Orthospinus franciscoensis, Poptella brevispina e Tetragonopterus argenteus.

\section{[1] -4.}

Bivibranchia fowleri, Prochilodus nigricans, Semaprochilodus insignis, Chilodus punctatus, Hoplias malabaricus, crenuchus spilurus, Atopomesus pachyodus, Charax cf. leticiae, Compsura heterura, Ctenobrycon hauxwellianus, Galeocharax knerii, Hemigrammus unilineatus, Microschemobrycon casiquiare, Moenkhausia xinguensis, Paracheirodon axelrodi, Phenacogaster pectinatus e Serrabrycon magoi.

\section{[2] -5 .}

Nannocharax fasciatus, Curimata ocellata, Potamorhina latior, schizodon fasciatus, Arnoldichthys spilopterus, Characidium bahiensis, Astyanax mexicanus, Axelrodia reisei, Brittanichthys axelrodi, Bryconadenos tanaothoros, Deuterodon iguape, Hyphessobrycon compressus, Markiana nigripinnis, Myleus setiger, Odontostilbe pequira, Piabina argentea, Probolus heterostomus, Rhinobrycon negrensis, Roeboexodon guyanensis e stygichthys typhlops.

\section{[3] - 6 .}

Neolebias unifasciatus, Parodon nasus, Leporinus fasciatus, Copeina cf. guttata, Aphyocharax pusillus, Bryconamericus exodon, Gnathocharax steindachneri, Hollandichthys multifasciatus, Landonia latidens, Metynnis lippincottianus, oligosarcus argenteus e Rhoadsia altipinna.

$$
\text { [4] - } 7 .
$$

Citharinus latus, Distichodus notospilus, Xenocharax spilurus, Apareiodon piracicabae, Leporellus vittatus, Roestes molossus, Lebiasina bimaculata, Erythrinus erythrinus, Bryconalestes longipinnis, Chalceus epakros, Diapoma terofali, Glandulocauda melanogenys, Hemibrycon polyodon e Rachoviscus graciliceps.

$$
\text { [5] - } 8 \text {. }
$$

Anodus orinocensis, Hemiodus unimaculatus, Anostomus anostomus, Carnegiella strigata, Bryconops alburnoides, Paragoniates alburnus e Piaractus mesopotamicus.

$$
\text { [6] }-9 .
$$


Hemistichodus vaillanti, Thoracocharax stellatus, Gilbertolus atratoensis, Boulengerella maculata, Piabucina astrigata, Brycon pesu, Clupeacharax cf. engrauloides e Iguanodectes geisleri.

$$
[7]-10 \text {. }
$$

Phenagoniates macrolepis e Salminus hilarii.

[8] - 11 .

Brycinus macrolepidotus e Triportheus albus.

\section{[9] - 12 ou mais.}

Chanos chanos, Gasteropelecus sternicla, Acestrorhynchus falcirostris, Hydrolycus tatauaia, Hepsetus odoe e Agoniates halecinus.

\section{[-] - inaplicável.}

Olivaichthys mesembrinus.

\section{[?] - indeterminado.}

Saccodon wagneri, Erythrinoidea fam. nov. e Ctenolucius hujeta.

\section{1 - Desenvolvimento das zigapófises dorsais das vértebras caudais: \\ 58 ) .

$$
\text { [0] - pré-zigapófise maior que pós-zigapófise (Fig. } 57 \text { e Fig. }
$$

Olivaichthys mesembrinus, Xenocharax spilurus, Anostomus anostomus, Gasteropelecus sternicla, Thoracocharax stellatus, Hydrolycus tatauaia, Roestes molossus, Boulengerella maculata, Ctenolucius hujeta, Lebiasina bimaculata, Piabucina astrigata, Arnoldichthys spilopterus, Bryconalestes longipinnis, Characidium bahiensis, Agoniates halecinus, Astyanax mexicanus, Brycon pesu, Bryconops alburnoides, Charax cf. leticiae, Clupeacharax cf. engrauloides, ctenobrycon hauxwellianus, Iguanodectes geisleri, Landonia latidens, Metynnis lippincottianus, Myleus setiger, Poptella brevispina, Probolus heterostomus e Triportheus albus.

\section{[1] - iguais.}

Chanos chanos, Gymnotus aff. carapo, Citharinus latus, Distichodus notospilus, Hemistichodus vaillanti, Neolebias unifasciatus, Nannocharax fasciatus, Apareiodon piracicabae, Parodon nasus, Anodus orinocensis, Bivibranchia fowleri, Hemiodus unimaculatus, Curimata ocellata, Curimatopsis macrolepis, Potamorhina latior, Prochilodus nigricans, Semaprochilodus insignis, Caenotropus labyrinthicus, Chilodus punctatus, Leporellus vittatus, Leporinus fasciatus, Schizodon fasciatus, Acestrorhynchus falcirostris, Gilbertolus atratoensis, Erythrinoidea fam. nov, Copeina cf. guttata, Hepsetus odoe, Brycinus macrolepidotus, Chalceus epakros, Crenuchus spilurus, Aphyocharax pusillus, Atopomesus pachyodus, Axelrodia reisei, Brittanichthys axelrodi, Bryconadenos tanaothoros, Bryconamericus exodon, Compsura heterura, Deuterodon iguape, Diapoma terofali, Galeocharax knerii, Glandulocauda melanogenys, Gnathocharax steindachneri, Gymnocorymbus ternetzi, Hemibrycon polyodon, Hemigrammus unilineatus, Hollandichthys multifasciatus, Hyphessobrycon compressus, Knodus meridae, Markiana nigripinnis, Microschemobrycon casiquiare, Moenkhausia xinguensis, odontostilbe pequira, oligosarcus argenteus, orthospinus franciscoensis, Paracheirodon axelrodi, Piabina argentea, Rachoviscus graciliceps, Rhinobrycon negrensis, Rhoadsia altipinna, Roeboexodon guyanensis, Salminus hilarii, Serrabrycon magoi e Tetragonopterus argenteus.

\section{[2] - pós-zigapófise maior que pré-zigapófise.}

Catostomus commersonnii, Carnegiella strigata, Erythrinus erythrinus, Hoplias malabaricus, Phenacogaster pectinatus, Phenagoniates macrolepis, Piaractus mesopotamicus e Stygichthys typhlops.

\section{[?] - indeterminado.}

Saccodon wagneri e Paragoniates alburnus. 
[0] - reta não sobrepondo vértebra anterior.

Gymnotus aff. Carapo, Distichodus notospilus, Hemistichodus vaillanti, Neolebias unifasciatus, Nannocharax fasciatus, Xenocharax spilurus, Apareiodon piracicabae, Parodon nasus, Carnegiella strigata, Gasteropelecus sternicla, Acestrorhynchus falcirostris, Erythrinoidea fam. nov, Brycinus macrolepidotus, crenuchus spilurus, Astyanax mexicanus, Atopomesus pachyodus, Axelrodia reisei, Brittanichthys axelrodi, Bryconadenos tanaothoros, Bryconamericus exodon, Charax cf. leticiae, Compsura heterura, Deuterodon iguape, Gnathocharax steindachneri, Gymnocorymbus ternetzi, Hemibrycon polyodon, Hemigrammus unilineatus, Hollandichthys multifasciatus, Hyphessobrycon compressus, Knodus meridae, Markiana nigripinnis, Microschemobrycon casiquiare, Moenkhausia xinguensis, Odontostilbe pequira, Orthospinus franciscoensis, Paracheirodon axelrodi, Phenacogaster pectinatus, Phenagoniates macrolepis, Piabina argentea, Probolus heterostomus, Rachoviscus graciliceps, Rhinobrycon negrensis, Rhoadsia altipinna, Salminus hilarii, Serrabrycon magoi, Stygichthys typhlops e Tetragonopterus argenteus.

[1] - inclinada anteriormente, não sobrepondo vértebra anterior.

Chanos chanos, Citharinus latus, Anodus orinocensis, Bivibranchia fowleri, Hemiodus unimaculatus, Curimata ocellata, Curimatopsis macrolepis, Potamorhina latior, Prochilodus nigricans, Semaprochilodus insignis, Caenotropus labyrinthicus, Chilodus punctatus, Leporellus vittatus, Leporinus fasciatus, Schizodon fasciatus, Gilbertolus atratoensis, Copeina cf. guttata, Piabucina astrigata, Erythrinus erythrinus, Hoplias malabaricus, Hepsetus odoe, Arnoldichthys spilopterus, Bryconalestes longipinnis, Chalceus epakros, Characidium bahiensis, Aphyocharax pusillus, Diapoma terofali, oligosarcus argenteus, Piaractus mesopotamicus e Roeboexodon guyanensis.

[2] - muito inclinada, sobrepondo vértebra anterior (Fig. 57 e Fig. 58).

Olivaichthys mesembrinus, Anostomus anostomus, Thoracocharax stellatus, Hydrolycus tatauaia, Roestes molossus, Boulengerella maculata, Ctenolucius hujeta, Lebiasina bimaculata, Piabucina astrigata, Agoniates halecinus, Brycon pesu, Bryconops alburnoides, Clupeacharax cf. engrauloides, ctenobrycon hauxwellianus, Galeocharax knerii, Glandulocauda melanogenys, Iguanodectes geisleri, Landonia latidens, Metynnis lippincottianus, Myleus setiger, Poptella brevispina e Triportheus albus.

\section{[-] - inaplicável.}

Catostomus commersonnii.

[?] - indeterminado.

Saccodon wagneri e Paragoniates alburnus.

$$
[1,2] \text { - polimórfico. }
$$

Piabucina astrigata.

\section{3 - Pós-zigapófises dorsais das vértebras caudais:}

\section{posteriores.}

[0] - não sobrepondo, ou sobrepondo dorsalmente as vértebras

Chanos chanos, Catostomus commersonnii, Gymnotus aff. carapo, Citharinus latus, Distichodus notospilus, Hemistichodus vaillanti, Neolebias unifasciatus, Nannocharax fasciatus, Xenocharax spilurus, Apareiodon piracicabae, Parodon nasus, Anodus orinocensis, Bivibranchia fowleri, Hemiodus unimaculatus, Curimata ocellata, Curimatopsis macrolepis, Potamorhina latior, Prochilodus nigricans, Semaprochilodus insignis, Caenotropus labyrinthicus, Chilodus punctatus, Anostomus anostomus, Leporellus vittatus, Leporinus fasciatus, Schizodon fasciatus, Carnegiella strigata, Gasteropelecus sternicla, Thoracocharax stellatus, Acestrorhynchus falcirostris, Gilbertolus atratoensis, Erythrinoidea fam. nov, Boulengerella maculata, ctenolucius hujeta, Copeina cf. guttata, Lebiasina bimaculata, Piabucina astrigata, Erythrinus erythrinus, Hoplias malabaricus, Hepsetus odoe, Arnoldichthys spilopterus, Brycinus macrolepidotus, Bryconalestes longipinnis, Chalceus epakros, Characidium bahiensis, Crenuchus spilurus, Aphyocharax pusillus, Astyanax mexicanus, Atopomesus pachyodus, Axelrodia reisei, Brittanichthys axelrodi, Brycon pesu, Bryconadenos tanaothoros, Bryconamericus exodon, 
Charax cf. leticiae, Clupeacharax cf. engrauloides, Compsura heterura, ctenobrycon hauxwellianus, Deuterodon iguape, Diapoma terofali, Galeocharax knerii, Glandulocauda melanogenys, Gnathocharax steindachneri, Gymnocorymbus ternetzi, Hemibrycon polyodon, Hemigrammus unilineatus, Hollandichthys multifasciatus, Hyphessobrycon compressus, Iguanodectes geisleri, Knodus meridae, Landonia latidens, Markiana nigripinnis, Microschemobrycon casiquiare, Moenkhausia xinguensis, odontostilbe pequira, oligosarcus argenteus, orthospinus franciscoensis, Paracheirodon axelrodi, Phenacogaster pectinatus, Phenagoniates macrolepis, Piabina argentea, Piaractus mesopotamicus, Poptella brevispina, Probolus heterostomus, Rachoviscus graciliceps, Rhinobrycon negrensis, Rhoadsia altipinna, Roeboexodon guyanensis, Salminus hilarii, Serrabrycon magoi, Stygichthys typhlops, Tetragonopterus argenteus e Triportheus albus.

[1] - sobrepondo lateralmente as vértebras posteriores (Fig. 57 e Fig. 58).

Olivaichthys mesembrinus, Hydrolycus tatauaia, Roestes molossus, Agoniates halecinus, Bryconops alburnoides, Metynnis lippincottianus e Myleus setiger.

\section{[?] - indeterminado.}

Saccodon wagneri e Paragoniates alburnus.

344 - Articulação entre as zigapófises ventrais das vértebras caudais:

57)

[0] - sem articulação, ou semelhante a articulação dorsal (Fig.

Chanos chanos, Olivaichthys mesembrinus, Gymnotus aff. carapo, Citharinus latus, Distichodus notospilus, Hemistichodus vaillanti, Neolebias unifasciatus, Nannocharax fasciatus, Xenocharax spilurus, Apareiodon piracicabae, Parodon nasus, Anodus orinocensis, Bivibranchia fowleri, Hemiodus unimaculatus, Curimata ocellata, Curimatopsis macrolepis, Potamorhina latior, Prochilodus nigricans, Semaprochilodus insignis, Caenotropus labyrinthicus, Chilodus punctatus, Anostomus anostomus, Leporellus vittatus, Leporinus fasciatus, Schizodon fasciatus, Carnegiella strigata, Gasteropelecus sternicla, Thoracocharax stellatus, Acestrorhynchus falcirostris, Gilbertolus atratoensis, Hydrolycus tatauaia, Roestes molossus, Erythrinoidea fam. nov, Boulengerella maculata, Ctenolucius hujeta, Copeina cf. guttata, Lebiasina bimaculata, Piabucina astrigata, Erythrinus erythrinus, Hoplias malabaricus, Hepsetus odoe, Arnoldichthys spilopterus, Brycinus macrolepidotus, Bryconalestes longipinnis, Chalceus epakros, Characidium bahiensis, Crenuchus spilurus, Agoniates halecinus, Aphyocharax pusillus, Astyanax mexicanus, Atopomesus pachyodus, Axelrodia reisei, Brittanichthys axelrodi, Brycon pesu, Bryconadenos tanaothoros, Bryconamericus exodon, Bryconops alburnoides, Charax cf. leticiae, Clupeacharax cf. engrauloides, Compsura heterura, Ctenobrycon hauxwellianus, Deuterodon iguape, Diapoma terofali, Galeocharax knerii, Glandulocauda melanogenys, Gnathocharax steindachneri, Gymnocorymbus ternetzi, Hemibrycon polyodon, Hemigrammus unilineatus, Hollandichthys multifasciatus, Hyphessobrycon compressus, Iguanodectes geisleri, Knodus meridae, Landonia latidens, Markiana nigripinnis, Microschemobrycon casiquiare, Moenkhausia xinguensis, Odontostilbe pequira, Oligosarcus argenteus, Orthospinus franciscoensis, Paracheirodon axelrodi, Phenacogaster pectinatus, Phenagoniates macrolepis, Piabina argentea, Piaractus mesopotamicus, Poptella brevispina, Probolus heterostomus, Rachoviscus graciliceps, Rhinobrycon negrensis, Rhoadsia altipinna, Roeboexodon guyanensis, Salminus hilarii, Serrabrycon magoi, Stygichthys typhlops, Tetragonopterus argenteus e Triportheus albus.

[1] - articulação inversa à dorsal (Fig. 58) .

Metynnis lippincottianus e Myleus setiger.

$$
\text { [-] - inaplicável. }
$$

Catostomus commersonnii.

\section{[?] - indeterminado.}

Saccodon wagneri e Paragoniates alburnus. 


\section{[0] - formando um arco sutil, contínua ao restante da costela.}

Chanos chanos, Catostomus commersonnii, Olivaichthys mesembrinus, Gymnotus aff. carapo, Citharinus latus, Distichodus notospilus, Xenocharax spilurus, Curimata ocellata, Curimatopsis macrolepis, Prochilodus nigricans, Carnegiella strigata, Gasteropelecus sternicla, Thoracocharax stellatus, Acestrorhynchus falcirostris, Gilbertolus atratoensis, Hydrolycus tatauaia, Roestes molossus, Erythrinoidea fam. nov, Boulengerella maculata, Ctenolucius hujeta, Copeina cf. guttata, Lebiasina bimaculata, Piabucina astrigata, Erythrinus erythrinus, Hoplias malabaricus, Hepsetus odoe, Arnoldichthys spilopterus, Brycinus macrolepidotus, Bryconalestes longipinnis, Chalceus epakros, Characidium bahiensis, Crenuchus spilurus, Astyanax mexicanus, Atopomesus pachyodus, Axelrodia reisei, Brycon pesu, Bryconadenos tanaothoros, Bryconamericus exodon, Bryconops alburnoides, Charax cf. leticiae, Clupeacharax cf. engrauloides, Compsura heterura, Ctenobrycon hauxwellianus, Deuterodon iguape, Diapoma terofali, Galeocharax knerii, Glandulocauda melanogenys, Gnathocharax steindachneri, Gymnocorymbus ternetzi, Hemibrycon polyodon, Hemigrammus unilineatus, Hollandichthys multifasciatus, Hyphessobrycon compressus, Iguanodectes geisleri, Knodus meridae, Landonia latidens, Markiana nigripinnis, Metynnis lippincottianus, Microschemobrycon casiquiare, Moenkhausia xinguensis, Myleus setiger, Odontostilbe pequira, Oligosarcus argenteus, Paracheirodon axelrodi, Paragoniates alburnus, Phenacogaster pectinatus, Phenagoniates macrolepis, Piabina argentea, Piaractus mesopotamicus, Poptella brevispina, Probolus heterostomus, Rachoviscus graciliceps, Rhinobrycon negrensis, Rhoadsia altipinna, Roeboexodon guyanensis, Salminus hilarii, Serrabrycon magoi, stygichthys typhlops e Tetragonopterus argenteus.

[1] - quase horizontal, formando um ângulo mais agudo com o restante da costela.

Hemistichodus vaillanti, Neolebias unifasciatus, Nannocharax fasciatus, Apareiodon piracicabae, Parodon nasus, Anodus orinocensis, Bivibranchia fowleri, Hemiodus unimaculatus, Potamorhina latior, Semaprochilodus insignis, Caenotropus labyrinthicus, Chilodus punctatus, Anostomus anostomus, Leporellus vittatus, Leporinus fasciatus, Schizodon fasciatus, Agoniates halecinus, Aphyocharax pusillus, Brittanichthys axelrodi, orthospinus franciscoensis e Triportheus albus.

\section{[?] - indeterminado.}

Saccodon wagneri.

346 - Face medial da porção proximal da costela da quinta vértebra: [LUCENA, 1993: 81 modificado; BUCKUP, 1998: 51; OYAKAWA, 1998: 76; TOLEdoPIZA, 2000: 52 modificado; ZANATA, 2000: 88; BENINE, 2004: 60; ZANATA \& VARI, 2005: 115; NetTO-FERREIRA，2006: 217]

$$
\text { [0] - lisa. }
$$

Chanos chanos, Catostomus commersonnii, Olivaichthys mesembrinus, Gymnotus aff. carapo, Citharinus latus, Distichodus notospilus, Hemistichodus vaillanti, Neolebias unifasciatus, Nannocharax fasciatus, Xenocharax spilurus, Apareiodon piracicabae, Parodon nasus, Bivibranchia fowleri, Curimata ocellata, Curimatopsis macrolepis, Potamorhina latior, Prochilodus nigricans, Semaprochilodus insignis, Caenotropus labyrinthicus, Chilodus punctatus, Anostomus anostomus, Leporellus vittatus, Leporinus fasciatus, Schizodon fasciatus, Gasteropelecus sternicla, Gilbertolus atratoensis, Boulengerella maculata, Ctenolucius hujeta, Copeina cf. guttata, Lebiasina bimaculata, Piabucina astrigata, Erythrinus erythrinus, Hoplias malabaricus, Hepsetus odoe, Arnoldichthys spilopterus, Brycinus macrolepidotus, Bryconalestes longipinnis, Characidium bahiensis, Aphyocharax pusillus, Astyanax mexicanus, Atopomesus pachyodus, Axelrodia reisei, Brittanichthys axelrodi, Bryconadenos tanaothoros, Bryconamericus exodon, Charax cf. leticiae, Compsura heterura, Ctenobrycon hauxwellianus, Diapoma terofali, Hemibrycon polyodon, Hemigrammus unilineatus, Hollandichthys multifasciatus, Iguanodectes geisleri, Knodus meridae, Landonia latidens, Markiana nigripinnis, Metynnis lippincottianus, Microschemobrycon casiquiare, Moenkhausia xinguensis, Myleus setiger, odontostilbe pequira, Oligosarcus argenteus, orthospinus franciscoensis, Paracheirodon axelrodi, Paragoniates alburnus, Phenacogaster pectinatus, Phenagoniates macrolepis, Piabina argentea, Poptella brevispina, Rachoviscus graciliceps, Rhinobrycon negrensis, Rhoadsia altipinna, Salminus hilarii, Serrabrycon magoi, stygichthys typhlops e Tetragonopterus argenteus.

[1] - com processo direcionado medialmente. 
Anodus orinocensis, Hemiodus unimaculatus, Carnegiella strigata, Thoracocharax stellatus, Acestrorhynchus falcirostris, Hydrolycus tatauaia, Roestes molossus, Erythrinoidea fam. nov, Chalceus epakros, Crenuchus spilurus, Agoniates halecinus, Brycon pesu, Bryconops alburnoides, Clupeacharax cf. engrauloides, Deuterodon iguape, Galeocharax knerii, Glandulocauda melanogenys, Gnathocharax steindachneri, Gymnocorymbus ternetzi, Hyphessobrycon compressus, Piaractus mesopotamicus, Probolus heterostomus, Roeboexodon guyanensis e Triportheus albus.

\section{[?] - indeterminado.}

Saccodon wagneri.

347 - Porção póstero-medial das costela anteriores:

[TOLEDO-PIZA, 2000: 52 modificado; ZANATA, 2000: 90 e 91 modificados; ZANATA \& VARI, 2005: 116 \& 117 modificados]

[0] - lisa.

Chanos chanos, Catostomus commersonnii, olivaichthys mesembrinus, Citharinus latus, Bivibranchia fowleri, Curimatopsis macrolepis, Caenotropus labyrinthicus, chilodus punctatus, Anostomus anostomus, Leporellus vittatus, Leporinus fasciatus, schizodon fasciatus, Carnegiella strigata, Gasteropelecus sternicla, Thoracocharax stellatus , Acestrorhynchus falcirostris, Gilbertolus atratoensis, Roestes molossus, Erythrinoidea fam. nov, Boulengerella maculata, Ctenolucius hujeta, Copeina cf. guttata, Lebiasina bimaculata, Piabucina astrigata, Erythrinus erythrinus, Hepsetus odoe, Chalceus epakros, Characidium bahiensis, Atopomesus pachyodus, Brycon pesu, Bryconamericus exodon, Bryconops alburnoides, Charax cf. leticiae, Galeocharax knerii, Glandulocauda melanogenys, Hollandichthys multifasciatus, Hyphessobrycon compressus, Microschemobrycon casiquiare, Phenacogaster pectinatus, Piabina argentea, Probolus heterostomus e Salminus hilarii.

\section{[1] - com projeção posterior na primeira costela.}

Gymnotus aff. carapo, Distichodus notospilus, Neolebias unifasciatus, Xenocharax spilurus, Apareiodon piracicabae, Parodon nasus, Hemiodus unimaculatus, Curimata ocellata, Prochilodus nigricans, Semaprochilodus insignis, Hydrolycus tatauaia, Hoplias malabaricus, Brycinus macrolepidotus, Bryconalestes longipinnis, Agoniates halecinus, Aphyocharax pusillus, Astyanax mexicanus, Bryconadenos tanaothoros, Clupeacharax cf. engrauloides, Compsura heterura, Ctenobrycon hauxwellianus, Diapoma terofali, Gnathocharax steindachneri, Gymnocorymbus ternetzi, Hemibrycon polyodon, Hemigrammus unilineatus, Iguanodectes geisleri, Knodus meridae, Landonia latidens, Moenkhausia xinguensis, Odontostilbe pequira, orthospinus franciscoensis, Paragoniates alburnus, Poptella brevispina, Rachoviscus graciliceps, Rhinobrycon negrensis, Roeboexodon guyanensis, Stygichthys typhlops, Tetragonopterus argenteus e Triportheus albus.

\section{[2] - com projeção posterior na primeira e segunda costela.}

Hemistichodus vaillanti, Nannocharax fasciatus, Anodus orinocensis, Potamorhina latior, Arnoldichthys spilopterus, Crenuchus spilurus, Axelrodia reisei, Brittanichthys axelrodi, Deuterodon iguape, Markiana nigripinnis, Metynnis lippincottianus, Myleus setiger, oligosarcus argenteus, Paracheirodon axelrodi, Phenagoniates macrolepis, Piaractus mesopotamicus, Rhoadsia altipinna e Serrabrycon magoi.

\section{[?] - indeterminado.}

Saccodon wagneri.

348 - Superfície dorsal das três costelas anteriores:

[VARI, 1983: 98; LANGEANI, 1998: 66]

\section{[0] - como nas demais costelas.}

Chanos chanos, Catostomus commersonnii, Olivaichthys mesembrinus, Gymnotus aff. carapo, Citharinus latus, Distichodus notospilus, Hemistichodus vaillanti, Neolebias unifasciatus, Nannocharax fasciatus, Xenocharax spilurus, Apareiodon piracicabae, Parodon nasus, Saccodon wagneri, Anodus orinocensis, Hemiodus unimaculatus, Curimata ocellata, Curimatopsis macrolepis, Potamorhina latior, Prochilodus nigricans, 
Semaprochilodus insignis, Anostomus anostomus, Leporellus vittatus, Leporinus fasciatus, Schizodon fasciatus, Carnegiella strigata, Gasteropelecus sternicla, Thoracocharax stellatus, Acestrorhynchus falcirostris, Gilbertolus atratoensis, Hydrolycus tatauaia, Roestes molossus, Erythrinoidea fam. nov, Boulengerella maculata, Ctenolucius hujeta, Copeina cf. guttata, Lebiasina bimaculata, Piabucina astrigata, Erythrinus erythrinus, Hoplias malabaricus, Hepsetus odoe, Arnoldichthys spilopterus, Brycinus macrolepidotus, Bryconalestes longipinnis, Chalceus epakros, Characidium bahiensis, Crenuchus spilurus, Agoniates halecinus, Aphyocharax pusillus, Astyanax mexicanus, Atopomesus pachyodus, Axelrodia reisei, Brittanichthys axelrodi, Brycon pesu, Bryconadenos tanaothoros, Bryconamericus exodon, Bryconops alburnoides, Charax cf. leticiae, Clupeacharax cf. engrauloides, Compsura heterura, Ctenobrycon hauxwellianus, Deuterodon iguape, Diapoma terofali, Galeocharax knerii, Glandulocauda melanogenys, Gnathocharax steindachneri, Gymnocorymbus ternetzi, Hemibrycon polyodon, Hemigrammus unilineatus, Hollandichthys multifasciatus, Hyphessobrycon compressus, Iguanodectes geisleri, Knodus meridae, Landonia latidens, Markiana nigripinnis, Metynnis lippincottianus, Microschemobrycon casiquiare, Moenkhausia xinguensis, Myleus setiger, odontostilbe pequira, oligosarcus argenteus, orthospinus franciscoensis, Paracheirodon axelrodi, Paragoniates alburnus, Phenacogaster pectinatus, Phenagoniates macrolepis, Piabina argentea, Piaractus mesopotamicus, Poptella brevispina, Probolus heterostomus, Rachoviscus graciliceps, Rhinobrycon negrensis, Rhoadsia altipinna, Roeboexodon guyanensis, Salminus hilarii, Serrabrycon magoi, Stygichthys typhlops, Tetragonopterus argenteus e Triportheus albus.

\section{[1] - com projeção dorsal junto à base.}

Bivibranchia fowleri, Caenotropus labyrinthicus, Chilodus punctatus.

\section{9 - Origem dos epineurais:}

[Toledo-PizA, 2000: 66; ZANATA, 2000: 96; MoReira, 2002: 85; ZanatA \& VARI, 2005: 123; NeTTO-FERREIRA, 2006: 226; LIMA, 2006: 47]

\section{[0] - ao lado do aparelho de Weber, ou posterior.}

Catostomus commersonnii, Gymnotus aff. carapo, Xenocharax spilurus, Apareiodon piracicabae, Parodon nasus, Anodus orinocensis, Bivibranchia fowleri, Hemiodus unimaculatus , Curimata ocellata, Curimatopsis macrolepis, Potamorhina latior, Prochilodus nigricans, Semaprochilodus insignis, Leporellus vittatus, Leporinus fasciatus, Schizodon fasciatus, Gasteropelecus sternicla, Copeina cf. guttata, Lebiasina bimaculata, Piabucina astrigata, Erythrinus erythrinus, Hoplias malabaricus, Hepsetus odoe, Arnoldichthys spilopterus, Bryconalestes longipinnis, Characidium bahiensis, Crenuchus spilurus, Aphyocharax pusillus, Astyanax mexicanus, Atopomesus pachyodus, Axelrodia reisei, Brittanichthys axelrodi, Brycon pesu, Bryconadenos tanaothoros, Bryconamericus exodon, Bryconops alburnoides, Charax cf. leticiae, Compsura heterura, ctenobrycon hauxwellianus, Deuterodon iguape, Diapoma terofali, Galeocharax knerii, Glandulocauda melanogenys, Gnathocharax steindachneri, Gymnocorymbus ternetzi, Hemibrycon polyodon, Hemigrammus unilineatus, Hollandichthys multifasciatus, Hyphessobrycon compressus, Iguanodectes geisleri, Knodus meridae, Landonia latidens, Markiana nigripinnis, Metynnis lippincottianus, Microschemobrycon casiquiare, Moenkhausia xinguensis, Myleus setiger, odontostilbe pequira, oligosarcus argenteus, orthospinus franciscoensis, Paracheirodon axelrodi, Paragoniates alburnus, Phenacogaster pectinatus, Phenagoniates macrolepis, Piabina argentea, Piaractus mesopotamicus, Poptella brevispina, Probolus heterostomus, Rachoviscus graciliceps, Rhinobrycon negrensis, Rhoadsia altipinna, Roeboexodon guyanensis, Salminus hilarii, Serrabrycon magoi, stygichthys typhlops e Tetragonopterus argenteus.

\section{[1] - anterior ao aparelho de Weber.}

Chanos chanos, Citharinus latus, Distichodus notospilus, Caenotropus labyrinthicus, Chilodus punctatus, Carnegiella strigata, Thoracocharax stellatus, Acestrorhynchus falcirostris, Gilbertolus atratoensis, Hydrolycus tatauaia, Roestes molossus, Boulengerella maculata, Ctenolucius hujeta, Brycinus macrolepidotus, Chalceus epakros, Agoniates halecinus, Clupeacharax cf. engrauloides e Triportheus albus.

\section{[-] - inaplicável.}

olivaichthys mesembrinus e Erythrinoidea fam. nov.

[?] - indeterminado.

Hemistichodus vaillanti, Neolebias unifasciatus, Nannocharax fasciatus, Saccodon wagneri e Anostomus anostomus. 
350 - Myorhabdoi:

[TOLEDO-PIZA, 2000: 67]

[0] - ausente.

Chanos chanos, Catostomus commersonnii, olivaichthys mesembrinus, Gymnotus aff. carapo, Distichodus notospilus, Hemistichodus vaillanti, Neolebias unifasciatus, Apareiodon piracicabae, Parodon nasus, Saccodon wagneri, Anodus orinocensis, Bivibranchia fowleri, Hemiodus unimaculatus, Curimata ocellata, Curimatopsis macrolepis, Potamorhina latior, Prochilodus nigricans, Semaprochilodus insignis, Caenotropus labyrinthicus, Chilodus punctatus, Anostomus anostomus, Leporellus vittatus, Leporinus fasciatus, Schizodon fasciatus, Acestrorhynchus falcirostris, Gilbertolus atratoensis, Roestes molossus, Erythrinoidea fam. nov, Boulengerella maculata, Ctenolucius hujeta, copeina cf. guttata, Lebiasina bimaculata, Piabucina astrigata, Erythrinus erythrinus, Hoplias malabaricus, Hepsetus odoe, Arnoldichthys spilopterus, Brycinus macrolepidotus, Bryconalestes longipinnis, Chalceus epakros, Characidium bahiensis, Crenuchus spilurus, Agoniates halecinus, Aphyocharax pusillus, Astyanax mexicanus, Atopomesus pachyodus, Axelrodia reisei, Brittanichthys axelrodi, Brycon pesu, Bryconadenos tanaothoros, Bryconamericus exodon, Bryconops alburnoides, Charax cf. leticiae, Clupeacharax cf. engrauloides, Compsura heterura, Ctenobrycon hauxwellianus, Deuterodon iguape, Diapoma terofali, Galeocharax knerii, Glandulocauda melanogenys, Gnathocharax steindachneri, Gymnocorymbus ternetzi, Hemibrycon polyodon, Hemigrammus unilineatus, Hollandichthys multifasciatus, Hyphessobrycon compressus, Iguanodectes geisleri, Knodus meridae, Landonia latidens, Markiana nigripinnis, Metynnis lippincottianus, Microschemobrycon casiquiare, Moenkhausia xinguensis, Myleus setiger, Odontostilbe pequira, Oligosarcus argenteus, orthospinus franciscoensis, Paracheirodon axelrodi, Paragoniates alburnus, Phenacogaster pectinatus, Phenagoniates macrolepis, Piabina argentea, Piaractus mesopotamicus, Poptella brevispina, Probolus heterostomus, Rachoviscus graciliceps, Rhinobrycon negrensis, Rhoadsia altipinna, Roeboexodon guyanensis, Salminus hilarii, Serrabrycon magoi, Stygichthys typhlops, Tetragonopterus argenteus e Triportheus albus.

\section{[1] - presente.}

Citharinus latus, Nannocharax fasciatus, Xenocharax spilurus, Carnegiella strigata, Gasteropelecus sternicla, Thoracocharax stellatus e Hydrolycus tatauaia.

\subsubsection{Sistema da linha lateral no flanco e escamas}

351 - Linha lateral:

[OYAKAWA, 1998: 95, modificado; ZANATA, 2000: 125, modificado e ZANATA \& VARI, 2005: 163, modificado]

\section{[0] - incompleta.}

Neolebias unifasciatus, Curimatopsis macrolepis, Carnegiella strigata, Gasteropelecus sternicla, Thoracocharax stellatus, Erythrinoidea fam. nov, Boulengerella maculata, Ctenolucius hujeta, Copeina cf. guttata, Lebiasina bimaculata, Piabucina astrigata, Crenuchus spilurus, Aphyocharax pusillus, Axelrodia reisei, Compsura heterura, Diapoma terofali, Gnathocharax steindachneri, Hemigrammus unilineatus, Hollandichthys multifasciatus, Hyphessobrycon compressus, Microschemobrycon casiquiare, Paracheirodon axelrodi, Paragoniates alburnus, Phenacogaster pectinatus, Phenagoniates macrolepis e Serrabrycon magoi.

\section{[1] - terminando ao final do pedúnculo caudal.}

Catostomus commersonnii, Olivaichthys mesembrinus, Gymnotus aff. carapo, Citharinus latus, Distichodus notospilus, Nannocharax fasciatus, Xenocharax spilurus, Erythrinus erythrinus, Hoplias malabaricus, Atopomesus pachyodus, Ctenobrycon hauxwellianus, Deuterodon iguape, Iguanodectes geisleri, Landonia latidens, Metynnis lippincottianus, odontostilbe pequira, Piabina argêntea e Poptella brevispina.

\section{[2] - terminando na nadadeira caudal.}

Chanos chanos, Hemistichodus vaillanti, Apareiodon piracicabae, Parodon nasus, Saccodon wagneri, Anodus orinocensis, Bivibranchia fowleri, Hemiodus unimaculatus, Curimata ocellata, Potamorhina latior, Prochilodus nigricans, Semaprochilodus insignis, Caenotropus labyrinthicus, Chilodus punctatus, Anostomus anostomus, Leporellus vittatus, 
Leporinus fasciatus, Schizodon fasciatus, Acestrorhynchus falcirostris, Hydrolycus tatauaia, Hepsetus odoe, Brycinus macrolepidotus, Bryconalestes longipinnis, Chalceus epakros, Agoniates halecinus, Brycon pesu, Bryconadenos tanaothoros, Bryconamericus exodon, Bryconops alburnoides, Charax cf. leticiae, Galeocharax knerii, Gymnocorymbus ternetzi, Hemibrycon polyodon, Knodus meridae, Markiana nigripinnis, Moenkhausia xinguensis, Myleus setiger, Oligosarcus argenteus, orthospinus franciscoensis, Probolus heterostomus, Rhinobrycon negrensis, Tetragonopterus argenteus e Triportheus albus.

\section{[-] - inaplicável.}

Stygichthys typhlops.

[?] - indeterminado.

Gilbertolus atratoensis, Roestes molossus, Arnoldichthys spilopterus, Characidium bahiensis, Astyanax mexicanus, Brittanichthys axelrodi, Clupeacharax cf. engrauloides, Glandulocauda melanogenys, Piaractus mesopotamicus, Rachoviscus graciliceps, Rhoadsia altipinna, Roeboexodon guyanensis e Salminus hilarii.

352 - Forma da linha lateral:

[ZANATA \& VARI, 2005: 164, modificado]

\section{[0] - reta.}

Catostomus commersonnii, Olivaichthys mesembrinus, Gymnotus aff. carapo, Citharinus latus, Distichodus notospilus, Hemistichodus vaillanti, Neolebias unifasciatus, Nannocharax fasciatus, Xenocharax spilurus, Apareiodon piracicabae, Parodon nasus, Saccodon wagneri, Bivibranchia fowleri, Hemiodus unimaculatus, Curimata ocellata, Potamorhina latior, Prochilodus nigricans, Semaprochilodus insignis, Caenotropus labyrinthicus, Chilodus punctatus, Anostomus anostomus, Leporellus vittatus, Leporinus fasciatus, Schizodon fasciatus, Hydrolycus tatauaia, Erythrinus erythrinus, Hoplias malabaricus, Galeocharax knerii e Metynnis lippincottianus.

\section{[1] - ligeiramente curvada ventralmente.}

Chanos chanos, Anodus orinocensis, Acestrorhynchus falcirostris, Boulengerella maculata, Ctenolucius hujeta, Aphyocharax pusillus, Atopomesus pachyodus, Axelrodia reisei, Bryconadenos tanaothoros, Bryconamericus exodon, Bryconops alburnoides, Charax cf. leticiae, Ctenobrycon hauxwellianus, Deuterodon iguape, Gymnocorymbus ternetzi, Hemibrycon polyodon, Hemigrammus unilineatus, Iguanodectes geisleri, Knodus meridae, Landonia latidens, Markiana nigripinnis, Moenkhausia xinguensis, Myleus setiger, odontostilbe pequira, Oligosarcus argenteus, Orthospinus franciscoensis, Paragoniates alburnus, Phenacogaster pectinatus, Phenagoniates macrolepis, Piabina argentea, Poptella brevispina, Probolus heterostomus, Rhinobrycon negrensis e Tetragonopterus argenteus.

\section{[2] - bastante curvada ventralmente.}

Carnegiella strigata, Gasteropelecus sternicla, Thoracocharax stellatus, Hepsetus odoe, Brycinus macrolepidotus, Bryconalestes longipinnis, Chalceus epakros, Brycon pesu e Diapoma terofali.

\section{[3] - com curvatura brusca.}

Agoniates halecinus e Triportheus albus.

\section{[-] - inaplicável.}

Curimatopsis macrolepis, Erythrinoidea fam. nov., Copeina cf. guttata, Lebiasina bimaculata, Piabucina astrigata, Crenuchus spilurus, Compsura heterura, Gnathocharax steindachneri, Hollandichthys multifasciatus, Hyphessobrycon compressus, Microschemobrycon casiquiare, Paracheirodon axelrodi, Serrabrycon magoi e Stygichthys typhlops.

\section{[?] - indeterminado.}

Gilbertolus atratoensis, Roestes molossus, Arnoldichthys spilopterus, Characidium bahiensis, Astyanax mexicanus, Brittanichthys axelrodi, Clupeacharax cf. engrauloides, Glandulocauda melanogenys, Piaractus mesopotamicus, Rachoviscus graciliceps, Rhoadsia altipinna, Roeboexodon guyanensis e Salminus hilarii. 


\section{3 - Linha lateral no pedunculo caudal: [ZANATA, 2000: 124, modificado]}

\section{[0] - aproximadamente na porção mediana.}

Chanos chanos, Catostomus commersonnii, olivaichthys mesembrinus, Gymnotus aff. carapo, Citharinus latus, Distichodus notospilus, Hemistichodus vaillanti, Neolebias unifasciatus, Nannocharax fasciatus, Xenocharax spilurus, Apareiodon piracicabae, Parodon nasus, Saccodon wagneri, Anodus orinocensis, Bivibranchia fowleri, Hemiodus unimaculatus, Curimata ocellata, Potamorhina latior, Prochilodus nigricans, Semaprochilodus insignis, Caenotropus labyrinthicus, Chilodus punctatus, Anostomus anostomus, Leporellus vittatus, Leporinus fasciatus, Schizodon fasciatus, Acestrorhynchus falcirostris, Hydrolycus tatauaia, Erythrinus erythrinus, Hoplias malabaricus, Hepsetus odoe, Atopomesus pachyodus, Bryconamericus exodon, Charax cf. leticiae, Ctenobrycon hauxwellianus, Deuterodon iguape, Galeocharax knerii, Gymnocorymbus ternetzi, Hemibrycon polyodon, Iguanodectes geisleri, Knodus meridae, Landonia latidens, Metynnis lippincottianus, Myleus setiger, odontostilbe pequira, oligosarcus argenteus, Orthospinus franciscoensis, Piabina argentea, Poptella brevispina, Probolus heterostomus e Rhinobrycon negrensis.

\section{[1] - na porção ventral.}

Brycinus macrolepidotus, Bryconalestes longipinnis, Chalceus epakros, Agoniates halecinus, Bryconadenos tanaothoros, Bryconops alburnoides, Clupeacharax cf. engrauloides, Markiana nigripinnis, Moenkhausia xinguensis, Tetragonopterus argenteus e Triportheus albus.

\section{[-] - inaplicável.}

Curimatopsis macrolepis, Carnegiella strigata, Gasteropelecus sternicla, Thoracocharax stellatus, Erythrinoidea fam. nov., Boulengerella maculata, Ctenolucius hujeta, Copeina cf. guttata, Lebiasina bimaculata, Piabucina astrigata, Crenuchus spilurus, Aphyocharax pusillus, Axelrodia reisei, Compsura heterura, Diapoma terofali, Gnathocharax steindachneri, Hemigrammus unilineatus, Hollandichthys multifasciatus, Hyphessobrycon compressus, Microschemobrycon casiquiare, Paracheirodon axelrodi, Paragoniates alburnus, Phenacogaster pectinatus, Phenagoniates macrolepis, Serrabrycon magoi e stygichthys typhlops.

\section{[?] - indeterminado.}

Gilbertolus atratoensis, Roestes molossus, Arnoldichthys spilopterus, Characidium bahiensis, Astyanax mexicanus, Brittanichthys axelrodi, Brycon pesu, Glandulocauda melanogenys, Piaractus mesopotamicus, Rachoviscus graciliceps, Rhoadsia altipinna, Roeboexodon guyanensis e Salminus hilarii.

354 - Tamanho das escamas acima e abaixo da linha lateral:

[ZANATA \& VARI, 2005: 169, modificado]

\section{[0] - aproximadamente iguais.}

Chanos chanos, Catostomus commersonnii, Gymnotus aff. carapo, Citharinus latus, Distichodus notospilus, Hemistichodus vaillanti, Neolebias unifasciatus, Nannocharax fasciatus, Xenocharax spilurus, Apareiodon piracicabae, Parodon nasus, Saccodon wagneri, Anodus orinocensis, Bivibranchia fowleri, Hemiodus unimaculatus, Curimatopsis macrolepis, Potamorhina latior, Prochilodus nigricans, Semaprochilodus insignis, Caenotropus labyrinthicus, Chilodus punctatus, Anostomus anostomus, Leporellus vittatus, Leporinus fasciatus, Schizodon fasciatus, Carnegiella strigata, Gasteropelecus sternicla, Acestrorhynchus falcirostris, Hydrolycus tatauaia, Erythrinoidea fam. nov, Boulengerella maculata, Ctenolucius hujeta, Copeina cf. guttata, Lebiasina bimaculata, Piabucina astrigata, Erythrinus erythrinus, Hoplias malabaricus, Hepsetus odoe, Crenuchus spilurus, Agoniates halecinus, Aphyocharax pusillus, Atopomesus pachyodus, Axelrodia reisei, Brycon pesu, Bryconamericus exodon, Bryconops alburnoides, Charax cf. leticiae, Compsura heterura, Ctenobrycon hauxwellianus, Deuterodon iguape, Diapoma terofali, Galeocharax knerii, Gnathocharax steindachneri, Gymnocorymbus ternetzi, Hemibrycon polyodon, Hemigrammus unilineatus, Hollandichthys multifasciatus, Hyphessobrycon compressus, Iguanodectes geisleri, Knodus meridae, Landonia latidens, Markiana nigripinnis, Metynnis lippincottianus, Microschemobrycon casiquiare, Moenkhausia xinguensis, Myleus setiger, Odontostilbe pequira, oligosarcus argenteus, 
orthospinus franciscoensis, Paracheirodon axelrodi, Paragoniates alburnus, Phenacogaster pectinatus, Phenagoniates macrolepis, Piabina argentea, Poptella brevispina, Probolus heterostomus, Rhinobrycon negrensis, Serrabrycon magoi, Stygichthys typhlops e Tetragonopterus argenteus.

\section{[1] - escamas maiores dorsalmente (até 50\%).}

Brycinus macrolepidotus, Bryconalestes longipinnis e Bryconadenos tanaothoros.

\section{[2] - escamas maiores dorsalmente (acima de 50\%).}

Chalceus epakros e Triportheus albus.

\section{[-] - inaplicável.}

Olivaichthys mesembrinus.

\section{[?] - indeterminado.}

Curimata ocellata, Thoracocharax stellatus, Gilbertolus atratoensis, Roestes molossus, Arnoldichthys spilopterus, Characidium bahiensis, Astyanax mexicanus, Brittanichthys axelrodi, Clupeacharax cf. engrauloides, Glandulocauda melanogenys, Piaractus mesopotamicus, Rachoviscus graciliceps, Rhoadsia altipinna, Roeboexodon guyanensis e Salminus hilarii.

\section{5 - Base da nadeira adiposa:}

\section{[0] - com escamas.}

Citharinus latus, Distichodus notospilus, Xenocharax spilurus, Parodon nasus, Anodus orinocensis, Bivibranchia fowleri, Hemiodus unimaculatus, Curimata ocellata, Potamorhina latior, Prochilodus nigricans, Semaprochilodus insignis, Caenotropus labyrinthicus, Anostomus anostomus, Leporellus vittatus, Leporinus fasciatus, Schizodon fasciatus, Boulengerella maculata, Ctenolucius hujeta, Hepsetus odoe, Bryconamericus exodon, Clupeacharax cf. engrauloides, Ctenobrycon hauxwellianus, Diapoma terofali, Landonia latidens, Metynnis lippincottianus, Myleus setiger, Paragoniates alburnus, Gymnocorymbus ternetzi e Poptella brevispina.

\section{[1] - sem escamas.}

Hemistichodus vaillanti, Neolebias unifasciatus, Nannocharax fasciatus, Apareiodon piracicabae, Saccodon wagneri, Curimatopsis macrolepis, Chilodus punctatus, Gasteropelecus sternicla, Thoracocharax stellatus, Acestrorhynchus falcirostris, Hydrolycus tatauaia, Piabucina astrigata, Brycinus macrolepidotus, Bryconalestes longipinnis, Chalceus epakros, Crenuchus spilurus, Agoniates halecinus, Aphyocharax pusillus, Atopomesus pachyodus, Axelrodia reisei, Brittanichthys axelrodi, Brycon pesu, Bryconadenos tanaothoros, Bryconops alburnoides, Charax cf. leticiae, Compsura heterura, Deuterodon iguape, Gnathocharax steindachneri, Hemibrycon polyodon, Hemigrammus unilineatus, Hollandichthys multifasciatus, Hyphessobrycon compressus,' Iguanodectes geisleri, Knodus meridae, Markiana nigripinnis, Microschemobrycon casiquiare, Moenkhausia xinguensis, Odontostilbe pequira, Oligosarcus argenteus, Orthospinus franciscoensis, Paracheirodon axelrodi, Phenacogaster pectinatus, Piabina argentea, Probolus heterostomus, Rhinobrycon negrensis, Serrabrycon magoi, Stygichthys typhlops, Tetragonopterus argenteus e Triportheus albus.

\section{[-] - inaplicável.}

Chanos chanos, Catostomus commersonnii, Olivaichthys mesembrinus, Gymnotus aff. carapo, Carnegiella strigata, Erythrinoidea fam. nov., Copeina cf. guttata, Lebiasina bimaculata, Erythrinus erythrinus, Hoplias malabaricus e Phenagoniates macrolepis.

\section{[?] - indeterminado.}

Gilbertolus atratoensis, Roestes molossus, Arnoldichthys spilopterus, Characidium bahiensis, Astyanax mexicanus, Galeocharax knerii, Glandulocauda melanogenys, Piaractus mesopotamicus, Rachoviscus graciliceps, Rhoadsia altipinna, Roeboexodon guyanensis e Salminus hilarii. 
[LUCENA, 1993: 24; VARI, 1995: 74; VARI ET AL., 1995: 36; BUCKUP, 1998: 18;

ZANATA, 2000: 128; ZANATA \& VARI, 2005: 168 e NetTo-Ferreira, 2006: 286]

\section{[0] - exposto.}

Citharinus latus, Distichodus notospilus, Hemistichodus vaillanti, Neolebias unifasciatus, Nannocharax fasciatus, Xenocharax spilurus, Anodus orinocensis, Bivibranchia fowleri, Hemiodus unimaculatus, Curimata ocellata, Curimatopsis macrolepis, Potamorhina latior, Prochilodus nigricans, Semaprochilodus insignis, Caenotropus labyrinthicus, Chilodus punctatus, Anostomus anostomus, Leporellus vittatus, Leporinus fasciatus, Acestrorhynchus falcirostris, Hydrolycus tatauaia, Bryconalestes longipinnis, Crenuchus spilurus, Agoniates halecinus, Aphyocharax pusillus, Atopomesus pachyodus, Axelrodia reisei, Brittanichthys axelrodi, Bryconadenos tanaothoros, Bryconamericus exodon, Bryconops alburnoides, Charax cf. leticiae, Compsura heterura, Ctenobrycon hauxwellianus, Deuterodon iguape, Diapoma terofali, Galeocharax knerii, Gnathocharax steindachneri, Gymnocorymbus ternetzi, Hemibrycon polyodon, Hemigrammus unilineatus, Hollandichthys multifasciatus, Hyphessobrycon compressus, Iguanodectes geisleri, Knodus meridae, Landonia latidens, Markiana nigripinnis, Metynnis lippincottianus, Microschemobrycon casiquiare, Moenkhausia xinguensis, Myleus setiger, odontostilbe pequira, oligosarcus argenteus, orthospinus franciscoensis, Paracheirodon axelrodi, Paragoniates alburnus, Phenacogaster pectinatus, Phenagoniates macrolepis, Piabina argentea, Poptella brevispina, Probolus heterostomus, Rhinobrycon negrensis, Serrabrycon magoi, Tetragonopterus argenteus e Triportheus albus.

\section{[1] - recoberto por escamas.}

Chanos chanos, Catostomus commersonnii, Gymnotus aff. carapo, Apareiodon piracicabae, Parodon nasus, Saccodon wagneri, Schizodon fasciatus, Carnegiella strigata, Gasteropelecus sternicla, Thoracocharax stellatus, Erythrinoidea fam. nov, Boulengerella maculata, Ctenolucius hujeta, Copeina cf. guttata, Lebiasina bimaculata, Piabucina astrigata, Erythrinus erythrinus, Hoplias malabaricus, Hepsetus odoe, Brycinus macrolepidotus, Chalceus epakros e Brycon pesu.

\section{[-] - inaplicável.}

Olivaichthys mesembrinus.

\section{[?] - indeterminado.}

Gilbertolus atratoensis, Roestes molossus, Arnoldichthys spilopterus, Characidium bahiensis, Astyanax mexicanus, Clupeacharax cf. engrauloides, Glandulocauda melanogenys, Piaractus mesopotamicus, Rachoviscus graciliceps, Rhoadsia altipinna, Roeboexodon guyanensis, Salminus hilarii e Stygichthys typhlops.

\section{7 - Sexta escama da linha lateral:}

\section{[0] - igual às escamas anterior e posterior.}

Chanos chanos, Catostomus commersonnii, Gymnotus aff. carapo, Citharinus latus, Distichodus notospilus, Hemistichodus vaillanti, Neolebias unifasciatus, Nannocharax fasciatus, Xenocharax spilurus, Apareiodon piracicabae, Parodon nasus, Saccodon wagneri, Anodus orinocensis, Bivibranchia fowleri, Hemiodus unimaculatus, Curimata ocellata, Curimatopsis macrolepis, Potamorhina latior, Prochilodus nigricans, Semaprochilodus insignis, Anostomus anostomus, Leporellus vittatus, Leporinus fasciatus, Schizodon fasciatus, Carnegiella strigata, Gasteropelecus sternicla, Thoracocharax stellatus Acestrorhynchus falcirostris, Hydrolycus tatauaia, Erythrinoidea fam. nov, Boulengerella maculata, Ctenolucius hujeta, Copeina cf. guttata, Erythrinus erythrinus, Hoplias malabaricus, Hepsetus odoe, Brycinus macrolepidotus, Bryconalestes longipinnis, Chalceus epakros, Crenuchus spilurus, Agoniates halecinus, Aphyocharax pusillus, Atopomesus pachyodus, Axelrodia reisei, Brycon pesu, Bryconadenos tanaothoros, Bryconamericus exodon, Bryconops alburnoides, Charax cf. leticiae, Compsura heterura, Ctenobrycon hauxwellianus, Deuterodon iguape, Diapoma terofali, Galeocharax knerii, Gnathocharax steindachneri, Gymnocorymbus ternetzi, Hemibrycon polyodon, Hemigrammus unilineatus, Hollandichthys multifasciatus, Hyphessobrycon compressus, Iguanodectes geisleri, Knodus meridae, Landonia latidens, Markiana nigripinnis, Metynnis lippincottianus, Microschemobrycon casiquiare, Moenkhausia xinguensis, Myleus setiger, odontostilbe pequira, Oligosarcus argenteus, orthospinus franciscoensis, Paragoniates alburnus, Phenacogaster pectinatus, Phenagoniates macrolepis, Piabina argentea, Poptella brevispina, Probolus heterostomus, Rhinobrycon negrensis, Serrabrycon magoi, Tetragonopterus argenteus e Triportheus albus. 


\section{[1] - menor que às escamas anterior e posterior.}

Caenotropus labyrinthicus e Chilodus punctatus.

\section{[-] - inaplicável.}

Olivaichthys mesembrinus, Lebiasina bimaculata, Piabucina astrigata, Paracheirodon axelrodi e Stygichthys typhlops.

\section{[?] - indeterminado.}

Gilbertolus atratoensis, Roestes molossus, Arnoldichthys spilopterus, Characidium bahiensis, Astyanax mexicanus, Brittanichthys axelrodi, Clupeacharax cf. engrauloides, Glandulocauda melanogenys, Piaractus mesopotamicus, Rachoviscus graciliceps, Rhoadsia altipinna, Roeboexodon guyanensis e Salminus hilarii.

\section{8 - Bainha de escamas da nadadeira anal:}

[0] - ausente.

Gymnotus aff. carapo, Hemistichodus vaillanti, Neolebias unifasciatus, Nannocharax fasciatus, Anodus orinocensis, Bivibranchia fowleri, Hemiodus unimaculatus, Caenotropus labyrinthicus, Chilodus punctatus, Leporellus vittatus, Leporinus fasciatus, Schizodon fasciatus, Erythrinoidea fam. nov, Boulengerella maculata, Erythrinus erythrinus, Hoplias malabaricus, Hepsetus odoe, Brycinus macrolepidotus, Chalceus epakros, Crenuchus spilurus, Bryconops alburnoides, Charax cf. leticiae, Iguanodectes geisleri, Paracheirodon axelrodi, Piabina argentea, Rhinobrycon negrensis, Serrabrycon magoi e Stygichthys typhlops.

\section{[1] - poucas fileiras de escamas, não atingindo metade dos raios.}

Citharinus latus, Distichodus notospilus, Xenocharax spilurus, Apareiodon piracicabae, Parodon nasus, Saccodon wagneri, Curimata ocellata, Curimatopsis macrolepis, Potamorhina latior, Prochilodus nigricans, Semaprochilodus insignis, Anostomus anostomus, Carnegiella strigata, Gasteropelecus sternicla, Thoracocharax stellatus, Acestrorhynchus falcirostris, Ctenolucius hujeta, copeina cf. guttata, Lebiasina bimaculata, Piabucina astrigata, Bryconalestes longipinnis, Agoniates halecinus, Aphyocharax pusillus, Atopomesus pachyodus, Axelrodia reisei, Brycon pesu, Bryconadenos tanaothoros, Bryconamericus exodon, Compsura heterura, Ctenobrycon hauxwellianus, Deuterodon iguape, Diapoma terofali, Galeocharax knerii, Hemibrycon polyodon, Hemigrammus unilineatus, Hollandichthys multifasciatus, Hyphessobrycon compressus, Knodus meridae, Landonia latidens, Microschemobrycon casiquiare, Moenkhausia xinguensis, Odontostilbe pequira, Oligosarcus argenteus, orthospinus franciscoensis, Paragoniates alburnus, Phenacogaster pectinatus, Phenagoniates macrolepis, Poptella brevispina, Probolus heterostomus, Tetragonopterus argenteus e Triportheus albus. raios.

[2] - muitas fileiras, alcançando ou ultrapassando a metade dos

Chanos chanos, Hydrolycus tatauaia, Gymnocorymbus ternetzi, Markiana nigripinnis e Myleus setiger.

[-] - inaplicável.

Catostomus commersonnii, Olivaichthys mesembrinus e Gnathocharax steindachneri.

[?] - indeterminado.

Gilbertolus atratoensis, Roestes molossus, Arnoldichthys spilopterus, Characidium bahiensis, Astyanax mexicanus, Brittanichthys axelrodi, Clupeacharax cf. engrauloides, Glandulocauda melanogenys, Metynnis lippincottianus, Piaractus mesopotamicus, Rachoviscus graciliceps, Rhoadsia altipinna, Roeboexodon guyanensis e Salminus hilarii.

359 - Linha mediana prédorsal:

[ZANATA, 2000: 129] 


\section{[0] - coberta por escamas.}

Chanos chanos, Catostomus commersonnii, Gymnotus aff. carapo, Citharinus latus, Distichodus notospilus, Hemistichodus vaillanti, Neolebias unifasciatus, Nannocharax fasciatus, Xenocharax spilurus, Apareiodon piracicabae, Parodon nasus, Saccodon wagneri, Anodus orinocensis, Bivibranchia fowleri, Hemiodus unimaculatus, Curimata ocellata, curimatopsis macrolepis, Prochilodus nigricans, Semaprochilodus insignis, Anostomus anostomus, Leporellus vittatus, Leporinus fasciatus, Schizodon fasciatus, Carnegiella strigata, Gasteropelecus sternicla, Thoracocharax stellatus, Acestrorhynchus falcirostris, Hydrolycus tatauaia, Erythrinoidea fam. nov, Boulengerella maculata, Ctenolucius hujeta, Copeina cf. guttata, Lebiasina bimaculata, Piabucina astrigata, Erythrinus erythrinus, Hoplias malabaricus, Hepsetus odoe, Brycinus macrolepidotus, Bryconalestes longipinnis, Chalceus epakros, Crenuchus spilurus, Agoniates halecinus, Aphyocharax pusillus, Atopomesus pachyodus, Axelrodia reisei, Brittanichthys axelrodi, Brycon pesu, Bryconadenos tanaothoros, Bryconamericus exodon, Bryconops alburnoides, Clupeacharax cf. engrauloides, Compsura heterura, Ctenobrycon hauxwellianus, Deuterodon iguape, Diapoma terofali, Galeocharax knerii, Gnathocharax steindachneri, Gymnocorymbus ternetzi, Hemibrycon polyodon, Hemigrammus unilineatus, Hollandichthys multifasciatus, Hyphessobrycon compressus, Iguanodectes geisleri, Knodus meridae, Landonia latidens, Markiana nigripinnis, Microschemobrycon casiquiare, Moenkhausia xinguensis, Odontostilbe pequira, Oligosarcus argenteus, Orthospinus franciscoensis, Paracheirodon axelrodi, Paragoniates alburnus, Phenacogaster pectinatus, Phenagoniates macrolepis, Piabina argentea, Poptella brevispina, Probolus heterostomus, Rhinobrycon negrensis, Serrabrycon magoi, Stygichthys typhlops, Tetragonopterus argenteus e Triportheus albus.

\section{[1] - sem escamas.}

Potamorhina latior, Chilodus punctatus, Charax cf. leticiae, Metynnis lippincottianus e Myleus setiger.

\section{[-] - inaplicável.}

olivaichthys mesembrinus.

[?] - indeterminado.

Caenotropus labyrinthicus, Gilbertolus atratoensis, Roestes molossus, Arnoldichthys spilopterus, Characidium bahiensis, Astyanax mexicanus, Glandulocauda melanogenys, Piaractus mesopotamicus, Rachoviscus graciliceps, Rhoadsia altipinna, Roeboexodon guyanensis e Salminus hilarii.

\section{0 - Comprimento da escama:}

\section{[0] - maior que a altura.}

Chanos chanos, Gymnotus aff. carapo, Anodus orinocensis, Hemiodus unimaculatus, Leporinus fasciatus, Schizodon fasciatus, Thoracocharax stellatus, Chalceus epakros, Bryconops alburnoides, Iguanodectes geisleri, Metynnis lippincottianus, Myleus setiger e odontostilbe pequira.

\section{[1] - aproximadamente igual.}

Catostomus commersonnii, Apareiodon piracicabae, Parodon nasus, Saccodon wagneri, Potamorhina latior, Semaprochilodus insignis, Anostomus anostomus, Erythrinoidea fam. nov, Piabucina astrigata, Erythrinus erythrinus, Hoplias malabaricus, Hepsetus odoe, crenuchus spilurus e Brycon pesu.

\section{[2] - menor que a altura.}

Citharinus latus, Distichodus notospilus, Hemistichodus vaillanti, Neolebias unifasciatus, Xenocharax spilurus, Bivibranchia fowleri, Curimata ocellata, Curimatopsis macrolepis, Prochilodus nigricans, Caenotropus labyrinthicus, chilodus punctatus, Leporellus vittatus, Carnegiella strigata, Gasteropelecus sternicla, Acestrorhynchus falcirostris, Gilbertolus atratoensis, Hydrolycus tatauaia, Roestes molossus, Boulengerella maculata, ctenolucius hujeta, Copeina cf. guttata, Lebiasina bimaculata, Brycinus macrolepidotus, Bryconalestes longipinnis, Characidium bahiensis, Agoniates halecinus, Aphyocharax pusillus, Astyanax mexicanus, Atopomesus pachyodus, Axelrodia reisei, Bryconadenos tanaothoros, Bryconamericus exodon, Charax cf. leticiae, Clupeacharax cf. engrauloides, Compsura heterura, Ctenobrycon hauxwellianus, Deuterodon iguape, Diapoma terofali, Galeocharax knerii, Gnathocharax steindachneri, Gymnocorymbus ternetzi, Hemibrycon polyodon, Hemigrammus unilineatus, Hollandichthys multifasciatus, 
Hyphessobrycon compressus, Knodus meridae, Landonia latidens, Markiana nigripinnis, Microschemobrycon casiquiare, Moenkhausia xinguensis, oligosarcus argenteus, orthospinus franciscoensis, Paracheirodon axelrodi, Paragoniates alburnus, Phenacogaster pectinatus, Phenagoniates macrolepis, Piabina argentea, Poptella brevispina, Probolus heterostomus, Rhinobrycon negrensis, Salminus hilarii, Tetragonopterus argenteus e Triportheus albus.

\section{[-] - inaplicável.}

olivaichthys mesembrinus.

\section{[?] - indeterminado.}

Nannocharax fasciatus, Arnoldichthys spilopterus, Brittanichthys axelrodi, Glandulocauda melanogenys, Piaractus mesopotamicus, Rachoviscus graciliceps, Rhoadsia altipinna, Roeboexodon guyanensis, Serrabrycon magoi e Stygichthys typhlops.

\section{1 - Escama alongada na porção dorsal da inserção da nadadeira peitoral:}

\section{[0] - ausente.}

Catostomus commersonnii, Olivaichthys mesembrinus, Gymnotus aff. carapo, Citharinus latus, Distichodus notospilus, Hemistichodus vaillanti, Neolebias unifasciatus, Nannocharax fasciatus, Xenocharax spilurus, Apareiodon piracicabae, Parodon nasus, Saccodon wagneri, Anodus orinocensis, Bivibranchia fowleri, Hemiodus unimaculatus, Curimata ocellata, Curimatopsis macrolepis, Potamorhina latior, Prochilodus nigricans, Semaprochilodus insignis, Caenotropus labyrinthicus, Chilodus punctatus, Anostomus anostomus, Leporellus vittatus, Leporinus fasciatus, Schizodon fasciatus, Carnegiella strigata, Gasteropelecus sternicla, Thoracocharax stellatus, Acestrorhynchus falcirostris, Hydrolycus tatauaia, Boulengerella maculata, Ctenolucius hujeta, Copeina cf. guttata, Lebiasina bimaculata, Piabucina astrigata, Erythrinus erythrinus, Hoplias malabaricus, Hepsetus odoe, Brycinus macrolepidotus, Bryconalestes longipinnis, Chalceus epakros, Crenuchus spilurus, Aphyocharax pusillus, Atopomesus pachyodus, Axelrodia reisei, Brittanichthys axelrodi, Bryconadenos tanaothoros, Bryconamericus exodon, Bryconops alburnoides, Charax cf. leticiae, Compsura heterura, Ctenobrycon hauxwellianus, Deuterodon iguape, Diapoma terofali, Galeocharax knerii, Gnathocharax steindachneri, Gymnocorymbus ternetzi, Hemibrycon polyodon, Hemigrammus unilineatus, Hollandichthys multifasciatus, Hyphessobrycon compressus, Iguanodectes geisleri, Knodus meridae, Landonia latidens, Markiana nigripinnis, Metynnis lippincottianus, Microschemobrycon casiquiare, Moenkhausia xinguensis, Myleus setiger, odontostilbe pequira, oligosarcus argenteus, orthospinus franciscoensis, Paracheirodon axelrodi, Paragoniates alburnus, Phenacogaster pectinatus, Phenagoniates macrolepis, Piabina argentea, Poptella brevispina, Probolus heterostomus, Rhinobrycon negrensis, Serrabrycon magoi, Stygichthys typhlops e Tetragonopterus argenteus.

\section{[1] - presente.}

Chanos chanos, Agoniates halecinus, Brycon pesu, Clupeacharax cf. engrauloides e Triportheus albus.

\section{[?] - indeterminado.}

Gilbertolus atratoensis, Roestes molossus, Erythrinoidea fam. nov., Arnoldichthys spilopterus, Characidium bahiensis, Astyanax mexicanus, Glandulocauda melanogenys, Piaractus mesopotamicus, Rachoviscus graciliceps, Rhoadsia altipinna, Roeboexodon guyanensis e Salminus hilarii.

362 - Tipo de escama:

[VARI, 1979: 50; LUCENA, 1993: 119, modificado e TOLEDo-PIZA, 2000: 68, modificado]

\section{[0] - ciclóide.}

Chanos chanos, Catostomus commersonnii, Gymnotus aff. carapo, Citharinus latus, Apareiodon piracicabae, Parodon nasus, Saccodon wagneri, Bivibranchia fowleri, 
Curimatopsis macrolepis, Semaprochilodus insignis, Chilodus punctatus, Anostomus anostomus, Leporellus vittatus, Leporinus fasciatus, Schizodon fasciatus, Carnegiella strigata, Gasteropelecus sternicla, Thoracocharax stellatus, Acestrorhynchus falcirostris, Gilbertolus atratoensis, Hydrolycus tatauaia, Roestes molossus, Erythrinoidea fam. nov, Copeina cf. guttata, Lebiasina bimaculata, Piabucina astrigata, Erythrinus erythrinus, Hoplias malabaricus, Hepsetus odoe, Arnoldichthys spilopterus, Brycinus macrolepidotus, Bryconalestes longipinnis, Chalceus epakros, Characidium bahiensis, Crenuchus spilurus, Agoniates halecinus, Aphyocharax pusillus, Astyanax mexicanus, Atopomesus pachyodus, Axelrodia reisei, Brittanichthys axelrodi, Brycon pesu, Bryconadenos tanaothoros, Bryconamericus exodon, Bryconops alburnoides, charax cf. leticiae, Clupeacharax cf. engrauloides, Compsura heterura, Deuterodon iguape, Diapoma terofali, Gnathocharax steindachneri, Gymnocorymbus ternetzi, Hemibrycon polyodon , Hemigrammus unilineatus, Hollandichthys multifasciatus, Hyphessobrycon compressus, Iguanodectes geisleri, Knodus meridae, Landonia latidens, Markiana nigripinnis, Metynnis lippincottianus, Microschemobrycon casiquiare, Moenkhausia xinguensis, Myleus setiger, odontostilbe pequira, oligosarcus argenteus, orthospinus franciscoensis, Paracheirodon axelrodi, Paragoniates alburnus, Phenacogaster pectinatus, Phenagoniates macrolepis, Piabina argentea, Poptella brevispina, Probolus heterostomus, Rhinobrycon negrensis, Serrabrycon magoi, Stygichthys typhlops, Tetragonopterus argenteus e Triportheus albus.

[1] - crenada.

Anodus orinocensis, Hemiodus unimaculatus, Curimata ocellata e Caenotropus labyrinthicus.

\section{[2] - espinóide.}

Potamorhina latior, Prochilodus nigricans, Boulengerella maculata, Ctenolucius hujeta, ctenobrycon hauxwellianus e Galeocharax knerii.

\section{[3] - ctenóide.}

Distichodus notospilus, Hemistichodus vaillanti, Neolebias unifasciatus, Nannocharax fasciatus e Xenocharax spilurus.

\section{[-] - inaplicável.}

Olivaichthys mesembrinus.

\section{[?] - indeterminado.}

Glandulocauda melanogenys, Piaractus mesopotamicus, Rachoviscus graciliceps, Rhoadsia altipinna, Roeboexodon guyanensis e Salminus hilarii.

363 - Circuli na porção posterior das escamas:

[LUCENA, 1993: 118; BUCKUP, 1998: 80, modificado; ZANATA, 2000: 131]

\section{[0] - ausentes ou pouco desenvolvidas.}

Chanos chanos, Bivibranchia fowleri, Hemiodus unimaculatus, Curimata ocellata, Caenotropus labyrinthicus, Chilodus punctatus, Anostomus anostomus, Leporellus vittatus, schizodon fasciatus, Carnegiella strigata, Gasteropelecus sternicla, Thoracocharax stellatus, Gilbertolus atratoensis, Hydrolycus tatauaia, Roestes molossus, Boulengerella maculata, Ctenolucius hujeta, Characidium bahiensis, Agoniates halecinus, Atopomesus pachyodus, Axelrodia reisei, Bryconadenos tanaothoros, Bryconamericus exodon, Bryconops alburnoides, Charax cf. leticiae, Clupeacharax cf. engrauloides, Compsura heterura, Deuterodon iguape, Diapoma terofali, Galeocharax knerii, Gnathocharax steindachneri, Gymnocorymbus ternetzi, Hemibrycon polyodon, Hemigrammus unilineatus, Hollandichthys multifasciatus, Hyphessobrycon compressus, Iguanodectes geisleri, Knodus meridae, Landonia latidens, Markiana nigripinnis, Microschemobrycon casiquiare, Moenkhausia xinguensis, Odontostilbe pequira, Oligosarcus argenteus, orthospinus franciscoensis, Paracheirodon axelrodi, Paragoniates alburnus, Phenacogaster pectinatus, Phenagoniates macrolepis, Piabina argentea, Poptella brevispina, Probolus heterostomus, Rhinobrycon negrensis, Serrabrycon magoi, Tetragonopterus argenteus e Triportheus albus.

\section{[1] - bem desenvolvidas.}

Catostomus commersonnii, Gymnotus aff. carapo, Citharinus latus, Distichodus notospilus, Hemistichodus vaillanti, Neolebias unifasciatus, Nannocharax fasciatus, Xenocharax spilurus, Apareiodon piracicabae, Parodon nasus, Saccodon wagneri, Anodus orinocensis, 
Curimatopsis macrolepis, Potamorhina latior, Prochilodus nigricans, Semaprochilodus insignis, Leporinus fasciatus, Acestrorhynchus falcirostris, Erythrinoidea fam. nov, Copeina cf. guttata, Lebiasina bimaculata, Piabucina astrigata, Erythrinus erythrinus, Hoplias malabaricus, Hepsetus odoe, Arnoldichthys spilopterus, Brycinus macrolepidotus, Bryconalestes longipinnis, Chalceus epakros, Crenuchus spilurus, Aphyocharax pusillus, Astyanax mexicanus, Brycon pesu, Ctenobrycon hauxwellianus, Metynnis lippincottianus e Myleus setiger.

\section{[-] - inaplicável.}

olivaichthys mesembrinus.

[?] - indeterminado.

Brittanichthys axelrodi, Glandulocauda melanogenys, Piaractus mesopotamicus, Rachoviscus graciliceps, Rhoadsia altipinna, Roeboexodon guyanensis, Salminus hilarii e Stygichthys typhlops.

\section{4 - Forma dos circuli da porção posterior das escamas: [ZANATA, 2000: 132, modificado]}

\section{[0] - acompanhando a margem da escama.}

Catostomus commersonnii, Gymnotus aff. carapo, Citharinus latus, Hemistichodus vaillanti, Neolebias unifasciatus, Nannocharax fasciatus, Xenocharax spilurus, Anodus orinocensis, Curimata ocellata, Curimatopsis macrolepis, Potamorhina latior, Acestrorhynchus falcirostris, Gilbertolus atratoensis, Erythrinoidea fam. nov, Ctenobrycon hauxwellianus, Metynnis lippincottianus e Myleus setiger.

\section{[1] - direcionados para a margem posterior.}

Distichodus notospilus, Apareiodon piracicabae, Parodon nasus, Saccodon wagneri, Semaprochilodus insignis, Anostomus anostomus, Copeina cf. guttata, Lebiasina bimaculata, Piabucina astrigata, Erythrinus erythrinus, Hoplias malabaricus, Arnoldichthys spilopterus, Brycinus macrolepidotus, Characidium bahiensis, Crenuchus spilurus, Aphyocharax pusillus, Astyanax mexicanus, Brycon pesu.

\section{[2] - irregulares.}

Prochilodus nigricans, Leporellus vittatus, Leporinus fasciatus, Hepsetus odoe, Bryconalestes longipinnis e Chalceus epakros.

\section{[-] - inaplicável.}

Chanos chanos, Olivaichthys mesembrinus, Bivibranchia fowleri, Hemiodus unimaculatus, Caenotropus labyrinthicus, Chilodus punctatus, schizodon fasciatus, Carnegiella strigata, Gasteropelecus sternicla, Thoracocharax stellatus, Hydrolycus tatauaia, Roestes molossus, Boulengerella maculata, Ctenolucius hujeta, Agoniates halecinus, Atopomesus pachyodus, Axelrodia reisei, Bryconadenos tanaothoros, Bryconamericus exodon, Bryconops alburnoides, Charax cf. leticiae, Clupeacharax cf. engrauloides, Compsura heterura, Deuterodon iguape, Diapoma terofali, Galeocharax knerii, Gnathocharax steindachneri, Gymnocorymbus ternetzi, Hemibrycon polyodon, Hemigrammus unilineatus, Hollandichthys multifasciatus, Hyphessobrycon compressus, Iguanodectes geisleri, Knodus meridae, Landonia latidens, Markiana nigripinnis, Microschemobrycon casiquiare, Moenkhausia xinguensis, Odontostilbe pequira, Oligosarcus argenteus, orthospinus franciscoensis, Paracheirodon axelrodi, Paragoniates alburnus, Phenacogaster pectinatus, Phenagoniates macrolepis, Piabina argentea, Poptella brevispina, Probolus heterostomus,, Rhinobrycon negrensis, Serrabrycon magoi, Tetragonopterus argenteus e Triportheus albus.

\section{[?] - indeterminado.}

Brittanichthys axelrodi, Glandulocauda melanogenys, Piaractus mesopotamicus, Rachoviscus graciliceps, Rhoadsia altipinna, Roeboexodon guyanensis, Salminus hilarii e Stygichthys typhlops.

365 - Radii:

[ZANATA, 2000: 133; e NetTo-FerReira, 2006: 283, modificado] 


\section{[0] - reduzidos ou ausentes.}

Hemistichodus vaillanti, Neolebias unifasciatus, Nannocharax fasciatus, Xenocharax spilurus, Bivibranchia fowleri, Curimata ocellata, Potamorhina latior, Acestrorhynchus falcirostris, Gilbertolus atratoensis, Hydrolycus tatauaia, Roestes molossus, Charax cf. leticiae, Galeocharax knerii, Hyphessobrycon compressus, Iguanodectes geisleri, Landonia latidens, Markiana nigripinnis, Metynnis lippincottianus e Myleus setiger.

\section{[1] - presentes.}

Chanos chanos, Catostomus commersonnii, Gymnotus aff. carapo, Citharinus latus, Distichodus notospilus, Apareiodon piracicabae, Parodon nasus, Saccodon wagneri, Anodus orinocensis, Hemiodus unimaculatus, Curimatopsis macrolepis, Prochilodus nigricans, Semaprochilodus insignis, Caenotropus labyrinthicus, Chilodus punctatus, Anostomus anostomus, Leporellus vittatus, Leporinus fasciatus, Schizodon fasciatus, Carnegiella strigata, Gasteropelecus sternicla, Thoracocharax stellatus, Erythrinoidea fam. nov, Boulengerella maculata, Ctenolucius hujeta, Copeina cf. guttata, Lebiasina bimaculata, Piabucina astrigata, Erythrinus erythrinus, Hoplias malabaricus, Hepsetus odoe, Arnoldichthys spilopterus, Brycinus macrolepidotus, Bryconalestes longipinnis, Chalceus epakros, Characidium bahiensis, Crenuchus spilurus, Agoniates halecinus, Aphyocharax pusillus, Astyanax mexicanus, Atopomesus pachyodus, Axelrodia reisei, Brycon pesu, Bryconadenos tanaothoros, Bryconamericus exodon, Bryconops alburnoides, Clupeacharax cf. engrauloides, Compsura heterura, Ctenobrycon hauxwellianus, Deuterodon iguape, Diapoma terofali, Gnathocharax steindachneri, Gymnocorymbus ternetzi, Hemibrycon polyodon, Hemigrammus unilineatus, Hollandichthys multifasciatus, Knodus meridae, Microschemobrycon casiquiare, Moenkhausia xinguensis, Odontostilbe pequira, oligosarcus argenteus, Orthospinus franciscoensis, Paracheirodon axelrodi, Paragoniates alburnus, Phenacogaster pectinatus, Phenagoniates macrolepis, Piabina argentea, Poptella brevispina, Probolus heterostomus, Rhinobrycon negrensis, serrabrycon magoi, Tetragonopterus argenteus e Triportheus albus.

\section{[-] - inaplicável.}

Olivaichthys mesembrinus.

\section{[?] - indeterminado.}

Brittanichthys axelrodi, Glandulocauda melanogenys, Piaractus mesopotamicus, Rachoviscus graciliceps, Rhoadsia altipinna, Roeboexodon guyanensis, Salminus hilarii, Stygichthys typhlops.

366 - Posição dos Radii:

[ZANATA, 2000: 134]

\section{[0] - restrito à porção posterior da escama.}

Chanos chanos, Citharinus latus, Distichodus notospilus, Anodus orinocensis, Hemiodus unimaculatus, Curimatopsis macrolepis, Caenotropus labyrinthicus, Chilodus punctatus, Gasteropelecus sternicla, Gilbertolus atratoensis, Characidium bahiensis, crenuchus spilurus, Agoniates halecinus, Aphyocharax pusillus, Astyanax mexicanus, Atopomesus pachyodus, Axelrodia reisei, Bryconadenos tanaothoros, Bryconamericus exodon, Bryconops alburnoides, Clupeacharax cf. engrauloides, Compsura heterura, Ctenobrycon hauxwellianus, Deuterodon iguape, Diapoma terofali, Gnathocharax steindachneri, Gymnocorymbus ternetzi, Hemibrycon polyodon, Hemigrammus unilineatus, Hollandichthys multifasciatus, Knodus meridae, Microschemobrycon casiquiare, odontostilbe pequira, Orthospinus franciscoensis, Paracheirodon axelrodi, Paragoniates alburnus, Phenacogaster pectinatus, Phenagoniates macrolepis, Piabina argentea, Poptella brevispina, Probolus heterostomus, Rhinobrycon negrensis, Serrabrycon magoi e Tetragonopterus argenteus.

[1] - origem no centro da escama, anterior e posteriormente direcionados.

Catostomus commersonnii, Gymnotus aff. carapo, Apareiodon piracicabae, Parodon nasus, Saccodon wagneri, Prochilodus nigricans, Semaprochilodus insignis, Anostomus anostomus, Leporellus vittatus, Leporinus fasciatus, Schizodon fasciatus, Carnegiella strigata, Thoracocharax stellatus, Erythrinoidea fam. nov, Boulengerella maculata, Ctenolucius hujeta, Copeina cf. guttata, Lebiasina bimaculata, Piabucina astrigata, Erythrinus erythrinus, Hoplias malabaricus, Hepsetus odoe, Arnoldichthys spilopterus, Brycinus 
macrolepidotus, Bryconalestes longipinnis, Chalceus epakros, Brycon pesu, Moenkhausia xinguensis, Oligosarcus argenteus e Triportheus albus.

\section{[-] - inaplicável.}

olivaichthys mesembrinus, Hemistichodus vaillanti, Neolebias unifasciatus, Nannocharax fasciatus, Xenocharax spilurus, Bivibranchia fowleri, Curimata ocellata, Potamorhina latior, Acestrorhynchus falcirostris, Hydrolycus tatauaia, Roestes molossus, Charax cf. leticiae, Galeocharax knerii, Hyphessobrycon compressus, Iguanodectes geisleri, Landonia latidens, Markiana nigripinnis, Metynnis lippincottianus e Myleus setiger.

\section{[?] - indeterminado.}

Brittanichthys axelrodi, Glandulocauda melanogenys, Piaractus mesopotamicus, Rachoviscus graciliceps, Rhoadsia altipinna, Roeboexodon guyanensis, Salminus hilarii e Stygichthys typhlops.

367 - Anostomose nos Radii:

[ZANATA, 2000: 135; e NetTo-FERREIRA, 2006: 284]

\section{[0] - ausente.}

Chanos chanos, Catostomus commersonnii, Citharinus latus, Anodus orinocensis, Hemiodus unimaculatus, Curimatopsis macrolepis, Semaprochilodus insignis, Caenotropus labyrinthicus, Chilodus punctatus, Gasteropelecus sternicla, Gilbertolus atratoensis, Erythrinoidea fam. nov, Hepsetus odoe, Arnoldichthys spilopterus, Brycinus macrolepidotus, Characidium bahiensis, Crenuchus spilurus, Aphyocharax pusillus, Astyanax mexicanus, Atopomesus pachyodus, Axelrodia reisei, Bryconadenos tanaothoros, Bryconamericus exodon, Clupeacharax cf. engrauloides, Compsura heterura, Ctenobrycon hauxwellianus, Deuterodon iguape, Diapoma terofali, Gnathocharax steindachneri, Gymnocorymbus ternetzi, Hemibrycon polyodon, Hemigrammus unilineatus, Hollandichthys multifasciatus, Knodus meridae, Microschemobrycon casiquiare, Odontostilbe pequira, orthospinus franciscoensis, Paracheirodon axelrodi, Phenacogaster pectinatus, Phenagoniates macrolepis, Piabina argentea, Poptella brevispina, Probolus heterostomus, Rhinobrycon negrensis, Serrabrycon magoi e Tetragonopterus argenteus.

\section{[1] - presente.}

Gymnotus aff. carapo, Distichodus notospilus, Apareiodon piracicabae, Parodon nasus, Saccodon wagneri, Prochilodus nigricans, Anostomus anostomus, Leporellus vittatus, Leporinus fasciatus, Schizodon fasciatus, Carnegiella strigata, Thoracocharax stellatus , Boulengerella maculata, Ctenolucius hujeta, Copeina cf. guttata, Lebiasina bimaculata, Piabucina astrigata, Erythrinus erythrinus, Hoplias malabaricus, Bryconalestes longipinnis, Chalceus epakros, Agoniates halecinus, Brycon pesu, Bryconops alburnoides, Moenkhausia xinguensis, Oligosarcus argenteus, Paragoniates alburnus e Triportheus albus.

\section{[-] - inaplicável.}

Olivaichthys mesembrinus, Hemistichodus vaillanti, Neolebias unifasciatus, Nannocharax fasciatus, Xenocharax spilurus, Bivibranchia fowleri, Curimata ocellata, Potamorhina latior, Acestrorhynchus falcirostris, Hydrolycus tatauaia, Roestes molossus, Charax cf. leticiae, Galeocharax knerii, Hyphessobrycon compressus, Iguanodectes geisleri, Landonia latidens, Markiana nigripinnis, Metynnis lippincottianus e Myleus setiger.

\section{[?] - indeterminado.}

Brittanichthys axelrodi, Glandulocauda melanogenys, Piaractus mesopotamicus, Rachoviscus graciliceps, Rhoadsia altipinna, Roeboexodon guyanensis, Salminus hilarii e Stygichthys typhlops.

368 - Orientação dos Radii:

[ZANATA, 2000: 136]

\section{[0] - divergentes.}


Chanos chanos, Catostomus commersonnii, Gymnotus aff. carapo, Citharinus latus, Apareiodon piracicabae, Parodon nasus, Saccodon wagneri, Anodus orinocensis, Hemiodus unimaculatus, Curimatopsis macrolepis, Prochilodus nigricans, Semaprochilodus insignis, Caenotropus labyrinthicus, Chilodus punctatus, Anostomus anostomus, Leporellus vittatus, Leporinus fasciatus, Schizodon fasciatus, Carnegiella strigata, Gasteropelecus sternicla, Thoracocharax stellatus, Gilbertolus atratoensis, Erythrinoidea fam. nov, Boulengerella maculata, ctenolucius hujeta, Copeina cf. guttata, Lebiasina bimaculata, Piabucina astrigata, Erythrinus erythrinus, Hoplias malabaricus, Hepsetus odoe, Arnoldichthys spilopterus, Brycinus macrolepidotus, Bryconalestes longipinnis, Chalceus epakros, Characidium bahiensis, Crenuchus spilurus, Agoniates halecinus, Aphyocharax pusillus, Astyanax mexicanus, Atopomesus pachyodus, Axelrodia reisei, Brycon pesu, Bryconadenos tanaothoros, Bryconamericus exodon, Clupeacharax cf. engrauloides, Compsura heterura, Ctenobrycon hauxwellianus, Deuterodon iguape, Diapoma terofali, Gnathocharax steindachneri, Gymnocorymbus ternetzi, Hemibrycon polyodon, Hemigrammus unilineatus, Hollandichthys multifasciatus, Knodus meridae, Microschemobrycon casiquiare, Moenkhausia xinguensis, Odontostilbe pequira, oligosarcus argenteus, Orthospinus franciscoensis, Paracheirodon axelrodi, Paragoniates alburnus, Phenacogaster pectinatus, Phenagoniates macrolepis, Piabina argentea, Poptella brevispina, Probolus heterostomus , Rhinobrycon negrensis, Serrabrycon magoi, Tetragonopterus argenteus e Triportheus albus.

\section{[1] - convergentes.}

Distichodus notospilus, Bryconops alburnoides.

\section{[-] - inaplicável.}

Olivaichthys mesembrinus, Hemistichodus vaillanti, Neolebias unifasciatus, Nannocharax fasciatus, Xenocharax spilurus, Bivibranchia fowleri, Curimata ocellata, Potamorhina latior, Acestrorhynchus falcirostris, Hydrolycus tatauaia, Roestes molossus, Charax cf. leticiae, Galeocharax knerii, Hyphessobrycon compressus, Iguanodectes geisleri, Landonia latidens, Markiana nigripinnis, Metynnis lippincottianus e Myleus setiger.

\section{[?] - indeterminado.}

Brittanichthys axelrodi, Glandulocauda melanogenys, Piaractus mesopotamicus, Rachoviscus graciliceps, Rhoadsia altipinna, Roeboexodon guyanensis, Salminus hilarii e Stygichthys typhlops.

\section{9 - Posição do Focus:}

\section{[0] - na porção anterior da escama.}

Citharinus latus, Anodus orinocensis, Curimata ocellata, Curimatopsis macrolepis, Leporinus fasciatus, Gilbertolus atratoensis, Hepsetus odoe, Bryconalestes longipinnis, Characidium bahiensis, Crenuchus spilurus, Agoniates halecinus, Aphyocharax pusillus, Astyanax mexicanus, Atopomesus pachyodus, Axelrodia reisei, Bryconadenos tanaothoros, Bryconamericus exodon, Bryconops alburnoides, Charax cf. leticiae, Clupeacharax cf. engrauloides, Compsura heterura, Deuterodon iguape, Diapoma terofali, Gnathocharax steindachneri, Gymnocorymbus ternetzi, Hemibrycon polyodon, Hemigrammus unilineatus, Hollandichthys multifasciatus, Hyphessobrycon compressus, Iguanodectes geisleri, Landonia latidens, Metynnis lippincottianus, Moenkhausia xinguensis, odontostilbe pequira, oligosarcus argenteus, orthospinus franciscoensis, Paracheirodon axelrodi, Paragoniates alburnus, Phenacogaster pectinatus, Phenagoniates macrolepis, Piabina argentea, Poptella brevispina, Probolus heterostomus, Rhinobrycon negrensis e Serrabrycon magoi.

\section{[1] - aproximadamente mediano.}

Chanos chanos, Catostomus commersonnii, Gymnotus aff. carapo, Hemistichodus vaillanti, Apareiodon piracicabae, Parodon nasus, Saccodon wagneri, Bivibranchia fowleri, Potamorhina latior, Prochilodus nigricans, Semaprochilodus insignis, Caenotropus labyrinthicus, Chilodus punctatus, Anostomus anostomus, Leporellus vittatus, Schizodon fasciatus, Carnegiella strigata, Gasteropelecus sternicla, Thoracocharax stellatus , Acestrorhynchus falcirostris, Hydrolycus tatauaia, Roestes molossus, Erythrinoidea fam. nov, Copeina cf. guttata, Lebiasina bimaculata, Piabucina astrigata, Erythrinus erythrinus, Hoplias malabaricus, Arnoldichthys spilopterus, Brycinus macrolepidotus, Chalceus epakros, Brycon pesu, Ctenobrycon hauxwellianus, Galeocharax knerii, Knodus meridae, Microschemobrycon casiquiare, Myleus setiger, Tetragonopterus argenteus e Triportheus albus.

[2] - na porção posterior da escama. 
Distichodus notospilus, Neolebias unifasciatus, Nannocharax fasciatus, Xenocharax spilurus, Hemiodus unimaculatus, Boulengerella maculata, Ctenolucius hujeta e Markiana nigripinnis.

\section{[-] - inaplicável.}

olivaichthys mesembrinus.

\section{[?] - indeterminado.}

Brittanichthys axelrodi, Glandulocauda melanogenys, Piaractus mesopotamicus, Rachoviscus graciliceps, Rhoadsia altipinna, Roeboexodon guyanensis, Salminus hilarii e Stygichthys typhlops.

\section{0 - Escamas da série medio ventral: (Minimamente conectado).}

\section{[0] - como demais escamas.}

Chanos chanos, Catostomus commersonnii, Gymnotus aff. carapo, Citharinus latus, Distichodus notospilus, Hemistichodus vaillanti, Neolebias unifasciatus, Nannocharax fasciatus, Xenocharax spilurus, Apareiodon piracicabae, Parodon nasus, Saccodon wagneri, Anodus orinocensis, Bivibranchia fowleri, Hemiodus unimaculatus , Curimata ocellata, Curimatopsis macrolepis, Potamorhina latior, Prochilodus nigricans, Semaprochilodus insignis, Caenotropus labyrinthicus, Chilodus punctatus, Anostomus anostomus, Leporellus vittatus, Leporinus fasciatus, Schizodon fasciatus, Carnegiella strigata, Gasteropelecus sternicla, Thoracocharax stellatus, Acestrorhynchus falcirostris, Gilbertolus atratoensis, Hydrolycus tatauaia, Roestes molossus, Erythrinoidea fam. nov, Boulengerella maculata, Ctenolucius hujeta, Copeina cf. guttata, Lebiasina bimaculata, Piabucina astrigata, Erythrinus erythrinus, Hoplias malabaricus, Hepsetus odoe, Arnoldichthys spilopterus, Brycinus macrolepidotus, Bryconalestes longipinnis, Chalceus epakros, Characidium bahiensis, Crenuchus spilurus, Agoniates halecinus, Aphyocharax pusillus, Astyanax mexicanus, Atopomesus pachyodus, Axelrodia reisei, Brittanichthys axelrodi, Brycon pesu, Bryconadenos tanaothoros, Bryconamericus exodon, Bryconops alburnoides, Charax cf. leticiae, Clupeacharax cf. engrauloides, Compsura heterura, ctenobrycon hauxwellianus, Deuterodon iguape, Diapoma terofali, Galeocharax knerii, Glandulocauda melanogenys, Gnathocharax steindachneri, Gymnocorymbus ternetzi, Hemibrycon polyodon, Hemigrammus unilineatus, Hollandichthys multifasciatus, Hyphessobrycon compressus, Iguanodectes geisleri, Knodus meridae, Landonia latidens, Markiana nigripinnis, Microschemobrycon casiquiare, Moenkhausia xinguensis, odontostilbe pequira, Oligosarcus argenteus, Orthospinus franciscoensis, Paracheirodon axelrodi, Paragoniates alburnus, Phenacogaster pectinatus, Phenagoniates macrolepis, Piabina argentea, Poptella brevispina, Probolus heterostomus, Rachoviscus graciliceps, Rhinobrycon negrensis, Rhoadsia altipinna, Roeboexodon guyanensis, Salminus hilarii, Serrabrycon magoi, Stygichthys typhlops, Tetragonopterus argenteus e Triportheus albus.

\section{[1] - modificadas com espinhos.}

Metynnis lippincottianus, Myleus setiger e Piaractus mesopotamicus.

\section{[-] - inaplicável.}

olivaichthys mesembrinus.

\subsubsection{Bexiga natatória e trato digestivo}

371 - porção posterior da câmara posterior da bexiga natatória: [ZANATA, 2000: 119, modificado]

\section{[0] - arredondada.}

Catostomus commersonnii, Hemistichodus vaillanti, Nannocharax fasciatus, Xenocharax spilurus, Carnegiella strigata, Gasteropelecus sternicla, Thoracocharax stellatus, Arnoldichthys spilopterus, Brycinus macrolepidotus, Bryconalestes longipinnis, Aphyocharax pusillus, Astyanax mexicanus, Atopomesus pachyodus, Axelrodia reisei, Bryconamericus exodon, Charax cf. leticiae, clupeacharax cf. engrauloides, Compsura 
heterura, Ctenobrycon hauxwellianus, Deuterodon iguape, Galeocharax knerii, Glandulocauda melanogenys, Gnathocharax steindachneri, Gymnocorymbus ternetzi, Hemibrycon polyodon, Hollandichthys multifasciatus, Iguanodectes geisleri, Knodus meridae, Markiana nigripinnis, odontostilbe pequira, oligosarcus argenteus, orthospinus franciscoensis, Paracheirodon axelrodi, Paragoniates alburnus, Phenacogaster pectinatus, Phenagoniates macrolepis, Piabina argentea, Probolus heterostomus, Rhinobrycon negrensis, Roeboexodon guyanensis, Serrabrycon magoi e stygichthys typhlops.

\section{[1] - pontuda.}

Gymnotus aff. carapo, Citharinus latus, Distichodus notospilus, Neolebias unifasciatus, Apareiodon piracicabae, Parodon nasus, Anodus orinocensis, Bivibranchia fowleri, Hemiodus unimaculatus, Curimata ocellata, Curimatopsis macrolepis, Potamorhina latior, Prochilodus nigricans, Semaprochilodus insignis, Caenotropus labyrinthicus, Chilodus punctatus, Anostomus anostomus, Leporellus vittatus, Leporinus fasciatus, Schizodon fasciatus, Acestrorhynchus falcirostris, Hydrolycus tatauaia, Boulengerella maculata, Ctenolucius hujeta, Copeina cf. guttata, Lebiasina bimaculata, Piabucina astrigata, Erythrinus erythrinus, Hoplias malabaricus, Hepsetus odoe, Chalceus epakros, characidium bahiensis, Crenuchus spilurus, Agoniates halecinus, Brycon pesu, Bryconops alburnoides, Metynnis lippincottianus, Moenkhausia xinguensis, Myleus setiger, Poptella brevispina, Salminus hilarii, Tetragonopterus argenteus e Triportheus albus.

\section{[?] - indeterminado.}

Chanos chanos, Olivaichthys mesembrinus, Saccodon wagnerigilbertolus atratoensis, Roestes molossus, Erythrinoidea fam. nov., Brittanichthys axelrodi, Bryconadenos tanaothoros, Diapoma terofali, Hemigrammus unilineatus, Hyphessobrycon compressus, Landonia latidens, Microschemobrycon casiquiare, Piaractus mesopotamicus, Rachoviscus graciliceps e Rhoadsia altipinna.

\section{2 - Término da câmara posterior da bexiga natatória: [ZANATA \& VARI, 2005: 200]}

\section{[0] - acompanhando a forma da bexiga.}

Catostomus commersonnii, Gymnotus aff. carapo, Citharinus latus, Distichodus notospilus, Hemistichodus vaillanti, Neolebias unifasciatus, Xenocharax spilurus, curimatopsis macrolepis, Carnegiella strigata, Gasteropelecus sternicla, Thoracocharax stellatus , ctenolucius hujeta, Copeina cf. guttata, Lebiasina bimaculata, Erythrinus erythrinus, Hepsetus odoe, Arnoldichthys spilopterus, Brycinus macrolepidotus, Bryconalestes longipinnis, Characidium bahiensis, Crenuchus spilurus, Aphyocharax pusillus, Astyanax mexicanus, Atopomesus pachyodus, Axelrodia reisei, Bryconamericus exodon, Charax cf. leticiae, clupeacharax cf. engrauloides, Compsura heterura, Ctenobrycon hauxwellianus, Deuterodon iguape, Galeocharax knerii, Glandulocauda melanogenys, Gnathocharax steindachneri, Gymnocorymbus ternetzi, Hemibrycon polyodon , Hollandichthys multifasciatus, Iguanodectes geisleri, Knodus meridae, Markiana nigripinnis, Moenkhausia xinguensis, Odontostilbe pequira, oligosarcus argenteus, Orthospinus franciscoensis, Paracheirodon axelrodi, Paragoniates alburnus, Phenacogaster pectinatus, Phenagoniates macrolepis, Piabina argentea, Poptella brevispina, Probolus heterostomus, Rhinobrycon negrensis, Roeboexodon guyanensis, Salminus hilarii, Serrabrycon magoi e stygichthys typhlops.

\section{[1] - formando uma ponta afilada.}

Apareiodon piracicabae, Parodon nasus, Anodus orinocensis, Bivibranchia fowleri, Hemiodus unimaculatus, Curimata ocellata, Potamorhina latior, Prochilodus nigricans, Semaprochilodus insignis, Caenotropus labyrinthicus, Chilodus punctatus, Anostomus anostomus, Leporellus vittatus, Leporinus fasciatus, schizodon fasciatus, Acestrorhynchus falcirostris, Hydrolycus tatauaia, Boulengerella maculata, Piabucina astrigata, Hoplias malabaricus, Chalceus epakros, Agoniates halecinus, Brycon pesu, Bryconops alburnoides, Metynnis lippincottianus, Myleus setiger, Tetragonopterus argenteus e Triportheus albus.

\section{[?] - indeterminado.}

Chanos chanos, Olivaichthys mesembrinus, Nannocharax fasciatus, Saccodon wagneri, Gilbertolus atratoensis, Roestes molossus, Erythrinoidea fam. nov., Brittanichthys axelrodi, Bryconadenos tanaothoros, Diapoma terofali, Hemigrammus unilineatus, Hyphessobrycon compressus, Landonia latidens, Microschemobrycon casiquiare, Piaractus mesopotamicus, Rachoviscus graciliceps e Rhoadsia altipinna. 


\section{3 - Câmara posterior da bexiga natória:}

\section{[0] - reta.}

Catostomus commersonnii, Gymnotus aff. carapo, Distichodus notospilus, Hemistichodus vaillanti, Neolebias unifasciatus, Nannocharax fasciatus, Xenocharax spilurus, Apareiodon piracicabae, Parodon nasus, Anodus orinocensis, Bivibranchia fowleri, Hemiodus unimaculatus, Curimata ocellata, Curimatopsis macrolepis, Potamorhina latior, Prochilodus nigricans, Semaprochilodus insignis, Caenotropus labyrinthicus, Chilodus punctatus, Anostomus anostomus, Leporellus vittatus, Leporinus fasciatus, Schizodon fasciatus, Carnegiella strigata, Gasteropelecus sternicla, Thoracocharax stellatus, Acestrorhynchus falcirostris, Hydrolycus tatauaia, Erythrinoidea fam. nov, Boulengerella maculata, Ctenolucius hujeta, Copeina cf. guttata, Lebiasina bimaculata, Piabucina astrigata, Erythrinus erythrinus, Hoplias malabaricus, Hepsetus odoe, Arnoldichthys spilopterus, Brycinus macrolepidotus, Bryconalestes longipinnis, Chalceus epakros, Characidium bahiensis, Crenuchus spilurus, Agoniates halecinus, Aphyocharax pusillus, Atopomesus pachyodus, Axelrodia reisei, Brycon pesu, Bryconamericus exodon, Bryconops alburnoides, Charax cf. leticiae, Clupeacharax cf. engrauloides, Deuterodon iguape, Hemibrycon polyodon, Iguanodectes geisleri, Knodus meridae, Paracheirodon axelrodi, Piabina argentea, Rhinobrycon negrensis, Roeboexodon guyanensis, Salminus hilarii, Serrabrycon magoi, stygichthys typhlops e Triportheus albus.

\section{[1] - curvada ventralmente.}

Citharinus latus, Astyanax mexicanus, Compsura heterura, Ctenobrycon hauxwellianus, Galeocharax knerii, Glandulocauda melanogenys, Gnathocharax steindachneri, Gymnocorymbus ternetzi, Hollandichthys multifasciatus, Markiana nigripinnis, Metynnis lippincottianus, Moenkhausia xinguensis, Myleus setiger, Odontostilbe pequira, oligosarcus argenteus, Orthospinus franciscoensis, Paragoniates alburnus, Phenacogaster pectinatus, Phenagoniates macrolepis, Poptella brevispina, Probolus heterostomus e Tetragonopterus argenteus.

\section{[?] - indeterminado.}

Chanos chanos, Olivaichthys mesembrinus, Saccodon wagneri, Gilbertolus atratoensis, Roestes molossus, Brittanichthys axelrodi, Bryconadenos tanaothoros, Diapoma terofali, Hemigrammus unilineatus, Hyphessobrycon compressus, Landonia latidens, Microschemobrycon casiquiare, Piaractus mesopotamicus, Rachoviscus graciliceps e Rhoadsia altipinna.

\section{4 - Extensão da bexiga natatória:}

\section{[0] - anterior à nadadeira anal.}

Catostomus commersonnii, Citharinus latus, Distichodus notospilus, Hemistichodus vaillanti, Neolebias unifasciatus, Nannocharax fasciatus, Xenocharax spilurus, Apareiodon piracicabae, Parodon nasus, Curimatopsis macrolepis, Prochilodus nigricans, Semaprochilodus insignis, Anostomus anostomus, Leporellus vittatus, Leporinus fasciatus, Carnegiella strigata, Gasteropelecus sternicla, Thoracocharax stellatus Acestrorhynchus falcirostris, Hydrolycus tatauaia, Erythrinoidea fam. nov, Boulengerella maculata, Ctenolucius hujeta, Copeina cf. guttata, Lebiasina bimaculata, Piabucina astrigata, Erythrinus erythrinus, Hoplias malabaricus, Hepsetus odoe, Arnoldichthys spilopterus, Brycinus macrolepidotus, Bryconalestes longipinnis, Chalceus epakros, Characidium bahiensis, Crenuchus spilurus, Agoniates halecinus, Aphyocharax pusillus, Astyanax mexicanus, Atopomesus pachyodus, Axelrodia reisei, Brycon pesu, Bryconamericus exodon, Bryconops alburnoides, Charax cf. leticiae, Clupeacharax cf. engrauloides, Compsura heterura, Ctenobrycon hauxwellianus, Deuterodon iguape, Galeocharax knerii, Glandulocauda melanogenys, Gnathocharax steindachneri, Gymnocorymbus ternetzi, Hemibrycon polyodon, Hollandichthys multifasciatus, Iguanodectes geisleri, Knodus meridae, Markiana nigripinnis, Metynnis lippincottianus, Moenkhausia xinguensis, odontostilbe pequira, oligosarcus argenteus, orthospinus franciscoensis, Paracheirodon axelrodi, Paragoniates alburnus, Phenacogaster pectinatus, Phenagoniates macrolepis, Piabina argentea, Poptella brevispina, Probolus heterostomus, Rhinobrycon negrensis, Roeboexodon guyanensis, Salminus hilarii, Serrabrycon magoi, stygichthys typhlops, Tetragonopterus argenteus e Triportheus albus.

\section{[1] - posterior à nadadeira anal.}


Gymnotus aff. carapo, Anodus orinocensis, Bivibranchia fowleri, Hemiodus unimaculatus, Curimata ocellata, Potamorhina latior, Caenotropus labyrinthicus, Chilodus punctatus, Schizodon fasciatus e Myleus setiger.

\section{[?] - indeterminado.}

Chanos chanos, Olivaichthys mesembrinus, Saccodon wagneri, Gilbertolus atratoensis, Roestes molossus, Brittanichthys axelrodi, Bryconadenos tanaothoros, Diapoma terofali, Hemigrammus unilineatus, Hyphessobrycon compressus, Landonia latidens, Microschemobrycon casiquiare, Piaractus mesopotamicus, Rachoviscus graciliceps e Rhoadsia altipinna.

\section{5 - Porção anterior da câmara posterior da bexiga natatória:}

\section{[0] - convexa.}

Catostomus commersonnii, Gymnotus aff. carapo, Distichodus notospilus, Hemistichodus vaillanti, Neolebias unifasciatus, Nannocharax fasciatus, Xenocharax spilurus, Apareiodon piracicabae, Parodon nasus, Hemiodus unimaculatus, Curimata ocellata, Curimatopsis macrolepis, Anostomus anostomus, Leporellus vittatus, Leporinus fasciatus, Erythrinoidea fam. nov, Copeina cf. guttata, Chalceus epakros, Aphyocharax pusillus, Astyanax mexicanus, Atopomesus pachyodus, Axelrodia reisei, Bryconamericus exodon, compsura heterura, Deuterodon iguape, Hemibrycon polyodon, Hollandichthys multifasciatus, Knodus meridae, Odontostilbe pequira, oligosarcus argenteus, Paracheirodon axelrodi, Phenacogaster pectinatus, Piabina argentea, Rhinobrycon negrensis e Stygichthys typhlops.

\section{[1] - inteiramente côncava.}

Carnegiella strigata, Gasteropelecus sternicla, Thoracocharax stellatus, Agoniates halecinus, Bryconops alburnoides, Paragoniates alburnus e Triportheus albus.

\section{[2] - côncava lateralmente.}

Anodus orinocensis, Potamorhina latior, Prochilodus nigricans, Semaprochilodus insignis, Schizodon fasciatus, Piabucina astrigata, Erythrinus erythrinus, Hoplias malabaricus, Brycinus macrolepidotus e Roeboexodon guyanensis.

\section{[3] - côncava dorsalmente.}

Caenotropus labyrinthicus, Chilodus punctatus, Acestrorhynchus falcirostris, Boulengerella maculata, Ctenolucius hujeta, Lebiasina bimaculata, Hoplias malabaricus, Hepsetus odoe, Arnoldichthys spilopterus, Bryconalestes longipinnis, Crenuchus spilurus, Brycon pesu, Charax cf. leticiae, clupeacharax cf. engrauloides, Ctenobrycon hauxwellianus, Glandulocauda melanogenys, Gnathocharax steindachneri, Gymnocorymbus ternetzi, Markiana nigripinnis, Moenkhausia xinguensis, orthospinus franciscoensis, Phenagoniates macrolepis, Poptella brevispina, Probolus heterostomus, Salminus hilarii e Tetragonopterus argenteus.

\section{[?] - indeterminado.}

Chanos chanos, Olivaichthys mesembrinus, Saccodon wagneri, Citharinus latus, Bivibranchia fowleri, Gilbertolus atratoensis, Hydrolycus tatauaia, Roestes molossus, Characidium bahiensis, Brittanichthys axelrodi, Bryconadenos tanaothoros, Diapoma terofali, Galeocharax knerii, Hemigrammus unilineatus, Hyphessobrycon compressus, Iguanodectes geisleri, Landonia latidens, Metynnis lippincottianus, Microschemobrycon casiquiare, Myleus setiger, Piaractus mesopotamicus, Rachoviscus graciliceps, Rhoadsia altipinna e Serrabrycon magoi.

\section{[1,2] - polimórfico.}

Hoplias malabaricus.

376 - Porção anterior da câmara anterior da bexiga natatória:

\section{[0] - arredondada.}


Neolebias unifasciatus, Curimatopsis macrolepis, Carnegiella strigata, Gasteropelecus sternicla, Thoracocharax stellatus, Erythrinoidea fam. nov, Boulengerella maculata, Ctenolucius hujeta, Copeina cf. guttata, Hepsetus odoe, Arnoldichthys spilopterus, Brycinus macrolepidotus, Bryconalestes longipinnis, Agoniates halecinus, Aphyocharax pusillus, Astyanax mexicanus, Brycon pesu, Clupeacharax cf. engrauloides, Compsura heterura, Ctenobrycon hauxwellianus, Deuterodon iguape, Galeocharax knerii, Gymnocorymbus ternetzi, Hollandichthys multifasciatus, Metynnis lippincottianus, Myleus setiger, odontostilbe pequira, orthospinus franciscoensis, Paragoniates alburnus, Poptella brevispina, Probolus heterostomus, Tetragonopterus argenteus e Triportheus albus.

[1] - reta, ou com protuberância pouco desenvolvidas.

Citharinus latus, Distichodus notospilus, Hemistichodus vaillanti, Nannocharax fasciatus, Apareiodon piracicabae, Parodon nasus, Saccodon wagneri, Hemiodus unimaculatus, Potamorhina latior, Prochilodus nigricans, Semaprochilodus insignis, Caenotropus labyrinthicus, Chilodus punctatus, Leporellus vittatus, Leporinus fasciatus, Lebiasina bimaculata, Piabucina astrigata, Erythrinus erythrinus, Hoplias malabaricus, Chalceus epakros, Characidium bahiensis, Crenuchus spilurus, Atopomesus pachyodus, Axelrodia reisei, Bryconamericus exodon, Bryconops alburnoides, Charax cf. leticiae, Gnathocharax steindachneri, Hemibrycon polyodon, Iguanodectes geisleri, Knodus meridae, Markiana nigripinnis, Moenkhausia xinguensis, oligosarcus argenteus, Paracheirodon axelrodi, Phenacogaster pectinatus, Phenagoniates macrolepis, Piabina argentea, Rhinobrycon negrensis, Roeboexodon guyanensis, Salminus hilarii, Serrabrycon magoi e Stygichthys typhlops.

\section{[2] - com duas protuberâncias arredondadas.}

Catostomus commersonnii, Gymnotus aff. carapo, Xenocharax spilurus, Anodus orinocensis, Bivibranchia fowleri, Curimata ocellata, Schizodon fasciatus e Hydrolycus tatauaia.

\section{[?] - indeterminado.}

Chanos chanos, Olivaichthys mesembrinus, Anostomus anostomus, Acestrorhynchus falcirostris, Gilbertolus atratoensis, Roestes molossus, Brittanichthys axelrodi, Bryconadenos tanaothoros, Diapoma terofali, Glandulocauda melanogenys, Hemigrammus unilineatus, Hyphessobrycon compressus, Landonia latidens, Microschemobrycon casiquiare, Piaractus mesopotamicus, Rachoviscus graciliceps e Rhoadsia altipinna.

\section{7 - Altura das câmaras da bexiga natatória:}

\section{[0] - altura da câmara anterior maior que posterior.}

Gymnotus aff. carapo, Hemistichodus vaillanti, Neolebias unifasciatus, Nannocharax fasciatus, Parodon nasus, Prochilodus nigricans, Leporellus vittatus, Carnegiella strigata, Gasteropelecus sternicla, Thoracocharax stellatus, Hepsetus odoe, Agoniates halecinus, Astyanax mexicanus, Brycon pesu, Bryconamericus exodon, Bryconops alburnoides, Clupeacharax cf. engrauloides e Myleus setiger.

\section{[1] - da mesma altura.}

Catostomus commersonnii, Apareiodon piracicabae, Curimatopsis macrolepis, Potamorhina latior, Semaprochilodus insignis, Anostomus anostomus, Leporinus fasciatus, Schizodon fasciatus, Acestrorhynchus falcirostris, Erythrinoidea fam. nov, Boulengerella maculata, Ctenolucius hujeta, Copeina cf. guttata, Lebiasina bimaculata, Piabucina astrigata, Erythrinus erythrinus, Hoplias malabaricus, Arnoldichthys spilopterus, Brycinus macrolepidotus, Bryconalestes longipinnis, Chalceus epakros, crenuchus spilurus, Aphyocharax pusillus, Axelrodia reisei, Compsura heterura, Deuterodon iguape, Glandulocauda melanogenys, Gnathocharax steindachneri, Hemibrycon polyodon Hollandichthys multifasciatus, Knodus meridae, Metynnis lippincottianus, Moenkhausia xinguensis, Odontostilbe pequira, Paracheirodon axelrodi, Phenagoniates macrolepis, Piabina argentea, Serrabrycon magoi, Stygichthys typhlops e Triportheus albus.

\section{[2] - altura da câmara posterior maior que anterior.}

Citharinus latus, Distichodus notospilus, Xenocharax spilurus, Anodus orinocensis, Bivibranchia fowleri, Hemiodus unimaculatus, Curimata ocellata, Caenotropus labyrinthicus, Chilodus punctatus, Hydrolycus tatauaia, characidium bahiensis, Atopomesus pachyodus, Charax cf. leticiae, ctenobrycon hauxwellianus, Galeocharax knerii, Gymnocorymbus ternetzi, Iguanodectes geisleri, Markiana nigripinnis, oligosarcus 
argenteus, orthospinus franciscoensis, Paragoniates alburnus, Phenacogaster pectinatus, Poptella brevispina, Probolus heterostomus, Rhinobrycon negrensis, Roeboexodon guyanensis, Salminus hilarii e Tetragonopterus argenteus.

\section{[?] - indeterminado.}

Chanos chanos, Olivaichthys mesembrinus, Saccodon wagneri, Gilbertolus atratoensis, Roestes molossus, Brittanichthys axelrodi, Bryconadenos tanaothoros, Diapoma terofali, Hemigrammus unilineatus, Hyphessobrycon compressus, Landonia latidens, Microschemobrycon casiquiare, Piaractus mesopotamicus, Rachoviscus graciliceps e Rhoadsia altipinna.

378 - Musculatura intrínseca da bexiga natatória:

[ZANATA, 2000: 120, modificado]

[0] - ausente.

Catostomus commersonnii, Gymnotus aff. carapo, Hemistichodus vaillanti, Neolebias unifasciatus, Nannocharax fasciatus, Bivibranchia fowleri, Curimatopsis macrolepis, Carnegiella strigata, Gasteropelecus sternicla, Thoracocharax stellatus, Erythrinoidea fam. nov, Boulengerella maculata, Copeina cf. guttata, Lebiasina bimaculata, Arnoldichthys spilopterus, Brycinus macrolepidotus, Bryconalestes longipinnis, Characidium bahiensis, Crenuchus spilurus, Aphyocharax pusillus, Astyanax mexicanus, Atopomesus pachyodus, Axelrodia reisei, Bryconamericus exodon, Charax cf. leticiae, Clupeacharax cf. engrauloides, Compsura heterura, Ctenobrycon hauxwellianus, Deuterodon iguape, Galeocharax knerii, Glandulocauda melanogenys, Gnathocharax steindachneri, Gymnocorymbus ternetzi, Hemibrycon polyodon, Hollandichthys multifasciatus, Iguanodectes geisleri, Knodus meridae, Odontostilbe pequira, Orthospinus franciscoensis, Paracheirodon axelrodi, Paragoniates alburnus, Phenacogaster pectinatus, Phenagoniates macrolepis, Piabina argentea, Poptella brevispina, Probolus heterostomus, Rhinobrycon negrensis, Roeboexodon guyanensis, Serrabrycon magoi, stygichthys typhlops, Tetragonopterus argenteus e Triportheus albus.

\section{[1] - formando uma faixa lateral.}

Hemiodus unimaculatus, Hydrolycus tatauaia e Erythrinus erythrinus.

\section{[2] - faixa bifurcada anteriormente.}

Citharinus latus, Distichodus notospilus, Xenocharax spilurus, Apareiodon piracicabae, Parodon nasus, Anodus orinocensis, Curimata ocellata, Potamorhina latior, Prochilodus nigricans, Semaprochilodus insignis, Caenotropus labyrinthicus, Chilodus punctatus, Anostomus anostomus, Leporellus vittatus, Leporinus fasciatus, Schizodon fasciatus, Acestrorhynchus falcirostris, Ctenolucius hujeta, Piabucina astrigata, Hoplias malabaricus, Hepsetus odoe, Chalceus epakros, Agoniates halecinus, Brycon pesu, Bryconops alburnoides, Moenkhausia xinguensis, Myleus setiger, Oligosarcus argenteus e Salminus hilarii.

\section{[?] - indeterminado.}

Chanos chanos, Olivaichthys mesembrinus, Saccodon wagneri, Gilbertolus atratoensis, Roestes molossus, Brittanichthys axelrodi, Bryconadenos tanaothoros, Diapoma terofali, Hemigrammus unilineatus, Hyphessobrycon compressus, Landonia latidens, Markiana nigripinnis, Metynnis lippincottianus, Microschemobrycon casiquiare, Piaractus mesopotamicus, Rachoviscus graciliceps e Rhoadsia altipinna.

\section{9 - Parede lateral da câmara anterior da bexiga natatória:}

$$
\text { [0] - reta. }
$$

Curimatopsis macrolepis, Prochilodus nigricans, Carnegiella strigata, Gasteropelecus sternicla, Thoracocharax stellatus, Acestrorhynchus falcirostris, Hydrolycus tatauaia, Erythrinoidea fam. nov, Boulengerella maculata, Ctenolucius hujeta, Erythrinus erythrinus, Hoplias malabaricus, Hepsetus odoe, Arnoldichthys spilopterus, Brycinus macrolepidotus, Agoniates halecinus, Astyanax mexicanus, Clupeacharax cf. engrauloides, Galeocharax knerii, Gymnocorymbus ternetzi, Markiana nigripinnis, Metynnis lippincottianus, Myleus setiger, Paragoniates alburnus, Tetragonopterus argenteus e Triportheus albus. 


\section{[1] - com constrição mediana.}

Gymnotus aff. carapo, Apareiodon piracicabae, Parodon nasus, Saccodon wagneri, Anodus orinocensis, Bivibranchia fowleri, Hemiodus unimaculatus, Curimata ocellata, Potamorhina latior, Semaprochilodus insignis, Caenotropus labyrinthicus, Anostomus anostomus, Leporellus vittatus, Leporinus fasciatus, schizodon fasciatus, crenuchus spilurus, Hemibrycon polyodon, Orthospinus franciscoensis, Poptella brevispina, Probolus heterostomus, Rhinobrycon negrensis, Roeboexodon guyanensis, Salminus hilarii e Serrabrycon magoi.

\section{[2] - convergindo posteriormente.}

Catostomus commersonnii, Citharinus latus, Distichodus notospilus, Hemistichodus vaillanti, Neolebias unifasciatus, Xenocharax spilurus, Chilodus punctatus, Copeina cf. guttata, Lebiasina bimaculata, Piabucina astrigata, Bryconalestes longipinnis, Chalceus epakros, Characidium bahiensis, Aphyocharax pusillus, Atopomesus pachyodus, Axelrodia reisei, Brycon pesu, Bryconamericus exodon, Bryconops alburnoides, Charax cf. leticiae, Ctenobrycon hauxwellianus, Deuterodon iguape, Gnathocharax steindachneri, Hollandichthys multifasciatus, Iguanodectes geisleri, Knodus meridae, Moenkhausia xinguensis, odontostilbe pequira, Oligosarcus argenteus, Paracheirodon axelrodi, Phenacogaster pectinatus, Phenagoniates macrolepis, Piabina argêntea e Stygichthys typhlops.

\section{[?] - indeterminado.}

Chanos chanos, Olivaichthys mesembrinus, Nannocharax fasciatus, Gilbertolus atratoensis, Roestes molossus, Brittanichthys axelrodi, Bryconadenos tanaothoros, Compsura heterura, Diapoma terofali, Glandulocauda melanogenys, Hemigrammus unilineatus, Hyphessobrycon compressus, Landonia latidens, Microschemobrycon casiquiare, Piaractus mesopotamicus, Rachoviscus graciliceps e Rhoadsia altipinna.

\section{0 - Conexão entre as câmaras da bexiga:}

\section{[0] - mediana.}

Catostomus commersonnii, Gymnotus aff. carapo, Citharinus latus, Distichodus notospilus, Hemistichodus vaillanti, Neolebias unifasciatus, Nannocharax fasciatus, Xenocharax spilurus, Bivibranchia fowleri, Hemiodus unimaculatus, Anostomus anostomus, Leporellus vittatus, Carnegiella strigata, Gasteropelecus sternicla, Thoracocharax stellatus, Hydrolycus tatauaia, Erythrinoidea fam. nov, Boulengerella maculata, Copeina cf. guttata, Erythrinus erythrinus, Aphyocharax pusillus, Astyanax mexicanus, Atopomesus pachyodus, Axelrodia reisei, Bryconamericus exodon, Charax cf. leticiae, Compsura heterura, Ctenobrycon hauxwellianus, Deuterodon iguape, Galeocharax knerii, Glandulocauda melanogenys, Gnathocharax steindachneri, Gymnocorymbus ternetzi Hemibrycon polyodon, Hollandichthys multifasciatus, Iguanodectes geisleri, Markiana nigripinnis, Moenkhausia xinguensis, Odontostilbe pequira, Oligosarcus argenteus, orthospinus franciscoensis, Paracheirodon axelrodi, Paragoniates alburnus, Phenacogaster pectinatus, Phenagoniates macrolepis, Piabina argentea, Poptella brevispina, Probolus heterostomus, Rhinobrycon negrensis, Roeboexodon guyanensis, Serrabrycon magoi, Stygichthys typhlops e Tetragonopterus argenteus.

\section{[1] - ventral.}

Apareiodon piracicabae, Parodon nasus, Anodus orinocensis, Curimata ocellata, curimatopsis macrolepis, Potamorhina latior, Prochilodus nigricans, Semaprochilodus insignis, Caenotropus labyrinthicus, Chilodus punctatus, Leporinus fasciatus, Schizodon fasciatus, Acestrorhynchus falcirostris, Ctenolucius hujeta, Lebiasina bimaculata, Piabucina astrigata, Hoplias malabaricus, Hepsetus odoe, Brycinus macrolepidotus, Bryconalestes longipinnis, Chalceus epakros, Characidium bahiensis, crenuchus spilurus, Agoniates halecinus, Brycon pesu, Bryconops alburnoides, Clupeacharax cf. engrauloides, Knodus meridae, Metynnis lippincottianus, Myleus setiger, Salminus hilarii e Triportheus albus.

\section{[?] - indeterminado.}

Chanos chanos, Olivaichthys mesembrinus, Saccodon wagneri, Gilbertolus atratoensis, Roestes molossus, Arnoldichthys spilopterus, Brittanichthys axelrodi, Bryconadenos tanaothoros, Diapoma terofali, Hemigrammus unilineatus, Hyphessobrycon compressus, Landonia latidens, Microschemobrycon casiquiare, Piaractus mesopotamicus, Rachoviscus graciliceps e Rhoadsia altipinna. 


\section{1 - Porção interna anterior da câmara posterior da bexiga natatória: [NetTo-FeRREIRA, 2006: 280]}

\section{[0] - lisa ou com septos.}

Catostomus commersonnii, Gymnotus aff. carapo, Citharinus latus, Distichodus notospilus, Hemistichodus vaillanti, Neolebias unifasciatus, Nannocharax fasciatus, Xenocharax spilurus, Apareiodon piracicabae, Parodon nasus, Anodus orinocensis, Bivibranchia fowleri, Hemiodus unimaculatus, Curimata ocellata, Curimatopsis macrolepis, Potamorhina latior, Prochilodus nigricans, Semaprochilodus insignis, Caenotropus labyrinthicus, Chilodus punctatus, Anostomus anostomus, Leporellus vittatus, Leporinus fasciatus, Schizodon fasciatus, Carnegiella strigata, Gasteropelecus sternicla, Thoracocharax stellatus, Acestrorhynchus falcirostris, Hydrolycus tatauaia, Erythrinoidea fam. nov, Boulengerella maculata, Ctenolucius hujeta, Copeina cf. guttata, Piabucina astrigata, Hoplias malabaricus, Hepsetus odoe, Arnoldichthys spilopterus, Brycinus macrolepidotus, Bryconalestes longipinnis, Chalceus epakros, Characidium bahiensis, Crenuchus spilurus, Agoniates halecinus, Aphyocharax pusillus, Astyanax mexicanus, Atopomesus pachyodus, Axelrodia reisei, Brycon pesu, Bryconamericus exodon, Bryconops alburnoides, Charax cf. leticiae, Clupeacharax cf. engrauloides, Compsura heterura, Ctenobrycon hauxwellianus, Deuterodon iguape, Galeocharax knerii, Glandulocauda melanogenys, Gnathocharax steindachneri, Gymnocorymbus ternetzi, Hemibrycon polyodon, Hollandichthys multifasciatus, Iguanodectes geisleri, Knodus meridae, Markiana nigripinnis, Metynnis lippincottianus, Microschemobrycon casiquiare, Moenkhausia xinguensis, Myleus setiger, odontostilbe pequira, oligosarcus argenteus, orthospinus franciscoensis, Paracheirodon axelrodi, Paragoniates alburnus, Phenacogaster pectinatus, Phenagoniates macrolepis, Piabina argentea, Piaractus mesopotamicus, Poptella brevispina, Probolus heterostomus, Rachoviscus graciliceps, Rhinobrycon negrensis, Roeboexodon guyanensis, Salminus hilarii, Serrabrycon magoi, Stygichthys typhlops, Tetragonopterus argenteus e Triportheus albus.

\section{[1] - trabeculada.}

Lebiasina bimaculata e Erythrinus erythrinus.

\section{[?] - indeterminado.}

Chanos chanos, Olivaichthys mesembrinus, Saccodon wagneri, Gilbertolus atratoensis, Roestes molossus, Brittanichthys axelrodi, Bryconadenos tanaothoros, Diapoma terofali, Hemigrammus unilineatus, Hyphessobrycon compressus, Landonia latidens e Rhoadsia altipinna.

\section{[0] - aproximadamente igual a altura.}

Charax cf. leticiae e Phenacogaster pectinatus.

\section{[1] - maior que a altura.}

Catostomus commersonnii, Gymnotus aff. carapo, Citharinus latus, Distichodus notospilus, Hemistichodus vaillanti, Neolebias unifasciatus, Nannocharax fasciatus, Xenocharax spilurus, Apareiodon piracicabae, Parodon nasus, Anodus orinocensis, Bivibranchia fowleri, Hemiodus unimaculatus, Curimata ocellata, Curimatopsis macrolepis, Prochilodus nigricans, Semaprochilodus insignis, Caenotropus labyrinthicus, chilodus punctatus, Anostomus anostomus, Leporellus vittatus, Leporinus fasciatus, Schizodon fasciatus, Carnegiella strigata, Gasteropelecus sternicla, Thoracocharax stellatus Acestrorhynchus falcirostris, Hydrolycus tatauaia, Erythrinoidea fam. nov, Boulengerell'a maculata, Ctenolucius hujeta, Copeina cf. guttata, Lebiasina bimaculata, Piabucina astrigata, Erythrinus erythrinus, Hoplias malabaricus, Hepsetus odoe, Arnoldichthys spilopterus, Brycinus macrolepidotus, Bryconalestes longipinnis, chalceus epakros, Characidium bahiensis, Crenuchus spilurus, Agoniates halecinus, Aphyocharax pusillus, Astyanax mexicanus, Atopomesus pachyodus, Axelrodia reisei, Brycon pesu, Bryconamericus exodon, Bryconops alburnoides, Clupeacharax cf. engrauloides, Compsura heterura, Ctenobrycon hauxwellianus, Deuterodon iguape, Galeocharax knerii, Glandulocauda melanogenys, Gymnocorymbus ternetzi, Hemibrycon polyodon, Hollandichthys multifasciatus, Iguanodectes geisleri, Knodus meridae, Markiana nigripinnis, Metynnis lippincottianus, Moenkhausia xinguensis, Myleus setiger, odontostilbe pequira, 
Oligosarcus argenteus, Orthospinus franciscoensis, Paracheirodon axelrodi, Paragoniates alburnus, Phenagoniates macrolepis, Piabina argentea, Poptella brevispina, Probolus heterostomus, Rhinobrycon negrensis, Roeboexodon guyanensis, Salminus hilarii, Serrabrycon magoi, Stygichthys typhlops, Tetragonopterus argenteus e Triportheus albus.

\section{[?] - indeterminado.}

Chanos chanos, Olivaichthys mesembrinus, Saccodon wagneri, Potamorhina latior, Gilbertolus atratoensis, Roestes molossus, Brittanichthys axelrodi, Bryconadenos tanaothoros, Diapoma terofali, Gnathocharax steindachneri, Hemigrammus unilineatus, Hyphessobrycon compressus, Landonia latidens, Microschemobrycon casiquiare, Piaractus mesopotamicus, Rachoviscus graciliceps e Rhoadsia altipinna.

\section{3 - Espessura da porção anterior da câmara posterior:}

\section{[0] - maior que a porção posterior.}

Citharinus latus, Apareiodon piracicabae, Parodon nasus, Anodus orinocensis, Bivibranchia fowleri, Hemiodus unimaculatus, Curimata ocellata, Curimatopsis macrolepis, Potamorhina latior, Prochilodus nigricans, Semaprochilodus insignis, Caenotropus labyrinthicus, Chilodus punctatus, Anostomus anostomus, Carnegiella strigata, Gasteropelecus sternicla, Thoracocharax stellatus, Hydrolycus tatauaia, Erythrinoidea fam. nov, Piabucina astrigata, Hoplias malabaricus, Hepsetus odoe, Chalceus epakros, crenuchus spilurus, Agoniates halecinus, Axelrodia reisei, Brycon pesu, Bryconops alburnoides, Ctenobrycon hauxwellianus, Galeocharax knerii, Gnathocharax steindachneri, Gymnocorymbus ternetzi, Metynnis lippincottianus, Moenkhausia xinguensis, Myleus setiger, Orthospinus franciscoensis, Poptella brevispina e Triportheus albus.

\section{[1] - aproximadamente de mesma espessura.}

Catostomus commersonnii, Distichodus notospilus, Hemistichodus vaillanti, Neolebias unifasciatus, Nannocharax fasciatus, Xenocharax spilurus, Leporinus fasciatus, Copeina cf. guttata, Lebiasina bimaculata, Arnoldichthys spilopterus, Brycinus macrolepidotus, Bryconalestes longipinnis, Characidium bahiensis, Aphyocharax pusillus, Astyanax mexicanus, Atopomesus pachyodus, Bryconamericus exodon, Charax cf. leticiae, Clupeacharax cf. engrauloides, Compsura heterura, Deuterodon iguape, Hemibrycon polyodon , Hollandichthys multifasciatus, Knodus meridae, Markiana nigripinnis, Odontostilbe pequira, Oligosarcus argenteus, Paracheirodon axelrodi, Piabina argentea, Rhinobrycon negrensis, Roeboexodon guyanensis, Salminus hilarii, Serrabrycon magoi e stygichthys typhlops.

\section{[2] - menor que a porção posterior.}

Gymnotus aff. carapo, Leporellus vittatus, Schizodon fasciatus, Acestrorhynchus falcirostris, Boulengerella maculata, Ctenolucius hujeta, Erythrinus erythrinus, Glandulocauda melanogenys, Iguanodectes geisleri, Paragoniates alburnus, Probolus heterostomus e Tetragonopterus argenteus.

\section{[?] - indeterminado.}

Chanos chanos, Olivaichthys mesembrinus, Gilbertolus atratoensis, Roestes molossus, Brittanichthys axelrodi, Bryconadenos tanaothoros, Diapoma terofali, Hemigrammus unilineatus, Hyphessobrycon compressus, Landonia latidens, Microschemobrycon casiquiare, Phenacogaster pectinatus, Phenagoniates macrolepis, Piaractus mesopotamicus, Rachoviscus graciliceps e Rhoadsia altipinna.

\section{4 - Espessura do ductus pneumaticus:}

$$
\text { [0] - fino. }
$$

Catostomus commersonnii, Neolebias unifasciatus, Nannocharax fasciatus, Xenocharax spilurus, Apareiodon piracicabae, Parodon nasus, Saccodon wagneri, Anodus orinocensis, Bivibranchia fowleri, Hemiodus unimaculatus, Curimata ocellata, Curimatopsis macrolepis, Potamorhina latior, Prochilodus nigricans, Semaprochilodus insignis, Caenotropus labyrinthicus, Chilodus punctatus, Anostomus anostomus, Leporellus vittatus, Leporinus fasciatus, Acestrorhynchus falcirostris, Hydrolycus tatauaia, Erythrinoidea fam. nov, Boulengerella maculata, Ctenolucius hujeta, Copeina cf. guttata, Hoplias 
malabaricus, Hepsetus odoe, Arnoldichthys spilopterus, Brycinus macrolepidotus, Bryconalestes longipinnis, Characidium bahiensis, crenuchus spilurus, Agoniates halecinus, Aphyocharax pusillus, Astyanax mexicanus, Atopomesus pachyodus, Axelrodia reisei, Brycon pesu, Bryconamericus exodon, Bryconops alburnoides, Charax cf. leticiae, Clupeacharax cf. engrauloides, Compsura heterura, Ctenobrycon hauxwellianus, Deuterodon iguape, Diapoma terofali, Galeocharax knerii, Glandulocauda melanogenys, Gnathocharax steindachneri, Gymnocorymbus ternetzi, Hemibrycon polyodon, Hemigrammus unilineatus, Hollandichthys multifasciatus, Hyphessobrycon compressus, Iguanodectes geisleri, Knodus meridae, Landonia latidens, Markiana nigripinnis, Metynnis lippincottianus, Microschemobrycon casiquiare, Moenkhausia xinguensis, Myleus setiger, odontostilbe pequira, oligosarcus argenteus, orthospinus franciscoensis, Paracheirodon axelrodi, Paragoniates alburnus, Phenacogaster pectinatus, Phenagoniates macrolepis, Piabina argentea, Piaractus mesopotamicus, Poptella brevispina, Probolus heterostomus , Rachoviscus graciliceps, Rhinobrycon negrensis, Rhoadsia altipinna, Roeboexodon guyanensis, Salminus hilarii, Serrabrycon magoi, Stygichthys typhlops, Tetragonopterus argenteus e Triportheus albus.

\section{[1] - grosso.}

Gymnotus aff. carapo, Citharinus latus, Distichodus notospilus, Hemistichodus vaillanti, Schizodon fasciatus, Lebiasina bimaculata, Piabucina astrigata, Erythrinus erythrinus e chalceus epakros.

\section{[?] - indeterminado.}

Chanos chanos, Olivaichthys mesembrinus, Carnegiella strigata, Gasteropelecus sternicla, Thoracocharax stellatus, Gilbertolus atratoensis, Roestes molossus, Brittanichthys axelrodi e Bryconadenos tanaothoros.

\section{5 - relação entre o ductus pneumaticus e o duto inter-câmaras:}

\section{[0] - separados.}

Catostomus commersonnii, Gymnotus aff. carapo, Citharinus latus, Distichodus notospilus, Hemistichodus vaillanti, Neolebias unifasciatus, Xenocharax spilurus, Apareiodon piracicabae, Parodon nasus, Anodus orinocensis, Bivibranchia fowleri, Hemiodus unimaculatus, Curimata ocellata, Curimatopsis macrolepis, Potamorhina latior, Prochilodus nigricans, Semaprochilodus insignis, Caenotropus labyrinthicus, Anostomus anostomus, Leporellus vittatus, Leporinus fasciatus, Schizodon fasciatus, Acestrorhynchus falcirostris, Hydrolycus tatauaia, Boulengerella maculata, ctenolucius hujeta, Copeina cf. guttata, Lebiasina bimaculata, Piabucina astrigata, Erythrinus erythrinus, Hepsetus odoe, Arnoldichthys spilopterus, Brycinus macrolepidotus, Bryconalestes longipinnis, Chalceus epakros, Characidium bahiensis, Crenuchus spilurus, Agoniates halecinus, Aphyocharax pusillus, Astyanax mexicanus, Atopomesus pachyodus, Axelrodia reisei, Brycon pesu, Bryconamericus exodon, Bryconops alburnoides, Charax cf. leticiae, Clupeacharax cf. engrauloides, Compsura heterura, Ctenobrycon hauxwellianus, Deuterodon iguape, Galeocharax knerii, Glandulocauda melanogenys, Gnathocharax steindachneri, Gymnocorymbus ternetzi, Hemibrycon polyodon, Hollandichthys multifasciatus, Knodus meridae, Markiana nigripinnis, Moenkhausia xinguensis, odontostilbe pequira, Oligosarcus argenteus, orthospinus franciscoensis, Paracheirodon axelrodi, Paragoniates alburnus, Phenacogaster pectinatus, Phenagoniates macrolepis, Piabina argentea, Poptella brevispina, Probolus heterostomus, Rhinobrycon negrensis, Roeboexodon guyanensis, Salminus hilarii, Serrabrycon magoi, stygichthys typhlops, Tetragonopterus argenteus e Triportheus albus.

\section{[1] - juntos.}

Chilodus punctatus e Hoplias malabaricus.

\section{[?] - indeterminado.}

Chanos chanos, Olivaichthys mesembrinus, Nannocharax fasciatus, Saccodon wagneri, Carnegiella strigata, Gasteropelecus sternicla, Thoracocharax stellatus, Gilbertolus atratoensis, Roestes molossus, Erythrinoidea fam. nov., Brittanichthys axelrodi, Bryconadenos tanaothoros, Diapoma terofali, Hemigrammus unilineatus, Hyphessobrycon compressus, Iguanodectes geisleri, Landonia latidens, Metynnis lippincottianus, Microschemobrycon casiquiare, Myleus setiger, Piaractus mesopotamicus, Rachoviscus graciliceps e Rhoadsia altipinna. 


\section{6 - Ligação do ductus pneumaticus ao trato digestivo:}

\section{[0] - lateral, no lado esquerdo.}

Catostomus commersonnii, Caenotropus labyrinthicus, Erythrinoidea fam. nov, Boulengerella maculata, Ctenolucius hujeta, Lebiasina bimaculata, Piabucina astrigata, Erythrinus erythrinus, Hoplias malabaricus, Hepsetus odoe, Chalceus epakros, Agoniates halecinus, Bryconops alburnoides e Salminus hilarii.

\section{[1] - dorso-lateral esquerda.}

Gymnotus aff. carapo, Citharinus latus, Neolebias unifasciatus, Saccodon wagneri, Hemiodus unimaculatus, Prochilodus nigricans, Semaprochilodus insignis, Anostomus anostomus, Leporellus vittatus, Leporinus fasciatus, Schizodon fasciatus, Carnegiella strigata, Gasteropelecus sternicla, Thoracocharax stellatus, Acestrorhynchus falcirostris, Hydrolycus tatauaia, Copeina cf. guttata, Arnoldichthys spilopterus, Brycinus macrolepidotus, Bryconalestes longipinnis, Characidium bahiensis, Aphyocharax pusillus, Atopomesus pachyodus, Brycon pesu, Bryconamericus exodon, Clupeacharax cf. engrauloides, Deuterodon iguape, Glandulocauda melanogenys, Gymnocorymbus ternetzi, Hemibrycon polyodon, Hollandichthys multifasciatus, Iguanodectes geisleri, Knodus meridae, Markiana nigripinnis, Moenkhausia xinguensis, Myleus setiger, oligosarcus argenteus, Orthospinus franciscoensis, Paragoniates alburnus, Phenagoniates macrolepis, Piabina argentea, Poptella brevispina, Rhinobrycon negrensis, Roeboexodon guyanensis, Serrabrycon magoi, Stygichthys typhlops e Triportheus albus.

\section{[2] - dorsal.}

Parodon nasus, Anodus orinocensis, Curimata ocellata, Curimatopsis macrolepis, Potamorhina latior, Astyanax mexicanus, Axelrodia reisei, Compsura heterura, Metynnis lippincottianus, Odontostilbe pequira, Paracheirodon axelrodi e Tetragonopterus argenteus.

\section{[3] - dorso-lateral direita.}

Distichodus notospilus, Hemistichodus vaillanti, Nannocharax fasciatus, Xenocharax spilurus, Bivibranchia fowleri, Ctenobrycon hauxwellianus e Phenacogaster pectinatus.

\section{[?] - indeterminado.}

Chanos chanos, Olivaichthys mesembrinus, Apareiodon piracicabae, Saccodon wagneri, Chilodus punctatus, Gilbertolus atratoensis, Roestes molossus, crenuchus spilurus, Brittanichthys axelrodi, Bryconadenos tanaothoros, Charax cf. leticiae, Diapoma terofali, Galeocharax knerii, Gnathocharax steindachneri, Hemigrammus unilineatus, Hyphessobrycon compressus, Landonia latidens, Microschemobrycon casiquiare, Piaractus mesopotamicus, Probolus heterostomus, Rachoviscus graciliceps e Rhoadsia altipinna.

\section{7 - Posição do trato digestivo:}

[0] - trato digestivo homogeneamente por toda a cavidade
abdominal.
Catostomus commersonnil, Gymnotus aff. carapo, Citharinus latus, Distichodus notospilus,
Hemistichodus vaillanti, Neolebias unifasciatus, Nannocharax fasciatus, Xenocharax
spilurus, Hemiodus unimaculatus , Curimata ocellata, Curimatopsis macrolepis,
Potamorhina latior, Prochilodus nigricans, Semaprochilodus insignis, Schizodon
fasciatus, Carnegiella strigata, Gasteropelecus sternicla, Thoracocharax stellatus
Acestrorhynchus falcirostris, Hydrolycus tatauaia, Erythrinoidea fam. nov, Boulengerella
maculata, Ctenolucius hujeta, Lebiasina bimaculata, Hoplias malabaricus, Hepsetus odoe,
Arnoldichthys spilopterus, Brycinus macrolepidotus, Bryconalestes longipinnis, Chalceus
epakros, Characidium bahiensis, Crenuchus spilurus, Agoniates halecinus, Aphyocharax
pusillus, Astyanax mexicanus, Atopomesus pachyodus, Brycon pesu, Bryconamericus exodon,
Bryconops alburnoides, Charax cf. leticiae, Clupeacharax cf. engrauloides, Compsura
heterura, ctenobrycon hauxwellianus, Deuterodon iguape, Glandulocauda melanogenys,
Gnathocharax steindachneri, Gymnocorymbus ternetzi, Hemibrycon polyodon, Hollandichthys
multifasciatus, Iguanodectes geisleri, Knodus meridae, Markiana nigripinnis, Metynnis
lippincottianus, Moenkhausia xinguensis, Myleus setiger, odontostilbe pequira,


oligosarcus argenteus, orthospinus franciscoensis, Paracheirodon axelrodi, Paragoniates alburnus, Phenacogaster pectinatus, Phenagoniates macrolepis, Piabina argentea, Poptella brevispina, Probolus heterostomus, Rhinobrycon negrensis, Roeboexodon guyanensis, Salminus hilarii, Serrabrycon magoi, Stygichthys typhlops, Tetragonopterus argenteus e Triportheus albus.

\section{[1] - trato digestivo mais concentardo anteriormente.}

Apareiodon piracicabae, Parodon nasus, Anodus orinocensis, Bivibranchia fowleri, Caenotropus labyrinthicus, Chilodus punctatus, Anostomus anostomus, Leporellus vittatus, Copeina cf. guttata, Piabucina astrigata, Erythrinus erythrinus e Axelrodia reisei.

\section{[?] - indeterminado.}

Chanos chanos, Olivaichthys mesembrinus, Saccodon wagneri, Leporinus fasciatus, Gilbertolus atratoensis, Roestes molossus, Brittanichthys axelrodi, Bryconadenos tanaothoros, Diapoma terofali, Galeocharax knerii, Hemigrammus unilineatus, Hyphessobrycon compressus, Landonia latidens, Microschemobrycon casiquiare, Piaractus mesopotamicus, Rachoviscus graciliceps e Rhoadsia altipinna.

\section{8 - Posição do estômago:}

\section{[0] - parte anterior próximo da parte anterior do fígado.}

Catostomus commersonnii, Gymnotus aff. carapo, Citharinus latus, Distichodus notospilus, Hemistichodus vaillanti, Neolebias unifasciatus, Nannocharax fasciatus, Xenocharax spilurus, Apareiodon piracicabae, Parodon nasus, Saccodon wagneri, Anodus orinocensis, Bivibranchia fowleri, Hemiodus unimaculatus, Curimata ocellata, Curimatopsis macrolepis, Potamorhina latior, Prochilodus nigricans, Semaprochilodus insignis, Caenotropus labyrinthicus, Carnegiella strigata, Gasteropelecus sternicla, Thoracocharax stellatus, Acestrorhynchus falcirostris, Copeina cf. guttata, Lebiasina bimaculata, Piabucina astrigata, Hepsetus odoe, Arnoldichthys spilopterus, Brycinus macrolepidotus, Bryconalestes longipinnis, Chalceus epakros, Characidium bahiensis, Crenuchus spilurus, Atopomesus pachyodus, Axelrodia reisei, Brycon pesu, Bryconamericus exodon, Charax cf. leticiae, Clupeacharax cf. engrauloides, Compsura heterura, Ctenobrycon hauxwellianus, Deuterodon iguape, Glandulocauda melanogenys, Gnathocharax steindachneri, Gymnocorymbus ternetzi, Hemibrycon polyodon, Hollandichthys multifasciatus, Iguanodectes geisleri, Knodus meridae, Markiana nigripinnis, Metynnis lippincottianus, Moenkhausia xinguensis, Myleus setiger, Odontostilbe pequira, Oligosarcus argenteus, orthospinus franciscoensis, Paracheirodon axelrodi, Paragoniates alburnus, Phenacogaster pectinatus, Piabina argentea, Poptella brevispina, Probolus heterostomus, Rhinobrycon negrensis, Roeboexodon guyanensis, Salminus hilarii, Serrabrycon magoi, Stygichthys typhlops, Tetragonopterus argenteus e Triportheus albus.

\section{[1] - parte anterior posterior a parte anterior do fígado.}

Chilodus punctatus, Anostomus anostomus, Leporellus vittatus, Leporinus fasciatus, Schizodon fasciatus, Hydrolycus tatauaia, Boulengerella maculata, Ctenolucius hujeta, Erythrinus erythrinus, Agoniates halecinus, Aphyocharax pusillus, Astyanax mexicanus, Bryconops alburnoides e Phenagoniates macrolepis.

\section{[?] - indeterminado.}

Chanos chanos, Olivaichthys mesembrinus, Gilbertolus atratoensis, Roestes molossus, Erythrinoidea fam. nov., Hoplias malabaricus, Brittanichthys axelrodi, Bryconadenos tanaothoros, Diapoma terofali, Galeocharax knerii, Hemigrammus unilineatus, Hyphessobrycon compressus, Landonia latidens, Microschemobrycon casiquiare, Piaractus mesopotamicus, Rachoviscus graciliceps e Rhoadsia altipinna.

\section{9 - Posição da câmara pilórica:}

\section{[0] - esquerda.}

Saccodon wagneri, Copeina cf. guttata, Lebiasina bimaculata, Piabucina astrigata e Hoplias malabaricus. 


\section{[1] - ventral.}

Neolebias unifasciatus, Xenocharax spilurus, Leporinus fasciatus, Erythrinus erythrinus e Knodus meridae.

\section{[2] - direita.}

Gymnotus aff. carapo, Citharinus latus, Distichodus notospilus, Hemistichodus vaillanti, Nannocharax fasciatus, Apareiodon piracicabae, Parodon nasus, Anodus orinocensis, Bivibranchia fowleri, Hemiodus unimaculatus, Curimata ocellata, Curimatopsis macrolepis, Potamorhina latior, Prochilodus nigricans, semaprochilodus insignis, Caenotropus labyrinthicus, Chilodus punctatus, Anostomus anostomus, Leporellus vittatus, Schizodon fasciatus, Carnegiella strigata, Gasteropelecus sternicla, Thoracocharax stellatus, Acestrorhynchus falcirostris, Hydrolycus tatauaia, Boulengerella maculata, Ctenolucius hujeta, Hepsetus odoe, Arnoldichthys spilopterus, Brycinus macrolepidotus, Bryconalestes longipinnis, Chalceus epakros, Characidium bahiensis, Crenuchus spilurus, Agoniates halecinus, Aphyocharax pusillus, Astyanax mexicanus, Atopomesus pachyodus, Axelrodia reisei, Brycon pesu, Bryconamericus exodon, Bryconops alburnoides, Charax cf. leticiae, Clupeacharax cf. engrauloides, Compsura heterura, Ctenobrycon hauxwellianus, Deuterodon iguape, Glandulocauda melanogenys, Gnathocharax steindachneri, Gymnocorymbus ternetzi, Hemibrycon polyodon, Hollandichthys multifasciatus, Iguanodectes geisleri, Markiana nigripinnis, Metynnis lippincottianus, Moenkhausia xinguensis, Myleus setiger, odontostilbe pequira, oligosarcus argenteus, orthospinus franciscoensis, Paracheirodon axelrodi, Paragoniates alburnus, Phenacogaster pectinatus, Phenagoniates macrolepis, Piabina argentea, Poptella brevispina, Probolus heterostomus, Rhinobrycon negrensis, Roeboexodon guyanensis, Salminus hilarii, Serrabrycon magoi, stygichthys typhlops, Tetragonopterus argenteus e Triportheus albus.

\section{[-] - inaplicável.}

Catostomus commersonnii e Erythrinoidea fam. nov.

\section{[?] - indeterminado.}

Chanos chanos, Olivaichthys mesembrinus, Gilbertolus atratoensis, Roestes molossus, Brittanichthys axelrodi, Bryconadenos tanaothoros, Diapoma terofali, Galeocharax knerii, Hemigrammus unilineatus, Hyphessobrycon compressus, Landonia latidens, Microschemobrycon casiquiare, Piaractus mesopotamicus, Rachoviscus graciliceps e Rhoadsia altipinna.

\section{0 - Conexão com a câmara pilórica:}

\section{[0] - anterior.}

Acestrorhynchus falcirostris, Hydrolycus tatauaia, Lebiasina bimaculata, Arnoldichthys spilopterus, Bryconalestes longipinnis, Agoniates halecinus, Aphyocharax pusillus, Atopomesus pachyodus, Brycon pesu, Bryconops alburnoides, Charax cf. leticiae, ctenobrycon hauxwellianus, Glandulocauda melanogenys, Hemibrycon polyodon Hollandichthys multifasciatus, Moenkhausia xinguensis, oligosarcus argenteus, Paragoniates alburnus, Phenacogaster pectinatus, Piabina argentea, Probolus heterostomus, Roeboexodon guyanensis, Salminus hilarii, serrabrycon magoi e Tetragonopterus argenteus.

\section{[1] - mediana.}

Gymnotus aff. carapo, Leporellus vittatus, Leporinus fasciatus, Carnegiella strigata, Gasteropelecus sternicla, Thoracocharax stellatus, Copeina cf. guttata, Piabucina astrigata, Erythrinus erythrinus, Hoplias malabaricus, Brycinus macrolepidotus, Chalceus epakros, Characidium bahiensis, Crenuchus spilurus, Astyanax mexicanus, Bryconamericus exodon, Gnathocharax steindachneri, Gymnocorymbus ternetzi, Iguanodectes geisleri, Knodus meridae, Markiana nigripinnis, Metynnis lippincottianus, Myleus setiger, Odontostilbe pequira, Orthospinus franciscoensis, Phenagoniates macrolepis, Poptella brevispina, Rhinobrycon negrensis e Triportheus albus.

\section{[2] - posterior.}

Citharinus latus, Distichodus notospilus, Hemistichodus vaillanti, Neolebias unifasciatus, Nannocharax fasciatus, Xenocharax spilurus, Apareiodon piracicabae, Parodon nasus, Saccodon wagneri, Anodus orinocensis, Bivibranchia fowleri, Hemiodus unimaculatus, Curimata ocellata, Curimatopsis macrolepis, Potamorhina latior, Prochilodus nigricans, Semaprochilodus insignis, Caenotropus labyrinthicus, Chilodus punctatus, Anostomus anostomus, Schizodon fasciatus, Boulengerella maculata, Ctenolucius 
hujeta, Hepsetus odoe, Axelrodia reisei, Clupeacharax cf. engrauloides, Compsura heterura, Deuterodon iguape, Paracheirodon axelrodi e Stygichthys typhlops.

\section{[-] - inaplicável.}

Catostomus commersonnii E Erythrinoidea fam. nov.

\section{[?] - indeterminado.}

Chanos chanos, Olivaichthys mesembrinus, Gilbertolus atratoensis, Roestes molossus, Brittanichthys axelrodi, Bryconadenos tanaothoros, Diapoma terofali, Galeocharax knerii, Hemigrammus unilineatus, Hyphessobrycon compressus, Landonia latidens, Microschemobrycon casiquiare, Piaractus mesopotamicus, Rachoviscus graciliceps E Rhoadsia altipinna.

\section{1 - Conexão com a câmara pilórica:}

\section{[0] - esquerda.}

Copeina cf. guttata, Lebiasina bimaculata, Piabucina astrigata, Erythrinus erythrinus, Hoplias malabaricus e Arnoldichthys spilopterus.

\section{[1] - ventral.}

Gymnotus aff. carapo, Citharinus latus, Distichodus notospilus, Hemistichodus vaillanti, Neolebias unifasciatus, Nannocharax fasciatus, Xenocharax spilurus, Apareiodon piracicabae, Parodon nasus, Saccodon wagneri, Anodus orinocensis, Bivibranchia fowleri, Hemiodus unimaculatus, Curimata ocellata, Curimatopsis macrolepis, Potamorhina latior, Prochilodus nigricans, Semaprochilodus insignis, Caenotropus labyrinthicus, Chilodus punctatus, Anostomus anostomus, Leporellus vittatus, Leporinus fasciatus, Schizodon fasciatus, Carnegiella strigata, Gasteropelecus sternicla, Thoracocharax stellatus, Hydrolycus tatauaia, Brycinus macrolepidotus, Bryconalestes longipinnis, Chalceus epakros, Characidium bahiensis, crenuchus spilurus, Aphyocharax pusillus, Astyanax mexicanus, Atopomesus pachyodus, Axelrodia reisei, Brycon pesu, Bryconamericus exodon, Bryconops alburnoides, Charax cf. leticiae, Clupeacharax cf. engrauloides, Compsura heterura, Ctenobrycon hauxwellianus, Deuterodon iguape, Glandulocauda melanogenys, Gnathocharax steindachneri, Gymnocorymbus ternetzi, Hemibrycon polyodon, Hollandichthys multifasciatus, Iguanodectes geisleri, Knodus meridae, Markiana nigripinnis, Metynnis lippincottianus, Moenkhausia xinguensis, Myleus setiger, odontostilbe pequira, oligosarcus argenteus, Orthospinus franciscoensis, Paracheirodon axelrodi, Paragoniates alburnus, Phenacogaster pectinatus, Phenagoniates macrolepis, Piabina argentea, Poptella brevispina, Probolus heterostomus, Rhinobrycon negrensis, Roeboexodon guyanensis, Salminus hilarii, Serrabrycon magoi, Stygichthys typhlops, Tetragonopterus argenteus e Triportheus albus.

\section{[2] - direita.}

Acestrorhynchus falcirostris, Boulengerella maculata, Ctenolucius hujeta, Hepsetus odoe e Agoniates halecinus.

\section{[-] - inaplicável.}

Catostomus commersonnii, Erythrinoidea fam. nov.

\section{[?] - indeterminado.}

Chanos chanos, Olivaichthys mesembrinus, Gilbertolus atratoensis, Roestes molossus, Brittanichthys axelrodi, Bryconadenos tanaothoros, Diapoma terofali, Galeocharax knerii, Hemigrammus unilineatus, Hyphessobrycon compressus, Landonia latidens, Microschemobrycon casiquiare, Piaractus mesopotamicus, Rachoviscus graciliceps E Rhoadsia altipinna.

\section{[0] - ausentes.}

Catostomus commersonnii, Erythrinoidea fam. nov, Brycon pesu, Compsura heterura e Stygichthys typhlops. 


\section{[1] - poucos.}

Gymnotus aff. carapo, Citharinus latus, Distichodus notospilus, Hemistichodus vaillanti, Neolebias unifasciatus, Nannocharax fasciatus, Xenocharax spilurus, Apareiodon piracicabae, Parodon nasus, Saccodon wagneri, Anodus orinocensis, Bivibranchia fowleri, Hemiodus unimaculatus, Curimata ocellata, Curimatopsis macrolepis, Potamorhina latior, Caenotropus labyrinthicus, Chilodus punctatus, Anostomus anostomus, Leporellus vittatus, Leporinus fasciatus, Schizodon fasciatus, Carnegiella strigata, Gasteropelecus sternicla, Thoracocharax stellatus, Acestrorhynchus falcirostris, Hydrolycus tatauaia, Boulengerella maculata, Ctenolucius hujeta, Copeina cf. guttata, Lebiasina bimaculata, Piabucina astrigata, Erythrinus erythrinus, Hepsetus odoe, Arnoldichthys spilopterus, Brycinus macrolepidotus, Bryconalestes longipinnis, Chalceus epakros, Characidium bahiensis, Crenuchus spilurus, Agoniates halecinus, Aphyocharax pusillus, Astyanax mexicanus, Atopomesus pachyodus, Axelrodia reisei, Bryconamericus exodon, Bryconops alburnoides, Charax cf. leticiae, Clupeacharax cf. engrauloides, Ctenobrycon hauxwellianus, Deuterodon iguape, Glandulocauda melanogenys, Gnathocharax steindachneri, Gymnocorymbus ternetzi, Hemibrycon polyodon, Hollandichthys multifasciatus, Iguanodectes geisleri, Knodus meridae, Markiana nigripinnis, Metynnis lippincottianus, Moenkhausia xinguensis, Myleus setiger, Odontostilbe pequira, Oligosarcus argenteus, orthospinus franciscoensis, Paracheirodon axelrodi, Paragoniates alburnus, Phenacogaster pectinatus, Phenagoniates macrolepis, Piabina argentea, Poptella brevispina, Probolus heterostomus, Rhinobrycon negrensis, Roeboexodon guyanensis, Serrabrycon magoi, Tetragonopterus argenteus e Triportheus albus.

\section{[2] - numerosos.}

Prochilodus nigricans, Semaprochilodus insignis, Hoplias malabaricus e Salminus hilarii.

\section{[?] - indeterminado.}

Chanos chanos, Olivaichthys mesembrinus, Gilbertolus atratoensis, Roestes molossus, Brittanichthys axelrodi, Bryconadenos tanaothoros, Diapoma terofali, Galeocharax knerii, Hemigrammus unilineatus, Hyphessobrycon compressus, Landonia latidens, Microschemobrycon casiquiare, Piaractus mesopotamicus, Rachoviscus graciliceps e Rhoadsia altipinna.

\section{3 - Lobos laterais do fígado:}

[0] - esquerdo mais longo que o direito.

Citharinus latus, Distichodus notospilus, Hemistichodus vaillanti, Neolebias unifasciatus, Nannocharax fasciatus, Xenocharax spilurus, Bivibranchia fowleri, Hemiodus unimaculatus, Caenotropus labyrinthicus, Leporinus fasciatus, Carnegiella strigata, Gasteropelecus sternicla, Thoracocharax stellatus, Acestrorhynchus falcirostris, Hydrolycus tatauaia, Erythrinoidea fam. nov, Boulengerella maculata, Ctenolucius hujeta, Copeina cf. guttata, Lebiasina bimaculata, Erythrinus erythrinus, Hoplias malabaricus, Hepsetus odoe, Arnoldichthys spilopterus, Characidium bahiensis, Crenuchus spilurus, Agoniates halecinus, Aphyocharax pusillus, Astyanax mexicanus, Axelrodia reisei, Brycon pesu, Clupeacharax cf. engrauloides, Glandulocauda melanogenys, Gnathocharax steindachneri, Hollandichthys multifasciatus, Paragoniates alburnus, Piabina argêntea e Rhinobrycon negrensis.

\section{[1] - aproximadamente do mesmo tamanho.}

Anodus orinocensis, Chilodus punctatus, Anostomus anostomus, schizodon fasciatus, Brycinus macrolepidotus, Bryconops alburnoides, Charax cf. leticiae, Compsura heterura, Iguanodectes geisleri, Metynnis lippincottianus, Moenkhausia xinguensis, Odontostilbe pequira, Paracheirodon axelrodi, Phenacogaster pectinatus, Roeboexodon guyanensis, Serrabrycon magoi, Tetragonopterus argenteus e Triportheus albus.

\section{[2] - direito mais longo que o esquerdo.}

Catostomus commersonnii, Gymnotus aff. carapo, Apareiodon piracicabae, Parodon nasus, Saccodon wagneri, Curimata ocellata, Curimatopsis macrolepis, Potamorhina latior, Prochilodus nigricans, Semaprochilodus insignis, Leporellus vittatus, Piabucina astrigata, Bryconalestes longipinnis, Chalceus epakros, Atopomesus pachyodus, Bryconamericus exodon, Ctenobrycon hauxwellianus, Deuterodon iguape, Gymnocorymbus ternetzi, Hemibrycon polyodon, Markiana nigripinnis, Myleus setiger, oligosarcus argenteus, Orthospinus franciscoensis, Phenagoniates macrolepis, Poptella brevispina, Probolus heterostomus, Salminus hilarii e Stygichthys typhlops.

[?] - indeterminado. 
Chanos chanos, olivaichthys mesembrinus, Gilbertolus atratoensis, Roestes molossus, Brittanichthys axelrodi, Bryconadenos tanaothoros, Diapoma terofali, Galeocharax knerii, Hemigrammus unilineatus, Hyphessobrycon compressus, Knodus meridae, Landonia latidens, Microschemobrycon casiquiare, Piaractus mesopotamicus, Rachoviscus graciliceps e Rhoadsia altipinna.

\section{4 - Lobo ventral do fígado:}

\section{[0] - não-individualizado.}

Catostomus commersonnii, Hemistichodus vaillanti, Nannocharax fasciatus, Caenotropus labyrinthicus, Carnegiella strigata, Gasteropelecus sternicla, Thoracocharax stellatus , Erythrinoidea fam. nov, Boulengerella maculata, ctenolucius hujeta, Erythrinus erythrinus, Hoplias malabaricus e Agoniates halecinus.

\section{[1] - mais curto que lobos laterais.}

Citharinus latus, Anodus orinocensis, Bivibranchia fowleri, Hemiodus unimaculatus , curimata ocellata, Curimatopsis macrolepis, Potamorhina latior, Prochilodus nigricans, Semaprochilodus insignis, Anostomus anostomus, Leporellus vittatus, Leporinus fasciatus, Schizodon fasciatus, Acestrorhynchus falcirostris, Hydrolycus tatauaia, Hepsetus odoe, Arnoldichthys spilopterus, Chalceus epakros, Aphyocharax pusillus, Atopomesus pachyodus, Axelrodia reisei, Brycon pesu, Bryconamericus exodon, Bryconops alburnoides, Charax cf. leticiae, Clupeacharax cf. engrauloides, Ctenobrycon hauxwellianus, Gnathocharax steindachneri, Hemibrycon polyodon, Metynnis lippincottianus, Moenkhausia xinguensis, Myleus setiger, orthospinus franciscoensis, Paragoniates alburnus, Phenagoniates macrolepis, Roeboexodon guyanensis, Salminus hilarii, Serrabrycon magoi, stygichthys typhlops e Triportheus albus.

\section{[2] - igual aos lobos laterais.}

Chilodus punctatus, Copeina cf. guttata, Brycinus macrolepidotus, Characidium bahiensis, oligosarcus argenteus, Phenacogaster pectinatus e Poptella brevispina.

\section{[3] - maior.}

Gymnotus aff. carapo, Distichodus notospilus, Neolebias unifasciatus, Xenocharax spilurus, Apareiodon piracicabae, Parodon nasus, Saccodon wagneri, Lebiasina bimaculata, Piabucina astrigata, Bryconalestes longipinnis, Crenuchus spilurus, Astyanax mexicanus, Compsura heterura, Deuterodon iguape, Glandulocauda melanogenys, Gymnocorymbus ternetzi, Hollandichthys multifasciatus, Iguanodectes geisleri, Markiana nigripinnis, odontostilbe pequira, Paracheirodon axelrodi, Piabina argentea, Probolus heterostomus, Rhinobrycon negrensis e Tetragonopterus argenteus.

\section{[?] - indeterminado.}

Chanos chanos, Olivaichthys mesembrinus, Gilbertolus atratoensis, Roestes molossus, Brittanichthys axelrodi, Bryconadenos tanaothoros, Diapoma terofali, Galeocharax knerii, Hemigrammus unilineatus, Hyphessobrycon compressus, Knodus meridae, Landonia latidens, Microschemobrycon casiquiare, Piaractus mesopotamicus, Rachoviscus graciliceps e Rhoadsia altipinna.

\section{5 - Maior lobo do fígado:}

[0] - curto.

Citharinus latus.

$$
\text { [1] - médio. }
$$

Gymnotus aff. carapo, Hemistichodus vaillanti, Anodus orinocensis, Bivibranchia fowleri, Hemiodus unimaculatus, Curimata ocellata, Curimatopsis macrolepis, Potamorhina latior, Prochilodus nigricans, Semaprochilodus insignis, Anostomus anostomus, Schizodon fasciatus, Carnegiella strigata, Gasteropelecus sternicla, Thoracocharax stellatus, Hydrolycus tatauaia, Boulengerella maculata, Characidium bahiensis, Astyanax mexicanus, Bryconops alburnoides, Charax cf. leticiae, clupeacharax cf. engrauloides, Glandulocauda melanogenys, Gnathocharax steindachneri, Hollandichthys multifasciatus, Iguanodectes geisleri, Markiana nigripinnis, Metynnis lippincottianus, Moenkhausia xinguensis, Myleus 
setiger, oligosarcus argenteus, orthospinus franciscoensis, Phenacogaster pectinatus, Poptella brevispina, Rhinobrycon negrensis, Roeboexodon guyanensis, Serrabrycon magoi e Tetragonopterus argenteus.

\section{[2] - longo.}

Catostomus commersonnii, Distichodus notospilus, Neolebias unifasciatus, Nannocharax fasciatus, Xenocharax spilurus, Apareiodon piracicabae, Parodon nasus, Saccodon wagneri, Caenotropus labyrinthicus, Chilodus punctatus, Leporellus vittatus, Leporinus fasciatus, Acestrorhynchus falcirostris, Erythrinoidea fam. nov, Ctenolucius hujeta, Copeina cf. guttata, Lebiasina bimaculata, Piabucina astrigata, Erythrinus erythrinus, Hoplias malabaricus, Hepsetus odoe, Arnoldichthys spilopterus, Brycinus macrolepidotus, Bryconalestes longipinnis, Chalceus epakros, Crenuchus spilurus, Agoniates halecinus, Aphyocharax pusillus, Atopomesus pachyodus, Axelrodia reisei, Brycon pesu, Bryconamericus exodon, Compsura heterura, Ctenobrycon hauxwellianus, Deuterodon iguape, Gymnocorymbus ternetzi, Hemibrycon polyodon, Odontostilbe pequira, Paracheirodon axelrodi, Paragoniates alburnus, Phenagoniates macrolepis, Piabina argentea, Probolus heterostomus, Salminus hilarii, Stygichthys typhlops e Triportheus albus.

\section{[?] - indeterminado.}

Chanos chanos, Olivaichthys mesembrinus, Gilbertolus atratoensis, Roestes molossus, Brittanichthys axelrodi, Bryconadenos tanaothoros, Diapoma terofali, Galeocharax knerii, Hemigrammus unilineatus, Hyphessobrycon compressus, Knodus meridae, Landonia latidens, Microschemobrycon casiquiare, Piaractus mesopotamicus, Rachoviscus graciliceps e Rhoadsia altipinna.

\subsubsection{Miscelânea}

396 - Pseudotímpano.

[ZANATA, 2000: 121, modificado e ZANATA \& VARI, 2005: 199]

\section{[0] - ausente.}

Chanos chanos, Catostomus commersonnii, Apareiodon piracicabae, Parodon nasus, Saccodon wagneri, Anodus orinocensis, Bivibranchia fowleri, Hemiodus unimaculatus, Curimata ocellata, Curimatopsis macrolepis, Potamorhina latior, Prochilodus nigricans, Semaprochilodus insignis, Chilodus punctatus, Leporellus vittatus, Leporinus fasciatus, Schizodon fasciatus, Acestrorhynchus falcirostris, Hydrolycus tatauaia, Boulengerella maculata, Ctenolucius hujeta, Copeina cf. guttata, Lebiasina bimaculata, Piabucina astrigata, Erythrinus erythrinus, Hoplias malabaricus, Hepsetus odoe, Brycinus macrolepidotus, Bryconalestes longipinnis, Chalceus epakros, Agoniates halecinus, Aphyocharax pusillus, Astyanax mexicanus, Brycon pesu, Bryconadenos tanaothoros, Bryconamericus exodon, Bryconops alburnoides, Clupeacharax cf. engrauloides, Ctenobrycon hauxwellianus, Deuterodon iguape, Diapoma terofali, Gymnocorymbus ternetzi, Hemibrycon polyodon, Hemigrammus unilineatus, Hollandichthys multifasciatus, Hyphessobrycon compressus, Iguanodectes geisleri, Knodus meridae, Landonia latidens, Markiana nigripinnis, Moenkhausia xinguensis, oligosarcus argenteus, orthospinus franciscoensis, Paragoniates alburnus, Phenagoniates macrolepis, Piabina argentea, Piaractus mesopotamicus, Poptella brevispina, Probolus heterostomus, Rhinobrycon negrensis, Salminus hilarii, Serrabrycon magoi, Stygichthys typhlops e Triportheus albus.

\section{[1] - presente.}

Olivaichthys mesembrinus, Gymnotus aff. carapo, Citharinus latus, Distichodus notospilus, Hemistichodus vaillanti, Neolebias unifasciatus, Nannocharax fasciatus, Xenocharax spilurus, Carnegiella strigata, Gasteropelecus sternicla, Thoracocharax stellatus, Crenuchus spilurus, Atopomesus pachyodus, Axelrodia reisei, Brittanichthys axelrodi, Charax cf. leticiae, Compsura heterura, Galeocharax knerii, Gnathocharax steindachneri, Metynnis lippincottianus, Microschemobrycon casiquiare, Myleus setiger, Odontostilbe pequira, Paracheirodon axelrodi, Phenacogaster pectinatus e Tetragonopterus argenteus.

\section{[?] - indeterminado.}

Caenotropus labyrinthicus, Anostomus anostomus, Gilbertolus atratoensis, Roestes molossus, Erythrinoidea fam. nov., Arnoldichthys spilopterus, Characidium bahiensis, Glandulocauda melanogenys, Rachoviscus graciliceps, Rhoadsia altipinna e Roeboexodon guyanensis. 


\section{[0] - limitado a porção anterior à primeira costela.}

Olivaichthys mesembrinus, Carnegiella strigata, Gasteropelecus sternicla, Axelrodia reisei, Brittanichthys axelrodi e Gnathocharax steindachneri.

[1] - anterior a primeira costela e entre esta e a segunda costela.

Gymnotus aff. carapo, Hemistichodus vaillanti, Neolebias unifasciatus, Nannocharax fasciatus, Atopomesus pachyodus, Charax cf. leticiae, Paracheirodon axelrodi e Phenacogaster pectinatus.

\section{[2] - limitado a porção entre à primeira e a segunda costela.}

Citharinus latus, Distichodus notospilus, Xenocharax spilurus, Thoracocharax stellatus, Crenuchus spilurus, Compsura heterura, Galeocharax knerii, Microschemobrycon casiquiare, odontostilbe pequira e Tetragonopterus argenteus.

[3] - entre a primeira e segunda costela e entre a segunda e terceira.

Metynnis lippincottianus.

\section{[-] - inaplicável.}

Chanos chanos, Catostomus commersonnii, Apareiodon piracicabae, Parodon nasus, Saccodon wagneri, Anodus orinocensis, Bivibranchia fowleri, Hemiodus unimaculatus, Curimata ocellata, Curimatopsis macrolepis, Potamorhina latior, Prochilodus nigricans, Semaprochilodus insignis, Chilodus punctatus, Leporellus vittatus, Leporinus fasciatus, Schizodon fasciatus, Acestrorhynchus falcirostris, Hydrolycus tatauaia, Boulengerella maculata, Ctenolucius hujeta, Copeina cf. guttata, Lebiasina bimaculata, Piabucina astrigata, Erythrinus erythrinus, Hoplias malabaricus, Hepsetus odoe, Brycinus macrolepidotus, Bryconalestes longipinnis, Chalceus epakros, Agoniates halecinus, Aphyocharax pusillus, Astyanax mexicanus, Brycon pesu, Bryconadenos tanaothoros, Bryconamericus exodon, Bryconops alburnoides, Clupeacharax cf. engrauloides, Ctenobrycon hauxwellianus, Deuterodon iguape, Diapoma terofali, Gymnocorymbus ternetzi, Hemibrycon polyodon, Hemigrammus unilineatus, Hollandichthys multifasciatus, Hyphessobrycon compressus, Iguanodectes geisleri, Knodus meridae, Landonia latidens, Markiana nigripinnis, Moenkhausia xinguensis, oligosarcus argenteus, orthospinus franciscoensis, Paragoniates alburnus, Phenagoniates macrolepis, Piabina argentea, Piaractus mesopotamicus, Poptella brevispina, Probolus heterostomus, Rhinobrycon negrensis, Salminus hilarii, Serrabrycon magoi, Stygichthys typhlops e Triportheus albus.

\section{[?] - indeterminado.}

Caenotropus labyrinthicus, Anostomus anostomus, Gilbertolus atratoensis, Roestes molossus, Erythrinoidea fam. nov., Arnoldichthys spilopterus, Characidium bahiensis, Glandulocauda melanogenys, Myleus setiger, Rachoviscus graciliceps, Rhoadsia altipinna e Roeboexodon guyanensis.

\section{8 - Limite dorsal do pseudotímpano:}

[0] - limitado pelo lateralis superficialis.

Gymnotus aff. Carapo, Citharinus latus, Distichodus notospilus, Hemistichodus vaillanti, Neolebias unifasciatus, Nannocharax fasciatus, Xenocharax spilurus, Crenuchus spilurus, Atopomesus pachyodus, Charax cf. leticiae, Compsura heterura, Galeocharax knerii, Gnathocharax steindachneri, Metynnis lippincottianus, Microschemobrycon casiquiare, Odontostilbe pequira, Paracheirodon axelrodi, Phenacogaster pectinatus e Tetragonopterus argenteus.

[1] - limitado pelo obliquus superioris.

Carnegiella strigata, Gasteropelecus sternicla, Thoracocharax stellatus e Metynnis lippincottianus.

[2] - limitado pelo obliquus inferioris. 
Axelrodia reisei, Brittanichthys axelrodi e Paracheirodon axelrodi.

\section{[-] - inaplicável.}

Chanos chanos, Catostomus commersonnii, olivaichthys mesembrinus, Apareiodon piracicabae, Parodon nasus, Saccodon wagneri, Anodus orinocensis, Bivibranchia fowleri, Hemiodus unimaculatus, Curimata ocellata, Curimatopsis macrolepis, Potamorhina latior, Prochilodus nigricans, Semaprochilodus insignis, Chilodus punctatus, Leporellus vittatus, Leporinus fasciatus, Schizodon fasciatus, Acestrorhynchus falcirostris, Hydrolycus tatauaia, Boulengerella maculata, Ctenolucius hujeta, Copeina cf. guttata, Lebiasina bimaculata, Piabucina astrigata, Erythrinus erythrinus, Hoplias malabaricus, Hepsetus odoe, Brycinus macrolepidotus, Bryconalestes longipinnis, Chalceus epakros, Agoniates halecinus, Aphyocharax pusillus, Astyanax mexicanus, Brycon pesu, Bryconadenos tanaothoros, Bryconamericus exodon, Bryconops alburnoides, Clupeacharax cf. engrauloides, Ctenobrycon hauxwellianus, Deuterodon iguape, Diapoma terofali, Gymnocorymbus ternetzi, Hemibrycon polyodon, Hemigrammus unilineatus, Hollandichthys multifasciatus, Hyphessobrycon compressus, Iguanodectes geisleri, Knodus meridae, Landonia latidens, Markiana nigripinnis, Moenkhausia xinguensis, oligosarcus argenteus, orthospinus franciscoensis, Paragoniates alburnus, Phenagoniates macrolepis, Piabina argentea, Piaractus mesopotamicus, Poptella brevispina, Probolus heterostomus Rhinobrycon negrensis, Salminus hilarii, Serrabrycon magoi, Stygichthys typhlops e Triportheus albus.

\section{[?] - indeterminado.}

Caenotropus labyrinthicus, Anostomus anostomus, Gilbertolus atratoensis, Roestes molossus, Erythrinoidea fam. nov., Arnoldichthys spilopterus, Characidium bahiensis, Glandulocauda melanogenys, Myleus setiger, Rachoviscus graciliceps, Rhoadsia altipinna e Roeboexodon guyanensis.

\section{$[1,2]$ - polimórfico.}

Metynnis lippincottianus e Paracheirodon axelrodi.

399 - Nadadeira adiposa:

[VARI, 1995: 81; e NeTto-FerReira, 2006: 240]

\section{[0] - presente.}

Olivaichthys mesembrinus, Gymnotus aff. carapo, Citharinus latus, Distichodus notospilus, Hemistichodus vaillanti, Neolebias unifasciatus, Nannocharax fasciatus, Xenocharax spilurus, Apareiodon piracicabae, Parodon nasus, Saccodon wagneri, Anodus orinocensis, Bivibranchia fowleri, Hemiodus unimaculatus, Curimata ocellata, Curimatopsis macrolepis, Potamorhina latior, Prochilodus nigricans, Semaprochilodus insignis, Caenotropus labyrinthicus, Chilodus punctatus, Anostomus anostomus, Leporellus vittatus, Leporinus fasciatus, Schizodon fasciatus, Gasteropelecus sternicla, Thoracocharax stellatus, Acestrorhynchus falcirostris, Gilbertolus atratoensis, Hydrolycus tatauaia, Roestes molossus, Boulengerella maculata, Ctenolucius hujeta, Piabucina astrigata, Hepsetus odoe, Arnoldichthys spilopterus, Brycinus macrolepidotus, Bryconalestes longipinnis, Chalceus epakros, Characidium bahiensis, Crenuchus spilurus, Agoniates halecinus, Aphyocharax pusillus, Astyanax mexicanus, Atopomesus pachyodus, Axelrodia reisei, Brittanichthys axelrodi, Brycon pesu, Bryconadenos tanaothoros, Bryconamericus exodon, Bryconops alburnoides, Charax cf. leticiae, Clupeacharax cf. engrauloides, Compsura heterura, Ctenobrycon hauxwellianus, Deuterodon iguape, Diapoma terofali, Galeocharax knerii, Gnathocharax steindachneri, Gymnocorymbus ternetzi, Hemibrycon polyodon, Hemigrammus unilineatus, Hollandichthys multifasciatus, Hyphessobrycon compressus, Iguanodectes geisleri, Knodus meridae, Landonia latidens, Markiana nigripinnis, Metynnis lippincottianus, Microschemobrycon casiquiare, Moenkhausia xinguensis, Myleus setiger, Odontostilbe pequira, oligosarcus argenteus, orthospinus franciscoensis, Paracheirodon axelrodi, Paragoniates alburnus, Phenacogaster pectinatus, Piabina argentea, Piaractus mesopotamicus, Poptella brevispina, Probolus heterostomus, Rhinobrycon negrensis, Rhoadsia altipinna, Roeboexodon guyanensis, Salminus hilarii, Serrabrycon magoi, Stygichthys typhlops, Tetragonopterus argenteus e Triportheus albus.

\section{[1] - ausente.}

Chanos chanos, Catostomus commersonnii, Carnegiella strigata, Erythrinoidea fam. nov, Copeina cf. guttata, Lebiasina bimaculata, Erythrinus erythrinus, Hoplias malabaricus e Phenagoniates macrolepis. 


\section{0 - Músculo sônico:}

\section{[0] - ausente.}

Chanos chanos, Catostomus commersonnii, Olivaichthys mesembrinus, Gymnotus aff. carapo, Citharinus latus, Distichodus notospilus, Hemistichodus vaillanti, Neolebias unifasciatus, Nannocharax fasciatus, Xenocharax spilurus, Apareiodon piracicabae, Parodon nasus, Saccodon wagneri, Bivibranchia fowleri, Curimatopsis macrolepis, Chilodus punctatus, Anostomus anostomus, Carnegiella strigata, Gasteropelecus sternicla, Thoracocharax stellatus, Acestrorhynchus falcirostris, Gilbertolus atratoensis, Hydrolycus tatauaia, Roestes molossus, Boulengerella maculata, Ctenolucius hujeta, Copeina cf. guttata, Lebiasina bimaculata, Piabucina astrigata, Erythrinus erythrinus, Hoplias malabaricus, Hepsetus odoe, Arnoldichthys spilopterus, Brycinus macrolepidotus, Bryconalestes longipinnis, Chalceus epakros, Characidium bahiensis, Crenuchus spilurus, Agoniates halecinus, Aphyocharax pusillus, Astyanax mexicanus, Atopomesus pachyodus, Axelrodia reisei, Brittanichthys axelrodi, Brycon pesu, Bryconadenos tanaothoros, Bryconamericus exodon, Bryconops alburnoides, Charax cf. leticiae, Clupeacharax cf. engrauloides, Compsura heterura, Ctenobrycon hauxwellianus, Deuterodon iguape, Diapoma terofali, Galeocharax knerii, Glandulocauda melanogenys, Gnathocharax steindachneri, Gymnocorymbus ternetzi, Hemibrycon polyodon, Hemigrammus unilineatus, Hollandichthys multifasciatus, Hyphessobrycon compressus, Iguanodectes geisleri, Knodus meridae, Landonia latidens, Markiana nigripinnis, Metynnis lippincottianus, Microschemobrycon casiquiare, Moenkhausia xinguensis, Myleus setiger, Odontostilbe pequira, Oligosarcus argenteus, orthospinus franciscoensis, Paracheirodon axelrodi, Paragoniates alburnus, Phenacogaster pectinatus, Phenagoniates macrolepis, Piabina argentea, Piaractus mesopotamicus, Poptella brevispina, Probolus heterostomus, Rachoviscus graciliceps, Rhinobrycon negrensis, Rhoadsia altipinna, Roeboexodon guyanensis, Salminus hilarii, Serrabrycon magoi, Stygichthys typhlops, Tetragonopterus argenteus e Triportheus albus.

\section{[1] - presente.}

Anodus orinocensis, Hemiodus unimaculatus, Curimata ocellata, Potamorhina latior, Prochilodus nigricans, Semaprochilodus insignis, Caenotropus labyrinthicus, Leporellus vittatus, Leporinus fasciatus e Schizodon fasciatus.

\section{[?] - indeterminado.}

Glandulocauda melanogenys e Rachoviscus graciliceps.

[?] - indeterminado.

Erythrinoidea fam. nov.

\section{1 - Sulco suprapeitoral:}

\section{[0] - ausente.}

Catostomus commersonnii, Olivaichthys mesembrinus, Gymnotus aff. carapo, Citharinus latus, Distichodus notospilus, Hemistichodus vaillanti, Neolebias unifasciatus, Nannocharax fasciatus, Xenocharax spilurus, Parodon nasus, Saccodon wagneri, Curimata ocellata, Curimatopsis macrolepis, Potamorhina latior, Prochilodus nigricans, Semaprochilodus insignis, Caenotropus labyrinthicus, Chilodus punctatus, Anostomus anostomus, Leporellus vittatus, Leporinus fasciatus, schizodon fasciatus, Carnegiella strigata, Gasteropelecus sternicla, Thoracocharax stellatus, Acestrorhynchus falcirostris, Gilbertolus atratoensis, Hydrolycus tatauaia, Roestes molossus, Erythrinoidea fam. nov, Boulengerella maculata, Ctenolucius hujeta, copeina cf. guttata, Lebiasina bimaculata, Piabucina astrigata, Erythrinus erythrinus, Hoplias malabaricus, Hepsetus odoe, Arnoldichthys spilopterus, Brycinus macrolepidotus, Bryconalestes longipinnis, Chalceus epakros, Characidium bahiensis, Crenuchus spilurus, Agoniates halecinus, Aphyocharax pusillus, Astyanax mexicanus, Atopomesus pachyodus, Axelrodia reisei, Brittanichthys axelrodi, Brycon pesu, Bryconadenos tanaothoros, Bryconamericus exodon, Bryconops alburnoides, Charax cf. leticiae, Clupeacharax cf. engrauloides, Compsura heterura, Ctenobrycon hauxwellianus, Deuterodon iguape, Diapoma terofali, Galeocharax knerii, Glandulocauda melanogenys, Gnathocharax steindachneri, Gymnocorymbus ternetzi, Hemibrycon polyodon, Hemigrammus unilineatus, Hollandichthys multifasciatus, Hyphessobrycon compressus, Iguanodectes geisleri, Knodus meridae, Landonia latidens, Markiana nigripinnis, Metynnis lippincottianus, Microschemobrycon casiquiare, Moenkhausia xinguensis, Myleus setiger, Odontostilbe pequira, Oligosarcus argenteus, orthospinus franciscoensis, Paracheirodon axelrodi, Paragoniates alburnus, Phenacogaster pectinatus, Phenagoniates macrolepis, Piabina argentea, Piaractus mesopotamicus, 
Poptella brevispina, Probolus heterostomus, Rachoviscus graciliceps, Rhinobrycon negrensis, Rhoadsia altipinna, Roeboexodon guyanensis, Salminus hilarii, Serrabrycon magoi, Stygichthys typhlops, Tetragonopterus argenteus e Triportheus albus.

\section{[1] - presente.}

Chanos chanos, Apareiodon piracicabae, Anodus orinocensis, Bivibranchia fowleri e Hemiodus unimaculatus.

\section{2 - Posição dos orifícios anterior e posterior das narinas: [OYAKAWA, $1998: 5$; e NETTO-FERREIRA, 2006: 271]}

\section{[0] - justapostos (Fig. 59B).}

Chanos chanos, Catostomus commersonnii, olivaichthys mesembrinus, Citharinus latus, Distichodus notospilus, Hemistichodus vaillanti, Neolebias unifasciatus, Nannocharax fasciatus, Xenocharax spilurus, Apareiodon piracicabae, Parodon nasus, Saccodon wagneri, Anodus orinocensis, Bivibranchia fowleri, Hemiodus unimaculatus, Curimata ocellata, Curimatopsis macrolepis, Potamorhina latior, Prochilodus nigricans, Semaprochilodus insignis, Caenotropus labyrinthicus, Chilodus punctatus, Leporellus vittatus, Carnegiella strigata, Gasteropelecus sternicla, Thoracocharax stellatus Acestrorhynchus falcirostris, Gilbertolus atratoensis, Hydrolycus tatauaia, Roestes molossus, Boulengerella maculata, Ctenolucius hujeta, Copeina cf. guttata, Lebiasina bimaculata, Piabucina astrigata, Hepsetus odoe, Arnoldichthys spilopterus, Brycinus macrolepidotus, Bryconalestes longipinnis, Chalceus epakros, Crenuchus spilurus, Agoniates halecinus, Aphyocharax pusillus, Astyanax mexicanus, Atopomesus pachyodus, Axelrodia reisei, Brittanichthys axelrodi, Brycon pesu, Bryconadenos tanaothoros, Bryconamericus exodon, Bryconops alburnoides, Charax cf. leticiae, Clupeacharax cf. engrauloides, Compsura heterura, Ctenobrycon hauxwellianus, Deuterodon iguape, Diapoma terofali, Galeocharax knerii, Glandulocauda melanogenys, Gnathocharax steindachneri, Gymnocorymbus ternetzi, Hemibrycon polyodon, Hemigrammus unilineatus, Hollandichthys multifasciatus, Hyphessobrycon compressus, Iguanodectes geisleri, Knodus meridae, Landonia latidens, Markiana nigripinnis, Metynnis lippincottianus, Microschemobrycon casiquiare, Moenkhausia xinguensis, Myleus setiger, Odontostilbe pequira, oligosarcus argenteus, orthospinus franciscoensis, Paracheirodon axelrodi, Paragoniates alburnus, Phenacogaster pectinatus, Phenagoniates macrolepis, Piabina argentea, Piaractus mesopotamicus, Poptella brevispina, Probolus heterostomus, Rachoviscus graciliceps, Rhinobrycon negrensis, Rhoadsia altipinna, Roeboexodon guyanensis, Salminus hilarii, Serrabrycon magoi, Stygichthys typhlops, Tetragonopterus argenteus e Triportheus albus.

\section{[1] - distantes entre si (Fig. 59A).}

Gymnotus aff. carapo, Anostomus anostomus, Leporinus fasciatus, Schizodon fasciatus, Erythrinoidea fam. nov, Erythrinus erythrinus, Hoplias malabaricus e characidium bahiensis.

403 - Orifício anterior da narina:

[OYAKAWA, $1998: 6$; e NETTO-FERREIRA, 2006: 273]

\section{[0] - não-tubular (Fig. 59B).}

Chanos chanos, Olivaichthys mesembrinus, Citharinus latus, Distichodus notospilus, Hemistichodus vaillanti, Neolebias unifasciatus, Nannocharax fasciatus, Xenocharax spilurus, Apareiodon piracicabae, Parodon nasus, Saccodon wagneri, Anodus orinocensis, Bivibranchia fowleri, Hemiodus unimaculatus, Curimata ocellata, Curimatopsis macrolepis, Potamorhina latior, Prochilodus nigricans, semaprochilodus insignis, Caenotropus labyrinthicus, Leporellus vittatus, Carnegiella strigata, Gasteropelecus sternicla, Thoracocharax stellatus, Acestrorhynchus falcirostris, Gilbertolus atratoensis, Hydrolycus tatauaia, Roestes molossus, Erythrinoidea fam. nov, Boulengerella maculata, Ctenolucius hujeta, Copeina cf. guttata, Hepsetus odoe, Arnoldichthys spilopterus, Brycinus macrolepidotus, Bryconalestes longipinnis, Chalceus epakros, Characidium bahiensis, Agoniates halecinus, Aphyocharax pusillus, Astyanax mexicanus, Atopomesus pachyodus, Axelrodia reisei, Brittanichthys axelrodi, Brycon pesu, Bryconadenos tanaothoros, Bryconamericus exodon, Bryconops alburnoides, Charax cf. leticiae, Clupeacharax cf. engrauloides, Compsura heterura, Ctenobrycon hauxwellianus, Deuterodon iguape, Diapoma terofali, Galeocharax knerii, Glandulocauda melanogenys, Gnathocharax steindachneri, Gymnocorymbus ternetzi, Hemibrycon polyodon, Hemigrammus unilineatus, Hollandichthys multifasciatus, Hyphessobrycon compressus, Iguanodectes geisleri, Knodus meridae, Landonia latidens, Markiana nigripinnis, Metynnis lippincottianus, Microschemobrycon casiquiare, Moenkhausia xinguensis, Myleus setiger, 
Odontostilbe pequira, oligosarcus argenteus, orthospinus franciscoensis, Paracheirodon axelrodi, Paragoniates alburnus, Phenacogaster pectinatus, Piabina argentea, Piaractus mesopotamicus, Poptella brevispina, Probolus heterostomus, Rachoviscus graciliceps, Rhinobrycon negrensis, Rhoadsia altipinna, Roeboexodon guyanensis, Salminus hilarii, Serrabrycon magoi, Stygichthys typhlops, Tetragonopterus argenteus e Triportheus albus.

\section{[1] - tubular (Fig. 59A).}

Catostomus commersonnii, Gymnotus aff. carapo, Chilodus punctatus, Anostomus anostomus, Leporinus fasciatus, Schizodon fasciatus, Lebiasina bimaculata, Piabucina astrigata, Erythrinus erythrinus, Hoplias malabaricus e Crenuchus spilurus.

\section{[?] - indeterminado.}

Phenagoniates macrolepis.

404 - Membrana adiposa sobre o olho:

[ZANATA, 2000: 144, modificado; ZANATA \& VARI, 2005: 197, modificado; LIMA, 2006: 63; e NetTo-FerReira, 2006: 274, modificado]

\section{(Minimamente conectado) .}

[0] - ausente, ou pouco desenvolvida (Fig. 59B).

Catostomus commersonnii, Olivaichthys mesembrinus, Citharinus latus, Distichodus notospilus, Hemistichodus vaillanti, Neolebias unifasciatus, Nannocharax fasciatus, Xenocharax spilurus, Apareiodon piracicabae, Saccodon wagneri, Curimatopsis macrolepis, Carnegiella strigata, Gasteropelecus sternicla, Thoracocharax stellatus , Acestrorhynchus falcirostris, Gilbertolus atratoensis, Roestes molossus, Erythrinoidea fam. nov, Boulengerella maculata, Ctenolucius hujeta, Copeina cf. guttata, Lebiasina bimaculata, Piabucina astrigata, Erythrinus erythrinus, Hoplias malabaricus, Hepsetus odoe, Crenuchus spilurus, Aphyocharax pusillus, Astyanax mexicanus, Atopomesus pachyodus, Axelrodia reisei, Brittanichthys axelrodi, Bryconadenos tanaothoros, Bryconamericus exodon, Charax cf. leticiae, clupeacharax cf. engrauloides, Compsura heterura, ctenobrycon hauxwellianus, Deuterodon iguape, Diapoma terofali, Glandulocauda melanogenys, Gnathocharax steindachneri, Gymnocorymbus ternetzi, Hemibrycon polyodon , Hemigrammus unilineatus, Hollandichthys multifasciatus, Hyphessobrycon compressus, Iguanodectes geisleri, Knodus meridae, Landonia latidens, Markiana nigripinnis, Microschemobrycon casiquiare, Odontostilbe pequira, Paracheirodon axelrodi, Paragoniates alburnus, Phenacogaster pectinatus, Phenagoniates macrolepis, Piaractus mesopotamicus, Poptella brevispina, Rachoviscus graciliceps, Rhinobrycon negrensis, Rhoadsia altipinna, Salminus hilarii, Serrabrycon magoi e Tetragonopterus argenteus.

\section{[1] - recobrindo bordas do olho (Fig. 60B).}

Prochilodus nigricans, Semaprochilodus insignis, Caenotropus labyrinthicus, Chilodus punctatus, Anostomus anostomus, Leporellus vittatus, Leporinus fasciatus, Schizodon fasciatus, Hydrolycus tatauaia, Arnoldichthys spilopterus, Brycinus macrolepidotus, Bryconalestes longipinnis, Chalceus epakros, Brycon pesu, Galeocharax knerii, Metynnis lippincottianus, Moenkhausia xinguensis, Myleus setiger, oligosarcus argenteus, orthospinus franciscoensis, Piabina argentea, Probolus heterostomus, Triportheus albus.

\section{[2] - recobrindo todo, ou quase todo o olho (Fig. 60A).}

Chanos chanos, Gymnotus aff. carapo, Anodus orinocensis, Bivibranchia fowleri, Hemiodus unimaculatus, Curimata ocellata, Potamorhina latior, Agoniates halecinus e Bryconops alburnoides.

\section{[-] - inaplicável.}

Stygichthys typhlops.

\section{[?] - indeterminado.}

Parodon nasus, Characidium bahiensis e Roeboexodon guyanensis.

405 - 0lho:

[FINK \& FINK, 1981, 16 modificado] 
(Minimamente conectado).

[0] - ausente .

Stygichthys typhlops.

[1] - pequeno.

Olivaichthys mesembrinus, Gymnotus aff. carapo, Erythrinoidea fam. Nov.

\section{[2] - desenvolvido.}

Chanos chanos, Catostomus commersonnil, Citharinus latus, Distichodus notospilus, Hemistichodus vaillanti, Neolebias unifasciatus, Nannocharax fasciatus, Xenocharax spilurus, Apareiodon piracicabae, Parodon nasus, Saccodon wagneri, Anodus orinocensis, Bivibranchia fowleri, Hemiodus unimaculatus, Curimata ocellata, Curimatopsis macrolepis, Potamorhina latior, Prochilodus nigricans, Semaprochilodus insignis, Caenotropus labyrinthicus, Chilodus punctatus, Anostomus anostomus, Leporellus vittatus, Leporinus fasciatus, Schizodon fasciatus, Carnegiella strigata, Gasteropelecus sternicla, Thoracocharax stellatus, Acestrorhynchus falcirostris, Gilbertolus atratoensis, Hydrolycus tatauaia, Roestes molossus, Boulengerella maculata, Ctenolucius hujeta, Copeina cf. guttata, Lebiasina bimaculata, Piabucina astrigata, Erythrinus erythrinus, Hoplias malabaricus, Hepsetus odoe, Arnoldichthys spilopterus, Brycinus macrolepidotus, Bryconalestes longipinnis, Chalceus epakros, Characidium bahiensis, Crenuchus spilurus, Agoniates halecinus, Aphyocharax pusillus, Astyanax mexicanus, Atopomesus pachyodus, Axelrodia reisei, Brittanichthys axelrodi, Brycon pesu, Bryconadenos tanaothoros, Bryconamericus exodon, Bryconops alburnoides, Charax cf. leticiae, Clupeacharax cf. engrauloides, Compsura heterura, Ctenobrycon hauxwellianus, Deuterodon iguape, Diapoma terofali, Galeocharax knerii, Glandulocauda melanogenys, Gnathocharax steindachneri, Gymnocorymbus ternetzi, Hemibrycon polyodon, Hemigrammus unilineatus, Hollandichthys multifasciatus, Hyphessobrycon compressus, Iguanodectes geisleri, Knodus meridae, Landonia latidens, Markiana nigripinnis, Metynnis lippincottianus, Microschemobrycon casiquiare, Moenkhausia xinguensis, Myleus setiger, odontostilbe pequira, Oligosarcus argenteus, orthospinus franciscoensis, Paracheirodon axelrodi, Paragoniates alburnus, Phenacogaster pectinatus, Phenagoniates macrolepis, Piabina argentea, Piaractus mesopotamicus, Poptella brevispina, Probolus heterostomus, Rachoviscus graciliceps, Rhinobrycon negrensis, Rhoadsia altipinna, Roeboexodon guyanensis, Salminus hilarii, Serrabrycon magoi, Tetragonopterus argenteus e Triportheus albus.

406 - Ossos escleróticos:

[FINK \& FINK, 1981: 17]

[0] - ausente.

olivaichthys mesembrinus, Gymnotus aff. carapo, Erythrinoidea fam. nov, Hepsetus odoe e Glandulocauda melanogenys.

\section{[1] - presentes.}

Catostomus commersonnii, Citharinus latus, Hemistichodus vaillanti, Nannocharax fasciatus, Xenocharax spilurus, Apareiodon piracicabae, Parodon nasus, Saccodon wagneri, Anodus orinocensis, Hemiodus unimaculatus, Curimata ocellata, Curimatopsis macrolepis, Potamorhina latior, Prochilodus nigricans, Semaprochilodus insignis, Caenotropus labyrinthicus, Anostomus anostomus, Leporellus vittatus, Leporinus fasciatus, Schizodon fasciatus, Carnegiella strigata, Acestrorhynchus falcirostris, Hydrolycus tatauaia, Roestes molossus, Boulengerella maculata, Ctenolucius hujeta, copeina cf. guttata, Lebiasina bimaculata, Piabucina astrigata, Erythrinus erythrinus, Hoplias malabaricus, Arnoldichthys spilopterus, Brycinus macrolepidotus, Bryconalestes longipinnis, Chalceus epakros, Characidium bahiensis, Crenuchus spilurus, Agoniates halecinus, Astyanax mexicanus, Atopomesus pachyodus, Axelrodia reisei, Brycon pesu, Bryconadenos tanaothoros, Bryconamericus exodon, Bryconops alburnoides, Clupeacharax cf. engrauloides, Compsura heterura, Ctenobrycon hauxwellianus, Deuterodon iguape, Diapoma terofali, Galeocharax knerii, Gnathocharax steindachneri, Gymnocorymbus ternetzi, Hemibrycon polyodon, Hollandichthys multifasciatus, Iguanodectes geisleri, Landonia latidens, Metynnis lippincottianus, Microschemobrycon casiquiare, Moenkhausia xinguensis, Myleus setiger, Orthospinus franciscoensis, Phenacogaster pectinatus, Phenagoniates macrolepis, Piabina argentea, Piaractus mesopotamicus, Rachoviscus graciliceps, Roeboexodon guyanensis, Salminus hilarii e Triportheus albus. 


\section{[-] - inaplicável.}

Stygichthys typhlops.

\section{[?] - indeterminado.}

Chanos chanos, Distichodus notospilus, Neolebias unifasciatus, Bivibranchia fowleri, Chilodus punctatus, Gasteropelecus sternicla, Thoracocharax stellatus, Gilbertolus atratoensis, Aphyocharax pusillus, Brittanichthys axelrodi, Charax cf. leticiae, Hemigrammus unilineatus, Hyphessobrycon compressus, Knodus meridae, Markiana nigripinnis, Odontostilbe pequira, oligosarcus argenteus, Paracheirodon axelrodi, Paragoniates alburnus, Poptella brevispina, Probolus heterostomus, Rhinobrycon negrensis, Rhoadsia altipinna, Serrabrycon magoi e Tetragonopterus argenteus.

407 - Cartilagens esclerótica:

\section{[0] - duas (dorsal e ventral).}

Catostomus commersonnii, Citharinus latus, Hemistichodus vaillanti, Nannocharax fasciatus, Xenocharax spilurus, Apareiodon piracicabae, Parodon nasus, Saccodon wagneri, Anodus orinocensis, Hemiodus unimaculatus, Curimata ocellata, Curimatopsis macrolepis, Potamorhina latior, Prochilodus nigricans, Semaprochilodus insignis, Caenotropus labyrinthicus, Anostomus anostomus, Leporellus vittatus, Leporinus fasciatus, Schizodon fasciatus, Acestrorhynchus falcirostris, Copeina cf. guttata, Lebiasina bimaculata, Piabucina astrigata, Erythrinus erythrinus, Hoplias malabaricus, Hepsetus odoe, Brycinus macrolepidotus, Characidium bahiensis, crenuchus spilurus, Atopomesus pachyodus, Gnathocharax steindachneri, Iguanodectes geisleri, Landonia latidens, Metynnis lippincottianus, Myleus setiger, Piaractus mesopotamicus, Rachoviscus graciliceps, Salminus hilarii

\section{[1] - uma (ventral).}

Roestes molossus, Bryconalestes longipinnis, Agoniates halecinus, Axelrodia reisei, Brycon pesu, Bryconadenos tanaothoros, Bryconamericus exodon, Bryconops alburnoides, Clupeacharax cf. engrauloides, Compsura heterura, Deuterodon iguape, Diapoma terofali, Hemibrycon polyodon, Hollandichthys multifasciatus, Microschemobrycon casiquiare, Moenkhausia xinguensis, Orthospinus franciscoensis, Phenacogaster pectinatus, Phenagoniates macrolepis, Piabina argentea, Roeboexodon guyanensis e Triportheus albus.

\section{[2] - nenhuma.}

Boulengerella maculata, Ctenolucius hujeta, Arnoldichthys spilopterus, Chalceus epakros, Astyanax mexicanus, Glandulocauda melanogenys e Gymnocorymbus ternetzi.

[3] - quatro em "X".

Carnegiella strigata.

\section{[-] - inaplicável.}

Olivaichthys mesembrinus, Gymnotus aff. carapo, Erythrinoidea fam. nov. e Stygichthys typhlops.

\section{[?] - indeterminado.}

Chanos chanos, Distichodus notospilus, Neolebias unifasciatus, Bivibranchia fowleri, Chilodus punctatus, Gasteropelecus sternicla, Thoracocharax stellatus, Gilbertolus atratoensis, Hydrolycus tatauaia, Aphyocharax pusillus, Brittanichthys axelrodi, Charax cf. leticiae, Ctenobrycon hauxwellianus, Galeocharax knerii, Hemigrammus unilineatus, Hyphessobrycon compressus, Knodus meridae, Markiana nigripinnis, Odontostilbe pequira, oligosarcus argenteus, Paracheirodon axelrodi, Paragoniates alburnus, Poptella brevispina, Probolus heterostomus, Rhinobrycon negrensis, Rhoadsia altipinna, Serrabrycon magoi e Tetragonopterus argenteus.

408 - Região abdominal:

[0] - com escamas. 
Chanos chanos, Catostomus commersonnii, Olivaichthys mesembrinus, Gymnotus aff. carapo, Citharinus latus, Distichodus notospilus, Hemistichodus vaillanti, Neolebias unifasciatus, Nannocharax fasciatus, Xenocharax spilurus, Apareiodon piracicabae, Parodon nasus, Saccodon wagneri, Anodus orinocensis, Bivibranchia fowleri, Hemiodus unimaculatus, Curimata ocellata, Curimatopsis macrolepis, Potamorhina latior, Prochilodus nigricans, Semaprochilodus insignis, Caenotropus labyrinthicus, Chilodus punctatus, Anostomus anostomus, Leporellus vittatus, Leporinus fasciatus, Schizodon fasciatus, Carnegiella strigata, Gasteropelecus sternicla, Thoracocharax stellatus , Acestrorhynchus falcirostris, Gilbertolus atratoensis, Hydrolycus tatauaia, Roestes molossus, Erythrinoidea fam. nov, Boulengerella maculata, Ctenolucius hujeta, Copeina cf. guttata, Lebiasina bimaculata, Piabucina astrigata, Erythrinus erythrinus, Hoplias malabaricus, Hepsetus odoe, Arnoldichthys spilopterus, Brycinus macrolepidotus, Bryconalestes longipinnis, Chalceus epakros, Characidium bahiensis, Crenuchus spilurus, Agoniates halecinus, Aphyocharax pusillus, Astyanax mexicanus, Atopomesus pachyodus, Axelrodia reisei, Brittanichthys axelrodi, Brycon pesu, Bryconadenos tanaothoros, Bryconamericus exodon, Bryconops alburnoides, Charax cf. leticiae, Clupeacharax cf. engrauloides, Compsura heterura, Ctenobrycon hauxwellianus, Deuterodon iguape, Diapoma terofali, Galeocharax knerii, Glandulocauda melanogenys, Gnathocharax steindachneri, Gymnocorymbus ternetzi, Hemibrycon polyodon, Hemigrammus unilineatus, Hollandichthys multifasciatus, Hyphessobrycon compressus, Iguanodectes geisleri, Knodus meridae, Landonia latidens, Markiana nigripinnis, Microschemobrycon casiquiare, Moenkhausia xinguensis, Odontostilbe pequira, Oligosarcus argenteus, orthospinus franciscoensis, Paracheirodon axelrodi, Paragoniates alburnus, Phenacogaster pectinatus, Phenagoniates macrolepis, Piabina argentea, Poptella brevispina, Probolus heterostomus, Rachoviscus graciliceps, Rhinobrycon negrensis, Rhoadsia altipinna, Roeboexodon guyanensis, Salminus hilarii, Serrabrycon magoi, Stygichthys typhlops, Tetragonopterus argenteus e Triportheus albus.

\section{[1] - com espinhos.}

Metynnis lippincottianus, Myleus setiger e Piaractus mesopotamicus.

409 - Bulbo olfativo:

[Fink \& Fink, 1981: 123; Buckup, 1998: 75 e Zanata \& Vari, 2005: 196]

\section{[0] - curto.}

Chanos chanos, Anodus orinocensis, Bivibranchia fowleri, Hemiodus unimaculatus Curimata ocellata, Curimatopsis macrolepis, Potamorhina latior, Prochilodus nigricans, Semaprochilodus insignis, Caenotropus labyrinthicus, Chilodus punctatus, Anostomus anostomus, Leporellus vittatus, Leporinus fasciatus, Schizodon fasciatus, Carnegiella strigata, Gasteropelecus sternicla, Thoracocharax stellatus, Acestrorhynchus falcirostris, Gilbertolus atratoensis, Hydrolycus tatauaia, Roestes molossus, Erythrinoidea fam. nov, Boulengerella maculata, Ctenolucius hujeta, Copeina cf. guttata, Lebiasina bimaculata, Piabucina astrigata, Erythrinus erythrinus, Hoplias malabaricus, Hepsetus odoe, Arnoldichthys spilopterus, Brycinus macrolepidotus, Bryconalestes longipinnis, Chalceus epakros, Characidium bahiensis, Crenuchus spilurus, Agoniates halecinus, Aphyocharax pusillus, Astyanax mexicanus, Atopomesus pachyodus, Axelrodia reisei, Brittanichthys axelrodi, Brycon pesu, Bryconadenos tanaothoros, Bryconamericus exodon, Bryconops alburnoides, Charax cf. leticiae, Clupeacharax cf. engrauloides, compsura heterura, Ctenobrycon hauxwellianus, Deuterodon iguape, Diapoma terofali, Galeocharax knerii, Glandulocauda melanogenys, Gnathocharax steindachneri, Gymnocorymbus ternetzi, Hemibrycon polyodon, Hemigrammus unilineatus, Hollandichthys multifasciatus, Hyphessobrycon compressus, Iguanodectes geisleri, Knodus meridae, Landonia latidens, Markiana nigripinnis, Metynnis lippincottianus, Microschemobrycon casiquiare, Moenkhausia xinguensis, Myleus setiger, Odontostilbe pequira, oligosarcus argenteus, orthospinus franciscoensis, Paracheirodon axelrodi, Paragoniates alburnus, Phenacogaster pectinatus, Phenagoniates macrolepis, Piabina argentea, Piaractus mesopotamicus, Poptella brevispina, Probolus heterostomus, Rachoviscus graciliceps, Rhinobrycon negrensis, Rhoadsia altipinna, Roeboexodon guyanensis, Salminus hilarii, Serrabrycon magoi, Stygichthys typhlops, Tetragonopterus argenteus e Triportheus albus.

\section{[1] - alongado.}

Apareiodon piracicabae, Parodon nasus, Saccodon wagneri, Catostomus commersonnii, olivaichthys mesembrinus, Gymnotus aff. carapo, Citharinus latus, Distichodus notospilus, Hemistichodus vaillanti, Neolebias unifasciatus, Nannocharax fasciatus e Xenocharax spilurus. 


\subsection{ANÁLISE}

Como mais detalhado em Métodos e Materiais, a busca realizada utilizou-se de implementações que auxiliam em explorar mais intensamente o espaço de árvores evitando o problema comumente conhecido como "ilhas de árvores", ou ótimos locais. Este tipo de abordagem é fundamental em matrizes com muitos táxon e tem se tornado padrão em análises com mais 100 terminais. As três categorias destas implementações forma utilizadas (perturbação nos dados, intercâmbio de clados entre cladogramas mais curtos e rearranjo de ramos restritos a subconjuntos), conferindo segurança ao resultado encontrado. Esta busca gerou dois cladogramas mais parcimoniosos (Fig. 61), de 5163 passos. 0 Índice de Consistência destes cladogramas foi de 0.114 e o de Retenção de $\odot .525$. Um sumário das topologias encontradas nestes cladogramas é apresentada na forma de um consenso estrito com os suportes de Bremer por clado (Fig. 62). A otimização dos caractere não foi feita com base no cladograma de consenso e sim nos cladogramas fundamentais, e são apresentadas apenas as transições comuns às duas topologia(Apêndice 2), utilizando os números dos clados dados na Fig. 63. 


\subsection{CONSIDERAÇõES GERAIS SOBRE O PRESENTE ESTUDO}

0 presente estudo representa o mais abrangente versando sobre as relações filogenéticas de grandes grupos de characiformes (Tabela 3 ). Neste estudo foram incluídos representantes das 18 famílias de Characiformes reconhecidas atualmente (BUCKUP, 1998; NELSON, 2006). Procurei incluir no mínimo dois gêneros por família, quando aplicável, com o objetivo de se testar também o monofiletismo de cada família. 0 único outro estudo a se avaliar as 18 famílias conjuntamente foi ORTí \& MEYER (1997), entretanto neste estudo a representatividade em cada família foi muito pequena, principalmente de Characidae. Apesar deste incremento no número de terminais em relação a estudos prévios, a representatividade ainda é modesta diante da diversidade global de Characiformes, já que apenas cerca de $36 \%$ dos gêneros e $6 \%$ das espécies de characiformes foram incluídas. Por isto, como explicitado em Métodos e Materiais, os terminais foram cuidadosamente selecionados de forma a incluir a maior diversidade morfológica e taxonômica. Ao contrário do proposto por WeItzMAn \& MALABARBA (1998), uma abordagem global de characiformes e de Characidae como a realizada aqui, mesmo utilizando apenas caracteres tradicionais é, a meu ver, a melhor maneira de abordar um problema tão complexo. A compartimentalização e delimitação de grupos, baseados em alguns caracteres, é muito suscetível a erro, já que mesmo caracteres tradicionalmente ditos "bons" são sujeitos a homoplasias. Além disto, a falta de um conhecimento e representatividade do grupo-externo leva muitas vezes a graves problemas de polarização, o que certamente acarreta em mudanças significativas das topologias encontradas.

0 baixo valor do índice de consistência, como encontrado no presente estudo $(\odot, 114)$, é esperado em análises de grandes grupos (SANDERSon \& Donoghue, 1989). Em grupos tão inclusivos, é esperado que o tempo evolutivo seja muito maior que em grupos menos inclusivos, permitindo que uma estrutura possa modificar a sua forma repetidas vezes de maneira semelhante, ou ainda que retorne ao estado plesiomórfico em momentos subseqüentes à sua modificação. A importância de homoplasias como mantenedoras da estrutura de cladogramas já foi abordada anteriormente (KÄLLERSJö ET AL., 1999), e a conclusão é que mesmo caracteres extremamente homoplásticos possuem grande importância para sustentar a topologia principalmente de ramos distais. É interessante notar que apesar deste índice, a congruência 
entre os dois cladogramas fundamentais encontrados é quase total, variando apenas na posição de Astyanax mexicanus, que se desloca apenas um nó (Fig. 61).

Como pode ser observado, diferenças profundas nas relações entre as famílias de Characiformes são apresentadas entre a topologia obtida neste e nos estudos anteriores. Resumidamente, a ordem Characiformes aparece composta por dois grandes grupos chamados aqui informalmente de CLADO A e CLADO B. 0 primeiro (CLADO A) é composto pelas famílias crenuchidae, Distichodontidae (parafilético com a inclusão de Citharinidae), Parodontidae, Hemiodontidae, Anostomidae, Chilodontidae, Curimatidae e Prochilodontidae. 0 outro grupo (CLADO B) é composto por todas as dez famílias remanescentes. Apenas três famílias de characiformes não foram corroboradas como monofiléticas: Distichodontidae, com a inclusão de Citharinidae; Alestidae com a inclusão de Serrasalminae e; Lebiasinidae com a inclusão de Erythrinidae. A família Characidae é delimitada com a exclusão dos gêneros Brycon e Salminus.

Abaixo são discutidos os clados mais relevantes, e algumas das sinapomorfias destes clados. Uma lista completa das sinapomorfias de todos os clados pode ser encontrada no Apêndice 2 .

\subsection{MONOFILETISMO DE CHARACIFORMES}

Este estudo não se propõe a formular hipóteses a respeito das relações em Ostariophysi, nem a testar o monofiletismo da ordem Characiformes. Para tal, seria necessária a inclusão de inúmeros terminais das demais ordens de ostariophysi, e dos vários grupos de Clupeomorpha. Entretanto, o número de dados levantados, bem como as novas relações em Characiformes aqui propostas, me permitem algumas considerações sobre este assunto.

Apesar das várias proposições de que Characiformes seria um grupo natural (eg. RoBerTs, 1973), somente FINK \& FINK (1981) o fizeram com base explícita em características derivadas compartilhadas; sugerindo sete sinapomorfias para a ordem: presença de um forame no pró-ótico; abertura dorso-medial da fossa pós-temporal; cápsula lagenar grande; dentes de substituição em fossa ou criptas; dentes multicúspides; presença do processo transverso do terceiro arco neural; e hipural 1 separado do centro composto. Alguns destes caracteres foram questionados por GAYET (1986), mas rebatidos por FINK \& FINK (1996), que mantiveram as mesmas sinapomorfias para Characiformes. Um dos 
caracteres criticados por GAYET (1986) é a presença de um forame no pró-ótico. Ao contrário do afirmado por GAYET (1986) e de acordo com FINK \& FINK (1996), todos os Characiformes examinados possuem o forame. Por outro lado, forames semelhantes ao de characiformes são encontrados em outros grupos relacionados à Characiformes, como Cypriniformes e Clupeomorpha. FINK \& FINK (1981; 1996) argumentaram, entretanto, que o forame de characiformes é único devido a sua posição ventralmente ao otólito utricular, e que o forame em cypriniformes seria o forame vago. Apesar de ter codificado este caráter como proposto por FINK \& FINK $(1981 ; 1996)$, ou seja, sinapomórfico para Characiformes, acredito que mais estudos, principalmente de anatomia mole, em relação a este forame são necessários a fim de se estabelecer com mais confiança a relação de homologia entre os diversos forames no pró-ótico nestes grupos. A presença de dentes multicúspides como sinapomorfia de characiformes também foi criticada por GAYET (1986), sob a alegação de que os dentes multicúspides seriam resultado da fusão de diversos dentes unicúspides. Entretanto, como observado por TRAPANI ET AL. (2005), pequenas cúspides aparentemente se formando separadas durante a desenvolvimento dos dentes nada mais é que artifício da ossificação dos dentes, já que a base do dente se ossifica mais tardiamente. Entretanto, ao se otimizar o caráter 10 (número de cúspides dos dentes pré-maxilares) nos cladogramas obtidos, podemos observar que a presença de dentes multicúspides não é sinapomorfia inequívoca para Characiformes. Mais ainda, das 17 otimizações possíveis para este caráter, apenas em duas o dente multicúspide aparece como sinapomorfia de characiformes. Isto sem mencionar a dificuldade adicional de otimização deste caráter visto Chanos e Catostomus não possuírem dentes. Os outros estados de caráter propostos por FINK \& FINK (1981) como sinapomorfias de Characiformes, mesmo não presente em todas as espécies (eg. cápsula lagenar pequena em Ctenoluciidae), concordam com as observações do presente estudo.

\subsection{CHARACIFORMES BASAIS}

0 único ponto de concordância entre todas as análises filogenéticas prévias de grandes grupos em Characiformes (excetuando UJ, 1990) é que as famílias Distichodontidae e Citharinidae formam um grupo monofilético como grupo mais basal em Characiformes. Esta relação foi primeiramente estabelecida em VARI (1979), que propôs 14 sinapomorfias unindo as duas famílias. A hipótese de que este grupo seria basal em Characiformes foi proposta por FINK \& FINK (1981) com base em quatro caracteres presentes em Distichodontidae e Citharinidae 
e considerado pelos autores como plesiomórficos para characiformes (arco neural da quarta vértebra autógeno, junção sincondral entre os arcos da terceira e quarta vértebra, osso pélvico bifurcado e bulbo olfativo alongado). Estudos morfológicos posteriores não buscaram ou puderam corroborar esta hipótese. Todos estes, ou enraizaram o cladograma em uma espécie de Distichodontidae, ou utilizaram um terminal composto (sumário de características de outros otophysi). Sendo assim, o teste da posição basal de Distichodontidae + Citharinidae, só foi realizado nas duas filogenias moleculares de Characiformes (ORTí \& MEYer, 1997; CALCAGnOtTo ET AL., 2005), onde foram incluídos mais de um terminal de otophysi. É digno de menção, porém, o fato de que ORTí \& MEYER (1997) obtiveram Characiformes nãomonofilético, com Distichodontidae + Citharinidae mais próximos a Siluriformes em algumas de suas análises. Em CALCAgnotto ET AL. (2005) o clado composto por Distichodontidae e Citharinidae e o clado composto por todos os Characiformes menos estas duas famílias estão entre os mais sustentados de toda a análise.

Esta hipótese, amplamente aceita, contrasta com a obtida no presente estudo, onde Characiformes é dividido em dois grandes grupos suprafamiliares, sendo que Distichodontidae (não monofilético) + Citharinidae não estão na posição mais basal de nenhum destes clados. Todos os estados de caracteres apontados por FINK \& FINK (1981) como indicativos de uma posição basal de Citharinidae + Distichodontidae em Characiformes, foram corroborados como presentes quase exclusivamente nestas duas famílias. Entretanto, pela topologia dos cladogramas encontrados, estes não podem ser otimizados como proposto por aqueles autores (ie. como plesiomorfias para a ordem), e são mais parcimoniosamente otimizados como sinapomorfias para estas duas famílias ou grupos mais abrangentes. À primeira vista, isto pode parecer decorrente das relações no grupo-externo, já que todos os demais Otophysi (Cypriniformes, Siluriformes e Gymnotiformes) aparecem como grupo-irmão de Characiformes, ao contrário do proposto por FINk \& Fink (1981) onde Cypriniformes é o Otophysi mais basal. Entretanto, mesmo otimizando estes caracteres em um cladograma com as relações de Otophysi como propostas por FINK \& FINK (1981), não é possível recobrálos como plesiomórficos para Characiformes, e sim como reversões. É interessante notar que ao se enraizar o cladograma de Buckup (1998) entre crenuchidae e o resto dos Characiformes é possível obter um agrupamento monofilético composto de Anostomoidea (sensu Buckup, 1998), Parodontidae, Citharinidae e Distichodontidae. Um teste adicional a 
hipótese apresentada por mim, seria a inclusão de mais alguns terminais de ostariophysi e clupeomorpha.

\subsection{MONOFILETISMO DO CLADO A}

Um clado composto exclusivamente pelas famílias crenuchidae, Distichodontidae (parafilética), Citharinidae, Parodontidae, Hemiodontidae, Prochilodontidae, Curimatidae, Anostomidae e Chilodontidae (Fig. 61) é proposto pela primeira vez neste estudo. Este clado possui nove sinapomorfias não-ambíguas (Apêndice 2). Dentre estas sinapomorfias, podemos destacar a presença do processo ânteroventral do mesetmóide (caráter 85:1), terceira fossa pós-temporal presente entre o epoccipital e o exoccipital (caráter 111:2) e nove ou menos raios ramificados na nadadeira anal (caráter 292:0). Os processos ântero-dorsais do mesetmóide (Fig. 34) que são chamados também de mesetmóide trifurcado (VARI, 1979) são processos que se articulam com o pré-maxilar, e que não devem ser confundidas com as asas laterais do mesetmóide (WEITZMAN, 1962). Este caráter foi apontado por FINK \& FINK (1981) como uma sinapomorfia de Characiphysi, por estar presente também em Gymnotiformes e Siluriformes. Esta estrutura em Gymnotus é um pouco diferente da encontrada em Characiformes (mas foi codificada como igual, seguindo estes autores) e em olivaichthys é ausente, assim, a presença destes processos é interpretada como sinapomorfia para o CLADO A, com reversão em Hemiodontidae + Anostomoidea (sensu BuckUp, 1998), reaparecendo em Prochilodontidae e Anodus. 0 interessante deste caráter é que a presença destes processos permite uma conexão "elástica" com o mesetmóide, seja por meio de uma fossa articular no mesetmóide (Crenuchidae e Distichodontidae) ou por meio de uma depressão no pré-maxilar. No CLADO B do presente estudo (ver abaixo), o pré-maxilar se posiciona dorsalmente ao mesetmóide de forma fixa. Outro caráter interessante é a presença de uma terceira fossa pós-temporal. Apesar deste caráter ter sido codificado como maximamente conectado, permitindo o surgimento da fossa em diferentes posições independentemente, o caráter também poderia ter sido codificado como dois, um presença/ausência da fossa e o outro da posição da fossa. Na forma como foi codificado, a fossa entre o epoccipital e o exoccipital surge na base do CLADO A, se transformando em fossa restrita ao epoccipital no clado (Parodontidae (Hemiodontidae(Anostomoidea))), com o desaparecimento da fossa em Anostomoidea e reaparecimento restrita ao epoccipital (estado 1) e entre o epoccipital e exoccipital (estado 2) em Curimatidae. Caso 
tivesse optado pela segunda opção de codificação, a presença da fossa seria sinapomorfia do CLADO A com reversão em Anostomoidea.

\subsection{RELAÇõES DE DISTICHODONTIDAE E CITHARINIDAE}

Como mencionado acima (5.3), este é o primeiro estudo que gera uma hipótese onde Distichodontidae e Citharinidae não formam o grupoirmão de todos os outros characiformes. 0 monofiletismo de Distichodontidae também é contestado pela primeira vez desde que foi proposto (VARI, 1979). A relação de grupo-irmão entre Distichontidae (incluindo Citharinidae) com (Parodontidae (Hemiodontidae, Anostomoidea)) é suportada aqui por 13 sinapomorfias não-ambíguas, dentre estas podemos destacar os dentes fracamente implantados no prémaxilar (13:1), o processo ascendente do maxilar no mesmo plano ou anterior ao pré-maxilar (23:1), quilha ventral no osso pélvico (268:1) e a porção proximal da primeira costela angulosa (345:1). Um caráter muito interessante neste clado é a redução da associação dos dentes no pré-maxilar. É possível observar uma "tendência" a uma implantação cada vez mais fraca dos dentes, até a completa ausência (Curimatidae e Anodus) ou a implantação no lábio (Prochilodontidae). Esta mudança na forma de inserção dos dentes destes peixes, está intimamente relacionada à mudança dos hábitos alimentares nestes peixes, quando comparado com os grupos basais do CLADO B e os grupos basais de Siluriformes e Gymnotiformes. Passando de predadores, a raspadores, micro-predadores e iliófagos. Anostomidae pode parecer uma exceção, já que são herbívoros e notórios pelos dentes robustos, mas os seus dentes são fracamente implantados nas maxilas, sem qualquer ossificação entre os dentes e os ossos. Além disto, nas espécies deste grupo (CLADO A, exceto Crenuchidae) a primeira costela é angulosa. Nos demais Characiformes a costela forma um arco da sua base à extremidade distal, mas neste grupo a porção proximal é quase paralela á coluna vertebral, e bruscamente se direciona ventralmente, conferindo o aspecto anguloso à costela.

$\mathrm{Na}$ presente análise, as espécies incluídas atualmente em Distichodontidae não formam um grupo monofilético, já que Citharinidae foi recobrada como mais relacionada à Xenocharax (Fig. 63; Clado 105) tendo como sucessivos grupos-irmão outras espécies de Distichodontidae. Este grupo (Clado 108; Distichodontidae e Citharinidae) é sustentado por 16 sinapomorfias não-ambíguas, incluindo as plesiomorfias utilizadas por FINK \& FINK (1981) para posicionar Distichodontidae + Citharinidae na base de Characiformes. 
Apesar de Distichodontidae ter sido após VARI (1979) amplamente considerado monofilético, as evidências fornecidas pelo autor são poucas (seis sinapomorfias). Destas, três não foram avaliadas por mim, a conexão da seção A1 do adductor mandibulae na maxila e a mobilidade entre o mesetmóide e o pré-maxilar (este na verdade foi avaliado indiretamente em uma série de caracteres morfológicos que permitem esta mobilidade [ver acima]). As outras três o são interpretados como sinapomorfias de Distichodontidae, com reversão em Citharinus (escama ctenóide [362:3] e osso pélvico bifurcado [255:๑]), sinapomorfia para um grupo menos inclusivo de Distichodontidae (posição do supra-orbital [173:๑]) ou como plesiomórfico para o Distichosontidae como proposto aqui (processos posteriores do etmóide lateral [100:0]). ROBERTs (1969) apesar de não realizar uma análise filogenética sugeriu que Citharidium poderia ser um "intermediário" entre Xenocharax e Citharinus.

\subsection{RELAÇõES DE PARODONTIDAE, HEMIODONTIDAE E ANOSTOMOIDEA}

Estas seis famílias foram frequentemente vistas como grupos "relacionados", com composições diferentes (eg. GüNTHER, 1865), onde muitas vezes em conjunto também com espécies de Citharinidae e crenuchidae (eg. BOULENGER, 1904). VARI (1983) estabeleceu uma relação mais próxima entre as quatro famílias que atualmente compõem o grupo Anostomoidea (Curimatidae, Prochilodontidae, Anostomidae e Chilodontidae), mas não se estende nos comentários acerca das relações deste grupo com outras famílias de characiformes, se limitando a dizer que alguns caracteres encontrados em outras famílias, observados também em um ou mais membros de Anostomoidea seriam homoplástico. A hipótese de um Anostomoidea monofilético tem sido corroborada em estudos que se seguiram (ver INTRODUÇÃO), assim como no presente estudo, assim não serão abordadas nesta discussão. Em dois dos quatro cladogramas fundamentais de Buckup (1998), Parodontidae aparece como grupo-irmão de Anostomoidea, e em todos os cladogramas Hemiodontidae é considerado grupo-irmão de todos os characiformes, exceto Distichodontidae, Citharinidae, Crenuchidae, Parodontidae e Anostomoidea. Esta hipótese levou LANGEANI (1998) a considerar uma série de caracteres presentes em Hemiodontidae e Anostomoidea, e principalmente entre Hemiodontidae e Parodontidae como homoplásticos. $\mathrm{Na}$ hipótese aqui proposta, das 17 sinapomorfias de LANGEANI (1998), algumas como a terceira fossa pós-temporal restrita ao epoccipital, inserção fraca dos dentes nas maxilas, projeção posterior do cleitro e 
forma das asas laterais do uro-hial podem ser interpretadas também como plesiomórficas para Hemiodontidae. CALCAgnOTTO ET AL. (2005) propuseram um grupo fracamente suportado composto por Hemiodontidae + Parodontidae como grupo-irmão de Anostomoidea. Na presente análise, este grupo recobrado por CALCAGNOTTO ET AL (2005) é sustentado por 18 sinapomorfias não ambíguas. Algumas destas são: mais de uma fileira de dentes de substituição no pré-maxilar (caráter 15:1), terceira fossa pós-temporal restrita ao epoccipital (caráter 111:1), processo posterior do epoccipital (caráter 113:1), basibranquial 1 reduzido ou ausente (caráter 201:1) e trato digestivo concentrado anteriormente (caráter 387:1). Todos estes caracteres sofrem reversão em algum grupo mais restrito. Um caráter adicional pode ainda corroborar a relação entre estas seis famílias: a presença de músculo sônico (caráter 400:1), apesar de ser interpretado como tal em apenas uma das quatro possíveis otimizações. Este caráter, na verdade, é mais complexo e é melhor descrito como aparato sonoro, visto que conjuga modificações nas costelas e musculatura da parede do corpo. Estas modificações só estão presentes em machos e apenas na época reprodutiva. A produção de som possivelmente desempenha um papel crucial durante a reprodução, possivelmente na atração da fêmea. Como estas modificações não estão presentes em todos os espécimes, já que depende do período reprodutivo, a sua codificação como ausente pode não ser significativa. 0 fato de não ser atribuído como sinapomorfia deste clado é em decorrência da codificação como indeterminado nos gêneros de menor porte destas famílias (ie. Bivibranquia, Curimatops e Chilodus )

Já a relação entre Hemiodontidae + Anostomoidea é sustentada por 13 sinapomorfias não-ambíguas, dentre elas o faringobranquial 3 sem dentes (caráter 208:1) e osso pélvico com porção anterior em forma de meia-lua (caráter 255:2). As relações recobradas em Anostomoidea são as mesmas encontradas por VARI (1983), VARI (1989a), VARI ET AL. (1995) E CASTRO \& VARI (2004).

\subsection{MONOFILETISMO E RELAÇõES DO CLADO B}

Este clado é coincidente com o clado 12 de Buckup (1998), para o qual o autor fornece cinco sinapomorfias: mesetmóide sem projeção ântero-ventral, asa lateral do mesetmóide bem desenvolvida, interdigitação da sínfise do dentário, mais de uma fileira de dentes no pré-maxilar e mais de 13 raios na nadadeira anal. Exceto pela interdigitação da sínfise do dentário, nenhum dos outros caracteres 
puderam ser otimizados nos meus resultados de forma não ambígua neste nó. 0 mesetmóide com projeção ântero-ventral é considerado aqui como uma sinapomorfia do CLADO A. Este clado é sustentado no presente estudo por 13 sinapomorfias não-ambíguas e possui índice de Bremer de 1. Entre estas é possível observar que existe uma mudança radical na organização da maxila superior. Estas modificações podem ser sumarizadas em dois caracteres: o pré-maxilar dorsal ao mesetmóide (caráter 5:1) e o ramo ascendente do pré-maxilar conspícuo (caráter $27: 1$ ). Neste grupo os peixes geralmente apresentam, então, um processo grande do pré-maxilar repousando sobre a asa lateral do mesetmóide, estas estruturas são fortemente ligadas a por meio de tecido conjuntivo, tornando o pré-maxilar imóvel. Esta imobilidade certamente permitiu uma manipulação de alimentos mais duros, e com isto a exploração de um espectro alimentar mais amplo.

o CLADO B é composto por dois sub-clados, o primeiro (Clado 154) composto por Lebiasinidae (contendo Erythrinidae e Erythrinoidea fam. nov.) + Alestidae (incluindo Serrasalminae) e o segundo (Clado 143) é composto por um clado formado por Characidae (exceto Brycon e Salminus) e outro por Salminus, Brycon, Cynodontidae, Acestrorhynchidae, Hepsetidae e Ctenoluciidae. Como resultado desta topologia, Erythrinoidea em sua concepção atual é polifilética, com duas de suas famílias mais relacionadas com Alestidae (incluindo Serrasalmidae) em um clado distinto das demais famílias, estas por sua vez mais relacionadas às famílias Acestrorhynchidae, Cynodontidae e Characidae. É interessante notar que apesar do polifiletismo de Erythrinoidea ser uma hipótese nova, todos os grupos que aparecem mais relacionados a um dos componentes deste grupo (Ctenoluciidae, Hepsetidae, Lebiasinidae e Erythrinidae) já haviam sido propostos anteriormente como próximo de Erythrinoidea (sensu BuckUp, 1998). Alestidae foi proposto como o grupo-irmão de (Hepsetidae (Ctenoluciidae, Lebiasinidae)) por CALCAGNOTTO ET AL (2005), enquanto ZANATA \& VARI (2005) recobrou Alestidae como grupo irmão de Hepsetidae + Erythrinidae (esta porção do cladograma não foi apresentada na publicação, apresentada apenas em NetTo-Ferreira, 2006: fig. 7). Já Acestrorhynchidae foi considerado por BuckuP (1998) como grupo-irmão de Erythrinoidea, e por NeTTO-FERREIRA (2006) de um grupo menos inclusivo composto por Ctenoluciidae + Hepsetidae.

o grupamento composto apenas por Hepsetidae, Ctenoluciidae, Erythrinidae e Lebiasinidae, foi sustentado em estudos anteriores por quatro sinapomorfias (LUCENA, 1993; VARI, 1995), cinco sinapomorfias 
(OYAKAWA, 1998) ou 11 sinapomorfias (BuckUP, 1998). Sendo elas, nasal lamelar, ausência do canal supra-orbital no parietal, espinho do supraoccipital recoberto por escamas, discreto ligamento entre 0 tripus e a base da quarta costela pleural, ausência de fontanela, rinesfenóide ausente, canal supra-orbital não se ligando ao canal pterótico, supra-orbital ausente, espinho do terceiro arco neural ausente ou lateral, costela da quinta vértebra com processo medial na sua base, nadadeira anal curta, um epural, um par de uroneural e dilatator operculi se extendendo anteriormente. Todos estes estados de caráter, exceto pelo ligamento entre o tripus e a quarta costela pleural e o dilatator operculi não avaliados aqui, estão de fato presente em todos os Erythrinoidea (sensu Buckup, 1998) ou em algum de seus sub-grupos. Entretanto, nas topologias obtidas foram otimizados como originados independentemente. NetTo-FerReIRA (2006) forneceu seis sinapomorfias para o grupo que inclui Erythrinoidea, Acestrorhynchidae e crenuchidae, das quais cinco (sendo uma modificada) foram incluídas na presente análise. Isto mostra que mesmo com quase toda a evidência levantada até hoje para uma relação próxima entre as famílias de Erythrinoidea (sensu Buckup, 1998) incluída na análise, ainda sim não foi possível recobrar este grupo como monofilético ou parafilético (com inclusão Acestrorhynchidae, crenuchidae e Alestidae), demonstrando que a evidência para a não-relação mais próxima entre estas quatro famílias é ainda maior.

0 clado 154 composto por Lebiasinidae, com a inclusão de Erythrinidae, como grupo-irmão de Alestidae com a inclusão de Serrasalmidae é sustentado por seis sinapomorfias não-ambíguas (índice de Bremer 1), dentre elas a ausência de fontanela no frontal (caráter 105:๑), ausência de fontanela no parietal (caráter 108:1) e margem dorso-lateral do crânio reta, sem entalhe (caráter 110:0). Como mencionado acima estes caracteres já foram propostos como sinapomorfia de Erythrinoidea (sensu Buckup, 1998).

Já o clado 143 composto por Characidae (excluindo Brycon e Salminus), como grupo-irmão de (Salminus (Brycon (Cynodontidae (Acestrorhynchidae (Hepsetidae, Ctenoluciidae))))) é suportado por 12 sinapomorfias não ambíguas (índice de Bremer 2), dentre elas temos lamelas divergentes ventrais do mesetmóide desenvolvidas (caráter 91:๑), ossificação dorsal do basi-hial ausente (caráter 182:1) e redução na crista lateral dos primeiros pterigióforos da nadadeira anal (caráter 289:๑). 


\subsection{RELAÇõES DE ERYTHRINIDAE E LEBIASINIDAE}

Como mencionado na introdução, uma relação mais próxima entre Lebiasinidae e Erythrinidae já foi também sugerida por LuCENA (1993), Buckup (1998; em dois de seus quatro cladogramas fundamentais), OYAKAWA (1998) e Netto-Ferreira (2006), contra Vari (1995) e Calcagnotto et al. (2005). A similaridade da morfologia externa entre os peixes destas famílias, principalmente entre Lebiasininae e Erythrinus + Hoplerythrinus é notável. Apesar de WeITZMAN (1964) considerar como resultado de convergência, a presente análise corrobora que estas similaridades devem ser decorrentes de uma relação mais próxima entre estas duas famílias. Este clado (157) é suportado aqui por 21 sinapomorfias não ambíguas, com suporte de bremer igual a 7 . Uma modificação quase exclusiva deste grupo (ocorrendo homoplasticamente em Arnoldichthys e Saccodon) é o posicionamento da câmara pilórica do estômago à esquerda da câmara cardíaca (caráter 189:๑) e a conexão desta câmara com câmara cardíaca também à esquerda (caráter 191: $\odot$ ) . Em quase todos os Characiformes a câmara pilórica do estômago está presente normalmente como uma projeção ventral da câmara cardíaca que se direciona anteriormente até quase o esôfago. Neste ponto ela se dobra dorso-lateralmente, formando uma alça normalmente do lado direito da câmara cardíaca, então se direcionando posteriormente, onde se conecta ao intestino. Este clado (Erythrinidae e Lebiasinidae) é único tanto na conexão como na posição da câmara pilórica que estão à esquerda da câmara cardíaca. Neste clado também ocorre a redução nas asas laterais do uro-hial (caráter 197:๑) e a presença de uma série interna de dentes interna completa no dentário, com reversão a uma série incompleta em Erythrinidae. Um estado de caráter que não pode ser otimizado de forma não-ambígua é a inclinação anterior do epural mediano (caráter 299:2). Apesar deste caráter ocorrer quase exclusivamente neste clado, a inclinação posterior deste epural em Piabucina (estado $\odot$ ) permite a otimização independente do estado 2 para Lebiasina e Copeina + Erythrinidae.

OYAKAWA (1998) propôs que a família Lebiasinidae não seria monofilética, e que Pyrrhulininae e Lebiasininae seriam grupos-irmãos sucessivos de Erythrinidae, fornecendo como evidência oito sinapomorfias não-ambíguas. Entretanto, NeTTO-FeRREIRA (2006) refutou esta hipótese, e considerou a família Lebiasinidae monofilética baseado em 25 sinapomorfias, sendo sete delas exclusivas. No presente estudo, Lebiasinidae é parafilética, e Pyrrhulininae grupo-irmão de Erythrinidae, ao contrário de OYAKAWA (1998). Esta relação é sustentada 
por nove sinapomorfias, mas possui um suporte de Bremer pequeno (2). De todas as sinapomorfias propostas por NetTo-FerReIRA (2006) para Lebiasinidae, no presente trabalho, não avaliei 10 destes caracteres, logo a questão do não-monofiletismo de Lebiasinidae é considerada provisória aqui, dependendo da avaliação destes caracteres adicionais na análise de parcimônia global.

Recentemente, foi descoberto em serrapilheiras alagadas no Rio Negro, um peixe que é um dos Characiformes mais distintos morfológicamente, chamado aqui de Erythrinoidea fam. nov. Possivelmente pelo seu hábito extremamente especializado, ele possui características únicas que muitas vezes só estão presentes em outros otophysi não-Characiformes (eg. órbito-esfenóide separados [de Pinna, Com. Pes.]). É interessante notar que externamente esta espécie é tão modificada, que antes de se examinar exemplares diafanizados, não se podia afirmar com precisão a qual ordem este peixe pertencia. Devido a esta grande modificação morfológica, muitos dos caracteres avaliados no presente estudo foram codificados como indeterminados ou inaplicáveis, e possivelmente por esta razão, durante análises preliminares esta espécie aparecia como grupo mais basal em Characiformes. Entretanto, após a codificação de alguns caracteres de maxilas e dentição, esta espécie foi recobrada como grupo-irmão de Erythrinidae, com base em 20 sinapomorfias. Esta espécie está sendo descrita atualmente, $e$ os autores (PETRY ET AL.) chegaram independentemente a mesma hipótese de que esta espécie, descrita por eles também como família nova, é relacionada a Erythrinoidei (de Pinna, com. pess.). 0 suporte de Bremer deste clado é relativamente alto (7).

\subsection{RELAÇõES DE ALESTIDAE E SERRASALMIDAE}

As relações em Alestidae foram intensamente estudadas nos últimos cinco anos (Murray \& Stewart, 2002; Calcagnotto et al., 2005; Zanata \& Vari, 2005). Todos estes estudos corroboraram a família Alestidae como monofilética, ou pelo menos o seu componente africano. Sendo que ZANATA \& VARI (2005) propuseram Chalceus, um gênero neotropical, como grupoirmão das espécies africanas classificadas em Alestidae. Assim, estes autores incluíram Chalceus em Alestidae, tornando esta a única família de Characiformes com componentes tanto africanos como neotropicais. Na hipótese de CALCAGNOTTO ET AL. (2005), Chalceus é considerado o grupo mais basal de Characidae (incluindo Acestrorhynchidae) enquanto que Alestidae (restrito somente aos gêneros africanos) é o grupo-irmão de 
(Hepsetidae (Ctenoluciidae, Lebiasinidae)). Um ponto em que Calcagnotto ET AL. (2005) e ZANATA \& VARI (2005) concordam é a posição de Arnoldichthys como grupo-irmão de todos os Alestidae africanos (gênero não incluído por MURRAY \& STEWART, 2002). Ao analisar as sinapomorfias de Alestidae (incluindo Chalceus), ZANATA \& VARI (2005) comentaram que grande parte delas são dependentes de otimização, sendo interpretadas como surgindo na base de Alestidae (incluindo Chalceus) e revertendo no clado que inclui todos os Alestidae exceto chalceus e Arnoldichthys. Existe uma diferença muito grande também em termos de número de transições entre o clado que inclui todos os Alestidae excluindo Chalceus em relação ao clado que inclui todos os Alestidae excluindo Chalceus e Arnoldichthys (sete vs. 15). Este mesmo padrão é encontrado por CALCAGNOTTO ET AL. (2005), onde eles obtiveram valores bem diferentes de suporte de Bremer e "Bootstrap" para Alestidae (4 e < $50 \%)$ e para o clado incluindo todos os Alestidae menos Arnoldichthys (24 e 100\%). Isto demonstra que o grupo composto por todos os Alestidae, menos Chalceus e Arnoldichthys é muito melhor corroborado do que os clados que incluem Arnoldichthys e Chalceus. Este fato é relevante para atual análise, já que na hipótese obtida, Serrasalminae, um grupo tradicionalmente visto como uma subfamília de Characidae, aparece como um subgrupo de Alestidae. Na verdade, pela presente hipótese, Serrasalminae é grupo-irmão de um grupo monofilético composto pelos Alestidae exceto Arnoldichthys e Chalceus. Este grupo composto por todos os Alestidae e Serrasalminae, é corroborado por 15 sinapomorfias (suporte de Bremer 3), dentre estas podemos destacar a forma mais baixa dos dentes (caráter 36:1), o endopterigóide não alcançando o palatino (caráter 63:2) e a inclinação mais horizontal do raio pró-corrente ventral mais anterior (caráter 311:1). Já o clado composto por Alestidae e Serrasalminae, menos Chalceus, é corroborado por 12 sinapomorfias (suporte de Bremer 3) dentre estas a projeção posterior na base da primeira e da segunda costela (caráter 347:2) e a forma da câmara anterior da bexiga natatória (caracteres 376:@ e 379:@). Já o clado composto por Serrasalminae e Alestidae (menos Chalceus e Arnoldichthys) possui 13 sinapomorfias (suporte de Bremer 3) dentre elas a mandíbula curta (caráter 32:0) e uma projeção lateral do palatino em direção ao maxilar (caráter 50:1). Três das seis sinapomorfias apontadas por ZANATA \& VARI (2005) para Alestidae não foram analisadas por mim, entretanto, duas destas também estão presentes em Serrasalminae (prémaxilares com interdigitações e porção anterior do ectopterigóide 
estreita), o terceiro caráter (ligamento entre o neurocrânio e o ectopterigóide) não pode ser avaliado inequivocamente.

\subsection{RELAÇÕES DE BRYCON, SALMINUS, ACESTRORHYNCHIDAE, CYNODONTIDAE, CTENOLUCIIDAE E HEPSETIDAE}

Este clado apresenta na sua base dois gêneros usualmente atribuídos à família Characidae, Salminus e Brycon. A posição destes dois gêneros em Characidae e a possível proximidade filogenética entre eles tem sido objeto de vários estudos. Tendo sido considerados como próximos, ao menos em algumas classificações tradicionais (eg. GÉRY, 1977), uma idéia questionada por RoBERTs (1969). Em análises moleculares, Brycon e Salminus têm sido considerados como proximamente aparentados (ORTí \& MEYER, 1997), ou ainda Salminus como um grupo incluído em Brycon (CALCAGnotTo ET AL, 2005). Por outro lado as duas únicas análises morfológicas a incluir estes dois gêneros, obtiveram relações distantes entre eles. A primeira, ZANATA (2000), recobrou Salminus como grupo-irmão de Hoplias + Hepsetus e Brycon como grupoirmão de Characidae, excetuando Bryconops. A segunda (LIMA, 2006) recobrou Salminus como grupo-irmão de Acestrorhynchidae e Brycon em uma tritomia com Lignobrycon + Triportheus e (Hydrolycus (Acestrorhynchus, Salminus). Mesmo obtendo em sua análise Salminus como grupo-irmão de Acestrorhynchus, LIMA (2006) fez uma longa discussão sobre o posicionamento de salminus em characiformes. Indicando através da presença de diversos estados de caracteres considerados pelo autor como possivelmente plesiomórficos para Characidae, que o gênero poderia ser basal em Characidae, grupo-irmão de Alestidae+Characidae, grupo-irmão de Erythrinoidea, ou ainda relacionado de alguma forma à Cynodontidae, Acestrorhynchidae e Erythrinoidea. Os cladogramas para as relações de Salminus obtidos por ZANATA (2000) e LIMA (2006) são parcialmente corroborados no presente estudo, já que este gênero aparece como relacionado a uma clado que compreende Acestrorhynchus e Hepsetus. Este clado, com Salminus na base é corroborado por 14 sinapomorfias e possui índice de Bremer 2 . Dentre as sinapomorfias que o sustentam podemos destacar 0 anel orbital completo (caráter 174:1) e a margem lateral do tripus aproximadamente reta (caráter 324:1). Já Brycon, visto como um Characidae basal ou generalizado (WEITZMAN, 1962; BuckUP, 1998) é aparece como mais relacionado à (Cynodontidae (Acestrorhynchidae (Ctenoluciidae e Hepsetidae))). Este clado é suportado por 11 caracteres e com índice de Bremer de 2. 
0 clado 146 composto por (Cynodontidae (Acestrorhynchidae (Ctenoluciidae e Hepsetidae))) é parcialmente concordante com duas hipóteses anteriores. Isto porque a relação mais próxima de Acestrorhynchidae + Cynodontidae já havia sido proposta por LUCENA \& MENEZES (1998) e a relação de (Acestrorhynchidae (Ctenoluciidae e Hepsetidae)) já havia sido proposta por Netto-Ferreira (2006). É interessante notar que LUCENA \& MENEZES (1998) não incluíram nenhum representante de Hepsetidae ou de Ctenoluciidae e que Netto-Ferreira (2006) não incluiu nenhum representante de Cynodontidae. Este clado composto por estas quatro famílias é suportado por 13 sinapomorfias e possuí índice de Bremer igual a 2. Podendo ser destacadas, o tamanho diminuto do osso corono-meckeliano (caráter 43:0) e a origem dos epineurais anterior ao aparelho de weber (caráter 349:1). 0 segundo caráter foi proposto por LUCENA \& MENEZES (1998) como sinapomorfia para Cynodontidae + Acestrorhynchidae.

A relação de Ctenoluciidae + Hepsetidae corrobora as propostas de Roberts (1969) e NetTo-Ferreira (2006). Esse clado é suportado por 27 sinapomorfias e possuindo suporte de bremer de 19, um dos mais altos de toda a análise. Dentre estes podemos destacar a origem do ductus pneumaticus no lado esquerdo do esôfago/estômago (caráter 386:๑).

\subsection{MONOFILETISMO DE CHARACIDAE E CONSIDERAÇÕES SOBRE SEUS SUBGRUPOS}

Uma delimitação de Characidae, sem incluir Brycon e Salminus é proposta aqui pela primeira vez. Como mencionado acima, os dois gêneros já foram considerados como basais ou fora de characidae independentemente (BUCKUP, 1998; ZANATA, 2000), mas também foram considerados como proximamente relacionados entre si dentro de Characidae (CALCAGNotTo ET AL., 2005). Uma concepção de Characidae muito parecida a esta foi proposta por ORTí \& MEYER (1997), exceto por posicionarem Gnathocharax fora de Characidae, e mais relacionado à Ctenoluciidae. Characidae como aqui delimitado (sem Brycon e Salminus) é suportado por 12 sinapomorfias e possui suporte de Bremer de 2 . Entre as sinapomorfias para este clado podemos destacar o supraorbital ausente (caráter 168:1), asas laterais do uro-hial reduzidas (caráter 197:0), abertura do canal do cerato-hial anterior na sua porção póstero-dorsal (caráter 189:1), primeira divisão dos raios da anal na sua porção distal (caráter 294:1) e número de vértebras précaudais igual ou menor que o número de vértebras caudais (caráter 334:1). A inclusão de numerosos terminais de Characidae teve como principal objetivo uma proposição mais adequada de um grupo 
monofilético ao qual se pudesse atribuir o nome characidae e a definição de possíveis grupos monofiléticos excluídos de Characidae. Também objetivou testar as hipóteses de que Roestinae, Alestidae e Serrasalminae seriam grupos não proximamente relacionados à Characidae. Abaixo são feitas algumas breves considerações sobre os agrupamentos tidos como monofiléticos e o status filogenético das subfamílias aceitas atualmente (REIS ET AL., 2003).

Recentemente, Malabarba \& Weitzman (2003; Fig.16) forneceram uma hipótese de relações em Characidae baseados em quatro caracteres. Pela proposta destes autores, Characidae incluiria todos os terminais usualmente incluídos em Characidae, além de Roestinae, Gasteropelecidae e Serrasalminae, baseado na presença de ganchos nas nadadeiras de machos maduros. Este caráter é de difícil codificação, visto que a presença destes ganchos pode ser sazonal, necessitando uma análise de grande quantidade de material coletado nos períodos reprodutivos. Dentro deste grande grupo, um outro grupo composto pela maior parte das subfamílias reconhecidas em characidae, é delimitado pelos autores pela ausência de supra-orbital. Outro menos inclusivo, denominado pelos autores de clado A, seria definido por possuir quatro dentes na série do dentário e nadadeira dorsal com oito raios ramificados. Nenhum dos clados propostos por estes autores é corroborado na presente análise. Entretanto, foi possível recobrar parcialmente o clado A destes autores (clado 180), com a exclusão de Glandulocaudinae e Stervardiinae. Este clado como proposto por MALABARABa \& Weitzman (2003) também foi corroborado pela análise de Calcagnotto et al. (2005).

A subfamília Characinae não é monofilética, sendo que nenhuma das espécies incluídas desta subfamília estariam mais relacionadas entre si do que com outros characidae. Charax aparece em um clado com Galeocharax e oligosarcus (clado 183). Gnathocharax está posicionado em clado distinto (190) mais proximamente relacionado à Roeboexodon. Por fim, Phenacogaster está incluído no clado 174 junto com alguns Characidae incertae sedis, Cheirodontinae e Rhoadisinae. Esta hipótese para Characinae é parcialmente concordante com LuCENA (1993). Este autor também dividiu o que se reconhece como characinae em três grupos não relacionados. o primeiro na base de Characidae excluindo Agoniates é composto pelas espécies de Heterocharacini e Roestes. Um outro grupo seria composto pelo resto de Characinae e os gêneros de Cynopotaminae (sensu Menezes, 1976). Este clado é equivalente ao clado 182 da presente hipótese. E o terceiro grupo seria composto por Phenacogaster e 
Aphyocharax. Clado este não recobrado aqui, apesar de concordante com a hipótese de LUCENA (1993) de que Phenacogaster não seria mais relacionado com outras espécies de Characinae.

Outra subfamília não corroborada aqui é Cheirodontinae (sensu MALABARBA, 1998), já que o gênero Rhoadsia (único membro incluído da subfamília Rhoadsinae) está mais relacionado com Compsura do que este com Odontostilbe (estes dois últimos representantes de Cheirodontinae). Apesar destes dois grupos, Cheirodontinae e Rhoadsinae serem bem distinto na sua morfologia externa, todas as sinapomorfias apontadas por MALABARBA (1998) para Cheirodontinae (presença de pseudotímpano, ausência de mancha umeral [não avaliada aqui], dentes pedunculados e uma única fileira de dentes) estão também presente em Rhoadsia.

Uma grande subfamília de Characidae, Glandulocaudinae, foi recentemente sugerida como não monofilética, baseados em caracteres histológicos (WeITZMAN ET AL., 2005). Como resultado os autores restringiram Glandulocaudinae ao que era considerada tribo Glandulocaudini e elevaram o grupo composto pelo restante das espécies à subfamília Stervardiinae. Ainda consideraram estas duas como possuindo relações incertas no clado A (de Weitzmann \& Malabarba, 2003). Glandulocaudinae como proposto por estes autores não foi testado aqui, visto que só um terminal foi incluído. Entretanto, Stervardiinae, cujos gêneros Landonia e Diapoma foram incluídos não foi corroborada como monofilética. Landonia seria grupo-irmão do clado 137, enquanto Diapoma seria o grupo-irmão do clado 134. Entretanto, os caracteres propostos por WEITZMAN ET AL. (2005) não foram avaliados aqui.

A subfamília Stethaprioninae definido como monofilética por REIS (1989) é considerada parafilética devido a inclusão de ctenobrycon, um gênero com o corpo alto como os Stethaprioninae.

A subfamília Tetragonopterinae (sensu GéRY, 1977) sempre foi considerada um grupo problemático, por ser na verdade composto por todos aqueles gêneros que não se encaixavam em nenhuma outra subfamília. Uma visão conservadora foi adotada recentemente, ao restringir a subfamília Tetragonopterinae ao gênero Tetragonopterus (REIS ET AL., 2003). A presente hipótese confirma o não-monofiletismo de Tetragonopterinae, sendo que estaria restrito apenas aos gêneros Tetragonopterus e Markiana (clado 195). Esta mesma hipótese de relacionamento mais próximo entre estes dois gêneros já havia sido proposta por LUCENA (1993). 
A subfamília Paragoniatinae foi proposta recentemente como monofilética com a inclusão de Aphyocharax (QUEVEDo, 2007) e a exclusão de uma das espécies de suas espécies, Leptagoniates pi, esta mais relacionada à Phenacogaster. A proposta do autor de um grupo monofilético composto por Aphyocharax, Paragoniates e Phenagoniates é corroborada aqui (clado 165).

Uma relação mais próxima entre Triportheus e Agoniates é proposta, corroborando a hipótese de ZANATA (2000).

A família Gasteropelecidae sempre foi considerada como um grupo com grandes probabilidades de ser monofilético devido a inúmeras autapomorfias, mas a sua relação com os demais characiformes sempre foi considerada incerta (WEITZMAN, 1964). o único estudo a incluir representantes desta família foi ORTí \& MEYER (1997) que recobrou um grupo monofilético composto por Cynodontidae e Gasteropelecidae. Na presente análise, Gasteropelecidae ocupa um clado distal de characidae (clado 130) como grupo-irmão de clupeacharax, um gênero que também apresenta quilha peitoral, apesar de menos desenvolvida que em Gasteropelecidae.

Um dos gêneros enigmáticos de Characiformes, stygichthys, foi recobrado como grupo-irmão de Rachoviscus. Stygichthys é o único Characiformes estritamente freático, tendo diversas modificações geralmente associadas a este hábito como a redução dos olhos e dos canais da linha sensorial. Estas características podem ter um grande impacto no posicionamento deste gênero. Assim o posicionamento do mesmo em Characidae é considerado provisório. 


\section{LITERATURA CITADA}

AlEXANDER, R. MCN., 1962. The structure of the weberian apparatus in the Cyprini. Proceedings of the Zoological Society of London, 139 (3): $452-473$.

Boulenger, G.A. 1904. Fishes (Systematic Account of the Teleostei). Pp: 475-727. Em: The Cambridge Natural History. Macmillan and Co. Ltd, Londres.

BRIDGE, T.W. \& A. C. HADDON, 1894. Contributions to the anatomy of fishes. II. The air-bladder and Weberian ossicles in the siluroid fishes. Phil. Trans. (B) 184: 65-334.

BRITTO, M. R., 2003. Análise filogenética da ordem Siluriformes, com ênfase nas relações na superfamília Loricarioidea (Teleostei: Ostariophysi). Tese de doutorado não publicada. Universidade de São Paulo, São Paulo, Brasil. 527 pp.

Buckup, P. A., 1991. The Characidiinae: a phylogenetic study of the South American darters and their relationships with other characiform fishes. Tese de doutorado não publicada, University of Michigan, Ann Arbor. 391 pp.

BuckUP, P. A., 1998. Relationships of the Characidiinae and phylogeny of characiform fishes (Teleostei: Ostariophysi). Pp: 123-144. Em: Phylogeny and Classification of the Neotropical Fishes. Eds: L. R. Malabarba, R. E Reis, R. P. Vari, Z. M. S. Lucena e C. A. S. Lucena. Edipucrs, Porto Alegre.

Buckup, P. A., C. Zamprogno, F. Vieira \& R. L. TeiXeIRA, 2000. Waterfall climbing in Characidium (Crenuchidae: Characidiinae) from eastern Brazil. Ichthyological Explorations Freshwaters 11(3): 273-278.

Calcagnotto, D., S.A. Schaffer \& R. DeSalle. 2005. Relationships among characiform Wshes inferred from analysis of nuclear and mitochondrial gene sequences. Molecular phylogenetics and Evolution, 36: 135-153.

CAstro, R. M. C. \& M. M. C. e CASTRO, 1987. Proposta de uma nomenclatura osteológica para Characiformes (Pisces: Ostariophysi). Boletim do Museu Paraense Emílio Goeldi, série Zoologia 3 (1): 25-32.

CASTRO, R. M. C. \& R. P. VARI. 2004. Detritivores of the South American fish family Prochilodontidae (Teleostei: Ostariophysi: Characiformes): a phylogenetic and revisionary study. Smithsonian Contributions to Zoology, 622: 1-189.

DI DARIO, F. 2005. Relações filogenéticas entre os grandes grupos de Clupeomorpha e suas possíveis relações com Ostariophysi. Tese de doutorado, não publicada. Universidade de São Paulo.

EIgENMANN, C. H., 1910. Catalogue of the fresh-water fishes of tropical and south temperate America. In: Reports of the Princeton University expeditions to Patagonia 1896-1899. Zoology. Fishes Patagonia v. 3 (pt 4), p. 375-511.

Eigenmann, C. H., 1917. The American Characidae [Part 1]. Mem. Mus. Comp. Zool. v. 43 (pt 1), p. 1-102.

FINK, S. V. \& W. L. FINK, 1981. Interrelationships of Ostariophysan Fishes (Teleostei). Zoological Journal of the Linnean Society, 72: $297-353$.

FINK, S. V. \& W. L. FINK, 1996. Interrelationships of Ostariophysan Fishes (Teleostei). Pp. 209-249. Em: Interrelationships of 
Fishes.M. L. J. Stiassny, L. R. Parenti, \& G. D. Johnson (Eds.). Academic Press, San Diego.

FINK, S. V., P. H. GREENWOOD, \& W. L. FINK, 1984. A critique of recent work on fossil ostariophysan fishes. Copeia 4: 1033-1041

Fink, W. L. \& S. H. WeItZMAn. 1974. The so-called cheirodontin fishes of Central America with description of two new species (Pisces, Characidae). Smithsonian Contributions to Zoology, 172: 1-46.

Forey, P. L., C. J. Humphries, I. L. Kitching, R. W. Scotland, D. J. Siebert \& D. M. WILlians, 1993. Cladistics - a Practical course in Systematics. Oxford University Press, New York.

GAYET, M., 1981. Contribution à l'étude anatomique et systématique de l'ichthyofaune cénomanienne du Portugal. II- Les osteriophysaires. Comm. Serv. Geol. Portugal 67: 173-190.

GAYET, M., 1986. Rammalichthys Gayet du Cénomanien inferiéur marin de Ramallah (Judée), une introduction aux relations phylogénétiques des 0stariophysi. Mém. Mus. Natl. Hist. Nat., Ser. C (Paris), 51: 1-81.

GérY, J., 1977. Characoids of the World T. F. H. Publications, Neptune City, New Jersey.

GILL, T., 1893. Families and subfamilies of fishes. Mem. National Acad. Sci., 6:127-138.

GILL, T., 1895. The differential characters of characinoid and erythrinoid fishes. Proc. U.S. Nat. Mus., 18: 205-209.

Gosline, W. A. 1989. Two patterns of differentiation in the jaw musculature of teleostean fishes. J. Zool., Lond., 218: 649-661

Goloboff, P.A. 1999. Analyzing large data sets in reasonable times: Solutions for composite optima. Cladistics 15:415-428.

Goloboff, P.A. 2002. Techniques for analyzing large data sets. Pp. 7079. Em: Techniques in Molecular Systematics and Evolution. R. Desalle, G. Giribet, and W. Wheeler (eds.). Brikhäuser Verlag, Basel.

GolobofF, P. A., J. Farris \& K. Nixon. 2003. T.N.T: Tree Analysis Using New Technology. Programa e documentação disponível pelos autores, e em wWw.zmuc.dk/public/phylogeny.

GREGORY, W. K. \& G. M. CONRAD, 1938. The phylogeny of the characin fishes. Zoologica (N.Y.), 23 (17): 319-360.

GREenWOOD, P. H., D. E. RoSEn, S. H. Weitzman \& G. S. Myers, 1966. Phyletic studies of teleostean fishes with a provisional classification of living forms. Bulletin of the American Museum of Natural History, 131: 339-456.

GüntheR, A., 1864. Catalogue of the fishes in the British Museum. Catalogue of the Physostomi, containing the families Siluridae, Characinidae, Haplochitonidae, Sternoptychidae, Scopelidae, Stomiatidae in the collection of the British Museum. Cat. Fishes v. 5, p. i-xxii + 1-455.

HENNIG, W. 1950. Grundzüge einer Theorie der phylogenetischen Systematik. Deutsche Zentralverlag, Berlin.

HENNIG, W. 1966. Phylogenetic Systematics. University of Illinois Press, Urbana, $263 \mathrm{pp}$.

HoLmBeRG, E. L., 1891. Sobre algunos peces nuevos ó poco conocidos de la República Argentina. Rev. Argent. Hist. Nat. Buenos Aires v. 1, p. $180-193$. 
HowES, G.J. 1976. The cranial musculature and taxonomy of characoid fishes of the tribes Cynodontini and Characini. Bulletin of the British Museum of Natural History (Zoology), 23:203-248.

Ingenito, L. F. S. \& P. A. BuckUP, 2005. A new species of Parodon from the Serra da Mantiqueira, Brazil (Teleostei: Characiformes: Parodontidae). Copeia, 765-771.

Källersjö, M., V.A. Albert, \& J.S. Farris. 1999. Homoplasy increases phylogenetic structure. Cladistics, 15:91-93.

KITCHING, I., P. ForeY, C. J. Humphries \& D. Williams. 1998. Cladistics: The Theory and Pratice of Parsimony Analysis. $2^{\mathrm{a}}$ ed. The Systematic Association Publication $\mathrm{n}^{\circ}$ 11, $228 \mathrm{pp}$.

LANGEANI, F. 1998. Phylogenetic study of the Hemiodontidae (Ostariohysi: Characiformes). Pp:145-160. Em: Phylogeny and Classification of neotropical fishes. Malabarba, L. R., R. E. Reis, R. P. VARI, Z. M. S. LUCENA \& C. A. LUCENA (eds.). EDIPUCRS. Porto Alegre.

Leviton, A. E., R. H. Gibbs Jr., E. HeAl \& C. E. Dawson. 1985. Standards in herpetology and ichthyology: Part I. Standard symbolic codes for institutional resource collections in herpetology and ichthyology. Copeia 1985: 802-832.

LIMA, F.C.T. 2006. Revisão taxonômica e relações filogenéticas do gênero Salminus (Teleostei: 0stariophysi: Characiformes: Characidae). Tese de doutorado não publicada, $253 \mathrm{pp}$. Universidade de São Paulo, São Paulo, Brasil.

LIPPISTSCH, E. 2001. The use of lepidological characters for cichlid phylogeny. Journal of Aquariculture and Aquatic Sciences IX: 2001.

LUCENA, C. A. S., 1993. Estudo filogenético da família Characidae com uma discussão dos grupos naturais propostos (Teleostei, Ostariophysi, Characiformes). Tese de doutorado não publicada, Universidade de São Paulo,158 pp.

LUCENA, C. A. S. 1998. Relações filogenéticas e definição do gênero Roeboides, Günther (Ostariophysi; Characiformes; Characidae). Comunicações do Museu de Ciência e Tecnologia, PUCRS Série Zoologia Porto Alegre, 11: 19-59.

LUCENA, C. A. S. \& N. A. Menezes, 1998. A phylogenetic analysis of the Roestes Günther and Gilbertolus Eigenmann, with a hypothesis on the relationships of the Cynodontidae and Acestrorhynchidae (Teleostei: Ostariophysi: Characiformes). Pp. 261-278. Em: Phylogeny and Classification of the Neotropical Fishes. L. R. Malabarba, R. E Reis, R. P. VARI, Z. M. S. LUCENA \& C. A. S. LUCENA (EDS.). Edipucrs, Porto Alegre.

Lundberg, J. G., L. G. MARshall, J. Guerrero, B. Horton, M. C. S. L. MALABARBA \& F. WESSELINGH, 1998. The stage for Neotropical fish diversification: a history of Tropical South Americans rivers. Pp. 13-68. Em: Phylogeny and Classification of neotropical fishes. Malabarba. L. R., R. E. Reis, R. P. VARI, Z. M. S. Lucena \& C. A. LUCENA (eds.), EDIPUCRS. Porto Alegre.

MACHADO-AlLISON, A., 1983. Estudios sobre la sistemática de la subfamilia Serrasalminae (Pises, Characidae), parte II, Discusión sobre la condición monofilética de la subfamilia. Acta Biol. Venez. 11: $145-195$.

MADDISON D. R. 1991 The discovery and importance of multiple islands of most-parsimonious trees. Systematic Zoology 40: 315-328 
MALABARBA, L. R., 1998. Monophyly of the Cheirodontinae, characters and major clades (Ostariophysi: Characida. Pp: 193-233 Em: Phylogeny and Classification of neotropical fishes. MALABARBA, L. R., R. E. ReIs, R. P. VARI, Z. M. S. LUCENA \& C. A. LUCENA (eds.). EDIPUCRS. Porto Alegre.

Malabarba, L.R. \& S.H. Weitzman. 2003. Description of a new genus with six new species from Southern Brazil, Uruguay and Argentina, with a discussion of a putative characid clade (Teleostei: Characiformes: Characidae). Comunicações do Museu de Ciências e Tecnologia, PUCRS, Série Zoologia, 16(1):67-151.

MENEZES, N.A. 1974. Redescription of the genus Roestes (Pisces, Characidae). Papéis Avulsos de Zoologia, 27(17):219-225.

MENEZES, N.A. 1976. On the Cynopotaminae, a new subfamily of Characidae (Osteichthys, Ostariophysi, Characoidei). Arquivos de Zoologia, S. Paulo, 28(2):1-91.

MONOD, T. \& J. GAUDANT, 1998. Un nom pour les poisson Characiformes de l'éocene inférieur et moyen du bassin de Paris et du sud de la France: Alestoides eocaenicus nov. gen., nov. sp. Cybium 22(1): 15-20.

MoREIRA, C. R., 2002. Relações Filogenéticas em Iguanodectinae (Characidae: Characiformes: Teleostei). Dissertação de Mestrado não publicada, Universidade de São Paulo, Brasil. 276 pp.

MülleR, J., 1842. Beobachtungen über die Schwimmblase der Fische, mit Bezug aug einige neue Fischgattungen. Arch. Ana. Physiol. 307-329.

MülleR, J. \& F. H. TROSCHEL, 1845. Horae ichthyologicae. Beschriebung und Abbildung neuer Fische; die Familie Characinen. Berlin.

MURRAY, A.M. \& K.M. STEWART. 2002. Phylogenetic relationships of the African genera Alestes and Brycinus (Teleostei, Characiformes, Alestidae). Canadian Journal of Zoology, 80:1887-1899.

Nelson, E.M., 1961. The swim bladder in the Serrasalmidae, with notes on additional morphological features. Fieldiana zool. 39(56):603-624.

Nelson, J. S., 2006. Fishes of the World. $4^{\text {a }}$ edição. John Wiley \& Sons. New York. 601p.

Netto-Ferreira, A.L. 2006. Relações filogenéticas dos gêneros de Lebiasinidae (Ostariophysi, Characiformes). Dissertação de mestrados não publicada, Universidade Federal do Rio de Janeiro/Museu Nacional, Brasil. 375 pp.

NIXON, K.C. 1999. The Parsimony Ratchet, a new method for rapid parsimony analysis. Cladistics 15: 407-414.

NiXon, K.C. \& J.M. CARPENTER, 1993. On Outgroups. Cladistics. 9:413-426

ORTÍ, G. \& A. MEYER, 1997. The radiation of characiform fishes and the limits of resolution of mitochondrial ribosomal DNA sequences. Syst. Biol., 46: 75-100.

Ortí, G., P. Petry, J. I. R. Porto, M. Jegú \& A. Meyer, 1996. Patterns of nucleotide change in mitochondrial ribossomal RNA genes and phylogeny of piranhas. Journal Molecular Evolution, 42: 169-182.

OTERO, 0. \& M. GAYET, 2001. Palaeoichthyofaunas from the lower oligocene and Miocene of the Arabian plate: palaeoecological and palaeobiogeographical implications. Palaeogeogr., Palaeoclimat., Palaeoecol. 165: 141-169.

OYAKAWA, 0. T., 1998. Relações Filogenéticas das Famílias Pyrrhulinidae, Lebiasinidae $\underline{\text { e Erythrinidae (Osteichthyes: }}$ Characiformes). Tese de 
doutorado não publicada, 200 pp. Universidade de São Paulo, São Paulo, Brasil.

Pavanelli, C. S., 1999. Revisão taxonômica da família Parodontidae (Ostariophysi: Characiformes). Tese de doutorado não publicada, 332 pp. Universidade de São Paulo, São Paulo, Brasil.

Pavanelli, C. S., 2003. Parodontidae. Pp. 46-50. Em: Check List of the Freshwater Fishes of South and Central America.Reis, R. E., S. 0. Kullander \& C. J. Ferraris Jr (eds.). Edipucrs, Porto Alegre.

Paugr, D., C. Lévêque \& G. G. Teugels, 2003. Poissons d’Eaux Douces et Saumâtres de l'Afrique de l'Ouest. Tome I. IRD Éditions, MRAC, Tervuren, Bélgica. 457p.

DE PINNA, M.C.C., 1991. Concepts and Tests of Homology in the Cladistic Paradigm. Cladistics, 7:367-394.

DE PINNA, M.C.C. 1992. A new subfamily of Trichomycteridae (Teleostei, Siluriformes), lower loricarioid relationships and a discussion on the impact of additional taxa for phylogenetic analysis. Zoological Journal of the Linnean Society 106:175-229.

Pollock, D. D., D. J. ZWICKL, J. A. MCGUIRE \& D. M. HILLIS. 2002. Increased taxon sampling is advantageous for phylogenetic inference. Systematic Biology, 51(4): 664-671.

PRENDINI, L. 2001. Species or supraspecific taxa as terminals in cladistic analysis? Groundplan versus exemplars revisited. Systematic Biology, 50(2):290-300.

QueVEDo, R. 2006. Estudo taxonômico e filogenéticos da subfamília Paragoniatinae Géry (Characiformes: Characidae). Tese de doutorado não publicada, $288 \mathrm{pp}$. Universidade Federal do Rio Grande do Sul, Porto Alegre, Brasil.

REGAN, C. T. 1911. The classification of the teleostean fishes of the order Ostariophysi.--I. Cyprinoidea. Ann. Mag. Nat. Hist. (Ser. 8) v. 8 (no. 43), p. 13-32.

REIS, R. E., 1989. Systematic revision of the Neotropical characid subfamily Stethaprioninae (Pisces, Characiformes). Comun. Mus. Ciênc. PUCRS, Ser. Zool. Porto Alegre, 2(6): 3-86.

ROBERTS, T. R. 1969. Osteology and relationships of characoid fishes, particulary the genera Hepsetus, Salminus, Hoplias, Ctenolucius, and Acestrorhynchus. Proceedings of the California Academy of Sciences, 36(15): 391-500.

ROBERTS, T. R. 1973a. Osteology and relationships of the Prochilodontidae, a South American family of characoid fishes. Bulletin of the Museum of Comparative Zoology, 145:213-235.

RoBERTS, T. S. 1973b. Interrelationships of ostariophysans, p. 373-395. Em: Interrelationships of Fishes. P. H. Greenwood, R. S. Miles, and C. Patterson (eds.). Academic Press, London.

ROBERTS, T. R. 1974. Osteology and classification of the Neotropical characoid fishes of the families Hemiodontidae (including Anodontinae) and Parodontidae. Bulletin of the Museum of Comparative Zoology, 146:411-472.

Rosen, D. E., 1972. Origin of the characid fish genus Bramocharax and a description of a second, more primitive, species in Guatemala. Amererican Museum Novitates, 2500: 1-21.

RYDIN, C. \& M. KÄLLERSJö. 2002. Taxon sampling and seed plant phylogeny. Cladistics, 18(5):485-513. 
SAItoH, K., M. MiYa, J.g. InOUe, N.B. Ishiguro, \& M. NISHIdA. 2003. Mitochondrial genomics of Ostariophysan fishes: perspectives on phylogeny and biogeography. Journal of Molecular Evolution, $56: 464-472$.

Sazima, I. 1983. Scale-eating in characoids and other fishes. Environmental Biology of Fishes, 9(2):87-101.

SPRINGER, V. G. \& G. D. JOHNSON. 2000. Use and advantages of ethanol solution of alizarin red $\mathrm{S}$ dye for staining bone in fishes. Copeia no.1: $300-301$.

SсHUн, R.T. 2000. Biological Systematics: Principles and Applications. Cornell University Press, $236 \mathrm{pp}$.

Scotland, R., \& T. PENNIngton, 2000. Homology and Systematics: coding Characters for Phylogenetic Analysis. The Systematic Association Special Volume Series 58. Taylor \& Francis 217 pp.

SWOFFORD, D. L., 2002. PAUP*: Phylogenetic analysis using parcimony and other methods versão 4.0b10. Sinauer Associates, Sunderland, Massachusetts.

SLOWINSKI, J.B. 1993. "Ordered" versus "Unordered" Characters. Systematic Biology. 42(2):155-165.

SPRINGER, V. G. \& G. D. JOHNSON, 2000. Use and advantages of ethanol solution of alizarin red $S$ dye for staining bone in fishes. Copeia, 2000(1): 300-301.

StARnes, W. C. \& I. SChindleR, 1993. Comments on the genus Apareiodon Eigenmann (Characiformes: Parodontidae) with the description of a new species from the Gran Sabana region of eastern venezuela. Copeia: $754-762$.

TAYLOR, R. \& C.C. VAN DYKE, 1985. Revised Procedures for staining and Clearing Small Fishes and Other Vertebrates for Bone and Cartilage Study. Cybium 9(2):107-119.

Toledo-PizA, M., 2000. The Neotropical fish subfamily Cynodontinae (Teleostei: Ostariophysi: Characiformes): a phylogenetic study and a revision of Cynodon and Rhaphiodon. Amererican Museum Novitates, 3286:1-88.

UJ, A. 1990. Etude comparative de l'osteologie cranienne des poisson de la familie des characidae et son importance phylogenetique. Tese de doutorado não publicada, Universite de Geneve, 191 pp

VARI, R. P., 1979. Anatomy, relationships and classification of the families Citharinidae and Distichodontidae (Pisces, Characoidea). Bulletin of the British Museum (Natural History - Zoological Series.) 36(5): 261-344

VARI, R. P., 1983. Phylogenetic relationships of the families Curimatidae, Prochilodontidae, Anostomidae, and Chilodontidae (Pisces: Characiformes). Smithsonian Contributions to Zoology, 378: $1-60$.

VARI, R. P., 1984. Systematics of the neotropical characiform genus Potamorhina (Pisces: Characiformes). Smithsonian Contributions to Zoology, 400: 1-36.

VARI, R. P., 1989a. A phylogenetic study of the neotropical characiform family Curimatidae (Pisces: Characiformes). Smithsonian Contributions to Zoology, 471: 1-71.

VARI, R. P., 1989b. Systematics of the neotropical characiform genus Curimata Bosc (Pisces: Characiformes). Smithsonian Contributions to Zoology, 474: 1-63. 
VARI, R. P., 1989c. Systematics of the neotropical characiform genus Psectrogaster Eigenmann and Eigenmann (Pisces: Characiformes). Smithsonian Contributions to Zoology, 481: 1-43.

VARI, R. P., 1989d. Systematics of the neotropical characiform genus Pseudocurimata (Pisces: Characiformes). Smithsonian Contributions to Zoology, 490: 1-28.

VARI, R. P., 1991. Systematics of the neotropical characiform genus Steindachnerina Fowler (Pisces: Characiformes). Smithsonian Contributions to Zoology, 507: 1-118.

VARI, R. P., 1992a. Systematics of the neotropical characiform genus Curimatella Eigenmann and Eigenmann (Pisces: Characiformes), with summary comments on the Curimatidae. Smithsonian Contributions to Zoology, 533: 1-48.

VARI, R. P., 1992b. Systematics of the neotropical characiform genus Cyphocharax Fowler (Pisces: Characiformes). Smithsonian Contributions to Zoology, 529: 1-137.

VARI, R.P., 1995. The neotropical fish family Ctenoluciidae (Teleostei: Ostariophysi: Characiformes): Supra and intrafamilial phylogenetic relationships, with a revisionary study. Smithsonian Contributions to Zoology, 564: 1-97.

VARI, R. P., 1998. Higher level phylogenetic concepts within characiformes (Ostariophysi), a historical review. Pp: 111-122 em: Malabarba, L. R., R. E. Reis, R. P. Vari, Z. M. S. Lucena \& C. A. Lucena (eds.), Phylogeny and Classification of neotropical fishes. EDIPUCRS. Porto Alegre.

VARI, R. P., R. M. C. CASTRO \& S. J. RAREDon, 1995. The neotropical fish family Chilodontidae (Teleostei: Characiformes): a phylogenetic study and a revision of Caenotropus Günther. Smithsonian Contributions to Zoology, 577: 1-32.

VARI, R. P. \& A S. HAROLD, 1998. The genus creagrutus (Teleostei: Characiformes: Characidae): monophyly, relatioships, and undectected diversity. Pp. 245-260. Em: Phylogeny and Classification of neotropical fishes MALABARBA. L. R., R. E. ReIs, R. P. VARI, Z. M. S. LUCENA \& C. A. LUCENA (eds.). EDIPUCRS. Porto Alegre.

VARI, R. P. \& A. S. HAROLD, 2002. Neotropical fishes of the genus Creagrutus (Teleostei: Ostariophysi: Characiformes): a phylogenetic study and a revision of the species east of the Andes. Smithsonian Contributions to Zoology, 612:1-239.

Weitzman, S. H., 1954. The osteology and relationships of the south American characid fishes of the subfamily Gasteropelecinae. Amererican Museum Novitates, 4(1): 212-263.

WeItZMAN, S. H., 1960. Further notes on the relationships and classification of the South American characid fishes of the subfamily Gasteropelecinae. Stanford Ichthyological Bulletin, $7(4)$ : 217-2397.

Weitzman, S. H. 1962. The osteology of Brycon meeki, a generalized characid fish, with an osteological definition of the family. Stanford Ichthyological Bulletin, 8: 1-77.

WEITZMAN, S. H. 1964. Osteology and relationships of South American characid fishes of subfamilies Lebiasininae and Erythrininae with special reference to subtribe Nannostomina. Proceedings of the United States Museum, 116 (3499):127-169. 
WeItzman, S. H. 1974. Osteology and evolutionary relationships of the Sternoptychidae, with a new classification of stomiatoid families. Bulletin of the American Museum of Natural History 153 (3):327478 .

Weitzman, S. H. \& L. R. Malabarba, 1998. Perspectives about the phylogeny and classification of the Characidae (Teleostei: Characiformes). Pp. 161-170. Em: Phylogeny and Classification of neotropical fishes. Malabarba, L. R., R. E. Reis, R. P. VARI, Z. M. S. Lucena \& C. A. LUCENA (eds.), EDIPUCRS. Porto Alegre.

Weitzman, S.H., N. A. Menezes, H.-G. Evers \& J.R. Burns. 2005. Putative relationships among inseminating and externally fertilizing characids, with a description of a new genus and species of Brazilian inseminating fish bearing an anal-fin gland in males (Characiformes: Characidae). Neotropical ichthyology, 3(3):329360 .

WeItZman, S. H. \& R. P. VARI, 1988. Miniaturization in South American freshwater fishes; an overview and discussion. Proceedings of the Biological Society of Washington 101(2): 444-465.

WIENS, J. J., 2000. Phylogenetic Analysis of Morphological Data. Smithsonian Institution Press, $220 \mathrm{pp}$.

WILEY, E. 0. 1981. Phylogenetics - the Theory and Practice of Phylogenetic Systematics. Wiley, New York, 439 pp.

Wiley, E. O., Siegel-Causey, D. R., Brooks, D. R., \& Funk, V. A., 1991. The Compleat Cladist - a Primer of Phylogenetic Procedures. The University of Kansas, Museum of Natural History, Special Publication $\mathrm{n} .19$.

WINTERBOTTOM, R. 1974., A descriptive synonymy of the striated muscles of the Teleostei. Proceedings of the Academy of Natural Sciences of Philadelphia, 125 (12): 225-317.

WINTERBOTTOM, R., 1980. Systematics, osteology and phylogenetic relationships of fishes of the ostariophysan subfamily Anostominae (Characoidei, Anostomidae). Life Sci. Contr. ROM, 123:1-112

ZANATA, A. M. 2000. Estudo das relações filogenéticas do gênero Brycon Müller \& Troschel. Tese de doutorado não publicada, $358 \mathrm{pp}$. Universidade de São Paulo, São Paulo, Brasil.

ZWICKL, D. J. \& D. M. HILLIS. 2002. Increased taxon sampling greatly reduces phylogenetic error. Systematic Biology 51:588-598. 
Tabela 1. Matriz de dados. 
Chanos chanos

Catostomus commersonnii Olivaichthys mesembrinus Gymnotus aff. carapo Citharinus latus Distichodus notospilus Hemistichodus vaillanti Neolebias unifasciatus Nannocharax fasciatus Xenocharax spilurus Apareiodon piracicabae Parodon nasus Saccodon wagneri Anodus orinocensis Bivibranchia fowleri Hemiodus unimaculatus Curimata ocellata Curimatopsis macrolepis Potamorhina latior Prochilodus nigricans Semaprochilodus insignis Caenotropus labyrinthicus Chilodus punctatus Anostomus anostomus Leporellus vittatus Leporinus fasciatus Schizodon fasciatus Carnegiella strigata Gasteropelecus sternicla Thoracocharax stellatus Acestrorhynchus falcirostris Gilbertolus atratoensis Hydrolycus tatauaia Roestes molossus Erythrinoidea fam. nov Boulengerella maculata Ctenolucius hujeta Copeina cf. guttata Lebiasina bimaculata Piabucina astrigata Erythrinus erythrinus Hoplias malabaricus Hepsetus odoe Arnoldichthys spilopterus Brycinus macrolepidotus Bryconalestes longipinnis Chalceus epakros Characidium bahiensis Crenuchus spilurus Agoniates halecinus Aphyocharax pusillus Astyanax mexicanus Atopomesus pachyodus Axelrodia reisei Brittanichthys axelrodi Brycon pesu Bryconadenos tanaothoros Bryconamericus exodon Bryconops alburnoides Charax cf. leticiae

Clupeacharax cf. engrauloides Compsura heterura Ctenobrycon hauxwellianus Deuterodon iguape Diapoma terofali Galeocharax knerii Glandulocauda melanogenys Gnathocharax steindachneri Gymnocorymbus ternetzi Hemibrycon polyodon Hemigrammus unilineatus Hollandichthys multifasciatus Hyphessobrycon compressus Iguanodectes geisleri Knodus meridae Landonia latidens Markiana nigripinnis Metynnis lippincottianus Microschemobrycon casiquiare Moenkhausia xinguensis Myleus setiger

Odontostilbe pequira
1

20

30

40

$11110 ?-\ldots-\ldots-\ldots--1001001-100000110---\ldots-2-010 ?--? 0$ $000000-\ldots-------10010000000000100------2-$ ? ? $1---20$ $00-100----1201--010010110110220110--0010020 ? ? ? 110 ? 0$ $21110004--1100-00100----000-00011001000110 ? ? 1100 ?-$ $11011004--0111000100000001000201100100001001110021$ $110110141-0111000100000001000001001101101002100010$ $01011004--0111000100000011000001000101001001110010$ $110110141-0111000100000001001001001100001001110010$ $01011002--0111000100000001000001000101101002100000$ $110110141-0110000000000001001101101100001011110010$ $01001002--211101010001100000100110010---1-01110010$ $01001002--21110101000110000001001100100101001110010$ 01 ? $00002--211101010001100000 ? 00110010---1-011100 ? 0$ $110100-\ldots---?-3---0001010000002011001$ ? - - ? - $0111--11$ $11-0-0----21110--10000100000100110010---1-0111--00$ $11010004--211101010000100000210110010---2-01110001$ $10-100-\ldots----3---1000111010001011001 ?---1-0111--10$ $10-100-\ldots----3---1000101010100011001$ ? - - - $1-0111$ - 1010 $10-100-\ldots----3---1010201010002011001$ ? - - - $1001111--10$ $10-10004--3112-1010101010101200103010-001002000010$ $10-10004--3112-1000001010101200103010-001-020000010$ $11000104--1112-0010000000101-21100010--01-01110011$ $11000104--1112-00100000000101-21100010-101001110011$ $21000102--2011000100020000101-201040101001002100110$ $01000102--3011-0010002000101-201040101001002100110$ $11000102--3011-0010002000101-201040101001002100110$ 01 ? $00102--201100010002001101-20104010100100102100110$ $2111010-1-2000000100000000011100100110000001110100$ $2111010-1-2000000100000000011100100110000001110100$ $210101101-20000001000000000111001001100000001110100$ $11120104--1100-01000101100102200212100020100110000$

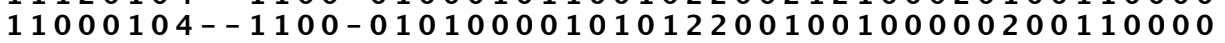
$12010104--1100-010100001001122001021000 \& 0200110000$ $12110104--1100-01010000101112200100100000200110000$

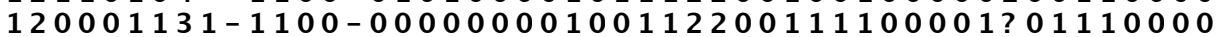
$10-20104--1100-00000021110002200222100010010110000$ $10-20104--1100-01000021110002200222100010010110110000$ $21110104--1100-00100000101012200001101002001110000$ $11110104--2110000100000100011200001101002001110010$ $11110104--2110000000000100011200001101002001110000$ $12000104--1100-010000001010102001121000000011110000$ $12000104--1100-01000000101112200112100000110110000$

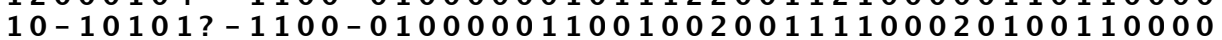
$111101111-2000100000001100010200100110001001110 ? 10$ $111101110-20001001001111001102000000120010022110100$

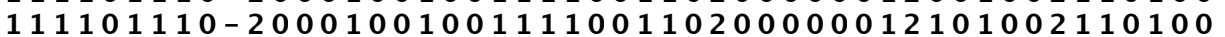
11110124102000000000001100012210102010001001110000 $01001004--1100-00100000100010001100100101001110000$ $10-11004--2110000000001100000100102101001001110000$ $120001110-2100000000100100012 ? 00100100022211110$ ? 00 ?

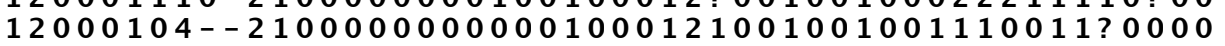
$120101120-200010000000010001110010011121000001110100$ $1200010-1-1100-00100000100002100100110111001110010$

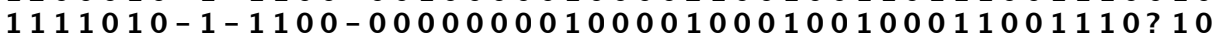
$1100010-1-1000-00000000100000100100100111001110000$ 12110124112000100000000100012200112002000001110100 $121101100-20100000000011010111000001120021001110$ ? 00 $120101110-2000000010001100011100000111001001110100$ 12010123102010000000000100010200100110120001110 ? 10 $12010104--1100-010101001010121001101000000211110010$ $120001101-2000000010000100011100100112100001110100$

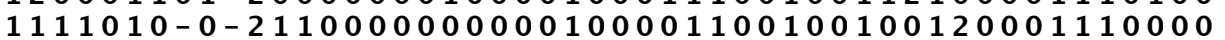
$121101120-2000100000000100011100000112000001110 ? ? 0$ $121101111-2000100000000100011100000112100001110$ ? ?

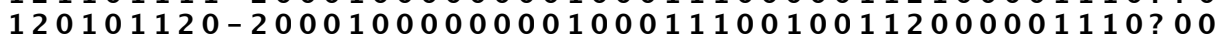
$1211011 ? ?-1100-01010000100012200110100000001110010$ $220101121-2000000000000100011100000112020001110$ ? 00 $21110104--1100-00010000100002200200100020000110010$ $121101111-20000000000001000011001001121000001110 ? 10$

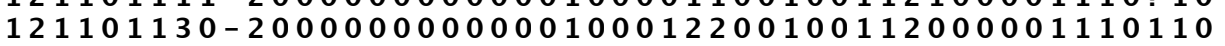
$121101121-20000000000011000111001001122100001110 ? ? 0$ $120101111-2000000000000100012200100110020001110010$ $111101111-21100000000001000011001001121000001110$ ? 0 $111101101-2010000110000101010200000110022002110100$ $120101120-2000100000000101011200000112001001110110$ $120101110-211000000000010001220000011200010011110 \% 0 \%$ $120101130-2000-00000001100010200000112100002110$ ? 0 $121101110-? 0001000000101010102000000121 ? 20011$ ? 01 ? 0 $1201010-1-2000000100001100001100100100111001110 ? 10$ $120101121-2000100100000100011100100112000001110100$ $121101110-? 000-001000101010102000000120020011$ ? 01 ? 0 $1111010-1-2110000000000100011000100100011001110$ ? 00 
Oligosarcus argenteus Orthospinus franciscoensis Paracheirodon axelrodi Paragoniates alburnus Phenacogaster pectinatus Phenagoniates macrolepis Piabina argentea Piaractus mesopotamicus Poptella brevispina

Probolus heterostomus Rachoviscus graciliceps Rhinobrycon negrensis Rhoadsia altipinna Roeboexodon guyanensis Salminus hilarii Serrabrycon magoi Stygichthys typhlops Tetragonopterus argenteus Triportheus albus $120101121-2000100000000100011100100112100001110 ? 00$ $1211010-1-20100000000001000010001001101200011110010$ $1211010-1-2 ? 00000000001100012100100100000001110000$ $121101141-2000000000000100012100100100011001110010$ $1201010-1-2110000000000100012100100100002001110000$ $121101130-2000100000000100011100000110102001110100$ $120101110-? 000-00000000100001200010012010001110100$ $121101121-2000100000001100011100100112000001110110$ $12110101--2200-00000000100012100100112000001110000$ $121101101-2000000000000100001100100100000001110 ? 10$ $111101130-2000100000001100001100100102101001110$ ? ? 0 $1111010-1-2100000100000100001100100100120001110 ? 10$ $110001---10-0-000000110000200010011002000111000$ $121201141-1100-0000000010011220011111000000001110000$ $121101131-2000000000000101012200100101000001110010$ $120101141-2100000000000101011100100100000001000 ? 10$ $121101141-2000100000000100011100000112100001110 ?$ ? 0 22100113102000100000000100001 ? 00002012001001110 ? 00 
Chanos chanos

Catostomus commersonnii Olivaichthys mesembrinus Gymnotus aff. carapo Citharinus latus Distichodus notospilus Hemistichodus vaillanti Neolebias unifasciatus Nannocharax fasciatus Xenocharax spilurus Apareiodon piracicabae Parodon nasus Saccodon wagneri Anodus orinocensis Bivibranchia fowleri Hemiodus unimaculatus Curimata ocellata Curimatopsis macrolepis Potamorhina latior Prochilodus nigricans Semaprochilodus insignis Caenotropus labyrinthicus Chilodus punctatus Anostomus anostomus Leporellus vittatus Leporinus fasciatus Schizodon fasciatus Carnegiella strigata Gasteropelecus sternicla Thoracocharax stellatus Acestrorhynchus falcirostris Gilbertolus atratoensis Hydrolycus tatauaia Roestes molossus Erythrinoidea fam. nov Boulengerella maculata Ctenolucius hujeta Copeina cf. guttata Lebiasina bimaculata Piabucina astrigata Erythrinus erythrinus Hoplias malabaricus Hepsetus odoe Arnoldichthys spilopterus Brycinus macrolepidotus Bryconalestes longipinnis Chalceus epakros Characidium bahiensis Crenuchus spilurus Agoniates halecinus Aphyocharax pusillus Astyanax mexicanus Atopomesus pachyodus Axelrodia reisei Brittanichthys axelrodi Brycon pesu Bryconadenos tanaothoros Bryconamericus exodon Bryconops alburnoides Charax cf. leticiae

Clupeacharax cf. engrauloides Compsura heterura Ctenobrycon hauxwellianus Deuterodon iguape Diapoma terofali Galeocharax knerii Glandulocauda melanogenys Gnathocharax steindachneri Gymnocorymbus ternetzi Hemibrycon polyodon Hemigrammus unilineatus Hollandichthys multifasciatus Hyphessobrycon compressus Iguanodectes geisleri Knodus meridae Landonia latidens Markiana nigripinnis Metynnis lippincottianus Microschemobrycon casiquiare Moenkhausia xinguensis Myleus setiger

Odontostilbe pequira
$011001--0100201011020011101010021000210-0100010210$ $011001--0$ ? $001200010200011-1101000--00 ? 10-01011000200$ $0----1--0---0-1$ ? $0002-0010011101120000 ? 20-010000000210$ $---?----0---2-000102000100001100--01220-0111011000111$ $011001--0100110001010010101011111001200211$ ? 0011200 011001101100110001010010001012121110101021110011200 $011001--0100010001120010001012120101$ ? $0-211$ ? 00211100 $011000--010002000101001000101110--0121021110021100$ $011001--010101000102001000101111020100-21100000200$ 01100010010012000100001000101113020122021111011110 $011011--010020000101001110101211100101021110001110$ $011011--010020000101001100101211110011010211100001110$ $011011--010020$ ? ? 01010011201012121110101201110001100 $001011--010020000101001000101011100110-11111020110$ $021011--010110000102001100001111110000-21110020010$ $011011--010010000101001110001011101000$ $001001--000010000111001000100112130010-01101130200$ $011001--010010000112001000100112130000-01101132010$ $001001--011010000111001000100112130010-01101132010$ $011011--011010000111001001001112110101031110132210$ $011011--01110100001110110010011121110101103111111322000$ $010001--000020000112011110101012100001101101132010$ $010001--000020000112011110101012100001101101132010$ $020001--00000000011201110110120110000100110111020000$ $020001--000000000111011101101202110002101111102010$ $120001--00000000011111110110120211000021111111002010$ $120001--000000000111111101001212110002101111122010$ $100001--010120000111001000100100--0022001101112200$ $100001--010120000111001000100100--0022001101112200$ $100001--010120000111001000100100--0022001111112200$ $10000000000020100000101110000000--00022001000000010$ $000001--0000210000000010101101110000120011011020010$ $1000002001002000000000100011011300001100101 ? 020010$ $000001--0100200000000110001102110000110010$ ? ? 020010 $100001--0002000001010000001$ ? $111000-40110111010$ ? 10000101 $10000020100220100000100100100100--0012001101102111$ $00100010000120100000100100100100--00012001101102011$ $011001--010222010-02001100111200--000200111011012200$ $01100010010120100-02001100110200--0001101111011201$ $01000010010120110-02000110110200--000110011111002200$ $00000011000120100000201110111100--1001101011002210$ $00000021000120100001201110111100--1021011111102111$ $000001--01002000000000111011111021101012001100002011$ $011001--0100120000010011101102120000011011 ? 1021100$ $101001--010002000101001110010212110021101111021100$ $101001--010012100101001100110011110021101111021100$ $011001--010012100001001100110212110011001111022100$ $0111-000010022100102101110110100--0101111100021010$ $00100010110022110100001110111010--0121131101001100$ $001001--010220100000 ? 011100101110000220011111021010$ $0111-1--010021110101001120110200--0022111111010000$ $001001--010101110000001010010011000022101001020000$ $0111-1--010022000101001010010202110022211001021000$

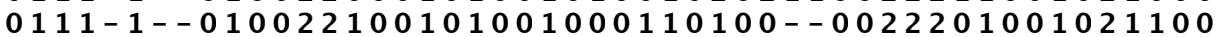
$011000001000220011010010101110100--001111111000020100$ $0011-1--0100211000000010100102011100211001011020000$

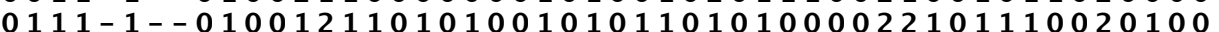
$0111-1--0100 ? 2010001001010010200--002222011101020100$

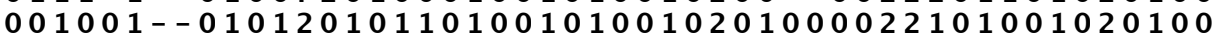
$001001--000020110000001110010001000122111001000100$ $001001--010021101100001000010200--0022001111021100$

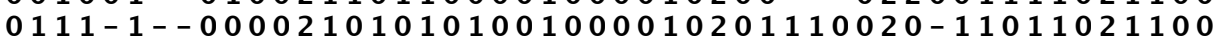
$0011-1--010121110101001010010001000021001001021100$ $0011-1--010121110101001000010201000022101001021100$ $0011-1--01002110010100111011102000--0022211010011021100$ $101001--000021110000000120010202000012001011000100$ $0011-1--010012100001001000010200--0022201111021100$ $001001--010021010000001000110100--0022001001021100$ $001001--010021110001001010110001000022101011021100$

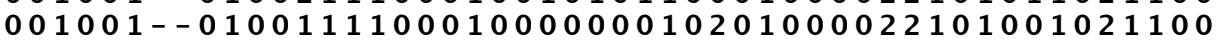
$001001--010121000100001010110000--0022101101020200$ $0011-1--010120110000001000010210--00022101001011100$ $001001--01012$ ? $1000010011101102000--00222101110000202000$ $021001--01011010111201111001022010000022101110110200000$

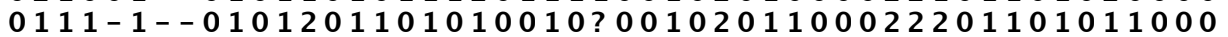

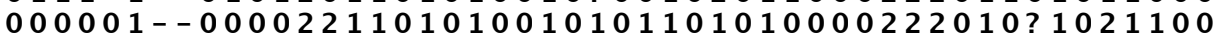
$010001--010111110001001010010103000022101001022100$ $111001--00010000000100111001020100002210101011121100$ $0011-1--010022100101000010110201000021101001021010$ $0111-1--0100210100010011000002021100221010$ ? 1021100

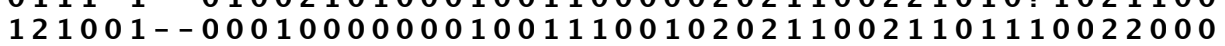
$0111-1--010021110101001110111200--0021001101021100$ 
Oligosarcus argenteus Orthospinus franciscoensis Paracheirodon axelrodi Paragoniates alburnus Phenacogaster pectinatus Phenagoniates macrolepis Piabina argentea Piaractus mesopotamicus Poptella brevispina

Probolus heterostomus Rachoviscus graciliceps Rhinobrycon negrensis Rhoadsia altipinna Roeboexodon guyanensis Salminus hilarii Serrabrycon magoi Stygichthys typhlops Tetragonopterus argenteus Triportheus albus
$51 \quad 60$ 70 80 90 100

100000000020110000001100110102000012001001020100 $001001--01002111000000101001000100-0220010 ? 1021100$ $001001--010022100101001010$ ? $100000--002101101101020200$ $001001--010022100001001110110001000021101101020100$ $0111-1--010022000101001010010001000121101101021100$ $001001--000022110101001010010201000021101111010000$ $0111-1--010001110001001010110201000022201111021010$ $111001--0101100001000011100102020100212010 ? 1021200$ $001001--010021110001001010010201000021101001021100$ $001001--010020110101001110110201000021101001021100$ $0011-1--01002$ ? $1001010010101110100--00021001001020200$ $0111-1--010022110101001110010101100021101001020200$ $001001--010022110101001110010201010021001000021100$ $001001--01002101010$ ? 001110110202000022201001011000 $000001--000120100000001100100201000012101011001010$ $001001--010022110101001000110101000022101001021100$ $001001--010001000000001100110000--002221111101000201$ $001101--010021100001001100010202020022101001021100$ $001001--010120101101001000000201010022101011021010$ 
Chanos chanos

Catostomus commersonnii Olivaichthys mesembrinus Gymnotus aff. carapo Citharinus latus Distichodus notospilus Hemistichodus vaillanti Neolebias unifasciatus Nannocharax fasciatus Xenocharax spilurus Apareiodon piracicabae Parodon nasus Saccodon wagneri Anodus orinocensis Bivibranchia fowleri Hemiodus unimaculatus Curimata ocellata Curimatopsis macrolepis Potamorhina latior Prochilodus nigricans Semaprochilodus insignis Caenotropus labyrinthicus Chilodus punctatus Anostomus anostomus Leporellus vittatus Leporinus fasciatus Schizodon fasciatus Carnegiella strigata Gasteropelecus sternicla Thoracocharax stellatus Acestrorhynchus falcirostris Gilbertolus atratoensis Hydrolycus tatauaia Roestes molossus Erythrinoidea fam. nov Boulengerella maculata Ctenolucius hujeta Copeina cf. guttata Lebiasina bimaculata Piabucina astrigata Erythrinus erythrinus Hoplias malabaricus Hepsetus odoe Arnoldichthys spilopterus Brycinus macrolepidotus Bryconalestes longipinnis Chalceus epakros Characidium bahiensis Crenuchus spilurus Agoniates halecinus Aphyocharax pusillus Astyanax mexicanus Atopomesus pachyodus Axelrodia reisei Brittanichthys axelrodi Brycon pesu Bryconadenos tanaothoros Bryconamericus exodon Bryconops alburnoides Charax cf. leticiae

Clupeacharax cf. engrauloides Compsura heterura Ctenobrycon hauxwellianus Deuterodon iguape Diapoma terofali Galeocharax knerii Glandulocauda melanogenys Gnathocharax steindachneri Gymnocorymbus ternetzi Hemibrycon polyodon Hemigrammus unilineatus Hollandichthys multifasciatus Hyphessobrycon compressus Iguanodectes geisleri Knodus meridae Landonia latidens Markiana nigripinnis Metynnis lippincottianus Microschemobrycon casiquiare Moenkhausia xinguensis Myleus setiger

Odontostilbe pequira
$10---0-0100020210210-111001000000010000201100 ? 0000$

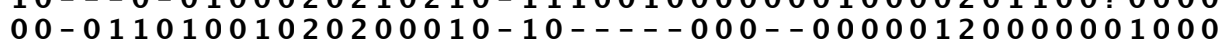
$00-011110110202-000101111011---20-0011--0--------1$ ? 0-??0-11010200-0001011--1-1---1--1001--0--- - - $00-011110012-020120100100011001000 ? 00111100 ? 00000001$ $00-0110100121010110110101011100022011000000011000000000$ $00-001010012001010011010001110001000001111110012000$ $10-01101001210101001101010111000100001100010003000$ $00-01101001210101001101010111000100100010010001010$ $00-01101001210101201101010111101010000001100100002011$ $00-010-1101111201101011000110000 ? 00000100010111001$

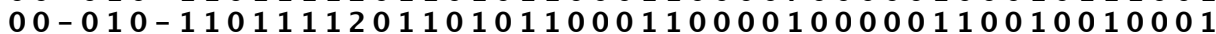
$00-010-1101111101001011000 ? 1 ? ? ? 0 ? ? ? ? ? ? ? ? ? ? ? ? ? ? ? ? ? ?$ 11000111001101201001001000110010000000120110113011 11000111001111201001001000110000001000110110012011 110001110011112010010010 ? 0110000000000110010001000

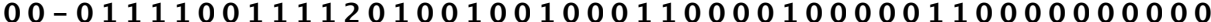
$00-01111001211101101000----000--0---0-10000003000$ $00-011110011112011010010101100001000001100110002010$ $00-01111001011201201001000111010101000111010001100$ $00-01111001011201201001001111010101000111010101110$ $10-011110010-01011010010001100000101110011000000022010$ $10-011110010-0101101001000110000010100011100100002010$ $00-011$ ? 1001010201001001100110000101100020000002000 $00-01111001011201001011010110000000100020010002010$

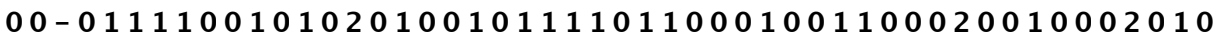
$00-01111001010101001001110110000001100020010000000$ $10-100-? 101020001011101111010-$

$10-100-? 101020101011101110100011121010010000003000$ $10-100-? 101020201011101010100011121010010000003010$ 110011010000201110110010101102120 ? ? 010121110003001 1100011100120100120110100011011002101100201110012011 $110011110002101010 ? 1001011100012100000001110213001$ 11 ? 00111001210101201001000110112021010020111012011

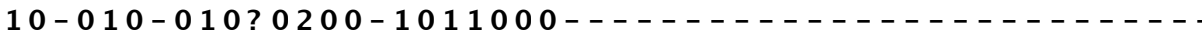
$10-010-0110021111011010----101--10100110010003101$ $10-010-0110011111011010----1101--1010000100100003101$ $10-010-11000-0101011101111100000221000010010002010$ $10-010-1100010111011001011100001221000010010000000$ $10-010-110001021101100111111000001110000000110011000030001$ $10-010-1100010111001000----111--11001011010003001$ $10-010-1110010111001000----1111-? 11101110110011000030001$ $10-010-11100111110110011101111000001000011100100113001$ $10-010-1110000101001101000010010110000011001100112001$ $10-010-11010001011011011000100101000000011011000101011$ $10-0110100110010110110111001100110100000001110100000011$ $10-010-1100100101001101010110011000000010010003011$ $10-010-10002000-101110101011-010210000120000--0001$ $10-01101001210001011101010010010211000020000003001$ 11000101001011201001101110000001000010121100003011

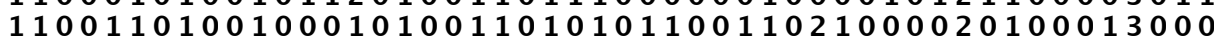
$10-00101001000101201100010110012021000120110013011$ $11000101001000001001 ? 01010110012000011000-00003011$ $1110010100101000101110101101100112002---0-1000000130011$ $11100111001010001001101010110011000---0-00010013011$ $110000-1001000101101101110010012021010020110003011$ 11000101001000000001101000110012000010020100012000 11000111001000001001101000110012000010010100012001 111001010010001011011010111110112002101001001100011 $10-01101001010101201101010110012000000110000103011$ 11000111001000101101101000001011000010010000010011

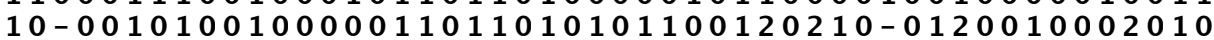
11000101001010001201101000110012021000110110012010 11000101001010101101101010111012021000100110013011

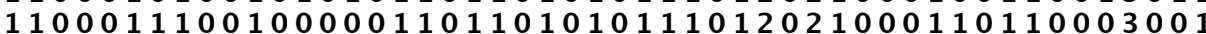
$10-01101001010111101001010100010000000110000103001$ $10-001010010000$ ? 1101100010110012021011010000003011 11010111001000101011101000111010021010020110113001 11100101001010101201101000110012000000120110013011

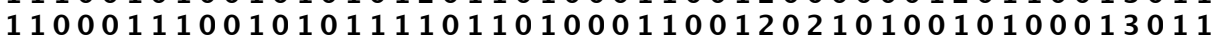
11000111001010101201101000111012000001120110012011 $10-01111001010101101101000111012100000110010013011$ 1 ? ? 10111001010001011 ? $0100011001200--11-10000003011$ 110001010010001010111010101100120210010000000000000 11000101001000001001 ? 01010111012000010000110012010 $10-10101001010001101$ ? $0101010110011202100000---1000-10$ $10-01111001000101201101000110011021010020110012001$ $10-0111100101010120110101011001200210001100111001001$ $110 ? 0101001010001001 ? 01000110012000011020000003011$ 11100111001010101101101010111012021010100100012010

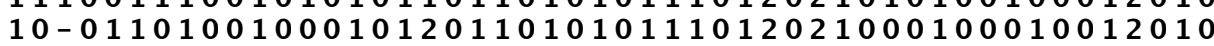
$10-10101001010001101$ ? 01010110012000001100110013001 
Oligosarcus argenteus Orthospinus franciscoensis Paracheirodon axelrodi Paragoniates alburnus Phenacogaster pectinatus Phenagoniates macrolepis Piabina argentea Piaractus mesopotamicus Poptella brevispina

Probolus heterostomus Rachoviscus graciliceps Rhinobrycon negrensis Rhoadsia altipinna Roeboexodon guyanensis Salminus hilarii Serrabrycon magoi Stygichthys typhlops Tetragonopterus argenteus Triportheus albus
(1)

11100111001010001201101010110012020000110110013011

$1111011100101000101110100011101110--000-1000-003010$

$10-01111001010001101 ? 01000110012000011010000013001$

11000111001010101201101010110012001000100000000010

$10-01111001010101211101000110012021011000010012000$

11000111001010101001101010110012000001000110012000

$10-011 ? 10010001012011 ? 101011 ? 012000010010010002101$

11100111001010101201101000110012020001110110012011

11000111001010101201101000111012000001121110013011

$10-1111100101000101110101011101200000111011101003011$

11000101001010101001101010110012021011010000002010

11000101001010001201101000110012000001110010002000

11000111001010101101101010110012001000121110013001

$10-01101001010211101001011111011100000011010103101$ 1100010100101000110110101011101200210010020100013011 $10-011010010101010-1$ ? $1111011-$ ? ? 20 ? ? 0? 0 ? - 0 ? ? - - - - -

11000111001010101201101000111012021001110110012010

11000101001011201101001010100012021010020111013010 
Chanos chanos

Catostomus commersonnii Olivaichthys mesembrinus Gymnotus aff. carapo Citharinus latus Distichodus notospilus Hemistichodus vaillanti Neolebias unifasciatus Nannocharax fasciatus Xenocharax spilurus Apareiodon piracicabae Parodon nasus Saccodon wagneri Anodus orinocensis Bivibranchia fowleri Hemiodus unimaculatus Curimata ocellata Curimatopsis macrolepis Potamorhina latior Prochilodus nigricans Semaprochilodus insignis Caenotropus labyrinthicus Chilodus punctatus Anostomus anostomus Leporellus vittatus Leporinus fasciatus Schizodon fasciatus Carnegiella strigata Gasteropelecus sternicla Thoracocharax stellatus Acestrorhynchus falcirostris Gilbertolus atratoensis Hydrolycus tatauaia Roestes molossus Erythrinoidea fam. nov Boulengerella maculata Ctenolucius hujeta Copeina cf. guttata Lebiasina bimaculata Piabucina astrigata Erythrinus erythrinus Hoplias malabaricus Hepsetus odoe Arnoldichthys spilopterus Brycinus macrolepidotus Bryconalestes longipinnis Chalceus epakros Characidium bahiensis Crenuchus spilurus Agoniates halecinus Aphyocharax pusillus Astyanax mexicanus Atopomesus pachyodus Axelrodia reisei Brittanichthys axelrodi Brycon pesu Bryconadenos tanaothoros Bryconamericus exodon Bryconops alburnoides Charax cf. leticiae

Clupeacharax cf. engrauloides Compsura heterura Ctenobrycon hauxwellianus Deuterodon iguape Diapoma terofali Galeocharax knerii Glandulocauda melanogenys Gnathocharax steindachneri Gymnocorymbus ternetzi Hemibrycon polyodon Hemigrammus unilineatus Hollandichthys multifasciatus Hyphessobrycon compressus Iguanodectes geisleri Knodus meridae Landonia latidens Markiana nigripinnis Metynnis lippincottianus Microschemobrycon casiquiare Moenkhausia xinguensis Myleus setiger

Odontostilbe pequira
- - - - 0- - - - - $0200-100001--01120000001111000-0120110010$

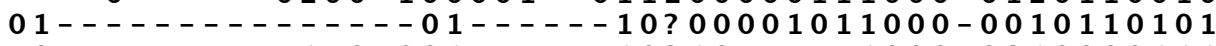
$-0--------1-0-001-----10 ? 10-----10000-03100000111$

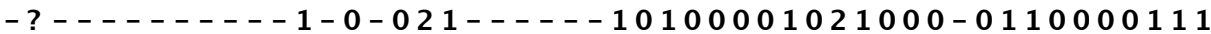
$00101 ?$ ? 00 ? $102001110001-1012100200211001001100000-1$ $0001021000102001100001-001010020011100101111000111$ $0001010000102001100001-1010000200111001111100000111$ - - - - - - - - $022000--000001-111101100020011111001111100000000001$ $0---0--00--02000100001-101210000000110010111100000101$ $0001020001102002100001-001010020021100101110000101$ $0001111001102100010001-111210120001100100100001110$ $0 ? 01111001102100010001-111200120001100100100001110$ ?????????? $\begin{aligned} & \text { ? ? } 21000 \\ & 0\end{aligned}$ $0011110101112001110001-111120020011020100211111120$ $0011100101102002110001-101110020001100101211011120$ $00121121001020011000011-1111100020011110010002111111120$ $0011111100102002110011-111020000001100100110110000$ $001011010010 \& 002000001-101120020111100101110110000$ $000210-100102011 \& 10001-111010001111100100111110010$ $1010110100102000110011-110010101011100101111001111$ $1000122101102000100011-101011101011100101111001111$ $0000101101102002100001-10110000101110110011000 ? 101$

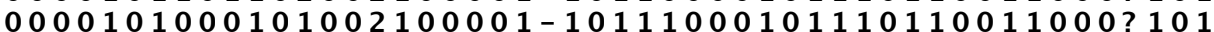

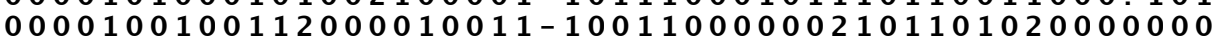
$0011012100102002110011-100100000011101101121000000$ $0001001100112000110011-100100100002101101121000111$

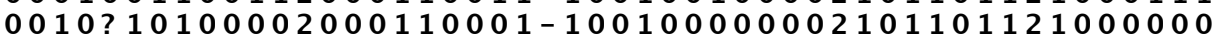

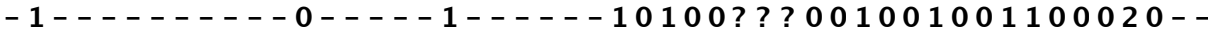

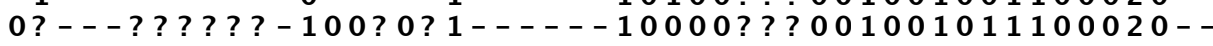
0 $0002110011102002020101-1010000000100201001201100$ - ? 001 ? 101010 ? ? 02000 ? ? 10 ? $011-0011020020000110101011110100001$ $0002021-01102000110001-110010020001110101220002001$ $1001010101101002110001-10112002001101010111000$ ? 001

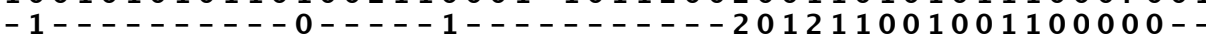
- 1 - - - - - - 1120002020100011000112000110101011111112000

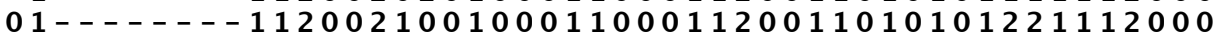

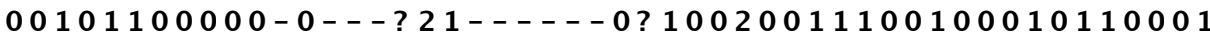
$0011110010112002021 \ldots-\cdots 1010020011100101111110001$

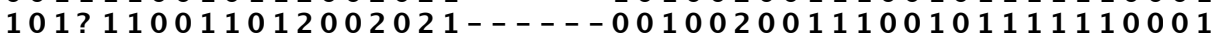
$0002100001112010101-\ldots--0 ? 10010011010101211112001$ $001211-120112002101------0$ ? 100100110101012111112001 $00121101111120001001001110 ? 101200011001001101100-$ $0011111000102000100001-111210020011100101110110000$ $0010010100112000110101-110 ? 00020011100101110110120$

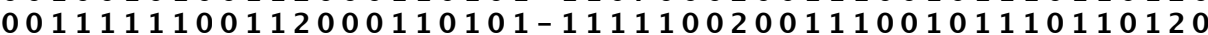
$0002120100112002110001-001100020011100100110110110$

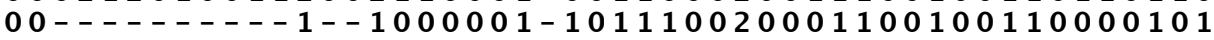
$00020000001-1---001-\ldots---111002000110010021000000--$ 10020001011020020 ? $0001-101110020011100100110110002$ $-1-y_{1}$ $001202-001102002111-\ldots--1110020111100111111110000$ $0001020000--1-01011-----11220022012110011111111100000$

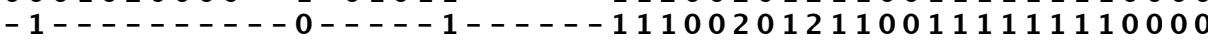

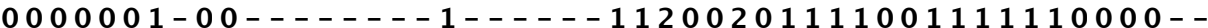
$1002020101112002120001-111110020111100101110112120$ $0000020001102002111-n_{-1}$ $0001021001102002111 \ldots \ldots--1110020111100111111110001$ $0010111001102002100001-101110020111100100110112110$ 1?--0??????0?-??? 11 - - - - 11220022011110110111111110000000 - - - - 0 - - - - $102002010001-1010200201111001010111110000$

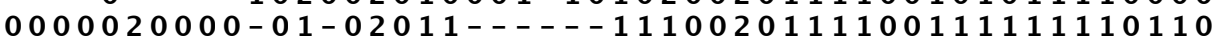
$00 ? 0020001102001011-\ldots--1010020111100111111110000$ 00 ? $0020001102001011-\ldots---1110020111100111111112111$

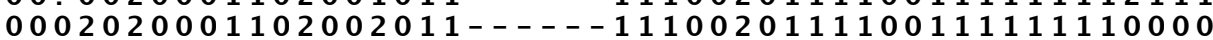
$0002011110112000111 \ldots-\cdots--1120120102020101111000000$

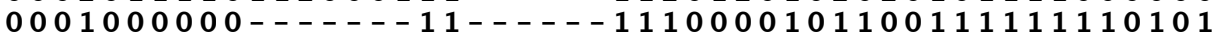

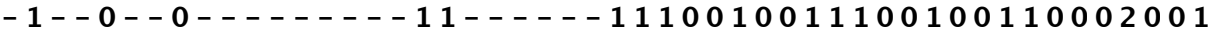
$0000020001102000011-\ldots--11110020111100111110110000$

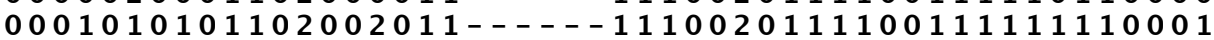
$0000020001101-02011-\ldots--11100 ? 0111100111111110001$

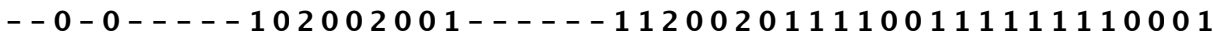

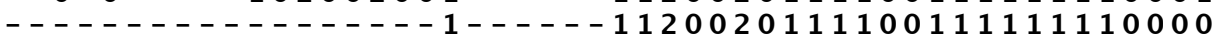
$0001100000101-02020001-0-1210020111100101111110110$ $0002000000102002011-\ldots$

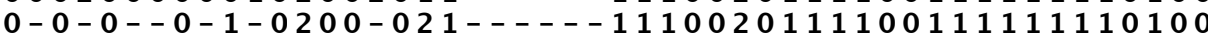
$0000000100102000011 \ldots \ldots--1110020111100111111110000$ $0--0$ - - - - $02200-01010--00121100220111111001100111011121100$ $0002000001102002011 \ldots \ldots-1110020111100111111000000$

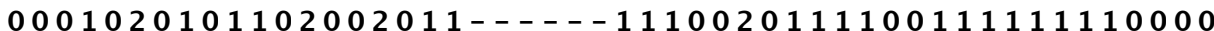
$1010110100102001110001-100110020121100101110112110$ $00000000001-1-02011$ - - - - 1110020111100111111110000 
Oligosarcus argenteus Orthospinus franciscoensis Paracheirodon axelrodi Paragoniates alburnus Phenacogaster pectinatus Phenagoniates macrolepis Piabina argentea Piaractus mesopotamicus Poptella brevispina Probolus heterostomus Rachoviscus graciliceps Rhinobrycon negrensis Rhoadsia altipinna Roeboexodon guyanensis Salminus hilarii Serrabrycon magoi Stygichthys typhlops Tetragonopterus argenteus Triportheus albus
151 160 170 180 190 200

$\begin{array}{ll} & \end{array}$ $0001020101102001011 \ldots \ldots--1110020111100111110110000$

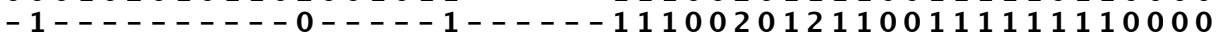
$0002000001112002011-\ldots--1110020111100111111112000$ $00-1020001101-02101-\ldots---1120002011111001111111111000$ $001202000011020002021-\ldots$ $010102-001102002021-\ldots---111002011110011111111000$ \& $1011012101102002110101--01110020101010101211112100$ $0000020101102002011 \ldots-\cdots-1110020111100110110112001$ $0000020101101002011-\ldots--11110020111100111111112000$

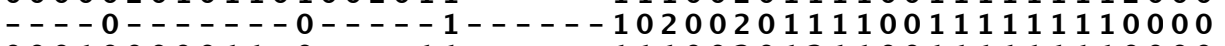
$00010000011-0,---11-\ldots--11100201211001111111110000$ $-1--0----101002011-----11110002001111100011111111111000110$ $0002020101102001111-\ldots--01110020111110011111111120000$ $0002020101112000120001-111110020111110101111112101$ $0001020001102002001-----111002011111001111111112001$

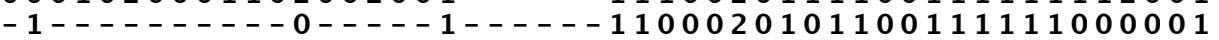
$0000001001102002111 \ldots-\cdots-1110020111100111111110000$ $0011100101102001110001-111110000001100100110110010$ 
Chanos chanos

Catostomus commersonnii Olivaichthys mesembrinus Gymnotus aff. carapo Citharinus latus Distichodus notospilus Hemistichodus vaillanti Neolebias unifasciatus Nannocharax fasciatus Xenocharax spilurus Apareiodon piracicabae Parodon nasus Saccodon wagneri Anodus orinocensis Bivibranchia fowleri Hemiodus unimaculatus Curimata ocellata Curimatopsis macrolepis Potamorhina latior Prochilodus nigricans Semaprochilodus insignis Caenotropus labyrinthicus Chilodus punctatus Anostomus anostomus Leporellus vittatus Leporinus fasciatus Schizodon fasciatus Carnegiella strigata Gasteropelecus sternicla Thoracocharax stellatus Acestrorhynchus falcirostris Gilbertolus atratoensis Hydrolycus tatauaia Roestes molossus Erythrinoidea fam. nov Boulengerella maculata Ctenolucius hujeta Copeina cf. guttata Lebiasina bimaculata Piabucina astrigata Erythrinus erythrinus Hoplias malabaricus Hepsetus odoe Arnoldichthys spilopterus Brycinus macrolepidotus Bryconalestes longipinnis Chalceus epakros Characidium bahiensis Crenuchus spilurus Agoniates halecinus Aphyocharax pusillus Astyanax mexicanus Atopomesus pachyodus Axelrodia reisei Brittanichthys axelrodi Brycon pesu Bryconadenos tanaothoros Bryconamericus exodon Bryconops alburnoides Charax cf. leticiae

Clupeacharax cf. engrauloides Compsura heterura Ctenobrycon hauxwellianus Deuterodon iguape Diapoma terofali Galeocharax knerii Glandulocauda melanogenys Gnathocharax steindachneri Gymnocorymbus ternetzi Hemibrycon polyodon Hemigrammus unilineatus Hollandichthys multifasciatus Hyphessobrycon compressus Iguanodectes geisleri Knodus meridae Landonia latidens Markiana nigripinnis Metynnis lippincottianus Microschemobrycon casiquiare Moenkhausia xinguensis Myleus setiger

Odontostilbe pequira
$101100-11-02000110-1000--1--1-02001011110110101110$ $111000-11-0201211310000--?-$ ? 0 ? 10000 ? $00001-011100000110$ $111100111 ? 1201011000010--1--1-0--1-00---100000011-$ $111-00 ? 11$ ? $1021---00001001--1-0001-00011010000000$ ? $201000 ? 1110020----1101000100-0220000001010000100010$ $10010000011211001000001010100-02000000120000100110$ $00000000011211011000001010100-020000000010000100110$ $00100000011211011000001100100-020000000110000000010$ $21 ? 00001010221011000000--0-? ? ? 12000010110100100110$ $01010001011211011000001010100-020000001010000000010$ 11100001011221210300001110010102100011120000100110 $1110000101122121030000111001010021000011020000 ? 00110$ 11100001011211210300001110110112101000111020000000110 21110001110210010000001110110002001001020000000111 $211000011112211----10100--0-10002000100011100000000112$ 111100000110212103001010101100020001001010100001100111 $111100011002200100-1101110110002000001020100100012$

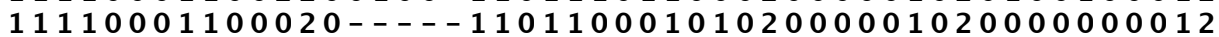
$11110001100020-----1101010010002000001020100000012$ $11111001100 ? 20-\ldots-011011001100002001001020000100011$

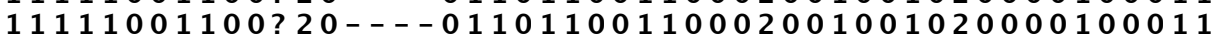
$10100011100 ? 11$ ? - ? $11000-00-10100000010111000000112$

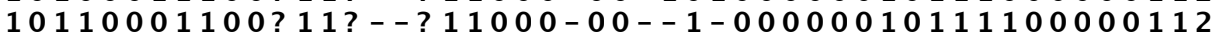

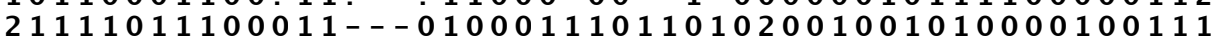
20110011100211011010001110110102001001020010000111 211100111002110110100011101101002001011020010100111

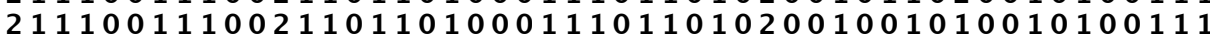
$011110-1101121001000010--1--1-0--0011---0011-00011$ $011110-1101121001000010--1--1-0--0011---0011-00011$ $011110-1101121001000010--1--1-0--0011---0011-00010$ $101100100011211002000010001-1-02001011021110100011$

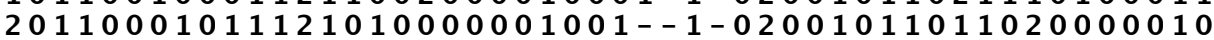
$20110010011201100100001001--1-02001111010020010010$ $201100000112111000000010001-1-02001011011020000010$ 001000111 ? $11111011000000--1--1-1001-0000-01---0-002$ $10110010011121111100001011--1-02000011021011000011$ $10110011011121011100001011--1-020000011021011000010$ $1010002001121101100000110011010001-010110000100012$ 10100020011211011000001110110102010011120000000011 101000200112110110000011101101002001011120000000010 101000100112111001000011101101000000001120100000002 10000010011201100100001110110102000001120100000002

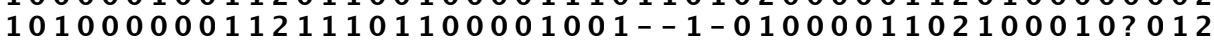
01100001011101011000001100110002000011010010000011 201000000111110110000011101101002001011020010100011 $2010000101110101100000111001 ? 002001011010010000011$ 10110000011101100000001110010002000011010010100011 $1010000001112101100000110011011200000 ? 0110000100100$ 00111100011111011000001100100112000001110100100100 $101111100111211001000011101-1-020000111010010101110$ 10101000011111000000001110010101000012020000000112 101010011111110000000011101100002001011010000000011 10100001111121011000001100110000000011110100000101 $2010000101111101100000110011000-01-0101-00000000111$ $1010000001111100000000110001000001-011000000001001$ 201100000111210000000010100101002001011021010101011 10101001011111011000001100010102000011010000001011 10100001011121011000001110010102000011010000000011

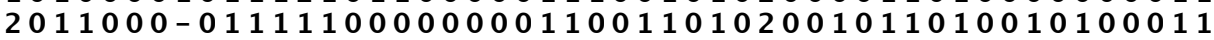
10100001011111000000001110010002000011021000000012 $101000011111111011000001011--1-020000111010010101010$

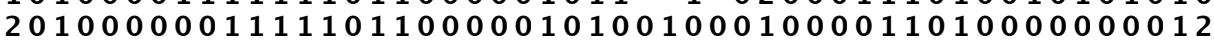
101000011111010010000011110010001001011011010000012 10111000011111001000001100110002000011010010001011 $1010000001111101100000 ? ? ? 0$ ? 1010102001011010010000012 10100000011111100100001110010002000011020000001011 10111001011111011000001100010001000010110000000011 $00100001111111000000001101--1-02001111010011-00011$ 101010010111110100000011100100020001011010000000011

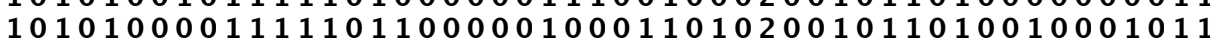
201000010111010110000010100100002000011010010000012

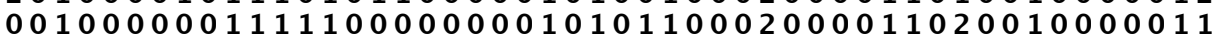
101000110111110000000010000100000 ? 01011010010000011 $201000 ? 1111221011000001100010102000011010010100110$ 1010000101121101100000111001010100000110100100101112 10101000011111011000001110110002000011010000001111 101010000111110110000011100101002001011010010001011

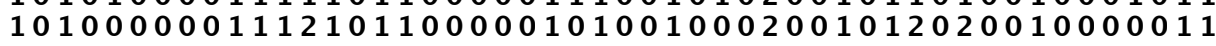
10101000011121011000001100110001000010110000000112

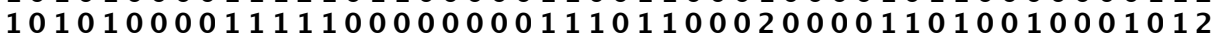

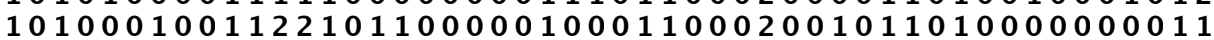
10101000011111001000001110110001000010110000001111 
Oligosarcus argenteus Orthospinus franciscoensis Paracheirodon axelrodi Paragoniates alburnus Phenacogaster pectinatus Phenagoniates macrolepis Piabina argentea Piaractus mesopotamicus Poptella brevispina

Probolus heterostomus Rachoviscus graciliceps Rhinobrycon negrensis Rhoadsia altipinna Roeboexodon guyanensis Salminus hilarii Serrabrycon magoi Stygichthys typhlops Tetragonopterus argenteus Triportheus albus
201 210 220 230 240 250 10101000011111000000001110010002001011010010000011 $1010000101111101100000110011000001-0110100000000012$ $101010 ? 1011111000000001111--1-01000112010010000012$ 10101001011111000000001110110001001011011000000012 $10101001011111011000001101--1-01000012010000000112$ 10100000011121011000001110110102001011010000000111 10100010011121001000001000110002001011020010100011 20100000011121000000001110010002001011010010000011 10101000011111000000001110110002001011010010000011 $20100001011111011000000--0-1$ ? ? ? 00000011020010000010 10100001011121011000001110110101000010010000000011 10101000011111011000001010110001000011010010000011 10101001011111000000001010110102000011011010001011 001100000111110001000010101101020011011020010001011 10110001011111000000001110110001000011110010000011 $21100001111111011000000--1--1-000$ ? - 0001001000 ? 0000 10101000011121000000001110010002001011010010001011 $11111000011111111000001111--1-02$ ? 001111010010011010 
Chanos chanos

Catostomus commersonnii Olivaichthys mesembrinus Gymnotus aff. carapo Citharinus latus Distichodus notospilus Hemistichodus vaillanti Neolebias unifasciatus Nannocharax fasciatus Xenocharax spilurus Apareiodon piracicabae Parodon nasus Saccodon wagneri Anodus orinocensis Bivibranchia fowleri Hemiodus unimaculatus Curimata ocellata Curimatopsis macrolepis Potamorhina latior Prochilodus nigricans Semaprochilodus insignis Caenotropus labyrinthicus Chilodus punctatus Anostomus anostomus Leporellus vittatus Leporinus fasciatus Schizodon fasciatus Carnegiella strigata Gasteropelecus sternicla Thoracocharax stellatus Acestrorhynchus falcirostris Gilbertolus atratoensis Hydrolycus tatauaia Roestes molossus Erythrinoidea fam. nov Boulengerella maculata Ctenolucius hujeta Copeina cf. guttata Lebiasina bimaculata Piabucina astrigata Erythrinus erythrinus Hoplias malabaricus Hepsetus odoe Arnoldichthys spilopterus Brycinus macrolepidotus Bryconalestes longipinnis Chalceus epakros Characidium bahiensis Crenuchus spilurus Agoniates halecinus Aphyocharax pusillus Astyanax mexicanus Atopomesus pachyodus Axelrodia reisei Brittanichthys axelrodi Brycon pesu Bryconadenos tanaothoros Bryconamericus exodon Bryconops alburnoides Charax cf. leticiae

Clupeacharax cf. engrauloides Compsura heterura Ctenobrycon hauxwellianus Deuterodon iguape Diapoma terofali Galeocharax knerii Glandulocauda melanogenys Gnathocharax steindachneri Gymnocorymbus ternetzi Hemibrycon polyodon Hemigrammus unilineatus Hollandichthys multifasciatus Hyphessobrycon compressus Iguanodectes geisleri Knodus meridae Landonia latidens Markiana nigripinnis Metynnis lippincottianus Microschemobrycon casiquiare Moenkhausia xinguensis Myleus setiger

Odontostilbe pequira
$0300 \& 1301020103000001-1000 ? 0 \& 000110000010010000121$ $030040303000103-00001-10000030010100011100010110122$ --0000 ? $13020103-00000-1001$ ? 00411010000000001111010120

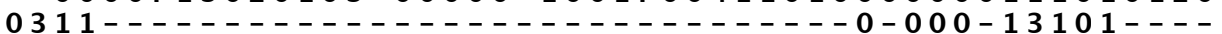
00003110102010100010113000103010010000011120010110 $000030101020113-001010200010301000000000111111010110$ $000030302020100-00101$ ? 2001118010010000011101010121 $011120101020103-001012200110 \& 010010000011000000110$ $011010102000100-0010012000103110010000111001000110$ $000040201020113-0010102001103010000000011110010110$ 02001130300010100110112001003111010001111101010110 12001130300010000010112001103111000001111100010110 01102130300010100010112001102110000001111100000110 01004230300010201010113001102200010000011010000100 101132303010103100 ? $0110-01102200010000010000000100$ 10104230300010111010113001102200010000010000000100 $001040201010001-1010112001102200000001011000000100$ 11002210101010301010122001111201000000011000010100 $0100201130201010001000300110 \& 200000000011010000031$ 01002101100010101010102001202200000000011000000100 01002101202000101010102001202200000000011000000100 $0100 \& 20030201001101000200110 \& 200000000011000010100$ $120022003010100110100020012022000000000100 \& 1010101$ 12002120101010300010022001103100000000010001100101 11002220302010100010023001203100000000011000000101 11003220102011100010022000203100000000011001100101 110022 ? 0101000110010002000203110000000010001000101 $1-1001-112--00310-001-0-21011310100000001121100111$ $131001-112--0031--001-0-21011210100000001121100111$ $--1001-112--0031--0---0-210130102100000001131100122$ $0 ? 1111300010113100111-1011001200110000001020100110$ 0110111 ? ? 0012031 ? 0000 ? ? 10210101220110000000010300 ? 0110 $0 ? 1111 ? 010001020000000310101211010000001103000011$ ? 0 ? 10110 ? ? 001101000001 ? 201101130 ? 100000001131000110 - ? ? 1131110 ? ? 2031?? 0? ? ? ? ? 01 ? ? 104410100000000 ? ? 111111012 ? $0210 \& 1300000103100101-1011010310210000011101010010$ $0210 \& 1300000103100101-10110103112100000111010000000$ $111011201000111100001-1001010311100000011101010122$ $1110 \& 1202010103100001-1001010300100000011001000112$ $010011301010103100001-0-01010300100000011001000120$ ? $110 \& 1202000103111001-100101 \& 200100000011101010122$ ? $20011302000103111001-10010130111100000111 \& 1010022$ $120121300010101100011-1001010400110000011000001100$ $110011211020113000011-100100320001000001 ? ? 1 ? 000100$ 0101211100101031 ? $0011-1001001300100000011010001000$ 01011110001010011001022001001310000000001011001000 $111021210000100000011220010031001100000100 \& 1000000$ 1100212130 ? $0103000000-100$ ? 11 ? 1110010000011101100110 11002111300010300000022001113011000000011100010101 $0211012130101131100000301101 \& 200100000000020100110$

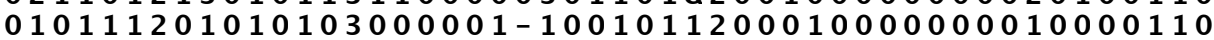
$110011111001103000001-1001111 ? 000110000001010100110$ $110011001000100010011-10110112010101010010 \& 0100110$

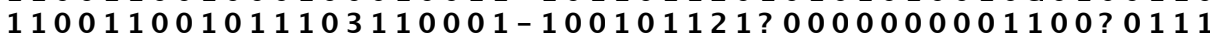
0111111130011031100112200110112000110000000011100111 01101121101010201000122001011200110000001020000110 $111111101011103010001-1011010310010000010010100110$ 11111110100110311001122011010300000000001010100122 0 ? 002220100 ? 10311001122011011210010000011030100110 $111011011101101010001-101101120001010110001031100110$ $12100121102000210-001-1020010301110000001030100110$ $111111101000103000011-10011112100000000011101001 \& 0$ $120011011000103010011-1011211210000111001131100110$ $011111101010103010011-1001111210010000000020100110$ $1211001010011030100 ? 1-1-110103000 ? 0000001020100110$ $11001100 ? 001103010001-1011011200010000001030110111$

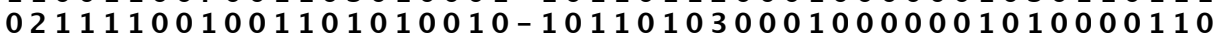
$031111000111103110-10-1021010300110000001020100110$ $111101012101000010010-1011111210010110001131100110$ $011111111010103010011-0011010300010000001020100110$ ?21011011000102010011-1001111200010001001020100120 $121101011001103100011-10111112000100010010 \& 0100110$ $121110011001103100001-1011111210010001000$ ? 01 ? 01110 $010012201001103100010-100101120 ? 00000100 ? ? 201$ ? 0110 $021111101010100010001-1001010310010000001011100111$ 01111111101110001001122011011200010000001 ? \& 01 ? 0110 $121111001001102000101-1011011200000101001031 ? 00111$ $111001112001100000000-1011103000001100000131011110$ $111111001001102010010-1001011201010000001010110111$ $111111111001102010011-1001111200010 ? 00000020100110$

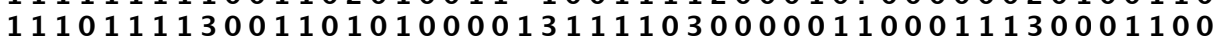
$111111101001103110011-10011112000000000010101$ ? 0110 
Oligosarcus argenteus Orthospinus franciscoensis Paracheirodon axelrodi Paragoniates alburnus Phenacogaster pectinatus Phenagoniates macrolepis Piabina argentea Piaractus mesopotamicus Poptella brevispina

Probolus heterostomus Rachoviscus graciliceps Rhinobrycon negrensis Rhoadsia altipinna Roeboexodon guyanensis Salminus hilarii Serrabrycon magoi Stygichthys typhlops Tetragonopterus argenteus Triportheus albus
1111111??02010300011?-1011011200010000?01020100110 $1100 \& 1011001101000000-10112112000101110010 \& 0000110$ $111101002001103010010-1001011210010000001010000110$ $12111100 ? 02110111000 ?-1021011200110101001031100110$ $010011012001101010010-1011011210010101001030000110$

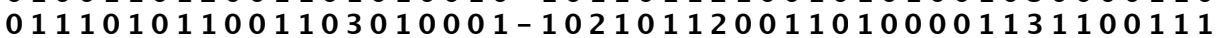
11111110101010301000122000010300010000001010100110 11001211300011201000013100113000100100001121000110 $110011011101101100011-1011212100010101001030100110$ $111111001011103000001-1001111200010000001020100110$ 1211011020211030 ? 001 ? -101001120 ? 01000000 ? ? 201 ? 0110 $111111101021103010001-101101030001000000001010012 \&$ $111111101021103010001-101111120001010100102010 \& 110$ $010111101011103010010-1001011210010000000020000110$ $11001120 ? 01010300000 ?-10011112001000000000200 ? 0110$ $111111101000102010001-1001111200010000000010110111$ $2211012000202--100011020010104001000000 ? 10 \& 1000120$ $111111011001000010111-1011111200010000001031000110$ 03110121100010100001003101011200110000001020100111 
Chanos chanos

Catostomus commersonnii Olivaichthys mesembrinus Gymnotus aff. carapo Citharinus latus Distichodus notospilus Hemistichodus vaillanti Neolebias unifasciatus Nannocharax fasciatus Xenocharax spilurus Apareiodon piracicabae Parodon nasus Saccodon wagneri Anodus orinocensis Bivibranchia fowleri Hemiodus unimaculatus Curimata ocellata Curimatopsis macrolepis Potamorhina latior Prochilodus nigricans Semaprochilodus insignis Caenotropus labyrinthicus Chilodus punctatus Anostomus anostomus Leporellus vittatus Leporinus fasciatus Schizodon fasciatus Carnegiella strigata Gasteropelecus sternicla Thoracocharax stellatus Acestrorhynchus falcirostris Gilbertolus atratoensis Hydrolycus tatauaia Roestes molossus Erythrinoidea fam. nov Boulengerella maculata Ctenolucius hujeta Copeina cf. guttata Lebiasina bimaculata Piabucina astrigata Erythrinus erythrinus Hoplias malabaricus Hepsetus odoe Arnoldichthys spilopterus Brycinus macrolepidotus Bryconalestes longipinnis Chalceus epakros Characidium bahiensis Crenuchus spilurus Agoniates halecinus Aphyocharax pusillus Astyanax mexicanus Atopomesus pachyodus Axelrodia reisei Brittanichthys axelrodi Brycon pesu Bryconadenos tanaothoros Bryconamericus exodon Bryconops alburnoides Charax cf. leticiae

Clupeacharax cf. engrauloides Compsura heterura Ctenobrycon hauxwellianus Deuterodon iguape Diapoma terofali Galeocharax knerii Glandulocauda melanogenys Gnathocharax steindachneri Gymnocorymbus ternetzi Hemibrycon polyodon Hemigrammus unilineatus Hollandichthys multifasciatus Hyphessobrycon compressus Iguanodectes geisleri Knodus meridae Landonia latidens Markiana nigripinnis Metynnis lippincottianus Microschemobrycon casiquiare Moenkhausia xinguensis Myleus setiger

Odontostilbe pequira
$110111100000220100001000--0-1100000001129110000001$ $120001000100220001111101001-1101001--0-202-0-00000$ $110001001100221010111011011011010011-0---02100000-$ - - - - - - - - - - - - 1011110110110100110 ? 1 - 0 - -0101000001000 112110111000210012110111001011010000000014110000001 112110111000220012111111001011010000000014100000101 1121101110002200121101110010100100000001610001020 ? 11211011100022001211011100010110100000001310001010 ? 1121101110002200121100110011100111000010210001020 ? $112110111000221012110111001 ? 110100000000040000001000$ 122101101000111010110111011100000000110014100010100 $12210110100011101011011101110000000110003100010100 \%$ 12210110100021001 ? 1 1 ? 11 ? ? 1 ? 0? ? 0? ? ? ? 0? ? ? ? ? ? ? 0? 12211010100022001011111101100100010000105110011200 $122111001000220010110111011000000001-0101110010010$

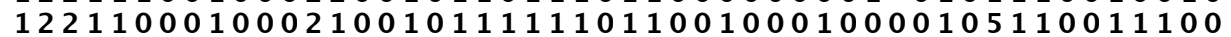
12210100100021001011011100100100100010012110000100 11110100100021001011011101110000000110010110000000 01210100100122001011011101100000100010002110010200 02210100100021001011111100100000100110011110000100

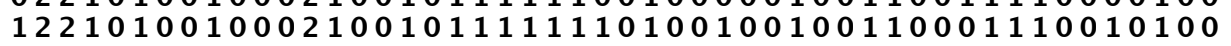
$122101001000100010110111001001001101-00000110010011$ 0101010010001000101101110010000011018 \& 001110010011 12110100100021001011011101110000110000001502001000 ? 12210100100021101011011100100100110000014110010000 02210100100021101011111100100000110000001311100100000 12210100100011 ? 01011111100100000110100002110010000 $110101001000210010110111011101001111-0015200001001$

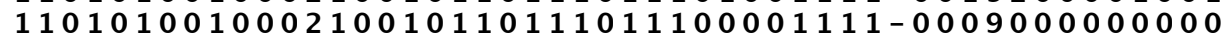
$011101001000220010110111001101001111-0016020001001$ 122101121000022001011111110100000110000129100001001

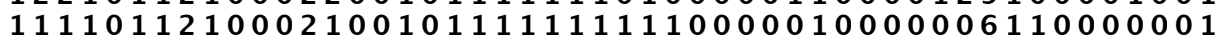
$0201002-100022101 ? 111111001 ? 01100110000009021001101$ 12010112100021101211 ? 111101 ? 00 ? 0011000014021001001 1001111 ? $110-00021$ ? 110111111 ? 000000001 ? 0 ? ? ? $100000100-$ $01210110100022001011011111100100000000 ? 26020000001$ 011101101000210010110111111001000000001 ? 0020000001 $111101001000110010110111011100000001-0103110000000$ $111101101000220010110111111101000001-01144020000000$

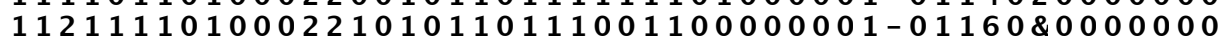
10011100111021121211011111110000000100104210000000 $110111001110211212111111111101001001-0101210000100$ $011101101000220012110111101001000101-01299110000000$ 01010100100111001111011100100100000100112010000200 02211112100122101011111111100100000100108100000101 12210100100122101011111101100100001000004010000100 02210100100122001011111101100100010000114110001001 11010100100021001011001100100100000000112010000000 11010000100011001011111100100100000100101100001200 02010110100122101011011100110010111000019021011101

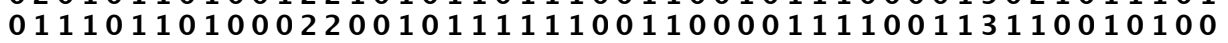
0121011010012200101111110011000001111000120000000100 010101001000220010110111001101000011001011000000000

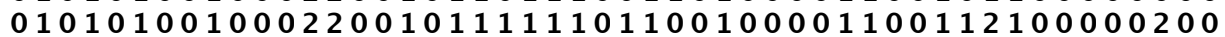
0101011210002200101111110110010000011000102100010200 1221010210002200101111111011010001000010106020001000 11110100100022001011111101100100011100112100000100 11010100100022001011111101100100011110011131000000000 12210110100022101011111110110100111000015021001000 01010100100022001011111110110100100100001000000000 11010100100022001011111101100010011010026020001101 $0111010010002200101111110110010000 \& 1000111000001000$ 11010100100022001011111110010010010111000001020000100 1101010010002210101111110010000001110000021000011200 11010110100022001011111100100100001100014110000100 111101001000220010111111001000000011000111200010000 112101001000220011111111001001000011000014120001000 11110110100021001211011100100000011100113100001100 $110101011000220010111111011001000011 ? 0000100001100$

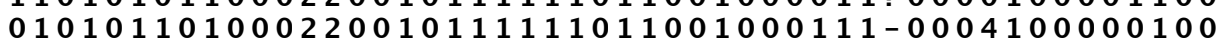

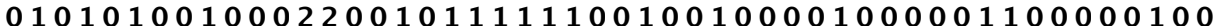
01010100100022001111111100100100001100113100000000

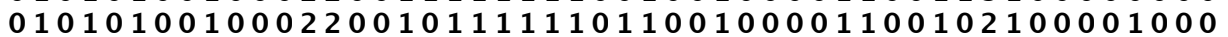
01010100100022001011111110110100000000116020000100 $1101010010002200101111110010010001111-01220100000100$ 11110100100022001011111100100000011100103020000100 01010100100022001011111100100100001100002100000200 112100111000211010111111111 ? 011000011000013021100200 010101001000220010111111001000000001100101100000000 02110100100022001011111100100100011100001100000100 121101111001211010111111111001001111000011202111002000 01010100100022001011111100110100001100112100000100 
Oligosarcus argenteus Orthospinus franciscoensis Paracheirodon axelrodi Paragoniates alburnus Phenacogaster pectinatus Phenagoniates macrolepis Piabina argentea Piaractus mesopotamicus Poptella brevispina

Probolus heterostomus Rachoviscus graciliceps Rhinobrycon negrensis Rhoadsia altipinna Roeboexodon guyanensis Salminus hilarii Serrabrycon magoi Stygichthys typhlops Tetragonopterus argenteus Triportheus albus
10011100013110000200 11010100100022001011111100100100001100000100010100 010101001000220010111111011001001011100111100000200 $110101001000210010111111101110000011 ? 00115 ? ? ? ? 00100$ 011101001000220010111111100110100001100011200000000 01010110100022001011011100110000000100127200000200 11010000100022001011111100100100011100112100000000 $021101101000221010111111111 ? 0100001000005210001200$ 010101001001221010111111001001000011000000020000100 11010100100022001011111100110100001100002000001000

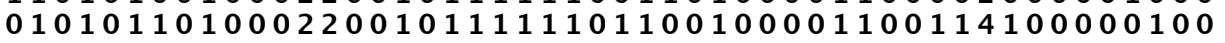
11010100100022001011111101100100011110122100000100 $0101010010002 \& 001011111100100100011100013100000200$ 012101101000221010111111100100100001100012110001100 $122101001000220 ? 1011011110100100010100107100000000$ 01010100100022001011111100100100111100111100000200 $100101101000221010111111111001000011-01222200000100$ 0101010010002200101111110010010000110000010100000100 020101001001221010111111110110100011000008020011101 
Chanos chanos

Catostomus commersonnii Olivaichthys mesembrinus Gymnotus aff. carapo Citharinus latus Distichodus notospilus Hemistichodus vaillanti Neolebias unifasciatus Nannocharax fasciatus Xenocharax spilurus Apareiodon piracicabae Parodon nasus Saccodon wagneri Anodus orinocensis Bivibranchia fowleri Hemiodus unimaculatus Curimata ocellata Curimatopsis macrolepis Potamorhina latior Prochilodus nigricans Semaprochilodus insignis Caenotropus labyrinthicus Chilodus punctatus Anostomus anostomus Leporellus vittatus Leporinus fasciatus Schizodon fasciatus Carnegiella strigata Gasteropelecus sternicla Thoracocharax stellatus Acestrorhynchus falcirostris Gilbertolus atratoensis Hydrolycus tatauaia Roestes molossus Erythrinoidea fam. nov Boulengerella maculata Ctenolucius hujeta Copeina cf. guttata Lebiasina bimaculata Piabucina astrigata Erythrinus erythrinus Hoplias malabaricus Hepsetus odoe Arnoldichthys spilopterus Brycinus macrolepidotus Bryconalestes longipinnis Chalceus epakros Characidium bahiensis Crenuchus spilurus Agoniates halecinus Aphyocharax pusillus Astyanax mexicanus Atopomesus pachyodus Axelrodia reisei Brittanichthys axelrodi Brycon pesu Bryconadenos tanaothoros Bryconamericus exodon Bryconops alburnoides Charax cf. leticiae

Clupeacharax cf. engrauloides Compsura heterura Ctenobrycon hauxwellianus Deuterodon iguape Diapoma terofali Galeocharax knerii Glandulocauda melanogenys Gnathocharax steindachneri Gymnocorymbus ternetzi Hemibrycon polyodon Hemigrammus unilineatus Hollandichthys multifasciatus Hyphessobrycon compressus Iguanodectes geisleri Knodus meridae Landonia latidens Markiana nigripinnis Metynnis lippincottianus Microschemobrycon casiquiare Moenkhausia xinguensis Myleus setiger

Odontostilbe pequira
02100-10200100-100010???????????????????????? 0--1 $01000-10-0100101100100000021020001100000--002020--1$ $0100---(--0----10-10$ $01000-10000001011101010010200100121010021112311100$ $1100000010200101000001010 ? 1222000101010022110101200$ 01000000102031110112010000122200111030022110321200 $0200010000203100---1000000100200111030022110011100$ $0000010000203100---2010000000200110010012110321100$ 1100010000 ? $03100---200-000100$ ? $00110 ? 30022110021100$ $1100000010203100---2000000222200110030012110321200$ 020001101010011111010110001121101000 ? $1022112320--0$ $02000010101001111101011000102110100021022112320--0$ $020001101010011111010-----1--1----0-1$ ? $0021122320--0$ $02100000000011010000011012222110100021022111110--0$ $02000000002000-0---101101$ ? $220100100031022110110--0$ $02000000000010-10002011010121100100010022110110--0$ 0200 ? $00010201000---0011010222110100020022112110--0$ $00--010010200101000000100000010010100020022112110--0$ $0200000011102100---1011012112110 ? 00020022112110--0$ $02000000102021211101011002102010100010022122110--0$ $02000000101001111001011002112110100010022122110--0$ $020000010 ? 2010-1000101101312211010000102211002$ ? ? 0 $02000101012000-100010110131222101001 ? 1122111220--0$ $0200000010100011111010110000 ? 1210010001112211111$ ? ? 0 $02000000002000211101011000102100120011121112120--0$ 0200000000000121110001100011211011001 ? $1111110120--0$ $02000010000000-11101011012212110121010012211111110--0$ $102-0-10102000-1110100000100000010 ? ? 10021110011011$ $102-0110102000-1000100000100000010 ? ? 10021110011010$ $102-$ ? $110100000-1110100000100000010 ?$ ? 100221110011210 $0210010010200100---1011003 ? 12010120010020210120--0$ 0? ? ? ? ? ? ? 2 ? 000000000 ? ? ? ? ? ? ? ? ? ? ? ? ? ? ? ? ? ? ? ? 0 $12000100202000-0---101100 ? 221000100010120110110--0$

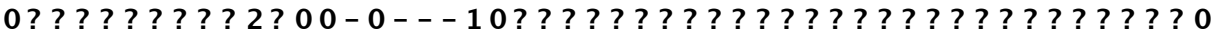
$00--0-10001$ ? $010110010 ?$ ? $000010000100 ? 00 ?---0002 ? ? ? 1$ $001-0010002020-11102011003010000120000122210010--0$ $001-0010102020-11102010003012010120000122210020--0$ $00--0-10102001111101010000010200110011001010220--1$ $00--0-1-102001111101010003110211111000000010320--1$ $00--011-101001111101011002112210101001001012320--0$ $01000-10001001111101010002111001121001111010020--1$ $01000-1000100111110101100 \& 112010100100 ? 01020020-1$ $0220001000100121100001000300201010100000022210120--0$ 0???????????011110010000030100?011001002001012???0 $02211110002001111001000002010010110010021111220--0$ $02211100102001211100000003010210110010020112320--0$ $02212110000001211101011000112210101000021112120--0$ 0?? ? ? ? ? ? ? 2? 0011000001000 ? 12021011001002111021 ? ? 0 $00--01000010011100000100031101101000 ? 0021110321200$ $02310100102100-10100011001002010100000120210020--0$

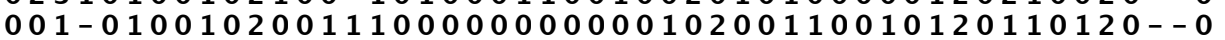
0?????????2?01110000000100000000110020121110310--0 $01100100102000-10000000000120200110010020112121100$ $001-0100102000-100000000001102001000210022110121020$

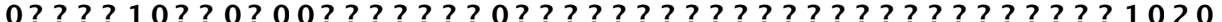
022 ? $0110101101111101011003002210100010020100120--0$

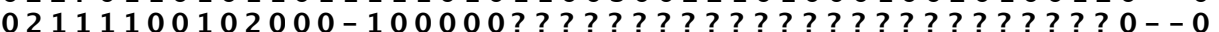
$02100000102000-10000000000100200110010021112120--0$ $02110100000000-10110011001102210100000120111110--0$ $02100100012000-0---00000031202000100 ? 0020111111100$ $0 ? ? 1 ? 0$ ? ? ? $02100-10000000003000010110010022110110--0$ $00--0100102000-10000000100010 ? 001100200022101321200$ $01100000102021010001000103020200100030020112120--0$ $01100100102000-10000000000010200110010022112320--0$

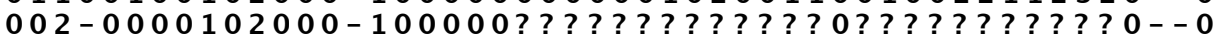
$02000 ? 00102020-0---100010 ? 0200001000 ? ? ? ? ? ? ? ? ?$ ? 1200 0? ? ? ? ? ? ? ? ? ? ? ? ? ? 000103 ? 10 ? 0012001002011031 ? ? ? $00--0100-02000-100000001031102000$ ? 000 ? 002111101111000 $02100200202000-10000000103020000100010021112320--0$

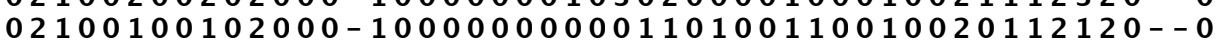

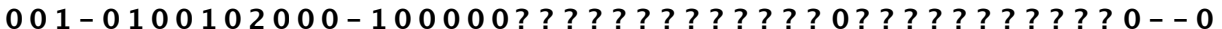
$00--0100102000-10000000100010200110010020110310--0$ $00--0100102000-0--00$ ? ? ? ? ? ? ? ? ? ? 0? ? ? ? ? ? ? ? ? 0--0 $01100100000000-0---000000 ? 120200120 ? 10021111310--0$ $02100100102000-10001000000110210110010011111$ ? ? ? $0--0$ $01100000102000-0--00$ ? ? ? ? ? ? ? ? ? ? 0? ? ? ? ? ? ? $0--0$ $02110100202000-0---200010312 ? 000110010021112310--0$ $01000000 ? 1000100---011110$ ? 01 ? 010100 ? $200211111113 \& 0$

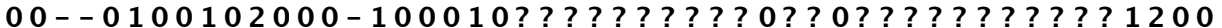
$02110100102000-11100010103112200100010020111110--0$ $0210000021000100---111111$ ? 0020010100 ? 10021112111 ? ? 0 $01100100100000-10000000100010200110020021111321200$ 
Oligosarcus argenteus Orthospinus franciscoensis Paracheirodon axelrodi Paragoniates alburnus Phenacogaster pectinatus Phenagoniates macrolepis Piabina argentea Piaractus mesopotamicus Poptella brevispina

Probolus heterostomus Rachoviscus graciliceps Rhinobrycon negrensis Rhoadsia altipinna Roeboexodon guyanensis Salminus hilarii Serrabrycon magoi Stygichthys typhlops Tetragonopterus argenteus Triportheus albus
351 360 370 380 390 400

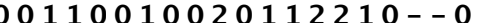

$02100100102000-10000000103020100100010021112110--0$

$00--010-002000-10000000000110200110020022111321180$ $001-0000102000-10100000101020000120010020110120-0$ $001-0100102000-100000001001202000 ? 0030020111211100$ $001-0-00102000-100000001031102001$ ? $0010121112120--1$ $01100100002000-10000000000110200110010020110320--0$

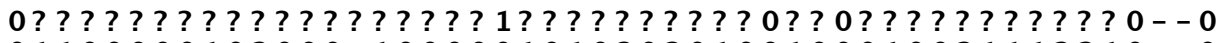
$01100000102000-10000010103020100100010021112210--0$ $02100100102000-100000001030201001200 ? 0020112320-0$

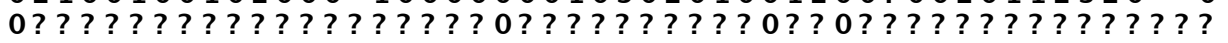
$02100100002000-10000000000120100110010021110310-0$

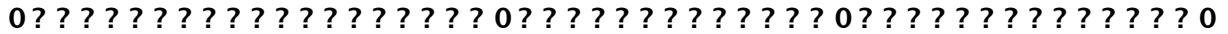

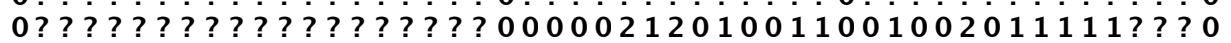
0?????????2?????????010003122110110000020122120--0 $00--010000 ? 000-1000000000 ? 1101001100100201111110--0$ $0---01 ?-00$ ? 00 ? ? ? ? ? ? ? $000000110200110010022102120--0$ $02110100102000-10001011103020000120020020111311200$ $02312100102100-11101011001010010100010021111120--0$ 
Chanos chanos

Catostomus commersonnii Olivaichthys mesembrinus Gymnotus aff. carapo Citharinus latus

Distichodus notospilus Hemistichodus vaillanti Neolebias unifasciatus Nannocharax fasciatus Xenocharax spilurus Apareiodon piracicabae Parodon nasus

Saccodon wagneri

Anodus orinocensis

Bivibranchia fowleri

Hemiodus unimaculatus

Curimata ocellata

Curimatopsis macrolepis

Potamorhina latior

Prochilodus nigricans

Semaprochilodus insignis

Caenotropus labyrinthicus

Chilodus punctatus

Anostomus anostomus

Leporellus vittatus

Leporinus fasciatus

Schizodon fasciatus

Carnegiella strigata

Gasteropelecus sternicla

Thoracocharax stellatus

Acestrorhynchus falcirostris

Gilbertolus atratoensis

Hydrolycus tatauaia

Roestes molossus

Erythrinoidea fam. nov

Boulengerella maculata

Ctenolucius hujeta

Copeina cf. guttata

Lebiasina bimaculata

Piabucina astrigata

Erythrinus erythrinus

Hoplias malabaricus

Hepsetus odoe

Arnoldichthys spilopterus

Brycinus macrolepidotus

Bryconalestes longipinnis

Chalceus epakros

Characidium bahiensis

Crenuchus spilurus

Agoniates halecinus

Aphyocharax pusillus

Astyanax mexicanus

Atopomesus pachyodus

Axelrodia reisei

Brittanichthys axelrodi

Brycon pesu

Bryconadenos tanaothoros

Bryconamericus exodon

Bryconops alburnoides

Charax cf. leticiae

Clupeacharax cf. engrauloides

Compsura heterura

Ctenobrycon hauxwellianus

Deuterodon iguape

Diapoma terofali

Galeocharax knerii

Glandulocauda melanogenys

Gnathocharax steindachneri

Gymnocorymbus ternetzi

Hemibrycon polyodon

Hemigrammus unilineatus

Hollandichthys multifasciatus

Hyphessobrycon compressus

Iguanodectes geisleri

Knodus meridae

Landonia latidens

Markiana nigripinnis

Metynnis lippincottianus

Microschemobrycon casiquiare

Moenkhausia xinguensis

Myleus setiger

Odontostilbe pequira
401

$010022 ? ? 00$

0001021001

$00000010-01$

$0011210-01$

00000021001

$0000002 ? ? 01$

00000021001

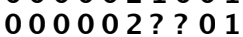

00000021001

00000021001

01000021001

0000 ? 21001

00000021001

1100221000

010022 ? ? 00

11000221000

1000221000

00000021000

1000221000

1000121000

1000121000

1000121000

000112 ? ? 00

0011121000

1000121000

1011121000

1011121000

0000021300

0000002 ? ? 00

000002 ? ? 00

0000021000

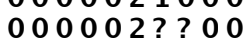

$0000121 ? 00$

0000021100

? $010010-00$

0000021200

0000021200

0000021000

0001021000

00011021000

0011021000

0011021000

0000020000

0000121200

0000121000

$\begin{array}{llllllllllll}0 & 0 & 0 & 0 & 1 & 1 & 1 & 0 & 0\end{array}$

0000121200

0010 ? 021000

0001021000

0000221100

0000002 ? ? 00

0000021200

0000021000

00000021100

000002 ? ? 00

0000121100

0000021100

0000021100

00000221100

000002 ? ? 00

0000021100

0000021100

0000021 ? 00

0000021100

00000021100

$0000121 ? 00$

0000020200

0000021000

0000021200

00000021100

000002 ? ? 00

0000021100

0000002 ? ? 00

0000021000

000002 ? ? 00

0000021000

000002 ? ? 00

0000121010

0000021100

0000121100

0000121010

000002 ? ? 00 
Oligosarcus argenteus

Orthospinus franciscoensis

Paracheirodon axelrodi

Paragoniates alburnus

Phenacogaster pectinatus

Phenagoniates macrolepis

Piabina argentea

Piaractus mesopotamicus

Poptella brevispina

Probolus heterostomus

Rachoviscus graciliceps

Rhinobrycon negrensis

Rhoadsia altipinna

Roeboexodon guyanensis

Salminus hilarii

Serrabrycon magoi

Stygichthys typhlops

Tetragonopterus argenteus

Triportheus albus
401

410

? $2 ? 00$

0000121100

000002 ? ? 00

$0000002 ? ? 00$

00000021100

000 ? 021100

0000121100

0000021010

0000002 ? ? 00

$00000112 ? ? 00$

0000021000

$000002 ? ? 00$

000002 ? ? 00

0000 ? 21100

0000021000

000002 ? ? 00

$0000-0--00$

$0000002 ? ? 00$

0000121100 
Tabela. 2. Índices de consistência e retenção de cada caráter. Variação dos indices entre os cladogramas 0 e 1 apresentados em negrito.

Índices de consistência

\begin{tabular}{|c|c|c|c|c|c|c|c|c|c|c|}
\hline & +0 & +1 & +2 & +3 & +4 & +5 & +6 & +7 & +8 & +9 \\
\hline 0 & 0.154 & 0.118 & 0.040 & 0.125 & 0.333 & 0.500 & 0.133 & 0.103 & 0.111 & 1.000 \\
\hline 10 & 250 & 143 & 091 & 0.375 & 0.111 & 0.500 & .250 & 0.071 & 0.167 & 0.500 \\
\hline 20 & 0.167 & 0.222 & .063 & 0.250 & 0.333 & 0.067 & .125 & 0.071 & 0.069 & 0.074 \\
\hline 30 & 0.500 & 0.500 & 0.105 & 0.500 & 0.167 & 0.250 & 0.143 & 0.125 & 0.048 & 0.125 \\
\hline 40 & 0.095 & 0.286 & 0.200 & 0.182 & 0.333 & 0.200 & -- & 0.200 & 0.100 & 0.333 \\
\hline 50 & 0.111 & 0.105 & 0.111 & 0.067 & 0.333 & 0.100 & 0.333 & 1.000 & 0.250 & 0.077 \\
\hline 60 & 0.500 & 0.111 & 0.100 & 0.067 & 0.053 & 0.091 & 0.200 & 0.056 & 0.250 & 0.087 \\
\hline 70 & 0.333 & 0.250 & .143 & 0.050 & 0.065 & 0.500 & 0.045 & 0.111 & 0.143 & 0.086 \\
\hline 80 & 0.091 & 0.094 & 0.071 & 0.167 & 0.500 & 0.125 & 0.100 & 0.087 & 0.074 & 0.200 \\
\hline 90 & 0.500 & 0.053 & 0.053 & 0.067 & 0.200 & 0.136 & 0.074 & 0.063 & 0.067 & 0.167 \\
\hline 100 & 0.200 & 0.067 & .200 & 0.143 & 0.100 & 0.100 & 0.050 & 0.333 & 0.125 & 0.250 \\
\hline 110 & 0.167 & 0.333 & 0.087 & 0.143 & 0.071 & 0.143 & 0.500 & 0.067 & & 0.500 \\
\hline 120 & 0.100 & 0.250 & 0.167 & 0.091 & $\begin{array}{l}0.050 \\
0.053\end{array}$ & 0.167 & 0.167 & 0.167 & $\begin{array}{l}0.056 \\
0.053\end{array}$ & 0.667 \\
\hline 130 & 0.111 & 0.080 & 0.133 & 0.100 & 0.043 & 0.200 & 0.067 & 0.056 & 0.059 & 0.067 \\
\hline 140 & 0.091 & 0.067 & 0.053 & 0.200 & 0.250 & 0.056 & 094 & 0.200 & 0.042 & 0.043 \\
\hline 150 & 0.125 & 0.100 & 0.067 & 0.083 & 0.100 & 0.083 & .118 & 0.063 & 0.500 & 0.056 \\
\hline 160 & 0.333 & 0.091 & .100 & .000 & .500 & .077 & .059 & & & 333 \\
\hline 170 & 0.250 & 1.000 & -- & 0.167 & 0.091 & 0.111 & 0.125 & 0.087 & 0.333 & 0.200 \\
\hline 180 & 0.222 & 0.333 & 0.111 & 0.080 & 0.333 & 0.143 & 0.200 & 1.000 & 1.000 & 0.167 \\
\hline 190 & 0.056 & 214 & 286 & .053 & 071 & .071 & 111 & & & 0.100 \\
\hline 200 & 0.087 & 0.100 & 0.333 & 0.063 & 0.059 & 0.500 & 0.167 & 0.038 & 0.083 & 0.333 \\
\hline 210 & 0.167 & 0.125 & 0.071 & 0.250 & 0.200 & 0.053 & 0.059 & 0.300 & 0.333 & 0.250 \\
\hline 220 & 0.250 & .500 & .125 & .091 & .043 & .100 & 056 & 500 & 111 & 0.091 \\
\hline 230 & 0.200 & 0.105 & 1.000 & 0.167 & 0.059 & 0.250 & 0.125 & 0.125 & 0.067 & 0.118 \\
\hline 240 & 0.111 & 0.100 & 0.111 & 0.333 & 0.053 & 0.500 & 0.067 & 0.067 & 0.167 & 0.080 \\
\hline 250 & 0.083 & 0.136 & 0.043 & 0.059 & 0.148 & 0.182 & $\begin{array}{l}0.088 \\
0.091\end{array}$ & 0.056 & 0.130 & 0.400 \\
\hline 260 & 0.061 & 0.067 & 0.222 & 0.125 & 0.083 & 0.056 & 0.048 & 0.500 & 0.200 & 0.053 \\
\hline 270 & 0.059 & 154 & 103 & .250 & 0.100 & 0.091 & 167 & 143 & 243 & 0.114 \\
\hline 280 & 0.045 & .100 & .167 & .048 & .000 & 0.125 & .333 & 0.091 & 0.333 & 0.100 \\
\hline 290 & 0.053 & 0.067 & 0.094 & 0.045 & 0.067 & 0.077 & 0.333 & 0.200 & 0.158 & 0.095 \\
\hline 300 & 0.043 & 0.118 & .057 & 1.000 & & 0.167 & 0.095 & 0.250 & 0.500 & 0.500 \\
\hline 310 & 1.000 & 0.143 & 0.250 & .118 & 0.063 & 1.000 & 0.500 & 0.143 & -- & -- \\
\hline 320 & 0.059 & 0.250 & 0.500 & -- & 0.091 & 0.048 & -- & 0.059 & 0.500 & 0.043 \\
\hline 330 & 0.333 & 0.500 & 0.067 & $\begin{array}{l}0.059 \\
0.063\end{array}$ & 0.111 & 0.067 & 0.250 & & 0.077 & 0.065 \\
\hline 340 & 0.087 & 0.083 & 0.083 & 0.167 & 1.000 & 0.111 & 0.059 & 0.063 & 0.500 & 0.100 \\
\hline 350 & 0.250 & 0.091 & 0.231 & 0.143 & 0.500 & 0.143 & 0.111 & 1.000 & 0.095 & 0.250 \\
\hline 360 & 0.105 & 0.250 & 0.300 & 0.077 & 0.143 & 0.077 & 0.091 & 0.059 & 0.500 & 0.087 \\
\hline 370 & 1.000 & 0.091 & 0.083 & 0.091 & 0.167 & 0.130 & 0.100 & 0.071 & 0.118 & $\begin{array}{l}0.091 \\
0.087\end{array}$ \\
\hline 38 & & & & & & & & & & 0.286 \\
\hline 390 & 0.095 & 0.500 & & 0.067 & & 0.100 & & & & 0.167 \\
\hline 400 & 0.200 & 0.333 & 0.200 & 0.125 & 0.091 & 0.500 & 0.250 & 0.188 & 1.000 & 0.500 \\
\hline
\end{tabular}


Tabela.2. Continuação

Índices de retenção

\begin{tabular}{|c|c|c|c|c|c|c|c|c|c|c|}
\hline & +0 & +1 & +2 & +3 & +4 & +5 & +6 & +7 & +8 & +9 \\
\hline 0 & 0.353 & 0.732 & 0.429 & 0.440 & 0.778 & 0.952 & 0.698 & 0.620 & 0.529 & -- \\
\hline 10 & 0.710 & 0.733 & 0.667 & 0.844 & 0.500 & 0.800 & 0.667 & 0.649 & 0.375 & 0.000 \\
\hline 20 & 0.375 & 0.696 & 0.400 & 0.857 & 0.333 & 0.563 & 0.222 & 0.639 & 0.500 & 0.576 \\
\hline 30 & 0.500 & 0.963 & 0.514 & 0.714 & 0.412 & 0.571 & 0.838 & 0.632 & 0.231 & 0.391 \\
\hline 40 & 0.648 & 0.286 & 0.333 & 0.550 & 0.333 & 0.500 & -- & 0.810 & 0.526 & 0.500 \\
\hline 50 & 0.429 & 0.667 & 0.619 & 0.333 & 0.714 & 0.308 & 0.200 & -- & 0.000 & 0.478 \\
\hline 60 & 0.500 & 0.484 & 0.455 & 0.588 & 0.617 & 0.667 & 0.200 & 0.514 & 0.800 & 0.447 \\
\hline 70 & 0.333 & 0.625 & 0.333 & 0.612 & 0.383 & 0.800 & 0.432 & 0.765 & 0.793 & 0.373 \\
\hline 80 & 0.677 & 0.508 & 0.567 & 0.375 & 0.500 & 0.588 & 0.679 & 0.588 & 0.444 & 0.400 \\
\hline 90 & 0.000 & 0.538 & 0.526 & 0.263 & 0.765 & 0.537 & 0.537 & 0.423 & 0.548 & 0.286 \\
\hline 100 & 0.778 & 0.650 & 0.429 & 0.250 & 0.809 & 0.571 & 0.457 & 0.333 & 0.632 & 0.400 \\
\hline 110 & 0.615 & 0.778 & 0.364 & 0.667 & 0.422 & 0.455 & 0.750 & 0.606 & 0.429 & 0.000 \\
\hline \multirow[t]{2}{*}{120} & 0.727 & 0.700 & 0.375 & 0.286 & 0.472 & 0.286 & 0.167 & 0.583 & 0.370 & 0.667 \\
\hline & & & & & 0.500 & & & & 0.333 & \\
\hline 130 & 0.652 & 0.701 & 0.480 & 0.514 & 0.488 & 0.500 & 0.440 & 0.227 & 0.628 & 0.317 \\
\hline 140 & 0.167 & 0.576 & 0.400 & 0.200 & 0.250 & 0.553 & 0.370 & 0.333 & 0.477 & 0.421 \\
\hline 150 & 0.125 & 0.182 & 0.364 & 0.488 & 0.667 & 0.500 & 0.118 & 0.545 & 0.500 & 0.452 \\
\hline 160 & 0.000 & 0.412 & 0.438 & 1.000 & 0.000 & 0.226 & 0.590 & 0.361 & 0.886 & 0.714 \\
\hline 170 & 0.400 & 1.000 & -- & 0.000 & 0.412 & 0.467 & 0.517 & 0.222 & 0.333 & 0.556 \\
\hline 180 & 0.611 & 0.500 & 0.810 & 0.258 & 0.429 & 0.400 & 0.429 & 1.000 & 1.000 & 0.878 \\
\hline 190 & 0.370 & 0.214 & 0.444 & 0.571 & 0.618 & 0.606 & 0.407 & 0.500 & 0.375 & 0.455 \\
\hline 200 & 0.344 & 0.625 & 0.333 & 0.559 & 0.448 & 0.000 & 0.444 & 0.432 & 0.607 & 0.857 \\
\hline 210 & 0.667 & 0.563 & 0.366 & 0.571 & 0.429 & 0.500 & 0.543 & 0.417 & 0.714 & 0.625 \\
\hline 220 & 0.571 & 0.667 & 0.417 & 0.615 & 0.313 & 0.471 & 0.320 & 0.800 & 0.619 & 0.667 \\
\hline 230 & 0.200 & 0.553 & 1.000 & 0.286 & 0.556 & 0.625 & 0.696 & 0.300 & 0.417 & 0.516 \\
\hline 240 & 0.429 & 0.308 & 0.673 & 0.600 & 0.280 & 0.000 & 0.176 & 0.517 & 0.375 & 0.511 \\
\hline 250 & 0.463 & 0.387 & 0.463 & 0.610 & 0.582 & 0.571 & $\begin{array}{l}0.587 \\
0.600\end{array}$ & 0.514 & 0.429 & 0.400 \\
\hline 260 & 0.295 & 0.588 & 0.300 & 0.000 & 0.214 & 0.500 & 0.556 & 0.500 & 0.852 & 0.438 \\
\hline 270 & 0.385 & 0.476 & 0.490 & 0.000 & 0.500 & 0.000 & 0.804 & 0.800 & 0.600 & 0.492 \\
\hline 280 & 0.382 & 0.250 & 0.667 & 0.500 & 1.000 & 0.462 & 0.333 & 0.375 & 0.500 & 0.780 \\
\hline 290 & 0.143 & 0.481 & 0.667 & 0.432 & 0.682 & 0.429 & 0.500 & 0.333 & 0.529 & 0.269 \\
\hline 300 & 0.450 & 0.500 & 0.582 & 1.000 & 0.643 & 0.545 & 0.472 & 0.571 & 0.000 & 0.750 \\
\hline 310 & 1.000 & 0.333 & 0.250 & 0.545 & 0.348 & 1.000 & 0.000 & 0.500 & -- & -- \\
\hline 320 & 0.500 & 0.250 & 0.000 & -- & 0.524 & 0.487 & -- & 0.429 & 0.889 & 0.290 \\
\hline 330 & 0.000 & 0.875 & 0.417 & $\begin{array}{l}0.600 \\
0.625\end{array}$ & 0.814 & 0.563 & 0.625 & -- & 0.707 & 0.408 \\
\hline 340 & 0.472 & 0.353 & 0.551 & 0.167 & 1.000 & 0.600 & 0.304 & 0.464 & 0.500 & 0.471 \\
\hline 350 & 0.500 & 0.524 & 0.730 & 0.400 & 0.333 & 0.556 & 0.619 & 1.000 & 0.387 & 0.250 \\
\hline 360 & 0.320 & 0.250 & 0.417 & 0.657 & 0.429 & 0.333 & 0.655 & 0.407 & 0.000 & 0.533 \\
\hline 370 & 1.000 & 0.756 & 0.593 & 0.524 & 0.444 & 0.487 & 0.538 & 0.409 & 0.500 & $\begin{array}{l}\mathbf{0 . 5 8 3} \\
0.563\end{array}$ \\
\hline 380 & 0.548 & 0.000 & 0.000 & 0.455 & 0.125 & 0.000 & 0.367 & 0.364 & 0.308 & 0.375 \\
\hline 390 & $\begin{array}{l}0.635 \\
0.615\end{array}$ & 0.778 & 0.143 & 0.378 & 0.429 & 0.514 & 0.640 & 0.333 & 1.000 & 0.375 \\
\hline 400 & 0.556 & 0.500 & 0.429 & 0.300 & 0.487 & 0.333 & 0.250 & 0.519 & 1.000 & 0.875 \\
\hline
\end{tabular}


Tabela 3. Comparação entre os estudos com objetivo mais amplos em Characiformes

\begin{tabular}{l|cccccc} 
& Grupo-externo & Grupo-interno & Famílias** & $\begin{array}{c}\text { Gêneros de } \\
\text { Characiformes }\end{array}$ & $\begin{array}{c}\text { Gêneros de } \\
\text { Characidae** Caracteres }\end{array}$ \\
\hline Buckup, 1991 e 1998 & $1^{* * *}$ & 27 & 16 & 27 & 7 & 80 \\
Lucena, 1993 & $1^{* *}$ & 68 & 8 & 64 & 48 & 121 \\
Ortí \& Meyer, 1997 & 11 & 41 & 18 & 41 & - & 8349 \\
Calcagnotto et al., & 10 & 124 & 16 & 71 & - & - \\
2005 & 4 & 97 & 18 & 97 & 52 & 410 \\
Presente estudo & & & & 41410
\end{tabular}

* sensu Buckup, 1998

* * sensu Reis et al., 2003

*** grupo composto 


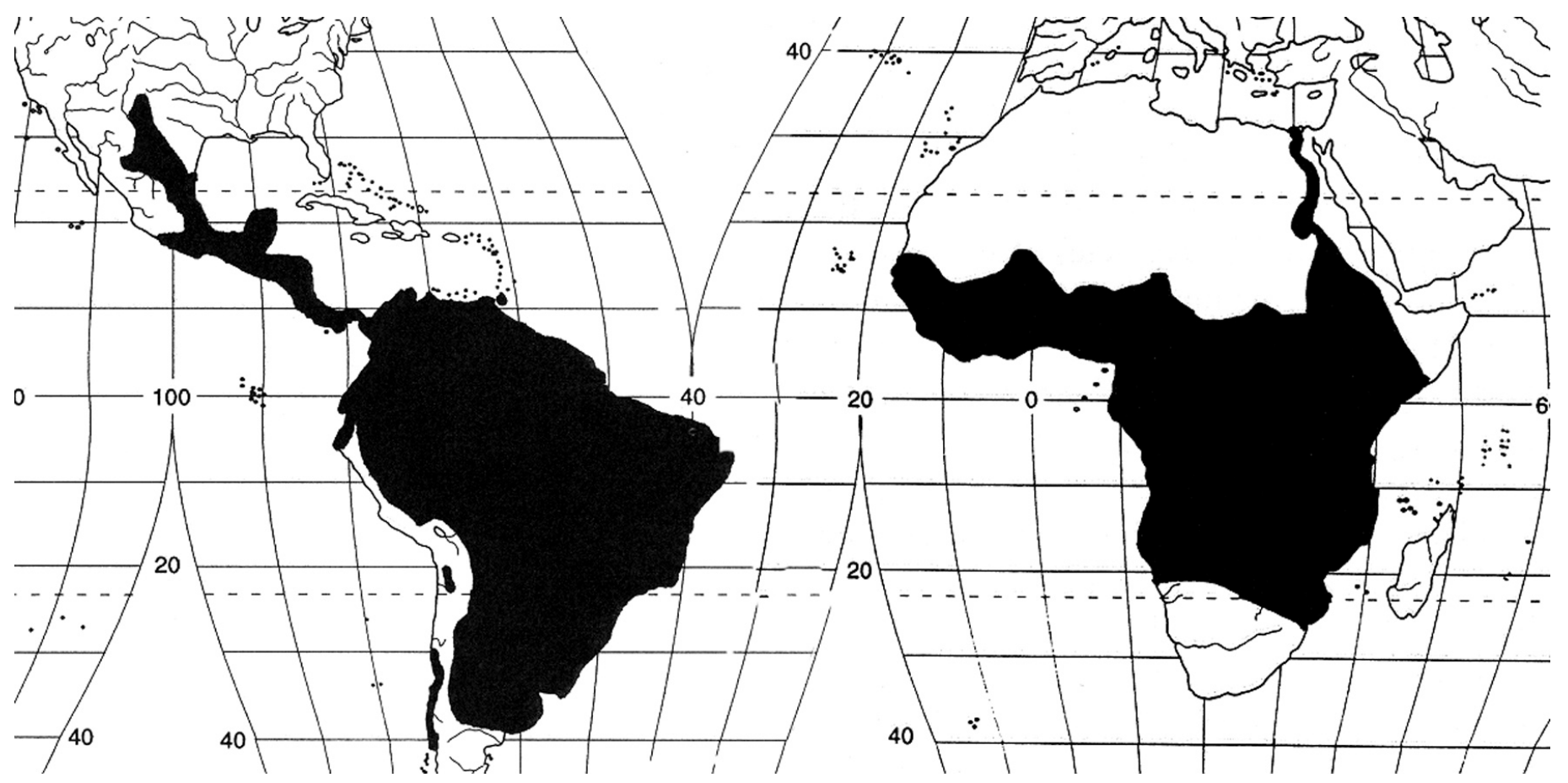

Figura 1. Distribuição dos peixes da ordem Characiformes. Adaptado de Berra (2001). 


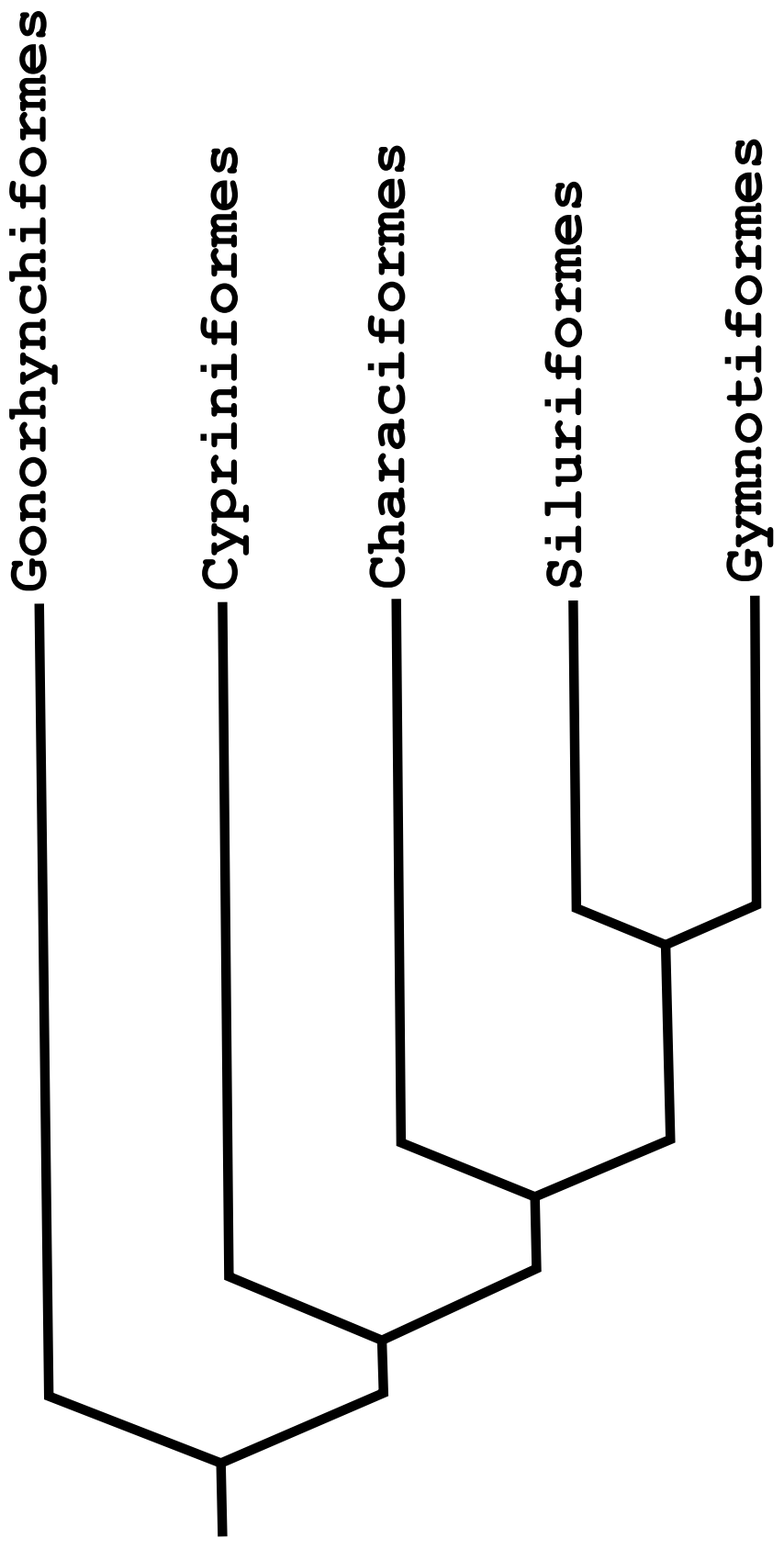

Figura 2. Cladograma das inter-relações entre as ordens de Ostariophysi, segundo Fink \& Fink (1981). 


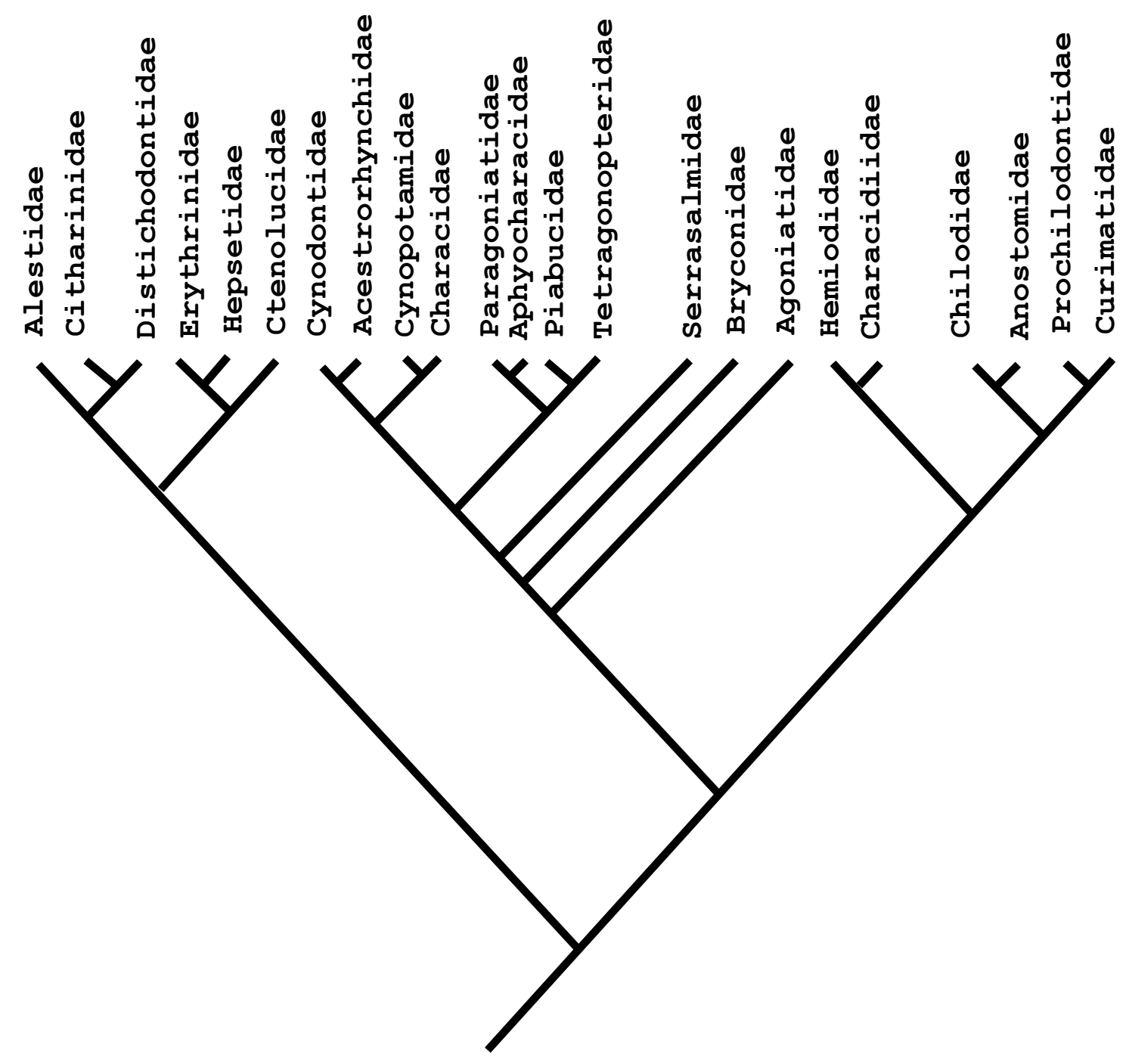

Figura 3. Cladograma das relações filogenéticas entre as famílias da Ordem Characiformes, segundo Uj (1990). 


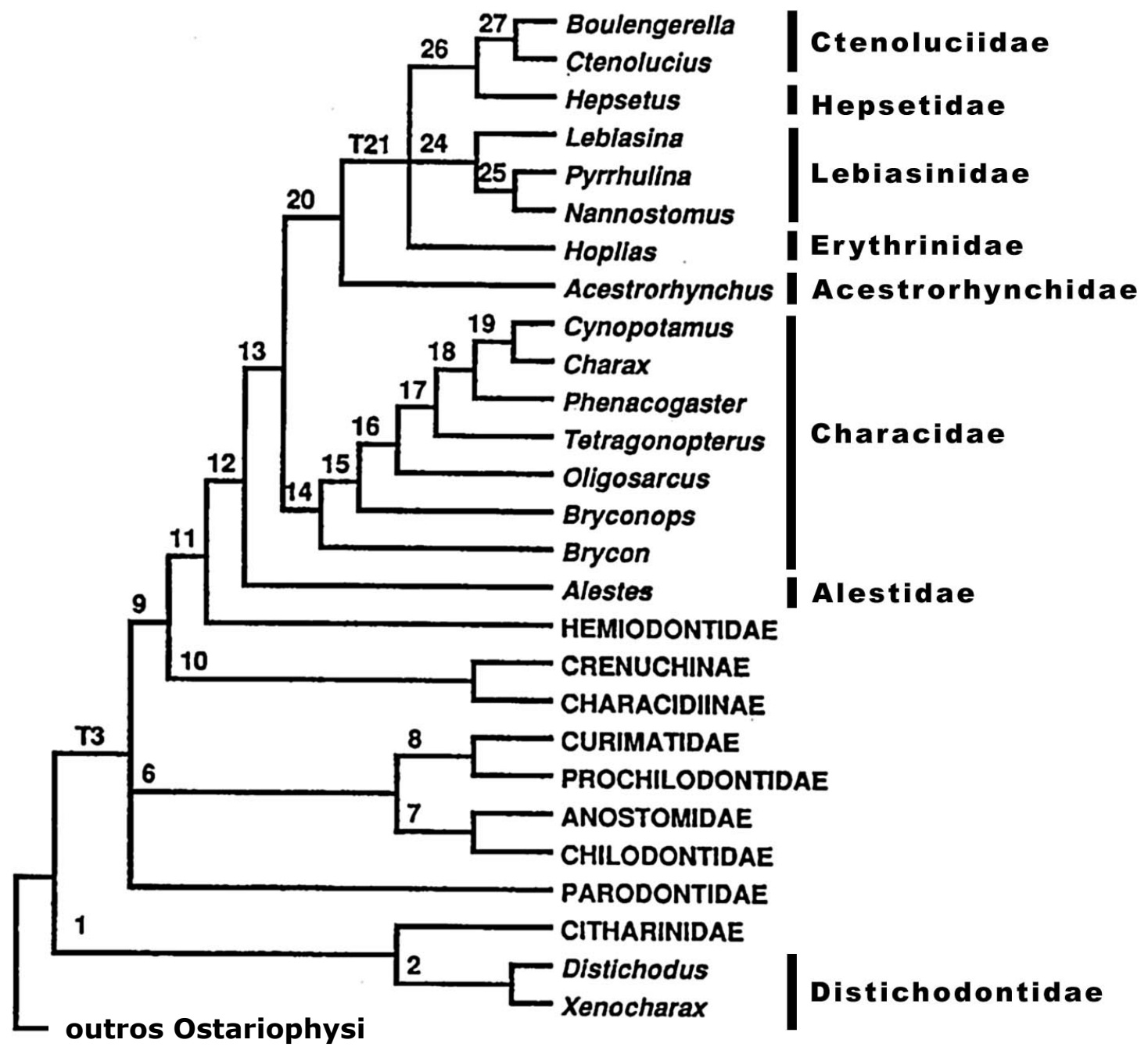

Figura 4. Cladograma de consenso estrito das relações filogenéticas entre gêneros da Ordem Characiformes, segundo Buckup (1998). 


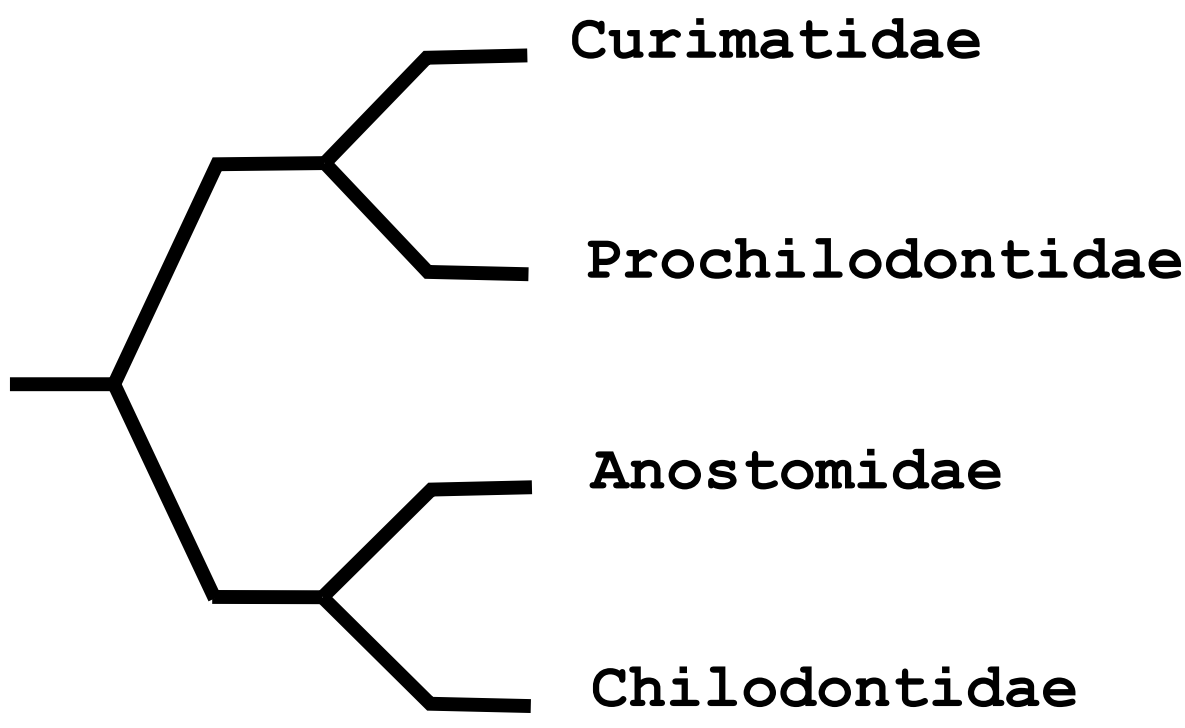

Figura 5. Cladograma mais parcimonioso para as relações filogenéticas entre as famílias Curimatidae, Prochilodontidae, Anostomidae e Chilodontidae, segundo Vari (1983). 


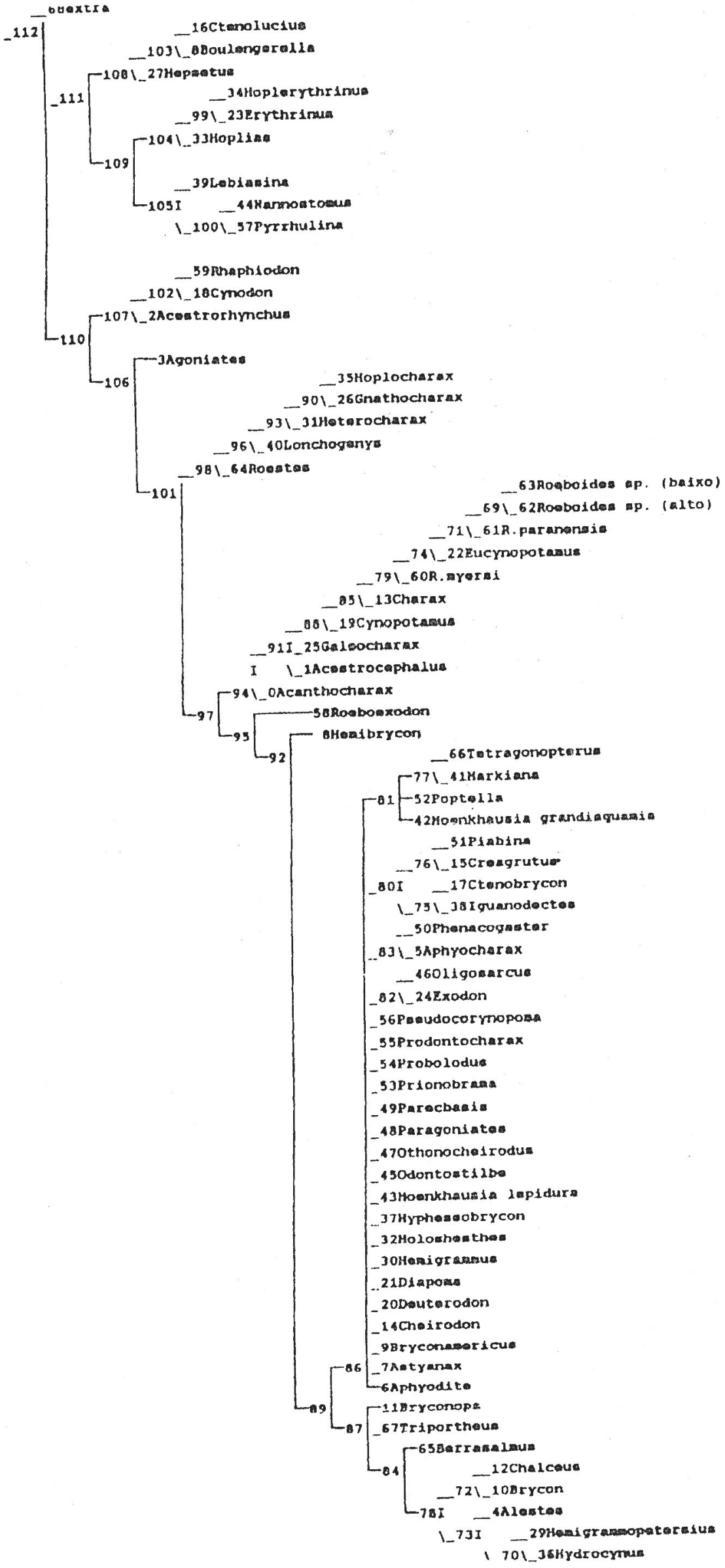

Figura 6. Cladograma de consenso estrito das relações entre gêneros da Ordem Characiformes, segundo Lucena (1993). 


\section{CYNODONTIDAE}

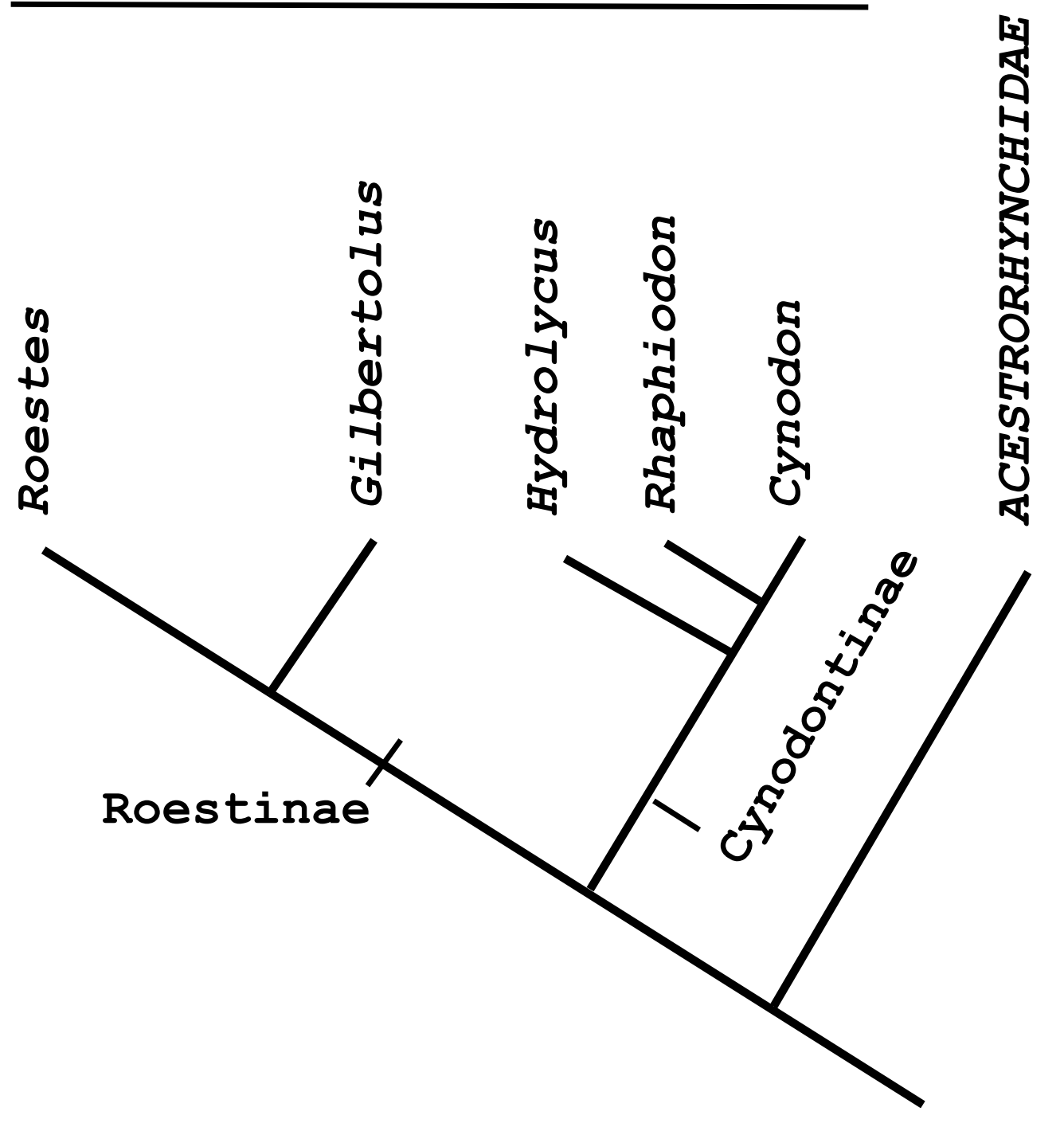

Figura 7. Esquema das relações filogenéticas entre os peixes das famílias Acestrorhynchidae e Cynodontidae segundo Lucena e Menezes (1998) e Toledo-Piza (2000). 


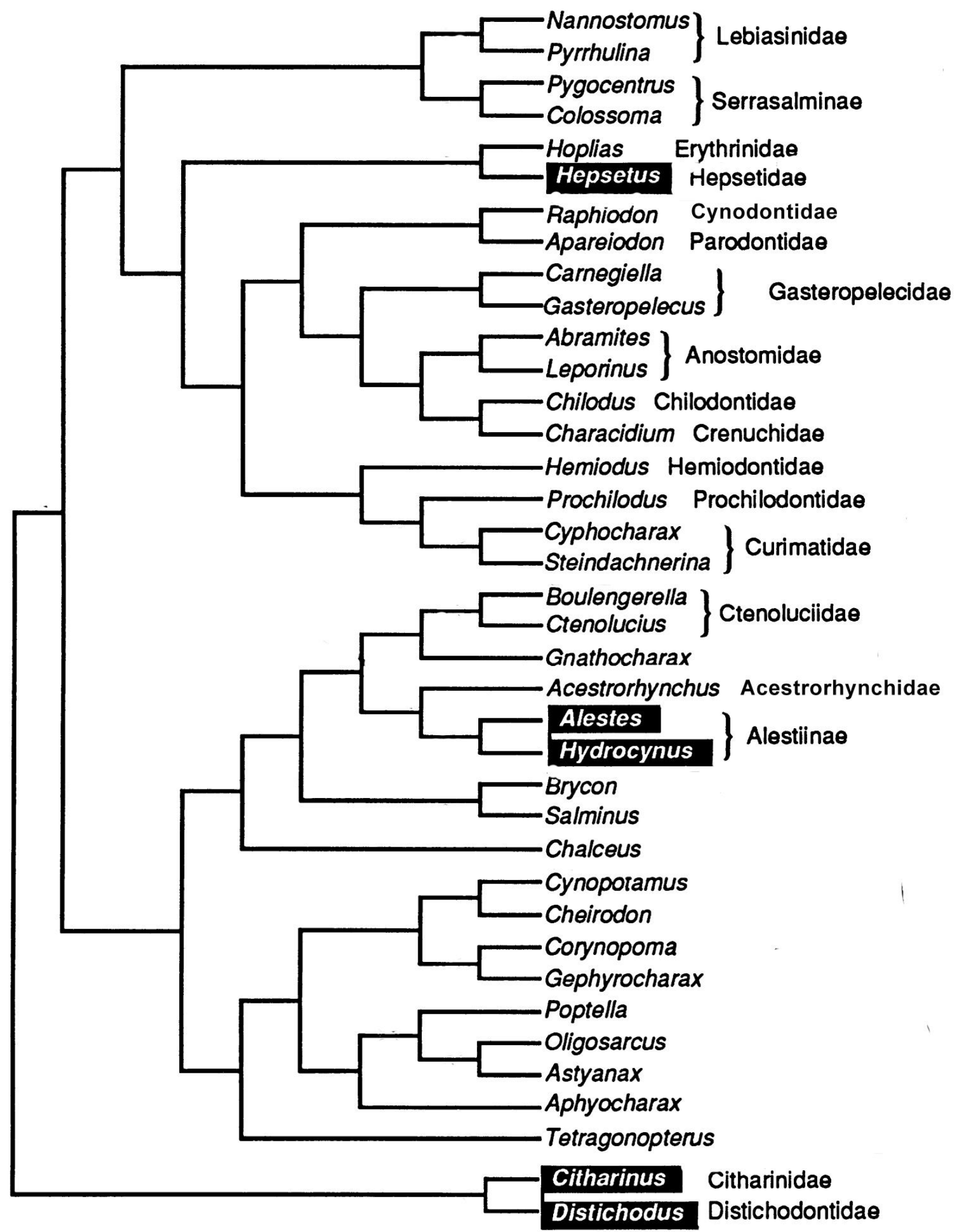

Figura 8. Cladograma mais parcimonioso das relações em Characiformes, obtido através da pesagem dos caracteres, segundo Ortí e Meyer (1997). 


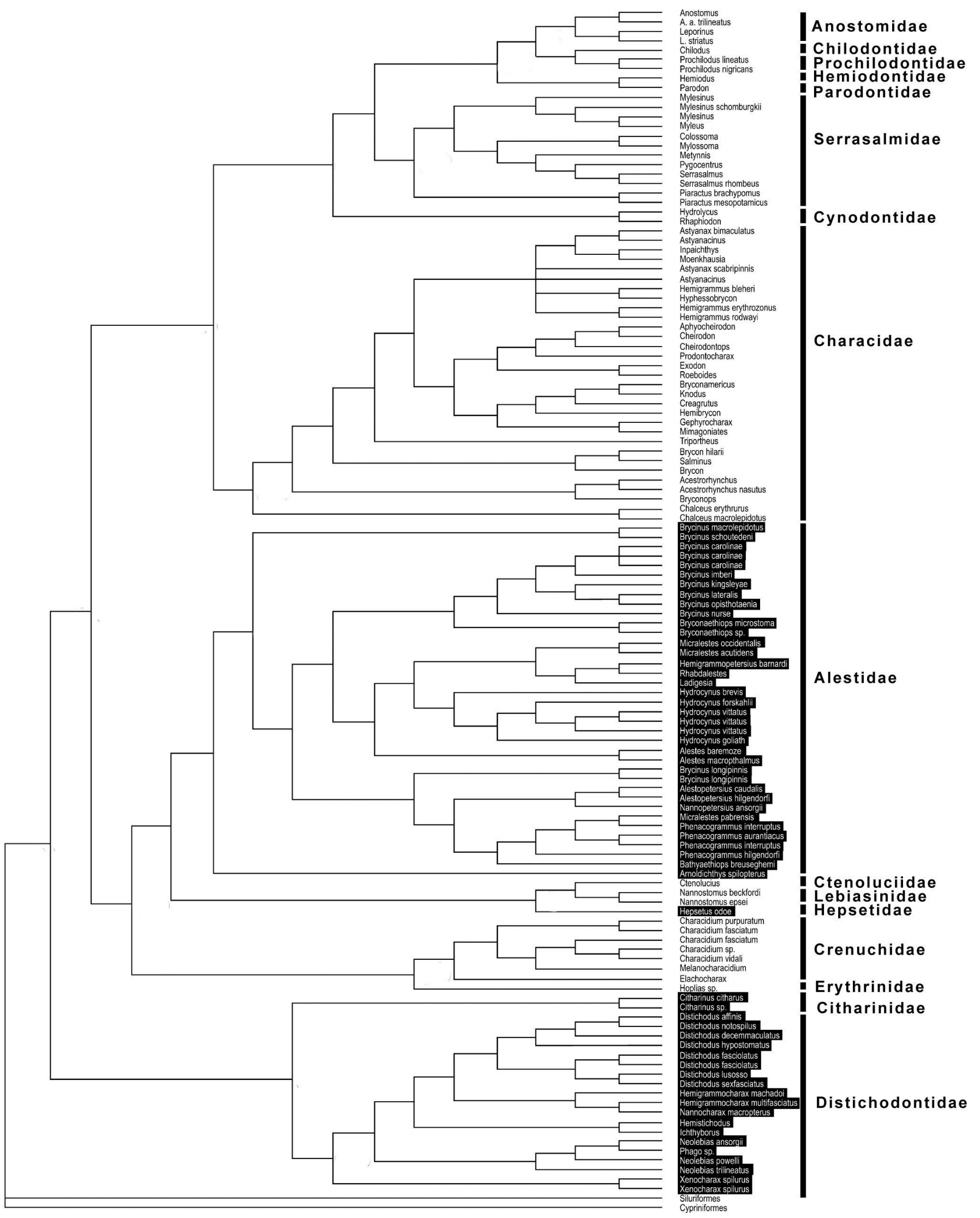

Figura 9. Cladograma de consenso estrito das relações em Characiformes, segundo Calcagnotto et al (2005). 


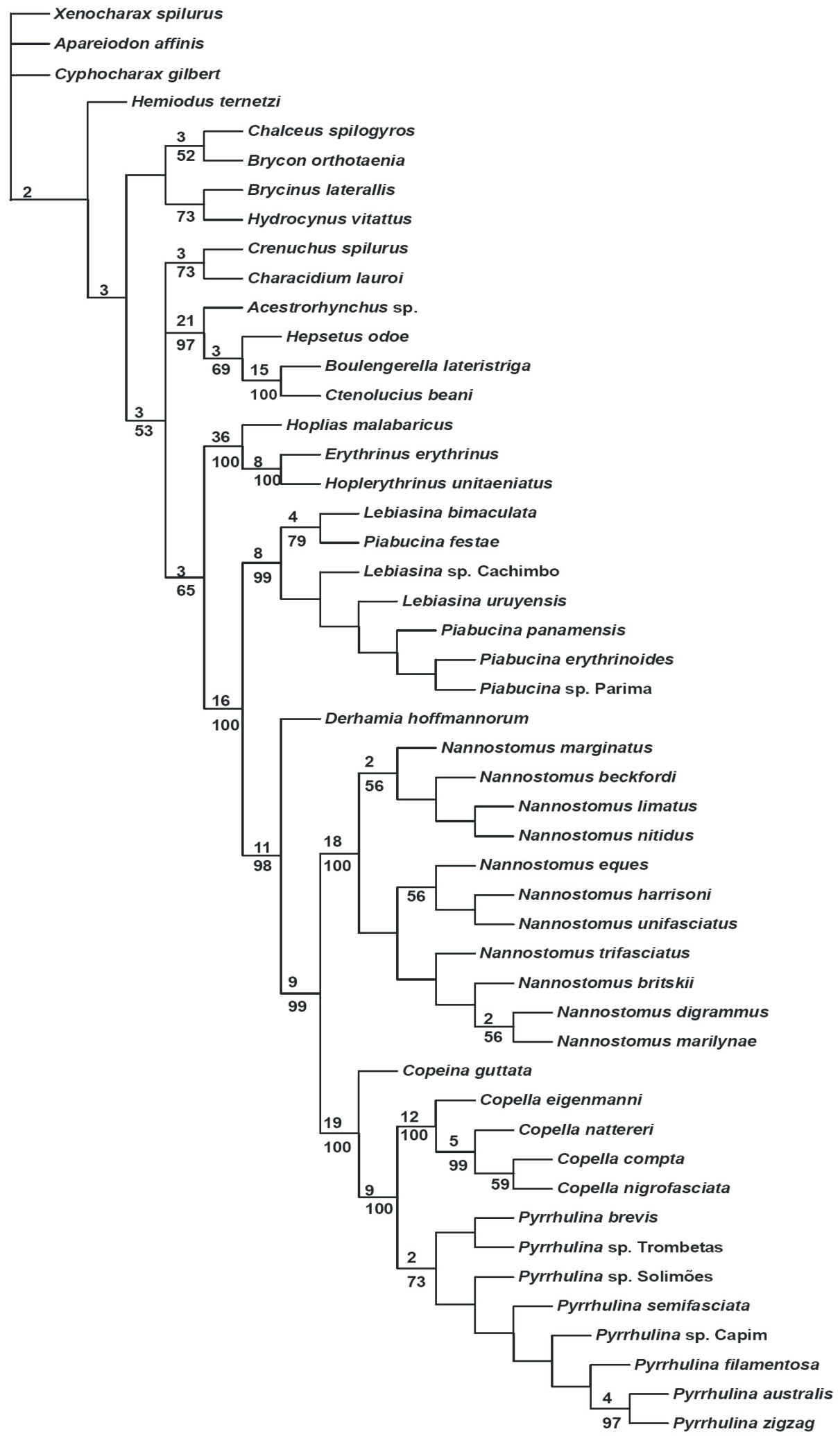

Figura 10. Cladograma de consenso estrito das relações em Lebiasinidae, segundo Netto-Ferreira (2006). 

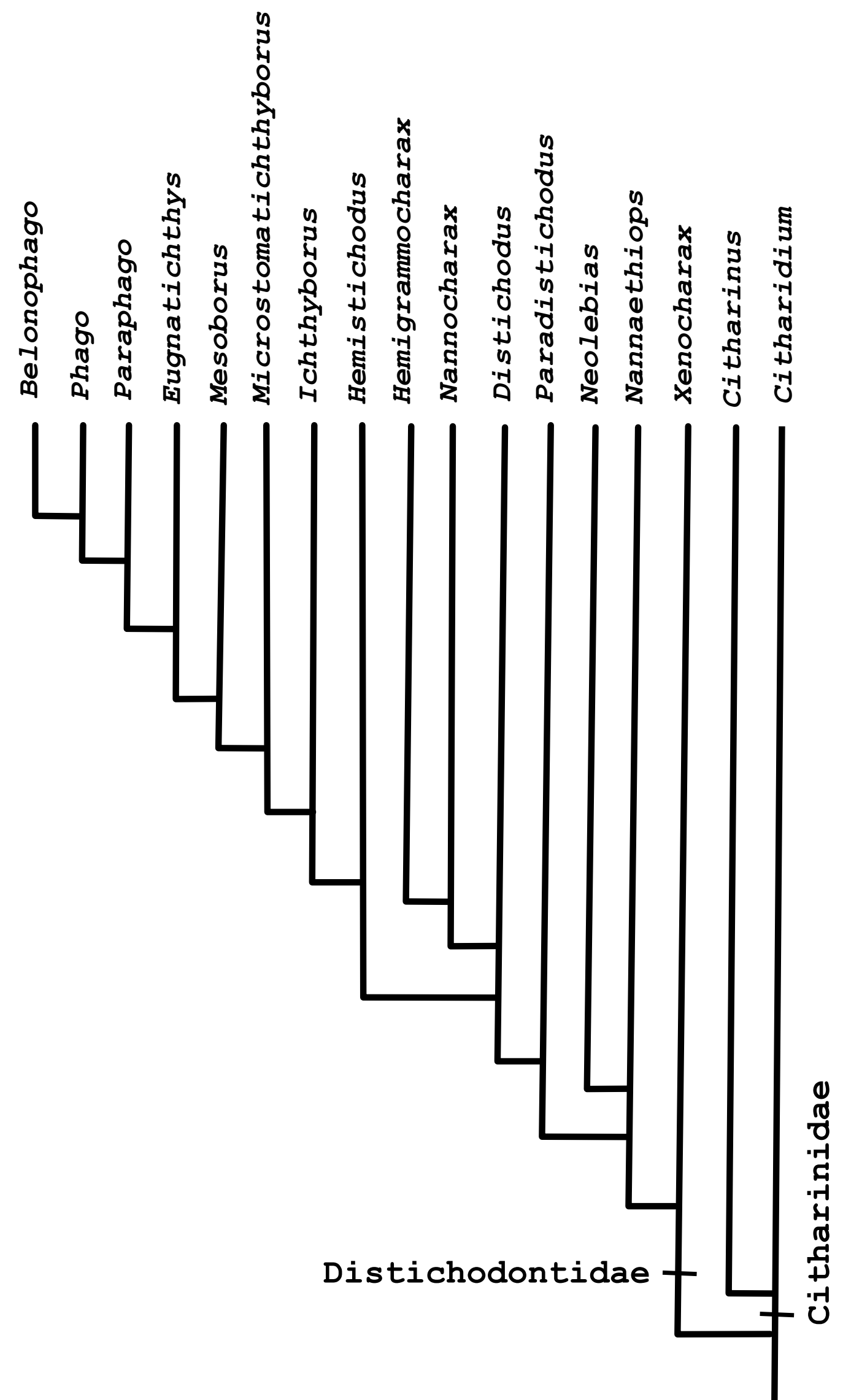

Figura 11. Cladograma mais parcimonioso para as relações filogenéticas entre os peixes das familias Citharinidae e Distichodontidae segundo Vari (1979). 


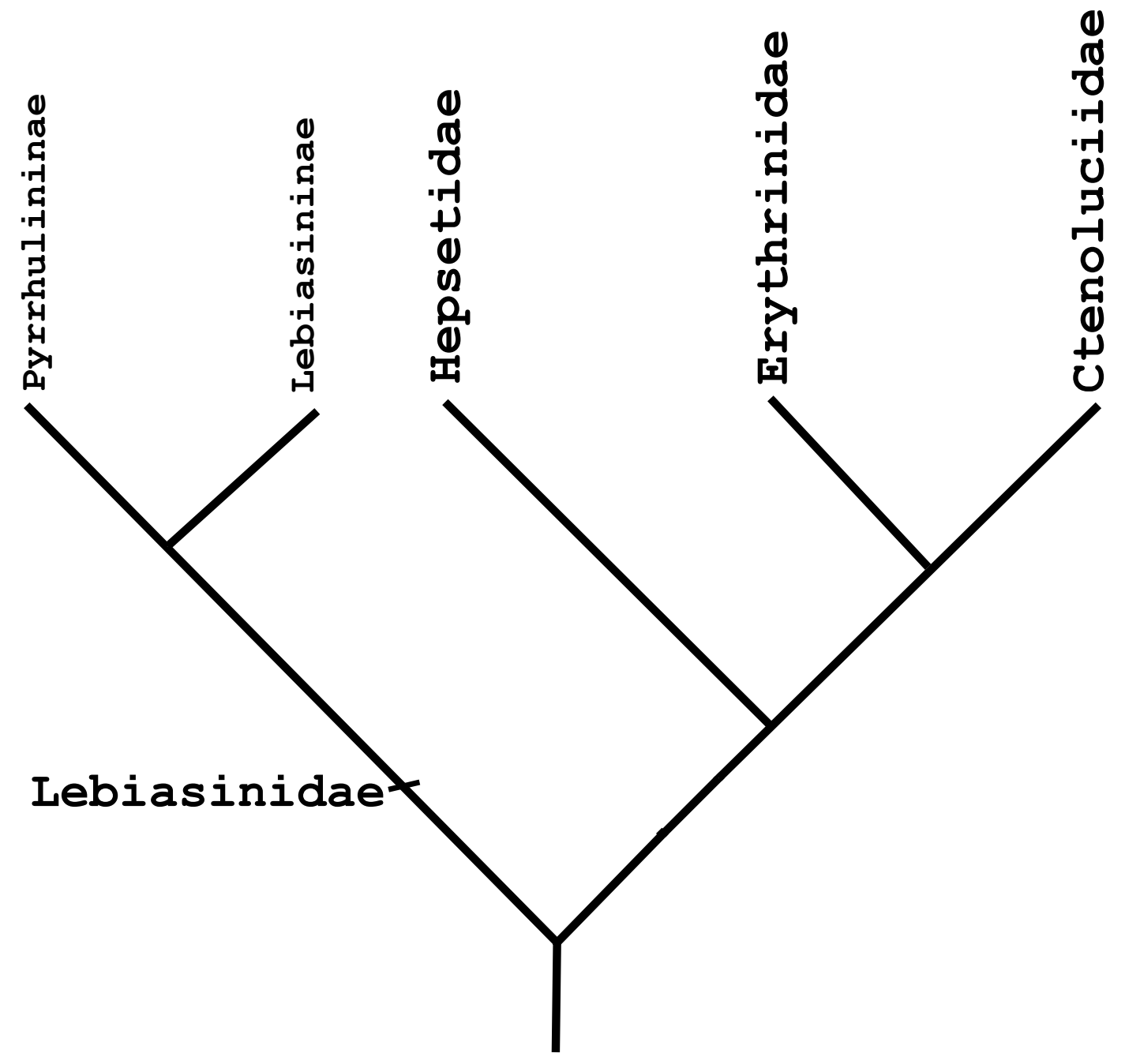

Figura 12. Cladograma das relações filogenéticas entre as

famílias Lebiasinidae, Hepsetidae, Erythrinidae e Ctenoluciidae segundo Vari (1995). 


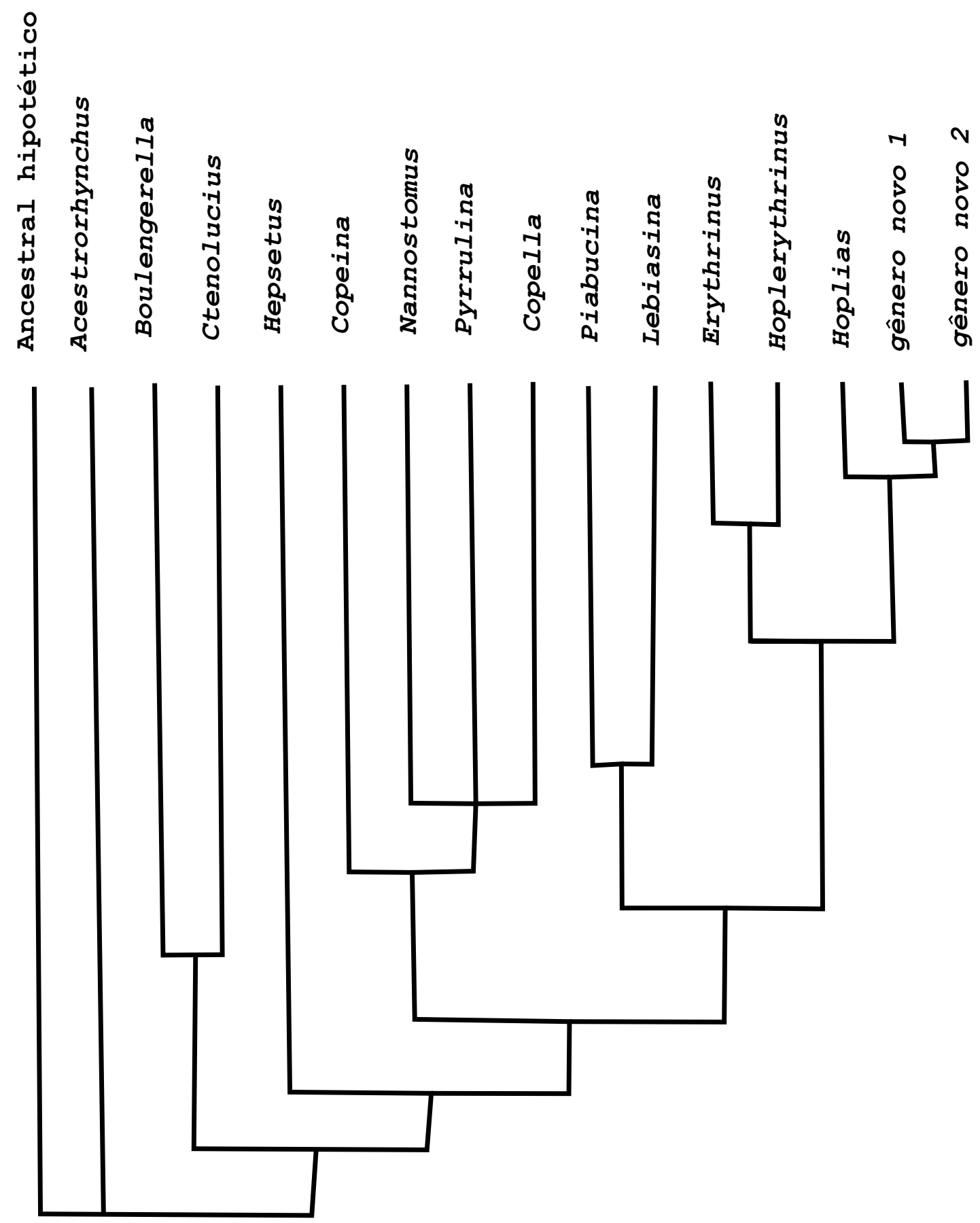

Figura 13. Cladograma de consenso estrito das relações em Erythrinoidea, segundo Oyakawa (1998). 


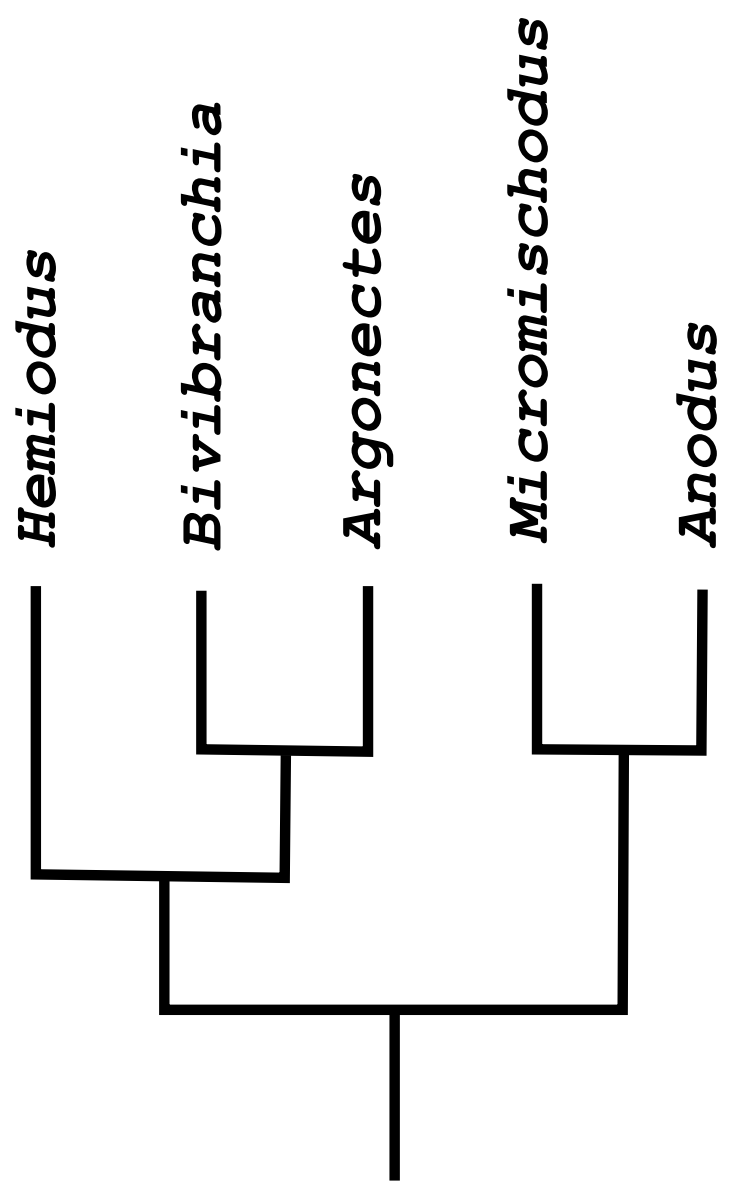

Figura 14. Cladograma das relações entre os gêneros de Hemiodontidae, segundo Langeani (1998). 


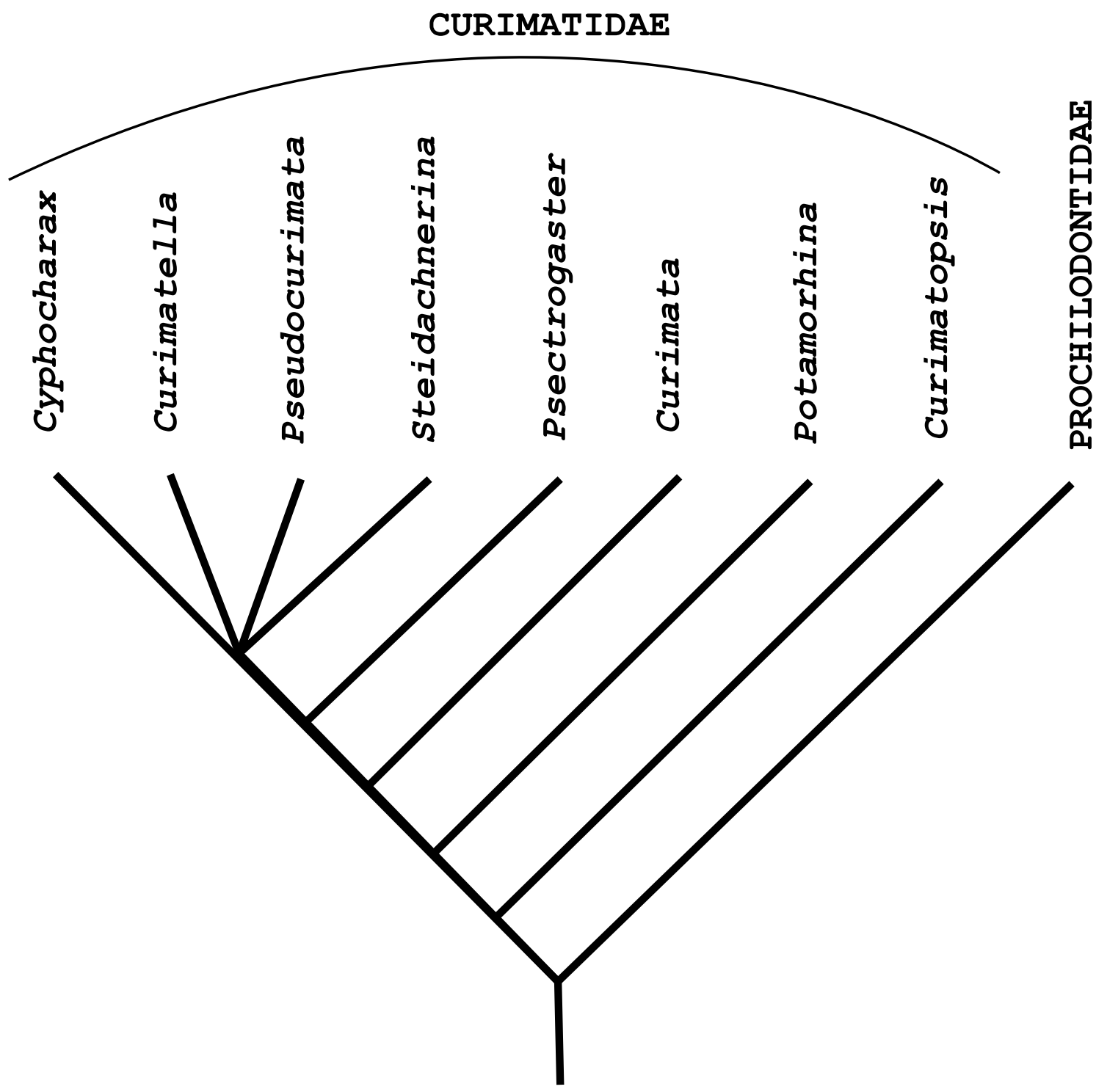

Figura 15. Cladograma mais parcimonioso para as relações

filogenéticas entre os gêneros da família Curimatidae segundo Vari (1989). 


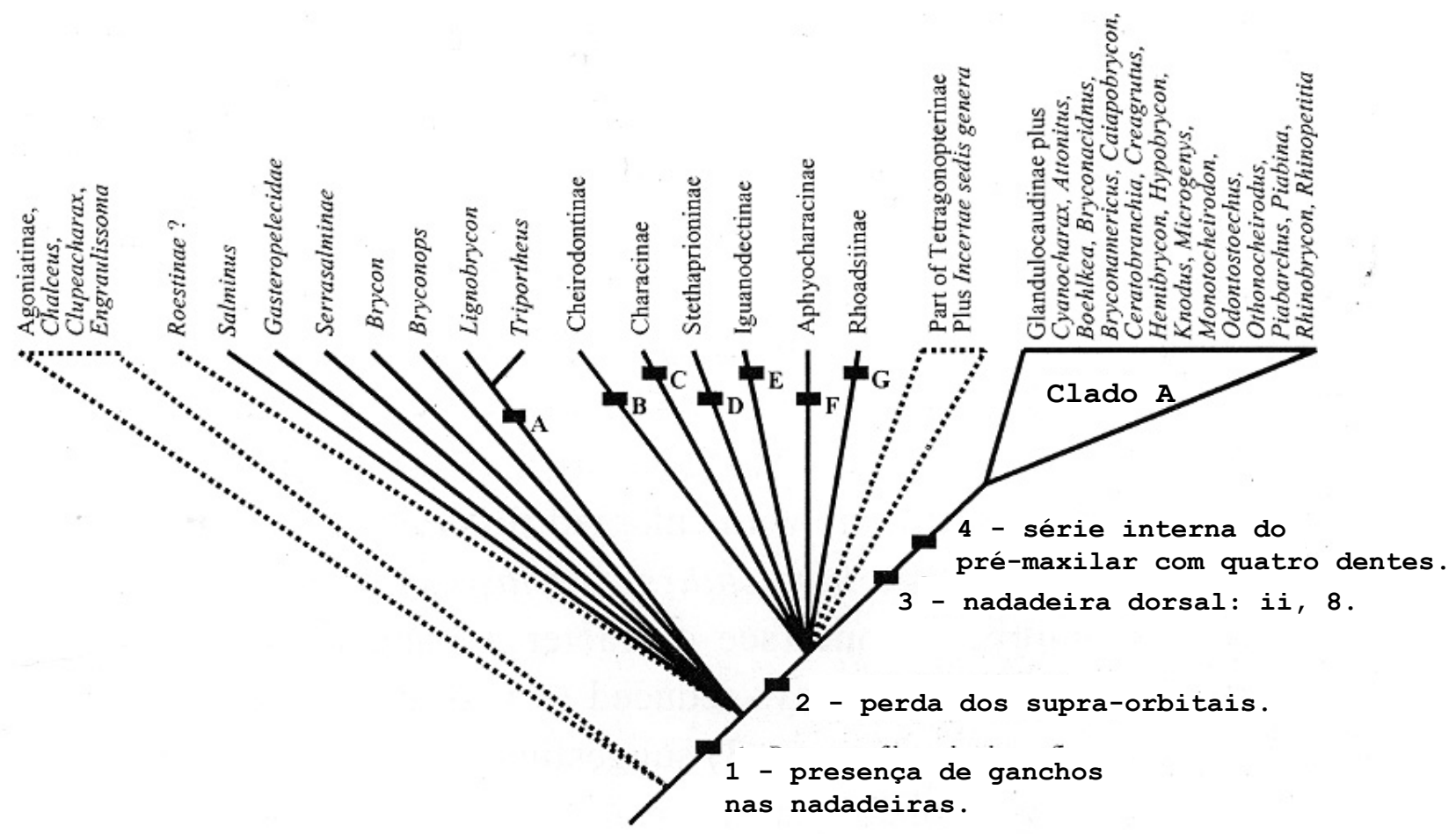

Figura 16. Esquema das relações filogenéticas na família Characidae, segundo Malabarba e Weitzman (2003). 


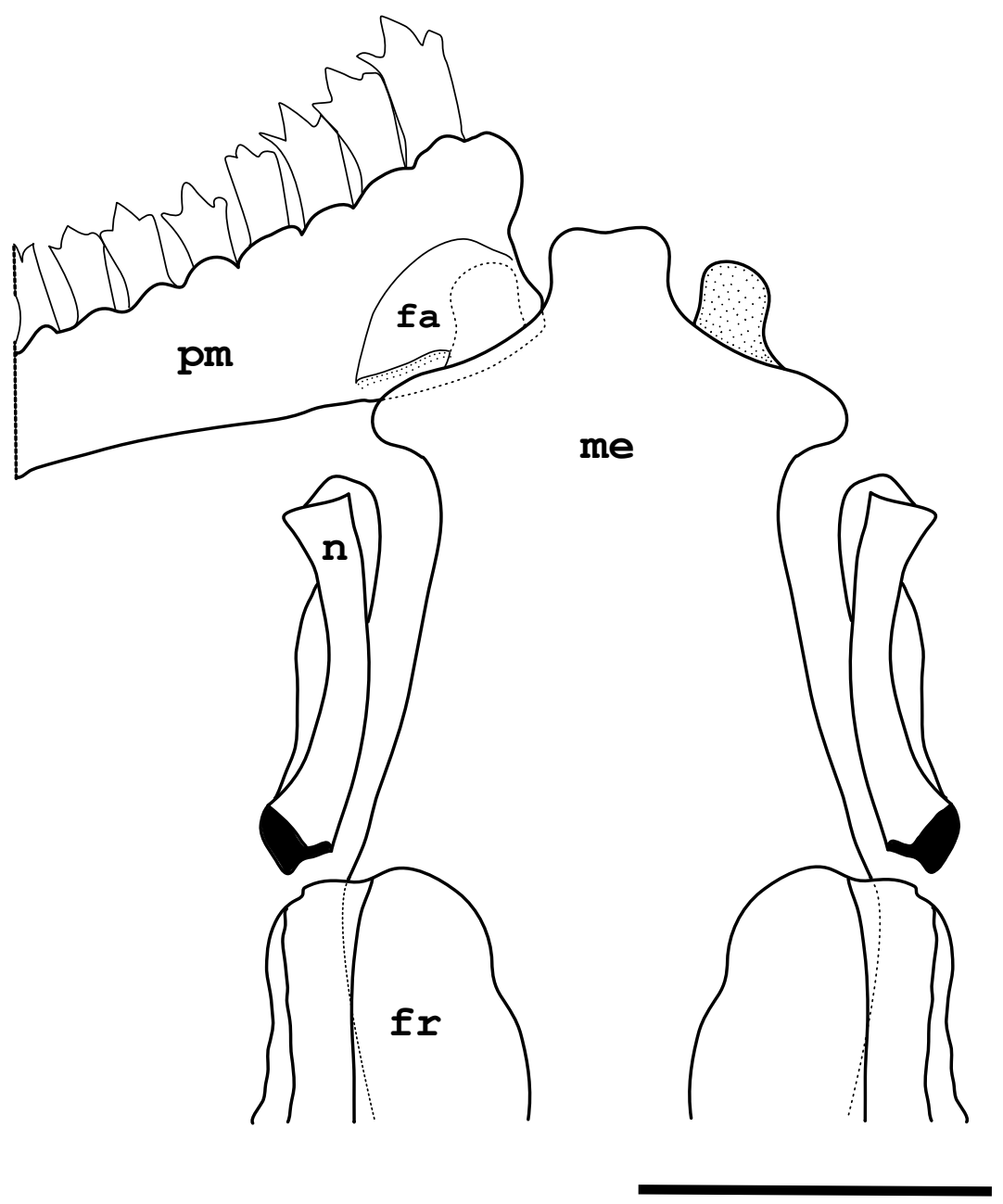

Figura 17. Vista dorsal do mesetmóide e estruturas associadas de Crenuchus spilurus (MZUSP 62317). Anterior para cima. fa = fossa articular, $\mathbf{f r}=$ frontal, $\mathbf{m e}=$ mesetmóide, $\mathbf{n}=$ nasal $e$ pm = pré-maxilar. Barra de escala $=1 \mathrm{~mm}$. 


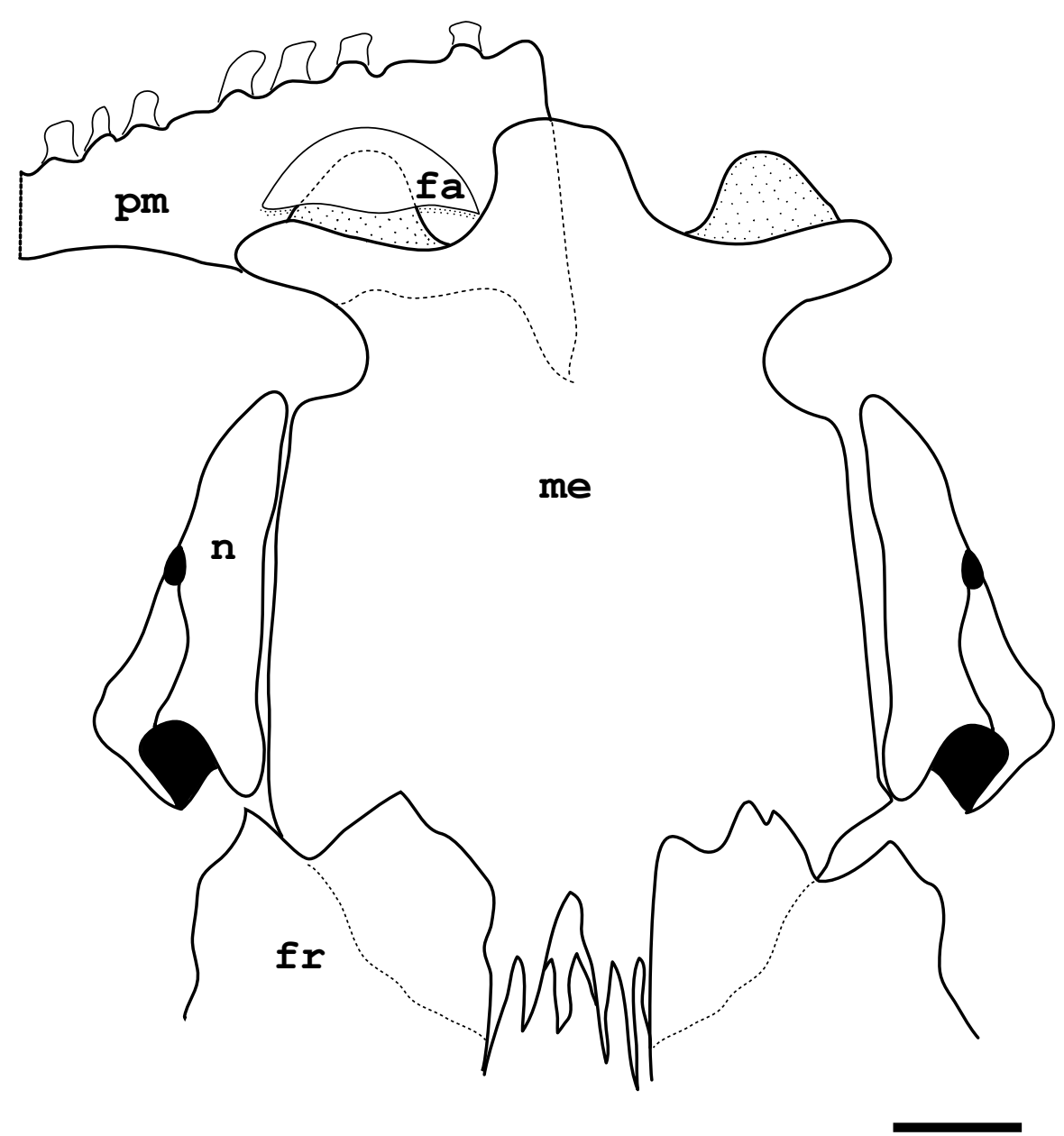

Figura 18. Vista dorsal do mesetmóide e estruturas associadas de Xenocharax spilurus (AMNH 230302). Anterior para cima. fa = fossa articular, $\mathbf{f r}=$ frontal, $\mathbf{m e}=$ mesetmóide, $\mathbf{n}=$ nasal $\mathrm{e}$ pm = pré-maxilar. Barra de escala $=1 \mathrm{~mm}$. 


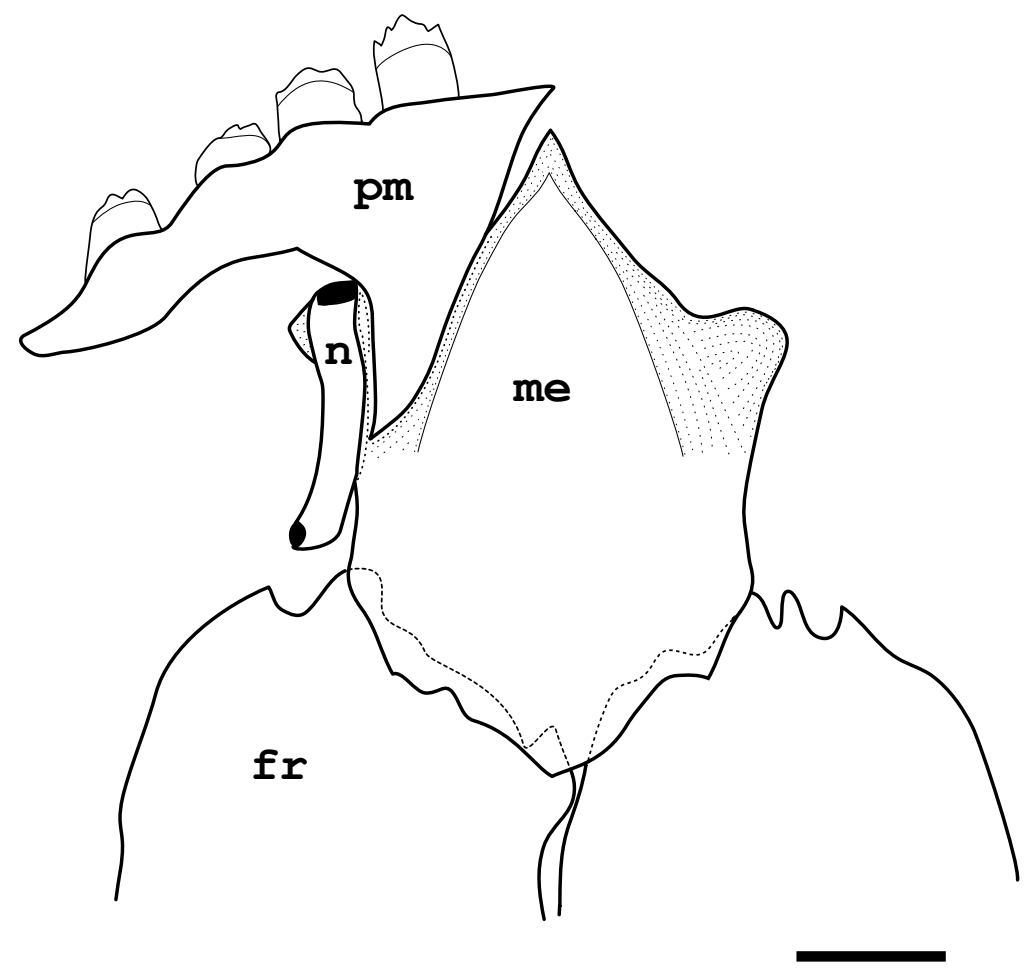

Figura 19. Vista dorsal do mesetmóide e estruturas associadas de Astyanax mexicanus (UMMZ 203208). Anterior para cima. fr = frontal, $\mathbf{m e}=$ mesetmóide, $\mathbf{n}=$ nasal e $\mathbf{p m}=$ pré-maxilar. Barra de escala $=1 \mathrm{~mm}$. 


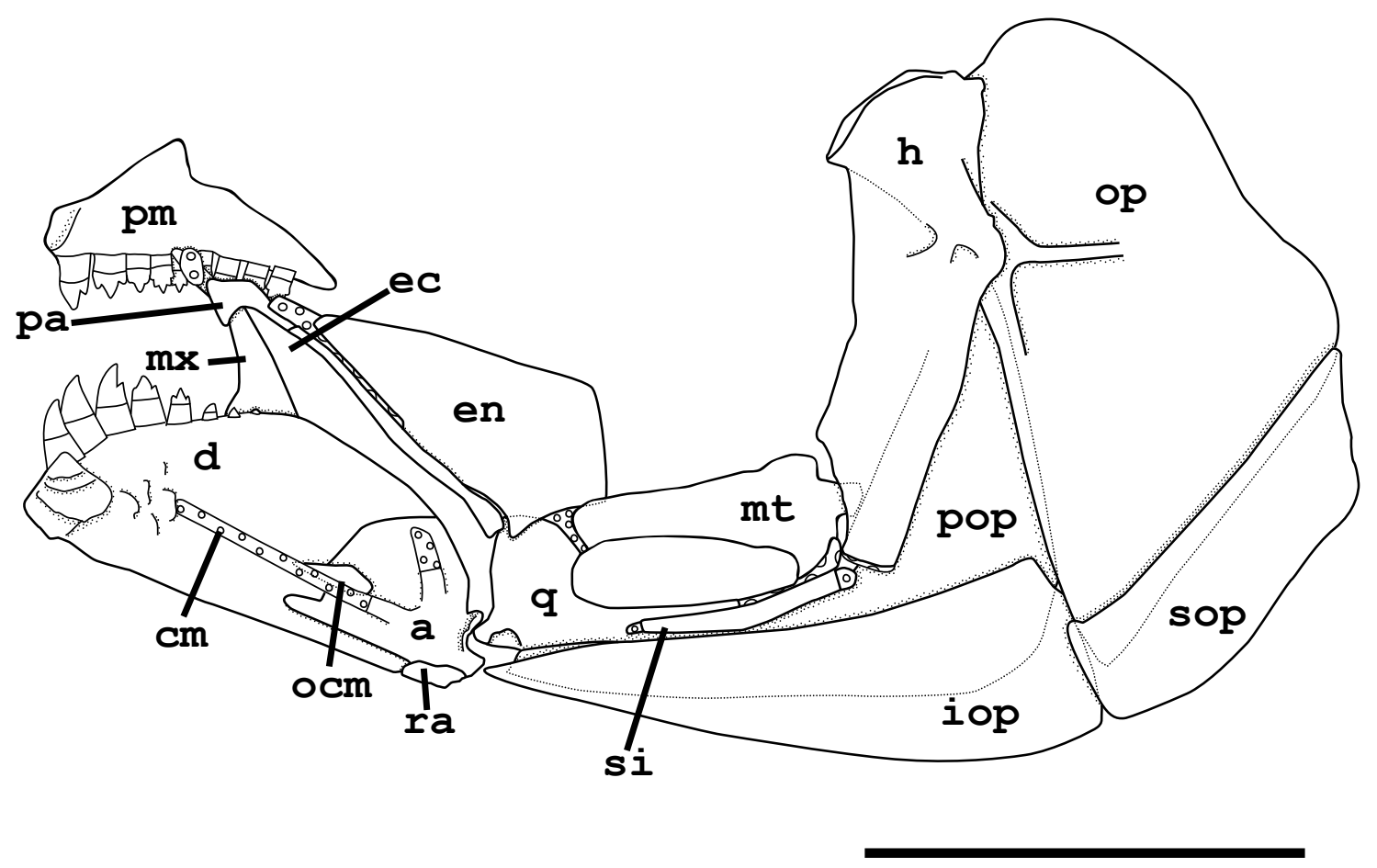

Figura 20. Vista medial do suspensório mandibular e série opercular de Arnoldichthys spilopterus (MRAC 154445-459). Anterior para esquerda. a = ângulo-articular, $\mathbf{c m}=$ cartilagem de Meckel, $\mathbf{d}=$ dentário, ec = ectopterigóide, en = endopterigóide, $\mathbf{h}=$ hiomandibular, $\mathbf{i o p}=$ interopérculo, $\mathbf{m t}=$ metapterigóide, $\mathbf{m x}=$ maxilar, ocm = osso corono-meckeliano, op $=$ opérculo, $\mathbf{p a}=$ palatino, $\mathbf{p m}=$ pré-maxilar, $\mathbf{p o p}=$ préopérculo, $\mathbf{q}=$ quadrado, $\mathbf{r a}=$ retroarticular, $\mathbf{s i}=$ simplético, sop $=$ subopérculo. Barra de escala $=5 \mathrm{~mm}$. 


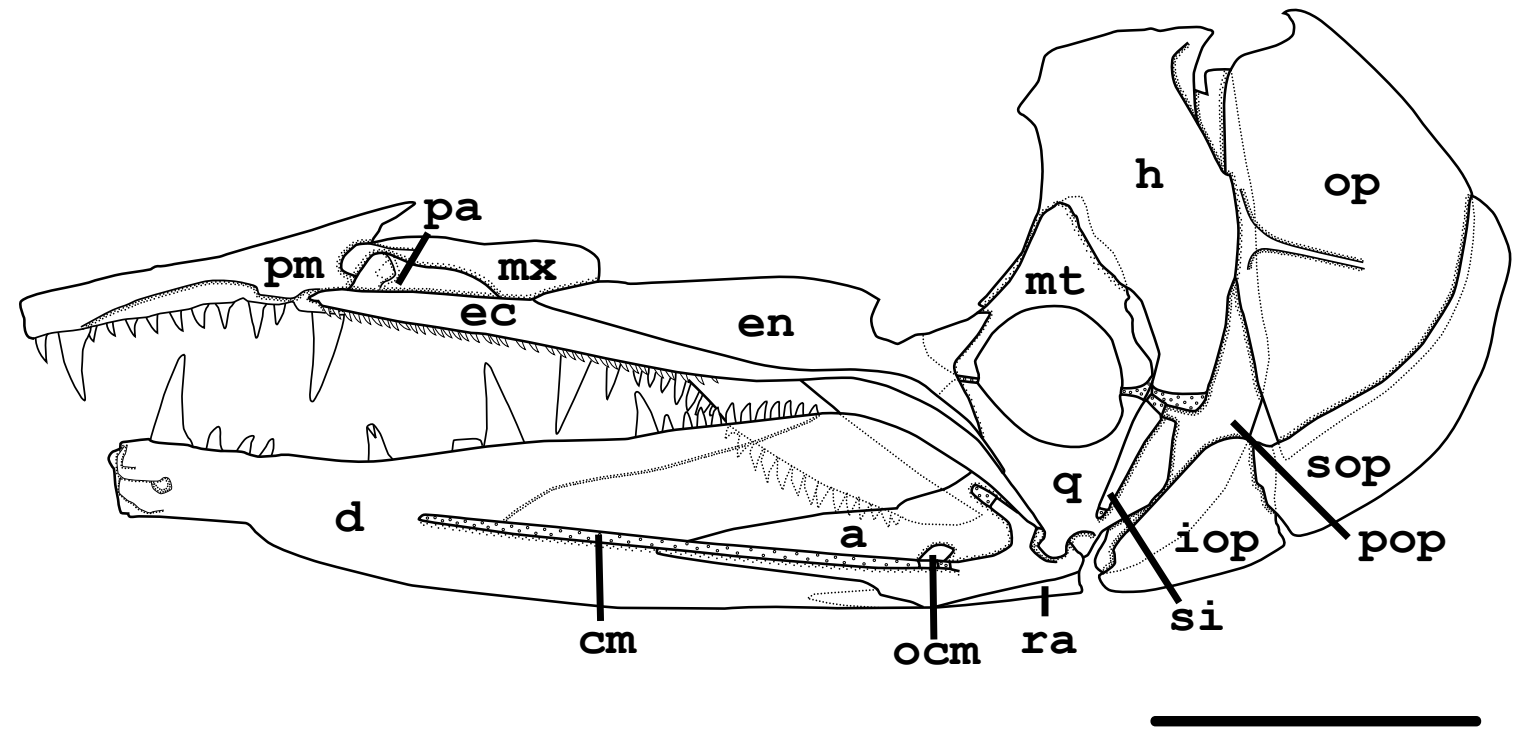

Figura 21. Vista medial do suspensório mandibular e série opercular de Acestrorhynchus falcirostris (MZUSP 36824). Anterior para esquerda. a = ângulo-articular, $\mathbf{c m}=$ cartilagem de Meckel, $\mathbf{d}=$ dentário, ec = ectopterigóide, en = endopterigóide, $\mathbf{h}=$ hiomandibular, $\mathbf{i o p}=$ interopérculo, $\mathbf{m t}=$ metapterigóide, $\mathbf{m x}$ = maxilar, ocm = osso corono-meckeliano, op $=$ opérculo, $\mathbf{p a}=$ palatino, $\mathbf{p m}=$ pré-maxilar, $\mathbf{p o p}=$ préopérculo, $\mathbf{q}=$ quadrado, $\mathbf{r a}=$ retroarticular, $\mathbf{s i}=$ simplético, sop = subopérculo. Barra de escala $=10 \mathrm{~mm}$. 


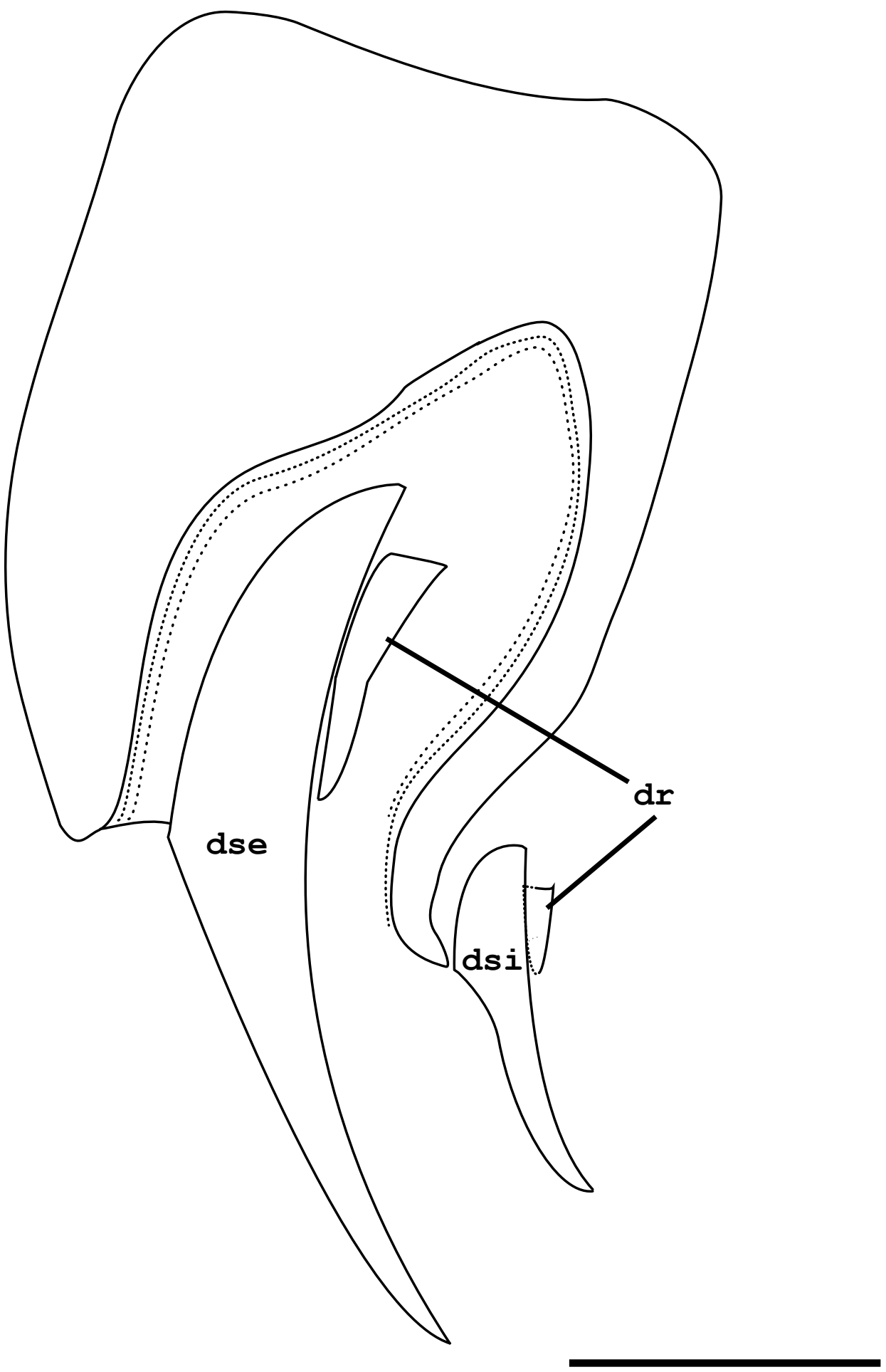

Figura 22. Vista medial do pré-maxilar e dentes associados de Distichodus notospilus (AMNH 230295). dse = dente da série externa, dsi = dente da série interna e dr = dente de reposição. Anterior para esquerda. Barra de escala $=0,5 \mathrm{~mm}$. 


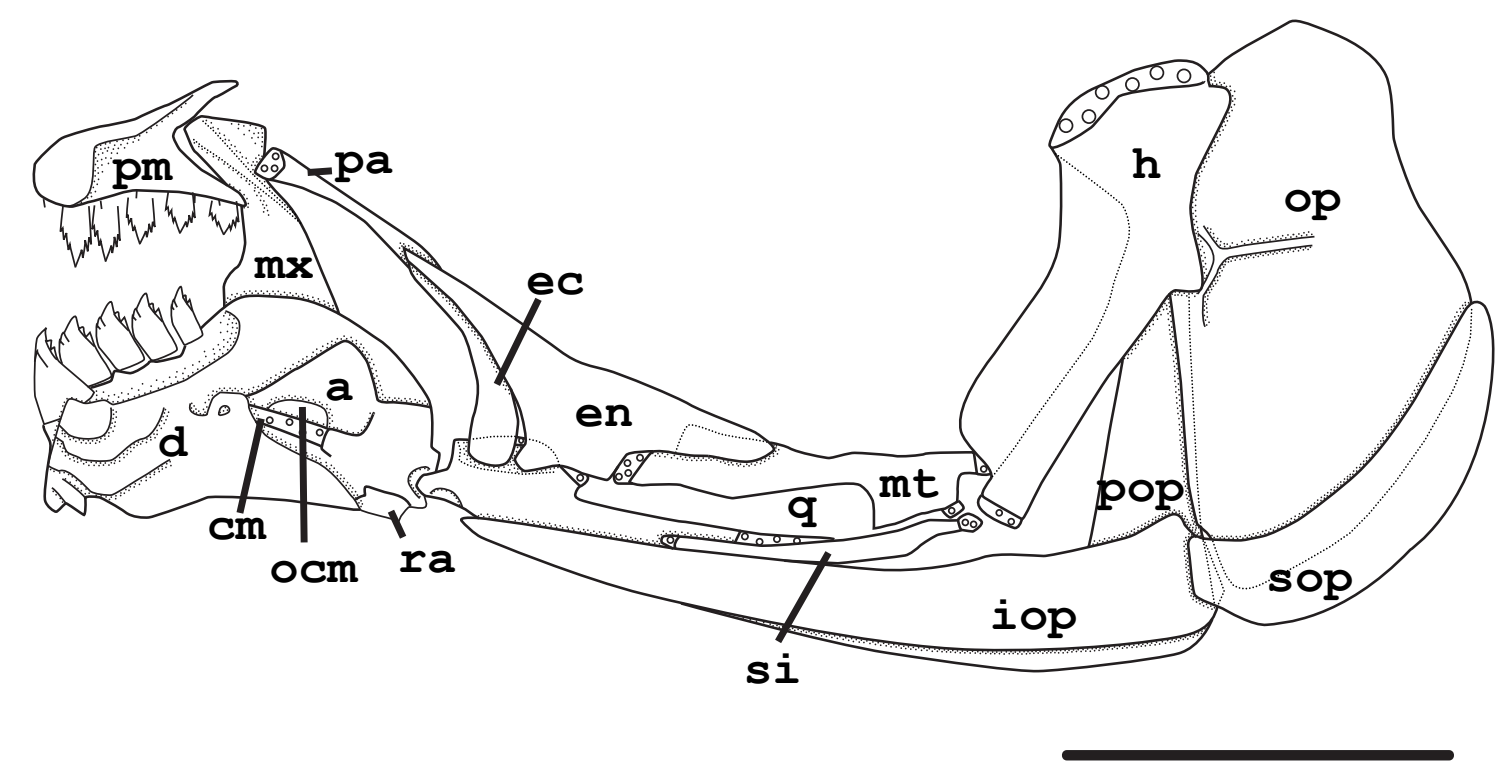

Figura 23. Vista medial do suspensório mandibular e série opercular de Iguanodectes geisleri (MZUSP 29614). Anterior para esquerda. a = ângulo-articular, $\mathbf{c m}=$ cartilagem de Meckel, $\mathbf{d}=$ dentário, ec = ectopterigóide, en = endopterigóide, $\mathbf{h}=$ hiomandibular, $\mathbf{i o p}=$ interopérculo, $\mathbf{m t}=$ metapterigóide, $\mathbf{m x}$ = maxilar, ocm = osso corono-meckeliano, op $=$ opérculo, $\mathbf{p a}=$ palatino, $\mathbf{p m}=$ pré-maxilar, $\mathbf{p o p}=$ préopérculo, $\mathbf{q}=$ quadrado, ra = retroarticular, $\mathbf{s i}=$ simplético, sop = subopérculo. Barra de escala $=2 \mathrm{~mm}$. 


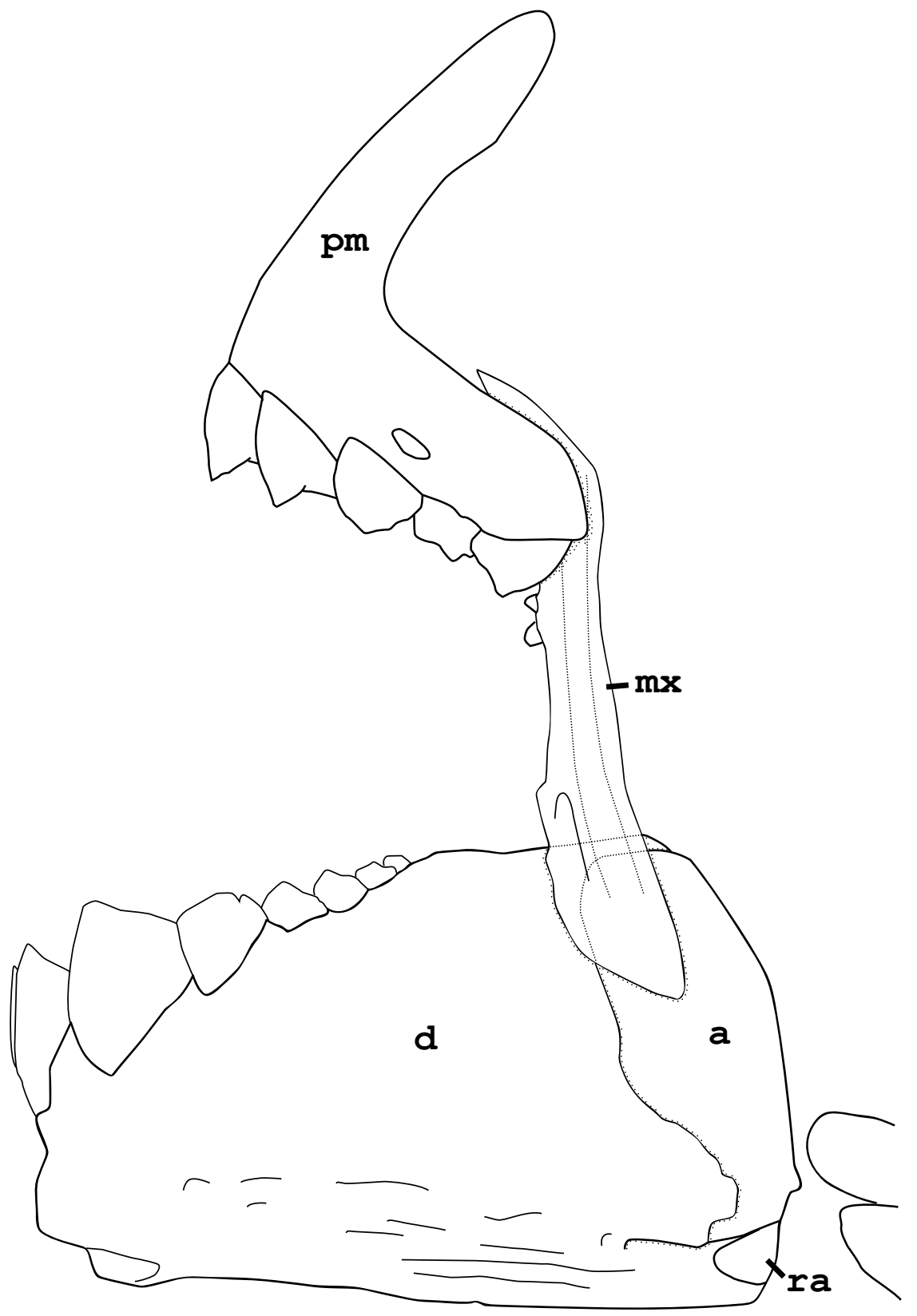

Figura 24. Vista lateral das maxilas de Piaractus mesopotamicus (MZUSP 15166). Anterior para esquerda. a = ânguloarticular, $\mathbf{d}=$ dentário, $\mathbf{m x}=$ maxilar, $\mathbf{p m}=$ pré-maxilar e ra = retroarticular. Barra de escala $=10 \mathrm{~mm}$. 


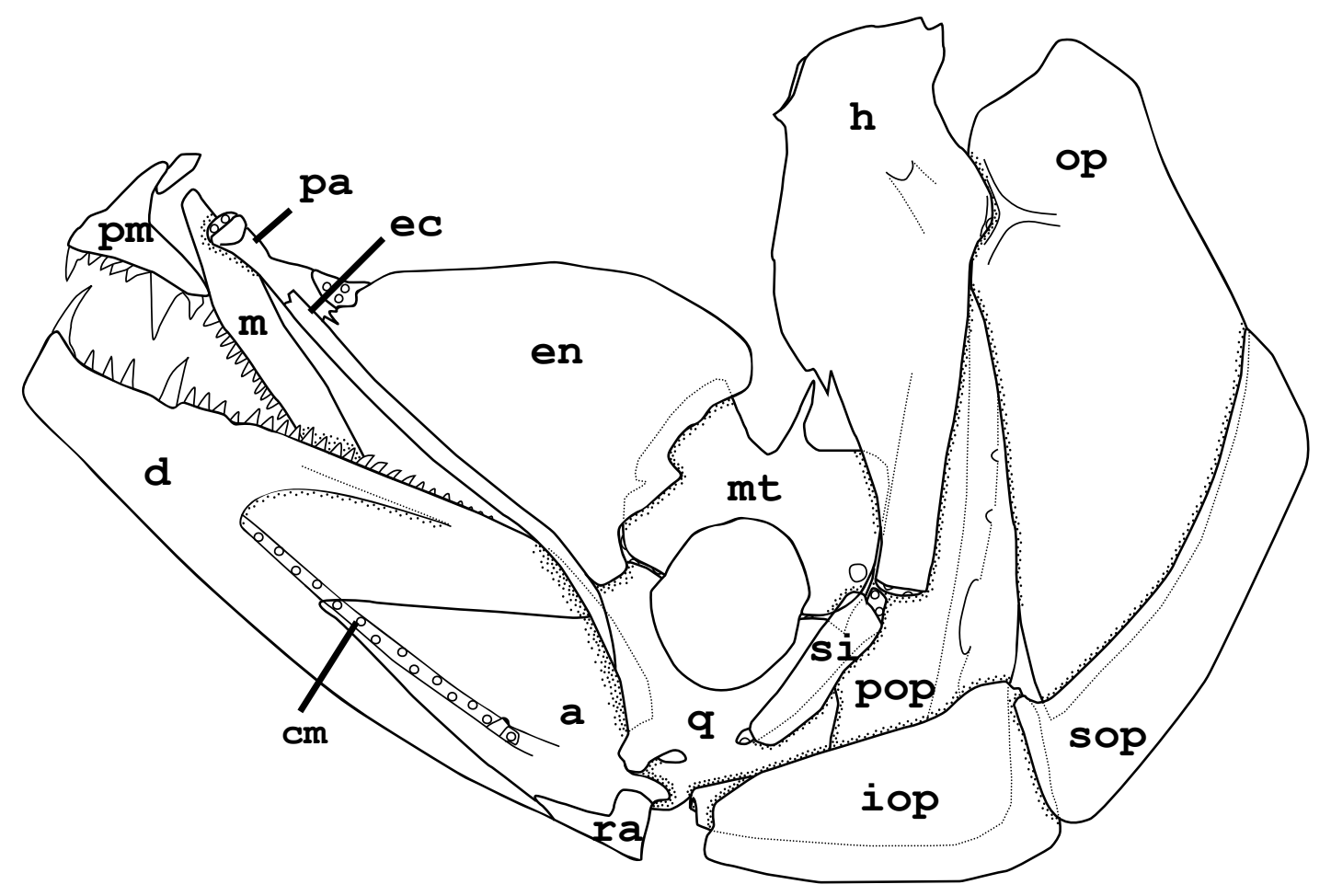

Figura 25. Vista medial do suspensório mandibular e série opercular de Charax gibbosus (ROM 674425). Anterior para esquerda. a = ângulo-articular, $\mathbf{c m}=$ cartilagem de Meckel, $\mathbf{d}$ = dentário, ec = ectopterigóide, en = endopterigóide, $\mathbf{h}=$ hiomandibular, iop = interopérculo, $\mathbf{m t}=$ metapterigóide, $\mathbf{m x}=$ maxilar, op $=$ opérculo, $\mathbf{p a}=$ palatino, $\mathbf{p m}=$ pré-maxilar, $\mathbf{p o p}$ = pré-opérculo, $\mathbf{q}=$ quadrado, ra = retroarticular, $\mathbf{s i}=\mathbf{s i m}-$ plético, sop = subopérculo. Barra de escala $=5 \mathrm{~mm}$. 


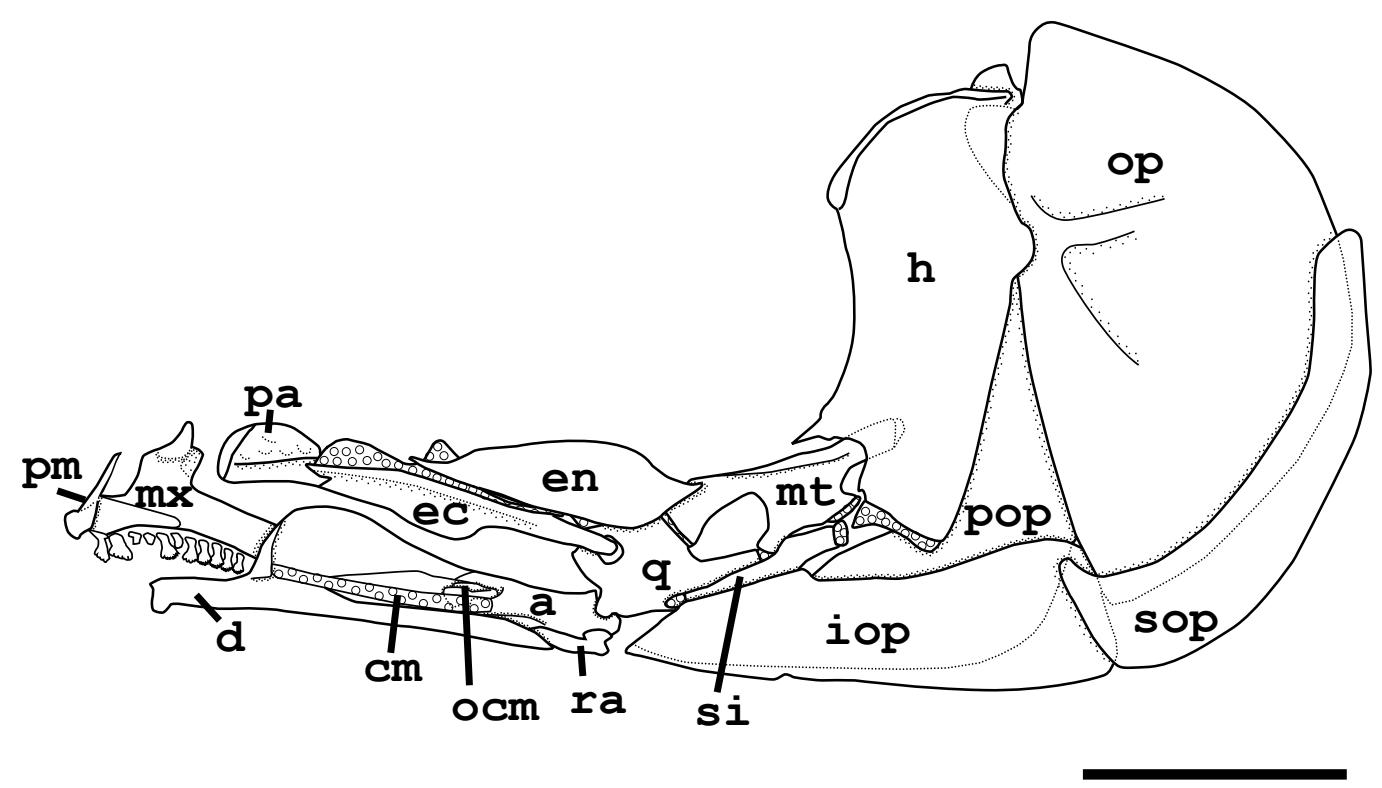

Figura 26. Vista medial do suspensório mandibular e série opercular de Hemiodus unimaculatus (MZUSP 29673). Anterior para esquerda. a = ângulo-articular, $\mathbf{c m}=$ cartilagem de Meckel, $\mathbf{d}=$ dentário, ec = ectopterigóide, en = endopterigóide, $\mathbf{h}=$ hiomandibular, $\mathbf{i o p}=$ interopérculo, $\mathbf{m t}=$ metapterigóide, $\mathbf{m x}=$ maxilar, ocm = osso corono-meckeliano, op $=$ opérculo, $\mathbf{p a}=$ palatino, $\mathbf{p m}=$ pré-maxilar, $\mathbf{p o p}=$ préopérculo, $\mathbf{q}=$ quadrado, ra = retroarticular, $\mathbf{s i}=$ simplético, sop $=$ subopérculo. Barra de escala $=5 \mathrm{~mm}$. 


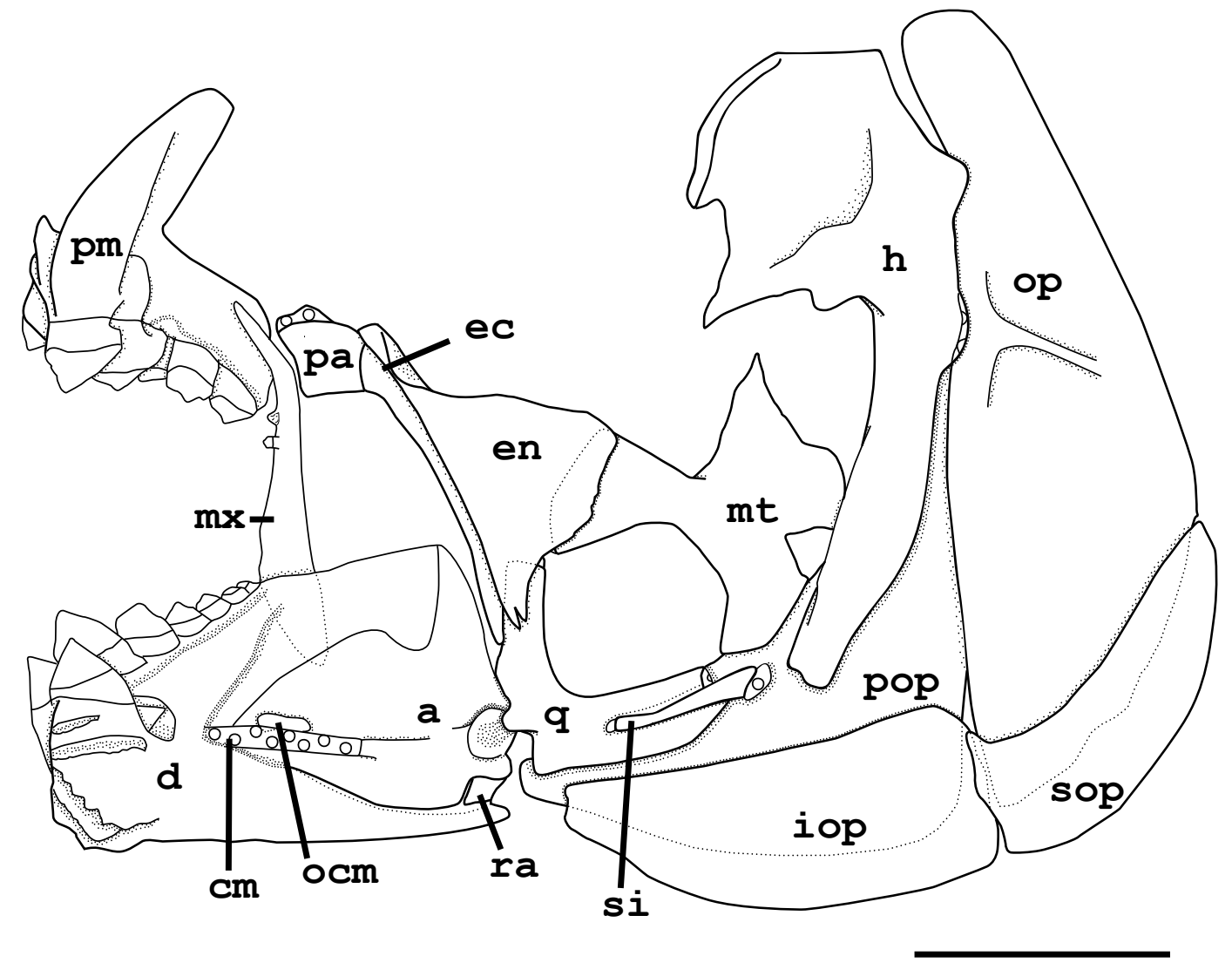

Figura 27. Vista medial do suspensório mandibular e série opercular de Piaractus mesopotamicus (MZUSP 15166). Anterior para esquerda. a = ângulo-articular, $\mathbf{c m}=$ cartilagem de Meckel, $\mathbf{d}=$ dentário, ec = ectopterigóide, en = endopterigóide, $\mathbf{h}=$ hiomandibular, $\mathbf{i o p}=$ interopérculo, $\mathbf{m t}=$ metapterigóide, $\mathbf{m x}=$ maxilar, ocm = osso corono-meckeliano, op $=$ opérculo, $\mathbf{p a}=$ palatino, $\mathbf{p m}=$ pré-maxilar, $\mathbf{p o p}=$ préopérculo, $\mathbf{q}=$ quadrado, ra = retroarticular, $\mathbf{s i}=$ simplético, sop $=$ subopérculo. Barra de escala $=10 \mathrm{~mm}$. 


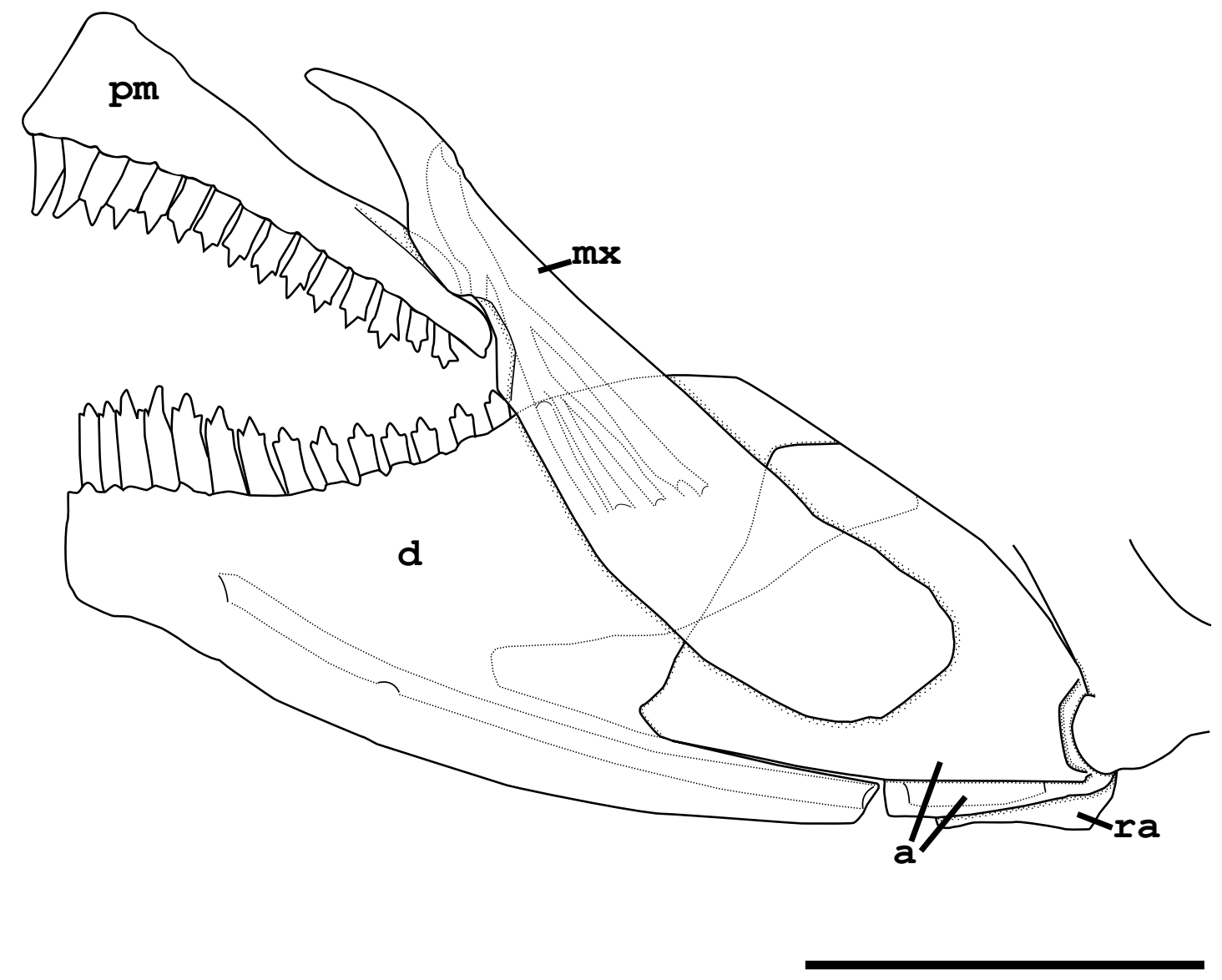

Figura 28. Vista lateral das maxilas de Crenuchus spilurus (MZUSP 7479). Anterior para esquerda. a = ângulo-articular, d = dentário, $\mathbf{m x}=$ maxilar, $\mathbf{p m}=$ pré-maxilar e ra = retroarticular. Barra de escala $=2 \mathrm{~mm}$. 


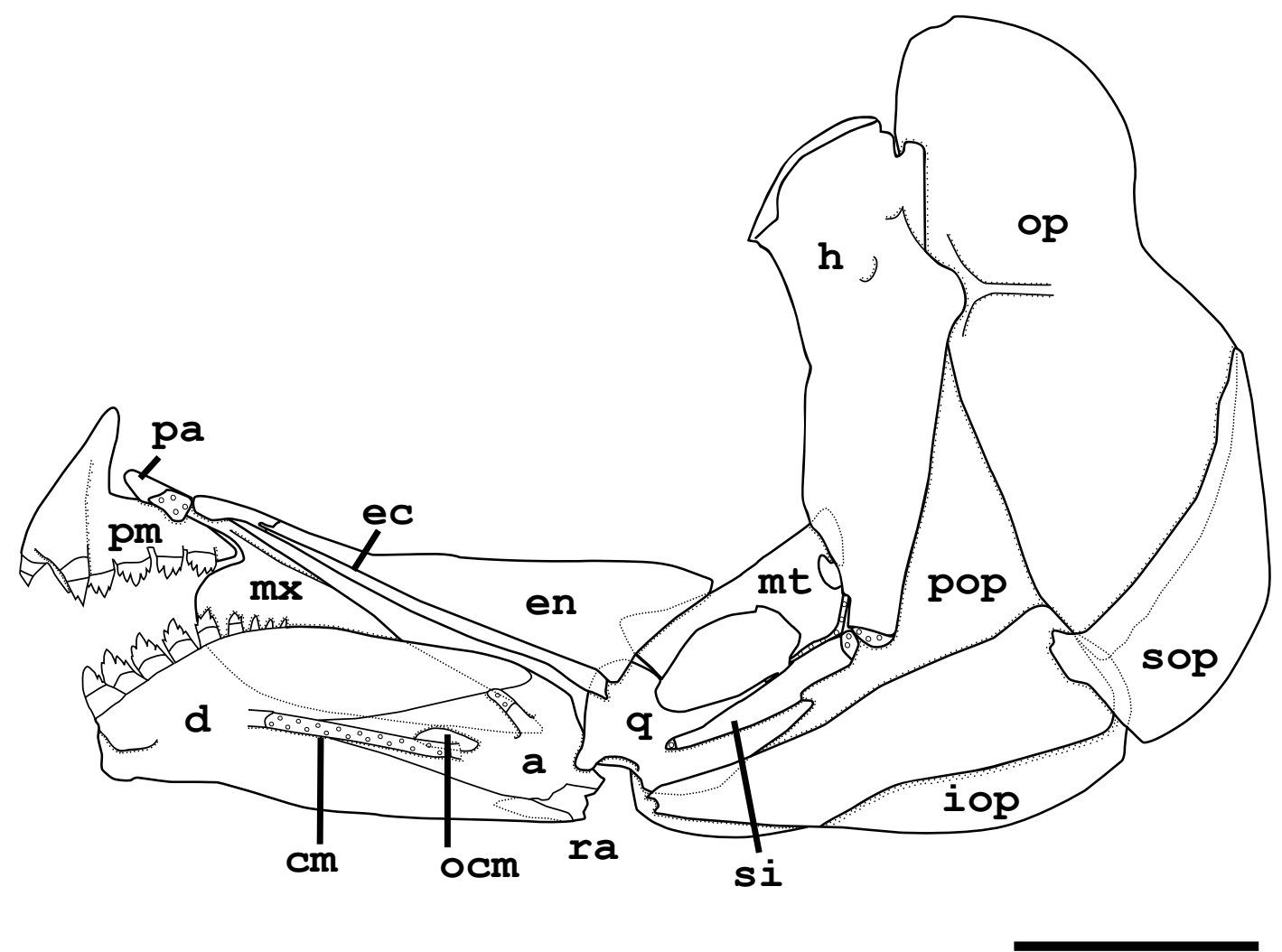

Figura 29. Vista medial do suspensório mandibular e série opercular de Bryconops alburnoides (MZUSP 34590). Anterior para esquerda. a = ângulo-articular, $\mathbf{c m}=$ cartilagem de Meckel, $\mathbf{d}=$ dentário, ec = ectopterigóide, en = endopterigóide, $\mathbf{h}=$ hiomandibular, $\mathbf{i o p}=$ interopérculo, $\mathbf{m t}=$ metapterigóide, $\mathbf{m x}$ = maxilar, ocm = osso corono-meckeliano, op $=$ opérculo, $\mathbf{p a}=$ palatino, $\mathbf{p m}=$ pré-maxilar, $\mathbf{p o p}=$ préopérculo, $\mathbf{q}=$ quadrado, ra = retroarticular, si = simplético, sop = subopérculo. Barra de escala $=5 \mathrm{~mm}$. 


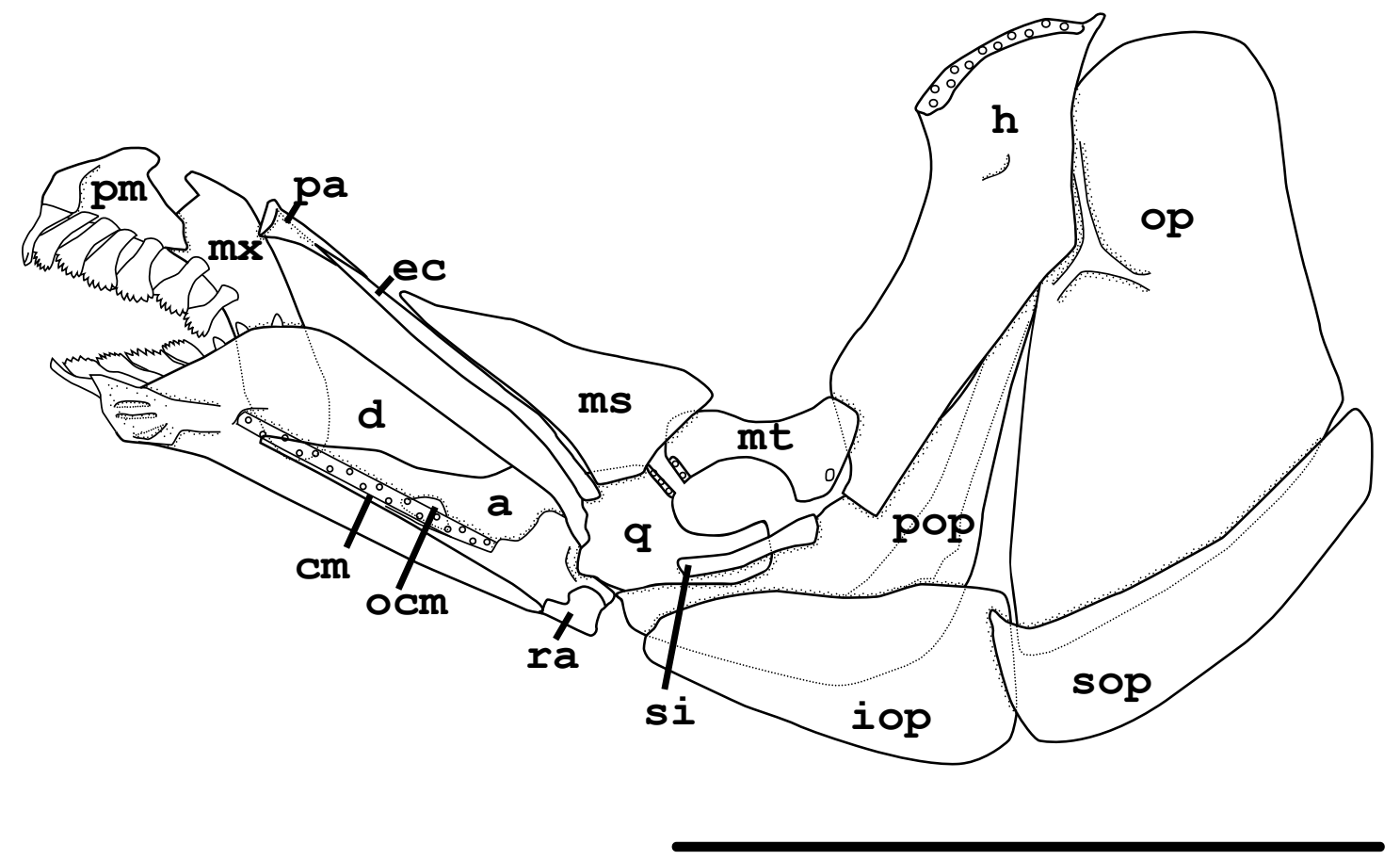

Figura 30. Vista medial do suspensório mandibular e série opercular de Rhoadsia altipinna (FMNH 93168). Anterior para esquerda. a = ângulo-articular, $\mathbf{c m}=$ cartilagem de Meckel, $\mathbf{d}$ = dentário, ec = ectopterigóide, $\mathbf{h}=$ hiomandibular, $\mathbf{i o p}=$ interopérculo, $\mathbf{m s}=$ mesopterigóide, $\mathbf{m t}=$ metapterigóide, $\mathbf{m x}=$ maxilar, $\mathbf{o c m}=$ osso corono-meckeliano, op = opérculo, $\mathbf{p a}=$ palatino, $\mathbf{p m}=$ pré-maxilar, $\mathbf{p o p}=$ pré-opérculo, $\mathbf{q}=$ quadrado, ra $=$ retroarticular, $\mathbf{s i}=$ simplético, sop = subopérculo. Barra de escala $=5 \mathrm{~mm}$. 

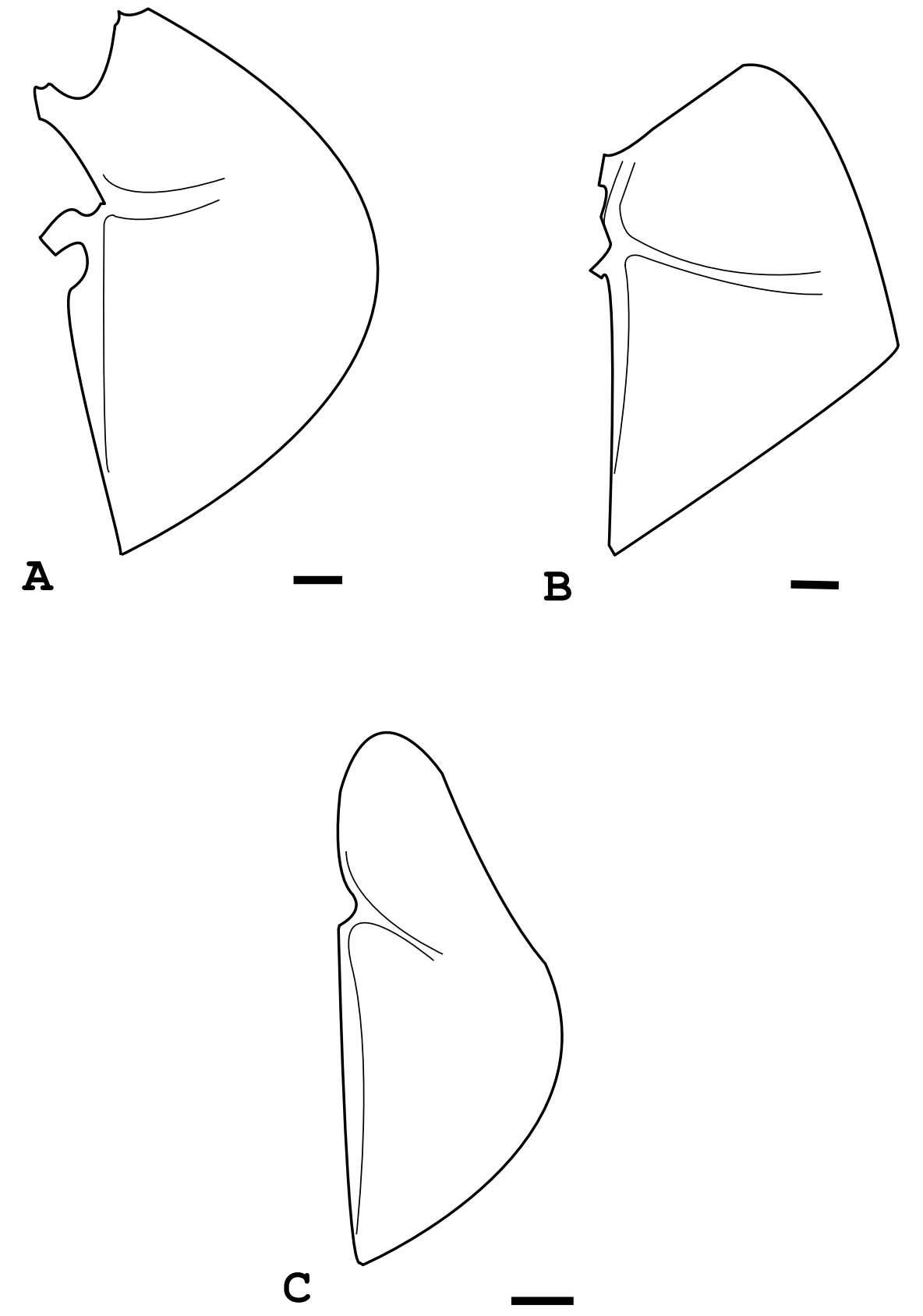

Figura 31. Vista lateral do opérculo de: (A) Hemiodus unimaculatus (MZUSP 29673); (B) Hepsetus odoe (MZUSP 84469) e; (C) Hollandichthys multifasciatus (MZUSP 78596). Anterior para esquerda. Barra de escala = 


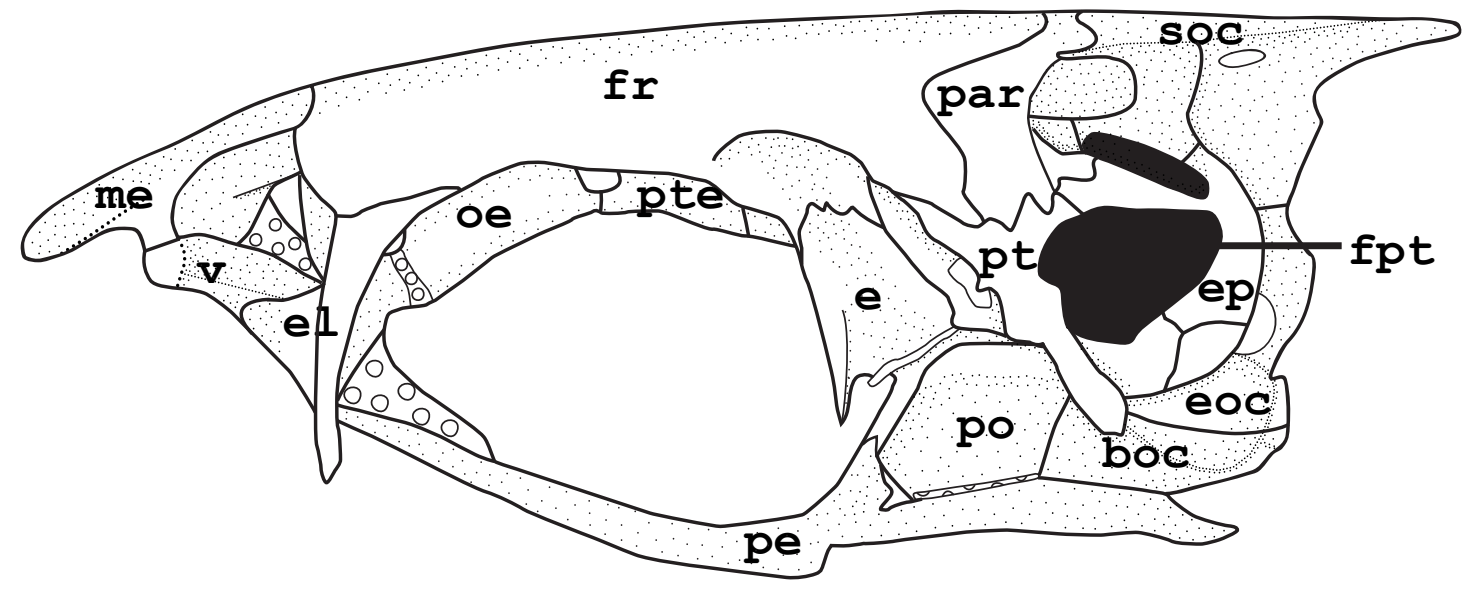

Figura 32. Vista lateral do neurocrânio de Bryconops alburnoides (MZUSP 34590). Anterior para esquerda. boc = basioccipital, e = esfenótico, el = etmóide lateral, eoc = exoccipital, ep = epoccipital, fpt = fossa pós-temporal, fr $=$ frontal, me = mesetmóide, oe = órbito-esfenóide, par = parietal, $\mathbf{p e}=$ paraesfenóide, po $=$ pró-ótico, pt $=$ pterótico, pte = pteroesfenóide, $\mathbf{s o c}=$ supra-occipital e v = vômer. Barra de escala $=10 \mathrm{~mm}$. 


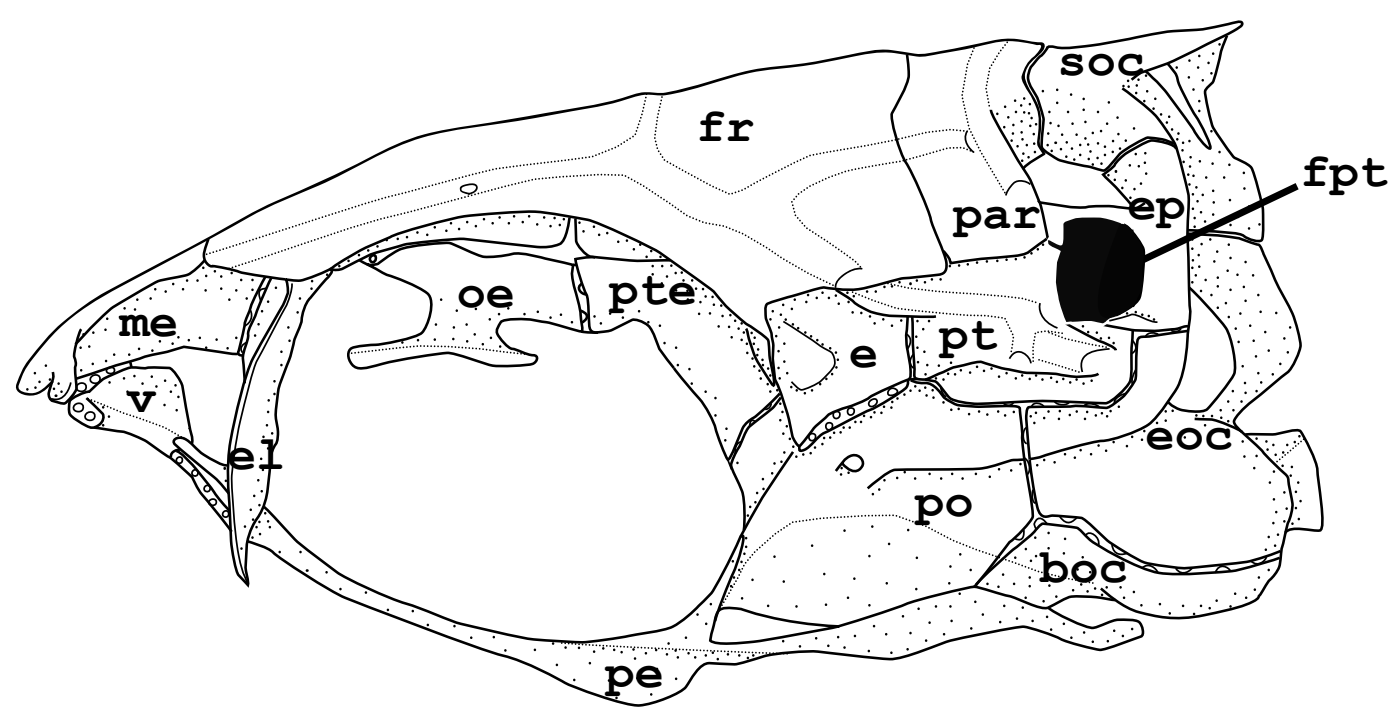

Figura 33. Vista lateral do neurocrânio de Compsura heterura (MZUSP 54621). Anterior para esquerda. boc = basioccipital, e = esfenótico, $\mathbf{e l}=$ etmóide lateral, eoc = exoccipital, $\mathbf{e p}=$ epoccipital, fpt = fossa pós-temporal, fr = frontal, $\mathbf{m e}=$ mesetmóide, oe = órbito-esfenóide, par = parietal, pe $=$ paraesfenóide, po = pró-ótico, pt = pterótico, pte = pteroesfenóide, $\mathbf{s o c}=$ supra-occipital e $\mathbf{v}=$ vômer. Barra de escala = $2 \mathrm{~mm}$. 


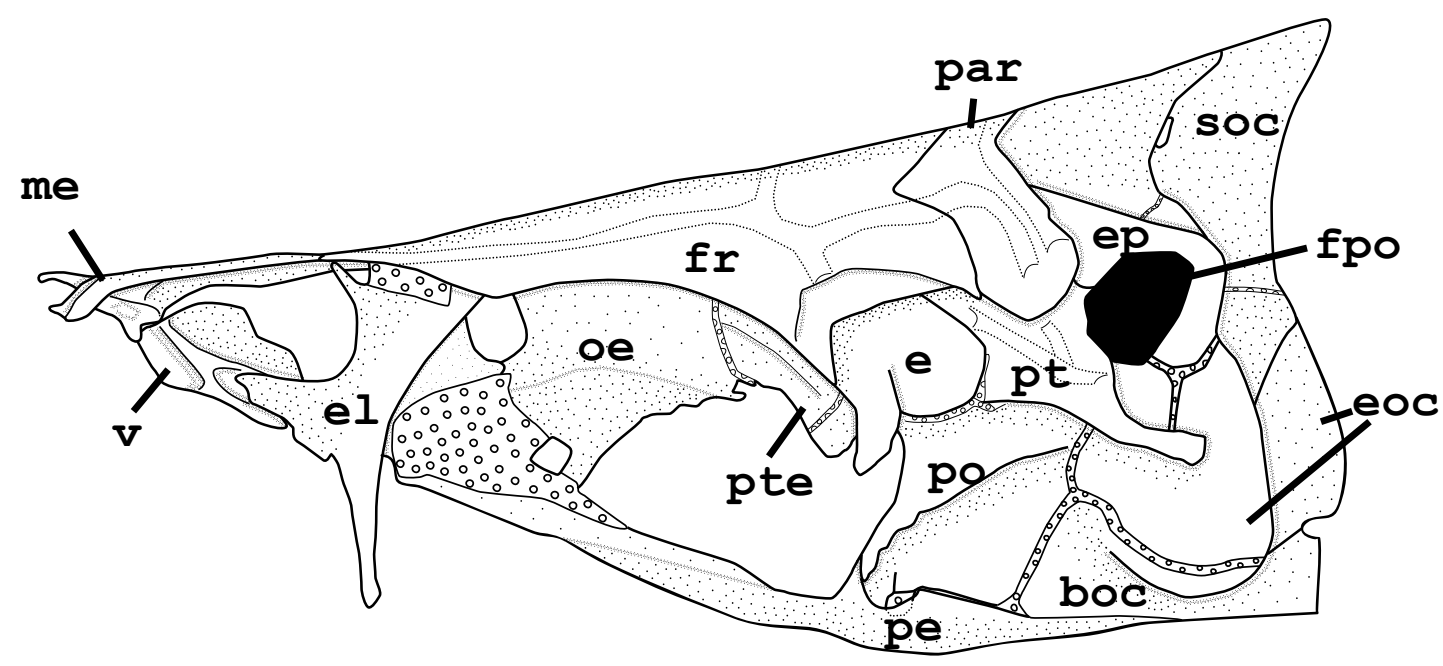

Figura 34. Vista lateral do neurocrânio de Xenocharax spilurus (AMNH 230302). Anterior para esquerda. boc = basioccipital, e = esfenótico, el = etmóide lateral, eoc = exoccipital, ep = epoccipital, $\mathbf{f p t}=$ fossa pós-temporal, $\mathbf{f r}=$ frontal, $\mathbf{m e}$ = mesetmóide, oe = órbito-esfenóide, par = parietal, pe $=$ paraesfenóide, po = pró-ótico, pt $=$ pterótico, pte $=$ pteroesfenóide, $\mathbf{s o c}=$ supra-occipital e $\mathbf{v}=$ vômer. Barra de escala = $5 \mathrm{~mm}$. 


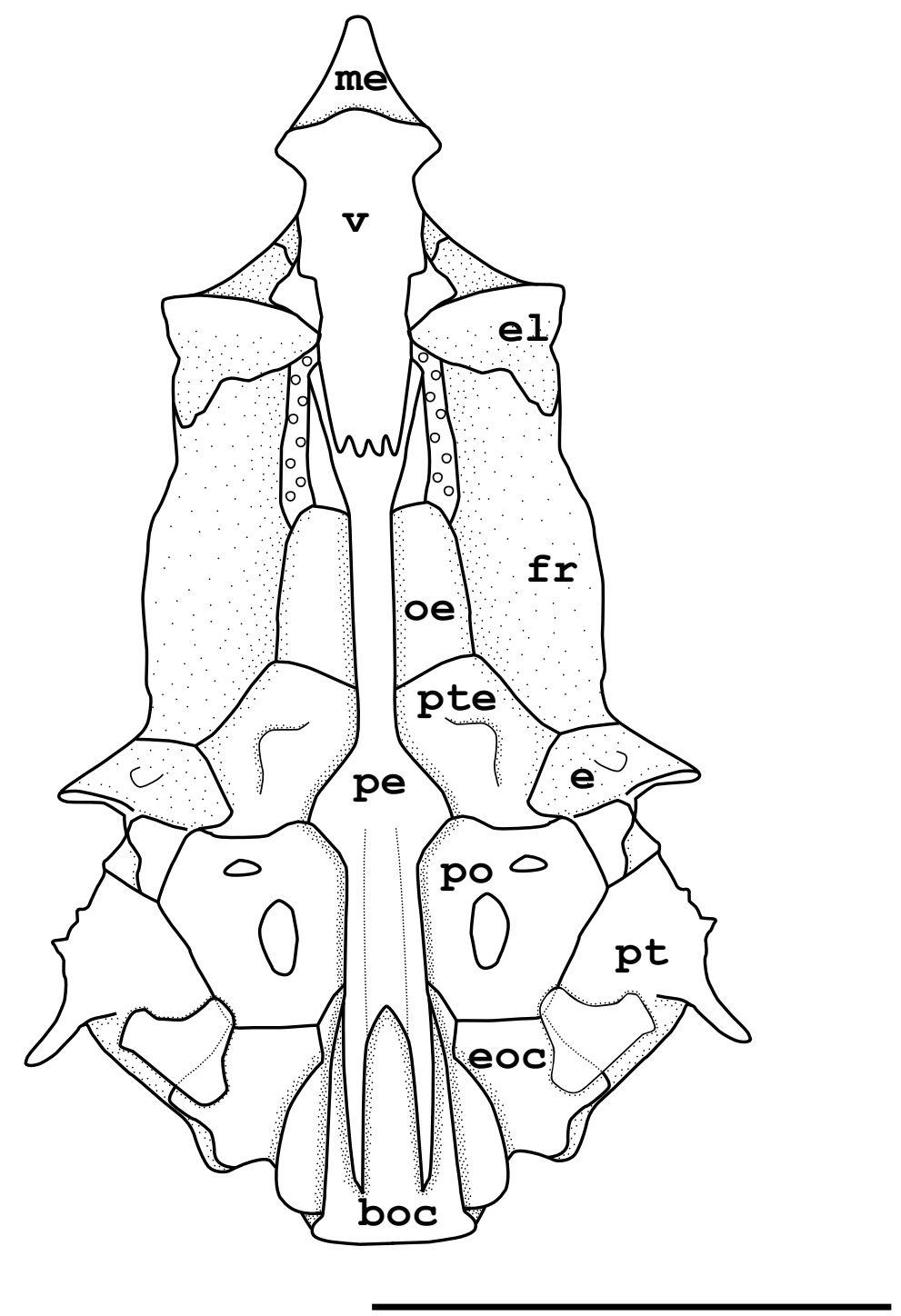

Figura 35. Vista ventral do neurocrânio de Bryconops alburnoides (MZUSP 34590). Anterior para cima. boc = basioccipital, $\mathbf{e}=$ esfenótico, el = etmóide lateral, eoc = exoccipital, $\mathbf{f r}=$ frontal, $\mathbf{m e}=$ mesetmóide, oe =órbito-esfenóide, $\mathbf{p e}=$ paraesfenóide, po $=$ pró-ótico, pt $=$ pterótico, pte $=$ pteroesfenóide e $\mathbf{v}=$ vômer. Barra de escala $=10 \mathrm{~mm}$. 


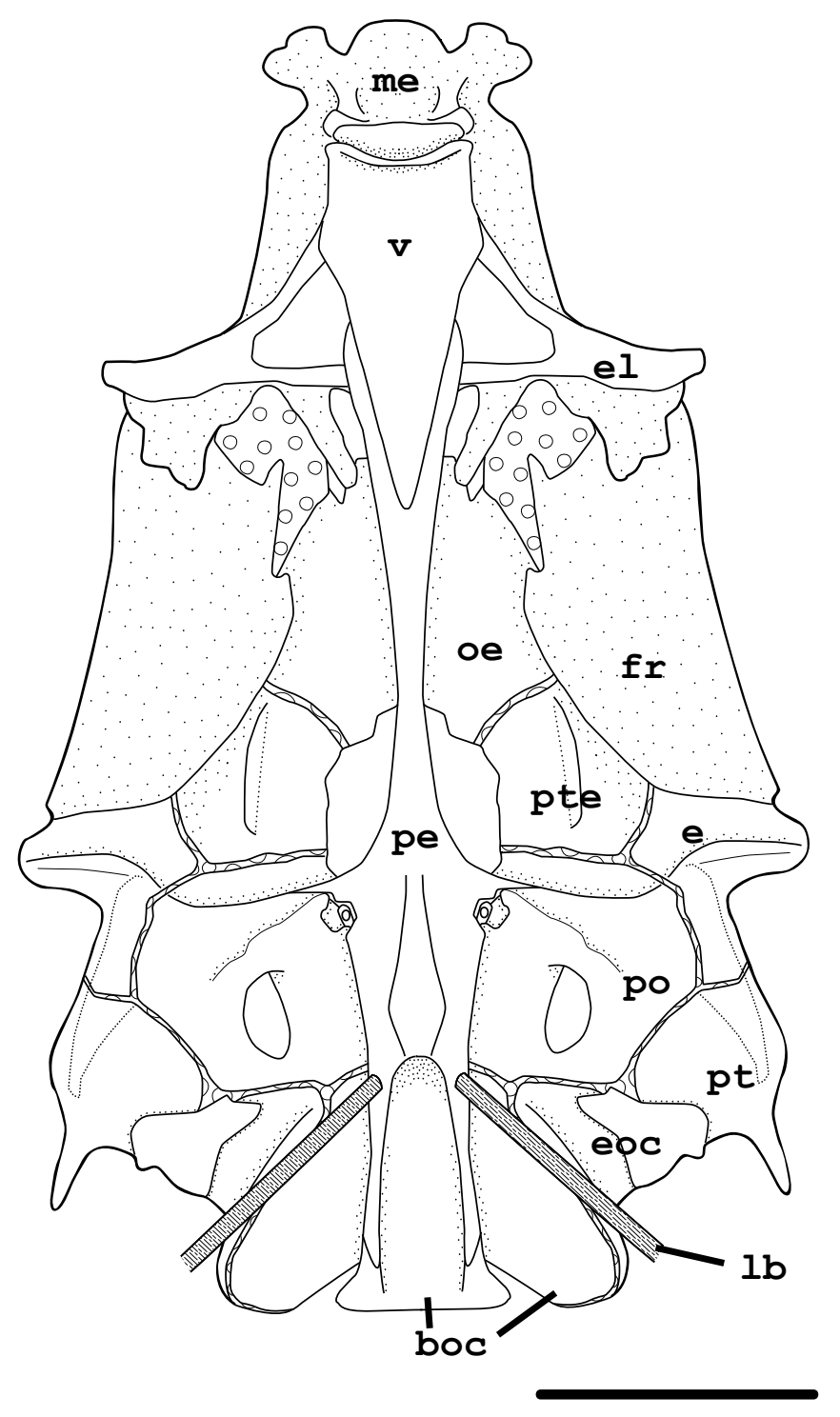

Figura 36. Vista ventral do neurocrânio de Xenocharax spilurus (AMNH 230302). Anterior para cima. boc = basioccipital, e = esfenótico, $\mathbf{e l}=$ etmóide lateral, eoc = exoccipital, $\mathbf{f r}=$ frontal, $\mathbf{l b}=$ ligamento de Baudelot, me = mesetmóide, oe = órbito-esfenóide, pe = paraesfenóide, po = pró-ótico, pt $=$ pterótico, pte $=$ pteroesfenóide e $\mathbf{v}=$ vômer. Barra de 


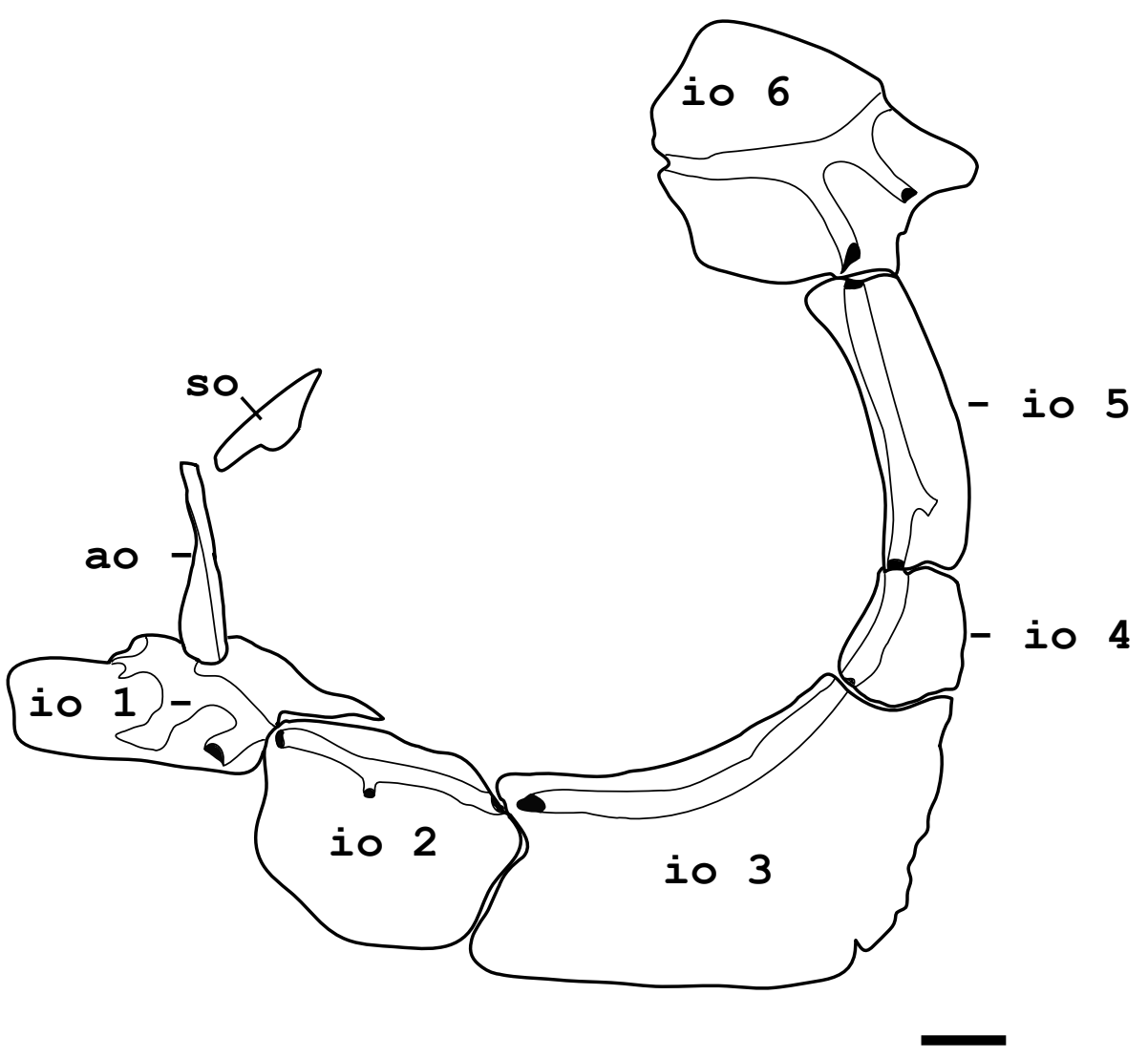

Figura 37. Série infra-orbital de Distichodus notospilus $($ AMNH 230295). Anterior para esquerda. ao = antorbital, io 1-6 = infra-orbitais e so = supra-orbital. Barra de escala = $1 \mathrm{~mm}$. 


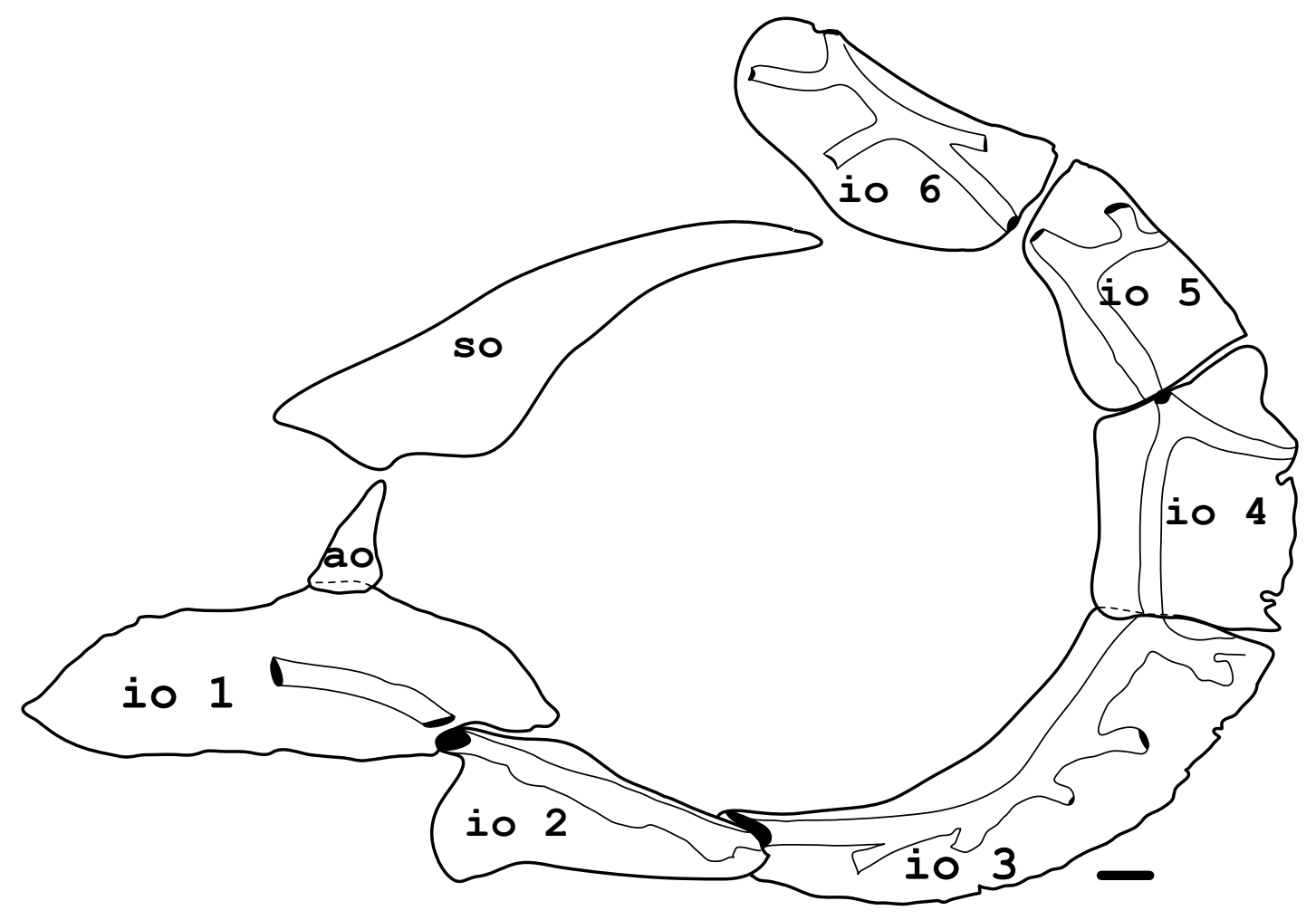

Figura 38. Série infra-orbital de Prochilodus nigricans (MZUSP 4837). Anterior para esquerda. ao = antorbital, io 1-6 = infra-orbitais e so = supra-orbital. Barra de escala $=1$ $\mathrm{mm}$. 


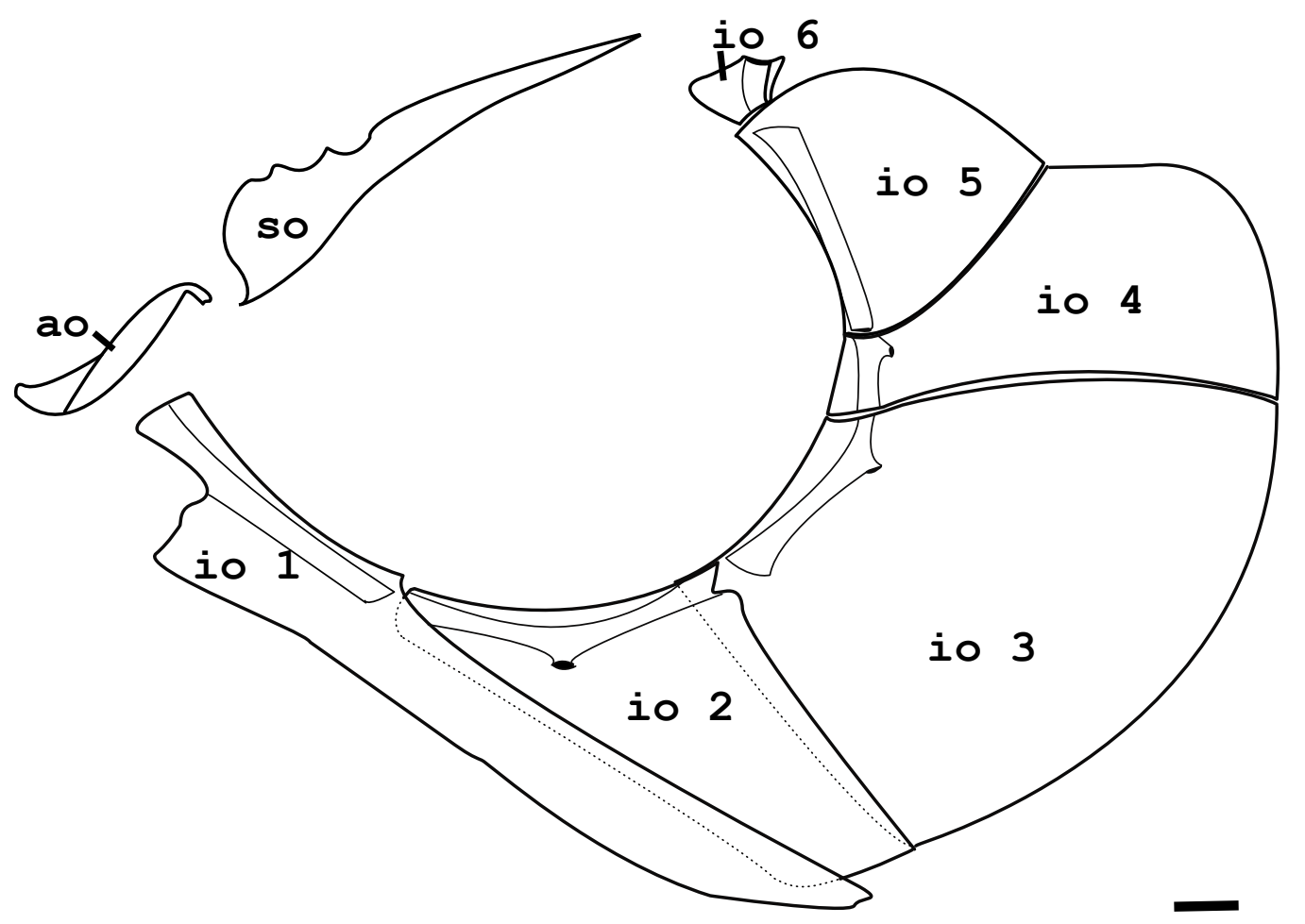

Figura 39. Série infra-orbital de Acestrorynchus falcirostris (MZUSP 36824). Anterior para esquerda. ao = antorbital, io 1-6 = infra-orbitais e so = supra-orbital. Barra de escala = $1 \mathrm{~mm}$. 


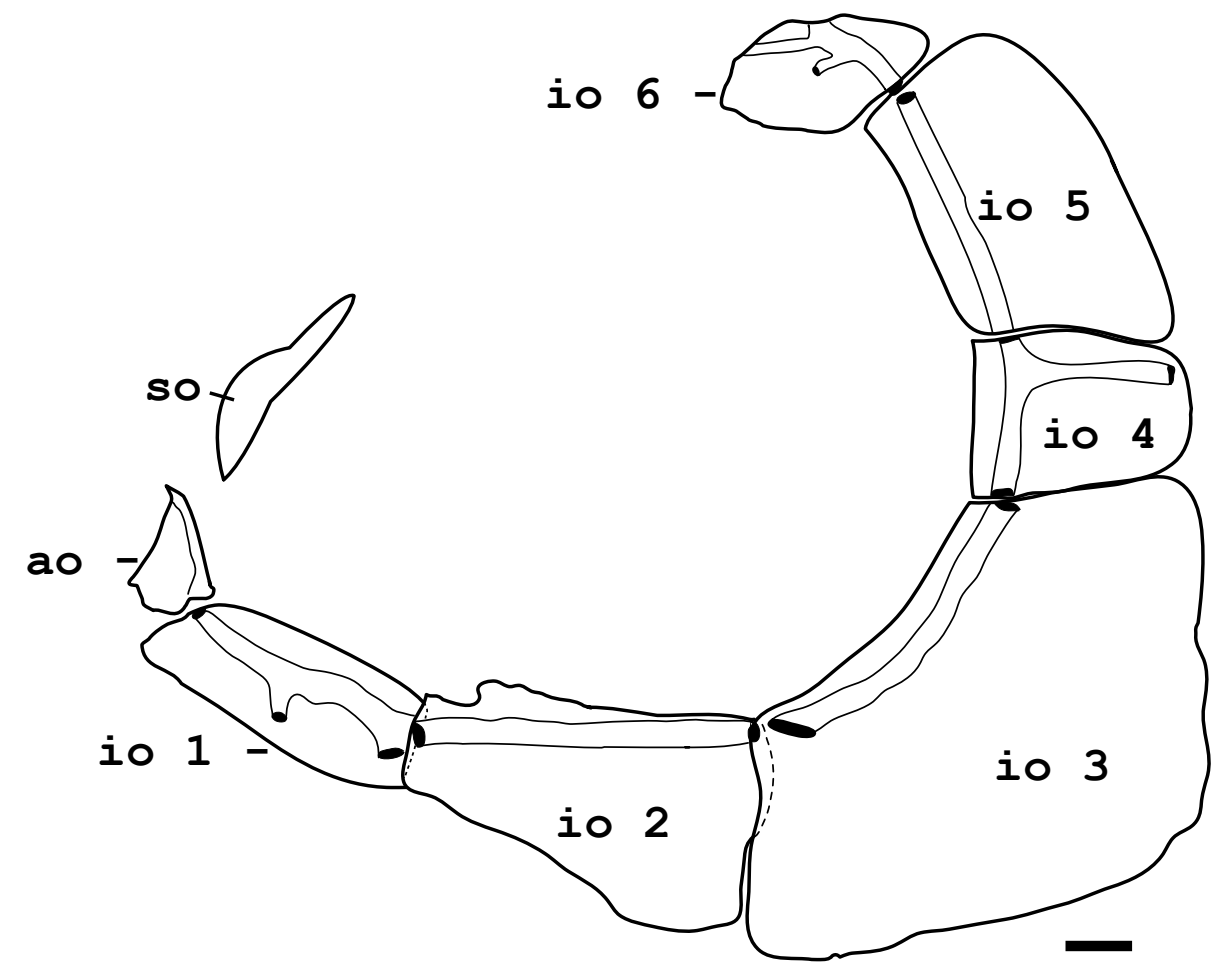

Figura 40. Série infra-orbital de Chalceus epakros (MZUSP 6706). Anterior para esquerda. ao = antorbital, io $\mathbf{1 - 6}=$ infra-orbitais e so = supra-orbital. Barra de escala $=1 \mathrm{~mm}$. 


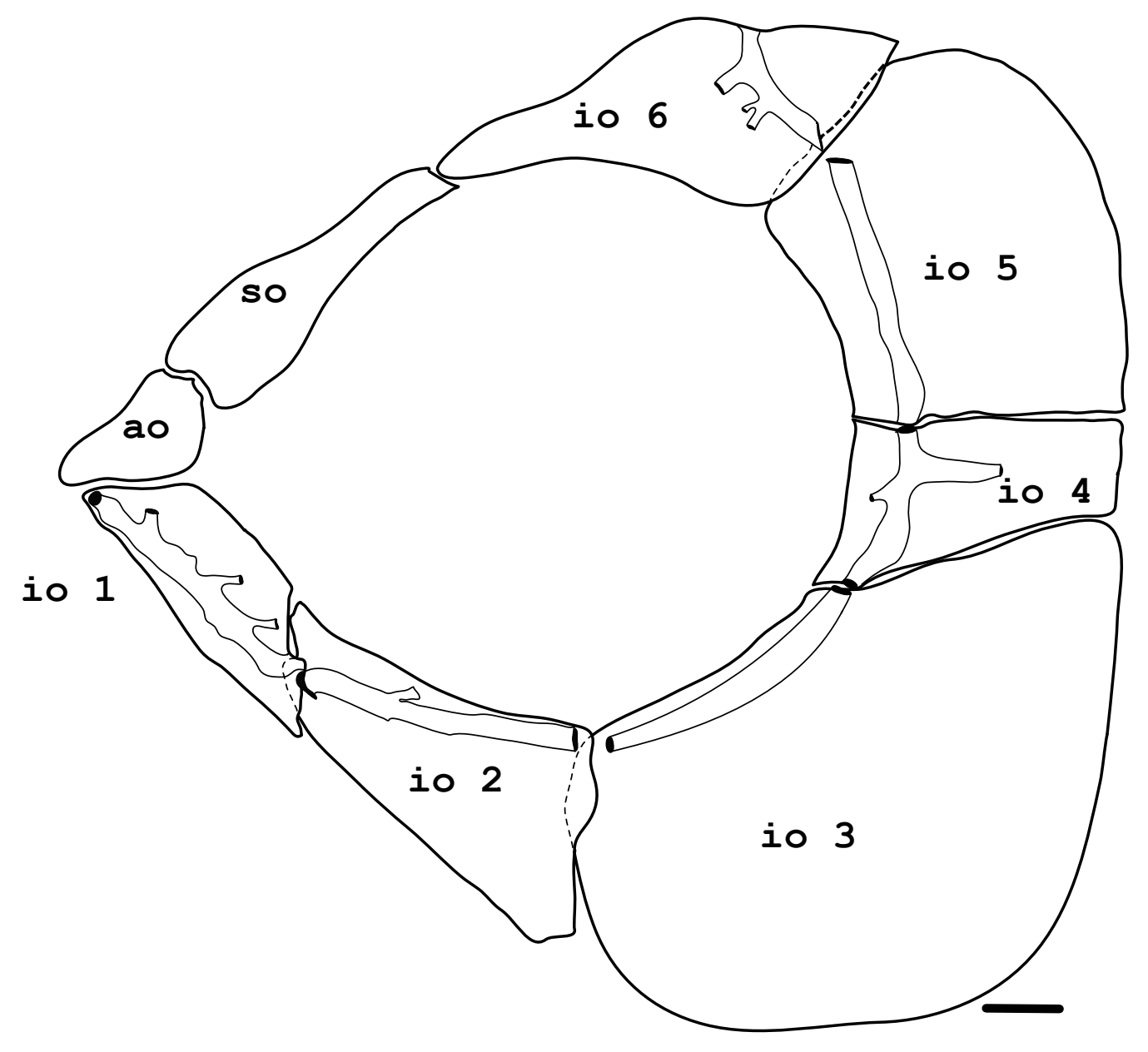

Figura 41. Série infra-orbital de Brycon pesus (MZUSP 36794). Anterior para esquerda. ao = antorbital, io $\mathbf{1 - 6}=$ infraorbitais e so = supra-orbital. Barra de escala $=1 \mathrm{~mm}$. 


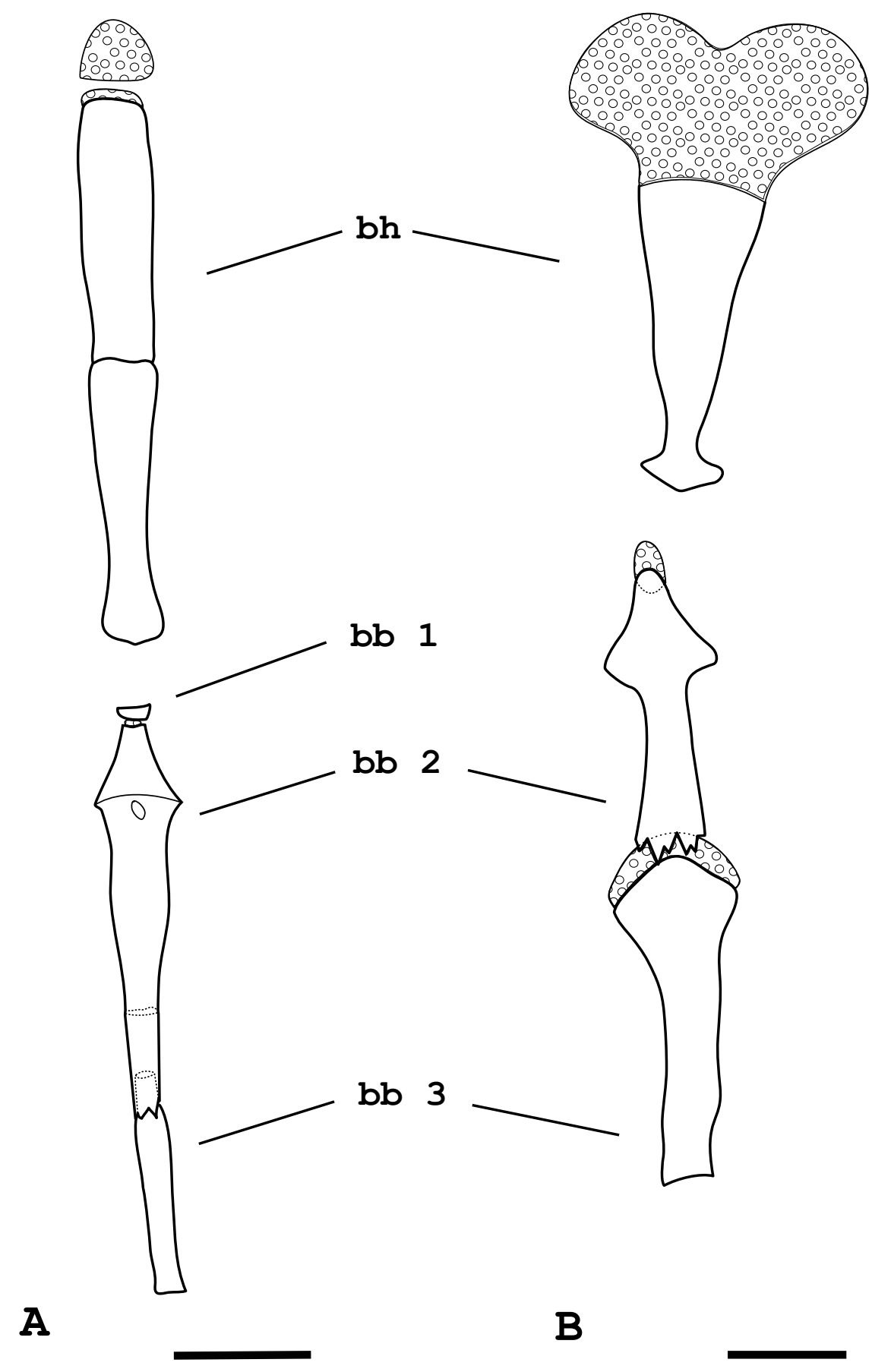

Figura 42. Vista ventral do basi-hial e basibranquiais de: (A) Hemiodus unimaculatus (MZUSP 29673) e (B) Potamorhina latior (MZUSP 6866). Cartilagens preenchidas com pequenos círculos. Anterior para cima. $\mathbf{b} \mathbf{b}=$ basibranquiais e $\mathbf{b h}=$ basi-hial. Barra de escala $=1 \mathrm{~mm}$. 
A

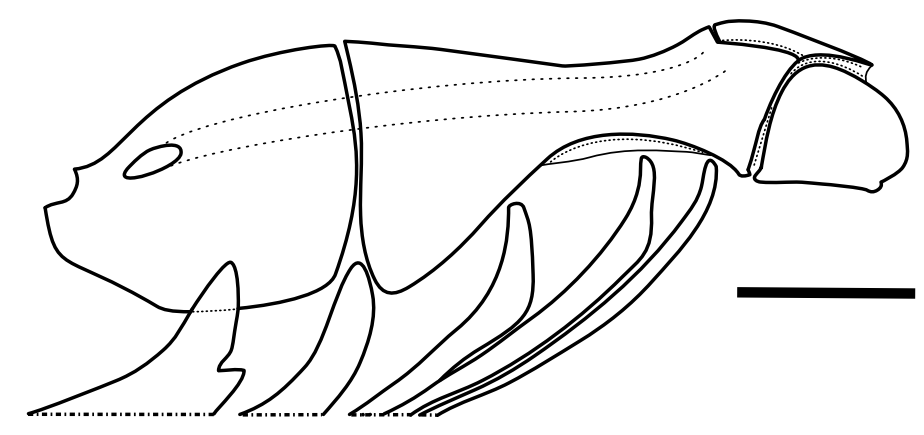

B
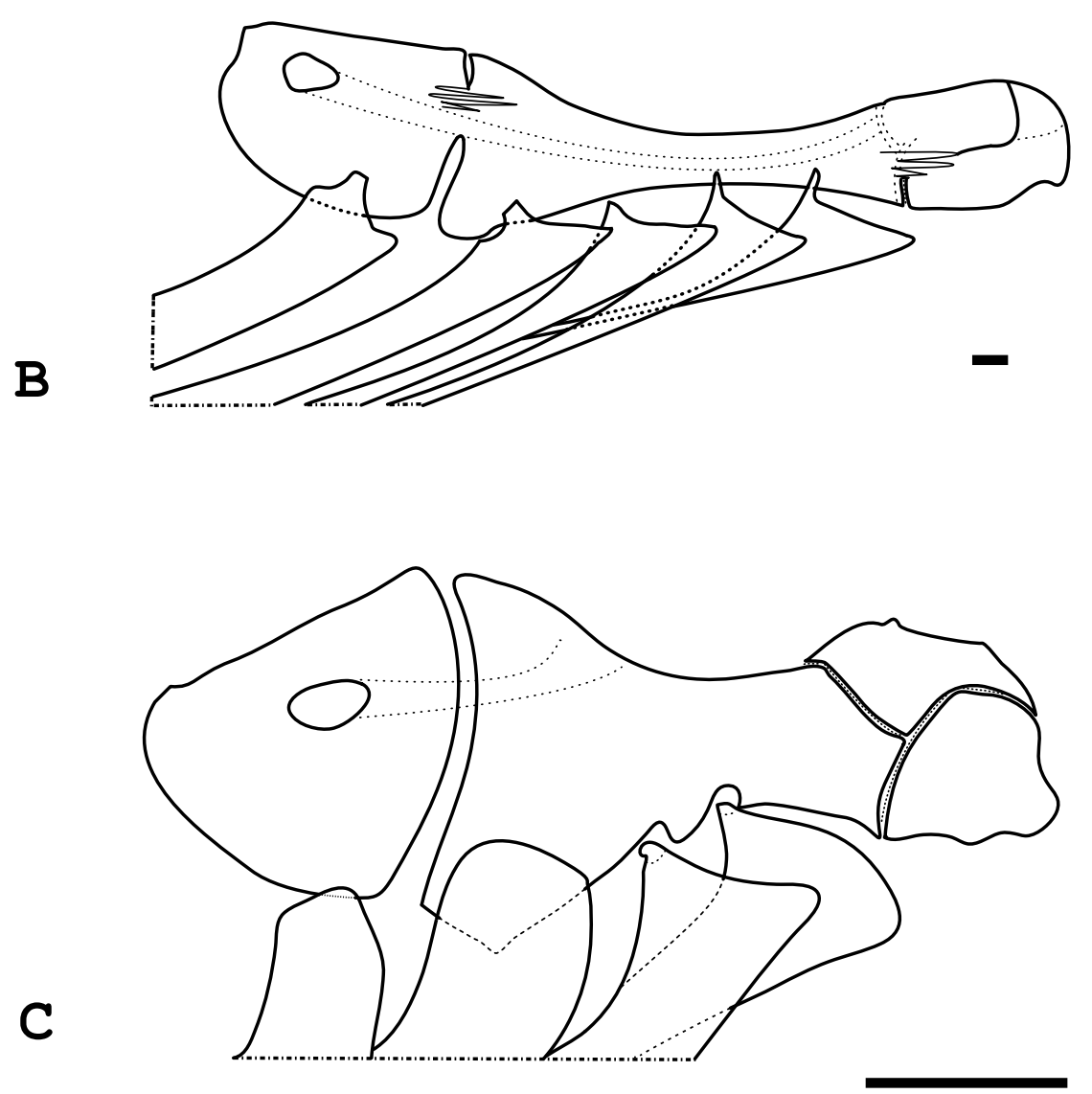

Figura 43. Vista lateral do arco hióide e raios branquiostégios de: (A) Crenuchus spilurus (MZUSP 62317); (B) Anodus orinocensis (MZUSP 21280) e (C) Gymnocorymbus ternetzi (MZUSP 78951). Barra de escala $=1 \mathrm{~mm}$. 

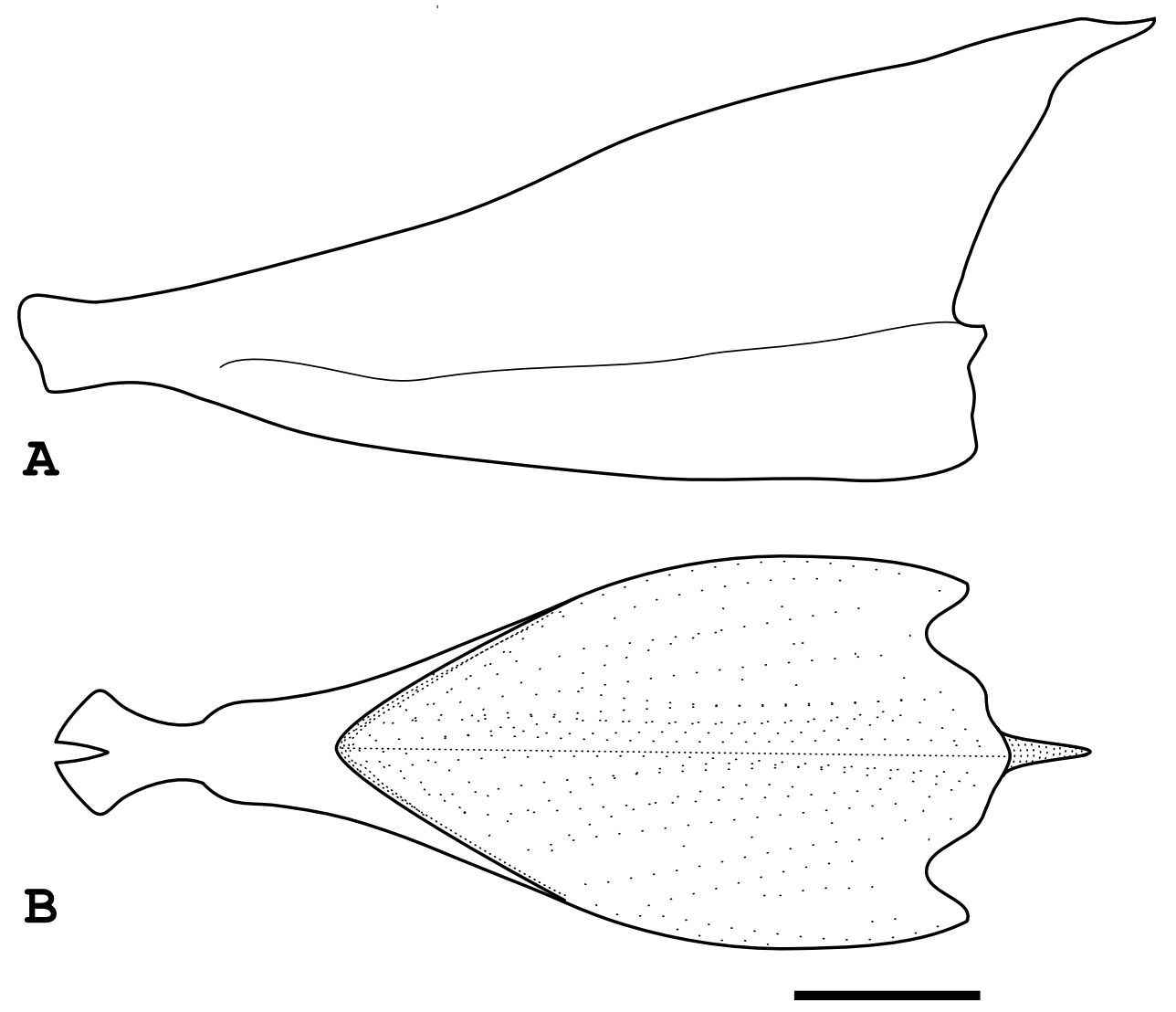

Figura 44. Uro-hial de Chalceus epakros (MZUSP 6706): (A) vista lateral e (B) vista ventral. Anterior à esquerda. Barra de escala $=1 \mathrm{~mm}$. 

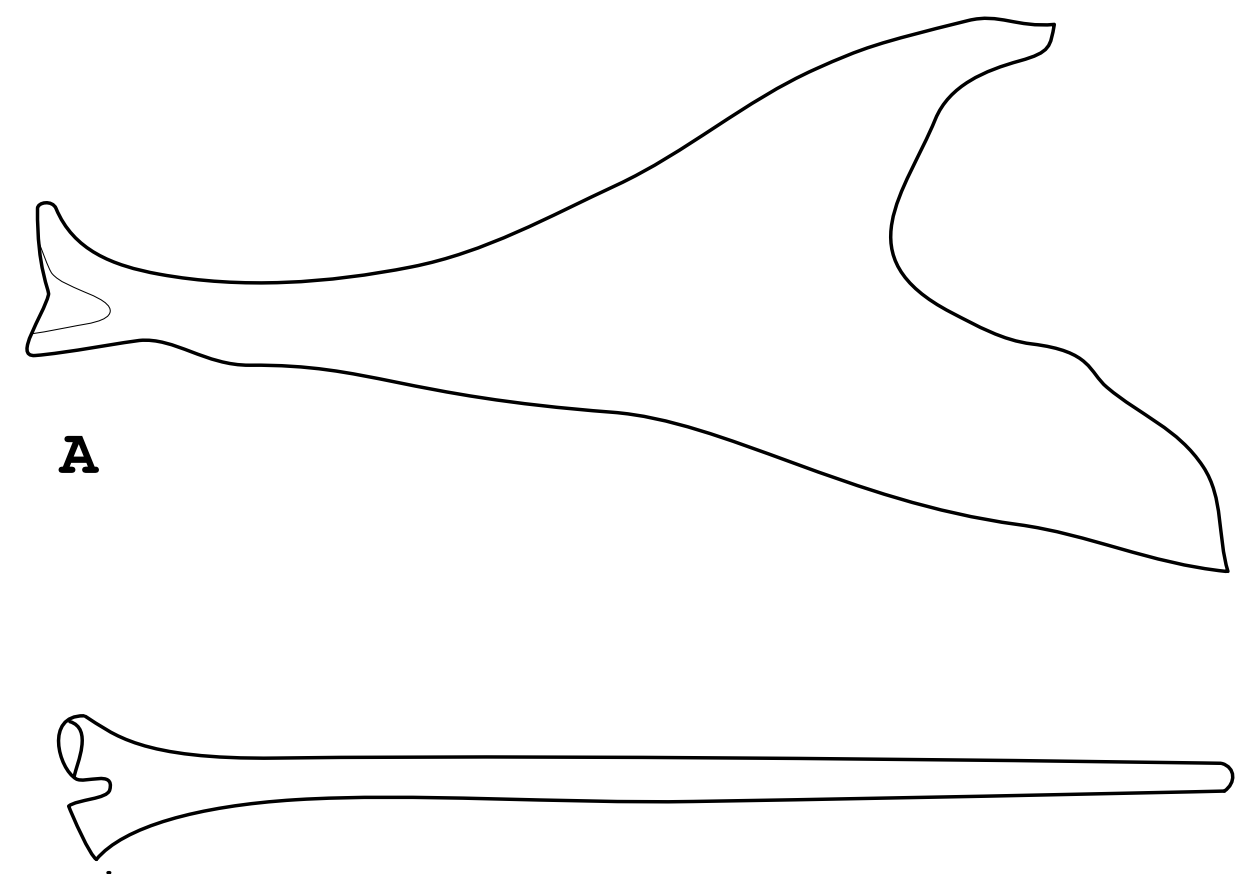

B

Figura 45. Uro-hial Crenuchus spilurus (MZUSP 62317) :

(A) vista lateral e (B) vista ventral. Anterior à esquerda. Barra de escala $=1 \mathrm{~mm}$. 


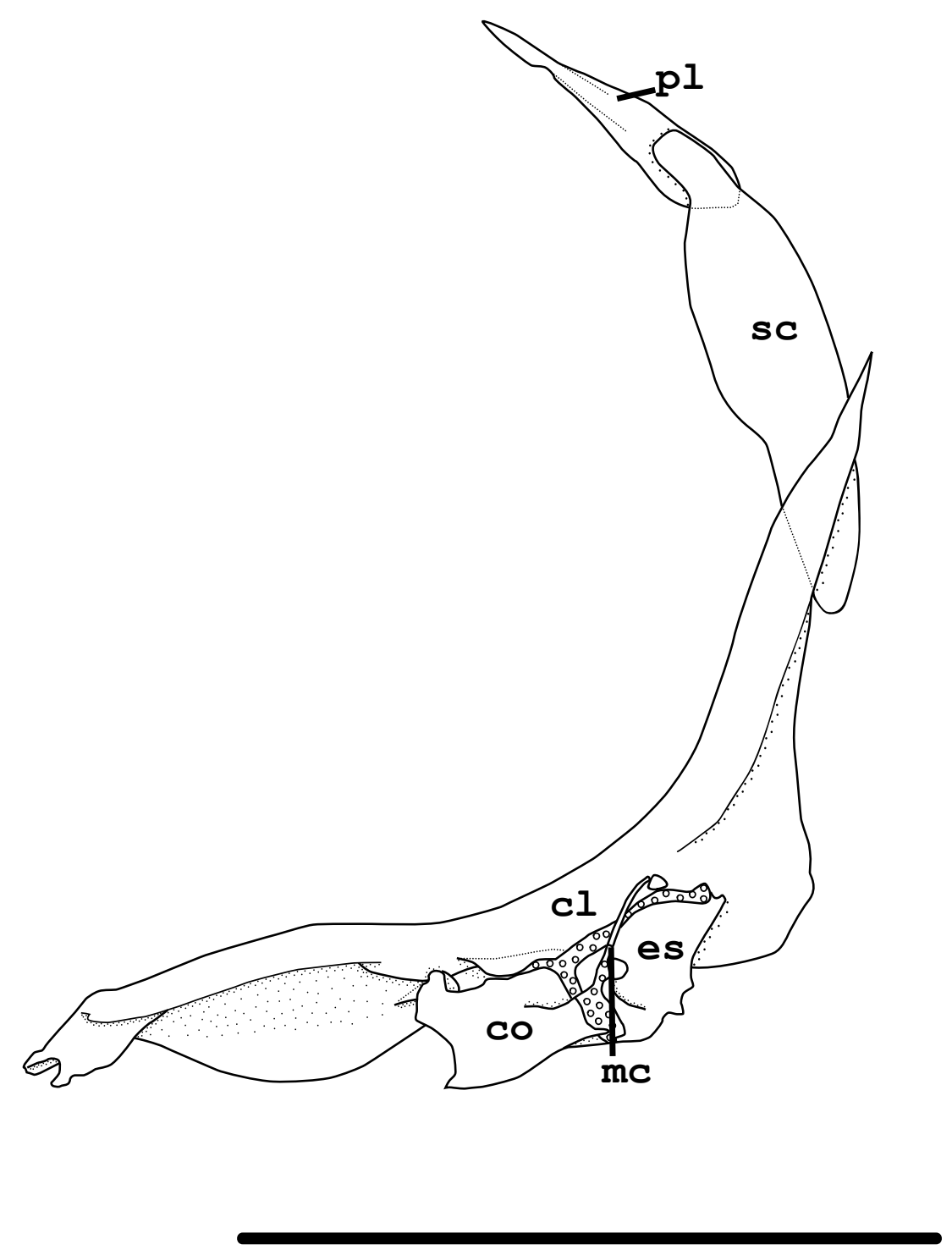

Figura 46. Vista medial da cintura peitoral direita de Stygichthys typhlops (MZUSP 87678). Anterior para esquerda. $\mathbf{c l}=$ cleitro, $\mathbf{c o}=$ coracóide, ee = extra-escapular, es = escápula, $\mathbf{m c}=$ mesocoracóide, $\mathbf{p l}=$ pós-temporal, $\mathbf{s c}=$ supracleitro. Barra de escala $=5 \mathrm{~mm}$. 


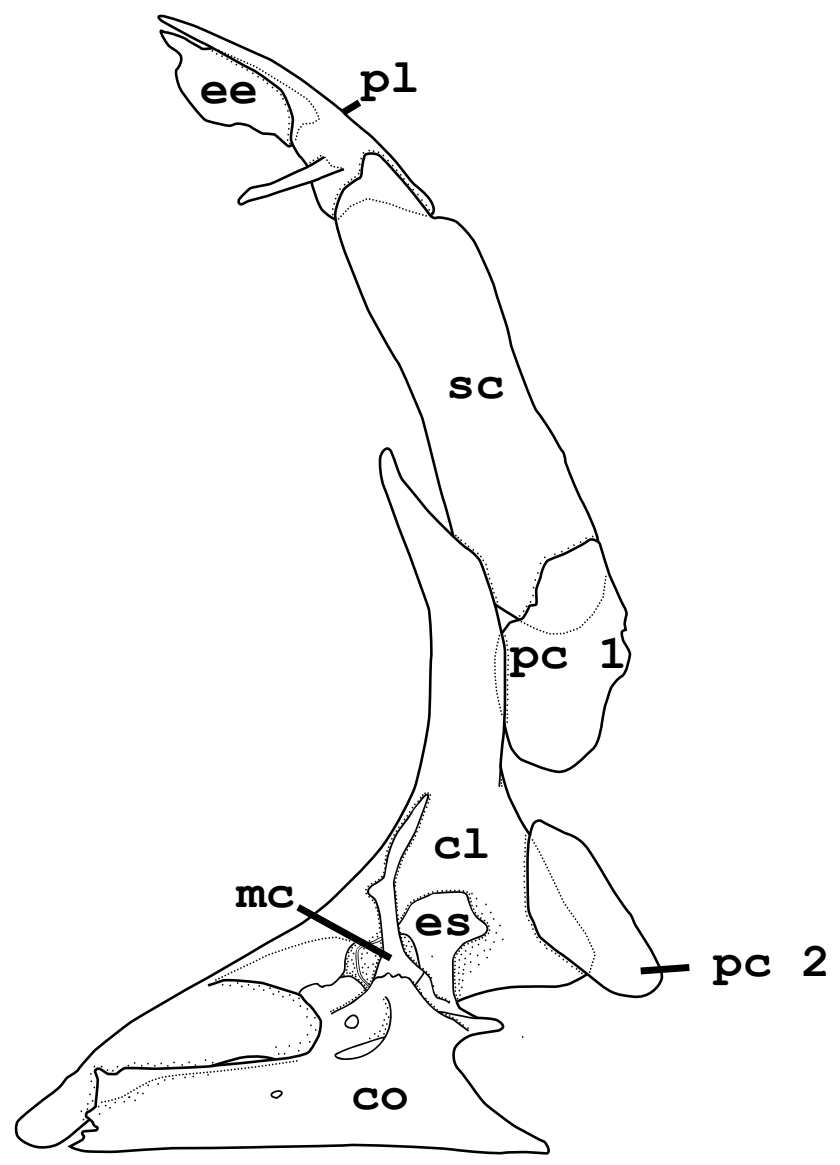

Figura 47. Vista medial da cintura peitoral direita de Acestrorynchus falcirostris (MZUSP 36824). Anterior para esquerda. $\mathbf{c l}=$ cleitro, $\mathbf{c o}=$ coracóide, ee = extra-escapular, es $=$ escápula, $\mathbf{m c}=$ mesocoracóide, pc $\mathbf{1 - 2}=$ pós-cleitros, pl = pós-temporal, $\mathbf{s c}=$ supracleitro. Barra de escala $=5 \mathrm{~mm}$. 


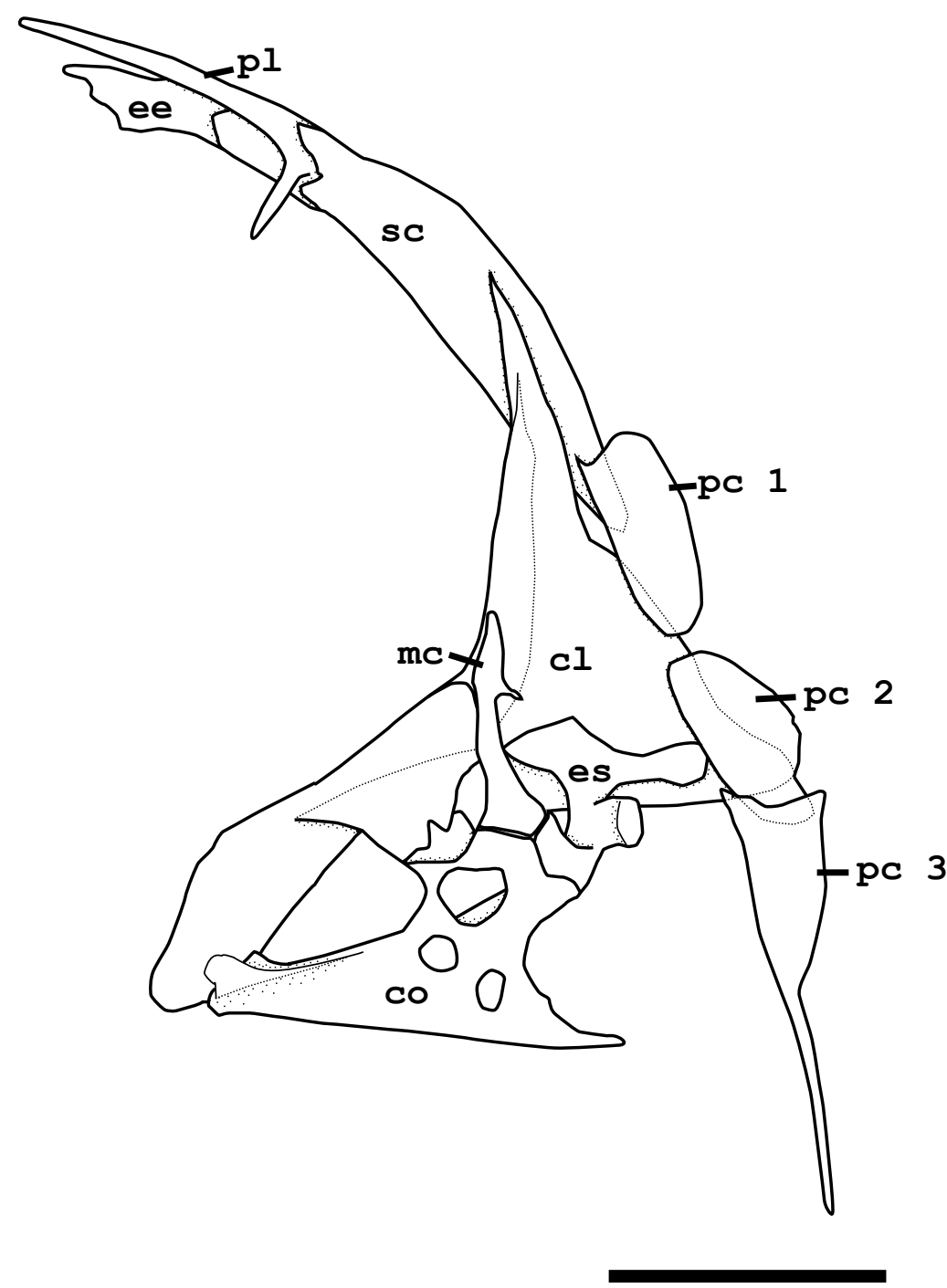

Figura 48. Vista medial da cintura peitoral direita de Hemiodus unimaculatus (MZUSP 83937). Anterior para esquerda. $\mathbf{c l}=$ cleitro, $\mathbf{c o}=$ coracóide, ee = extra-escapular, es = escápula, $\mathbf{m c}=$ mesocoracóide, pc $\mathbf{1 - 3}=$ pós-cleitros, pl = pós-temporal, $\mathbf{s c}=$ supracleitro. Barra de escala $=10 \mathrm{~mm}$. 


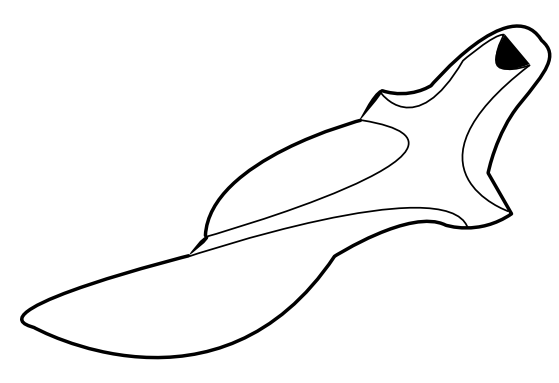

A

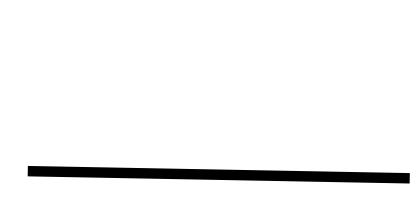

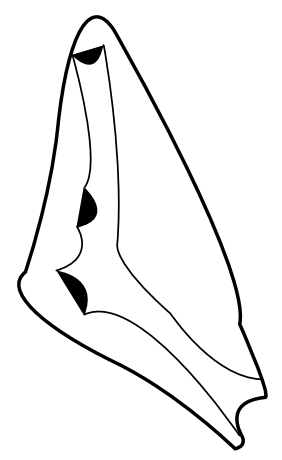

B

Figura 49. Vista lateral do extra-escapular de: (A) Bivibranchia fowleri (MZUSP 29628) e (B) Hollandichthys multifasciatus (MZUSP 78956). Anterior para esquerda. Barra de escala = $1 \mathrm{~mm}$. 

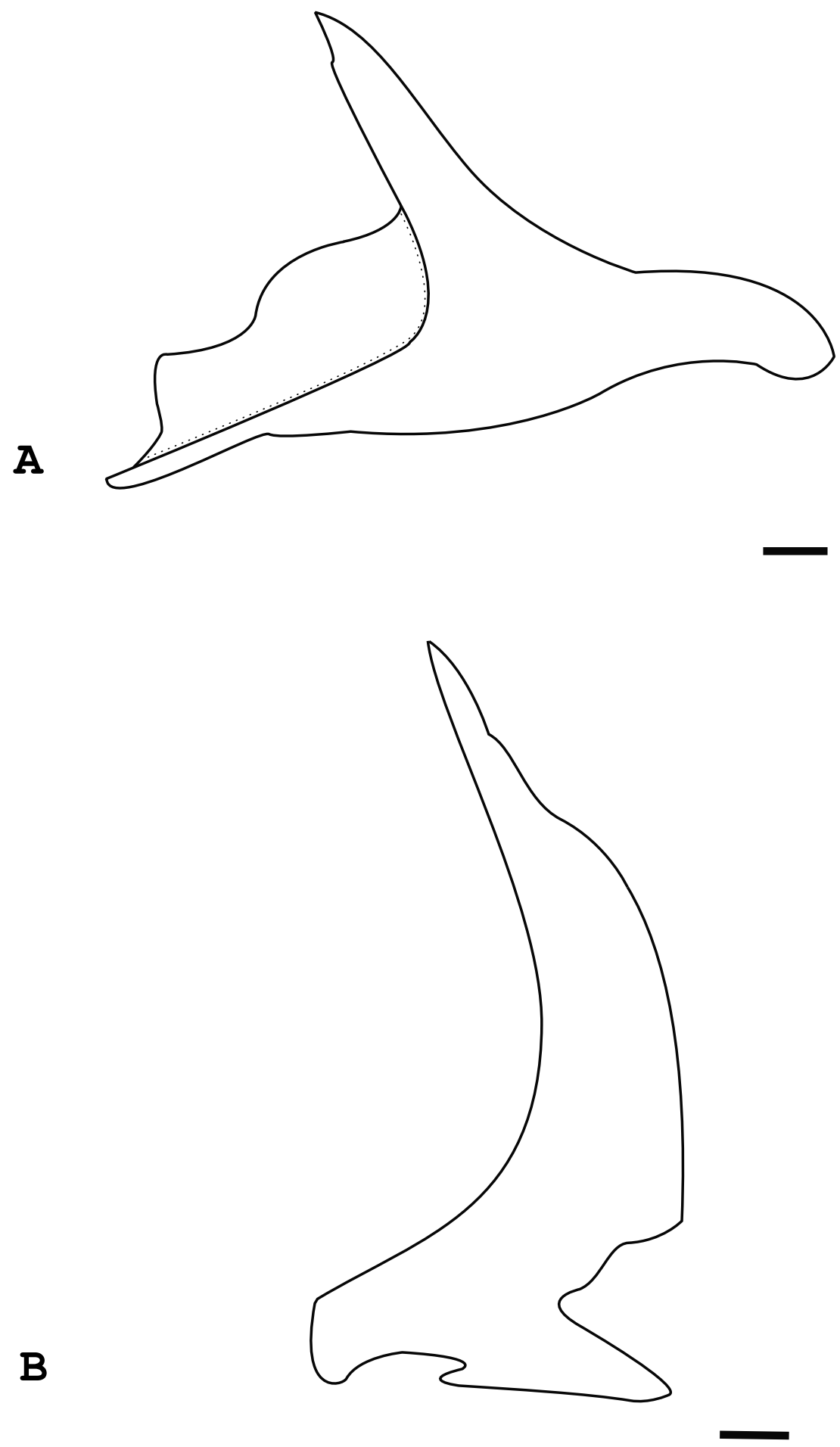

Figura 50. Vista lateral do cleitro de: (A) Apareiodon piracicabae (MZUSP 53885) e (B) Charax cf. leticiae (MZUSP 59511). Anterior para esquerda. Barra de escala $=1 \mathrm{~mm}$.

390 

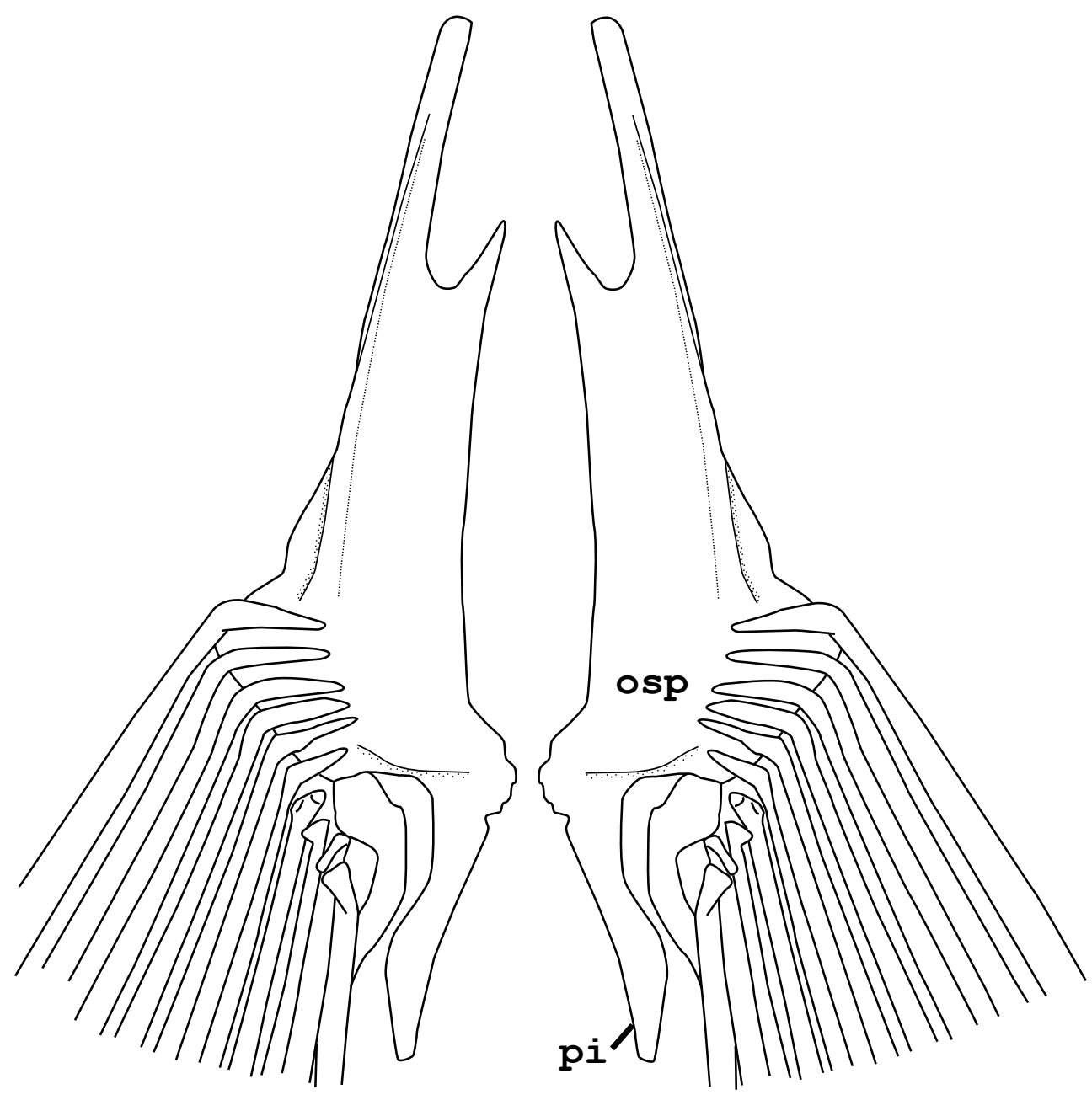

Figura 51. Vista dorsal da cintura pélvica de Xenocharax spilurus (AMNH 230302). osp = osso pélvico e pi = processo isquiático. Esquírola pélvica não representada. Barra de escala $=2 \mathrm{~mm}$. 


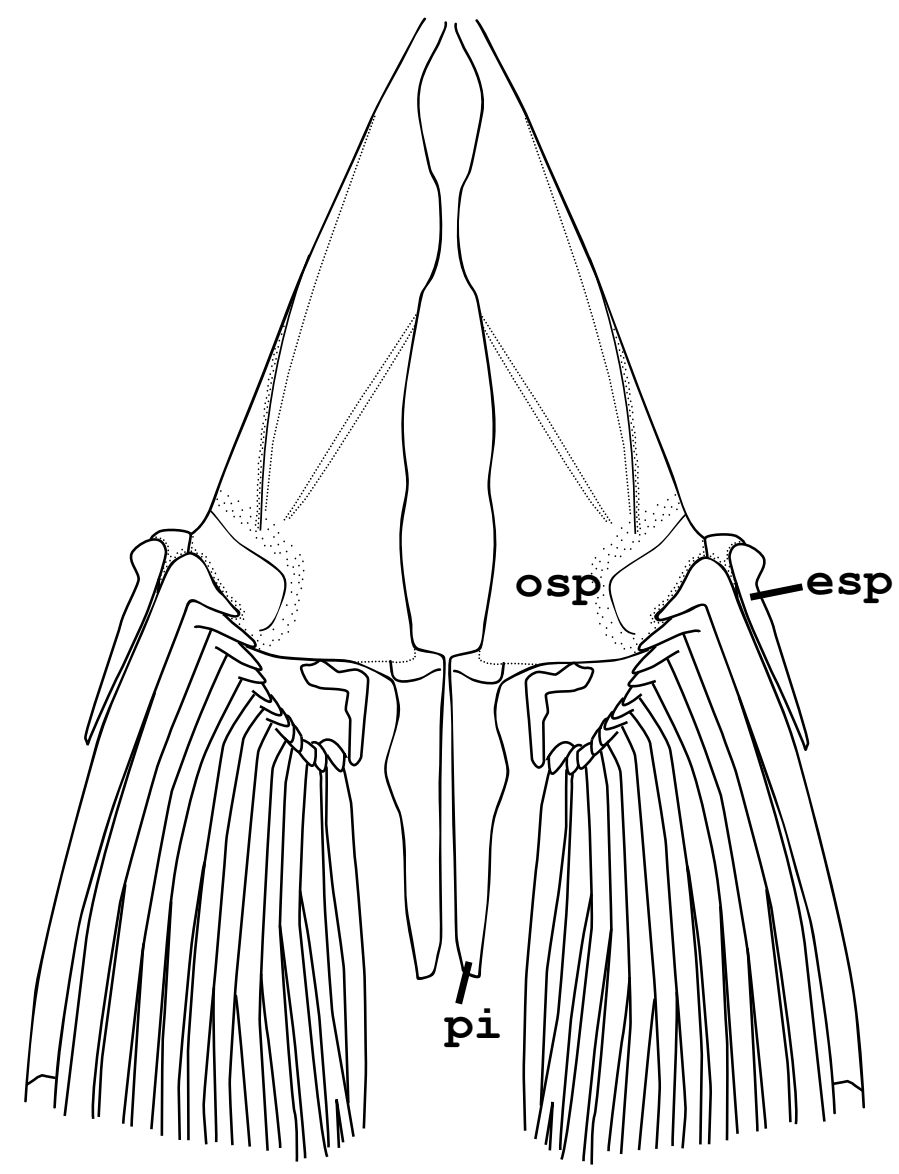

Figura 52. Vista dorsal da cintura pélvica de Anodus orinocensis (MZUSP 21280). osp = osso pélvico, esp = esquírola pélvica e pi $=$ processo isquiático. Barra de escala $=3 \mathrm{~mm}$. 


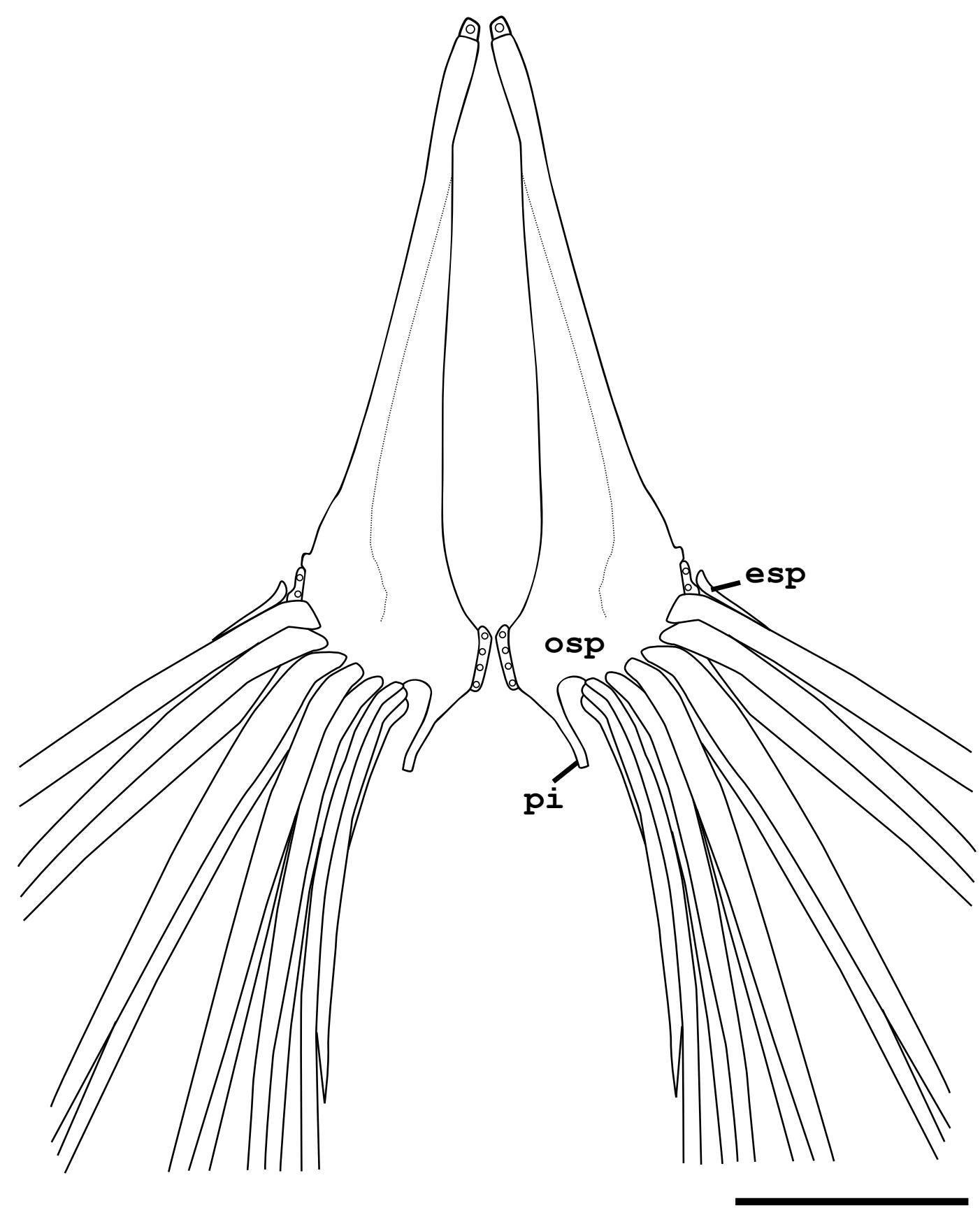

Figura 53. Vista dorsal da cintura pélvica de Hollandichthys multifasciatus (MZUSP 78956). osp = osso pélvico, esp = esquírola pélvica e pi = processo isquiático. Barra de escala = $2 \mathrm{~mm}$. 


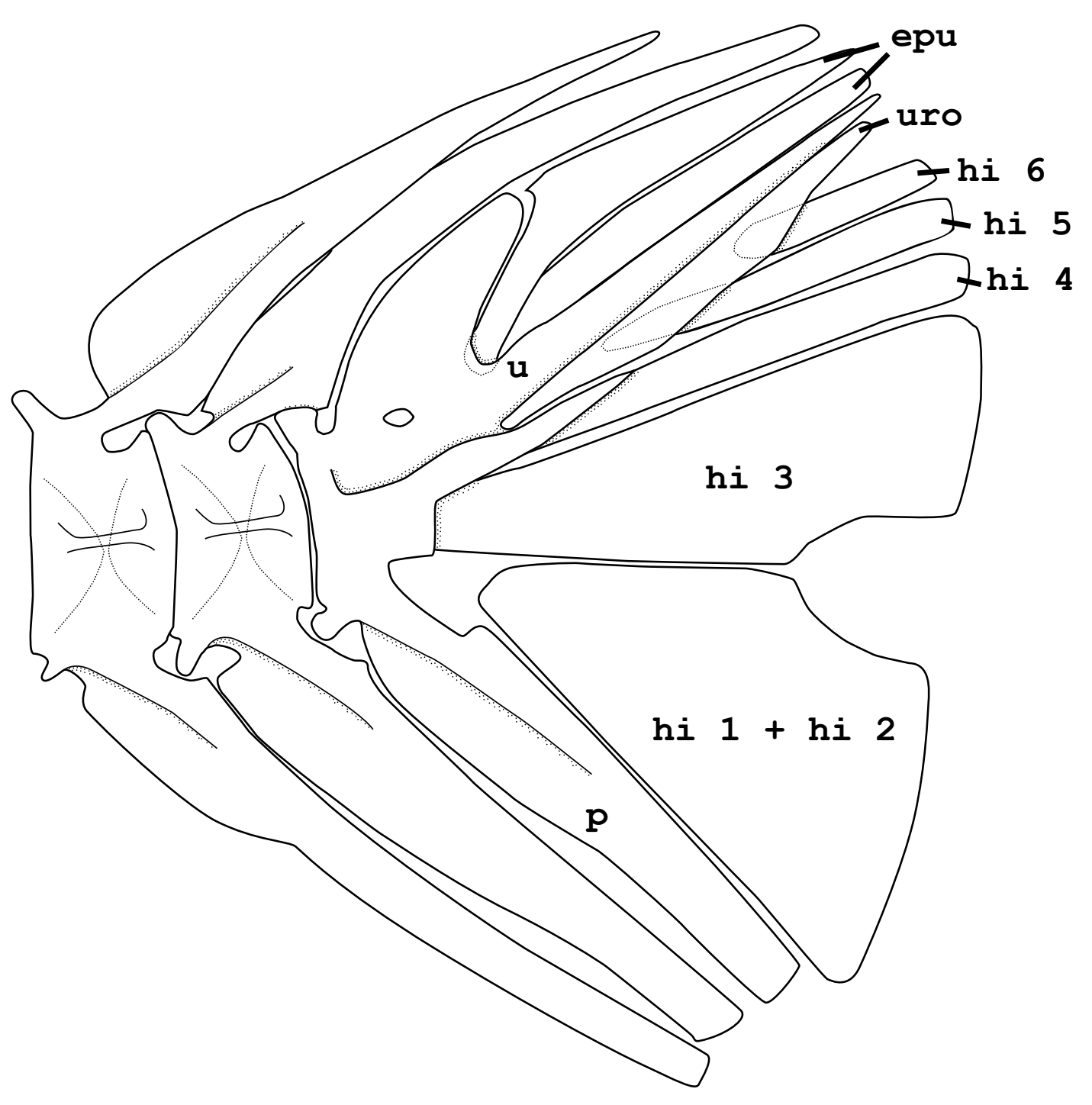

Figura 54. Vista lateral do esqueleto caudal e vértebras associadas de Xenocharax spilurus (AMNH 230302). epu = epural, hi $\mathbf{1 - 6}$ = hipurais, $\mathbf{p}=$ paripural, $\mathbf{u}=$ uróstilo e uro = uroneural. Barra de escala $=3 \mathrm{~mm}$. Anterior para esquerda. Barra de escala $=5 \mathrm{~mm}$. 


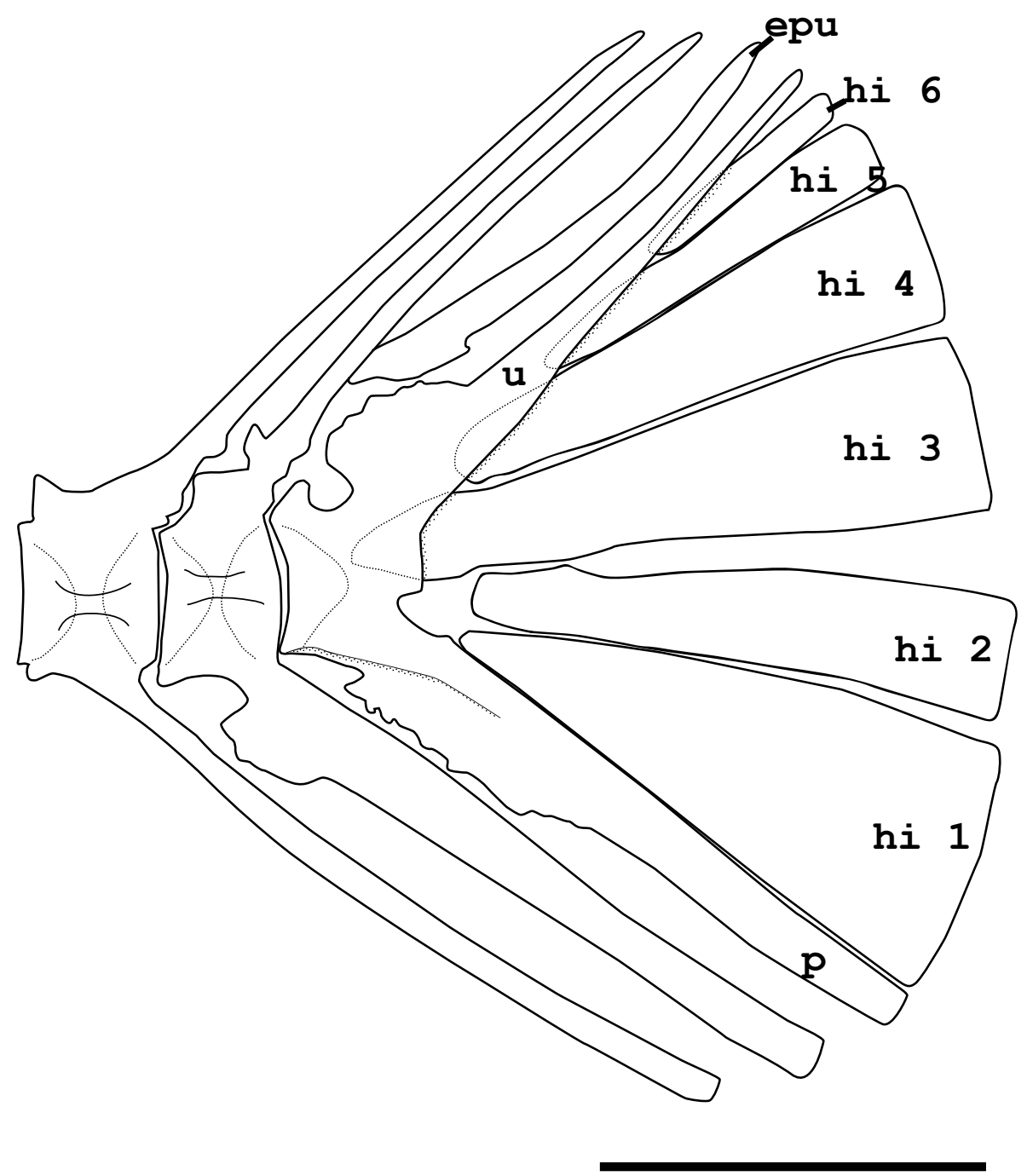

Figura 55. Vista lateral do esqueleto caudal e vértebras associadas de Erythrinus erythrinus (MZUSP 44564). epu = epural, hi $\mathbf{1 - 6}=$ hipurais, $\mathbf{p}=$ paripural e $\mathbf{u}=$ uróstilo. Barra de escala $=3 \mathrm{~mm}$. Anterior para esquerda. Barra de escala $=5 \mathrm{~mm}$. 


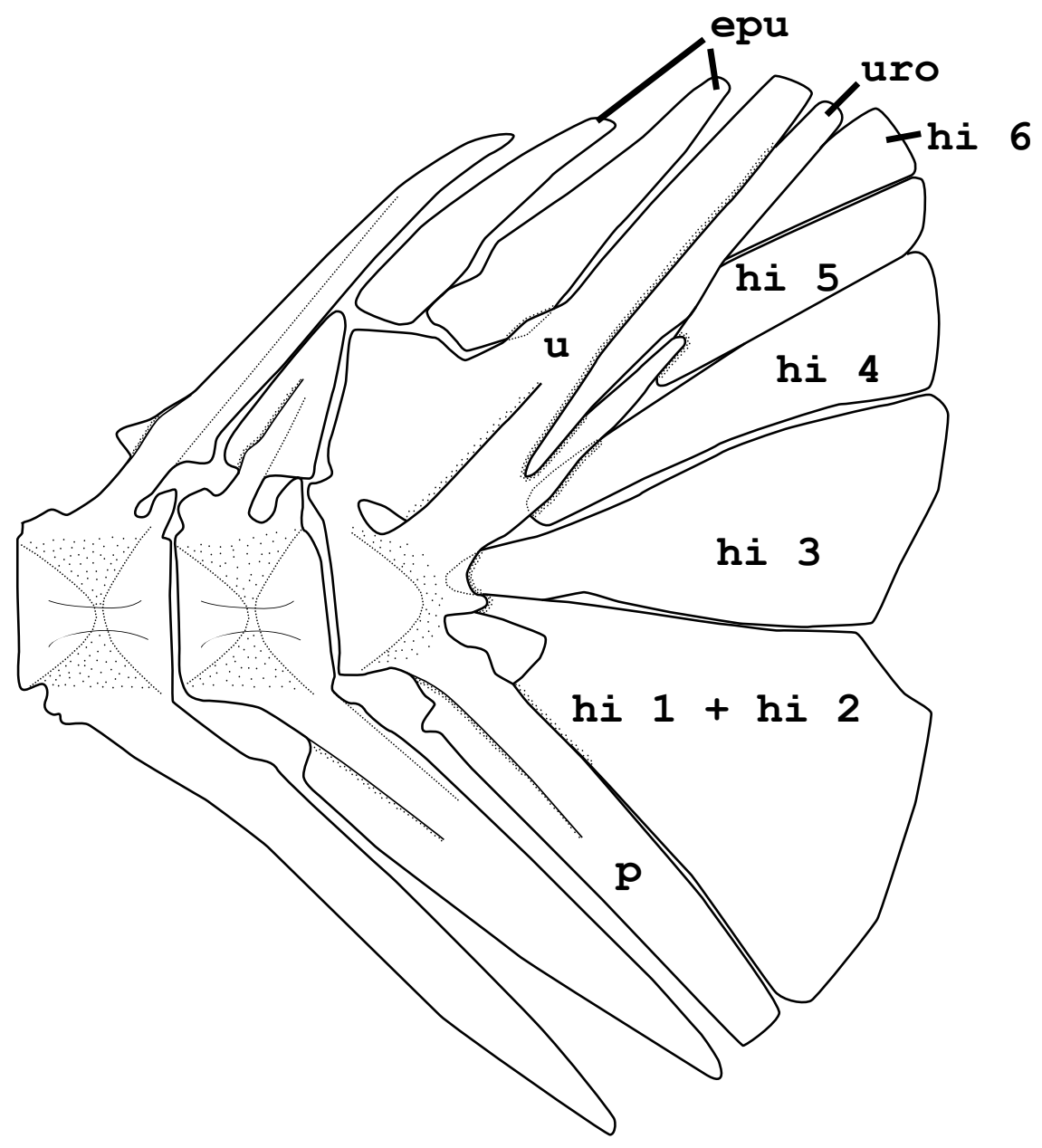

Figura 56. Vista lateral do esqueleto caudal e vértebras associadas de Metynnis lippincottianus (MZUSP 6888). Anterior para esquerda. epu = epural, hi $\mathbf{1 - 6}=$ hipurais, $\mathbf{p}=$ paripural, $\mathbf{u}=$ uróstilo e uro = uroneural. Barra de escala $=3$ $\mathrm{mm}$. 


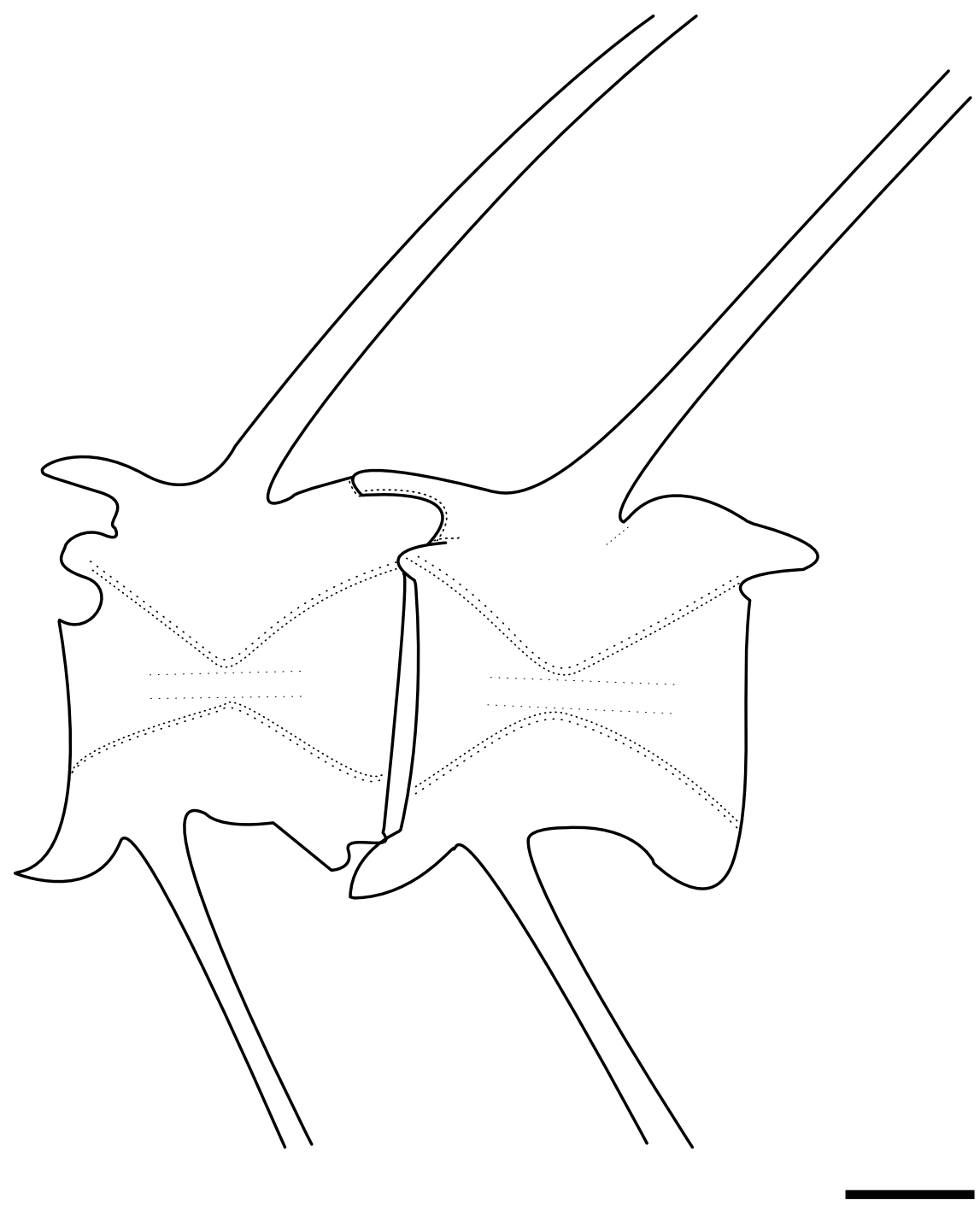

Figura 57. Vista lateral das vértebras caudais anteriores de Bryconops alburnoides (MZUSP 34590). Anterior para esquerda. Barra de escala $=1 \mathrm{~mm}$. 


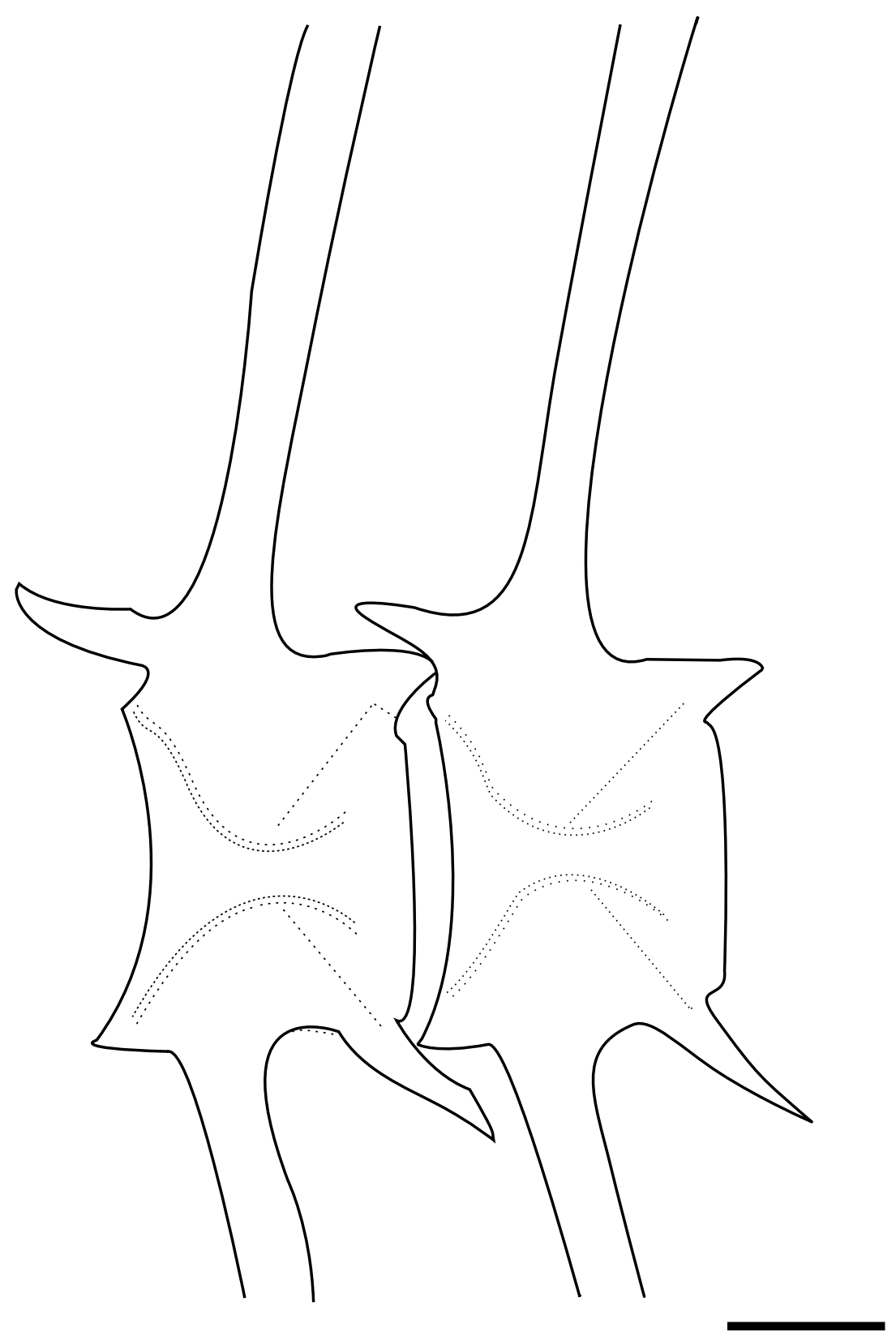

Figura 58. Vista lateral das vértebras caudais anteriores de Metynnis lippincottianus (MZUSP 6888). Anterior para esquerda. Barra de escala $=1 \mathrm{~mm}$. 

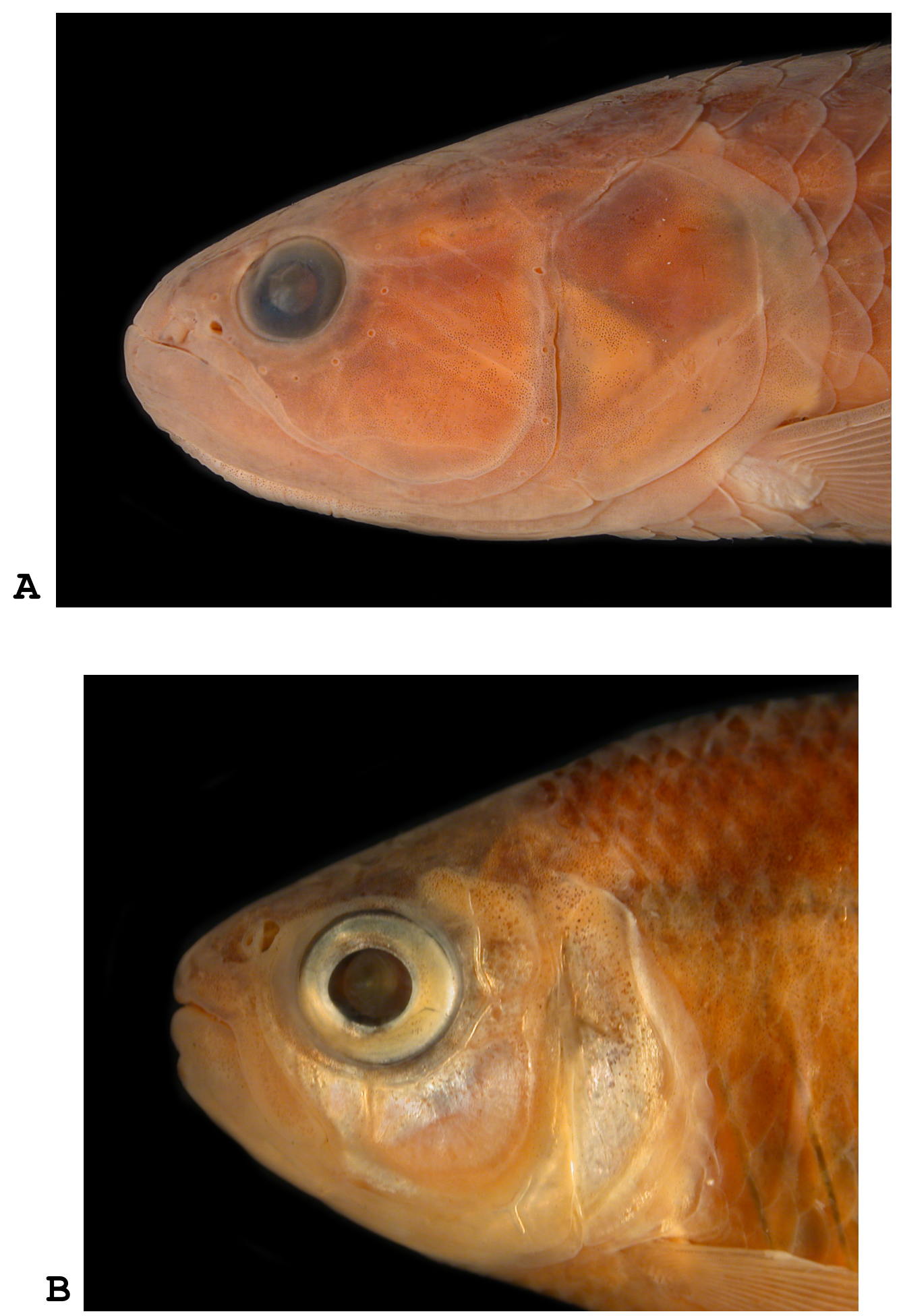

Figura 59. Vista lateral da cabeça de (A) Erythrinus erythrinus (MZUSP 44564), 129,8 mm CP, e (B) Astyanax mexicanus (UMMZ 203208), 62,96 mm CP. 

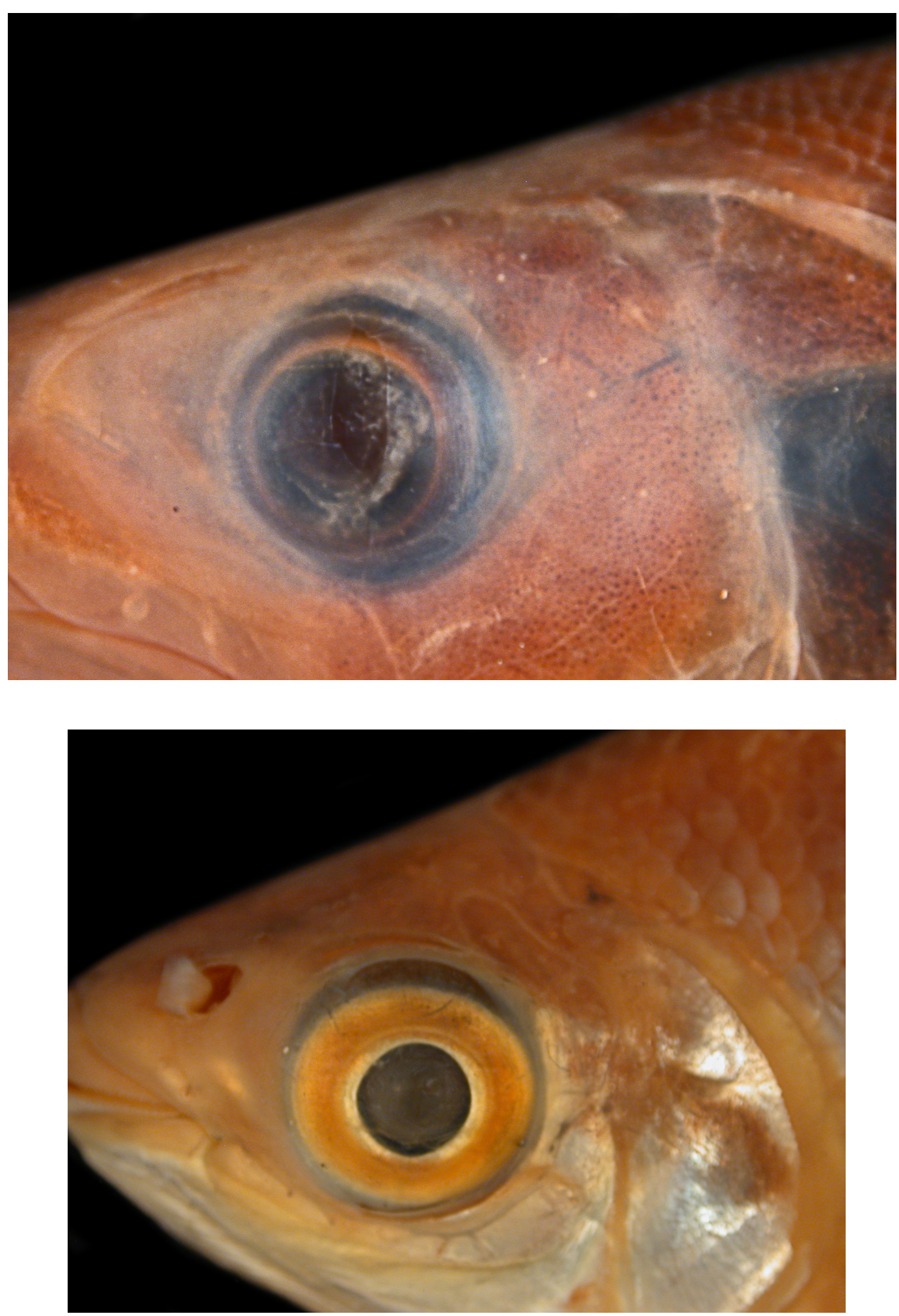

Figura 60. Vista lateral do olho de (A) Anodus orinocensis (MZUSP 21280), 153,3 mm CP e (B) Prochilodus nigricans (MZUSP $4837), 116,3 \mathrm{~mm} \mathrm{CP}$. 
Cladograma 0:

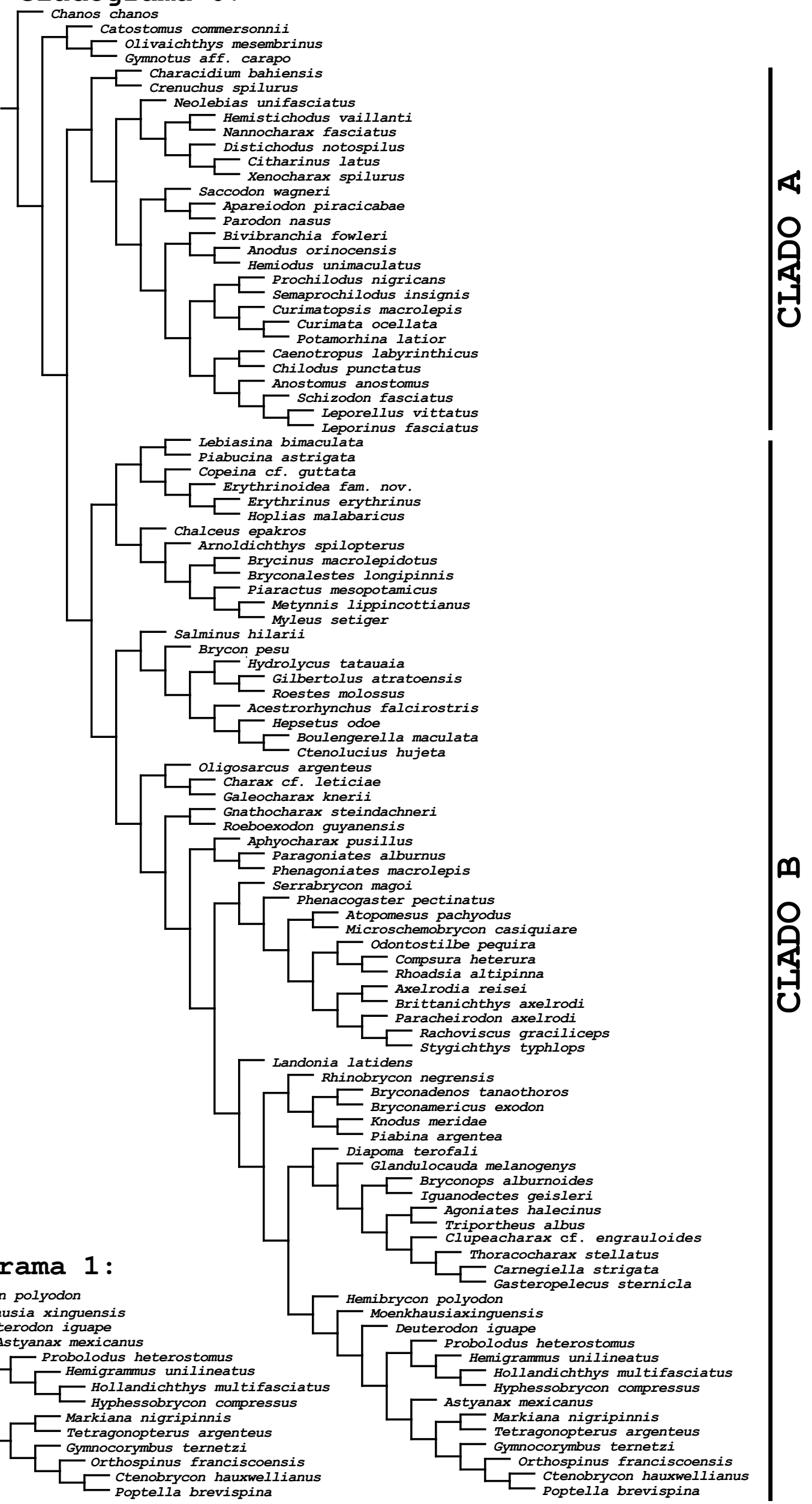

Figura 61. Cladogramas fundamentais mais parcimoniosos com CI $=0,11, \mathrm{RI}=0,53$ e 5.163 passos. 


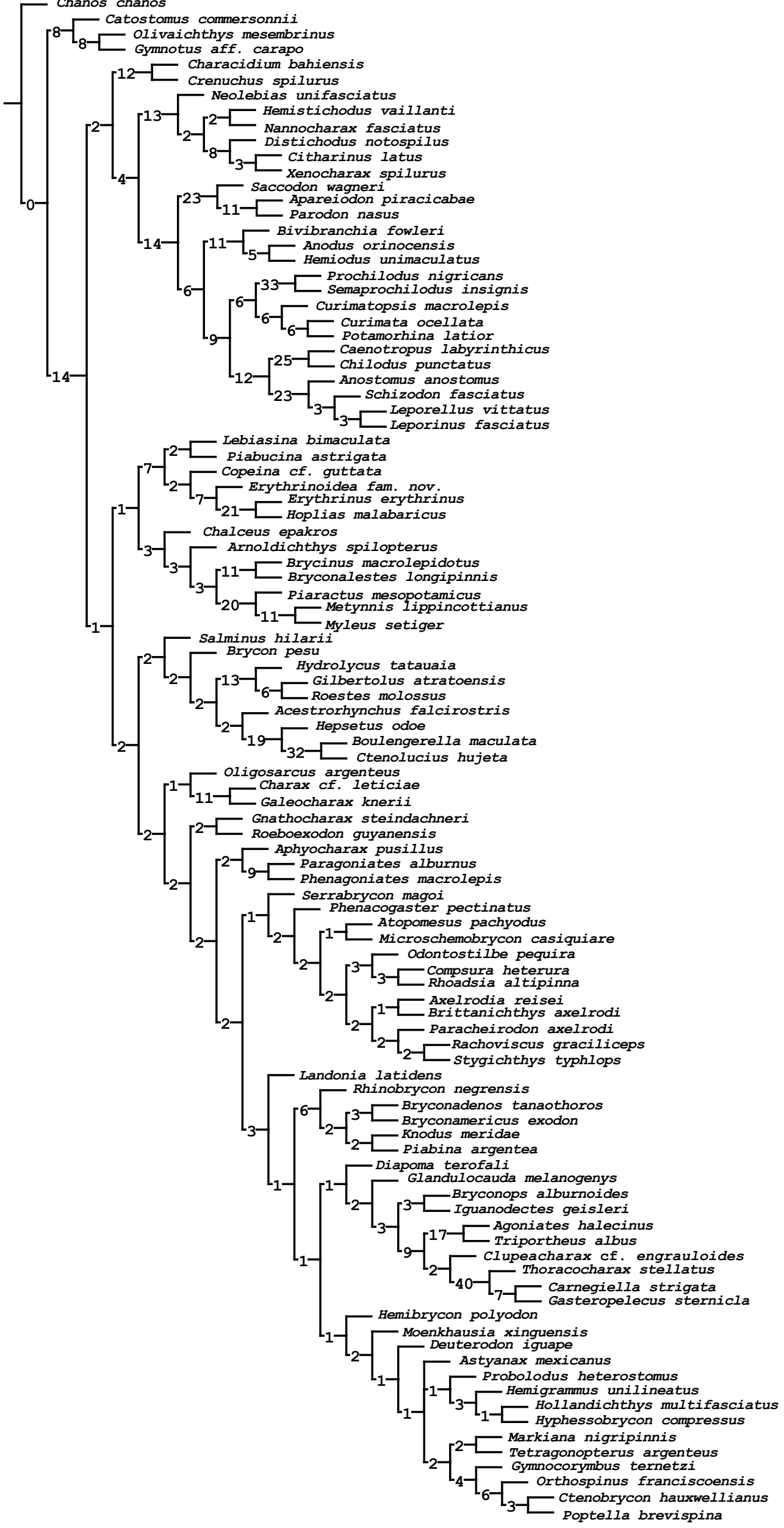

Figura 62. Cladograma de consenso estrito com o suporte de Bremer para os ramos. 
Cladograma 0 :

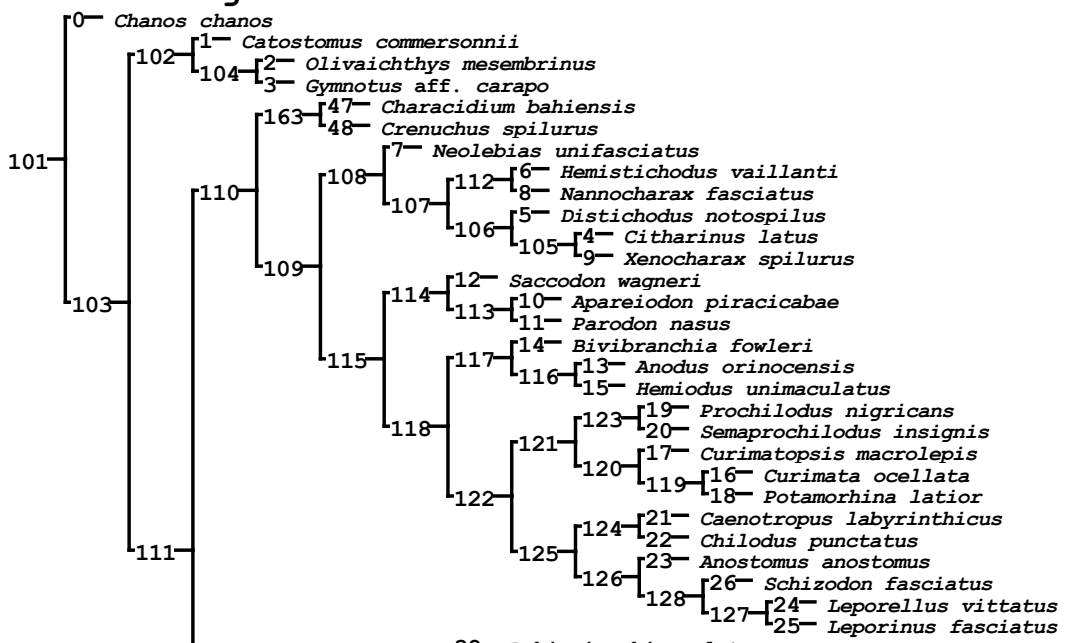

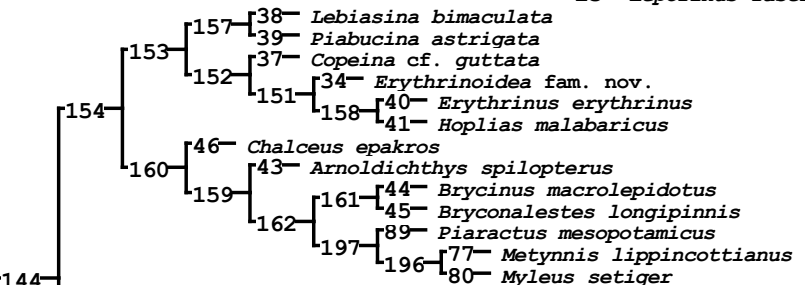

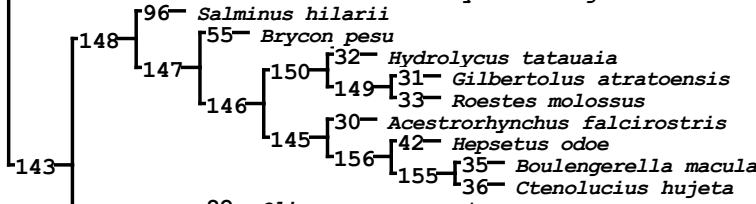

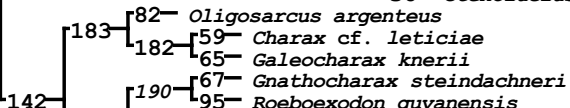

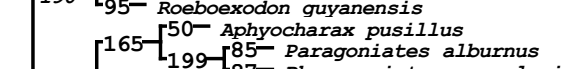

Cladograma 1 :
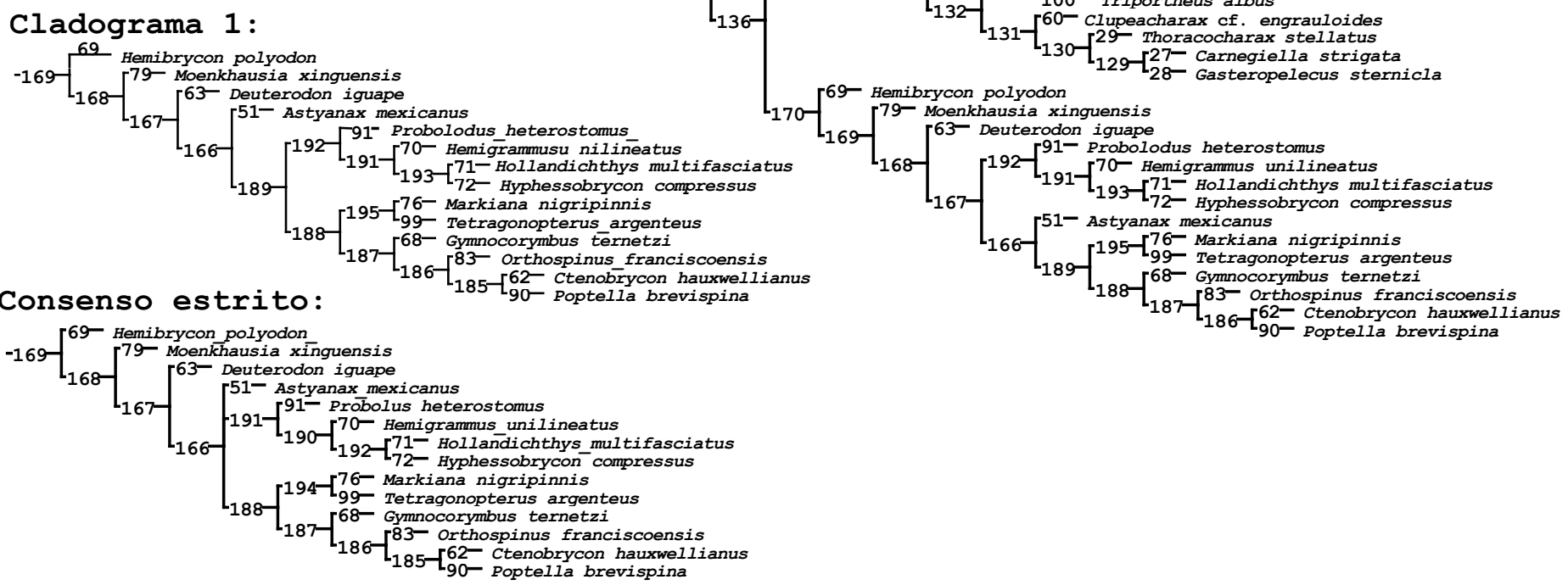

Figura 63. Número dos clados referidos no texto e as varia- 
Apêndice 1. Lista das transições por caráter e número de passos de cada caráter. Números dos clados se referem aos dois cladogramas fundamentais.

Cladograma A :

Caráter $\odot$ (13 passos)

Raiz: 1

Clado 102: $1 \rightarrow 0$

Gymnotus aff. carapo: $\odot->2$

Characidium bahiensis: $1 \rightarrow$

Clado $114: 1 \rightarrow 0$

Copeina cf. guttata: $1 \rightarrow 2$

Gnathocharax steindachneri: 1 -> 2

Clado 126: $1 \rightarrow 012$

Anostomus anostomus: $012->2$

Schizodon fasciatus: $01 \rightarrow 0$

Leporellus vittatus: $01 \rightarrow 0$

Leporinus fasciatus: $01 \rightarrow 1$

Glandulocauda melanogenys: 1 -> 2

Clado 130: $1 \rightarrow 2$

Triportheus albus: 1 -> 2

Caráter 1 (17 passos)

Raiz: 1

Clado 102: 1 -> 01

Catostomus commersonnii: $01->0$

Olivaichthys mesembrinus: $01 \rightarrow$

Gymnotus aff. carapo: $01-1$

Clado 143: 1 -> 2

Crenuchus spilurus: 1 -> 0

Clado 190: 2 ->

Clado 151: $1 \rightarrow 2$

Clado 121: $1 \rightarrow 0$

Clado 145: $2 \rightarrow 1$

Clado 197: 1 -> 2

Clado 156: $1 \rightarrow 0$

Gilbertolus atratoensis: $2 \rightarrow 1$

Rhinobrycon negrensis: 2 -> 1

Clado 177: 2 -> 12

Clado 185: $12 \rightarrow 1$

Clado 175: $12 \rightarrow 1$

Clado 198: $12 \rightarrow>2$

Iguacladoctes geisleri: 2 -> 1

clado 130: $2 \rightarrow 1$

Hyphessobrycon compressus: 2 -> 1

Caráter 2 (25 passos)

Caráter 2

Catostomus commersonnii: 1 -> $\theta$

Clado 110: $1 \rightarrow \odot$

Roeboexodon guyanensis: 1 -> $\odot$

Charax cf. leticiae: 1 -> 0

Clado 150: 1 -> 01

Aphyocharax pusillus: $01->0$

Hydrolycus tatauaia: $01->0$

Piaractus mesopotamicus: $1 \rightarrow 0$

Landonia latidens: $1 \rightarrow 0$

Paragoniates alburnus: $01->1$

Phenagoniates macrolepis: $01 \rightarrow 0$

Gilbertolus atratoensis: $01 \rightarrow 0$

Roestes molossus: $01 \rightarrow 1$

Clado 135: $1 \rightarrow 0$

Clado 171: 1 -> 0

Moenkhausia xinguensis: $1 \rightarrow 0$

Bryconamericus exodon: $1 \rightarrow 0$

Knodus meridae: 1 - $\rightarrow$

Brittanichthys axelrodi: $1 \rightarrow 0$

Iguacladoctes geisleri: $0 \rightarrow 1$

stygichthys typhlops: $1 \rightarrow 0$

Triportheus albus: $\odot->1$

Ariportheus albus: $1>1$

Clado 129: $0 \rightarrow 1$

Markiana nigripinnis: 1 ->

Markiana nigripinnis: $1->0$

Orthospinus franciscoensis: 1 -> $\odot$

Caráter 3 (16 passos)

Raiz: 1

Catostomus commersonnii: 1 -> 0

Clado 115: $1 \rightarrow 01$

Characidium bahiensis: 1 -> 0

Clado 114: 01 ->

Salminus hilarii: $1 \rightarrow$

Clado 151: $1 \rightarrow 0$

Bivibranchia fowleri: 01 -> 0

Clado 116: $01 \rightarrow 1$

Clado 121: $01 \rightarrow 1$

Clado 125: $01 \rightarrow 0$

Roeboexodon guyanensis: 1 -> $\odot$

Clado 145: $1 \rightarrow 12$

Aphyocharax pusillus: 1 -> 0

Acestrorhynchus falcirostris: $12 \rightarrow 2$

Hepsetus odoe: 12 ->

Clado 155: $12 \rightarrow 2$

Gilbertolus atratoensis: 1 -> 0

Atopomesus pachyodus: 1 -> 0

Clado 132: 1 -> 01

Brittanichthys axelrodi: 1 -> 0

Clado 164: $01 \rightarrow 0$

Clupeacharax engrauloides: 01 -> 0

Clado 130: $01 \rightarrow 1$

Caráter 4 ( 3 passos)

Raiz: $\odot$
Clado 110: $\odot \rightarrow 01$

Clado 163: $01 \rightarrow 1$

Clado 108: $01 \rightarrow 1$

Clado 118: 01 -> 0

Saccodon wagneri: $01 \rightarrow 0$

Clado 113: 01 -> 1
Caráter 5 (2 passos)

Raiz: 0

Clado 144: $0->1$

Clado 125: $0 \rightarrow 1$

Caráter 6 (15 passos)

Raiz: 0

Clado 108: $\odot->01$

Neolebias unifasciatus: 01 -> 1

Salminus hilarii: $0->1$

Chalceus epakros: $012->2$

Clado 159: $012 \rightarrow 1$

Clado 112: $\bullet 12 \rightarrow \odot$

Brycon pesu: $0->0$

Distichodus notospilus: 01 -> 1

Clado 139: $\odot \rightarrow 1$

Galeocharax knerii: 0 -> 1

Erythrinoidea fam. nov: $0->1$

Citharinus latus: 01 -> $\odot$

Xenocharax spilurus: 01 ->

$\begin{array}{lll}\text { Clado 172: } & 1 \rightarrow 0 \\ \text { Clado 200: } & 0 & \rightarrow\end{array}$

Clado 200: $0->1$

Probolus heterostomus : $1 \rightarrow$

Clado 129: 1 -> 0

Caráter 7 ( 39 passos)

Raiz: 4

$\begin{array}{lll}\text { Clado } 114: & 4 & -> \\ \text { Clado 159: } & ->1\end{array}$

Nannocharax fasciatus: $4 \rightarrow 2$

Clado 139: 4 -> 34

Erythrinoidea fam. nov: 4 -> 3

Clado 126: $4 \rightarrow 2$

Clado 138: $34 \rightarrow>2$

Landonia latidens: $2 \rightarrow 1$

Serrabrycon magoi: $34 \rightarrow$

Hepsetus odoe: 4 -> 1

Phenacogaster pectinatus: $34->4$

Rhinobrycon negrensis: $2 \rightarrow 3$

Hemibrycon polyodon : 2 -> 3

Clado 178: $2 \rightarrow 1$

Clado 133: $2 \rightarrow 12$

Clado 168: $2 \rightarrow 12$

Bryconadenos tanaothoros: 1 -> 0

Piabina argentea: $2 \rightarrow 3$

Deuterodon iguape: 12 -> 1

Bryconops alburnoides: 12 -> 3

Iguacladoctes geisleri: $12 \rightarrow 0$

Clado 166: $12 \rightarrow 2$

Rachoviscus graciliceps: $34->0$

Stygichthys typhlops: 34 -> 4

Agoniates halecinus: $12->1$

Triportheus albus: $12 \rightarrow 3$

Probolus heterostomus : $12->1$

Clado 195: 2 -> 3

Hemigrammus unilineatus: $12->2$

Clado 193: $12 \rightarrow 1$

Gymnocorymbus ternetzi: 2 -> 1

Tetragonopterus argenteus: $3 \rightarrow 4$

Caráter 8 ( 9 passos)

Raiz: 1

Clado 162: 1 ->

Clado 138: $1 \rightarrow$

Clado 134: $0 \rightarrow>1$

Clado 169: $\odot \rightarrow 1$

Compsura heterura: $1 \rightarrow 0$

Agoniates halecinus: $1 \rightarrow 0$

Astyanax mexicanus: $1 \rightarrow \odot$

Astyanax mexicanus: $1->0$

Ctenobrycon hauxwellianus: $1 \rightarrow \odot$

Caráter 9 ( $\odot$ passos)

Caráter 9

Caráter 10 (12 passos)

Raiz: 12

Clado 104: 12 -> 1

Clado 109: $12 \rightarrow 012$

Clado 143: 12 -> 1

Clado 108: $012 \rightarrow$

Clado 115: 012 -> 2

Characidium bahiensis: $12->1$

Crenuchus spilurus: $12 \rightarrow 2$

Clado 160: $12 \rightarrow 2$

Clado 152: $12 \rightarrow 1$

Clado 157: $12 \rightarrow 2$

Clado 140: 1 -> 2

Oligosarcus argenteus: 1 -> 12

Brycon pesu: $1 \rightarrow 2$

Clado 121: 2 -> 23

Clado 123: $23 \rightarrow 3$

Clado 124: $2 \rightarrow 1$

Atopomesus pachyodus: 2 ->

Clado 175: 2 -> 1

Caráter 11 (14 passos)

Raiz: 1

Olivaichthys mesembrinus: 1 -> 2

Clado 160: $1 \rightarrow 0$

Brycon pesu: $1 \rightarrow 0$

Clado 139: 1 -> 01

Roeboexodon guyanensis: 1 -> 0

Clado 126: 1 -> 0

Clado 174: $01->0$

Landonia latidens: $01 \rightarrow 1$

Clado 137: 01 -> 0

Atopomesus pachyodus: $0->1$

Clado 185: $0 \rightarrow 1$

Axelrodia reisei: 0 -> 1

Stygichthys typhlops: $0->1$

Agoniates halecinus: $0 \rightarrow 1$

Probolus heterostomus : $0->2$

Caráter 12 (11 passo)

Caráter

Raiz: 0

$\begin{array}{ll}\text { Clado 110: } 0 & ->01 \\ \text { Clado 109: } 01 \text {-> } 1\end{array}$

Characidium bahiensis: $01->0$

Characidium bahiensis: $01 \overrightarrow{->}$

Crenuchus spilurus:

Landonia latidens: $0 \rightarrow 1$

Phenagoniates macrolepis: 0 -> 1

Clado 185: $\odot \rightarrow 01$

Bryconadenos tanaothoros: 0 -> 1

Odontostilbe pequira: $01-1$

Clado 181: $0 \rightarrow 1$

Paracheirodon axelrodi: $\odot->1$

Compsura heterura: $01 \rightarrow 1$

Rhoadsia altipinna: $01 \rightarrow 0$

Hyphessobrycon compressus: $\odot \rightarrow 1$

Caráter 13 ( 8 passos)

Raiz: 0

Olivaichthys mesembrinus: 0 -> 1

Clado 109: $0 \rightarrow 1$

Clado 122: $1 \rightarrow 12$

Clado 121: $12 \rightarrow>2$

Xenocharax spilurus: $1 \rightarrow 0$

Anodus orinocensis: $1 \rightarrow 3$

Clado 120: 2 -> 3

Clado 124: 12 -> 2

Clado 126: 12 -> 1

Carater 14

Raiz: 0

Clado 148: $\odot \quad->02$

Clado 159: $\odot \rightarrow>2$

Brycon pesu: $02->$

Clado 137: $0 \rightarrow 02$

Rhinobrycon negrensis: $02->2$

Clado 134: $02 \rightarrow 0$

Hemibrycon polyodon : $02->0$

Clado 169: $02 \rightarrow 2$

Clado 178: $02 \rightarrow>0$

Clado 194: 02 -> 2

Clado 192: 2 -> 02

Triportheus albus: $\odot->2$

Clado 191: $02 \rightarrow 0$

Gymnocorymbus ternetzi: 2 -> 0

Caráter 15 ( 2 passos)

Raiz: 0

Clado 115: $\odot \rightarrow 1$

Clado 125: $1 \rightarrow 0$

Caráter 16 (4 passos)

Raiz: 0

Clado 182: $\odot \rightarrow 1$

Clado 146: $0 \rightarrow 1$

Clado 158: $\theta->1$

Caráter 17 (14 passos)

Raiz: 1

Clado 144: $1 \rightarrow 0$

Crenuchus spilurus: $1->0$

Copeina cf. guttata: $\odot \rightarrow 1$

Lebiasina bimaculata: $0->1$

Clado 161: $\odot \rightarrow 1$

Xenocharax spilurus: $1 \rightarrow 0$

Anodus orinocensis: 1 -> 0

Semaprochilodus insignis: 1 -> 0

Myleus setiger: $0 \rightarrow 1$

Clado 171: $\theta \rightarrow 1$

Moenkhausia xinguensis: $0 \rightarrow 1$

Rhoadsia altipinna: $0->1$

Iguacladoctes geisleri: $0 \rightarrow 1$

Clado 130: $0 \rightarrow 1$

Caráter 18 (6 passos)

Raiz: 0

Clado 182: $0 \rightarrow 1$

Gnathocharax steindachneri: 0 -> 1

Clado 150: $\odot \rightarrow 1$

Bryconamericus exodon: $0 \rightarrow 1$

Iguacladoctes geisleri: $0 \rightarrow 1$

Clupeacharax engrauloides: $0 \rightarrow 1$

Caráter 19 ( 2 passos)

Raiz: 0 
Raiz: 1

Clado 111: $1 \rightarrow 0$

Charax cf. leticiae: $0->1$

Clado 161: $0 \rightarrow 1$

Anodus orinocensis: $0->$

Acestrorhynchus falcirostris: 0 -> 1

Agoniates halecinus: $0 \rightarrow 1$

Caráter 21 (9 passos)

Raiz: 0

$\begin{array}{lll}\text { Clado } 115: & 0->01 \\ \text { Clado } 114: & 01 \rightarrow 1\end{array}$

Clado 117: $01 \rightarrow 0$

Clado 162: 0 -> 01

Clado 121: $01->1$

Clado 161: $01->1$

Clado 124: $01 \rightarrow 0$

Clado 126: $01->2$

Piaractus mesopotamicus: $01->0$

Clado 196: $01 \rightarrow 1$

Clado 155: $0 \rightarrow 2$

Potamorhina latior: 1 ->

Caráter 22 (16 passos)

Raiz: 0

clado 104: $\odot \rightarrow 01$

Olivaichthys mesembrinus: 01 ->

Clado 115: $0 \rightarrow 01$

Crenuchus spilurus: $0->1$

Clado 160: $0 \rightarrow 1$

Clado 114: $01 \rightarrow>1$

$\begin{array}{lll}\text { Clado 117: } & 01->1 \\ \text { Clado 122: } & 01-> & 0\end{array}$

Roeboexodon guyanensis: $\odot \rightarrow 1$

Clado 145: $\odot \rightarrow 1$

Clado 197: $1 \rightarrow 0$

Paragoniates alburnus: $\odot$-> 1

Curimata ocellata: $0->1$

Clado 180: 0 -> 01

Rhinobrycon negrensis: 01 -> 1

Clado 178: 01 ->

Clado 194: $01 \rightarrow$

Microschemobrycon casiquiare: 0 -> 1

Hemigrammus unilineatus: $0 \rightarrow 1$

Markiana nigripinnis: $0 \rightarrow 1$

Maptella brevispina: $0 \rightarrow 1$

Caráter 23 (4 passos)

Raiz: 1

Catostomus commersonnii: 1 -> $\odot$

Clado 109: $1 \rightarrow 0$

Clado 121: $\odot \rightarrow 1$

Clado 121: $0 \rightarrow 1$

Caráter 24 ( 3 passos)

Caráter 24

Hemistichodus vaillanti: $0->1$

Clado 155: $0 \rightarrow 1$

Schizodon fasciatus: $\odot->1$

Caráter 25 (15 passos)

Raiz: 01

Chanos chanos: $01 \rightarrow$

Clado 103: 01 -> 0

Olivaichthys mesembrinus: $\odot$-> 1

Clado 108: $0 \rightarrow 1$

Clado 183: $\odot \rightarrow 01$

Clado 152: $\odot \rightarrow 01$

Clado 122: $0 \rightarrow 1$

Oligosarcus argenteus: 01 -> 1

Copeina cf. guttata: $01 \rightarrow 1$

Charax cf. leticiae: $01 \rightarrow 1$

Galeocharax knerii: $01 \rightarrow 0$

Erythrinoidea fam. nov: $01 \rightarrow 0$

Clado 158: $01 \rightarrow 1$

Clado 149: $0 \rightarrow 1$

Clado 196: $\odot \rightarrow$

Serrabrycon magoi: $0 \rightarrow 1$

Bryconadenos tanaothoros: 0 -> 1

Knodus meridae: $0 \rightarrow$

Knodus meridae: $0 \rightarrow>1$
Iguacladoctes geisleri: $0 \rightarrow 1$

$\begin{array}{lll}\text { Iguacladoctes geisleri: } & 0 & -> \\ \text { Stygichthys typhlops: } 0 & ->1\end{array}$

Stygichthys typhlops:
Caráter 26 ( 8 passos)

Raiz: $\odot$

Raiz: 0 Olivaichthys mesembrinus: $0->1$

Salminus hilarii: 01 -> 1

Brycon pesu: 01 ->

Clado 146: $01 \rightarrow 1$

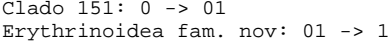

Clado 161: $0 \rightarrow 1$

Erythrinus erythrinus: 01 ->

Hoplias malabaricus: 01 -> 1

Clado 155: $1 \rightarrow 0$

Gilbertolus atratoensis: 1 -> 0

Caráter 27 ( 14 passos)

Raiz: $\odot$

Clado 144: 0 -> 1

Characidium bahiensis: $0 \rightarrow 1$

Clado 122: $0 \rightarrow 1$

Clado 190: $1 \rightarrow 0$

Clado 145: $1 \rightarrow 0$

Piaractus mesopotamicus: 1 -> 0

Clado 119: $1 \rightarrow 0$
Clado 172: $1 \rightarrow 0$

Rhinobrycon negrensis: 1 -> 0

Odontostilbe pequira: $0 \rightarrow 1$

Stygichthys typhlops: $0 \rightarrow 1$

Triportheus albus: $1 \rightarrow \odot$

Gymnocorymbus ternetzi: 1 -> 0

Hyphessobrycon compressus: 1 -> $\odot$
Caráter 28 (29 passos)

Raiz: 0

Clado 111: $0 \rightarrow 01$

Clado 144: $01 \rightarrow 12$

Olivaichthys mesembrinus: $\odot$-> 2

Clado 163: $01 \rightarrow 0$

Clado 143: $12 \rightarrow 2$

Clado 115: $01 \rightarrow 1$

Neolebias unifasciatus: 01 -> 1

Clado 107: $01->0$
Clado 152: $12->2$

Clado 157: 12 -> 1

Chalceus epakros: $12 \rightarrow 2$

Clado 159: 12 -> 0

Xenocharax spilurus: $\odot->1$

Xenocharax spilurus: $\Theta->$

Hemiodus unimaculatus : $1->2$

Clado 120: $1 \rightarrow 0$

Clado 123: $1 \rightarrow 2$

Erythrinus erythrinus: $2->0$

Piaractus mesopotamic

Hepsetus odoe: 2 - $>0$

Clado 172: $2 \rightarrow 12$

Clado 177: $12 \rightarrow 1$

Hemibrycon polyodon : $1->2$

Atopomesus pachyodus: $12 \rightarrow 2$

Microschemobrycon casiquiare: 12 -> 1

Clado 181: $1 \rightarrow 0$

Brittanichthys axelrodi: 1 -> 0

Agoniates halecinus: $1 \rightarrow 2$

Probolus heterostomus : $1->2$

Markiana nigripinnis: $1 \rightarrow 0$

Hollandichthys multifasciatus: 1 -> 2

Caráter 29 ( 27 passos)

Raiz: 0

Clado 144: $\odot \rightarrow 12$

Olivaichthys mesembrinus: $0 \rightarrow 2$

Clado 154: 12 -> 2

Crenuchus spilurus: $0 \rightarrow 1$

Clado 142: 12 -> 1

Clado 148: $12 \rightarrow 2$

Clado 105: $0 \rightarrow 1$

Clado 116: $0 \rightarrow 1$

Clado 125: $0 \rightarrow-2$

Gnathocharax steindachneri: 1 -> 2

Roeboexodon guyanensis: 1 -> 0

Galeocharax knerii: 1 ->

Citharinus latus: $1 \rightarrow 2$

Anodus orinocensis: $1->2$

Clado 119: $0 \rightarrow 1$

Landonia latidens: 1 -> 2

Serrabrycon magoi: $1 \rightarrow 2$

Hemibrycon polyodon : $1->$

Hemibrycon polyodon : 1 ->

knodus meridae: $1->2$

Odontostilbe pequira: 1 -> 0

Clado 181: $1 \rightarrow 2$

Axelrodia reisei: $1 \rightarrow \odot$

Paracheirodon axelrodi: 1 ->

Markiana nigripinnis: $1 \rightarrow 2$

Hollandichthys multifasciatus: $1 \rightarrow 2$

Caráter 30 ( 2 passos)

Raiz: 0

Chalceus epakros: $\odot$-> 1

Clado 124: $\odot \rightarrow>$

Caráter 31 (2 passos)

Raiz: 1

Clado 144: 1 -> 0

Crenuchus spilurus: 1 -> $\theta$

Caráter 32 (19 passos)

Raiz: 1

Catostomus commersonnii: 1 -> 0

Clado 108: $1 \rightarrow 0$

Clado 153: 1 -> 01

Clado 157: $01 \rightarrow 0$

Copeina cf. guttata: $01->$

Copeina cf. guttat

Clado 151: 01 -> 1

Clado 162: $1 \rightarrow 0$

Clado 105: $0 \rightarrow 1$

Gnathocharax steindachneri: 1 -> 2

Gnathocharax steinda

Clado 145: $1 \rightarrow 12$

Clado 120: 01 -> 1

Acestrorhynchus falcirostris: 12 -> 2

Landonia latidens: $1 \rightarrow 0$

Hepsetus odoe: $12 \rightarrow 1$

Clado 155: $12 \rightarrow 2$

Clado 179: $1 \rightarrow 0$

Glandulocauda melanogenys: 1 -> $\odot$

Deuterodon iguape: $1 \rightarrow 0$

Iguacladoctes geisleri: 1 -> 0

Clado 195: $1 \rightarrow 0$

Ctenobrycon hauxwellianus: $1 \rightarrow 0$

Caráter 33 (8 passos)

Raiz: 0

Clado 148: $0 \rightarrow 1$

Clado 182: $0 \rightarrow>$

Clado 151: $0 \rightarrow 1$

Clado 150: $1 \rightarrow 0$

Clado 123: $\rightarrow>3$

Clado 126: $\rightarrow>$

Piaractus mesopotamicus: $0->1$

Clado 155: $1 \rightarrow 2$

Caráter 34 (12 passos)

Raiz:

Clado 108: 0 -> 01

Crenuchus spilurus: $0 \rightarrow 2$

Clado 148: $\odot \rightarrow 012$

Clado 153: $0 \rightarrow 1$

Neolebias unifasciatus: 01 -> 1

Salminus hilarii: 012 -> 1

Clado 147: 012 -> 2

Chalceus epakros: $0->2$

Clado 112: 01 -> 0

Distichodus notospilus: 01 -> 1

Clado 158: $1 \rightarrow 2$

Citharinus latus: $01->0$

Xenocharax spilurus: 01 -> 1

Clado 149: 2 -> 0

Hepsetus odoe: 2 -> 1

Triportheus albus: $0->2$

Caráter 35 ( 4 passos)

Raiz: 1

Clado 160: 1 -> 01

Chalceus epakros: 01 -> $\odot$

Arnoldichthys spilopterus: 01 -> 1

Clado 162: $01 \rightarrow 0$

Triportheus albus: 1 -> 0

Caráter 36 ( 7 passos)

Raiz: 0

Clado 160: $\odot \rightarrow 1$

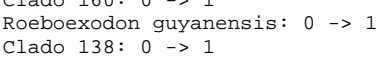

Rhinobrycon negrensis: $1 \rightarrow 0$

Atopomesus pachyodus: $0 \rightarrow 1$

Paracheirodon axelrodi: $0 \rightarrow 1$

Agoniates halecinus: $1 \rightarrow 0$

Caráter 37 (16 passos)

Raiz: 0

Crenuchus spilurus: 0 -> 1

Clado 153: $0 \rightarrow 01$

Clado 107: $0 \rightarrow 01$

Clado 118: $\theta \rightarrow 01$

Clado 157: $01 \rightarrow 1$

Clado 112: $01 \rightarrow 1$

Brycon pesu: $\theta_{->2}$

Copeina cf. guttata: $01->1$

Clado 151: $01 \rightarrow 0$

Clado 162: 0 -> 2

Distichodus notosp

Clado 105: $01 \rightarrow 0$

$\begin{array}{ll}\text { Clado 126: } & 01 \rightarrow 1 \\ \text { Clado 138: } 0 \rightarrow>2\end{array}$

Serrabrycon magoi: $0->1$

Clado 133: $2 \rightarrow 02$

Bryconamericus exodon: 2 ->

Piabina argentea: $2 \rightarrow 0$

Clado 181: $02->0$

Clupeacharax engrauloides: $02->2$

Agoniates halecinus: $02->0$

Triportheus albus: $02->2$

Hollandichthys multifasciatus: $2->0$

Caráter 38 (21 passo)

Raiz: 0

Olivaichthys mesembrinus: 0 -> 1

Characidium bahiensis: $\Theta->1$

Clado 114: 0 -> 01

Distichodus notospilus: $0->1$

Nannocharax fasciatus: $0 \rightarrow 1$

Parodon nasus: 01 -> 1

Clado 124: 0 -> 01

Aphyocharax pusillus: $0->1$

Bryconalestes longipinnis: $\theta \rightarrow 1$

Chilodus punctatus: $01 \rightarrow 1$

Metynnis lippincottianus: $0->1$

Clado 172: 0 -> 01

Rhinobrycon negrensis: $0->1$

Clado 171: $01 \rightarrow 1$

Clado 168: $0 \rightarrow 1$

Piabina argentea: $0->1$

Odontostilbe pequira: $01 \rightarrow$

Clado 184: $01 \rightarrow 1$

Axelrodia reisei: $01 \rightarrow 0$ 
Paracheirodon axelrodi: 012 -> 2

Clado 200: $012 \rightarrow 0$

Clado 131: 02 -> 0

Agoniates halecinus: 02 ->

Triportheus albus: $02 \rightarrow 0$

Hollandichthys multifasciatus: $\odot \quad->2$

Caráter 40 (21 passo)

Raiz: 2

Clado 111: 2 -> 12

Clado 110: 12 ->

Gymnotus aff, carapo: 2 -> 1

Clado 143: $12 \rightarrow 01$

Clado 148: $01 \rightarrow 0$

Clado 160: $12 \rightarrow 1$

Clado 157: $12 \rightarrow>2$

Oligosarcus argenteus: 01 -> 1

Clado 182: $01 \rightarrow 0$

Copeina cf. guttata: $12->2$

Clado 151: $12 \rightarrow 012$

Clado 116: 1 -> 12

Erythrinoidea fam. nov: $012 \rightarrow 1$

Clado 158: 012 -> $\odot$

Clado 197: $1->012$

Aphyocharax pusillus: $01->1$

Clado 199: 01 -> 012

Piaractus mesopotamicus: 012 -> 0

Clado 196: $012 \rightarrow 2$

Landonia latidens: $01 \rightarrow>1$
Serrabrycon magoi: $01 \rightarrow 0$

Serrabrycon magoi:

Clado 173: $01->1$
Paragoniates alburnus: $012 \rightarrow>0$

Phenagoniates macrolepis: $012 \rightarrow 2$

Clado 136: $01 \rightarrow 0$

Clado 180: $01->1$

Clado 198: $1 \rightarrow 0$

Clado 184: $1 \rightarrow 0$

Clado 164: 0 -> 012

IguaCladoctes geisleri: $0 \rightarrow>2$

Agoniates halecinus: $012 \rightarrow 2$

Triportheus albus: $012 \rightarrow 1$

caráter 41 ( 7 passos)

Carater

Clado 183: $\odot$-> 02

Oligosarcus argenteus: $02->2$

Clado 146: $\odot \rightarrow 012$

Charax cf. leticiae: $02->2$

Galeocharax knerii: $02 \rightarrow \infty$

Galeocharax knerii:

Clado 145: $012 \rightarrow 01$

Acestrorhynchus falcirostris: $01->1$

Hoplias malabaricus: $0 \rightarrow 1$

Hepsetus odoe: $01->1$

Clado 155: $01 \rightarrow 0$

Agoniates halecinus: $\odot->2$

Caráter 42 ( 5 passos)

Raiz:

Charax cf. leticiae: $0 \rightarrow 1$

Clado 158: $0 \rightarrow 1$

Xenocharax spilurus: $0 \rightarrow 1$

Clado 155: $0 \rightarrow>$

Agoniates halecinus: $\odot->1$

Caráter 43 (11 passo)

Raiz: 1

Oligosarcus argenteus: 1 -> 0

Clado 146: 1 -> 0

Distichodus notospilus: 1 -> 2

Nannocharax fasciatus: $1 \rightarrow 2$

Gnathocharax steindachneri: 1 -> 0

Clado 161: $1 \rightarrow 2$

Clado 123: 1 -> 2

Clado 126: 1 -> 2

Hoplias malabaricus: $1->0$

Iguacladoctes geisleri: $1->2$

Markiana nigripinnis: $1->2$

Markiana nigripinnis:

Carater 44

Chanos chanos: $01 \rightarrow 0$

Clado 103: $01 \rightarrow 1$

Clado 103: $01 \rightarrow 1$

Stygichthys typhlops: 1 ->

caráter 45 ( 5 passos)

Caráter

Raiz: 1

Distichodus notospilus: 1 ->

Nannocharax fasciatus: 1 -> 0

Clado 123: $1 \rightarrow 0$

Stygichthys typhlops: 1 -> 0

Stygichthys typhlops:
Caráter 46 ( 1 passo)

Caráter 4

Olivaichthys mesembrinus: 0 -> 1

Caráter 47 ( 5 passos)

Raiz: 0

Clado 159: 0 -> 01

Brycon pesu: $0 \rightarrow 1$

Clado 162: $01 \rightarrow 1$

Clado 126: $0 \rightarrow 1$

Clado 138: $0 \rightarrow 0$

Clado 137: $01 \rightarrow 1$

Clado 192: $1 \rightarrow 0$

Caráter 48 (20 passos)

Raiz: 02

Clado 111: 02 -> $\odot$

Clado 111: $02->0$

Clado 109: $0 \rightarrow 1$
Clado 117: $1 \rightarrow 01$

Clado 190: $\odot \rightarrow 01$

Clado 182: $0 \rightarrow$

Lebiasina bimaculata: $0->$

Arnoldichthys spilopterus: 0 -> 1

Nannocharax fasciatus: $1 \rightarrow 0$

Bivibranchia fowleri: $01 \rightarrow 0$

Gnathocharax steindachneri: 01 -> 1

Citharinus latus: 1 -> 2

Anodus orinocensis: $01->1$
Hemiodus unimaculatus : $01 \rightarrow 0$

Clado 174: $\odot \rightarrow-1$

Hemibrycon polyodon : $0->1$

Clado 185: $1 \rightarrow 01$

Knodus meridae: $0->1$

Odontostilbe pequira: $01 \rightarrow 0$

Brittanichthys axelrodi: $1 \rightarrow 0$

Compsura heterura: $01->0$

Bryconops alburnoides: $0->1$

Bryconops alburnoides

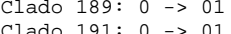

Gymnocorymbus ternetzi: 01 -> 1

Hollandichthys multifasciatus: 01 -> 1

Orthospinus franciscoensis: $01 \rightarrow 0$

Poptella brevispina: 01 -> 1

Caráter 49 ( 3 passos)

Raiz: $\odot$

Clado 116: $0 \rightarrow 1$

Citharinus latus: $0->1$

Clado 124: $0 \rightarrow 1$

Caráter 50 ( 9 passos)

Raiz: $\odot$

Clado 162: $\odot \rightarrow 1$

Galeocharax knerii: 0 -> 1

Erythrinoidea fam. nov: $0->1$

Acestrorhynchus falcirostris: 0 -> 1

Hydrolycus tatauaia: $0 \rightarrow 1$

Clado 128: $\odot \rightarrow 01$

Schizodon fasciatus: 01 -> 1

Boulengerella maculata: $0->1$

Leporellus vittatus: $01->0$

Leporinus fasciatus: $01->$

Clado 130: $0 \rightarrow 1$

Caráter 51 (19 passos)

Raiz: 1

Crenuchus spilurus: $1->0$

Clado 151: $1 \rightarrow 0$

Bivibranchia fowleri: 1 ->

Clado 161: $1 \rightarrow 0$

Anodus orinocensis: 1 -> $\theta$

Clado 126: $1 \rightarrow 2$

Aphyocharax pusillus: $0->1$

Clado 119: $1 \rightarrow$

Clado 173: $0 \rightarrow$

Myleus setiger: 1 -> 2

Microschemobrycon casiquiare: 1 -> 0

Moenkhausia xinguensis: 0 -> 1

Clado 198: 1 ->

Rhoadsia altipinna: $1->0$

Iguacladoctes geisleri: $\odot->2$

Markiana nigripinnis: $0 \rightarrow 1$

Caráter 52 (9 passos)

Raiz: 1

Clado 148: 1 -> 01

Salminus hilarii: $01 \rightarrow 0$

Brycon pesu: $01 \rightarrow 1$

Clado 146: $01 \rightarrow 0$

Clado 151: $1 \rightarrow \infty$

Piabucina astrigata: 1 -> 0

Clado 125: $1 \rightarrow 0$

Landonia latidens: $1 \rightarrow 0$

Ctenolucius hujeta: $\odot \rightarrow 1$

Ctenolucius huje

Markiana nigripinnis: $1 \rightarrow 0$

Caráter 53 (15 passos)

Raiz: $\odot$

Characidium bahiensis: $0->1$

Brycon pesu: $0 \rightarrow 1$

Aphyocharax pusillus: $0 \rightarrow 1$

Clado 137: $0 \rightarrow 1$

Clado 173: $0 \rightarrow 1$

Hemibrycon polyodon : $1->0$

Clado 176: 1 -> 01

Clado 133: $1 \rightarrow$

Clado 167: $1 \rightarrow$

Axelrodia reisei: $01 \rightarrow 1$

Brittanichthys axelrodi: 01 ->

Paracheirodon axelrodi: $01 \rightarrow 0$

Rhoadsia altipinna: 1 -> 0

Rachoviscus graciliceps: 01 ->

Stygichthys typhlops: $01 \rightarrow 0$

Tetragonopterus argenteus: $\Theta \rightarrow 1$

Hollandichthys multifasciatus: $\odot->1$

Ctenobrycon hauxwellianus: $0 \rightarrow 1$

Caráter 54 ( 3 passos)

Raiz: 0

Clado 115: $\odot \rightarrow 01$

Clado 114: $01 \rightarrow 1$

Clado 117: $01 \rightarrow 1$

Clado 125: $01 \rightarrow 0$

Clado 120: $01 \rightarrow 0$

Clado 123: $01 \rightarrow 1$

Caráter 55 (10 passos)

Raiz: 1

Clado 163: 1 -> 0

Neolebias unifasciatus: $1->0$

Clado 157: $1 \rightarrow 0$

Oligosarcus argenteus: 1 -> 0

Clado 146: $1 \rightarrow 01$

Clado 158: $1 \rightarrow 0$

Xenocharax spilurus: $1 \rightarrow 0$

Acestrorhynchus falcirostris: $01 \rightarrow 0$

Hydrolycus tatauaia: $01 \rightarrow 0$

Clado 149: $01 \rightarrow 1$

Hepsetus odoe: $01^{->1}$

Clado 155: $01 \rightarrow 0$

Brittanichthys axelrodi: $1 \rightarrow 0$

Caráter 56 ( 6 passos)

Raiz: 1

Clado 143: 1 -> 012

Characidium bahiensis: 1 -> 0

Clado 142: $012 \rightarrow 0$

Acestrorhynchus falcirostris: 012 -> 0

Hydrolycus tatauaia: $012->2$

Hoplias malabaricus: $1->2$

Boulengerella maculata: $012->2$

Ctenolucius hujeta: $012 \rightarrow 1$

Caráter 57 ( $\odot$ passos)

Raiz: 0

Caráter 58 (4 passos)

Raiz: 0

Crenuchus spilurus: $0->1$

Distichodus notospilus: $0->1$

Boulengerella maculata: $0->1$
Brittanichthys axelrodi: $0 \rightarrow 1$

Caráter 59 (13 passos)

Raiz: 1

Clado 183: 1 -> 0

Salminus hilarii: 1 -> 0

Clado 151: $1 \rightarrow 0$

Clado 125: $1 \rightarrow 0$

Clado 145: 1 -> 01

Acestrorhynchus falcirostris: $01->0$

Clado 196: 1 -> 0

Landonia latidens: 1 -> 0

Phenagoniates macrolepis: 1 -> 0

Hepsetus odoe: 01 -> 1

Clado 155: $01->0$

Gilbertolus atratoensis: $1 \rightarrow 0$

Curimata ocellata: $1 \rightarrow 0$

Brittanichthys axelrodi: 1 -> $\odot$

Compsura heterura: $1 \rightarrow 0$

Caráter 60 ( 2 passos)

Raiz: 0

Clado 123: $\odot \rightarrow 1$

Potamorhina latior: $0->1$

Caráter 61 (18 passos)

Raiz: 0

Clado 153: $\odot \rightarrow 1$

Salminus hilarii: $\odot \rightarrow$

Clado 152: 1 -> 12

Copeina cf. guttata: 12 -> 2

Nannocharax fasciatus: $0->1$

$\begin{array}{lll}\text { Bivibranchia fowleri: } 0 & ->1 \\ \text { Erythrinoidea fam. nov: } 12 & ->2\end{array}$

Clado 158: 12 -> 1

Clado 197: $0 \rightarrow 1$

Clado 155: $0 \rightarrow 1$

Boulengerella maculata: 1 -> 2

Clado 133: $\odot \rightarrow 1$

Clado 168: 0 -> 01

Knodus meridae: $0 \rightarrow 1$

Deuterodon iguape: $01->1$

Clupeacharax engrauloides: 1 -> 0

Agoniates halecinus: $1->2$

Astyanax mexicanus: $01 \rightarrow 1$

Probolus heterostomus : $01 \rightarrow 0$

Clado 191: $01 \rightarrow$

Clado 188: $01 \rightarrow$

Markiana nigripinnis: $01->1$

Tetragonopterus argenteus: $01 \rightarrow 0$

Ctenobrycon hauxwellianus: $0 \rightarrow 1$

Caráter 62 (20 passos)

Raiz: 2

Catostomus commersonnii: $2 \rightarrow 1$

Olivaichthys mesembrinus: $2 \rightarrow 0$ 
Chanos chanos: $01 \rightarrow 0$

Clado 102: 01 -> 012

Catostomus commersonnii: 012 -> 2

Clado 163: $01 \rightarrow$

Clado 108: 01 ->

Clado 115: $01 \rightarrow$

Clado 160: 01 ->

Neolebias unifasciatus: $1 \rightarrow 2$

Clado 141: 01 -> 1

Salminus hilarii: 01 -> 0

Clado 157: $01 \rightarrow \odot$

Clado 140: 1 -> 12

Oligosarcus argenteus: 01 -> 0

Brycon pesu: 01 -> 1

Copeina cf. guttata: $01>2$

Clado 151: $01 \rightarrow \odot$

Clado 139: $12 \rightarrow>2$

Galeocharax knerii: $01 \rightarrow 1$

Galeocharax knerii:

Xenocharax spilurus: $1 \rightarrow 2$

Aphyocharax pusillus: 12 -> 1

Clado 199: $12 \rightarrow 2$

Gilbertolus atratoensis: $0->1$

Clado 136: $2 \rightarrow$

Clado 194: $2->1$

Clado 185: 2 -> 12

Glandulocauda mela

Clado 133: $1->0$
Knodus meridae: $1->$

Knodus meridae: 1 -> 0 Odontostilbe pequira: 12 ->

Clado 200: $2 \rightarrow 12$

Compsura heterura: $12->1$

Rhoadsia altipinna: $12 \rightarrow 2$

Clado 192: 1 -> 01

Stygichthys typhlops: 12 -> 1

Clupeacharax engrauloides: $0->1$

Probolus heterostomus : $01 \rightarrow 0$

Hemigrammus unilineatus: $01 \rightarrow 1$
Hollandichthys multifasciatus: $01->0$

Caráter 64 (19 passos)

Raiz: 1

Clado 102: 1 -> 01

Catostomus commersonnii: $01->0$

Olivaichthys mesembrinus: $01->1$

Gymnotus aff. carapo: $01 \rightarrow 0$

Clado 109: $1 \rightarrow 0$

Clado 152: $1 \rightarrow 01$

Clado 159: $1 \rightarrow 0$

Clado 190: $1 \rightarrow$

Copeina cf. guttata: 01 -> 0

Clado 150: 1 -> 0

Erythrinoidea fam. nov: $01 \rightarrow 0$

Clado 158: $01 \rightarrow 1$

Bryconalestes longipinnis: $\odot->1$

Hepsetus odoe: $1 \rightarrow 0$

Phenacogaster pectinatus: 1 -> 0

Atopomesus pachyodus: $1 \rightarrow 0$

Moenkhausia xinguensis: $1 \rightarrow 0$

Bryconamericus exodon: $1->0$
Brittanichthys axelrodi: $1 \rightarrow 0$

Compsura heterura: $1 \rightarrow \odot$

Stygichthys typhlops: 1 -> 0

Clado 130: $1 \rightarrow 0$

Hemigrammus unilineatus: $1 \rightarrow \odot$

Caráter 65 (11 passo)

Raiz: $\odot$

Crenuchus spilurus: $\odot->1$

Clado 142: $\odot->$

Copeina cf guttata: $\odot->1$

Piabucina astrigata: $0 \rightarrow 1$

Clado 173: $\rightarrow$

Paragoniates alburnus: 1 -> 0

Clado 135: $1 \rightarrow 0$

Clado 185: $0 \rightarrow 1$

Clado 191: $1 \rightarrow 01$

Hemigrammus unilineatus: $01->0$ Tetragonopterus argenteus: $1->0$

Hollandichthys multifasciatus: $01{ }^{->}$

Hyphessobrycon compress
Caráter 66 ( 5 passos)

Raiz: 01

Chanos chanos: 01 ->

Clado 103: $01 \rightarrow \odot$

Clado 133: $\odot \rightarrow 01$

Clado 181: 01 ->

Brittanichthys axelrodi: $\odot->1$

Clupeacharax engrauloides: $01->1$

Clado 130: 01 -> 0

Agoniates halecinus: 01 -> $\odot$

Triportheus albus: $01 \rightarrow 1$

Caráter 67 (18 passos)

Raiz: 1

Clado 144: 1 -> 0

Olivaichthys mesembrinus: 1 -> 0

Clado 141: $0 \rightarrow 01$

Clado 140: $01 \rightarrow 1$

Clado 162: $0 \rightarrow 01$

Gnathocharax steindachneri: $01 \rightarrow$

Roeboexodon guyanensis: $01 \rightarrow 1$

Erythrinoidea fam nov: $0 \rightarrow 1$

Clado 161: $01 \rightarrow 1$

Piaractus mesopotamicus: $01->1$

Clado 196: $01 \rightarrow$

Paragoniates alburnus: 1 -> $\odot$

Paragoniates albur
Hemibrycon polyodon : $01 \rightarrow 0$

Glandulocauda melanogenys: $1 \rightarrow 0$

Moenkhausia xinguensis: $01 \rightarrow 0$

Bryconamericus exodon: $1 \rightarrow 0$

Piabina argentea: 1 -> 0

Deuterodon iguape: 01 -> 1

Clado 166: $01 \rightarrow$

Stygichthys typhlops: 1 -> $\theta$

Agoniates halecinus: $1 \rightarrow 0$

Probolus heterostomus : $01 \rightarrow 1$

Hemigrammus unilineatus: $01 \rightarrow 1$

Clado 193: $01 \rightarrow 0$

Ctenobrycon hauxwellianus: $\odot \rightarrow 1$

Caráter 68 (4 passos)

Raiz: 0

Clado 122: $0 \rightarrow-1$

Hemistichodus vaillanti: $0 \rightarrow 1$

Iguacladoctes geisleri: $0 \rightarrow 1$

Clado 130: $0 \rightarrow 1$

Caráter 69 (23 passos)

Raiz: 2

Clado 111: $2 \rightarrow 1$

Characidium bahiensis: 1 -> 2

as spilurus: $1 \rightarrow \theta$

Clado 153: 1 -> 12

Clado 157: $12 \rightarrow 2$

Clado 112: $1 \rightarrow 2$
Clado 140: $0 \rightarrow 1$

Clado 140: $0 \rightarrow 1$

Copeina cf. guttata: 12 -> 2

Clado 151: 12 -> 1

Bivibranchia fowleri: 1 -> 2

Clado 125: $1 \rightarrow 12$

Xenocharax spilurus: 1 -> 0

Clado 124: $12 \rightarrow 2$

Erythrinus erythrinus: 1 -> $\odot$

Piaractus mesopotamicus: $1 \rightarrow 0$

Curimatopsis macrolepis: 1 -> 2

Anostomus anostomus: $12->2$

Clado 128: 12 -> 1

Iguacladoctes geisleri: 1 -> 2

Stygichthys typhlops: $1->0$

Clupeacharax engrauloides: 1 -> 0

Agoniates halecinus: $1 \rightarrow \odot$

Astyanax mexicanus: $1->0$

Clado 191: 1 - $>01$

Hemigrammus unilineatus: 01 -> 0

Hollandichthys multifasciatus: $01->0$

Hyphessobrycon compressus: $01-1$

Orthospinus franciscoensis: 1 -> 0

Caráter 70 ( 6 passos)

Raiz: 0

Characidium bahiensis: $\odot$-> 1

Clado 145: $\odot \rightarrow 01$

Clado 158: $0->2$ 2 Acestrorhynchus falcirostris: $01->1$

Acestrorhynchus falci

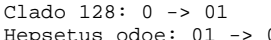

Hepsetus odoe: $01->1$
Clado 155: $01 \rightarrow-1$

Schizodon fasciatus: $01->1$

Leporellus vittatus: $01->$

Leporinus fasciatus: 01 -> 1

caráter 71 (4 passos)

Raiz: $\odot$

Clado 125: $\odot$-> 1

Semaprochilodus insignis: 0 -> 1

Roestes molossus: $0 \rightarrow 1$

Iguacladoctes geisleri: 0 -> 1

caráter 72 ( 7 passos)

Raiz: 1

Clado 102: 1 -> $\odot$

Piabucina astrigata: $1 \rightarrow 0$

Galeocharax knerii: $1 \rightarrow 0$

Erythrinoidea fam. nov: 1 -> $\odot$

Clado 155: $1 \rightarrow 0$

Hemibrycon polyodon : $1->0$

Microschemobrycon casiquiare: $1>0$

caráter 73 (20 passos)

Raiz: 1

Clado 108: $1 \rightarrow 0$

Clado 147: 1 -> 01

Brycon pesu: $01 \rightarrow 0$

Clado 121: 1 -> 0

Clado 139: $1 \rightarrow$

Gnathocharax steindachneri: 1 -> 0

Clado 145: 01 -> 1

Clado 150: 01 -> 0

Erythrinoidea fam. nov: 1 ->

Anodus orinocensis: 1 - $>$

Phenagoniates macrolepis: $1->0$

Rhinobrycon negrensis: $\odot->$

Diapoma terofali: $0 \rightarrow 1$

Clado 185: $\odot \rightarrow \odot 1$

Moenkhausia xinguensis: $0 \rightarrow 1$

Odontostilbe pequira: 01 -> 1

Compsura heterura: $01 \rightarrow 0$

Rhoadsia altipinna: $01 \rightarrow 1$

IguaCladoctes geisleri: $0->1$

Stygichthys typhlops: $0 \rightarrow 1$

Agoniates halecinus: $0->1$

Probolus heterostomus : $0 \rightarrow 1$

Tetragonopterus argenteus: $0 \rightarrow 1$

Hyphessobrycon compressus: $0 \rightarrow 1$

caráter 74 ( 31 passo)

Raiz: 1

Clado 104: $1 \rightarrow 0$

Clado 109: $1 \rightarrow$

Clado 154: 1 -> 01

Salminus hilarii: $1 \rightarrow 0$

Clado 159: $01 \rightarrow 1$

Saccodon wagneri: $0 \rightarrow 2$

Oligosarcus argenteus: $1->0$

Copeina cf. guttata: $01 \rightarrow 0$

Lebiasina bimaculata: $01 \rightarrow 0$

Piabucina astrigata: $01 \rightarrow 1$

Apareiodon piracicabae: $0 \rightarrow->1$

Gnathocharax steindachneri: $1->0$

Galeocharax knerii: $1 \rightarrow 2$

Clado 150: $1 \rightarrow 01$

Erythrinoidea fam. nov: 01 -> $\odot$

Clado 158: $01->1$

Citharinus latus: 0 -> 1

Hemiodus unimaculatus : $\odot->1$

Clado 124: $0 \rightarrow 1$

Aphyocharax pusillus: $1->2$

Hydrolycus tatauaia: 01 -> 0

Bryconalestes longipinnis: 1 -> 0

Serrabrycon magoi: $1 \rightarrow 0$

Clado 155: $1 \rightarrow 0$

Gilbertolus atratoensis: 01 -> 1

Roestes molossus: $01 \rightarrow 0$

Clado 136: $1 \rightarrow 01$

Clado 170: $01->$

Diapoma terofali: 01 -> 1

Glandulocauda melanogenys: $01->0$

Clado 181: $01 \rightarrow 1$

Clado 167: $0 \rightarrow 1$

Axelrodia reisei: $1->0$

Compsura heterura:

Stygichthys typhlops: 1 ->

Agoniates halecinus: $01 \rightarrow 1$

Triportheus albus: $01 \rightarrow 0$

Tetragonopterus argenteus: $1 \rightarrow 0$

Hollandichthys multifasciatus: 1 -> 0

Caráter 75 ( 2 passos)

Raiz: $\odot$

Clado 123: $\odot \rightarrow 1$

Clado 126: $\odot \rightarrow 1$

Caráter 76 (22 passos)

Raiz: 1

Gymnotus aff. carapo: 1 -> 0

Clado 117: $1 \rightarrow 01$

Clado 182: $1 \rightarrow 0$

Brycon pesu: $1 \rightarrow 0$

Clado 162: 1 -> 01

Bivibranchia fowleri: 01 ->

Clado 197: $01 \rightarrow 0$

Anodus orinocensis: $01->1$

Hemiodus unimaculatus : $01 \rightarrow 0$

Clado 123: $1 \rightarrow 0$

Acestrorhynchus falcirostris: 1 - $\odot$

Brycinus macrolepidotus: $01->0$

Bryconalestes longipinnis: $01->1$

Clado 137: $1 \rightarrow 0$

Phenagoniates macrolepis: $1->0$

Schizodon fasciatus: $1 \rightarrow 0$

Phenacogaster pectinatus: 1 -> 0

Diapoma terofali: $0 \rightarrow 1$

Atopomesus pachyodus: 1 -> 0

Bryconadenos tanaothoros: 0 -> 1

Piabina argentea: $0 \rightarrow 1$

Clado 184: $1 \rightarrow \odot$

Clado 192: $0 \rightarrow 1$

Clado 130: $\odot \rightarrow 1$

Gymnocorymbus ternetzi: $0 \rightarrow 1$

Hollandichthys multifasciatus: $1->$

Caráter 77 ( 9 passos)

Raiz: 0

Clado 111: $\theta \rightarrow 01$

Clado 144: $01 \rightarrow 1$

Olivaichthys mesembrinus: 0 -> 1

Clado 109: $01 \rightarrow 0$

Clado 163: $01->1$

Salminus hilarii: 1 ->

Clado 145: $1 \rightarrow 01$

Acestrorhynchus falcirostris: $01 \rightarrow 0$

Hepsetus odoe: $01 \rightarrow 1$

Clado 155: $01 \rightarrow 0$

Moenkhausia xinguensis: 1 -> 0 
Oligosarcus argenteus: 2 -> 1

Clado 146: $2 \rightarrow 1$

Clado 151: $2->1$

Hemistichodus vaillanti: $1 \rightarrow$

Bivibranchia fowleri: $01 \rightarrow 1$

Clado 116: $01 \rightarrow \odot$

Clado 121: $01 \rightarrow 1$

Clado 125: 01 -> 012

Gnathocharax steindachneri: 2 -> 1

Charax cf. leticiae: $2 \rightarrow 0$

Clado 124: $012 \rightarrow 0$

Acestrorhynchus falcirostris: $1>0$

Bryconalestes longipinnis: 2 -> 0

Landonia latidens: $2 \rightarrow 1$

Serrabrycon magoi: $2 \rightarrow 1$

Paragoniates alburnus: 2 -> 0

Roestes molossus: 1 - $>$

Phenacogaster pectinatus: 2 -> 0

Ctenolucius hujeta: $1 \rightarrow 4$

Rhinobrycon negrensis: 2 -> 1

Clado 176: $2 \rightarrow 012$

Bryconadenos tanaothoros: 2 -> 1

Clado 175: $012 \rightarrow 1$

Paracheirodon axelrodi: $01->0$

Clado 166: 2 -> 02

Rachoviscus graciliceps: $01 \rightarrow 1$

Stygichthys typhlops: $01-\odot$

clado 130: $2 \rightarrow 1$

Agoniates halecinus: $2 \rightarrow 1$
Astyanax mexicanus: $02 \rightarrow 0$

Clado 188: $02 \rightarrow 0$

Clado 195: $02->012$
Hemigrammus unilineatus: 2 ->

Markiana nigripinnis: 012 ->

Tetragonopterus argenteus: $012 \rightarrow 2$

Poptella brevispina: $0 \rightarrow 2$

Caráter 80 (11 passo)

Raiz: $\odot$

Clado 110: $0 \rightarrow 01$

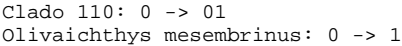

clado 109: $01 \rightarrow 1$

Characidium bahiensis: $01 \rightarrow 0$

Crenuchus spilurus: $01 \rightarrow 1$

Clado 160: $0 \rightarrow 1$

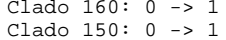

$\begin{array}{lll}\text { Clado } 15 \odot: & \odot & ->1 \\ \text { Clado } 197: 1 \rightarrow & ->0\end{array}$

Clado 126: 1 -> 01

Anostomus anostomus: 01 ->

Schizodon fasciatus: $01 \rightarrow 1$

Schizodon fasciatus:

Agoniates halecinus: $0 \rightarrow 1$

Astyanax mexicanus: $\odot \rightarrow 1$

Hollandichthys multifasciatus: $\odot->$

Caráter 81 ( 32 passos)

Raiz: 2

Clado 102: 2 -> 02

Catostomus commersonnii: $02->0$

Olivaichthys mesembrinus: $02 \rightarrow$

Gymnotus aff. carapo: $02 \rightarrow 0$

clado 163: $2 \rightarrow 0$

Clado 148: $2 \rightarrow 1$

Clado 153: 2 -> 0

Neolebias unifasciatus: 2 -> $\odot$

Clado 113: $2 \rightarrow 1$

Clado 117: $2 \rightarrow 1$

Clado 140: $2 \rightarrow 1$

Clado 105: 2 -> 123

Nannocharax fasciatus: 2 -> 1

Gnathocharax steindachneri: $2 \rightarrow 0$

Charax cf leticiae: $\rightarrow 1$

Clado 145: $1 \rightarrow 0$

Citharinus latus: 123 -> 1

$\begin{array}{lll}\text { Citharinus latus: } 123-> & 1 \\ \text { Xenocharax spilurus: } 123 \rightarrow 3 & \rightarrow>3\end{array}$

Aphyocharax pusillus: $1 \rightarrow 0$

Aphyocharax pusillus: $1->$

Hydrolycus tatauaia: $1->3$

Anostomus anostomus: $2 \rightarrow 1$

Anostomus anostomus: 2
Hepsetus odoe: $0 \rightarrow 2$

Metynnis lippincottianus: 2 -> 1

Clado 135: $1 \rightarrow 01$

Diapoma terofali: $01 \quad>0$

Diapoma terofali: $01->0$
Atopomesus pachyodus: $1->2$

Atopomesus pachyod

Clado 176: $\odot 1->0$

Glandulocauda melanogenys: 01

Bryconamericus exodon: $1 \rightarrow 0$

Odontostilbe pequira: $01 \rightarrow 0$

Clado 184: $01 \rightarrow 1$

Clado 181: $01 \rightarrow 1$

Clado 131: $01 \rightarrow 0$

Clado 164: $01 \rightarrow 1$

Clado 191: $1 \rightarrow 0$

Clado 195: 1 -> 123

Markiana nigripinnis: 123 -> 3

Tetragonopterus argenteus: 123 -> 2

Caráter 82 (14 passos)

Raiz: 01

Chanos chanos: $01-1$

Olivaichthys mesembrinus: $01->$

Clado 115: 01 -> 1

Clado 115: $01 \rightarrow$

Salminus hilarii: $01 \rightarrow 0$

Salminus hilarii: $01->0$
Chalceus epakros: $01->1$
Clado 112: $01->0$
Brycon pesu: $01 \rightarrow 1$

Arnoldichthys spilopterus: $01->0$

Distichodus notospilus: $01 \rightarrow 1$

Clado 150: $01 \rightarrow 0$

Clado 161: 01 -> 1

Citharinus latus: 01 -> 1

Xenocharax spilurus: $01->0$

Piaractus mesopotamicus: 01 -> 0

Hepsetus odoe: 01 -> 1

Metynnis lippincottianus: $01 \rightarrow 0$

Myleus setiger: $01 \rightarrow 1$

Rhinobrycon negrensis: 0 -> 1

Atopomesus pachyodus: $0 \rightarrow 1$

Moenkhausia xinguensis: $0 \rightarrow 1$

Knodus meridae: $0 \rightarrow 1$

Compsura heterura: $\odot \rightarrow 1$

Caráter 83 (18 passos)

Raiz: 0

Clado 111: $\odot \rightarrow 01$

Clado 109: 01 -> 1

Chalceus epakros: $01 \rightarrow$

Clado 113: $1 \rightarrow 0$

Clado 113: $1->0$
Brycon pesu: $\odot->1$

Brycon pesu: $\odot->1$
Arnoldichthys spilopterus: $01->0$

Clado 162: $01 \rightarrow 1$

Clado 105: 1 -> 012

Nannocharax fasciatus: 1 -> 2

Clado 125: 1 -> 01

Citharinus latus: 012 -> $\odot$

Xenocharax spilurus: $012->2$

Anodus orinocensis: $1->$

Clado 120: 1 -> 3

Clado 124: $01 \rightarrow \odot$

Clado 128: 01 -> 1

Metynnis lippincottianus: 1 -> 0

Clado 172: $\odot \rightarrow 01$

Atopomesus pachyodus: $01->1$

Microschemobrycon casiquiare: $01->$

Moenkhausia xinguensis: $0 \rightarrow 1$

Clado 184: $01 \rightarrow 1$

Triportheus albus: $0 \rightarrow 1$

Tetragonopterus argenteus: $\odot \quad->2$

caráter 84 ( 2 passos)

Raiz: 0

Clado 158: $\odot \rightarrow 1$

Hepsetus odoe: $\Theta^{->1}$

Caráter 85 ( 8 passos)

Raiz: 0

Clado 104: $0 \rightarrow 01$

Clado 110: $\odot \rightarrow 1$

ymnotus aff. carapo: 01 -> 1

Clado 118: $1 \rightarrow$

Charax cf. leticiae: $\odot \rightarrow 1$

Erythrinoidea fam. nov: $0->1$

Anodus orinocensis: $0 \rightarrow$

Clado 123: 0 -> 1

Phenacogaster pectinatus: $0->1$

Caráter 86 (20 passos)

Raiz: 2

Clado 111: 2 -> 1

Clado 110: $1 \rightarrow 01$

Clado 115: 01 -> 0

Characidium bahiensis: 01 -> $\odot$

Crenuchus spilurus: $01 \rightarrow 2$

Clado 153: 1 ->

Neolebias unifasciatus: $01->2$

Clado 141: $1 \rightarrow 2$

Brycon pesu: $1 \rightarrow 2$

Arnoldichthys spilopterus: 1 -> 0

Clado 162: $1 \rightarrow 2$

Distichodus notospilus: $01 \rightarrow 0$

Clado 105: $01 \rightarrow 2$

Nannocharax fasciatus: 01 -> 0

Clado 116: $\odot \rightarrow 01$

Charax cf. leticiae: $1 \rightarrow 2$

Charax cf. leticiae: $1->2$

Acestrorhynchus falcirostris: 1 -> 2

Hoplias malabaricus: $0 \rightarrow 2$

Clado 119: $0 \rightarrow 1$

Brittanichthys axelrodi: $2 \rightarrow 1$

Caráter 87 (23 passos)

Raiz: 1

lado 104: $1 \rightarrow 0$

Clado 143: $1 \rightarrow 12$

Clado 142: 12 -> 2

Clado 107: 1 -> 01

Salminus hilarii: $12 \rightarrow 2$

Clado 112: $01 \rightarrow \oplus$

Clado 117: 1 -> 01

Brycon pesu: 12 -> 1

Copeina cf. guttata: $1->2$

Distichodus notospilus: $01 \rightarrow 1$

Clado 105: 01 -> 012

Bivibranchia fowleri: $01 \rightarrow 0$

Clado 145: 12 -> 2

Citharinus latus: $012 \rightarrow 0$

Xenocharax spilurus: $012 \rightarrow 2$

Anodus orinocensis: $01 \rightarrow 0$

Hemiodus unimaculatus : $01 \rightarrow 1$

Clado 120: $1 \rightarrow 0$
Clado 199: $2 \rightarrow 1$

Hydrolycus tatauaia: $12 \rightarrow 1$

clado 128: $1 \rightarrow 2$

Clado 173: $2 \rightarrow 1$

Gilbertolus atratoensis: 12 -> 2 Roestes molossus: 12 -> 1

Metynnis lippincottianus: $1 \rightarrow 2$

Rhinobrycon negrensis: $2 \rightarrow 1$

Atopomesus pachyodus: 1 -> 2

Axelrodia reisei: 1 -> 2

Compsura heterura: $1->0$

Stygichthys typhlops: $1->2$

Probolus heterost

Clado 186: 2 -> 1

Caráter 88 (27 passos)

Raiz: 0

Clado 163: $0 \rightarrow 1$

Salminus hilarii: $0 \rightarrow 1$

Clado 159: $\odot \rightarrow 1$

Saccodon wagneri: $\odot->2$

Clado 140: $01 \rightarrow 1$

(a) $\rightarrow$

Lebiasina bimaculata

Gnathocharax steindachneri: $01->0$

Roeboexodon guyanensis: $01->2$

Charax cf. leticiae: $0 \rightarrow 1$

Erythrinoidea fam. nov: $01->1$

Clado 124: 01 -> 1

Erythrinus erythrinus: $01 \rightarrow 1$

Hoplias malabaricus: $01->0$

Piaractus mesopotamicus: 1 -> 2

Anostomus anostomus: $01 \rightarrow 0$

Clado 128: $01 \rightarrow 1$

Landonia latidens: 1 -> 2

Clado 179: $1 \rightarrow 12$

Clado 194: 12 -> 2

Atopomesus pachyodus: 1 -> 2

Clado 185: $1 \rightarrow 0$

Glandulocauda melanogenys: $1 \rightarrow 2$

Bryconadenos tanaothoros: 12 -> 1

Bryconamericus exodon: 12 -> 2

Clado 132: 1 -> 01

Axelrodia reisei: 1 -> 2

Clado 131: $01 \rightarrow$

Rachoviscus graciliceps: 1 -> $\odot$

Agoniates halecinus: $01->0$

Triportheus albus: $01 \rightarrow 1$

Clado 187: $1 \rightarrow 01$

Orthospinus franciscoensis: $01 \rightarrow 0$

Orthospinus franciscoensis: $01 \rightarrow$

Poptella brevispina: $01 \rightarrow 1$

Poptella brevispina:
Caráter 89 (15 passos)

Raiz: 0

Clado 110: $\odot$-> 0123

Clado 109: $0123 \rightarrow 02$

Clado 108: $02 \rightarrow 2$

Characidium bahiensis: $0123 \rightarrow 1$

Crenuchus spilurus: $0123 \rightarrow 3$

Saccodon wagneri: $02 \rightarrow 0$

Clado 113: 02 -> 2

Clado 117: 02 -> 012

Clado 122: 02 -> 0

Bivibranchia fowleri: $012->2$

Clado 116: $012 \rightarrow 1$

Charax cf. leticiae: $\odot \rightarrow 1$

Clado 123: $\odot \rightarrow 3$

Aphyocharax pusillus: $0 \rightarrow 1$

Hoplias malabaricus: $0 \rightarrow 1$

Leporinus fasciatus: $0 \rightarrow 1$

Atopomesus pachyodus: $0->1$

Brittanichthys axelrodi: $\odot \rightarrow$

Compsura heterura: $0->1$

Stygichthys typhlops: $0 \rightarrow 1$

Caráter 90 (2 passos)

Raiz: 01

Chanos chanos: $01 \rightarrow$

Clado 111: $01-1$

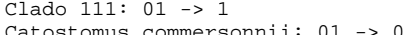

Clado 104: $01 \rightarrow 1$

Caráter 91 (19 passos)

Raiz: 1

Olivaichthys mesembrinus: 1 -> 0

Clado 143: $1 \rightarrow 0$

Clado 151: $1 \rightarrow 01$

Clado 165: $0 \rightarrow 1$

Erythrinoidea fam. nov: $01 \rightarrow 0$

Clado 197: $1 \rightarrow 01$

Clado 156: $\theta \rightarrow 1$

Erythrinus erythrinus: 01 -> 0 
Hollandichthys multifasciatus: 01 -> 0 Hyphessobrycon compressus: $01->1$ Caráter 92 (19 passos)

Raiz: 0

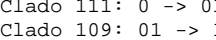

Clado 163: $01 \rightarrow$

Clado 154: $01 \rightarrow 1$

Clado 142: $01 \rightarrow$

Clado 148: $01 \rightarrow 1$

Clado 112: $1 \rightarrow 01$

Clado 122: 1 -> 01

Copeina cf. guttata: $1 \rightarrow 0$

Nannocharax fasciatus: $01 \rightarrow 0$

Clado 165: $0 \rightarrow 01$

Galeocharax knerii: $\odot \rightarrow 1$

Galeocharax kneri

Clado 145: $1 \rightarrow 0$

$\begin{array}{lll}\text { Clado 120: } & 01->0 \\ \text { Clado 123: } & 01->1\end{array}$

Clado 123: $\begin{array}{lll}01 & \rightarrow> \\ \text { Clado } 124: 01 & ->0\end{array}$

Aphyocharax pusillus: $01->1$

Anostomus anostomus: $01 \rightarrow 0$

Clado 128: $01 \rightarrow 1$

Paragoniates alburnus: $01->0$

Phenagoniates macrolepis: $01 \rightarrow 1$

Glandulocauda melanogenys: 01 -> 1

Bryconadenos tanaothoros: $0->1$

Piabina argentea: 0 ->

$\begin{array}{lll}\text { Clado 132: } & 01->1 \\ \text { Clado 181: } & 01-> & 0\end{array}$

Clado 181: $01->0$
Compsura heterura: $\odot \rightarrow 1$

Clado 129: $1 \rightarrow 0$

Gymnocorymbus ternetzi: $\odot->1$

Caráter 93 (15 passos)

Raiz: 01

Chanos chanos: 01 ->

Catostomus commersonnii: 01 -> 1

Clado 144: 01 -> 1

Olivaichthys mesembrinus: $01 \rightarrow$

Gymnotus aff. carapo: 01 -> 1

Clado 108: 01 - $>$

Characidium bahiensis: $01 \rightarrow 0$

Crenuchus spilurus: $01-1$

Clado 114: $01 \rightarrow 0$

Bivibranchia fowleri: 01 -> 0

Clado 116: $01 \rightarrow 1$

Xenocharax spilurus: $0->1$

Acestrorhynchus falcirostris: $01->0$

Prochilodus nigricans: $1 \rightarrow 0$

Prochilodus nigricans:

Hepsetus odoe: 01 1 $\rightarrow$

Myleus setiger: $1 \rightarrow$

Myleus setiger: $1->0$

Bryconadenos tanaothoros: $1->0$

Brittanichthys axelrodi: 1

Rhoadsia altipinna: $1->0$
Hyphessobrycon compressus: $1->0$

Hyphessobrycon compre
Caráter 94 ( 5 passos)

Caráter 94

Raiz: 0

Clado 122: 0 ->

Hoplias malabaricus: 0 -> 1

Clado 155: $\odot \rightarrow$

Metynnis lippincottianus: $0->1$

Clado 130: $0 \rightarrow$

Caráter 95 (22 passos)

Raiz: 012

Chanos chanos: 012 -> 1

$\begin{array}{lll}\text { Clado 102: } & 012->0 \\ \text { Clado 111: } & 012-> & 2\end{array}$

Crenuchus spilurus: $2 \rightarrow \odot$

Clado 153: $2 \rightarrow 01$

Clado 114: $2 \rightarrow 0$

Salminus hilarii: $2 \rightarrow 0$

Clado 106: $2 \rightarrow 1$

Clado 122: 2 -> 3

Clado 182: 2 ->

Copeina cf. guttata: 01 ->

Clado 151: $01 \rightarrow 0$

0

Lebiasina bimaculata: $01 \rightarrow 1$

Piabucina astrigata: $01->0$

Nannocharax fasciatus: $2 \rightarrow 0$

Roeboexodon guyanensis: 2 -> 1

Clado 145: 2 -> 0

Clado 126: $3 \rightarrow 0$

Paragoniates alburnus: $12 \rightarrow 2$

Phenagoniates macrolepis: $12->1$

Schizodon fasciatus: $0 \rightarrow 2$

Knodus meridae: $2 \rightarrow 1$

Stygichthys typhlops: 2 -> $\odot$

Clado 130: $2 \rightarrow 1$

Hollandichthys multifasciatus: 2 -> 1

Caráter 96 ( 27 passos)

Raiz: 0

Clado 111: $0 \rightarrow 1$

Clado 154: $1 \rightarrow 12$

Clado 183: $1 \rightarrow 0$

Clado 147: $1 \rightarrow 0$

Chalceus epakros: $12 \rightarrow 2$

Clado 159: $12 \rightarrow 1$

Clado 117: $1 \rightarrow 0$

Clado 122: $1 \rightarrow$

Copeina cf. guttata: 12 ->

Lebiasina bimaculata: 12 -> 1
Piabucina astrigata: $12->2$

Nannocharax fasciatus: $1 \rightarrow 0$

Clado 165: $1 \rightarrow 0$

Erythrinoidea fam. nov: $12 \rightarrow \odot$

Clado 158: $12 \rightarrow 2$

Clado 156: $0 \rightarrow 2$

Myleus setiger: $1->2$

Curimata ocellata: $2 \rightarrow 0$

Clado 180: 1 -> 01

Rhinobrycon negrensis: 01 -> 0

Clado 178: 01 -> 0

Clado 194: 01 -> 1

Clado 176: $1 \rightarrow 01$

Clado 198: 01 ->

Axelrodia reisei: 01 -> 1

Brittanichthys axelrodi: $01->0$

Clado 130: $1 \rightarrow 2$

Astyanax mexicanus: 1 -> $\theta$

$1 \rightarrow 01$

Hemigrammus unilineatus: $01->0$

Markiana nigripinnis: $1->2$

Hollandichthys multifasciatus: 01 -> 1

Hyphessobrycon compressus: $01-\rightarrow$

Caráter 97 (32 passos)

Raiz: 2

Clado 111: 2 -> 1

Gymnotus aff. carapo: $2 \rightarrow 1$

characidium bahiensis: $1 \rightarrow 0$

Clado 148: $1 \rightarrow 0$

Clado 153: 1 -> 12

Clado 107: $1 \rightarrow 12$

Clado 118: $1 \rightarrow 0$

Clado 157: $12 \rightarrow 2$

Copeina cf. guttata: $12 \rightarrow 2$

Distichodus notospilus: $12 \rightarrow 2$

Hemistichodus vaillanti: $12->1$
Nannocharax fasciatus: $12 \rightarrow>2$

Clado 165: 1 -> 01

Roeboexodon guyanensis: $1->0$

Erythrinoidea fam. nov: 12

Citharinus latus: $12->2$

Anodus orinocensis: $0->1$

Clado 123: $0 \rightarrow 2$

Aphyocharax pusillus: $01 \rightarrow 0$

Erythrinus erythrinus: $12 \rightarrow 2$

Hoplias malabaricus: $12->1$

Piaractus mesopotamicus: $1 \rightarrow 2$

Piaractus mesopotamicus: $1->2$

$\begin{array}{lll}\text { Paragoniates alburnus: } 01 & -> & 1 \\ \text { Phenagoniates macrolepis: } 01 & ->0\end{array}$

Myleus setiger: $1 \rightarrow 0$

Curimata ocellata: $0 \rightarrow 2$

Boulengerella maculata: $0 \rightarrow>$

Rhinobrycon negrensis: 1 -> 2

Clado 171: $1 \rightarrow 0$

Clado 194: $1 \rightarrow>$

Clado 198: $1 \rightarrow 2$

Clado 164: 1 -> 0

IguaCladoctes geisleri: 1 -> 0

Clado 130: 1 -> 2

Astyanax mexicanus: $1->0$

Clado 191: 1 -> 12

Hemigrammus unilineatus: $12->$

Hollandichthys multifasciatus: 12 -> 1

Hyphessobrycon compressus: $12,>2$

Caráter 98 (15 passos)

Raiz: 01

Chanos chanos: $01->1$

Catostomus commersonnii: 01 -> 0

Clado 104: 01 -> 1

Clado 154: $01 \rightarrow 0$

Clado 108: $01 \rightarrow 0$

Characidium bahiensis: $01->1$

Crenuchus spilurus: $01 \rightarrow 0$

Clado 142: $01 \rightarrow 0$

Clado 118: 01 -> 1

Salminus hilarii: $01 \rightarrow 1$

Saccodon wagneri: $01 \rightarrow 0$

Clado 113: $01 \rightarrow 1$

Brycon pesu: $01->$

Clado 146: $01 \rightarrow 1$

Clado 158: $\odot \rightarrow$

urus: $0 \rightarrow 1$

Semaprochilodus insignis: 1 ->

Anostomus anostomus: 1 ->

Curimata ocellata: 1 -> 0

Microschemobrycon casiquiare: 0 -> 1

Piabina argentea: $0 \rightarrow 1$

Clado 164: $\odot \rightarrow 1$

Caráter 99

Gymnotus aff. carapo: $\odot->$

Clado 151: $\odot \rightarrow 01$

Lebiasina bimaculata: $0 \rightarrow>$

Erythrinoidea fam. nov: $01 \rightarrow 1$

Clado 156: $\Theta \rightarrow 1$

Erythrinus erythrinus: 01 -> $\odot$

Hoplias malabaricus: $01->1$

Stygichthys typhlops: $0->1$

caráter 100 ( 5 passos)

Raiz: 1

Clado 102: $1 \rightarrow 0$

Clado 109: $1 \rightarrow 01$

Neolebias unifasciatus: 01 -> 1

Clado 107: $01 \rightarrow 0$

Clado 114: $01 \rightarrow 0$

Clado 117: 01 -> 1

Clado 121: $01 \rightarrow 0$

Clado 124: 01 -> 1

Caráter 101 (15 passos)

Raiz: 0

Clado 143: $\odot \rightarrow->1$

Clado 141: $01 \rightarrow 1$

Salminus hilarii: 01 -> $\odot$

Clado 147: $01 \rightarrow 1$

Oligosarcus argenteus: 01 -> 1

Clado 182: $01 \rightarrow 0$

Clado 182: $01->$

Clado 156: $1 \rightarrow 0$

Landonia latidens: 1 -> 0

Clado 185: 1 - $>01$

Glandulocauda melanogenys: 1 -> 0

Odontostilbe pequira: $01 \rightarrow 0$

Clado 200: $1 \rightarrow 0$

Compsura heterura: $01 \rightarrow 0$

Rhoadsia altipinna: $01 \rightarrow 1$

Clado 130: $1 \rightarrow 0$

Astyanax mexicanus: 1 -> 0

Clado 193: 1 -> 01

Markiana nigripinnis: 1 -> $\odot$

Hollandichthys multifasciatus: $01 \rightarrow 0$

Caráter 102 ( 5 passos)

Raiz: 0

Clado 176: $\odot \rightarrow 1$

Moenkhausia xinguensis: $0 \rightarrow 1$

Bryconops alburnoides: $0 \rightarrow 1$

Clado 188: $\odot \rightarrow 1$

Ctenobrycon hauxwellianus: 1 -> 0

Caráter 103 ( 7 passos)

Raiz: 0

Gnathocharax steindachneri: 0 -> 1

Landonia latidens: $0 \rightarrow 1$

Clado 198: $\odot \rightarrow 01$

Odontostilbe pequira: $0 \rightarrow 1$

Paracheirodon axelrodi: $01 \rightarrow 1$

Rachoviscus graciliceps: $01 \rightarrow 1$

Stygichthys typhlops: $01->0$

Clado 130: $0 \rightarrow 1$

Hyphessobrycon compressus: 0 -> 1

Caráter 104 (10 passos)

Raiz: 1

Clado 142: 1 -> 01

Clado 117: $1 \rightarrow 0$

Clado 190: $01 \rightarrow$

Oligosarcus argenteus: 01 -> 0

Clado 182: $01 \rightarrow 1$

Brycon pesu: $1 \rightarrow 0$

Hemistichodus vaillanti: $1 \rightarrow 0$

Clado 139: $01 \rightarrow 0$

Clado 165: $01 \rightarrow 1$

Clado 149: $1 \rightarrow 0$

Markiana nigripinnis: 0 -> 1

Hollandichthys multifasciatus: $0->1$

Caráter 105 (10 passos)

Raiz: 01

Chanos chanos: $01->0$

Clado 103: $01 \rightarrow 1$

Gymnotus aff. carapo: 1 -> 0

Clado 154: 1 -> 0

Characidium bahiensis: 1 -> 0

Clado 114: 1 -> 0

Brycon pesu: $1 \rightarrow 0$

Clado 162: $\theta \rightarrow 01$

Clado 197: $01 \rightarrow 1$

Clado 156: $1 \rightarrow 0$

Brycinus macrolepidotus: $01->0$

Bryconalestes longipinnis: $01 \rightarrow 1$

Clado 130: $1 \rightarrow 0$

Caráter 106 (20 passos)

Raiz: 0

Clado 104: $0 \rightarrow 01$

Olivaichthys mesembrinus: 01 -> 1

Clado 115: $0 \rightarrow 01$

Clado 118: $01 \rightarrow 1$

Clado 190: $\Theta \rightarrow 1$

Clado 150: $\odot \rightarrow 1$

Citharinus latus: 0 -> 1

Clado 199: $\theta \rightarrow 1$ 
Chanos chanos: $01 \rightarrow 0$

Clado 103: 01 -> 1

Erythrinoidea fam. nov: 1 -> 0

Clado 155: $1 \rightarrow 0$

Caráter 108 (8 passos)

Raiz: 01

Chanos chanos: 01 ->

Clado 103: 01 -> $\odot$

Gymnotus aff. carapo: $0 \rightarrow 1$

Clado 154: $0 \rightarrow 1$

Clado 114: $0 \rightarrow 1$

Clado 162: 1 -> 01

Clado 197: $01 \rightarrow$

Clado 156: 01 - 1 idotus: $01 \rightarrow 1$

Bryconalestes longipinnis: $01->0$

Clado 130: $0 \rightarrow 1$

Caráter 109 (4 passos)

Raiz: $\odot$

Raiz: 0 (n) mesembrinus: $0-1$

Olivaichthys mesembrinus: $0 \rightarrow 1$

Arnoldichthys spilop

Hoplias malabaricus: 0 -> 1

Caráter 110 ( 6 passos)

Raiz: 01

Chanos chanos: 01 ->

Clado 103: $01 \rightarrow 1$

Clado 154: $1 \rightarrow 0$

Characidium bahiensis: 1 ->

Clado 146: $1 \rightarrow 01$

Clado 162: $\odot \rightarrow 1$

Clado 145: $01->0$
Hydrolycus tatauaia: $01->0$

Clado 149: $01 \rightarrow 1$

Caráter 111 ( 6 passos)

Raiz: 0

Clado 110: $\odot \rightarrow$

Clado 115: $2 \rightarrow 1$

Clado 122: $1 \rightarrow 01$

Clado 125: $01 \rightarrow 0$

Clado 150: $0 \rightarrow 2$

Clado 120: $01 \rightarrow 012$

Clado 123: $01->0$

Curimatopsis macrolepis: 012 -> 2

Clado 119: $012 \rightarrow 1$

Caráter 112 (23 passos)

Clado 111: 2 -> 1

Characidium bahiensis: $1 \rightarrow 0$

Clado 160: $1 \rightarrow 0$

Clado 160: 1 -> 0
Brycon pesu: 1 - $>0$

Hemistichodus vaillanti: $1 \rightarrow$

Hemistichodus vaillanti: $1->0$

Gnathocharax steindachneri: 1 ->

Erythrinoidea fam. nov: $1->$

Anodus orinocensis: $1->0$

Aphyocharax pusillus: $1->0$

Gilbertolus atratoensis: 1 - $>$

Metynnis lippincottianus: $\odot \rightarrow 1$

Boulengerella maculata: 1 -> 2

Clado 135: $1 \rightarrow 0$

Clado 179: $1 \rightarrow 01$

Clado 178: $01 \rightarrow 0$

Atopomesus pachyodus: 1 -> 0

Knodus meridae: $01 \rightarrow 0$

Piabina argentea: 01 -> 1

Clado 132: 0 -> 01

Compsura heterura: $1 \rightarrow 0$

Clado 164: 01 -> 1

Clupeacharax engrauloides: 01 -> $\odot$

Clado 130: $01->2$

Astyanax mexicanus: 1 -> $\odot$

Caráter 113 ( 7 passos)

Raiz: 0

Raiz: 0 Clado 115: 0 -> 1

Oligosarcus argenteus: $0 \rightarrow 1$

Clado 125: $1 \rightarrow 0$

Clado 125: $1 \rightarrow 0$

Gilbertolus atratoensis: $0 \rightarrow 1$

Gilbertolus atratoensis: 0

Leporellus vittatus:

Caráter 114 (28 passos)

Raiz: 2

Clado 111: 2 -> 1

Gymnotus aff. carapo: 2 -> 0

Clado 163: $1 \rightarrow 0$

Clado 115: 1 -> 12

Clado 118: $12 \rightarrow$

Salminus hilarii: 1 -> 2

Saccodon wagneri: $12 \rightarrow 1$

Clado 113: $12 \rightarrow 2$

Piabucina astrigata: $1->2$

Clado 139: $1 \rightarrow 0$

Erythrinoidea fam. nov: $1 \rightarrow 0$

Citharinus latus: $1->2$

Clado 124: 2 -> 1

Curimatopsis macrolepis: $2 \rightarrow 1$

Paragoniates alburnus: $1->0$

Gilbertolus atratoensis: $1 \rightarrow$

Schizodon fasciatus: $2 \rightarrow 1$

Phenacogaster pectinatus: $0 \rightarrow 1$

Clado 170: $0 \rightarrow 1$

Rhinobrycon negrensis: $\odot->1$

Clado 133: $\theta \rightarrow 1$

Piabina argentea: $0->1$

Clado 164: $1 \rightarrow 2$
Stygichthys typhlops: $\odot->1$

Thoracocharax stellatus : 1 -> 2

Carnegiella strigata: 1 -> $\odot$

Clado 187: 1 -> 01

Hyphessobrycon compressus: $1 \rightarrow 0$

Orthospinus franciscoensis: $01->$

Ctenobrycon hauxwellianus: $01>0$

Poptella brevispina: 01 -> 1

Caráter 115 ( 7 passos)

Raiz: 01

Chanos chanos: $01->1$

Clado 103: $\theta 1 \rightarrow 0$

Clado 153: $0 \rightarrow 01$

Salminus hilarii: $\odot->1$

Clado 157: $01 \rightarrow 1$

Copeina cf. guttata: $01->0$

Galeocharax knerii: $\odot \rightarrow 1$

Clado 145: $0 \rightarrow 1$

Clado 158: $01 \rightarrow 1$

Hemibrycon polyodon : $0->1$

Caráter 116 (2 passos)

Raiz: $\odot$

lado 111: $\odot \rightarrow 1$

Bryconadenos tanaothoros: 1 -> 0

Caráter 117 (30 passos)

Raiz: 012

Chanos chanos: 012 -> 2

Clado 103: $012 \rightarrow \odot$

Clado 143: $\odot \rightarrow 1$

Clado 106: $\odot \rightarrow$

Clado 113: $\odot \rightarrow 1$

Clado 122: $\odot \rightarrow 01$

Clado 146: $1 \rightarrow 01$

Clado 162: $\odot \rightarrow 1$

Clado 105: $1 \rightarrow 2$

Clado 121: $01 \rightarrow 1$

Gnathocharax steindachneri: 1 -> 0

Charax cf. leticiae: 1 -> 2

Clado 145: $01 \rightarrow 0$

Clado 197: 1 -> 2

Clado 123: 1 -> 2

Clado 124: $01 \rightarrow 1$

Clado 126: 01 -> 0

Aphyocharax pusillus: $1->0$

Hydrolycus tatauaia: $01->0$

Clado 149: $01 \rightarrow 2$

Phenagoniates macrolepis: 1 -> 2

Curimata ocellata: $1 \rightarrow 0$

Clado 180: $1 \rightarrow 0$

Phenacogaster pectinatus: 1 -> 2

Clado 172: 1 -> 01

Clado 171: $01 \rightarrow 0$

Clado 176: $01->0$

Clado 185: 01 -> 1

Clado 167: 1 -> 2

Rhoadsia altipinna: 1 -> 2

Iguacladoctes geisleri: $1 \rightarrow 0$

Clado 130: 1 -> 0

Agoniates halecinus: $1 \rightarrow 0$

Clado 193: 2 -> 1

Hyphessobrycon compressus: $1 \rightarrow 0$

Caráter 118 (13 passos)

Raiz: 01

Chanos chanos: 01 -> 1

Catostomus commersonnii: 01 -> 1

Clado 104: $01 \rightarrow 0$

Clado 109: $01 \rightarrow 0$

Clado 163: $01 \rightarrow 1$

Clado 143: $\theta 1 \rightarrow 0$

Clado 153: $01 \rightarrow 1$

Clado 160: $01 \rightarrow 0$

Gnathocharax steindachneri: 0 -> 1

Clado 145: $\odot \rightarrow 1$

Clado 158: $1 \rightarrow$

Phenagoniates macrolepis: $\odot->1$

Clado 176: $\odot \rightarrow 01$

Clado 176: $\odot->01$

Axelrodia reisei: $01 \rightarrow 1$

Axelrodia reisei: $01->1$

Iguacladoctes geisleri: $\odot->1$

Clado 130: $0 \rightarrow 1$

Hyphessobrycon compressus: $\odot->1$

Caráter 119 (2 passos)

Raiz: 01

Chanos chanos: $01->0$

Clado 111: $01 \rightarrow 1$

Catostomus commersonnii: $01->0$

Clastomus commerson $104: 01-1$

Caráter 120 (10 passos)

Raiz: 01

Clado 104: 01 -> 0

Clado 163: 01 -> 1

Clado 108: 01 -> 1

Clado 115: 01 -> 0

Clado 160: $01 \rightarrow 1$

Clado 141: 01 -> 1

Salminus hilarii: 01 -> 0

Clado 157: 01 -> 0

Brycon pesu: 01 -> 1

Clado 146: 01 -> 0

Copeina cf. guttata: 01 -> 1

Clado 151: $01 \rightarrow 0$

Charax cf, leticiae: $01 \rightarrow 1$

Galeocharax knerii: $01 \rightarrow 0$

Citharinus latus: $1->0$

Gilbertolus atratoensis: $0->1$

Triportheus albus: $1 \rightarrow \odot$

Caráter 121 (4 passos)

Raiz:

Clado 111: $1 \rightarrow 0$

Clado 114: $\odot \rightarrow 1$

Clado 155: $0 \rightarrow 1$

Clado 127: $0 \rightarrow 1$

Caráter 122 ( 6 passos)

Raiz: 1

Catostomus commersonnii: 1 -> $\odot$

Clado 151: 1 -> 0

Curimatopsis macrolepis: 1 ->

Clado 155: $1 \rightarrow 0$

Glandulocauda melanogenys: 1 -> 0

Astyanax mexicanus: $1 \rightarrow 0$

Caráter 123 (11 passo)

Raiz: 1

Clado 111: $1 \rightarrow 0$

Clado 153: 0 -> 01

Brycon pesu: $\odot->1$

Copeina cf. guttata: $01 \rightarrow 1$

Lebiasina bimaculata: $01 \rightarrow 0$

Piabucina astrigata: $01 \rightarrow 1$

Clado 161: $0 \rightarrow 1$

Clado 126: $\theta \rightarrow 1$

Clado 156: $\theta \rightarrow 01$

Hepsetus odoe: $01->1$

Leporellus vittatus: $1 \rightarrow 0$

Stygichthys typhlops: $0 \rightarrow 1$

Agoniates halecinus: $0 \rightarrow 1$

Clado 129: $0 \rightarrow 1$

Caráter 124 (20 passos)

Raiz: 01

Chanos chanos: $01 \rightarrow 0$

Clado 103: $01 \rightarrow 1$

Clado 115: $1 \rightarrow 0$

Arnoldichthys spilopterus: $1 \rightarrow 0$

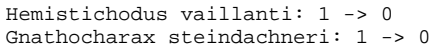

Citharinus latus: 1 -> 0

Clado 199: $1 \rightarrow 0$

Brycinus macrolepidotus: $1 \rightarrow \theta$

Clado 128: $0 \rightarrow 1$

Potamorhina latior: $0 \rightarrow 1$

Hemibrycon polyodon : $1 \rightarrow 0$

Clado 178: $1 \rightarrow 0$

Microschemobrycon casiquiare: 1 -> 0

1 -> 01

Paracheirodon axelrodi: 1 -> 0

Rhoadsia altipinna: $1 \rightarrow 0$

Clado 192: $01 \rightarrow 0$

Clupeacharax engrauloides: 1 -> 0

Astyanax mexicanus: $01 \rightarrow 1$

Clado 189: 01 -> 0

Orthospinus franciscoensis: 0 -> 1

Caráter 125 ( 6 passos)

Raiz: 0

Gymnotus aff. carapo: $0->1$

Clado 153: $0 \rightarrow 1$

Salminus hilarii: 0 -> 1

Hydrolycus tatauaia: $\odot \rightarrow 1$

Semaprochilodus insignis: $0 \rightarrow 1$

Bryconops alburnoides: $\odot->1$

Caráter 126 (6 passos)

Raiz: 1

Crenuchus spilurus: 1 -> 0

Clado 159: 1 -> 01

Brycon pesu: 1 -> 0

Arnoldichthys spilopterus: $01 \rightarrow 0$

Clado 161: $01 \rightarrow$

Clado 197: $01 \rightarrow$

Clupeacharax engrauloides: 1 -> 0

Agoniates halecinus: $1 \rightarrow 0$

Caráter 127 ( 6 passos)

Raiz: 01

Chanos chanos: 01 ->

Clado 103: $01->1$

Clado 153: $1 \rightarrow 0$

Clado 183: $1 \rightarrow 01$

Oligosarcus argenteus: $01->0$

Charax cf. leticiae: $01 \rightarrow 1$

Galeocharax knerii: $01 \rightarrow 0$ 
Clado 151: $\odot->01$
Clado 158: 01 -> 1

Acestrorhynchus falcirostris: $\odot \quad->2$

Clado 149: $\odot \rightarrow 1$

Caráter 130 ( 9 passos)

Raiz: $\odot$

Clado 111: $0 \rightarrow 01$

Clado 109: $01 \rightarrow 0$

Clado 163: $01 \rightarrow 1$

Clado 143: $01 \rightarrow 1$

Clado 160: $01 \rightarrow 1$

Clado 157: $01 \rightarrow$

Copeina cf. guttata: $01>0$

Clado 105: $\odot \rightarrow 1$

Clado 158: $01 \rightarrow 1$

Anodus orinocensis: $0 \rightarrow 1$

Clado 123: $0 \rightarrow 1$

Hepsetus odoe: $1 \rightarrow 0$

Hepsetus odoe: $1->0$

Agoniates halecinus: 1
caráter 131 ( 25 passos)

Raiz: 01

Chanos chanos: 01 -> 0

Clado 104: $01 \rightarrow 1$

Clado 110: $01 \rightarrow$

Olivaichthys mesembrinus: 1 -> 2

Clado 143: $01 \rightarrow 12$

Clado 142: $12 \rightarrow 2$

Salminus hilarii: 12 -> 1

Clado 147: $12 \rightarrow 2$

Clado 157: 01 -> 1

Chalceus epakros: $01 \rightarrow 1$

Copeina cf. guttata: $01->0$

Arnoldichthys spilopterus: $01-\odot$

Gnathocharax steindachneri: $2 \rightarrow 0$

Galeocharax knerii: $2 \rightarrow 0$

Clado 161: $01 \rightarrow 0$

Clado 197: $01 \rightarrow 2$

Aphyocharax pusillus: 2 -> 1

Clado 156: 2 -> 012

Hepsetus odoe: $012 \rightarrow 0$

Gilbertolus atratoensis: $2 \rightarrow 0$

Leporinus fasciatus: $0 \rightarrow 1$

Clado 132: $2 \rightarrow 12$

Brittanichthys axelrodi: $2 \rightarrow 0$

Paracheirodon axelrodi: $2 \rightarrow 1$

Clado 131: $12 \rightarrow 1$

Agoniates halecinus: $12->1$

Triportheus albus: $12->2$

Markiana nigripinnis:
Caráter 132 ( 15 passos)

Raiz: 0

Clado 110: 0 -> 012

Clado 109: $012 \rightarrow 1$

Clado 163: $012 \rightarrow 2$

Clado 153: $0 \rightarrow 2$

Salminus hilarii: $\odot \rightarrow$

Clado 159: $\odot \rightarrow 0$

Clado 117: $1->0$
Piabucina astrigata: $2->1$

Piabucina astrigata: $2->1$

Arnoldichthys spilopterus: $01->$
Distichodus notospilus: $1->2$

Clado 161: $01 \rightarrow 1$

Clado 197: $01 \rightarrow 0$

Citharinus latus: $1 \rightarrow 0$

Hydrolycus tatauaia: $0 \rightarrow 1$

Clado 128: 1 -> $\odot$

Paracheirodon axelrodi: 0 -> 1

Clado 130: $0 \rightarrow 1$

Hollandichthys multifasciatus: $0->1$

Caráter 133 (20 passos)

Raiz: $\odot$

Clado 163: $\odot \rightarrow>1$

$\begin{array}{llll}\text { Clado } 163: & 0 & \rightarrow>1 \\ \text { Clado 153: } & 0 & \rightarrow> & 02\end{array}$

Clado 141: $0>02$

Clado 147: $0 \rightarrow 02$

Clado 147: $0 \rightarrow>02$

$\begin{array}{lll}\text { Clado 152: } & 02 & ->012 \\ \text { Clado 140: } 02 & \rightarrow>2\end{array}$

Copeina cf. guttata: $012 \rightarrow$

Copeina cf. guttata: $012 \rightarrow>$

Lebiasina bimaculata: $02->$

Arnoldichthys spilopterus: $\odot \rightarrow 1$

Arnoldichthys spilopterus: $0->1$

Gnathocharax steindachneri: $02->$

Roeboexodon guyanensis:

Clado 145: $02 \rightarrow 012$

Clado 158: $012 \rightarrow 1$

Clado 156: 012 -> 1 : 02 ->

Hydrolycus tatauaia:
Clado 149: $\odot 2 \rightarrow 2$

Clado 149: $02->2$

Clado 196: $\odot \rightarrow 2$

Clado 173: $2 \rightarrow 0$

Paragoniates alburnus: 2 ->

Clado 179: 2 -> 0

Axelrodia reisei: $0->2$
Compsura heterura: $0->2$

Clado 192: 2 ->

Clupeacharax engrauloides: $2 \rightarrow 0$

Agoniates halecinus: $2 \rightarrow 0$

Gymnocorymbus ternetzi: 2 -> 0

Caráter 134 (23 passos)

Raiz: 01

Chanos chanos: 01 ->

Clado 103: $01, \rightarrow 0$

Gymnotus aff. carapo: $\odot \rightarrow 1$

Crenuchus spilurus: $0 \rightarrow 1$

Crenuchus spilurus:

$\begin{array}{llll}\text { Clado 153: } & \odot & -> & 01 \\ \text { Clado 118: } \odot ~ & \rightarrow>01\end{array}$
Clado 141: $\odot \rightarrow 1$

Clado 152: $01 \rightarrow 1$

Brycon pesu: $\odot \rightarrow 1$

Lebiasina bimaculata: $01 \rightarrow 1$

Piabucina astrigata: 01 -> $\odot$

Distichodus notospilus: $0 \rightarrow$

Bivibranchia fowleri: $01 \rightarrow 1$

Clado 116: $01 \rightarrow 0$

Clado 125: $01 \rightarrow 1$

Clado 123: $01 \rightarrow 1$

Clado 149: $0 \rightarrow 1$

Clado 196: $\theta \rightarrow 1$

Clado 119: $01->0$

Paragoniates alburnus: 1 -> 0

clado 172: $1 \rightarrow$

Leporellus vittatus: $1 \rightarrow 0$

clado 179: 1 :

Compsura heterura: $\odot \rightarrow 1$

Clado 192: $1 \rightarrow 0$

Clupeacharax engrauloides: $1 \rightarrow 0$

Agoniates halecinus: $1 \rightarrow 0$

clado 188: $1 \rightarrow 0$

Ctenobrycon hauxwellianus: $\odot->1$

Caráter 135 (5 passos)

Raiz: 0

Distichodus notospilus: $\odot->1$

Nannocharax fasciatus: $0 \rightarrow 1$

Clado 125: $\odot \rightarrow 01$

Clado 126: 01 -> 1

Caenotropus labyrinthicus: 01 -> 1

Chilodus punctatus: $01 \rightarrow 0$

Clado 155: $\odot \rightarrow 1$

Caráter 136 (15 passos)

Raiz: $\odot$

Olivaichthys mesembrinus: 0 -> 1

Clado 147: $\odot \rightarrow 01$

Brycon pesu: $01->1$

Gnathocharax steindachneri: 0 -> 1

Clado 199: 0 -> 1

Acestrorhynchus falcirostris: 01 -> 1

Clado 156: 01 -> 0

Hydrolycus tatauaia: $01->0$

Clado 149: 01 -> 1

Hoplias malabaricus: $0->1$

Piaractus mesopotamicus: $\odot \rightarrow 1$

Clado 137: $0 \rightarrow 1$

Clado 171: $0 \rightarrow 1$

Diapoma terofali: $1->$

Clado 168: $1 \rightarrow 0$

Piabina argentea: $1 \rightarrow 0$

Iguacladoctes geisleri: $1 \rightarrow 0$

Markiana nigripinnis: $0 \rightarrow 1$

caráter 137 (18 passos)

Raiz: 0

Clado 104: $0 \rightarrow$

Neolebias unifasciatus: 0 -> 1

Clado 151: $\Theta \rightarrow 01$

Clado 158: 01 -> 1

Citharinus latus: 0 -> 1

Clado 174: $\odot \rightarrow 01$

Clado 199: $\odot \rightarrow 1$

Serrabrycon magoi: $01 \rightarrow 1$

Phenacogaster pectinatus: $01 \rightarrow 0$

Rhinobrycon negrensis: $0 \rightarrow 1$

Clado 171: $01 \rightarrow 1$

Glandulocauda melanogenys: $0 \rightarrow 1$

Piabina argentea: $0->1$

Odontostilbe pequira: 01 -> 1

Compsura heterura: $01 \rightarrow 0$

Rhoadsia altipinna: $01 \rightarrow 1$

Iguacladoctes geisleri: $\odot \rightarrow$

Clado 192: 0 -> 1

Rachoviscus graciliceps: $\odot$-> 1

Tetragonopterus argenteus: $\odot \rightarrow 1$

Hollandichthys multifasciatus: $1 \rightarrow \odot$

Poptella brevispina: $0 \rightarrow 1$

Caráter 138 (17 passos)

Raiz: 01

Chanos chanos: 01 -> 0

Catostomus commersonnii: 01 -> 1

Clado 144: $01 \rightarrow 0$

Characidium bahiensis: 01 -> 1

Crenuchus spilurus: $01 \rightarrow \odot$

Clado 183: $0 \rightarrow$ 1

Distichodus notospilus: $1->0$

Nannocharax fasciatus: $1 \rightarrow 0$

Roeboexodon guyanensis: $0->1$

Clado 145: $\Theta \rightarrow 1$

lado 126: 1 ->

Clado 196: $\odot \rightarrow 1$

Clado 173: $\odot \rightarrow 01$

Phenacogaster pectinatus: 01 -> 1

Ctenolucius hujeta: $1 \rightarrow 0$

Clado 171: $01 \rightarrow 0$

Clado 177: $01 \rightarrow 1$

Diapoma terofali: 0 -> 1

Clado 169: $0 \rightarrow 1$

Agoniates halecinus: $0->1$

Markiana nigripinnis: 1 ->

Caráter 139 (30 passos)

Raiz: 2

Clado 109: $2 \rightarrow 1$

Clado 154: $2 \rightarrow$

Neolebias unifasciatus: $1 \rightarrow 0$

Salminus hilarii: 2 -> 1

Clado 182: 2 -> 1

Distichodus notospilus: 1 -> 0

Apareiodon piracicabae: $1 \rightarrow 0$

Anodus orinocensis: 1 -> 2

Clado 126: $1 \rightarrow 2$

Clado 138: 2 -> 12

Clado 199: 2 -> 012

Clado 156: $2 \rightarrow 1$

Hydrolycus tatauaia: 2 -> 0

Clado 137: $12 \rightarrow 1$

Paragoniates alburnus: 012 -> 1

Phenagoniates macrolepis: $012 \rightarrow 0$

Myleus setiger: $1 \rightarrow 0$

Phenacogaster pectinatus: 02 -> 0

Clado 177: 02 -> 012

Clado 169: 1 -> 0

Clado 194: 1 ->

Atopomesus pachyodus: $02 \rightarrow 0$

Microschemobrycon casiquiare: 02 -> 2

Clado 176: $012 \rightarrow 01$

Bryconadenos tanaothoros: 1 -> 2

Clado 198: 01 -> 1

Odontostilbe pequira: 012 -> 0

Clado 167: $\odot \rightarrow 2$

Axelrodia reisei: $01 \rightarrow 1$

Brittanichthys axelrodi: 01 -> 0

Compsura heterura: $012 \rightarrow 2$

Rhoadsia altipinna: $012->1$

Clado 164: $1 \rightarrow 2$

Iguacladoctes geisleri: 1 -> 0

clado 193: $2 \rightarrow 1$

Clado 187: $2 \rightarrow 1$

Tetragonopterus argenteus: 2 -> 1

Caráter 140 (11 passo)

Raiz: 0

Clado 148: 0 -> 01

Salminus hilarii: 01 -> 1

Brycon pesu: $01 \rightarrow 0$

Hemistichodus vaillanti: $\odot \rightarrow 1$

Roeboexodon guyanensis: $\theta->1$

Clado 161: $\Theta \rightarrow 1$

Clado 123: $0 \rightarrow 1$

Hydrolycus tatauaia: $01 \rightarrow 1$

Hydrolycus tatauaia: $01->1$
Clado 149: $01 \rightarrow 0$

Erythrinus erythrinus: $\odot->1$

Hepsetus odoe: $01 \rightarrow 1$

Clado 155: $01 \rightarrow 0$

Agoniates halecinus: $0->1$

pamus : $0 \rightarrow 1$

caráter 141 (15 passos)

Raiz: 01

Chanos chanos: $01->1$

Clado 103: $01->0$

Clado 141: $0 \rightarrow 1$

Clado 147: $0 \rightarrow->1$

Hemistichodus vaillanti: $\odot->1$

Bivibranchia fowleri: $01->$

Anodus orinocensis: $01->1$
Hemiodus unimaculatus : $01 \rightarrow 0$

Clado 199: $1 \rightarrow 0$

Clado 156: $1>0$

Clado 173: 1 -> 0

Rhinobrycon negrensis: 1 -> $\odot$

Clado 134: 1 -> 0

Odontostilbe pequira: $0 \rightarrow 1$

Clado 200: $\odot \rightarrow 01$

Clado 164: $0 \rightarrow 1$

Rachoviscus graciliceps: 01 -> 1

Clado 193: 1 -> 0

Caráter 142 (19 passos)

Raiz: 1

Clado 102: $1 \rightarrow 01$

Catostomus commersonnii: $01->0$

Clado 163: $1 \rightarrow 0$

Clado 142: 1 -> 01

Clado 183: $01 \rightarrow 0$

Clado 140: $01 \rightarrow 0$

Clado 190: $01 \rightarrow 1$

Clado 120: $1 \rightarrow 0$

Curimatopsis macrolepis: $01 \rightarrow 0$

Caenotropus labyrinthicus: 1 -> 
Rachoviscus graciliceps: 01 -> 1 Triportheus albus: $\odot \rightarrow 1$ Caráter 144 ( 8 passos)

Raiz: $\odot$

Clado 183: $0 \rightarrow 1$

Salminus hilarii: $\Theta->$

Apareiodon piracicabae: $0 \rightarrow 1$ Gnathocharax steindachneri: $0->1$ Anodus orinocensis: $\odot \rightarrow 1$

Hydrolycus tatauaia: $\odot \rightarrow 2$ Semaprochilodus insignis: $0->1$

Hepsetus odoe: $0 \rightarrow 1$

Caráter 145 (18 passos)

Raiz: 0

Clado 115: $\odot \rightarrow 01$

Clado 113: $01>01$

Clado 113: $01 \rightarrow 1$

Clado 122: 01 -> $\odot$

Arnoldichthys spilopterus: $0 \rightarrow 1$

Hemistichodus vaillanti: $0 \rightarrow-1$

Bivibranchia fowleri: $01 \rightarrow 1$

Clado 165: $01 \rightarrow 1$

Clado 150: 01

Anodus orinocensis: $01->1$

Hemiodus unimaculatus : $01 \rightarrow$

Landonia latidens: $01->0$

Serrabrycon magoi: $01 \rightarrow 1$

Clado 173: 01 - $>0$

Hepsetus odoe: $\odot->1$
Myleus setiger: $0 \rightarrow>1$

Clado 135: $01 \rightarrow>$

Clado 170: $01 \rightarrow 1$

Rhinobrycon negrensis: 01 -> 0

Clado 179: $01 \rightarrow 1$
Clado 175: $0 \rightarrow 1$

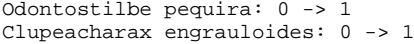

Triportheus albus: 0 -> 1

Hyphessobrycon compressus: 1 -> $\theta$

Caráter 146 (32 passos)

Raiz: 013

Chanos chanos: $013 \rightarrow 0$

Chanos chanos: $013 \rightarrow->0$

Clado 144: $013 \rightarrow 3$

Clado 109: $013 \rightarrow 0123$

Crenuchus spilurus: $013->3$

Neolebias unifasciatus: 0123 -> 3

clado 1

$\begin{array}{llll}\text { Clado 118: } & 0123 & -> & 123 \\ \text { Clado 159: } 3-> & 2 \\ \text { Clado 106: } & 0123 & -> & 02\end{array}$

Copeina cf. guttata: $3 \rightarrow 2$

Copeina cf. guttata: $3 \rightarrow 2$

Lebiasina bimaculata: $3 \quad->0$

Hemistichodus vaillanti: $0123 \rightarrow 2$

Hemistichodus vaillanti: $0123 \rightarrow 2$

Apareiodon piracicabae: $0123 \rightarrow 1$

$0123->$

Bivibranchia fowleri: 123 -> 2

Clado 125: $123 \rightarrow 2$

Clado 161: 2 -> 012

Citharinus latus: $02->0$

Xenocharax spilurus: $02 \rightarrow>2$

Anodus orinocensis: $123->3$

Hemiodus unimaculatus : $123 \rightarrow 1$

Clado 120: $123 \rightarrow 0123$

Clado 123: 123 -> 1

Clado 149: $3 \rightarrow 2$

Brycinus macrolepidotus: $012 \rightarrow 1$

Bryconalestes longipinnis: $012 \rightarrow$

Curimatopsis macrolepis: $0123 \rightarrow 3$

Phenagoniates macrolepis: $3 \rightarrow 2$

Metynnis lippincottianus: $2 \rightarrow 1$

Curimata ocellata: $0123 \rightarrow 0$

Potamorhina latior: $0123 \rightarrow$

Potamorhina latior: $0123 \rightarrow$

Schizodon fasciatu

Phenacogaster pectinatus: $3 \rightarrow 0$

Phenacogaster pectinatus: 3 ->

uensis: $3 \rightarrow 2$

Clado 184: $3 \rightarrow 2$

Clupeacharax engrauloides: $3 \rightarrow 0$

Clupeacharax engrauloides: $3 \rightarrow$

Hemigrammus unilineatus: 3 ->

Clado 186: $3 \rightarrow 2$

Caráter 147 ( 5 passos)

Raiz: 0

Salminus hilarii: $0->1$

Clado 123: $0 \rightarrow 1$

Piaractus mesopotamicus: $0->1$

Clado 155: $\odot \rightarrow 1$

Bryconops alburnoides: 0 -> 1

Caráter 148 (24 passos)

Raiz: $\odot$

Chalceus epakros: $0->1$

Clado 117: 0 -> 01

Brycon pesu: $0->1$

Copeina cf. guttata: $0 \rightarrow 1$

Nannocharax fasciatus: $0 \rightarrow 1$

Bivibranchia fowleri: 01 -> 1

Clado 139: $0 \rightarrow 1$

Charax cf leticiae: $\odot \rightarrow 1$

Clado 161: $0 \rightarrow 1$

Xenocharax spilurus: $0 \rightarrow 1$

Anodus orinocensis: $01->1$

Hemiodus unimaculatus : $01 \rightarrow 0$

Clado 124: $0 \rightarrow 1$
Clado 149: $\odot \rightarrow 1$

Semaprochilodus insignis: 0 -> 1

Myleus setiger: $0 \rightarrow 1$

Potamorhina latior: $0^{->} 1$

Clado 127: $0 \rightarrow 1$

Clado 179: 1 -> 01

Diapoma terofali: 1 -> 0

Clado 178: $01 \rightarrow 0$

Clado 185: 1 -> 01

Knodus meridae: $01->1$

Piabina argentea: $01 \rightarrow 0$

Odontostilbe pequira: $01 \rightarrow 0$

Compsura heterura: $01 \rightarrow 1$

Rhoadsia altipinna: $01->$

Iguacladoctes geisleri: $1 \rightarrow 0$

ado 129: 1 -> 01

Gasteropelecus sternicla: 01 -> 0

Markiana nigripinnis: 1 -> 0

Raiz: 01

Chanos chanos: 01 -> 0

Chanos chanos: 01

Clado 111: $01->1$

Catostomus commersonnii: $01 \rightarrow 0$

Clado 108: $1 \rightarrow 0$

lado 122: $1 \rightarrow$

Clado 140: 1 -> 01

Copeina cf. guttata: $1>0$

ebiasina bimaculata: $1 \rightarrow$

Clado 105: $0 \rightarrow 1$

Hemiodus unimaculatus : $1->0$

Aphyocharax pusillus: $01->0$

Landonia latidens: $01 \rightarrow \odot$

Serrabrycon magoi: $01->1$

$\begin{array}{lll}\text { Paragoniates alburnus: } 01-> & 1 \\ \text { Phenagoniates macrolepis: } 01 & \rightarrow>0\end{array}$

Myleus setiger: 1 -> $\odot$

Clado 136: $01 \rightarrow 1$

Clado 180: $01 \rightarrow 0$

Phenacogaster pectinatus: 01 -> 0

Clado 172: 01 -> 1

Moenkhausia xinguensis: $1 \rightarrow 0$

Bryconamericus exodon: $0->1$

Clado 184: $1 \rightarrow 0$

Paracheirodon axelrodi: $1->0$

IguaCladoctes geisleri: 1 -> 0

Clado 130: 1 -> 0

Triportheus albus: $1 \rightarrow 0$

Tetragonopterus argenteus: $1 \rightarrow 0$

Ctenobrycon hauxwellianus: $1 \rightarrow 0$

caráter 150 (8 passos)

Raiz: 0

Brycon pesu: $0->1$

Piabucina astrigata: $0 \rightarrow 1$

Charax cf. leticiae: $0 \rightarrow 1$

Clado 197: $0 \rightarrow 01$

Clado 123: $0 \rightarrow 1$

Clado 123: $\theta \rightarrow>1$

Piaractus mesopotamicus: $01 \rightarrow 1$

Roestes molossus: $01->1$

Metynnis lippincottianus: $01 \rightarrow 0$

Myleus setiger: $01 \rightarrow 1$

Agoniates halecinus: 0 - $>1$

Caráter 151 (10 passos)

Raiz: 0

Catostomus commersonnii: 0 -> 1

Gnathocharax steindachneri: $0->1$

Erythrinoidea fam. nov: $0 \rightarrow 1$

Aphyocharax pusillus: $0 \rightarrow 1$

Clado 155: $\theta \rightarrow 1$

Clado 176: $0 \rightarrow 01$

Piabina argentea: $\odot->1$

Clado 198: $01 \rightarrow 1$

Axelrodia reisei: $01 \rightarrow 1$

Brittanichthys axelrodi: 01 -> 0

Rhoadsia altipinna: $0 \rightarrow 1$

Clado 131: $0 \rightarrow 01$

Carnegiella strigata: 01 -> 1

Caráter

Raiz:

Clado 154: $0 \rightarrow 01$

Clado 153: 01 -> 1

Chalceus epakros: 01 -> 0

Clado 159: $01 \rightarrow 1$

Clado 117: $01 \rightarrow 1$

Citharinus latus: $\odot->1$

lado 124: $01 \rightarrow 0$

Clado 156: $0 \rightarrow 01$

Erythrinus erythrinus: 1 -> 0

Curimatopsis macrolepis: 01 -> 1

Prochilodus nigricans: $01 \rightarrow 1$

Semaprochilodus insignis: $01->0$

Anostomus anostomus: $01->0$

Phenagoniates macrolepis: $0->1$

Hepsetus odoe: $01->1$

Curimata ocellata: $01->1$

Potamorhina latior: $01 \rightarrow 0$

Schizodon fasciatus: $01 \rightarrow 1$

Leporellus vittatus: $01 \rightarrow 1$

Leporinus fasciatus: $01 \rightarrow$

Bryconops alburnoides: $\odot$

Triportheus albus: 01

Caráter 153 (24 passos)

Raiz: 2

Clado 109: 2 -> 1

Clado 157: $2 \rightarrow 12$

Clado 159: $2 \rightarrow 1$

Clado 122: $1 \rightarrow>$

Copeina cf. guttata: $2 \rightarrow 0$

ina $12 \rightarrow 1$

Clado 139: 2 -> 1

Hemiodus unimaculatus : $1 \rightarrow 2$

Clado 149: $2 \rightarrow 1$

Brycinus macrolepidotus: $1 \rightarrow 0$

Clado 196: 1 -> 01

Clado 119: $0 \rightarrow 012$

Myleus setiger: $01 \rightarrow 0$

Curimata ocellata: $012 \rightarrow 1$

Potamorhina latior: $012->2$

Clado 127: $\odot \rightarrow 1$

Clado 177: $1 \rightarrow 0$

Diapoma terofali: 1 -> 2

Microschemobrycon casiquiare: 1 -> 2

Clado 168: $1 \rightarrow 0$

Bryconadenos tanaothoros: 1 -> 0

Knodus meridae: 1 -> 2

Bryconops alburnoides: 1 -> 0

Agoniates halecinus: $1 \rightarrow 2$

Astyanax mexicanus: $0 \rightarrow 2$

Orthospinus franciscoensis: 0 -> 1

Caráter 154 (10 passos)

Raiz: 0

Clado 154: $0 \rightarrow 1$

Clado 115: $\odot \rightarrow 1$

Clado 162: $1 \rightarrow 01$

Clado 145: $\odot \rightarrow 1$

Citharinus latus: $\odot \rightarrow$

Brycinus macrolepidotus: $01->0$

Bryconalestes longipinnis: $01->1$
Piaractus mesopotamicus: $01->0$

Clado 128: 1 -> 01

Metynnis lippincottianus: $01->0$

Myleus setiger: $01 \rightarrow 1$

Clado 127: $01 \rightarrow 0$

Clado 181: $\Theta \rightarrow 1$

Triportheus albus: $0 \rightarrow 1$

Caráter 155 (24 passos)

Raiz: 1

Clado 163: 1 -> 01

Crenuchus spilurus: $01->0$

Clado 141: $12 \rightarrow 2$

Salminus hilarii: $12->2$

Salminus hilarii: $12->2$

Clado 106: $1 \rightarrow 2$

Brycon pesu: $12->2$

Bivibranchia fowleri: $1 \rightarrow 0$

Clado 125: $1 \rightarrow 01$

Clado 145: 12 ->

Clado 124: 01 ->

Hydrolycus tatauaia: 12 -> 2

Clado 149: 12 -> 1

Erythrinus erythrinus: 1 -> 0

Semaprochilodus insignis: $1 \rightarrow 2$

Anostomus anostomus: $01->0$

Paragoniates alburnus: $2 \rightarrow 0$

Potamorhina latior: $1->0$

Schizodon fasciatus: $01->1$

Clado 172: 2 -> 02

Leporellus vittatus: $01->1$

Leporinus fasciatus: $01->0$

Rhinobrycon negrensis: $2 \rightarrow 0$

Clado 134: $2 \rightarrow 0$

Hemibrycon polyodon : $2 \rightarrow 1$

Atopomesus pachyodus: $02 \rightarrow 2$

Microschemobrycon casiquiare: $02->0$

Knodus meridae: 2 - $>0$

Odontostilbe pequira: $02->0$

Brittanichthys axelrodi: $02->0$

Compsura heterura: $02 \rightarrow 2$

Bryconops alburnoides: $\odot \rightarrow 1$

Clado 195: $2 \rightarrow 0$

Caráter 156 (17 passos)

Raiz: 0

Clado 114: $\odot \quad->01$

Clado 113: $01 \rightarrow 1$

Clado 182: $0 \rightarrow 01$ 
Clado 118: $\odot \rightarrow 1$

Chalceus epakros: $01->1$

Clado 182: $0 \rightarrow 01$

Arnoldichthys spilopterus: 01 -> $\odot$

Clado 162: 01 -> 1

Roeboexodon guyanensis: 0 -> 1

Galeocharax knerii: 01 - $>1$

Acestrorhynchus falcirostris: $1->$

Hoplias malabaricus: $0 \rightarrow 1$

Chilodus punctatus: $1 \rightarrow 0$

Clado 170: $0 \rightarrow 01$

Hemibrycon polyodon : $01->1$

Moenkhausia xinguensis: $01-1$

Clado 168: $01 \rightarrow 0$

Clado 132: 0 -> 01

Clado 164: $01->1$

Clado 187: $\odot \rightarrow 01$

Clado 187: 0 -> 01 : $0->1$

Orthospinus franciscoensis: $01->1$

Ctenobrycon hauxwellianus: $01 \rightarrow 0$

Poptella brevispina: $01 \rightarrow 1$

caráter 158 ( 4 passos)

Raiz: 0

Clado 157: $\odot \rightarrow 1$

Clado 182: $\odot \rightarrow 01$

Galeocharax knerii: 01 -> 1

Clado 145: $\odot \rightarrow 1$

Hoplias malabaricus: $\odot->2$

Caráter 159 (18 passos)

Raiz: $\odot$

Clado 143: $\odot \rightarrow 01$

Clado 115: $0 \rightarrow 01$

Clado 148: $01 \rightarrow 1$

Clado 141: $01 \rightarrow 1$

Clado 183: $01 \rightarrow$

Clado 113: $01 \rightarrow>1$

Clado 122: 01 ->

Piabucina astrigata: $0 \rightarrow 1$

Clado 105: 0 -> 01

Bivibranchia fowleri: $01 \rightarrow 1$

Xenocharax spilurus: $01 \rightarrow 1$

Anodus orinocensis: $01-1$

Hemiodus unimaculatus : $01 \rightarrow 0$

Erythrinus erythrinus: $\odot->1$

Piaractus mesopotamicus: $0->1$

Semaprochilodus insignis: $0->1$

Semaprochilodus insignis: $0->1$

Phenagoniates macrolepis: $1 \rightarrow \odot$

Phenagoniates macrole

Atopomesus pachyodus: $01->0$

Microschemobrycon casiquiare: 01 -> 1

Glandulocauda melanogenys: $1 \rightarrow \odot$

Knodus meridae: $1 \rightarrow 0$

Iguacladoctes geisleri: 1 -> $\odot$

Markiana nigripinnis: 1 -> 0

Caráter 160 ( 3 passos)

Raiz: 1

Copeina cf. guttata: $1 \rightarrow 0$

Piabucina astrigata: $1 \rightarrow$

Schizodon fasciatus: $1 \rightarrow 0$

Caráter 161 (11 passo)

Raiz: $\odot$

Clado 144: $0 \rightarrow>1$

Clado 141: $1 \rightarrow 0$

Clado 159: $1 \rightarrow 01$

Clado 146: 1 -> 01

Arnoldichthys spilopterus: $01->0$

Charax cf. leticiae: $1 \rightarrow 0$

Clado 150: $01 \rightarrow$

Clado 161: $01 \rightarrow$

Clado 197: $01 \rightarrow$

Anodus orinocensis: $0 \rightarrow-1$

Acestrorhynchus falcirostris: $01 \rightarrow 0$

Acestrorhynchus faic

Anostomus anostomus: $0->1$

Anostomus anostomus: $0->1$

$\begin{array}{lll}\text { Paragoniates alburnus: } & 0 & ->1 \\ \text { Leporinus fasciatus: } 0 & ->1\end{array}$

Leporinus fasciatus:

Raiz: 2

Clado 102: $2->12$

Clado 104: $12 \rightarrow>1$

Clado 152: $2 \rightarrow 012$

Copeina cf. guttata: $012 \rightarrow>0$

Erythrinoidea fam. nov: $012 \rightarrow 0$

Clado 158: $012 \rightarrow 2$

Curimatopsis macrolepis: 2 -> 01

Chilodus punctatus: $2 \rightarrow 1$

Clado 173: $2 \rightarrow 1$

Roestes molossus: 2 ->

Rhinobrycon negrensis: 2 ->

Microschemobrycon casiquiare: $1->2$

Clado 176: $1 \rightarrow 0$

Iguacladoctes geisleri: 2 -> 1

Clado 192: 2 -> 12

Clado 130: 2 -> 01

Probolus heterostomus : $12 \rightarrow 1$

Thoracocharax stellatus : $01->$

Hemigrammus unilineatus: $12 \rightarrow 1$

Carnegiella strigata: $01 \rightarrow 0$

Gasteropelecus sternicla: $01 \rightarrow$

Hollandichthys multifasciatus: $12 \rightarrow 2$

Caráter 163 (1 passo)

Raiz: 0

Clado 114: $\odot \rightarrow 1$
Caráter 164 (2 passos)

Raiz: $\odot$

Erythrinus erythrinus: $0 \rightarrow 1$

Potamorhina latior: $0 \rightarrow 1$

Caráter 165 (26 passos)

Raiz: 12

Clado 144: 12 -> 2

Clado 115: 12 -> 012

Characidium bahiensis: 12 -> 1

Clado 107: 12 -> 1

Clado 114: $012 \rightarrow 0$

Salminus hilarii: 2 -> 0

Clado 159: $2 \rightarrow 02$

Clado 122: 012 -> 02

Clado 190: $2 \rightarrow 12$

Clado 182: 2 -> 02

Arnoldichthys spilopterus: $02->0$

Nannocharax fasciatus: $1 \rightarrow 0$

Bivibranchia fowleri: $012 \rightarrow>2$

Clado 116: $012 \rightarrow 1$

Roeboexodon guyanensis: 12 -> 1

Galeocharax knerii: $02 \rightarrow \odot$

Clado 161: $02 \rightarrow 0$

Clado 197: 02 -> 012

Xenocharax spilurus: 1 -> 2

Clado 120: $02->2$

Clado 123: $02 \rightarrow>0$

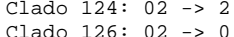

Hydrolycus tatauaia: $2->0$

Erythrinus erythrinus: $2 \rightarrow \theta$

Piaractus mesopotamicus: $012 \rightarrow 2$

Hepsetus odoe: $2 \rightarrow 0$

Myleus setiger: $012 \rightarrow 1$

Potamorhina latior: $2->1$

Leporellus vittatus: $0->2$

Atopomesus pachyodus: $2->$

Deuterodon iguape: $2 \rightarrow 1$

Triportheus albus:

Clado 188: $02 \rightarrow 012$

Gymnocorymbus ternetzi: $012 \rightarrow 0$

Clado 187: $012 \rightarrow 12$

Markiana nigripinnis: $02 \rightarrow 0$

Tetragonopterus argenteus: $02->2$

Orthospinus franciscoensis: $12 \rightarrow 1$

Ctenobrycon hauxwellianus: $12->1$

Poptella brevispina: $12 \rightarrow 2$

Caráter 166 (17 passos)

Raiz: 1

Clado 102: 1 -> 01

Clado 104: $01 \rightarrow 0$

Clado 163: $1 \rightarrow 0$

Clado 114: $1->0$

Clado 157: $1 \rightarrow>0$

Clado 140: $1 \rightarrow$

Oligosarcus argenteus: 1 -> 0

Acestrorhynchus falcirostris: 1 -> 0

Curimatopsis macrolepis: $1 \rightarrow$

Anostomus anostomus: $1->0$

Metynnis lippincottianus: $1 \rightarrow 0$

Potamorhina latior: 1 -> 01

Phenacogaster pectinatus: $\odot \rightarrow 1$

Boulengerella maculata: $1 \rightarrow 0$

Clado 178: $\odot \rightarrow 1$

Bryconops alburnoides: $0 \rightarrow 1$

Triportheus albus: $0 \rightarrow 1$

Astyanax mexicanus: $0 \rightarrow 1$

Tetragonopterus argenteus: $0->1$

Caráter 167 (26 passos)

Raiz: 0

Clado 144: 0 -> 12

Gymnotus aff. carapo: $0->2$

Clado 115: $0 \rightarrow 1$

Clado 142: $12 \rightarrow 1$

Clado 148: $12 \rightarrow 2$

Clado 153: $12 \rightarrow>2$

Clado 160: $12 \rightarrow>1$

Clado 151: $2 \rightarrow 02$

Clado 150: $2 \rightarrow 1$

Clado 158: $02 \rightarrow \theta$

Citharinus latus: $0->1$

Hemiodus unimaculatus : $1->0$

Clado 124: $1 \rightarrow 0$

lado 174: 1 -> 01

Aphyocharax pusillus: 1 -> 3

Clado 156: 2 - $\rightarrow 2$

Curimatopsis macrolepis: $1 \rightarrow 0$

Semaprochilodus insignis: $1 \rightarrow 0$

Landonia latidens: $1 \rightarrow 2$

Serrabrycon magoi: $01->0$

Phenagoniates macrolepis:

Hepsetus odoe: $02->0$
Phenacogaster pectinatus: $01->0$

Clado 172: 01 -> 1

Boulengerella maculata: $02->2$

Ctenolucius hujeta: $02 \rightarrow 0$

Piabina argentea: $1 \rightarrow 2$

Clado 181: 1 -> 012

Bryconops alburnoides: $012->0$

Iguacladoctes geisleri: $012 \rightarrow$

Agoniates halecinus: $1 \rightarrow 3$

Clado 193: 1 -> 01

Hollandichthys multifasciatus: 01 -> $\odot$

caráter 168 ( 6 passos)

Raiz: $\odot$

Clado 102: $\odot$->

Crenuchus spilurus: $0->1$

Clado 142: $0 \rightarrow 1$

Clado 153: $0 \rightarrow 1$

Clado 133: $1 \rightarrow 0$

Clado 130: $0 \rightarrow 1$

Caráter 169 (3 passos)

Raiz: 0

Clado 162: $\odot \rightarrow 1$

Clado 145: $0 \rightarrow 1$

Myleus setiger: 1 -> $\theta$

Caráter 170 (4 passos)

Raiz: 0

Clado 123: $\odot \rightarrow 1$

Clado 123: $0 \rightarrow 1$

Anostomus anostomus: $01 \rightarrow 1$

Curimata ocellata: $0->1$

Schizodon fasciatus: $01->0$

Clado 127: 01 -> 1

Caráter 171 ( 1 passo)

Raiz: 1

Clado 156: 1 -> 0

Caráter 172 ( 1 passo)

Raiz: 01

Hepsetus odoe: $01->1$

Clado 155: $01 \rightarrow 0$

Caráter 173 ( 6 passos)

Raiz: 1

Chalceus epakros: 1 -> 0

Clado 106: 1 -> 01

Distichodus notospilus: $01->$

Citharinus latus: $01 \rightarrow 1$

Xenocharax spilurus: $01->0$

Gilbertolus atratoensis: $1 \rightarrow 0$

Metynnis lippincottianus: $1 \rightarrow 0$

Iguacladoctes geisleri: 1 -> 0

Caráter 174 (11 passo)

Raiz: 0

Clado 148: $\odot \rightarrow 1$

Neolebias unifasciatus: $0 \rightarrow 1$

Clado 114: $0 \rightarrow 01$

Clado 159: $\rightarrow>01$

Clado 113: $01->1$

Arnoldichthys spilopterus: 01 -> 1

Clado 116: $0 \rightarrow 1$

Clado 161: $01 \rightarrow 1$

Clado 161: $01 \rightarrow 1$

Clado 197: $01->0$

Clado 149: $1 \rightarrow 0$

Clado 119: $1 \rightarrow 1$

Prochilodus nigricans: 0 -> 1

Triportheus albus: $\odot->1$

Raiz: 1

Clado 153: 1 -> 01

Clado 152: $01 \rightarrow 0$

Lebiasina bimaculata: 01 -> 1

Piabucina astrigata: $01->0$

Roeboexodon guyanensis: 1 -> $\odot$

Clado 126: $1 \rightarrow 0$

Clado 156: $1 \rightarrow 0$

Hydrolycus tatauaia: $1 \rightarrow 0$

Brycinus macrolepidotus: 1 -> 0

Prochilodus nigricans: 1 -> 0

Myleus setiger: $1 \rightarrow 0$

Caráter 176 (16 passos)

Raiz: 1

Clado 102: $1 \rightarrow 0$

Clado 108: $1 \rightarrow 0$

Clado 114: $1 \rightarrow 12$

Clado 157: 01 - $>0$

Arnoldichthys spilopterus: 1 -> 2

Nannocharax fasciatus: $\Theta->2$

Clado 121: 1 -> 01

Citharinus latus: $\odot->$

Clado 123: $01 \rightarrow 0$

Curimatopsis macrolepis: 01 -> 1

Clado 119: $01 \rightarrow 0$

Roestes molossus: $\odot->1$

Metynnis lippincottianus: 1 -> 2

Clado 131: $1 \rightarrow 0$ 
Curimata ocellata: $12->2$

Potamorhina latior: 12 -> 1

Phenacogaster pectinatus: $1->2$

Atopomesus pachyodus: $1->2$

Brittanichthys axelrodi: 1 -> 2

Clado 200: 1 -> 012

Clado 131: 1 -> 012

Rachoviscus graciliceps: 012 -> 2

Stygichthys typhlops: $012 \rightarrow 0$

Clupeacharax engrauloides: 012 -> 2

Clado 130: 012 -> 01

Thoracocharax stellatus : 01 -> 0

Clado 193: 1 -> 2

Carnegiella strigata: 01 -> 1

Gasteropelecus sternicla: $01->0$

caráter 178 ( 3 passos)

Raiz: 0

Olivaichthys mesembrinus: $0->1$

Semaprochilodus insignis: $0 \rightarrow 1$

Clado 155: $0 \rightarrow 1$

Caráter 179 ( 5 passos)

Raiz: 0

Clado 114: $\odot$-> 1

Galeocharax knerii: $\odot->$

Clado 123: $0 \rightarrow 1$

Clado 156: $0->1$

Leporinus fasciatus:

Caráter

Raiz: 0

Clado 111: $\odot->2$
Clado 122: 2 -> 0

Nannocharax fasciatus: 2 ->

Gnathocharax steindachneri: 2 -> 1

Clado 158: 2 -> 1

Acestrorhynchus falcirostris: 2 -> $\odot$

Curimatopsis macrolepis: $0 \rightarrow 2$

Glandulocauda melanogenys: 2 ->

Triportheus albus: $2 \rightarrow 0$

Caráter 181 ( 3 passos)

Raiz: 0

Clado 123: $\odot \rightarrow 1$

Clado 124: $0 \rightarrow 1$

Potamorhina latior: $\odot->1$

Caráter 182 ( 9 passos)

Raiz: $\odot$ Clado 102: $\odot \rightarrow 1$

$\begin{array}{lll}\text { Clado 102: } & \odot \rightarrow 1 \\ \text { Clado } 143: & ->1 \\ \text { Clado 146: } 1 \rightarrow 0 & ->0\end{array}$

Gnathocharax steindachneri: $1 \rightarrow \infty$

Erythrinoidea fam. nov: $\odot \rightarrow 1$

Clado 197: $0 \rightarrow 1$

Clado 120: $0 \rightarrow 01$

Curimatopsis macrolepis: 01 -> 1

Curimata ocellata: $01 \rightarrow 0$

Potamorhina latior: $01 \rightarrow 1$

Clado 164: $1 \rightarrow 0$

Caráter 183 (25 passos)

Raiz: 1

Clado 102: $1 \rightarrow 0$

Clado 163: $1 \rightarrow 0$

Clado 114: $1 \rightarrow 0$

Clado 183: 1 -> 01

Oligosarcus argenteus: 01 -> $\odot$

Clado 105: $1 \rightarrow 2$

Nannocharax fasciatus: $1 \rightarrow$

Bivibranchia fowleri: 1 -> 0

Charax cf. leticiae: $01 \rightarrow 1$
Galeocharax knerii: $01 \rightarrow 0$

Clado 150: 1 -> 01

Erythrinoidea fam. nov: 1 -> 2

Clado 126: $1 \rightarrow 0$

Hydrolycus tatauaia: 01 -> 0

Piaractus mesopotamicus: $1 \rightarrow 0$

Hepsetus odoe: $1 \rightarrow 0$

Gilbertolus atratoensis: $01 \rightarrow \odot$

Roestes molossus: $01 \rightarrow 1$

Myleus setiger: 1 -> 2

Curimata ocellata: $1 \rightarrow 0$

Leporellus vittatus: $0->1$

Rhinobrycon negrensis: $1->$

Atopomesus pachyodus: $1->2$

Axelrodia reisei: $1-\overrightarrow{2} 2 \rightarrow$

$\begin{array}{lll}\text { Paracheirodon axelrodi: } 1 & -> \\ \text { Stygichthys typhlops: } 1 & ->0\end{array}$

Stygichthys typhlops

Clado 130: 1 -> $\odot$ : 1 -> $\odot$

Triportheus albus: 1
Caráter 184 ( 6 passos)

Raiz: 1

Clado 104: 1 -> 12

Gymnotus aff. carapo: 12 -> 2

Galeocharax knerii: $1 \rightarrow 2$

Clado 126: 1 -> 2

Acestrorhynchus falcirostris: $1 \rightarrow \odot$

Leporellus vittatus: 2 -> 1

clado 130: $1 \rightarrow$

Caráter 185 ( 7 passos)

Raiz: 1

Clado 182: $1 \rightarrow 0$

Clado 146: $1 \rightarrow 01$

Clado 158: $1 \rightarrow 0$

Anodus orinocensis: $1 \rightarrow$

Acestrorhynchus falcirostris: $01 \rightarrow 0$

Hydrolycus tatauaia: $01>1$

Clado 149: $01 \rightarrow \odot$

Piaractus mesopotamicus: $1 \rightarrow 0$

Hepsetus odoe: $01 \rightarrow 1$
Clado 155: 01 -> 0

Caráter 186 (10 passos)

Raiz: $\odot$

Clado 148: 0 -> 01

Salminus hilarii: $01 \rightarrow 1$

Clado 182: $0 \rightarrow 1$

Brycon pesu: $01->0$

Galeocharax knerii: 1 -> 2

Clado 158: $\odot \rightarrow 1$

Anodus orinocensis: $\odot \rightarrow 2$

Acestrorhynchus falcirostris: 1 -> 2

Piaractus mesopotamicus: $\Theta \rightarrow 1$

Hepsetus odoe: $1 \rightarrow 0$

Caráter 187 (1 passo)

Caráter

Clado 125: 0 -> 1

Caráter 188 ( 1 passo)

Raiz: 0

Clado 111: $0 \rightarrow 1$

Caráter 189 ( 6 passos)

Raiz: 0

Clado 142: $\odot \rightarrow$

Neolebias unifasciatus: $0->1$

Hemistichodus vaillanti: $\odot->1$

Gnathocharax steindachneri:

Galeocharax knerii:

$\begin{aligned} \text { Clado 133: } & 1->0 \\ \text { Caráter 190 } & \text { (18 passos) }\end{aligned}$

Raiz: 0

Clado 111: 0 -> 01

Clado 163: 01 -> 0

Clado 143: $01 \rightarrow 1$

Clado 108: $01 \rightarrow 1$

$\begin{array}{ll}\text { Clado 114: } & 01->0 \\ \text { Clado 157: } & 01->1\end{array}$

Chalceus epakros: $01 \rightarrow 0$

Clado 159: $01 \rightarrow 1$

Copeina cf. guttata: $01->0$

Bivibranchia fowleri: $01 \rightarrow 1$

Clado 116: 01 -> 0

Gnathocharax steindachneri: 1 -> 0

Clado 145: 1 -> 01

Erythrinoidea fam. nov: 01 -> 0

Clado 158: $01 \rightarrow 1$

Citharinus latus: 1 -> $\odot$

Clado 123: $01->1$

Clado 124: $01 \rightarrow 0$

Clado 126: 01 -> 1

Acestrorhynchus falcirostris: $01 \quad>0$

Curimatopsis macrolepis: $01 \rightarrow 1$

Clado 119: $01 \rightarrow 0$

Hepsetus odoe: 01 -> $\odot$

Clado 155: $01 \rightarrow 1$

Metynnis lippincottianus: 1 -> 0

Clado 164: $1 \rightarrow 0$

Bryconops alburnoides: 1 -> 0

Carnegiella strigata: 1 ->

Poptella brevispina: 1 ->

Caráter 191 (14 passos)

Raiz: 1

Catostomus commersonnii: $1->0$
Olivaichthys mesembrinus: $1->3$

Crenuchus spilurus: $1 \rightarrow 2$

Neolebias unifasciatus: $1 \rightarrow 0$

Clado 117: 1 -> 2

Copeina cf. guttata: $1 \rightarrow 0$

Clado 158: 1 -> 2

Hydrolycus tatauaia: $1->2$

Piaractus mesopotamicus: $1 \rightarrow 2$

Anostomus anostomus: $1 \rightarrow 0$

Ctenolucius hujeta: 1 - $>2$

Clupeacharax engrauloides: $1 \rightarrow 0$

Thoracocharax stellatus : $1 \rightarrow 2$

Caráter 192 ( 7 passos)

Raiz: 12

Chanos chanos: $12 \rightarrow 2$

Clado 103: $12 \rightarrow 1$

Neolebias unifasciatus: $1 \rightarrow 0$

Clado 114: $1 \rightarrow 01$

Clado 113: $01 \rightarrow 0$

Clado 126: $1 \rightarrow 2$

Acestrorhynchus falcirostris: 1 -> 2

Hydrolycus tatauaia: $1 \rightarrow 2$

Ctenolucius hujeta: 1 -> 2

Caráter 193 (19 passos)

Raiz: $\odot$

Clado 143: $\odot$-> 01

Clado 142: 01 -> 1

Salminus hilarii: $01->1$

Clado 147: $\Theta 1 \rightarrow \oplus$

Saccodon wagneri: $0 \rightarrow 1$

Clado 117: $\Theta \rightarrow 1$

Distichodus notospilus: $0 \rightarrow 1$

Gnathocharax steindachneri: $1 \rightarrow 0$

Clado 158: $0 \rightarrow 1$

Clado 123: $\odot \rightarrow$

Aphyocharax pusillus: 1 -> 0

Piaractus mesopotamicus: $0 \rightarrow 1$

Clado 128: $\odot \rightarrow 1$

Clado 155: $\rightarrow$

Potamorhina latior: 0 -> 1

Clado 133: $1 \rightarrow 01$

Clado 164: 01 ->

Bryconops alburnoides: $01 \rightarrow 0$

Iguacladoctes geisleri: $01 \rightarrow 1$

Clupeacharax engrauloides: 01 -> 1

Clado 130: $01 \rightarrow 0$

Clado 188: 1 -> 0

Ctenobrycon hauxwellianus: $\odot->1$

Caráter 194 (14 passos)

Raiz: 1

Clado 104: $1 \rightarrow 0$

Clado 110: $1 \rightarrow 0$

Clado 182: $1 \rightarrow 0$

Clado 116: $\theta \rightarrow 1$

Gnathocharax steindachneri: 1 -> 0

Clado 150: $1 \rightarrow 01$

Erythrinoidea fam. nov: 1 -> $\odot$

Clado 120: $0 \rightarrow 1$

Aphyocharax pusillus: $1->0$

Hydrolycus tatauaia:

Gilbertolus atratoensis: $01 \rightarrow 1$

Roestes molossus: $01 \rightarrow 0$

Microschemobrycon casiquiare: 1 -> 0

Brittanichthys axelrodi: $1 \rightarrow 0$

Stygichthys typhlops: $1 \rightarrow \odot$

Clado 130: $1 \rightarrow 0$

Caráter 195 (14 passos)

Raiz: 1

Clado 104: $1 \rightarrow 0$

Clado 110: $1 \rightarrow 0$

Saccodon wagneri: $\odot->1$

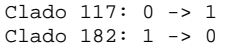

Gnathocharax steindachneri: 1 -> 0

Clado 150: $1 \rightarrow 0$

Erythrinoidea fam. nov: $1 \rightarrow 0$
Clado 120: $\odot \rightarrow 1$

Aphyocharax pusillus: $1 \rightarrow 0$

Microschemobrycon casiquiare: 1 -> $\odot$

Brittanichthys axelrodi: $1 \rightarrow 0$

Stygichthys typhlops: 1 -> 0

Clado 130: $1 \rightarrow 0$

Caráter 196 (18 passos)

Raiz: $\odot$

Clado 148: $\odot \rightarrow->2$

Salminus hilarii: 02 -> 2

Clado 113: $\odot \rightarrow 1$

Clado 117: $\odot \rightarrow 1$

Clado 190: $\odot \rightarrow 2$

Brycon pesu: $02->2$

Clado 158: $0 \rightarrow->2$

Clado 158: $\odot \rightarrow>2$
Clado 197: $\odot \rightarrow>2$

Clado 123: $\odot \rightarrow 1$

Acestrorhynchus falcirostris: $02 \rightarrow 0$

Hydrolycus tatauaia: $02 \rightarrow 2$

Serrabrycon magoi: $\Theta \rightarrow 2$

Paragoniates alburnus: $0->2$

Hepsetus odoe: $02 \rightarrow 0$

Clado 155: $02 \rightarrow 2$

Gilbertolus atratoensis: $02->0$

Phenacogaster pectinatus: $0 \rightarrow 1$

Deuterodon iguape: $0 \rightarrow 2$

Bryconops alburnoides: $\Theta->2$

Clado 130: $0 \rightarrow 2$

Probolus heterostomus : $0->2$

Poptella brevispina: $\odot \rightarrow 2$

Caráter 197 (18 passos)

Raiz: 01

Chanos chanos: $01->0$

Clado 103: 01 -> 1

Crenuchus spilurus: $1 \rightarrow 0$

Clado 142: $1 \rightarrow 0$

Clado 153: $1 \rightarrow 0$

Neolebias unifasciatus: $1 \rightarrow 0$

Clado 146: $1 \rightarrow 0$

Arnoldichthys spilopterus: $1 \rightarrow 0$

Citharinus latus: $1 \rightarrow 0$

Clado 120: $1 \rightarrow 0$

Clado 126: $1>0$

Landonia latidens: $\odot->1$

Leporinus fasciatus: $0 \rightarrow 1$

Clado 134: $0 \rightarrow 01$

Glandulocauda melanogenys: $01->1$

Bryconadenos tanaothoros: $0->1$

Knodus meridae: $0 \rightarrow 1$

Clado 132: 01 - $>\odot$

Clado 181: 01 ->

Deuterodon iguape: $\odot \rightarrow 1$

Compsura heterura: $0 \rightarrow$

Caráter 198 
Raiz: 01

Chanos chanos: $01 \rightarrow 0$

Clado 102: $01 \rightarrow 1$

Clado 108: $01 \rightarrow 1$

Clado 115: $01 \rightarrow 0$

Characidium bahiensis: 01 -> 1

Clado 142: 01 - $>0$

Clado 153: $01 \rightarrow 1$

Clado 160: $01 \rightarrow 0$

Salminus hilarii: 01 -> 1

Brycon pesu: 01 - $>0$

Gnathocharax steindachneri: $0 \rightarrow 1$

Clado $150: 01 \rightarrow 1$

Clado 150: $01 \rightarrow$

Clado 123:- $\rightarrow>1$

Serrabrycon magoi: $0->1$

Leporinus fasciatus: $0 \rightarrow 1$

Hemibrycon polyodon : $0 \rightarrow 1$

Clado 178: $\rightarrow 1$

Glandulocauda melanogenys: 0 -> 1

Piabina argentea: $0 \rightarrow 01$

$\begin{array}{lll}\text { Deuterodon iguape: } 0 & -> & 1 \\ \text { Stygichthys typhlops: } 0 & ->1\end{array}$

Stygichthys typhlops: $\Theta->1$

Agoniates halecinus:

Hemigrammus unilineatus: $01->1$

Hollandichthys multifasciatus: $01->1$

Hyphessobrycon compressus: $01 \rightarrow 0$

Poptella brevispina: $0 \rightarrow 1$

Caráter 200 ( 23 passos)

Raiz: 1

Clado 108: 1 -> 0

Crenuchus spilurus: 1 -> 0

Clado 148: 1 -> 012

Salminus hilarii: 012 -> 0

Clado 147: $012 \rightarrow 12$

$\begin{array}{lll}\text { Clado 117: } 1 & -> & 12 \\ \text { Brycon pesu: } 12 & ->2\end{array}$

Arnoldichthys spilopterus: $1 \rightarrow 0$

Distichodus notospilus: $\theta->1$

Nannocharax fasciatus: $\theta \rightarrow 2$

Bivibranchia fowleri: $12 \rightarrow$

Gnathocharax steindachneri: 1 -> $\odot$

Clado 145: $12 \rightarrow 1$

Erythrinoidea fam. nov: 1 -> $\odot$

Clado 161: $1->2$

Citharinus latus: $0->2$

$\begin{array}{lll}\text { Citharinus latus: } 0 & -> & 2 \\ \text { Anodus orinocensis: } 12 & \rightarrow>2\end{array}$

Anodus orinocensis: $12->2$
Hemiodus unimaculatus : $12 \rightarrow 1$

Clado 126: $1 \rightarrow 2$

Clado 181: 1 -> 2

Axelrodia reisei: 1 ->

Clado 200: $1 \rightarrow 2$

Compsura heterura: $1 \rightarrow 2$

Clado 130: $1 \rightarrow 0$

Hemigrammus unilineatus: $1->2$

Hollandichthys multifasciatus: $1 \rightarrow 0$

Poptella brevispina: 1 -> 2

Caráter 201 (10 passos)

Raiz: $\odot$

Clado 102: $0 \rightarrow 1$

Clado 115: $0 \rightarrow 1$

Arnoldichthys spilopterus: 0 ->

Nannocharax fasciatus: $0->1$

Xenocharax spilurus: $0 \rightarrow 1$

Clado 124: 1 -> $\odot$

Leporellus vittatus: $1->0$
Stygichthys typhlops: $\odot->1$

Clado 130: $0 \rightarrow 1$

Triportheus albus: $0 \rightarrow 1$

Caráter 202 ( 3 passos)

Raiz: 1

Clado 107: $1 \rightarrow 0$

Citharinus latus: $0 \rightarrow 1$

Hoplias malabaricus: $1->0$

Caráter 203 (16 passos)

Raiz: 01

Chanos chanos: $01->1$

Chanos chanos: 01

Catostomus commersonnii: $01->0$

Catostomus commersonnii: $01 \rightarrow 0$

Olivaichthys mesentinus: 01

0 -> 1

Clado 148: $0 \rightarrow 1$

Clado 118: 0 -> 01

Chalceus epakros: 0 -> 1

Clado 106: $0 \rightarrow 01$

Clado 122: 01 ->

Distichodus notospilus: $01->1$

Bivibranchia fowleri: $01 \rightarrow 0$

Clado 116: 01 -> 1

Citharinus latus: $01 \rightarrow 0$

Xenocharax spilurus: 01 -> 1

Caenotropus labyrinthicus: $1 \rightarrow 0$

Serrabrycon magoi: $0 \rightarrow 1$

Hepsetus odoe: 1 -> 0

Clado 134: 0 -> 1

Deuterodon iguape: $0 \rightarrow>1$

Iguacladoctes geisleri: 1 -> 0

Clupeacharax engrauloides: $1 \rightarrow 0$

Caráter 204 (17 passos)

Raiz: $\odot$

Crenuchus spilurus: 0 -> 1

Clado $142: 0 \rightarrow$

Clado 140: $\rightarrow>01$

Oligosarcus argenteus: 01 -> 1
Clado 182: 01 -> 0

Gnathocharax steindachneri: $01->0$

Roeboexodon guyanensis: 01 -> 1

Clado 123: $0 \rightarrow 1$

Anostomus anostomus: $0 \rightarrow 1$

Serrabrycon magoi: $1 \rightarrow 0$

Clado 180: 1 ->

Diapoma terofali: $1 \rightarrow 0$

Atopomesus pachyodus: $1->0$

Clado 176: 1 -> 0

Bryconadenos tanaothoros: $0->1$

Clado 181: 1 ->

Compsura heterura: $1>0$

Clupeacharax engrauloides: $1 \rightarrow 0$

Clado 191: $1 \rightarrow 0$

Raiz: 0

Crenuchus spilurus: $0 \rightarrow 1$

Agoniates halecinus: $\Theta \rightarrow 1$

Caráter 206 (12 passos)

Raiz: 01

Clado 111: 01 -> 0

Olivaichthys mesembrinus: 01 -> 1

Clado 153: $\odot \rightarrow 2$

Clado 146: $0->01$

Clado 151: $2 \rightarrow 1$

Clado 125: $0 \rightarrow 01$

Clado 197: $\odot \rightarrow 01$

Clado 126: 01 -> 1

Acestrorhynchus falcirostris: 01 -> 1

Hydrolycus tatauaia: $01 \rightarrow 1$

Clado 149: $01 \rightarrow 0$

Piaractus mesopotamicus: 01 -> 1

Caenotropus labyrinthicus: $01->1$

Chilodus punctatus: $01->0$

Hepsetus odoe: $01->0$

Clado 155: $01 \rightarrow 1$

Metynnis lippincottianus: $01 \rightarrow 0$

Myleus setiger: $01 \rightarrow 1$

Agoniates halecinus: $0 \rightarrow 1$

Hyphessobrycon compressus: $\odot \rightarrow 1$

Caráter 207 (26 passos)

Raiz: 1

Clado 111: $1 \rightarrow 0$

Clado 111: $1 \rightarrow 0$

Clado 141: $0>1$

Clado 141: $0 \rightarrow 01$

1 (1) 01

Arnoldichthys spilo

Clado 105: $0 \rightarrow$

Nannocharax fasciatus: $0 \rightarrow 1$

Charax cf. leticiae: $0 \rightarrow 1$

Erythrinoidea fam. nov: $0 \rightarrow 1$

Clado 174: $01 \rightarrow 1$

Aphyocharax pusillus: $01->$

Clado 199: 01 -> 1

Bryconalestes longipinnis: $\odot->1$

Landonia latidens: $01->0$

Gilbertolus atratoensis: $0 \rightarrow 1$

Clado 180: $01 \rightarrow 1$

Ctenolucius hujeta: $0->1$

Clado 170: $01 \rightarrow 0$

Diapoma terofali: 01 -> 0

Clado 134: $01 \rightarrow 1$

Microschemobrycon casiquiare: 1 -> 0

Clado 185: 1 -> 0

Piabina argentea: $1->0$

Brittanichthys axelrodi: 1 -> 0

Clado 164: 1 -> 0

Astyanax mexicanus: $0 \rightarrow 1$

Clado 191: 0 -> 01

Hemigrammus unilineatus: $01->1$

Gymnocorymbus ternetzi: $0 \rightarrow 1$

Hollandichthys multifasciatus: $01->0$

Hyphessobrycon compressus: $01 \rightarrow 1$

Ctenobrycon hauxwellianus: $0 \rightarrow 1$

caráter 208 (12 passos)

Raiz: 1

Clado 111: $1 \rightarrow 0$

Gnathocharax steindachneri: $0->1$

Erythrinoidea fam. nov:

Citharinus latus: $0 \rightarrow 1$

Hemiodus unimaculatus : 1 ->

Atopomesus pachyodus

Clado 131: $\odot \rightarrow 1$

Iguacladoctes geisleri: $0->1$

Stygichthys typhlops: $0 \rightarrow 1$

Astyanax mexicanus: $0 \rightarrow 1$

Ctenobrycon hauxwellianus: 0 -> 1

caráter 209 (3 passos)

Raiz: 1

Clado 122: $1 \rightarrow \oplus$

Acestrorhynchus falcirostris: 1 -> 0

Clado 130: 1 -> 0

Caráter 210 ( 6 passos)

Raiz: 01

Chanos chanos: 01 -> 0

Clado 111: 01 -> 1

Catostomus commersonnii: $01->$

Clado 104: $01->1$

Clado 122: $1 \rightarrow$

Nannocharax fasciatus: 1 -> 0

Citharinus latus: $1 \rightarrow 0$

Anodus orinocensis: 1 ->

Caráter 211 (16 passos)

Raiz: 2

Clado 111: 2 -> 12

Gymnotus aff. Carapo: 2 -> 0

Clado 109: 12 -> 2

Clado 163: 12 ->

Clado 143: $12 \rightarrow 1$

Clado 153: $12 \rightarrow 2$

Clado 160: $12 \rightarrow 1$

Clado 122: $2 \rightarrow 02$

Clado 150: $1 \rightarrow 12$

Erythrinoidea fam. nov: 2 -> 1

Citharinus latus: $2 \rightarrow 0$

Hemiodus unimaculatus : $2->0$

Hydrolycus tatauaia: $12 \rightarrow 2$

Curimatopsis macrolepis: $02 \rightarrow 0$

Anostomus anostomus: $02->0$

Clado 128: 02 -> 2

Hepsetus odoe: 1 -> 2

Gilbertolus atratoensis: 12 -> 1

Roestes molossus: $12 \rightarrow 2$

Myleus setiger: $1->2$

Curimata ocellata: $02->2$

Potamorhina latior: $02 \rightarrow$

Knodus meridae: $1 \rightarrow$

Iguacladoctes geisleri: 1 -> 2

Caráter 212 (28 passos)

Raiz: 0

Clado 111: $0 \rightarrow 1$

Gymnotus aff. carapo: $\odot->2$

Characidium bahiensis: $1->2$

Clado 160: $1 \rightarrow 0$

Clado 147: $1 \rightarrow 2$
Clado 113: $1 \rightarrow 2$

Oligosarcus argenteus: 1 ->

Nannocharax fasciatus: 1 -> 2

Clado 121: 1 -> 2

Clado 197: $\odot \rightarrow 2$

Citharinus latus: $1 \rightarrow 2$

Hemiodus unimaculatus : $1->2$

Hydrolycus tatauaia: $2 \rightarrow 0$

Hoplias malabaricus: $1 \rightarrow 0$

Brycinus macrolepidotus: $\odot \rightarrow 1$

Hepsetus odoe: $2->1$

ssus: $2 \rightarrow 1$

Clado 180: $1 \rightarrow 12$

Rhinobrycon negrensis: 12 -> 2

Clado 171: 1 -> 2

Bryconadenos tanaothoros: 12 -> 1

Bryconamericus exodon: $12->2$

Knodus meridae: $12 \rightarrow>1$

Iguacladoctes geisleri: $1->2$

Iguacladoctes geisler

Agoniates halecinus: 1 -> 2

Hemigrammus unilineatus: $1 \rightarrow 0$

Tetragonopterus argenteus: 1 -> 2

Clado 186: 1 -> 012

Ctenobrycon hauxwellianus: $012->0$

Poptella brevispina: 012 -> 2

Caráter 213 ( 4 passos)

Raiz: 01

Chanos chanos: $01->\odot$

Clado 103: $01 \rightarrow 1$

Clado 121: $1 \rightarrow 0$

Citharinus latus: $1 \rightarrow 0$

Anodus orinocensis: $1->0$

Caráter 214 (10 passos)

Raiz: 0

Catostomus commersonnii: $0 \rightarrow 2$

Clado 114: $0 \rightarrow$-> 2

Chalceus epakros: 0 -> 1

Clado 146: $0 \rightarrow 1$

Galeocharax knerii: $0->1$

Clado 158: $\odot \rightarrow 1$

Hemiodus unimaculatus : $0->2$

Gilbertolus atratoensis: $1 \rightarrow>0$

Gilbertolus atratoensis: 1

Ctenolucius hujeta:

Caráter 215 (19 passos)

Raiz: 1

Chalceus epakros: $1 \rightarrow$

Distichodus notospilus: 1 -> $\odot$ 
Clado 156: $0->1$

Clado 128: $01->1$ Phenagoniates macrolepis: $\odot->1$

Clado 172: $0 \rightarrow 1$

Clado 169: $1>01$

Moenkhausia xinguensis: $01 \rightarrow 0$

Deuterodon iguape: 01 -> 1

Clado 167: $01 \rightarrow$

Brittanichthys axelrodi: $1 \rightarrow 0$

Bryconops alburnoides: $1 \rightarrow 0$

Agoniates halecinus: $1 \rightarrow \theta$

Hemigrammus unilineatus: $0->1$

Markiana nigripinnis: $0->1$

Ctenobrycon hauxwellianus: $0 \rightarrow 1$

Caráter 217 (10 passos)

Raiz:

Catostomus commersonnii: $\odot->3$

Clado 148: $0 \rightarrow 01$

Salminus hilarii: $01->1$

Galeocharax knerii: $0 \rightarrow 1$

Clado 145: $01 \rightarrow 012$

Clado 145: $01 \rightarrow 012$

Hemiodus unimaculatus : $\odot \rightarrow 3$

Hemiodus unimaculatus : $0->3$
Acestrorhynchus falcirostris: $012 \quad>2$

Clado 156: $012->1$
Hydrolycus tatauaia: $01 \rightarrow 1$

Clado 149: $01 \rightarrow 0$

Agoniates halecinus: $\odot->1$

Caráter 218 ( 3 passos)

Raiz: $\odot$

Catostomus commersonnii: $0->1$

Bivibranchia fowleri: $0 \rightarrow 1$

Clado 125: $0 \rightarrow 1$

Caráter 219 ( 4 passos)

Raiz: 01

Chanos chanos: 01 -> 1

Clado 103: $01 \rightarrow 0$

Clado 122: $0 \rightarrow 01$

Clado 121: $01 \rightarrow 1$

Citharinus latus: $0 \rightarrow 1$

Clado 124: $01 \rightarrow 1$

Caráter 220 (4 passos)

Carater

Clado 118: $\odot$-> 01

Bivibranchia fowleri: $01 \quad->1$

Clado 121: $01 \rightarrow 1$

Clado 121: $01->1$

Citharinus latus: 0 ->

Anodus orinocensis: $01,>0$

Anodus orinocensis: $01->0$
Hemiodus unimaculatus : $01 \rightarrow 1$

Hemiodus unimaculatus :

Caráter 221

Raiz: 0 Olivaichthys mesembrinus: $\odot->1$

Olivaichthys mesent
Clado 130: $0 \rightarrow 1$

$\begin{array}{lll}\text { Clado 130: } & \odot->1 \\ \text { Caráter } 222 \text { ( } 8 \text { passos) }\end{array}$

Caráter

Clado 111: $\odot->$

Gymnotus aff. carapo: $0 \rightarrow 1$

Nannocharax fasciatus: $1 \rightarrow$

Bivibranchia fowleri: $1 \rightarrow 0$

Erythrinoidea fam. nov: $1-\infty$

Clado 124: $1 \rightarrow 0$

Clado 200: $1 \rightarrow 0$

Clado 130: $1 \rightarrow 0$

Caráter 223 (11 passo)

Raiz: 01

Clado 111: 01 -> 1

Gymnotus aff. carapo: 01 -> 0

Clado 148: $1 \rightarrow 0$

Clado 107: $1 \rightarrow 0$

Roeboexodon guyanensis: 1 -> 0

Clado 197: $1 \rightarrow$

Hemiodus unimaculatus : 1 -> 0

Potamorhina latior: $1 \rightarrow \odot$

Hemibrycon polyodon : $1->0$

Hemibrycon polyodon

Clado 184: $1 \rightarrow 0$

Clupeacharax engrauloides: $01 \quad>0$

Clupeacharax engr

Clado 191: 1 -> 0

Caráter 224

Clado 144: 01 -> 1
Gymnotus aff. carapo: 01 -> 0

Gymnotus aff. carapo

Clado 163: $01->0$
Neolebias unifasciatus: $01 \rightarrow 0$

Clado 107: $01 \rightarrow 1$

Clado 114: $01 \rightarrow 1$

Clado 159: $1 \rightarrow 01$

Clado 146: 1 ->

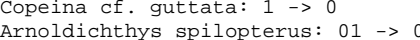

Clado 116: $01 \rightarrow 1$

Gnathocharax steindachneri: 1 -> 0

Clado 161: 01 -> 1

Citharinus latus: $1 \rightarrow$

Clado 123: $01 \rightarrow 0$

Clado 124: $01 \rightarrow$

Clado 126: 01 ->

Piaractus mesopotamicus: $01->0$

Curimatopsis macrolepis: $01 \rightarrow 0$

Clado 119: $01 \rightarrow 1$

Phenagoniates macrolepis: $1->0$

Metynnis lippincottianus: 01 ->
Myleus setiger: $01 \rightarrow 0$

Clado 136: 1 - 01

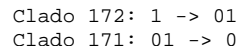

Hemibrycon polyodon : $01 \rightarrow 0$

Clado 176: $01 \rightarrow 0$

Clado 185: 01 -> 1

Glandulocauda melanogenys: 01 -> 0

Moenkhausia xinguensis: $01 \rightarrow 1$

Bryconadenos tanaothoros: $1 \rightarrow$

Clado 132: $01 \rightarrow 1$

Clado 181: $01->0$

Clado 167: iguape:

Hyphessobrycon compressus: 1 -> 0

Caráter 225 (10 passos)

Raiz: 1

Clado 111: $1 \rightarrow 0$

Gnathocharax steindachneri: 0 -> 1

Erythrinoidea fam. nov: $\theta->1$

Clado 199: $0 \rightarrow 1$

Acestrorhynchus falcirostris: $01 \quad>0$

Clado 156: 01 -> 1

Hydrolycus tatauaia: $01->1$

Gilbertolus atratoensis: 01 -> 1

Roestes molossus: $01 \rightarrow 0$

Clado 132: $\odot \rightarrow 01$

Clado 131: $01 \rightarrow$

Stygichthys typhlops: $0->1$

Agoniates halecinus: $01->$

Triportheus albus: $01 \rightarrow 1$

Caráter 226 (18 passos)

Raiz: 1

Chalceus epakros: $1 \rightarrow 0$

Clado 113: $1 \rightarrow$

Clado 182: $1 \rightarrow$

Brycon pesu: 1 -> 0

Clado 165: $1 \rightarrow 01$

Clado 120: 1 -> 01

Aphyocharax pusillus: $01->0$

Bryconalestes longipinnis: 1 -> 0

Curimatopsis macrolepis: $01 \rightarrow 0$

Metynnis lippincottianus: $1 \rightarrow 0$

Curimata ocellata: $01 \rightarrow 1$

Potamorhina latior: $01->$

Clado 179: 1 -> 01

Glandulocauda melanogenys: 1 -> $\odot$

Knodus meridae: $01-\rightarrow$

Knodus meridae: $01->0$

Brittanichthys axelrodi: $1 \rightarrow \odot$

Compsura heterura: $1 \rightarrow 0$

Iguacladoctes geisleri: $1 \rightarrow 0$

Clado 189: $1 \rightarrow 0$

Clado 191: 1 -> 01

Hemigrammus unilineatus: $01->$

Hollandichthys multifasciatus: $01->1$

Hyphessobrycon compressus: $01 \rightarrow \odot$

caráter 227 (2 passos)

Raiz: 1

Clado 108: 1 -> 0

Crenuchus spilurus: 1 -> $\odot$

Caráter 228 (9 passos)

Raiz: 01

Chanos chanos: 01 -> 1

Clado 111: $01 \rightarrow 0$

Catostomus commersonnii: 01 -> 0

Clado 104: $01 \rightarrow 1$

Clado 146: $\theta \rightarrow 1$

Gnathocharax steindachneri: 0 -> 1

Erythrinoidea fam. nov: $\odot \rightarrow 1$

Clado 199: $\odot \rightarrow 1$

Chilodus punctatus: $\odot->1$

Clado 132: $\odot \rightarrow 1$

Stygichthys typhlops: 01 -> 1

caráter 229 (11 passo)

Raiz: 1

Clado 160: $1 \rightarrow \oplus$

Clado 118: $1 \rightarrow 01$

Clado 183: $1 \rightarrow 0$

Clado 117: $01 \rightarrow 0$

Clado 125: $01->1$

Clado 139: 1 -> 01

Clado 123: $01->0$

Clado 174: 01 -> 0

Brycinus macrolepidotus: $\odot$-> 1

Curimatopsis macrolepis: $01 \rightarrow$

Clado 119: 01 -> 0

Landonia latidens: 01 -> 0

Clado 137: $01 \rightarrow 1$

Clado 169: $1 \rightarrow 0$

Glandulocauda melanogenys: 1 -> $\odot$

Markiana nigripinnis: $0 \rightarrow 1$

Caráter 230 ( 5 passos)

Raiz: 0

Catostomus commersonnii: $\odot->1$

Clado 163: 0 -> 1

Saccodon wagneri: $0 \rightarrow>1$

Nannocharax fasciatus: $0->1$

Erythrinoidea fam nov: $0 \rightarrow 1$

Caráter 231 (19 passos)

Raiz: 2

Clado 102: $2 \rightarrow 0$

Clado 152: $2 \rightarrow 0$

Clado 140: $2 \rightarrow 12$

Clado 165: $12 \rightarrow 1$

Clado 124: $2 \rightarrow 0$

Clado 138: $12->2$

Hoplias malabaricus: $\odot \rightarrow 2$

Hepsetus odoe: 2 -> 1

Rhinobrycon negrensis: 2 -> 1

Atopomesus pachyodus: $1 \rightarrow 0$

Clado 176: $1 \rightarrow 0$

Glandulocauda melanogenys: 2 -> 1

Knodus meridae: 2 -> 1

Hyphessobrycon compressus: $2 \rightarrow 0$

Ctenobrycon hauwellianus: $2 \rightarrow 1$

Caráter 232 ( 1 passo)

Raiz: 0

Clado 114: $0 \rightarrow 1$

Caráter 233 ( 6 passos)

Raiz: 0

Clado 104: $0 \rightarrow 1$

Clado 153: $\odot \rightarrow 01$

Copeina cf. guttata: $01->1$

Lebiasina bimaculata: $01 \rightarrow 1$

Piabucina astrigata: $01 \rightarrow 0$

Erythrinoidea fam. nov: $01 \rightarrow 1$

Clado 158: $01 \rightarrow 0$

Clado 176: $\odot \rightarrow 01$

Clado 175: 01 ->

Paracheirodon axelrodi: 01 -> 1

Rachoviscus graciliceps: $01 \rightarrow 0$

Caráter 234 (17 passos)

Raiz: 01

Chanos chanos: $01->1$

Clado 111: $01 \rightarrow \odot$

Clado 148: $\Theta \rightarrow 1$

Clado 118: $0 \rightarrow 01$

Clado 117: $01 \rightarrow 1$

Oligosarcus argenteus: $0 \rightarrow 1$

Piabucina astrigata: $0 \rightarrow 1$

Clado 162: $0 \rightarrow 1$

Gnathocharax steindachneri: 0 -> 1

Clado 120: $01 \rightarrow 0$

Clado 123: $01 \rightarrow 1$

Clado 124: $01 \rightarrow$

Clado 126: $01 \rightarrow 1$

Clado 156: $1>0$

Phenacogaster pectinatus: 0 -> 1

Diapoma terofali: $0 \rightarrow 1$

Hiapoma terofali: $->1$
Piabina argentea: $0->1$

Clado 167: $\odot \rightarrow 01$

Bryconops alburnoides: 0 -> 1

Clado 166: $01 \rightarrow 1$

Probolus heterostomus : $01->1$

Clado 191: 01 ->

Caráter 235 (4 passos)

Raiz: 0

Gnathocharax steindachneri: 0 -> 1

Hydrolycus tatauaia: $0 \rightarrow 1$

Paragoniates alburnus: $0->$

Clado 132: $0 \rightarrow 1$

Caráter 236 ( 8 passos)

Raiz: 01

Chanos chanos: $01->1$

Clado 102: $01 \rightarrow \odot$

Clado 110: 01 ->

Clado 144: $01 \rightarrow 1$

Clado 114: $0 \rightarrow 1$

Clado 151: 1 -> 0

Nannocharax fasciatus: 0 -> 1

Clado 124: 0 -> 1

Leporinus fasciatus: $0 \rightarrow 1$

Stygichthys typhlops: $1 \rightarrow 0$

Caráter 237 (16 passos)

Raiz: 1

Clado 102: $1 \rightarrow 0$

Clado 102: $1 \rightarrow 0$

Characidium bahiensis: 1 -> 0

Clado 152: 1 - 01

Copeina cf. guttata: 01 -> 0

Clado 105: $\odot \rightarrow 1$

Clado 165: $1 \rightarrow 3$

Erythrinoidea fam. nov: $01->0$

Clado 158: $01 \rightarrow 1$

Clado 124: 1 ->

Metynnis lippincottianus: 1 -> 3

Clado 172: 1 -> 01

Rhinobrycon negrensis: 1 -> 0

Atopomesus pachyodus: $01 \rightarrow 1$ 
Bivibranchia fowleri: $0->1$ Erythrinoidea fam. nov: $1 \rightarrow 0$

$\begin{array}{lll}\text { Clado 124: } & 0 & \rightarrow>1 \\ \text { Clado 174: } & 0 & \rightarrow>1\end{array}$

Serrabrycon magoi: 01 -> 1

Phenacogaster pectinatus: $01 \rightarrow 0$

Clado 172: 01 -> 1

Glandulocauda melanogenys: $\odot$-> 1

Clado 184: 1 -> 0

Brittanichthys axelrodi: $1 \rightarrow 0$

Rachoviscus graciliceps: $1 \rightarrow 0$

Caráter 239 (17 passos)

Raiz: 1

Clado 148: $1 \rightarrow 2$

Clado 153: 1 -> 12

Clado 114: $1 \rightarrow>2$

Clado 157: $12 \rightarrow>$

Clado 182: $1->2$

Clado 162:

notospilus: 1 -> 2

Clado 121: $1 \rightarrow 2$

Clado 158: $12 \rightarrow 2$

Anodus orinocensis: 1 -> 2

Aphyocharax pusillus: $1 \rightarrow 2$

Brycinus macrolepidotus: $12 \rightarrow 2$

Bryconalestes longipinnis: $12->1$

Piaractus mesopotamicus: $12->2$

Metynnis lippincottianus:

Myleus setiger: $12 \rightarrow 1$

$\begin{array}{ll}\text { Clado } 127: 1 & 1>2 \\ \text { Clado } 176: 1->0\end{array}$

Clado 176: 1 -> $\odot$

Rachoviscus graciliceps: $0 \rightarrow 2$

Hollandichthys multifasciatus: 1 -> 2

Caráter 240 ( 9 passos)

Raiz: 0

Olivaichthys mesembrinus: 0 -> 1

Clado 183: $\odot \rightarrow 01$

Clado 147: $0 \rightarrow 1$

Oligosarcus argenteus: $01 \rightarrow 1$

Roeboexodon guyanensis: $\theta \rightarrow 1$

Charax cf leticiae: $01 \rightarrow 1$

Galeocharax knerii: $01 \rightarrow 0$

Gleocharax knerii:

Hydrolycus tatauaia: $1 \rightarrow 0$

Hydrolycus tatauaia: $1 \rightarrow 0$

Phenacogaster pectinatus: $0->1$

Caráter 241 (10 passos)

Caráter

Raiz: 1 : 1 -> 0

Olivaichthys mesembrinus: 1 -> $\odot$

Crenuchus spilurus: $0 \rightarrow 1$

Nannocharax fasciatus: 0 -> 1

Acestrorhynchus falcirostris: 0 -> 1

Clado 119: $\odot \rightarrow 1$

Chilodus punctatus: $0 \rightarrow 1$

Atopomesus pachyodus: $0 \rightarrow 1$

Stygichthys typhlops: $0 \rightarrow 1$

Caráter 242 (18 passos)

Raiz: 1

Clado 104: $1 \rightarrow 0$

Clado 110: $1 \rightarrow 0$

Clado 153: $1 \rightarrow 0$

Clado 140: $1 \rightarrow 0$

Clado 182: $1 \rightarrow 0$

Clado 150: $1 \rightarrow 2$

Clado 128: $0 \rightarrow 1$

Serrabrycon magoi: $0 \rightarrow 1$

Paragoniates alburnus: $0 \rightarrow 1$

Hepsetus odoe: $1 \rightarrow 0$
Myleus setiger: $1 \rightarrow 0$

Clado 136: $\rightarrow$

Glandulocauda melanogenys: 1 -> 0

Knodus meridae: $0 \rightarrow 1$

Knodus meridae: $0>1$

Rachoviscus graciliceps: $0->1$

Rachoviscus graciliceps: 0

Astyanax mexicanus: $1->0$

Gymnocorymbus ternetzi:

Raiz: 0

Raiz: $\odot$ Gnathocharax steindachneri: 0 -> 1

Clado 155: $0 \rightarrow 1$

Clado 130: $0 \rightarrow 1$

Caráter 244 (19 passos)

Raiz: 01

Chanos chanos: 01 -> 1

Clado 103: $01 \rightarrow 0$

Clado 163: $0 \rightarrow 1$

Clado 107: $\odot \rightarrow 1$

Clado 147: $0 \rightarrow 01$

Chalceus epakros: $\odot->1$

Clado 113: $0 \rightarrow 01$

Brycon pesu: $01->1$

Copeina cf. guttata: $0 \rightarrow 1$

Apareiodon piracicabae: 01 -> 1

Clado 150: 01 -> $\odot$

Xenocharax spilurus: $1->0$

Hemiodus unimaculatus : $\theta \rightarrow 1$

Clado 123: $0 \rightarrow 1$

Clado 126: $0 \rightarrow 1$

Acestrorhynchus falcirostris: $01 \rightarrow 1$

Brycinus macrolepidotus: $\rightarrow 1$

Brycinus macrolepidotus: $0->1$

Hepsetus odoe: $01 \rightarrow 1$

Clado 155: $01 \rightarrow \odot$
Curimata ocellata: $\odot->1$

Leporellus vittatus: $1 \rightarrow 0$

Clado 133: $\odot \rightarrow 1$

Triportheus albus: $1 \rightarrow 0$

Caráter 245 (2 passos)

Raiz: 0

Hydrolycus tatauaia: $\odot->1$

Triportheus albus: $\odot->1$

Caráter 246 (15 passos)

Raiz: 01

Chanos chanos: 01 -> 1

Clado 103: $\theta 1 \rightarrow \theta$

Clado 148: $\odot \rightarrow 01$

Salminus hilarii: $01 \rightarrow 1$

Brycon pesu: $01->1$

Roeboexodon guyanensis: $0->1$

Galeocharax knerii: $0 \rightarrow 1$

Galeocharax knerii: $0 \rightarrow>$

Clado 170: $\theta \rightarrow 1$

Bryconadenos tanaothoros: $0->1$

Knodus meridae: $\odot \rightarrow 1$

Odontostilbe pequira: $\odot->1$

Clado 132: $\odot \rightarrow 01$

Clado 167: $1 \rightarrow$

Brittanichthys axelrodi: $0 \rightarrow 1$

Clado 164: 01 -> 1

Clupeacharax engrauloides: $01->1$

Clado 130: $01->\odot$

Clado 195: $0->1$

Caráter 247

Chanos chanos: 01 -> 1

Catostomus commersonnii: $01->$

$\begin{array}{ll}\text { Clado 110: } & 01 \rightarrow 1 \\ \text { Clado 144: } & 01 \rightarrow 0\end{array}$

Olivaichthys mesembrinus: $01 \rightarrow 1$

Gymnotus aff. carapo: $01 \rightarrow 0$

Neolebias unifasciatus: $1->0$

Clado 105: $1 \rightarrow 0$

Clado 121: $1 \rightarrow 0$

Clado 165: $\odot \rightarrow 01$

Aphyocharax pusillus: $01->1$

Landonia latidens: $0 \rightarrow 1$

Paragoniates alburnus: $01 \rightarrow$

Phenagoniates macrolepis: 01 -> 1

Clado 171: $0 \rightarrow 1$

Clado 194: $\odot->$

Odontostilbe pequira: $0->1$

Axelrodia reisei: $0->$

guacladoctes geisleri: 0 -> 1

Agoniates halecinus: $0 \rightarrow 1$

Caráter 248

Gymnotus aff. carapo: 1 -> 0

lado 163: $1 \rightarrow 0$

Clado 151: $1 \rightarrow$

Atopomesus pachyodus: 1 -> 0

Brittanichthys axelrodi: 1 -> 0

Stygichthys typhlops: $1 \rightarrow 0$

Caráter 249 (25 passos)

Raiz: 0

Clado 144: $\odot \rightarrow 1$

Clado 118: $0 \rightarrow 12$

Clado 152: $1 \rightarrow 2$

Piabucina astrigata: 1 -> 0

Bivibranchia fowleri: 12 -> 2

Clado 116: $12 \rightarrow 1$

Clado 165: 1 -> 2

Charax cf. leticiae: $1 \rightarrow 2$

Clado 150: $1 \rightarrow 0$

Clado 120: $12->2$

Clado 123: $12 \rightarrow>1$

Clado 124: $12>1$

Hepsetus $12->1$

Phenacogaster pectinatus: $1->2$

Ctenolucius hujeta: $1 \rightarrow \odot$

$\begin{array}{ll}\text { Ctenolucius hujeta: } 1 & -> \\ \text { Diapoma terofali: } 1-> & 2\end{array}$

Microschemobrycon casiquiare: 1 ->

Clado 133: $1 \rightarrow 01$

Moenkhausia xinguensis: $1->2$

Knodus meridae: $1 \rightarrow 2$

Clado 198: 1 -> 01

Clado 132: 01 -> 0

Clado 200: $012 \rightarrow 0$

Claco 200: 012 $>0$

Bryconops alburnoides: $01-1$

Iguacladoctes geisleri: $01 \rightarrow 0$

Clado 129: 0 - $>1$

Hemigrammus unilineatus: 1 -> 2

Ctenobrycon hauxwellianus: $1->2$

caráter 250 (24 passos)

Raiz: $\odot$

Clado 111: $0 \rightarrow 01$

Clado 163: $01 \rightarrow 1$

Clado 154: $01 \rightarrow 1$

Clado 108: $01->0$

Clado 183: $01 \rightarrow 1$

Salminus hilarii: $01 \rightarrow 1$

Clado 147: 01 - > 0

Saccodon wagneri: $01 \rightarrow 0$

Clado 190: $01 \rightarrow$

Piabucina astrigata: $1 \rightarrow 0$

Apareiodon piracicabae: $01 \rightarrow$

Parodon nasus: $01 \rightarrow 1$

Bivibranchia fowleri: 01 -> 1

Clado 161: 1 ->

Anodus orinocensis: $01 \rightarrow 0$

Hemiodus unimaculatus : $01 \rightarrow 1$

Clado 123: $01->0$
Clado 126: $01->1$

Aphyocharax pusillus: 01 -> 0

Curimatopsis macrolepis: $01 \rightarrow 1$

Clado 119: 01 -> 0

Caenotropus labyrinthicus: 01 -> 0

Chilodus punctatus: $01 \rightarrow 1$

Landonia latidens: $01 \rightarrow 0$

Serrabrycon magoi: $01 \rightarrow$

Paragoniates alburnus: 01 -> 1

Phenagoniates macrolepis: $01 \rightarrow 0$

Hepsetus odoe: $0 \rightarrow 1$

Clado 180: 01 -> 1

Phenacogaster pectinatus: $01->0$

Clado 172: $01 \rightarrow 1$

Diapoma terofali: 01 -> 1

Clado 134: 01 $\rightarrow$ : $\theta$

Hemibrycon polyodon : 01 -> $\odot$

Moenkhausia xinguensis:

Knodus meridae: 1 - $>0$

Deuterodon iguape: 01 -> 0

Clado 167: $01 \rightarrow 1$

Brittanichthys axelrodi: 1 -> 0

Clado 131: $0 \rightarrow 1$

Stygichthys typhlops: 1 -> 2

Caráter 251 (22 passos)

Raiz: 3

Clado 111: $3 \rightarrow 1$

Clado 107: $1 \rightarrow 01$

Clado 106: $01 \rightarrow 0$

Clado 113: 1 -> 2

Hemistichodus vaillanti: $01 \rightarrow 0$

Nannocharax fasciatus: $01->1$

Bivibranchia fowleri: 01 -> 0

Gnathocharax steindachneri: 1 -> 3

Clado 145: 1 -> 12

Anodus orinocensis: $01 \rightarrow 1$

Hemiodus unimaculatus : $01 \rightarrow \odot$

Clado 156: $12 \rightarrow$

Hoplias malabaricus: $1->2$

Anostomus anostomus: $1 \rightarrow 2$

Anostomus anostoms: $1 \rightarrow 2$

Paragoniates alburnus: $1->$

Curimata ocellata:

Clado 135: $1->2$
Knodus meridae: $1 \rightarrow>2$

Knodus meridae: 1

Clado 200: $1 \rightarrow 2$

IguaCladoctes geisleri: 12 -> 1

clado 130: $2 \rightarrow 23$

Triportheus albus: 2 -> 3

Clado 191: 1 ->

Gasteropelecus sternicla: 23 -> 3

Markiana nigripinnis: 1 -> 2

Ctenobrycon hauxwellianus: $1 \rightarrow 2$

Caráter 252 (23 passos)

Raiz: 0

Clado 144: 0 -> 1

Gymnotus aff. carapo: $0 \rightarrow 1$

Neolebias unifasciatus: $0 \rightarrow 1$

Salminus hilarii: 1 -> 0

Clado 159: 1 -> 0

Saccodon wagneri: 0 -> 1

Clado 117: $0 \rightarrow 01$

Piabucina astrigata: $1 \rightarrow 0$

Nannocharax fasciatus: $\theta->$

Bivibranchia fowleri: $01 \rightarrow 1$

Roeboexodon guyanensis: $1 \rightarrow 0$

Galeocharax knerii: 1 : $>$

Anodus orinocensis: $01 \rightarrow 0$

Hemiodus unimaculatus : $01 \rightarrow 1$

Aphyocharax pusillus: $1 \rightarrow 0$

Aphyocharax pusillus: $1 \rightarrow 0$

Hepsetus odoe: $1>0$

Curimata ocellata: $\Theta \rightarrow 1$

Phenacogaster pectinatus: 1 -> 0

Atopomesus pachyodus: 1 - $>0$

Clado 181: $1 \rightarrow 0$

Axelrodia reisei: 1 -> $\odot$

Astyanax mexicanus: 1 ->

Clado 187: $1 \rightarrow 0$ 
Axelrodia reisei: 1 -> 0

Clado 131: $01 \rightarrow \odot$

Clado 164: 01 -> 1

Astyanax mexicanus: 1 -> 0

Hemigrammus unilineatus: $1 \rightarrow \odot$

Clado 187: $1 \rightarrow 0$

Caráter 254 (27 passos)

Raiz: 23

Chanos chanos: 23 -> 34

Clado 111: 23 -> 2

Catostomus commersonnii: 23 -> 4

Clado 104: $23 \rightarrow 0123$

Clado 144: $23->1$

Olivaichthys mesembrinus: 0123 -> 0

Clado 107: 2 -> 23

Chalceus epakros: $1 \rightarrow 2$

Clado 106: $23 \rightarrow 3$

Clado 113: $2 \rightarrow 1$

Clado 117: $2 \rightarrow 3$

Lebiasina bimaculata: 1 -> 12

Hemistichodus vaillanti: $23 \rightarrow 3$

Nannocharax fasciatus: $23 \rightarrow 1$

Clado 116: $3 \rightarrow 4$

Xenocharax spilurus: $3 \rightarrow 4$

Clado 156: $1 \rightarrow 12$

Erythrinus erythrinus: 1 -> 01

Brycinus macrolepidotus: 1 -> 2

Caenotropus labyrinthicus: $2 \rightarrow 23$

Phenagoniates macrolepis: $1 \rightarrow \odot$

Hepsetus odoe: $12 \rightarrow 2$

Metynnis lippincottianus: 1 -> 0

Curimata ocellata: $2 \rightarrow 4$

Leporinus fasciatus: 2 -> 3

Diapoma terofali: $1 \rightarrow 0$

Clado 198: $1 \rightarrow \odot$
Clado 132: $1->\odot$

Bryconops alburnoides: $1 \rightarrow 2$

Gymnocorymbus ternetzi: $1->0$

Hollandichthys multifasciatus: $1 \rightarrow 0$

orthospinus franciscoensis: 1 -> 01

Caráter 255 (11 passo)

Raiz: 1

Clado 102: $1 \rightarrow 0$

Clado 102: $1 \rightarrow 0$

Clado 118: 1 -> 2

Citharinus latus: $\odot->1$

Clado 123: $2 \rightarrow 1$

Piaractus mesopotamicus: $1 \rightarrow 2$

Clado 119: $2 \rightarrow 0$

Anostomus anostomus: $2->1$

$\begin{array}{ll}\text { Anostomus anostomus: } 2 & -> \\ \text { Diapoma terofali: } 1 \text { - } & 0\end{array}$

Diapoma terofali:

Hyphessobrycon compressus: 1 -> 0

Hyphessobrycon compres

Raiz: 3

Clado 111: $3 \rightarrow 2$

Clado 108: $2 \rightarrow 1$

Clado 115: $2 \rightarrow 23$

Clado 142: $2 \rightarrow 1$

Clado 114: $23 \rightarrow$

Clado 117: 23 -> 3

Clado 122: $23 \rightarrow 12$

Clado 182: $1 \rightarrow 0$

Clado 151: 2 -> 23

Clado 162: $2 \rightarrow 1$

Hemistichodus vaillanti: 1 -> 3

Clado 121: 12 -> 1

Gnathocharax steindachneri: 1 -> 0

Clado 145: 2 -> 3

Clado 150: $2 \rightarrow 12$

Erythrinoidea fam. nov: 23 -> 3

Xenocharax spilurus: $1 \rightarrow 2$

Clado 123: $1 \rightarrow 0$

Clado 124: $12 \rightarrow>0$

Aphyocharax pusillus: $1 \rightarrow 2$

Clado 199: $1 \rightarrow 0$

Clado 149: $12 \rightarrow>1$

Erythrinus erythrinus: $23->$

Hoplias malabaricus: $23->3$

173: 1 -> 01

Roestes molossus: 1 -> 0

Curimata ocellata: $1->2$

Clado 171: $01 \rightarrow 0$

Clado 185: $01->1$

Clado 133: $1 \rightarrow 2$

Clado 167: $1 \rightarrow 01$

Axelrodia reisei: $01 \rightarrow 0$

Brittanichthys axelrodi: 01 -> 1

Paracheirodon axelrodi: $01 \rightarrow 0$

$\begin{array}{ll}\text { Clado 200: } & 01->1 \\ \text { Clado 192: } & 01->0\end{array}$

Stygichthys typhlops: 1 -> 2

Astyanax mexicanus: $01 \rightarrow 1$

Clado 189: 01 ->

Caráter 257 (18 passos)

Raiz: 0

Clado 104: 0 -> 01

Olivaichthys mesembrinus: $01 \rightarrow 1$

Clado 163: $\rightarrow 1$

Clado 163: $0 \rightarrow 1$

Clado 160: $\odot->1$
Brycon pesu: $\odot->1$

Charax cf. leticiae: $0 \rightarrow 1$
Erythrinoidea fam. nov: $\odot->1$

Clado 123: $0 \rightarrow 1$

Bryconalestes longipinnis: 1 -> 0

Landonia latidens: $0 \rightarrow 1$

Phenagoniates macrolepis: 0 -> 1

Potamorhina latior: $0 \rightarrow 1$

Phenacogaster pectinatus: $0->1$

Clado 170: $\odot->1$

Clado 132: $\odot \rightarrow$

Deuterodon iguape: $1 \rightarrow 0$

Brittanichthys axelrodi: $\Theta \rightarrow 1$

Probolus heterostomus : $1 \rightarrow 0$

Markiana nigripinnis: $1 \rightarrow 0$

Caráter 258 ( 23 passos)

Raiz: 13

Chanos chanos: 13 -> 1

Clado 102: $13 \rightarrow 3$

Clado 144: 13 -> 1

Clado 163: 13 -> 3

Clado 108: $13 \rightarrow 1$

Clado 160: 1 -> 01

Clado 114: 13 -> 3

Chalceus epakros: 01 -> 0

Clado 112: $1 \rightarrow 2$

Clado 117: $13 \rightarrow$

ebiasina bimaculata: 1 -> 2

Arnoldichthys spilopterus: 01 -> 1

Clado 162: 01 -> 013

Clado 121: $13 \rightarrow 1$

Gnathocharax steindachneri: 1 -> $\odot$

Clado 145: $1 \rightarrow 0$

Clado 158: $1->2$

Clado 161: $013 \rightarrow$

Clado 197: 013 -> 3

Clado 124: $13 \rightarrow 3$

Clado 126: 13 -> 1

Semaprochilodus insignis: $1 \rightarrow 2$

Metynnis lippincottianus: 3 -> 2

Potamorhina latior: 1 -> 3

Phenacogaster pectinatus: 1 -> 2

Leporellus vittatus: 1 ->

Clado 198: 1 -> 2

Brittanichthys axelrodi: 1 -> 3

Stygichthys typhlops: $2 \rightarrow 0$

$\begin{array}{lll}\text { Agoniates halecinus: } 1 ~ & -> & 3 \\ \text { Gymnocorymbus ternetzi: } 1 ~ & ->2\end{array}$

caráter 259 ( 5 passos)

Raiz: 0

Gnathocharax steindachneri: $\odot$-> 1

Charax cf. leticiae: $\odot \rightarrow 1$

Clado 130: $0 \rightarrow>$

Gymnocorymbus ternetzi: 0 -> 1

Poptella brevispina: $0 \rightarrow 1$

60 (33 passos)

Raiz: 02

Chanos chanos: 02 -> 2

Clado 111: 02 -> 0

Catostomus commersonnii: $\odot 2 \rightarrow \infty$

Olivaichthys mesembrinus: $02 \rightarrow 2$

Clado 143: $\odot \rightarrow 01$

Clado 108: $0 \rightarrow 2$

Clado 148: $01->1$

Clado 183: 01 -> 012

Clado 157: $\Theta \rightarrow 1$

Clado 190: $01 \rightarrow 1$

Oligosarcus argenteus: 012 -> 2

Clado 182: 012 ->

Arnoldichthys spilopterus: $\odot$-> 2

Nannocharax fasciatus: $2 \rightarrow 0$

Bivibranchia fowleri: 01 -> 1

Clado 116: $01 \rightarrow 0$

Clado 125: $01 \rightarrow 1$

Clado 150: $1 \rightarrow 0$

Clado 161: $0 \rightarrow 1$

Clado 120: $01>1$

Clado 123: $01 \rightarrow 01$

Aphyocharax pusillus: $01->$

Clado 199: 01 -> 012

Prochilodus nigricans: $012->0$

Semaprochilodus insignis: $012 \rightarrow$

Caenotropus labyrinthicus: 1 ->

Landonia latidens: $01->1$

$\begin{array}{lll}\text { Paragoniates alburnus: } 012 & -> & 2 \\ \text { Phenagoniates macrolepis: } 012 & ->0\end{array}$

Clado 155: $1 \rightarrow 0$

Potamorhina latior: 1 -> 2

Clado 127: $1 \rightarrow$

Clado 180: $01 \rightarrow 012$

Clado 135: $01 \rightarrow 0$

Rhinobrycon negrensis: 012 -> 2

Clado 179: $012 \rightarrow 01$

Hemibrycon polyodon : $01 \rightarrow 1$

Clado 194: $01 \rightarrow 1$

Moenkhausia xinguensis: 01 -> 0

Bryconadenos tanaothoros: $01 \rightarrow 1$

Bryconamericus exodon: $01->0$

Deuterodon iguape: $01->1$

Axelrodia reisei: $\odot->1$

Clado 200: $0 \rightarrow 2$

Rhoadsia altipinna: $\odot \rightarrow 2$

Clado 131: $\theta \rightarrow 02$

Clado 166: $01 \rightarrow->0$

Clupeacharax engrauloides: 02 -> 2

Agoniates halecinus: $0 \rightarrow 1$

Probolus heterostomus : 01 -> 1

Clado 191: 01 ->

Caráter 261 (15 passos)

Raiz: 0

Clado 142: $0 \rightarrow 01$

Clado 141: 01 -> 1

Oligosarcus argenteus: 01 -> 0

Clado 182: 01 -> 1

Aphyocharax pusillus: 1 -> 0

Clado 149: $\odot \rightarrow 1$

Clado 196: $0 \rightarrow 1$

Serrabrycon magoi: 1 -> 0

Hemibrycon polyodon : $1 \rightarrow 0$

Clado 194: $1 \rightarrow 0$

Atopomesus pachyodus: 1 -> 0

Clado 132: $1 \rightarrow 0$

Deuterodon iguape: $1->0$

Compsura heterura: $1 \rightarrow 0$

Stygichthys typhlops: $1->0$

Hemigrammus unilineatus: $1 \rightarrow 0$

Ctenobrycon hauxwellianus: $1 \rightarrow 0$

aráter 262 (9 passos)

Raiz: 1

Erythrinoidea fam. nov: 1 -> 2

Semaprochilodus insignis: $1 \rightarrow 0$

Gilbertolus atratoensis: $1 \rightarrow 2$

Curimata ocellata: $1 \rightarrow 0$

Schizodon fasciatus: $1 \rightarrow 0$
Clado 131: $1 \rightarrow 0$

Stygichthys typhlops: 1 -> 2

Gymnocorymbus ternetzi: $1 \rightarrow 0$

Tetragonopterus argenteus: $1 \rightarrow 0$

caráter 263 ( 8 passos)

Raiz: 0

Clado 106: 0 -> 01

Copeina cf. guttata: $\odot->1$

Arnoldichthys spilopterus: 0 -> 1

Distichodus notospilus: 01 -> 1

Citharinus latus: 01 - $>0$

Xenocharax spilurus: $01->1$

Acestrorhynchus falcirostris: $0 \rightarrow 1$

Piaractus mesopotamicus: $0 \rightarrow 1$

Leporinus fasciatus: $0 \rightarrow 1$

Caráter 264 ( 36 passos)

Raiz: 3

Clado 115: $3 \rightarrow 1$

Clado 160: $3 \rightarrow 03$

Chalceus epakros: $\odot 3->\odot$

Clado 112: $3 \rightarrow 0$

Brycon pesu: 3 ->

Copeina cf. guttata: $3->1$

Arnoldichthys spilopterus: $03->3$

Parodon nasus: $1 \rightarrow 0$

Bivibranchia fowleri: 1 -> 3

Charax cf. leticiae: $3 \rightarrow 1$

lado 197: 03 -> 0123

Citharinus latus: 3 -> 1

Anodus orinocensis: $1->$

Clado 124: $1 \rightarrow 0$

Clado 174: 3 -> 23

Hydrolycus tatauaia: $3->2$

Brycinus macrolepidotus: $03->3$

Bryconalestes longipinnis: $03->0$

Piaractus mesopotamicus: $0123 \rightarrow 2$

Curimatopsis macrolepis: $1 \rightarrow 3$

Anostomus anostomus: $1 \rightarrow 3$

Landonia latidens: $3 \rightarrow 0$

Serrabrycon magoi: $23 \rightarrow 2$

Paragoniates alburnus: $3 \rightarrow 1$

Hepsetus odoe: $3 \rightarrow 1$

Roestes molossus: $3 \rightarrow 1$

Metynnis lippincottianus: 0123 -> 0

Myleus setiger: $0123 \rightarrow 1$

Phenacogaster pectinatus: 23 -> 1

Clado 171: 23 -> 023

Clado 177: $23 \rightarrow 3$

Atopomesus pachyodus: $023->0$

Microschemobrycon casiquiare: $023->2$

Glandulocauda melanogenys: 3 -> 1

Moenkhausia xinguensis: $3 \rightarrow 2$

Knodus meridae: $3 \rightarrow 0$

Clupeacharax engrauloides: $3 \rightarrow 2$

Triportheus albus: $3 \rightarrow 1$

Clado 189: $3 \rightarrow 0$

Hemigrammus unilineatus: 3 -> 2 
Triportheus albus: 1 -> 0

Clado 193: $0 \rightarrow 1$

Poptella brevispina: $0 \rightarrow 1$

caráter 266 (21 passo)

Raiz: 0

Clado 142: $0 \rightarrow 01$

Clado 118: $\odot \rightarrow 01$

Clado 141: $01 \rightarrow 1$

Oligosarcus argenteus: 01 -> 0

Clado 182: $01 \rightarrow 1$

Brycon pesu: $0 \rightarrow 1$

Clado 151: $\rightarrow 01$

Clado 162: $\odot \rightarrow->1$

Bivibranchia fowleri: 01 -> 0

Clado 116: $01 \rightarrow 1$

Clado 121: $01 \rightarrow 1$

Clado 158: $01 \rightarrow 1$

Clado 124: $01 \rightarrow 1$

Clado 126: 01 ->

Aphyocharax pusillus: $1 \rightarrow 0$

Metynnis lippincottianus: $1 \rightarrow 0$

Potamorhina latior: $1 \rightarrow 0$

Clado 133: $1 \rightarrow 01$

Clado 167: $1 \rightarrow 0$

Clado 200: $1 \rightarrow 01$

Compsura heterura: $1 \rightarrow 0$

Clado 131: $01 \rightarrow 0$

Bryconops alburnoides: $01->1$

Iguacladoctes geisleri: $01 \rightarrow$

Stygichthys typhlops: $01-0$

Agoniates halecinus: $01->1$

Triportheus albus: $01->0$
Hemigrammus unilineatus: $\theta->1$

Gymnocorymbus ternetzi: $\odot \rightarrow 1$

Tetragonopterus argenteus: $0->1$

Ctenobrycon hauxwellianu

Caráter 267 (2 passos)

Raiz: $\odot$

Apareiodon piracicabae: $\odot \rightarrow->1$

Clado 158: $01 \rightarrow 1$

Caráter 268 ( 5 passos)

Raiz: 0

Clado 109: $0->1$

Oligosarcus argenteus: $\odot->1$

Clado 145: $\odot \rightarrow 01$

Acestrorhynchus falcirostris: $01->1$

Hepsetus odoe: $01->0$

clado 155: $01 \rightarrow 1$

Clado 155: $01 \rightarrow 1$
Clado 195: $0 \rightarrow>1$

Caráter 269 (19 passos)

Raiz: 0

Clado 142: $\odot \rightarrow 01$

Clado 160: $0 \rightarrow 1$

Clado 190: $01 \rightarrow$

Oligosarcus argenteus: 01 -> 1

Clado 182: $01 \rightarrow 0$

Clado 165: $01 \rightarrow 0$

Clado 145: $0 \rightarrow>0$

Clado 197: $1 \rightarrow 0$

Acestrorhynchus falcirostris: $01 \rightarrow 1$

Landonia latidens: $01 \rightarrow 1$

Serrabrycon magoi:

Clado 173: $01->1$

Clado 155: $01 \rightarrow 0$

Clado 136: $01 \rightarrow 1$

Clado 180: 01 -> 0

Bryconamericus exodon: $\odot->1$

Clado 132: 1 -> 01

Axelrodia reisei: 1 -> 0

Rhoadsia altipinna: $1 \rightarrow$

Clado 131: $01 \rightarrow 0$

Agoniates halecinus: $01->0$

Triportheus albus: $01 \rightarrow 1$

Astyanax mexicanus: $1 \rightarrow 0$

Probolus heterostomus : $1 \rightarrow 0$

Markiana nigripinnis: 1 - $>0$

Hyphessobrycon compressus: $1 \rightarrow 0$

Hyphessobrycon compressus: $1 \rightarrow 0$

Orthospinus franciscoe
caráter 270 (17 passos)

Caráter

Raiz: 1 Clado 104: 1 -> 01

Clado 104: $1->01$
Olivaichthys mesembrinus: $01 \rightarrow 0$

Olivaichthys mese

Clado 163: $1 \rightarrow 0$

$\begin{array}{lll}\text { Clado 190: } 1 & \rightarrow & \odot \\ \text { Clado 162: } 1 & -> & 01\end{array}$

Nannocharax fasciatus: 1 ->

Nannocharax fasciatu

Clado 125: 1 -> $\odot$

Clado 197: $01->0$
Hydrolycus tatauaia: $1->0$

Brycinus macrolepidotus: $01->1$

Bryconalestes longipinnis: $\odot 1->$

Potamorhina latior: $1 \rightarrow \odot$

Phenacogaster pectinatus: 1 -> 0

Clado 134: 1 - $>01$

Microschemobrycon casiquiare: $1 \rightarrow 0$

Glandulocauda melanogenys: $01 \rightarrow 0$

Paracheirodon axelrodi: $1 \rightarrow 0$

$\begin{array}{ll}\text { Clado 131: } & 01->1 \\ \text { Clado 164: } & 01->0\end{array}$

Bryconops alburnoides: $01 \rightarrow 1$

Iguacladoctes geisleri: $01 \rightarrow$

clado 188: $1 \rightarrow 01$

Gymnocorymbus ternetzi: $01 \rightarrow 0$

Orthospinus franciscoensis: $->1$

Clado 186: $01 \rightarrow 1$
Caráter 271 (13 passos)

Raiz: 2

Clado 109: 2 -> 12

Clado 115: $12 \rightarrow 1$

Neolebias unifasciatus: $12 \rightarrow>2$

Clado 107: 12 -> 012

Clado 106: $012 \rightarrow 01$

Clado 122: $1 \rightarrow$

Clado 146: 2 -> 02

Distichodus notospilus: $01 \rightarrow 0$

Nannocharax fasciatus: $012 \rightarrow 1$

Clado 197: 2 -> 1

Citharinus latus: 01 -> 1

Xenocharax spilurus: $01 \rightarrow$

Clado 126: $\odot \rightarrow 02$

Hydrolycus tatauaia: $02->\odot$

Curimatopsis macrolepis: $\odot \rightarrow 2$

Anostomus anostomus: $02->2$

Curimata ocellata: $0 \rightarrow 1$

Schizodon fasciatus: $02->0$

Clado 127: $02 \rightarrow 2$

Clado 198: $2 \rightarrow 02$

Clado 132: 2 -> 02

Clado 164: $02 \rightarrow 0$

Stygichthys typhlops: 02 -> 0

caráter 272 (29 passos)

Raiz: 1

Clado 110: $1 \rightarrow 12$
Clado 109: $12 \rightarrow>2$

Characidium bahiensis: 12 -> 1

Crenuchus spilurus: $12 \rightarrow>2$

Clado 160: $1 \rightarrow 12$

Clado 147: 1 -> 12

Chalceus epakros: 12 -> 2

Brycon pesu: 12 -> 2

Piabucina astrigata: $1 \rightarrow 0$

Arnoldichthys spilopterus: 12 -> 1

Bivibranchia fowleri: $2 \rightarrow 0$

Clado 116: 2 -> 3

Clado 145: $12 \rightarrow>1$

Clado 197: $12 \rightarrow 123$

Citharinus latus: $2->3$

Hydrolycus tatauaia: $12->3$

Brycinus macrolepidotus: 12 -> 1

Bryconalestes longipinnis: $12->2$

Piaractus mesopotamicus: $123 \rightarrow 3$

Landonia latidens: $1 \rightarrow 2$

Gilbertolus atratoensis: 12 -> 1

Roestes molossus: $12 \rightarrow 2$

Metynnis lippincottianus: $123->1$

Myleus setiger: $123 \rightarrow 3$

Potamorhina latior: 2 -> 3

Leporellus vittatus: $2 \rightarrow 3$

Hemibrycon polyodon : $1 \rightarrow 0$

Bryconamericus exodon: $1 \rightarrow 2$

Piabina argentea: 1 -> 2

Brittanichthys axelrodi: $1 \rightarrow 2$

Clado 164: $1 \rightarrow 3$

Bryconops alburnoides: $1->2$

Stygichthys typhlops: 1 -> 2

Clado 130: $1 \rightarrow 0$

Caráter 273 ( 4 passos)

Raiz: $\odot$

Clado 197: $\odot$-> 01

Hydrolycus tatauaia: $\odot->$

Piaractus mesopotamicus: $01->1$

Metynnis lippincottianus: $01 \rightarrow 0$

Myleus setiger: $01->1$

Triportheus albus: $\odot->1$

Caráter 274 (20 passos)

Raiz: 0

Clado 183: $\odot \rightarrow 1$

Clado 146: $\odot \rightarrow->1$

Gnathocharax steindachneri: $\odot->2$

Clado 138: $\odot \rightarrow 1$

Acestrorhynchus falcirostris: $01->1$

Hydrolycus tatauaia: $01 \rightarrow 0$

Hydrolycus tatauaia:

Clado 149: $01 \rightarrow->1$

Hepsetus odoe: $01->0$

Clado 155: $01->1$

Gilbertolus atratoensis: $012->2$

Gilbertolus atratoensis: 012

Phenacogaster pectinatus: 0 -> 1

Clado 169: 1 ->

Clado 194: 1 ->

Atopomesus pachyodus: $\odot->1$

Rhoadsia altipinna: 0 -> 1

Clado 131: $1 \rightarrow 2$

Iguacladoctes geisleri: $1->0$

Rachoviscus graciliceps: $\bullet \rightarrow 1$

Triportheus albus: $1 \rightarrow 0$

Clado 189: $\odot \rightarrow 1$

Clado 193: $\odot \rightarrow 1$

Caráter 275 (11 passo)

Raiz: 01

Chanos chanos: $01->0$

Clado 111: 01 -> 1

Catostomus commersonnii: $01->0$

Olivaichthys mesembrinus: $01 \rightarrow 1$

Clado 107: 1 -> 01

Distichodus notospilus: $01->0$

Hemistichodus vaillanti: $01 \rightarrow 1$

Nannocharax fasciatus: $01 \rightarrow$

Citharinus latus: 01 1 $\rightarrow 0$

Xenocharax spilurus: $01->1$

Piaractus mesopotamicus: $1 \rightarrow 0$

Clado 128: 1 -> 01

Schizodon fasciatus: $01 \rightarrow 0$

Leporellus vittatus: $01 \rightarrow 1$

Leporinus fasciatus: $01 \rightarrow 0$

Piabina argentea: 1 -> 0

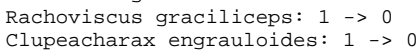

Caráter 276 (12 passos)

Raiz: 0

Clado 110: $0 \rightarrow 1$

Salminus hilarii: $0 \rightarrow 1$

Apareiodon piracicabae: 1 -> 0

Clado 197: $0 \rightarrow 1$

Clado 123: $1->2$

Clado 128: 1 -> 2

Serrabrycon magoi: $0 \rightarrow 1$

Clado 169: $\odot \rightarrow 1$

Clado 185: $0 \rightarrow 1$

Markiana nigripinnis: 1 -> 0

Caráter 277 ( 7 passos)

Clado 111: $0 \rightarrow 01$

Clado 109: $01->0$

Clado 163: $01 \rightarrow>1$

Clado 143: $01 \rightarrow>1$

Clado 153: $01 \rightarrow>1$

Hemistichodus vaillanti: $\odot->1$

Acestrorhynchus falcirostris: 1 -> 0

Piaractus mesopotamicus: $0 \rightarrow 1$

Curimatopsis macrolepis: $0 \rightarrow 1$

Caráter 278 (37 passos)

Raiz: 23

Catostomus commersonnii: 23 -> 3

Clado 104: $23 \rightarrow 0123$

Clado 144: 23 -> 123

Olivaichthys mesembrinus: 0123 -> 0

Clado 143: $123 \rightarrow 1$

Crenuchus spilurus: 23 -> 3

Clado 153: $123 \rightarrow 0$

Clado 160: $123 \rightarrow 3$

Clado 107: $23 \rightarrow 3$

Saccodon wagneri: $23 \rightarrow 2$

Hemistichodus vaillanti: 3 -> 23

Gnathocharax steindachneri: $1 \rightarrow 0$

Clado 150: $1 \rightarrow 12$

Clado 158: $\odot \rightarrow 01$

Clado 161: $3 \rightarrow 1$

Clado 126: $2->3$

Clado 156: 1 ->

Hydrolycus tatauaia: $12->$

Hoplias malabaricus: $01->3$

Curimatopsis macrolepis: 2 -> 1

Caenotropus labyrinthicus: 2 -> 012

Clado 137: 1 -> 0

Phenagoniates macrolepis: 1 -> 9

Gilbertolus atratoensis: $12 \rightarrow 2$

Roestes molossus: $12 \rightarrow 1$

Potamorhina latior: $2 \rightarrow 12$

Clado 169: $\odot \rightarrow 1$

Clado 133: $\odot \rightarrow 1$

Stygichthys typhlops: 1 -> 0

Clupeacharax engrauloides: 1 -> 0

Agoniates halecinus: $1 \rightarrow 01$

Thoracocharax stellatus : $1>3$

Poptella brevispina: 1

Raiz: 01

Chanos chanos: 01 ->

Chanos Chanos: $01->0$

Clado 104: $01 \rightarrow 01234$

Clado 104: $01 \rightarrow>012$

Clado 144: $01->2$

Clado 108: $01 \rightarrow 0$

Clado 115: $01 \rightarrow 1$

Characidium bahiensis: 01 -> 1

Crenuchus spilurus: $01 \rightarrow 0$

Clado 153: $2 \rightarrow 3$

Clado 118: $1 \rightarrow 2$

Chalceus epakros: 2 -> 1

Nannocharax fasciatus: $0 \rightarrow 1$

Gnathocharax steindachneri: 2 -> 3

Erythrinoidea fam.
Clado 158: $3 \rightarrow 3$ 
Clado 104: 0 -> 01

Clado 110: $\odot \rightarrow$

Olivaichthys mesembrinus: 01 -> 1

Clado 118: $1->0$
Clado 152: $\odot->1$

Roeboexodon guyanensis: $0->1$

Hydrolycus tatauaia: $0 \rightarrow 1$

Erythrinus erythrinus: $1 \rightarrow 0$

Bryconalestes longipinnis: 0 -> 1

Clado 155: 0 -> 1

Schizodon fasciatus: 0 -> 1

$\begin{array}{lll}\text { Phenacogaster pectinatus: } & 0 & ->1 \\ \text { Bryconadenos tanaothoros: } & 0 & ->1\end{array}$

Knodus meridae: $0 \rightarrow 1$

Deuterodon iguape: $0 \rightarrow 1$

Paracheirodon axelrodi: $\odot->1$

Compsura heterura: $\odot->1$

Bryconops alburnoides: $0->1$

Clado 130: $0 \rightarrow 1$

Gymnocorymbus ternetzi: $\odot->1$

Hyphessobrycon compressus: $0->1$

Ctenobrycon hauxwellianus: $0 \rightarrow 1$

Caráter 281 (10 passos)

Raiz: 0

Clado 102: $\odot \rightarrow 1$

Crenuchus spilurus: $0->1$

Clado 113: $0 \rightarrow 1$

Copeina cf. guttata: $0->1$

Clado 149: $\odot \rightarrow 01$

Hoplias malabaricus: $0->1$

Curimatopsis macrolepis: $0 \rightarrow 1$

Gilbertolus atratoensis: $01 \rightarrow 1$

Ctenolucius hujeta: $0 \rightarrow 1$

Clado 171: $0 \rightarrow 1$

Clupeacharax engrauloides: 0 -> 1

Caráter 282 (12 passos)

Raiz: 01

Chanos chanos: 01 ->

Clado 102: $01 \rightarrow$

Clado 110: $01 \rightarrow 0$

Clado 142: $01 \rightarrow 0$

Clado 148: $01 \rightarrow$

Clado 153: $01 \rightarrow$

Chalceus epakros: 01 -> 1

Arnoldichthys spilopterus: $01->0$

Gnathocharax steindachneri: $0->1$

Gnathocharax steinda

Brycinus macrolepidotus: $01->1$

Brycinus macrolepidotus: $01->1$

Bryconalestes longipinnis: $01->$

Piaractus mesopota

Clado 196: $01 \rightarrow>0$
Clado 155: $1 \rightarrow 2$

Clado 155: $1 \rightarrow 2$

Stygichthys typhlops: $\odot->1$
Thoracocharax stellatus : $1->2$

Thoracocharax stellatus

Caráter

Raiz: 1

Clado 115: 1 -> 01

Crenuchus spilurus: $1 \rightarrow 0$

Clado 153: $1 \rightarrow 0$

Salminus hilarii: 1 -> 0

Clado 106: 1 - $>01$

Saccodon wagneri: $01 \rightarrow \odot$

Clado 117: $01 \rightarrow 1$

Clado 122: $01 \rightarrow$

Clado 162: 1 -> 0

Distichodus notospilus: $01->0$

Apareiodon piracicabae: $01 \rightarrow 1$

Parodon nasus: $01 \rightarrow$

Clado 150: 1 -> 0

Citharinus latus: $01->1$

Xenocharax spilurus: $01 \rightarrow 0$

Hoplias malabaricus: $0 \rightarrow 1$

Clado 185: 1 - 01

Clado 185: 1 -> 01

Odontostilbe pequira: $01 \rightarrow 0$

Axelrodia reisei: 1 -> $\odot$

Axelrodia reisei: $1->0$

Rhoadsia altipinna: $01 \rightarrow 1$

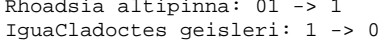

Iguacladoctes geisleri: $1->$

Stygichthys typhlops: $1 \rightarrow 0$
Agoniates halecinus: $1 \rightarrow 0$

Agoniates halecinus:

Clado 129: $1->0$

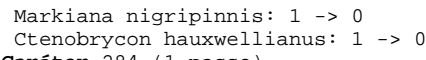

Caráter 284 ( 1 passo)

Raiz: 0

Clado 196: 0 -> 1

Caráter 285 ( 8 passos)

Raiz: $\odot$

Charax cf. leticiae: $0 \rightarrow 1$

Clado 197: $0 \rightarrow 1$

Clado 199: $0 \rightarrow 1$

Phenacogaster pectinatus: $\odot \rightarrow 1$

Atopomesus pachyodus: $0 \rightarrow 1$

Rhoadsia altipinna: 0 -> 1

Clado 189: $0 \rightarrow 01$

Clado 188: 01 ->

Markiana nigripinnis: 01 -> 1

Tetragonopterus argenteus: $01->0$

Caráter 286 ( 3 passos)

Raiz: $\odot$ Charax cf. leticiae: $\odot \rightarrow 1$

Clado 188: $0 \rightarrow 1$

Poptella brevispina: 1 -> $\odot$

caráter 287 (11 passo)
Raiz: $\odot$

Catostomus commersonnii: $0 \rightarrow 1$

Clado 114: $\odot \rightarrow 1$

Paragoniates alburnus: $0->1$

Curimata ocellata: $0 \rightarrow 1$

Phenacogaster pectinatus: 0 -> 1

Atopomesus pachyodus: $0->1$
Rhoadsia altipinna: $0->1$

Iguacladoctes geisleri: $\odot->1$

Clado 191: $0 \rightarrow 1$

Clado 187: $0 \rightarrow 1$

Markiana nigripinnis: $0->1$

Caráter 288 (3 passos)

Raiz: $\odot$

Catostomus commersonnii: $\odot->1$

Clado 114: $\odot \rightarrow 1$

Nannocharax fasciatus: $0 \rightarrow 1$

Caráter 289 (10 passos)

Raiz: 1

Clado 104: $1 \rightarrow 0$

Clado 143: $1 \rightarrow 0$

Clado 162: $1 \rightarrow 01$

Erythrinoidea fam nov: 1 -> 0

Clado 156: 0 -> 1

Hydrolycus tatauaia: $\odot->1$

Brycinus macrolepidotus: $01->1$

Bryconalestes longipinnis: $01->$

Piaractus mesopotamicus: $01 \rightarrow 0$
Metynnis lippincottianus: $01 \rightarrow 0$

Myleus setiger: $01 \rightarrow 1$

Bryconadenos tanaothoros: $0->1$

Bryconops alburnoides: $0 \rightarrow 1$

Caráter 290 (19 passos)

Raiz: $\odot$

$\begin{array}{lll}\text { Clado 111: } 0 & ->1 \\ \text { Clado 118: } 1 \text {-> } & 01\end{array}$

Salminus hilarii: $1 \rightarrow 0$

Chalceus epakros: 1 -> 0

Bivibranchia fowleri: 01 -> 0

Clado 121: 01 -> 1

Roeboexodon guyanensis: 1 -> 0

Anodus orinocensis: $01->1$

Hemiodus unimaculatus : $01 \rightarrow 0$

Aphyocharax pusillus: $\rightarrow 0$

Caenotropus labyrinthicus: 01 -> 1

Chilodus punctatus: $01 \rightarrow 0$

Anostomus anostomus: 01 -> 0

Serrabrycon magoi: $1 \rightarrow 0$

Metynnis lippincottianus: 1 -> 0

Schizodon fasciatus: 01 ->

Clado 127: $01 \rightarrow 1$

Rhinobrycon negrensis: 1 -> 0

Clado 169: $1 \rightarrow 01$

Moenkhausia xinguensis: $01 \rightarrow 0$

Bryconadenos tanaothoros: $1 \rightarrow 0$

Clado 175: $1 \rightarrow 0$

Deuterodon iguape: 01 -> $\odot$

Clado 167: $01 \rightarrow 1$

Agoniates halecinus: 1 -> 0

Hyphessobrycon compressus: $1 \rightarrow 0$

Caráter 291 (15 passos)

Raiz: 0

Clado 104: $\theta \rightarrow 1$

Clado 110: $\odot \rightarrow 01$

Clado 163: 01 -> 1

Neolebias unifasciatus: 01 -> 0

Clado 114: $01->1$

Clado 118: $01 \rightarrow 0$

Clado 152: $0 \rightarrow 1$

Clado 106: $01 \rightarrow 1$

Hemistichodus vaillanti: $01->1$

Nannocharax fasciatus: $01 \rightarrow 0$

Clado 197: $0 \rightarrow 1$

Phenagoniates macrolepis: 0 -> 1

Clado 155: $\theta \rightarrow 1$

Roestes molossus: $0 \rightarrow 1$

Axelrodia reisei: $0 \rightarrow 1$

Compsura heterura: $\odot \rightarrow 1$

Clado 130: $0 \rightarrow 1$

Gymnocorymbus ternetzi: $0->1$

Ctenobrycon hauxwellianus: $0 \rightarrow 1$

Caráter 292 ( 32 passos)

Raiz: 1

Catostomus commersonnii: 1 -> 0

Clado 110: $1 \rightarrow 0$

Gymnotus aff. carapo: 1 -> 3

Clado 143: $1 \rightarrow 2$

Clado 153: $1 \rightarrow 01$

Clado 157: 01 -> 0

Chalceus epakros: 1 -> 01

Clado 106: $0 \rightarrow 1$

Clado 182: $2 \rightarrow 3$

Copeina cf. guttata: $01->0$

Clado 150: $2 \rightarrow 3$

Erythrinoidea fam. nov: $01->1$

Clado 197: 1 -> 2

$\begin{array}{lll}\text { Citharinus latus: } 1 & -> & 2 \\ \text { Anodus orinocensis: } 0 & ->1\end{array}$

Clado 174: 2 -> 12

Aphyocharax pusillus: 2 -> 1

Clado 199: 2 -> 3

Clado 156: $2 \rightarrow 0$

Erythrinus erythrinus: $01 \rightarrow 0$

Hoplias malabaricus: $01 \rightarrow 12$

Clado 196: 2 -> 3

Chilodus punctatus: $0 \rightarrow 01$

Landonia latidens: 2 -> 23

Serrabrycon magoi: $12->1$

Potamorhina latior: $0->1$

Clado 180: 2 ->

Phenacogaster pectinatus: 12 -> 3

Clado 172: 12 -> 1

Atopomesus pachyodus: 1 -> 12

Glandulocauda melanogenys: 2 -> 1

Rhoadsia altipinna: 1 -> 2

Clado 131: 2 -> 23

Bryconops alburnoides: 2 -> 3

Rachoviscus graciliceps: 1 -> 2

Stygichthys typhlops: $1 \rightarrow 01$

Clupeacharax engrauloides: 23 -> 3

Astyanax mexicanus: 2 -> 1

Clado 189: 2 -> 3

Thoracocharax stellatus : 23 -> 3

Clado 129: 23 -> 2

Hollandichthys multifasciatus: 2 -> 23

Orthospinus franciscoensis: $3 \rightarrow 23$

Caráter 293 (22 passos)

Raiz: 0

Clado 102: $\odot \rightarrow 1$

Characidium bahiensis: $\Theta->1$

Clado 107: $0 \rightarrow 01$

Clado 112: $01 \rightarrow 1$

Distichodus notospilus: $01->1$

Clado 105: 01 -> 0

Apareiodon piracicabae: $0 \rightarrow 1$

Clado 125: $\odot \rightarrow 01$

Charax cf. leticiae: $\odot->1$

Clado 126: $01 \rightarrow 1$

Clado 199: $\odot \rightarrow 1$

Brycinus macrolepidotus: $1 \rightarrow 0$

Caenotropus labyrinthicus: $01 \rightarrow 0$

Chilodus punctatus: $01 \rightarrow 1$

Clado 155: $0 \rightarrow>1$

Roestes molossus: 0 -> 1

Myleus setiger: $1 \rightarrow 0$

Leporellus vittatus: $1->0$

Knodus meridae: $0 \rightarrow 1$

Brittanichthys axelrodi: $\odot->1$

Stygichthys typhlops: $0->1$

Clado 130: $\odot \rightarrow 1$

Clado 189: $\odot \rightarrow 01$

Clado 195: $01 \rightarrow$

Gymnocorymbus ternetzi: 01 -> 1

Orthospinus franciscoensis: $01 \rightarrow 0$

Ctenobrycon hauxwellianus: $01 \rightarrow 1$

Poptella brevispina: 01 - $>0$

Caráter 294 (15 passos)

Raiz: $\odot$

Characidium bahiensis: $0->1$

Clado 142: $0 \rightarrow 1$

Roeboexodon guyanensis: $1->0$

Erythrinoidea fam. nov: $0 \rightarrow 1$

Aphyocharax pusillus: $1 \rightarrow 0$

Acestrorhynchus falcirostris: 0 -> 1

Anostomus anostomus: $0 \rightarrow 1$

Phenacogaster pectinatus: 1 -> 0

Leporinus fasciatus: $0 \rightarrow 1$

Clado 176: 1 - $>01$

Glandulocauda melanogenys: $1 \rightarrow 0$

Axelrodia reisei: $01 \rightarrow 0$

Brittanichthys axelrodi: 01 -> 1

Paracheirodon axelrodi: $01 \rightarrow 0$

Rachoviscus graciliceps: $01 \rightarrow 1$

Stygichthys typhlops: $01 \rightarrow 0$

Clado 195: $1 \rightarrow 01$

Tetragonopterus argenteus: $01 \rightarrow \odot$

Orthospinus franciscoensis: $1 \rightarrow 0$

Caráter 295 (13 passos)

Raiz: 0

Clado 102: $0 \rightarrow 1$

Crenuchus spilurus: $0->1$

Clado 107: $\theta \rightarrow 01$

Clado 152: $0 \rightarrow 1$

Clado 106: $01 \rightarrow$

Clado 113: $01>1$

Hemistichodus vaillanti: 01 -> 1

Nannocharax fasciatus: $01->0$ 
Clado 153: 1 -> 12

Clado 160: $1 \rightarrow 0$

Clado 118: $1->\odot$

Lebiasina bimaculata: $12 \rightarrow 1$

Piabucina astrigata: $12 \rightarrow>2$

Hemistichodus vaillanti: 1 -> 2

Clado 197: $0 \rightarrow 01$

Clado 156: 1 -> 01

Piaractus mesopotamicus: 01 -> 1

Hepsetus odoe: $01-\rightarrow$

Metynnis lippincottianus: $01 \rightarrow 1$

Myleus setiger: $01->0$

Potamorhina latior:

Boulengerella maculata: 01 -> 1

Ctenolucius hujeta: $01->\odot$

Rhinobrycon negrensis: $1 \rightarrow 2$

Bryconamericus exodon: 1 -> 2

Compsura heterura: $1 \rightarrow 12$

Stygichthys typhlops: 1 -> 2

Thoracocharax stellatus : 1 -> 2

Hemigrammus unilineatus: $1 \rightarrow$

Caráter 299 ( 21 passo)

Raiz: 01

Chanos chanos: $01->$

Clado 103: $01 \rightarrow 0$

Catostomus commersonnii: $\odot->2$

Crenuchus spilurus: $0 \rightarrow 1$

Clado 153: $0 \rightarrow 02$

Clado 152: 02 ->

Lebiasina bimaculata: $02->2$

Piabucina astrigata: $02 \rightarrow 0$

Hemistichodus vaillanti: $\odot \rightarrow 1$

Clado 125: $0 \rightarrow 01$

Galeocharax knerii: 0 -> 1

Clado 126: 01 ->

Caenotropus labyrinthicus: $01->0$

Chilodus punctatus: $01->1$
Serrabrycon magoi: $0 \rightarrow 1$

Phenagoniates macrolepis: $\odot$-> 1

Potamorhina latior: $0 \rightarrow 1$

Rhinobrycon negrensis: $\odot->12$

Microschemobrycon casiquiare: 0 -> 1

Bryconamericus exodon: $\odot \rightarrow 2$

Knodus meridae: $0 \rightarrow 1$

Clado 175: $\odot \rightarrow 1$

Clado 130: $0 \rightarrow 012$

Triportheus albus: $\odot->1$

Thoracocharax stellatus : 012 -> 2

Clado 129: $012 \rightarrow 1$

Markiana nigripinnis: 0 -> 1

Caráter 300 (23 passos)

Raiz: 1

Clado 142: $1 \rightarrow 0$

Gnathocharax steindachneri: 0 -> 1

Galeocharax knerii: $0 \rightarrow$

Clado 138: $0 \rightarrow 1$

Clado 156: 1 -> $\odot$

Hydrolycus tatauaia: $1->0$

Bryconalestes longipinnis: 0 -> 1

Clado 196: $0 \rightarrow 1$

Prochilodus nigricans: 1 -> 0

Chilodus punctatus: $1 \rightarrow \odot$

Paragoniates alburnus: $\odot->1$

Potamorhina latior: $1->0$
Leporinus fasciatus: $1 \rightarrow 0$

Clado 170: 1 -> 0

Deuterodon iguape: $0 \rightarrow 1$

Clado 164: 1 -> 0

Iguacladoctes geisleri: 1 -> 0

Stygichthys typhlops: $\odot->1$

Probolus heterostomus : $\odot->1$

Thoracocharax stellatus : $1>\odot$

Clado 188: $0 \rightarrow 1$

Clado 188: $0->1$
Poptella brevispina: $1 \rightarrow 0$

Caráter 301 (17 passos)

Raiz: 1

Raiz: 1 catostomus commersonnii: 1 -> 2

Clado 115: $1 \rightarrow 2$

Clado 115: $1 \rightarrow 2$
Clado 148: $1 \rightarrow 2$

Clado 148: $1 \rightarrow>2$

Chalceus epakros: 12 -> 2

Chalceus epakros: $12 \rightarrow 2$

Clado 151: 1 -> 01 Arnoldichthys spilopterus: 12 -> 1

Clado 162: $12 \rightarrow 2$
Erythrinoidea fam. nov: $01 \rightarrow 0$

Clado 120: $2->12$
Clado 156: $2->1$

Clado 156: $2 \rightarrow 1$

Erythrinus erythrinus: $01->$
Hoplias malabaricus: $01->1$

Curimatopsis macrolepis: $12 \rightarrow 1$

Chilodus punctatus: $2 \rightarrow 1$

Gilbertolus atratoensis: 2 -> 1

Metynnis lippincottianus: $2 \rightarrow 1$

Curimata ocellata: $12 \rightarrow 2$

Potamorhina latior: 12 -> 1

Clado 164: 1 -> 2

Bryconops alburnoides: 1 -> 2

Stygichthys typhlops: $1 \rightarrow 0$

Caráter 302 ( 35 passos)

Raiz: 0

Clado 111: $0 \rightarrow 01$

Clado 111: $0->01$

Clado 144: $01 \rightarrow>1$

Clado 163: $01 \rightarrow 0$
Clado 148: 1 -> 12

Salminus hilarii: $12 \rightarrow>2$

Chalceus epakros: $1 \rightarrow 2$

Clado 140: 1 -> 01

Brycon pesu: $12->$

Piabucina astrigata: $1->2$

Arnoldichthys spilopterus: $1 \rightarrow 0$

Roeboexodon guyanensis: 1 -> 2

Charax cf. leticiae: $1 \rightarrow 0$

Clado 150: $12 \rightarrow 01$

Clado 161: $1 \rightarrow 2$

Aphyocharax pusillus: $01->1$

Clado 199: $01 \rightarrow 0$

Acestrorhynchus falcirostris: 12 -> 2

Hydrolycus tatauaia: $01 \rightarrow 0$

Curimatopsis macrolepis: $2 \rightarrow 1$

Chilodus punctatus: $2->0$

Anostomus anostomus: $2 \rightarrow 1$

Landonia latidens:

Clado 137: 01 - $>0$

Serrabrycon magoi: $01->$

Hepsetus odoe: $12->1$

Gilbertolus atratoensis: 01 -> 1

Roestes molossus: $01 \rightarrow 0$

Metynnis lippincottianus: 1 -> 2

Clado 172: 01 1 $\rightarrow$ o

Boulengerella maculata: $12>2$

Ctenolucius hujeta: $12 \rightarrow 1$

Glandulocauda melanogenys: $\odot$-> 2

Moenkhausia xinguensis: $0->1$
Bryconadenos tanaothoros: 0 - $>1$

Compsura heterura: $\odot \rightarrow 1$

Bryconops alburnoides: $\odot->2$
Astyanax mexicanus: $\odot->2$

Thoracocharax stellatus : $\odot->1$

Caráter 303 (1 passo)

Raiz: 1

Clado 102: 1 -> 0

Caráter 304 ( 6 passos)

Raiz: 01

Chanos chanos: $01->1$

Clado 103: $01->0$

Clado 108: $0 \rightarrow 1$

Clado 117: $0 \rightarrow 1$

Clado 151: $0 \rightarrow 1$

Piabucina astrigata: $0->1$

Brycinus macrolepidotus: $0->1$

Brycinus macrolepidot

Raiz: 1

Clado 108: 1 -> 0

Crenuchus spilurus: $1->0$

Hydrolycus tatauaia: $1 \rightarrow 0$

Metynnis lippincottianus: $1->$

Piabina argentea: $1 \rightarrow$

Caráter 306

Raiz: 01

Chanos chanos: $01->1$

Clado 103: $01->0$

Clado 109: $0 \rightarrow 01$

Clado 108: 01 -> 1

Clado 142: $\odot \rightarrow 01$

Clado 114: 01 -> 1

Clado 118: $01 \rightarrow 0$

Clado 157: $0 \rightarrow 1$

Clado 190: 01 -> 1

Oligosarcus argenteus: $01->1$

Clado 182: $01 \rightarrow 0$

Clado 146: $0 \rightarrow 1$

Clado 162: $0 \rightarrow 01$

Clado 139: $01 \rightarrow 0$

Erythrinoidea fam. nov: $0->1$

Clado 197: $01 \rightarrow 1$

Anodus orinocensis: $0->1$

Aphyocharax pusillus: $01 \rightarrow 1$

Hydrolycus tatauaia: $1 \rightarrow 2$

Bydrolycus tatauaia: $1->2$

Brycinus macrolepidotus: $01->1$

Bryconalestes longipinnis: $01->$

Phenagoniates macrolepis: $01 \rightarrow 1$

Diapoma terofali: $0 \rightarrow 1$

Diapoma terofali: $0->1$
Hemibrycon polyodon : $0^{->1}$

$\begin{array}{llll}\text { Hemibrycon polyodon : } & 0 & -> & 1 \\ \text { Brittanichthys axelrodi: } & 0 & ->1\end{array}$

Brittanichthys axelr

Bryconops alburnoides: $\odot \rightarrow 1$

Agoniates halecinus: $0 \rightarrow 1$

Astyanax mexicanus: $0->1$

Caráter 307 ( 8 passos)

Raiz: 0

Clado 108: $\odot \rightarrow 1$

Clado 147: $\odot \rightarrow 2$

Oligosarcus argenteus: $\odot->2$

Clado 156: 2 ->

Brycinus macrolepidotus: $\odot \rightarrow 2$

Clado 196: $\odot \rightarrow 1$

Brittanichthys axelrodi: $0->2$

Gymnocorymbus ternetzi: $0->1$

Caráter 308 ( 2 passos)

Raiz: 01

Chanos chanos: $01 \rightarrow 0$

Clado 111: $01 \rightarrow 1$

Catostomus commersonnii: $01->$

Olivaichthys mesembrinus: $01 \rightarrow 1$

caráter 309 (2 passos)

Raiz: $\odot$

Clado 102: $\odot \rightarrow 1$

Clado 151: 0 -> 1

Caráter 310 ( 2 passos)

Nannocharax fasciatus: $\odot \rightarrow 9$

Clado 158: $\odot$-> 1

Caráter 311 ( 7 passos)

Raiz: 0

Clado 160: $0 \rightarrow 1$

Clado 197: 1 -> 01

Piaractus mesopotamicus: $01 \rightarrow 0$

Metynnis lippincottianus: $01->$

Myleus setiger: $01 \rightarrow 1$

Potamorhina latior: 0 -> 1

Clado 164: $0 \rightarrow 1$

Astyanax mexicanus: $0 \rightarrow 1$

Poptella brevispina: $0->1$

Caráter 312 (8 passos)

Crenuchus spilurus: 2 -> 1

Clado 152: $2 \rightarrow 12$

Copeina cf. guttata: 12 -> 1

Copeina cf. guttata: $12 \rightarrow 1$
Arnoldichthys spilopterus: $2 \rightarrow 1$

Erythrinoidea fam. nov: $12 \rightarrow 0$

Clado 158: $12 \rightarrow 2$

Clado 124: $2 \rightarrow 1$

Schizodon fasciatus: 2 -> 1

Caráter 313 (17 passos)

Raiz: 2

Clado 110: 2 -> 12

Clado 163: $12 \rightarrow>1$

Clado 108: $12 \rightarrow 2$

Clado 114: $12 \rightarrow 1$

Clado 152: $2->1$

Arnoldichthys spilopterus: 2 -> 1

Bivibranchia fowleri: 12 -> 2

Gnathocharax steindachneri: 2 -> 1

Erythrinoidea fam. nov: 1 -> 0

Citharinus latus: 2 -> 1

Anodus orinocensis: $12 \rightarrow 2$

Hemiodus unimaculatus : $12 \rightarrow 1$

Clado 124: $1 \rightarrow 0$

Clado 149: $2 \rightarrow 1$

Paragoniates alburnus: 2 -> 1

Potamorhina latior: $1 \rightarrow 2$

Ctenolucius hujeta: $2->1$

Rhoadsia altipinna: $2 \rightarrow 01$

Clado 129: $2 \rightarrow 1$

Caráter 314 ( 16 passos)

Raiz: 0

Clado 104: $\odot \rightarrow 01$

Olivaichthys mesembrinus: 01 -> 1

Clado 113: $\odot \rightarrow$

Oligosarcus argenteus: $\odot \rightarrow 1$

Piabucina astrigata: $0 \rightarrow 1$

Clado 162: $\odot \rightarrow 1$

Roeboexodon guyanensis: $\odot->1$

Clado 150: $\theta \rightarrow 01$

Clado 158: $\odot \rightarrow 1$

Xenocharax spilurus: $0 \rightarrow 1$

Hydrolycus tatauaia: $01->1$

Clado 128: $\odot \rightarrow 01$

Gilbertolus atratoensis: 01 -> 0

Roestes molossus: 01 -> 1

Clado 127: 01 -> 1

Deuterodon iguape: $0 \rightarrow 1$

Clado 164: $\odot \rightarrow 1$

Bryconops alburnoides: $\odot \rightarrow 1$

Stygichthys typhlops: $0 \rightarrow 1$

Poptella brevispina: $0 \rightarrow 1$

Caráter 315 ( 2 passos)

Raiz: 01

Chanos chanos: $01 \rightarrow 1$

Clado 103: $01 \rightarrow \odot$

Clado 151: $0 \rightarrow>2$

Caráter 316 ( 2 passos)

Raiz: 01

Chanos chanos: $01->0$

Clado 111: $01 \rightarrow 1$

Catostomus commersonnii: $01->0$

Clado 104: 01 ->

Caráter 317 (14 passos)

Raiz: 0

Catostomus commersonnii: 0 -> 1

Clado 108: $\odot \rightarrow 2$ 
Clado 109: 01 -> 0

Characidium bahiensis: $01->0$

Crenuchus spilurus: $01 \rightarrow 1$

Clado 153: $1 \rightarrow 0$

Salminus hilarii: 1 ->

Arnoldichthys spilopterus: 1 -> 0

Distichodus notospilus: $0->1$

Clado 116: 0 -> 1

Gnathocharax steindachneri: 1 -> $\odot$

Clado 123: $0 \rightarrow 1$

Clado 156: 1 -> 0

Hoplias malabaricus: $\theta->1$

Clado 128: $0 \rightarrow 01$

Phenagoniates macrolepis: $1 \rightarrow 0$

Schizodon fasciatus: $01->1$

Leporellus vittatus: $01 \rightarrow 0$

Leporinus fasciatus: $01 \rightarrow 1$

Atopomesus pachyodus: $1 \rightarrow 0$

Clado 130: $1 \rightarrow 0$

Agoniates halecinus: $1 \rightarrow 0$

aráter 321 (4 passos)

Raiz: 01

Chanos chanos: 01 ->

Clado 111: 01 - $>1$

Catostomus commersonnii: 01 -> 1

Clado 104: 01 ->

Characidium bahiensis: 1 -> 0

Nannocharax fasciatus: 1 ->

Caráter 322 ( 2 passos)

Raiz: 01

Chanos chanos: $01->0$

Clado 111: $01 \rightarrow 1$

Catostomus commersonnii: 01 -> $\odot$

Clado 104: 01 -> 1

Caráter 323 (1 passo)

Raiz: 01

Chanos chanos: $01 \rightarrow \odot$

Clado 103: $01 \rightarrow 1$

Caráter 324 (11 passo)

Raiz: 0

Clado 148: $\odot \rightarrow 1$

Clado 151: $0 \rightarrow 1$

Lebiasina bimaculata: $0 \rightarrow 1$

Clado 162: $0->01$

Charax cf. leticiae: $\odot->1$

Hydrolycus tatauaia: $1 \rightarrow 0$

Hydrolycus tatauaia: $1->0$

Bryconalestes longipinnis: $01->0$

Semaprochilodus insignis: $\odot \rightarrow 1$

Clado 181: $0 \rightarrow 1$

Stygichthys typhlops: $\odot->1$

Triportheus albus: $0 \rightarrow 1$

Caráter 325 (21 passo)

Raiz: 0

Clado 104: $0 \rightarrow 1$

Clado 154: $\odot \rightarrow 1$

Clado 115: $0 \rightarrow 01$

Clado 113: 01 -> 1

Clado 117: $01->1$
Piabucina astrigata: $1->0$

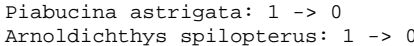

Clado 123: $01 \rightarrow 0$

Clado 124: $01 \rightarrow 0$

Curimatopsis macrolepis: 01 -> 1

Anostomus anostomus: $01 \rightarrow 1$

Clado 128: $01 \rightarrow 0$

Paragoniates alburnus: 0 -> 1

Clado 155: 0 -> 1

Gilbertolus atratoensis: $0 \rightarrow 1$

Curimata ocellata: $01->0$

Potamorhina latior: $01->1$

Clado 180: $0 \rightarrow 01$

Rhinobrycon negrensis: 01 -> 1

Hemibrycon polyodon : $0 \rightarrow 1$

Clado 178: $01 \rightarrow 1$

Clado 194: $01 \rightarrow$

Compsura heterura: $0 \rightarrow 1$

Compsura heterura:

Clupeacharax engrauloides: $01->1$

Clupeacharax engrauloides: $01 \rightarrow 1$

Thoracocharax ste 11

Gymnocorymbus ternetzi: $\odot->1$

Hyphessobrycon compressus: $0 \rightarrow 1$

Caráter 326 ( 1 passo)

Raiz: 01

Chanos chanos: $01->0$

Clado 103: 01 -> 1

Caráter 327 (17 passos)

Raiz: $\odot$

Clado 153: $\odot \rightarrow 1$

Clado 114: $0 \rightarrow 01$

Clado 183: $\odot \rightarrow 01$

Clado 147: $\odot \rightarrow 01$

Clado 113: 01 ->

Oligosarcus argenteus: $01 \rightarrow 1$

Brycon pesu: $01->1$

Nannocharax fasciatus: $0->1$

Clado 165: $0 \rightarrow 1$

Charax cf. leticiae: $01 \rightarrow 1$

Galeocharax knerii: $01 \rightarrow 0$

Clado 145: $01 \rightarrow 0$

Curimatopsis macrolepis: $0->1$

Anostomus anostomus: $0 \rightarrow 1$

Gilbertolus atratoensis: $01 \rightarrow 1$

Phenacogaster pectinatus: $0->1$
Atopomesus pachyodus: $\odot->1$

Clado 133: $0 \rightarrow 1$

Clupeacharax engrauloides: $1 \rightarrow 0$

Astyanax mexicanus: $0 \rightarrow 1$

Probolus heterostomus : $0->1$

Caráter 328 (2 passos)

Raiz: 1

Clado 111: $1 \rightarrow 0$

Clado 108: $0 \rightarrow 1$

Caráter 329 (23 passos)

Raiz: 1

Gymnotus aff. carapo: 1 -> 0

Clado 115: $1 \rightarrow 0$

Clado 153: 1 -> 01

Clado 152: $01 \rightarrow 0$

Lebiasina bimaculata: $01 \rightarrow$

Piabucina astrigata: $01->0$

Clado 116: $0 \rightarrow 1$

Clado 165: $1 \rightarrow 0$

Gnathocharax steindachneri: 1 -> 0

Galeocharax knerii: 1 ->

Acestrorhynchus falcirostris: 1 -> 0

Clado 149: 1 -> 0

Hoplias malabaricus: $0->1$

Semaprochilodus insignis: $0 \rightarrow 1$

Caenotropus labyrinthicus: $0 \rightarrow 1$

Landonia latidens: $1 \rightarrow 0$

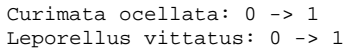

Microschemobrycon casiquiare: 1 -> 0

Deuterodon iguape: $1 \rightarrow 0$

Clupeacharax engrauloides: 1 -> 0

Agoniates halecinus: $1 \rightarrow 0$

Astyanax mexicanus: $1 \rightarrow 0$

Gasteropelecus sternicla: 1 -> 0

Caráter 330 ( 3 passos)

Raiz: 0

Hydrolycus tatauaia: $\odot->1$

Clupeacharax engrauloides: $\odot \rightarrow 1$

Agoniates halecinus: $0 \rightarrow 1$

Caráter 331 ( 2 passos)

Raiz: 0

Clado 102: $0 \rightarrow 1$

Clado 102: $0 \rightarrow>1$

Caráter 332 (15 passos)

Raiz: 0

Gymnotus aff. carapo: $0->1$

Clado 122: $\odot->1$

Nannocharax fasciatus: $\odot->1$

Charax cf. leticiae: $\odot \rightarrow 1$

Aphyocharax pusillus: $0->1$

Acestrorhynchus falcirostris: 0 -> 1

Hoplias malabaricus: $0 \rightarrow 1$

Curimatopsis macrolepis: $1 \rightarrow 0$

Serrabrycon magoi: $0 \rightarrow 1$

Myleus setiger: $\odot \rightarrow 1$

Paracheirodon axelrodi: $0->1$

Bryconops alburnoides: $0 \rightarrow 1$

Clado 130: $0 \rightarrow 1$

Agoniates halecinus: $0 \rightarrow 1$

Ctenobrycon hauxwellianus: $\odot \rightarrow 1$

Caráter 333 (17 passos)

Raiz: $\odot$

Clado 143: $0 \rightarrow 1$

Chalceus epakros: $\odot->1$

Clado 182: $1 \rightarrow 0$

Nannocharax fasciatus: $0->1$

Clado 116: $0->1$

Clado 125: 0

Clado 173: $1 \rightarrow 0$

Phenagoniates macrolepis: 1 -> 0

Clado 155: $1 \rightarrow 0$

Myleus setiger: $0->1$

Diapoma terofali: $01 \rightarrow 0$

Glandulocauda melanogenys: $01 \rightarrow \odot$

Clandulocauda melanos

Clado 132: 01 -> 1

Clado 167: 1 - 01

Clado $167: 1->$ 01

Bryconops alburnoides: $01 \rightarrow 1$

i: $01 \rightarrow 0$

Clado 192: $01 \rightarrow 0$

Astyanax mexicanus: $01 \rightarrow 1$

Clado 189: $01 \rightarrow 0$

Caráter 334 ( 9 passos)

Raiz: 0

Clado 102: $\odot \rightarrow 1$

Clado 142: $0 \rightarrow 1$

Clado 162: $\odot$-> 01

Charax cf. leticiae: $1 \rightarrow 0$

Clado 150: $0 \rightarrow 01$

Clado 197: 01 -> 1

Hydrolycus tatauaia: $01 \rightarrow 1$

Brycinus macrolepidotus: 01 - $>0$

Bryconalestes longipinnis: $01->1$

Phenagoniates macrolepis: $1 \rightarrow 0$

Gilbertolus atratoensis: $01 \rightarrow 0$

Roestes molossus: $01 \rightarrow 1$

Compsura heterura: $1 \rightarrow 01$

Iguacladoctes geisleri: $1 \rightarrow 0$

Caráter 335 ( 15 passos)

Raiz: 01

Chanos chanos: $01->0$

Clado 103: 01

Clado 108: 1 -> 0

Characidium bahiensis: 1 -> 0

Clado 160: 1 -> 01

Clado 147: $1 \rightarrow 0$

Chalceus epakros: $01 \rightarrow 0$

Arnoldichthys spilopterus: $01->1$

Clado 116: $1 \rightarrow 0$

Clado 197: $01->0$

Clado 126: 1 -> 01

Brycinus macrolepidotus: $01->1$
Bryconalestes longipinnis: $01->0$

Clado 119: 1 -> 0

Anostomus anostomus: $01->0$

Hepsetus odoe: $0 \rightarrow 1$

Schizodon fasciatus: 01 -> 1

Clado 127: $\theta 1 \rightarrow \theta$

Clado 133: $1 \rightarrow$

Clado 130: $0 \rightarrow 1$

Caráter 336 (4 passos)

Raiz: $\odot$

Clado 114: $\odot \rightarrow 01$

Clado 113: $01 \rightarrow 1$

Clado 121: $\theta \rightarrow 1$

Chilodus punctatus: $\odot->01$

Rhinobrycon negrensis: $\odot->1$

Clado 131: 0 -> 01

Clupeacharax engrauloides: 01 -> 1

Caráter 337 ( 1 passo)

Raiz: 01

Chanos chanos: $01->1$

Clado 103: $01->0$

Caráter 338 (13 passos)

Raiz: 1

Clado 109: $1 \rightarrow 0$

Clado 183: $1 \rightarrow 0$

Clado 117: $0 \rightarrow 1$

Clado 162: 1 -> 01

Nannocharax fasciatus: $0->1$

Roeboexodon guyanensis: $1 \rightarrow 0$

Clado 150: $1 \rightarrow 0$

Clado 197: $01 \rightarrow 0$

Brycinus macrolepidotus: 01 -> 1

Bryconalestes longipinnis: $01-1$

Clado 136: $1 \rightarrow 0$

Phenacogaster pectinatus: 1 -> 0

Clado 184: $1 \rightarrow 0$

Iguacladoctes geisleri: $\odot->1$

d93: $0 \rightarrow 1$

Caráter 339 ( 31 passo)

Raiz: 2

Clado 111: 2 -> 1

Crenuchus spilurus: 1 -> $\odot$

Clado 148: $1 \rightarrow 0$

Clado 152: $1 \rightarrow 0$

Clado 117: $1->0$

Clado 162: $1 \rightarrow>01$

Nannocharax fasciatus: 1 -> 0

Parodon nasus: 1 -> 0

Charax cf. leticiae: $1 \rightarrow \odot$

Clado 145: $0 \rightarrow 2$

Clado 161: $01 \rightarrow 0$

Xenocharax spilurus: 1 -> 0

Clado 124: $1 \rightarrow 0$

Piaractus mesopotamicus: $01->0$

Clado 196: 01 -> 1

Semaprochilodus insignis: $1 \rightarrow 0$

Landonia latidens: 1 -> 0

Phenagoniates macrolepis: 1 -> 2

Roestes molossus: $0->$

Potamorhina latior: 1

Schizodon fasciatus: $1 \rightarrow 0$

Clado 170: $1 \rightarrow 0$

Rhinobrycon negrensis: 1 -> 2

Clado 171: 1 -> 0

Knodus meridae: 1 -> 2

Brittanichthys axelrodi: $1 \rightarrow \odot$

Stygichthys typhlops: $1->2$

Clupeacharax engrauloides: 1 -> 2

Triportheus albus: $1 \rightarrow 0$

Astyanax mexicanus: $\odot->1$

Gasteropelecus sternicla: 1 -> 0 
Apareiodon piracicabae: 3 -> 4 Bivibranchia fowleri: $123 \rightarrow 1$ Clado 116: 123 -> 5

Clado 121: 123 -> 12 soeboexodon guyanensis: 3 -> 2

Clado 161: $34 \rightarrow 4$

Clado 123: $12 \rightarrow 1$

Clado 124: $123 \rightarrow 1$

Clado 126: 123 -> 23

Clado 174: $3 \rightarrow 1$

Acestrorhynchus falcirostris: 6789 ->

Hydrolycus tatauaia: $6789 \rightarrow 9$

Clado

Erythrinus erythrinus: $34->4$

Hoplias malabaricus: $34->1$

Brycinus macrolepidotus: $4 \rightarrow 8$

Piaractus mesopotamicus: $34 \rightarrow 5$

Clado 196: $34 \rightarrow 3$

Curimatopsis macrolepis: 12 -> 0

Clado 119: $12 \rightarrow 2$

Caenotropus labyrinthicus: $1 \rightarrow 0$

Anostomus anostomus: $23 \rightarrow 5$

Phenagoniates macrolepis: 5 -> 7

Hepsetus odoe: $6789->9$

Roestes molossus: $6 \rightarrow$

Myleus setiger: $3 \rightarrow 2$

Schizodon fasciatus: $23 \rightarrow 2$

Clado 127: $23 \rightarrow 3$

Clado 136: $3 \rightarrow 34$

Clado 180: 3 ->

Boulengerella maculata: 6789 -> 6

Leporellus vittatus: 3 -> 4

Clado 135: $34 \rightarrow 4$
Clado 177: $1 \rightarrow 2$

Hemibrycon polyodon : 34 -> 4

Clado 169: $34 \rightarrow 2$
Clado 133: $4 \rightarrow 56$

Moenkhausia xinguensis: $2 \rightarrow 1$

Bryconamericus exodon: 2 -> 3

Knodus meridae: $2 \rightarrow$

Clado 132: $56 \rightarrow$

Paracheirodon axelrodi: 2 -> 1

Compsura heterura: $2 \rightarrow 1$

Rhoadsia altipinna: 2 ->

Clado 164: $6 \rightarrow 8$

Bryconops alburnoides: $56 \rightarrow 5$

Iguacladoctes geisleri: $56 \rightarrow 5$

Iguacladoctes geisleri: $56 \rightarrow>4$

Rachoviscus graciliceps: 2 ->
Agoniates halecinus: 8 -> 9

Agoniates halecinus:

Clado 189: $2 \rightarrow 012$

Hemigrammus unilineatus: $2 \rightarrow 1$

Hemigramus unilineatus: 2 ->

Carnegiella strigata: $6->5$

Gasteropelecus sternicla: $6->$

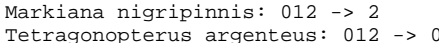

Tetragonopterus argenteus: $012->0$
Hollandichthys multifasciatus: $2 \rightarrow 3$

Ctenobrycon hauxwellianus: $0 \rightarrow 1$

caráter 341 (24 passos)

Raiz: 1

Catostomus commersonnii: 1 -> 2

Olivaichthys mesembrinus: 1 ->

Characidium bahiensis: $1 \rightarrow 0$

Clado 147: 1 -> 01

Clado 157: $1 \rightarrow 0$

Clado 159: $1 \rightarrow 0$

Brycon pesu: $01 \rightarrow 0$

Charax cf. leticiae: $1 \rightarrow 0$

Clado 158: 1 -> 2

Xenocharax spilurus: $1 \rightarrow 0$

Clado 199: $1 \rightarrow 12$

Acestrorhynchus falcirostris: 01 -> 1

Hydrolycus tatauaia: $01 \rightarrow 0$

Hydrolycus tatauaia: $01->0$

$\begin{array}{lll}\text { Brycinus macrolepidotus: } & 0 & ->1 \\ \text { Piaractus mesopotamicus: } 0-> & ->2\end{array}$

Piaractus mesopotamicus: 0

Anostomus anostomus: $1->$
Landonia latidens: $1->$

Phenagoniates macrolepis: 12 ->

Hepsetus odoe: $01->1$

Hepsetus odoe: $01->1$

:

Gilbertolus atratoensis: $01 \rightarrow 1$

Roestes molossus: $01->0$

Clado 133: $1->0$
Stygichthys typhlops: $1->2$

$\begin{array}{lll}\text { Stygichthys typhlops: } 1->2 & -> \\ \text { Astyanax mexicanus: } 1->0\end{array}$

Astyanax mexicanus: $1 \rightarrow 0$

Carnegiella strigata: $\odot \rightarrow 2$

Clado 186: 1 ->

Caráter 342 (24 passos)

Raiz: 01

Chanos chanos: 01 -> 1

Clado 103: $01 \rightarrow \odot$

Olivaichthys mesembrinus: 0 -> 2

Clado 154: $0 \rightarrow 1$

Characidium bahiensis: 0 -> 1

Clado 118: $0 \rightarrow 1$

Clado 147: $0 \rightarrow 2$

Clado 157: 1 -> 12

Oligosarcus argenteus: $\odot \rightarrow 1$

Lebiasina bimaculata: $12 \rightarrow 2$

Roeboexodon guyanensis: $\theta>1$

Galeocharax knerii: $\odot->2$

Erythrinoidea fam. nov: 1 - $>0$

Citharinus latus: $0 \rightarrow 1$
Aphyocharax pusillus: $0 \rightarrow 1$

Acestrorhynchus falcirostris: 2 -> 0

Brycinus macrolep

Anostomus anostomus: $1->2$

Landonia latidens: $0 \rightarrow 2$

Hepsetus odoe: 2 -> 1

Gilbertolus atratoensis: 2 -> 1

Clado 135: $0 \rightarrow 012$

Diapoma terofali: 012 -> 1

Clado 134: $012 \rightarrow$

Clado 129: $2 \rightarrow 0$

Clado 186: $\odot \rightarrow 2$

Caráter 343 ( 6 passos)

Raiz: 0

Olivaichthys mesembrinus: $0->1$

Clado 150: $\odot \rightarrow 01$

Hydrolycus tatauaia: $01->1$

Gilbertolus atratoensis: 01 -> 0

$01 \rightarrow 1$

Bryconops alburnoides: $0->1$

Agoniates halecinus: $0 \rightarrow 1$

Caráter 344 (1 passo)

Raiz: 0

Clado 196: $0 \rightarrow 1$

Caráter 345 ( 9 passos)

Raiz: 0

Clado 109: $0->1$

Clado 106: $1 \rightarrow 0$

Clado 121: 1 -> 01

Aphyocharax pusillus: $\odot->1$

Curimatopsis macrolepis: $01->0$

Prochilodus nigricans: $01->0$

Semaprochilodus insignis: $01 \rightarrow 1$

Curimata ocellata: $01 \rightarrow 0$

Potamorhina latior: $01->1$

Clado 164: $0 \rightarrow 1$

Orthospinus franciscoensis: 0 -> 1

Caráter 346 (17 passos)

Raiz: $\odot$

Crenuchus spilurus: $0->1$

Clado 147: $0 \rightarrow>1$

Chalceus epakros: $\odot \rightarrow 1$

Clado 190: 0 -> 1

Galeocharax knerii: 0 -> 1

Erythrinoidea fam. nov: $\odot->1$

Piaractus mesopotamicus: $\odot->1$

Gilbertolus atratoensis: $1 \rightarrow 0$

Clado 134: $\odot \rightarrow 1$

Deuterodon iguape: $\odot \rightarrow 1$

Iguacladoctes geisleri: $1->0$

Probolus heterostomus : $0 \rightarrow 1$

Gasteropelecus sternicla: $1 \rightarrow$

$\begin{array}{lll}\text { Gymnocorymbus ternetzi: } 0 & ->1 \\ \text { Hyphessobrycon compressus: } 0 & ->1\end{array}$

caráter 347 ( 32 passos)

Raiz: 0

Gymnotus aff. carapo: $\odot->1$

Clado 109: $\odot \rightarrow 1$

Crenuchus spilurus: $0 \rightarrow 2$

Clado 141: $\odot \rightarrow 1$

Clado 159: $0 \rightarrow$

Clado 112: 1 -> 2

Oligosarcus argenteus: $0->2$

Bivibranchia fowleri: 1 -> 0

Clado 125: 1 -> 0

Citharinus latus: 1 -> 0

Anodus orinocensis:

Hydrolycus tatauaia: $0 \rightarrow 1$

Hydrolycus tatauaia: $0->1$

Curimatopsis macrolepis: 1 -> $\odot$

Curimatopsis macrolepis: 1

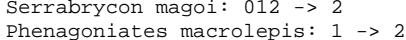

Potamorhina latior: $1 \rightarrow 2$

Potamorhina latior: 1 -> 2 $012->0$

Clado 171: $012 \rightarrow 0$

Clado 176: $012 \rightarrow 12$

Clado 185: $012 \rightarrow 12$

Glandulocauda melanogenys: 1 -> 0

Bryconamericus exodon: 1 - $>0$

Piabina argentea: 1 ->

Clado 175: 12 -> 2

Odontostilbe pequira: $12 \rightarrow 1$

Deuterodon iguape: $1 \rightarrow 2$

Paracheirodon axelrodi: $12->2$

Clado 200: $12 \rightarrow 1$

Compsura heterura: $12->1$

Rhoadsia altipinna: $12 \rightarrow 2$

Bryconops alburnoides: 1 -> $\odot$

Clado 192: $1 \rightarrow 01$

Clado 130: $1 \rightarrow 0$

Probolus heterostomus : $01 \rightarrow 0$

作

Clado 193: 01 -> 0

Markiana nigripinnis: 1 -> 2

Caráter 348 (2 passos)

Raiz: 0

Bivibranchia fowleri: 0 -> 1

Clado 124: $\odot \rightarrow 1$

Caráter 349 (10 passos)

Raiz: 01

Chanos chanos: $01->1$

Clado 103: $01 \rightarrow 0$

Clado 108: $0 \rightarrow-01$

Clado 146: $0 \rightarrow 1$

Distichodus notospilus: 01 -> 1

Citharinus latus: $01->1$

Clado 124: $0 \rightarrow 1$

Brycinus macrolepidotus: $0 \rightarrow 1$

Hepsetus odoe: $1 \rightarrow 0$

Clado 132: $\rightarrow 1$

Gasteropelecus sternicla: 1 -> 0

Caráter 350 (4 passos)

Raiz: 0

Clado 105: 0 -> 1

Nannocharax fasciatus: $0->1$

Hydrolycus tatauaia: $0 \rightarrow 1$

Clado 130: $0 \rightarrow 1$

Caráter 351 (22 passos)

Raiz: 2

Clado 102: $2 \rightarrow 1$

Clado 110: $2 \rightarrow 02$

Clado 108: 02 -> 01

Clado 115: $02 \rightarrow 2$

Crenuchus spilurus: 02 ->

Clado 153: 2 -> 0

Neolebias unifasciatus: $012 \rightarrow 0$

Clado 107: $012 \rightarrow 12$

Clado 141: $2 \rightarrow 0$
Clado 106: $12 \rightarrow 1$

Hemistichodus vaillanti: 12 -> 2

Nannocharax fascia

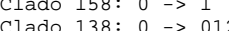

Curimatopsis macrolepis: $2 \rightarrow 0$

Landonia latidens: $012->1$

Clado 137: 012 -> 2

Clado 155: $2 \rightarrow 0$

Metynnis lippincottianus: 2 -> 1

Diapoma terofali: $2 \rightarrow \theta$

Atopomesus pachyodus: $0 \rightarrow 1$

Piabina argentea: $2 \rightarrow 1$

Odontostilbe pequira: $1 \rightarrow 1$

Deuterodon iguape: $2 \rightarrow 1$

Clade 131: $2 \rightarrow$ iguape:

Iguacladoctes geisleri: 2 -> 1

Clado 130: $02 \rightarrow 0$

Clado 191: $2 \rightarrow 0$

Clado 186: $2 \rightarrow 1$

Caráter 352 (13 passos)

Raiz: 01

Chanos chanos: $01->1$

Clado 103: $01 \rightarrow 0$

Clado 143: $0 \rightarrow 01$

Clado 142: $01 \rightarrow 1$

Clado 160: $0 \rightarrow->2$

Chalceus epakros: 02 -> 2

Brycon pesu: 01 -> 2

Galeocharax knerii: 1 -> 0

Clado 145: $01 \rightarrow$

Clado 161: $02 \rightarrow 2$

Clado 197: 02 -> 012

Anodus orinocensis: $0->1$

Hydrolycus tatauaia: $01->0$

Hepsetus odoe: $1 \rightarrow 2$

Metynnis lippincottianus: $012->0$

Myleus setiger: $012 \rightarrow 1$

Clado 135: $1 \rightarrow 12$

Diapoma terofali: $12->2$

Clado 132: $12 \rightarrow 123$

Clado 181: $12 \rightarrow>1$

Clado 130: $123 \rightarrow 2$

Caráter 353 ( 7 passos)

Raiz: 0

Clado 160: $0 \rightarrow 01$

Chalceus epakros: 01 -> 1

Clado 161: $01 \rightarrow 1$

Clado 196: $01 \rightarrow 0$

Clado 135: $0 \rightarrow 01$

Moenkhausia xinguensis: 0 -> 1

Bryconadenos tanaothoros: $0->1$

Clado 132: $01 \rightarrow 1$

Bryconops alburnoides: $01->1$

Iguacladoctes geisleri: $01 \rightarrow$

Clado 195: 0 -> 1

Caráter 354 ( 4 passos)

Raiz: $\odot$ 
Bryconamericus exodon: 1 -> 0 Clupeacharax engrauloides: 1 -> Gymnocorymbus ternetzi: $1->2$

Clado 186: 1 - > 0

Caráter 356 ( 9 passos)

Raiz: 1

Clado 111: 1 -> 01

Clado 110: $01 \rightarrow 0$

Clado 142: $01 \rightarrow$

Clado 153: $01 \rightarrow 1$

Clado 114: $0 \rightarrow 1$

Chalceus epakros: $01 \rightarrow 1$

Brycon pesu: 01 -> 1

Acestrorhynchus falcirostris: $01 \rightarrow$

Clado 156: 01 -> 1

Hydrolycus tatauaia: $01 \rightarrow 0$

Brycinus macrolepidotus: $01 \rightarrow 1$

Bryconalestes longipinnis: $01->\odot$

Clado 196: $01 \rightarrow 0$

Schizodon fasciatus: $0->1$

Clado 131: 0 -> 01

$\begin{array}{lll}\text { Caráter } 357 & (1 \text { passo) } \\ \text { Caráta: } & & \end{array}$

Caráter 357

Clado 124: $0 \rightarrow 1$

Caráter 358 ( 21 passo)

Raiz: 02

Chanos chanos: 02 -> 2

Clado 103: $\odot 2 \rightarrow \odot$

Clado 144: $0 \rightarrow 01$

Clado 143: $01 \rightarrow 1$

$\begin{array}{ll}\text { Clado } 114: 0 & 0>1 \\ \text { Clado } 157: 01 \rightarrow 1\end{array}$

Chalceus epakros: $\odot 1 \rightarrow \odot$

Clado 106: $0 \rightarrow 1$

Copeina cf. guttata: 01 -> 1

Clado 151: $01 \rightarrow$

Clado 121: $0 \rightarrow 1$

Charax cf. leticiae: $1 \rightarrow 0$

Clado 150: 1 -> 12

Clado 197: $01 \rightarrow 012$

Clado 156: 1 -> 01

Hydrolycus tatauaia: $12 \rightarrow 2$

Brycinus macrolepidotus: $01->0$

Bryconalestes longipinnis: $01>1$

Anostomus anostomus: $0 \rightarrow 1$

Serrabrycon magoi: 1 -> 0

Hepsetus odoe: $01->0$

Boulengerella maculata: $01->0$

Ctenolucius hujeta: $01 \rightarrow 1->$

Ctenolucius hujeta: $01->1$
Rhinobrycon negrensis: $1->0$

Rhinobrycon negrensis: $1->$
Piabina argentea: $1 \rightarrow 0$

Clado 198: $1 \rightarrow$

Clado 181: 1 ->

Gymnocorymbus ternetzi: 1 -> 2

Markiana nigripinnis: 1 -> 2

Caráter 359 (4 passos)

Raiz: 0

Charax cf. leticiae: $0 \rightarrow 1$

Clado 197: $0 \rightarrow 01$

Clado 124: $0 \rightarrow 01$

Clado 196: $01 \rightarrow 1$

Chilodus punctatus: $01->1$

Potamorhina latior: $0 \rightarrow 1$

Caráter 360 (19 passos)

Raiz: 0

Clado 111: 0 -> 2

Catostomus commersonnii: $\odot \rightarrow 1$

Crenuchus spilurus: $2 \rightarrow 1$

Clado 160: $2 \rightarrow 02$

Clado 114: $2 \rightarrow 1$

Chalceus epakros: $02 \rightarrow 0$

Brycon pesu: 2 -> 1

Brycon pesu: 2 ->

Clado 151: $2 \rightarrow 1$

Clado 116: $2 \rightarrow 0$

Clado 161: $02 \rightarrow>2$

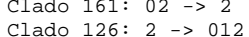

Clado 196: $02 \rightarrow>0$

insignis: $2 \rightarrow 1$

Anostomus anostomus: 012 - $>1$

Clado 128: 012 -> 02

Hepsetus odoe: 2 -> 1

Potamorhina latior: 2 -> 1

Schizodon fasciatus: $02 \rightarrow 0$

Leporellus vittatus: $02 \rightarrow>2$

Leporinus fasciatus: 02

Odontostilbe pequira: $2 \rightarrow$

Clado 181: $2 \rightarrow 0$

Thoracocharax stellatus : 2 -> 0

Caráter 361 ( 4 passos)

Raiz: 01

Chanos chanos: $01 \rightarrow 1$

Clado 103: $01 \rightarrow>$

Brycon pesu: $0->1$

Clado 132: $0 \rightarrow 01$

Clado 164: $01 \rightarrow 1$

Clupeacharax engrauloides: 01 -> 1

Clado 130: 01 -> 0

Caráter 362 (10 passos)

Raiz: 0

Clado 108: $0 \rightarrow>3$

Clado 108: 0 - $\rightarrow 3$

Galeocharax knerii: $0 \rightarrow>2$

Galeocharax knerii: 0

Clado 119: $0 \rightarrow 012$
Prochilodus nigricans: $0->2$

Caenotropus labyrinthicus: $0 \rightarrow 1$

Clado 155: $\odot \rightarrow 2$

Curimata ocellata: $012 \rightarrow 1$

Potamorhina latior: 012 -> 2

Ctenobrycon hauxwellianus: $0->2$

Caráter 363 (13 passos)

Raiz: 01

Chanos chanos: $01->0$

Clado 103: $01 \rightarrow 1$

Characidium bahiensis: $1 \rightarrow 0$

Clado 142: $1 \rightarrow 0$

Clado 118: 1 -> 01

Clado 121: $01 \rightarrow 1$

Clado 121: $01 \rightarrow 1$

Clado 125: $01 \rightarrow$

Anodus orinocensis: $01->1$

Hemiodus unimaculatus : $01 \rightarrow 0$

Aphyocharax pusillus: $0->1$

Clado 155: $1 \rightarrow 0$

Curimata ocellata: 1 -> 0

Leporinus fasciatus: $->1$

Astyanax mexicanus: $0 \rightarrow 1$

Ctenobrycon hauxwellianus: $\odot->1$

caráter 364 (14 passos)

Raiz: 01

Clado 102: 01 -> 0

Clado 111: $01 \rightarrow 1$

Clado 108: $1 \rightarrow 0$

Chalceus epakros: $1->2$

Clado 117: $1 \rightarrow 01$

Clado 146: $1 \rightarrow 0$

Distichodus notospilus: $0 \rightarrow 1$

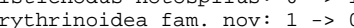

Clado 197: 1 -> 01

Anodus orinocensis: 01 -> 0

Clado 120: $1 \rightarrow 0$

Clado 156: $\odot \rightarrow->2$

Bryconalestes longipinnis: 1 -> 2

Clado 196: 01 ->

Prochilodus nigricans: 1 -> 2

Clado 128: $1 \rightarrow 12$

Hepsetus odoe: $02->2$

Clado 127: $12->2$

Clado 189: 1 -> 01

Ctenobrycon hauxwellianus: 01 -> 0

Caráter 365 (13 passos)

Raiz: 1

Clado 108: 1 -> 01

Neolebias unifasciatus: $01 \rightarrow 0$

Clado 112: $01 \rightarrow 0$

Clado 182: 1 -> 0

Distichodus notospilus: 01 -> 1

Bivibranchia fowleri: 1 ->

Clado 150: $01 \rightarrow \odot$

Citharinus latus: 01 - 1

Xenocharax spilurus: 01 -> 0

Acestrorhynchus falcirostris: $01 \rightarrow 0$

Clado 156: $01 \rightarrow 1$

Clado 196: $01 \rightarrow 0$

Clado 119: $1 \rightarrow 0$

Landonia latidens: 1 ->

Iguacladoctes geisleri: $1 \rightarrow$

Markiana nigripinnis: 1 -> 0

Hyphessobrycon compressus: $1 \rightarrow 0$

caráter 366 (11 passo)

Raiz: 01

Chanos chanos: $01->0$

Clado 102: $01 \rightarrow 1$

Clado 110: $01 \rightarrow 0$

Clado 144: $01 \rightarrow 1$

Clado 114: $0 \rightarrow 1$

Clado 141: $1 \rightarrow 0$

Clado 150: $1 \rightarrow 01$

Clado 123: $0->1$

Gilbertolus atratoensis: $01 \rightarrow 0$

Moenkhausia xinguensis: $0 \rightarrow 1$

Clado 130: $\odot \rightarrow 01$

Triportheus albus: $0 \rightarrow 1$

Thoracocharax stellatus : 01 -> 1

Carnegiella strigata: $01 \rightarrow 1$

Gasteropelecus sternicla: 01 ->

Caráter 367 (17 passos)

Raiz: 0

Clado 104: $\odot \rightarrow 01$

Clado 144: $\odot \rightarrow 01$

Gymnotus aff. carapo: 01 -> 1

Clado 153: 01 -> 1

Clado 114: $\odot \rightarrow 1$

Clado 141: 01 - 0

Chalceus epakros: 01 -> 1

Oligosarcus argenteus: $01->1$

Brycon pesu: 01 - > 1

Arnoldichthys spilopterus: $01->0$

Distichodus notospilus: $0 \rightarrow 1$

Erythrinoidea fam. nov: $1 \rightarrow$

Clado 126: $0 \rightarrow 1$

Brycinus macrolepidotus: $01->0$

Bryconalestes longipinnis: $01->$

Prochilodus nigricans: $0 \rightarrow 1$

Paragoniates alburnus: $0 \rightarrow 1$

Hepsetus odoe: $01 \rightarrow 0$

clado 155: 01 - $>1$

Gilbertolus atratoensis: 01 -> 0

Clado 134: $0 \rightarrow 01$

Clado 133: 01 ->

Moenkhausia xinguensis: 0 -> 1

Clupeacharax engrauloides: $1 \rightarrow 0$

Caráter 368 (2 passos)

Raiz: 0

Distichodus notospilus: 0 -> 1

Clado 181: $\odot \rightarrow 01$

Bryconops alburnoides: 01 -> 1

Caráter 369 (23 passos)

Raiz: 1

Clado 163: $1 \rightarrow 0$

Clado 108: $1 \rightarrow 2$

Clado 142:

Hemistichodus vaillanti: 2 -> 1

Clado 116: 1 -> 012

Galeocharax knerii: $0 \rightarrow 1$

Citharinus latus: 2 -> $\odot$

Anodus orinocensis: $012 \rightarrow 0$

Hemiodus unimaculatus : $012 \rightarrow 2$

Clado 120: $1 \rightarrow 01$

Bryconalestes longipinnis: 1 -> 0

Bryconalestes longipinnis: $1->0$

Curimatopsis macrolepis: 01

Hepsetus odoe: $012->$
Clado 155: $012 \rightarrow>2$

Gilbertolus atratoensis: $1 \rightarrow 0$

Metynnis lippincottianus: 1 -> 0

Curimata ocellata: $01 \rightarrow \odot$

Potamorhina latior: $01->1$
Leporinus fasciatus: $1->0$

Microschemobrycon casiquiare: $0->1$

Knodus meridae: 0 -> 1

Clado 130: $\odot \rightarrow 1$

Triportheus albus: $0 \rightarrow 1$

Clado 195: $\odot$-> 012

Markiana nigripinnis: 012 -> 2

Tetragonopterus argenteus: $012->1$

Ctenobrycon hauxwellianus: $\theta->1$

Caráter 370 ( 2 passos)

Clado $197: 0 \rightarrow 2$

Caráter 371 (11 passo)

Raiz: 1

Catostomus commersonnii: 1 -> $\odot$

Clado 142: $1 \rightarrow 0$

Clado 159: $1 \rightarrow 01$

Clado 112: $1 \rightarrow 0$

Arnoldichthys spilopterus: 01 -> 0

Clado 161: $01 \rightarrow 0$

Xenocharax spilurus: 1 -> $\odot$

Clado 196: $01 \rightarrow 1$

Moenkhausia xinguensis: $0->1$

Clado 164: $0 \rightarrow$

Bryconops alburnoides: $\odot->1$

Tetragonopterus argenteus: $0->1$

Poptella brevispina: $\odot->1$

Caráter 372 (12 passos)

Raiz: 0

Clado 115: $0 \rightarrow 1$

Clado 147: $0 \rightarrow 1$

Chalceus epakros: 0 -> 1

Piabucina astrigata: $\odot \rightarrow 1$

Clado 197: $\odot$-> 01

Clado 156: 1 -> 01

Hoplias malabaricus: $0 \rightarrow 1$

Clado 196: 01 -> 1

Curimatopsis macrolepis: 1 -> 0

Hepsetus odoe: $01->0$

Boulengerella maculata: $01 \rightarrow 1$

Ctenolucius hujeta: $01 \rightarrow 0$

Clado 164: $0 \rightarrow 1$

Bryconops alburnoides: $\odot->1$

Bryconops alburnoides: $0->1$

caráter 373 (11 passo)

Raiz: 0

Clado 183: $\odot \rightarrow 01$

Oligosarcus argenteus: $01->1$

Gnathocharax steindachneri: $0->1$

Charax cf. leticiae: $01->0$ 
Crenuchus spilurus: $03->3$

Clado 148: $03 \rightarrow 3$

Clado 152: 03 -> 0

Clado 157: 03 -> 023

Chalceus epakros: $03 \rightarrow 0$

Clado 159: 03 -> 3

Clado 190: 03 -> 023

Oligosarcus argenteus: $03->0$

Lebiasina bimaculata: $023 \rightarrow 3$

Piabucina astrigata: $023 \rightarrow 2$

Clado 139: $03 \rightarrow 0$

Gnathocharax steindachneri: 023 -> 3

Roeboexodon guyanensis: $023 \rightarrow->$

Charax cf leticiae: $03 \rightarrow 3$

Clado 158: $0 \rightarrow 2$

Clado 158: $0->2$ : 1 : $0->2$

$\begin{array}{lll}\text { Clado 123: } & 0 & -> \\ \text { Clado 124: } & 0 & ->3\end{array}$

Clado 124: $0->3$ Aphyocharax pusillus: $03->0$

Hoplias malabaricus: 2 -> 23

Brycinus macrolepidotus: $3 \rightarrow 2$

Paragoniates alburnus: 013 - $->1$

Potamorhina latior: $0->2$

Schizodon fasciatus: $\odot \rightarrow 2$

Clado 135: 0 -> 013

Glandulocauda melanogenys: $013 \rightarrow 3$

Moenkhausia xinguensis: $\odot->3$

Clupeacharax engrauloides: 1 -> 3

Clado 189: $\odot \rightarrow 3$

Probolus heterostomus : $\odot->3$

Caráter 376 (20 passos)

Raiz: 12

Clado 102: $12 \rightarrow>2$

Clado 111: $12 \rightarrow>1$

Neolebias unifasciatus: $1 \rightarrow 0$

Clado 147: $1 \rightarrow 0$

Clado 152: $1 \rightarrow 01$

Clado 159: $1 \rightarrow 0$

Clado 117: $1 \rightarrow 12$

Copeina cf. guttata: $01 \rightarrow 0$

Clado 165: $\rightarrow 01$

Galeocharax knerii: $1->0$

Clado 150: $\odot \rightarrow>2$ thrinoidea fam. nov: $01 \rightarrow \odot$

Xenocharax spilurus: $1 \rightarrow 2$

Xenocharax spilurus: $1->2$
Anodus orinocensis: $12 \rightarrow>2$

Hemiodus unimaculatus : $12 \rightarrow 1$

Aphyocharax pusillus: $01->$

Hydrolycus tatauaia: $02 \rightarrow 2$

Curimatopsis macrolepis: $1 \rightarrow 0$

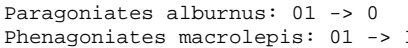

Curimata ocellata: $1->2$
Schizodon fasciatus: $1->2$

Schizodon fasciatus:

Clado 185: $1 \rightarrow 0$

Clado 168: $1 \rightarrow 0$
Clado 132: $1 \rightarrow 0$

Markiana nigripinnis: $\odot$->

Caráter 377 (28 passos)

Raiz: 1

Clado 104: 1 -> 01

Gymnotus aff. carapo: 01 -> $\odot$

Clado 143: $1 \rightarrow 12$

Clado 108: 1 -> 0

Characidium bahiensis: $1 \rightarrow 2$

Clado 183: $12 \rightarrow 2$

Salminus hilarii: $12 \rightarrow 2$

Clado 106: $\odot \rightarrow 2$

Clado 117: $1 \rightarrow 2$

Clado 140: $12 \rightarrow 1$

Clado 140: $12->1$

Gnathocharax steindachneri: 12 -> 1

Roeboexodon guyanensis: $12 \rightarrow 2$

Clado 145: $12 \rightarrow 1$

Clado 145: $12->1$

Hydrolycus tatauaia: $12 \rightarrow>$

Hydrolycus tatauaia: $12->2$

Prochilodus nigrican

Clado 173: $1->12$

Paragoniates alburnus:

Hepsetus odoe: $1 \rightarrow 0$

Myleus setiger: $1->0$
Curimata ocellata: $1->2$

Phenacogaster pectinatus: $12 \rightarrow 2$

Leporellus vittatus: 1 - 0

Rhinobrycon negrensis: 1 -> 2

Clado 177: $12 \rightarrow 1$

Clado 178: $1 \rightarrow 01$

Atopomesus pachyodus: $12->2$

Clado 133: $1 \rightarrow 0$

Bryconamericus exodon: 01 -> 0

Clado 167: 1 -> 12

Iguacladoctes geisleri: $\odot \rightarrow>2$

Clado 166: 12 -> 012

Triportheus albus: $\odot->1$

Astyanax mexicanus: $012 \rightarrow$

Clado 189: $012 \rightarrow 2$

Probolus heterostomus : $12 \rightarrow 2$

Hollandichthys multifasciatus: $12,>1$

Caráter 378 (17 passos)

Raiz: 0

Clado 115: 0 -> 2
Clado 148: $\odot \rightarrow>2$

Chalceus epakros: $0 \rightarrow 2$

Clado 106: $\odot \rightarrow 2$

Oligosarcus argenteus: $\odot \rightarrow 2$

Piabucina astrigata: $\theta \rightarrow 2$

Bivibranchia fowleri: $2 \rightarrow 0$

$\begin{array}{ll}\text { Clado 150: } 2 & \rightarrow 12 \\ \text { Clado 158: } \odot->012\end{array}$

Clado 197: $\odot \rightarrow 02$

Hemiodus unimaculatus : $2 \rightarrow 1$

Hydrolycus tatauaia: $12->1$

Erythrinus erythrinus: $012 \rightarrow 1$

Hoplias malabaricus: $012->2$

Curimatopsis macrolepis

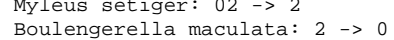

Moulenkhausia xinguensis: $\bullet->2$

Bryconops alburnoides: $0 \rightarrow 2$

Agoniates halecinus: $0 \rightarrow 2$

Caráter 379 (22 passos)

Raiz: 2

Clado 104: 2 -> 12

Gymnotus aff. carapo: 12 -> 1

Clado 115: $2 \rightarrow 1$

Crenuchus spilurus: 2 -> 1

Salminus hilarii: $2 \rightarrow 1$

Clado 159: $2 \rightarrow$

$\begin{array}{ll}\text { Clado 146: } & 2 \rightarrow 0 \\ \text { Clado 151: } 2 & ->0\end{array}$

Roeboexodon guyanensis: 2 -> 1

Galeocharax knerii: $2 \rightarrow \Theta$

Bryconalestes longipinnis: $\odot \rightarrow 2$

Curimatopsis macrolepis: $1 \rightarrow 0$

Prochilodus nigricans: $1 \rightarrow \infty$

Chilodus punctatus: $1 \rightarrow 2$

Serrabrycon magoi: $2 \rightarrow 1$

Paragoniates alburnus: $2 \rightarrow 0$

Rhinobrycon negrensis: $2 \rightarrow 1$

Hemibrycon polyodon : 2 -> 1

Clado 132: $2 \rightarrow 0$

Clado 166: $2 \rightarrow 0$

Clado 187: $\odot \rightarrow 1$

Ctenobrycon hauxwellianus: 1 -> 2

Caráter 380 (15 passos)

Raiz: 01

Clado 102: $01->0$

Clado 111: $01 \rightarrow 1$

Clado 108: 1 -> 0

Clado 142: $1 \rightarrow 0$

Clado 152: $1 \rightarrow 0$

Clado 117: $1 \rightarrow 01$

Bivibranchia fowleri: $01 \rightarrow 0$

Clado 150: $1 \rightarrow 01$

Anodus orinocensis: $01->1$

Hemiodus unimaculatus : $01->$

Hydrolycus tatauaia: 01 ->

Hoplias malabaricus: $0 \rightarrow 1$
Anostomus anostomus: $1 \rightarrow 0$

Anostomus anostomus: $1->0$

Boulengerella maculata: $1 \rightarrow 0$
Leporellus vittatus: $1 \rightarrow 0$

Clado 133: $0 \rightarrow 01$

Knodus meridae: $\odot->1$

Clado 164: $01 \rightarrow 1$

Bryconops alburnoides: $01->1$

Iguacladoctes geisleri: $01 \rightarrow 0$

Clupeacharax engrauloides: $01->1$

Clado 130: 01 -> 0

Caráter 381 ( 2 passos)

Raiz: 0

Lebiasina bimaculata: $0 \rightarrow 1$

Erythrinus erythrinus: $0 \rightarrow 1$

Caráter 382 (2 passos)

Raiz: 1

Charax cf. leticiae: 1 -> 0

Phenacogaster pectinatus: $1 \rightarrow 0$

Caráter 383 (26 passos)

Raiz: 1

Clado 104: 1 -> 12

Gymnotus aff. carapo: $12 \rightarrow 2$

Clado 115: $1 \rightarrow 0$

Crenuchus spilurus: $1->0$

Clado 147: $1 \rightarrow 0$

Chalceus epakros: $1 \rightarrow \odot$

Clado 151: $1 \rightarrow$ :

Piabucina astrigata: 1 -> 0

Gnathocharax steindachneri: 1 -> 0

Galeocharax knerii: 1 -> 0

Clado 145: $\odot \rightarrow 02$

Clado 197: $1 \rightarrow 01$

Citharinus latus: $1 \rightarrow \oplus$

Clado 199: 1 -> 12

Acestrorhynchus falcirostris: $02->2$

Erythrinus erythrinus: $\odot \rightarrow 2$

Clado 196: $01 \rightarrow 0$

Clado 128: 0 -> 2

Paragoniates alburnus:

Hepsetus odoe: $02->$

Leporinus fasciatus: 2 -> 1

Clado 135: $1 \rightarrow 012$

Glandulocauda melanogenys: 012 -> 2

Clado 133: $012 \rightarrow 02$

Moenkhausia xinguensis: 1 -> 0

Clado 175: $1 \rightarrow 01$

Axelrodia reisei: $01 \rightarrow 0$

Bryconops alburnoides: $02->0$

Iguacladoctes geisleri: 02 -> 2

Clupeacharax engrauloides: $0->1$

Clado 188: $1 \rightarrow 0$

Tetragonopterus argenteus: 1 -> 2

Caráter 384 ( 8 passos)

Raiz: 0

Clado 104: 0 -> 01

Gymnotus aff. carapo: 01 -> 1

Clado 107: $\theta \rightarrow 01$

Clado 157: $0 \rightarrow 1$

Chalceus epakros: $\odot->1$

Distichodus notospilus: $01 \rightarrow 1$

Hemistichodus vaillanti: $01 \rightarrow 1$

Nannocharax fasciatus: $01 \rightarrow 0$

Citharinus latus: $01 \rightarrow 1$

Xenocharax spilurus: $01->0$

Erythrinus erythrinus: $\Theta->1$

Schizodon fasciatus: $\theta->1$

Caráter 385 ( 2 passos)

Raiz: 0

Hoplias malabaricus: $\odot->1$

Chilodus punctatus: $\odot \rightarrow 1$

Caráter 386 (22 passos)

Raiz: 1

Catostomus commersonnii: 1 -> 0

Clado 154: 1 -> 01

Clado 107: 1 -> 3

Salminus hilarii: $1 \rightarrow 0$

Clado 157: $01 \rightarrow 0$

Chalceus epakros: 01 -> 0

Clado 159: $01 \rightarrow 1$

Clado 113: $1 \rightarrow 12$

Copeina cf. guttata: 01 -> 1

Clado 151: $01 \rightarrow 0$

Parodon nasus: 12 -> 2

Bivibranchia fowleri: $1>3$

Citharinus latus: $3 \rightarrow 1$

Anodus orinocensis: $1->$

Clado 120: 1 > 2

Clado 124: $1 \rightarrow 0$

Caenotropus labyrinthicus: $01 \rightarrow 0$

Metynnis lippincottianus: $1->2$

Phenacogaster pectinatus: $1 \rightarrow 3$

Clado 177: 1 -> 2

Clado 200: 2 -> 12

Bryconops alburnoides: 1 -> 0

Stygichthys typhlops: 12 -> 1

Agoniates halecinus: $1 \rightarrow 0$

Astyanax mexicanus: 1 -> 2

Tetragonopterus argenteus: $1 \rightarrow 2$

Ctenobrycon hauxwellianus: $1 \rightarrow 3$

caráter 387 ( 8 passos)

Raiz: $\odot$

Clado 115: 0 -> 1

Copeina cf. guttata: $\odot \rightarrow 1$

Piabucina astrigata: $0 \rightarrow 1$

Clado 121: $1 \rightarrow 0$

Hemiodus unimaculatus : $1 \rightarrow 0$

Erythrinus erythrinus: $0 \rightarrow 1$

Schizodon fasciatus: $1 \rightarrow 0$

Clado 175: $0 \rightarrow 01$

Axelrodia reisei: 01 -> 1

Caráter 388 ( 10 passos)

Raiz: 0

Clado 151: $0 \rightarrow 01$

Clado 125: $0 \rightarrow 01$

Clado 165: $\odot \rightarrow 01$

Clado 150: $\theta \rightarrow 01$

Clado 126: 01 - $>1$

Aphyocharax pusillus: $01->1$

Hydrolycus tatauaia: 01 -> 1

Erythrinus erythrinus: $01->1$

Caenotropus labyrinthicus: $01->0$

Chilodus punctatus: $01 \rightarrow 1$

Paragoniates alburnus: $01->0$

Phenagoniates macrolepis: $01 \rightarrow$

Clado 155: $0 \rightarrow 1$

Bryconops alburnoides: $0->1$

Agoniates halecinus: $0 \rightarrow 1$

Astyanax mexicanus: $0->1$

Caráter 389 ( 7 passos)

Raiz: 2

Clado 153: 2 -> 0

Neolebias unifasciatus: 2 -> 1 
Odontostilbe pequira: 2 -> 1

Deuterodon iguape: $0 \rightarrow 2$

Clado 131: 01 -> 012

Bryconops alburnoides: $01 \rightarrow 0$

Iguacladoctes geisleri: 01 -> 1

Clado 166: $0 \rightarrow 1$

Clupeacharax engrauloides: 012 -> 2

Clado 130: 012 -> 1

Agoniates halecinus: 01 -> 0

Triportheus albus: $01 \rightarrow 1$

Tetragonopterus argenteus: $1 \rightarrow 0$

Ctenobrycon hauxwellianus: $1 \rightarrow$

caráter 391 (4 passos)

Raiz: 1

Clado 153: $1 \rightarrow 0$

Arnoldichthys spilopterus: 1 -> 0

Clado 145: 1 -> 2

Agoniates halecinus: $1->2$

Caráter 392 (8 passos)

Raiz: 1

Catostomus commersonnii: 1 -> 0

Salminus hilarii: $1 \rightarrow 2$

Brycon pesu: $1 \rightarrow 0$

Erythrinoidea fam. nov: $1->0$

Clado 123: $1 \rightarrow 2$

Hoplias malabaricus: 1 -> 2

Clado 184: 1 -> 01

Clado 200: 1 -> 01

Compsura heterura: $01->0$

Stygichthys typhlops: 01 -> $\odot$

Caráter 393 ( 30 passos)

Raiz: 0

Clado 102: $02->2$

Clado 163: $02 \rightarrow>$

Clado 108: $02 \rightarrow 0$

Clado 114: 02 -> 2

Clado 141: $02 \rightarrow>0$

Clado 183: 02 -> 012

Salminus hilarii: $02->2$

$\begin{array}{ll}\text { Clado 147: } & 02 \rightarrow \infty \\ \text { Clado 152: } & 02 \rightarrow \infty\end{array}$

Chalceus epakros: 02 -> 2

Clado 117: $02 \rightarrow 0$

Clado 122: 02 2 $\rightarrow 012$

Oligosarcus argenteus: $012 \rightarrow 2$

Lebiasina bimaculata: $\odot 2->0$

Piabucina astrigata: $02->2$

Piabucina astrigata: $\odot 2 \rightarrow \overrightarrow{2}-\overrightarrow{ }$

Arnoldichthys spilop

Clado 162: $02->12$
Clado 121: $012 \rightarrow>2$

Clado 121: $012->2$

Roeboexodon guyanensis: $\odot->$

Charax cf. leticiae: $012 \rightarrow 1$

Charax cf. leticiae: $012 \rightarrow>$

Anodus orinocensis:

Brycinus macrolepidotus: $12 \rightarrow 1$

Bryconalestes longipinnis: $12 \rightarrow 2$

Caenotropus labyrinthicus: $01 \rightarrow 0$

Chilodus punctatus: $01 \rightarrow 1$

Anostomus anostomus: $01 \rightarrow 1$

Phenagoniates macrolepis: $0->2$

Metynnis lippincottianus: $12 \rightarrow 1$

Myleus setiger: $12 \rightarrow 2$

Schizodon fasciatus: 01 -> 1

Clado 127: 01 -> 012

Leporellus vittatus: $012 \rightarrow>2$

Leporinus fasciatus: 012 -> 0

Clado 170: $0 \rightarrow 2$

Clado 171: $1 \rightarrow 12$

Clado 178: $\odot \rightarrow 02$

Atopomesus pachyodus: $12->2$

Moenkhausia xinguensis:

Mryconamericus exodon: $02 \rightarrow 2$

Clado $175: 1 \rightarrow 01$

Clado 175: $1 \rightarrow 01$

Axelrodia reisei: $01 \rightarrow 0$

Stygichthys typhlops: $12->2$

Stygichthys typhlops: $12->$

Astyanax mexicanus: 2 -> $\odot$

Astyanax mexicanus:

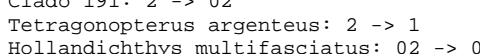

Hollandichthys multifasc

Caráter

Catostomus commersonnii: $3 \rightarrow 0$

Clado 144: $3 \rightarrow 13$

Clado 143: 13 ->

Characidium bahiensis: 3 -> 2

Clado 153: $13 \rightarrow 0123$

Clado 160: $13 \rightarrow 1$

Clado 118: $3 \rightarrow 1$

Clado 157: 0123 ->

Clado 112: $3 \rightarrow 0$

Oligosarcus argenteus: $1 \rightarrow 2$

Copeina cf. guttata: $0123 \rightarrow 2$

Clado 151: 0123 ->

Clado 161: 1 -> 123

Citharinus latus: 3 ->

Clado 124: 1 -> 012

Brycinus macrolepidotus: 123 -> 2

Bryconalestes longipinnis: $123 \rightarrow 3$

Caenotropus labyrinthicus: $012 \rightarrow 0$

Chilodus punctatus: $012 \rightarrow 2$

Clado 155: $1 \rightarrow 0$
Clado 180: 1 -> 13

Phenacogaster pectinatus: 1 -> 2
Rhinobrycon negrensis: $13->3$

Clado 185: $1 \rightarrow 3$

Glandulocauda melanogenys: 1 -> 3

Clado 168: $1 \rightarrow 3$

Bryconamericus exodon: 13 -> 1

Piabina argentea: $13 \rightarrow>$

Paracheirodon axelrodi: 1 -> 3

Iguacladoctes geisleri: $1 \rightarrow 3$

Clado 130: 1 -> 0

Agoniates halecinus: $1 \rightarrow 0$

Clado 187: 3 -> 1

Poptella brevispina: $1>2$

Caráter 395 (20 passos)

Raiz: 2

Clado 104: $2 \rightarrow 12$

Gymnotus aff. carapo: $12 \rightarrow 1$

Characidium bahiensis: $2 \rightarrow 1$

Clado 142: $2 \rightarrow 1$

Hemistichodus vaillanti: $2->1$

Clado 165: $1 \rightarrow 2$
Clado 150: $2 \rightarrow 12$

$\begin{array}{lll}\text { Clado 150: } & 2 \rightarrow 12 \\ \text { Clado 197: } & 2 \rightarrow 12\end{array}$

Citharinus latus: $2 \rightarrow 0$

Clado 124: $1 \rightarrow 2$

Hydrolycus tatauaia: 12 -> 1

Clado 196: $12 \rightarrow 1$

Clado 127: $1 \rightarrow 2$

Clado 172: 1 -> 2

Boulengerella maculata: 2 -> 1

Clado 179: $1 \rightarrow 2$

Hemibrycon polyodon : $1->$

Deuterodon iguape:

Probolus heterostomus : $1->$

Gymnocorymbus ternetzi: 1 -> 2

Ctenobrycon hauxwellianus: $1 \rightarrow 2$

Caráter 396 (10 passos)

Raiz: 0

Clado 104: $0 \rightarrow 1$

Clado 110: $\odot \rightarrow 01$

Clado 108: $01 \rightarrow 1$

Clado 115: $01->0$

Crenuchus spilurus:

Clado 190: $\odot \rightarrow 01$

Gnathocharax steindachneri: 01 -> 1

Clado 196: $\odot \rightarrow 1$

Clado 173: $\Theta \rightarrow 1$

$1 \rightarrow 01$

(typhlops: 01 -> 0

Clado 130: $0 \rightarrow 1$

Tetragonopterus argenteus: $\odot->1$

Caráter 397 (11 passo)

Raiz: 1

Olivaichthys mesembrinus: 1 -> 0

Clado 163: $1 \rightarrow 12$

Clado 154: 1 -> 13 12 -> 2

Clado 106: $1 \rightarrow 2$

Clado 190: 1 -> 01

Gnathocharax steindachneri: 01 -> $\odot$

Galeocharax knerii: $1 \rightarrow 2$

Clado 138: 1 -> 12

Metynnis lippincottianus: $13 \rightarrow 3$

Clado 136: 12 -> 2

Microschemobrycon casiquiare: 1 -> 2

Clado 185: $1 \rightarrow 2$

Clado 175: $1 \rightarrow 0$

Clado 129: $2 \rightarrow 0$

Caráter 398 (2 passos)

Raiz: $\odot$

Metynnis lippincottianus: 0 -> 01

Clado 135: $0 \rightarrow 01$

Clado 176: $0 \rightarrow 02$

Clado 175: $02->2$

Caráter 399 ( 6 passos)

Raiz: 01

Chanos chanos: 01

Chanos chanos: 01

Clado 111: 01 : $>0$ -

Clado 104: $01 \rightarrow 0$

Clado 153: $\odot->01$

Clado 152: 01 -> 1

Lebiasina bimaculata: $01 \rightarrow 1$

Piabucina astrigata: $01 \rightarrow 0$

Phenagoniates macrolepis: $\odot->1$

Carnegiella strigata: $0 \rightarrow 1$

caráter 400 ( 5 passos)

Raiz: 0

Clado 118: $\odot$-> 01

Bivibranchia fowleri: 01 -> 0

Clado 116: $01 \rightarrow 1$

Clado 123: 01 -> 1

Curimatopsis macrolepis: 01 -> 0

Clado 119: 01 -> 1

Caenotropus labyrinthicus: 01 -> 1

Chilodus punctatus: $01 \rightarrow 0$

Anostomus anostomus: $01->0$

Clado 128: $01 \rightarrow 1$

Caráter 401 ( 3 passos)

Raiz: 01

Chanos chanos: 01 -> 1

Clado 103: $01->0$

Clado 117: $01>1$

Caráter 402 ( 5 passos)

Raiz: 0

Gymnotus aff. carapo: $0->1$

Characidium bahiensis: $0 \rightarrow 1$

$\begin{array}{lll}\text { Clado 151: } & 0 & ->1 \\ \text { Clado 126: } & 0 & ->1\end{array}$

Leporellus vittatus: $1 \rightarrow 0$

Caráter 403 ( 8 passos)

Raiz: 0

Clado 102: $\odot \rightarrow 01$

Catostomus commersonnii: $01>1$

Olivaichthys mesembrinus: $01 \rightarrow 0$

Gymnotus aff. carapo: $01 \rightarrow 1$

Crenuchus spilurus: $0 \rightarrow 1$

Clado 157: $\odot \rightarrow 1$

Clado 125: $0 \rightarrow 01$

Clado 158: $\odot \rightarrow 1$

Clado 126: $01 \rightarrow 1$

Caenotropus labyrinthicus: 01 -> $\odot$

Chilodus punctatus: $01 \rightarrow 1$

eporellus vittatus: $1 \rightarrow 0$

Caráter 404 (22 passos)

Raiz: 012

Chanos chanos: $012->2$

Clado 103: 012 -> 0

Gymnotus aff. carapo: 0 -> 2

Clado 160: $\odot \rightarrow 1$

Clado 118: $\odot \rightarrow 1$

Clado 183: $0 \rightarrow 01$

Clado 117: $1 \rightarrow 2$

Oligosarcus argenteus: $01 \rightarrow 1$

Brycon pesu: $0 \rightarrow 1$

Charax cf. leticiae: $01->0$

Galeocharax knerii: $01 \rightarrow 1$

Hydrolycus tatauaia: $0 \rightarrow 1$

Piaractus mesopotamicus: $1 \rightarrow 0$

Curimatopsis macrolepis: $1 \rightarrow 0$

Clado 119: $1 \rightarrow 2$

Moenkhausia xinguensis: 0 -> 1

Piabina argentea: $0->1$

Clado 164: $\odot \rightarrow 1$

Bryconops alburnoides: $0 \rightarrow 2$

Agoniates halecinus: $1 \rightarrow 2$

Probolus heterostomus : $0 \rightarrow 1$

Orthospinus franciscoensis: $0->1$

Caráter 405 ( 4 passos)

Raiz: 2

Clado 104: 2 -> 1

Erythrinoidea fam. nov: 2 -> 1

Stygichthys typhlops: $2 \rightarrow 0$

Caráter 406 (4 passos)

Raiz: 1

Clado 104: 1 -> 0

Erythrinoidea fam. nov: $1 \rightarrow 0$

Hepsetus odoe: $1 \rightarrow 0$

Glandulocauda melanogenys: $1 \rightarrow \odot$

Caráter 407 (16 passos)

Raiz: 0

Clado 143: $\odot \rightarrow 01$

Clado 160: $\odot \rightarrow 02$

Salminus hilarii: $01 \rightarrow$

Chalceus epakros: $02->2$

Clado 140: $01->1$
Brycon pesu: $01->1$

Arnoldichthys spilopterus: 02 -> 2

Clado 162: $02 \rightarrow 0$

Gnathocharax steindachneri: $01 \rightarrow 0$

Roeboexodon guyanen

Bryconalestes longipinnis: $0 \rightarrow 1$

Landonia latidens: 1 ->

Clado 155: $0 \rightarrow>2$

Roestes molossus: 01 -> 1

Atopomesus pachyodus: $1 \rightarrow 0$

Glandulocauda melanogenys: $1 \rightarrow 2$

IguaCladoctes geisleri: 1 -> 0

Clado 166: $1 \rightarrow 12$

Rachoviscus graciliceps: 01 -> 0

Clado 130: 1 -> 13

Astyanax mexicanus: $12 \rightarrow>2$

Carnegiella strigata: 13 -> 3

Gymnocorymbus ternetzi: $12->2$

Caráter 408 ( 1 passo)

Raiz: $\odot$ 
Leporinus fasciatus: 01 -> 1

Glandulocauda melanogenys: 1 -> 2

Clado 130: $1 \rightarrow 2$

Triportheus albus: 1 -> 2

Caráter 1 (17 passos)

Raiz: 1

Clado 102: 1 -> 01

Catostomus commersonnii: $01 \rightarrow 0$

Olivaichthys mesembrinus: 01 ->

Gymnotus aff. carapo: $01 \rightarrow 1$

Clado 143: $1 \rightarrow 2$

Crenuchus spilurus: $1->0$

Clado 190: $2 \rightarrow 1$

Clado 151: $1 \rightarrow 2$

Clado 121: 1 -> $\odot$

Clado 145: $2 \rightarrow 1$

Clado 197: $1 \rightarrow 2$

Gilbertolus atratoensis: $2 \rightarrow 1$

Rilbertolus atratoensis: $2->$

Rhinobrycon negrensi

Clado 184: $12 \rightarrow 1$

Clado 174: $12 \rightarrow>$

Clado 198: $12 \rightarrow$

Iguacladoctes geisleri: 2 -> 1

Clado 130: 2 -> 1

Hyphessobrycon compressus: 2 -> 1

Caráter 2 (25 passos)

Raiz: 1

Catostomus commersonnii: 1 -> 0

Clado 110: $1 \rightarrow 0$

$\begin{array}{lll}\text { Clado 151: } 1 & ->0 \\ \text { Clado 165: } 1->01\end{array}$

Roeboexodon guyanensis: 1 -> 0

Charax cf. leticiae: $1->0$

Clado 150: 1 -> 01

Aphyocharax pusillus: $01 \rightarrow$

Hydrolycus tatauaia: $01 \rightarrow 0$

Piaractus mesopotamicus: $1 \rightarrow 0$

Landonia latidens: $1 \rightarrow 0$

Paragoniates alburnus: 01 -> 1

Phenagoniates macrolepis: $01 \rightarrow$

Gilbertolus atratoensis: $01 \rightarrow 0$

Gilbertolus atratoensis: $01->$

Rlado $135: 1 \rightarrow$

Clado 135: $1 \rightarrow 0$

Moenkhausia xinguensis: 1 -> 0

Bryconamericus exodon: $1 \rightarrow 0$

Knodus meridae: $1 \rightarrow$

Brittanichthys axelrodi: $1 \rightarrow 0$

Iguacladoctes geisleri: $\odot \rightarrow 1$

Astyanax mexicanus: $1 \rightarrow 0$

Stygichthys typhlops: 1 -> 0

Triportheus albus: $0 \rightarrow 1$

Clado 129: $0 \rightarrow 1$

Markiana nigripinnis: 1 -> 0

Orthospinus franciscoensis: 1 -> $\theta$

Hollandichthys multifasciatus: 1 - 0

Caráter 3 (16 passos)

Raiz: 1

Catostomus commersonnii: 1 -> 0

Clado 115: 1 -> 01

Characidium bahiensis: 1 -> 0

Clado 114: 01 -> 0

Salminus hilarii: 1 -> 2

Clado 151: 1 -> 0

Bivibranchia fowleri: $01->0$

Clado 116: $01 \rightarrow 1$

Clado 121: $01 \rightarrow 1$

Clado 125: 01 ->

Roeboexodon guyanensis: $1 \rightarrow 0$

Clado 145: 1 -> 12

Aphyocharax pusillus: 1 -> 0

Acestrorhynchus falcirostris: 12 -> 2

Hepsetus odoe: $12 \rightarrow 1$

Hepsetus odoe: 12

Gilbertolus atratoensis: 1 ->

Atopomesus pachyodus: 1 : $>0$

Atopomesus pachyod

Brittanichthys axelrodi: $1 \rightarrow 0$

Brittanichthys axe

Clado 164: 01 -> 0

Clupeacharax engrauloides: 01 -> 0

Clado 130: 01 -> 1

Caráter 4 ( 3 passos)

Raiz: 0

Clado 110: $\odot$-> 01

Clado 163: $01 \rightarrow 1$

Clado 108: $01 \rightarrow$

Clado 118: $01->0$

Saccodon wagneri: 01

Clado 113: $01 \rightarrow 1$
Caráter 5 ( 2 passos)

Raiz: $\odot$

Clado 144: 0 -> 1

Clado 125: $0 \rightarrow>1$

Caráter 6 (15 passos)

Raiz: 0

Clado 108: $\odot \rightarrow 01$

Clado 160: $0 \rightarrow 012$

Neolebias unifasciatus: 01 -> 1

Salminus hilarii: $0 \rightarrow 1$

Chalceus epakros: $012 \rightarrow$

Clado 159: $012 \rightarrow 1$

Clado 159: $012 \rightarrow>$

Clado 112: 01 -> 0

Brycon pesu: $0->2$

Clado 139: $0 \rightarrow 1$
Galeocharax knerii: 0 -> 1

Erythrinoidea fam. nov: $0->1$

Citharinus latus: $01 \rightarrow 0$

Xenocharax spilurus: $01 \rightarrow 1$

Clado 171: $1 \rightarrow 0$

Bryconops alburnoides: 1 -> 2

Clado 129: $1 \rightarrow 0$

Probolus heterostomus : $1 \rightarrow \theta$

Caráter 7 (39 passos)

Raiz: 4

Clado 114: $4 \rightarrow 2$

Clado 114: $4 \quad \rightarrow>$

Nannocharax fasciatus: $4 \rightarrow 2$

Clado 139: 4 -> 34

Erythrinoidea fam. nov: 4 -> 3

Clado 126: $4 \rightarrow 2$

Clado 138: $34 \rightarrow 2$

Landonia latidens: $2 \rightarrow 1$

Serrabrycon magoi: $34 \rightarrow 3$

Hepsetus odoe: $4 \rightarrow 1$

Phenacogaster pectinatus: $34 \rightarrow 4$

Rhinobrycon negrensis: 2 -> 3

Hemibrycon polyodon : 2 -> 3

Clado 177: $2 \rightarrow 1$

Clado 133: $2 \rightarrow 12$

Bryconadenos tanaothoros: 1 -> 0

Piabina argentea: 2 -> 3

Deuterodon iguape: $2 \rightarrow 1$

Clado 131: $12->0$

Bryconops alburnoides: $12 \rightarrow 3$

Iguacladoctes geisleri: $12 \rightarrow 0$

Rachoviscus graciliceps: $34 \rightarrow 0$

Stygichthys typhlops: $34 \rightarrow 4$

Agoniates halecinus: $12->1$
Triportheus albus: $12 \rightarrow 3$

Clado 192: 2 -> 12

Clado 195: $2 \rightarrow 3$

Probolus heterostomus : $12->1$

Gymnocorymbus ternetzi: $2->1$

Tetragonopterus argenteus: $3 \rightarrow 4$

Hemigrammus unilineatus: $12 \rightarrow 2$

Clado 193: $12 \rightarrow 1$

Caráter 8 ( 9 passos)

Raiz: 1

Clado 162: $1 \rightarrow 0$

Clado 138: $1 \rightarrow 0$

Clado 134: $0 \rightarrow 1$

Clado 168: $\odot->1$

Compsura heterura: $1 \rightarrow 0$

Astyanax mexicanus: $1 \rightarrow 0$

Agoniates halecinus: $1 \rightarrow 0$

Markiana nigripinnis: $1 \rightarrow 0$

Ctenobrycon hauxwellianus: $1 \rightarrow 0$

Caráter 9 ( $\odot$ passos $)$

Raiz: 0

Caráter 10 (12 passos)

Raiz: 12

Clado 104: $12->1$

Clado 109: $12 \rightarrow 012$

Clado 143: $12 \rightarrow 1$

Clado 108: $012 \rightarrow$

Clado 115: $012 \rightarrow>$

Characidium bahiensis: $12 \rightarrow$

Crenuchus spilurus: $12 \rightarrow 2$

Clado 160: $12 \rightarrow 2$

Clado 152: 12 -> 1

Clado 157: $12 \rightarrow>2$

Clado 140: $1 \rightarrow 2$

Oligosarcus argenteus: 1 -> 12

Brycon pesu: $1 \rightarrow 2$

Clado 121: $2 \rightarrow 23$

Clado 123: $23 \rightarrow 3$

Clado 124: $2 \rightarrow 1$

Clado 127: $2 \rightarrow 3$

Atopomesus pachyodus: 2 ->

Clado 174: $2 \rightarrow 1$

Caráter 11 (14 passos)

Raiz: 1

Olivaichthys mesembrinus: 1 -> 2

Clado 160: $1 \rightarrow 0$

Brycon pesu: $1 \rightarrow 0$

Clado 139: $1 \rightarrow 01$

Roeboexodon guyanensis: 1 -> 0

Clado 126: $1 \rightarrow 0$

Clado 173: $01 \rightarrow 0$

Landonia latidens: 01 -> 1

Clado 137: 01 - $>0$

Atopomesus pachyodus: $\odot->1$

Clado 184: $\odot \rightarrow 1$

Axelrodia reisei: $0 \rightarrow 1$

Stygichthys typhlops: $0->1$

Agoniates halecinus: $0->1$

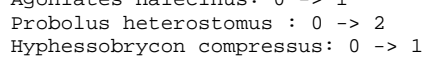

Caráter 12 (11 passo)

Raiz: 0

Clado 110: $\odot \rightarrow 01$

Clado 109: 01 -> 1

Characidium bahiensis: $01 \rightarrow$

Crenuchus spilurus: $01 \rightarrow 1$

Clado 157: $0 \rightarrow 1$

Landonia latidens: 0 -> 1

Phenagoniates macrolepis: $0->1$

Clado 184: 0 -> 01

Bryconadenos tanaothoros: $0->1$

Odontostilbe pequira: $01 \rightarrow 1$

Clado 180: $\odot \rightarrow 1$

Paracheirodon axelrodi: 0 -> 1

Compsura heterura: $01 \rightarrow 1$

Rhoadsia altipinna: $01 \rightarrow 0$

Hyphessobrycon compressus: $\odot->1$

Caráter 13 (8 passos)

Raiz: $\odot$

Olivaichthys mesembrinus: 0 -> 1

Clado 109: $0 \rightarrow 1$

Clado 122: $1 \rightarrow 1$

Clado 121: $12 \rightarrow 2$

Xenocharax spilurus: $1 \rightarrow 0$

Anodus orinocensis: $1 \rightarrow 3$

Clado 120: $2 \rightarrow 3$

Clado 124: $12 \rightarrow 3$

Clado 124: $12 \rightarrow>2$

Caráter 14 ( 9 passos $)$

Raiz: 0

Clado 148: $\odot \rightarrow->2$

Clado 159: $\odot \rightarrow 2$

Brycon pesu: $02->2$

Clado 137: $\theta \rightarrow 02$

Rhinobrycon negrensis: 02 -> 2

Diapoma terofali: $02 \rightarrow 2$

Clado 134: $02 \rightarrow 0$

Hemibrycon polyodon : $02->0$

Clado 168: $02 \rightarrow 2$

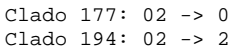

Clado 194: 02 -> 2

Clado 192: $2 \rightarrow 02$

Clado 191: 02 2 $\rightarrow 0$

Gymnocorymbus ternetzi: 2 -> 0

Caráter 15 ( 2 passos)

Raiz: 0

Clado 115: $0 \rightarrow>1$

Clado 125: $1 \rightarrow 0$

Caráter 16 ( 4 passos)

Raiz: 0

Clado 181: $0 \rightarrow 1$

Clado 146: $0 \rightarrow 1$

Clado 158: $0 \rightarrow 1$

Boulengerella maculata: $1 \rightarrow 0$

Caráter 17 (14 passos)

Raiz: 1

Clado 144: 1 -> 0

Crenuchus spilurus: $1->0$

Copeina of guttata: $\theta->1$

Lebiasina bimaculata: $0 \rightarrow 1$

Clado 161: $0 \rightarrow 1$

Xenocharax spilurus: $1 \rightarrow 0$

Anodus orinocensis: $1 \rightarrow 0$

Semaprochilodus insignis: 1 -> 0

Myleus setiger: $0 \rightarrow 1$

Clado 170: $0 \rightarrow 1$

Moenkhausia xinguensis: $\odot->1$

Rhoadsia altipinna: $0->1$

Iguacladoctes geisleri: $0 \rightarrow 1$

Clado 130: $0 \rightarrow 1$

Caráter 18 ( 6 passos)

Raiz: 0

Clado 181: $\odot \rightarrow 1$

Gnathocharax steindachneri: 0 -> 1

Clado 150: $0 \rightarrow 1$

Bryconamericus exodon: $0->1$

Iguacladoctes geisleri: $0 \rightarrow>1$

Clupeacharax engrauloides: $0 \rightarrow 1$

Caráter 19 ( 2 passos)

Raiz: 0

Prochilodus nigricans: $\odot->1$

Potamorhina latior: $0->1$

Caráter 20 ( 6 passos)

Raiz: 1

Clado 111: $1 \rightarrow 0$

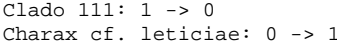

Charax Cf: leticiae:

Anodus orinocensis: $0 \rightarrow 1$

Acestrorhynchus falcirostris: 0 -> 1

Agoniates halecinus: $0 \rightarrow 1$

caráter 21 ( 9 passos)

Raiz: 0

Clado 115: $\odot \rightarrow 01$ 
Curimata ocellata: $0->1$

Clado 179: $\odot \rightarrow 01$

Rhinobrycon negrensis: 01 -> 1

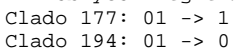

Microschemobrycon casiquiare: 0 -> 1

Markiana nigripinnis: $0 \rightarrow 1$

Hemigrammus unilineatus: $0 \rightarrow 1$

Poptella brevispina: $0 \rightarrow 1$

Caráter 23 (4 passos)

Raiz: 1

Catostomus commersonnii: $1 \rightarrow 0$

Clado 109: 1 -> 0

Clado 121: $0 \rightarrow 1$

Clado 130: 1 -> $\odot$

Caráter 24 ( 3 passos)

Raiz: 0

Hemistichodus vaillanti: $0 \rightarrow 1$

Schizodon fasciatus: 0 -> 1

Caráter 25 (15 passos)

Raiz: 01

Chanos chanos: 01 ->

Clado 103: $01 \rightarrow 0$

Olivaichthys mesembrinus: 0 -> 1

Clado 108: $0 \rightarrow 1$

Clado 182: $0 \rightarrow->1$

$\begin{array}{lll}\text { Clado 152: } & 0 & ->01 \\ \text { Clado 122: } & 0 & ->1\end{array}$

Clado 122: $0 \rightarrow 1$

Oligosarcus argenteus: $01->1$

Copeina cf. guttata: $01 \rightarrow 1$

Charax cf. leticiae: $01 \rightarrow 1$

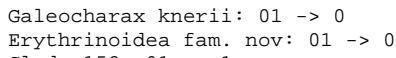

Clado 158: $01 \rightarrow 1$

Clado 149: $0 \rightarrow 1$

Clado 196: $0 \rightarrow 1$

Serrabrycon magoi: $0 \rightarrow 1$

Bryconadenos tanaothoros: 0 -> 1

Knodus meridae: $0 \rightarrow 1$

Iguacladoctes geisleri: $\odot->1$

stygichthys typhlops: $0 \rightarrow 1$

Caráter 26 ( 8 passos)

Raiz: $\odot$

Olivaichthys mesembrinus: $0->1$

Salminus hilarii: 01 -> 1

Brycon pesu: $01 \rightarrow 0$

Clado 146: $01->1$

Clado 151: $\odot->01$

Erythrinoidea fam. nov: 01 -> 1

Clado 161: $0 \rightarrow 1$

Erythrinus erythrinus: $01 \rightarrow 0$

Hoplias malabaricus: $01 \rightarrow 1$

Clado 155: 1 -> 0

Gilbertolus atratoensis: 1 -> 0

Caráter 27 (14 passos)

Raiz: 0

Clado 144: 0 -> 1

Characidium bahiensis: $0->1$

Clado 122: $0 \rightarrow 1$

Clado 190: $1 \rightarrow 0$

Clado 145: $1 \rightarrow 0$

Piaractus mesopotamicus: $1 \rightarrow 0$

Clado 119: $1->0$
Clado 171: $1->0$

Rhinobrycon negrensis: 1 -> $\odot$

Odontostilbe pequira: $0 \rightarrow 1$

Stygichthys typhlops: $\odot->$

Triportheus albus: $1 \rightarrow \theta$

Gymnocorymbus ternetzi: $1 \rightarrow 0$

Hyphessobrycon compressus: $1->0$

Caráter 28 (29 passos)

Raiz: 0

Clado 111: $0 \rightarrow 01$

$\begin{array}{lll}\text { Clado 111: } 0 & ->01 \\ \text { Clado } 144: & 01->12\end{array}$

Olivaichthys mesembrinus: 0 -> 2

Clado 163: $01 \rightarrow \odot$

Clado 163: $01->0$
Clado 143: $12 \rightarrow>2$

Clado 143: $12 \rightarrow>2$

Neolebias unifasciatus: $01 \rightarrow 1$

Clado 107: $01 \rightarrow \odot$

Clado 107: $01->0$

Clado 157: $12 \rightarrow 1$

Chalceus epakros: 12 -> 2

Chalceus epakros:

Clado 159: $12->0$

Xenocharax spilurus: $\odot->1$
Anodus orinocensis: $1 \rightarrow 0$

Anodus orinocensis: $1->0$
Hemiodus unimaculatus $: 1 \rightarrow 2$

Clado 120: $1 \rightarrow 0$

Clado 123: $1 \rightarrow 2$

Erythrinus erythrinus: $2 \rightarrow 0$

Piaractus mesopotamicus: $\odot \rightarrow-1$

Clado 137: $2 \rightarrow 1$

Hepsetus odoe: 2 -> 0

Clado 171: $2 \rightarrow 12$

Clado 176: 12 ->

Hemibrycon polyodon : 1 -> 2

Atopomesus pachyodus: $12 \rightarrow>2$

Microschemobrycon casiquiare: $12 \rightarrow 1$

Clado 180: $1 \rightarrow 0$

Brittanichthys axelrodi: 1 -> 0

Agoniates halecinus: $1 \rightarrow 2$

Probolus heterostomus : $1->2$

Markiana nigripinnis: $1 \rightarrow 0$

Hollandichthys multifasciatus: $1->2$

caráter 29 ( 27 passos)
Raiz: $\odot$

Clado 144: $\odot$-> 12

Olivaichthys mesembrinus: 0 -> 2

Clado 154: 12 -> 2

Crenuchus spilurus: $\odot \rightarrow 1$

Clado 142: $12 \rightarrow 1$

Clado 148: 12 -> 2

Clado 105: $0 \rightarrow 1$

Clado 116: $\odot \rightarrow 1$

Clado 125: $\odot->2$

Gnathocharax steindachneri: 1 -> 2

Roeboexodon guyanensis: $1 \rightarrow 0$

Galeocharax knerii: 1 -> 2

Citharinus latus: $1 \rightarrow 2$

Anodus orinocensis: $1->2$

lado 119: $0 \rightarrow 1$

Landonia latidens: $1 \rightarrow 2$

Serrabrycon magoi: $1 \rightarrow 2$

Kemibrycon polyodon : $1->2$

Odontostilbe pequira: $1 \rightarrow 0$

lado 180: 1 ->

Axelrodia reisei: $1 \rightarrow 0$

Paracheirodon axelrodi: 1 ->

Markiana nigripinnis: 1 -> 2

Hollandichthys multifasciatus: $1->2$

Caráter 30 (2 passos)

Raiz: 0

Chalceus epakros: $\odot->1$

Clado 124: $0 \rightarrow 1$

Caráter 31 (2 passos)

Raiz: 1

Clado 144: $1 \rightarrow 0$

Crenuchus spilurus: 1 -> $\odot$

Caráter 32 (19 passos)

Raiz: 1

Catostomus commersonnii: 1 -> $\odot$

Clado 108: $1 \rightarrow 0$

Clado 153: $1 \rightarrow 01$

Clado 157: $01 \rightarrow 0$

Clado 122: $1 \rightarrow 01$

Copeina cf. guttata: $01->0$

Clado 151: $01 \rightarrow 1$

Clado 162: $1 \rightarrow 0$

Clado 105: $0 \rightarrow 1$

Gnathocharax steindachneri: 1 -> 2

Clado 145: $1 \rightarrow 12$

Clado 145: $1->12$

$\begin{array}{lll}\text { Clado } 120: & 01 & ->1 \\ \text { Clado } 123: & 01 & ->0\end{array}$

Acestrorhynchus falcirostris: $12->2$

Landonia latidens: 1 -> 0

Hepsetus odoe: 12 -> 1

Clado 155: $12 \rightarrow 2$

Clado 178: $1 \rightarrow 0$

Glandulocauda melanogenys: 1 -> $\odot$

Deuterodon iguape: $1 \rightarrow 0$

Iguacladoctes geisleri: $1->0$

Triportheus albus:

Clado 195: 1 -> 0

Ctenobrycon hauxwellianus: 1 -> 0

caráter 33 (8 passos)

Raiz: 0

$\begin{array}{lll}\text { Clado 148: } & 0 & ->1 \\ \text { Clado 181: } & 0 & \rightarrow>1\end{array}$

Clado 151: $0 \rightarrow$

Clado 150: $1 \rightarrow 0$

Clado 123: $\odot \rightarrow>3$

Clado 126: $\theta \rightarrow>$

Piaractus mesopotamicus: $0 \rightarrow 1$

Clado 155: 1 -> 2

Caráter 34 (12 passos)

Raiz: 0

Clado 108: $\odot \rightarrow 01$

Crenuchus spilurus: $\odot->2$

Clado 148: $0 \rightarrow 012$

Clado 148: $0 \rightarrow 01$

Clado 153: $0 \rightarrow 1$
Neolebias unifasciatus: $01->1$

Salminus hilarii: $012 \rightarrow>1$
Clado 147: $012 \rightarrow 2$

Chalceus epakros: $0 \rightarrow 2$

Clado 112: $01 \rightarrow 0$

Distichodus notospilus: $01 \rightarrow 1$

Clado 158: $1 \rightarrow 2$

Citharinus latus: 01 -> $\odot$

Xenocharax spilurus: $01->1$

Clado 149: $2 \rightarrow 0$

Hepsetus odoe: 2 -> 1

Triportheus albus: $0->2$

Caráter 35 (4 passos)

Raiz: 1

Clado 160: 1 -> 01

Chalceus epakros: $01 \rightarrow 0$

Brycon pesu: 1 -> 0

Arnoldichthys spilopterus: 01 -> 1

Clado 162: 01 -> 0

Triportheus albus: 1 -> 0

Caráter 36 ( 7 passos)

Raiz: 0

Clado 160: $\odot \rightarrow 1$

Roeboexodon guyanensis: $0->1$

Clado 138: $0 \rightarrow 1$

Rhinobrycon negrensis: $1 \rightarrow 0$

Atopomesus pachyodus: $0 \rightarrow 1$

Paracheirodon axelrodi: 01

Agoniates halecinus: $1 \rightarrow \odot$

Caráter 37 (16 passos)

Raiz: 0

Crenuchus spilurus: 0 -> 1

Clado 153: $0 \rightarrow 01$

Clado 107: $0 \rightarrow 01$

Clado 118: $0 \rightarrow 01$

Clado 157: $01 \rightarrow 1$

Clado 112: $01 \rightarrow 1$

Brycon pesu: $0 \rightarrow 2$

Copeina cf. guttata: 01 -> 1

Clado 151: $01 \rightarrow 0$

Clado 162: $\rightarrow>2$

Distichodus notospilus: 01 -> 1

Clado 105: $01 \rightarrow 0$

Clado 126: $01->1$

Serrabrycon magoi: $0 \rightarrow 1$

Clado 133: $2 \rightarrow 02$

Clado 133: 20 - 2201

Bryconamericus exodon: 2 ->

Piabina argentea: 2 ->

Clupeacharax engrauloides: 02 -> 2

Clado 130: $02 \rightarrow 0$

Agoniates halecinus: $02->0$

Triportheus albus: $02 \rightarrow 2$

Hollandichthys multifasciatus: 2 -> 0

Caráter 38 (21 passo)

Raiz: 0

Olivaichthys mesembrinus: $0->1$

Characidium bahiensis: $0 \rightarrow 1$

Clado 114: $0 \rightarrow 01$

Distichodus notospilus: $0 \rightarrow 1$

Nannocharax fasciatus: $\odot \rightarrow 1$

Parodon nasus: 01 -> 1

Clado 124: 0 -> 01

Aphyocharax pusillus: $0->1$

Bryconalestes longipinnis: $\odot->1$

Chilodus punctatus: $01 \rightarrow 1$

Metynnis lippincottianus: 0 -> 1

Clado 171: 0 -> 01

Rhinobrycon negrensis: 0 -> 1

Clado 170: $01 \rightarrow 1$

Piabina argentea: $\odot->1$

Odontostilbe pequira: $01 \rightarrow 0$

Clado 183: 01 -> 1

Axelrodia reisei: $01->0$

Brittanichthys axelrodi: $01->1$

Paracheirodon axelrodi: $01 \rightarrow 1$

Clado 200: $01 \rightarrow 0$

Bryconops alburnoides: $0->1$

Clupeacharax engrauloides: $\Theta \rightarrow 1$

Probolus heterostomus : $1 \rightarrow 0$

Clado 185: 1 - $>0$

Hollandichthys multifasciatus: 1 -> 0

Caráter 39 ( 16 passos)

Raiz: 0

Gymnotus aff. carapo: $0->1$

Clado 190: $0 \rightarrow 2$

Oligosarcus argenteus: $\odot->2$

Clado 145: $\odot \rightarrow 2$

Aphyocharax pusillus: $0 \rightarrow 1$

Hydrolycus tatauaia: $\odot \rightarrow 01$

Piaractus mesopotamicus: $\odot \rightarrow 1$

Clado 172: $\odot \rightarrow 1$

Clado 155: $2 \rightarrow 1$

Clado 134: $\odot \rightarrow 02$

Glandulocauda melanogenys: $02->2$

Bryconadenos tanaothoros: $0 \rightarrow 2$

Clado 198: 1 -> 012

Clado 183: $1 \rightarrow 2$

Clado 180: $02 \rightarrow$

Paracheirodon axelrodi: $012->2$

Clado 200: $012 \rightarrow 0$

Clado 131: 02 -> 0

Agoniates halecinus: $02->2$

Triportheus albus: $02 \rightarrow 0$

Hollandichthys multifasciatus: $\odot->2$

Caráter 40 (21 passo)

Raiz: 2

Clado 111: 2 -> 12

Clado 110: $12 \rightarrow 1$

Gymnotus aff. carapo: 2 -> 1 
Clado 179: 01 -> 1

Piabina argentea: $1->2$

Clado 198: $1 \rightarrow 0$

Clado 183: $1->0$

Iguacladoctes geisleri: $\odot \rightarrow 2$

Agoniates halecinus: $012 \rightarrow 2$

Triportheus albus: $012 \rightarrow 1$

Caráter 41 ( 7 passos)

Raiz: 0

Clado 182: $\odot \quad->02$

Oligosarcus argenteus: $02->2$

Clado 146: $0 \rightarrow 012$

Charax cf leticiae: $02 \rightarrow 2$

Galeocharax knerii: $02 \rightarrow 0$

Clado 145: $012 \rightarrow 01$

Clado 150: 012 -> 2 .

Acestrorhynchus falcirostris:

Hepsetus odoe: $01->1$

Hepsetus odoe: 01 -

Agoniates halecinus: $\odot \rightarrow 2$

aráter 42 (5 passos)

Raiz: $\odot$

Charax cf. leticiae: $0->1$

Clado 158: $0 \rightarrow$

Xenocharax spilurus: $0 \rightarrow 1$

Clado 155: $0 \rightarrow 1$

Agoniates halecinus: $0 \rightarrow 1$

Caráter 43 (11 passo)

Raiz: 1

Oligosarcus argenteus: 1 -> 0

Clado 146: $1 \rightarrow 0$

Distichodus notospilus: $1->2$

Nannocharax fasciatus: $1 \rightarrow 2$

Gnathocharax steindachneri: 1 -> $\odot$

Clado 161: $1 \rightarrow 2$

Clado 123: $1 \rightarrow 2$

Clado 126: 1 ->

Hoplias malabaricus: $1 \rightarrow 0$

Iguacladoctes geisleri: $1 \rightarrow 2$

Markiana nigripinnis: $1 \rightarrow 2$

Caráter 44 ( 3 passos)

Raiz: 01

Chanos chanos: $01->0$

Clado 103: 01 - $>1$

Clado 123: 1 -> 0

caráter 45 ( 5 passos)

Raiz: 1

Raiz: 1

Nannocharax fasciatus: $1 \rightarrow 0$

Clado 123: $1 \rightarrow 0$

126: $1 \rightarrow 0$

Stygichthys typhlops: 1 -> 0

Caráter 46 ( 1 passo)

Raiz: 0

Olivaichthys mesembrinus: 0 -> 1

Caráter 47 ( 5 passos)

Raiz: 0

Clado 159: $\odot$-> 01

Brycon pesu: $0 \rightarrow 1$

Clado 162: $01 \rightarrow 1$

Clado 126: $0 \rightarrow 1$

Clado 138: $0 \rightarrow 01$

Clado 137: $01 \rightarrow 1$

Clado 192: 1 -> $\odot$

Caráter 48 (20 passos)

Raiz: 02

Clado 111: 02 -> 0

Catostomus commersonnii: 02 -> 2

Clado 109: $0 \rightarrow 1$

Clado 117: $1 \rightarrow 01$

Clado 190: $\rightarrow>01$

Clado 181: $0 \rightarrow 1$

Lebiasina bimaculata: $\odot \quad->1$

Arnoldichthys spilopterus: 0 -> 1

Nannocharax fasciatus: $1->0$

Givibranchia fowleri: $01->0$

Gnathocharax steindachner

Citharinus latus: $1->2$

Anodus orinocensis: $01->1$

Hemiodus

Clado 173: $\odot \rightarrow 1$

Hemibrycon polyodon : $0->$

Clado 184: 1 -> 01

Knodus meridae: $0 \rightarrow 1$

Odontostilbe pequira: $01->0$

Brittanichthys axelrodi: $1->$

Compsura heterura: $01->0$

Rhoadsia altipinna: $01->1$
Bryconops alburnoides: $0->1$

Clado 189: $\odot \rightarrow->1$

Probolus heterostomus : $01 \rightarrow$

Gymnocorymbus ternetzi: $01 \rightarrow$

Orthospinus franciscoensis: $01 \rightarrow 0$

Hollandichthys multifasciatus: $01 \rightarrow 1$

Poptella brevispina: $01 \rightarrow 1$

Caráter 49 ( 3 passos)

Raiz: 0

Clado 116: 0 -> 1

Citharinus latus: $0 \rightarrow 1$

Clado 124: $0 \rightarrow 1$

Caráter 50 ( 9 passos)

Raiz: 0

Clado 162: $0 \rightarrow 1$

Galeocharax knerii: 0 -> 1
Erythrinoidea fam. nov: $\odot->1$

Acestrorhynchus falcirostris: 0 -> 1

Hydrolycus tatauaia: $0 \rightarrow 1$

Clado 128: $\odot \rightarrow 01$

Schizodon fasciatus: 01 -> 1

Boulengerella maculata: $0 \rightarrow 1$

Leporellus vittatus: $01->0$
Leporinus fasciatus: $01->1$

Clado 130: $0 \rightarrow 1$

Caráter 51 (19 passos)

Raiz: 1

Clado 143: 1 ->

Crenuchus spilurus: $1->0$

Clado 151: 1 -> 0

Bivibranchia fowleri: $1 \rightarrow 2$

Anodus orinocensis: $1 \rightarrow \odot$

Clado 126: $1 \rightarrow 2$

Aphyocharax pusillus: $0->1$

Aphyocharax pusiliu

Clado 119: 1 ->

Myleus setiger: 1 -> 2

Myleus setiger: 1

Microschemobrycon casiquiare: 1 -> 0

Moenkhausia xinguensis: $0 \rightarrow 1$

Clado 198: $1 \rightarrow 0$

Rhoadsia altipinna: 1 -> $\odot$

Iguacladoctes geisleri: $0->2$

Markiana nigripinnis: 0 ->

caráter 52 ( 9 passos)

Raiz: 1

Clado 148: 1 -> 01

Salminus hilarii: $01 \rightarrow 0$

Brycon pesu: 01 -> 1

Clado 146: $01 \rightarrow \odot$
Clado 151: $1 \rightarrow \odot$

Piabucina astrigata: 1 -> 0

Clado 125: 1 - $>$

Landonia latidens: $1 \rightarrow 0$

Ctenolucius hujeta: $0 \rightarrow 1$

Clado 130: 1 -> 0

Markiana nigripinnis: 1 -> 0

Caráter 53 (15 passos)

Raiz: 0

Characidium bahiensis: 0 -> 1

Brycon pesu: $0->1$

Aphyocharax pusillus: $0->1$

lado 137: $\odot->1$

Clado 172: $0 \rightarrow 1$

Hemibrycon polyodon : 1 -> 0

Clado 175: 1 -> 01

Clado 133: $1 \rightarrow$

Axelrodia reisei: $01 \rightarrow$

Axelrodia reisei: $01->1$

Brittanichthys axelrodi: $01 \rightarrow 0$

Paracheirodon axelrodi: 01

$\begin{array}{ll}\text { Rhoadsia altipinna: } 1-> & 0 \\ \text { Rachoviscus graciliceps: } & 01->1\end{array}$

Rachoviscus graciliceps: $01->$
Stygichthys typhlops: $01->0$

Stygichthys typhlops: $01->$

Tetragonopterus argenteus: $\odot->1$
Hollandichthys multifasciatus: $\Theta_{-1} \rightarrow 1$

Hollandichthys multifasciatus: $\odot->$

Ctenobrycon hauxwell
caráter 54 ( 3 passos)

Raiz: 0

Clado 115: $\odot->01$

Clado 114: $01 \rightarrow 1$

Clado 117: 01 -> 1

Clado 125: $01 \rightarrow 0$

Clado 120: $01 \rightarrow 0$

Clado 123: 01 -> 1

Caráter 55 (10 passos)

Raiz: 1

Clado 163: 1 -> 0

Neolebias unifasciatus: $1 \rightarrow 0$

lado 157: 1 ->

lido 157: 1 i 0

Clado 146: $\rightarrow 01$

Clado 146: $1 \rightarrow 01$

Xenocharax spilurus: $1->0$

Xenocharax spilurus: 1 -> 0 : 01 -> 0

Hydrolycus tatauaia: $01 \rightarrow 0$

Clado 149: $01 \rightarrow 1$

Hepsetus odoe: $01->1$

Clado 155: $01 \rightarrow 0$

Brittanichthys axelrodi: $1 \rightarrow 0$

Caráter 56 ( 6 passos)

Raiz: 1

Clado 143: 1 -> 012

Characidium bahiensis: 1 -> 0

Clado 142: $012 \rightarrow 0$

Acestrorhynchus falcirostris: 012 -> 0

Hydrolycus tatauaia: $012->2$

Hoplias malabaricus: $1 \rightarrow 2$

Boulengerella maculata: 012 -> 2

Ctenolucius hujeta: $012 \rightarrow 1$

Caráter 57 ( $\odot$ passos)

Raiz: 0

Caráter 58 ( 4 passos)

Raiz: 0

Crenuchus spilurus: $0 \rightarrow 1$

Distichodus notospilus: $0 \rightarrow 1$

Boulengerella maculata: $0 \rightarrow 1$

Brittanichthys axelrodi: $0 \rightarrow 1$

caráter 59 (13 passos)

Raiz: 1

Clado 182: $1 \rightarrow 0$

Salminus hilarii: $1 \rightarrow 0$

Clado 151: $1 \rightarrow$

Clado 125: $1 \rightarrow 0$

Clado 145: 1 -> 01

Acestrorhynchus falcirostris: $01 \rightarrow 0$

Clado 196: 1 -> 0

Landonia latidens: 1 -> 0

Phenagoniates macrolepis: 1 -> 0

Hepsetus odoe: 01 -> 1

Clado 155: $01 \rightarrow 0$

Gilbertolus atratoensis: $1 \rightarrow 0$

Curimata ocellata: 1 -> 0

Brittanichthys axelrodi: $1 \rightarrow 0$

Compsura heterura: $1 \rightarrow 0$

Caráter 60 ( 2 passos)

Raiz: 0

Clado 123: 0 -> 1

Potamorhina latior: $0 \rightarrow 1$

Caráter 61 (18 passos)

Raiz: 0

Clado 153: $\odot \rightarrow 1$

Salminus hilarii: $\odot \rightarrow 1$

Clado 152: $1 \rightarrow 12$

Copeina cf. guttata: $12 \rightarrow 2$

Cannocharax fasciatus: $\theta->$

Bivibranchia fowleri: 0 -> 1

Erythrinoidea fam. nov: $12 \rightarrow 2$

Clado 158: 12 -> 1

Clado 197: $\odot \rightarrow>1$
Clado 155: $\odot->1$

Boulengerella maculata: 1 -> 2

Clado 133: $\odot \rightarrow 1$

Clado 167: $\odot \rightarrow 01$

Knodus meridae: $0->1$

Deuterodon iguape: $01 \rightarrow 1$

Astyanax mexicanus: $01 \rightarrow 1$

Clupeacharax engrauloides: $1 \rightarrow 0$

Agoniates halecinus: $1 \rightarrow 2$

Clado 187: $01 \rightarrow 0$

Probolus heterostomus : $01 \rightarrow 0$

Clado 191: 01 -> 1

Markiana nigripinnis: 01 -> 1

Tetragonopterus argenteus: $01->0$

Ctenobrycon hauxwellianus: $\theta \rightarrow 1$

Caráter 62 (20 passos)

Raiz: 2

Catostomus commersonnii: 2 -> 1

Olivaichthys mesembrinus: $2 \rightarrow 0$

Clado 108: $2 \rightarrow 0$

Clado 160: $2 \rightarrow 1$

Clado 118: $2 \rightarrow 12$

Clado 106: $\odot \rightarrow 1$

Bivibranchia fowleri: 12 -> 1

Clado 121: $12 \rightarrow 1$

Erythrinoidea fam. nov: 2 -> 0

Anodus orinocensis: $12 \rightarrow 2$

Hemiodus unimaculatus : $12->1$

Clado 124: $012 \rightarrow 2$

Clado 126: 012 -> 0

Brycinus macrolepidotus: 1 -> 0

Clado 196: $1 \rightarrow 0$

Hemibrycon polyodon : $2->1$
Clado 177: $2 \rightarrow 12$

Glandulocauda melanogenys: $2 \rightarrow 1$

Bryconadenos tanaothoros: $12->1$
Piabina argentea: $2 \rightarrow 0$

Iguacladoctes geisleri: 2 -> 1

Astyanax mexicanus: 2 -> 0

Stygichthys typhlops: $2->0$

Markiana nigripinnis: 2 -> 1

Caráter 63 (30 passos)

Raiz: 01

Chanos chanos: $01->0$

Clado 102: 01 : $>012$

Clatostomus commersonnii: $012 \rightarrow 2$

Clado 163: $01 \rightarrow 2$

Clado 108: $01 \rightarrow 1$

Clado 115: $01 \rightarrow 0$

Clado 160: 01 ->

Neolebias unifasciatus: 1 -> 2

Clado 141: $01 \rightarrow 1$

Salminus hilarii: 01 -> $\odot$

Clado 157: $01 \rightarrow 0$ 
Stygichthys typhlops: 12 -> 1

Clupeacharax engrauloides: $\odot \rightarrow 1$

Clado 192: 1 -> 01

Probolus heterostomus : $01 \rightarrow 0$

Hemigrammus unilineatus: $01->1$

Hollandichthys multifasciatus: 01 -> 0

Caráter 64 (19 passos)

Raiz: 1

Clado 102: 1 -> 01

Catostomus commersonnii: $01->0$

olivaichthys mesembrinus: 01 -> 1

Gymnotus aff. Carapo: 01:

Clado 109: 1 -> $\odot$

Clado 152: 1 -> 01

Clado 159: $1 \rightarrow 0$

Copeina cf. guttata: 01 -> 0

1 -> 0

Erythrinoidea fam. nov: $01 \rightarrow 0$
Clado 158: $01 \rightarrow 1$

Bryconalestes longipinnis: 0 -> 1

Hepsetus odoe: $1 \rightarrow 0$

Phenacogaster pectinatus: $1->0$

Atopomesus pachyodus: $1 \rightarrow 0$

Moenkhausia xinguensis: $1 \rightarrow \oplus$

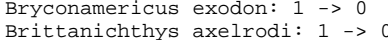

Brittanichthys axelrodi: $1 \rightarrow$

Compsura heterura: $1->0$
Stygichthys typhlops: $1->0$

Clado 130: $1 \rightarrow 0$

Hemigrammus unilineatus: $1->0$

Caráter 65 (11 passo)

Raiz: $\odot$

Crenuchus spilurus: $0->1$

Clado 142: $\odot \rightarrow$

Copeina cf. guttata: $0 \rightarrow>1$

Piabucina astrigata: $0 \rightarrow 1$

Clado 172: 1 ->0

Paragoniates alburnus: $1->0$

Clado 135: $1 \rightarrow 0$

Clado 184: $0 \rightarrow 1$

Clado 191: $1 \rightarrow 01$

Tetragonopterus argenteus: $1->0$

Hollandichthys multifasciatus: 01 -> 1

Hollandichthys multifasciatus: $01->$

Hyphessobrycon compr
caráter 66 ( 5 passos)

Raiz: 01

Chanos chanos: $01->1$

Clado 103: $01 \rightarrow \odot$

Clado 133: $0 \rightarrow 01$

Clado 180: 01 ->

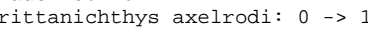

:

Clado 130: $01->0$

Agoniates halecinus: $01->0$

Triportheus albus: 01 - $>1$

Caráter 67 (18 passos)

Raiz: 1

Clado 144: 1 -> 0

Olivaichthys mesembrinus: 1 -> $\odot$

Clado 141: $\odot \rightarrow 01$

Clado 140: $01 \rightarrow 1$

Clado 162: $0 \rightarrow 01$

Gnathocharax steindachneri: $01->0$

Roeboexodon guyanensis: $01 \rightarrow$

Erythrinoidea fam, nov: 0 -> 1

Clado 161: 01 -> 1

Piaractus mesopotamicus: 01 -> 1

Clado 196: 01 -> 0

Paragoniates alburnus: 1 -> 0

Clado 169: $1 \rightarrow 0$

Glandulocauda melanogenys: 1 -> $\odot$

Bryconamericus exodon: $1 \rightarrow 0$

Piabina argentea: $1 \rightarrow 0$

Stygichthys typhlops: $1->0$

Agoniates halecinus: $1->0$

Probolus heterostomus : $01 \rightarrow 1$

Hemigrammus unilineatus: $01 \rightarrow 1$

Clado 193: $01 \rightarrow 0$

Ctenobrycon hauxwellianus: $0 \rightarrow 1$

caráter 68 (4 passos)

Raiz: 0

Clado 122: $\odot \rightarrow 1$

Hemistichodus vaillanti: $0 \rightarrow 1$

Iguacladoctes geisleri: $\odot \rightarrow 1$

Clado 130: $0 \rightarrow 1$

Caráter 69 ( 23 passos)

Raiz: 2

Clado 111: $2 \rightarrow 1$

Clado 143: $1 \rightarrow 0$

Characidium bahiensis: 1 -> 2

Crenuchus spilurus: $1->0$

Clado 153: 1 -> 12:

Clado 157: $12 \rightarrow>$

Clado 112: $1 \rightarrow 2$

Clado 140: $\odot \rightarrow$

Copeina cf, guttata: $12 \rightarrow 2$

Clado 151: $12 \rightarrow 1$

Bivibranchia fowleri: 1 -> 2

Clado 125: $1 \rightarrow 12$

Xenocharax spilurus: 1 -> 0

Clado 124: $12 \rightarrow 2$

Erythrinus erythrinus: 1 -> 0

Piaractus mesopotamicus: $1 \rightarrow 0$
Curimatopsis macrolepis: 1 -> 2

Anostomus anostomus: $12->2$

Clado 128: 12 -> 1

Iguacladoctes geisleri: 1 -> 2

Astyanax mexicanus: $1->0$

Stygichthys typhlops: $1->0$

Clupeacharax engrauloides: 1 -> 0

Agoniates halecinus: $1 \rightarrow 0$

Clado 191: 1 -> 01

Hemigrammus unilineatus: $01->0$

Orthospinus franciscoensis: $1->0$

Hollandichthys multifasciatus: $01->0$

Hyphessobrycon compressus: $01-1$

Caráter 70 ( 6 passos)

Raiz: 0

Characidium bahiensis: $0 \rightarrow 1$

Clado 145: $\odot \rightarrow 01$

Clado 158: $\odot \rightarrow 2$

Acestrorhynchus falci

Hepsetus odoe: $01->0$

Clado 155: $01->1$

Clado 155: $01->1$

Schizodon fasciatus: $01->1$

Leporinus fasciatus: $01 \rightarrow 1$

caráter 71 ( 4 passos)

Caráter

Clado 125: $\odot$-> 1

Semaprochilodus insignis: $0->1$

Roestes molossus: $0 \rightarrow 1$

Iguacladoctes geisleri: $\odot->1$

Caráter 72 ( 7 passos)

Raiz: 1

Clado 102: $1 \rightarrow \odot$

Piabucina astrigata: $1 \rightarrow 0$

Galeocharax knerii: $1 \rightarrow \odot$

Erythrinoidea fam. nov: 1 -> $\odot$

Clado 155: $1 \rightarrow 0$

Hemibrycon polyodon : $1->0$

Microschemobrycon casiquiare: $1>0$

Caráter 73 (20 passos)

Raiz: 1

Clado 108: $1 \rightarrow 0$

Clado 108: $1 \rightarrow 0$

Brycon pesu: $01->0$

$\begin{array}{lll}\text { Brycon pesu: } & -1 & -> \\ \text { Clado 121: } 1-> & 0\end{array}$

Gnathocharax steindachneri: 1 -> $\odot$

Clado 145: $01 \rightarrow 1$

Clado 150: $01 \rightarrow 0$

Erythrinoidea fam. nov: 1 -> 0

Anodus orinocensis: $1 \rightarrow 0$

Phenagoniates macrolepis: 1 ->

Rhinobrycon negrensis: $0 \rightarrow 1$

Diapoma terofali: $0 \rightarrow 1$

Clado 184: $0 \rightarrow 01$

Moenkhausia xinguensis: $0->1$

Odontostilbe pequira: 01 -> 1

Compsura heterura: $01->0$

Rhoadsia altipinna: $01->1$

Stygichthys typhlops: $0->1$

Agoniates halecinus: $\odot \rightarrow 1$

Probolus heterostomus : $0 \rightarrow 1$

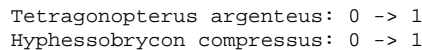

caráter 74 (31 passo)

Raiz: 1

Clado 104: $1 \rightarrow 0$

Clado 109: $1 \rightarrow 0$

Clado 154: 1 -> 01

Salminus hilarii: $1 \rightarrow 0$

Clado 159: 01 -> 1

Saccodon wagneri: $\theta>2$

Oligosarcus argenteus: 1 -> 0

Copeina cf. guttata: $01->$

Lebiasina bimaculata: $01 \rightarrow 0$

Piabucina astrigata: 01 -> 1

Apareiodon piracicabae: $0 \rightarrow 1$

Gnathocharax steindachneri:

Galeocharax knerii:

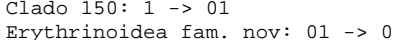

Clado 158: $01 \rightarrow 1$

Citharinus latus: $0 \rightarrow 1$

Hemiodus unimaculatus : $\odot->1$

Clado 124: $0 \rightarrow$

Aphyocharax pusillus: 1 -> 2

Hydrolycus tatauaia: $01->$

Bryconalestes longipinnis: 1 -> 0

Serrabrycon magoi: $1 \rightarrow 0$

Clado 155: 1 - 0

Gilbertolus atratoensis: $01 \rightarrow 1$

Roestes molossus: $01 \rightarrow 0$

Clado 136: $1 \rightarrow 01$

Clado 169: $01 \rightarrow 0$

Diapoma terofali: 01 -> 1

Glandulocauda melanogenys: 01 -> 0

Clado 180: $01 \rightarrow 1$
Clado 166: $\odot \rightarrow 1$

Axelrodia reisei: 1 -> 0

Compsura heterura: $1 \rightarrow 0$

Clado 131: 01 -> 0

Stygichthys typhlops: $1->0$

Agoniates halecinus: $01->$

Tetragonopterus argenteus: $1 \rightarrow 0$ Hollandichthys multifasciatus: 1 - 0 Caráter 75 ( 2 passos)

Raiz: 0

Clado 123: $\odot \rightarrow 1$

Clado 126: $0 \rightarrow 1$

Caráter 76 (22 passos)

Raiz: 1

Gymnotus aff. carapo: 1 -> 0

Clado 117: 1 -> 01

Clado 181: $1 \rightarrow 0$

Brycon pesu: 1 -> 0

Clado 162: 1 -> 01

Bivibranchia fowleri: $01 \rightarrow 0$

Clado 197: 01 -> $\odot$

Anodus orinocensis: $01->1$

Hemiodus unimaculatus : $01 \rightarrow 0$

Clado 123: $1 \rightarrow 0$

Acestrorhynchus falcirostris: 1 -> 0

Brycinus macrolepidotus: $01->0$

Bryconalestes longipinnis: $01->$

Clado 137: 1 - $>$

Schizodon fasciatus: 1 : $1->0$

Phenacogaster pectinatus: 1 -> 0

Diapoma terofali: $0 \rightarrow 1$

Atopomesus pachyodus: 1 -> $\odot$

Bryconadenos tanaothoros: $0->1$

Piabina argentea: $0 \rightarrow 1$

Clado 183: $1 \rightarrow 0$

Clado 130: $0 \rightarrow 1$

Clado 192: $\odot \rightarrow 1$

Gymnocorymbus ternetzi: 0 -> 1

Hollandichthys multifasciatus: 1 -> 0

Caráter 77 ( 9 passos)

Raiz: 0

Clado 111: $0 \rightarrow 01$

Clado 144: $01 \stackrel{->1}{->}$

Olivaichthys mesembrinus: 0 -> 1

Clado 109: $01 \rightarrow 0$

Salminus hilarii: 1 -> 0

Clado 145: 1 -> 01

Acestrorhynchus falcirostris: $01 \rightarrow 0$

Hepsetus odoe: $01-1$

Clado 155: 01 -> 0

Moenkhausia xinguensis: 1 -> 0

Clado 130: $1 \rightarrow 0$

Triportheus albus: 1 -> 0

Caráter 78 ( 7 passos)

Raiz: 1

Clado 144: $1 \rightarrow 0$

Olivaichthys mesembrinus: 1 -> $\odot$

Characidium bahiensis: 1 - $\rightarrow$

Clado 152: $0 \rightarrow 1$

Clado 120: $1->0$

Hepsetus odoe: $0->1$
Odontostilbe pequira: $0->1$

Odontostilbe pequira:
Caráter 79 ( 35 passos)

Raiz: 01

Chanos chanos: 01 ->

Clado 111: 01 - 012

Catostomus commersonnii: $01 \rightarrow 0$

Clado 104: $01 \rightarrow 1$

Clado 110: $012 \rightarrow 01$

Clado 144: $012 \rightarrow 2$

Clado 108: 01 -> 1

Characidium bahiensis: 01 -> 1

Crenuchus spilurus:

Clado 114: 01 -> 2

Oligosarcus argenteus: 2 -> 1

Clado 146: $2 \rightarrow 1$

Clado 151: 2 -> 1 Distichodus notospilus: $1->2$

Distichodus notospilus: $1->2$

Bivibranchia fowleri: $01 \quad->1$

Bivibranchia fowler

Clado 121: $01->1$

Clado 125: 01 -> 012

Charax cf. leticiae: $2 \rightarrow 0$

Clado 124: $012 \rightarrow 0$

Acestrorhynchus falcirostris: $1 \rightarrow 0$

Bryconalestes longipinnis: $2 \rightarrow 0$

Landonia latidens: $2 \rightarrow 1$ 
Raiz: $\odot$

Clado 110: $\odot \rightarrow 01$

Olivaichthys mesembrinus: $\odot->1$

Clado 109: 01 -> 1

Characidium bahiensis: 01 -> 0

Crenuchus spilurus: $01 \rightarrow 1$

Clado 160: $0 \rightarrow 1$

Clado 150: $\odot \rightarrow 1$

Clado 197: $1 \rightarrow 0$

Clado 126: 1 -> 01

Anostomus anostomus: $01 \rightarrow 0$

Clado 127: $01 \rightarrow 0$

Astyanax mexicanus: $\odot->1$

Agoniates halecinus: $0->1$

caráter 81 ( 32 passos)

Raiz: 2

Clado 102: $2 \rightarrow 02$

Catostomus commersonnii: $02->0$

Olivaichthys mesembrinus: 02 ->

Gymnotus aff. carapo: $02 \rightarrow 0$

clado 163: $2 \rightarrow 0$

Clado 148: $2 \rightarrow 1$

Clado 153: $2 \rightarrow 0$

Neolebias unifasciatus: 2 -> 0

Clado 113: 2 -> 1

Clado 117: $2 \rightarrow 1$

Clado 140: $2 \rightarrow 1$
Clado 105: $2 \rightarrow 123$

Nannocharax fasciatus: 2 ->

Gnathocharax steindachneri: $2>0$

Charax cf. leticiae: $2 \rightarrow 1$

Clado 145: $1 \rightarrow 0$

$\begin{array}{lll}\text { Citharinus latus: } 123 \text { - } & 1 \\ \text { Xenocharax spilurus: } 123 & ->3\end{array}$

Aphyocharax pusillus: $1->0$

Hydrolycus tatauaia: $1 \rightarrow 3$

Bryconalestes longipinnis:

Anostomus anostomus:

Metynnis lippincottianus: 2 -> 1

Clado 135: $1 \rightarrow 01$

Diapoma terofali: $01->\odot$

Atopomesus pachyodus: $1 \rightarrow 2$

Clado 175: $01 \rightarrow 0$

Glandulocauda melanogenys: $01->\odot$

Moenkhausia xinguensis: $1 \rightarrow 2$

Bryconamericus exodon: $1 \rightarrow 0$

Odontostilbe pequira: $01->0$

Clado 183: $01 \rightarrow 1$

Clado 180: $01 \rightarrow 1$

Clado 131: $01 \rightarrow$

Clado 164: $01 \rightarrow 1$

Clado 195: $1 \rightarrow 12$

Clado 191: 1 -> 0

Markiana nigripinnis: 123 -> 3

Tetragonopterus argenteus: $123->2$

Caráter 82 (14 passos)

Raiz: 01

Chanos chanos: 01 ->

Olivaichthys mesembrinus: 01 ->

Clado 115: $01 \rightarrow 1$

Clado 142: $01 \rightarrow 0$

Salminus hilarii: $01 \rightarrow 0$

Chalceus epakros: $01->1$

Clado 112: $01->0$

Arnoldichthys spilopterus: $01 \rightarrow 0$

Distichodus notospilus: $01->$

Clado 150: $01 \rightarrow 0$

Citharinus latus: 01 -> 1

Xenocharax spilurus: $01 \rightarrow 0$

Piaractus mesopotamicus: $01 \rightarrow 0$

Hepsetus odoe: $01 \rightarrow 1$

Metynnis lippincottianus: $01->$

Metynnis lippincottianus:

Rhinobrycon negrensis: $0->1$

Rhinobrycon negrensis: $0->1$

Atopomesus pachyodus: $0->1$

Moenkhausia xinguensis:

$\begin{array}{lll}\text { Knodus meridae: } 0 & ->1 \\ \text { Compsura heterura: } 0 & ->1\end{array}$

Compsura heterura: 83 (18 passos)

Caráter 83

Clado 111: $\odot \rightarrow 01$

Clado 109: $01 \rightarrow 1$

Clado 143: $01 \rightarrow 0$

Chalceus epakros: 01 -> 1

Clado 113: $1 \rightarrow 0$
Brycon pesu: $\odot \rightarrow 1$

Arnoldichthys spilopterus: $01->0$

Clado 162: $01 \rightarrow 1$

Clado 105: 1 -> 012

Nannocharax fasciatus: 1 -> 2

Clado 125: 1 -> 01

Citharinus latus: $012 \rightarrow 0$

Xenocharax spilurus: $012->2$

Anodus orinocensis: $1 \rightarrow 0$

Clado 120: 1 -> 3

Clado 124: $01 \rightarrow$

Clado 124: $01->0$ : 01 -> 0

Clado 128: $01 \rightarrow 1$

Metynnis lippincottianus: $1 \rightarrow 0$

Atopomesus pachyodus: $01-1$
Microschemobrycon casiquiare: $01->0$

Moenkhausia xinguensis: 0 -> 1

Clado 183: 01 -> 1

Triportheus albus: $0 \rightarrow 1$

Tetragonopterus argenteus: $\odot \rightarrow 2$

Caráter 84 (2 passos)

Raiz: 0

Clado 158: $\odot \rightarrow 1$

Hepsetus odoe: $\Theta \rightarrow 1$

Caráter 85 ( 8 passos)

Raiz: 0

Clado 104: $0 \rightarrow->1$

Clado 110: $0 \rightarrow 1$

Gymnotus aff carapo: $01->1$

Clado 118: $1 \rightarrow 0$

Charax cf. leticiae: $0 \rightarrow 1$

Erythrinoidea fam. nov: $0 \rightarrow 1$

Anodus orinocensis: $0 \rightarrow 1$

Clado 123: $0 \rightarrow 1$

Phenacogaster pectinatus: $0->1$

Caráter 86 (20 passos)

Raiz: 2

Clado 111: 2 -> 1

Clado 110: $1 \rightarrow 01$

Clado 115: $01 \rightarrow 0$

Characidium bahiensis: 01 -> $\odot$

Crenuchus spilurus: $01 \rightarrow 2$

Clado 153: $1 \rightarrow 0$

Neolebias unifasciatus: 01 -> 2

Clado 141: 1 -> 2

Brycon pesu: 1 -> 2

Arnoldichthys spilopterus: $1 \rightarrow 0$

Distichodus notospilus: 01 -> 0

Clado 105: $01 \rightarrow 2$

Nannocharax fasciatus: 01 -> 0

Clado 116: 0 -> 01

Charax cf. leticiae: $1 \rightarrow 2$

Anodus orinocensis: $01 \rightarrow 1$

Acestrorhynchus falcirostris: 1 -> 2

Hoplias malabaricus: $\theta->2$

Clado 119: $\odot \rightarrow 1$

Brittanichthys axelrodi: 2 -> 1

Caráter 87 ( 23 passos)

Raiz: 1

Clado 104: $1 \rightarrow 0$

Clado 143: 1 -> 12

Clado 142: $12 \rightarrow 2$

Clado 107: 1 -> 01

Salminus hilarii: 12 -> 2

Clado 112: $01 \rightarrow 0$

Clado 117: 1 -> 01

Brycon pesu: $12->1$

Copeina cf. guttata: $1->2$

Clado 105: 01 -> 012

Bivibranchia fowleri: 01 -> 0

Clado 145: 12 -> 2

Citharinus latus: 012 -> 0

Xenocharax spilurus: $012->2$

Anodus orinocensis: $01->0$

Hemiodus unimaculatus : $01 \rightarrow 1$

Clado 120: $1 \rightarrow 0$

Clado 199: $2 \rightarrow 1$

Hydrolycus tatauaia: 12 -> 1

Clado 128: 1 ->

Clado 172: 2 -> 1

Gilbertolus atratoensis: 12 -> 2

Roestes molossus: 12 -> 1

Metynnis lippincottianus: $1 \rightarrow$

Rhinobrycon negrensis: 2 -> 1

Atopomesus pachyodus: $1 \rightarrow 2$

Axelrodia reisei: $1 \rightarrow 2$

Compsura heterura: $1 \rightarrow 0$

Stygichthys typhlops: 1 -> 2

Probolus heterostomus: $1->2$

Clado 185: $2 \rightarrow 1$

Caráter 88 (27 passos)

Raiz: $\odot$

Clado 163: $\odot \rightarrow 1$

Clado 141: $0 \rightarrow 01$

Salminus hilarii: 0 -> 1

159: $\odot \rightarrow 1$

Saccodon wagneri: $0->2$

Clado 140: $01 \rightarrow 1$

Clado 151: $0 \rightarrow 01$

Lebiasina bimacula

Clado 125: $0 \rightarrow 01$

Gnathocharax steindachneri: $01->0$

Roeboexodon guyanensis: $01->2$

Charax cf. leticiae: $0->1$

Erythrinoidea fam. nov: $01 \rightarrow 1$

Clado 124: $01 \rightarrow 1$

Erythrinus erythrinus: 01 -> 1

Hoplias malabaricus: $01 \rightarrow 0$

Piaractus mesopotamicus: $1 \rightarrow 2$

Anostomus anostomus: $01->0$

Clado 128: 01 -> 1

Landonia latidens: 1 -> 2

Clado 178: 1 -> 12

Clado 194: $12 \rightarrow->2$

Atopomesus pachyodus: 1 -> 2

Clado 184: $1 \rightarrow$

Glandulocauda melanogenys: 1 -> 2

Bryconadenos tanaothoros: $12 \rightarrow>1$

Bryconanoricus

Clado 132: 1 -> 01

Axelrodia reisei: 1 -> 2

Clado 131: 01 -> 0

Rachoviscus graciliceps: 1 -> 0

Agoniates halecinus: $01 \rightarrow \odot$

Triportheus albus: $01 \rightarrow 1$

Clado 186: 1 -> 01

Orthospinus franciscoensis: 01 ->

Ctenobrycon hauxwellianus: $01 \rightarrow 0$

Poptella brevispina: $01 \rightarrow 1$

Caráter 89 (15 passos)

Raiz: 0

Clado 110: $\odot$-> 0123

Clado 109: $0123 \rightarrow->0123$

Clado 108: $02->2$

Characidium bahiensis: 0123 -> 1

Crenuchus spilurus: $0123 \rightarrow 3$

Saccodon wagneri: $02 \rightarrow \odot$

Clado 113: $02 \rightarrow 2$

Clado 117: 02 -> 012

Clado 122: $02 \rightarrow 0$

Bivibranchia fowleri: 012 -> 2

Clado 116: $012 \rightarrow 1$

(eticiae: $\odot \rightarrow 1$

$->3$

Aphyocharax pusillus: $0 \rightarrow 1$

Hoplias malabaricus: $0 \rightarrow 1$

Leporinus fasciatus: $0->1$

$\begin{array}{lll}\text { Atopomesus pachyodus: } 0 & -> & 1 \\ \text { Brittanichthys axelrodi: } 0 & ->1\end{array}$

Compsura heterura: $\odot \rightarrow 1$

Stygichthys typhlops: $0 \rightarrow 1$

Caráter 90 ( 2 passos)

Raiz: 01

Chanos chanos: $01 \rightarrow 0$

Clado 111: 01 -> 1

Catostomus commersonnii: 01 -> 0

Clado 104: 01 -> 1

Caráter 91 (19 passos)

Raiz: 1

Olivaichthys mesembrinus: $1 \rightarrow 0$

Clado 143: $1 \rightarrow 0$

Clado 151: $1 \rightarrow 01$

Clado 165: $\odot \rightarrow 1$

Erythrinoidea fam. nov: $01 \rightarrow \odot$

Clado 197: $1 \rightarrow 01$

Clado 156: $0 \rightarrow 1$

Erythrinus erythrinus: $01->0$

Hoplias malabaricus: $01->1$

Piaractus mesopotamicus: $01 \rightarrow 0$

Clado 172: $0 \rightarrow 01$

Metynnis lippincottianus: 01 -> 0

Myleus setiger: $01 \rightarrow 1$

Phenacogaster pectinatus: 01 -> 1

Clado 178: $0 \rightarrow 1$

Clado 170: $01 \rightarrow 0$

Clado 134: $0 \rightarrow 1$

Odontostilbe pequira: $01->1$

Clado 183: $01 \rightarrow 0$

Axelrodia reisei: $01 \rightarrow 0$

Brittanichthys axelrodi: $01->1$

Paracheirodon axelrodi: $01 \rightarrow 1$

Bryconops alburnoides: 1 - $>0$

Rachoviscus graciliceps: 01 -> $\odot$

Stygichthys typhlops: $01-1$

Triportheus albus: $1 \rightarrow 0$

Clado 191: $\odot \rightarrow 01$

Hemigrammus unilineatus: $01 \rightarrow 1$

Hollandichthys multifasciatus: $01 \rightarrow 0$

Hyphessobrycon compressus: $01-1$

Caráter 92 (19 passos)

Raiz: 0

Clado 111: 0 -> 01

Clado 109: $01 \rightarrow->1$

Clado 163: $01 \rightarrow 0$

Clado 154: $01 \rightarrow 1$

Clado 154: $01->1$

Clado 142: $01 \rightarrow>0$

Clado 148: $01 \rightarrow>$

Clado 112: $1 \rightarrow 01$

Clado 122: $1->01$

Copeina cf. guttata: $1->0$

Clado 165: $\odot \rightarrow 01$

Galeocharax knerii: 0 -> 1

Clado 145: $1 \rightarrow 0$ 
Gymnotus aff. carapo: 01 -> 1

Clado 108: $01 \rightarrow 0$

Characidium bahiensis: $01 \rightarrow 0$

Crenuchus spilurus: $01 \rightarrow 1$

Clado 114: 01 -> $\odot$

Bivibranchia fowleri: 01 -> 0

Clado 116: $01 \rightarrow 1$

Clado 145: 1 -> 01

Xenocharax spilurus: $\odot \rightarrow 1$

Acestrorhynchus falcirostris: 01 -> 0

Prochilodus nigricans: 1 -> 0

Hepsetus odoe: $01 \rightarrow$

Clado 155: $01 \rightarrow 1$

Myleus setiger: $1 \rightarrow 0$

Bryconadenos tanaothoros: $1->0$

Brittanichthys axelrodi: $1 \rightarrow 0$

Rhoadsia altipinna: $1->0$

Hyphessobrycon compressus: 1 ->

Caráter 94 ( 5 passos)

Raiz: 0

Clado 122: $\odot$-> 1

Hoplias malabaricus: $\odot->1$

Clado 155: $0 \rightarrow 1$

Metynnis lippincottianus: $\odot->1$

Clado 130: $0 \rightarrow 1$

Caráter 95 (22 passos)

Raiz: 012

Chanos chanos: 012 -> 1

Clado 102: $012 \rightarrow>0$

Clado 111: 012 -> 2
Crenuchus spilurus: $2 \rightarrow 0$

Clado 153: $2 \rightarrow 01$

Clado 114: 2 -> 0

Salminus hilarii: 2 -> 0

Clado 106: 2 -> 1

Clado 122: $2 \rightarrow 3$
Clado 181: $2 \rightarrow 0$

Copeina cf. guttata: 01 -> 1

Clado 151: $01 \rightarrow 0$

Lebiasina bimaculata: $01 \rightarrow 1$

Piabucina astrigata: $01 \rightarrow 0$

Nannocharax fasciatus: $2 \rightarrow 0$

Clado 165: $\rightarrow 12$

Roeboexodon guyanensis: $2 \rightarrow 1$

Clado 145: $2 \rightarrow \infty$

Clado 126: $3 \rightarrow 0$

Aphyocharax pusillus: $12->1$

Aphyocharax pusillus: $12->1$

Paragoniates alburnus: $12 \quad->2$

Shenagoniates macrolepis: 12

Schizodon fasciatus: 0
Knodus meridae: $2 \rightarrow 1$

Stygichthys typhlops: 2 -> 0

Clado 130: $2 \rightarrow 1$

Hollandichthys multifasciatus: 2 -> 1

Caráter 96 ( 27 passos)

Raiz: 0

Clado 111: $\odot \rightarrow>1$

Clado 154: $1 \rightarrow 12$

Clado 182: $1 \rightarrow 0$

Clado 147: $1 \rightarrow 0$

Chalceus epakros: 12 -> 2

Clado 159: $12 \rightarrow 1$

Clado $117: 1 \rightarrow 0$
Clado $122: 1 \rightarrow 2$

Copeina cf. guttata: $12->2$

Lebiasina bimaculata: $12 \rightarrow>1$

Piabucina astrigata: $12 \rightarrow>2$
Nannocharax fasciatus: $1 \rightarrow 0$

Clado 165: $1 \rightarrow 0$

Erythrinoidea fam. nov: 12 -> $\odot$

Clado 158: $12 \rightarrow 2$

Clado 158: $12 \rightarrow>$

Myleus setiger: 1 -> 2

Curimata ocellata: $2 \rightarrow 0$

Clado 179: $1 \rightarrow 01$

Rhinobrycon negrensis: 01 -> 0

Clado 177: $01 \rightarrow 0$

$\begin{array}{ll}\text { Clado 177: } & 01-> \\ \text { Clado 194: } 01->1\end{array}$

Clado 175: $1 \rightarrow 01$

Clado 198: $01 \rightarrow 0$

Clado 180: $1 \rightarrow 0$

Axelrodia reisei: $01->1$

Brittanichthys axelrodi: 01 ->

Astyanax mexicanus: $1 \rightarrow 0$

Clado 130: 1 -> 2

$1 \rightarrow 01$

Markiana nigripinnis: 1 -> 2

Hemigrammus unilineatus: $01->$

Hollandichthys multifasciatus: 01 -> 1

Hyphessobrycon compressus: 01 : $\rightarrow \odot$

Caráter 97 (32 passos)

Raiz: 2

Clado 111: 2 -> 1

Gymnotus aff. carapo: 2 -> 1

Characidium bahiensis: $1 \rightarrow 0$

Clado 148: $1 \rightarrow 0$

Clado 153: $1 \rightarrow 12$

Clado 107: $1 \rightarrow 12$

Clado 118: $1 \rightarrow 0$

Clado 157: $12 \rightarrow$

Copeina cf. guttata: $12->2$

Distichodus notospilus: $12 \rightarrow>2$

Hemistichodus vaillanti: $12 \rightarrow 1$

Nannocharax fasciatus: $12 \rightarrow 2$

Clado 165: $1 \rightarrow 01$

Roeboexodon guyanensis: 1 -> $\odot$
Erythrinoidea fam. nov: $12 \rightarrow 1$

Citharinus latus: $12 \rightarrow 2$

Xenocharax spilurus: $12->1$

Clado 123: $0 \rightarrow 2$

Aphyocharax pusillus: $01 \rightarrow 0$

Erythrinus erythrinus: $12->$

Hoplias malabaricus: $12 \rightarrow 1$

Piaractus mesopotamicus: $1 \rightarrow 2$

Paragoniates alburnus: $01->1$

Phenagoniates macrolepis: $01 \rightarrow 0$

Myleus setiger: $1->0$

Curimata ocellata: $\rightarrow 2$

Boulengerella maculata: $0 \rightarrow 1$

Rhinobrycon negrensis: $1 \rightarrow 2$

Clado 170: $1 \rightarrow 0$

Clado 194: $1 \rightarrow 0$

Clado 198: $1 \rightarrow 2$

Clado 164: 1 -> 0

Iguacladoctes geisleri: $1->0$

Astyanax mexicanus: $1 \rightarrow 0$

Clado 130: $1 \rightarrow 2$

Hemigrammus unilineatus: $12->2$

Hemigrammus unilineatus: $12->2$
Hollandichthys multifasciatus: $12 \rightarrow 1$

Hollandichthys multifasciatus: 12 ->
Hyphessobrycon compressus: 12 -> 2

Hyphessobrycon compre
Caráter 98 (15 passos)

Caráter 98

Raiz: 01 Chanos chanos: $01->1$

Catostomus commersonnii: $01->0$

Clado 104: $01 \rightarrow 1$

$\begin{array}{lll}\text { Clado 154: } & 01->0 \\ \text { Clado 108: } & 01 \text { - } & 0\end{array}$

Characidium bahiensis: 01 -> 1

Crenuchus spilurus: $01 \rightarrow 0$

Clado 142: $01 \rightarrow 0$

Clado 118: $01 \rightarrow 1$

Salminus hilarii: $01 \rightarrow 1$

Clado 113: $01 \rightarrow 1$

Brycon pesu: 01 -> 0

Clado 146: $01 \rightarrow 1$

Clado 158: $0 \rightarrow 1$

Xenocharax spilurus: $0 \rightarrow 1$

Semaprochilodus insignis: 1 -> 0

Anostomus anostomus: 1 ->

Curimata ocellata: $1 \rightarrow 0$
Microschemobrycon casiquiare: $\odot->1$

Picroschemobrycon casiquina argentea: $0 \rightarrow 1$

Piabina argentea:

Clado 164: 0 - $>1$
Caráter 99 ( 6 passos)

Raiz: $\odot$

Gymnotus aff. carapo: $\odot->1$

Lebiasina bimaculata: $\odot->1$

Eythrinoidea fam. nov: $01 \rightarrow 1$

Clado 156: $\odot \rightarrow 1$

Erythrinus erythrinus: $01->0$

Hoplias malabaricus: $01->1$

Stygichthys typhlops: $0->1$

Caráter 100 ( 5 passos)

Raiz: 1

Clado 102: 1 -> 0

Clado 109: 1 -> 01

Neolebias unifasciatus: 01 -> 1

Clado 107: $01 \rightarrow 0$

Clado 114: $01->0$

Clado 117: $01 \rightarrow 1$

Clado 121: $\theta 1 \rightarrow 0$

Clado 124: $01 \rightarrow 1$

Clado 126: $01 \rightarrow 0$

Caráter 101 (15 passos)

Raiz: $\odot$

Clado 143: $\odot \rightarrow 01$

Clado 141: $01 \rightarrow 1$

Salminus hilarii: $01 \rightarrow 0$

Clado 147: $01 \rightarrow 1$

Clado 117: $0 \rightarrow 1$

Oligosarcus argenteus: 01 ->

Clado 181: $01 \rightarrow 0$

Clado 199: $1 \rightarrow 0$

Clado 156: $1 \rightarrow 0$

Landonia latidens: 1 -> 0

Clado 184: $1 \rightarrow 01$

Glandulocauda melanogenys: 1 -> $\odot$

Odontostilbe pequira: $01 \rightarrow 0$

Clado 200: $1 \rightarrow 0$

Compsura heterura: $01->0$

Rhoadsia altipinna: $01 \rightarrow 1$

Astyanax mexicanus: $1 \rightarrow 0$

Clado 130: 1 - $>0$

Markiana nigripinnis: 1 -> 0

Clado 193: 1 - 01

Hollandichthys multifasciatus: $01->0$

Caráter 102 ( 5 passos)

Raiz: 0

Clado 175: $\odot \rightarrow 1$

Moenkhausia xinguensis: $0 \rightarrow 1$

Bryconops alburnoides: $0 \rightarrow 1$

Clado 187: 0 -> 1

Ctenobrycon hauxwellianus: $1 \rightarrow 0$

Caráter 103 ( 7 passos)

Raiz: $\odot$

Gnathocharax steindachneri: 0 -> 1

Landonia latidens: $\odot \rightarrow 1$

Clado 198: $\rightarrow 01$

Odontostilbe pequira: $0 \rightarrow 1$

Paracheirodon axelrodi: 01 -> 1 Rachoviscus graciliceps: $01->1$ Stygichthys typhlops: $01 \rightarrow 0$

Clado 130: $\odot \rightarrow 1$

Hyphessobrycon compressus: $\odot->1$

Caráter 104 (10 passos)

Raiz: 1

Clado 142: $1 \rightarrow 01$

Clado 117: $1 \rightarrow 0$

Clado 190: $01 \rightarrow$

Oligosarcus argenteus: 01 -> 0

Clado 181: $01 \rightarrow 1$

Hemistichodus vaillanti: $1 \rightarrow 0$

Clado 139: $01 \rightarrow 0$

Clado 165: $01 \rightarrow$

Clado 149: $1 \rightarrow 0$

Clado 149: $1 \rightarrow 0$

Markiana nigripinnis: $\odot->1$

Mollandichthys multifasciatus: $\odot->1$

Hollandichthys multifascior

Raiz: 01

Chanos chanos: 01 -> 0

Clado 103: 01 -> 1

Gymnotus aff. carapo: 1 -> 0

Clado 154: 1 -> 0

Characidium bahiensis: 1 -> 0

Clado 114: 1 -> $\odot$

Brycon pesu: $1 \rightarrow 0$

Clado 162: $0 \rightarrow 01$

Clado 197: $01 \rightarrow 1$
Clado 156: $1 \rightarrow 0$

Brycinus macrolepidotus: $01 \rightarrow 0$

Bryconalestes longipinnis: $01->1$

Clado 130: $1 \rightarrow 0$

Caráter 106 (20 passos)

Raiz: 0

Clado 104: 0 -> 01

Olivaichthys mesembrinus: 01 -> 1

Clado 115: $0 \rightarrow 01$

Clado 118: $01 \rightarrow 1$

Clado 190: $\odot \rightarrow 1$

Clado 150: $0 \rightarrow 1$

Citharinus latus: $\odot \rightarrow 1$

Clado 199: $\odot \rightarrow 1$

Metynnis lippincottianus: $0 \rightarrow 1$

Clado 136: 0 -> 01

Phenacogaster pectinatus: $0->1$

Diapoma terofali: $01 \rightarrow 1$

Clado 134: 01 -> 0

1 $01 \rightarrow 1$

Clado 175: $0 \rightarrow 01$

Moenkhausia xinguensis: $01->1$

Bryconamericus exodon: $\odot \rightarrow 1$

Piabina argentea: $\odot \rightarrow 1$

Deuterodon iguape: $01->$

Axelrodia reisei: $01 \rightarrow 0$

Brittanichthys axelrodi: 01 -> 1

Paracheirodon axelrodi: $01 \rightarrow 1$

Clado 131: $\odot \rightarrow 01$

Astyanax mexicanus: $01 \rightarrow 0$

Clado 189: $01 \rightarrow 1$

Rachoviscus graciliceps: 01 -> 1

Stygichthys typhlops: $01 \rightarrow 0$

Clupeacharax engrauloides: 01 -> 1

Gymnocorymbus ternetzi: $1 \rightarrow 0$

Ctenobrycon hauxwellianus: 1 -> 0

Caráter 107 ( 3 passos)

Raiz: 01

Chanos chanos: 01 ->

Clado 103: $01->1$

Erythrinoidea fam. nov: 1 -> 0

Clado 155: $1 \rightarrow 0$

Caráter 108 (8 passos)

Raiz: 01

Chanos chanos: $01 \rightarrow 1$

Clado 103: 01 - $>0$

Gymnotus aff. carapo: $\odot->1$

Clado 154: $0 \rightarrow 1$

Clado 114: $0 \rightarrow 1$

Clado 162: $1 \rightarrow 01$

Clado 197: $01 \rightarrow 0$

Clado 156: $\theta \rightarrow 1$

Brycinus macrolepidotus: $01->1$

Bryconalestes longipinnis: $01->0$

Clado 130: $0 \rightarrow 1$ 
Clado 122: 1 -> 01

Clado 125: $01 \rightarrow$

Clado 150: $0 \rightarrow>2$

Clado 120: $01 \rightarrow 01$

Clado 123: $01 \rightarrow 0$

Curimatopsis macrolepis: 012 -> 2

Clado 119: 012 -> 1

Caráter 112 (23 passos)

Raiz: 2

Clado 111: 2 -> 1

Characidium bahiensis: 1 -> 0

Clado 160: $1 \rightarrow 0$

Brycon pesu: $1->0$

Hemistichodus vaillanti: $1 \rightarrow 0$

Gnathocharax steindachneri: 1 -> 0

Erythrinoidea fam. nov: $1 \rightarrow 2$

Anodus orinocensis: $1 \rightarrow 0$

Aphyocharax pusillus: $1->0$

Acestrorhynchus falcirostris: 1 ->

Gilbertolus atratoensis: $1->0$

Metynnis lippincottianus: $\rightarrow>$

Boulengerella macula

Clado 178: $1 \rightarrow 01$

Clado 177: $01 \rightarrow 0$

Atopomesus pachyodus: 1 ->

Knodus meridae: $01 \rightarrow 0$

Piabina argentea: $01 \rightarrow 1$

Clado 132: $0 \rightarrow 01$

Compsura heterura: $1->$

Clado 164: $01 \rightarrow 1$

Astyanax mexicanus: 1 -> 0

Clupeacharax engrauloides: 01 -> $\odot$

Clado 130: $01 \rightarrow 2$

Markiana nigripinnis: 1 -> 0

Caráter 113 ( 7 passos)

Raiz: 0

Clado 115: $\odot$-> 1

Oligosarcus argenteus: $\odot->1$

Clado 125: $1 \rightarrow 0$

Clado 156: $0 \rightarrow 1$

Gilbertolus atratoensis: $0 \rightarrow 1$

Leporellus vittatus: $0 \rightarrow 1$

Clado 164: $0 \rightarrow>1$

Caráter 114 (28 passos)

Raiz: 2

Clado 111: 2 ->

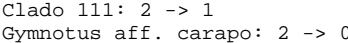

Gymnotus aff. carapo $163: 1 \rightarrow 0$

Clado 115: 1 -> 12

Clado 118: $12 \rightarrow 2$

Salminus hilarii: 1 -> 2

Saccodon wagneri: $12 \rightarrow 1$

Piabucina astrigata: 1 -> 2

Clado 139: $1 \rightarrow$

Erythrinoidea fam. nov: 1 -> 0

Citharinus latus: 1 -> 2

Clado 124: $2 \rightarrow 1$

Curimatopsis macrolepis: 2 -> 1

Paragoniates alburnus: $1 \rightarrow 0$

Gilbertolus atratoensis: 1 -> 0

Schizodon fasciatus: $2 \rightarrow 1$

Phenacogaster pectinatus: $0 \rightarrow 1$

Clado 169: $0 \rightarrow 1$

Rhinobrycon negrensis: 0 -> 1

Clado 133: $0 \rightarrow>1$

Piabina argentea: $\odot->1$

Clado 164: 1 -> 2

Stygichthys typhlops: $0 \rightarrow 1$

Thoracocharax stellatus : 1 -> 2

Carnegiella strigata: $1->0$

Clado 186: $\rightarrow 01$

orthospinus franciscoensis: $01->$

Hyphessobrycon compressus: $1->0$

Poptella brevispina: 01 - 1

Poptella brevispina:
Caráter 115 ( 7 passos)

Raiz: 01

Raiz: 01 (7) $01-1$

Clado 103: $01 \rightarrow \odot$

Clado 103: $01->0$

Salminus hilarii: $\Theta->1$

Salminus hilarii:

Clado 157: $01->1$

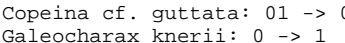

Galeocharax knerii:

Clado 145: $\odot \rightarrow 1$

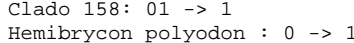

Hemibrycon polyodon :

Raiz: $\odot$

Clado 111: 0 -> 1

Bryconadenos tanaothoros: 1 -> 0

Caráter 117 (30 passos)

Raiz: 012

Chanos chanos: 012 -> 2

Clado 103: 012 -> 0

Clado 143: $0 \rightarrow 1$

Clado 106: $0 \rightarrow 1$

Clado 113: $0 \rightarrow 1$

Clado 122: $0 \rightarrow 01$

Clado 146: $1 \rightarrow 01$

Clado 162: $0 \rightarrow 1$

Clado 105: $1 \rightarrow 2$

Clado 121: $01 \rightarrow$

Gnathocharax steindachneri: 1 -> $\odot$

Charax cf. leticiae: $1 \rightarrow 2$
Clado 145: 01 -> 0

Clado 197: $1 \rightarrow 2$

Clado 123: $1 \rightarrow 2$

Clado 124: $01->1$

Aphyocharax pusillus: 1 ->

Hydrolycus tatauaia: 01 ->

Clado 149: $01 \rightarrow 2$

Phenagoniates macrolepis: 1 -> 2

Curimata ocellata: 1 -> 0

Clado 179: $1 \rightarrow 0$

Phenacogaster pectinatus: 1 -> 2

Clado 171: $1 \rightarrow 01$

Clado 170: $01 \rightarrow 0$

Clado 175: $01 \rightarrow 0$

Clado 175: $01 \rightarrow 0$

Clado 184: $01 \rightarrow 1$

Rhoadsia altipinna: $1 \rightarrow 2$

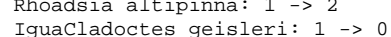

Clado 130: 1 -> 0

Agoniates halecinus: 1 -> 0

Clado 193: $2 \rightarrow 1$

Hyphessobrycon compressus: 1 -> 0

Caráter 118 (13 passos)

Raiz: 01

Chanos chanos: 01 -> 1

Catostomus commersonnii: 01 -> 1

Clado 104: $01 \rightarrow 0$

$\begin{array}{lll}\text { Clado 109: } & 01->0 \\ \text { Clado 163: } & 01 \rightarrow 1 & ->1\end{array}$

Clado 163: $01 \rightarrow 1$

Clado 143: $01 \rightarrow 0$

Clado 153: $01 \rightarrow 1$

Clado 160: $01 \rightarrow 0$

Gnathocharax steindachneri: 0 -> 1

Clado 145: $\odot \rightarrow 1$

Phenagoniates macrolepis: $0 \rightarrow 1$

Clado 175: $0 \rightarrow 01$

Clado 198: $01 \rightarrow 1$

Axelrodia reisei: $01 \rightarrow 1$

Brittanichthys axelrodi: $01->0$

Iguacladoctes geisleri: $\theta \rightarrow 1$

Clado 130: $0 \rightarrow 1$

Hyphessobrycon compressus: $0->1$

Caráter 119 (2 passos)

Raiz: 01

Chanos chanos: $01->0$

Clado 111: $01 \rightarrow 1$

Catostomus commersonnii: 01 -> 0

Clado 104: $01 \rightarrow 1$

Caráter 120 (10 passos)

Raiz: 01

Clado 104: $01 \rightarrow 0$

Clado 163: $01>1$

Clado 108: $01 \rightarrow 1$

Clado 115: $01 \rightarrow 0$

$\begin{array}{lll}\text { Clado 160: } & 01->1 \\ \text { Clado 141: } & 01->1\end{array}$

Salminus hilarii: $01 \rightarrow 0$

Clado 157: $01 \rightarrow 0$

Brycon pesu: $01 \rightarrow 1$

Clado 146: $01 \rightarrow 0$

Copeina cf. guttata: $01->1$

Clado 151: $01 \rightarrow \odot$

Charax cf. leticiae: $01 \rightarrow$

Galeocharax knerii: 01 -> 0

Citharinus latus: $1 \rightarrow 0$

Gilbertolus atratoensis: $\odot->1$
Triportheus albus: $1 \rightarrow \odot$

Caráter 121 (4 passos)

Raiz: 1

Clado 111: 1 ->

Clado 114: $0 \rightarrow 1$

Clado 155: $\theta \rightarrow 1$

Clado 127: $\rightarrow>1$

Caráter 122 ( 6 passos)

Caráter 12

Catostomus commersonnii: $1 \rightarrow 0$

Clado 151: 1 -> 0

Curimatopsis macrolepis: 1 -> 0

Clado 155: $1 \rightarrow 0$

Glandulocauda melanogenys: 1 -> 0

Astyanax mexicanus: $1->0$

Caráter 123 (11 passo)

Raiz: 1

Clado 111: $1 \rightarrow 0$

Clado 153: 0 -> 01

Brycon pesu: $\odot \rightarrow$

Copeina cf. guttata: 01 -> 1

Lebiasina bimaculata: $01 \rightarrow 0$

Piabucina astrigata: $01 \rightarrow 1$

Clado 161: $\odot \rightarrow 1$

Clado 126: $\Theta \rightarrow$

Clado 156: $\odot \rightarrow 01$

Hepsetus odoe: $01->1$

Leporellus vittatus: 1 -> 0

Stygichthys typhlops: $0 \rightarrow$

Agoniates halecinus: $0 \rightarrow 1$

Clado 129: 0 -> 1

Caráter 124 (19 passos)

Raiz: 01

Chanos chanos: $01 \rightarrow 0$

Clado 103: $01 \rightarrow 1$

Arnoldichthys spilopterus: $1->0$

Hemistichodus vaillanti: $1 \rightarrow 0$

Citharinus latus: 1 -> $\odot$

Clado 199: $1 \rightarrow 0$

Clado 149: $1 \rightarrow 0$

Brycinus macrolepidotus: 1 -> $\odot$

Clado 128: 0 -> 1

Potamorhina latior: $0->1$

Hemibrycon polyodo

Microschemobrycon casiquiare: 1 -> 0

Paracheirodon axelrodi: 1 -> $\odot$

Rhoadsia altipinna: $1 \rightarrow 0$

Clado 189: 1 -> 0

Clupeacharax engrauloides: 1 -> 0

orthospinus franciscoensis: $\odot->$

Caráter 125 ( 6 passos)

Raiz: $\odot$

Gymnotus aff. carapo: $\odot \rightarrow 1$

Clado 153: $\odot \rightarrow 1$

Salminus hilarii: $0 \rightarrow 1$

Hydrolycus tatauaia: $0->1$

Semaprochilodus insignis: $0->$

Bryconops alburnoides:

Caráter 126

Crenuchus spilurus: 1 -> 0

Clado 159: $1 \rightarrow 01$

Brycon pesu: $1 \rightarrow 0$

Arnoldichthys spilopterus: $01->0$

Clado 161: $01 \rightarrow 0$

Clado 197: $01 \rightarrow 1$

Clupeacharax engrauloides: 1 -> 0

Agoniates halecinus: $1 \rightarrow 0$

Caráter 127 ( 6 passos)

Raiz: 01

Chanos chanos: $01->0$

Clado 103: $01 \rightarrow 1$

Clado 153: $1 \rightarrow 0$

Clado 182: 1 -> 01

Oligosarcus argenteus: $01 \rightarrow 0$

Charax cf. leticiae: $01 \rightarrow 1$

Galeocharax knerii: $01 \rightarrow 0$

Hydrolycus tatauaia: $1 \rightarrow$

Clado 132: $1 \rightarrow 0$

Caráter 128 ( 19 passos)

Raiz: 0

Clado 108: $\odot \rightarrow 1$

Salminus hilarii: $0 \rightarrow 1$

Clado 151: $0 \rightarrow 01$

Gnathocharax steindachneri: 0 -> 1

Clado 158: $01 \rightarrow 1$

Citharinus latus: $1 \rightarrow 0$

Clado 123: $0 \rightarrow 1$

Clado 156: $0 \rightarrow 1$

Serrabrycon magoi: $0->1$

Myleus setiger: $0 \rightarrow 1$

Diapoma terofali: $\rightarrow$

Clado 168: $0 \rightarrow 01$

Moenkhausia xinguensis: $01->1$

Knodus meridae: $0 \rightarrow 1$

Clado 198: $\odot \rightarrow 1$

Deuterodon iguape: 01 -> 1

Bryconops alburnoides: $0->1$

Astyanax mexicanus: $01 \rightarrow 0$

Clupeacharax engrauloides: $\odot$-> 1

Clado 192: $01 \rightarrow 1$

Markiana nigripinnis: 01 -> 0

Tetragonopterus argenteus: $01->1$

Hyphessobrycon compressus: $1 \rightarrow 0$

Caráter 129 ( 3 passos)

Raiz: 0

Clado 151: $\odot \rightarrow->1$

Clado 158: $01 \rightarrow 01$

Acestrorhynchus falcirostris: 0 -> 2

Clado 149: $0 \rightarrow 1$

Caráter 130 ( 9 passos)

Raiz: 0

Clado 111: $\odot->01$

Clado 109: $01 \rightarrow 0$

Clado 163: 01 -> 1

Clado 143: $01 \rightarrow 1$

Clado 160: $01 \rightarrow 1$

Clado 157: $01 \rightarrow$

Copeina cf. guttata: $01->0$

Clado 105: $\odot \rightarrow 1$

Clado 158: 01 -> 1

Anodus orinocensis: 0 ->

Clado 123: $\odot \rightarrow 1$ 
Clado 197: 01 -> 2

Aphyocharax pusillus: 2 -> 1

Clado 156: 2 -> 012

Hepsetus odoe: 012 -> $\odot$

Gilbertolus atratoensis: 2 -> $\odot$

Leporinus fasciatus: $0 \rightarrow 1$

Clado 132: 2 -> 12

Brittanichthys axelrodi: 2 -> 0

Paracheirodon axelrodi: 2 -> 1

Clado 131: 12 -> 1

Agoniates halecinus: $12 \rightarrow 1$

Triportheus albus: $12 \rightarrow 2$

Markiana nigripinnis: 2 -> 1

Caráter 132 (15 passos)

Raiz: $\odot$

Raiz: 0 : 0 - 012

Clado 109: $012 \rightarrow->1$

Clado 163: $012 \rightarrow 2$

Clado 163: $012 \rightarrow>$

Salminus hilarii: $0->1$

Clado 159: $\odot \rightarrow 01$

Clado 117: $1 \rightarrow 0$

Piabucina astrigata: 2 -> 1

Arnoldichthys spilopterus: 01 -> 1

Distichodus notospilus: 1 -> 2

Clado 161: $01 \rightarrow 1$

Clado 197: 01 - $>$

Citharinus latus: $1 \rightarrow 0$

Hydrolycus tatauaia: $0 \rightarrow 1$

Clado 128: $1 \rightarrow 0$

Paracheirodon axelrodi: $\odot->1$

Clado 130: $0 \rightarrow 1$

Hollandichthys multifasciatus: $\odot->1$

Caráter 133 (20 passos)

Raiz: 0

Clado 163: $\odot \rightarrow 1$

Clado 153: $0 \rightarrow>02$

Clado 141: $\odot \rightarrow 02$

Clado 147: $0 \rightarrow 02$

Clado 152: $02 \rightarrow 012$

Clado 140: $02 \rightarrow 2$

Brycon pesu: 02 -> 2

Copeina cf. guttata: $012 \rightarrow 2$

Lebiasina bimaculata: $02 \rightarrow>2$

Lebiasina bimaculata: $02 \rightarrow$

Arnoldichthys spilopterus: $\odot \rightarrow 1$

Arnoldichthys spilopterus: $0->1$

Gnathocharax steindachneri: $02->$

Roeboexodon guyanens

$\begin{array}{lll}\text { Clado } 145: & 02->012 \\ \text { Clado } 158: & 012 \rightarrow>1\end{array}$

$\begin{array}{lll}\text { Clado 158: } & 012 & ->1 \\ \text { Clado 156: } & 012 \rightarrow>1\end{array}$

Hydrolycus tatauaia: $02->0$

Clado 149: $02 \rightarrow 2$

Clado 149: $02->2$

$\begin{array}{lll}\text { Clado 196: } & 0 & \rightarrow> \\ \text { Clado } 172: & 2 & \rightarrow>0\end{array}$

Paragoniates alburnus: 2 ->

Paragoniates albur

Clado 178: 2 - $\rightarrow$
Axelrodia reisei: $\odot \rightarrow>2$

Axelrodia reisei: $0->2$
Compsura heterura: $0 \rightarrow>2$

Compsura heterura: $0 \rightarrow 2$

Clupeacharax engrauloides:

Clado 192: $2 \rightarrow 0$

Gymnocorymbus ternetzi: 2 -> $\odot$

Caráter 134 (23 passos)

Raiz: 01

Chanos chanos: $01->1$

Clado 103: 01 ->

Gymnotus aff. carapo: $0 \rightarrow 1$

Crenuchus spilurus: $0->1$

Clado 153: $0 \rightarrow 01$

Clado 118: $0 \rightarrow 01$

Clado 141: $\odot \rightarrow 1$

Clado 152: $01 \rightarrow 1$

Brycon pesu: $0 \rightarrow$

Lebiasina bimaculata: $01->1$

Piabucina astrigata: $01->0$

Distichodus notospilus: $0 \rightarrow 1$

Bivibranchia fowleri: $01->1$

Bivibranchia fowle

Clado 116: $01 \rightarrow>$

Clado 125: $01 \rightarrow>1$

Clado 149: $0 \rightarrow 1$

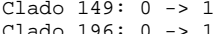

Clado 119: $01 \rightarrow 0$

Paragoniates alburnus: $1->0$

Clado 171: $1 \rightarrow 0$
Leporellus vittatus: $1 \rightarrow 0$

Clado 178: $1->0$

Clado 189: 1 -> 01

Clupeacharax engrauloides: 1 ->

Agoniates halecinus: $1 \rightarrow 0$

Clado 192: $01 \rightarrow 0$

Clado 187: $01 \rightarrow 0$

Clado 195: $01 \rightarrow 1$

Ctenobrycon hauxwellianus: 0 -> 1

Caráter 135 ( 5 passos)

Raiz: 0

Distichodus notospilus: $0 \rightarrow 1$

Nannocharax fasciatus: $0 \rightarrow 1$

Clado 125: $0 \rightarrow 01$

Clado 126: $01 \rightarrow 1$

Caenotropus labyrinthicus: 01 -> 1

Chilodus punctatus: $01 \rightarrow 0$

Clado 155: $\odot \rightarrow 1$

Caráter 136 (15 passos)

Raiz: $\odot$
Olivaichthys mesembrinus: 0 -> 1

Clado 147: $\odot \rightarrow 01$

Brycon pesu: 01 -> 1

Gnathocharax steindachneri: 0 -> 1

Clado 199: $0 \rightarrow 1$

Acestrorhynchus falcirostris: $01 \rightarrow 1$

Clado 156: 01 - $>0$

Hydrolycus tatauaia: $01->0$

Clado 149: 01 -> 1

Hoplias malabaricus: 0 -> 1

Piaractus mesopotamicus: $\Theta \rightarrow 1$

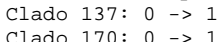

Diapoma terofali: $1 \rightarrow \theta$

Clado 167: $1 \rightarrow 0$

Piabina argentea: $1 \rightarrow 0$

Iguacladoctes geisleri: $1 \rightarrow 0$

Markiana nigripinnis: $0 \rightarrow 1$

Caráter 137 (18 passos)

Raiz: $\odot$

Clado 104: 0 -> 1

Neolebias unifasciatus: $0->1$

Clado 151: $0 \rightarrow 01$

Citharinus latus: $0->1$

Citharinus latus:

Clado 173: $0 \rightarrow 01$

Clado 199: 0 -> 1 : $1 \rightarrow 1$

Phenacogaster pectinatus: $01->0$

Rhinobrycon negrensis: $0 \rightarrow 1$

Clado 170: $01 \rightarrow 1$

Clado 175: 01 -> 0

Glandulocauda melanogenys: $\odot$-> 1

Piabina argentea: $0 \rightarrow 1$

Odontostilbe pequira: $01 \rightarrow 1$

Compsura heterura: $01 \rightarrow 0$

Rhoadsia altipinna: $01->1$

Iguacladoctes geisleri: $0->1$

Rachoviscus graciliceps: $0->1$

Clado 192: $0 \rightarrow 1$

Tetragonopterus argenteus: $0 \rightarrow 1$

Hollandichthys multifasciatus: $1 \rightarrow 0$

Poptella brevispina: $0 \rightarrow 1$

Caráter 138

Raiz: 01

Chanos chanos: $01 \rightarrow 0$

Catostomus commersonnii: $01->1$

Clado 144: $01 \rightarrow 0$

Clado 109: 01 -> 1

Characidium bahiensis: 01 -> 1

Crenuchus spilurus: $01 \rightarrow 0$

Clado 182: $0 \rightarrow 1$

Distichodus notospilus: $1->0$

Nannocharax fasciatus: $1 \rightarrow 0$

is: $0 \rightarrow 1$

Clado 145: $\odot \rightarrow 1$

Clado 126: $1 \rightarrow 0$

Clado 196: $\odot \rightarrow 1$

Clado 172: 0 -> 01

Phenacogaster pectinatus: 01 -> 1

Ctenolucius hujeta: $1 \rightarrow \odot$

Clado 170: $01 \rightarrow 0$

Clado 176: $01->1$

Diapoma terofali: $0 \rightarrow 1$

Clado 168: $\odot \rightarrow 1$

Agoniates halecinus: $\odot \rightarrow 1$

Markiana nigripinnis: 1 ->

Caráter 139 (30 passos)

Raiz: 2

Clado 109: 2 -> 1

Clado 154: 2 ->

Neolebias unifasciatus: $1 \rightarrow \theta$

Salminus hilarii: $2 \rightarrow 1$

Clado 181: $2 \rightarrow 1$

Distichodus notospilus: $1->0$

Apareiodon piracicabae: 1 -> 0

Anodus orinocensis: 1 -> 2

Clado 126: $1 \rightarrow 2$

Clado 138: 2 -> 12

Clado 199: $2 \rightarrow 012$

Clado 156: $2 \rightarrow 1$

Hydrolycus tatauaia: $2 \rightarrow 0$

Clado 137: $12 \rightarrow 1$

Paragoniates alburnus: $012->1$

Phenagoniates macrolepis: $012 \rightarrow 0$

Myleus setiger: $1->0$

Phenacogaster pectinatus: $02->0$

Clado 176: 02 -> 012

$\begin{array}{lll}\text { Clado 168: } & 1 \rightarrow 0 \\ \text { Clado 194: } & 1 \rightarrow 0\end{array}$

Atopomesus pachyodus: $02->0$

Microschemobrycon casiquiare: $02->2$

Clado 175: $012 \rightarrow 01$

Bryconadenos tanaothoros: 1 -> 2

Clado 198: 01 -> 1

Odontostilbe pequira: 012 -> 0

Clado 166: $\odot \rightarrow 2$

Axelrodia reisei: $01 \rightarrow 1$

Brittanichthys axelrodi: $01->0$

Compsura heterura: $012 \rightarrow 2$

Rhoadsia altipinna: 012 ->

Clado 164: $1 \rightarrow 2$

Iguacladoctes geisleri: $1 \rightarrow 0$

clado 186:2 $>$ : 1

Tetragonopterus argenteus: $2 \rightarrow 1$

Tetragonopterus a

Caráter 140 (11 passo)

Raiz:

Clado 148: $\odot \rightarrow->1$

Salminus hilarii: $01 \rightarrow 1$

Brycon pesu: $01 \rightarrow 0$

Hemistichodus vaillanti: $0->1$

Roeboexodon guyanensis: $\odot \rightarrow 1$

Clado 161: $\Theta \rightarrow 1$

Clado 123: $0 \rightarrow 1$

Acestrorhynchus falcirostris: $01 \rightarrow 1$

Hydrolycus tatauaia: $01 \rightarrow 1$

Clado 149: $01 \rightarrow 0$

Erythrinus erythrinus: $\Theta->1$

Hepsetus odoe: $01 \rightarrow 1$

Clado 155: 01 - $>0$

Agoniates halecinus: $0->1$

$\begin{array}{lll}\text { Agoniates halecinus: } 0 & -> & 1 \\ \text { Probolus heterostomus : } & 0 & ->1\end{array}$

Caráter 141 (15 passos)

Raiz: 01

Chanos chanos: $01->1$

Clado 103: $01 \rightarrow 0$

Clado 141: $0 \rightarrow 1$

Clado 147: $0->1$

Hemistichodus vaillanti: $0->1$

Bivibranchia fowleri: $01->$

Anodus orinocensis: $01->1$
Hemiodus unimaculatus : $01->0$

Hemiodus unimaculatu
Clado 199: $1 \rightarrow 0$

Clado 156: $1 \rightarrow 0$

Clado 172: $1 \rightarrow 0$

Rhinobrycon negrensis: 1 -> 0

Clado 134: $1 \rightarrow 0$

Odontostilbe pequira: $\odot \rightarrow 1$

Clado 200: $\odot \rightarrow 01$

Clado 164: $\odot \rightarrow 1$

Rachoviscus graciliceps: 01 -> 1

Clado 193: 1 -> 6

Caráter 142 (19 passos)

Raiz: 1

Clado 102: 1 -> 01

Catostomus commersonnii: 01 -> $\odot$

Clado 163: $1 \rightarrow 0$

Clado 142: $1 \rightarrow 01$

Clado 182: $01 \rightarrow 0$

Clado 140: $01 \rightarrow>0$

Clado 190: $01 \rightarrow 1$

Curimatopsis macrolepis: $01->$

Caenotropus labyrinthicus: $1 \rightarrow 0$

Anostomus anostomus: $1 \rightarrow 0$

Phenagoniates macrolepis: $0 \rightarrow 1$

Hepsetus odoe: $1 \rightarrow 0$

Curimata ocellata: $01->$

Potamorhina latior: $01 \rightarrow 1$

Clado 176: $\odot \rightarrow 01$

Diapoma terofali: $\odot->1$

Clado 194: $\odot \rightarrow 1$

Clado 184: 01 ->

Clado 167: $\Theta \rightarrow 1$

Axelrodia reisei: $01 \rightarrow 0$

Brittanichthys axelrodi: 01 -> 1

Paracheirodon axelrodi: $01 \rightarrow 0$

Bryconops alburnoides: $\odot->1$

Rachoviscus graciliceps: $01>1$

Triportheus albus: $0 \rightarrow 1$

Hyphessobrycon compressus: $1->0$

Caráter 143 ( 5 passos)

Raiz: 0

Clado 149: $\odot \rightarrow->$

Metynnis lippincottianus: $0->1$

Clado 198: $\odot \rightarrow 01$

Bryconops alburnoides: $\odot->1$

Rachoviscus graciliceps: $01->1$

Triportheus albus: $0 \rightarrow 1$

Caráter 144 (8 passos)

Carater

Clado 182: $\odot \rightarrow 1$

Salminus hilarii: $0 \rightarrow 1$

Apareiodon piracicabae: $0 \rightarrow 1$

Gnathocharax steindachneri: $0 \rightarrow 1$

Anodus orinocensis: $0 \rightarrow 1$

Hydrolycus tatauaia: $0 \rightarrow 2$ 
Clado 178: $01 \rightarrow 1$

Clado 174: $0 \rightarrow 1$

Odontostilbe pequira: $0->$

Clupeacharax engrauloides: 0 -> 1

Triportheus albus: $0 \rightarrow 1$

Hyphessobrycon compressus: 1 -> $\odot$

Caráter 146 (32 passos)

Raiz: 013

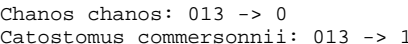

Clado 144: $013 \rightarrow 3$

Clado 109: $013 \rightarrow 0123$

Crenuchus spilurus: 013 -> 3

Neolebias unifasciatus: $0123 \rightarrow 3$

Clado 118: 0123 -> 123

Clado 159: 3 -> 2

Clado 106: 0123 -> 02

Copeina cf. guttata: $3->2$

Lebiasina bimaculata: 3 -> 0

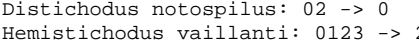

Nannocharax fasciatus: $0123 \rightarrow->$

Nannocharax fasciatus: $0123->1$

Apareiodon piracicabae:

Bivibranchia fowleri: 123 -> 2

Clado 125: $123 \rightarrow 2$

Clado 161: $2 \rightarrow 012$

Citharinus latus: $02->0$

Xenocharax spilurus: $02->2$

Anodus orinocensis: $123->3$

Hemiodus unimaculatus : $123 \rightarrow 1$

Clado 123: $123->1$

Brycinus macrolepidotus: 012 -> 1

Bryconalestes longipinnis: $012 \rightarrow$

Curimatopsis macrolepis: $0123 \rightarrow 3$

Phenagoniates macrolepis: $3 \rightarrow 2$

Metynnis lippincottianus: $2 \rightarrow 1$

Curimata ocellata: $0123 \rightarrow 0$

Potamorhina latior: $0123 \rightarrow 2$

Schizodon fasciatus: $2 \rightarrow 0$

Clado 179: $3 \rightarrow 2$

Phenacogaster pectinatus: $3 \rightarrow 0$

Moenkhausia xinguensis: $3 \rightarrow 2$

Clado 183: $3 \rightarrow 2$

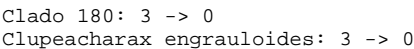

Clupeacharax engr

Hemigrammus unilineatus: $3 \rightarrow 2$

Caráter 147 ( 5 passos)

Raiz: $\odot$

Raiz: $\odot$ halminus hilarii: $\odot->$

Salminus hilarii: $\odot \rightarrow$

Clado 123: $0->1$ Piaractus mesopotamicus: $0 \rightarrow 1$

Piaractus mesopota

Clado 155: $\odot->1$
Bryconops alburnoides: $\odot \rightarrow 1$

Bryconops alburnoides:

Raiz: 0

Chalceus epakros: $\odot->1$

Clado 117: $\odot \rightarrow 01$

Brycon pesu: $0 \rightarrow 1$

Copeina cf. guttata: $0->1$

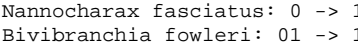

Clado 139: $0 \rightarrow 1$

Charax cf. leticiae: $\odot->1$

Clado 161: 0 -> 1

Xenocharax spilurus: $0 \rightarrow 1$

Anodus orinocensis: $01 \rightarrow 1$

Hemiodus unimaculatus : $01 \rightarrow 0$

Clado 124: $0 \rightarrow 1$

Semaprochilodus insignis: $\odot->1$

Myleus setiger: $0 \rightarrow 1$

Potamorhina latior: $0->1$

Potamorhina latior
Clado 127: $0->1$
Clado 17801

Diapoma terofali: $1 \rightarrow 0$

Clado 177: $01 \rightarrow \odot$

Clado 184: 1 -> 01

Knodus meridae: $01->1$

Piabina argentea: $01 \rightarrow$

Piabina argentea: $01->0$

Odontostilbe pequira: $01 \rightarrow$

Compsura heterura: $01 \rightarrow 1$

$\begin{array}{lll}\text { Rhoadsia altipinna: } 01 & -> & 0 \\ \text { Iguacladoctes geisleri: } 1 & ->0\end{array}$

Iguacladoctes geisleri: $1->0$
Clado 129: $1->01$
Gasteropelecus sternicla: $01->$

Gasteropelecus sternicla: 01
Markiana nigripinnis: 1 -> 0

Markiana nigripinnis:
Caráter 149 (23 passos)

Raiz: 01

Chanos chanos: 01 ->

Clado 111: 01 -> 1

Catostomus commersonnii: $01 \rightarrow \odot$

Olivaichthys mesembrinus: $01 \rightarrow$

Clado 108: $1 \rightarrow 0$

Clado 122: $1 \rightarrow 0$

Clado 140: $1 \rightarrow 01$

Copeina cf. guttata: $1 \rightarrow 0$

Lebiasina bimaculata: $1 \rightarrow 0$

Clado 105: $\rightarrow$

Hemiodus unimaculatus : $1 \rightarrow$

Aphyocharax pusillus: $01 \rightarrow 0$

Landonia latidens: $01 \rightarrow 0$

Serrabrycon magoi: $01->1$
Paragoniates alburnus: 01 -> 1 Phenagoniates macrolepis: $01 \rightarrow 0$ Myleus setiger: $1->$

Clado 136: $01 \rightarrow 1$

Phenacogaster pectinatus: 01 -> 0

Clado 171: 01 -> 1

Moenkhausia xinguensis: 1 -> 0

Bryconamericus exodon: $0 \rightarrow 1$

Clado 183: 1 -> 0

Paracheirodon axelrodi: 1 -> 0

Iguacladoctes geisleri: $1 \rightarrow$

clado 130: $1 \rightarrow 0$

Triportheus albus: $1 \rightarrow 0$

Tetragonopterus argenteus: $1 \rightarrow 0$

Ctenobrycon hauxwellianus: $1 \rightarrow 0$

Caráter 150 (8 passos)

Raiz: $\odot$

Brycon pesu: $\odot->1$

Piabucina astrigata: $0 \rightarrow 1$

Charax cf. leticiae: $0 \rightarrow 1$

Clado 197: $\odot \rightarrow 01$

$\begin{array}{lll}\text { Clado 123: } & 0 & ->1 \\ \text { Clado 149: } & 0 & \rightarrow>01\end{array}$

Piaractus mesopotamicus: 01 -> 1

Roestes molossus: 01 -> 1

Metynnis lippincottianus: $01->$

Myleus setiger: $01 \rightarrow 1$

Agoniates halecinus: $\odot->1$

caráter 151 (10 passos)

Raiz: 0

Catostomus commersonnii: $\Theta->1$

Gnathocharax steindachneri: $0->1$

Erythrinoidea fam. nov: $0 \rightarrow 1$

Aphyocharax pusillus: $0 \rightarrow 1$

Clado 155: $0 \rightarrow 1$

Clado 175: $0 \rightarrow 01$

Piabina argentea: $\odot \rightarrow 1$

Clado 198: 01 -> 1

Axelrodia reisei: $01 \rightarrow 1$

Brittanichthys axelrodi: $01->$

Rhoadsia altipinna: $\theta \rightarrow 1$

Clado 131: $\odot \rightarrow 01$

Carnegiella strigata: 01 -> 1

Caráter 152 (15 passos)

Raiz: 0

Clado 154: $0 \rightarrow 01$

Clado 153: 01 -> 1

Clado 118: 0 -> 01

Chalceus epakros: $01 \rightarrow 0$

Clado 159: $01 \rightarrow 1$

Clado 117: $01 \rightarrow 1$

Citharinus latus: $\odot->1$

Clado 124: 01 ->

Clado 156: 0 -> 01

Erythrinus erythrinus: 1 -> 0

Curimatopsis macrolepis: $01 \rightarrow$

$\begin{array}{lll}\text { Prochilodus nigricans: } 01 \quad->1 \\ \text { Semaprochilodus insignis: } 01 & \rightarrow>0\end{array}$

Semaprochilodus insignis: 01

Anostomus anostomus: $01->0$

Hepsetus odoe: $01->1$

Curimata ocellata: $01 \rightarrow 1$

Potamorhina latior: $01 \rightarrow 0$

Schizodon fasciatus: $01 \rightarrow$

Leporellus vittatus: $01->1$

Leporinus fasciatus: $01->0$

Bryconops alburnoides: $0 \rightarrow 1$

Astyanax mexicanus: $0 \rightarrow 1$

Triportheus albus: $0 \rightarrow 1$

Caráter 153 (24 passos)

Raiz: 2

Clado 109: $2 \rightarrow 1$

Clado 157: $2 \rightarrow 12$

Clado 159: $2 \rightarrow 1$

Clado 159: $2 \rightarrow 1$

Copeina cf. guttata: 2 -> $\odot$

Lebiasina bimaculata: $12 \rightarrow 1$

Clado 139 : bimacu

Citharinus latus: 1 -> 0

Hemiodus unimaculatus : $1 \rightarrow$

Clado 149: $2 \rightarrow 1$

Brycinus macrolepidotus: 1 -> 0

Clado 196: 1 -> 01

Clado 119: $0 \rightarrow 012$

Myleus setiger: $01 \rightarrow 0$

Curimata ocellata: $012->1$

Clado 127: $0 \rightarrow 1$

Clado 176: $1 \rightarrow$

Diapoma terofali: 1 -> 2

Microschemobrycon casiquiare: 1 -> 2

Clado 167: 1 ->

Bryconadenos tanaothoros: 1 -> 0

Knodus meridae: 1 -> 2

Bryconops alburnoides: 1 -> 0

Astyanax mexicanus: $0 \rightarrow 2$

Agoniates halecinus: $1 \rightarrow 2$

Orthospinus franciscoensis: 0 -> 1

Caráter 154 (10 passos)

Raiz: 0

Clado 154: $\theta \rightarrow 1$

Clado 115: $0 \rightarrow 1$

Clado 162: $1 \rightarrow 01$

Clado 145: $\rightarrow \rightarrow 1$

Citharinus latus: 0

Brycinus macrolepidotus: 01 ->

Bryconalestes longipinnis: $01->1$

Piaractus mesopotamicus: $01 \rightarrow 0$

Clado 128: 1 -> 01

Metynnis lippincottianus: 01 -> $\odot$

Myleus setiger: $01 \rightarrow 1$

Clado 127: $01 \rightarrow 0$

Triportheus albus: $0 \rightarrow 1$

Caráter 155 (24 passos)

Raiz: 1

Clado 163: $1 \rightarrow 01$

Clado 143: 1 -> 12

Crenuchus spilurus: 01 -> 0

Clado 141: $12 \rightarrow 2$

Clado 182: $12->1$

Chalceus epakros: 1 -> 2

Clado 106: 1 -> 2

Brycon pesu: 12 -> 2

Bivibranchia fowleri: 1 -> 0

Clado 125: $1 \rightarrow 01$

Clado 145: $12 \rightarrow 1$

Clado 124: $01 \rightarrow$

Hydrolycus tatauaia: 12 -> 2

Clado 149: 12 -> 1

Erythrinus erythrinus: 1 -> 0

Semaprochilodus insignis: $1->2$

Anostomus anostomus: $01 \rightarrow 0$

Paragoniates alburnus: $2 \rightarrow$

Potamorhina latior: 1 -> $\odot$

Schizodon fasciatus: $01 \rightarrow 1$

Clado 171: 2 - 02

Leporellus vittatus: 01 -> 1

Leporinus fasciatus: $01->0$

Rhinobrycon negrensis: $2 \rightarrow 0$

Clado 134: $2 \rightarrow 0$

Hemibrycon polyodon : $2->1$

Atopomesus pachyodus: $02->2$

Microschemobrycon casiquiare: $02->0$

Knodus meridae: $2 \rightarrow$

Odontostilbe pequira: $02->0$

Brittanichthys axelrodi: $02->0$

Compsura heterura: $02->2$

Bryconops alburnoides: $0->1$

Clado 195: $2 \rightarrow 0$

Caráter 156 (17 passos)

Raiz: $\odot$

Clado 114: $0 \rightarrow 01$

Clado 113: 01 -> 1

Clado 181: $0 \rightarrow 01$

Arnoldichthys spilopterus: $\odot \rightarrow-1$

Distichodus notospilus: $0 \rightarrow 1$

Galeocharax knerii: $01 \rightarrow 1$

Hemiodus unimaculatus : $0 \rightarrow 2$

Clado 124: $0 \rightarrow 1$

Hydrolycus tatauaia: $\odot->1$

Bryconalestes longipinnis: 0 -> 1

Clado 119: $\odot \rightarrow 01$

Semaprochilodus insignis: $0 \rightarrow 2$

Curimata ocellata: $01 \rightarrow 1$

Clado 127: 0 - $\rightarrow 012$

Leporellus vittatus: $012 \rightarrow 2$

Leporinus fasciatus: $012 \rightarrow 1$

Clado 175: $\odot \rightarrow 01$

Bryconamericus exodon: 0 -> 1

Brittanichthys axelrodi: $01 \rightarrow 1$

Bryconops alburnoides: $0->1$
Tetragonopterus argenteus: $0 \rightarrow 1$

Caráter 157 (16 passos)

Raiz: 0

Clado 148: $\odot \rightarrow 1$

Clado 160: $\odot \rightarrow 01$

Clado 118: $0 \rightarrow 1$

Chalceus epakros: $01 \rightarrow 1$
Clado 181: $\odot \rightarrow 01$

Arnoldichthys spilopterus: $01->0$

Clado 162: 01 -> 1

Roeboexodon guyanensis: $\odot$-> 1

Galeocharax knerii: $01 \rightarrow 1$

Acestrorhynchus falcirostris: $1>0$

Hoplias malabaricus: $0 \rightarrow 1$

Chilodus punctatus: 1 -> 0

Clado 169: $0 \rightarrow 01$

Hemibrycon polyodon : $01->1$

Moenkhausia xinguensis: $01 \rightarrow 1$

Clado 167: $01 \rightarrow 0$

Clado 132: $\odot \rightarrow 01$

Clado 164: 01 -> 1 
Clado 141: 01 -> 1

Clado 182: $01 \rightarrow$

Clado 113: $01 \rightarrow 1$

Piabucina astrigata: $\odot$-> 1

Clado 105: 0 -> 01

Bivibranchia fowleri: 01 -> 1

Xenocharax spilurus: $01 \rightarrow 1$

Anodus orinocensis: $01 \rightarrow 1$

Hemiodus unimaculatus : $01 \rightarrow 0$

Erythrinus erythrinus: $\Theta->1$

Piaractus mesopotamicus: $0->1$

Semaprochilodus insignis: $0>1$

Phenagoniates macrolepis: $1 \rightarrow \odot$

Clado 171: $1 \rightarrow 01$

Clado 176: $01->0$

Atopomesus pachyodus: $01->0$

Microschemobrycon casiquiare: 01 -

Knodus meridae: $1 \rightarrow 0$

Iguacladoctes geisleri: $1>\odot$

Markiana nigripinnis: $1->0$

caráter 160 ( 3 passos)

Raiz: 1

Copeina cf. guttata: $1 \rightarrow 0$

Piabucina astrigata: $1 \rightarrow 0$

Schizodon fasciatus: 1 ->

Caráter 161 (11 passo)

Raiz: $\odot$

Clado 144: $\odot \rightarrow$

Clado 141: $1>0$

Clado 159: $1 \rightarrow 01$

Clado 146: 1 -> 01

Arnoldichthys spilopterus: $01 \rightarrow 0$

Charax cf. leticiae: $1 \rightarrow 0$

Clado 150: $01 \rightarrow$

Clado 161: $01 \rightarrow 1$

Clado 197: 01 ->

Anodus orinocensis: $0 \rightarrow$

Acestrorhynchus falcirostris: $01 \rightarrow 0$

Clado 156: 01 -> 1

Anostomus anostomus: $0 \rightarrow 1$

Paragoniates alburnus: $0->1$

Leporinus fasciatus: $\odot \rightarrow 1$

Caráter 162 (20 passos)

Raiz: 2 : $2 \rightarrow 12$

Clado 102: $2 \rightarrow 12$

Clado 104: $12 \rightarrow>$

Clado 163: $2 \rightarrow 1$

Copeina cf. guttata: $012 \rightarrow>0$

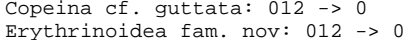

Erythrinoidea fam. nov

Curimatopsis macrolepis: 2 -> 01

Chilodus punctatus: $2 \rightarrow$

Clado 172: 2 -> 1

Roestes molossus: $2 \rightarrow 1$

Rhinobrycon negrensis: 2 -> 0

Microschemobrycon casiquiare: $1->2$

Clado 175: $1 \rightarrow 0$

Iguacladoctes geisleri: 2 -> 1

Clado 130: $2 \rightarrow 01$

Clado 192: 2 -> 12

Thoracocharax stellatus : $01 \rightarrow$

Probolus heterostomus : $12 \rightarrow 1$

Carnegiella strigata: 01 -> 0

Gasteropelecus sternicla: 01 -> 1

Hemigrammus unilineatus: $12 \rightarrow 1$

Hollandichthys multifasciatus: $12 \rightarrow 2$

Caráter 163 (1 passo)

Raiz: 0

Clado 114: $0 \rightarrow 1$

Caráter 164 ( 2 passos)

Raiz: $\odot$

Erythrinus erythrinus: $\odot \rightarrow 1$

Erythrinus erythrinus: $0->$

Caráter 165 (26 passos)

Raiz: 12

Clado 144: 12 -> 2

Clado 144: $12 \rightarrow 012$

Characidium bahiensis: 12 -> 1

Clado 107: $12 \rightarrow 1$

Cladminus hilarii: 2 ->

Salminus hilarii: 2

Clado 159: $2 \rightarrow 02$
Clado 122: $012 \rightarrow>02$

Clado 122: $012 \rightarrow 0$

Clado 190: 2 -> 12

Clado 181: $2 \rightarrow 02$

Arnoldichthys spilopterus: $02->$

Nannocharax fasciatus: $1 \rightarrow 0$

Bivibranchia fowleri:

Clado 116: 012 -> 1

Roeboexodon guyanensis: $12 \rightarrow$

Galeocharax knerii: 02 -> 0

Clado 161: 02 -> 0

Clado 197: 02 -> 012

Xenocharax spilurus: 1 -> 2

Clado 120: $02 \rightarrow>2$

Clado 123: $02 \rightarrow>$

Clado 124: $02 \rightarrow>$

Clado 126: $02 \rightarrow$

Hydrolycus tatauaia: $2 \rightarrow 0$

Hydrolycus tatauaia: 2 - $>0$

Piaractus mesopotamicus: $012 \rightarrow 2$

Hepsetus odoe: $2 \rightarrow 0$

Myleus setiger: $012->1$
Potamorhina latior: 2 -> 1

Leporellus vittatus: $0 \rightarrow 2$

Atopomesus pachyodus: $2 \rightarrow 1$

Deuterodon iguape: $2 \rightarrow 1$

Triportheus albus:

Clado 187: 02 -> 012

Gymnocorymbus ternetzi: 012 -> 0

Clado 186: 012 -> 12

Markiana nigripinnis: 02 -> 0

Tetragonopterus argenteus: $02 \rightarrow 2$

Orthospinus franciscoensis: $12 \rightarrow-1$

Orthospinus franciscoensis: $12 \rightarrow>1$

Poptella brevispina: $12 \rightarrow 2$

Caráter 166 (17 passos)

Raiz: 1

Clado 102: 1 -> 01

Clado 104: $01 \rightarrow 0$

Clado 163: $1 \rightarrow 0$

Clado 114: $1 \rightarrow 0$

lado 157: $1 \rightarrow$

lado 140: $1 \rightarrow 0$

Oligosarcus argenteus: 1 -> $\theta$

Acestrorhynchus falcirostris: 1 -> 0

Curimatopsis macrolepis: 1 ->

Anostomus anostomus: $1 \rightarrow 0$

Metynnis lippincottianus: $1 \rightarrow 0$

Potamorhina latior: 1 -> 01

Phenacogaster pectinatus: $0 \rightarrow 1$

Boulengerella maculata: $1>0$

Clado 177: $\odot \rightarrow 1$

Bryconops alburnoides: $0 \rightarrow 1$

Astyanax mexicanus: $0->1$

Triportheus albus: $0 \rightarrow 1$

Tetragonopterus argenteus: $0 \rightarrow 1$

Caráter 167 (26 passos)

Raiz: 0

Clado 144: $\odot \rightarrow 12$

Gymnotus aff. carapo: $0->2$

Clado 115: $0 \rightarrow 1$

Clado 142: $12->1$

Clado 148: $12 \rightarrow 2$

Clado 153: $12 \rightarrow>2$

Saccodon wagneri: $1->2$

Arnoldichthys spilopterus: 1 -> $\odot$

Clado 150: $2 \rightarrow 1$

Clado 158: $02->0$

Citharinus latus: $\odot->1$

Hemiodus unimaculatus : $1 \rightarrow 0$

Clado 124: $1 \rightarrow 0$

Clado 173: $1 \rightarrow 01$

Aphyocharax pusillus: $1->3$

Clado 156: $2 \rightarrow 02$

Curimatopsis macrolepis: $1 \rightarrow \odot$

Semaprochilodus insignis: $1 \rightarrow 0$

Landonia latidens: $1 \rightarrow 2$

Serrabrycon magoi: $01 \rightarrow->$

Phenagoniates macrolepis:

Hepsetus odoe: $02->0$
Phenacogaster pectinatus: $01 \rightarrow 0$

Clado 171: $01 \rightarrow 1$

Boulengerella maculata: $02->2$

Ctenolucius hujeta: $02 \rightarrow 0$

Piabina argentea: $1->2$

Clado 180: 1 -> 012

Bryconops alburnoides: $012->0$
Iguacladoctes geisleri: $012 \rightarrow>2$

Agoniates halecinus: $1 \rightarrow 3$

Clado 193: 1 -> 01

Hollandichthys multifasciatus: 01 -> 0

Caráter 168 ( 6 passos)

Raiz: 0

Clado 102: $\odot \rightarrow 1$

Crenuchus spilurus: $0 \rightarrow 1$

Clado 142: $0 \rightarrow 1$

Clado 153: $\odot \rightarrow 1$

Clado 133: $1 \rightarrow 0$

Clado 130: $0 \rightarrow 1$

Caráter 169 ( 3 passos)

Raiz: 0

Clado 162: $\odot->1$

Clado 145: 0

Myleus setiger: 1 -> 0

Caráter 170 ( 4 passos)

Raiz: 0

Clado 123: $\odot \rightarrow 1$

Clado 126: $0 \rightarrow 01$

Anostomus anostomus: 01 -> 1

Curimata ocellata: $0 \rightarrow 1$

Schizodon fasciatus: 01 ->

Clado 127: 01 -> 1

Caráter 171 (1 passo)

Raiz: 1

Clado 156: 1 -> $\odot$

Caráter 172 ( 1 passo)

Raiz: 01

Hepsetus odoe: $01->1$

Clado 155: $01 \rightarrow 0$

Caráter 173 (6 passos)

Raiz: 1

Chalceus epakros: 1 ->

Clado 106: 1 - $>01$

Distichodus notospilus: $01->0$

Citharinus latus: 01 $->1$

Gilbertolus atratoensis: $1 \rightarrow 0$

Metynnis lippincottianus: 1 -> 0

Iguacladoctes geisleri: $1 \rightarrow 0$

Caráter 174 ( 11 passo)

Raiz: 0

Clado 148: 0 -> 1

Neolebias unifasciatus: $0 \rightarrow 1$

Clado 114: $0 \rightarrow 01$

Clado 159: $\odot \rightarrow 01$

Clado 113: $01 \rightarrow$

Arnoldichthys spilopterus: 01 -> 1

Clado 116: $0 \rightarrow 1$

Clado 161: 01 -> 1

Acestrorhynchus falcirostris: 1 -> 0

Clado 149: $1 \rightarrow 0$

Clado 119: $0 \rightarrow 1$

Prochilodus nigricans: 0 -> 1

Triportheus albus: $0 \rightarrow 1$

Raiz: 1

Clado 153: 1 -> 01

Clado 152: 01 -> 0

Lebiasina bimaculata: $01->1$

Piabucina astrigata: $01 \rightarrow \odot$

Roeboexodon guyanensis: 1 -> 0

Clado 126: $1 \rightarrow 0$

Clado 156: $1->0$
Hydrolycus tatauaia: $1 \rightarrow 0$

Brycinus macrolepidotus: $1 \rightarrow 0$

Prochilodus nigricans: $1 \rightarrow 0$

Myleus setiger: $1 \rightarrow 0$

Caráter 176 (16 passos)

Raiz: 1

Clado 102: $1 \rightarrow 0$

Clado 108: $1>0$

Clado 153: $1 \rightarrow 01$

Clado 114: $1 \rightarrow 12$

Clado 157: $01 \rightarrow 0$

Clado 113: $12 \rightarrow>2$

Clado 146: $1 \rightarrow 0$

Arnoldichthys spilopterus: 1 -> 2

Nannocharax fasciatus: $0 \rightarrow 2$

Clado 121: 1 -> 01

Citharinus latus: $\odot->2$

Curimatopsis macrolepis: 01 -> 1

Clado 119: $01 \rightarrow 0$

Roestes molossus: $0->1$

Metynnis lippincottianus: 1 -> 2

Clado 131: $1 \rightarrow 0$

Iguacladoctes geisleri: 1 -> 2

Rachoviscus graciliceps: 1 -> $\odot$

Ctenobrycon hauxwellianus: $1 \rightarrow$

caráter 177 (23 passos)

Raiz: 12

Chanos chanos: 12 ->

Clado 103: $12->1$

Chalceus epakros: 1 ->

Clado 181: $1 \rightarrow 2$

Hemistichodus vaillanti: 1 -> 0

Parodon nasus: $1 \rightarrow 0$

Clado 145: 1 -> 01

Anodus orinocensis: $1->2$

Clado 120: 1 -> 12

Acestrorhynchus falcirostris: $01 \rightarrow 0$

Clado 149: $1 \rightarrow 2$

Brycinus macrolepidotus: 1 -> 0

Curimatopsis macrolepis: $12 \rightarrow>2$

Caenotropus labyrinthicus: $1 \rightarrow$

Clado 128: 1 ->0

Hepsetus odoe: $01->1$

Clado 155: $01 \rightarrow 0$

Curimata ocellata: $12->2$

Potamorhina latior: $12 \rightarrow 1$

Phenacogaster pectinatus: 1 -> 2

Atopomesus pachyodus: $1 \rightarrow 2$

Brittanichthys axelrodi: $1 \rightarrow 2$

Clado 200: $1 \rightarrow 012$

Clado 131: $1 \rightarrow 012$

Rachoviscus graciliceps: 012 -> 2

Stygichthys typhlops: $012->0$

Clupeacharax engrauloides: $012 \rightarrow 2$

Clado 130: $012 \rightarrow 01$

Thoracocharax stellatus : 01 -> 0

Carnegiella strigata: 01 -> 1

Gasteropelecus sternicla: 01 -> 0 
Acestrorhynchus falcirostris: 2 -> 0 Curimatopsis macrolepis: $\odot->2$ Glandulocauda melanogenys: $2 \rightarrow \odot$ Triportheus albus: $2 \rightarrow 0$ Caráter 181 ( 3 passos)

Raiz: 0

Clado 123: $0 \rightarrow->$

Clado 124: $0 \rightarrow 1$

Potamorhina latior: 0 -> 1

Caráter 182 (9 passos)

Raiz: $\odot$

Clado 102: $\odot \rightarrow 1$

Clado 143: $0 \rightarrow 1$

Clado 146: $1 \rightarrow$

Gnathocharax steindachneri: 1 -> $\odot$

Erythrinoidea fam. nov: $0 \rightarrow 1$

Clado 197: $\odot \rightarrow 1$

Clado 120: 0 -> 01

Curimata ocellata: $01->$

Curimata ocellata: $01 \rightarrow 0$

Clado 164: 1 - $>$ o

Caráter 183 (25 passos)

Raiz: 1

Clado 102: $1 \rightarrow 0$

Clado 163: $1>0$

$\begin{array}{lll}\text { Clado 114: } 1 & \rightarrow & 0 \\ \text { Clado 182: } 1 & \rightarrow>01\end{array}$

Clado 182: 1 -> 01

Oligosarcus argenteus: $01 \rightarrow 0$

Clado 105: 1 -> 2

Nannocharax fasciatus: 1 ->

Bivibranchia fowleri: $1 \rightarrow 0$

Charax cf. leticiae: $01 \rightarrow 1$

Galeocharax knerii: 01 -> $\odot$

Clado 150: 1 -> 01

Erythrinoidea fam. nov: 1 -> 2

Clado 126: 1 -> 0

Hydrolycus tatauaia: $01 \rightarrow 0$

Piaractus mesopotamicus: $1 \rightarrow 0$

Hepsetus odoe: 1 -> 0

Gilbertolus atratoensis: $01 \rightarrow 0$

Roestes molossus: 01 -> 1

Myleus setiger: $1 \rightarrow 2$

Curimata ocellata: $1 \rightarrow 0$

Leporellus vittatus: $0->1$

Rhinobrycon negrensis: $1->2$

Atopomesus pachyodus: $1 \rightarrow 2$

Atopomesus pachyodus: $1->2$

Axelrodia reisei: $1 \rightarrow 2$

Paracheirodon axelrodi: $1>2$

Stygichthys typhlops: 1 -> 0

Clado 130: $1 \rightarrow 0$

Triportheus albus: 1 -> 0

Caráter 184 ( 6 passos)

Raiz: 1

Clado 104: 1 -> 12

Gymnotus aff. carapo: 12 -> 2

Galeocharax knerii: $1 \rightarrow 2$

Clado 126: 1 -> 2

Acestrorhynchus falcirostris: $1 \rightarrow \odot$

Leporellus vittatus: $2 \rightarrow 1$

Clado 130: $1 \rightarrow 0$

Caráter 185 ( 7 passos)

Raiz: 1

Clado 181: $1 \rightarrow 0$

Clado 146: $1 \rightarrow 01$

Clado 158: 1 -> $\odot$

Anodus orinocensis: $1 \rightarrow$

Acestrorhynchus falcirostris: $01->0$

Hydrolycus tatauaia: $01->$

Clado 149: $01 \rightarrow 0$

Piaractus mesopotamicus: 1 -> $\odot$

Hepsetus odoe: $01 \rightarrow$

Clado 155: $01 \rightarrow 0$

Caráter 186 (10 passos)

Raiz:

Raiz: 0 : $\rightarrow 01$

Clado $148: 0->01$
Salminus hilarii: $01 \quad \rightarrow 1$

Clado 181: $\odot \rightarrow 1$

Brycon pesu: $01->0$

Brycon pesu: $01->$

Galeocharax knerii: 1 ->

Galeocharax knerii: $1 \rightarrow 2$

Anodus orinocensis: $0 \rightarrow 2$

Anodus orinocensis: $0->2$

Acestrorhynchus falcirostris: $1->$

Hepsetus odoe: 1 -> 0

Caráter 187 ( 1 passo)

Raiz: $\odot$

$\begin{array}{cll}\text { Clado 125: } & 0 & ->1 \\ \text { Caráter } 188 \text { ( } 1 \text { passo }\end{array}$

Raiz: $\odot$

Clado 111: 0 -> 1

Caráter 189 ( 6 passos)

Raiz: 0

Clado 142: $0 \rightarrow 1$

Neolebias unifasciatus: $0 \rightarrow 1$

Hemistichodus vaillanti: $0 \rightarrow 1$

Gnathocharax steindachneri: $1 \rightarrow 0$

Galeocharax knerii: 1 -> 0

Clado 133: 1 -> 0

Caráter 190 (18 passos)

Raiz: $\odot$

Clado 111: $0 \rightarrow 01$

Clado 111: $01>01$

Clado 143: $01 \rightarrow$

Clado 108: $01 \rightarrow 1$
Clado 114: 01 -> 0

Clado 157: 01 -> 1

Chalceus epakros: $01 \rightarrow 0$

Clado 159: 01 -> 1

Copeina cf. guttata: $01 \rightarrow 0$

Bivibranchia fowleri: $01 \rightarrow 1$

Clado 116: 01 -> 0

Gnathocharax steindachneri: 1 -> 0

Clado 145: 1 -> 01

Erythrinoidea fam. nov: $01->0$

Clado 158: $01 \rightarrow 1$

Citharinus latus: 1 -> 0

Clado 123: $01 \rightarrow 1$

Clado 124: $01 \rightarrow 0$

Clado 126: $01->1$

Curimatopsis macrolepis: $01 \rightarrow 1$

Clado 119: $01 \rightarrow 0$

Clado 119: $01->0$
Hepsetus odoe: $01 \rightarrow 0$

Clado 155: $01->1$

Metynnis lippincottianus: 1 -> 0

Clado 164: $1 \rightarrow 0$

Bryconops alburnoides: 1 -> 0

Carnegiella strigata: $1 \rightarrow 0$

Poptella brevispina: $1 \rightarrow 0$

caráter 191 (14 passos)

Raiz: 1

Catostomus commersonnii: 1 -> 0

Olivaichthys mesembrinus: $1 \rightarrow 3$

Crenuchus spilurus: $1 \rightarrow 2$

Neolebias unifasciatus: 1 -> $\odot$

Clado 117: 1 -> 2

Copeina cf. guttata: 1 -> 0

Clado 158: $1 \rightarrow 2$

Hydrolycus tatauaia: 1 -> 2

Piaractus mesopotamicus: 1 -> 2

Anostomus anostomus: $1 \rightarrow 0$

Ctenolucius hujeta: $1 \rightarrow 2$

Clupeacharax engrauloides: $1 \rightarrow 0$

Thoracocharax stellatus : $1 \rightarrow 2$

Caráter 192 (7 passos)

Raiz: 12

Chanos chanos: $12->2$

Clado 103: 12 $>1$

Neolebias unifasciatus: $1->0$

Clado 114: $1 \rightarrow 01$

Clado 113: 01 -> 0

Clado 126: 1 -> 2

Hydrolycus tatauaia: $1 \rightarrow 2$

Hydrolycus tatauaia: $1->2$
Ctenolucius hujeta: 1 - $>2$

Caráter 193 (19 passos)

Raiz: 0

Clado 143: $\odot \rightarrow->1$

Clado 142: 01 -> 1

Salminus hilarii: $01 \rightarrow 1$

Clado 147: $01 \rightarrow 0$

Clado 157: $\odot \rightarrow 1$

Saccodon wagneri: $0 \rightarrow 1$

Clado 117: 0 -> 1

Distichodus notospilus: $0->1$

Gnathocharax steindachneri: 1 -> 0

Clado 158: $\odot \rightarrow 1$

Clado 123: $\odot \rightarrow$

Aphyocharax pusillus: $1 \rightarrow 0$

Piaractus mesopotamicus: $0 \rightarrow 1$

Clado 128: $\odot \rightarrow 1$

Clado 155: $\odot \rightarrow$

Potamorhina latior: 0 -> 1

Clado 133: 1 - $>01$
Clado 164: 01 - 0

Bryconops alburnoides: $01 \rightarrow 0$

Iguacladoctes geisleri: 01 -> 1

clupeacharax engrauloides: $01 \rightarrow 1$

Clado 130: $01->0$

Clado 187: $1 \rightarrow 0$

Ctenobrycon hauxwellianus: $0 \rightarrow 1$

Caráter 194 (14 passos)

Raiz: 1

Clado 104: $1 \rightarrow 0$

lado 110: $1 \rightarrow$

Clado 181: $1 \rightarrow 0$

$1 \rightarrow 0$

Clado 150: $1 \rightarrow 01$

Erythrinoidea fam. nov: 1 ->

Clado 120: $0 \rightarrow 1$

Aphyocharax pusillus: 1 ->

Hydrolycus tatauaia: 01 ->

Gilbertolus atratoensis: 01 -> 1

Roestes molossus: $01 \rightarrow 0$

Microschemobrycon casiquiare: 1 -> 0

Brittanichthys axelrodi: 1 -> 0

Stygichthys typhlops: 1 -> $\odot$

Clado 130: $1 \rightarrow 0$

Caráter 195 (14 passos)

Raiz: 1

Clado 104: $1 \rightarrow$

Clado 110: $1 \rightarrow 0$

Saccodon wagneri: $0->1$

Clado 117: $\odot \rightarrow 1$

Clado 181: $1 \rightarrow>$

Gnathocharax steindachneri: 1 -> 0

Clado 150: 1 -> 0

Erythrinoidea fam. nov: $1 \rightarrow 0$

Aphyocharax pusillus: $1->0$

Microschemobrycon casiquiare: 1 -> $\odot$

Brittanichthys axelrodi: $1 \rightarrow$

Stygichthys typhlops: 1 -> 0

Clado 130: $1 \rightarrow 0$

Caráter 196 (18 passos)

Raiz: 0

Clado 148: $\Theta \rightarrow>2$

Salminus hilarii: 02 -> 2

Clado 113: $0 \rightarrow 1$

Clado 117: $\odot \rightarrow 1$

Clado 190: $\odot \rightarrow 2$

Brycon pesu: $02->2$

Clado 158: $0 \rightarrow>2$

Clado 197: $0->2$

Acestrorhynchus falcirostris: $02 \rightarrow 0$

Hydrolycus tatauaia: $02 \rightarrow 2$

Serrabrycon magoi: $0->2$

Paragoniates alburnus: $\odot->2$

Paragoniates alburnus:

Hepsetus odoe: 02 2 $->$

Gilbertolus atratoensis: $02->0$

Phenacogaster pectinatus: $0 \rightarrow 1$

Deuterodon iguape: $0 \rightarrow 2$

Bryconops alburnoides: $\Theta \rightarrow 2$

Clado 130: $\odot \rightarrow>2$

Probolus heterostomus : $0 \rightarrow 2$

Poptella brevispina: $\odot \rightarrow 2$

Caráter 197 (18 passos)

Raiz: 01

Chanos chanos: 01 -> 0

Clado 103: 01 -> 1

Crenuchus spilurus: $1 \rightarrow 0$

Clado 142: $1 \rightarrow 0$

Clado 153: 1 -> 0

Neolebias unifasciatus: 1 -> 0

Clado 146: $1 \rightarrow 0$

Arnoldichthys spilopterus: 1 -> $\odot$

Citharinus latus: 1 -> $\theta$

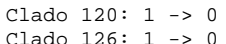

Landonia latidens: $\odot->1$

Leporinus fasciatus: $\theta->1$

Clado 134: $0 \rightarrow 01$

Glandulocauda melanogenys: $01->1$

Bryconadenos tanaothoros: $0 \rightarrow 1$

Knodus meridae: $0 \rightarrow 1$

Clado 132: $01 \rightarrow 0$

Clado 180: $01 \rightarrow 1$

Deuterodon iguape: $\odot->1$

Compsura heterura: $0 \rightarrow 1$

Caráter 198 (17 passos)

Raiz: 01

Chanos chanos: 01 -> 1

Clado 111: 01 - $>0$

Catostomus commersonnii: $01 \rightarrow 0$

Clado 104: $01 \rightarrow 1$

Clado 114: $0 \rightarrow 1$

Chalceus epakros: $\odot->1$

Clado 117: $\odot->2$
Brycon pesu: $\odot \rightarrow 2$

Distichodus notospilus: $\odot->1$

Hemistichodus vaillanti: $\Theta \rightarrow 1$

Clado 161: $0 \rightarrow 2$

Clado 123: $\Theta \rightarrow 1$

Myleus setiger: $0 \rightarrow 1$

Potamorhina latior: $0->1$

Leporinus fasciatus: $0 \rightarrow 1$

Clado 183: $\odot \rightarrow 1$

Clado 180: $0 \rightarrow 1$

Deuterodon iguape: $0->1$

Triportheus albus: $\theta-1$

Caráter 199 (20 passos)

Raiz: 01

Chanos chanos: $01->0$

Clado 102: $01 \rightarrow 1$

Clado 108: 01 -> 1

Characidium bahiensis: 01 -> 1

Clado 142: $01 \rightarrow 0$

Clado 153: $01 \rightarrow 1$

Clado 160: $01 \rightarrow 0$

Salminus hilarii: 01 -> 
Clado 148: 1 -> 012

Salminus hilarii: $012 \rightarrow>0$
Clado 147: $012 \rightarrow>12$

Clado 117: $1->12$
Brycon pesu: $12->2$

Arnoldichthys spilopterus: $1 \rightarrow 0$

Distichodus notospilus: $\theta \rightarrow 1$

Nannocharax fasciatus: $0 \rightarrow 2$

Bivibranchia fowleri: $12 \rightarrow 2$

Gnathocharax steindachneri: $1 \rightarrow 0$

Clado 145: $12 \rightarrow 1$

Clado 150: 12 -> 2 nov: 1 -> 0

Clado 161: 1 -> 2

Citharinus latus: $\odot->2$

Anodus orinocensis: $12->2$

Hemiodus unimaculatus : $12 \rightarrow>1$

Clado 126: $1 \rightarrow 2$

Axelrodia reisei: 1 -> 2

Compsura heterura: $1->2$

Compsura heterura:

Hemigrammus unilineatus: 1 ->

Hollandichthys multifasciatus: $1 \rightarrow$

Poptella brevispina: 1 -> 2

Caráter 201 (10 passos)

Raiz: $\odot$

Clado 102: $\odot \rightarrow$

Clado 115: $\odot \rightarrow 1$

Arnoldichthys spilopterus: 0 -> 1

Nannocharax fasciatus: $0 \rightarrow 1$

Xenocharax spilurus: $\odot->1$

Clado 124: $1 \rightarrow 0$

Leporellus vittatus: $1->0$
Stygichthys typhlops: $0->1$

Clado 130: $0 \rightarrow 1$

Triportheus albus: $0 \rightarrow 1$

Caráter 202 ( 3 passos)

Raiz: 1

Clado 107: 1 -> 0

Citharinus latus: $\odot->1$

Hoplias malabaricus: $1->$

Caráter 203 (16 passos)

Raiz: 01

Chanos chanos: 01 -> 1

Clado 111: $01->0$

Catostomus commersonnii: $01 \rightarrow 0$

Olivaichthys mesembrinus: $01 \rightarrow 1$

Clivaichthys mesembrinus:

Crenuchus spilurus:

Clado 148: 0 -> 1

Chalceus epakros: $\odot$-> 1

Chalceus epakros:

Clado 106: $\odot->\odot 1$

Distichodus notospilus: $01->1$

Distichodus notospilus: $01->1$

Clado 116: 01 -> 1

Citharinus latus: $01 \rightarrow 0$

Xenocharax spilurus: $01->1$

Caenotropus labyrinthicus: $1 \rightarrow 0$

Serrabrycon magoi: $0 \rightarrow 1$

Hepsetus odoe: $1 \rightarrow 0$

Clado 134: $0 \rightarrow 1$

Deuterodon iguape: $0 \rightarrow 1$

Iguacladoctes geisleri: $1 \rightarrow 0$

Clupeacharax engrauloides: $1 \rightarrow 0$

Caráter 204 (17 passos)

Raiz: 0

Crenuchus spilurus: $\odot->1$

Clado 142: $0 \rightarrow 01$

Clado 140: $01 \rightarrow$

Oligosarcus argenteus: 01 -> 1

Clado 181: 01 -> 0

Gnathocharax steindachneri: 01 -> $\odot$

Roeboexodon guyanensis: $01 \rightarrow 1$

Clado 123: $0 \rightarrow 1$

Anostomus anostomus: $\odot->1$

Anostomus anostomus: $\odot->$

Serrabrycon magoi:

Clado 179: 1 - $\rightarrow$ : 1 ->

Diapoma terofali: $1->0$

Atopomesus pachyodus

Bryconadenos tanaothoros: $0->1$

Clado 180: $1 \rightarrow$

Compsura heterura: $1 \rightarrow 0$

Clupeacharax engrauloides: $1 \rightarrow 0$

Clado 191: $1 \rightarrow 0$

Clado 185: 1 -> 0

Caráter 205 ( 2 passos)

Raiz: $\odot$

Crenuchus spilurus: $0->1$

Agoniates halecinus: $\odot \rightarrow 1$

Caráter 206 (12 passos)

Raiz: 01

Clado 111: 01 -> 0

Olivaichthys mesembrinus: 01 ->

Clado 153: $0 \rightarrow 2$

Clado 146: $0 \rightarrow 01$

Clado 151: $2 \rightarrow 1$

Clado 125: $0 \rightarrow 01$

Clado 197: $0 \rightarrow 01$

Clado 126: $01 \rightarrow$

Acestrorhynchus falcirostris: 01 -> 1

Hydrolycus tatauaia: $01 \rightarrow 1$

Clado 149: $01 \rightarrow 0$

Piaractus mesopotamicus: 01 -> 1
Caenotropus labyrinthicus: 01 -> 1 Chilodus punctatus: $01 \rightarrow 0$

Hepsetus odoe: $01->0$

Clado 155: 01 - 1

Metynnis lippincottianus: 01 -> 0

Myleus setiger: $01 \rightarrow 1$

Agoniates halecinus: $\odot->1$
Hyphessobrycon compressus: $\odot->1$

Caráter 207 (26 passos)

Raiz: 1

Clado 111: $1 \rightarrow 0$

Clado 115: $0 \rightarrow 1$

Clado 141: $\theta \rightarrow 01$

Clado 190: $01 \rightarrow 1$

Arnoldichthys spilopterus: $\odot->1$

Nannocharax fasciatus: $0->1$

Charax cf. leticiae: $0->1$

Erythrinoidea fam. nov: $0 \rightarrow 1$

Hemiodus unimaculatus : $1 \rightarrow 0$

Clado 173: $01 \rightarrow 1$

Aphyocharax pusillus: $01 \rightarrow 0$

Bryconalestes longipinnis: $\odot->1$

Landonia latidens: 01 -> $\odot$

Gilbertolus atratoensis: $\odot->1$

Clado 179: 01 -> 1

Ctenolucius hujeta: $0->1$

Clado 169: $01 \rightarrow 0$

Diapoma terofali: $01 \rightarrow 0$

Clado 134: $01->1$

Microschemobrycon casiquiare: 1 -> 0

Clado 184: $1 \rightarrow$

Piabina argentea: $1 \rightarrow 0$

Brittanichthys axelrodi: 1 -> $\odot$

Clado 164: $1 \rightarrow 0$

Astyanax mexicanus: $0 \rightarrow 1$

Clado 191: $\odot \rightarrow 01$

Gymnocorymbus ternetzi: 0 -> 1

Hemigrammus unilineatus: $01->$

Hollandichthys multifasciatus: $01->0$

Hyphessobrycon compressus: $01-1$

caráter 208 (12 passos)

Raiz: 1

Clado 111: $1 \rightarrow 0$

Clado 118: $\odot \rightarrow$

Gnathocharax steindachneri: $0->1$

Erythrinoidea fam. nov: $0 \rightarrow 1$

Citharinus latus: $0 \rightarrow 1$

Hemiodus unimaculatus : $1 \rightarrow 0$

Atopomesus pachyodus: $0->1$

Clado 131: $0 \rightarrow 1$

Iguacladoctes geisleri: $0 \rightarrow 1$

Astyanax mexicanus: $0->1$

Stygichthys typhlops: $0 \rightarrow 1$

Ctenobrycon hauxwellia
Caráter 209 ( 3 passos)

Caráter 209

Clado 122: $1 \rightarrow 0$

Acestrorhynchus falcirostris: 1 -> 0

Clado 130: $1 \rightarrow 0$

Caráter 210 ( 6 passos)

Raiz: 01

Chanos chanos: $01->0$

Clado 111: $01 \rightarrow 1$

Catostomus commersonnii: 01 -> $\odot$

Clado 104: $01->1$

Nannocharax fasciatus: $1 \rightarrow 0$

Citharinus latus: $1 \rightarrow 0$

Anodus orinocensis: $1 \rightarrow$

Caráter 211 (16 passos)

Raiz: 2

Clado 111: 2 -> 12

Gymnotus aff. carapo: $2 \rightarrow 0$

Clado 109: $12 \rightarrow 2$

Clado 163: $12 \rightarrow 1$

Clado 143: $12 \rightarrow 1$

Clado 153: $12 \rightarrow 2$

Clado 160: 12 -> 1

Clado 122: 2 -> 02

Erythrinoidea fam. nov: $2 \rightarrow 1$

Citharinus latus: 2 -> 0

Hemiodus unimaculatus : $2 \rightarrow$

Hydrolycus tatauaia: $12 \rightarrow 2$

Curimatopsis macrolepis: $02->$

Anostomus anostomus: $02->$

Clado 128: 02 -> 2

Hepsetus odoe: 1 -> 2

Gilbertolus atratoensis: 12 -> 1

Roestes molossus: $12 \rightarrow 2$

Myleus setiger: $1->2$

Curimata ocellata: $02->2$

Potamorhina latior: $02->$

Knodus meridae: $1->2$

Iguacladoctes geisleri: 1 -> 2

Caráter 212 (28 passos)

Raiz: 0

Clado 111: $0 \rightarrow 1$

Gymnotus aff. carapo: $0 \rightarrow 2$

Characidium bahiensis: $1 \rightarrow 2$

Clado 160: $1 \rightarrow 0$

Clado 147: $1->2$
Clado 113: $1 \rightarrow 2$

Oligosarcus argenteus: 1 -> 2

Nannocharax fasciatus: 1 -> 2

Clado 121: $1 \rightarrow 2$

Clado 197: $\odot->2$
Citharinus latus: 1 -> 2

Hemiodus unimaculatus : 1 -> 2

Hydrolycus tatauaia: $2 \rightarrow 0$

Hoplias malabaricus: $1 \rightarrow 0$

Brycinus macrolepidotus: $\odot->1$

Hepsetus odoe: $2 \rightarrow 1$

Roestes molossus: 2 -> 1

Clado 179: 1 -> 12

Rhinobrycon negrensis: 12 -> 2

Clado 170: 1 -> 2

Bryconadenos tanaothoros: 12 -> 1

Bryconamericus exodon: $12 \rightarrow 2$

Knodus meridae: $12 \rightarrow 1$

Piabina argentea: $12 \rightarrow 2$

Iguacladoctes geisleri: $1 \rightarrow 2$
Clado 130: $1 \rightarrow 2$

Agoniates halecinus: $1->2$

Tetragonopterus argenteus: 1 ->

Hemigrammus unilineatus: $1 \rightarrow 0$

Clado 185: 1 -> 012

Ctenobrycon hauxwellianus: $012 \rightarrow 0$

Poptella brevispina: 012 -> 2

Caráter 213 ( 4 passos)

Raiz: 01

Chanos chanos: $01->0$

Clado 103: $01->1$

Clado 121: $1 \rightarrow 0$

Citharinus latus: 1 -> 0

Anodus orinocensis: $1->0$

Caráter 214 (10 passos)

Raiz: 0

Catostomus commersonnii: $\odot \rightarrow 2$

Clado 114: $\odot \rightarrow 2$

Chalceus epakros: $\odot$-> 1

Clado 146: $0 \rightarrow 1$

Galeocharax knerii: 0 -> 1

Clado 158: $0 \rightarrow 1$

Hemiodus unimaculatus : $\odot \rightarrow 2$

Gilbertolus atratoensis: $1 \rightarrow 0$

Ctenolucius hujeta: $1 \rightarrow 0$

Clado 164: 0 - $>1$

Caráter 215 (19 passos)

Raiz: 1

Clado 143: 1 -> 0

Chalceus epakros: $1->0$

Distichodus notospilus: 1 -> 0

Clado 158: $1 \rightarrow 0$

Piaractus mesopotamicus: 1 -> $\odot$

Piaractus mesopotamicus: $1->0$

Phenagoniates macrol

Gilbertolus atratoensis: $0 \rightarrow 1$

Clado 171: $\odot \rightarrow 1$

Clado 168: $1 \rightarrow 0$

Odontostilbe pequira: $1>0$

Brittanichthys axelrodi: 1 -> 0

Bryconops alburnoides: 1 -> 0

Clado 130: $1 \rightarrow 0$

Agoniates halecinus: $1 \rightarrow 0$

Gymnocorymbus ternetzi: $\odot->1$

Markiana nigripinnis: $0->1$

Hemigrammus unilineatus: $0 \rightarrow 1$

Caráter 216 (17 passos)

Raiz: 1

Clado 143: 1 -> 0

Chalceus epakros: 1 -> $\odot$

Clado 125: $\odot \rightarrow 01$

Clado 158: $1 \rightarrow$

Clado 138: $0 \rightarrow 1$

Clado 156: $0->1$

Phenagoniates macrolepis: $0->1$

Clado 171: $0 \rightarrow 1$

Clado 171: $0 \rightarrow 1$

Moenkhausia xinguensis: $01 \rightarrow 0$

Deuterodon iguape: 01 -> 1

Clado 166: $01 \rightarrow 0$

Brittanichthys axelrodi: $1 \rightarrow 0$

Bryconops alburnoides: $1 \rightarrow 0$

Agoniates halecinus: $1->0$

Markiana nigripinnis: $0->1$

$\begin{array}{ll}\text { Hemigrammus unilineatus: } 0 & ->1 \\ \text { Ctenobrycon hauxwellianus: } 0->1 & ->1\end{array}$

Ctenobrycon hauxwellianus
Caráter 217 (10 passos) 
Clado 125: $\odot->1$

Caráter 219 (4 passos)

Raiz: 01

Chanos chanos: 01 -> 1

Clado 103: $01 \rightarrow$

Clado 122: $0 \rightarrow 01$

Clado 121: $01 \rightarrow 1$

Citharinus latus: $\odot \rightarrow 1$

Clado 124: $01 \rightarrow 1$

Clado 126: 01 -> 0

Caráter 220 ( 4 passos)

Raiz: 0

Clado 118: $\odot$-> 01

Bivibranchia fowleri: $01->1$

Clado 121: $01 \rightarrow 1$

Citharinus latus: $\odot \rightarrow 1$

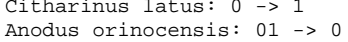

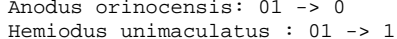

Caráter 221 ( 2 passos)

Caráter 221

Olivaichthys mesembrinus: 0 -> 1

Clado 130: 0 -> 1

caráter 222 ( 8 passos)

Raiz: $\odot$

Clado 111: $\odot->1$

Gymnotus aff. carapo: $\odot \rightarrow 1$

Nannocharax fasciatus: $1 \rightarrow$

Bivibranchia fowleri: $1->0$
Erythrinoidea fam. nov: $1 \rightarrow 0$

Clado 124: $1 \rightarrow 0$

Clado 200: $1 \rightarrow 0$

Clado 130: $1 \rightarrow 0$

Caráter 223 (11 passo)

Raiz: 01

Clado 111: 01 -> 1

Gymnotus aff. carapo: $01->0$

Clado 148: 1 ->0

Clado 107: $1 \rightarrow 0$

Roeboexodon guyanensis: $1 \rightarrow 0$

Clado 197: $1 \rightarrow 0$

Hemiodus unimaculatus : $1 \rightarrow 0$

Potamorhina latior: $1 \rightarrow 0$

Hemibrycon polyodon : $1 \rightarrow 0$

Clado 183: $1 \rightarrow 0$

Clado 183: $1 \rightarrow 0$

Clupeacharax engrauloides: 01 -> $\odot$

Caráter 224 (23 passos)

Raiz: 01

Clado 144: 01 -> 1

Gymnotus aff. carapo: $01->$

Clado 163: $01 \rightarrow 0$

Neolebias unifasciatus: $01 \rightarrow 0$

Clado 107: $01 \rightarrow 1$

Clado 114: 01 -> 1

Clado 159: $1->01$

Clado 146: $1->0$
Copeina cf. guttata: $1->0$

Arnoldichthys spilopterus: $01 \rightarrow 0$

Clado 116: $01 \rightarrow 1$

Gnathocharax steindachneri: 1 -> $\odot$

Clado 161: $01 \rightarrow 1$

Citharinus latus: $1 \rightarrow \odot$

Clado 123: $01 \rightarrow 0$

Clado 124: $01 \rightarrow 0$

Clado 126: 01 -> 1

Piaractus mesopotamicus: $01->0$

Curimatopsis macrolepis: $01->0$

Clado 119: 01 -> 1

Phenagoniates macrolepis: 1 -> 0

Clado 155: $\odot \rightarrow 1$

Metynnis lippincottianus: $01->1$

Myleus setiger: $01 \rightarrow 0$

Clado 136: $1 \rightarrow 01$

Clado 171: 1 -> 01

Hemibrycon polyodon : $01->0$

Hemibrycon polyodon

Clado 184: $01->1$ ( $12>$

Moenkhausia xinguensis: $01->1$

Bryconadenos tanao

Clado 132: $01 \rightarrow 1$

Clado 180: $01->0$
Deuterodon iguape: $01->0$

Deuterodon iguape:

Clado 166: 01 -> 1

Hyphessobrycon compressus: 1 -> 0

Caráter 225 (10 passos)

Raiz: 1

Clado 111: 1 -> $\odot$

Clado 146: $0 \rightarrow 01$

Gnathocharax steindachneri: $0->1$

Erythrinoidea fam. nov: $0 \rightarrow 1$

Clado 199: $0 \rightarrow 1$

Acestrorhynchus falcirostris: $01 \rightarrow 0$

Clado 156: 01 -> 1

Hydrolycus tatauaia: $01->1$

Gilbertolus atratoensis: 01 -> 1

Roestes molossus: $01 \rightarrow 0$

Clado 132: $0 \rightarrow 01$

Clado 131: $01 \rightarrow 1$

Stygichthys typhlops: $0->1$

Agoniates halecinus: $01-1$

Triportheus albus: 01 - 1

Caráter 226 (18 passos)

Raiz: 1
Chalceus epakros: 1 -> $\odot$

Clado 113: $1 \rightarrow 0$

Clado 181: $1 \rightarrow 0$

Brycon pesu: $1 \rightarrow 0$

Clado 165: $1 \rightarrow 01$
Clado 120: $1 \rightarrow 01$

Aphyocharax pusillus: $01->0$

Bryconalestes longipinnis: $1 \rightarrow 0$

Curimatopsis macrolepis: $01 \rightarrow 0$

Metynnis lippincottianus: $1 \rightarrow 0$

Curimata ocellata: $01 \rightarrow 1$

Potamorhina latior: $01 \rightarrow 0$

Clado 178: $1 \rightarrow 01$

Clado 177: $01 \rightarrow 0$

Knodus meridae: $01 \rightarrow \odot$

Knodus meridae: $\odot 1$ - $>0$

Brittanichthys axelrodi: $1 \rightarrow 0$

Brittanichthys axelrodi: $1 \rightarrow$
Compsura heterura: $1 \rightarrow 0$

Iguacladoctes geisleri: $1 \rightarrow \theta$

Clado 189: 1 -> 01

Clado 188: $01 \rightarrow 0$

Probolus heterostomus : $01 \rightarrow 1$

Hemigrammus unilineatus: $01->$

Hollandichthys multifasciatus: $01->1$

Hyphessobrycon compressus: $01-0$

Caráter 227 (2 passos)

Raiz: 1

Clado 108: 1 -> 0

Crenuchus spilurus: 1 -> 0

Caráter 228 (9 passos)

Raiz: 01

Chanos chanos: 01 -> 1

Clado 111: $01->0$

Catostomus commersonnii: 01 -> $\odot$

Clado 104: $01 \rightarrow 1$

Clado 146: $0 \rightarrow 1$

Gnathocharax steindachneri: 0 -> 1

Erythrinoidea fam. nov: $0->1$

Clado 199: 0 - $>1$

Chilodus punctatus: $0->1$

Clado 132: $\theta \rightarrow 1$

Clado 200: $\rightarrow 01$

Stygichthys typhlops: $01 \rightarrow 1$

Caráter 229 (11 passo)

Raiz: 1

Clado 160: $1 \rightarrow 0$

Clado 118: $1 \rightarrow 01$

Clado 182: $1 \rightarrow 0$

Clado 117: 01 -> $\odot$

Clado 125: $01 \rightarrow 1$

Clado 139: $1 \rightarrow 01$

Clado 123: $01 \rightarrow 0$

Brycinus macrolepidotus: $\odot->1$

Curimatopsis macrolepis: $01->$

Clado 119: 01 -> $\theta$

Landonia latidens: 01 -> 0

Clado 137: $01 \rightarrow 1$

Clado 168: 1 -> 0

Glandulocauda melanogenys: 1 -> $\odot$

Markiana nigripinnis: $0 \rightarrow 1$

Caráter 230 ( 5 passos)

Raiz: 0

Catostomus commersonnii: $\odot->1$

Clado 163: $\odot->1$

Saccodon wagneri: $0->1$

Nannocharax fasciatus: $0 \rightarrow 1$

Erythrinoidea fam. nov: $0->$

Caráter 231 (19 passos)

Raiz: 2

Clado 102: $2 \rightarrow 0$

Clad $102: 2 \rightarrow>0$

Clado 140: 2 -> 12

Clado 165: $12 \rightarrow$

Clado 165: $12 \rightarrow 1$

Clado 124: $2 \rightarrow 0$

Clado 138: $12 \rightarrow 2$

Hoplias malabaricus: $\odot->$

Hepsetus odoe: $2 \rightarrow 1$

Rhinobrycon negrensis: $2->1$

Rhinobrycon negrensis: 2 -> 1

Atopomesus pachyodus: $1 \rightarrow 0$

Glandulocauda melanogenys: 2 -> 1

Knodus meridae: 2 -> 1

Hyphessobrycon compressus: $2 \rightarrow 0$

Ctenobrycon hauxwellianus: 2 -> 1

Caráter 232 ( 1 passo)

Raiz: 0

Clado 114: $\odot \rightarrow 1$

Caráter 233 ( 6 passos)

Raiz: 0

Clado 104: $\odot \rightarrow 1$

Clado 153: $0 \rightarrow 01$

Copeina cf. guttata: $01->1$

Lebiasina bimaculata: $01 \rightarrow 1$

Piabucina astrigata: $01 \rightarrow 0$

Erythrinoidea fam. nov: $01 \rightarrow 1$

Clado 158: 01 -> 0

Clado 175: $\odot \rightarrow 01$

Clado 174: 01 -> 1

Paracheirodon axelrodi: $01 \rightarrow 1$

Rachoviscus graciliceps: $01 \rightarrow$

caráter 234 (17 passos)

Raiz: 01

Chanos chanos: 01 -> 1

Clado 111: 01 : $\rightarrow$

Clado 148: $\odot \rightarrow 1$

Clado 118: $0 \rightarrow 01$

Clado 117: 01 -> 1

Oligosarcus argenteus: 0 -> 1

Piabucina astrigata: $0 \rightarrow 1$

Clado 162: 0 -> 1

Gnathocharax steindachneri: 0 -> 1

Clado 120: $01 \rightarrow$

Clado 123: 01 -> 1

Clado 124: $01 \rightarrow>$

Clado 126: $01 \rightarrow 1$

Clado 156: $1 \rightarrow 0$

Phenacogaster pectinatus: 0 -> 1

Diapoma terofali: $0 \rightarrow 1$

Hemibrycon polyodon : $0_{->1}$

Piabina argentea: $\odot->$

Clado 166: $\odot \rightarrow 1$

Bryconops alburnoides: 0 -> 1

Clado 191: 1 -> 0

Caráter 235 (4 passos)

Raiz: 0

Gnathocharax steindachneri: 0 -> 1

Hydrolycus tatauaia: $0 \rightarrow 1$

Paragoniates alburnus: $0->1$

Clado 132: $0 \rightarrow 1$

Caráter 236 ( 8 passos)

Raiz: 01

Chanos chanos: $01->1$

Clado 102: $01 \rightarrow 0$

Clado 110: $01 \rightarrow 0$

Clado 144: $01 \rightarrow 1$

Clado 114: $\odot \rightarrow 1$
Clado 151: $1 \rightarrow 0$

Nannocharax fasciatus: $\odot->1$

Clado 124: $\odot \rightarrow 1$

Leporinus fasciatus: $0 \rightarrow 1$

Stygichthys typhlops: 1 -> 0

Caráter 237 (16 passos)

Raiz: 1

Clado 102: $1 \rightarrow 0$

Clado 108: 1 -> 0

Characidium bahiensis: 1 -> 0

Clado 152: 1 -> 01

Copeina cf. guttata: $01 \rightarrow 0$

Clado 105: $0 \rightarrow 1$

Erythrinoidea fam. nov: $01 \rightarrow 0$

Clado 158: $01 \rightarrow 1$

Clado 124: $1 \rightarrow 0$

Metynnis lippincottianus: 1 -> 3

Rhinobrycon negrensis: 1 -> 0

Atopomesus pachyodus: $01->1$

Microschemobrycon casiquiare: $01->$

Odontostilbe pequira: $01 \rightarrow$

Clado 183: 01 -> 1

Axelrodia reisei: $01 \rightarrow 0$

Brittanichthys axelrodi: $01->1$

Paracheirodon axelrodi: $01 \rightarrow 0$

Rachoviscus graciliceps: $01->1$

Stygichthys typhlops: $01 \rightarrow 0$

Caráter 238 (15 passos)

Raiz: 1

Clado 144: 1 -> 01

Clado 143: $01 \rightarrow 0$

Clado 115: 1 -> 0

Clado 153: $01 \rightarrow 1$

Clado 160: $01 \rightarrow 0$

Clado 105: $1 \rightarrow 0$

Hemistichodus vaillanti: 1 -> 0

Apareiodon piracicabae: $0 \rightarrow 1$

Bivibranchia fowleri: $0->1$

Erythrinoidea fam. nov: $1->0$

Clado 124: $0 \rightarrow 1$

Clado 124: $0 \rightarrow 1$

Serrabrycon magoi: $01->1$

Phenacogaster pectinatus: $01 \rightarrow 0$

Clado 171: $01 \rightarrow 1$

Glandulocauda melanogenys: $\odot \quad->1$

Clado 183: $1 \rightarrow 0$

Brittanichthys axelrodi: $1 \rightarrow \theta$ 
Caráter 240 (9 passos)

Raiz:

Olivaichthys mesembrinus: 0 -> 1

Clado 182: $\odot \rightarrow 01$

Clado 147: $0 \rightarrow 1$

Oligosarcus argenteus: $01->1$

Roeboexodon guyanensis: $0->1$

Charax cf leticiae: $01 \rightarrow 1$

Galeocharax knerii: $01 \rightarrow 0$

Clado 124: $0 \rightarrow 1$

Hydrolycus tatauaia: $1 \rightarrow 0$

Phenacogaster pectinatus: $0->1$

Ctenobrycon hauxwellianus: $0-1$

Caráter 241 (10 passos)

Raiz: 1

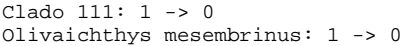

Crenuchus spilurus: $0 \rightarrow 1$

Clado 151: $0 \rightarrow 1$

Nannocharax fasciatus: $\odot->1$

Acestrorhynchus falcirostris: $0->1$

Clado 119: $0 \rightarrow 1$

Chilodus punctatus: $0 \rightarrow 1$

Atopomesus pachyodus: $0 \rightarrow 1$

Stygichthys typhlops: $0->1$

Caráter 242 (18 passos)

Raiz: 1

Clado 104: $1 \rightarrow 0$

Clado 110: $1 \rightarrow 0$

Clado 153: $1->0$
Clado 140: $1->0$

Clado 140: $1 \rightarrow 0$

Clado 181: $1 \rightarrow 0$
Clado 150: $1 \rightarrow 2$

Clado 128: 0 -> 1

Serrabrycon magoi: $0 \rightarrow 1$

Paragoniates alburnus: $0^{1}>1$

Hepsetus odoe: $1 \rightarrow 0$
Myleus setiger: $1 \rightarrow 0$

Clado 136: $\odot$->

Glandulocauda melanogenys: 1 -> $\odot$

Knodus meridae: $0 \rightarrow 1$

Rhoadsia altipinna: $0 \rightarrow$

Astyanax mexicanus: $1->$

Rachoviscus graciliceps: $0->1$

Rachoviscus graciliceps: $0->$

Garáter 243 ( 3 passos)

Raiz: $\odot$

Gaiz: $\odot$ athocharax steindachneri: 0 -> 1

Clado 155: $0->1$
Clado 130: $0->1$

Caráter 244 (19 passos)

Raiz: 01

Chanos chanos: 01 ->

Clado 103: $01 \rightarrow 0$

Clado 163: $0 \rightarrow 1$

Clado 107: $0->1$

Clado 147: $0 \rightarrow 01$

Chalceus epakros: $\odot \rightarrow$

Clado 113: $\odot \rightarrow 01$

Brycon pesu: 01 -> 1

Copeina cf. guttata: $0 \rightarrow 1$

Apareiodon piracicabae: $01->1$

clado 150: $01 \rightarrow 0$

Xenocharax spilurus: $1 \rightarrow 0$

Hemiodus unimaculatus : $\odot \rightarrow 1$

Clado 123: $0 \rightarrow 1$

Clado 126: $0 \rightarrow 1$

Acestrorhynchus falcirostris: 01 -> 1

Brycinus macrolepidotus: $0->1$

Piaractus mesopotamicus: $0 \rightarrow$

Hepsetus odoe: $01 \rightarrow$

Clado 155: 01 - $>$

Curimata ocellata: $\odot->1$

Leporellus vittatus: $1->0$

Clado 133: $0 \rightarrow 1$

Triportheus albus: 1 -> $\odot$

Caráter 245 ( 2 passos)

Raiz: $\odot$

Rydrolycus tatauaia: $\odot->1$

Hydrolycus tatauaia: $0->$
Triportheus albus: $0->1$

Triportheus albus: $\Theta$->

Caráter 246

Chanos chanos: 01 ->

Clado 103: $01 \rightarrow 0$

Clado 148: $0 \rightarrow 01$

Salminus hilarii: 01 -> 1

Brycon pesu: $01 \rightarrow$

Clado 146: $01 \rightarrow 0$

Roeboexodon guyanensis: $\odot \rightarrow 1$

Galeocharax knerii: $0 \rightarrow$

Landonia latidens: $\odot \rightarrow 1$

Clado 169: $\odot \rightarrow 1$

Bryconadenos tanaothoros: 0 -> 1

Knodus meridae: $0->1$

Odontostilbe pequira: $\odot \rightarrow 1$

Clado 132: $\odot \rightarrow 01$

Clado 166: $1>0$

Brittanichthys axelrodi: $0 \rightarrow 1$

Clado 164: 01 -> 1

Clupeacharax engrauloides: 01 -> 1

Clado 130: $01 \rightarrow$

Clado 195: $0 \rightarrow 1$

Caráter 247 (15 passos)

Raiz: 01

Chanos chanos: 01 ->

Catostomus commersonnii: 01 -> $\odot$

Clado 110: $01 \rightarrow 1$
Clado 144: 01 -> $\odot$

Olivaichthys mesembrinus: 01 -> 1

Gymnotus aff. carapo: $01->0$
Neolebias unifasciatus: $1 \rightarrow 0$

Clado 105: $1 \rightarrow$

Clado 121: $1 \rightarrow 0$

Clado 165: $0 \rightarrow 01$

Aphyocharax pusillus: $01->1$

Landonia latidens: 0 -> 1

Paragoniates alburnus: $01 \rightarrow$

Phenagoniates macrolepis: $01 \rightarrow 1$

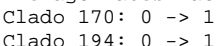

Odontostilbe pequira: $0->1$

Axelrodia reisei: $0 \rightarrow 1$

Iguacladoctes geisleri: $\odot->1$

Agoniates halecinus: $0 \rightarrow 1$

Caráter 248 ( 6 passos)

Raiz: 1

Gymnotus aff. carapo: 1 -> $\odot$

Clado 163: 1 ->

Atopomesus pachyodus: $1 \rightarrow 0$

Atopomesus pachyodus: $1->0$

Brittanichthys axelrodi: $1->$

Stygichthys typhlops:
Caráter 249 (25 passos)

Caráter

Clado 144: $\odot \rightarrow 1$

Clado 118: $0 \rightarrow 12$

Clado 152: $1 \rightarrow$

Piabucina astrigata: 1 -> $\odot$

Bivibranchia fowleri: $12 \rightarrow 2$

Clado 116: $12 \rightarrow 1$

Clado 165: $1 \rightarrow 2$

Charax cf. leticiae: $1 \rightarrow 2$

Clado 150: $1 \rightarrow 0$

Clado 120: $12 \rightarrow 2$

Clado 123: $12 \rightarrow 1$

Clado 124: $12 \rightarrow>2$

Hepsetus odoe: $1 \rightarrow$

Phenacogaster pectinatus: 1 -> 2

Ctenolucius hujeta: $1->\odot$
Diapoma terofali: $1->2$

Microschemobrycon casiquiare: 1 -> 2

Clado 133: 1 - 01

Moenkhausia xinguensis: $1->2$

Knodus meridae: $1->2$

Clado 198: 1 -> 012

Clado 132: 01 -> $\theta$

Paracheirodon axelrodi: 012 -> 2

Clado 200: $012 \rightarrow 0$

Compsura heterura: 1 -> 2

Bryconops alburnoides: $01 \rightarrow 1$

Iguacladoctes geisleri: $01 \rightarrow \odot$

Clado 129: $0 \rightarrow 1$

Hemigrammus unilineatus: $1->2$

Ctenobrycon hauxwellian
Caráter 250 (24 passos)

Raiz: 0

Clado 111: $\odot->01$

Clado 163: 01 -> 1

Clado 154: $01 \rightarrow 1$

Clado 108: $01 \rightarrow 0$

Clado 182: 01 -> 1

Salminus hilarii: $01 \rightarrow 1$

Clado 147: 01 -> $\odot$

Saccodon wagneri: 01 -> 0

Clado 190: $01 \rightarrow 0$

Piabucina astrigata: $1 \rightarrow 0$

Apareiodon piracicabae: $01 \rightarrow 0$

Parodon nasus: $01-1$

Bivibranchia fowleri: 01 -> 1

Clado 161: $1 \rightarrow 0$

Anodus orinocensis: $01->0$

Hemiodus unimaculatus : $01 \rightarrow 1$

Clado 123: $01 \rightarrow 0$

Clado 126: $01 \rightarrow 1$

Aphyocharax pusillus: $01->0$

Curimatopsis macro

Caenotropus labyrinthicus: $01->0$

Chilodus punctatus: $01->1$

Landonia latidens: $01 \rightarrow 0$

Serrabrycon magoi: $01->1$

Paragoniates alburnus: $01->1$

Hepsetus odoe: $\odot \rightarrow$

Clado 179: 01 -> 1

Phenacogaster pectinatus: $01->0$

Clado 171: $01 \rightarrow 1$

Diapoma terofali: $01 \rightarrow 1$

Clado 134: $01->0$

Hemibrycon polyodon : 01 -> $\odot$

Moenkhausia xinguensis: $01 \rightarrow 1$

Knodus meridae: $1 \rightarrow \odot$

Deuterodon iguape: $01->0$

Clado 166: 01 -> 1

Brittanichthys axelrodi: $1 \rightarrow 0$

Clado 131: $0 \rightarrow>1$

Stygichthys typhlops: 1 -> 2

Caráter 251 (22 passos)

Raiz: 3

Clado 111: $3 \rightarrow 1$

Clado 107: $1 \rightarrow 01$

Clado 106: $01 \rightarrow 0$

Clado 113: 1 -> 2

Clado 117: 1 -> 01

Hemistichodus vaillanti: $01 \rightarrow 0$

Nannocharax fasciatus: $01 \rightarrow 1$

Bivibranchia fowleri: $01>0$

Gnathocharax steindachneri: 1 -> 3

Clado 145: 1 -> 12

Anodus orinocensis: $01->1$
Hemiodus unimaculatus : $01 \rightarrow 0$

Clado 156: 12 -> 2

Hoplias malabaricus: $1 \rightarrow 2$

Chilodus punctatus: $1->2$

Anostomus anostomus: $1 \rightarrow 2$

Paragoniates alburnus: $1 \rightarrow$

Curimata ocellata: $1 \rightarrow 0$

Clado 135: 1 -> 2

Knodus meridae: 1 -> 2

Clado 180: $2 \rightarrow 12$

Clado 200: 1 -> 2

Iguacladoctes geisleri: $12 \rightarrow 1$

Clado 130: 2 -> 23

Triportheus albus: 2 -> 3

Clado 191: 1 ->

Gasteropelecus sternicla: 23 -> 3

Markiana nigripinnis: 1 -> 2

Ctenobrycon hauxwellianus: 1 -> 2

caráter 252 ( 23 passos)

Raiz: 0

Clado 144: $\odot \rightarrow 1$

Gymnotus aff. carapo: $0 \rightarrow 1$

Neolebias unifasciatus: $0->1$

Salminus hilarii: $1 \rightarrow \theta$

Clado 159: $1 \rightarrow 0$

Saccodon wagneri: $0->1$

Clado 117: $0 \rightarrow 01$

Piabucina astrigata: 1 -> 0

Nannocharax fasciatus: $0 \rightarrow 1$

Bivibranchia fowleri: $01 \rightarrow 1$

Roeboexodon guyanensis: $1 \rightarrow 0$

Galeocharax knerii: 1 -> $\odot$

Anodus orinocensis: $01->0$

Hemiodus unimaculatus : $01 \rightarrow 1$

Aphyocharax pusillus: $1->$

Hoplias malabaricus: $1->0$

Clado 196: $\odot \rightarrow 1$

Hepsetus odoe: $1->0$

Curimata ocellata: $\theta \rightarrow 1$

Phenacogaster pectinatus: 1 -> 0

Atopomesus pachyodus: $1 \rightarrow 0$

Clado 180: $1 \rightarrow 0$

Axelrodia reisei: 1 -> $\odot$

Astyanax mexicanus: $1 \rightarrow 0$

Clado 186: $1 \rightarrow 0$

Caráter 253 (17 passos)

Gymnotus aff. carapo: $\odot \rightarrow 1$

Clado 142: 0 -> 01

Neolebias unifasciatus: $0->1$

Clado 141: 01 -> 1

Oligosarcus argenteus: $01 \rightarrow 1$

Clado 181: $01 \rightarrow$

Clado 146: $\odot \rightarrow 01$

Bivibranchia fowleri: 0 -> 1

Clado 161: $0 \rightarrow 1$

Acestrorhynchus falcirostris: 01 -> 1

Hydrolycus tatauaia: $01 \rightarrow 1$

Clado 149: 01 - $>0$

Hepsetus odoe: 01 -> 1

Clado 155: 01 - $>0$

Phenacogaster pectinatus: 1 -> 0

Atopomesus pachyodus: 1 -> 0

Clado 133: 1 -> 01

Clado 180: 01 -> 0

Axelrodia reisei: $1 \rightarrow 0$

Clado 131: 01 -> 0

Clado 164: $01 \rightarrow 1$

Astyanax mexicanus: $1 \rightarrow 0$

Clado 186: $1 \rightarrow 0$

Hemigrammus unilineatus: $1 \rightarrow \infty$

Caráter 254 (27 passos)

Raiz: 23

Chanos chanos: 23 -> 34

Clado 111: 23 -> 2

Catostomus commersonnii: 23 -> 4

Clado 104: $23 \rightarrow 0123$

Clado 144: $2 \rightarrow 1$

Olivaichthys mesembrinus: $0123 \rightarrow 0$ 
Clado 132: 1 -> $\odot$

Bryconops alburnoides: 1 -> 2 Gymnocorymbus ternetzi: $1 \rightarrow 0$ Orthospinus franciscoensis: 1 -> 01 Hollandichthys multifasciatus: $1 \rightarrow 0$ Caráter 255 (11 passo)

Raiz: 1

Clado 102: $1 \rightarrow \oplus$

Clado 108: $1 \rightarrow 0$

Clado 118: $1 \rightarrow 2$

Citharinus latus: 0 -> 1

Clado 123: $2 \rightarrow 1$

Piaractus mesopotamicus: $1 \rightarrow 2$

Clado 119: $2 \rightarrow$

Anostomus anostomus: $2 \rightarrow 1$

Diapoma terofali: $1 \rightarrow 0$

Clado 180: $1 \rightarrow 2$

Hyphessobrycon compressus: 1 -> 0

Caráter 256 (33 passos)

Raiz: 3

Clado 111: $3 \rightarrow 2$

Clado 108: $2 \rightarrow 1$

Clado 115: 2 -> 23

Crenuchus spilurus: 2 ->

Clado 142: $2 \rightarrow 1$

Clado 114: $23 \rightarrow$

Clado 117: $23 \rightarrow 3$

Clado 122: $23 \rightarrow 12$

Clado 181: $1 \rightarrow \odot$

Clado 151: $2 \rightarrow 23$

Piabucina astrigata: 2 -> 3

Clado 162: $2 \rightarrow 1$

Hemistichodus vaillanti: 1 -> 3

Clado 121: $12 \rightarrow 1$

Gnathocharax steindachneri: 1 -> $\odot$

Clado 145: $2 \rightarrow 3$

Clado 150: 2 -> 12

Erythrinoidea fam. nov: 23 -> 3

Xenocharax spilurus: $1->2$

Clado 123: 1 -> $\odot$

Clado 124: $12 \rightarrow 0$

Clado 126: $12 \rightarrow$

Aphyocharax pusillus: $1 \rightarrow 2$

Clado 199: $1 \rightarrow 0$

Clado 149: $12 \rightarrow 1$

Erythrinus erythrinus: $23->2$

Hoplias malabaricus: $23->3$

Clado 172: $1 \rightarrow 01$

Roestes molossus: 1 - $>0$

Roestes molossus: 1 -> 0

Phenacogaster pectinatus: 01 -> 0

Clado 170: $\odot 1 \rightarrow \odot$

Clado 170: 01 -> 0

Clado 184: 01 -> 1 andulocauda melanogenys: 1 -> $\odot$

Clado 133: $1->2$
Axelrodia reisei: 01 -> 0

Axelrodia reisei: $01 \rightarrow 0$

Brittanichthys axelrodi: $01->1$

Paracheirodon axel

Clado 200: $01 \rightarrow 1$

Clado 189: 1 -> 0
Stygichthys typhlops: 1 -> 2

Stygichthys typhlops:
Caráter 257 (18 passos)

Raiz: $\odot$

Clado 104: $\odot \rightarrow 01$

Olivaichthys mesembrinus: 01 ->

Clado 163: $0 \rightarrow 1$

Clado 160: 0 -> 1

Brycon pesu: $0 \rightarrow 1$

Charax cf. leticiae: $0 \rightarrow 1$

Erythrinoidea fam nov: $0 \rightarrow 1$

Clado 123: $0 \rightarrow 1$

Bryconalestes longipinnis: 1 -> 0

Landonia latidens: $\rightarrow$

Phenagoniates macrolepis: 0 -> 1

Potamorhina latior: $0 \rightarrow 1$

Phenacogaster pectinatus: $0 \rightarrow 1$

Clado 169: $0 \rightarrow 1$

Clado 169: $0 \rightarrow->1$

Clado 132: $0->1$

Brittanichthys axelrodi: $0 \rightarrow 1$

Brittanichthys axelrodi: $\odot->$

Markiana nigripinnis: $1 \rightarrow 0$

Markiana nigripinnis:
Caráter 258 ( 23 passos)

Raiz: 13

Chanos chanos: 13 -> 1

Clado 102: $13 \rightarrow 3$

Clado 144: $13 \rightarrow 1$

Clado 163: $13 \rightarrow$

Clado 108: $13 \rightarrow 1$

Clado 160: $1 \rightarrow 01$

Clado 114: 13 -> 3

Chalceus epakros: $01 \rightarrow \odot$

Clado 112: $1 \rightarrow 2$

Lebiasina bimaculata: 1 -> 2

Arnoldichthys spilopterus: 01 -> 1

Clado 162: 01 -> 013

Clado 121: $13 \rightarrow 1$

Gnathocharax steindachneri: $1 \rightarrow 0$

Clado 145: $1 \rightarrow 0$
Clado 158: $1 \rightarrow 2$

Clado 161: $013 \rightarrow 0$

Clado 197: $013 \rightarrow 3$

Clado 124: $13 \rightarrow 3$

Clado 126: $13 \rightarrow 1$

Semaprochilodus insignis: 1 -> 2

$\begin{array}{lll}\text { Semaprochilodus insignis: } 1 & -> & 2 \\ \text { Metynnis lippincottianus: } 3 & -> & 2\end{array}$
Potamorhina latior: 1 -> 3

Phenacogaster pectinatus: 1 -> 2

Leporellus vittatus: 1 -> 3

Clado 198: $1 \rightarrow 2$

Brittanichthys axelrodi: 1 -> 3

Stygichthys typhlops: $2->0$

$\begin{array}{lll}\text { Agoniates halecinus: } 1 ~ & -> & 3 \\ \text { Gymnocorymbus ternetzi: } 1 & \rightarrow>2\end{array}$

caráter 259 ( 5 passos)

Raiz: 0

Gnathocharax steindachneri: 0 -> 1

Charax cf leticiae: $\theta \rightarrow 1$

Clado 130: $0 \rightarrow 2$

Gymnocorymbus ternetzi: 0 -> 1

Poptella brevispina: $\theta \rightarrow 1$

Caráter 260 (33 passos)

Raiz: 02

Chanos chanos: 02 -> 2

Clado 111: $02 \rightarrow 0$

Catostomus commersonnii: $02->0$

Olivaichthys mesembrinus: $02 \rightarrow 2$

Clado 143: $\odot \rightarrow 01$

Clado 108: $0>2$

Clado 148: $\theta 1->1$

Clado 118: $01 \rightarrow 01$

Clado 182: $01 \rightarrow>01$

Clado 157: $0->1$

Oligosarcus argenteus: $012 \rightarrow>2$

Clado 181: 012 ->

Arnoldichthys spilopterus: $\odot->2$

Nannocharax fasciatus: $2 \rightarrow 0$

Bivibranchia fowleri: $01->1$

Clado 116: $01 \rightarrow 0$

Clado 125: 01 -> 1

Clado 150: $1 \rightarrow 0$

Clado 161: $0 \rightarrow 1$

Clado 120: $01 \rightarrow>1$

Clado 173: $01 \rightarrow 0$

Aphyocharax pusillus: $01 \rightarrow 1$

Clado 199: 01 -> 012

Prochilodus nigricans: $012 \rightarrow 0$

Semaprochilodus insignis: $012 \rightarrow>2$

Caenotropus labyrinthicus: $1 \rightarrow 2$

Landonia latidens: 01 -> 1

Paragoniates alburnus: $012 \rightarrow 2$

Phenagoniates macrolepis: $012 \rightarrow 0$

Clado 155: $1 \rightarrow 0$

Potamorhina latior: 1 -> 2

lado 127: $1 \rightarrow 2$

Clado 179: 01 -> 012

Clado 135: $01 \rightarrow 0$

( 12

Clado 178: 012 -> 01

Hemibrycon polyodon : 01 -> 1

Clado 194: 01 -> 1

Moenkhausia xinguensis: 01 -> 0

Bryconadenos tanaothoros: 01 -> 1

Bryconamericus exodon: $01->0$

Deuterodon iguape: $01->1$

Clado 166: $01 \rightarrow 0$

Axelrodia reisei: $0 \rightarrow 1$

Clado 200: $0 \rightarrow 2$

Rhoadsia altipinna: $\odot->2$

Clado 131: $0 \rightarrow 02$

Clupeacharax engrauloides: 02 -> 2

Agoniates halecinus: $0 \rightarrow 1$

Probolus heterostomus : $0 \rightarrow 1$

Caráter 261 (15 passos)

Raiz: 0

Clado 142: $\odot \rightarrow 01$

Clado 141: $01 \rightarrow 1$

Oligosarcus argenteus: 01 -> 0

Clado 181: $01 \rightarrow 1$

Aphyocharax pusillus: $1 \rightarrow 0$

Aphyocharax pusil

Clado 149: $\odot \rightarrow$

Serrabrycon magoi: $1 \rightarrow$

Serrabrycon magoi: $1->0$

Hemibrycon polyo

Atopomesus pachyodus: 1 -> 0

Clado 132: $1 \rightarrow 0$

Deuterodon iguape: $1 \rightarrow 0$

Compsura heterura: $1 \rightarrow 0$

Stygichthys typhlops: $1->0$

Hemigrammus unilineatus: $1->0$

Ctenobrycon hauxwellianu

Caráter 262

Erythrinoidea fam. nov: 1 -> 2

Semaprochilodus insignis: $1 \rightarrow$

Gilbertolus atratoensis: $1 \rightarrow 2$

Curimata ocellata: $1 \rightarrow \odot$

Schizodon fasciatus: $1 \rightarrow 0$

Clado 131: $1 \rightarrow 0$

Stygichthys typhlops: $1->2$

Gymnocorymbus ternetzi: $1 \rightarrow 0$

Tetragonopterus argenteus: $1 \rightarrow 0$

Caráter 263 ( 8 passos)

Raiz: 0

Clado 106: $\odot \rightarrow 01$

Copeina cf. guttata: $0 \rightarrow 1$

Arnoldichthys spilopterus: $\odot->1$

Distichodus notospilus: $01->1$

Citharinus latus: $01 \rightarrow 0$

Xenocharax spilurus: $01->1$

Acestrorhynchus falcirostris: 0 -> 1

Piaractus mesopotamicus: $\odot \rightarrow 1$

Leporinus fasciatus: $0 \rightarrow>1$

Agoniates halecinus: $\Theta$

Caráter 264 ( 36 passos)

Raiz: 3

Clado 115: $3 \rightarrow 1$

Chalceus epakros: $03->\odot$

Clado 112: $3 \rightarrow 0$

Brycon pesu: $3 \rightarrow 2$

Copeina cf. guttata: $3 \rightarrow 1$

Arnoldichthys spilopterus: 03 -> 3

Parodon nasus: $1 \rightarrow 0$

Bivibranchia fowleri: $1 \rightarrow 3$

Charax cf. leticiae: $3 \rightarrow 1$

Clado 197: 03 -> 0123

Citharinus latus: $3->1$

Anodus orinocensis: $1->2$

Clado 124: $1 \rightarrow 0$

Hydrolycus tatauaia: $3->2$
Brycinus macrolepidotus: $03->3$

Brycinus macrolepidotus: $03->3$

Bryconalestes longipinnis: $03->0$
Piaractus mesopotamicus: $0123->2$

Curimatopsis macrolepis: $1->3$

Anostomus anostomus: $1 \rightarrow 3$

Landonia latidens: $3 \rightarrow 0$

Serrabrycon magoi: $23->2$

Paragoniates alburnus: $3 \rightarrow 1$

Hepsetus odoe: $3 \rightarrow 1$

Roestes molossus: 3 -> 1

Metynnis lippincottianus: $0123 \rightarrow 0$

Myleus setiger: $0123 \rightarrow 1$

Phenacogaster pectinatus: 23 -> 1

Clado 170: 23 -> 023

Clado 176: 23 -> 3

Atopomesus pachyodus: $023->0$

Microschemobrycon casiquiare: $023 \rightarrow 2$

Glandulocauda melanogenys: $3 \rightarrow 1$

Moenkhausia xinguensis: 3 -> 2

Knodus meridae: $3 \rightarrow$

Clupeacharax engrauloides: $3 \rightarrow 2$

Triportheus albus: $3 \rightarrow 1$

Clado 188: $3 \rightarrow 0$

Markiana nigripinnis: $0->2$

$\begin{array}{lll}\text { Markiana nigripinnis: } 0 & -> & 2 \\ \text { Hemigrammus unilineatus: } 3 & ->2\end{array}$

Ctenobrycon hauxwellianus: $1->3$

ctenobrycon hauxwellian

Raiz: $\odot$

Clado 153: $\odot \rightarrow 1$

Clado 117: $0 \rightarrow 01$

Bivibranchia fowleri: 01 -> 1

Gnathocharax steindachneri: 0 -> 1

Clado 145: $0 \rightarrow 1$

Clado 161: $\theta \rightarrow 1$

Anodus orinocensis: $01->0$

Hemiodus unimaculatus : $01-1$

Clado 124: $0 \rightarrow 1$

Paragoniates alburnus: $\Theta \rightarrow 1$

Gilbertolus atratoensis: $0->1$

Schizodon fasciatus: $0 \rightarrow 1$

Clado 133: $0 \rightarrow 1$

Bryconamericus exodon: 0 -> 1

Clado 174: $\odot \rightarrow 1$

Odontostilbe pequira: $0->1$

Stygichthys typhlops: $0->1$

Triportheus albus: $1 \rightarrow \theta$

Clado 193: $\odot \rightarrow 1$

Poptella brevispina: $\odot \rightarrow 1$

Caráter 266 (21 passo)

Raiz: $\odot$

Clado 142: $\odot->01$

Clado 118: $0 \rightarrow 01$

Clado 118: $0 \rightarrow 01$

Oligosarcus argenteus: 01 -> 0

Clado 181: $01 \rightarrow 1$

Clado 151: $0 \rightarrow 01$

Clado 162: $\rightarrow>1$

C $\rightarrow 0$

Clado 116: $01 \rightarrow 1$

Clado 121: 01 ->

Clado 158: $01 \rightarrow>1$ 
Apareiodon piracicabae: $\odot$-> 1

$\begin{array}{lll}\text { Clado 158: } & 01 & ->1 \\ \text { Caráter 268 } & \text { ( } 5 \text { passos) }\end{array}$

Raiz: 0

Clado 109: $0 \rightarrow 1$

Oligosarcus argenteus: 0 -> 1

Clado 145: $0 \rightarrow>01$

Acestrorhynchus falcirostris: 01 -> 1

Hepsetus odoe: 01 ->

Clado 155: $01 \rightarrow 1$

Caráter 269 (19 passos)

Raiz: $\odot$

Clado 142: $\odot \quad->01$

Clado 160: $0 \rightarrow 01$

Clado 100: 01

Oligosarcus argenteus: 01 -> 1

Clado 181: $01 \rightarrow 0$

Clado 165: $01 \rightarrow$

Clado 145: $0 \rightarrow 01$

Acestrorhynchus falcirostris: $01->1$

Landonia latidens: $01->1$

Serrabrycon magoi: $01->$

Clado 172: $01 \rightarrow 1$

Hepsetus odoe: $01->$

Clado 155: $01 \rightarrow 0$

Clado 136: $01->1$

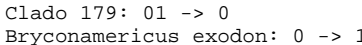

Bryconamericus exodon

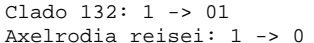

Rhoadsia altipinna: $1 \rightarrow \odot$

Clado 131: $01 \rightarrow 0$

Astyanax mexicanus: $1 \rightarrow 0$

Agoniates halecinus: $01 \rightarrow$

Triportheus albus: $01->1$

Probolus heterostomus : $1 \rightarrow 0$

Markiana nigripinnis: $1 \rightarrow 0$

Orthospinus franciscoensis: $1->0$
Hyphessobrycon compressus: $1 \rightarrow 0$

Caráter 270 (17 passos)

Raiz: 1

Clado 104: $1 \rightarrow 01$

Olivaichthys mesembrinus: $01->0$

Clado 163: $1 \rightarrow 0$

Clado 190: $1 \rightarrow \odot$

Clado 162: 1 -> 01

Nannocharax fasciatus: 1 ->

Clado 125: $1 \rightarrow 0$

Clado 197: $01 \rightarrow 0$

Hydrolycus tatauaia: 1 -> 0

Brycinus macrolepidotus: 01 -> 1

Bryconalestes longipinnis: $01 \rightarrow 0$

Potamorhina latior: 1 -> 0

Phenacogaster pectinatus: 1 -> 0

Clado 134: 1 -> 01

Microschemobrycon casiquiare: $1->0$

Glandulocauda melanogenys: 01 - $>0$

Paracheirodon axelrodi: $1 \rightarrow 0$

Clado 131: $01 \rightarrow 1$

Clado 164: 01 ->

Bryconops alburnoides: $01 \rightarrow 1$

Iguacladoctes geisleri: $01 \rightarrow$

Clado 187: 1 -> 01

Gymnocorymbus ternetzi: 01 ->

Orthospinus franciscoensis: $01->0$

Clado 185: $01 \rightarrow 1$

Caráter 271 (13 passos)

Raiz: 2

Clado 109: 2 -> 12

Clado 109: $2 \rightarrow 12$

Neolebias unifasciatus: 12 ->

Clado 107: $12 \rightarrow 012$

Clado 106: $012 \rightarrow>$

Clado 122: $1 \rightarrow 0$

ius: $01->0$

Distichodus notospilus: $01->0$

Nannocharax fasciatus: $012 \rightarrow 1$

Citharinus latus: $01->1$
Xenocharax spilurus: $01->0$

Hydrolycus tatauaia: $02->0$

Curimatopsis macrolepis: $\odot->$

Anostomus anostomus: $02->2$

Curimata ocellata: $\odot \rightarrow 1$

Schizodon fasciatus: 02 -> 0

Clado 127: $02->2$

Clado 198: $2 \rightarrow 02$

Clado 132: $2 \rightarrow 02$

Clado 164: $02->0$

Stygichthys typhlops: $02->0$

Caráter 272 (29 passos)

Raiz: 1

Clado 110: 1 -> 12

Clado 109: $12 \rightarrow>2$

Characidium bahiensis: 12 -> 1

Crenuchus spilurus: $12 \rightarrow>2$

Clado 160: 1 -> 12:

Clado 147: $1 \rightarrow 12$

Chalceus epakros: 12 -> 2

Brycon pesu: 12 ->

Piabucina astrigata: 1 -> 0

Arnoldichthys spilopterus: $12 \rightarrow 1$

Bivibranchia fowleri: $2 \rightarrow 0$

Clado 116: $2 \rightarrow 3$
Clado 145: 12 -> 1

Clado 197: 12 -> 123

Citharinus latus: $2 \rightarrow 3$

Hydrolycus tatauaia: $12->3$

Brycinus macrolepidotus: 12 -> 1

Bryconalestes longipinnis: 12 -> 2

Piaractus mesopotamicus: $123 \rightarrow 3$

Landonia latidens: $1 \rightarrow 2$

Gilbertolus atratoensis: 12 -> 1

Roestes molossus: 12 -> 2

Metynnis lippincottianus: $123->1$

Myleus setiger: $123->3$

Leporellus vittatus: $2 \rightarrow 3$

Hemibrycon polyodon: $1-3$

Hemibrycon polyodon : $1->0$
Bryconamericus exodon: $1->2$
Piabina argentea: $1->2$

Brittanichthys axelrodi: 1 -> 2

Brittanichthys axe

Bryconops alburnoides: $1->2$

Stygichthys typhlops: $1 \rightarrow 2$

Clado 130: $1 \rightarrow 0$

Caráter 273 ( 4 passos)

Raiz: $\odot$

lado 197: $\odot \rightarrow 01$

Hydrolycus tatauaia: $\odot->1$

Piaractus mesopotamicus: 01 -> 1

Myleus setiger: $01 \rightarrow 1$

Triportheus albus: $0->1$

caráter 274 (20 passos)

Raiz: 0

Clado 182: $0 \rightarrow 1$

Clado 146: $0 \rightarrow 01$

Gnathocharax steindachneri: 0 -> 2

Clado 138: $\odot \rightarrow 1$

Clado 199: $\odot \rightarrow$

Acestrorhynchus falcirostris: 01 -> 1

Hydrolycus tatauaia: 01 -> 0

Clado 149: 01 -> 012

Clado 196: $0 \rightarrow 1$

Hepsetus odoe: $01 \rightarrow 0$

Clado 155: $01 \rightarrow 1$

Gilbertolus atratoensis: $012->2$

Roestes molossus: 012 -> 1

Phenacogaster pectinatus: $\odot->1$

Clado 168: $1 \rightarrow 0$

Atopomesus pachyodus: $0->1$

Rhoadsia altipinna: $0->1$

Clado 131: $1 \rightarrow 2$

Iguacladoctes geisleri: $1 \rightarrow 0$

Rachoviscus graciliceps: $0->1$

Triportheus albus: $1 \rightarrow 0$

Clado 188: $0 \rightarrow 1$

Clado 193: $\odot$

Caráter 275 (11 passo)

Raiz: 01

Chanos chanos: $01->0$

Clado 111: 01 -> 1

Catostomus commersonnii: 01 -> 0

Olivaichthys mesembrinus: $01 \rightarrow 1$

Clado 107: $1 \rightarrow 01$

Distichodus notospilus: $01->0$

Hemistichodus vaillanti: $01 \rightarrow$

Nannocharax fasciatus: $01->0$

Citharinus latus: $01 \rightarrow 0$

Xenocharax spilurus: $01->1$

Clado 128: 1 -> 01

Schizodon fasciatus: $01->0$

Leporellus vittatus: $01 \rightarrow 1$

Leporinus fasciatus: $01 \rightarrow$

Piabina argentea: $1->0$

Rachoviscus graciliceps: 1 -> 0

Clupeacharax engrauloides: $1 \rightarrow \odot$

caráter 276 (12 passos)

Raiz: 0

Clado 110: $0 \rightarrow 1$

Salminus hilarii: $0->1$

Apareiodon piracicabae: 1 -> $\theta$

Clado 197: $\odot \rightarrow 1$

Chilodus punctatus: 1 -> 2

Clado 128: 1 -> 2

Serrabrycon magoi: $\odot \rightarrow 1$

Clado 168: $\odot \rightarrow 1$

Clado 184: $\odot \rightarrow$

Clado 186: 1 ->

Markiana nigripinnis: 1 -> 0

Caráter 277 ( 7 passos)

Raiz: $\odot$

Clado 111: $0 \rightarrow 01$

Clado 109: $01 \rightarrow 0$

Clado 163: $01 \rightarrow 1$

Clado 143: $01 \rightarrow 1$

Clado 153: 01 -> 1

Hemistichodus vaillanti: $0->1$

Acestrorhynchus falcirostris: $1 \rightarrow 0$

Piaractus mesopotamicus: $0 \rightarrow 1$

Curimatopsis macrolepis: $0 \rightarrow 1$

Caráter 278 (37 passos)

Raiz: 23

Catostomus commersonnii: 23 -> 3

Clado 104: $23 \rightarrow 0123$

Clado 144: $23 \rightarrow 123$

Olivaichthys mesembrinus: $0123->0$

Clado 143: $123 \rightarrow 1$

Crenuchus spilurus: 23 -> 3

Clado 153: $123 \rightarrow 0$

Clado 160: 123 -> 3

Clado 107: 23 -> 3

Clado 118: 23 -> 2

Saccodon wagneri: 23 -> 2

Clado 113: 23 -> 3

Hemistichodus vaillanti: $3 \rightarrow 23$

Gnathocharax steindachneri: $1 \rightarrow 0$

Clado 150: $1 \rightarrow 12$

Clado 158: $\odot \rightarrow 01$

Clado 161: $3 \rightarrow 1$

Clado 126: $2 \rightarrow 3$

Hydrolycus tatauaia: $12->2$

Hydrolycus tatauaia: $12->2$

Curimatopsis macrolepis: 2 -> 1

Caenotropus labyrinthicus: $2 \rightarrow 012$

Phenagoniates macrolepis: 1 -> 9

Gilbertolus atrator

Roestes molossus: 12 -> 1

Potamorhina latior: 2 -> 12

Clado 168: $0 \rightarrow 1$

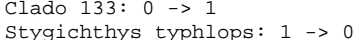

Clupeacharax engrauloides: $1 \rightarrow 0$

Agoniates halecinus: 1 -> 01

Thoracocharax stellatus : 1 -> 3

Poptella brevispina: $1 \rightarrow 2$

Caráter 279 ( 35 passos)

Raiz: 01

Chanos chanos: $01 \rightarrow$

Catostomus commersonnii: 01 -> 0

Clado 104: 01 -> 01234

Clado 144: $01 \rightarrow 2$

Olivaichthys mesembrinus: 01234 -> 4

Clado 108: $01 \rightarrow 0$

Clado 115: $01 \rightarrow 1$

Characidium bahiensis: 01 -> 1

Crenuchus spilurus: $01 \rightarrow 0$

Clado 153: $2 \rightarrow 3$

Clado 118: $1 \rightarrow 2$

Chalceus epakros: 2 -> 1

Nannocharax fasciatus: $0 \rightarrow 1$

Gnathocharax steindachneri: 2 -> 3

Erythrinoidea fam. nov: $3 \rightarrow 4$

Clado 158: $3 \rightarrow 2$

Clado 161: $2 \rightarrow>3$

Clado 197: $2 \rightarrow 0$

$\begin{array}{ll}\text { Clado 126: } & 2 \rightarrow 1 \\ \text { Clado 156: } & 2 \rightarrow 3\end{array}$

Hydrolycus tatauaia: $2->1$

Hoplias malabaricus: $2 \rightarrow$

Clado 137: $2 \rightarrow 3$

Hepsetus odoe: $3 \rightarrow 4$

Roestes molossus: 2 -> 3

Clado 168: $3 \rightarrow 2$
Clado 133: $3 \rightarrow 2$

Clado 133: 3 ->

Stygichthys typhlops: 2 -> 4

clupeacharax engrauloides: $2 \rightarrow$

Thoracocharax stellatus : 2 -> $\odot$

Carnegiella strigata: $2 \rightarrow 3$

Poptella brevispina: $2 \rightarrow 1$

Caráter 280 (22 passos)

Raiz: 0

Clado 104: $0 \rightarrow 01$

Clado 110: $0 \rightarrow 1$

Olivaichthys mesembrinus: $01 \rightarrow 1$

Clado 118: $1 \rightarrow 0$

Clado 152: $0 \rightarrow 1$

Roeboexodon guyanensis: $\odot->1$

Hydrolycus tatauaia: $0 \rightarrow 1$

Erythrinus erythrinus: $1->0$

Bryconalestes longipinnis: $\theta->1$

Clado 155: $0 \rightarrow 1$

Schizodon fasciatus: $\odot->1$

Phenacogaster pectinatus: $0 \rightarrow 1$

Bryconadenos tanaothoros: $0 \rightarrow 1$

Knodus meridae: $0 \rightarrow 1$

Deuterodon iguape: $0 \rightarrow-1$

Axelrodia reisel: $0 \rightarrow 1$

Paracheirodon axelrodi: 0 -> 1

Compsura heterura: $\Theta \rightarrow 1$

Bryconops alburnoides: $0 \rightarrow 1$

Clado 130: $\odot \rightarrow 1$

Gymnocorymbus ternetzi: $\odot->1$

Hyphessobrycon compressus: $0->1$ 
Clado 102: 01 -> $\odot$

Clado 110: $01 \rightarrow 0$

Clado 142: $01 \rightarrow 0$

Clado 148: $01 \rightarrow 1$

Clado 153: $01 \rightarrow$

Chalceus epakros: 01 -> 1

$\begin{array}{lll}\text { Arnoldichthys spilopterus: } & 01 & ->0 \\ \text { Gnathocharax steindachneri: } 0 & \rightarrow & 1\end{array}$

Clado 199: 0 -> 1

Brycinus macrolepidotus: $01->1$

Bryconalestes longipinnis: $01->0$

Piaractus mesopotamicus: $01 \rightarrow 1$

Clado 196: $\theta 1 \rightarrow 0$

Clado 155: $1 \rightarrow 2$

Stygichthys typhlops: $0->1$

Thoracocharax stellatus : $1 \rightarrow 2$

Caráter 283 ( 21 passo)

Caráter

Raiz: 1 : 115 : 1 -> 01

Clado 115: $1->01$

Clado 153: $1 \rightarrow 0$

Salminus hilarii: $1 \rightarrow 0$

Salminus hilarii: $1 \rightarrow$

Saccodon wagneri: 01 -> 0

Clado 117: $01 \rightarrow 1$

Clado 122: $01->0$

Clado 162: $1 \rightarrow \odot$

Apareiodon piracicabae: $01 \rightarrow$

Parodon nasus: $01 \rightarrow \Theta$

Clado 150: $1 \rightarrow 0$

Citharinus latus: $01 \rightarrow 1$

Xenocharax spilurus: $01 \rightarrow 0$

Hoplias malabaricus: $0 \rightarrow 1$

Clado 184: 1 -> 01

Bryconamericus exodon: 1 -> 0

Odontostilbe pequira: $01->0$

Axelrodia reisei: $1 \rightarrow 0$

Compsura heterura: $01->0$

Rhoadsia altipinna: $01 \rightarrow 1$

Iguacladoctes geisleri: $1->0$

Stygichthys typhlops: $1 \rightarrow 0$

Agoniates halecinus: $1 \rightarrow 0$

Clado 129: $1 \rightarrow 0$

Markiana nigripinnis: 1 -> 0

Ctenobrycon hauxwellianus: $1 \rightarrow \oplus$

Caráter 284 ( 1 passo)

Caráter 28

Clado 196: $0 \rightarrow>1$

Caráter 285 ( 8 passos)

Raiz: $\odot$

Charax cf. leticiae: $\odot->1$

Clado 197: $0 \rightarrow 1$

Clado 199: $\odot \rightarrow 1$

Phenacogaster pectinatus: 0 ->

Atopomesus pachyodus: $0 \rightarrow$

Rhoadsia altipinna: $\odot \rightarrow$

Clado 188: 0 -> 01

Clado 187: 01 -> 1

Markiana nigripinnis: 01 -> 1

Tetragonopterus argenteus: $01->0$

caráter 286 ( 3 passos)

Raiz: $\odot$

Charax cf. leticiae: $0->1$

Clado 187: $\odot \rightarrow 1$

Poptella brevispina: 1 -> $\odot$

Caráter 287 (11 passo)

Raiz: $\odot$

Catostomus commersonnii: $0->1$

Clado 114: $0 \rightarrow 1$

Paragoniates alburnus: $0 \rightarrow 1$

Curimata ocellata: $0 \rightarrow 1$

Phenacogaster pectinatus: 0 -> 1

Atopomesus pachyodus: $0 \rightarrow 1$

Rhoadsia altipinna: $0->1$

Iguacladoctes geisleri: $0 \rightarrow 1$

Clado 191: $0 \rightarrow 1$

Clado 186: $0->1$

Markiana nigripinnis:

aráter 288 ( 3 passos)

Raiz: 0

Catostomus commersonnii: $0->1$

Clado 114: $0 \rightarrow 1$

Nannocharax fasciatus: $0 \rightarrow 1$

Caráter 289 (10 passos)

Raiz: 1

Clado 104: $1 \rightarrow 0$

Clado 143: $1 \rightarrow 0$

Clado 162: $1 \rightarrow 01$

Erythrinoidea fam. nov: 1 -> $\odot$

Clado 156: $\odot \rightarrow$

Hydrolycus tatauaia: $\odot \rightarrow 1$

Brycinus macrolepidotus: 01 -> 1

Bryconalestes longipinnis: $01 \rightarrow 0$

Piaractus mesopotamicus: $01 \rightarrow 0$

Metynnis lippincottianus: $01 \rightarrow 0$

Myleus setiger: $01-1$

Bryconadenos tanaothoros: 0 -> 1

Bryconops alburnoides: $\odot->1$

Caráter 290 (19 passos)

Raiz: $\odot$

Clado 111: $0 \rightarrow 1$

Clado 118: 1 -> 01

Salminus hilarii: $1 \rightarrow 0$

Bivibranchia fowleri: 01 -> 0
Clado 121: 01 -> 1

Roeboexodon guyanensis: 1 -> 0

Anodus orinocensis: $01 \rightarrow 1$

Hemiodus unimaculatus : $01 \rightarrow 0$

Aphyocharax pusillus: $1 \rightarrow 0$

Caenotropus labyrinthicus: 01 -> 1

Chilodus punctatus: $01 \rightarrow 0$

Anostomus anostomus: $01 \rightarrow \theta$

Serrabrycon magoi: 1 -> 0

Metynnis lippincottianus: 1 -> 0

Schizodon fasciatus: $01->0$

Clado 127: 01 -> 1

Rhinobrycon negrensis: 1 -> 0

Clado 168: 1 -> 01

Moenkhausia xinguensis: 01 -> 0

Bryconadenos tanaothoros: $1 \rightarrow 0$

Clado 174: $1 \rightarrow 0$

Deuterodon iguape: $01->0$

Agoniates halecinus: 1 -> 0

Hyphessobrycon compressus: 1 -> 0

Caráter 291 (15 passos)

Raiz: $\odot$

Clado 104: $\odot \rightarrow 1$

Clado 110: $0 \rightarrow 01$

lado 163: 01 -> 1

Neolebias unifasciatus: $01->0$

Clado 114: $01->1$

Clado 118: $01 \rightarrow 0$

Clado 152: $\odot \rightarrow 1$

Clado 106: 01 -> 1

Hemistichodus vaillanti: $01->1$

Nannocharax fasciatus: $01->0$

Clado 197: 0 -> 1

Phenagoniates macrolepis: 0 -> 1

Clado 155: 0 -> 1

Roestes molossus: $0 \rightarrow 1$

Axelrodia reisei: $0 \rightarrow 1$

Compsura heterura: $0 \rightarrow 1$

Clado 130: $0 \rightarrow 1$

Gymnocorymbus ternetzi: $0 \rightarrow 1$

Ctenobrycon hauxwellianus: $0 \rightarrow 1$

Caráter 292 ( 32 passos)

Raiz: 1

Catostomus commersonnii: $1 \rightarrow 0$

Clado 110: $1 \rightarrow 0$

Gymnotus aff. carapo: 1 -> 3

Clado 143: $1 \rightarrow 2$

Clado 153: 1 -> 01

Clado 157: $01 \rightarrow 0$

Chalceus epakros: 1 -> 01

Clado 106: $\odot \rightarrow 1$

lado 181: $2 \rightarrow$

Copeina cf. guttata: $01 \rightarrow 0$

lado 150: 2 ->

Erythrinoidea fam. nov: $01->1$

Clado 197: 1 -> 2

Citharinus latus: 1 -> 2

Anodus orinocensis: $\odot \rightarrow 1$

Clado 173: 2 -> 12

Aphyocharax pusillus: 2 -> 1

Clado 199: $2 \rightarrow 3$

Clado 156: $2 \rightarrow$

Erythrinus erythrinus: $01->0$

Hoplias malabaricus: $01 \rightarrow 12$

Clado 196: 2 -> 3

Chilodus punctatus: $0->01$

Landonia latidens: $2 \rightarrow 23$

Serrabrycon magoi: $12 \rightarrow>1$

Potamorhina latior: $0->1$

Clado 179: 2 -> 1

Phenacogaster pectinatus: 12 -> 3

Clado 171: $12 \rightarrow 1$

Atopomesus pachyodus: 1 -> 12

Glandulocauda melanogenys: 2 -> 1

Rlanducauda melanogenys:

Clado 131: $2 \rightarrow 23$

Bryconops alburnoides: $2 \rightarrow$

Astyanax mexicanus: 2 -> 1

Rachoviscus graciliceps: 1 -> 2

Stygichthys typhlops: $1->01$

Clupeacharax engrauloides: $23->3$

Clado 188: $2 \rightarrow 3$

Thoracocharax stellatus : $23->3$

Clado 129: $23 \rightarrow 2$

Orthospinus franciscoensis: 3 -> 23

Hollandichthys multifasciatus: $2->23$

caráter 293 (22 passos)

Raiz: 0

Clado 102: $\odot \rightarrow 1$

Clado 154: $0 \rightarrow 1$

Characidium bahiensis: 0 -> 1

Clado 107: $\odot \rightarrow 01$

Clado 112: 01 -> 1

Distichodus notospilus: 01 -> 1

Clado 105: 01 - $>0$

Apareiodon piracicabae: 0 -> 1

Clado 125: $\odot \rightarrow 01$

Charax cf. leticiae: 0 -> 1

Clado 126: $01 \rightarrow 1$

Clado 199: $0 \rightarrow 1$

Brycinus macrolepidotus: 1 -> 0

Caenotropus labyrinthicus: $01 \rightarrow$

Chilodus punctatus: $01 \rightarrow 1$

Clado 155: $0 \rightarrow 1$

Roestes molossus: $0->1$

Myleus setiger: 1 - 0

Leporellus vittatus: 1 -> 0

Knodus meridae: $0->$

Brittanichthys axelrodi: $0 \rightarrow 1$

Stygichthys typhlops: $0 \rightarrow 1$

Clado 130: $0 \rightarrow 1$

Clado 188: $0 \rightarrow 01$

Clado 195: 01 ->

Gymnocorymbus ternetzi: 01 -> 1

Orthospinus franciscoensis: $01 \rightarrow$

Ctenobrycon hauxwellianus: $01->1$

Poptella brevispina: $01 \rightarrow 0$

Caráter 294 (15 passos)

Raiz: 0

Characidium bahiensis: $\Theta->1$

Clado 142: $0 \rightarrow 1$

Roeboexodon guyanensis: 1 -> 0

Erythrinoidea fam. nov: $\odot->1$

Aphyocharax pusillus: 1 -> 0

firostris: $0 \rightarrow 1$

Anostomus anostomus: $0 \rightarrow 1$

Phenacogaster pectinatus: $1 \rightarrow 0$

Leporinus fasciatus: $\odot \rightarrow 1$

Clado 175: $1 \rightarrow 01$

Glandulocauda melanogenys: 1 -> 0

Axelrodia reisei: $01 \rightarrow 0$

Brittanichthys axelrodi: $01->1$

Paracheirodon axelrodi: $01 \rightarrow 0$

Rachoviscus graciliceps: 01 -> 1

Stygichthys typhlops: $01->0$

Clado 195: 1 - 01

Tetragonopterus argenteus: $01->0$

orthospinus franciscoensis: $1 \rightarrow 0$

Caráter 295 (13 passos)

Raiz: 0

Clado 102: $0 \rightarrow 1$

Crenuchus spilurus: $0->1$

Clado 107: 0 -> 01

Clado 152: $0 \rightarrow 1$

Clado 106: $01 \rightarrow 1$

Clado 113: $0 \rightarrow 1$

Hemistichodus vaillanti: 01 -> 1

Nannocharax fasciatus: $01 \rightarrow 0$

Galeocharax knerii: $0 \rightarrow 1$

Clado 124: $0 \rightarrow 1$

Curimatopsis macrolepis: $0->1$

Currabrycon magoi: 0 -> 1

Metynnis lippincottianus: $0->1$

Microschemobrycon casiquiare: 0 -> 1

Microschemobrycon casiqu

Caráter

Clado 162: $\odot \rightarrow 01$

Clado 161: $01 \rightarrow 1$

Piaractus mesopotamicus: 01 -> 0

Clado 196: $01 \rightarrow 1$

Hepsetus odoe: $\odot \rightarrow 1$

Rhoadsia altipinna: $\odot->01$

Caráter 297 ( 5 passos)

Raiz: 1

Chalceus epakros: 1 -> 0

Clado 161: $1 \rightarrow 0$

Hoplias malabaricus: $1 \rightarrow 0$

Clado 155: $1 \rightarrow$

Potamorhina latior: 1 -> 0

Caráter 298 (19 passos)

Raiz: 2

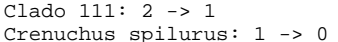

Clado 153: $1 \rightarrow 12$

Clado 160: $1 \rightarrow 0$

Clado 118: $1 \rightarrow 0$

Clado 152: 12 ->

Lebiasina bimaculata: $12 \rightarrow>$

Piabucina astrigata: $12 \rightarrow 2$

Hemistichodus vaillanti: $1 \rightarrow 2$

Clado 197: 0 -> 01

Clado 156: 1 -> 01

Piaractus mesopotamicus: 01 -> 1

Hepsetus odoe: $01 \rightarrow 0$

Metynnis lippincottianus: 01 -> 1

Myleus setiger: $01 \rightarrow 0$

Potamorhina latior: $0 \rightarrow 3$

Boulengerella maculata: 01 -> 1 
Phenagoniates macrolepis: $\odot->1$

Potamorhina latior: $\Theta \rightarrow 1$

Rhinobrycon negrensis: $\odot->12$

Microschemobrycon casiquiare: $0->1$

Bryconamericus exodon: $\odot->2$

Knodus meridae: $\odot \rightarrow 1$

Clado 174: $\theta \rightarrow 1$

Clado 130: $0 \rightarrow 012$

Triportheus albus: 0 -> 1

Thoracocharax stellatus : 012 -> 2

Clado 129: 012 -> 1

Markiana nigripinnis: $\odot->1$

Caráter 300 (23 passos)

Raiz: 1

Clado 142: $1 \rightarrow 0$

Clado 142: $1 \rightarrow 0$

Gnathocharax steindachneri: 0 -> 1

Galeocharax knerii: $0 \rightarrow 1$

Galeocharax kneri: $138: 0 \rightarrow 1$

Clado 138: $0 \rightarrow 1$

Hydrolycus tatauaia: $1 \rightarrow 0$

Bryconalestes longipinnis: $\odot->1$

$0 \rightarrow 1$

Prochilodus nigricans: 1 -> 0

Chilodus punctatus: $1 \rightarrow \infty$

Paragoniates alburnus: $0->1$

Potamorhina latior: $1->0$
Leporinus fasciatus: $1 \rightarrow 0$

Leporinus fasciatus: $1->$
Clado 169: $1->0$

Deuterodon iguape: $\odot \rightarrow 1$

Clado 164: $1 \rightarrow 0$

Iguacladoctes geisleri: $1 \rightarrow 0$

Stygichthys typhlops: $0 \rightarrow 1$

Thoracocharax stellatus : $1 \rightarrow 0$

Clado 187: $0 \rightarrow 1$

Probolus heterostomus : $0->1$

Poptella brevispina: 1 -> 0

Caráter 301 (17 passos)

Raiz: 1

Catostomus commersonnii: $1 \rightarrow 2$

Clado 115: 1 -> 2

Clado 148: $1 \rightarrow 2$

Clado 160: $1 \rightarrow 12$

Chalceus epakros: $12->2$

Clado 151: 1 -> 01

Arnoldichthys spilopterus: 12 -> 1

Clado 162: $12 \rightarrow 2$

Elado 162: $12->2$ fryrinoidea fam. nov: $01->0$

Clado 120: $2 \rightarrow 12$

$\begin{array}{ll}\text { Clado 120: } & 2->12 \\ \text { Clado 156: } 2->1\end{array}$

Erythrinus erythrinus: $01 \rightarrow 0$

Hoplias malabaricus: $01->1$

Hoplias malabaricus: $01->1$

Curimatopsis macrolepis: 12

Chilodus punctatus: $2->1$

Gilbertolus atratoensis: $2 \quad>1$

Metynnis lippincottianus: 2

Curimata ocellata: $12 \rightarrow>2$

Potamorhina latior: $12 \quad->1$

Clado 164: $1 \rightarrow 2$

Bryconops alburnoides: $1 \rightarrow 2$

Stygichthys typhlops: $1 \rightarrow 0$

Caráter 302 ( 35 passos)

Raiz: $\odot$

Clado 111: $0 \rightarrow 01$

Clado 144: $01 \rightarrow 1$

Clado 109: $01 \rightarrow$

Clado 163: $01 \rightarrow>$

Clado 148: $1 \rightarrow 12$

Salminus hilarii: $12->2$
Chalceus epakros: $1->2$

Clado 140: 1 -> 01

Brycon pesu: $12->2$

Clado 151: $1 \rightarrow 0$

Piabucina astrigata: $1->2$

Arnoldichthys spilopterus: $1 \rightarrow 0$

Roeboexodon guyanensis: $1 \rightarrow 2$

Charax cf. leticiae: 1 - $>0$

Charax cf: leticiae

Clado 150: $12 \rightarrow>01$

Clado 161: $1->2$ phyocharax pusillus: $01->1$

Acestrorhynchus falcirostris: $12 \rightarrow$

Hydrolycus tatauaia: $01 \rightarrow 0$

Curimatopsis macrolepis: $2->1$

Chilodus punctatus: $2 \rightarrow 0$

Anostomus anostomus: $2 \rightarrow 1$

Landonia latidens:

Clado 137: $01 \rightarrow 0$

Serrabrycon magoi: $01->$

Hepsetus odoe: $12 \rightarrow 1$

Gilbertolus atratoensis: 01 -> 1

Roestes molossus: $01 \rightarrow$

Metynnis lippincottianus: 1 -> 2

Phenacogaster pectinatus: 01 - $>1$

Clado 171: 01 -> $\odot$

Boulengerella maculata: $12 \rightarrow>$

Ctenolucius hujeta: $12->1$

Glandulocauda melanogenys: $\odot \rightarrow$

Moenkhausia xinguensis: $0 \rightarrow 1$

Bryconadenos tanaothoros: $0->1$

Compsura heterura: $0 \rightarrow 1$

Bryconops alburnoides: $0 \rightarrow 2$

Bryconops alburnoides: $\Theta \overrightarrow{ }->$

Thoracocharax stellatus : $\odot>\rightarrow$

Caráter 303 (1 passo)

Raiz: 1
Clado 102: 1 -> $\odot$

Caráter 304 ( 6 passos)

Raiz: 01

Chanos chanos: 01 -> 1

Clado 103: 01 -> 0

Clado 108: $0 \rightarrow 1$

Clado 117: $0 \rightarrow>1$

Piabucina astrigata: $\Theta \rightarrow 1$

Brycinus macrolepidotus: $0->1$

Caráter 305 (6 passos)

Raiz: 1

Clado 108: 1 -> 0

Crenuchus spilurus: $1->0$

Clado 116: $1 \rightarrow 0$

Hydrolycus tatauaia: 1 -> 0

Metynnis lippincottianus: 1 -> 0

Piabina argentea: $1 \rightarrow 0$

Caráter 306 (21 passo)

Raiz: 01

Chanos chanos: 01 -> 1

Clado 103: $01 \rightarrow 0$

Clado 109: 01

Clado 108: $01->1$

Clado 142: $0 \rightarrow 01$

Clado 114: $01 \rightarrow 1$

Clado 118: $01 \rightarrow 0$

$\begin{array}{ll}\text { Clado 157: } & 0 \rightarrow>1 \\ \text { Clado 190: } & 01->1\end{array}$

Oligosarcus argenteus: 01 -> 1

Clado 181: $01 \rightarrow 0$

Clado 146: $\odot \rightarrow 1$

Clado 162: $\odot \rightarrow 01$

Clado 139: $01 \rightarrow 0$

Erythrinoidea fam. nov: 0 -> 1

Clado 197: 01 -> 1

Anodus orinocensis: $0 \rightarrow 1$

Aphyocharax pusillus: $01 \rightarrow 1$

Hydrolycus tatauaia: 1 -> 2

Brycinus macrolepidotus: $01->1$

Bryconalestes longipinnis: $01->0$

Paragoniates alburnus: $01->$

Phenagoniates macrolepis: $01 \rightarrow 1$

Diapoma terofali: $0 \rightarrow 1$

Hemibrycon polyodon : $0->1$

Brittanichthys axelrodi: $0 \rightarrow 1$

Clado 200: $0 \rightarrow 1$

Bryconops alburnoides: $\odot->1$

Astyanax mexicanus: $0 \rightarrow 1$

Agoniates halecinus: $0 \rightarrow 1$

Caráter 307 ( 8 passos)

Raiz: 0

Clado 108: $\odot \rightarrow 1$

Oligosarcus argenteus: $\odot->2$

Clado 156: 2 ->

Brycinus macrolepidotus: $\odot->2$

Clado 196: $\odot \rightarrow 1$

Brittanichthys axelrodi: $0->2$

Gymnocorymbus ternetzi: $0->1$

caráter 308 (2 passos)

Raiz: 01

Chanos chanos: $01->0$

Clado 111: $01 \rightarrow 1$

Catostomus commersonnii: 01 -> 0

Olivaichthys mesembrinus: $01 \rightarrow 1$

Caráter 309 (2 passos)

Raiz: 0

Clado 102: $\odot->1$

Clado 151: $0 \rightarrow>1$

Caráter 310 ( 2 passos)

Raiz: $\odot$

Nannocharax fasciatus: $\odot->9$

Clado 158: $0 \rightarrow 1$

Caráter 311 ( 7 passos)

Caráter

Clado 160: $0 \rightarrow 1$

Piaractus mesopotamicus: $01 \rightarrow 0$

Metynnis lippincottianus: $01 \rightarrow 0$

Myleus setiger: $01 \rightarrow 1$

Potamorhina latior: 0 - $>1$

Clado 164: $0 \rightarrow 1$

Astyanax mexicanus: $\odot->1$

Poptella brevispina: $0 \rightarrow 1$

Caráter 312 ( 8 passos)

Raiz: 2

Crenuchus spilurus: 2 -> 1

Clado 152: $2 \rightarrow 12$

Clado 113: 2 ->

Copeina cf. guttata: 12 -> 1

Arnoldichthys spilopterus: $2 \rightarrow 1$

Erythrinoidea fam. nov: $12 \rightarrow 0$

Clado 158: $12 \rightarrow 2$

Clado 124: $2 \rightarrow 1$

Schizodon fasciatus: 2 -> 1

Caráter 313 (17 passos)

Raiz: 2

Clado 110: 2 -> 12

Clado 163: $12 \rightarrow 1$

Clado 108: $12 \rightarrow 2$

Clado 114: $12 \rightarrow 1$

Clado 152: $2 \rightarrow 1$

Clado 122: $12 \rightarrow 1$

Arnoldichthys spilopterus: 2 -> 1

Bivibranchia fowleri: $12 \rightarrow>2$

Gnathocharax steindachneri: 2 -> 1

Erythrinoidea fam. nov: $1 \rightarrow 0$

Citharinus latus: 2 -> 1

Anodus orinocensis: $12->2$

Clado 124: $1 \rightarrow 0$

Clado 149: $2 \rightarrow 1$

Clado 196: $2 \rightarrow 1$

Paragoniates alburnus: 2 -> 1

Potamorhina latior: $1->2$

Ctenolucius hujeta: $2 \rightarrow 1$

Rhoadsia altipinna: $2 \rightarrow 01$

Clado 129: $2 \rightarrow 1$

Caráter 314 (16 passos)

Raiz: 0

Clado 104: $0 \rightarrow 01$

Olivaichthys mesembrinus: $01->1$

Clado 113: $0 \rightarrow 1$

Oligosarcus argenteus: $\odot \rightarrow 1$

Piabucina astrigata: $0 \rightarrow 1$

Clado 162: $0 \rightarrow 1$

Roeboexodon guyanensis: $0->1$

Clado 150: $\odot \rightarrow 01$

Clado 158: $0 \rightarrow 1$

Xenocharax spilurus: $\odot \rightarrow 1$

Hydrolycus tatauaia: $01 \rightarrow 1$

Clado 128: $\odot \rightarrow 01$

Gilbertolus atratoensis: 01 -> 0

Roestes molossus: $01-1$

Clado 127: $01 \rightarrow 1$

Deuterodon iguape: 0 -> 1

Clado 164: $\odot \rightarrow 1$

Bryconops alburnoides: $\odot->1$

Stygichthys typhlops: $0 \rightarrow 1$

Poptella brevispina: $\odot \rightarrow 1$

Caráter 315 ( 2 passos)

Raiz: 01

Chanos chanos: 01 -> 1

Clado 103: $01 \rightarrow 0$

Clado 151: $0 \rightarrow 2$

Caráter 316 ( 2 passos)

Raiz: 01

Chanos chanos: 01 ->

Clado 111: $01 \rightarrow 1$

Catostomus commersonnii: 01 -> $\theta$

Clado 104: $01 \rightarrow 1$

Caráter 317 (14 passos)

Raiz: 0

Catostomus commersonnii: $\odot->1$

Clado 108: $\Theta \rightarrow 2$

Arnoldichthys spilopterus: $\odot->1$

Gnathocharax steindachneri: $0 \rightarrow>2$

Clado 158: $012 \rightarrow 2$

Hepsetus odoe: $0 \rightarrow 2$

Roestes molossus: $0 \rightarrow 2$

Glandulocauda melanogenys: $0 \rightarrow 1$

Hollandichthys multifasciatus: $\odot \rightarrow 1$

Caráter 318 ( 1 passo)

Raiz: 01

Chanos chanos: $01->0$

Clado 103: $01 \rightarrow 1$

Caráter 319 (1 passo)

Raiz: 01

Chanos chanos: $01->0$

Clado 103: $01 \rightarrow 1$

Caráter 320 (17 passos)

Raiz: 1

Clado 110: 1 -> 01

Clado 109: $01 \rightarrow 0$

Characidium bahiensis: 01 -> 0

Crenuchus spilurus: $01->1$

Clado 153: $1 \rightarrow 0$

Salminus hilarii: $1 \rightarrow \theta$

Arnoldichthys spilopterus: 1 -> $\odot$

Distichodus notospilus: $0 \rightarrow 1$

Clado 116: $0 \rightarrow 1$

Gnathocharax steindachneri: 1 -> $\odot$

Clado 123: $0 \rightarrow 1$

Clado 156: 1 -> 0

Hoplias malabaricus: $0 \rightarrow 1$

Clado 128: $0 \rightarrow 01$

Phenagoniates macrolepis: 1 -> 0

Schizodon fasciatus: $01 \rightarrow 1$ 
Raiz: $\odot$

Clado 148: $0 \rightarrow$

Clado 151: $0 \rightarrow 1$

Lebiasina bimaculata: $0 \rightarrow 1$

Clado 162: 0 -> 01

Charax cf. leticiae: $0 \rightarrow 1$

Clado 197: 01 -> 1

Hydrolycus tatauaia: 1 -> $\odot$

Brycinus macrolepidotus: $01->1$

Bryconalestes longipinnis: $01->\odot$
Semaprochilodus insignis: $\odot->1$

Clado 180: $\odot \rightarrow->$

Stygichthys typhlops: $0->1$

Triportheus albus: $0 \rightarrow 1$

Caráter 325 (21 passo)

Clado 104: $0 \rightarrow 1$

Clado 154: $0 \rightarrow 1$

Clado 115: $0 \rightarrow 01$

Clado 113: $01 \rightarrow 1$

Clado 117: $01 \rightarrow$

Piabucina astrigata: $1 \rightarrow$

Arnoldichthys spilopterus: 1 -> 0

Clado 123: $01 \rightarrow \odot$

Clado 124: $01 \rightarrow$

Curimatopsis macrolepis: 01 -> 1

Anostomus anostomus: $01 \rightarrow 1$

Clado 128: 01 -> 0

Paragoniates alburnus: $0 \rightarrow 1$

Clado 155: $0 \rightarrow 1$

Gilbertolus atratoensis: $0->1$

Curimata ocellata: $01 \rightarrow 0$

Potamorhina latior: $01 \rightarrow 1$

Clado 179: 0 -> 01

Rhinobrycon negrensis: 01 -> 1

Hemibrycon polyodon : $0 \rightarrow 1$

Clado 177: $01 \rightarrow$

Clado 194: $01 \rightarrow 0$

Clado 175: $0 \rightarrow 1$

Compsura heterura: $\theta \rightarrow 1$

Clado 131: $\odot$-> 01

Clupeacharax engrauloides: $01 \rightarrow 1$

Thoracocharax stellatus : $01 \rightarrow 0$

Clado 129: 01 - 1

Gymnocorymbus ternetzi: $\odot \rightarrow 1$

$\begin{array}{lll}\text { Gymnocorymbus ternetzi: } 0 & -> & 1 \\ \text { Hyphessobrycon compressus: } & 0 & ->1\end{array}$

caráter 326 ( 1 passo)

Raiz: 01

Chanos chanos: $01 \rightarrow 0$

Clado 103: 01 ->

Caráter 327 (17 passos)

Raiz:

Clado 153: $\odot \rightarrow>1$

Clado 114: $0 \rightarrow 01$

Clado 182: $0 \rightarrow 01$

Clado 113: $01->1$

Clado 113: $01->1$

Oligosarcus argenteus:

Brycon pesu: $01->1$
Nannocharax fasciatus: $0 \rightarrow 1$

Clado 165: $0 \rightarrow 1$ - $01 \rightarrow 1$

Charax cf. leticiae: $01 \rightarrow 1$
Galeocharax knerii: $01 \rightarrow 0$

Clado 145: $01 \rightarrow 0$

Curimatopsis macrolepis: $\odot->1$

Anostomus anostomus: $0 \rightarrow 1$

Gilbertolus atratoensis: $01 \rightarrow 1$

Phenacogaster pectinatus: 0 -> 1

Atopomesus pachyodus: $0 \rightarrow 1$

Clado 133: $0 \rightarrow 1$

Odontostilbe pequira: $0 \rightarrow 1$

Astyanax mexicanus: $0 \rightarrow 1$

Clupeacharax engrauloides: $1 \rightarrow 0$

Probelus heterostomus : $\rightarrow 1$

Caráter 328 ( 2 passos)

Caráter

Raiz: 1 1 1 - $>0$

Clado 111: $1->0$

Caráter 329 (23 passos)

Raiz: 1

Gymnotus aff. carapo: 1 -> 0

Gymnotus aff. carapo

Clado 115: $1 \rightarrow 0$

Clado 153: $1->\odot 1$

Clado 152: $01 \rightarrow>$

Lebiasina bimaculata: $01 \rightarrow$

Piabucina astrigata: $01 \rightarrow 0$

Clado 116: $0 \rightarrow 1$

Clado 165: 1 -> 0

Gnathocharax steindachneri: 1 -> $\odot$

Galeocharax knerii: 1 ->

Acestrorhynchus falcirostris: $1 \rightarrow \odot$

Clado 149: 1 ->

Hoplias malabaricus: $\odot->1$

Semaprochilodus insignis: $0 \rightarrow 1$

Caenotropus labyrinthicus: $0->1$

Landonia latidens: $1 \rightarrow$

Curimata ocellata: $0 \rightarrow 1$

Leporellus vittatus: $0 \rightarrow 1$

Microschemobrycon casiquiare: $1->0$

Clado 167: $1 \rightarrow 01$

Deuterodon iguape: $01->0$

Astyanax mexicanus: $01 \rightarrow 0$

Clado 189: $01 \rightarrow 1$

Clupeacharax engrauloides: 1 -> $\odot$

Agoniates halecinus: $1 \rightarrow \theta$

Gasteropelecus sternicla: 1 -> 0
Caráter 330 (3 passos)

Raiz: 0

Hydrolycus tatauaia: $0 \rightarrow 1$

Clupeacharax engrauloides: $\odot \rightarrow 1$

Agoniates halecinus: $0 \rightarrow 1$

Caráter 331 (2 passos)

Raiz: 0

Clado 102: $0 \rightarrow 1$

Clado 108: $0 \rightarrow 1$

Caráter 332 (15 passos)

Raiz: $\odot$

Gymnotus aff. carapo: $0->1$

Clado 122: $\odot \rightarrow 1$

Nannocharax fasciatus: $\Theta->1$

Charax cf . leticiae: $0->1$

Aphyocharax pusillus: $->1$

Acestrorhynchus falcirostris: 0 -> 1

Hoplias malabaricus: $0->1$

Curimatopsis macrolepis: $1->0$

Serrabrycon magoi: $0 \rightarrow 1$

Serrabrycon magoi: $\Theta$->

Paracheirodon axelrodi: $0->1$

Bryconops alburnoides: $0->1$

Clado 130: $0 \rightarrow 1$

Agoniates halecinus: $0->1$

Ctenobrycon hauxwellianus: $0 \rightarrow 1$

Caráter 333 (16 passos)

Raiz: $\odot$

Clado 143: $\odot$-> 1

Chalceus epakros: 0 -> 1

Clado 181: 1 - $>0$

Nannocharax fasciatus: 0 -> 1

Clado 116: $\odot \rightarrow 1$

Clado 125: $\odot \rightarrow 1$

Roeboexodon guyanensis: 1 -> 0

Clado 172: 1 ->

Phenagoniates macrolepis: 1 -> $\odot$

Clado 155: 1 -> 0

Myleus setiger: $0 \rightarrow 1$

Clado 135: $1 \rightarrow 01$

Diapoma terofali: 01 -> 0

Glandulocauda melanogenys: 01 -> 0

Clado 132: 01 -> 1

Rhoadsia altipinna: $\odot->1$

Bryconops alburnoides: $01 \rightarrow 1$

Iguacladoctes geisleri: $01 \rightarrow 0$

Clado 189: $1 \rightarrow 0$

Caráter 334 (9 passos)

Raiz: 0

Clado 102: $\odot \rightarrow 1$

Clado 142: $0 \rightarrow$

ado 162: $0 \rightarrow 01$

Charax cf. leticiae: 1 -> $\odot$

Clado 150: $\odot \rightarrow 01$

Clado 197: 01 - $>1$

Hydrolycus tatauaia: $01->1$

Brycinus macrolepidotus: $01 \rightarrow 0$

Bryconalestes longipinnis: $01->1$

Phenagoniates macrolepis: $1->0$

Gilbertolus atratoensis: 01

Roestes molossus: $01 \rightarrow 1$

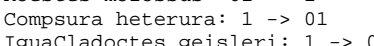

Iguacladoctes geisleri
Caráter 335 ( 15 passos)

Raiz: 01

Chanos chanos: $01 \rightarrow$

Clado 103: $01 \rightarrow 1$

Clado 108: 1 -> 0

Characidium bahiensis: 1 -> 0

Clado 160: $1 \rightarrow 01$

Clado 147: $1 \rightarrow 0$

Chalceus epakros: 01 -> 0

Arnoldichthys spilopterus: 01 -> 1

Clado 116: $1 \rightarrow \odot$

Clado 197: $01 \rightarrow 0$

Clado 126: $1->01$ 01

Brycinus macrolepidotus: $01->1$

Bryconalestes longi

Anostomus anostomus: $01->0$

Ansetus odoe: $\theta \rightarrow 1$

Schizodon fasciatus: $01 \rightarrow 1$

Clado 127: $01 \rightarrow 0$

Clado 133: $1 \rightarrow 0$

Clado 130: $\odot \rightarrow 1$

Hemigrammus unilineatus: 1 -> 0

Caráter 336 (4 passos)

Raiz: 0

Clado 114: $\odot \rightarrow 01$

Clado 113: $01->1$

lado 121: $\Theta \rightarrow 1$

Chilodus punctatus: $0->01$

Rhinobrycon negrensis: $\odot \rightarrow 1$

Clado 131: $\odot \rightarrow 01$

Clupeacharax engrauloides: 01 -> 1

Caráter 337 (1 passo)

Raiz: 01

Chanos chanos: 01 -> 1

Clado 103: $01 \rightarrow 0$

Caráter 338 (13 passos)

Raiz: 1

Clado 109: $1 \rightarrow 0$

Clado 182: $1 \rightarrow 0$

Clado 117: $0 \rightarrow 1$

Clado 162: $1 \rightarrow 01$

Nannocharax fasciatus: $\odot \rightarrow 1$

Roeboexodon guyanensis: $1 \rightarrow 0$

Clado 150: $1 \rightarrow 0$

Clado 197: $01 \rightarrow 0$

Brycinus macrolepidotus: $01->1$

Bryconalestes longipinnis: $01->$

Clado 136: 1 -> 0

Phenacogaster pectinatus: $1 \rightarrow 0$

Clado 183: 1 -> 0

Iguacladoctes geisleri: $\odot->1$

Clado 193: $0 \rightarrow 1$

Caráter 339 (31 passo)

Raiz: 2

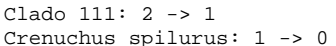

Clado 148: $1 \rightarrow 0$

Clado 152: $1 \rightarrow 0$

Clado 117: 1 -> 0

Clado 162: 1 -> 01

Nannocharax fasciatus: $1->0$

Charax cf. leticiae: 1 -> $\theta$

Clado 145: $0 \rightarrow 2$

Clado 161: $01 \rightarrow 0$

Xenocharax spilurus: $1 \rightarrow 0$

Clado 124: $1 \rightarrow 0$

Piaractus mesopotamicus: 01 -> 0

Clado 196: 01 -> 1

Semaprochilodus insignis: 1 -> 0

Landonia latidens: 1 -> 0

Phenagoniates macrolepis: 1 -> 2

Roestes molossus: $0->1$

Potamorhina latior: $1->0$

Schizodon fasciatus:
Clado 169: $1 \rightarrow 0$

Rhinobrycon negrensis: 1 -> 2

Clado 170: 1 -> 0

Knodus meridae: $1 \rightarrow 2$

Brittanichthys axelrodi: 1 -> 0

Astyanax mexicanus: $0 \rightarrow 1$

Stygichthys typhlops: 1 -> 2

Clupeacharax engrauloides: 1 -> 2

Triportheus albus: $1 \rightarrow 0$

Gasteropelecus sternicla: 1 -> 0

Hollandichthys multifasciatus: $0 \rightarrow 1$

Caráter 340 (103 passos)

Chanos chanos: 3456789 -> 9

Clado 103: $3456789 \rightarrow 34$

Clado 102: $34 \rightarrow 0$

Clado 110: $34 \rightarrow 3$

Clado 163: $3 \rightarrow 2$

Crenuchus spilurus: 2 -> 1

Clado 142: $34 \rightarrow 3$

Clado 148: $34->67$

Clado 107: $3 \rightarrow 34$

Clado 118: $3 \rightarrow 123$

Salminus hilarii: $67 \quad \rightarrow 7$

Clado 157: 34 -> 4

Chalceus epakros: $34 \rightarrow 4$

Clado 106: 34 ->

Clado 181: $3 \rightarrow 1$

Brycon pesu: $67 \rightarrow 6$

Clado 146: $67 \rightarrow 6789$

Copeina cf. guttata: $34->3$

Piabucina astrigata: $4 \rightarrow 6$

Arnoldichthys spilopterus: $34->2$

Hemistichodus vaillanti: 34 -> 6

Nannocharax fasciatus: $34 \rightarrow 2$

Apareiodon piracicabae: $3 \rightarrow 4$

Bivibranchia fowleri: $123 \rightarrow 1$

Clado 116: $123 \rightarrow 5$

Clado 121: $123 \rightarrow 12$

Roeboexodon guyanensis: 3 -> 2

Clado 161: $34 \rightarrow 4$

Clado 123: 12 -> 1

Clado 124: $123 \rightarrow 1$

Clado 173: $3 \rightarrow 1$

Clado 199: $3 \rightarrow 5$

Acestrorhynchus falcirostris: 6789 -> 9

Hydrolycus tatauaia: $6789 \rightarrow 9$

Clado 149: $6789 \rightarrow 6$

Erythrinus erythrinus: $34 \rightarrow 4$ 
Knodus meridae: 2 -> 0

Clado 132: 56 ->

Paracheirodon axelrodi: 2 -> 1

Compsura heterura: $2->1$

Rhoadsia altipinna: 2 ->

Clado 164: 6 ->

Bryconops alburnoides: 56 -> 5

Iguacladoctes geisleri: $56 \rightarrow 6$

Rachoviscus graciliceps: $2 \rightarrow$

Agoniates halecinus: $8 \rightarrow 9$

Clado 188: 2 -> 012

Clado 187: $012 \rightarrow 0$

Carnegiella strigata: 6 -> 5

Gasteropelecus sternicla: 6 -> 9

Markiana nigripinnis: 012 -> 2

Tetragonopterus argenteus: $012->0$

Hemigrammus unilineatus: 2 -> 1

Hollandichthys multifasciatus: 2 ->

Caráter 341 (24 passos)

Caráter

Catostomus commersonnii: $1 \rightarrow 2$

Olivaichthys mesembrinus: $1 \rightarrow 0$

Characidium bahiensis: $1 \rightarrow 0$

Clado 147: 1 -> 01

Clado 157: $1 \rightarrow>0$

$\begin{array}{lll}\text { Clado 159: } 1 & \rightarrow & 0 \\ \text { Brycon pesu: } 01 & \rightarrow>0\end{array}$

Charax cf. leticiae: $1->0$

Clado 158: $1 \rightarrow 2$

Xenocharax spilurus: $1 \rightarrow 0$

Clado 199: 1 -> 12

Acestrorhynchus falcirostris: 01 -> 1

Hydrolycus tatauaia: $01->0$

Brycinus macrolepidotus: $0->1$

Anostomus mesopotamicus: $>0$

Landonia latidens: $1 \rightarrow 0$

Phenagoniates macrolepis: 12 -> 2

Hepsetus odoe: $01 \rightarrow$

Clado 155: 01 - $>$

Gilbertolus atratoensis: 01 -> 1

Roestes molossus: $01 \rightarrow 0$

Phenacogaster pectinatus: $1->2$

Clado 133: 1 -> 0

Astyanax mexicanus: $1 \rightarrow 0$

Stygichthys typhlops: $1 \rightarrow 2$

$\begin{array}{lll}\text { Stygichthys typhlops: } 1->2 & 2 \\ \text { Probolus heterostomus : } 1->0 & 0\end{array}$

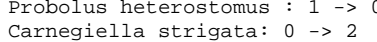

Carnegiella strigata

Caráter 342 (24 passos)

Raiz: 01

Chanos chanos: 01 ->

Clado 103: $01 \rightarrow 0$

Olivaichthys mesembrinus: $0->2$

Clado 154: 0 -> 1

Characidium bahiensis: $\odot->1$

Clado 118: $\odot \rightarrow 1$

Clado 147: $0 \rightarrow>2$

Clado 157: $1 \rightarrow 12$

Oligosarcus argenteus: $\odot \rightarrow 1$

Lebiasina bimaculata: $12 \rightarrow 2$

Roeboexodon guyanensis: $\Theta->1$

Galeocharax knerii: $0 \rightarrow>2$

Erythrinoidea fam. nov: $1 \rightarrow 0$

Citharinus latus: $0 \rightarrow 1$

Aphyocharax pusillus: $0->1$

Acestrorhynchus falcirostris: $2 \rightarrow 0$

Brycinus macrolepidotus: $1 \rightarrow 0$

Clado 196: $1 \rightarrow 2$

Anostomus anostomus: $1 \rightarrow 2$

Landonia latidens: $0 \rightarrow 2$

Hepsetus odoe: $2 \rightarrow 1$

Gilbertolus atratoensis: $2 \rightarrow 1$

Clado 135: $0 \rightarrow 012$

Diapoma terofali: 012 -> 1

Clado 134: $012 \rightarrow 2$

Clado 129: $2 \rightarrow 0$

Clado 129: $2 \rightarrow>0$

Caráter 343 ( 6 passos)

Raiz: $\odot$

Raiz: 0 Olivaichthys mesembrinu

Olivaichthys mesembrinus: 0 -> 1

Clado 150: $\odot \rightarrow 01$

Hydrolycus tatauaia: $01->1$

Clado 196: $\odot \rightarrow 1$

Gilbertolus atratoensis: $01->0$

Roestes molossus: $01 \rightarrow 1$

Bryconops alburnoides: $\odot->$

Agoniates halecinus: $0 \rightarrow 1$

Caráter 344 ( 1 passo)

Raiz: 0

Clado 196: $\odot \rightarrow 1$

Caráter 345 ( 9 passos)

Raiz: $\odot$

Clado 109: $\odot \rightarrow 1$

Clado 106: $1 \rightarrow 0$

Clado 121: 1 -> 01

Aphyocharax pusillus: $\odot \rightarrow 1$

Curimatopsis macrolepis: $01 \rightarrow 0$

Prochilodus nigricans: $01 \rightarrow 0$

Semaprochilodus insignis: $01 \rightarrow$

Curimata ocellata: $01 \rightarrow 0$

Potamorhina latior: $01->1$

Brittanichthys axelrodi: $\odot \rightarrow$

Clado 164: $0->1$
Orthospinus franciscoensis: 0 -> 1

Caráter 346 ( 17 passos)
Raiz: $\odot$

Crenuchus spilurus: $0 \rightarrow 1$

Clado 147: $\odot \rightarrow 1$

Chalceus epakros: $0 \rightarrow 1$

Clado 190: $\odot \rightarrow$

Clado 116: $\odot \rightarrow$

Galeocharax knerii: 0 -> 1

Erythrinoidea fam. nov: $0 \rightarrow 1$

Clado 156: 1 -> 0

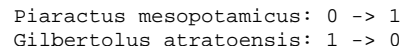

Clado 134: $\odot \rightarrow 1$

Deuterodon iguape: $\odot \rightarrow 1$

Iguacladoctes geisleri: $1 \rightarrow 0$

Probolus heterostomus : $0->1$

Gasteropelecus sternicla: $1->$

Hyphessobrycon compressus: $\odot->1$

Hyphessobrycon compres)
caráter 347 ( 32 passos)

Raiz: 0

Gymnotus aff. carapo: $\odot->1$

Clado 109: $\odot \rightarrow 1$

Crenuchus spilurus: $\odot->2$

Clado 141: $0 \rightarrow 1$

Clado 159: $0 \rightarrow 2$

Clado 112: $1 \rightarrow 2$

Oligosarcus argenteus: $0->2$
Bivibranchia fowleri: $1 \rightarrow 0$

Bivibranchia fowler

Clado 125: 1 ->0

Clado 161: $2 \rightarrow 1$
Citharinus latus: $1 \rightarrow 0$

Anodus orinocensis: $1 \rightarrow 2$

Clado 173: 1 - $>012$

Hydrolycus tatauaia: $0 \rightarrow 1$

Hoplias malabaricus: $0 \rightarrow 1$

Curimatopsis macrolepis: 1 -> 0

Serrabrycon magoi: 012 -> 2

Phenagoniates macrolepis: $1 \rightarrow 2$

Potamorhina latior: $1 \rightarrow 2$

Phenacogaster pectinatus: 012 -> 0

Clado 170: $012 \rightarrow 0$

Clado 175: $012 \rightarrow 12$

Clado 184: $012 \rightarrow 12$

Glandulocauda melanogenys: $1 \rightarrow 0$

Bryconamericus exodon: $1 \rightarrow 0$

Piabina argentea: $1 \rightarrow 0$

Clado 174: $12 \rightarrow 2$

Odontostilbe pequira: $12 \rightarrow 1$

Deuterodon iguape: $1 \rightarrow 2$

Deuterodon iguape: $1 \rightarrow->2$
Paracheirodon axelrodi: $12 \rightarrow>2$

Paracheirodon axelr
Clado 200: $12 \rightarrow 1$

Compsura heterura: $12->1$

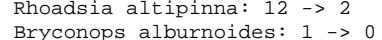

Bryconops alburno:

Clado 130: 1 -> 0

Clado 192: $1 \rightarrow 01$

Markiana nigripinnis: $1->2$

Hemigrammus unilineatus: 01 - $>1$

Clado 193: $01 \rightarrow 0$

Caráter 348 (2 passos)

Raiz: 0

Bivibranchia fowleri: $\odot->1$

Clado 124: $0 \rightarrow 1$

Caráter 349 (10 passos)

Raiz: 01

Chanos chanos: 01 -> 1

Clado 103: $01 \rightarrow 0$
Clado 108: $\odot \rightarrow 01$

Chalceus epakros: $0 \rightarrow 1$

Clado 146: $\odot \rightarrow 1$

Distichodus notospilus: $01->1$

Citharinus latus: $01 \rightarrow 1$

Xenocharax spilurus: $01 \rightarrow$

Clado 124: $0 \rightarrow 1$

Brycinus macrolepidotus: $0 \rightarrow 1$

Hepsetus odoe: $1 \rightarrow 0$

Hepsetus odoe: 1
Clado 132: $\odot \rightarrow 1$

Gasteropelecus sternicla: 1 -> 0

Caráter 350 (4 passos)

Raiz: $\odot$

Clado 105: $\odot \rightarrow 1$

Nannocharax fasciatus: $\odot \rightarrow 1$

Hydrolycus tatauaia: $\odot \rightarrow 1$

clado 130: $0 \rightarrow 1$

Caráter 351 (22 passos)

Raiz: 2

Clado 102: 2 -> 1

Clado 110: $2 \rightarrow 02$

Clado 108: $02->012$

Clado 115: 02 -> 2

Crenuchus spilurus: $\odot 2$-> $\odot$

Clado 153: $2 \rightarrow 0$

Neolebias unifasciatus: $012 \rightarrow 0$

Clado 107: $012 \rightarrow 12$

Clado 141: $2 \rightarrow 0$

Clado 106: $12 \rightarrow 1$

Hemistichodus vaillanti: $12->2$

Nannocharax fasciatus: $12->1$

Clado 158: $0 \rightarrow 1$

Clado 138: $0 \rightarrow 012$

Curimatopsis macrolepis: 2 -> 0

Landonia latidens: $012 \rightarrow 1$

Clado 137: $012 \rightarrow$

Clado 137: $012->$

Metynnis lippincottianus: 2 -> 1

Diapoma terofali: $2 \rightarrow 0$

Atopomesus pachyodus: $0->1$

Piabina argentea: 2 -> 1

Odontostilbe pequira: $0 \rightarrow 1$

Deuterodon iguape: $2 \rightarrow 1$

Clado 131: 2 -> 02

Iguacladoctes geisleri: 2 -> 1

clado 130: $02->0$

Clado 191: $2 \rightarrow 0$

Clado 185: $2 \rightarrow 1$

Caráter 352 (13 passos)

Raiz: 01

Chanos chanos: $01->1$

Clado 103: $01->0$

Clado 143: $0 \rightarrow 01$

Clado 142: 01 -> 1

Chalceus epakros: $02->2$

Brycon pesu: $01->2$

Galeocharax knerii: 1 -> 0

Clado 145: $01 \rightarrow 1$

Clado 197: $\odot 2$ -

Clado 197: 02 -> 012

Anodus orinocensis: $0->1$

Hydrolycus tatauaia: $01 \rightarrow 0$

Hepsetus odoe: $1 \rightarrow>2$

Metynnis lippincottianus: 012 -> 0

Myleus setiger: $012 \rightarrow 1$

Clado 135: 1 -> 12

Diapoma terofali: $12->2$

Clado 132: $12 \rightarrow 123$

Clado 180: $12 \rightarrow 1$

Clado 164: $123 \rightarrow 3$
Clado 130: $123 \rightarrow 2$

Caráter 353 ( 7 passos)

Raiz: 0

Clado 160: 0 -> 01

Chalceus epakros: 01 -> 1

Clado 161: 01 -> 1

Clado 196: 01 ->

Clado 135: $\theta \rightarrow 01$

Moenkhausia xinguensis: 0 -> 1

Bryconadenos tanaothoros: $\theta->1$

Clado 132: $01 \rightarrow 1$

Bryconops alburnoides: 01 -> 1

Iguacladoctes geisleri: $01->0$

Clado 195: 0 -> 1

Caráter 354 (4 passos)

Raiz: 0

Chalceus epakros: $0->2$

Clado 161: $0 \rightarrow 1$

Bryconadenos tanaothoros: 0 -> 1

Triportheus albus: $0 \rightarrow 2$

Caráter 355 (14 passos)

Raiz: 1

Clado 118: $1 \rightarrow 0$

Clado 106: $1 \rightarrow 0$

Parodon nasus: 1 -> 0

Clado 197: $1 \rightarrow 01$

Clado 199: $1 \rightarrow 01$

Clado 156: $1 \rightarrow 0$

Clado 196: $01 \rightarrow 0$

Curimatopsis macrolepis: $\odot \rightarrow 1$

Chilodus punctatus: $\odot \rightarrow 1$

Landonia latidens: $1 \rightarrow 0$

Paragoniates alburnus: $01->0$

Diapoma terofali: 1 -> 0

Bryconamericus exodon: 1 -> 0

Clupeacharax engrauloides: 1 -> 0

Gymnocorymbus ternetzi: $1->2$

Clado 185: 1 -> 0

Caráter 356 ( 9 passos)

Raiz: 1

Clado 111: 1 -> 01

Clado 110: $01 \rightarrow 0$

Clado 110: $01>0$

Clado 142: $01 \rightarrow>0$

Clado 153: $01 \rightarrow>$

Chalceus epakros: 01 -> 1

Chalceus epakros: 01

Brycon pesu: 1 - 1 irostris: 01 ->

Clado 156: $01 \rightarrow 1$

Hydrolycus tatauaia: $01->0$

Brycinus macrolepidotus: $01 \rightarrow 1$

Bryconalestes longipinnis: $01 \rightarrow 0$

Clado 196: $01 \rightarrow 0$

Schizodon fasciatus: 0 -> 1 
Clado 156: 1 -> 01

Hydrolycus tatauaia: 12 -> 2 Brycinus macrolepidotus: $01->0$ Bryconalestes longipinnis: 01 -> 1 Anostomus anostomus: $0 \rightarrow 1$ Serrabrycon magoi: $1 \rightarrow 0$ Hepsetus odoe: $01->0$ Myleus setiger: $012->$ Boulengerella maculata: $01 \rightarrow \odot$ Ctenolucius hujeta: $01 \rightarrow 1$ Rhinobrycon negrensis: $1 \rightarrow$ Piabina argentea: $1 \rightarrow \odot$

Clado 198: 1 -> 0

Gymnocorymbus ternetzi: $1->2$

Caráter 359 ( 4 passos)

Raiz: 0

Charax cf. leticiae: $\odot->1$

Clado 197: $0 \rightarrow 01$

Clado 124: $0 \rightarrow 01$

Clado 196: 01 -> 1

Chilodus punctatus: $01->1$

Potamorhina latior: $0 \rightarrow 1$

Caráter 360 (19 passos)

Raiz: $\odot$

Clado 111: 0 -> 2

Catostomus commersonnii: $0->1$

Crenuchus spilurus: $2 \rightarrow 1$

Clado 160: $2 \rightarrow 02$

Clado 114: $2 \rightarrow 1$

Chalceus epakros: $02->0$

Brycon pesu: $2 \rightarrow 1$

Clado 151: $2 \rightarrow 1$

Piabucina astrigata: 2 -> 1

Clado 116: $2 \rightarrow 0$

Clado 161: 02 -> 2

Clado 126: 2 -> 012

Clado 196: 02 -> 0

Semaprochilodus insignis: 2 -> 1

Anostomus anostomus: $012 \rightarrow 1$

Clado 128: $012 \rightarrow 02$
Hepsetus odoe: $2 \rightarrow 1$

Potamorhina latior: 2 -> 1

Schizodon fasciatus: $02 \rightarrow 0$

Leporellus vittatus: $02 \rightarrow>2$

Leporinus fasciatus: $02 \rightarrow 0$

Odontostilbe pequira: $2 \rightarrow 0$

Clado 180: $2 \rightarrow 0$

Thoracocharax stellatus : 2 -> $\odot$

Caráter 361 (4 passos)

Raiz: 01

Chanos chanos: $01->1$

Clado 103: $01 \rightarrow$

Brycon pesu: $0 \rightarrow>1$

Clado 132: $->01$

Clado 164: 01 -> 1

Clupeacharax engrauloides: 01 -> 1

Clado 130: 01 -> 0

Caráter 362 (10 passos)

Raiz: 0

Clado 108: $\odot \rightarrow 3$

Clado 116: $\odot \rightarrow 1$

Galeocharax knerii: $0 \rightarrow$

Citharinus latus: $3 \rightarrow 0$

Clado 119: 0 -> 012

Prochilodus nigricans: $0->2$

Caenotropus labyrinthicus: $0 \rightarrow 1$

Clado 155: $\odot->2$

Curimata ocellata: $012 \rightarrow 1$

Potamorhina latior: 012 -> 2

Ctenobrycon hauxwellianus: $0 \rightarrow 2$

Caráter 363 (13 passos)

Raiz: 01

Chanos chanos: 01 ->

Clado 103: $01 \rightarrow 1$

Characidium bahiensis: 1 -> 0

Clado 142: $1 \rightarrow 0$

Bivibranchia fowleri: $01 \quad->0$

Clado 121: $01 \rightarrow 1$

Clado 121: $01->1$

Clado 125: $01->0$

Anodus orinocensis: $01->1$

Anodus orinocensis: $01->1$

Hemiodus unimaculatus : $01->$

Aphyocharax pusill

Clado 155: $1->0$

Curimata ocellata: $1->0$

Leporinus fasciatus: $0 \rightarrow 1$

Astyanax mexicanus: $\odot->1$
Ctenobrycon hauxwellianus: $\odot->1$

Caráter 364 (14 passos)

Raiz: 01

Clado 102: $01 \rightarrow$

Clado 111: $01 \rightarrow 1$

Clado 108: $1 \rightarrow 0$

Chalceus epakros: 1 -> 2

Clado 117: $1 \rightarrow 01$

Clado 146: $1 \rightarrow 0$

Distichodus notospilus: $\odot \rightarrow 1$

Erythrinoidea fam nov: $1 \rightarrow 0$

Clado 197: 1 -> 01

Anodus orinocensis: $01 \rightarrow 0$

Clado 120: $1 \rightarrow 0$

Clado 156: $\rightarrow$ o

Bryconalestes longipinnis: 1 -> 2

Clado 196: $01 \rightarrow 0$
Prochilodus nigricans: 1 -> 2

Clado 128: $1 \rightarrow 12$

Hepsetus odoe: 02 -> 2

Clado 127: $12 \rightarrow 2$

Clado 189: 1 -> 01

Ctenobrycon hauxwellianus: 01 -> 0

Caráter 365 (13 passos)

Raiz: 1

Clado 108: 1 -> 01

Neolebias unifasciatus: $01 \rightarrow 0$

Clado 112: 01 -> 0

Clado 181: $1 \rightarrow 0$

Clado 146: $1 \rightarrow 01$

Distichodus notospilus: $01->1$

Bivibranchia fowleri: 1 -> 0

Clado 150: $01 \rightarrow 0$

Citharinus latus: $01 \rightarrow 1$

$\begin{array}{lll}\text { Citharinus latus: } 01 & ->1 \\ \text { Xenocharax spilurus: } 01 & ->0\end{array}$

Acestrorhynchus falcirostris: $01->0$

Clado 156: $01 \rightarrow 1$

Clado 196: $01 \rightarrow 0$

Clado 119: $1 \rightarrow 0$

Landonia latidens: $1 \rightarrow 0$

Iguacladoctes geisleri: $1->$

Markiana nigripinnis: 1 -> 0

Hyphessobrycon compressus: 1 -> 0

caráter 366 (11 passo)

Raiz: 01

Chanos chanos: $01->0$

Clado 102: $01 \rightarrow 1$

Clado 110: $01 \rightarrow 0$

Clado 144: $01 \rightarrow 1$

Clado 114: $\odot \rightarrow 1$

Clado 141: $1 \rightarrow 0$

Clado 150: $1 \rightarrow 01$

Clado 123: $0->1$

Gilbertolus atratoensis: $01 \rightarrow 0$

Moenkhausia xinguensis: $0->1$

Clado 130: $\odot \rightarrow 01$

Triportheus albus: $\odot \rightarrow 1$

Thoracocharax stellatus : $01 \rightarrow 1$

Carnegiella strigata: $01 \rightarrow 1$

Gasteropelecus sternicla: $01 \rightarrow 0$

Caráter 367 (17 passos)

Clado 104: $\odot->01$

Clado 144: $\odot \rightarrow 01$

Gymnotus aff. carapo: $01 \rightarrow 1$

Clado 153: 01 - $>1$

Clado 114: $0 \rightarrow 1$

Clado 141: $01->\odot$

Chalceus epakros: $01 \rightarrow 1$
Oligosarcus argenteus: $01 \rightarrow 1$

Oligosarcus argenteus:

Arnoldichthys spilopterus: $01->$

Distichodus notospilus: $0 \rightarrow 1$

Erythrinoidea fam. nov: $1 \rightarrow 0$

Clado 126: $\odot \rightarrow 1$

Brycinus macrolepidotus: $01->0$

Bryconalestes longipinnis: $01->1$

Prochilodus nigricans: $0 \rightarrow 1$

Paragoniates alburnus: $\odot \rightarrow 1$

Hepsetus odoe: $01 \rightarrow 0$

Clado 155: $01 \rightarrow 1$

Gilbertolus atratoensis: $01 \rightarrow 0$

Clado 134: $0->01$

Moenkhausia xinguensis: $0 \rightarrow 1$

Clupeacharax engrauloides: $1 \rightarrow 0$

Gasteropelecus sternicla: $1 \rightarrow 0$

Caráter 368 (2 passos)

Raiz: 0

Distichodus notospilus: 0 -> 1

Clado 180: $\rightarrow$ notosp

Bryconops alburnoides: $01-1$

caráter 369 ( 23 passos)

Raiz: 1

Clado 163: 1 ->0

Clado 108: $1 \rightarrow 2$

Clado 142: 1 ->

Hemistichodus vaillanti: $2 \rightarrow 1$

Clado 116: 1 -> 012

Galeocharax knerii: $\odot->1$

Citharinus latus: 2 - $>$

Anodus orinocensis: $012->0$

Clado 120: $1 \rightarrow 01$

Clado 156: 1 -> 01

Bryconalestes longipinnis: $1 \rightarrow 0$

Curimatopsis macrolepis: $01 \rightarrow 0$

Hepsetus odoe: $012 \rightarrow 0$

Clado 155: $012 \rightarrow 2$

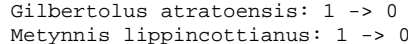

Curimata ocellata: $01->0$

Potamorhina latior: $01 \rightarrow 1$

Leporinus fasciatus: $1 \rightarrow 0$

Microschemobrycon casiquiare: 0 -> 1

Knodus meridae: $0 \rightarrow 1$

Clado 130: $0 \rightarrow 1$

Triportheus albus: $\odot \rightarrow 1$

Clado 195: $0 \rightarrow 012$

Markiana nigripinnis: 012 -> 2

Tetragonopterus argenteus: 012 -> 1

Ctenobrycon hauxwellianus: $0 \rightarrow 1$

Caráter 370 ( 2 passos)

Raiz:

Clado 197: $\odot \rightarrow 2$

Caráter 371 (11 passo)

Raiz: 1

Catostomus commersonnii: 1 -> 0

Clado 142: $1 \rightarrow 0$

Clado 159: $1 \rightarrow 01$

Clado 112: $1 \rightarrow 0$

Arnoldichthys spilopterus: 01 -> 0

Clado 161: $01 \rightarrow 0$

Xenocharax spilurus: 1 -> 0

Clado 196: 01 -> 1

Moenkhausia xinguensis: $0 \rightarrow 1$

Clado 164: $\odot \rightarrow 1$

Bryconops alburnoides: $0->1$

Tetragonopterus argenteus: $0 \rightarrow 1$

Poptella brevispina: $\odot \rightarrow 1$

Caráter 372 (12 passos)

Raiz: $\odot$

Clado 115: $0 \rightarrow 1$

Chalceus epakros: $\odot->1$

Piabucina astrigata: $0->1$

Clado 197: $\odot \rightarrow 01$

Clado 156: $1 \rightarrow 01$

Hoplias malabaricus: $0->1$

Clado 196: 01 -> 1

Curimatopsis macrolepis: $1->$

Hepsetus odoe: $01->$

Boulengerella maculata: 01 -> 1

Ctenolucius hujeta: $01 \rightarrow \odot$
Clado 164: $\odot \rightarrow>1$

Bryconops alburnoides: $\odot->1$

Tetragonopterus argenteus: $\odot->1$

Caráter 373 (11 passo)

Raiz: 0

Clado 182: $\odot$-> 01

Oligosarcus argenteus: 01 -> 1

Gnathocharax steindachneri: $0->1$

Charax cf. leticiae: $01 \rightarrow 0$

Galeocharax knerii: $01 \rightarrow 1$

Clado 197: $\odot \rightarrow 01$

Citharinus latus: $\odot->1$

Clado 199: $\Theta \rightarrow 1$

Clado 196: $01->1$

Clado 168: $\odot \rightarrow 01$

Glandulocauda melanogenys: $\odot->1$

Moenkhausia xinguensis: $01 \rightarrow 1$

Deuterodon iguape: $01 \rightarrow 0$

Clado 166: $01 \rightarrow 1$

Caráter 374 ( 6 passos)

Raiz: 0

Clado 104: 0 -> 01

Gymnotus aff. carapo: $01->1$

Clado 117: $0 \rightarrow 1$

Clado 124: $0 \rightarrow 1$

Clado 119: $0 \rightarrow 1$

Myleus setiger: $\odot->1$

Schizodon fasciatus: $0->1$

Caráter 375 ( 23 passos)

Raiz: 03

Clado 102: 03 -> 0

Clado 109: $03 \rightarrow 0$

Crenuchus spilurus: $03 \rightarrow 3$

Clado 148: $03 \rightarrow 3$

Clado 152: $03 \rightarrow 0$

Clado 157: 03 -> 023 : 03

Clado 159: $03 \rightarrow 3$

Clado 190: 03 - $>$ 023

Oligosarcus argenteus: $03 \rightarrow \odot$

Lebiasina bimaculata: $023 \rightarrow 3$

Lilasina bimaculata: $023 \rightarrow$

Piabucina astrigata:

Gnathocharax steindachneri: 023 -> 3

Roeboexodon guyanensis: $023 \rightarrow 2$

Charax cf. leticiae: $03->3$

Clado 158: $0 \rightarrow 2$

Anodus orinocensis: $\odot->$

Clado 123: $0 \rightarrow 2$

Clado 124: $0 \rightarrow 3$

Aphyocharax pusillus: $03 \rightarrow \odot$

Clado 199: 03 -> 013

Hoplias malabaricus: 2 -> 23

Brycinus macrolepidotus: $3 \rightarrow 2$ 
Clado 152: 1 -> 01

Clado 159: $1 \rightarrow 0$

Clado 117: 1 -> 12

Copeina cf. guttata: $01 \rightarrow 0$

Bivibranchia fowleri: $12 \rightarrow 2$

Clado 165: 1 -> 01

Galeocharax knerii: 1 -> 0

Clado 150: $\odot$-> 02

Erythrinoidea fam. nov: $01 \rightarrow 0$

Clado 158: 01 -> 1

Xenocharax spilurus: $1->2$

Anodus orinocensis: $12 \rightarrow$

Hemiodus unimaculatus : $12 \rightarrow 1$

Aphyocharax pusillus: $01 \rightarrow 0$

Hydrolycus tatauaia: $02->2$

Curimatopsis macrolepis: $1>0$

Paragoniates alburnus: 01 - $>0$

Phenagoniates macrolepis: 01 -> 1

Curimata ocellata: $1 \rightarrow 2$

Schizodon fasciatus: $1->$

Clado 184: $1 \rightarrow 0$

Clado 167: $1 \rightarrow 0$

Markiana nigripinnis: $\odot->$

Caráter 377 ( 28 passos)

Raiz: 1

Clado 104: 1 -> 01

Gymnotus aff. carapo: 01 -> $\odot$

Clado 143: $1 \rightarrow 12$

Clado 108: $1 \rightarrow 0$

Characidium bahiensis: 1 -> 2

Clado 182: $12 \rightarrow 2$

Salminus hilarii: 12 -> 2

Clado 106: $\odot \rightarrow 2$

Clado 117: 1 -> 2

Clado 140: $12 \rightarrow>1$

Brycon pesu: $12 \rightarrow 0$

作 $12 \rightarrow 1$

Roeboexodon guyanensis: $12 \rightarrow 2$

Clado 145: $12 \rightarrow 1$

Clado 124: $1 \rightarrow 2$

Hydrolycus tatauaia: $12->2$

Prochilodus nigricans: $1 \rightarrow$

Clado 172: $1 \rightarrow 12$

Paragoniates alburnus: 1 -> 2

Hepsetus odoe: $1 \rightarrow 0$

Myleus setiger: $1 \rightarrow 0$

Curimata ocellata: $1 \rightarrow>2$

Phenacogaster pectinatus: $12 \rightarrow 2$

Leporellus vittatus: 1 - 0

Rhinobrycon negrensis: 1 -> 2

Clado 176: $12 \rightarrow 1$

Atopomesus pachyodus: $12->2$

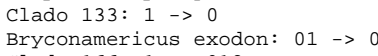

Clado 166: 1 -> 012

Iguacladoctes geisleri: $\odot->$
Astyanax mexicanus: $012 \quad->0$

Triportheus albus: $\odot \rightarrow 1$

clado 188: $12 \rightarrow>2$

Probolus heterostomus : 12 -> 2

Hollandichthys multifasciatus: 12 -> 1

Caráter 378 (17 passos)

Raiz: 0

Clado 115: $0 \rightarrow>2$

Clado 148: $0 \rightarrow>2$

Chalceus epakros: $0 \rightarrow 2$

Clado 106: 0 -> 2

Oligosarcus argenteus: $\odot->2$

Piabucina astrigata: $0 \rightarrow 2$

Bivibranchia fowleri: 2 -> $\odot$

Clado 150: $2 \rightarrow 12$

Clado 197: $\odot \rightarrow-02$

Hemiodus unimaculatus : $2 \rightarrow 1$

$\begin{array}{lll}\text { Hemiodus unimaculatus : } & 2->1 \\ \text { Hydrolycus tatauaia: } 12 & ->1\end{array}$

Erythrinus erythrinus: $012 \rightarrow 1$

Erythrinus erythrinus: $012 \rightarrow->1$

Curimatopsis macrolepis: $2 \rightarrow 0$

Myleus setiger: $02 \rightarrow 2$

Boulengerella maculata: $2 \rightarrow 0$
Moenkhausia xinguensis: $\odot->2$

Bryconops alburnoides: $0 \rightarrow$

Agoniates halecinus: $\odot \rightarrow 2$

Caráter 379 (23 passos)

Raiz: 2

Clado 104: 2 -> 12

Gymnotus aff. carapo: 12 -> 1

Clado 115: $2 \rightarrow 1$

Crenuchus spilurus: 2 -> 1

Salminus hilarii: $2 \rightarrow 1$

Clado 159: $2 \rightarrow$

Clado 146: $2 \rightarrow 0$

Clado 151: $2 \rightarrow 0$

Roeboexodon guyanensis: 2 -> 1

Galeocharax knerii: 2 -> 0

Bryconalestes longipinnis: $\odot \rightarrow$

Curimatopsis macrolepis: $1 \rightarrow 0$

Prochilodus nigricans: $1->0$

Chilodus punctatus: $1 \rightarrow 2$

Chilodus punctatus: $1->$

Paragoniates alburnus: $2 \rightarrow 0$

Rhinobrycon negrensis: $2 \rightarrow 1$

Hemibrycon polyodon : $2 \rightarrow 1$
Clado 132: $2 \rightarrow 0$

Clado 166: 2 -> 02

Astyanax mexicanus: $02->0$

Clado 188: $02 \rightarrow 0$

Clado 192: 02 -> 012

Probolus heterostomus : 012 -> 1

Clado 186: $0 \rightarrow 1$

Hollandichthys multifasciatus: 012 -> 2

Ctenobrycon hauxwellianus: 1 -> 2

Caráter 380 (15 passos)

Raiz: 01

Clado 102: 01 -> 0

Clado 111: $01 \rightarrow 1$

Clado 108: $1 \rightarrow 0$

Clado 142: $1 \rightarrow 0$

Clado 152: $1 \rightarrow 0$

Clado 117: 1 -> 01

Bivibranchia fowleri: $01 \rightarrow 0$

lado 150: 1 -> 01

Anodus orinocensis: $01->1$

Hemiodus unimaculatus : $01 \rightarrow 0$

Hydrolycus tatauaia: $01->0$

Hoplias malabaricus: $0 \rightarrow 1$

Anoulengerella maculata: $1->0$

Leporellus vittatus: 1 - $>0$

Clado 133: $0 \rightarrow 01$

Knodus meridae: $0->1$

Clado 164: $01 \rightarrow 1$

Bryconops alburnoides: 01 -> 1

Iguacladoctes geisleri: $01->0$

Clupeacharax engra

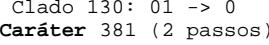

Raiz: 0

Lebiasina bimaculata: $0->1$

Erythrinus erythrinus: $0 \rightarrow 1$

Caráter 382 (2 passos)

Raiz: 1

Charax cf. leticiae: 1 -> 0

Phenacogaster pectinatus: $1 \rightarrow 0$

Caráter 383 (26 passos)

Raiz: 1

Clado 104: 1 -> 12

Gymnotus aff. carapo: $12->2$
Clado 115: 1 - $>0$

Crenuchus spilurus: $1->0$

Clado 147: $1 \rightarrow 0$

Chalceus epakros: 1 -> $\theta$

Clado 151: $1 \rightarrow 0$

Piabucina astrigata: 1 -> 0

Gnathocharax steindachneri: 1 -> 0

Galeocharax knerii: 1 ->

Clado 145: $\odot \rightarrow 02$

Clado 197: $1 \rightarrow 01$

Citharinus latus: $1 \rightarrow \odot$

Clado 199: 1 -> 12

Acestrorhynchus falcirostris: 02 -> 2

Erythrinus erythrinus: $0 \rightarrow 2$

Clado 196: $01 \rightarrow 0$

Clado 128: $0 \rightarrow 2$

Paragoniates alburnus: $12->2$

Hepsetus odoe: $02 \rightarrow 0$

Clado 155: $02->2$

Leporinus fasciatus: 2 -> 1

Clado 135: $1 \rightarrow 012$

Glandulocauda melanogenys: 012 -> 2

Clado 133: 012 -> 02

Moenkhausia xinguensis: 1 -> 0

Clado 174: $1 \rightarrow 01$

Clado 132: $02 \rightarrow 0$

Axelrodia reisei: 01 -> 0

Bryconops alburnoides: $\odot 2 \rightarrow \theta$

Iguacladoctes geisleri: $02 \rightarrow$

clupeacharax engrauloides: $0 \rightarrow 1$

Clado 187: $1 \rightarrow 0$

Probolus heterostomus : 1 -> 2

Tetragonopterus argenteus: $1->2$

Tetragonopterus argente

Raiz: 0

Clado 104: $\odot \rightarrow 01$

Gymnotus aff. carapo: $01->1$

Clado 107: $\odot \rightarrow 01$

Clado 157: $0 \rightarrow 1$

Chalceus epakros: $\odot->1$

Distichodus notospilus: 01 -> 1

Hemistichodus vaillanti: $01 \rightarrow 1$

Hemistichodus vaillanti: $01->1$

Citharinus latus: $01 \rightarrow 1$

Xenocharax spilurus: 01 -> 0

Erythrinus erythrinus: $0 \rightarrow 1$

Schizodon fasciatus: $0 \rightarrow 1$

Caráter 385 ( 2 passos)

Raiz: $\odot$

Hoplias malabaricus: $0 \rightarrow 1$

Chilodus punctatus: $\odot \rightarrow 1$

Caráter 386 (22 passos)

Raiz: 1

Catostomus commersonnii: 1 -> 0

Clado 154: $1 \rightarrow 01$

Clado 107: 1 -> 3

Salminus hilarii: 1 -> $\odot$

Clado 157: $01 \rightarrow 0$

Chalceus epakros: 01 -> 0

Clado 159: $01 \rightarrow 1$

Copeina cf. guttata: $01->1$

Clado 151: 01 -> 0

Parodon nasus: 12 -> 2

Bivibranchia fowleri: 1 -> 3

Citharinus latus: 3 -> 1

Anodus orinocensis: $1->2$

Clado 120: 1 -> 2

Clado 124: $1 \rightarrow 01$

Clado 156: $1 \rightarrow 0$

Caenotropus labyrinthicus: $01 \rightarrow 0$

Metynnis lippincottianus: $1 \rightarrow 2$

Phenacogaster pectinatus: $1 \rightarrow 3$

$\begin{array}{ll}\text { Clado } 176: 1 & ->2 \\ \text { Clado 200: } 2->12\end{array}$

Bryconops alburnoides: 1 -> 0

Astyanax mexicanus: $1 \rightarrow 2$

Stygichthys typhlops: $12->1$

Agoniates halecinus: $1 \rightarrow 0$

Tetragonopterus argenteus: $1 \rightarrow 2$

Ctenobrycon hauxwellianus: $1 \rightarrow 3$

caráter 387 ( 8 passos)

Raiz: 0

Clado 115: $\odot \rightarrow 1$

Copeina cf. guttata: $\odot \rightarrow 1$

Piabucina astrigata: $0 \rightarrow 1$

Clado 121: $1 \rightarrow 0$

Hemiodus unimaculatus : $1 \rightarrow 0$

Erythrinus erythrinus: $0 \rightarrow 1$

Schizodon fasciatus: 1 -> 0

Clado 174: $\odot \rightarrow 01$

Axelrodia reisei: 01 -> 1

Caráter 388 (10 passos)

Raiz: 0

Clado 151: $\odot \rightarrow 01$

Clado 125: $0 \rightarrow 01$

Clado 165: $0 \rightarrow 01$

Clado 150: $0 \rightarrow 01$

Clado 126: $01 \rightarrow$

Aphyocharax pusillus: $01->1$

Hydrolycus tatauaia: $01 \rightarrow 1$

Erythrinus erythrinus: 01 -> 1

Caenotropus labyrinthicus: $01 \rightarrow 0$

Chilodus punctatus: $01 \rightarrow 1$

Paragoniates alburnus: $01->0$

Phenagoniates macrolepis: $01 \rightarrow 1$

Clado 155: $0 \rightarrow 1$

Bryconops alburnoides: 0 -> 1

Astyanax mexicanus: $0->1$

Agoniates halecinus: $0 \rightarrow 1$

Caráter 389 ( 7 passos)

Raiz: 2

Clado 153: 2 -> 0

Neolebias unifasciatus: 2 -> 1

Saccodon wagneri: $2 \rightarrow 0$

Xenocharax spilurus: 2 - $>1$

Erythrinus erythrinus: $\odot->$

Leporinus fasciatus: $2 \rightarrow 1$

Knodus meridae: $2 \rightarrow 1$

Caráter 390 (22 passos)

Raiz: 1

Clado 109: $1 \rightarrow 2$

Clado 143: $1 \rightarrow 0$

Lebiasina bimaculata: 1 -> 0

Arnoldichthys spilopterus: 1 -> 0

Gnathocharax steindachneri: $0 \rightarrow 1$

Clado 156: $\odot \rightarrow 2$

Bryconalestes longipinnis: 1 -> 0

Phenagoniates macrolepis: $0 \rightarrow 1$

Clado 127: $2 \rightarrow 1$

Clado 179: $\odot \rightarrow 1$

Clado 176: $0 \rightarrow>2$

Clado 133: $0 \rightarrow 01$

Piabina argentea: 1 ->

Odontostilbe pequira: $2 \rightarrow$

ape: $012 \rightarrow 2$

Clado 166: 012 -> 01

Clado 131: 01 -> 012

Bryconops alburnoides: 01 -> 0

Iguacladoctes geisleri: $01 \rightarrow 1$

Astyanax mexicanus: $01 \rightarrow 1$

Clupeacharax engrauloides: 012 -> 2

Clado 130: $012 \rightarrow 1$

Agoniates halecinus: $01->0$

Triportheus albus: $01 \rightarrow 1$ 
Caráter 393 ( 30 passos)

Raiz: 0

Clado 102: 02 ->

Clado 163: 02 ->

Clado 108: 02 ->

Clado 114: $02 \rightarrow>2$

Clado 141: 02 -> $\odot$

Clado 182: 02 -> 012

Salminus hilarii: 02 -> 2

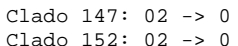

Chalceus epakros: $02 \rightarrow>2$

Clado 117: $02 \rightarrow 0$

Clado 122: $02 \rightarrow 012$

Oligosarcus argenteus: $012->2$

Lebiasina bimaculata: $02 \rightarrow 0$

Piabucina astrigata: $02->2$

Arnoldichthys spilopterus: $\odot 2->\odot$

Clado 162: $02 \rightarrow 12$

Clado 121: $012 \rightarrow 2$

Clado 125: $012 \rightarrow 01$

Roeboexodon guyanensis: $\odot \rightarrow 1$

gurae: $012 \rightarrow 1$

Anodus orinocensis:

Clado 173: 0 - 1 idotus: $12 \rightarrow 1$

Brycinus macrolepidotus: $12->1$

Bryconalestes longipinnis: $12 \rightarrow 2$

Caenotropus labyrinthicus: 01

Chilodus punctatus: $01 \rightarrow 1$

Anostomus anostomus: $01->1$

Metynnis lippincottianus: $12 \rightarrow 1$

Myleus setiger: $12 \rightarrow 2$

Schizodon fasciatus: 01 -> 1

Clado 127: 01 -> 012

Leporellus vittatus: $012 \rightarrow>2$

Leporinus fasciatus: $012 \rightarrow 0$

Clado 169: $0 \rightarrow 2$

Clado 170: $1 \rightarrow 12$

Clado 177: $\odot \rightarrow 02$

Atopomesus pachyodus: 12 -> 2

Moenkhausia xinguensis: $2 \rightarrow 1$

Bryconamericus exodon: $02 \rightarrow 2$

Clado 174: $\rightarrow 01$

Clado 174: $1 \rightarrow 01$

Axelrodia reisei: $01->0$

Astyanax mexicanus: $2->0$

Astyanax mexicanus: $2 \quad->0$
Stygichthys typhlops: $12->2$

Stygichthys typhlops: 12

Triportheus albus:

Tetragonopterus argenteus: 2 -> 1

Hollandichthys multifasciatus: 02 -> Hollandichthys multifa
Caráter 394 (27 passos)

Caráter 394

Raiz: 3

Catostomus commersonnii: 3 -> 0

Clado 144: $3 \rightarrow 13$

Clado 143: 13 ->

Characidium bahiensis: 3 -> 2

Clado 153: 13 -> 0123

Clado 160: $13 \rightarrow 1$

$\begin{array}{lll}\text { Clado } 118: & 3-> & 1 \\ \text { Clado } 157: & 0123 & ->\end{array}$

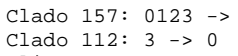

Oligosarcus argenteus: $1 \rightarrow 2$

Copeina cf. guttata: $0123 \rightarrow 2$

Clado 151: 0123 ->

Clado 161: 1 -> 123

Citharinus latus: 3 -> 1

Clado 124: 1 -> 01

Brycinus macrolepidotus: $123 \rightarrow 2$

Bryconalestes longipinnis: $123 \rightarrow$

Caenotropus labyrinthicus: $012->$

Chilodus punctatus: $012 \rightarrow 2$

Clado 155: $1 \rightarrow 0$

Clado 155: $1 \rightarrow 0$

Phenacogaster pectinatus: $1->2$

Rhinobrycon negrensis: $13->3$

Rhinobrycon negrensis: $13 \rightarrow 3$
Clado 184: $1 \rightarrow 3$

Glandulocauda melanogenys: 1 -> 3

Bryconamericus exodon: 13 -> 1

Bryconamericus exodon: $13 \rightarrow$

Piabina argentea: 13 $->3$

Paracheirodon axelrodi: $1->3$

Agoniates halecinus: 1 ->

Clado 186: $3 \rightarrow$

Poptella brevispina: $1 \rightarrow 2$

Caráter 395 (20 passos)

Raiz: 2

Clado 104: 2 -> 12

Gymnotus aff. carapo: $12->1$

Characidium bahiensis: 2 -> 1

Clado 142: $2 \rightarrow 1$

Clado 118: $2 \rightarrow 1$

Hemistichodus vaillanti: 2 -> 1

Clado 165: $1 \rightarrow 2$

Clado 150: $2 \rightarrow 12$

Clado 197: $2 \rightarrow 12$

Citharinus latus: $2 \rightarrow 0$

Clado 124: 1 ->

Hydrolycus tatauaia: $12 \rightarrow 1$

Clado 196: $12 \rightarrow 1$

Clado 127: $1 \rightarrow 2$

Clado 127: $1->2$

Boulengerella maculata: 2 -> 1
Clado 178: 1 -> 2

Hemibrycon polyodon : 1 -> 2

Deuterodon iguape:

Probolus heterostomus : $1->$

Gymnocorymbus ternetzi: 1 ->

Ctenobrycon hauxwellianus: 1 -> 2

Caráter 396 (10 passos)

Raiz: 0

Clado 104: $0 \rightarrow 1$

Clado 110: $\theta \rightarrow 01$

Clado 108: $01 \rightarrow 1$

Clado 115: $01 \rightarrow 0$

Crenuchus spilurus: $01 \rightarrow 1$

Clado 190: $0 \rightarrow 01$

Gnathocharax steindachneri: 01 -> 1

Clado 196: $0 \rightarrow 1$

Clado 172: $0 \rightarrow 1$

lado 200: 1 -> 01

tygichthys typhlops: 01 -> 0

Clado 130: $\odot \rightarrow 1$

Tetragonopterus argenteus: $\odot->1$

Caráter 397 (11 passo)

Raiz: 1

Olivaichthys mesembrinus: $1->0$

Clado 163: $1 \rightarrow 12$

Clado 154: 1 -> 13

Crenuchus spilurus: $12 \rightarrow 2$

Clado 106: $1 \rightarrow 2$

Clado 190: 1 -> 01

Gnathocharax steindachneri: $01->0$

Galeocharax knerii: $1 \rightarrow 2$

Clado 138: 1 -> 12

Metynnis lippincottianus: 13 -> 3

Clado 136: 12 -> 2

Microschemobrycon casiquiare: 1 -> 2

Clado 184: $1 \rightarrow 2$

Clado 174: $1 \rightarrow 0$

Clado 129: 2 -> 0

Caráter 398 (2 passos)

Raiz: 0

Metynnis lippincottianus: 0 -> 01

Clado 135: $\theta \rightarrow 01$

Clado 175: $0 \rightarrow>02$

Clado 174: $02->2$

Caráter 399 ( 6 passos)

Raiz: 01

Raiz: 01 (

Chanos chanos: 01

Clado 111: $01>0$

Clado 104: $01 \rightarrow 0$

Clado 153: $\odot \rightarrow 01$

Clado 152: 01 -> 1

Lebiasina bimaculata: 01 -> 1

Piabucina astrigata: $01 \rightarrow 0$

Phenagoniates macrolepis: $0 \rightarrow 1$

Carnegiella strigata: $0 \rightarrow 1$

caráter 400 ( 5 passos)

Raiz: 0

Clado 118: $0 \rightarrow 01$

Bivibranchia fowleri: 01 -> 0

Clado 116: 01 -> 1

Clado 123: 01 -> 1

Curimatopsis macrolepis: 01 -> 0

Clado 119: 01 -> 1

Caenotropus labyrinthicus: 01 -> 1

Chilodus punctatus: $01 \rightarrow 0$

Anostomus anostomus: $01 \rightarrow$

Clado 128: 01 -> 1

Caráter 401 ( 3 passos)

Raiz: 01

Chanos chanos: $01->1$

Clado 103: $01 \rightarrow 0$

Clado 103: $01->$

Apareiodon piracicabae: $0->1$

Caráter 402 ( 5 passos)

Carater $\odot$

Gymnotus aff. carapo: $0->1$

Characidium bahiensis: $0 \rightarrow 1$

Clado 151: $0 \rightarrow 1$

Clado 126: $\odot->$

eporellus vittatus: 1 -> 0

Caráter 403 ( 8 passos)

Raiz: 0

Clado 102: $\odot \rightarrow 01$

Catostomus commersonnii: $01 \rightarrow 1$

Olivaichthys mesembrinus: $01 \rightarrow 0$

Gymnotus aff. carapo: $01 \rightarrow 1$

Crenuchus spilurus: $0 \rightarrow-1$

Clado 157: $0 \rightarrow 1$

Clado 125: $\odot \rightarrow 01$

Clado 158: $\odot \rightarrow 1$

Clado 126: $01 \rightarrow 1$

Caenotropus labyrinthicus: 01 -> 0

Chilodus punctatus: $01 \rightarrow 1$

Leporellus vittatus: 1 -> 0

Caráter 404 (22 passos)

Raiz: 012

Chanos chanos: $012->$

Clado 103: 012 -> 0

Gymnotus aff carapo: $\theta->2$

Clado 160: $\odot \rightarrow 1$

Clado 118: $0 \rightarrow 1$

Clado 182: $0 \rightarrow 01$

Clado 117: $1 \rightarrow 2$
Oligosarcus argenteus: $01->1$

Brycon pesu: $0 \rightarrow 1$

Charax cf. leticiae: $01 \rightarrow 0$

Galeocharax knerii: 01 -> 1

Hydrolycus tatauaia: $0 \rightarrow 1$

Piaractus mesopotamicus: $1 \rightarrow 0$

Curimatopsis macrolepis: $1 \rightarrow 0$

Clado 119: $1 \rightarrow 2$

Moenkhausia xinguensis: 0 -> 1

Piabina argentea: $0->1$

Clado 164: $0 \rightarrow 1$

Bryconops alburnoides: $0->2$

Agoniates halecinus: $1 \rightarrow 2$

Probolus heterostomus : $0 \rightarrow 1$

Orthospinus franciscoensis: $0_{->1}$

Caráter 405 ( 4 passos)

Raiz: 2

Clado 104: 2 -> 1

Erythrinoidea fam. nov: $2>1$

Stygichthys typhlops: $2 \rightarrow 0$

Caráter 406 (4 passos)

Raiz: 1

Clado 104: $1 \rightarrow 0$

Erythrinoidea fam. nov: $1 \rightarrow 0$

Hepsetus odoe: $1 \rightarrow 0$

Glandulocauda melanogenys: 1 -> $\odot$

Caráter 407 (16 passos)

Raiz: 0

Clado 143: $\odot \rightarrow 01$

Clado 160: $0 \rightarrow 02$

Salminus hilarii: $01 \rightarrow$

Chalceus epakros: $02 \rightarrow 2$

Clado 140: $01->1$
Brycon pesu: $01->1$

Arnoldichthys spilopterus: 02 -> 2

Clado 162: 02 2 $>0$

Gnathocharax steindachneri: $01 \rightarrow 0$

Roeboexodon guyanensis: 01 -> 1

Clado 145: 01 -> 0

Bryconalestes longipinnis: 0 -> 1

Landonia latidens: $1 \rightarrow 0$

Clado 155: $0 \rightarrow 2$

Roestes molossus: $01->1$

Atopomesus pachyodus: $1 \rightarrow 0$

Glandulocauda melanogenys: 1 -> 2

Clado 198: 1 -> 01

Iguacladoctes geisleri: 1 -> 0

Rachoviscus graciliceps: $01->0$

Rachoviscus gracilice

Carnegiella strigata: 13 -> 3

Gymnocorymbus ternetzi: $1 \rightarrow 2$

caráter 408 ( 1 passo)

Raiz: 0

Clado 197: $\odot \rightarrow->$

Caráter 409 ( 2 passos)

Clado 102: $0 \rightarrow 1$

Clado 108: $0 \rightarrow 1$ 
Apêndice 2. Lista de transições comuns aos dois cladogramas fundamentais. Número do clado se refere ao número no consenso estrito

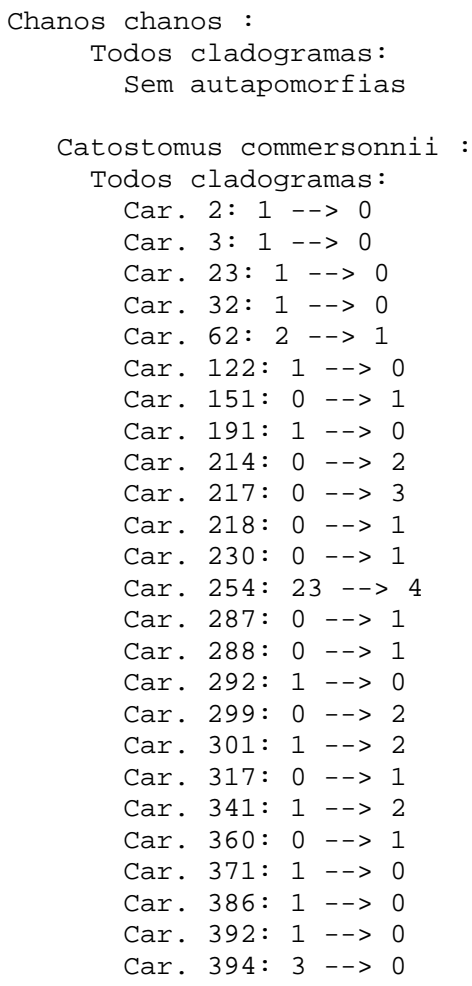

Olivaichthys mesembrinus

Todos cladogramas: Car. 11: $1-->2$ Car. 13: $0-->1$

Car. 25: $0 \quad->1$ Car. 26: $\odot-->1$ Car. 28: $\odot \quad-->2$ Car. 29: $\odot-\rightarrow 2$ Car. 38: $\odot-->1$ Car. 46: $0-\rightarrow 1$ Car. 62: $2-\rightarrow 0$ Car. 67: $1->0$

Car. 77: $0-->1$ Car. 78: $1-\rightarrow 0$ Car. 80: $0-->1$ Car. 91: 1 - $>0$ Car. 109: $0-->1$ Car. 131: $1-->2$ Car. 136: $0-->1$ Car. 178: $0-\rightarrow 1$ Car. 191: $1->3$ Car. 221: $0-\rightarrow 1$ Car. 240: $0-\rightarrow>1$ Car. 241: $1-->0$ Car. 341: $1-\rightarrow 0$ Car. 342: 0 - $>2$ Car. 343: $\odot-\rightarrow 1$ Car. 397: $1-->0$

Gymnotus aff. carapo : Todos cladogramas:

Car. $\odot: 0-->2$

Car. 39: $\odot-->1$

Car. 40: $2-->1$

Car. 76: $1->0$

Car. 97: $2-->1$

Car. 99: $0-->1$
Car. 105: $1-->0$

Car. 108: $0->1$

Car. 114: $2-->0$

Car. 125: $0-->1$

Car. 134: $0->1$

Car. 167: $0-->2$

Car. 211: 2 - $>0$

Car. 212: $\odot-\rightarrow 2$

Car. 222: $0-->1$

Car. 248: $1->0$

Car. 252: $\odot-\rightarrow 1$

Car. 253: $0-->1$

Car. 292: 1 - $>3$

Car. 329: 1 - $>0$

Car. 332: $0->1$

Car. 347: $0-->1$

Car. 402: $0-->1$

Car. 404: $0-->2$

Citharinus latus : Todos cladogramas:

Car. 29: 1 - 2

Car. 48: $1-\rightarrow 2$

Car. 49: $\odot \quad->1$

Car. 74: $0-->1$

Car. 106: $\odot->1$

Car. 114: $1-->2$

Car. 120: $1->0$

Car. 124: $1->0$

Car. 128: $1-->0$

Car. 132: $1-->0$

Car. 137: $0-->1$

Car. 152: $0-->1$

Car. 153: $1-->0$

Car. 154: $0-->1$

Car. 167: $0-\rightarrow 1$

Car. 176: $0-->2$

Car. 190: $1-->0$

Car. 197: $1-->0$

Car. 200: $\odot-->2$

Car. 202: $0-\rightarrow 1$

Car. 208: $\odot->1$

Car. 210: $1-->0$

Car. 211: $2-->0$

Car. 212: $1-->2$

Car. 213: $1-->0$

Car. 219: $\odot-\rightarrow 1$

Car. 220: $0-->1$

Car. 224: $1-\rightarrow 0$

Car. 255: $\odot-\rightarrow 1$

Car. 264: $3-->1$

Car. 272: $2->3$

Car. 292: $1-->2$

Car. 313: $2-->1$

Car. 342: $0->1$

Car. 347: $1-->0$

Car. 362: $3-\rightarrow 0$

Car. 369: $2->0$

Car. 373: $0 .->1$

Car. 383: $1-\rightarrow 0$

Car. 386: $3-->1$

Car. 394: $3-->1$

Car. 395: $2-->0$

Distichodus notospilus : Todos cladogramas:

Car. 38: $0-->1$

Car. 43: $1-->2$

Car. 45: $1-->0$

Car. 58: $\odot-\rightarrow 1$

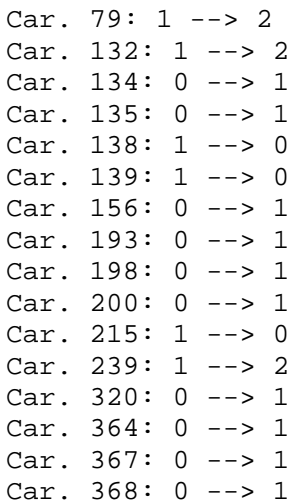

Hemistichodus vaillanti : Todos cladogramas:

Car. 24: $0-->1$

Car. 68: $\odot-\rightarrow 1$

Car. 79: $1-->2$

Car. 104: $1->0$

Car. 112: 1 - $>0$

Car. 124: $1-->0$

Car. 140: $0->1$

Car. 141: $0-->1$

Car. 145: $0-->1$

Car. 177: $1-->0$

Car. 189: $0-->1$

Car. 198: $0-->1$

Car. 238: 1 - -> 0

Car. 256: $1-->3$

Car. 277: $0->1$

Car. 298: $1-->2$

Car. 299: $0-\rightarrow 1$

Car. 340: $34->6$

Car. 369: 2 - $>1$

Car. 395: $2-->1$

Neolebias unifasciatus : Todos cladogramas:

Car. 55: $1-\rightarrow \infty$

Car. 63: $1->2$

Car. 81: 2 - $>0$

Car. 86: $01-->2$

Car. 137: $0-->1$

Car. 139: 1 - $>0$

Car. 174: $0-->1$

Car. 189: $0-->1$

Car. 191: $1-->0$

Car. 192: $1-\rightarrow 0$

Car. 197: $1-\rightarrow 0$

Car. 247: 1 - $>0$

Car. 252: $0-->1$

Car. 253: $\odot-->1$

Car. 376: $1->0$

Car. 389: 2 - $>1$

NannoCar.ax fasciatus : Todos cladogramas:

Car. 7: $4-->2$

Car. 38: $\odot-->1$

Car. 43: $1-->2$

Car. 45: $1->0$

Car. 48: $1->0$

Car. 61: $0-\rightarrow 1$

Car. 81: $2-->1$

Car. 83: $1-->2$

Car. 95: $2-->0$ 
Car. 96: $1-->0$

Car. 135: $0-->1$

Car. 138: $1-->0$

Car. 148: $0 \quad->1$

Car. 165: 1 - $>0$

Car. 176: $0-->2$

Car. 180: $2-->0$

Car. 183: 1 - $>0$

Car. 200: $\odot-->2$

Car. 201: $0-->1$

Car. 207: $0-->1$

Car. 210: $1-->0$

Car. 212: $1-->2$

Car. 222: 1 - $>0$

Car. 230: $0-->1$

Car. 236: $0-->1$

Car. 241: $0-->1$

Car. 252: $0-->1$

Car. 254: $23-->1$

Car. 260: $2-->0$

Car. 270: $1-->0$

Car. 279: $0-->1$

Car. 288: $0-->1$

Car. 310: $0-->9$

Car. 321: 1 - -> 0

Car. 327: $0-->1$

Car. 332: $0-->1$

Car. 333: $\odot-->1$

Car. 338: $0-->1$

Car. 339: $1-->0$

Car. 340: $34-->2$

Car. 350: $0-->1$

XenoCar.ax spilurus : Todos cladogramas:

Car. 13: $1->0$

Car. 17: $1-->0$

Car. 28: $\odot-->1$

Car. 42: $0-->1$

Car. 55: $1-->0$

Car. 63: 1 - $>2$

Car. 69: 1 - $->0$

Car. 93: $0-->1$

Car. 98: $\odot-->1$

Car. 148: $0-->1$

Car. 165: $1-->2$

Car. 201: $0-->1$

Car. 244: 1 - $>0$

Car. 254: $3-->4$

Car. 256: $1-->2$

Car. 314: $0-->1$

Car. 339: $1-->0$

Car. 341: $1-->0$

Car. 371: $1-->0$

Car. 376: $1-->2$

Car. 389: 2 - -> 1

Apareiodon piracicabae : Todos cladogramas:

Car. 74: $0-->1$

Car. 139: $1-->0$

Car. 144: $0-->1$

Car. 238: $\odot-->1$

Car. 267: $0-->1$

Car. 276: $1-->0$

Car. 293: $0-->1$

Car. 340: $3-->4$

Car. 401: $0-->1$

Parodon nasus :

Todos cladogramas:

Car. 177: $1 \ldots 0$

Car. 264: $1-->0$

Car. 339: $1->0$

Car. 355: $1 \ldots$

Car. 377: $1-->0$
Saccodon wagneri:

Todos cladogramas:

Car. 74: $\odot-->2$

Car. 88: 0 --> 2

Car. 167: $1-->2$

Car. 193: $0 \quad->1$

Car. 195: $0 \quad->1$

Car. 230: $0-->1$

Car. 252: 0 - -> 1

Car. 389: $2-->0$

Anodus orinocensis: Todos cladogramas:

Car. 13: 1 - -> 3

Car. 17: $1-->0$

Car. 20: $0-->1$

Car. 28: 1 - -> $\odot$

Car. 29: $1-->2$

Car. 51: $1-->0$

Car. 73: 1 -->0

Car. 83: $1-->0$

Car. 85: $0-->1$

Car. 97: $0-->1$

Car. 112: $1-->0$

Car. 130: 0 - -> 1

Car. 139: $1-->2$

Car. 144: $0 \quad->1$

Car. 161: $0-->1$

Car. 177: $1-->2$

Car. 185: $1-->0$

Car. 186: $\odot-->2$

Car. 210: $1-->0$

Car. 213: 1 - -> $\odot$

Car. 239: $1-->2$

Car. 264: $1-->2$

Car. 292: $\odot-->1$

Car. 306: $0-->1$

Car. 347: $1-->2$

Car. 352: $\odot-->1$

Car. 375: $\odot-->2$

Car. 386: $1-->2$

Car. 393: $\odot-->1$

Bivibranchia fowleri Todos cladogramas:

Car. 51: $1-->2$

Car. 61: 0 --> 1

Car. 69: $1-->2$

Car. 155: $1-->0$

Car. 183: $1-->0$

Car. 218: $0-->1$

Car. 222: $1-->0$

Car. 238: $0-->1$

Car. 253: $\odot-->1$

Car. 264: $1-->3$

Car. 272: $2-->0$

Car. 347: $1-->0$

Car. 348: $0-->1$

Car. 365: $1-->0$

Car. 378: $2-->0$

Car. 386: $1-->3$

Hemiodus unimaculatus : Todos cladogramas:

Car. 28: 1 --> 2

Car. 74: $0-->1$

Car. 149: $1-->0$

Car. 153: $1-->2$

Car. 156: $0-->2$

Car 167: 1 - $>0$

Car. 207: $1-->0$

Car. 208: $1-->0$

Car. 211: $2-->0$

Car. 212: $1-->2$

Car. 214: $\odot-->2$

Car. 217: $0-->3$

Car. 223: $1-->0$
Car. 244: $0-->1$

Car. 378: $2-->1$

Car. 387: $1-->0$

Curimata ocellata :

Todos cladogramas:

Car. 22: $0-->1$

Car. 59: $1-->0$

Car. 96: $2-->0$

Car. 97: $0-->2$

Car. 98: $1-->0$

Car. 117: $1 \ldots$

Car. 170: $0-->1$

Car. 183: $1-->0$

Car. 244: $0-->1$

Car. 251: $1-->0$

Car. 252: $0 \quad-->1$

Car. 254: $2-->4$

Car. 256: $1-->2$

Car. 262: $1-->0$

Car. 271: $0-->1$

Car. 287: $\odot-->1$

Car. 329: $0-->1$

Car. 363: $1-->0$

Car. 376: $1-->2$

Car. 377: $1-->2$

Curimatopsis macrolepis : Todos cladogramas:

Car. 69: 1 - $>2$

Car. 114: $2-->1$

Car. 122: $1-->0$

Car. 162: $2-->01$

Car. 166: $1-->0$

Car. 167: $1-->0$

Car. 180: $0-->2$

Car. 264: $1-->3$

Car. 271: $0-->2$

Car. 277: $\odot-->1$

Car. 278: $2-->1$

Car. 281: $0 \quad->1$

Car. 295: $\odot-->1$

Car. 302: $2-->1$

Car. 327: $0-->1$

Car. 332: $1-->0$

Car. 340: $12-->0$

Car. 347: 1 - -> $\odot$

Car. 351: $2-->0$

Car. 355: $0-->1$

Car. 372: $1-->0$

Car. 376: $1-->0$

Car. 378: $2-->0$

Car. 379: $1-->0$

Car. 404: 1 --> 0

Potamorhina latior :

Todos cladogramas:

Car. 19: $0-->1$

Car. 21: $1-->2$

Car. 29: $1-->2$

Car. 60: $0-->1$

Car. 124: $\odot-->1$

Car. 148: $0-->1$

Car. 155: $1 \ldots$

Car. 164: $0-->1$

Car. 165: $2-->1$

Car. 181: $0-->1$

Car. 193: $0-->1$

Car. 198: $0-->1$

Car 223: $1 \ldots$

Car. 257: $\odot-->1$

Car. 258: $1-->3$

Car. 260: $1-->2$

Car. 266: $1-->0$

Car. 270: $1-->0$

Car. 272: 2 - -> 3

Car. 292: $0-->1$ 
Car. 297: $1-->0$

Car. 298: 0 - $>3$

Car. 299: $0-->1$

Car. 300: $1-->0$

Car. 311: $0-->1$

Car. 313: $1-->2$

Car. 339: $1-->0$

Car. 347: $1-->2$

Car. 359: $\odot-->1$

Car. 360: $2-->1$

Car. 375: $\odot-->2$

Prochilodus nigricans : Todos cladogramas:

Car. 19: $\odot-->1$

Car. 93: $1-->0$

Car. 174: $0-->1$

Car. 175: $1-->0$

Car. 300: 1 - $>0$

Car. 362: $\odot-->2$

Car. 364: $1-->2$

Car. 367: $0-->1$

Car. 377: $1-->0$

Car. 379: $1-->0$

Semaprochilodus insignis

Todos cladogramas: Car. 17: $1-->0$ Car. 71: $\odot-->1$

Car. 98: $1-->0$

Car. 125: $0-->1$

Car. 144: $0-->1$

Car. 148: $0-->1$

Car. 155: $1-->2$

Car. 156: $0-->2$

Car. 159: $0-->1$

Car. 167: $1-->0$

Car. 178: $0-->1$

Car. 258: $1-->2$

Car. 262: 1 - $>0$

Car. 324: $0-->1$

Car. 329: $0-->1$

Car. 339: 1 - $>0$

Car. 360: $2-->1$

Caenotropus labyrinthicus

Todos cladogramas:

Car. 142: 1 - $->0$

Car. 159: $0 \quad->1$

Car. 177: $1-->0$

Car. 203: 1 - $>0$

Car. 260: $1-->2$

Car. 329: $\odot-->1$

Car. 340: 1 - $>0$

Car. 362: $0-->1$

Chilodus punctatus

Todos cladogramas:

Car. 157: $1-->0$

Car. 162: $2-->1$

Car. 228: $0-->1$

Car. 241: $0 \quad->1$

Car. 251: $1-->2$

Car. 276: $1-->2$

Car. 300: $1-->0$

Car. 301: $2-->1$

Car. 302: $2-->0$

Car. 355: $\odot-->1$

Car. 379: $1-\rightarrow 2$

Car. 385: $0 \quad->1$

Anostomus anostomus :

Todos cladogramas:

Car. 81: $2-->1$

Car. 98: $1-->0$
Car. 142: $1-->0$

Car. 161: $0-->1$

Car. 166: $1-->0$

Car. 191: $1-->0$

Car. 204: $0-->1$

Car. 251: $1-->2$

Car. 255: $2-->1$

Car. 264: $1-->3$

Car. 294: 0 - -> 1

Car. 302: $2-->1$

Car. 327: $0-->1$

Car. 340: $23-->5$

Car. 341: $1-->0$

Car. 342: $1-->2$

Car. 358: $\odot-->1$

Car. 380: $1-->0$

Leporellus vittatus : Todos cladogramas:

Car. 113: $0-->1$

Car. 123: $1-->0$

Car. 134: $1-\rightarrow>0$

Car. 165: $0-->2$

Car. 183: $0-->1$

Car. 184: $2-->1$

Car. 201: $1-->0$

Car. 244: $1-->0$

Car. 258: $1-->3$

Car. 272: $2-->3$

Car. 293: $1-->0$

Car. 329: $\odot-->1$

Car. 340: $3-->4$

Car. 377: $1-->0$

Car. 380: $1-->0$

Car. 402: $1-->0$

Car. 403: $1-->0$

Leporinus fasciatus :

Todos cladogramas:

Car. 89: $0-->1$

Car. 131: $\odot-->1$

Car. 161: $\odot-->1$

Car. 179: $0-->1$

Car. 197: $\odot-->1$

Car. 198: $0-->1$

Car. 199: $0-->1$

Car. 236: $\odot-->1$

Car. 254: $2-->3$

Car. 263: $\odot-->1$

Car. 294: $0-->1$

Car. 300: $1-\rightarrow 0$

Car. 363: $\odot-->1$

Car. 369: $1-->0$

Car. 383: $2-->1$

Car. 389: $2-->1$

Schizodon fasciatus :

Todos cladogramas:

Car. 24: 0 --> 1

Car. 76: $1-->0$

Car. 95: $0-->2$

Car. 114: $2-->1$

Car. 146: $2-->0$

Car. 160: $1-->0$

Car. 262: $1-->0$

Car. 265: $0-->1$

Car. 280: $0 \quad->1$

Car. 312: $2-->1$

Car. 339: $1-->0$

Car. 356: $0-->1$

Car. 374: $0-->1$

Car. 375: $0-->2$

Car. 376: $1-\rightarrow>2$

Car. 384: $0-->1$

Car. 387: $1-->0$

Carnegiella strigata :
Todos cladogramas:

$$
\begin{aligned}
& \text { Car. 114: } 1-->0 \\
& \text { Car. 190: } 1-->0 \\
& \text { Car. 279: } 2-->3 \\
& \text { Car. 340: } 6-->5 \\
& \text { Car. 341: } \odot-->2 \\
& \text { Car. 399: } \odot-->1
\end{aligned}
$$

Gasteropelecus sternicla

Todos cladogramas:

Car. 329: 1 - $>0$

Car. 339: $1-->0$

Car. 340: $6-->9$

Car. 346: $1-->0$

Car. 349: $1-->0$

Car. 367: $1-->0$

Thoracocar.ax stellatus

Todos cladogramas:

Car. 114: $1-->2$

Car. 191: $1-->2$

Car. 278: $1-->3$

Car 279: 2 - $>0$

Car. 282: $1-->2$

Car. 298: $1-->2$

Car. 300: $1-->0$

Car. 302: $0-->1$

Car. 360: $2-->0$

Acestrorhynchus

falcirostris :

Todos cladogramas: Car. 20: 0 - -> 1

Car. 50: $0-->1$

Car. 76: $1-->0$

Car. 79: $1-->0$

Car. 86: $1-->2$

Car. 112: $1-->2$

Car. 129: $0-->2$

Car. 157: $1-->0$

Car. 166: $1-->0$

Car. 174: $1-->\odot$

Car. 180: $2-->0$

Car. 184: $1-->0$

Car. 186: $1-->2$

Car. 192: $1-->2$

Car. 209: $1-->0$

Car. 241: $0-->1$

Car. 263: $0-->1$

Car. 277: $1-->0$

Car. 294: $0-->1$

Car. 329: 1 - -> $\odot$

Car. 332: $0-->1$

Car. 342: $2-->0$

Gilbertolus atratoensis : Todos cladogramas:

Car. 1: $2-->1$

Car. 3: $1-->0$

Car. 26: $1-->0$

Car. 59: $1-->0$

Car. 63: $0-->1$

Car. 112: $1-->0$

Car. 113: $0-->1$

Car. 114: $1-->0$

Car. 120: $0-->1$

Car. 131: $2-->0$

Car. 173: $1-->0$

Car. 207: $0-->1$

Car. 214: $1-->0$

Car. 215: $\odot-->1$

Car. 262: $1-->2$

Car. 265: $0-->1$

Car. 301: $2-->1$

Car. 325: $0-->1$ 
Car. 342: 2 --> 1

Car. 346: 1 - -> 0

Car. 369: $1-->0$

Hydrolycus tatauaia : Todos cladogramas:

Car. 50: $0-->1$

Car. 81: $1-->3$

Car. 125: 0 --> 1

Car. 127: $1-->0$

Car. 132: $0-->1$

Car. 139: 2 - $>0$

Car. 144: $0-->2$

Car. 156: $0-->1$

Car. 165: 2 - -> 0

Car. 175: $1-->0$

Car. 191: 1 --> 2

Car. 192: $1-->2$

Car. 212: $2-->0$

Car. 235: $\odot \quad->1$

Car. 240: $1-->0$

Car. 245: 0 - $>1$

Car. 264: $3-->2$

Car. 270: $1-->0$

Car. 272: $12-->3$

Car. 273: $\odot-->1$

Car. 279: $2-->1$

Car. 280: $0 \quad->1$

Car. 289: $0-->1$

Car. 300: $1-->0$

Car. 305: $1-->0$

Car. 306: $1-->2$

Car. 324: $1->0$

Car. 330: $0-->1$

Car. 347: $0-->1$

Car. 350: $0-->1$

Car. 404: $0-->1$

Roestes molossus:

Todos cladogramas:

Car. 71: 0 - -> 1

Car. 79: $1-->2$

Car. 162: $2-->1$

Car. 176: $0 \quad->1$

Car. 212: $2-->1$

Car. 256: 1 - -> 0

Car. 264: 3 - -> 1

Car. 279: 2 - $>3$

Car. 291: $0 \quad-->1$

Car. 293: $0-->1$

Car. 317: $0-->2$

Car. 339: 0 - -> 1

Car. 340: $6-->4$

Erythrinoidea fam. nov :

Todos cladogramas:

Car. 6: $0-->1$

Car. 7: $4-->3$

Car. 50: $\odot-->1$

Car. 62: $2-->0$

Car. 67: $0-->1$

Car. 72: $1-->0$

Car. 73: $1-->0$

Car. 85: $0-->1$

Car. 96: $12-->0$

Car. 107: $1-\rightarrow 0$

Car. 112: $1-->2$

Car. 114: $1-->0$

Car. 151: $0-->1$

Car. 182: $0 \quad->1$

Car. 183: $1-->2$

Car. 194: 1 --> 0

Car. 195: $1 \ldots$

Car. 200: $1->0$

Car. 207: 0 - $>1$

Car. 208: $\odot \quad->1$

Car. 211: $2-->1$
Car. 222: 1 --> 0

Car. 225: $\odot-->1$

Car. 228: $\odot-->1$

Car. 230: $0-->1$

Car. 238: $1-->0$

Car. 257: $\odot-->1$

Car. 262: $1-->2$

Car. 279: $3-->4$

Car. 289: 1 - $>0$

Car. 294: $\odot-->1$

Car. 306: $0-->1$

Car. 312: $12-->0$

Car. 313: $1-->0$

Car. 342: $1-->0$

Car. 346: 0 - -> 1

Car. 364: $1-->0$

Car. 367: 1 - $>0$

Car. 392: $1-->0$

Car. 405: $2-->1$

Car. 406: $1-->0$

Boulengerella maculata :

Todos cladogramas:

Car. 16: $1-->0$

Car. 50: $0-->1$

Car. 58: $0-->1$

Car. 61: $1-->2$

Car. 97: $0-->1$

Car. 112: $1-->2$

Car. 166: 1 - $>0$

Car. 295: $0-->1$

Car. 378: $2-->0$

Car. 380: $1-->0$

Car. 395: $2-->1$

Ctenolucius hujeta :

Todos cladogramas:

Car. 52: 0 - -> 1

Car. 79: $1-->4$

Car. 138: $1-->0$

Car. 191: 1 --> 2

Car. 192: $1-->2$

Car. 207: $0-->1$

Car. 214: $1-->0$

Car. 249: $1-->0$

Car. 281: $0-->1$

Car. 313: $2-->1$

Copeina cf. guttata :

Todos cladogramas:

Car. 0: $1-->2$

Car. 17: $0-->1$

Car. 63: $01-->2$

Car. 65: $0-->1$

Car. 87: $1-->2$

Car. 92: $1-->0$

Car. 146: $3-->2$

Car. 148: $\odot-->1$

Car. 149: $1-->0$

Car. 153: $2-->0$

Car. 160: $1-->0$

Car. 191: 1 - -> $\odot$

Car. 224: $1-->0$

Car. 244: $0-->1$

Car. 263: $0-->1$

Car. 264: $3-->1$

Car. 281: $\odot-->1$

Car. 387: $0-->1$

Lebiasina bimaculata : Todos cladogramas:

Car. 17: $0-->1$

Car. 48: $0-->1$

Car. 88: $0-->1$

Car. 99: $\odot-->1$

Car. 146: $3-->0$

Car. 149: $1-->0$
Car. 258: 1 --> 2

Car. 324: $\odot-->1$

Car. 381: $0-->1$

Car. 390: $1-->0$

Piabucina astrigata :

Todos cladogramas:

Car. 52: $1-->0$

Car. 65: $0-->1$

Car. 72: $1-->0$

Car. 114: $1-->2$

Car. 132: 2 - $>1$

Car. 150: $0-->1$

Car. 159: $0 \quad->1$

Car. 160: $1-->0$

Car. 234: $\odot-->1$

Car. 249: 1 - -> 0

Car. 250: $1-->0$

Car. 252: $1 \ldots$

Car. 256: $2-->3$

Car. 272: $1-->0$

Car. 302: $1-->2$

Car. 304: $\odot-->1$

Car. 314: $0-->1$

Car. 325: $1-->0$

Car. 340: $4-->6$

Car. 360: $2-->1$

Car. 372: $0-->1$

Car. 378: $0-->2$

Car. 383: $1-->0$

Car. 387: $\odot-->1$

Erythrinus erythrinus : Todos cladogramas:

Car. 28: 2 - -> $\odot$

Car. 69: $1-->0$

Car. 140: $0-->1$

Car. 152: $1-->0$

Car. 155: $1-->0$

Car. 159: $\odot-->1$

Car. 164: $0-->1$

Car. 165: $2-->0$

Car. 280: $1-->0$

Car. 381: $0-->1$

Car. 383: $\odot-->2$

Car. 384: $\odot-->1$

Car. 387: $\odot-->1$

Car. 389: $0-->1$

Hoplias malabaricus : Todos cladogramas:

Car. 41: 0 - -> 1

Car. 43: $1-->0$

Car. 56: $1-->2$

Car. 86: $0-->2$

Car. 89: $0-->1$

Car. 94: $\odot-->1$

Car. 109: $0-->1$

Car. 136: $0-->1$

Car. 157: 0 - -> 1

Car. 158: $\odot-->2$

Car. 202: $1-->0$

Car. 212: $1-->0$

Car. 231: $0-->2$

Car. 251: $1-->2$

Car. 252: $1-->0$

Car. 278: $01-->3$

Car. 279: 2 - $>0$

Car. 281: $0-->1$

Car. 283: $0-->1$

Car. 297: $1-->0$

Car. 320: $\odot-->1$

Car. 329: $0-->1$

Car. 332: $0-->1$

Car. 340: $34-->1$

Car. 347: $0-->1$

Car. 372: $\odot-->1$ 
Car. 380: $0-->1$

Car. 385: $0-->1$

Car. 392: $1-->2$

Hepsetus odoe :

Todos cladogramas

Car. 7: $4-->1$

Car. 28: $2-->0$

Car. 34: $2-->1$

Car. 64: $1-->0$

Car. 78: $0-->1$

Car. 81: $\odot-->2$

Car. 84: $0-->1$

Car. 130: $1-->0$

Car. 142: $1-->0$

Car. 144: $0-->1$

Car. 145: $\odot-->1$

Car. 165: 2 - $>0$

Car. 183: $1->0$

Car. 186: $1-->0$

Car. 203: 1 - $>0$

Car. 211: $1-->2$

Car. 212: $2-->1$

Car. 231: 2 -> 1

Car. 242: 1 - -> 0

Car. 249: $1-->2$

Car. 250: $0-->1$

Car. 252: $1-->0$

Car. 264: $3-->1$

Car. 279: $3-->4$

Car. 296: $0-->1$

Car. 317: $0-->2$

Car. 335: $0-->1$

Car. 342: $2-->1$

Car. 349: $1->0$

Car. 352: $1-->2$

Car. 360: $2-->1$

Car. 377: $1-->0$

Car. 406: $1 \ldots$

Arnoldichthys spilopterus

Todos cladogramas:

Car. 48: $0-->1$

Car. 86: $1-->0$

Car. 109: $0-->1$

Car. 124: $1-->0$

Car. 133: $0-->1$

Car 145: $0 \quad->1$

Car. 156: $0-->1$

Car. 167: $1-->0$

Car. 176: $1-->2$

Car. 197: $1-\rightarrow 0$

Car. 200: 1 - -> 0

Car. 201: $\odot-->1$

Car. 207: $0-->1$

Car. 260: $0-->2$

Car. 263: $0-->1$

Car. 302: $1-->0$

Car. 312: 2 - -> 1

Car. 313: 2 --> 1

Car. 317: 0 - -> 1

Car. 320: $1-->0$

Car. 325: $1-->0$

Car. 340: $34-->2$

Car. 390: $1-->0$

Car. 391: $1-->0$

Brycinus macrolepidotus :

Todos cladogramas:

Car. 62: $1-\rightarrow 0$

Car. 124: $1 \ldots$

Car. 153: 1 - $>0$

Car. 175: $1-->0$

Car. 177: 1 - $>$

Car. 212: 0 - -> 1

Car. 229: $0-->1$
Car. 244: $0-->1$

Car. 254: $1-->2$

Car. 293: $1-->0$

Car. 304: $0-->1$

Car. 307: $\odot-->2$

Car. 340: $4-->8$

Car. 341: $0-->1$

Car. 342: $1-->0$

Car. 349: $0-->1$

Car. 375: $3-->2$

Bryconalestes longipinnis

Todos cladogramas:

Car. 38: $0-->1$

Car. 64: $0-->1$

Car. 74: 1 - -> 0

Car. 79: $2-->0$

Car. 81: $2-->1$

Car. 156: $0 \quad->1$

Car. 207: $0-->1$

Car. 226: $1-->0$

Car. 257: 1 - $>0$

Car. 280: $0-->1$

Car. 300: $0-->1$

Car. 364: $1-->2$

Car. 369: $1-->0$

Car. 379: $0-->2$

Car. 390: $1-->0$

Car. 407: $\odot-->1$

Chalceus epakros :

Todos cladogramas:

Car. 30: $0-->1$

Car. 34: $0-->2$

Car. 148: $0-->1$

Car. 155: $1-->2$

Car. 173: 1 - -> $\odot$

Car. 177: $1-->0$

Car. 198: $\odot-->1$

Car 203: 0 - -> 1

Car. 214: $0-->1$

Car. 215: $1-->0$

Car. 216: $1-->0$

Car. 226: $1-->0$

Car. 244: $0-->1$

Car. 254: $1-->2$

Car. 279: $2-->1$

Car. 290: $1-->0$

Car. 297: $1-->0$

Car. 302: $1-->2$

Car. 333: $0-->1$

Car. 346: $0-->1$

Car. 349: $0-->1$

Car. 354: $\odot-->2$

Car. 364: $1-->2$

Car. 372: 0 - -> 1

Car. 378: $\odot-->2$

Car. 383: $1-->0$

Car. 384: $\odot-->1$

Car.acidium bahiensis : Todos cladogramas:

Car. $0: 1_{-->0}$

Car. 3: $1-->0$

Car. 27: $0-->1$

Car. 38: $0-->1$

Car. 53: $0-->1$

Car. 56: $1-->0$

Car. 69: 1 - -> 2

Car. 70: $0-->1$

Car. 78: $1-->0$

Car. 97: 1 --> 0

Car. 105: $1-->0$

Car. 110: $1-->0$

Car. 112: 1 - $>0$

Car. 212: $1-->2$
Car. 237: $1-->0$

Car. 293: $\odot-->1$

Car. 294: $0-->1$

Car. 321: $1 \ldots$

Car. 335: $1-->0$

Car. 341: $1-->0$

Car. 342: 0 - -> 1

Car. 363: $1-->0$

Car. 377: 1 --> 2

Car. 394: $3-->2$

Car. 395: $2-->1$

Car. 402: $\odot-->1$

Crenuchus spilurus :

Todos cladogramas:

Car. 1: 1 - $>0$

Car. 17: $1-->0$

Car. 22: $0-->1$

Car. 29: $0-->1$

Car. 31: $1-->0$

Car. 34: $0-->2$

Car. 37: $0-->1$

Car. 51: $1-->0$

Car. 58: $0-->1$

Car. 65: $0-->1$

Car. 69: $1-->0$

Car. 86: $01-->2$

Car. 95: $2-->0$

Car. 126: $1->0$

Car. 134: $0-->1$

Car. 168: $0-->1$

Car. 191: $1-->2$

Car. 197: $1-->0$

Car. 200: $1-->0$

Car. 203: $0-->1$

Car. 204: $0-->1$

Car. 205: $0-->1$

Car. 227: $1-->0$

Car. 241: 0 - -> 1

Car. 256: $2-->1$

Car. 281: 0 - -> 1

Car. 283: $1-->0$

Car. 295: $0-->1$

Car. 298: $1-->0$

Car. 299: $\odot-->1$

Car. 305: $1-->0$

Car. 312: $2-->1$

Car. 339: $1-->0$

Car. 340: $2-->1$

Car. 346: $\odot-->1$

Car. 347: $0-->2$

Car. 360: $2-->1$

Car. 379: $2-->1$

Car. 383: $1-->0$

Car. 403: $\odot-->1$

Agoniates halecinus : Todos cladogramas:

Car. 8: $1-->0$

Car. 11: $0 \quad->1$

Car. 20: $0-->1$

Car. 28: $1-->2$

Car. 36: $1-->0$

Car. 41: $0-->2$

Car. 42: $0-->1$

Car. 61: $1-->2$

Car. 67: $1-->0$

Car. 69: $1-->0$

Car. 73: $0-->1$

Car. 79: $2-->1$

Car. 80: $0-->1$

Car. 117: $1-->0$

Car. 123: $0-->1$

Car. 126: 1 - $>0$

Car. 130: $1-->0$

Car. 133: $2-->0$

Car. 134: $1-->0$ 
Car. 138: $0-->1$

Car. 140: $0-->1$

Car. 150: $0-->1$

Car. 153: $1-->2$

Car. 167: $1-->3$

Car. 199: $0-->2$

Car. 205: $0-->1$

Car. 206: $0-->1$

Car. 212: $1-->2$

Car. 215: $1-->0$

Car. 216: $1->0$

Car. 217: $0-->1$

Car. 247: $0-->1$

Car. 258: $1-->3$

Car. 260: $0-->1$

Car. 263: $0-->1$

Car. 283: $1->0$

Car. 290: $1-->0$

Car. 306: $0-->1$

Car. 320: $1-->0$

Car. 329: $1-->0$

Car. 330: $0-->1$

Car. 332: $0-->1$

Car. 340: $8-->9$

Car. 343: $0-->1$

Car. 378: $0-->2$

Car. 386: $1-->0$

Car. 388: $\odot \quad->1$

Car. 391: $1->2$

Car. 394: $1-\rightarrow>$

Car. 404: 1 --> 2

Aphyocar ax pusillus :

Todos cladogramas:

Car. 3: $1-\rightarrow 0$

Car. 38: $\odot-->1$

Car. 39: $0-->1$

Car. 51: $\odot-->1$

Car. 53: $0-->1$

Car. 74: $1-->2$

Car. 81: 1 - $>0$

Car. 89: $0-->1$

Car. 112: $1-\rightarrow 0$

Car. 117: $1->0$

Car. 131: 2 --> 1

Car. 151: $0 \quad->1$

Car. 167: 1 --> 3

Car. 193: 1 - $>0$

Car. 194: $1-->0$

Car. 195: 1 - $>0$

Car. 239: 1 --> 2

Car. 252: $1-->0$

Car. 256: $1-->2$

Car. 261: $1-->0$

Car. 266: 1 - $>0$

Car. 290: 1 - $>0$

Car. 292: $2-->1$

Car. 294: $1-->0$

Car. 332: $0-->1$

Car. 342: $0 \quad-->1$

Car. 345: $0-->1$

Car. 363: $\odot \quad->1$

Astyanax mexicanus :

Todos cladogramas:

Car. 2: $1-\rightarrow 0$

Car. 8: $1-->0$

Car. 62: $2-->0$

Car. 69: $1-->0$

Car. 80: $0-->1$

Car. 96: $1-->0$

Car. 97: $1-->0$

Car. 101: $1-->0$

Car. 112: $1->0$

Car. 122: $1-->0$

Car. 152: $0-->1$

Car. 153: $0-->2$
Car. 166: $0-->1$

Car. 207: $0-->1$

Car. 208: $0-->1$

Car. 242: 1 - -> 0

Car. 252: $1-->0$

Car. 253: $1-->0$

Car. 269: 1 --> $\odot$

Car. 292: $2-->1$

Car. 302: $0-->2$

Car. 306: $0-->1$

Car. 311: $0-->1$

Car. 327: $0-->1$

Car. 339: $0-->1$

Car. 341: $1-->0$

Car. 363: $\odot-->1$

Car. 386: $1-->2$

Car. 388: $\odot-->1$

Car. 393: $2-->0$

Um dos cladogramas:

Car. 79: $2-->0$

Car. 106: $1-->0$

Car. 329: $1-->0$

Car. 407: $1-->2$

Atopomesus pachyodus : Todos cladogramas:

Car. 3: 1 - $>0$

Car. 10: $2-->1$

Car. 11: $0-->1$

Car. 36: $0-->1$

Car. 64: 1 -> 0

Car. 76: $1-->0$

Car. 81: 1 - -> 2

Car. 82: $0-->1$

Car. 87: $1-->2$

Car. 88: $1-->2$

Car. 89: $0-->1$

Car. 112: $1-->0$

Car. 165: $2-->1$

Car. 177: $1-->2$

Car. 183: $1-->2$

Car. 204: $1-->0$

Car. 208: $0-->1$

Car. 231: $1-->0$

Car. 241: $\odot-->1$

Car. 248: $1-->0$

Car. 252: $1-->0$

Car. 253: $1-->0$

Car. 261: 1 - $>0$

Car. 274: $\odot-->1$

Car. 285: $\odot-->1$

Car. 287: $\odot-->1$

Car. 320: $1-->0$

Car. 327: $\odot-->1$

Car. 351: $0-->1$

Car. 407: $1-->0$

Axelrodia reisei :

Todos cladogramas:

Car. 11: 0 --> 1

Car. 29: $1-->0$

Car. 74: 1 - $>0$

Car. 87: $1-->2$

Car. 88: $1-->2$

Car. 133: $0-->2$

Car. 183: $1-->2$

Car. 200: $1-->2$

Car. 247: $\odot-->1$

Car. 252: $1-->0$

Car. 253: $1-->0$

Car. 260: $0-->1$

Car. 269: $1-->0$

Car. 280: $0-->1$

Car. 283: $1-->0$

Car. 291: $0-->1$

Brittanichthys axelrodi :
Todos cladogramas:

Car. 2: $1-->0$

Car. 3: $1-->0$

Car. 28: $1-->0$

Car. 48: $1-->0$

Car. 55: $1-->0$

Car. 58: $0-->1$

Car. 59: $1-->0$

Car. 64: $1-->0$

Car. 66: $0-->1$

Car. 86: $2-->1$

Car. 89: $0-->1$

Car. 93: $1-->0$

Car. 131: $2-->0$

Car. 177: $1 \ldots->2$

Car. 194: $1-->0$

Car. 195: 1 - $>0$

Car. 207: 1 - $>0$

Car. 215: $1-->0$

Car. 216: $1-->0$

Car. 226: $1-->0$

Car. 238: $1-->0$

Car. 246: $0-->1$

Car. 248: $1-->0$

Car. 250: $1-->0$

Car. 257: $0-->1$

Car. 258: $1-->3$

Car. 272: $1-->2$

Car. 293: $0-->1$

Car. 306: $0-->1$

Car. 307: $\odot-->2$

Car. 339: $1-->0$

Car. 345: $0-->1$

Brycon pesu :

Todos cladogramas:

Car. 6: $0-->2$

Car. 10: $1-->2$

Car. 11: $1-->0$

Car. 35: $1-->0$

Car. 37: $\odot-->2$

Car. 47: $0-->1$

Car. 53: $0-->1$

Car. 76: $1-->0$

Car. 83: $0-->1$

Car. 86: $1-->2$

Car. 104: $1-->0$

Car. 105: $1-->0$

Car. 112: $1-->0$

Car. 123: $0-->1$

Car. 126: $1-->0$

Car. 134: $0-->1$

Car. 148: $0-->1$

Car. 150: $\odot-->1$

Car. 198: $0-->2$

Car. 226: $1-->0$

Car. 257: $\odot-->1$

Car. 264: $3-->2$

Car. 266: $0-->1$

Car. 352: $01-->2$

Car. 360: $2-->1$

Car. 361: $0-->1$

Car. 377: $12-->0$

Car. 392: $1-->0$

Car. 404: $0-->1$

Bryconadenos tanaothoros

Todos cladogramas:

Car. 7: 1-->0

Car. 12: $0-->1$

Car. 25: $0-->1$

Car. 39: $0-->2$

Car. 76: $0-->1$

Car. 79: $2-->1$

Car. 92: $0-->1$

Car. 93: $1-->0$ 
Car. 116: $1-->0$

Car. 139: $1-->2$

Car. 153: $1-->0$

Car. 197: 0 - $>1$

Car. 204: $0-->1$

Car. 224: 1 - $>0$

Car. 246: $0-->1$

Car. 280: $0-->1$

Car. 289: $\odot \quad->1$

Car. 290: $1-->0$

Car. 302: $0-->1$

Car. 353: $0 \quad->1$

Car. 354: $0-->1$

Bryconamericus exodon : Todos cladogramas:

Car. 2: 1 - -> 0

Car. 18: $0-->1$

Car. 37: $2-->1$

Car. 64: $1-->0$

Car. 67: $1-->0$

Car. 81: $1-->0$

Car. 106: $0-->1$

Car. 149: $0-->1$

Car. 156: $0 \quad->1$

Car. 265: $0 \quad->1$

Car. 269: $0-->1$

Car. 272: $1-->2$

Car. 283: $1->0$

Car. 298: 1 - $>2$

Car. 299: $0 \quad->2$

Car. 340: $2-->3$

Car. 347: $1->0$

Car. 355: $1-->0$

Bryconops alburnoides : Todos cladogramas:

Car. 6: $1-->2$

Car. 7: $12-->3$

Car. 38: $0-->1$

Car. 48: $0-->1$

Car. 91: $1-->0$

Car. 102: $0-->1$

Car. 125: $\odot \quad->1$

Car. 128: $0-->1$

Car. 142: $0-->1$

Car. 143: $0-->1$

Car. 147: $0-->1$

Car. 152: 0 - $>1$

Car. 153: 1 - $>0$

Car. 155: $0-->1$

Car. 156: $0-->1$

Car. 166: $0-->1$

Car. 190: $1-->0$

Car. 196: $\odot-->2$

Car. 215: $1->0$

Car. 216: $1-->0$

Car. 234: $\odot-->1$

Car. 254: $1-->2$

Car. 272: $1-->2$

Car. 280: $0-->1$

Car. 289: 0 - -> 1

Car. 292: 2 --> 3

Car. 301: $1-->2$

Car. 302: $0 \quad->2$

Car. 306: $0-->1$

Car. 314: $0-->1$

Car. 332: $0-->1$

Car. 343: $0-->1$

Car. 347: $1-->0$

Car. 371: $0 \quad->1$

Car. 372: $0-->1$

Car. 378: $\odot-->2$

Car. 386: $1->0$

Car. 388: $0-->1$

Car. 404: $\odot-->2$
Car.ax cf. leticiae :

Todos cladogramas:

Car. 2: 1 - $>0$

Car. 20: $0-->1$

Car. 42: $0-->1$

Car. 79: $2-->0$

Car. 81: 2 --> 1

Car. 85: $0-->1$

Car. 86: $1-->2$

Car. 88: $0-->1$

Car. 89: $0-->1$

Car. 117: $1-->2$

Car. 148: $0-->1$

Car. 150: $0-->1$

Car. 161: $1-->0$

Car. 207: $0-->1$

Car. 249: $1-->2$

Car. 257: $0-->1$

Car. 259: $\odot-->1$

Car. 264: $3-->1$

Car. 285: $0-->1$

Car. 286: $\odot-->1$

Car. 293: $0-->1$

Car. 302: $1-->0$

Car. 324: $0-->1$

Car. 332: $0-->1$

Car. 334: $1-->0$

Car. 339: 1 - $>0$

Car. 341: $1-->0$

Car. 358: $1-->0$

Car. 359: $\odot-->1$

Car. 382: $1-->0$

Clupeacar.ax cf.

engrauloides :

Todos cladogramas: Car. 18: $\odot-->1$

Car. 38: $0-->1$

Car. 61: $1-->0$

Car. 63: $0-->1$

Car. 69: $1-->0$

Car. 124: $1-->0$

Car. 126: $1-->0$

Car. 128: $\odot-->1$

Car. 133: $2-->0$

Car. 134: $1-->0$

Car. 145: $0-->1$

Car. 146: $3-->0$

Car. 191: 1 - > 0

Car. 203: $1-->0$

Car. 204: $1-->0$

Car. 264: $3-->2$

Car. 275: $1-->0$

Car. 278: $1-->0$

Car. 279: $2-->3$

Car. 281: $0-->1$

Car. 327: $1-->0$

Car. 329: $1-->0$

Car. 330: $\odot-->1$

Car. 339: $1-->2$

Car. 355: $1-->0$

Car. 367: $1-->0$

Car. 375: $1-->3$

Car. 383: $\odot-->1$

Compsura heterura :

Todos cladogramas:

Car. 8: 1 - $>0$

Car. 59: $1-->0$

Car. 64: $1-->0$

Car. 74: $1-->0$

Car. 82: $0-->1$

Car. 87: $1-->0$

Car. 89: $0-->1$

Car. 92: $0-->1$

Car. 112: $1-->0$

Car. 133: $0-->2$
Car. 134: $0-->1$

Car. 197: $0-->1$

Car. 200: $1-->2$

Car. 204: 1 - $>0$

Car. 226: $1-->0$

Car. 249: $1-->2$

Car. 261: $1-->0$

Car. 266: $1-->0$

Car. 280: $0-->1$

Car. 291: $0-->1$

Car. 302: $0-->1$

Car. 325: $0-->1$

Car. 340: $2-->1$

Ctenobrycon hauxwellianus

Todos cladogramas:

Car. 8: $1-\rightarrow>0$

Car. 32: $1-->0$

Car. 53: $0-->1$

Car. 61: $0-->1$

Car. 67: $0-->1$

Car. 102: $1-->0$

Car. 106: $1-->0$

Car. 134: $0-->1$

Car. 149: 1 - $>0$

Car. 176: $1-->0$

Car. 193: $0-->1$

Car. 207: $0-->1$

Car. 208: $0-->1$

Car. 216: $\odot-->1$

Car. 231: $2-->1$

Car. 240: $0-->1$

Car. 249: $1-->2$

Car. 251: $1-->2$

Car. 261: $1-->0$

Car. 264: $1-->3$

Car. 266: $0-->1$

Car. 280: $0-->1$

Car. 283: $1-->0$

Car 291: 0 - -> 1

Car. 332: $0-->1$

Car. 340: $0-->1$

Car. 362: $\odot-->2$

Car. 363: $0-->1$

Car. 369: $\odot-->1$

Car. 379: $1-->2$

Car. 386: $1-->3$

Car 390: $1 \ldots$

Car. 395: $1-->2$

Deuterodon iguape :

Todos cladogramas:

Car. 32: 1 --> 0

Car. 165: $2-->1$

Car. 196: $\odot-->2$

Car. 197: $\odot-->1$

Car. 198: $0-->1$

Car. 199: $0 \quad->1$

Car. 203: $0 \quad->1$

Car. 257: $1-->0$

Car. 261: 1 - -> $\odot$

Car. 280: $0-->1$

Car. 300: $0-->1$

Car. 314: $0-->1$

Car. 346: $0-->1$

Car. 347: $1-->2$

Car. 351: $2-->1$

Car. 395: $1-->2$

Um dos cladogramas:

Car. 7: 2 - $>1$

Car. 67: $0-->1$

Car. 106: $1-->0$

Car. 329: $1-->0$

Car. 390: $\odot-->2$

Diapoma terofali : 
Todos cladogramas:

Car. 73: $0-->1$

Car. 76: $0-->1$

Car. 128: $0-->1$

Car. 136: 1 - $>0$

Car. 138: $0-->1$

Car. 142: $0-->1$

Car. 148: 1 - $>0$

Car. 153: $1-->2$

Car. 204: 1 --> 0

Car. 234: $0-->1$

Car. 249: $1-->2$

Car. 254: 1 - $>0$

Car. 255: 1 - $>0$

Car. 306: $0-->1$

Car. 351: 2 --> 0

Car. 355: 1 - $>0$

Galeocar ax knerii :

Todos cladogramas:

Car. 6: $0-->1$

Car. 29: $1-->2$

Car. 50: $0-->1$

Car. 72: $1-->0$

Car. 74: $1-->2$

Car. 92: $0-->1$

Car. 115: $0-->1$

Car. 131: $2-->0$

Car. 179: $0-->1$

Car. 184: 1 --> 2

Car. 186: $1-->2$

Car. 189: 1 - $>0$

Car. 214: $0-->1$

Car. 217: $0-->1$

Car. 246: $0-->1$

Car. 252: 1 - $->0$

Car. 295: $0-->1$

Car. 299: $\odot-->1$

Car. 300: $0-->1$

Car. 329: 1 - $->0$

Car. 342: $0-->2$

Car. 346: $0-->1$

Car. 352: $1->0$

Car. 362: $\odot-->2$

Car. 369: $0-->1$

Car. 376: $1-->0$

Car. 379: 2 --> 0

Car. 383: $1->0$

Car. 397: 1 --> 2

Glandulocauda melanogenys

Todos cladogramas:

Car. $0: 1->2$

Car. 32: $1-->0$

Car. 62: $2-->1$

Car. 63: $1-->2$

Car. 67: $1-->0$

Car. 88: $1-->2$

Car. 101: $1-->0$

Car. 122: 1 - $>0$

Car. 137: $0-->1$

Car. 159: 1 - $>0$

Car. 180: 2 - $>0$

Car. 183: $1-\rightarrow 0$

Car. 199: $0-->1$

Car. 226: $1-->0$

Car. 229: $1-->0$

Car. 231: 2 --> 1

Car 237: $1 \ldots$

Car. 238: $\odot-->1$

Car. 242: $1-->0$

Car. 256: $1->0$

Car. 264: $3->1$

Car. 292: $2-->1$

Car. 294: $1-->0$

Car. 302: $0 \quad->2$
Car. 317: $0-->1$

Car. 347: $1-->0$

Car. 373: $\odot-->1$

Car. 394: 1 --> 3

Car. 406: $1-->0$

Car. 407: $1-->2$

Gnathocar .ax

steindachneri :

Todos cladogramas:

Car. $0: 1_{-\rightarrow 2}$

Car. 18: 0 - -> 1

Car. 29: $1-->2$

Car. 32: 1 - $>2$

Car. 43: 1 - $>0$

Car. 73: $1-->0$

Car. 74: $1-->0$

Car. 79: $2-->1$

Car. 81: $2-->0$

Car. 103: $0-->1$

Car. 112: $1-->0$

Car. 117: $1-->0$

Car. 118: $0-->1$

Car. 124: $1-->0$

Car. 128: $0 \quad->1$

Car. 131: $2-->0$

Car. 136: $0-->1$

Car. 144: $0-->1$

Car. 151: $0-->1$

Car. 180: $2-->1$

Car. 182: $1-->0$

Car. 189: $1-->0$

Car 190: 1 - $>0$

Car. 193: $1-->0$

Car. 194: $1-->0$

Car. 195: $1-->0$

Car. 199: $0-->1$

Car. 200: $1-->0$

Car. 208: $0-->1$

Car. 224: $1-->0$

Car. 225: $0-->1$

Car. 228: $\odot-->1$

Car. 234: $\odot-->1$

Car. 235: $\odot-->1$

Car. 243: $0-->1$

Car. 251: $1-->3$

Car. 256: $1 \ldots$

Car. 258: $1-->0$

Car. 259: 0 - -> 1

Car. 265: $0-->1$

Car. 274: $0-->2$

Car. 278: $1-->0$

Car. 279: $2-->3$

Car. 282: $\odot-->1$

Car. 300: $0-->1$

Car. 313: $2-->1$

Car. 317: $0-->2$

Car. 320: $1-->0$

Car. 329: $1-->0$

Car. 373: $\odot-->1$

Car. 383: $1-->0$

Car. 390: $0-->1$

Gymnocorymbus ternetzi :

Todos cladogramas:

Car. 7: $2-\rightarrow 1$

Car. 14: $2-->0$

Car. 27: 1 - -> $\odot$

Car. 76: $0-->1$

Car. 92: $\odot-->1$

Car. 106: $1-->0$

Car. 133: $2-->0$

Car. 207: $0-->1$

Car. 215: $0-->1$

Car. 242: $1-->0$

Car. 254: $1-->0$

Car. 258: $1-->2$
Car. 259: $\odot-->1$

Car. 262: 1 - $>0$

Car. 266: $\odot-->1$

Car. 280: $0-->1$

Car. 291: $0-->1$

Car. 307: $0-->1$

Car. 325: $0-->1$

Car. 346: $0-->1$

Car. 355: $1-->2$

Car. 358: $1-->2$

Car. 395: $1-->2$

Um dos cladogramas:

Car. 407: 1 --> 2

Hemibrycon polyodon

Todos cladogramas:

Car. 7: 2 --> 3

Car. 28: $1-->2$

Car. 29: $1-->2$

Car. 48: $0-->1$

Car. 53: $1-->0$

Car. 62: $2-->1$

Car. 72: $1-->0$

Car. 115: $\odot-->1$

Car. 124: 1 - $>0$

Car. 155: 2 - $>1$

Car. 199: $0-->1$

Car. 223: $1-->0$

Car. 234: $0-->1$

Car. 261: $1-->0$

Car. 272: $1-->0$

Car. 306: $0-->1$

Car 325: $0 \quad->1$

Car. 379: $2-->1$

Car. 395: $1-->2$

Hemigrammus unilineatus : Todos cladogramas:

Car. 22: $0-->1$

Car. 64: $1-->0$

Car. 79: 2 --> 0

Car. 146: $3-->2$

Car. 200: $1-->2$

Car. 212: $1-->0$

Car. 215: $0-->1$

Car. 216: $\odot-->1$

Car. 249: 1 --> 2

Car. 253: $1-->0$

Car. 261: 1 - $>0$

Car. 264: $3-->2$

Car. 266: $0-->1$

Car. 298: $1-->2$

Car. 335: $1-->0$

Car. 340: $2-->1$

Hollandichthys

multifasciatus :

Todos cladogramas:

Car. 2: 1 - $>0$

Car. 28: $1-->2$

Car. 29: $1-->2$

Car. 37: $2-->0$

Car. 38: $1-->0$

Car. 39: $0-->2$

Car. 53: $0-->1$

Car. 74: $1-->0$

Car. 76: $1-->0$

Car. 80: $0-->1$

Car. 95: $2-->1$

Car. 104: $\odot-->1$

Car. 132: $0-->1$

Car. 137: $1-->0$

Car. 200: $1-->0$

Car. 239: 1 --> 2

Car. 254: $1-->0$

Car. 317: $\odot-->1$

Car. 339: $0-->1$ 
Car. 340: $2-->3$

Hyphessobrycon compressus

Todos cladogramas:

Car. 1: $2-->1$

Car. 11: $0-->1$

Car. 12: $0-->1$

Car. 27: $1-->0$

Car. 73: $0-->1$

Car. 93: $1-->0$

Car. 103: $0-->1$

Car. 114: $1-\rightarrow>0$

Car. 117: $1-->0$

Car. 118: $0-->1$

Car. 128: $1-->0$

Car. 142: $1-->0$

Car. 145: 1 - $>0$

Car. 206: $0-->1$

Car. 224: $1-->0$

Car. 231: 2 - $>0$

Car. 255: 1 --> 0

Car. 269: $1-->0$

Car. 280: $0-->1$

Car. 290: $1-->0$

Car. 325: $0-->1$

Car. 346: $0-->1$

Car. 365: $1-->0$

Iguacladoctes geisleri :

Todos cladogramas:

Car. 1: $2-->1$

Car. 2: $0 \quad-->1$

Car. 7: $12-->0$

Car. 17: $0-->1$

Car. 18: $0-->1$

Car. 25: $0-->1$

Car. 32: $1-->0$

Car. 40: $\odot-->2$

Car. 43: $1-->2$

Car. 51: $\odot-->2$

Car. 62: $2-->1$

Car. 68: $\odot-->1$

Car. 69: $1-->2$

Car. 71: $0-->1$

Car. 73: $\odot-->1$

Car. 97: $1-->0$

Car. 117: $1->0$

Car. 118: $0-->1$

Car. 136: $1 \ldots$

Car. 137: $0-->1$

Car. 139: $1-->0$

Car. 148: $1-->0$

Car. 149: 1 --> 0

Car. 159: 1 - $>0$

Car. 162: $2-->1$

Car. 173: 1 - $>0$

Car. 176: $1-\rightarrow 2$

Car. 203: 1 - $>0$

Car. 208: $0 \quad->1$

Car. 211: $1-->2$

Car. 212: $1-->2$

Car. 226: 1 - $>0$

Car. 247: $0-->1$

Car. 274: $1-->0$

Car. 283: $1->0$

Car. 287: $0-->1$

Car. 300: $1-->0$

Car. 334: $1-->0$

Car. 338: $0-->1$

Car. 346: 1 - $>0$

Car. 351: $2-->1$

Car. 365: $1-->0$

Car. 377: $0-->2$

Car. 394: $1-->3$

Car. 407: 1 --> 0
Knodus meridae:

Todos cladogramas:

Car. 2: $1-\rightarrow 0$

Car. 25: 0 - -> 1

Car. 29: $1-->2$

Car. 48: 0 - -> 1

Car. 61: $0-->1$

Car. 63: $1-->0$

Car. 82: $0-->1$

Car. 95: $2-->1$

Car. 128: $0 \quad->1$

Car. 153: $1-->2$

Car. 155: $2-->0$

Car. 159: $1-->0$

Car. 197: 0 - -> 1

Car. 211: $1-->2$

Car. 231: $2-->1$

Car. 242: $0-->1$

Car. 246: $0-->1$

Car. 249: $1-->2$

Car. 250: $1-->0$

Car. 251: $1-->2$

Car. 264: $3-->0$

Car. 280: $0-->1$

Car. 293: $0-->1$

Car. 299: $0-->1$

Car. 339: $1-->2$

Car. 340: $2-->0$

Car. 369: $\odot-->1$

Car. 380: $\odot-->1$

Car. 389: $2-->1$

Landonia latidens :

Todos cladogramas:

Car. 2: 1 - -> $\odot$

Car. 7: $2-->1$

Car. 12: $0-->1$

Car. 29: $1-->2$

Car. 32: $1-->0$

Car. 52: $1-->0$

Car. 59: 1 - $>0$

Car. 79: $2-->1$

Car. 88: 1 - $>2$

Car. 101: $1-->0$

Car. 103: $0-->1$

Car. 167: $1-->2$

Car. 197: $0-->1$

Car. 246: $\odot-->1$

Car. 247: $0-->1$

Car. 257: $\odot-->1$

Car. 264: $3-->0$

Car. 272: $1-->2$

Car. 329: $1-->0$

Car. 339: $1-->0$

Car. 341: $1-->0$

Car. 342: $0-->2$

Car. 355: $1-->0$

Car. 365: $1-->0$

Car. 407: $1-->0$

Markiana nigripinnis : Todos cladogramas:

Car. 2: 1 - $>0$

Car. 8: $1-->0$

Car. 22: $0-->1$

Car. 28: $1-->0$

Car. 29: $1-->2$

Car. 43: 1 --> 2

Car. 51: $0-->1$

Car. 52: $1-->0$

Car. 62: $2-->1$

Car. 96: $1-->2$

Car. 101: 1 - $>0$

Car. 104: $0-->1$

Car. 112: $1-->0$

Car. 131: $2-->1$

Car. 136: $0-->1$
Car. 138: $1 \ldots 0$

Car. 148: $1 \ldots$

Car. 157: $0-->1$

Car. 159: 1 - $>0$

Car. 215: $0-->1$

Car. 216: $0-->1$

Car. 229: $0-->1$

Car. 251: $1-->2$

Car. 257: 1 - -> 0

Car. 264: 0 --> 2

Car. 269: $1-->0$

Car. 276: 1 - $>0$

Car. 283: 1 --> 0

Car. 287: $0-->1$

Car. 299: $0-->1$

Car. 347: $1-->2$

Car. 358: $1-->2$

Car. 365: $1-->0$

Car. 376: $0-->1$

Um dos cladogramas:

Car. 79: $2-->1$

Metynnis lippincottianus

Todos cladogramas:

Car. 38: $0-->1$

Car. 81: $2-->1$

Car. 83: $1-->0$

Car. 87: $1-->2$

Car. 94: $\odot-->1$

Car. 106: $0-->1$

Car. 112: $0-->1$

Car. 143: $0-->1$

Car. 146: $2-->1$

Car. 166: $1-->0$

Car. 173: $1-->0$

Car. 176: $1-->2$

Car. 190: $1-->0$

Car. 226: $1-->0$

Car. 237: $1-->3$

Car 254: 1 - $>0$

Car. 258: $3-->2$

Car. 266: $1-->0$

Car. 290: $1-->0$

Car. 295: $0-->1$

Car. 301: $2-->1$

Car. 302: $1-->2$

Car. 305: $1-->0$

Car. 351: $2-->1$

Car. 369: $1-->0$

Car. 386: $1-->2$

Microschemobrycon casiquiare :

Todos cladogramas:

Car. 22: $0-->1$

Car. 51: $1-->0$

Car. 72: $1-->0$

Car. 98: $0-->1$

Car. 124: $1 \ldots$

Car. 153: 1 --> 2

Car. 162: 1 - $>2$

Car. 194: 1 - $>0$

Car. 195: $1-->0$

Car. 207: 1 - -> 0

Car. 249: $1-->2$

Car. 270: $1-->0$

Car. 295: $0-->1$

Car. 299: $0-->1$

Car. 329: $1-->0$

Car. 369: $\odot-->1$

Car. 397: $1-->2$

Moenkhausia xinguensis : Todos cladogramas:

Car. 2: $1-->0$

Car. 17: $0-->1$ 
Car. 51: $0 \quad->1$

Car. 64: $1-->0$

Car. 73: $0-->1$

Car. 77: 1 - $>0$

Car. 81: $1-->2$

Car. 82: $\odot-->1$

Car. 83: $0-->1$

Car. 102: $0-->1$

Car. 146: $3-->2$

Car. 149: 1 - $>0$

Car. 249: $1-->2$

Car. 264: $3-->2$

Car. 301: $1-->2$

Car. 302: $0-->1$

Car. 340: $2-->1$

Car. 353: $0-->1$

Car. 366: $0-->1$

Car. 367: $0-->1$

Car. 371: $0-->1$

Car. 375: $\odot-->3$

Car. 378: $0-->2$

Car. 383: $1-->0$

Car. 393: $2-->1$

Car. 404: $0-->1$

Myleus setiger :

Todos cladogramas:

Car. 17: $0-->1$

Car. 51: $1-->2$

Car. 93: $1-->0$

Car. 96: $1-->2$

Car. 97: $1-->0$

Car. 128: $0-->1$

Car. 139: 1 - $>0$

Car. 145: $0-->1$

Car. 148: $0-->1$

Car. 149: $1-->0$

Car. 169: $1-->0$

Car. 175: 1 - $>0$

Car. 183: $1-->2$

Car. 198: 0 - $>1$

Car. 211: $1-->2$

Car. 242: $1-->0$

Car. 293: $1-->0$

Car. 332: $0-->1$

Car. 333: $0-->1$

Car. 340: $3-->2$

Car. 374: $0-->1$

Car. 377: $1-->0$

Odontostilbe pequira :

Todos cladogramas:

Car. 27: $0-->1$

Car. 29: 1 - -> 0

Car. 78: $0-->1$

Car. 103: $0-->1$

Car. 141: $0-->1$

Car. 145: $0-->1$

Car. 215: $1-->0$

Car. 246: $0-->1$

Car. 247: $0-->1$

Car. 265: $0 \quad-->1$

Car. 327: $0-->1$

Car. 351: $0-->1$

Car. 360: 2 -> $\odot$

Car. 390: $2-->1$

Oligosarcus argenteus : Todos cladogramas:

Car. 39: 0 - -> 2

Car. 43: $1-->0$

Car. 55: $1-->0$

Car. 74: $1-->0$

Car. 79: $2-->1$

Car. 113: $0-->1$

Car. 166: $1-->0$

Car. 212: $1-->2$
Car. 234: $0-->1$

Car. 268: $\odot-->1$

Car. 307: $\odot-->2$

Car. 314: $0-->1$

Car. 342: $0-->1$

Car. 347: $\odot-->2$

Car. 378: $\odot-->2$

Car. 394: $1-->2$

Orthospinus

franciscoensis :

Todos cladogramas:

Car. 2: 1 - 0

Car. 69: 1 - $>0$

Car. 124: $\odot-->1$

Car. 153: $0-->1$

Car. 269: 1 - $>0$

Car. 294: $1-->0$

Car. 345: $0-->1$

Car. 404: $0-->1$

Paracheirodon axelrodi :

Todos cladogramas:

Car. 12: $0-->1$

Car. 29: $1-->0$

Car. 36: $0-->1$

Car. 124: $1-->0$

Car. 131: 2 - $>1$

Car. 132: $0-->1$

Car. 149: $1-->0$

Car. 183: $1-->2$

Car. 270: $1-->0$

Car. 280: $0-->1$

Car. 332: $0-->1$

Car. 340: $2-->1$

Car. 394: $1-->3$

Paragoniates alburnus :

Todos cladogramas:

Car. 22: $0-->1$

Car. 65: 1 -->0

Car. 67: $1-->0$

Car. 79: $2-->0$

Car. 114: $1-->0$

Car. 133: $2-->0$

Car. 134: $1-->0$

Car. 155: $2-->0$

Car. 161: $0-->1$

Car. 196: $0-->2$

Car. 235: $0-->1$

Car. 242: $0-->1$

Car. 251: $1-->2$

Car. 264: $3-->1$

Car. 265: $\odot-->1$

Car. 287: $0-->1$

Car. 300: $0-->1$

Car. 313: 2 --> 1

Car. 325: $0-->1$

Car. 367: $\odot-->1$

Car. 377: $1-->2$

Car. 379: $2-->0$

Phenacogaster pectinatus

Todos cladogramas:

Car. 64: $1-\rightarrow 0$

Car. 76: $1-->0$

Car. 79: $2-->0$

Car. 85: $0-->1$

Car. 106: $0-->1$

Car. 114: $0-->1$

Car. 117: $1-->2$

Car. 146: $3-->0$

Car. 166: $0-->1$

Car. 177: $1-->2$

Car. 196: $\odot-->1$

Car. 234: $0-->1$
Car. 240: $0-->1$

Car. 249: 1 --> 2

Car. 252: $1-->0$

Car. 253: 1 - $>0$

Car. 257: $0-->1$

Car. 258: $1-->2$

Car. 264: $23-->1$

Car. 270: $1-->0$

Car. 274: $0-->1$

Car. 280: $0-->1$

Car. 285: $\odot-->1$

Car. 287: $\odot-->1$

Car. 292: $12-->3$

Car. 294: $1-->0$

Car. 327: $\odot-->1$

Car. 338: $1-->0$

Car. 341: $1-->2$

Car. 373: $0-->1$

Car. 382: $1-->0$

Car. 386: $1-->3$

Car. 394: $1-->2$

Phenagoniates macrolepis

Todos cladogramas:

Car. 12: $0-->1$

Car. 59: $1-->0$

Car. 73: $1-->0$

Car. 76: $1-->0$

Car. 117: $1-->2$

Car. 118: $\odot \quad->1$

Car. 142: $0-->1$

Car. 146: $3-->2$

Car. 152: $0-->1$

Car. 159: $1-->0$

Car. 167: 1--> 2

Car. 215: $0-->1$

Car. 216: $0-->1$

Car. 224: $1-->0$

Car. 254: $1-->0$

Car. 257: $\odot-->1$

Car. 278: $1-->9$

Car. 291: $\odot-->1$

Car. 299: $0-->1$

Car. 320: $1-->0$

Car. 333: $1-->0$

Car. 334: 1 --> 0

Car. 339: $1-->2$

Car. 340: $5-->7$

Car. 347: $1-->2$

Car. 390: $0-->1$

Car. 393: $\odot-->2$

Car. 399: $\odot-->1$

Piabina argentea :

Todos cladogramas:

Car. 7: $2-->3$

Car. 37: $2-->0$

Car. 38: $0-->1$

Car. 40: $1-->2$

Car. 62: $2-->0$

Car. 67: $1-->0$

Car. 76: $0-->1$

Car. 92: $0-->1$

Car. 98: $0-->1$

Car. 106: $0-->1$

Car. 114: $0-->1$

Car. 136: $1-->0$

Car. 137: $0-->1$

Car. 151: $0-->1$

Car. 167: 1 -> 2

Car. 207: $1-->0$

Car. 234: $0-->1$

Car. 272: $1-->2$

Car. 275: $1-->0$

Car. 305: $1 \ldots->0$

Car. 347: $1-->0$ 
Car. 351: $2-->1$

Car. 358: $1-->0$

Car. 390: $1-->0$

Car. 404: $0-->1$

Piaractus mesopotamicus : Todos cladogramas: Car. 2: $1-->0$

Car. 27: $1-->0$

Car. 28: $0-->1$

Car. 33: $0-->1$

Car. 39: $0-->1$

Car. 69: $1-->0$

Car. 88: $1-->2$

Car. 97: $1-->2$

Car. 136: $0-->1$

Car. 147: $0-->1$

Car. 156: $0-->2$

Car. 159: $0-->1$

Car. 183: $1-->0$

Car. 185: $1->0$

Car. 186: $0-->1$

Car. 191: $1-->2$

Car. 193: $0-->1$

Car. 215: $1-->0$

Car. 244: 0 --> 1

Car. 255: $1-->2$

Car. 263: $\odot \quad->1$

Car. 275: $1->0$

Car. 277: $0 \quad->1$

Car. 340: $34-->5$

Car. 341: $0-->2$

Car. 346: $0-->1$

Car. 404: $1-->0$

Poptella brevispina: Todos cladogramas:

Car. 22: $0-->1$

Car. 79: $0-->2$

Car. 137: $0-->1$

Car. 190: $1-->0$

Car. 196: $0-->2$

Car. 199: $0 \quad->1$

Car. 200: $1-->2$

Car. 259: $0-->1$

Car. 265: $0 \quad->1$

Car. 278: $1-->2$

Car. 279: 2 -> 1

Car. 286: 1 - $>0$

Car. 300: $1-->0$

Car. 311: $0-->1$

Car. 314: $0 \quad->1$

Car. 371: $0-->1$

Car. 394: $1-->2$

Probolus heterostomus :

Todos cladogramas:

Car. 6: $1-\rightarrow 0$

Car. 11: $\odot-->2$

Car. 28: $1-->2$

Car. 38: $1-->0$

Car. 73: $\odot-->1$

Car. 87: $2-->1$

Car. 140: $0-->1$

Car. 157: $0-->1$

Car. 196: $0-->2$

Car. 257: 1 --> 0

Car. 269: 1 - -> 0

Car. 300: $0-->1$

Car. 327: $0-->1$

Car. 341: $1->0$

Car. 346: $0-->1$

Car. 383: $1-->2$

Car. 395: $1-->2$

Car. 404: 0 - -> 1

Um dos cladogramas:

Car. 260: $0-->1$
Car. 375: $0-->3$

Car. 379: $2-->1$

Rachoviscus graciliceps : Todos cladogramas:

Car. 7: $34-->0$

Car. 88: $1-->0$

Car. 137: $0-->1$

Car. 176: $1-->0$

Car. 238: $1-->0$

Car. 239: $0-->2$

Car. 242: $0-->1$

Car. 274: $0-->1$

Car. 275: $1-->0$

Car. 292: $1-->2$

Car. 340: $2-->4$

Rhinobrycon negrensis : Todos cladogramas:

Car. 1: $2-->1$

Car. 7: $2-->3$

Car. 27: $1-->0$

Car. 36: $1-->0$

Car. 38: $0-->1$

Car. 73: $0-->1$

Car. 79: $2-->1$

Car. 82: $0-->1$

Car. 87: 2 --> 1

Car. 97: $1-->2$

Car. 114: $\odot-->1$

Car. 137: $\odot-->1$

Car. 141: $1-->0$

Car. 155: 2 - -> $\odot$

Car. 162: $2-->0$

Car. 183: $1-->2$

Car. 231: $2-->1$

Car. 237: $1-->0$

Car. 290: $1-->0$

Car. 298: $1-->2$

Car. 299: $0-->12$

Car. 336: $\odot-->1$

Car. 339: $1-->2$

Car. 358: $1-->0$

Car. 377: $1-->2$

Car. 379: $2-->1$

Rhoadsia altipinna :

Todos cladogramas:

Car. 17: 0 - -> 1

Car. 51: $1-->0$

Car. 53: $1-->0$

Car. 93: $1-->0$

Car. 117: $1-->2$

Car. 124: 1 - -> 0

Car. 151: $0-->1$

Car. 242: $0-->1$

Car. 260: $\odot-->2$

Car. 269: $1-->0$

Car. 274: $\odot-->1$

Car. 285: $\odot-->1$

Car. 287: $0-->1$

Car. 292: $1-->2$

Car. 313: 2 --> 01

Car. 333: $0-->1$

Car. 340: $2-->3$

Roeboexodon guyanensis :

Todos cladogramas:

Car. 2: $1-\rightarrow 0$

Car. 3: $1-->0$

Car. 11: $1-->0$

Car. 22: $0-->1$

Car. 29: $1-->0$

Car. 36: $0-->1$

Car. 88: $01-->2$

Car. 95: $2-->1$

Car. 97: $1-->0$
Car. 138: $0 \quad->1$

Car. 140: $0-->1$

Car. 157: $0-->1$

Car. 175: $1-->0$

Car. 223: $1-->0$

Car. 240: $0-->1$

Car. 246: $0-->1$

Car. 252: $1-->0$

Car. 280: $0-->1$

Car. 290: $1-->0$

Car. 294: $1-->0$

Car. 302: 1 - $>2$

Car. 314: $0-->1$

Car. 333: $1-->0$

Car. 338: $1-->0$

Car. 340: $3-->2$

Car. 342: $0-->1$

Car. 379: $2-->1$

Car. 393: $\odot-->1$

Salminus hilarii :

Todos cladogramas:

Car. 3: $1-->2$

Car. 6: $0-->1$

Car. 59: 1 - $>0$

Car. 61: $0-->1$

Car. 74: $1-->0$

Car. 77: $1-->0$

Car. 88: $0-->1$

Car. 95: $2-->0$

Car. 114: $1-->2$

Car. 115: $0-->1$

Car. 125: $0 \quad->1$

Car. 128: $0-->1$

Car. 132: $0-->1$

Car. 139: $2-->1$

Car. 144: $0-->1$

Car. 147: $0-->1$

Car. 165: 2 --> 0

Car. 252: $1-->0$

Car. 276: $0 \quad-->1$

Car. 283: $1-->0$

Car. 290: $1-->0$

Car. 320: $1-->0$

Car. 379: $2-->1$

Car. 386: $1-->0$

Car. 392: $1-->2$

Serrabrycon magoi :

Todos cladogramas:

Car. 25: 0 - -> 1

Car. 29: $1-->2$

Car. 37: $0-->1$

Car. 74: $1-->0$

Car. 79: $2-->1$

Car. 128: $\odot-->1$

Car. 196: $0-->2$

Car. 199: $0-->1$

Car. 203: $0-->1$

Car. 204: $1 \ldots->0$

Car. 242: $0-->1$

Car. 261: 1 - -> 0

Car. 276: $0-->1$

Car. 290: $1-->0$

Car. 295: $0-->1$

Car. 299: $0-->1$

Car. 332: $0-->1$

Car. 358: $1-->0$

Car. 379: $2-->1$

Stygichthys typhlops : Todos cladogramas:

Car. 2: 1 - 0

Car. 11: $0-->1$

Car. 25: $\odot-->1$

Car. 27: $0-->1$

Car. 44: $1-->0$ 


$$
\begin{aligned}
& \text { Car. 45: } 1-->\odot \\
& \text { Car. 62: } 2-->0 \\
& \text { Car. 64: } 1-->0 \\
& \text { Car. 67: } 1 \text { - }>0 \\
& \text { Car. 69: } 1-->0 \\
& \text { Car. 73: } 0-->1 \\
& \text { Car. 74: } 1-->0 \\
& \text { Car. 87: } 1-->2 \\
& \text { Car. 89: } 0 \text { - }>1 \\
& \text { Car. 95: } 2-->0 \\
& \text { Car. 99: } 0-->1 \\
& \text { Car. 114: } 0-->1 \\
& \text { Car. 123: } 0-->1 \\
& \text { Car. 183: } 1 \text { - }>0 \\
& \text { Car. 194: } 1 \ldots \\
& \text { Car. 195: } 1 \text {--> } 0 \\
& \text { Car. 199: } 0-->1 \\
& \text { Car. 201: } 0-->1 \\
& \text { Car. 208: } 0 \quad->1 \\
& \text { Car. 225: } 0-->1 \\
& \text { Car. 236: } 1-->0 \\
& \text { Car. 241: } 0-->1 \\
& \text { Car. 248: } 1 \quad->0 \\
& \text { Car. 250: } 1-->2 \\
& \text { Car. 256: } 1-->2 \\
& \text { Car. 258: } 2 \text {-> } 0 \\
& \text { Car. 261: } 1-->0 \\
& \text { Car. 262: } 1-->2 \\
& \text { Car. 265: } 0-->1 \\
& \text { Car. 272: } 1-->2 \\
& \text { Car. 278: } 1-->0 \\
& \text { Car. 279: } 2-->4 \\
& \text { Car. 282: } 0-->1 \\
& \text { Car. 283: } 1-->0 \\
& \text { Car. 293: } 0-->1 \\
& \text { Car. 298: } 1-->2 \\
& \text { Car. 300: } 0-->1 \\
& \text { Car. 301: } 1-->0 \\
& \text { Car. 314: } 0-->1 \\
& \text { Car. 324: } 0-->1 \\
& \text { Car. 339: } 1-->2 \\
& \text { Car. 341: } 1-->2 \\
& \text { Car. 405: } 2-->0
\end{aligned}
$$

Tetragonopterus argenteus

Todos cladogramas:

Car. 7: $3-->4$

Car. 53: $0-->1$

Car. 65: $1-->0$

Car. 73: $\odot-->1$

Car. 74: $1-->0$

Car. 83: $0-->2$

Car. 137: $\odot \quad->1$

Car. 139: 2 - $>1$

Car. 149: $1-->0$

Car. 156: 0 - $>1$

Car. 166: $0-->1$

Car. 212: $1-->2$

Car. 262: $1-->0$

Car. 266: $0-->1$

Car. 371: $0 \quad-->1$

Car. 372: $0-->1$

Car. 383: $1-->2$

Car. 386: $1 \ldots 2$

Car. 393: $2-->1$

Car. 396: $0 \quad-->1$

Um dos cladogramas:

Car. 128: $0-->1$

Car. 390: $1-->0$

Triportheus albus :

Todos cladogramas:

Car. $0: 1-->2$

Car. 2: $\odot-->1$

Car. 7: $12 \quad->3$

Car. 14: $0-->2$
Car. 27: $1-->0$

Car. 32: 1 - -> 0

Car. 34: $0-->2$

Car. 35: $1-->0$

Car. 77: $1-->0$

Car. 83: $\odot-->1$

Car. 91: $1-->0$

Car. 120: $1-->0$

Car. 142: $0-->1$

Car. 143: $0-->1$

Car. 145: $\odot-->1$

Car. 149: 1 - > 0

Car. 152: $0-->1$

Car. 154: $0-->1$

Car. 165: $2-->1$

Car. 166: $0-->1$

Car. 174: $0-->1$

Car. 180: $2-->0$

Car. 183: $1-->0$

Car. 198: 0 - -> 1

Car. 201: $0-->1$

Car. 244: $1-->0$

Car. 245: $\odot-->1$

Car. 251: $2-->3$

Car. 264: $3-->1$

Car. 265: $1-->0$

Car. 273: $\odot-->1$

Car. 274: $1-->0$

Car. 299: $\odot-->1$

Car. 324: $\odot-->1$

Car. 339: $1-->0$

Car. 354: $\odot-->2$

Car. 366: 0 - -> 1

Car. 369: $\odot-->1$

Car. 377: $\odot-->1$

Car. 393: $\odot-->1$

\section{Clado 102 :}

Todos cladogramas:

Car. $0: 1-\rightarrow 0$

Car. 72: $1-->0$

Car. 100: $1-->0$

Car. 168: $0-->1$

Car. 176: $1-->0$

Car. 182: $\odot-->1$

Car. 183: $1-->0$

Car. 201: $0-->1$

Car. 231: $2-->0$

Car. 237: $1-->0$

Car. 255: $1-->0$

Car. 281: $0-->1$

Car. 293: $\odot-->1$

Car. 295: $0-->1$

Car. 303: $1-->0$

Car. 309: $0-->1$

Car. 331: $\odot-->1$

Car. 334: $\odot-->1$

Car. 340: $34-->0$

Car. 351: $2-->1$

Car. 409: $0-->1$

Clado 103 :

Todos cladogramas:

No synapomorphies

Clado 104 :

Todos cladogramas:

Car. 74: $1-->0$

Car. 87: $1-->0$

Car. 137: $0-->1$

Car. 194: $1-->0$

Car. 195: $1-->0$

Car. 233: $0-->1$

Car. 242: $1-->0$

Car. 289: $1 \ldots$

Car. 291: $\odot-->1$

Car. 325: $0-->1$
Car. 396: $\odot-->1$

Car. 405: $2-->1$

Car. 406: $1-->0$

Clado 105 :

Todos cladogramas:

Car. 29: $0-->1$

Car. 32: $0-->1$

Car. 86: $01 \quad->2$

Car. 117: 1 - $>2$

Car. 130: $\odot-->1$

Car. 149: $0-->1$

Car. 183: 1 --> 2

Car. 207: $0-->1$

Car. 237: $\odot-->1$

Car. 238: $1-->0$

Car. 247: 1 - -> $\odot$

Car. 350: $0-->1$

Clado 106 :

Todos cladogramas:

Car. 62: 0 - -> 1

Car. 95: 2 --> 1

Car. 117: $0-->1$

Car 155: $1->2$

Car. 292: $0-->1$

Car. 345: $1-\rightarrow 0$

Car. 355: $1-->0$

Car. 358: $0-->1$

Car. 377: $\odot-->2$

Car. 378: $\odot-->2$

Car. 397: $1-->2$

Clado 107 :

Todos cladogramas:

Car. 202: $1-->0$

Car. 223: $1-->0$

Car. 244: $0-->1$

Car. 386: $1-->3$

Clado 108 :

Todos cladogramas:

Car. 25: $0-->1$

Car. 32: 1 - $>0$

Car. 62: $2-->0$

Car. 73: $1-->0$

Car. 128: $0-->1$

Car. 149: $1->0$

Car. 176: 1 - $>0$

Car. 200: $1-->0$

Car. 227: $1-->0$

Car. 237: $1-->0$

Car. 255: $1-->0$

Car. 256: 2 -> 1

Car. 260: $0-->2$

Car. 304: $0-->1$

Car. 305: $1-->0$

Car. 307: $0-->1$

Car. 317: $0 \quad->2$

Car. 328: $\odot \quad->1$

Car. 331: $0-->1$

Car. 335: 1 - $>0$

Car. 362: $0-->3$

Car. 364: $1 \ldots$

Car. 369: $1-->2$

Car. 377: $1-->0$

Car. 380: $1-->0$

Car. 409: $0-->1$

Clado 109 :

Todos cladogramas: Car. 13: $0-\rightarrow 1$

Car. 23: $1-->0$

Car. 48: $0-->1$

Car. 64: $1-->0$

Car. 74: $1-->0$

Car. 139: $2-->1$ 
Car. 153: $2-->1$

Car. 268: $0-->1$

Car. 302: $01-->2$

Car. 338: $1-->0$

Car. 345: $0-->1$

Car. 347: $0-->1$

Car. 390: 1 - $>2$

Clado 110 :

Todos cladogramas:

Car. 2: $1-->0$

Car. 85: $0-->1$

Car. 111: $0-->2$

Car. 194: 1 - > 0

Car. 195: $1 \ldots$

Car. 242: 1 --> 0

Car. 276: $0 \quad->1$

Car. 280: $0-->1$

Car. 292: $1-->0$

Clado 111 :

Todos cladogramas:

Car. 20: $1-->0$

Car. 69: $2-->1$

Car. 86: $2-->1$

Car. 96: $0-->1$

Car. 97: $2-->1$

Car. 112: 2 - > 1

Car. 114: 2 --> 1

Car. 116: $0 \quad->1$

Car. 121: $1-->0$

Car. 123: 1 - $>0$

Car. 180: $0-->2$

Car. 188: $0-->1$

Car. 207: $1-->0$

Car. 208: $1-->0$

Car. 212: $0-->1$

Car. 222: 0 - -> 1

Car. 225: $1-->0$

Car. 241: $1->0$

Car. 251: 3 --> 1

Car. 256: $3-->2$

Car. 290: $0-->1$

Car. 298: 2 - $>1$

Car. 328: $1-->0$

Car. 339: 2 --> 1

Car. 360: $0-->2$

Clado 112 :

Todos cladogramas:

Car. $0: 1-->0$

Car. 69: $1-->2$

Car. 258: $1-->2$

Car. 264: 3 --> 0

Car. 329: 1 - -> $\odot$

Car. 347: $1-->2$

Car. 371: $1-->0$

Car. 394: $3-->0$

Clado 113 :

Todos cladogramas:

Car. 81: $2-->1$

Car. 83: $1-->0$

Car. 117: $0-->1$

Car. 196: $0-->1$

Car. 212: $1-->2$

Car. 226: $1-->0$

Car. 251: $1-->2$

Car. 254: $2-->1$

Car. 281: $0 \quad-->1$

Car. 295: $0-->1$

Car. 312: $2-->1$

Car. 314: $0 \quad->1$

Clado 114 :

Todos cladogramas:

Car. $0: 1-->0$
Car. 7: $4-->2$

Car. 79: $01-->2$

Car. 95: $2-->0$

Car. 105: $1-->0$

Car. 108: $0-->1$

Car. 121: $0-->1$

Car. 163: $0 \quad->1$

Car. 166: $1-->0$

Car. 179: $0-->1$

Car. 183: $1-->0$

Car. 198: $0-->1$

Car. 214: $0-->2$

Car. 217: $0-->3$

Car. 232: $0-->1$

Car. 236: 0 - -> 1

Car. 239: $1-->2$

Car. 287: 0 - $>1$

Car. 288: $0-->1$

Car. 356: $\odot-->1$

Car. 358: $0-->1$

Car. 360: $2-->1$

Car. 366: $0-->1$

Car. 367: $0-->1$

Clado 115 :

Todos cladogramas:

Car. 15: $0-->1$

Car. 111: $2-->1$

Car. 113: $0-->1$

Car. 124: $1-->0$

Car. 154: 0 - -> 1

Car. 167: $\odot-->1$

Car. 201: $0 \quad->1$

Car. 207: $0-->1$

Car. 216: $1-->0$

Car. 238: $1-->0$

Car. 264: $3-->1$

Car. 301: $1-->2$

Car. 329: $1-->0$

Car. 372: $\odot-->1$

Car. 378: 0 - -> 2

Car. 379: $2-->1$

Car. 383: $1-->0$

Car. 387: $0-->1$

Clado 116 :

Todos cladogramas:

Car. 29: $0-->1$

Car. 49: $0-->1$

Car. 174: $\odot-->1$

Car. 194: $0-->1$

Car. 254: $3-->4$

Car. 272: $2-->3$

Car. 305: 1 - $>0$

Car. 320: $0-->1$

Car. 329: $\odot-->1$

Car. 333: $\odot-->1$

Car. 335: $1-->0$

Car. 340: $123-->5$

Car. 346: $0 \quad->1$

Car. 360: $2-->0$

Car. 362: $0-->1$

Clado 117 :

Todos cladogramas:

Car. 81: $2-->1$

Car. 96: $1-->0$

Car. 101: $0 \quad->1$

Car. 104: $1-->0$

Car. 132: 1 - -> $\odot$

Car. 191: $1-->2$

Car. 193: $0-->1$

Car. 195: $0-->1$

Car. 196: $0-->1$

Car. 198: $0-->2$

Car. 254: 2 - -> 3

Car. 304: $0-->1$
Car. 338: $0-->1$

Car. 339: $1-->0$

Car. 374: $0-->1$

Car. 377: $1-->2$

Car. 401: $0-->1$

Car. 404: $1-->2$

Clado 118 :

Todos cladogramas:

Car. 85: $1-->0$

Car. 97: $1-->0$

Car 157: $0-->1$

Car. 208: $0-->1$

Car. 249: $0-->12$

Car. 255: $1-->2$

Car. 279: $1-->2$

Car. 280: 1 - $>0$

Car. 298: $1-->0$

Car. 342: $0-->1$

Car. 355: $1-->0$

Car. 394: $3-->1$

Car. 395: $2-->1$

Car. 404: $0-->1$

Clado 119 :

Todos cladogramas:

Car. 27: 1 - $>0$

Car. 29: 0 - -> 1

Car. 51: $1-->0$

Car. 86: $0-->1$

Car. 174: $\odot-->1$

Car. 241: $0-->1$

Car. 255: $2-->0$

Car. 335: $1-->0$

Car. 365: $1-->0$

Car. 374: $0-->1$

Car. 404: $1-->2$

Clado 120 :

Todos cladogramas:

Car. 13: 2 --> 3

Car. 28: $1-->0$

Car. 78: $1 \ldots$

Car. 83: $1-->3$

Car. 87: $1-->0$

Car. 194: $0 \quad->1$

Car. 195: $0-->1$

Car. 197: $1-->0$

Car. 364: $1 \ldots$

Car. 386: $1-->2$

Clado 121 :

Todos cladogramas:

Car. 1: 1 --> 0

Car. 23: $0-->1$

Car. 73: $1-->0$

Car. 212: 1 --> 2

Car. 213: $1-->0$

Car. 239: $1-->2$

Car. 247: $1-->0$

Car. 336: $\odot-->1$

Car. 358: $\odot \quad->1$

Car. 387: $1-->0$

Clado 122 .

Todos cladogramas:

Car. 25: $0-->1$

Car. 27: $0-->1$

Car. 68: $0-->1$

Car. 94: 0 - $>1$

Car. 95: $2-->3$

Car. 96: $1-->2$

Car. 149: 1 - $>0$

Car. 153: 1 - $>0$

Car. 180: 2 - $>0$

Car. 209: $1-->0$

Car. 210: $1-->0$ 
Car. 271: $1-->0$

Car. 332: 0 --> 1

Clado 123 :

Todos cladogramas:

Car. 28: $1-->2$

Car. 33: $\odot-->3$

Car. 43: $1-->2$

Car. 44: $1-->0$

Car. 45: $1-->0$

Car. 60: $0-->1$

Car. 75: $0-->1$

Car. 76: $1-->0$

Car. 85: $0-->1$

Car. 89: $\odot \quad->3$

Car. 97: $0-->2$

Car. 117: 1 --> 2

Car. 128: $0 \quad->1$

Car. 130: $0-->1$

Car. 140: $0 \ldots->1$

Car. 147: $0-->1$

Car. 150: $0-->1$

Car. 170: $0-->1$

Car. 179: $0-->1$

Car. 181: 0 - -> 1

Car. 193: $0 \quad->1$

Car. 196: $0-->1$

Car. 198: $\odot \quad->1$

Car. 199: $0-->1$

Car. 204: $0-->1$

Car. 244: $0-->1$

Car. 255: $2-->1$

Car. 256: $1->0$

Car. 257: $0-->1$

Car. 276: $1-->2$

Car. 320: $0-->1$

Car. 366: $0-->1$

Car. 375: $0-->2$

Car. 392: $1-->2$

Clado 124 :

Todos cladogramas:

Car. 10: $2-->1$

Car. 30: $0-->1$

Car. 49: $\odot-->1$

Car. 74: $0-->1$

Car. 114: 2 -> 1

Car. 148: $0-->1$

Car 156: 0 - -> 1

Car. 167: 1 - $->0$

Car. 181: $0-->1$

Car. 199: $0 \quad->1$

Car. 201: $1-->0$

Car. 222: 1 --> 0

Car. 231: 2 --> 0

Car. 236: $0-->1$

Car. 237: 1 - $>0$

Car. 238: $0-->1$

Car. 240: $0-->1$

Car. 256: $12-->0$

Car. 264: $1-->0$

Car. 265: $\odot \quad->1$

Car. 295: $0 \quad->1$

Car. 312: $2-->1$

Car. 313: 1 - $>0$

Car. 339: $1->0$

Car. 348: $\odot-->1$

Car. 349: $0-->1$

Car. 357: $0-->1$

Car. 374: $0-->1$

Car. 375: $0-->3$

Car. 377: 1 --> 2

Car. 395: 1 --> 2

Clado 125 :

Todos cladogramas:

Car. 5: $0-->1$
Car. 15: $1-\rightarrow 0$

Car. 29: $0-->2$

Car. 52: $1-->0$

Car. 59: 1 - -> 0

Car. 71: $0-->1$

Car. 113: $1-->0$

Car. 187: 0 - -> 1

Car. 218: $0-->1$

Car. 270: $1-->0$

Car. 333: $0-->1$

Car. 347: $1-->0$

Clado 126 :

Todos cladogramas:

Car. 7: $4-->2$

Car. 11: $1-->0$

Car. 21: $01-->2$

Car. 33: $0-->4$

Car. 43: $1-->2$

Car. 45: 1 - -> 0

Car. 47: $0-->1$

Car. 51: $1-->2$

Car. 75: $0-->1$

Car. 95: $3-->0$

Car. 123: $0-->1$

Car. 138: $1-->0$

Car. 139: $1-->2$

Car 175: $1-->0$

Car. 183: $1-->0$

Car. 184: $1-->2$

Car. 192: $1-->2$

Car. 197: $1-->0$

Car. 200: 1 - $>2$

Car. 244: $0-->1$

Car. 278: $2-->3$

Car. 279: $2-->1$

Car. 366: $\odot-->1$

Car. 367: $\odot-->1$

Car. 402: $\odot-->1$

Clado 127 :

Todos cladogramas:

Car. 10: 2 - -> 3

Car. 121: $0-->1$

Car. 148: $\odot-->1$

Car. 153: $0-->1$

Car. 239: $1-->2$

Car. 260: $1-->2$

Car. 390: 2 --> 1

Car. 395: $1-->2$

Clado 128 :

Todos cladogramas:

Car. 87: 1 --> 2

Car. 124: $0-->1$

Car. 132: $1-->0$

Car. 177: $1-->0$

Car. 193: $0-->1$

Car. 242: $\odot-->1$

Car. 276: $1-->2$

Car. 383: $\odot-->2$

Clado 129 :

Todos cladogramas:

Car. 2: $0-->1$

Car. 6: $1-->0$

Car. 92: $1-->0$

Car. 123: $0-->1$

Car. 249: $0-->1$

Car. 283: 1 - $>0$

Car. 313: $2-->1$

Car. 342: $2-->0$

Car. 397: $2-->0$

Clado 130 :

Todos cladogramas:

Car. $0: 1-->2$
Car. 1: $2-->1$

Car. 17: $0-->1$

Car. 23: $1-->0$

Car. 50: $0-->1$

Car. 52: $1-->0$

Car. 64: $1-->0$

Car. 68: 0 - -> 1

Car. 76: $0-->1$

Car. 77: 1 - -> 0

Car. 79: $2-->1$

Car. 94: $0-->1$

Car. 95: $2-->1$

Car. 96: $1-->2$

Car. 97: $1-->2$

Car 101: $1 \ldots$

Car. 103: $0-->1$

Car. 105: 1 - -> 0

Car. 108: $0-->1$

Car. 112: $01-->2$

Car. 117: $1-->0$

Car. 118: $0-->1$

Car. 132: $0-->1$

Car. 149: $1-->0$

Car. 162: $2-->01$

Car. 168: 0 - $>1$

Car. 183: $1-->0$

Car. 184: $1-->0$

Car. 194: 1 - -> 0

Car. 195: $1-->0$

Car. 196: $0-->2$

Car. 200: $1-->0$

Car. 201: $0-->1$

Car. 209: 1 - $>0$

Car. 212: $1-->2$

Car. 215: $1-->0$

Car. 221: $0-->1$

Car. 222: $1-->0$

Car. 243: $0-->1$

Car. 259: $0-->2$

Car. 272: $1-->0$

Car. 280: 0 - $>1$

Car. 291: $0-->1$

Car. 293: $\odot-->1$

Car. 320: $1-->0$

Car. 332: $\odot-->1$

Car. 335: $0-->1$

Car. 347: $1-->0$

Car. 350: $0-->1$

Car. 369: $0-->1$

Car. 394: $1-->0$

Car. 396: $0-->1$

Clado 131 :

Todos cladogramas:

Car. 7: $12-->0$

Car. 176: $1->0$

Car. 208: 0 - -> 1

Car. 250: $0-->1$

Car. 262: $1-->0$

Car. 274: $1-->2$

Clado 132 :

Todos cladogramas:

Car. 127: $1-->0$

Car. 228: $\odot-->1$

Car. 235: $0-->1$

Car. 254: $1-->0$

Car. 257: $\odot-->1$

Car. 261: $1-->0$

Car. 282: $0-->1$

Car. 349: $0-->1$

Car. 376: $1-->0$

Car. 379: $2-->0$

Clado 133 :

Todos cladogramas:

Car. 53: $1-->0$ 
Car. 61: $0-->1$

Car. 63: $1-->0$

Car. 114: $0-->1$

Car. 168: $1-->0$

Car. 189: $1-->0$

Car. 244: $0-->1$

Car. 256: $1-->2$

Car. 265: $0-->1$

Car. 278: $\odot-->1$

Car. 279: $3-->2$

Car. 327: $0-->1$

Car. 335: $1-->0$

Car. 340: $4-->56$

Car. 341: $1-->0$

Car. 377: $1-->0$

Clado 134 :

Todos cladogramas: Car. 8: $0-->1$

Car. 91: $\odot-->1$

Car. 141: $1-->0$

Car. 155: $2-->0$

Car. 203: $0-->1$

Car. 346: $0-->1$

Clado 135 :

Todos cladogramas:

Car. 2: 1 - $>0$

Car. 65: $1-->0$

Car. 112: $1-->0$

Car. 251: 1 --> 2

Clado 136 :

Todos cladogramas: Car. 63: $2-->1$

Car. 242: $0-->1$

Car. 338: $1-->0$

Clado 137 :

Todos cladogramas:

Car. 28: 2 --> 1

Car. 53: $0-->1$

Car. 76: $1-->0$

Car. 136: $0-->1$

Car. 278: $1-->0$

Car. 279: $2-->3$

Clado 138 :

Todos cladogramas:

Car. 7: $34-->2$

Car. 8: $1-->0$

Car. 36: $0-->1$

Car. 37: $0-->2$

Car. 215: $0-->1$

Car. 216: $0-->1$

Car. 274: $0-->1$

Car. 300: $0-->1$

Clado 139 :

Todos cladogramas:

Car. 6: $0-\rightarrow 1$

Car. 73: $1-->0$

Car. 114: $1-->0$

Car. 148: $\odot-->1$

Car. 153: $2-->1$

Clado 140 :

Todos cladogramas:

Car. 10: $1-->2$

Car. 69: $\odot-->1$

Car. 81: $2-->1$

Car. 166: $1->0$

Car. 242: $1-\rightarrow>0$

Clado 141 :

Todos cladogramas:

Car. 86: $1-->2$
Car. 134: $0 \quad->1$

Car. 141: $0-->1$

Car. 161: $1-->0$

Car. 347: $0-->1$

Car. 351: $2-->0$

Car. 366: $1-->0$

clado 142 :

Todos cladogramas:

Car. 65: $\odot-->1$

Car. 168: $\odot-->1$

Car. 189: $0-->1$

Car. 197: $1-->0$

Car. 256: $2-->1$

Car. 294: $0-->1$

Car. 300: $1-->0$

Car. 334: $\odot-->1$

Car. 363: $1-->0$

Car. 369: $1-->0$

Car. 371: $1-->0$

Car. 380: $1-->0$

Car. 395: $2-->1$

clado 143 :

Todos cladogramas:

Car. 1: 1 -> 2

Car. 51: $1-->0$

Car. 69: $1-->0$

Car. 91: $1-->0$

Car. 117: $\odot-->1$

Car. 182: $0-->1$

Car. 215: $1-->0$

Car. 216: $1-->0$

Car. 289: $1-->0$

Car. 292: $1-->2$

Car. 333: $\odot-->1$

Car. 390: $1-->0$

Clado 144 :

Todos cladogramas:

Car. 5: $0-->1$

Car. 17: $1-->0$

Car. 27: $0-->1$

Car. 29: $0-->12$

Car. 31: $1-->0$

Car. 67: $1-->\odot$

Car. 78: $1-->0$

Car. 161: $\odot-->1$

Car. 167: 0 --> 12

Car. 249: $0-->1$

Car. 252: $0 \quad->1$

Car. 254: $2-->1$

Car. 279: $01-->2$

Clado 145 :

Todos cladogramas:

Car. 1: 2 - $>1$

Car. 22: $0-->1$

Car. 27: $1-->0$

Car. 39: $0-->2$

Car. 81: $1-->0$

Car. 92: 1 - $>0$

Car. 95: 2 --> 0

Car. 115: $0-->1$

Car. 118: $0-->1$

Car. 138: $\odot-->1$

Car. 154: $0-->1$

Car. 158: $\odot-->1$

Car. 169: $0-->1$

Car. 256: $2-->3$

Car. 258: $1-->0$

Car. 265: $0-->1$

Car. 339: $0-->2$

Car. 391: $1-->2$

Clado 146 :

Todos cladogramas:
Car. 16: $0 \quad->1$

Car. 43: $1-->0$

Car. 79: $2-->1$

Car. 176: $1-->0$

Car. 182: $1-->0$

Car. 197: $1-->0$

Car. 214: $0-->1$

Car. 224: $1-->0$

Car. 228: $\odot-->1$

Car. 306: $0-->1$

Car. 349: $0-->1$

Car. 364: $1-->0$

Car. 379: 2 --> 0

Clado 147 :

Todos cladogramas:

Car. 96: 1 - > 0

Car. 141: $0-->1$

Car. 212: $1-->2$

Car. 240: $0-->1$

Car. 307: $0-->2$

Car. 335: $1-->0$

Car. 342: $\odot-->2$

Car. 346: $0-->1$

Car. 372: $0-->1$

Car. 376: $1-->0$

Car. 383: $1-->0$

Clado 148 :

Todos cladogramas:

Car. 33: $0-->1$

Car. 81: $2-->1$

Car. 97: 1 --> $\odot$

Car. 157: $\odot-->1$

Car. 174: $0-->1$

Car. 203: $0-->1$

Car. 223: $1-->0$

Car. 234: $0-->1$

Car. 239: $1-->2$

Car. 301: $1-->2$

Car. 324: $\odot-->1$

Car. 339: $1-->0$

Car. 340: $34-->67$

Car. 378: $0-->2$

Clado 149 :

Todos cladogramas:

Car. 25: $0-->1$

Car. 34: 2 --> 0

Car. 104: $1-->0$

Car. 117: $01-->2$

Car. 124: $1-->0$

Car. 129: $0-->1$

Car. 134: $\odot-->1$

Car. 143: $0-->1$

Car. 146: $3-->2$

Car. 148: $\odot-->1$

Car. 153: $2-->1$

Car. 174: $1-->0$

Car. 177: $1-->2$

Car. 261: $0-->1$

Car. 313: $2-->1$

Car. 329: $1-->0$

Clado 150 :

Todos cladogramas:

Car. 18: $0-->1$

Car. 33: $1-->0$

Car. 64: $1-->0$

Car 80: $0 \quad->1$

Car. 106: $0-->1$

Car. 111: $0-->2$

Car. 145: $0-->1$

Car. 167: $2-->1$

Car. 195: $1-->0$

Car. 239: $2-->1$

Car. 242: $1-->2$ 
Car. 249: 1 --> 0

Car. 260: 1 --> 0

Car. 283: $1-->0$

Car 292: $2 \ldots->3$

Car. 338: $1-->0$

Car. 363: $1-->0$

Clado 151 :

Todos cladogramas:

Car. 1: $1-->2$

Car. 2: $1-->0$

Car. 3: $1-\rightarrow 0$

Car. 33: $0-->1$

Car. 51: $1-->0$

Car. 52: $1-->0$

Car. 59: $1-->0$

Car. 79: 2 --> 1

Car. 122: 1 - $>0$

Car. 206: $2-->1$

Car. 236: $1 \ldots$

Car. 241: $0-->1$

Car. 248: $1-->0$

Car. 302: $1-->0$

Car. 304: $0-->1$

Car. 309: 0 - -> 1

Car. 315: $0-->2$

Car. 324: $0-->1$

Car. 360: $2-->1$

Car. 379: $2-->0$

Car. 383: 1 - $>0$

Car. 402: $\odot-->1$

Clado 152 :

Todos cladogramas:

Car. 78: $0-->1$

Car. 231: $2-->0$

Car. 249: $1-->2$

Car. 280: 0 --> 1

Car. 291: $0-->1$

Car. 295: $0-->1$

Car. 313: $2-->1$

Car. 339: 1 - $>0$

Car. 380: $1-->0$

Clado 153 :

Todos cladogramas:

Car. 34: $0-->1$

Car. 61: $0-->1$

Car. 81: $2-->0$

Car. 86: $1-->0$

Car. 95: 2 --> 01

Car. 125: $0 \quad->1$

Car. 127: $1-\rightarrow 0$

Car. 132: $0 \quad->2$

Car. 168: $0-->1$

Car. 197: $1 \ldots$

Car. 206: $0-->2$

Car. 242: 1 - $>0$

Car. 265: $0-->1$

Car. 278: $123-->0$

Car. 279: $2-->3$

Car. 283: 1 --> 0

Car. 320: $1-->0$

Car. 327: $0-->1$

Car. 351: 2 - $>0$

Car. 389: $2-->0$

Car. 391: $1-->0$

Clado 154 :

Todos cladogramas:

Car. 105: $1-\rightarrow 0$

Car. 108: $0-->1$

Car. 110: $1-->0$

Car. 139: 2 - $->1$

Car. 154: $0-->1$

Car. 293: $\odot \quad-->1$

Car. 325: $0-->1$
Car. 342: $0-->1$

Clado 155 :

Todos cladogramas:

Car. 21: $0-->2$

Car. 24: $0-->1$

Car. 26: 1 --> 0

Car. 33: $1-->2$

Car. 39: 2 - -> 1

Car. 42: $0-->1$

Car. 61: $0-->1$

Car. 72: 1 - -> 0

Car. 74: $1-->0$

Car. 94: $\odot-->1$

Car. 107: $1-->0$

Car. 121: $0-->1$

Car. 122: 1 - $>0$

Car. 135: $0-->1$

Car. 147: $\odot-->1$

Car. 151: $0-->1$

Car. 178: $0-->1$

Car. 193: $0-->1$

Car. 215: $0-->1$

Car. 224: $\odot-->1$

Car. 243: 0 - -> 1

Car. 260: $1-->0$

Car. 280: $0-->1$

Car. 282: $1-->2$

Car. 291: $\odot-->1$

Car. 293: $\odot-->1$

Car. 297: 1 - $>0$

Car. 325: $0-->1$

Car. 333: 1 - $>0$

Car. 351: $2-->0$

Car. 362: $0-->2$

Car. 363: $1-->0$

Car. 388: $\odot-->1$

Car. 394: $1-->0$

Car. 407: $\odot-->2$

Clado 156 :

Todos cladogramas:

Car. 1: $1-->0$

Car. 91: $0-->1$

Car. 96: $0-->2$

Car. 99: $0-->1$

Car. 101: $1-->0$

Car. 105: $1-->0$

Car 108: $0-->1$

Car. 109: $0-->1$

Car. 113: $0-->1$

Car. 128: $0 \quad->1$

Car. 139: $2-->1$

Car. 141: $1-->0$

Car. 171: $1-->0$

Car. 175: $1-->0$

Car. 179: $0-->1$

Car. 216: $0-->1$

Car. 234: $1-->0$

Car. 278: 1 - -> 0

Car. 279: $2-->3$

Car. 289: $0-->1$

Car. 292: $2-->0$

Car. 300: $1-->0$

Car. 301: $2-->1$

Car. 307: $2-->0$

Car. 320: $1-->0$

Car. 346: $1-->0$

Car. 355: $1-->0$

Car. 386: $1-->0$

Car. 390: $0-->2$

Clado 157 :

Todos cladogramas:

Car. 12: $0-->1$

Car. 55: $1-->0$

Car. 158: $0-->1$
Car. 166: $1-->0$

Car. 193: $\odot-->1$

Car. 260: $\odot-->1$

Car. 306: $0-->1$

Car. 341: $1-->0$

Car. 384: $0-->1$

Car. 403: $0-->1$

Clado 158 :

Todos cladogramas:

Car. 16: $0-->1$

Car. 34: $1-->2$

Car. 42: $0-->1$

Car. 55: $1-->0$

Car. 70: $0 \quad->2$

Car. 84: $0-->1$

Car. 98: $0-->1$

Car. 118: 1 - $>0$

Car. 180: $2-->1$

Car. 185: $1-->0$

Car. 186: $0-->1$

Car. 191: $1-->2$

Car. 193: $0-->1$

Car. 196: $0-->2$

Car. 214: $0-->1$

Car. 215: $1-->0$

Car. 216: $1-->0$

Car. 217: 0 - $>1$

Car. 258: $1-->2$

Car. 279: $3-->2$

Car. 310: $0-->1$

Car. 314: $0-->1$

Car. 341: $1-->2$

Car. 351: $0-->1$

Car. 375: $\odot-->2$

Car. 403: $\odot-->1$

Clado 159 :

Todos cladogramas: Car. 7: $4-->1$

Car. 14: $0-->2$

Car. 28: $12-->0$

Car. 64: $1-->0$

Car. 88: $\odot-->1$

Car. 146: $3-->2$

Car. 153: $2-->1$

Car. 252: $1-->0$

Car. 341: $1-->0$

Car 347: $0-->2$

Car. 376: $1-->0$

Car. 379: $2-->0$

Clado 160 :

Todos cladogramas:

Car. 11: $1-->0$

Car. 22: $0-->1$

Car. 36: $0-->1$

Car. 62: $2-->1$

Car. 63: $01-->2$

Car. 80: $0-->1$

Car. 112: $1-->0$

Car. 212: 1 - $>0$

Car. 229: $1-->0$

Car. 257: $0-->1$

Car. 269: $0-->1$

Car. 298: $1-->0$

Car. 300: $1-->0$

Car. 311: $0-->1$

Car. 404: $0-->1$

Clado 161 :

Todos cladogramas:

Car 17: 0 - -> 1

Car. 20: $0-->1$

Car. 26: $0-->1$

Car. 43: $1-->2$

Car. 51: $1-->\odot$ 
Car. 123: $0-->1$

Car. 140: $0-->1$

Car. 148: $0-->1$

Car. 198: $0 \quad->2$

Car. 200: $1-->2$

Car. 250: 1 - $>$

Car. 253: $\odot-->1$

Car. 260: $0-->1$

Car. 265: 0 - -> 1

Car. 278: $3-->1$

Car. 279: 2 - $>3$

Car. 297: 1 - $>0$

Car. 302: $1-->2$

Car. 347: 2 --> 1

Car. 354: $0-->1$

Clado 162 :

Todos cladogramas:

Car. 8: 1 -> 0

Car. 32: $1-->0$

Car. 37: $0-->2$

Car. 50: $\odot-->1$

Car. 86: $1-->2$

Car. 110: $0-->1$

Car. 117: 0 - -> 1

Car. 169: $0 \quad->1$

Car. 234: $0-->1$

Car. 256: $2-->1$

Car. 266: $0-->1$

Car. 283: 1 - -> 0

Car. 314: $0-->1$

Clado 163 :

Todos cladogramas:

Car. 55: 1 - -> 0

Car. 63: $01-->2$

Car. 81: $2-->0$

Car. 88: $\odot-->1$

Car. 114: $1-->0$

Car. 133: $0-->1$

Car. 142: 1 - -> 0

Car. 162: $2-->1$

Car. 166: $1-->0$

Car. 183: 1 - -> 0

Car. 230: $0-->1$

Car. 244: 0 - -> 1

Car. 248: $1-->0$

Car. 257: $0-->1$

Car 270: $1 \ldots$

Car. 340: $3-->2$

Car. 369: $1-->0$

Clado 164 :

Todos cladogramas:

Car. 97: $1-->0$

Car. 98: $0-->1$

Car. 113: 0 - $>1$

Car. 114: $1-->2$

Car. 139: $1-->2$

Car. 141: $0 \quad->1$

Car. 182: 1 - $>0$

Car. 190: 1 - -> 0

Car. 207: $1-->0$

Car. 214: $0-->1$

Car. 272: 1 --> 3

Car. 300: $1-->0$

Car. 301: 1 --> 2

Car. 311: $0-->1$

Car. 314: $0-->1$

Car. 340: $6-->8$

Car. 345: $0-->1$

Car. 371: $0-->1$

Car. 372: $0 \quad->1$

Car. 395: $1-->2$

Car. 404: $0 \quad->1$

Clado 165 :
Todos cladogramas:

Car. 91: 0 - -> 1

Car. 96: $1-->0$

Car. 237: 1 - $>3$

Car. 249: $1-->2$

Car. 327: $0-->1$

Car. 329: $1-->0$

Car. 395: $1-->2$

Clado 166 :

Todos cladogramas:

Car. 53: 1 - -> 0

Car. 74: $0-->1$

Car. 117: $1-->2$

Car. 139: $0 \quad-->2$

Car. 246: $1-->0$

Car 266: $1 \ldots->0$

Um dos cladogramas:

Car. 234: $0-->1$

Clado 167 :

Todos cladogramas:

Car. 38: 0 --> 1

Car. 136: $1-->0$

Car. 142: $0-->1$

Car. 153: $1-->0$

Car. 376: $1-->0$

Car. 394: $1 \ldots->3$

Clado 168 :

Todos cladogramas:

Car. 8: $0-->1$

Car. 138: $0-->1$

Car. 139: $1-->0$

Car. 215: $1-->0$

Car. 229: 1 - -> 0

Car. 274: $1-->0$

Car. 276: $0-->1$

Car. 278: $0-->1$

Car. 279: $3-->2$

Car. 340: $34-->2$

Um dos cladogramas:

Car. 128: $0-->1$

Clado 169 :

Todos cladogramas:

Car. 114: $\odot-->1$

Car. 246: $0 \quad->1$

Car 257: 0 - -> 1

Car. 300: $1-->0$

Car. 339: $1-->0$

Car. 393: 0 --> 2

Um dos cladogramas:

Car. 67: 1 --> 0

Clado 170 :

Todos cladogramas:

Car. 2: 1 - $>0$

Car. 17: $0-->1$

Car. 97: 1 - $>0$

Car. 136: $0-->1$

Car. 212: $1-->2$

Car. 247: $\odot-->1$

Car. 281: $0-->1$

Car. 339: 1 --> 0

Clado 171 :

Todos cladogramas:

Car. 6: 1 -> 0

Car. 27: 1 --> 0

Car. 134: $1-->0$

Car. 215: $0 \quad->1$

Car. 216: $0-->1$

Car. 395: $1-->2$

Clado 172 :

Todos cladogramas:
Car. 39: $0 \quad->1$

Car. 51: $0-->1$

Car. 53: $0-->1$

Car. 65: 1 - $>0$

Car. 87: $2-->1$

Car. 133: $2-->0$

Car. 141: 1 --> 0

Car. 162: $2-->1$

Car. 333: $1-->0$

Car. 396: $\odot-->1$

Clado 173 :

Todos cladogramas:

Car. 48: $0-->1$

Car. 340: $3-->1$

Car. 393: $\odot-->1$

Clado 174 :

Todos cladogramas:

Car. 10: 2 - $>1$

Car. 145: $0-->1$

Car. 265: $0-->1$

Car. 290: $1-->0$

Car. 299: $0-->1$

Car. 397: $1-->0$

Clado 175 :

Todos cladogramas: Car. 102: $0-->1$ Car. 162: $1-->0$

Car. 204: $1-->0$

Car. 231: $1-->0$

Car. 239: 1 - $>0$

Car. 325: $0-->1$

Clado 176 :

Todos cladogramas:

Car. 153: $1->0$

Car. 340: $1-->2$

Car. 386: $1-->2$

Car. 390: $0-->2$

Clado 177 :

Todos cladogramas: Car. 7: $2-->1$

Car. 124: $1-->0$

Car. 166: $\odot-->1$

Car. 199: $0-->1$

Clado 178 :

Todos cladogramas:

Car. 32: $1-->0$

Car. 91: $\odot-->1$

Car. 133: 2 --> 0

Car. 134: $1-->0$

Car. 395: $1-->2$

Clado 179 :

Todos cladogramas:

Car. 51: $0-->1$

Car. 117: $1-->0$

Car. 146: $3-->2$

Car. 204: $1-->0$

Car. 292: $2-->1$

Car. 340: $3-->2$

Car. 390: $0-->1$

Clado 180 :

Todos cladogramas:

Car. 12: $0-->1$

Car. 28: $1-->0$

Car. 29: $1-->2$

Car. 96: 1 - -> $\odot$

Car. 146: $3-->0$

Car. 154: $0-->1$

Car. 198: $0-->1$

Car. 200: $1-->2$ 
Car. 204: 1 - $>0$

Car. 252: $1-->0$

Car. 255: $1-->2$

Car. 324: $0-->1$

Car. 358: $1-->0$

Car. 360: $2-->0$

Car. 393: $0-->1$

Clado 181 :

Todos cladogramas: Car. 16: $0-->1$

Car. 18: $\odot-->1$

Car. 33: $0-->1$

Car. 48: $0-->1$

Car. 76: $1-->0$

Car. 95: $2-->0$

Car. 139: $2-->1$

Car. 177: $1-->2$

Car. 185: $1-->0$

Car. 186: $0-->1$

Car. 194: $1-->0$

Car. 195: $1-->0$

Car. 226: $1-->0$

Car. 239: $1-->2$

Car. 242: $1-->0$

Car. 256: $1->0$

Car. 292: $2-->3$

Car. 333: $1-->0$

Car. 340: $3-->1$

Car. 365: $1-->0$

Car. 396: $\odot-->1$

Clado 182 :

Todos cladogramas: Car. 59: $1-\rightarrow 0$

Car. 96: $1-->0$

Car. 138: $0-->1$

Car. 144: $0-->1$

Car. 229: $1-->0$

Car. 274: $0-->1$

Car. 338: $1-->0$

Clado 183 :

Todos cladogramas: Car. 39: $1-->2$ Car. 40: $1-->0$

Car. 76: $1-->0$

Car. 146: $3-->2$

Car. 149: $1-->0$

Car. 198: $0-->1$

Car. 223: $1-->0$

Car. 238: $1-->0$

Car. 338: $1-->0$

Clado 184 :

Todos cladogramas:

Car. 11: 0 - -> 1

Car. 65: $0-->1$

Car. 88: $1-->0$

Car. 207: $1-->0$

Car. 276: $0-->1$

Car. 373: $0-->1$

Car. 376: $1-->0$

Car. 394: $1-->3$

Car. 397: 1 --> 2

Clado 185 :

Todos cladogramas: Car. 38: $1-->0$

Car. 87: $2-->1$

Car. 146: $3->2$

Car. 204: $1 \quad->0$

Car. 341: $1-->0$

Car. 342: $\odot-->2$

Car. 351: $2-->1$

Car. 355: $1-->0$
Clado 186 :

Todos cladogramas:

Car. 139: $2-->1$

Car. 252: 1 - -> 0

Car. 253: $1-->0$

Car. 264: 0 - -> 1

Car. 276: $1-->2$

Car. 287: $\odot-->1$

Car. 379: $\odot-->1$

Car. 394: $3-->1$

Clado 187 :

Todos cladogramas:

Car. 102: $0-->1$

Car. 193: $1-->0$

Car. 286: $0-->1$

Car. 300: $0-->1$

Car. 383: $1-->0$

Um dos cladogramas:

Car. 79: 2 - $>0$

Car. 134: $1-->0$

Clado 188 :

Todos cladogramas:

Car. 264: 3 --> 0

Car. 274: $0-->1$

Car. 292: 2 --> 3

Um dos cladogramas: Car. 226: $1-->0$ Car. 375: $\odot-->3$

Clado 189 :

Todos cladogramas:

Car. 1: $2-->1$

Car. 27: $1-->0$

Car. 39: $\odot-->2$

Car. 64: $1-->0$

Car. 106: $\odot-->1$

Car. 196: $0-->2$

Car. 270: $1-->0$

Car. 346: $\odot-->1$

Clado 190 :

Todos cladogramas: Car. 81: $1-->0$

Car. 204: $1-->0$

Car. 223: $1-->0$

Car. 251: $1-->2$

Car. 287: $\odot-->1$

Car. 351: $2-->0$

Um dos cladogramas:

Car. 234: $1-->0$

Clado 191 :

Todos cladogramas: Car. 47: $1-->0$

Car. 76: $0-->1$

Car. 133: $2-->0$

Car. 137: $0-->1$

Um dos cladogramas: Car. 134: $1-->0$

Clado 192 :

Todos cladogramas:

Car. 117: $2-->1$

Car. 139: $2-->1$

Car. 141: $1-->0$

Car. 177: $1-->2$

Car. 265: $0-->1$

Car 274: $0-->1$

Car. 338: $0-->1$

Clado 193 :

Todos cladogramas:

Car. 63: 2 --> 1

Car. 97: $1-->0$

Car. 139: $1-->0$
Car. 142: $0-->1$

Car. 247: $0-->1$

Car. 261: $1-->0$

Car. 274: $1-->0$

Clado 194 :

Todos cladogramas:

Car. 7: $2-->3$

Car. 32: $1-->0$

Car. 146: $3-->2$

Car. 155: $2-->0$

Car. 246: $\odot-->1$

Car. 268: $0-->1$

Car. 353: $0-->1$

Clado 195 :

Todos cladogramas:

Car. 25: $0-->1$

Car. 59: $1 \ldots 0$

Car. 62: 1 - $>0$

Car. 133: $0-->2$

Car. 134: $0-->1$

Car. 138: $0-->1$

Car. 252: $0-->1$

Car. 261: $\odot-->1$

Car. 274: $0-->1$

Car. 284: $\odot-->1$

Car. 292: $2-->3$

Car. 300: $0-->1$

Car. 307: $0-->1$

Car. 313: $2-->1$

Car. 342: $1-->2$

Car. 343: $\odot-->1$

Car. 344: $\odot-->1$

Car. 396: $0-->1$

Clado 196 :

Todos cladogramas:

Car. 1: $1-->2$

Car. 22: $1-->0$

Car. 61: $0-->1$

Car. 63: $2-->0$

Car. 80: $1-->0$

Car. 117: $1-->2$

Car. 131: $01-->2$

Car. 182: $\odot-->1$

Car. 196: $0 \quad->2$

Car. 212: $0-->2$

Car. 223: $1-->0$

Car. 269: $1-->0$

Car. 271: $2-->1$

Car. 276: $0-->1$

Car. 279: $2-->0$

Car. 285: $\odot-->1$

Car. 291: $0-->1$

Car. 292: $1-->2$

Car. 370: $\odot-->2$

Car. 408: $0-->1$

Clado 197 :

Todos cladogramas:

Car. 40: 1 --> 0

Car. 51: $1-->0$

Car. 97: $1-->2$

Car. 128: $0-->1$

Car. 254: $1-->0$

Car. 258: $1-->2$

Car. 358: $1-->0$

Clado 198 :

Todos cladogramas:

Car. 87: $2-->1$

Car. 101: $1-->0$

Car. 106: $0-->1$

Car. 124: $1-->0$

Car. 136: $\odot-->1$

Car. 137: $0-->1$ 
Car. 141: $1-->0$

Car. 225: $\odot-->1$

Car. 228: $\odot->1$

Car. 256: $1-\rightarrow 0$

Car. 274: $0-->2$

Car. 282: $0-\rightarrow 1$

Car. 285: $0->1$

Car. 292: $2-->3$

Car. 293: $0-->1$

Car. 340: $3-->5$

Car. 373: $0-->1$

Clado 199 :

Todos cladogramas:

Car. 6: $0-->1$

Car. 101: $1->0$

Car. 104: $0-\rightarrow 1$

Car. 200: $1-->2$

Car. 222: $1->0$

Car. 251: $1-\rightarrow>2$

Car. 260: $0-->2$

Car. 306: $0-->1$ 